\title{
Ostfränkische Sammlungen von Dichtung im 9. Jahrhundert
}

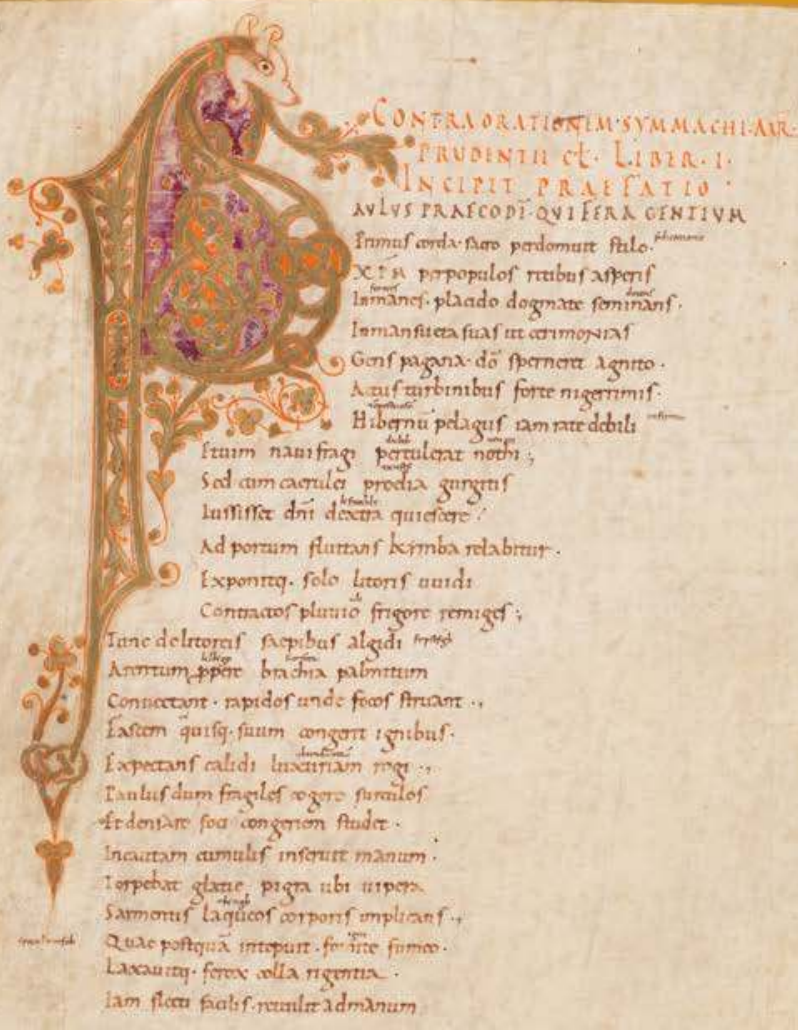




\section{Nova Mediaevalia \\ Quellen und Studien zum europäischen Mittelalter}

Band 19

Begründet von Nikolaus Henkel und Jürgen Sarnowsky

Herausgegeben von Martin Baisch, Christoph Dartmann, Philippe Depreux und Jürgen Sarnowsky 


\section{Till Hennings}

\section{Ostfränkische Sammlungen von Dichtung im 9. Jahrhundert}

Mit einer Abbildung

V\&R unipress 
Bibliografische Information der Deutschen Nationalbibliothek

Die Deutsche Nationalbibliothek verzeichnet diese Publikation in der Deutschen Nationalbibliografie; detaillierte bibliografische Daten sind im Internet über https://dnb.de abrufbar.

Die vorliegende Dissertation entstand im Rahmen des Sonderforschungsbereichs 950 »Manuskriptkulturen in Asien, Afrika und Europa «, Centre for the Study of Manuscript Cultures, gefördert durch die Deutsche Forschungsgemeinschaft (DFG). Der Druck wurde großzügig unterstützt vom Exzellenzcluster 2176 »Understanding Written Artefacts: Material, Interaction and Transmission in Manuscript Cultures«, Projektnr. 390893796, gefördert durch die DFG im Rahmen der Exzellenzstrategie des Bundes und der Länder, und vom Fachbereich Geschichte (Arbeitsbereich Mittelalterliche Geschichte) der Universität Hamburg.

( 2021, Vandenhoeck \& Ruprecht GmbH \& Co. KG, Theaterstraße 13, D-37073 Göttingen Dieses Werk ist als Open-Access-Publikation im Sinne der Creative-Commons-Lizenz BY International 4.0 (»Namensnennung«) unter dem DOI 10.14220/9783737012317 abzurufen. Um eine Kopie dieser Lizenz zu sehen, besuchen Sie https://creativecommons.org/licenses/by/4.0/. Jede Verwertung in anderen als den durch diese Lizenz zugelassenen Fällen bedarf der vorherigen schriftlichen Einwilligung des Verlages.

Umschlagabbildung: Burgerbibliothek Bern, Cod. 264, S. 236. Sammlung der Gedichte des Prudentius mit Prachtinitiale und althochdeutschen Glossen. Foto: Codices Electronici AG, www.e-codices.ch.

\section{Vandenhoeck \& Ruprecht Verlage | www.vandenhoeck-ruprecht-verlage.com}

ISSN 2198-6231

ISBN 978-3-7370-1231-7 
Parentibus Amicisque,

Alexae, Ralph,

Hanae, Henri

Atque Muri,

Comiti Fidelissimae.

Open-Access-Publikation im Sinne der CC-Lizenz BY 4.0

(C) 2021, Vandenhoeck \& Ruprecht GmbH \& Co. KG, Göttingen 
Open-Access-Publikation im Sinne der CC-Lizenz BY 4.0

(c) 2021, Vandenhoeck \& Ruprecht GmbH \& Co. KG, Göttingen ISBN Print: 9783847112310 - ISBN E-Lib: 9783737012317 


\section{Inhalt}

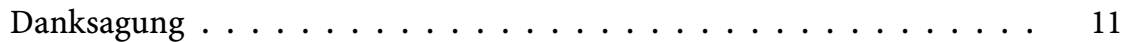

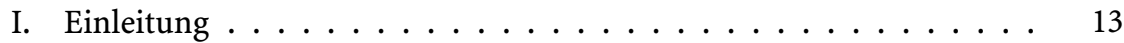

I.1 Dichtung und Gesellschaft . . . . . . . . . . . . . . 13

I.2 Sammlungen von Dichtung - Begriffsklärung und Ziele . . . . . 18

I.3 Aspekte der Forschung . . . . . . . . . . . . . . . 20

I.3.a Dichtung im Karolingerreich . . . . . . . . . . . . 20

I.3.b Textkritik und Textgeschichte . . . . . . . . . . 23

I.3.c Kodikologie . . . . . . . . . . . . . . . . . . 24

I.3.d Bibliotheksgeschichte . . . . . . . . . . . . 26

I.3.e Anthologien . . . . . . . . . . . . . . . 27

I.3.f Schule und Dichtung . . . . . . . . . . . . . . 29

I.4 Eingrenzung des behandelten Materials . . . . . . . . . 31

I.4.a Untersuchungszeitraum und -gebiet . . . . . . . . . . 31

I.4.b Dichtung außerhalb von Sammlungen . . . . . . . . 35

I.5 Zur Struktur der Arbeit . . . . . . . . . . . . . . . . . . . . . . . 39

II. Die Handschriftenlandschaft . . . . . . . . . . . . . . . . . 41

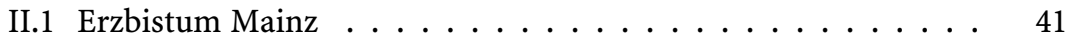

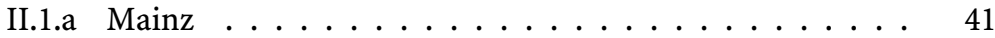

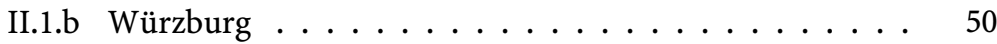

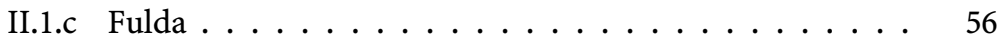

II.1.d St. Gallen . . . . . . . . . . . . . . . . . 78

II.1.e Reichenau . . . . . . . . . . . . . . . . . . . . 153

II.1.f Weißenburg . . . . . . . . . . . . . . . . . 180

II.1.g Murbach . . . . . . . . . . . . . . . . . 197

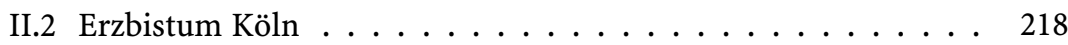

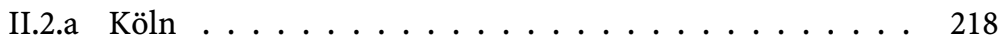

II.2.b Corvey . . . . . . . . . . . . . . . . . . . . . 225

II.2.c Lüttich . . . . . . . . . . . . . . . . . . . . . . 229 
II.3 Erzbistum Trier . . . . . . . . . . . . . . . . . . . . . . . 232

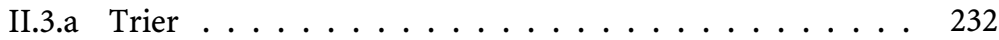

II.3.b Lorsch . . . . . . . . . . . . . . . . . . . . . . . . . . . 236

II.3.c Prüm . . . . . . . . . . . . . . . 258

II.4 Erzbistum Salzburg . . . . . . . . . . . . . . . . . . . . . . . . . . . . . . . 262

II.4.a Salzburg . . . . . . . . . . . . . . . . . . . . . . . . . . . . 262

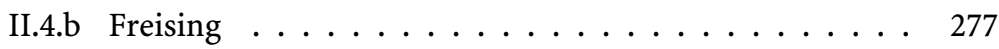

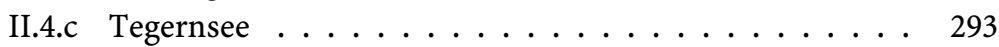

II.4.d Regensburg . . . . . . . . . . . . . . . . . . . . . . . . 395

II.4.e Passau ........................ 301

III. Analysen und Ergebnisse . . . . . . . . . . . . . . . . . . . . . . . . . . . . . . . . 315

III.1 Herkunft der Texte . . . . . . . . . . . . . . . . . . . . . . 315

III.1.a Westfrankenreich und andere Regionen . . . . . . . 315

III.1.b Ostfrankenreich . . . . . . . . . . . . . . . . 317

III.1.c Aus eigener Bibliothek . . . . . . . . . . . . . . . . . . . . . . . . . 318

III.2 Dichtung in Bibliothek und Katalogen . . . . . . . . . . . . . . . . . . . 319

III.2.a Ordnung der Bibliotheken . . . . . . . . . . . . . . . . . . . . . . . . 319

III.2.b Separatbibliotheken . . . . . . . . . . . . . . . . . 320

III.2.b.1 Schulbibliotheken . . . . . . . . . . . . . . . . . . 320

III.2.b.2 Persönliche Sammlungen . . . . . . . . . . . . . . 321

III.3 Persönliche Einflüsse auf die Sammlung von Dichtung . . . . . 322

III.4 Dichtung in den Handschriften . . . . . . . . . . . . . . . . . . . . . . . 324

III.4.a Ausstattung . . . . . . . . . . . . . . . . . . 324

III.4.b Schreiber und Wachstum der Handschriften . . . . . . 325

III.4.c Textgesellschaften . . . . . . . . . . . . . . . . . . . . . . . . . . . . . . . . . . . .

III.4.d Auxiliartexte . . . . . . . . . . . . . . . . . . . . . . . . . . . . . . . . . . . . . . .

III.4.e Dichtung als Nachtrag . . . . . . . . . . . . . . . . . . . 329

III.5 Typologie der Sammlungen . . . . . . . . . . . . . . . . 330

III.5.a Autorenhandschriften und Autoren-Sammelkodizes . . . 330

III.5.a.1 Christliche Dichter . . . . . . . . . . . . . 330

III.5.a.2 Heidnische Dichter . . . . . . . . . . . 333

III.5.a.3 Zeitgenössische Dichter . . . . . . . . . . . . . . . 335

III.5.b Schulhandschriften . . . . . . . . . . . . . . . . . . . . . . . . . . 338

III.5.c Vademecum . . . . . . . . . . . . . . . . . . . . . . . . . . . . . . . . . . . . .

III.5.d Anthologien . . . . . . . . . . . . . . . . . . . . . . . . . . . . . . . . . . . . . .

III.5.e Kleinere Sammlungen und Genres . . . . . . . . . . . . 342

III.5.e.1 Hagiographie . . . . . . . . . . . . . . . . . . . . . . . . 342

III.5.e.2 Inschriften, Tituli, Epitaphien $\ldots . . . . . .342$

III.5.e.3 Briefdichtung . . . . . . . . . . . . 343 
III.5.e.4 Hymnen . . . . . . . . . . . . . . . . . . . . . . . . . . . 344

III.6 Genre als pragmatische Kategorie . . . . . . . . . . . . . . . . . . . . . 344

III.7 Dichtung und Schule - eine Schlussperspektive . . . . . . . . 346

IV. Bibliografie . . . . . . . . . . . . . . . . . . . . . . . . . . . . . . 347

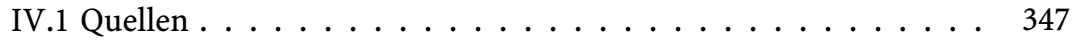

IV.1.a Sammelwerke . . . . . . . . . . . . . . . . . . . . . . . . . 347

IV.1.b Einzelausgaben . . . . . . . . . . . . . . . . . . . . . . . . . . 349

IV.2 Literatur . . . . . . . . . . . . . . . . . . . . 362

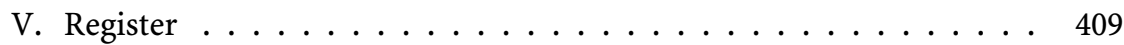

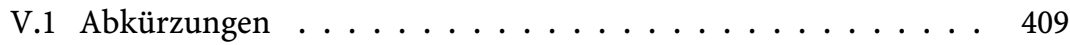

V.2 Handschriften . . . . . . . . . . . . . . . . . . . . . . . . . . . . . 410

V.3 Initien . . . . . . . . . . . . . . . . 418

V.4 Allgemeines Verzeichnis: Personen, Werke, Orte, Begriffe . . . . 425

V.5 Tabellarische Übersicht der Dichter in den Skriptorien . . . . . 436 
Open-Access-Publikation im Sinne der CC-Lizenz BY 4.0

(c) 2021, Vandenhoeck \& Ruprecht GmbH \& Co. KG, Göttingen ISBN Print: 9783847112310 - ISBN E-Lib: 9783737012317 


\section{Danksagung}

Den karolingischen Dichtern wäre es undenkbar erschienen, ihre Werke, an denen sie lange Jahre gearbeitet hatten, ohne poetische Danksagung und Widmung in die Welt treten zu lassen. Auch ich möchte mich an dieser Stelle, wenn auch in Prosa, bei all denen bedanken, ohne deren Rat und Hilfe diese Arbeit unmöglich gewesen wäre.

An erster Stelle gebührt hier der Dank meinem Doktorvater Philippe Depreux, der durch Anregung und Aufmunterung überhaupt erst den Anstoß zu dieser Arbeit gegeben hat. Von der Wahl des Themas über die Betreuung der Forschungsarbeit bis zum Abschluss des Buches hatte ich immer das Glück, bei ihm wissenschaftliche Freiheit und professionelle Anleitung zugleich zu finden. Ein besonderer Dank sei ihm hier auch für die zahlreichen Seminar- und Kongressteilnahmen ausgesprochen, bei denen ich meine Arbeit vorstellen und diskutieren konnte.

$\mathrm{Zu}$ großem Dank bin ich auch meinem Zweitbetreuer Marc-Aeilko Aris verpflichtet, der sich die Zeit genommen hat, die Arbeit auf ihren verschiedenen Stufen zu begleiten. Auch dem Drittgutachter der Dissertation, Peter Orth, verdanke ich eine Vielzahl fruchtbarer Hinweise und Vorschläge, durch die ich an vielen Stellen zu Verbesserungen angeregt wurde.

Dank gilt auch meinen Freunden und Kollegen vom Arbeitsbereich Mittelalterliche Geschichte der Universität Hamburg - von vielen seien hier nur Jérémy Winandy, Alexander Müller, Christoph Walther und Horst Lößlein genannt - die über den fachlichen Rat hinaus auch immer moralischen Beistand in den Mühen der Promotion geleistet haben.

Eine besondere Dankbarkeit empfinde ich auch gegenüber meinen Kollegen aus dem Sonderforschungsbereich $950 »$ Manuskriptkulturen in Asien, Afrika und Europa«, unter dessen Dach die Promotion stattgefunden hat. Ohne die zahllosen Diskussionen, Vorträge, Workshops und Konferenzen, auf denen Forscher verschiedenster Disziplinen sich über ihren gemeinsamen Gegenstand, die Handschrift, austauschen konnten, wäre diese Arbeit zweifellos eine ganz andere geworden. 
Eine Aufzählung aller Kommilitonen, mit denen mich die gemeinsame Erfahrung der Promotion freundschaftlich verbunden hat, würde den Rahmen dieser Danksagung überschreiten. Von ihnen bin ich jedoch Wiebke Beyer besonderen Dank schuldig, die immer Zeit für ihren Kollegen fand, ob für Kaffeekränzchen oder Kritik.

Meinen Eltern, meinen Freunden und meinen Lieben weiß ich keinen besseren Dank abzustatten, als dass ihnen diese Arbeit gewidmet sein soll.

Till Hennings 


\section{Einleitung}

\section{I.1 Dichtung und Gesellschaft}

Wenn ein kultivierter Mensch des 9. Jh. den Blick zurück auf seine Bildungslaufbahn warf, wird er sich kaum einer Zeit erinnert haben können, in der ihn nicht Dichtung in irgendeiner Form beschäftigte. Die Dichtung des Alten Testaments, die Psalmen, waren die ersten lateinischen Texte, mit denen die Schüler die gelehrte Sprache lesen und schreiben lernten. ${ }^{1}$ Fabelschreiber wie Avian und Moralschriftsteller wie Ps.-Cato waren die ersten Begleiter der Schüler in die Welt des klassischen Lateins. ${ }^{2}$ Die großen christlichen Dichter der Spätantike, die biblische Themen in klassische Formen gebracht hatten, waren unverzichtbare Studienbücher der lernenden Jugend.

Schon früh wurde darauf Wert gelegt, dass die Schüler das Latein nicht nur lesen, sondern schreiben und sprechen konnten. Ekkehard IV. hat uns in seiner Fortsetzung der Casus St. Galli eine Anekdote aufbewahrt, mit der er aus einer hundertjährigen Distanz die "gute alte Zeit« in der St. Galler Klosterschule zurückruft: ${ }^{3}$ Salomo III., Bischof von Konstanz und Abt von St. Gallen und selbst einst dort Schüler unter Notker Balbulus, ist zu Beginn des 10. Jh. zu Besuch im Kloster und visitiert die Schule. Die Schüler setzen ihn aus Spaß als ihren Lehrer ein, woraufhin er sie mit einer scherzhaften Strafe belegt, aus der sie sich befreien müssen:

1 Im Psalterfragment Karlsruhe, BSB Aug. Fr. 8 ist uns ein seltenes Zeugnis dieser frühen Übungen aufbewahrt. Die Silben sind hier durch Punkte getrennt und zwischen den Zeilen stehen zahlreiche unbeholfene Nachahmungen der Worte.

2 Die beiden Schriftsteller sind für Hoch- und Spätmittelalter im Elementarunterricht gut belegt: Michael Baldzunn, Schulbücher im Trivium des Mittelalters und der Frühen Neuzeit: die Verschriftlichung von Unterricht in der Text- und Überlieferungsgeschichte der "Fabulae" Avians und der deutschen "Disticha Catonis" (Quellen und Forschungen zur Literatur- und Kulturgeschichte, $44=(278))$, Berlin [u. a.] 2009.

3 Hans Frieder Haefele (Hrsg.), Ekkehardi IV. Casus Sancti Galli, St. Galler Klostergeschichten (Ausgewählte Quellen zur deutschen Geschichte des Mittelalters. Freiherr vom Stein-Gedächtnisausgabe 10), Darmstadt 1980. c. 26, S. 66. 
»[Und als er dagegen fragte]: ১Wie das?, redeten ihn die ganz Kleinen nach ihrem Wissen lateinisch an, die Mittleren rhythmisch, die übrigen aber metrisch, ja gar rhetorisch wie für die Rednerbühne. $\aleph^{4}$

Daraufhin freut Salomo sich, dass die Studien immer noch so gedeihen, wie sie es in seiner Jugend getan haben; er fühlt sich offenbar an die eigene Schulzeit erinnert. Die erzählende Quelle stimmt mit den Befunden der Handschriften überein, wie im Kapitel zu St. Gallen gezeigt werden wird: Nach dem Elementarunterricht lernten die Schüler zuerst rhythmische, dann klassisch-quantitative Dichtung und zwar bis zur aktiven Kompetenz in beiden Formen. Nicht nur Dichtung, sondern das Dichten selbst wurde gelehrt, wie man an den extemporierten Versen der Schüler sieht. Auch von solchen Schülergedichten sind eine Handvoll erhalten geblieben. ${ }^{5}$ Die Verwendung von Rhythmik und Metrik in der Schule ist kein Phänomen vom Ende des Jahrhunderts, die Kontinuität des Curriculums reicht viel weiter zurück: Schon in einer schulnahen Handschrift vom Beginn des 9. Jh. findet sich diese charakteristische Kombination. ${ }^{6}$ Salomos Schulerfahrung und die der Schüler zu Beginn des 10. Jh. ist also Teil einer alten St. Galler Tradition. ${ }^{7}$

Das Erlernen von Dichtung ist aber keineswegs ein Selbstzweck als bloße Schulübung. Dies zeigt der weitere Lebensweg Salomos. Schon das Kompendium seines Lehrers Notker Balbulus, das aus Formulae, Gedichten und Lektürempfehlungen besteht, enthält Dichtung nicht als Schulaufgabe, sondern im Anschluss an Urkunden und Briefe als Stilvorlage für die spätere Korrespondenz. Die bei Notker gelernten Fähigkeiten hatte Salomo später Gelegenheit anzuwenden. Er wendet sich mit einigen Trostepisteln an Bischof Dado von Verdun und exzelliert in Dichterwettkämpfen am Hofe. ${ }^{8}$ Gelegenheitsgedichte dieser Art hatten kaum eine Überlieferungschance, wenn sie nicht kodifiziert wurden. In der Tat ist von den Hofgedichten nichts erhalten. Bei der Sammlung der Briefgedichte dagegen scheint Salomo selbst die Hand im Spiel gehabt zu haben, denn sie sind in einer Handschrift vom Ende des Jahrhunderts enthalten, deren weitere Inhalte direkt auf die Empfehlungen seines Lehrers Notker zurückzugehen scheinen. ${ }^{9}$ Hier sehen wir Salomo als Abt direkt auf die Sammlung und $\mathrm{Zu}$ -

$4 » Q u o m o d o$ ? Parvuli latine pro nosse, medii rithmice, ceteri vero metrice, quasi pro rostris rhetorice aetiam, illum affantur.

5 Siehe unten S. 190-194 zu Wolfenbüttel, Cod. Guelf. 77 Weiss.

6 Leiden, Voss. Lat. Q. 69. Ähnliches Material auch in Neapel, Ms. IV G 68.

7 Studiis loco sancti Galli semper inolitis - auch dass Ekkehard fast hundert Jahre später die Anekdote zustimmend erzählt, deutet auf das weitere Bestehen dieses Curriculums, vgl. Peter SтотZ, »Dichten als Schulfach - Aspekte mittelalterlicher Schuldichtung", in: Mittellateinisches Jahrbuch 16 (1981), S. 1-16. S. 2.

8 Metro primus, et coram regibus plerumque pro ludicro cum aliis certator. HAEFele (Hrsg.): Casus Sancti Galli. S. 68.

9 Cod. Sang. 197. Die Empfehlungen stammen aus der Notatio de illustribus viris. 
sammenstellung von Dichtung einwirken. Dass er an der Begeisterung für Dichtung, die das Kloster zu dieser Zeit ergriff, teilhatte, zeigen auch die Gedichte, die in seinem Exemplar der Notkersammlung ergänzt wurden und die sich ebenfalls in den großen zeitgenössischen St. Galler Anthologien finden. ${ }^{10}$

War Salomo eine Ausnahme, ein seltener musischer Abt und Bischof unter seinen asketisch gestimmten Kollegen? Eine Gesamtschau über die Rolle der Dichtung in Literatur und Gesellschaft und über die zahlreichen Dichter des Jahrhunderts zeigt, dass Dichtung weit mehr war als nur eine Schulübung und -Fähigkeit, die man beim Eintritt ins Erwachsenenalter ablegte. Das Publikum der Dichtung war größer, als der Kreis der Dichter - Dichtung ist keine selbstreferentielle Kunstübung einer kleinen Gruppe Gelehrter, sondern war, wie an den zahllosen aus Patronatsbeziehungen entspringenden Dichtungen deutlich wird, ein probates Mittel zur Erlangung und Bewahrung der Gunst der Mächtigen. Ihren vollendeten Ausdruck findet diese Tendenz in den Dichterkreisen um Karl den Großen ${ }^{11}$ und später Karl den Kahlen. ${ }^{12}$ Auch wenn die Entourage eines Herrschers nicht geradezu am Hofe anwesend war, sondern verschiedene Stellen im Reich besetzte, adressierte man noch Dichtung an den abwesenden Patron. Das intendierte Publikum wurde durch die Performanz als "Vortragsdichtung" im Gegensatz zur Lesedichtung noch vermehrt. Voraussetzung dieser Rezeption über einen engen Gelehrtenkreis hinaus ist freilich eine grundsätzliche Rezeptivität des Publikums selbst, das heißt Latinität, die naturgemäß in kirchlichen Kreisen stärker vorauszusetzen ist. Dementsprechend richtet sich der Großteil der Gedichte an ein geistliches Publikum, zumal da natürlich auch bei mächtigen Bischöfen und Äbten Patronage zu erlangen war. Diese Kommunikation darf jedoch keinesfalls als einseitig von der niederen an die höhere Geistlichkeit gerichtet aufgefasst werden: Im Gegensatz zur Adressierung des Herrschers ist die Kommunikation der Geistlichen auch eine gegenseitige zwischen peers, die sich durch das geteilte Medium einer gereinigten Latinität als Zugehörige einer kulturellen Elite empfinden konnten. Zur Performanz am Hofe gesellt sich die Performanz der Gelehrten voreinander als gesellschaftliche Funktion der lateinischen Dichtung.

Ist nun jeder Abt und Bischof, ja jeder Mönch auch ein Dichter? Namentlich bekannte Dichter oder anonyme Verfasser größerer Werke bringen die Zahl der

10 Cod. Sang. 899, Zürich C 78.

11 Dieter Schaller, »Vortrags- und Zirkulardichtung am Hof Karls des Grossen«, in: Mittellateinisches Jahrbuch 6 (1970), S. 14-36.

12 Peter Godman, "Latin poetry under Charles the Bald and Carolingian poetry «, in: Charles the Bald. Court and kingdom, hrsg. von Margaret Templeton GiBson und Janet Loughland NeLson (BAR International series 101), Oxford 1981, S. 293-309. 
karolingischen Poeten auf ungefähr $70 .{ }^{13}$ Eine beachtliche Zahl, die aber kaum ins Gewicht fällt, wenn wir etwa an die Namenmassen der Abts- und Bischofsreihen oder gar die Heerscharen der Mönche in den Verbrüderungsbüchern denken. Selbst bei großen Verlusten karolingischer Dichtung - von denen insbesondere bei der Kleindichtung fraglos auszugehen ist - ist festzustellen, dass Dichtung auch innerhalb des geistlichen Standes eine Beschäftigung der wenigen war, anders als etwa Psalmengesang oder Bibellektüre.

Allerdings darf auch nicht von jedem Schreibkundigen erwartet werden, dass er ein Dichter sei. Ein angemessener Vergleichspunkt ist vielmehr die Zahl der Schriftsteller überhaupt. Von den ungefähr 50 bei Brunhölzl verzeichneten Autoren ${ }^{14}$ sind 29 auch als Dichter aufgetreten, ${ }^{15}$ ob mit Großwerken oder Kleindichtung wie Episteln oder Einleitungen. Bei einigen der nicht als Dichter erscheinenden darf man zudem misstrauisch sein, ob nicht kleinere Gedichte von ihrer Hand verlorengegangen sind. ${ }^{16}$ Von diesen Dichtern sind fast alle jedoch gleichzeitig auch in anderen Feldern schriftstellerisch tätig, ja ihre Dichtung ist nicht selten in Form von Einleitungen und Widmungen in diese anderen Werke integriert.

Die Kulturtechnik der Dichtung, die in der Elite vollendet wurde, ist aber durchaus auch in den weiteren kirchlichen Kreisen vorauszusetzen. Es sind gerade die kleinen, lokalen Dichtungen der zahllosen anonymi, die besonders starken Überlieferungsverlusten ausgesetzt waren. Insbesondere die Schülerund Lehrergedichte, die Schul- und Schreiberverse deuten auf eine versunkene Welt von Dichtung, in der auch der kleine Mönch sich im literarischen Spiel der

13 Nach den Registern in: Ernst Dümmler u. a. (Hrsg.), Poetae latini aevi Carolini (MGH Antiquitates), Berlin 1881-1939. Ähnlich, jedoch in Auswahl: Peter Godman, Poetry of the Carolingian Renaissance (Duckworth classical, medieval and Renaissance editions), London 1985.

14 Die Stichprobe (unter Ausschluss der Anonymi) nach Franz BrunhölzL, Geschichte der lateinischen Literatur des Mittelalters, 1: Von Cassiodor bis zum Ausklang der karolingischen Erneuerung, München 1996. S. 545-575. Der Zeitraum erstreckt sich ungefähr bis zum Ende des 9. Jh. Bei Max Manitius, Geschichte der lateinischen Literatur des Mittelalters. 1. Von Justinian bis zur Mitte des zehnten Jahrhunderts, München 1911. S. X f., sind ca. 80 Autoren genannt - die Verhältnisse bleiben sich gleich. Nicht berücksichtigt ist wegen des zeitlichen Rahmens Franz BRunhöLzL, Geschichte der lateinischen Literatur des Mittelalters, 2: Die Zwischenzeit vom Ausgang des karolingischen Zeitalters bis zur Mitte des 11. Jahrhunderts, München 1992.

15 Petrus von Pisa, Paulinus von Aquileia, Paulus Diaconus, Joseph Scotus, Theodulf, Angilbert, Dungal, Dicuil, Modoin, Einhard, Hrabanus Maurus, Brun Candidus, Walahfrid, Gottschalk, Ermenrich von Ellwangen, Paschasius Radbertus, Angelomus von Luxeuil, Agius von Corvey, Ermoldus Nigellus, Frechulf von Lisieux, Dhuoda, Florus von Lyon, Amalarius von Metz, Smaragdus von Saint-Mihiel, Sedulius Scottus, Johannes Scottus Eriugena, Lupus von Ferrières und Heiric von Auxerre. Man beachte das Fehlen frühkarolingischer Autoren.

16 So z. B. bei den Lehrern oder Grammatikern Rudolf von Fulda, Christian von Stablo, Remigius von Auxerre und Erchanbert. 
Eliten übte, um sich vielleicht, wie viele vor ihm, durch Talent und Fleiß zu ihnen emporzuarbeiten.

Hieraus ergeben sich zwei Beobachtungen über die Rolle der Dichtung in der karolingischen Literatur: 1. Dichtung ist ein zwar prominentes Genre, aber es gibt keine Dichter im Sinne einer ausschließlichen Beschäftigung hiermit. Dichtung ist als bloß formale Kategorie eine Form, die sich den verschiedensten Textgattungen anpassen kann, sei es als Primärtext in Form von Versversionen sonst prosaischer Texte wie etwa Viten oder Geschichtsschreibung, ${ }^{17}$ sei es als Komplementärtext zu größeren Werken. Sie kann somit mit den Inhalten der verschiedensten Genres erfüllt werden und eine gattungsübergreifende Funktion wahrnehmen. 2. Weist die weite Verbreitung dieser Fähigkeit innerhalb des Kreises der Schriftsteller auf die kommunikativ-interpersonelle Funktion der Form hin: Als weithin geteilte Kulturtechnik dient sie wie das Latein selbst als gegenseitiges Erkennungsmerkmal einer selbstbewussten kulturellen Elite. Durch ihre bloß formale, nicht inhaltliche Beschränkung eignet sie sich für dieses signalling mehr als jede andere inhaltlich gebundene Gattung der Literatur.

Die Basis der poetischen Bildung stellen die Bibliotheken dar. Von der ersten Schulhandschrift über den gelehrten Scholien-Band bis zur hier sorgsam verwahrten Prachthandschrift sind sie das universelle Rezeptorium, in dem die angesammelte Dichtung auf ihre Verwendung wartet. Von hier gelangte sie ad scholam, in die Schule, wie ein St. Galler Ausleihvermerk berichtet, und wurde dort von den Lehrern mit Anmerkungen versehen, von hier entnahm der Dichter die Bände, aus denen er die poetischen Zitate zum Schmuck des eigenen Werkes auswählen konnte, von hier lieh man an Freunde und Gönner seltene Texte aus. Das 9. Jh. ist die Blütezeit der karolingischen Bibliotheken, in der sie in einem Maße wuchsen, wie es erst wieder im Hochmittelalter erreicht werden sollte. Zahllose Dichter der Antike verdanken ihre Erhaltung dem Enthusiasmus der karolingischen Sammler, die in ihnen im Geiste der correctio die korrekte Latinität suchten, fanden und anwandten.

Die Fragmente der Bibliotheken, die Handschriften, sind neben den literarischen Quellen das Hauptzeugnis für die Sammlung und Verwendung von Dichtung in der Karolingerzeit. Während jedoch die karolingische Literatur, im Allgemeinen und in Einzelgattungen, eine Vielzahl von literaturgeschichtlichen Spezialuntersuchungen aufweisen kann, ${ }^{18}$ fehlt es bislang an einer synoptischen Erforschung der Überlieferung der Dichtung als Gattung im Gegensatz zu Untersuchungen zur Überlieferung einzelner Dichter. Letztere sind traditionell von

17 Wolfgang KIRsch, Laudes sanctorum. Geschichte der hagiographischen Versepik vom IV. bis X. Jahrhundert (Quellen und Untersuchungen zur lateinischen Philologie des Mittelalters 14), Stuttgart. S. 298.

18 Siehe unten S. 20-24 den Literaturüberblick. 
philologischen Fragen geleitet worden; mit der vorliegenden Arbeit wird versucht, kodikologische und philologische Grundlagenarbeit auch kulturhistorisch fruchtbar zu machen.

\section{I.2 Sammlungen von Dichtung - Begriffsklärung und Ziele}

Der Begriff Sammlung wird bewusst im doppelten Sinne gebraucht: Einerseits Gedichtsammlungen in Form der Handschriften selbst, die für Untersuchungsgebiet und -zeitraum so vollständig wie möglich erfasst wurden. Andererseits Sammlung von Dichtung als Tätigkeit, das heißt die Suche nach ihr, der Erwerb, die Zusammenstellung in Bibliothek und Handschriften, die hierbei leitenden Interessen der Sammler und natürlich die Sammlerpersönlichkeiten selbst.

Die Untersuchung orientierte sich an drei Hauptaspekten:

1. Quellen und Herkunft der Texte. Der Ort oder die Region, aus welchen eine Kloster- oder Kathedralbibliothek ihre Texte bezog, situiert sie im kulturellen Netzwerk der Karolingerzeit. Persönlichen als auch institutionellen Verbindungen wird in diesem Zusammenhang besondere Beachtung geschenkt. Die Erforschung der Beziehungen zwischen Handschriften und Textsammlungen verspricht einen neuen Blick auf die Beziehungen der verschiedenen Orte und Handelnden der kulturellen Produktion.

2. Die Herkunft der Texte leitet über in die Sammlungstätigkeit selbst, sowie die Zusammenstellung der Texte in Handschriften und Bibliothek. Untersucht werden insbesondere die Genese der einzelnen Handschrift und die enthaltenen Textgesellschaften. Hierin liegt der kodikologisch-paläographische Schwerpunkt der Arbeit. Zahlreiche Handschriften erfahren hier erstmals eine Untersuchung nach kodikologischen und textgeschichtlichen Gesichtspunkten, die über Katalogisierung und Textkritik hinausgehen.

3. Zuletzt wird die Nutzung der Handschriften untersucht, um Dichtung als Gattung in den institutionell-pragmatischen Kontext ihrer Sammlung und Produktion zu stellen. Die traditionelle Typologie von Gedichthandschriften wird hierbei einer Prüfung unterzogen und nach modernen kodikologischen Methoden neu bewertet. Eine wichtige Rolle hierbei spielt die Auseinandersetzung mit dem oft behaupteten schulischen Gebrauch von Dichtung und inwiefern sich dieser in den Handschriften widerspiegelt.

Die bisherigen Versuche einer Typologisierung beschränken sich meist auf im Vorübergehen gemachte Urteile in Katalogen oder Werken von nicht vorwiegend kodikologischem Forschungsinteresse. Drei Begriffe begegnen in der Forschung immer wieder: 
1. Autorenhandschriften ${ }^{19}$ sind solche, die Werke nur eines Dichters enthalten, und stellen somit eine scheinbar nur inhaltliche Kategorie dar. Diese überschneidet sich aber, wenn der Autor mit der Schule in Verbindung gebracht wird, oft konzeptionell mit den Schulhandschriften. Die Kategorie der Autorenhandschriften empfiehlt sich jedoch durch ihre Selbstevidenz, da tatsächlich zahllose Handschriften mit Werken nur eines Dichters erhalten oder in Katalogen verzeichnet sind. Diese breite Anwendung der Kategorie verschleiert jedoch beträchtliche Unterschiede besonders in Hinblick auf die Nutzung der Handschriften und sollte immer durch eine individuelle Würdigung modifiziert werden. Eine Unterart der Autorenhandschrift ist der von Glauche geprägte ${ }^{20}$ und ebenfalls in zahlreichen Handschriften vertretene Typus des "Autoren-Sammelkodex", in dem verschiedene Dichter in einem Band vereinigt werden. Glauche stellt diesen Typus als eine Art der Schulhandschrift dar, wiewohl er auch rein inhaltlich-formal verstanden und gebraucht werden kann.

2. Als Schulhandschrift werden sowohl Handschriften bezeichnet, die Dichtung und Grammatik vermischen, als auch solche, die mit der Schule verbundene Dichter enthalten. Die Kategorie vermischt somit pragmatische und inhaltliche Aspekte, oft unter Missachtung der kodikologischen Details. Die grundsätzlich korrekte Verbindung von Dichtung und Schule führt zur Reduktion von Gedichthandschriften auf diesen zwar wichtigen, aber nicht alle anderen ausschließenden pragmatischen Zusammenhang.

3. Anthologien werden Handschriften genannt, die fast ausschließlich kleinere Dichtung enthalten. Geprägt wurde der Begriff an den großen Sammlungen des Hochmittelalters (Carmina Burana, Codex Manesse ${ }^{21}$ ), die in Intentionalität und Komplexität der Sammlung die frühmittelalterlichen und insbesondere die ostfränkischen Sammlungen weit übertreffen. Da es im untersuchten Zeitraum Anthologien wie solche, auf die der Begriff ursprünglich wissenschaftlich angewandt wurde, nicht gibt, haftet ihm ein gewisser Anachronismus an. Kompliziert wird seine Verwendung noch durch die instinktive Bezeichnung "Anthologie« für größere und kleinere Gedichtsammlungen, die nur einen Teil einer Handschrift bilden, was der bei weitem

19 Dies ist kein etablierter Ausdruck wie Schulhandschrift, sondern ein Begriff, der aus den zahlreichen Paraphrasen desselben Gedankens wie »Werke«, "Sammelhandschrift der Werke«, »Vergil-Handschrift» oder oft nur dem Namen des Dichters als Bezeichnung der Handschrift hervorgeht.

20 Günter GlaUche, Schullektüre im Mittelalter. Entstehung und Wandlungen des Lektürekanons bis 1200 aus den Quellen dargestellt (Münchener Beiträge zur Mediävistik und Renaissance-Forschung 5), München 1978. S. 23-36.

21 Im volkssprachigen Falle spricht man von Liederhandschriften oder Chansonniers, die aber mutatis mutandis zeittypische Anthologien sind. 
häufigere Fall gegenüber reinen Anthologien ist. Der Begriff ist dennoch wegen seiner Betonung der Sammeltätigkeit beizubehalten, jedoch in seiner Anwendung auf vollständige Handschriften differenziert zu gebrauchen.

Diese drei Kategorien stellen ebenfalls idealtypisch drei verschiedene analytische Gesichtspunkte dar: Inhalt (Autorenhandschrift), Verwendung (Schulhandschrift) und Sammlung (Anthologie). Es ist jedoch klar, dass jede Handschrift unter all diesen Aspekten betrachtet zu werden verdient, sodass eine Trennung der Handschriften nur danach, wie je der eine oder andere Aspekt zu überwiegen scheint, von vornherein abzuweisen ist.

Ein weiteres schwerwiegendes Problem der bisherigen Kategorisierung ist, dass nur Handschriften darin erfasst werden, die zum größten Teil Dichtung enthalten, und damit a priori ein beträchtlicher Teil der Überlieferung ausgeschlossen wird. Ganze Gattungen wie Inschriften oder Formulardichtung werden kaum oder überhaupt nicht autonom überliefert, sondern in Anbindung an übergeordnete, nicht poetische Texte. Im Schlusskapitel soll eine neue Typologisierung der Handschriftenmassen versucht werden, in vollem Bewusstsein, dass eine scharfe Trennung zuletzt künstlich ist und in jedem einzelnen Falle anhand der Handschrift selbst zu korrigieren und zu verfeinern ist.

\section{I.3 Aspekte der Forschung}

Die vorliegende Arbeit liegt im Schnittpunkt verschiedener Forschungsfelder und setzt sich zum Ziel, die Trennung in historische, kodikologische und philologische Betrachtungsweisen auf interdisziplinäre Weise aufzuheben. Im folgenden Forschungsüberblick soll auf Aspekte der Forschung verwiesen werden, auf die sich die vorliegende Arbeit in ihren verschiedenen Interessen stützen kann. Ausführlichere Literaturangaben zu Einzelaspekten, insbesondere zu den Skriptorien, finden sich zu Beginn der Kapitel des Hauptteils.

\section{I.3.a Dichtung im Karolingerreich}

Übersichtsdarstellungen speziell zur karolingischen Dichtung bieten die Monographien von Godman und Stella, ${ }^{22}$ deren Schwerpunkt auf den Dichtern selbst, den von ihnen verwendeten Formen und Genres, sowie auf der gesell-

22 Insb. die Einleitung zu Godman: Poetry of the Carolingian Renaissance. Ebenso Francesco Stella, La Poesia carolingia (Le Lettere università 1, Le Antologie III), Florenz 1995. Ferner: Peter Godman, Poets and emperors: frankish politics and Carolingian poetry, Oxford 1987. 
schaftlichen Rolle von Dichtung liegt, wobei handschriftliche Erwägungen eine geringere Rolle spielen. $\mathrm{Zu}$ den Dichtern wird man auch in den allgemeineren Überblickswerken zur karolingischen Literatur ${ }^{23}$ oder zur lateinischen Dichtung $^{24}$ fündig.

Einigen Themen und Genres wurden Spezialuntersuchungen gewidmet, die einen Querschnitt durch die Dichtung der Zeit geben. Hervorzuheben ist hier Bernts Untersuchung zur Epigrammatik, die in vorbildlicher Weise das Zeugnis der Handschriften über die Editionen hinaus in Betracht zieht. ${ }^{25}$ Einzeluntersuchungen liegen ebenfalls vor zu Bibeldichtung, ${ }^{26}$ Lehrgedichten, ${ }^{27}$ Hagiographie, ${ }^{28}$ historischer Dichtung, ${ }^{29}$ Herrscherlob ${ }^{30}$ und zur biographischen Literatur

Peter Godman, »Louis `the Piousı and his poets«, in: Frühmittelalterliche Studien 19 (1985), S. 239-289. Godman: "Latin poetry under Charles the Bald and Carolingian poetry«. Peter Godman, "Il periodo carolingio", in: Lo Spazio Letterario del Medioevo, 1. Il Medioevo Latino. 3. La Ricezione del Testo, Rom 1995, S. 339-373.

23 Kritisch gehandhabt ist weiterhin ein guter Ausgangspunkt: Manitius: Geschichte, 1. Die literaturgeschichtliche Verfahrensweise Brunhölzls (Geschichte der lateinischen Literatur des Mittelalters, 1. Von Cassiodor bis zum Ausklang der karolingischen Erneuerung. München, 1996) kann den "Manitius", insbesondere was Textkritik und Kodikologie angeht, nicht ersetzen. Siehe auch mit weiterem zeitlichen Rahmen: Peter Dronke und Peter Hasler, Die Lyrik des Mittelalters: Eine Einführung (DTB. Wissenschaftliche Reihe 4287), München 1977. Gustav GRÖBER, Übersicht über die lateinische Litteratur von der Mitte des 6. Jahrhunderts bis zur Mitte des 14. Jahrhunderts [Neue Ausgabe des II. Bandes des Grundrisses der romanischen Philologie], München 1963.

24 Frederic James Edward RABY, A history of Christian-Latin poetry from the beginnings to the close of the middle ages, Oxford 1953. Frederic James Edward RABY, A history of secular Latin poetry in the middle ages, Oxford 1957. Joseph SzÖvÉRFFY, Weltliche Dichtungen des lateinischen Mittelalters. Ein Handbuch, 1: Von den Anfängen bis zum Ende der Karolingerzeit, Berlin 1979.

25 Günter Bernt, Das lateinische Epigramm im Übergang von der Spätantike zum frühen Mittelalter (Münchener Beiträge zur Mediävistik und Renaissance-Forschung 2), München 1968.

26 Francesco Stella, La poesia carolingia latina a tema biblico (Medioevo Latino. Biblioteca 9), Spoleto 1993. Dieter KARTsсноке, Bibeldichtung: Studien zur Geschichte der epischen Bibelparaphrase von Juvencus bis Otfrid von Weißenburg, München 1975. Reinhart Herzog, Die Bibelepik der lateinischen Spätantike (Theorie und Geschichte der Literatur und der schönen Künste 37), München 1975.

27 Thomas HAYe, Das lateinische Lehrgedicht im Mittelalter: Analyse einer Gattung (Mittellateinische Studien und Texte 22), Leiden [u. a.] 1997.

28 KIRSCH: Laudes sanctorum.

29 Alfred Ebenbauer, Carmen historicum. Untersuchungen zur historischen Dichtung im karolingischen Europa (Philologica Germanica 4), Wien 1978.

30 Franz Bittner, Studien zum Herrscherlob in der mittellateinischen Dichtung, [Diss. Universität Würzburg] 1962. 
unter Einbeziehung von metrischen Werken. ${ }^{31}$ Die Hymnenforschung hat traditionell einen starken kodikologischen Fokus. ${ }^{32}$

Besonders in neueren Arbeiten zu den karolingischen Dichtern sind philologisches Detail und historisches Interesse eine fruchtbare Verbindung eingegangen. Spezialuntersuchungen liegen vor zu Alkuin, ${ }^{33}$ Theodulf, ${ }^{34}$ Hrabanus, ${ }^{35}$ Walahfrid, ${ }^{36}$ Otfrid, ${ }^{37}$ Sedulius Scottus ${ }^{38}$ und Brun Candidus ${ }^{39}$. Ein unverzicht-

31 Walter Berschin, Biographie und Epochenstil im lateinischen Mittelalter, 3: Karolingische Biographie 750-920 n. Chr. (Quellen und Untersuchungen zur lateinischen Philologie des Mittelalters 10), Stuttgart 1991.

32 Klaus Gamber, Codices liturgici latini antiquiores (Spicilegium Friburgense. Subsidia 1, 1-3), Freiburg i. Ue 1968. Helmut GNeuss, Hymnar und Hymnen im englischen Mittelalter: Studien zur Überlieferung, Glossierung und Übersetzung lateinischer Hymnen in England; mit einer Textausgabe der lateinisch-altenglischen Expositio Hymnorum (Buchreihe der Anglia 12), Tübingen 1968. James Mearns, Early Latin hymnaries, Cambridge 1913.

33 Hans-Dieter Burghardt, Philologische Untersuchungen zur den Gedichten Alkuins, [Universität Heidelberg] 1960. Berührt wird seine Dichtung auch in: Donald Auberon Bullough, Alcuin: achievement and reputation (Education and society in the Middle Ages and Renaissance 16), Leiden [u.a.] 2002. Christiane VeYRARD-Cosme, Tacitus Nuntius: recherches sur l'écriture des Lettres d'Alcuin (Collection des Études Augustiniennes : Série Moyen Âge et Temps modernes 50), Paris 2013. Vera Fravventura (Hrsg.), L'Enchiridion in Psalmos di Alcuino di York. Edizione critica (Millennio Medievale 112, Testi 27), Florenz 2017.

34 Dieter Schaller, "Philologische Untersuchungen zu den Gedichten Theodulfs von Orléans", in: Deutsches Archiv für Erforschung des Mittelalters 18 (1962), S. 13-91. Alejandra de RiQueR, Teodulfo de Orleans y la epistola poética en la literatura carolingia (Instituto de Estudios Histórico - Literarios), Barcelona 1994.

35 Michele Camillo Ferrari, Il "Liber sanctae crucis" di Rabano Mauro. Testo, immagine, contesto (Lateinische Sprache und Literatur des Mittelalters 30), Bern 1999. Michel Jean-Louis PERRIN, "Le De laudibus sanctae crucis de Raban Maur et sa tradition manuscrite au IXe siècle«, in: Revue d'histoire des textes 19 (1989), S. 191-251. Hans-Georg MüLLER, Hrabanus Maurus - De laudibus sancta crucis - Studien zur Überlieferung und Geistesgeschichte mit dem Faksimile - Textabdruck aus Codex Reg. Lat. 124 der Vatikanischen Bibliothek (Mittellateinisches Jahrbuch. Beihefte 11), Stuttgart 1973. Vgl. auch Raymund Kоттje, Verzeichnis der Handschriften mit den Werken des Hrabanus Maurus (MGH Hilfsmittel 27), Hannover 2012. $\mathrm{Zu}$ seiner Kleindichtung liegt leider keine eingehende Untersuchung vor. (Ansätze hierzu in Hans Frieder Haefele, "'Decerpsi pollice flores. A Aus Hrabans Vermischten Gedichten«, in: Tradition und Wertung. Festschrift für Franz Brunhölzl zum 65. Geburtstag, hrsg. von Günter Bernt, Fidel Rädle und Gabriel Silagi, Sigmaringen 1989, S. 59-74.)

36 Noch unveröffentlicht ist: Jelle VIsSER, Sis memor Strabonis. Context and communicative value of Walahfrid Strabo's poetry, RMA Thesis, Universität Utrecht 2012. Ich danke dem Verfasser für die freundliche Mitteilung seiner Arbeit. Einzelne Werke Walahfrids wurden mit verstärktem Fokus auf die Handschriften neu veröffentlicht: Boris SolINSKI, »Le >De uita et fine sancti Mammae monachi< de Walahfrid Strabon: texte, traduction et notes", in: The journal of medieval Latin 12 (2002), S. 1-77. Hermann KnitTeL (Hrsg.), Heito und Walahfrid Strabo: Visio Wettini. Einf., lat.-dt. Ausg. und Erl., 3., erw. Aufl. (Reichenauer Texte und Bilder 12), Heidelberg 2009. Michael W. Herren, "The >De imagine Tetrici of Walahfrid Strabo: edition and translation «, in: The journal of medieval Latin 1 (1991), S. 118-139.

37 Das Evangelienbuch liegt in mehreren diplomatischen Ausgaben vor, siehe: »Handschriftencensus | Otfrid von Weißenburg: `Evangelienbuch«", http://www.handschriftencensus.de/ werke/1285 (abgerufen am 11.01.2019). 
bares, wenn auch veraltetes Findmittel stellt Dümmlers Repertorium zur Überlieferung der karolingischen Dichter dar. ${ }^{40}$

\section{I.3.b Textkritik und Textgeschichte}

Mit einigen der eben zitierten Titel befinden wir uns schon im Gebiet der Textkritik. Die klassische Philologie, die für die Überlieferung der klassischen Schriftsteller, ob heidnisch oder christlich, befragt werden muss, hat sich oft wenig für die Handschriften über ihren bloß textuellen Gehalt hinaus interessiert. Textgeschichtliche Arbeiten haben hier das Verständnis der späteren Rezeption bedeutend vermehrt. Zur antiken Dichtung ist hervorzuheben der von Reynolds herausgegebene enzyklopädische Sammelband zur Textgeschichte der klassischen Literatur. ${ }^{41}$ Explizit hieran orientiert sich das Sammelwerk "La trasmissione dei testi latini del Medioevo", in dem die Textgeschichte einiger Dichter von der Spätantike bis in die karolingische Zeit referiert wird. ${ }^{42}$ Bisweilen können diese mitunter recht kompakten Übersichten - ebenso wie die Einleitungen der kritischen Editionen - durch umfangreiche Monographien zur Überlieferung der einzelnen Dichter supplementiert werden..$^{43}$ Auch aus mittel-

38 Reinhard Düchting, Sedulius Scottus. Seine Dichtung, München 1968.

39 Gereon BeCht-Jördens (Hrsg.), Vita Aegil abbatis Fuldensis a Candido ad modestum edita prosa et versibus: ein Opus geminum des IX. Jahrhunderts; Einleitung und kritische Edition, Marburg 1994.

40 Ernst DüMmLeR, "Die handschriftliche Überlieferung der lateinischen Dichtungen aus der Zeit der Karolinger«, in: Neues Archiv der Gesellschaft für ältere deutsche Geschichtskunde 4 (1879), S. 87-159, 239-322, 511-582.

41 Leighton Durham ReynolDs, Texts and transmission: a survey of the Latin classics, Oxford 1983. Für eine allgemeine Überlieferungsgeschichte siehe weiterhin Leighton Durham REYNOLDS und Nigel Guy Wilson, Scribes and Scholars. A Guide to the Transmission of Greek and Latin Literature, Oxford 1968. Vgl. auch Bernhard BischOFF, "Paläographie und frühmittelalterliche Klassikerüberlieferung", in: Bischoff, Mittelalterliche Studien, 3, 1981, S. 5572.

42 Paolo Chiesa und Lucia Castaldi, La trasmissione dei testi latini del Medioevo, $5 \mathrm{Bd}$. (Millennio medievale. Strumenti e studi), Florenz 2004. Vgl. auch die relevanten Beiträge in: Lo spazio letterario del medioevo. 1. Il medioevo latino, 1-5, Roma 1992.

43 David J. Butterfield, The early textual history of Lucretius' De rerum natura, Cambridge 2013. Sesto Prete, "La tradition textuelle et les manuscrits d'Ausone», in: Revue française d'histoire du livre 46 (1985), S. 101-157. Harold C. GoтоFF, The Transmission of the Text of Lucan in the Ninth Century, Cambridge 1971. Widu-Wolfgang EHLERs, Untersuchungen zur handschriftlichen Überlieferung der Argonautica des C. Valerius Flaccus (Zetemata 52), München 1970. Georg LucK, Untersuchungen zur Textgeschichte Ovids (Bibliothek der klassischen Altertumswissenschaften 29), Heidelberg 1969. Ulrich KNocHe, Handschriftliche Grundlagen des Juvenaltextes (Philologus, Supplement 1), Leipzig 1940. Otto KeLler, Beschreibung der wichtigsten Horazhandschriften, Leipzig 1899. Rudolf PEIPER, Die handschriftliche Ueberlieferung des Ausonius, Leipzig 1879. 
lateinischer und mediävistischer Perspektive wird der Überlieferung der klassischen Dichter Aufmerksamkeit geschenkt, mit besonderem Augenmerk auf die Rezeption und Nutzung der Handschriften. ${ }^{44}$ Katalogwerke zu einzelnen Autoren liefern ebenfalls wertvolle Hinweise zu Herkunft und Einordnung der Handschriften, ${ }^{45}$ allen voran Munk Olsens umfassende Studien zur Überlieferung der antiken Literatur. ${ }^{46}$

\section{I.3.c Kodikologie}

Der paläographische Ausgangspunkt dieser Arbeit sind die Werke Bernhard Bischoffs, insbesondere der »Katalog der festländischen Handschriften ${ }^{47}$, sowie seine Einzeluntersuchungen zu verschiedenen Skriptorien ${ }^{48}$. Der Katalog lag in

44 Justin StOver, "Olybrius and the Einsiedeln Eclogues", in: The Journal of Roman Studies 105 (2015), S. 288-321. Tino LIснт, „Aratoris fortuna. Aufgang und Überlieferung der Historia apostolica", in: Quaerite faciem eius semper. Studien zu den geistesgeschichtlichen Beziehungen zwischen Antike und Christentum als Dankesgabe für Albrecht Dihle aus dem Heidelberger "Kirchenväterkolloquium», hrsg. von Andrea Jördens u. a. (Studien zur Kirchengeschichte 8), Hamburg 2008, S. 163-179. Tino Licht, »Horazüberlieferung im Frühmittelalter«, in: Ex Praeteritis Praesentia: Sprach-, literatur- und kulturwissenschaftliche Studien zu Wort- und Stoffgeschichten; Festschrift zum 70. Geburtstag von Theo Stemmler, hrsg. von Matthias Eitelmann und Nadine Stritzke (Anglistische Forschungen 370), Heidelberg 2006, S. 109-134. Louis HoLtz, "La redécouverte de Virgile aux VIIIe et IXe siècles d'après les manuscrits conservés", in: Publications de l'École française de Rome 80 (1985), S. 930. Dieter SCHALLER, »Frühkarolingische Corippus-Rezeption«, in: Wiener Studien 105 (1992), S. 173-187. Franz BRUNHöLzL, »Zur Überlieferung des Lukrez«, in: Hermes XC (1962), S. 97104. Siehe auch: Birger MunK OLsEn, »Bibliographie de la reception de la litterature classique du IXe au XVe siècle«, in: The classical tradition in the middle ages and the Renaissance, hrsg. von Claudio Leonardi und Birger Munk Olsen (Medioevo Latino. Biblioteca 15), Spoleto 1995. Karsten Friss-Jensen, Birger Munk Olsen und Ole Langwitz Smith, »Bibliography of classical scholarship in the Middle Ages and the early Renaissance (9th to 15th centuries) «, in: Medieval and Renaissance Scholarship, hrsg. von Nicholas Mann und Birger Munk Olsen (Mittellateinische Studien und Texte 21), Leiden 1997, S. 197-251.

45 Carl P. E. SPRINGER, The manuscripts of Sedulius: a provisional handlist (Transactions of the American Philosophical Society 5), Philadelphia 1995. Claudio Leonard, "I codici di Marziano Capella", in: Aevum 34 (1960), S. 1-99, 411-524. Claudia Villa, "I manoscritti di Orazio«, in: Aevum 66, 67, 68 (1992), S. 95-135, 55-103, 117-146.

46 Birger Munk Olsen, L'étude des auteurs classiques latins aux XIe et XIIe siècles, 4 Bände (Documents, études et répertoires), Paris 2009. Siehe auch: Birger Munk Olsen, »Les classiques latins dans les florilèges médiévaux antérieurs au XIII siècle«, in: Revue d'histoire des textes IX (1979), S. 47-121. (1980): 115-164.

47 Bernhard Bischoff, Katalog der festländischen Handschriften des neunten Jahrhunderts (mit Ausnahme der wisigotischen). 3. Bände. (Veröffentlichungen der Kommission für die Herausgabe der mittelalterlichen Bibliothekskataloge Deutschlands und der Schweiz), Wiesbaden 1998.

48 Bernhard Bischoff, Die südostdeutschen Schreibschulen und Bibliotheken in der Karolingerzeit. 1: Die bayerischen Diözesen. 2. Die vorwiegend österreichischen Diözesen., Wiesbaden 
verschiedenen Stufen der Fertigstellung vor und musste aus dem Nachlass herausgegeben werden. Das Ergebnis hat Kritik hervorgerufen. ${ }^{49}$ An Bischoffs Forschungsergebnissen wurde bisher jedoch kaum gerüttelt. Die Kritik an Bischoffs apodiktischer Vortragsweise im Katalog fasst Hoffmann zusammen: „So, wie die Dinge liegen, kann man jedenfalls die jetzt gedruckten Vorschläge der Lokalisierung und Datierung, soweit sie nicht auf bereits publizierten Studien beruhen, nur mit Vorbehalt annehmen, nämlich mit dem Vorbehalt, daß sie wahrscheinlich oder sogar sehr wahrscheinlich richtig sind, weil Bischoff sich selten geirrt haben dürfte; doch sind sie letztlich nicht bewiesen. ${ }^{50}$ Die meist nur summarischen Inhaltsangaben müssen überall durch die spezifischen Bibliothekskataloge ergänzt werden, die in ihrer Gründlichkeit ebenfalls variieren. ${ }^{51}$

Von besonderem Wert für die Situierung der Handschriften innerhalb ihres kulturellen und institutionellen Umfeldes sind die Spezialuntersuchungen zu einzelnen Skriptorien, ${ }^{52}$ oft als Teil einer zusammenfassenden Würdigung der kulturellen Zentren.

Ein leider seltener Gegenstand der Forschung sind einzelne Handschriften, in denen - anders als in fachlich begrenzten Betrachtungen - alle relevanten Aspekte einer Handschrift behandelt werden können. ${ }^{53}$ Viele der in dieser Arbeit

1960. Bernhard Bischoff, Die Abtei Lorsch im Spiegel ihrer Handschriften (Geschichtsblätter für den Kreis Bergstraße. Sonderband 10), Lorsch 1989. Bernhard Bischoff und Josef Hofmann, Libri Sancti Kyliani: die Würzburger Schreibschule und die Dombibliothek im VIII. und IX. Jahrhundert (Quellen und Forschungen zur Geschichte des Bistums und Hochstifts Würzburg 6), Würzburg 1952.

49 Hartmut Hoffmann, "Zum 2. Band von Bernhard Bischoffs `Katalog der festländischen Handschriften des 9. Jahrhunderts«", in: Deutsches Archiv für Erforschung des Mittelalters 61 (2005), S. 53-72. Zum dritten Band: David GANZ, Carolingian Manuscripts. The Verdict of the Master«, in: Francia 42 (2015), S. 253-274.

50 Hartmut Hoffmann, »Bernhard Bischoff und die Paläographie des 9. Jahrhunderts«, in: Deutsches Archiv für Erforschung des Mittelalters 55 (1999), S. 549-590. S. 559.

51 Die Kataloge nach dem neuen DFG-Standard sind zu finden in: "Übersicht über die in Deutschland seit 1991 erschienenen Kataloge abendländischer Handschriften «, in: Das Mittelalter 14 (2009), S. 17-28. Deutsche Forschungsgemeinschaft / Unterausschuss FüR Handschriftenkatalogisierung, Richtlinien Handschriftenkatalogisierung, 5., erweiterte Aufl., Bonn-Bad Godesberg 1992. S. 13f.

52 Einen Überblick über die meisten wichtigen Skriptorien aus germanistischer Perspektive, mit zahlreichen Querverbindungen zu Dichtung und Schule, bietet Martin J. Schubert (Hrsg.), Schreiborte des Mittelalters. Skriptorien, Werke, Mäzene, Berlin [u.a.] 2013. Einige der Skriptorien sind auch behandelt in: Émile LeSNe, Les livres, "Scriptoria« et Bibliothèques $d u$ commencement du VIII. à la fin du XI. siècle (Histoire de la propriété ecclésiastique en France IV (Mémoires et travaux 46)), Lille 1938. Vgl. hierzu auch die einleitenden bibliographischen Fußnoten der einzelnen Kapitel des Hauptteils dieser Arbeit.

53 Giorgia Vocino, "A Peregrinus's Vade Mecum: MS Bern 363 and the >Circle of Sedulius Scottus «, in: The Annotated Book in the Early Middle Ages, hrsg. von Mariken TeEuwen und Irene van Renswoude (Utrecht Studies in Medieval Literacy 38), Turnhout 2017, S. 87-123. Uwe GRupp, "Der Codex Sangallensis 397 - ein persönliches Handbuch Grimalds von St. Gallen?«, in: Deutsches Archiv für Erforschung des Mittelalters 70 (2014), S. 425-463. 
behandelten Handschriften erhalten zum ersten Mal eine nur ihnen gewidmete und über den modernen Bibliothekskatalog hinausgehende Behandlung.

\section{I.3.d Bibliotheksgeschichte}

Die Bibliothek ist der Ort der Sammlung schlechthin und die in ihr zu beobachtenden Textgesellschaften reflektieren als Makrokosmos den Mikrokosmos der Sammlung innerhalb der Handschriften. Oft ist von großen Bibliotheken kaum mehr als der Katalog übrig geblieben und selbst in den zeitgenössischen Inventaren ansonsten gut erhaltener Bestände finden sich zahlreiche verlorene Titel. Insofern kann eine Untersuchung der Sammlung von Dichtung weder an den mittelalterlichen Bibliothekskatalogen selbst, noch an der weiteren Bibliotheksgeschichte vorübergehen. Querschnittsartige Behandlungen von Bibliothekskatalogen liegen bisher nur in Bezug auf die Überlieferung der Klassiker vor. $^{54}$ Die Editionen der Reihe $"$ Mittelalterliche Bibliothekskataloge Deutsch-

Carmen Cardelle de Hartmann, »La miscelánea del códice München, BSB, Clm 14497, el >De ortu et obitu patriarcharum y el >De numeris $<$ pseudoisidoriano", in: Filologia mediolatina. Rivista della Fondazione Ezio Franceschini 19 (2012), S. 9-44. Lukas Wolfinger, "Die sogenannten >Carmina Salisburgensia und der Clm. 14743«, in: Quellen zur Salzburger Frühgeschichte, hrsg. von Herwig Wolfram (44), Wien 2006, S. 179-262. Samuel James BARrett, Notated verse in ninth-and tenth-century poetic collections. Diss. University of Cambridge, Cambridge 2000. Franz BrunhöLzL, Studien zum geistigen Leben in Passau im achten und neunten Jahrhundert (Abhandlungen der Marburger Gelehrten Gesellschaft 26), München 2000. Hans-Walter STORк, „Die Sammelhandschrift Zürich, Zentralbibliothek, C 78«, in: De Karolo rege et Leone papa. Der Bericht über die Zusammenkunft Karls des Großen mit Papst Leo III. in Paderborn 799 in einem Epos für Karl den Kaiser, hrsg. von Wilhelm Hentze (Studien und Quellen zur westfälischen Geschichte 36), Paderborn 1999, S. 105-118. Hildegard L. C. Tristram, "Die irischen Gedichte im Reichenauer Schulheft", in: Studia celtica et indogermanica: Festschrift für Wolfgang Meid zum 70. Geburtstag, hrsg. von Peter Anreiter und Erzsébet Jerem, Budapest 1999, S. 503-529. John Joseph Contreni, Codex Laudunensis 468. A Ninth-Century Guide to Virgil, Sedulius, and the Liberal Arts (Armarium codicum insignium 3), Turnhout 1984. Dieter SCHALlER, "Frühmittelalterliche lateinische Dichtung in einer ehemals St. Galler Handschrift", in: Zeitschrift für deutsches Altertum und deutsche Literatur 93 (1964), S. 272-291. Dieter SCHALLER, "Die karolingischen Figurengedichte des Cod. Bern. 212.", in: Medium aevum vivum: Festschrift für Walther Bulst, hrsg. von Hans Robert Jauss und Dieter SCHALler, Heidelberg 1960, S. 22-47. Leslie Webber JonEs, "Cologne MS. 106: A Book of Hildebald", in: Speculum 4 (1929), S. 27-61.

54 Birger Munk Olsen, Munk Olsen, L'étude des auteurs classiques latins 3, 1 (Documents, études et répertoires), Paris 1987. An Praktikabilität unübertroffen (jedoch abhängig vom überholten Gustav BECKER, Catalogi bibliothecarum antiqui, Bonn 1885) ist Max MANitıus, Handschriften antiker Autoren in mittelalterlichen Bibliothekskatalogen (Zentralblatt für Bibliothekswesen. Beiheft 67), Leipzig 1935. Zum Thema siehe auch Albert Derolez, Les catalogues de bibliothèques (Typologie des sources du moyen âge occidental 3), Turnhout 1979. 
lands und der Schweiz ${ }^{55}$ sind bekanntlich sehr zurückhaltend mit Identifikationen von Autoren oder gar Handschriften und konnten in dieser Hinsicht an zahlreichen Stellen ergänzt werden. Auch die Erkenntnisse der Editionen und Kommentare einzelner Kataloge konnten in Bezug auf die Dichtung vielfach vermehrt werden. ${ }^{56}$ Die Kataloge oder bei deren Mangel die erhaltenen Handschriften stehen im Mittelpunkt der bibliotheksgeschichtlichen Untersuchungen, ${ }^{57}$ in denen ein stärkerer Fokus als anderswo auf der Einordnung der Autoren und Handschriften in ihren zeitgenössischen Nutzungszusammenhang liegt.

\section{I.3.e Anthologien}

Obwohl Anthologien seit den 1990er Jahren stärker in den Fokus der Forschung gerückt sind, liegt der Schwerpunkt meist auf den hochmittelalterlichen ${ }^{58}$ oder spätantiken Sammlungen, ${ }^{59}$ bei letzteren insbesondere auf der Anthologia Lati-

55 Sowie das Schwesterprojekt Theodor Gotтlieb u. a. (Hrsg.), Mittelalterliche Bibliothekskataloge Österreichs, 1-5, Graz [u.a.] 1915- (1971).

56 Angelika HäsE, Mittelalterliche Bücherverzeichnisse aus Kloster Lorsch: Einleitung, Edition und Kommentar (Beiträge zum Buch- und Bibliothekswesen 42), Wiesbaden 2002. Wolfgang Milde, Der Bibliothekskatalog des Kloster Murbach aus dem 9. Jahrhundert: Ausgabe und Untersuchung von Beziehungen zu Cassiodors "Institutiones" (Euphorion. Beihefte 4), Heidelberg 1968. Karl-Ernst GeIth und Walter Berschin, »Die Bibliothekskataloge des Klosters Murbach aus dem IX. Jahrhundert«, in: Zeitschrift für Kirchengeschichte 83 (1972), S. 61-87. Alfred Holder und Karl Preisendanz, Grundstock der Bibliothek; die alten Kataloge; Zeugnisse zur Bibliotheksgeschichte. Neudr. d. Ausg. 1918 (Die Reichenauer Handschriften, 3. 1,2), Wiesbaden 1973.

57 Joachim M. РцотZек, "Zur Geschichte der Kölner Dombibliothek«, in: Glaube und Wissen im Mittelalter. Katalogbuch zur Ausstellung, München 1998, S. 15-64. Hermann-Josef ScHMALOR, "Die Bibliothek der ehemaligen Reichsabtei Corvey«, in: Westfälische Zeitschrift 147 (1997), S. 251-270. Isabel Кловцісн, Die Bibliothek des Klosters St. Maximin bei Trier bis zum 12. Jahrhundert, Trier 1996. Otto MAZAL, "Die Salzburger Dom- und Klosterbibliothek in karolingischer Zeit», in: Bibliothekswesen und Forschung. Festgabe für Otto Mazal (Studien zur Bibliotheksgeschichte 4), Graz 1982, S. 40-60. Johannes PöRnBACHER, „Freisings geistige Bedeutung im 8. und 9. Jahrhundert: Die Anfänge von Domschule und Bibliothek«, in: Jahresbericht. Dom-Gymnasium Freising (1960), S. 38-48. Hofman in: Bischoff/Hofmann: Libri Sancti Kyliani. Auch die Einleitungen der modernen Bibliothekskataloge bieten mitunter umfassende bibliotheksgeschichtliche Darstellungen, z. B. Michael KaUtZ, Bibliothek und Skriptorium des ehemaligen Klosters Lorsch: Katalog der erhaltenen Handschriften, Wiesbaden 2016. Günter Glauche, Hermann Knaus und Bernhard Bischoff (Hrsg.), Mittelalterliche Bibliothekskataloge Deutschlands und der Schweiz. 4, 2: Bistum Freising, Bistum Würzburg, München 1979. Hans Butzmann, "Die Weissenburger Handschriften. Einleitung zum Katalog (1964)«, in: Hans Butzmann: Kleine Schriften: Festgabe zum 70. Geburtstag. Als Festgabe der Herzog August Bibliothek Wolfenbüttel, hrsg. von Wolfgang MiLdE (Studien zur Bibliotheksgeschichte 1), Graz 1973, S. 48-103.

58 Eine Übersicht: Arthur George RIGG, "Anthologies and florilegia», in: Medieval Latin. An introduction and bibliographical guide 1996, S. 708-712. Besonderes Interesse schenkte die 
na, ${ }^{60} \mathrm{zu}$ deren Erweiterung und Kritik frühmittelalterliche Handschriften oft als bloße Textgeber herangezogen werden. ${ }^{61}$ Die großen hochmittelalterlichen Anthologien $^{62}$ zeigen einen Grad der Organisation und sammlerischen Absicht, der in den frühmittelalterlichen und insbesondere den ostfränkischen Sammlungen nicht zu finden ist. ${ }^{63}$ Phänomene wie thematische Gruppierung oder Übernahme von Gedichtsequenzen finden sich jedoch auch hier. Zudem ist die Beschränkung auf die lyrische Kleindichtung zwar der Fülle des hochmittelalterlichen Materials geschuldet, ${ }^{64}$ jedoch im Frühmittelalter angesichts der Vermischung nicht nur von poetischen Genres, sondern von Poesie und Prosa allgemein nicht aufrechtzuerhalten.

Hier geht die Erforschung der Anthologien von selbst über in die Erforschung der Sammelhandschriften, die in der Sammlung von Dichtung eine große Rolle spielen. Die Analyse ihrer Genese ${ }^{65}$ als auch ihrer Inhalte ${ }^{66}$ kann oft den entscheidenden Anstoß zur Beurteilung der enthaltenen Dichtung liefern.

Germanistik natürlicherweise den Liederhandschriften (Gisela KoRNRUMPF, «Art. Liederbücher, Liederhandschriften«, in: Lexikon des Mittelalters, 5, 1991, S. 1971-1974) und die Romanistik den Chansonniers (Giorgio Busetto, "Art. Canzoniere», in: Lexikon des Mittelalters, 2, 1983, S. 1468-1469; Hans-Erich KelLER, "Art. Chansonnier«, in: Lexikon des Mittelalters, 2, 1983, S. 1709.).

59 Siehe die Auswahl der Autoren in Joachim Gruber, "Art. Anthologie«, in: Lexikon des Mittelalters, 1, 1980, S. 695-699.

60 David R. Shackleton Bailey (Hrsg.), Libri Salmasiani aliorumque carmina (Bibliotheca scriptorum Graecorum et Romanorum Teubneriana), Stuttgart 1982.

61 So die weiteren Handschriften in Alexander RIESE und Franz Bücheler (Hrsg.), Anthologia latina, Leipzig 1868-1926. Für eine Neuauswertung siehe: Loriano ZURLI, The manuscript transmission of the "Anthologia Latina" (Anthologiarum Latinarum parerga 6, Anthologiarum Latinarum manuscripta 3), Hildesheim 2017.

62 Pascale Bourgain, "Réflexions sur la genése des chansonniers latins«, in: Convivio. Estudios sobre la poesía de cancionero, hrsg. von BeLtrán PePió und Juan Salvador PAREdes NúÑEz, Granada 2006, S. 241-262. Peter Dronke, "Le antologie liriche del Medioevo latino", in: Critica del testo. II, 1 (1999), S. 1000-1017. Für Handschriften und umfassende Bibliographien siehe: Arthur George RIGG, »Medieval Latin Poetic Anthologies I-III«, in: Mediaeval Studies $39,41,49$.

$63 \mathrm{Zu}$ frühmittelalterlichen Anthologien siehe insbesondere die zahlreichen Veröffentlichungen Francesco Stellas. Als Ausgangspunkt für die verschiedenen Studien kann dienen: Francesco Stella (Hrsg.), Corpus Rhythmorum Musicum Saec. IV-IX, 1. Songs in non-liturgical sources $=$ Canti di tradizione non liturgica. I, Lyrics $=$ Canzoni, Firenze 2007. Siehe hierzu mit vielen zusätzlichen Materialien die Projektseite »Corpus Rhythmorum Musicum (saec. IV-IX)«, http://www.corimu.unisi.it/ (abgerufen am 15.01.2019). Das Problem der Textgemeinschaften wird mit Bezug auf zahlreiche zeitgenössische Anthologien behandelt in: FERRARI: Liber sanctae crucis. Für den Forschungsstand ist es bezeichnend, dass zur großen Anthologie der Carmina Centulensia (Brüssel, BR, Ms. 10470-10473, Ludwig Traube (Hrsg.), MGH Poet. lat. 3, Berlin 1896. S. 274-368, 753-754) noch keine Monographie vorliegt.

64 Arthur George RIGG, "Medieval Latin Poetic Anthologies«, in: Mediaeval Studies 39 (1977), S. 281-330. S. 284.

65 Mit umfangreichem Forschungsüberblick: Patrick Andrist, Paul CANART und Marilena Maniaci, La syntaxe du codex: essai de codicologie structurale, Turnhout 2013. 


\section{I.3.f Schule und Dichtung}

Dichtung als Schullektüre ist ein dominantes Thema der Studien zur Rezeption und Produktion von Dichtung in der Karolingerzeit. Auch die vorliegende Arbeit wird sich an zahlreichen Stellen mit der oft summarisch angenommenen Verwendung von Dichtung als Schultext auseinanderzusetzen haben. In allgemeinen Darstellungen zur Bildungsgeschichte spielt Dichtung dagegen meist eine untergeordnete Rolle. ${ }^{67}$ Die Einzeluntersuchungen $\mathrm{zu}$ den verschiedenen Schulen stehen oft auf handschriftlicher Basis, ${ }^{68}$ nicht selten aus Mangel an literarischen Quellen. Über die Schullektüre im Allgemeinen war die Monographie Glauches ${ }^{69}$ äußerst einflussreich und ist bis heute durch die Kombination von literarischen, bibliothekarischen und handschriftlichen Quellen ein Vorbild. ${ }^{70}$ Insbesondere dem Gebrauch der lateinischen Klassiker im Unterricht wurde traditionell große Aufmerksamkeit geschenkt, ${ }^{71}$ was $\mathrm{zu}$ einer relativen Vernachlässigung der christlichen spätantiken Dichter in dieser Rolle geführt hat. Schule war aber nicht

66 Johann Peter Gumbert, »One book with many texts: the Latin tradition«, in: Codices Miscellanearum. Brussels Van Hulthem Colloquium, hrsg. von JANSEN-SIEBEN und Hans van DIJK (Archives et bibliothèques de Belgique. Numéro spécial 60), Brüssel 1999, S. 27-36. Siehe auch die Beiträge in Lucie Doležalová und Kimberly Ann Rivers, Medieval manuscript miscellanies (Medium aevum quotidianum. Sonderband 31), Krems 2013.

67 Vgl. z. B. den Index zu einschlägigen Dichtern in Pierre Riché, Ecoles et enseignement dans le haut Moyen Âge. Fin du Ve s. - milieu du XIe, Paris 1989. Andere Schwerpunkte setzt auch John J. Contreni, "Learning for God: Education in the Carolingian Age», in: The Journal of Medieval Latin 24 (2014), S. 89-129. Zur Dichtung in frühen Bibliotheken siehe: Bernhard BischоғF, "Die Bibliothek im Dienste der Schule«, in: Bischoff, Mittelalterliche Studien, 3, 1981, S. 213-233.

68 Siehe bei den Skriptorien die einleitenden Bibliographien zur Schule. Als Beispiele möchte ich nennen: John Joseph ConTRENI, The cathedral school of Laon from 850 to 930: its manuscripts and masters (Münchener Beiträge zur Mediävistik und Renaissance-Forschung 29), München 1978. Anna A. Grotans, Reading in medieval St. Gall (Cambridge studies in palaeography and codicology 13), Cambridge 2006.

69 Glauche: Schullektüre. Zusammenfassend: Günter Glauche, "Die Rolle der Schulautoren im Unterricht von 800 bis 1100«, in: La scuola nell'Occidente latino dell'alto medioevo (Settimane di studio del Centro italiano di studi sull'alto medioevo 19) 1972, S. 617-636.

70 Für eine aktuelle Bibliographie zum Thema siehe: Michael BALdzunN, »Schoolbooks«, in: Handbook of medieval studies. Terms - methods - trends, hrsg. von Albrecht Classen, Berlin [u.a.] 2010, S. 2061-2068. Rezeptionsstudien berühren ebenfalls häufig die Schule, zum Beispiel: Maria-Barbara QuINT, Untersuchungen zur mittelalterlichen Horaz-Rezeption (Studien zur klassischen Philologie 39), Frankfurt a. M. 1988. Hermann Lohmeyer, Vergil im deutschen Geistesleben bis auf Notker III (Germanische Studien 96), Berlin 1930.

71 Siehe mit zahlreichen bibliographischen Hinweisen: Birger Munk OLSEN, I classici nel canone scolastico altomedievale (Quaderni di cultura mediolatina 1), Spoleto 1991. Weiterhin als Übersicht nützlich ist auch: Maurice Roger, L'enseignement des lettres classiques d'Ausone à Alcuin, Paris 1905. 
nur Rezeptions- sondern auch Produktionsort von Dichtung ${ }^{72}$ - ein Aspekt der Nutzung, der bei der Auswertung von literarischen Zitaten stets in Betracht zu ziehen ist.

Für die Einordnung der Handschriften ist die Bewertung des Paratextes, insbesondere der Glossen und ihres Niveaus, oft von entscheidender Bedeutung. ${ }^{73}$ Die Glossenforschung zeichnet sich zudem durch einen traditionell starken Fokus auf die Handschriften aus, ${ }^{74}$ wie ihn andere Disziplinen nicht aufzuweisen haben. Zahlreiche Einzelstudien berühren die Rolle der Dichtung in der Schule anhand der glossographischen Quellen. ${ }^{75}$

72 Sтотz: "Dichten als Schulfach - Aspekte mittelalterlicher Schuldichtung«. Peter SтотZ, Dichten als Stoff-Vermittlung: Formen, Ziele, Wirkungen; Beiträge zur Praxis der Versifikation lateinischer Texte im Mittelalter, Zürich 2008. Paul KLopsch, Einführung in die Dichtungslehren des lateinischen Mittelalters (Das lateinische Mittelalter), Darmstadt 1980.

73 Gernot R. Wieland, "The glossed manuscript: classbook or library book? «, in: Anglo-Saxon England 14 (1985), S. 153-173.

74 Rolf Bergmann und Stefanie Stricker, Katalog der althochdeutschen und altsächsischen Glossenhandschriften, Berlin 2005. Rolf Bergmann und Stefanie Stricker (Hrsg.), Die althochdeutsche und altsächsische Glossographie. Ein Handbuch, Berlin [u.a.] 2009. Rolf BERGMANN (Hrsg.), Althochdeutsche und altsächsische Literatur, Berlin [u. a.] 2013.

75 Chiara Siмвоцотті, Gli »Inni di Murbach«: Edizione critica, commento e glossario (Ms. Junius 25) (Studi e ricerche 1), Alessandria 2009. Mechthild Gretsch und Helmut Gneuss, "Anglo-Saxon Glosses to a Theodorean Poem?", in: Latin Learning and English Lore. Studies in Anglo-Saxon Literature for Michael Lapidge, hrsg. von O'Brien O'KeEfFe und Andy OrCHARD (Toronto old English series 14), Toronto 2005, S. 9-46. Sinéad O'Sullivan, Early medieval glosses on Prudentius' Psychomachia: the Weitz tradition (Mittellateinische Studien und Texte 31), Leiden [u. a.] 2004. Elke Krotz, Auf den Spuren des althochdeutschen Isidor: Studien zur Pariser Handschrift, den Monseer Fragmenten und zum Codex Junius 25; mit einer Neuedition des Glossars Jc (Beiträge zur älteren Literaturgeschichte), Heidelberg 2002. Suzanne Reynolds, "Glossing Horace: Using the Classics in the Medieval Classroom«, in: Medieval manuscripts of the Latin classics. Production and use, hrsg. von Claudine A. Chavannes-Mazel und Margaret McFadden Smith, Los Altos Hills, Calif. 1996, S. 103-117. Dorothee ERTMER, Studien zur althochdeutschen und altsächsischen Juvencusglossierung (Studien zum Althochdeutschen 26), Göttingen 1994. Klaus SIEwERT, Die althochdeutsche Horazglossierung (Studien zum Althochdeutschen 8), Göttingen 1986. Peter PAULY, Die althochdeutschen Glossen der Handschriften Pommersfelden 2671 und Antwerpen 17.4: Untersuchungen zu ihrem Lautstand (Rheinisches Archiv 67), Bonn 1968. John Hendrik HesSELS, A Late Eighth-Century Latin-Anglo-Saxon Glossary Preserved in the Library of the Leiden University, Cambridge 1906. 


\section{I.4 Eingrenzung des behandelten Materials}

\section{I.4.a Untersuchungszeitraum und -gebiet}

Jede Begrenzung und Zerteilung eines zeitlichen und räumlichen Kontinuums sieht sich zu Recht dem Vorwurf des Anachronismus ausgesetzt. Darum soll hier kurz versucht werden, die Einschränkung auf das 9. Jahrhundert und auf das Ostfrankenreich zu begründen.

Die zeitliche Einschränkung ist sicherlich organischer als die räumliche. Obwohl die Geschichte vieler ostfränkischer Klöster und Bistümer in die Jahrhunderte vor dem untersuchten Zeitraum zurückreicht, tritt ihre Bildungsgeschichte erst im 9. Jh. ins volle Licht. Ob man es nach den erhaltenen Handschriften, der literarischen Produktion, dem Ruhm der Schulen beurteilt, das 9. Jh. war ohne Zweifel die Zeit der Blüte der ostfränkischen Bildungsstätten. War die karolingische Renaissance bis zum Tode Karls des Großen noch ein Phänomen, das um den Hof und die Person des Kaisers kreiste, war die Zeit von 814 bis zum Ende des Jahrhunderts die Epoche der intensiven Ausstrahlung der Ideale der correctio bis in die entlegensten Winkel des Reiches, nicht zuletzt durch die persönliche Kontinuität, in der Angehörige des Hofkreises zu Äbten und Bischöfen wurden und einer neuen Generation ihre Ideale vererbten. Das Ende der Untersuchung fällt mit dem Ende des Glanzes der Karolinger zusammen. Diözesen werden durch Kriege verwüstet, Klöster durch Wikinger, Ungarn, Sarazenen geplündert. Diese Katastrophen spiegeln sich deutlich im Einbruch der Handschriftenproduktion und -sammlung wider. Die klösterliche Kultur fällt am Ende des Jahrhunderts in einen Winterschlaf, aus dem sie erst in der neugewonnenen Sicherheit der ottonischen Epoche erwacht.

Die räumliche Trennung der Untersuchung kann sich nicht auf so natürliche Grenzen berufen wie die zeitliche. Die Selbstverständlichkeit, mit der traditionell die modernen Ländergrenzen auch der Mediävistik ihren Gegenstand eingrenzt haben, kann heute nicht mehr vorausgesetzt werden. Es stellen sich hier zwei miteinander verbundene Fragen: Was wird in dieser Arbeit unter »Ostfrankenreich « verstanden? Und inwiefern ist die geographische Einschränkung auf das Ostfrankenreich aus den Quellen gerechtfertigt?

Das 9. Jh., das mit dem unitären Reich Karls des Großen begann, ist Zeuge der "Geburt zweier Völker", die mit dem langsamen Verschwinden des Mittelreiches eine Grenze zueinander ausbilden. Das Ostfrankenreich ist dementsprechend im Untersuchungszeitraum vielfältigen territorialen und politischen Veränderungen unterworfen. ${ }^{76}$ Ein eigenständiges politisches Gebilde entsteht erst $843 \mathrm{mit}$

76 Dieter Hägermann, "Reichseinheit und Reichsteilung. Bemerkungen zur Divisio regnorum von 806 und zur Ordinatio Imperii von 817«, in: Historisches Jahrbuch 95 (1975), S. 278-307. 
der Teilung des Gesamtreiches unter den Söhnen Ludwigs des Frommen im Vertrag von Verdun. ${ }^{77}$ Jedoch kann das ostrheinische Gebiet schon vor seiner "staatlichen « Konstituierung als distinktive Landschaft im Frankenreich angesehen werden: ${ }^{78}$ Bayern und Sachsen waren, als neu erworbene bzw. eroberte Gebiete, eigene administrative Einheiten. ${ }^{79}$ Bayern, schon vor seiner Eingliederung in das Reich kulturell bedeutend, stellte die Machtbasis Ludwigs des Deutschen dar, der 817 von seinem Vater dort als Teilkönig eingesetzt wurde und sich seit 833 als rex bezeichnete, ohne Unterordnung unter den (kurzzeitig gestürzten) Kaiser Ludwig den Frommen. ${ }^{80}$ Die Gebietsgewinne von 833 - insbesondere Schwaben, Thüringen und Sachsen - deuteten schon die 843 verhandelten Grenzen an. Die Regionen - Bayern, Schwaben, Thüringen und Sachsen bilden einen festen, proto-deutschen Kulturkreis. ${ }^{81}$ Gegen Ende des 9. Jh. wird dieses Kerngebiet jedoch vermehrt um nach dem Tod Lothars II. herrenlos gewordene Gebiete Lotharingiens. Im Vertrag von Meersen 870 wurden der östliche Teil Lothringens dem Ostreich zugeschlagen; 880, im Vertrag von Ribemont, folgte auch der westliche Teil, der 870 noch Karl dem Kahlen zugeteilt worden war. ${ }^{82}$ Man sieht also, dass die geographische Grenze, die sich diese Arbeit gesetzt hat, sich kontinuierlich verändert. Die bedeutendste "Eroberung «, die durch eine Grenzverschiebung nach Westen für diese Untersuchung gemacht werden konnte, ist das Kloster Murbach. Auch die Skriptorien von Prüm und Lüttich

Franz-Reiner ERKENs, »Divisio legitima und unitas imperii،. Teilungspraxis und Einheitsstreben bei der Thronfolge im Frankenreich «, in: Deutsches Archiv für Erforschung des Mittelalters 52 (1996), S. 423-485. Franz-Reiner ERKENs, "Zerfall der Einheit - Die Reichsteilungen des 9. Jahrhunderts", in: Um Glaube und Herrschaft (600-1650) (Brockhaus. Die Bibliothek. Die Weltgeschichte 3), Leipzig 1998, S. 170-181.

77 Thomas BAUER, "Die Ordinatio Imperii von 817, der Vertrag von Verdun 843 und die Herausbildung Lotharingiens", in: Rheinische Vierteljahrsblätter 58 (1994), S. 1-24.

78 Walter MoнR, "Von der >Francia Orientalis« zum >Regnum Teutonicum«.", in: Archivum latinitatis medii aevi 27 (1957), S. 27-49.

79 Zur vorkarolingischen Geschichte Bayerns: Wilhelm Störmer, Die Baiuwaren. Von der Völkerwanderung bis Tassilo III. (Beck'sche Reihe 2181), München 2007. Zum Ende der agilolfingischen Herrschaft: Peter Classen, »Bayern und die politischen Mächte im Zeitalter Karls des Großen und Tassilos III.«, in: Classen, Ausgewählte Aufsätze (Vorträge und Forschungen 28), Sigmaringen 1983, S. 231-248. Zu Sachsen: Walther Lammers (Hrsg.), Die Eingliederung der Sachsen in das Frankenreich (Wege der Forschung 185), Darmstadt 1970.

80 Zur Krise von 833: Theodor SCHIEFFER, "Die Krise des karolingischen Imperiums", in: Aus Mittelalter und Neuzeit. Festschrift für Gerhard Kallen zum 70. Geburtstag, hrsg. von Josef Engel und Hans Martin Klinkenberg, Bonn 1957, S. 1-15. Mayke de Jong, The penitential state: authority and atonement in the age of Louis the Pious, 814-840, Cambridge [u. a.] 2010.

81 Zur Genese der Staaten und Grenzen: Carlrichard BRÜHL, Deutschland-Frankreich. Die Geburt zweier Völker, Köln, Wien 1995.

82 Eduard Hlawitschka, Lotharingien und das Reich an der Schwelle der deutschen Geschichte (MGH Schriften 21), Stuttgart 1968. S. 19, 20, $221 \mathrm{f}$. 
liegen nicht im Ostfrankenreich im engsten Sinne (843) und steuern dennoch wertvolle Beiträge zur Erforschung der Sammlung von Dichtung bei. ${ }^{83}$

Dieser staatliche Rahmen des Untersuchungsgebietes wird auch im kulturellen Bereich reflektiert. Das Patronatsgeflecht lief am Hof der Herrscher zusammen und war bestimmend für die Besetzung hoher Kirchenämter. In den so etablierten Netzwerken konnte auch Dichtung zirkulieren, ob als dedizierte Handschrift, als gewidmetes Werk oder in Tausch- und Leihbeziehungen zwischen Institutionen. Auch die Karrieremöglichkeiten der aufstrebenden jüngeren Generation waren durch diese Patronage definiert. Als Beispiel für das Wohlwollen der Mächtigen, das man sich durch Dichtung erwerben konnte, als auch für die Konsequenzen, die eine Verletzung der ausgedrückten Loyalität nach sich ziehen konnte, kann die Laufbahn Walahfrid Strabos gelten.

Eine analoge, aber nicht minder unscharfe Absteckung des Untersuchungsgebietes ergibt sich aus den Großräumen der Erzdiözesen: Mainz, Köln, Trier und Salzburg, wobei jedoch insbesondere das Erzbistum Trier mit den Suffraganen Metz, Toul und Verdun weit aus dem untersuchten Raum hinausragt. Die Diözesen bildeten bedeutende Foren des regionalen Austauschs, durch den persönlichen Kontakt auf Synoden und Reisen und durch institutionelle und individuelle Beziehungen der Kleriker. Gerade bei den grenzüberschreitenden Bistümern ist jedoch auch in eben diesen Beziehungen eine transnational integrierende Funktion festzustellen, mit der die kulturelle Einheit über den politischen Wandel hinweg aufrecht erhalten wurde.

Eine weitere ungefähre Umgrenzung kann anhand der Ausdehnung des althochdeutschen Sprachgebiets bzw. den Fundorten althochdeutscher Überlieferung gewonnen werden. ${ }^{84}$ Dieses Gebiet deckt sich auch ungefähr mit den anachronistischen Großräumen in Bischoffs Katalog. ${ }^{85}$ Der althochdeutsche Sprachraum ist damit ein weiterer Indikator für ein relativ geschlossenes Untersuchungsgebiet, wobei selbstverständlich der europaweite Gebrauch des Lateinischen die volkssprachigen Grenzen wiederum relativiert.

Das Ostfrankenreich stellt sich somit in politischer, kirchlicher und linguistischer Hinsicht als eine zwar im Werden begriffene, aber dennoch deutlich zu erkennende Einheit der Untersuchung dar. Die enge Verbindung der ostfrän-

83 Ein analoger Vorgang lässt sich bei LesNe: Livres, Scriptoria, Bibliothèques beobachten, wo France ebenfalls Reichenau und St. Gallen, Köln und Mainz umfasst.

84 Siehe die Karten in: Wolfgang Haubrichs, "Otfrid de Wissembourg, élève de Raban Maur, et l'héritage de l'école de Fulda au monastère de Wissembourg", in: Raban Maur et son temps, hrsg. von Philippe Depreux u. a. (Collection Haut Moyen Âge 9), Turnhout 2010, S. 155-172. S. $171 \mathrm{f}$. Stefan SONDEREGger und Werner VoGLER, "Deutsche Sprache und Literatur in Sankt Gallen«, in: Die Kultur der Abtei Sankt Gallen, hrsg. von Werner VoGLER, Zürich 1990, S. 161184. S. 162.

85 Norddeutschland, Nordwestdeutschland, Westdeutschland, Süddeutschland, Südwestdeutschland, Südostdeutschland, Belgien, Schweiz, Österreich. 
kischen Klöster und Bistümer miteinander wird ein wiederkehrendes Thema dieser Arbeit sein. Das grenzüberschreitende Erbe des Reichs Karls des Großen übt trotz der sich verstärkenden Trennung der Großräume weiterhin einen integrierenden Einfluss aus, der sich anlässlich der zahlreichen Verbindungen von ostfränkischen Bildungsstätten zeigen wird.

Diese Handschriftenlandschaft enthält fast alle bedeutenden ostfränkischen Skriptorien des 9. Jh., von den gut erhaltenen Beständen wie denen von St. Gallen und Lorsch bis zu einst reichen Sammlungen wie Fulda oder Corvey, die im Lauf der Zeit zerstört und zerstreut wurden. Einige Skriptorien treten überhaupt nicht in Erscheinung. Zahlreiche kleinere Skriptorien scheiden aus, weil ihre erhaltenen Bestände so gering sind, die Zuschreibung der Handschriften zweifelhaft ist und in diesen wenigen Handschriften ohnehin anscheinend keine Dichtung enthalten ist. ${ }^{86}$ Zahlreicher, aber zweifelhafter Provenienz, sind die Handschriften aus Niederaltaich, Kochel und Konstanz; auch hier ist keine Dichtung enthalten. Das Fehlen von Dichtung aus Benediktbeuern, Hersfeld, Kremsmünster und Metz dagegen erstaunt, da aus diesen Skriptorien mitunter mehr erhalten ist, als aus einigen hier behandelten. Hier war offenbar der Überlieferungszufall ${ }^{87}$ den Handschriften nicht gut gesonnen. Alles in allem aber ergeben die erhaltenen Handschriften ein durchaus repräsentatives Bild der Sammlung von Dichtung im 9. Jh. Etwaige Verzerrungen des Bildes durch Handschriftenverluste werden bei Gelegenheit der einzelnen Skriptorien besprochen. ${ }^{88}$

Aus dem Gebiet des Ostfrankenreiches sind insgesamt um die 2800 Handschriften überliefert. ${ }^{89}$ Die Durchsicht ergibt eine Gesamtzahl von ungefähr 180 Handschriften, die Dichtung in irgendeiner Form enthalten. Ganze Gattungen von Handschriften erweisen sich also als praktisch frei von jeder dichterischen Zugabe, wie etwa biblische Handschriften, Gesetzessammlungen oder Kirchenväter, welche hier und da einen eingestreuten Vers haben mögen, ohne dass Dichtung je ein fester Bestandteil derartiger Handschriften geworden wäre.

86 Dies sind: Amorbach, Augsburg, Chur, Disentis, Echternach, Eichstätt, Ellwangen, Halberstadt, Herford, Hildesheim, Koblenz, Kornelimünster, Münsterschwarzach, Seligenstadt, Schuttern, Straßburg, Taufers, Weltenburg, Werden (aber siehe S. 227 zu Düsseldorf, ULB, Ms. F 1) und Worms (aber siehe S. 181-185 zu Wolfenbüttel, HAB, Cod. Guelf. 91 Weiss.). Überhaupt nicht in Betracht kommen natürlich die zahlreichen Orte, denen überhaupt keine Handschriften mit Sicherheit zugeordnet werden können.

87 Arnold EscH, »Überlieferungs-Chance und Überlieferungs-Zufall als methodisches Problem des Historikers", in: Historische Zeitschrift 240 (1985), S. 529-570.

88 Hier ist besonders an den Verlust von separaten Schulbibliotheken zu denken.

89 Gezählt nach dem Register in Bischoff: Katalog. Es bestehen selbstverständlich zahllose Ungewissheiten in der Zuordnung der Handschriften. 


\section{I.4.b Dichtung außerhalb von Sammlungen}

Typen von Kleindichtung, die außerhalb der Reichweite der Untersuchung liegen, sollen im Folgenden kurz vorgestellt werden. ${ }^{90}$

Kolophone im weiteren Sinne: Einzelverse, Schreiberverse und verwandte Kleingedichte. ${ }^{91}$ Solche verstreuten Verse wurden meist nicht eigentlich gesammelt, sondern sind Zusätze, die mehr oder minder eng mit dem Haupttext verbunden sind.

Zuerst gibt es die Verse, die nach Vollendung der Handschrift eingetragen wurden: Schreiberverse und Federproben. ${ }^{92}$ Diese stehen in inhaltlich nur loser oder gar nicht feststellbarer Beziehung zur Handschrift. Wenn Schreiberverse nicht nur stereotyp Namen und Gebetserheischung des Schreibers angeben, sind sie wertvolle Quelle für die Entstehung der Handschrift. ${ }^{93}$ Der Widmungsvers am Ende des zweiten Teils von Cod. Sang. 152 weist die Handschrift als Geschenk an Ratpert aus, das Abt Hartmut im Skriptorium puerili pollice schreiben ließ. ${ }^{94}$ Der

90 Vgl. auch im Schlusskapitel S. 328f. zu »Auxiliartext« und »Dichtung als Nachtrag«.

91 Die Verse sind nur eine Unterklasse der Kolophone, die häufig, aber nicht immer, metrisch sind: Markus Schiegg, "Scribes' Voices: The Relevance and Types of Early Medieval Colophons", in: Studia Neophilologica (2015), S. 1-19. S. 8. Siehe auch: Lucien Reynhout, »Pour une typologie des colophons de manuscrits occidentaux«, in: Gazette du livre médiéval 13 (1988), S. 1-5. Lucien Reynhout, Étude sur le formulaire latin des colophons de manuscrits occidentaux (IIIe-XVIe siècle), Brüssel 2000. Kurt Otto SEIDEL, »Tres digiti scribunt totum corpusque laborat. Kolophone als Quelle für das Selbstverständnis mittelalterlicher Schreiber«, in: Das Mittelalter 7 (2002), S. 145-156.

92 DüMMLER: »Die handschriftliche Überlieferung«. S. 146-148, ist jedoch keinesfalls vollständig, da Dümmler sich hier hauptsächlich auf Notizen von MARTENE und Du Chesne stützt. Editionen in Dümmler u. a. (Hrsg.): MGH Poetae. 1, S. 87-98; 2, S. 649-687 passim, 4, 2, S. 614-666 passim, 4, 3, S. 1056-1071, S. 1109-1112. Den besten Zugang bietet: BÉNÉDICTINS DU Bouveret, Colophons de manuscrits occidentaux des origines au 16e siècle (Spicilegium Friburgense. Subsidia 2-3), Freiburg 1965. Diese Sammlung wurde hauptsächlich aus Katalogen geschöpft, siehe die Rezension von: Philip Levine, "Rezension zu: Colophons de manuscrits occidentaux des origines au XVIe siècle», in: Speculum 44 (1969), S. 107-110. Zu Schreibern im Allgemeinen siehe: Wilhelm WattenвACH, Das Schriftwesen im Mittelalter. Unveränd. Abdr. der 3. verm. Aufl., Hirzel, Leipzig 1896, Graz 1958. S. 416-534; Martin J. Schubert, Der Schreiber im Mittelalter (Das Mittelalter 7, 2), Berlin 2002. Johannes Duft, Mittelalterliche Schreiber; Bilder, Anekdoten und Sprüche aus der Stiftsbibliothek St. Gallen, St. Gallen 1961.

93 Oder auch zur Schreibtechnik, so die vielzitierten Verse: Tres digiti scribunt totum corpusque laborat, MGH Poet. 4, 3, S. 1062, XIV. Siehe hierzu Bernhard BIsсноғF, Paläographie des römischen Altertums und des abendländischen Mittelalters, 4., durchges. und erw. Aufl. (Grundlagen der Germanistik 24), Berlin 2009. S. 59. Kolophone wurden sogar zur Ermittlung der Schreibgeschwindigkeit ausgewertet: Michael Gullick, "How fast did scribes write?: Evidence from Romanesque manuscripts«, in: Making the medieval book: techniques of production, hrsg. von Linda L. BRownRIGG (Proceedings of the ... conference of the Seminar in the History of the Book to 1500 4), Los Altos Hills, Calif. 1995, S. 39-58.

94 Karl Strecker (Hrsg.), MGH Poet. lat. 4, 2.3, Berlin 1923. S. 1110, VI, ii, siehe auch die Anmerkung. 
gleiche Hartmut wird im Schreibervers von Cod. Sang. 23, p. 26 als Auftraggeber genannt. ${ }^{95}$

Einzelverse verwandter Art warnen vor Diebstahl und verfluchen den Dieb. ${ }^{96}$ Ein Beispiel, aus demselben oben zitierten, von Folchard geschriebenen Psalter: Auferat hunc librum nullus hinc omne per aevum, / cum Gallo partem quisquis habere uelit. ${ }^{97}$ Eine ähnliche Warnung, wohl von Hand des Bibliothekars, wird einer anderen kostbaren Psalmenhandschrift ${ }^{98}$ vorausgeschickt: [...] Non dubitet autem iram dei periculosius incurrere, / Siquis me praesumat a sancti Galli finibus spoliando auferre. ${ }^{99}$ Schreibervers und Schreiberfluch ist gemeinsam, dass sie in einem losen, zufälligen Verhältnis zum Haupttext der Handschrift stehen, und meist ohne Sinnverlust in andere Handschriften übertragen werden könnten; wie es in der Tat oft geschehen ist: der oben zitierte Tres digiti-Spruch war weitverbreitet und eine Vielzahl anderer Sprüche wurden nicht weniger formularisch gebraucht. ${ }^{100}$

Enger mit dem Text der Handschrift verbunden und häufiger als Schreiberverse sind einleitende Gedichte zu spezifischen Werken. Ob diese Teil der Tradition dieses Werkes waren oder ad hoc im Skriptorium beigegeben wurden, lässt sich oft nur ungenau dadurch entscheiden, ob das betreffende Vorwort mehrfach überliefert wurde oder nur in einer einzelnen Handschrift vorliegt, wobei letzterer Fall auch zufällig durch Handschriftenverlust eingetreten sein kann. Einige stehen in noch sehr spezifischer Beziehung zu Schreiber oder Stifter. Vier Verse zum Ende eines von Hartmut von St. Gallen gestifteten Psalters vereinen Buchtitel, Stifter und Buchfluch. ${ }^{101}$ Eine Handschrift der Homilien Gregors des Gro-

95 Ebd. S. 1111, IV, i. Jedoch ist nicht immer klar, ob der Subskribierende auch der Schreiber ist; es mag auch der Stifter gewesen sein: ScHIEgG: "Scribes' Voices«. S. 10; Hartmut HofFmanN, Buchkunst und Königtum im ottonischen und frühsalischen Reich (MGH Schriften 30, 1-2), Stuttgart 1986. 1, S. 42.

$96 \mathrm{Zu}$ diesem amüsanten Thema siehe: G.A. CRÜWELL, "Die Verfluchung der Bücherdiebe«, in: Archiv für Kulturgeschichte 4 (1906), S. 197-223. Marc Drogin, Anathema! Medieval Scribes and the history of Book Curses, Montclair, N.J. 1983.

97 »Wer mit dem heiligen Gallus (im Himmel) sein will, der stehle dieses Buch nicht, in alle Ewigkeit.« STRECKeR (Hrsg.): MGH Poet. lat. 4, 2.3. S. 1111, IV, ii.

98 Cod. Sang. 22, "Psalterium aureum«; Anton von Euw, Die St. Galler Buchkunst vom 8. bis zum Ende des 11. Jahrhunderts (Monasterium Sancti Galli 3), St. Gallen 2008. S. 400-408, Nr. 98. Strecker (Hrsg.): MGH Poet. lat. 4, 2.3. S. 1112, Anm. zu V, iii.

99 »Derjenige wird ohne Zweifel den gefährlichen Zorn Gottes erfahren, der es wagt mich aus dem Bezirk des Heiligen Gallus zu entfernen."

100 Vergleiche z.B. die zahllosen Variationen von Sicut nauigantibus portus bei: Lucien Reynhout, Formules latines de colophons (Bibliologia 25), Turnhout 2006. S. 85-94. Grundlegend zur Klassifizierung der Formeln: Lucien ReYNHouT, »Codicologie quantitative et paradigmes scientifiques. Une typologie des formules latines des colophons de manuscrits occidentaux «, in: Gazette du livre médiéval 39 (2001), S. 1-9.

101 Cod. Sang. 19, p. 134. Gustav SCHERRER, Verzeichniss der Handschriften der Stiftsbibliothek von St. Gallen, Halle 1875. S. 7. Strecker (Hrsg.): MGH Poet. lat. 4, 2.3. S. 1110, III, i. 
ßen aus Werden ist mit gleich drei Gedichten versehen: ${ }^{102}$ Im ersten empfiehlt sich der Schreiber Felwald den Lesern; die beiden folgenden, von anderer, aber zeitgenössischer Hand, sind Lobgedichte auf Gregor. Einer Cassiodorhandschrift aus St. Gallen wurde am Schluss der Institutiones ein Gedicht auf den Autor beigegeben, dass sich nur hier findet. ${ }^{103}$ Einer Augustinus-Handschrift des gleichen Skriptoriums sind Verse vorausgeschickt, die sowohl den Text ankündigen, als auch die Handschrift genau beschreiben: Von dem zweibändigen Werk aus 2 x12 Bücher der Civitas Dei werden bissenos [... in hoc corpore angekündigt. ${ }^{104}$ Überschriften und Anhänge dieser Art sind eng mit ihren Handschriften verbunden und sind über diese hinaus nicht weiter verbreitet worden.

Anders steht es mit poetischen Vorworten zu den Büchern der Bibel, die zusammen mit ihrem Haupttext kopiert wurden und oft weite Verbreitung fanden. ${ }^{105}$ Alkuin schrieb gleich drei Einleitungen zum Pentateuch, von denen zwei weitere Verbreitung fanden. ${ }^{106}$ Besonders die Psalmen wurden ausgiebig mit Einleitungen versehen, was bei ihnen - als meist separater Kodex - naheliegt. Zwei Gedichte, Hieronymus und Damasus zugeschrieben, fanden sehr weite Verbreitung. ${ }^{107}$

Der Beginn des Buches als »luogo privilegiato di comunicazione paratestuale ${ }^{108}$ wurde auch von den karolingischen Autoren als Gelegenheit genutzt, ihre eigenen Werke mit metrischen Einleitungen zu versehen. ${ }^{109}$ Von dieser weitverbreiteten Praxis und ihren Variationen können hier nur ein paar Beispiele gegeben werden. Das metrische Proömium steht als Widmung in enger Verwandtschaft zum epistolaren Gedichten, ja nimmt selbst meist die Form eines

Vergleiche auch die folgenden Verse, die einander ähnlich in alle Bände der von Hartmut kommissionierten Bibel eingetragen wurden.

102 Berlin, Ms. Theol. Lat. Fol. 356, f. 1v. Valentin Rose, Die Handschriften-Verzeichnisse der Königlichen Bibliotheken zu Berlin, 13: Verzeichniss der lateinischen Handschriften, Berlin 1901. 102-103. STRECKer (Hrsg.): MGH Poet. lat. 4, 2.3. S. 1057, V.

103 Cod. Sang. 199, p. 115. Scherrer: Stiftsbibliothek. S. 74. Strecker (Hrsg.): MGH Poet. lat. 4, 2.3. S. 1064, XVIII. Siehe auch S. 107 zu Cod. Sang. 870.

104 Cod. Sang. 178, p. 2. SCHERrer: Stiftsbibliothek. S. 63.

105 Donatien Bruyne, Prefaces to the Latin Bible, hrsg. von. Pierre-Maurice Bogaert und Thomas O'Loughlin (Studia traditionis theologiae 19), Turnhout 2015.

106 Ebd. S. 14-19.

107 Ebd. S. 66, Nr. 16, 17. Antonio Ferrua (Hrsg.), Epigrammata Damasiana (Sussidi allo studio delle antichità cristiane 2), Roma 1942. S. 219-229.

108 Francesco Stella, "Mito del libro e poesia libraria in età carolingia«, in: CentoPagine 4 (2010). S. 5.

109 Luigi MunZI, "Prologhi poetici latini di età carolingia«, in: Les prologues médiévaux, hrsg. von Jacqueline Hamesse (Textes et études du Moyen Âge 15) 2000, S. 87-111. Pavel Spunar, "Versus de Libris«, in: Calames et cahiers. Mélanges de codicologie et de paléographie offerts à Léon Gilissen, hrsg. von Jacques Charles LemaIRE und Emile van BALberghe (Scriptorium. Publications 9), Brüssel 1985, S. 177-181. КIRsch: Laudes sanctorum. S. 972-974. 
Widmungsbriefes an. ${ }^{110}$ Das Genre der eingeleiteten Schrift spielte keine Rolle von Bibelkommentaren über technische Traktate bis natürlich zu dichterischen Werken konnte alles mit einem Widmungsgedicht versehen werden. So leitet Modoin seine Ekloge an Karl mit einigen Versen ein, Mico empfiehlt seine prosodische Lehrschrift mit einem beispielhaften Gedicht, Frechulf von Lisieux eröffnet sein Geschichtswerk mit einem Briefgedicht, und auch der Grammatiker Smaragd von St. Mihiel schickt seinem Donatkommentar eine lange poetische Einleitung voraus. ${ }^{111}$ Die Beispiele ließen sich beliebig vermehren. Diese Proömien, so persönlich sie auch gehalten sein mögen, sind fest an den Text, den sie einleiten, gebunden, und teilen dessen Überlieferungsschicksale. Eigene Sammlungen solcher Vorworte hat es nicht gegeben.

Eine eigene Art der Sammlung bilden die biblischen Cantica, die dem Psalter in fester Ordnung beigegeben wurden und zusammen mit diesem im Stundengebet gesungen wurden. ${ }^{112}$ Die Sammlung der alt- und neutestamentlichen Gesänge reicht bis in die Antike zurück. ${ }^{113}$ Der genaue Übermittlungsweg der Praxis ist nicht bekannt; die frühesten handschriftlichen Beispiele stammen aus England, so im Vespasian-Psalter aus der Mitte des 8. Jh., ${ }^{114}$ dessen Cantica-Reihenfolge sich ebenso in der St. Galler Handschrift Zürich, ZB C 12 und in der von der Reichenau stammenden Handschrift Karlsruhe, BLB, Aug. Perg. 308 findet. Diese und die folgenden Handschriften folgen alle der römischen oder gallikanischen Anordnung der Cantica. ${ }^{115}$ Die Zusammenstellung bleibt mehr oder

110 Francesco Stella, "Poesia e comunicazione in eta carolingia», in: Comunicare e significare nell'alto medioevo (Settimane di studio del Centro italiano di studi sull'alto medioevo 25), Spoleto 2005, S. 615-649.

111 Modoin: Ernst DüMmLer (Hrsg.), MGH Poet. lat. 1, Berlin 1881. S. 382-392. Smaragd versieht auch die einzelnen Kapitel mit solchen Einleitungen: Bengt LöfstedT (Hrsg.), Smaragdus: Liber in Partibus Donati (CCCM 68), Turnhout 1986. Frechulf: Ernst DüMMLER (Hrsg.), MGH Poet. lat. 2, Berlin 1884. S. 668-669. Micon: Max MANiTiUs, "Micons von St. Riquier De Primis syllabis«, in: Münchener Museum für Philologie des Mittelalters und der Renaissance 1 (1912), S. 121-177. S. 124-126.

112 Thomas SCHIPPERges, »Vesperpsalmen, Hymnen, Cantica, Magnificat, Lamentationen «, in: Geschichte der Kirchenmusik. 1: Von den Anfängen bis zum Reformationsjahrhundert, hrsg. von Wolfgang Hochstein und Christoph Krummacher, Laaber 2011, S. 288-300. Markus Jenny, "Art. Cantica«, in: Theologische Realenzyklopädie, 7, 1981, S. 624-628. RAвY: A history of Christian-Latin poetry from the beginnings to the close of the middle ages. S. 30 . James MEARns, The canticles of the christian church eastern and western in early and medieval times, Cambridge 1914. S. 50-94.

113 Die AT-Cantica schon bei Benedikt, Regula c. 11: cantica Prophetarum und c. 13: Nam ceteris diebus canticum unumquemque die suo ex Prophetis, sicut psallit Ecclesia romana, dicantur.

114 London, British Library, Cotton Vespasian A I.

115 Nur durch den Zusatz des Nizäums im gallikanischen Psalter unterschieden, MEARNs: Canticles. S. 52, 65. Spezifisch untersucht in: Johann Маввӧск, Das Eindringen der Versio Gallicana des Psalteriums in die Psalterien der Benediktinerklöster Oberösterreichs (Dissertationen der Universität Graz 5), Graz 1970. 
weniger auch in den St. Galler Psaltern ${ }^{116}$, die Cantica enthalten, die gleiche, so im Wolfcoz Psalter, Cod. Sang. 20, ${ }^{117}$ p. 328-360, unter Ausfall einiger Stücke, jedoch der Rest in gleicher Reihenfolge; im Folchart-Psalter, Cod. Sang. 23, p. 337-359, ${ }^{118}$ p. 359-365, wo die Cantica auf zwei Lagen von dritter Hand geschrieben wurden und ihre Einheit durch die Initialisierung nur des ersten Canticums angezeigt wird; im Cod. Sang. 27, p. 645-700, wurden die Cantica ebenso wie die Psalmen glossiert. ${ }^{119}$ Ebenso wurden sie dem griechisch-lateinischen Psalter Cod. Sang. 17 (2) ${ }^{120}$ beigegeben. Bestand und Ordnung der Cantica sind von alters her durch die Anforderungen des Gottesdienstes festgelegt worden und gehören eher der Geschichte der Liturgie als der Dichtung an.

All diesen Arten von Dichtung ist gemeinsam, dass sie sich nicht zu eigenen Sammlungen zusammengefunden haben, sondern als Einleitungen, Anhänge, Nachträge eng an den Haupttext oder die Handschrift gebunden sind, deren Teil sie sind. Wo jedoch Ansätze zu einer Sammlung erkennbar sind oder wo die zerstreuten Verse einen Einblick in die Interessen der Sammler bieten, werden auch diese Zeugnisse ausgewertet.

\section{I.5 Zur Struktur der Arbeit}

Als organisatorisches Prinzip für die Fülle des handschriftlichen Materials wurde die Behandlung im Rahmen der einzelnen Skriptorien gewählt, ${ }^{121}$ die nach den Großräumen der Erzdiözesen angeordnet sind. Die Arbeit beginnt mit den Bonifaz auf besondere Weise verbundenen Stätten Mainz, Würzburg und Fulda. Darauf folgen die alemannisch-elsässischen Zentren. Die Erzdiözesen Köln und Trier decken das Berührungsgebiet zwischen West und Ost ab. Mit den Skriptorien der Klöster und Kathedralen des Erzbistums Salzburg wird der Osten des Reiches erfasst.

Durch die Behandlung nach Skriptorien kann gewährleistet werden, dass die einzelnen Handschriften nicht aus ihrem spezifischen Entstehungs- und Nut-

$116 \mathrm{Zu}$ den Psaltern St. Gallens allgemein: T. N. S. Tiвbetтs, Uses of the psalter in Carolingian St Gallen (Dissertation), Cambridge 2003.

117 Euw: Buchkunst. S. 326-329, Nr. 33.

118 Ebd. S. 394-399, Nr. 97.

119 Margaret Templeton GiBson, »Carolingian glossed psalters«, in: The Early Medieval Bible. Its Production, Decoration and Use, hrsg. von Richard GAmeson (Cambridge studies in palaeography and codicology), Cambridge 1994, S. 78-100. S. 80-86.

120 Walter Berschin, Der Septuagintapsalter in abendländischen Bibliotheken des Mittelalters, Tübingen 2012. S. 11-22.

121 Am nächsten kommt dieser Struktur: Schubert (Hrsg.): Schreiborte des Mittelalters. Paläographische Studien nehmen aus naheliegenden Gründen eine ähnliche Form an (BIsCHOFF: Schreibschulen.) 
zungszusammenhang gerissen werden. Die materiale Einheit der Handschriften soll auch in ihrer Untersuchung reflektiert werden, sodass sich bewusst gegen eine Behandlung nach Autoren und Werken entschieden wurde, ${ }^{122}$ wodurch insbesondere die zahlreichen Sammelhandschriften unter verschiedene Rubriken zerteilt worden wären. Ebenfalls lässt sich eine Trennung nach verschiedenen Handschriftentypen angesichts der Mehrdeutigkeit des Handschriftenbefundes nicht aufrechterhalten, ohne dem Material durch starre Schemata Gewalt anzutun. Bei der Behandlung entlang der Skriptorien und Handschriften wurde jedoch komparativen Aspekten große Aufmerksamkeit geschenkt und, wo immer möglich, Handschrift mit Handschrift und Sammlung mit Sammlung verglichen, um Gemeinsamkeiten und Unterschiede innerhalb der Handschriftenlandschaft aufzuzeigen. Im abschließenden analytischen Kapitel wird versucht, die verschiedenen Linien der Untersuchung unter direktem Rückgriff auf die Handschriften zusammenzuführen.

122 So gewählt in Munk Olsen: L'étude des auteurs classiques latins oder Reynolds: Texts and transmission. 


\section{Die Handschriftenlandschaft}

\section{II.1 Erzbistum Mainz}

\section{II.1.a Mainz}

Im Erzbistum Mainz ${ }^{123}$ befinden sich mit den Skriptorien der Maingegend und des Bodensees die bedeutendsten Schreibstätten des ostfränkischen Raumes. Was jedoch vom Skriptorium - oder den Skriptorien ${ }^{124}$ - der Bischofsstadt selbst erhalten ist, bleibt hinter der Produktion der klösterlichen Schreibstätten der Erzdiözese zurück. Eine Rekonstruktion des Bestandes der frühmittelalterlichen Bibliothek ist kaum noch möglich. ${ }^{125}$ Dass diese einen stattlichen Umfang gehabt haben muss, zeigt sich im Inhaltsverzeichnis der Retractationes Augustins in Clm 8107, in Mainz entstanden und noch bis 1479 in der Dombibliothek verblieben, wo neben einigen Werken des Kirchenvaters ein $h$ die Verfügbarkeit kennzeichnet. ${ }^{126}$ Die 47 Titel, wenn sie auch nicht in ganz so vielen Handschriften

123 Zum Bistum Mainz im Mittelalter umfassend: Marc-Aeilko ARIS und Friedhelm JüRGENSMEIER, Handbuch der Mainzer Kirchengeschichte (Beiträge zur Mainzer Kirchengeschichte, 6: 1,1;1,2;2), Würzburg 2000. Zur Gesamtgeschichte: Friedhelm JürgenSMEIER, Das Bistum Mainz: von der Römerzeit bis zum II. Vatikanischen Konzil (Beiträge zur Mainzer Kirchengeschichte 2), Frankfurt a. M. 1988. Zum Skriptorium: Britta Hedt Ke und Christoph Winterer, "Mainz", in: Schreiborte des deutschen Mittelalters: Skriptorien - Werke Mäzene, hrsg. von Martin J. Schubert, Berlin [u.a.] 2013, S. 347-372. Wallace Martin Lindsay und Paul Lehmann, "The early Mayence scriptorium «, in: Palaeographica latina, 4, 1925, S. 15-39.

124 Insbesondere Dom und das Kloster St. Alban kommen in Frage. HedtKe/Winterer: "Mainz«. S. 351.

125 Durch Fehlen eines zeitgenössischen Kataloges einerseits, andererseits durch die Verluste, die die Bibliothek schon vor dem katastrophalen Brand 1793 erlitt, durch den sie ganz vernichtet wurde. Zu Geschichte und Untergang: Franz FALK, Die ehemalige Dombibliothek zu Mainz, ihre Entstehung, Verschleppung und Vernichtung nach gedruckten und ungedruckten Quellen (Zentralblatt für Bibliothekswesen. Beiheft 18), Leipzig 1897. S. 552-725.

126 Wohl für habemus. Bernhard BischоғF, Katalog der festländischen Handschriften des neunten Jahrhunderts, 2: Laon - Paderborn (Veröffentlichungen der Kommission für die Herausgabe der mittelalterlichen Bibliothekskataloge Deutschlands und der Schweiz), 
enthalten waren, sind eine eindrucksvolle Sammlung - St. Gallen etwa verzeichnet nur 23 der Werke Augustins. ${ }^{127}$

Dass von den etwa hundert aus Mainz stammenden Handschriften ${ }^{128}$ nur eine Handvoll Dichtung enthält, ist umso merkwürdiger, als zwei der Erzbischöfe keine unbedeutenden Dichter waren.

Bonifaz' Dichtkunst ${ }^{129}$ wird schon von seinem Biographen gerühmt: tam grammaticae artis eloquentia et metrorum medullata facundiae modulatione (...) imbutus. ${ }^{130}$ In seinen Rätseln und Briefgedichten fließen dem Dichter immer wieder Phrasen aus Vergil und Aldhelm in die Feder, an einer Stelle sogar Martial. ${ }^{131} \mathrm{Ob}$ er diese Autoren aus dem Gedächtnis oder aus seiner persönlichen oder bischöflichen Bibliothek zitieren konnte, bleibt unklar; aus seinen Bitten um Bücher an seine Freunde geht jedoch hervor, dass ihm ganz essentielle Werke fehlten und dass ein etwaiger Mangel an Dichtung wohl hintangestellt werden musste. Er fragt ausschließlich nach Bibel und Kirchenvätern, sanctorum librorum munera und sanctorum patrum spiritalibus tractatibus. ${ }^{132}$ Dies ist gleichzeitig Indiz, dass in bonifatianischer Zeit noch kein Skriptorium in Mainz etabliert war. ${ }^{133}$ Seine persönliche Bibliothek, insofern sie rekonstruiert werden

Wiesbaden 2004. Nr. 3096. Die Liste der Werke in: Lindsay/Lehmann: »The early Mayence scriptorium«. S. 37-38.

127 Paul Lenmann (Hrsg.), Mittelalterliche Bibliothekskataloge Deutschlands und der Schweiz. 1: Bistümer Konstanz und Chur. 2: Bistum Mainz, Erfurt (Mittelalterliche Bibliothekskataloge Deutschlands und der Schweiz), München 1918. 1, S. 74, Z. 3-23.

128 Nicht mehr 50, wie bei HedtKe/Winterer: »Mainz«. S. 353, wo der später erschienene Bd. 3 von BISCHOFFs Katalog noch nicht berücksichtigt werden konnte.

129 Aloys RUPPEL, "Der heilige Bonifatius als Dichter«, in: Universitas: Dienst an Wahrheit und Leben; Festschrift für Bischof Dr. Albert Stohr, 2, hrsg. von Ludwig LenHART 1960, S. $28-41$.

130 Reinhold RAu und Lutz E. von PAdBerg (Hrsg.), Briefe des Bonifatius = Bonifatii epistulae: Willibalds Leben des Bonifatius; Nebst einigen zeitgenössischen Dokumenten (Ausgewählte Quellen zur deutschen Geschichte des Mittelalters 4b), Darmstadt 2011. S. 466, Z. 21-23. Für weitere Nachweise siehe: DüMmLER: »Die handschriftliche Überlieferung«. S. 98.

131 Dümmler (Hrsg.): MGH Poet. lat. 1. S. 1-19, passim; Martial: S. 20, Carmen VII, v. 20.

132 Rau/Padberg (Hrsg.): Bonifatiusbriefe. An die Äbtissin Eadburg Ep. 30, an Abt Duddo Ep. 34; um ein in Gold geschriebenes Exemplar der Petrusbriefe an Eadburg, Ep. 35; diese Anfragen jedoch vor seiner Mainzer Erzbischofswürde ( $a b 746)$. Aus dieser Zeit vielleicht die rührende Bitte an Daniel von Winchester, Ep. 63, um ein Buch der Propheten in großer Unziale wegen seines nachlassenden Augenlichtes. Auch seine römischen Beziehungen ließ Bonifatius zur Erlangung von Handschriften spielen, siehe Ep. 54. Zum Austausch von Büchern: John-Henry CLAY, »Gift-giving and books in the letters of St Boniface and Lul«, in: Journal of Medieval History 35 (2009), S. 313-325.

133 Oder nur eines, das in der Bonifatius unbequemen Kursive schrieb: quia librum (...) talem in hac terra, qualem desidero, adquirere non possum et caligantibus oculis minutas litteras ac connexas clare discere non possum (An Daniel wie vorh. Anm.). »(...) weil ich ein solches Buch, wie ich es benötige, in diesem Land nicht finden kann und ich die kleinen und verbundenen Buchstaben mit meinem schwindenden Augenlicht nicht lesen kann." 
kann, enthielt keine Dichtung - sofern man nicht die Anspielungen als Hinweise auf das Vorhandensein von Vergil und Aldhelm gelten lassen will. ${ }^{134}$

Bonifaz' Gedichte wurden anscheinend nicht zusammenfassend gesammelt und erscheinen im 9. Jh. zerstreut in Handschriften verschiedener Herkunft. ${ }^{135}$ Um nur einige der Textzeugen zu nennen: Die akrostischen Gedichte finden sich, im genrehaften Verbund mit Aldhelm, im aus Südwestdeutschland stammenden Kodex Einsiedeln, StB, Cod. 302 (450), p. 126-131. In der aus St. Gallen stammenden Handschrift Zürich, ZB, C 78 (451), f. 86r-86v, findet sich anonym die Dedikation an seine Schwester zu den Figurengedichten, Theodulfs Briefgedichten vorausgehend. ${ }^{136}$ Die einzige Notiz aus Mainz selbst ist der Nachtrag zur Cassiodorhandschrift Würzburg, UB, M.p.th.f. 29, f. 44r-v, ein Figurengedicht an Duddo zur Widmung der Grammatik, ${ }^{137}$ das aus einer Handschrift derselben kopiert worden sein könnte. Dass nicht einmal Spuren einer Sammlung seiner Dichtung in Mainz erscheinen, ist umso merkwürdiger, als sein Nachfolger Lul sich intensiv um das Andenken seines Vorgängers bemühte, dem er Begleiter und Freund gewesen war. Er veranlasste die Sammlung seiner Briefe, deren Zusammenstellung er durch mehrere Redaktionen persönlich beaufsichtigte. ${ }^{138}$ Ebenso gab er dessen Vita in Auftrag. ${ }^{139}$ Zudem rühmt er sich, von Bonifaz persönlich Unterricht in der Metrik erhalten zu haben: "Die Dichtkunst habe ich damals unter Anleitung unseres Meisters und Bischofs Bonifaz, der allen, aber besonders mir am Herzen liegt, gelernt. ${ }^{140}$ Ob eine eigentliche Sammlung von Bonifaz’

134 Ein Rekonstruktionsversuch bei: Hermann ScHÜLING, "Die Handbibliothek des Bonifatius. «, in: Archiv für Geschichte des Buchwesens 4 (1961), S. 285-348. Zu Bonifatius’ Verhältnis $\mathrm{zu}$ seinen Büchern siehe: Marc-Aeilko ARIs, »Der Trost der Bücher: Bonifatius und seine Bibliothek«, in: Bonifatius. Vom angelsächsischen Missionar zum Apostel der Deutschen, hrsg. von Michael ImHOF und Gregor Karl SтASCH, Petersberg 2004, S. 95-110.

135 DüMmLER (Hrsg.): MGH Poet. lat. 1. S. 1-3.

$136 \mathrm{Zu}$ weiteren Handschriften: Ebd. S. 1-3.

137 Das Gedicht: Rau/Padberg (Hrsg.): Bonifatiusbriefe. S. 366. DümmLer (Hrsg.): MGH Poet. lat. 1. S. 17. Zur Mainzer Herkunft der Handschrift: Bischoff/Hofmann: Libri Sancti Kyliani. S. 47. Die Grammatik ist ediert in: George John Gebauer und Bengt LöFstedt (Hrsg.), Bonifatii (Vynfreth) ars grammatica: accedit ars metrica (CCSL 133B), Turnhout 1980. Siehe darin auch zur Verfasserschaft der Ars metrica.

138 Rau/Padberg (Hrsg.): Bonifatiusbriefe. S. 9-22. Michael TANGL, "Studien zur Neuausgabe der Bonifatius-Briefe", in: Neues Archiv der Gesellschaft für ältere deutsche Geschichtskunde 40 (1916), S. 639-790. (1919): 23-101, passim.

139 Wilhelm Levison (Hrsg.), Vitae sancti Bonifatii archiepiscopi Moguntini (MGH SS rer. Germ. 57), Hannover 1905. S. VII-XLVII, 1-58. Die Beauftragung Willibalds mit der Vita in Kapitel 1.

140 Hanc itaque nuper metrice artis peritiam domini nostri omnium generalis meique specialis presulis venerandi Bonifacii sub magisterio didiceram. "S. Bonifatii et Lulli epistolae«, in: MGH Epist. 3, hrsg. von Wilhelm GundLACH 1892, S. 215-384. Nr. 98, S. 385, Z. 11-13. Da die beiden sich erst im Erwachsenenalter kennenlernten, geht es bei der gelernten ars wohl um Rätsel- und Figurengedichte insularer Art, wie sie in (nur) einem Textzeugen auf den Brief folgen (Wien, ÖNB Cod. 751; Zur Handschrift Ebd. S. 219). 
Dichtung veranstaltet wurde oder ob eine solche, auch wegen der Verfügbarkeit vieler Gedichte in den Briefen, ganz unterblieb, bleibt unklar. Ihre geringe Zahl zumindest muss nicht als Hindernis angesehen werden, da auch von anderen Dichtern, wie zum Beispiel Theodulf, Anthologien von nur wenigen Gedichten zirkulierten.

Auch die Gedichte des Hrabanus Maurus wurden hauptsächlich an seinem Wirkungsort als Abt, in Fulda, gesammelt, nicht jedoch an seinem Bischofssitz in Mainz. Dort trat er ohnehin weniger als Gelehrter ${ }^{141}$ und gar nicht als Dichter, sondern vielmehr als Kirchenpolitiker auf, der regional durch Kirchengründungen ${ }^{142}$ und überregional insbesondere durch die von ihm einberufenen Synoden ${ }^{143}$ wirkte. Die Überlieferung seines dichterischen Werkes wird anlässlich Fuldas näher behandelt. Von anderer Seite her tritt Hrabanus jedoch mit Mainz als Dichter in Verbindung. Gleich zwei Exemplare ${ }^{144}$ seines Liber de laudibus sanctae crucis verehrte er Mainzer Erzbischöfen, Haistulf und Otgar: »Nimm dieses Buch entgegen, oh frommer Otgar, höchster Priester, das ich einst mit Schreibrohr und Geist verfertigt habe. (...) Dieses Werk erbat einst dein ewig liebenswürdiger Vorgänger Haistulf, dem ich es auch geschenkt hatte. « ${ }^{145}$

141 Als Bischof widmete er seinem Weihbischof Thiotmar die Schrift De sacris ordinibus, siehe Marc-Aeilko ARIs, "Bildung und Wissenschaft«, in: Handbuch der Mainzer Kirchengeschichte, 1. Christliche Antike und Mittelalter, hrsg. von Marc-Aeilko ArIs und Friedhelm JürgensmeIER (Beiträge zur Mainzer Kirchengeschichte 6), Würzburg 2000, S. 841-862. S. 844. Ansonsten trat er in Mainz nicht literarisch in Erscheinung.

142 Franz STAAB, "Die Mainzer Kirche im Frühmittelalter», in: Handbuch der Mainzer Kirchengeschichte, 1. Christliche Antike und Mittelalter, hrsg. von Marc-Aeilko ARIS und Friedhelm JÜRGENSMEIER (Beiträge zur Mainzer Kirchengeschichte 6), Würzburg 2000, S. 87-194. S. 164.

143 Ebd. S. 166. Wilfried Hartmann, "Die Mainzer Synoden des Hrabanus Maurus«, in: Hrabanus Maurus. Lehrer, Abt und Bischof, hrsg. von Raymund Kоттје und Harald ZIMMERMANN (Akademie der Wissenschaften und der Literatur Mainz. Geistes- und Sozialwissenschaftliche Klasse. Einzelveröffentlichungen 4), Wiesbaden 1982, S. 130-144.

144 Die folgenden Verse werden von SpILling anders interpretiert: Das Haistulf zugedachte Exemplar wurde, weil es zu seinem Tode noch nicht fertiggestellt war, seinem Nachfolger Otgar übergeben: Herrad SpILling, Opus Magnentii Hrabani Mauri in honorem sanctae crucis conditum. Hrabans Beziehung zu seinem Werk (Fuldaer Hochschulschriften 18), Frankfurt a. M. 1992. S. 45-47. Haistulf wurde übrigens auch De institutione clericorum auf Bitte Aigils gewidmet: DüMmLER (Hrsg.): MGH Poet. lat. 2. S. 163, II, i.

145 Accipe, sancte pater Otgari, summe sacerdos, / Librum, quem dudum mente dedi et calamo. (...) / Hoc opus ergo tuus decessor semper amandus / Expetit Haistolfus, cui quoque hoc dederam. DüMmLer u. a. (Hrsg.): MGH Poetae.2, S. 162, Nr. V, Z. 1-2, 7-8. Zu den Widmungen: MüLler: De laudibus. S. 31-35. 
Das Widmungsexemplar für Otgar kann vielleicht mit Paris, BNF Lat. 2423 identifiziert werden, das nach dessen Tod von Hrabanus auf dem Mainzer Konzil (848) Radulf von Bourges übergeben wurde. ${ }^{146}$

Die erhaltenen Gedichthandschriften des Mainzer Skriptoriums können nicht mit der Pracht der Handschriften von Hrabanus' Kreuzgedichten wetteifern. Nicht zweifelsfrei Mainz zugeordnet werden kann das kleine Konvolut von Figurengedichten in Bern, BB, Ms. 212, f. 111-122, 123-126, das schon im 9. Jh. mit einer Mainzer Handschrift zusammengebunden wurde. ${ }^{147}$ Der zweite Teil, geschrieben im 1. Drittel des 9. Jh., zeigt Überschriften und Glossen einer Mainzer Hand. Die Gedichte wurden wahrscheinlich via St. Amand nach Mainz vermittelt - wie auch andere Texte - und dort gelesen und glossiert. ${ }^{148}$ Die sieben hier versammelten Figurengedichte von zeitgenössischen Autoren (Alkuin, Josephus Scottus, Theodulf) ${ }^{149}$ wurden von Alkuin für Karl den Großen zusammengestellt. ${ }^{150}$ Es handelt sich bei der schlichten Berner Handschrift offensichtlich nicht um das präsentierte Exemplar. ${ }^{151}$

Die umfangreichste poetische Handschrift aus dem Mainzer Skriptorium in St. Alban ist der Kodex Wien, ÖNB Cod. 969 aus dem 2. Viertel des 9. Jh. ${ }^{152}$ Er

146 Amédée BoINET, "Notice sur deux manuscrits carolingiens à miniatures exécutés à l'abbaye de Fulda", in: Bibliothèque de l'Ecole des Chartes 65 (1904), S. 355-363. S. 362; MüLLER: De laudibus. S. 84f.

$147 »$ Entstehungsort unbekannt (Hof?), Beziehungen zu Saint-Amand und Mainz, IX. Jh., 1. Drittel«: Bernhard BiscноғF, Katalog der festländischen Handschriften des neunten Jahrhunderts, 1: Aachen - Lambach (Veröffentlichungen der Kommission für die Herausgabe der mittelalterlichen Bibliothekskataloge Deutschlands und der Schweiz), Wiesbaden 1998. 1, Nr. 553. Hermann Hagen, Catalogus codicum bernensium 1878. S. $260 \mathrm{f}$.

148 SChaller: »Die karolingischen Figurengedichte des Cod. Bern. 212.« S. 42-46.

149 Nach der Handschrift ediert bei Hermann HAgEN, Carmina Medii Aevi maximan partem inedita, ex bibliothecis Helveticis collecta, Turin 1961. Nr. LXIX-LXXV. LXXIV ist in der Handschrift fälschlich Josephus zugeschrieben, tatsächlich stammt es von Alkuin. Zu Josephus: DüMmLER (Hrsg.): MGH Poet. lat. 1. S. 149-159. BRunhöLzL: Geschichte, 1. S. $286 f$.

150 SCHAller:»Die karolingischen Figurengedichte des Cod. Bern. 212.« FerRARI: Liber sanctae crucis. S. 214-218. Michel Jean-Louis Perrin, "Autour de la datation des poèmes d'Alcuin, Joseph Scot et Théodulf d'Orleans réunis dans le manuscrit Bernensis 212«, in: Rerum gestarum scriptor. Histoire et historiographie au Moyen Âge. Hommage à Michel Sot, hrsg. von Magali Coumert u. a., Paris 2012, S. 575-587. Michel Jean-Louis Perrin, »La poésie de cour carolingienne, les contacts entre Alcuin et Hraban Maur et les indices de l'influence d'Alcuin sur l'In honorem sanctae crucis", in: Annales de Bretagne 111 (2004), S. 333-352. S. 336-342.

151 Perrin: »Datation«. S. 578.

152 f. 8r: St. Albani. Bernhard Bischoff, Katalog der festländischen Handschriften des neunten Jahrhunderts, 3: Padua - Zwickau (Veröffentlichungen der Kommission für die Herausgabe der Mittelalterlichen Bibliothekskataloge Deutschlands und der Schweiz), Wiesbaden 2014. Nr. 7187. Hermann Julius Hermann, Die frühmittelalterlichen Handschriften des Abendlandes (Beschreibendes Verzeichnis der illuminierten Handschriften in Österreich, 8,1), Leipzig 1923. S. 120-122. 
vereint beliebte moralistische Texte - Aldhelm, ${ }^{153}$ Pseudo-Cato ${ }^{154}$ und Publilius Syrus - zu einem planvollen Ganzen. Zwei Schreiber teilen sich die Hauptarbeit in weitgehend gleicher Gestaltung: ${ }^{155}$ Der erste übernimmt f. 1r-55r Aldhelm: Carmen de virginitate auf den ersten sieben Quaternionen, ${ }^{156}$ der zweite schreibt Ps.-Cato, Publilius Syrus und Ps.-Seneca auf f. 56r-62v,62v-70r. Auf Aldhelm wurde mehr Sorgfalt verwandt, der Text ist durch Animalia als Initialen, Rotfüllungen im Zeilenanfang und durchgehende Lombarden geschmückt und gegliedert. Die Gestaltung der Initialen erinnert an insulare Vorbilder. ${ }^{157}$ Der Buchschmuck nimmt mit Fortschreiten des Textes ab und beschränkt sich beim zweiten Schreiber auf rote Füllsel der Zeilenfänge. ${ }^{158}$ Die Herkunft der Texte wirft ein Licht auf die Traditionsverhältnisse, in denen das Mainzer Skriptorium stand. Der Aldhelm-Text fließt aus der gleichen Quelle wie der des Cod. Sang. 242, einer von mehreren St. Galler Aldhelm-Kodizes, der dort in der 2. Hälfte des 9. Jahrhunderts geschrieben wurde. ${ }^{159}$ Die Vorlage war wahrscheinlich eine insulare Handschrift oder hing von einer solchen ab, wie mehrere entsprechende Varianten belegen. Das höhere Alter der Mainzer Handschrift legt nahe, dass die Vorlage zuerst in St. Alban vorlag und in der zweiten Hälfte des Jahrhunderts zur Abschrift in St. Gallen verfügbar war. Den gleichen Weg nahm der Text der Seneca und Paulus zugeschriebenen Briefe, ${ }^{160}$ dessen Vorlage, nachdem sie in Mainz kopiert worden war, nach St. Gallen wanderte und dort abgeschrieben wurde in dem kleinen Heft Zürich, ZB, C. 129, f. $95-106 .{ }^{161}$ Die Sentenzen des Publilius

153 Carmen de virginitate: Rudolf Ehwald (Hrsg.), Aldhelmi Opera (MGH AA 15), Berlin 1919. S. 342, Sigle V.

154 Benutzt, aber nicht verzeichnet: Marcus BoAs (Hrsg.), Disticha Catonis, Amsterdam 1952. S. LXXXIV.

155 Eigene Analyse und Pavel Spunar, »Les distiques de Caton dans le codex 969 de Vienne (Analyse paléographique)«, in: Listy filologické / Folia philologica 81 (1958), S. 50-53.

$156(\mathrm{IV}-1)^{7}+\mathrm{IV}^{15}+\mathrm{IV}^{23}+\mathrm{IV}^{31}+\mathrm{IV}^{39}+\mathrm{IV}^{47}+\mathrm{IV}^{55}+\mathrm{IV}^{63}+(\mathrm{IV}+1)^{70}$.

157 Ähnliche Gestaltung jedoch auch in St. Galler und Reichenauer Handschriften: HermanN: Die frühmittelalterlichen Handschriften des Abendlandes. S. 120. Siehe dort auch S. 122 für Abbildungen.

158 1r-v rot grüne Initialfüllungen in jeder Zeile, Initialen insular; $2 r-3 r$ rote Lombarden mit blau-gelber Füllung, 3v-4r rote Lombarden, $4 v-5 r$ schwarze Lombarden rote Füllung, $5 v-$ $55 \mathrm{r}$ rote Lombarden, ab 56r rote Füllsel in Anfangsbuchstaben jeder Zeile.

159 Die Verwandtschaft belegt durch zwei versetzte Verse: EHwald (Hrsg.): Aldhelmi Opera. S. 329-348, S. 342. Zur Aldhelm-Überlieferung allgemein: Michael LAPIDGE, »Aldhelmus Malmesberiensis abb. et Scireburnensis ep.", in: La trasmissione dei testi latini del Medioevo, 4, hrsg. von Paolo Chiesa und Lucia Castaldi 2012, S. 14-38.

160 Claude W. Barlow (Hrsg.), Epistolae Senecae ad Paulum et Pauli ad Senecam, Rom 1938. Insb. S. 23f. und das Stemma im Anhang. Umfassend zur Überlieferung: Leighton Durham Reynolds, The medieval tradition of Seneca's letters (Oxford classical \& philosophical monographs), London 1965.

161 Bischoff: Katalog, 3. Nr. 7584; Leo Cunibert Mohlberg, Katalog der Handschriften der Zentralbibliothek Zürich. 1: Mittelalterliche Handschriften, Zürich 1951. S. 62. BARLow (Hrsg.): Epistolae. S. 21. 
Syrus liegen hier in der weitverbreiteten Rezension $\Sigma$ vor. ${ }^{162}$ Von der Vorlage dieser Sammlung ging eine Vielzahl von französisch/süd-westdeutschen Handschriften hervor, die den Einfluss der Vorlage in diesem Raum verorten, was den territorial übergreifenden Einfluss einzelner Handschriften verdeutlicht. ${ }^{163} \mathrm{Ge}-$ brauchsspuren weist nur der Aldhelm-Text und dieser nur auf den ersten Seiten in Form von Glossen auf. Auf dem ersten Blatt ist beinahe jedes Wort lateinisch glossiert, f. 2 r noch sehr dicht; danach finden sich Glossen nur noch vereinzelt. ${ }^{164}$ Dies weist auf einen Gebrauch im Unterricht hin, wo nicht das ganze Werk studiert wurde. ${ }^{165}$ In einigen Nachträgen auf f. $55 \mathrm{v}^{166}$ befinden sich noch zwei Aachener Reminiszenzen, die in den Freiraum am Lagenende eingetragen wurden: Das auch bei Einhart zu findende Epitaph Karls des Großen, ${ }^{167}$ sowie eine Bauinschrift aus der Aachener Pfalzkapelle ${ }^{168}$. Die Bauinschrift ist nur hier belegt, das Epitaph als Einzelstück nur noch in Clm 14641, fol. $31^{169}$, mit der gleichen Variante annos XLVI (statt XLVII) feliciter rexit (danach bricht der Text gegenüber der längeren Version Einharts $a b)$. Die Variante steht gegen die sonstigen Textzeugen der Vita Karoli. Die Münchner Handschrift stammt aus dem Fuldaer Skriptorium und ist ähnlichen Datums wie Cod. 969, wobei das Epitaph »in insularer Minuskel der Hrabanus-Zeit« nachgetragen ist. ${ }^{170}$ Es ist nicht unwahrscheinlich, dass diese kleine Textgemeinschaft aus zwei Aachener Inschriften ein Souvenir von einem Besuch in der Kaiserstadt ist.

162 Reynolds: Texts and transmission. S. 327. Wilhelm Meyer, Die Sammlungen der Spruchverse des Publilius Syrus, Leipzig 1877. S. 4. Wilhelm Meyer (Hrsg.), Publilii Syri Mimi Sententiae, Leipzig 1880. S. 6-9. Francesco Giancottr, Ricerche sulla tradizione manoscritta delle sentenze di Publilio Siro, Messina 1963. S. 10, Sigle A. Francesco Giancotti (Hrsg.), Publilii Syri Sententiae (Testi Universitari), Turin 1968.

163 Meyer: Sammlungen. S. 7-12. Die Handschriften aus dem 9. Jh. sind: BNF Lat. 2676 s. IX 2/4, Loire Gebiet; BNF Lat. 7641 s. IX 1/4, Frankreich; Zürich Rh. 95 s. IX/X (?) Südwestdeutschland. Die Angaben auf briefliche Mitteilung Bischoffs an Reynolds: Texts and transmission. S. 327, Anm. 6, die Züricher Handschrift ist jedoch nicht in Bischoffs Katalog aufgeführt.

164 Bergmann/Stricker: Katalog. Nr. 930. Die deutschen Glossen bei: Elias von SteInMEYer und Eduard Sievers (Hrsg.), Die althochdeutschen Glossen, Berlin 1879. 2, Nr. DXVII.

165 Aldhelms Carmen de virginitate findet sich im Reichenauer Katalog unter die Grammatiker eingereiht und an ähnlicher Stelle vielleicht auch im Katalog von St. Riquier. LeHmanN (Hrsg.): MBK. 1, S. 250. GLAUCHE: Schullektüre. S. 28f.

166 Darauf Lagen-, Text- und Schreiberwechsel.

167 Oswald Holder-Egger (Hrsg.), Einhardi Vita Karoli Magni (MGH SS rer. Germ. 25), Hannover 1911. S. 35 Z. 25 - S. 36 Z. 1, S. 35, Anm. w), auch ebd. S. VII, Anm. 1. Weiterhin: DI 31, Aachen Dom, Nr. 9† (Helga Giersiepen), in: www.inschriften.net, urn:nbn:de:0238di031d001k0000900. Abgerufen am 2. November, 2016.

168 DI 31, Aachen Dom, Nr. 11a† (Helga Giersiepen), in: www.inschriften.net, urn:nbn:de:0238di031d001k00011a4. Abgerufen am 2. November, 2016.

169 Als Nachtrag auf der letzten Seite.

170 Bernhard Bischoff, Die südostdeutschen Schreibschulen und Bibliotheken in der Karolingerzeit, 1: Die bayerischen Diözesen, Wiesbaden 1960. 
Der Wiener Handschrift nahestehend ist die nur 21 Blätter zählende Handschrift Vatikan, BAV, Pal. lat. 239, in Mainz in der ersten Hälfte des 9. Jh. geschrieben. ${ }^{171}$ Einem Auszug aus Isidors Chronica major ${ }^{172}$ gehen hier drei Dichter voraus, und zwar (Ps.-)Paulinus von Nola, ${ }^{173}$ Ps.-Cato und Publilius Syrus. Bemerkenswert ist, dass keiner der beiden letzteren mit dem Text der Wiener Handschrift in Verbindung steht, obwohl diese sich wahrscheinlich zum Zeitpunkt der Kopie in Mainz befand. In der Tat stellen beide Sentenzensammlungen in ihrer Auswahl Sondergut dieser Handschrift dar. ${ }^{174}$ Ein Fingerzeig zur möglichen Herkunft ist, dass die seltene Sammlung der catonischen Monosticha vielleicht mit Alkuin oder Columban, zumindest aber mit insularen Kreisen verknüpft ist. ${ }^{175}$ Für eine westfränkische Transmission spricht der Chronica-Text, der der aus Frankreich stammenden Unzialhandschrift Paris, BNF, Lat. 10910 sehr nahe steht; Mommsen vermutet sogar eine direkte Abschrift. ${ }^{176}$ Dass die Handschrift nicht aus der Wiener, aus St. Alban stammenden, abgeschrieben worden ist, legt einen anderen Entstehungsort als das Kloster nahe, vielleicht am Dom, und dort vielleicht im Privatbesitz eines Klerikers, wozu auch das handliche Format passt. Die Handschrift wanderte im Übrigen schon bald nach Lorsch ab, wie der Vermerk Sancti Nazarii aus dem 10. Jh. beweist. ${ }^{177}$

Eng an die römische Handschrift schließt sich in Inhalt und Form Basel, UB, F III 15e, f. 26-55, aus dem 2. Viertel des 9. Jh., geschrieben von insular beein-

171 Beschreibung: Michael KAUTz, "Vatikan, Biblioteca Apostolica Vaticana, Pal. lat. 239«, http://bibliotheca-laureshamensis-digital.de/bav/bav_pal_lat_239?ui_lang=eng (abgerufen am 05.11.2018). Bischoff: Katalog, 3, S. 3. Nr. 6501.

172 »Isidori iunioris episcopi hispalensis Chronica maiora«, in: MGH SS Auct. Antiq. 11, hrsg. von Theodor Mommsen 1864, S. 391-506. S. 400, Sigle Y.

173 Poema coniugis ad uxorem: Wilhelm von Hartel und Margit Kamptner (Hrsg.), Paulini Nolani Carmina (CSEL 30), Wien 1999. S. 344-348. Eligius Dekkers, Clavis patrum Latinorum (CCSL), Turnhout 1995. Nr. 531.

174 Publilius in der Rezension П, Meyer: Sammlungen. S. 4, 13-21; Giancotti: Ricerche. S. 11. Giancotti (Hrsg.): Publilii Syri Sententiae. Sigle H. Zu den Monosticha des Ps.-Cato: Marcus BoAs, "Die Lorscher Handschrift der sog. Monosticha Catonis«, in: Rheinisches Museum für Philologie 72 (1917), S. 594-615. Insb. S. 598.

175 A. Streib, »Wer ist der Verfasser der Praecepta vivendi?«, in: Münchener Museum für Philologie des Mittelalters und der Renaissance 2 (1913), S. 343-364. Marcus BoAs, Alcuin und Cato, Leiden 1937. S. 44-50. Marie-Hélène Jullien, Clavis scriptorum latinorum medii aevi. Auctores Galliae, t. 2, Turnhout 1999. S. $75 \mathrm{f}$.

176 »Chronica maiora«. S. 400. Zum Lat. 10910: Bischoff: Katalog, 3, S. 3. Nr. 1667a.

177 Bischoff: Abtei Lorsch. S. 49. Dass die Handschrift mit dem Eintrag in den Lorscher Katalogen Nr. 237b (A-, B170, Ca297, D193) (B170: Item eiusdem liber prohiemiorum et chronica et de significatione nominum ad Orosium in uno codice) identisch ist, wie von HÄSE: Bücherverzeichnisse. S. 274, vermutet, halte ich wegen der weiteren dort genannten Werke Isidors für ausgeschlossen. 
flussten Mainzer Händen. ${ }^{178}$ Der anonymen Mahnschrift De conflictu vitiorum et virtutum, folgen die schon oben erwähnten Mahnverse Praecepta vivendi, ${ }^{179}$ die eng mit den Monosticha Catonis verwandt sind. Auch diese Handschrift wanderte in ein mit Mainz verbundenes Kloster ab, nach Fulda, dessen Signatur jedoch im Gegenteil zur Lorscher der vorherigen Handschrift erst aus dem 15. Jh. stammt. $^{180}$

Eine Sammelhandschrift mit hagiographischer Dichtung zum Mainzer Kathedralpatron $^{181}$ ist der Martinellus in Vatikan, BAV, Pal. lat. $845,{ }^{182} \mathrm{der}$ mit anderen Texten die zwei metrischen Viten des Heiligen von Paulinus von Périgueux $^{183}$ und Venantius Fortunatus ${ }^{184}$ enthält. Die Handschrift steht in Inhalt, Text und Gestaltung Vorbildern aus Tours nahe. ${ }^{185}$ Das Hauptanliegen der Handschrift ist die Sammlung hagiographischen Materials zum Patron, ${ }^{186}$ wozu man auf die schon in Tours etablierte und standardisierte Form des Martinellus zurückgreifen konnte. Die Schwesterhandschrift von Pal. lat. 845, Paris, BnF Lat. 13759 (Sigle L), ist sogar in Tours geschrieben und als Geschenk nach Corbie gesandt worden; ${ }^{187}$ ob die Mainzer Kopie auf eine direkt aus Tours dorthin gesandte Vorlage zurückgeht oder nur mittelbar mit einer solchen zusammenhängt, ist unklar.

Um zusammenzufassen: Aus der Schriftstätte Mainz sind, trotz einer reichen Gesamtproduktion und einer anscheinend umfangreichen Bibliothek, nur we-

178 Beschreibung auf http://www.e-codices.unifr.ch/en/description/ubb/F-III-0015e/Staub, abgerufen 2. November, 2016. Bischoff: Katalog, 1. Nr. 280. Die Verse finden sich in der letzten Lage III ${ }^{55}$.

179 Ediert als Alcuin, Carmen 62, DüMmLER (Hrsg.): MGH Poet. lat. 1, S. 1. S. 275-281, Sigle B. Siehe auch S. $122 \mathrm{f}$.

180 Karl Christ, Die Bibliothek des Klosters Fulda im 16. Jahrhundert: die HandschriftenVerzeichnisse (Zentralblatt für Bibliothekswesen 64), Leipzig 1933. S. 201, 220.

181 Eugen EwIG, "Die ältesten Mainzer Patrozinien und die Frühgeschichte des Bistums Mainz«, in: Spätantikes und fränkisches Gallien. Gesammelte Schriften 1, hrsg. von Hartmut AтsmA (Beihefte der Francia 3, 2), München 1979, S. 154-170.

182 »[Mainz, IX. Jh., 1. Viertel]«: Bischoff: Katalog, 3. Nr. 6562. Bergmann/Stricker: Katalog. Nr. 804. Enrico Stevenson und I. B. de Rossi, Codices Palatini Latini Bibliothecae Vaticanae, Rom 1866. S. $297 \mathrm{f}$.

183 Michael Petschenig, Karl Schenkl und Klaus Brandes (Hrsg.), Poetae Christiani minores (CSEL 16), Wien 1888. S. 3-15, Sigle P. Sylvie LABARRE (Hrsg.), Vie de saint Martin:prologue: livres I-III / Paulin de Périgueux (Sources chrétiennes 581), Paris 2016. S. 123f., Sigle P.

184 Friedrich Leo (Hrsg.), Venanti Honori opera poetica (MGH AA 4, 1), Berlin 1881. S. XXII, Sigle N.

185 Sylvie Labarre, "La transmission de Paulin de Périgueux: les principes d'une nouvelle édition«, in: Revue d'histoire des textes 7 (2012), S. 117-158. S. 124.

186 So gemeint vielleicht das Incipit der Vita Martini des Sulpicius Severus zu Beginn der Handschrift: Incipit uita sancti ac beatissimi patronis nostri Martini episcopi atque confessoris, das sich natürlich auch in der Vorlage auf Saint-Martin de Tours bezogen haben könnte.

187 Labarre: »La transmission de Paulin de Périgueux«. S. 121. 
nige Handschriften mit Dichtung erhalten. Das Maß der Verluste ist jedoch schwer einzuschätzen. Obwohl zwei der Erzbischöfe, Bonifatius und Hrabanus, sich auch als Dichter einen Namen machten, wurden ihre Werke nicht in Mainz, sondern an anderen Orten gesammelt. Die Haupteinflüsse auf Mainz sind die insulare Tradition, wie sich an Schriftbild und Herkunft der Texte zeigt, und der west-deutsch/west-fränkische Raum, wie die Sammlung der Karl gewidmeten Gedichte, die Aachener Reminiszenzen und der Tourenser Ursprung des Martinellus belegen. In Mainz vorhandene Handschriften wanderten nach Lorsch, Fulda und St. Gallen ab, wo sie Vorlage für neue Kodizes wurden. Die Rolle des Mainzer Skriptoriums in der Textüberlieferung steht jedoch in keinem Verhältnis zur politischen Bedeutung des Erzbistums.

\section{II.1.b Würzburg}

Die bonifatianische Bistumsgründung Würzburg, ${ }^{188}$ die schon im 7. Jh. Ort von Wirken und Passion des hl. Kilian gewesen war, erlangte auch durch die Domschule schnell überregionale Bedeutung als ein Zentrum der Gelehrsamkeit ${ }^{189}$ und wurde Ausbildungsstätte zahlreicher später bedeutender Personen ${ }^{190}$. Eine Schule am Dom darf schon für das späte 8. Jh. angenommen werden, wie Benutzungsspuren in den älteren Handschriften zeigen. ${ }^{191}$ Die frühen Handschriften zeigen deutlich die insulare Tradition, die von Bonifatius und dem Angelsachsen Burkart, dem ersten Bischof, ${ }^{192}$ dort etabliert wurde. ${ }^{193}$ Die geringe Zahl der Handschriften aus Würzburg, in denen Dichtung überliefert ist - keine

188 Ulrich WAgner (Hrsg.), Geschichte der Stadt Würzburg, 1, Von den Anfängen bis zum Ausbruch des Bauernkriegs, Stuttgart 2001. Klaus LindNeR, Untersuchungen zur Frühgeschichte des Bistums Würzburg und des Würzburger Raumes (Veröffentlichungen des MaxPlanck-Instituts für Geschichte 35), Göttingen 1972.

189 Hans Thurn, "Die Würzburger Domschule von ihren Anfängen bis zum Ausgang des Mittelalters: religionis et rei publicae seminarium?«, in: Würzburgs Domschule in alter und neuer Zeit, hrsg. von Günter Косн und Josef Pretscher, Würzburg 1990, S. 11-33.

190 Zum Beispiel der Bischöfe von Paderborn, Hathumar und Badurad: Alfred Wendehorst, Das Bistum Würzburg, Die Bischofsreihe bis 1254 (Germania sacra 1), Berlin 1962. S. 33. Für die spätere Zeit: Alfred Wendehorst, »Bischofssitz und königliche Stadt: Von der Karolingerzeit bis zum Wormser Konkordat«, in: Geschichte der Stadt Würzburg, 1: Von den Anfängen bis zum Ausbruch des Bauernkrieges, hrsg. von Ulrich WAGNER, Stuttgart 2001, S. 62-73. S. $65 \mathrm{f}$.

191 Rudolf ENDres, „Schulen und Hochschulen«, in: Geschichte der Stadt Würzburg, 1: Von den Anfängen bis zum Ausbruch des Bauernkrieges, hrsg. von Ulrich WAGNER, Stuttgart 2001, S. 313-321. S. 315 f.

192 Wendehorst: Das Bistum Würzburg, Die Bischofsreihe bis 1254. S. 18-24.

193 Bernhard Bischoff, "Panorama der Handschriftenüberlieferung aus der Zeit Karls des Großen «, in: Bischoff, Mittelalterliche Studien, 3, Stuttgart 1981, S. 5-38. S. 248. BIschoff/ Hofmann: Libri Sancti Kyliani. S. 5-12. 
davon enthält genug, um als Sammlung angesprochen zu werden - macht eine eingehende Darstellung des Skriptoriums unnötig. ${ }^{194}$ Es genüge hier darauf hinzuweisen, dass nach Abstreifung des insularen Einflusses, der insbesondere unter Burkart und Megingoz das Skriptorium beherrscht hatte, unter Bischof Wolfgar (810-832) die karolingische Minuskel die ältere Schrift verdrängte. ${ }^{195}$ Unter Hunbert und insbesondere Gozbald wurde vollends ein charakteristischer eigener Stil entwickelt. ${ }^{196}$ Nach Gozbalds Tod nahm die Produktion merklich ab. ${ }^{197}$ Dichter hat Würzburg nicht hervorgebracht und keiner wirkte dort, sodass eine lokale Traditionsbildung nicht stattfinden konnte. ${ }^{198}$

Die Bibliothek, wie sie aus den frühesten Handschriften rekonstruiert werden kann, spiegelt noch missionarische Bemühungen wieder. ${ }^{199}$ Die weitgehend geschlossene Erhaltung der Würzburger Handschriften in der Universitätsbibliothek Würzburg und der Bodleian Library bietet einen guten Einblick in die Sammlung. Der Schwerpunkt liegt, wie zu erwarten, auf Bibel, Liturgie und lateinischen Vätern. Die einzige Handschrift, die vollständig mit Dichtung gefüllt war, liegt nur noch fragmentarisch im Einbandstreifen aus Würzburg, UB, M.p.th.f. 145, Fragm. 23 (Reuß-Mappe) vor und enthielt einst die Evangeliendichtung des Juvencus. ${ }^{200}$ Die Kataloge zeichnen das gleiche Bild. Den Stand der

194 Eingehend in: Bischoff/Hofmann: Libri Sancti Kyliani; Glauche/Knaus/Bischoff (Hrsg.): MBK 4, 2. S. 948-977. Christopher KöHLER, »Würzburg", in: Schreiborte des deutschen Mittelalters: Skriptorien - Werke - Mäzene, hrsg. von Martin J. SCHubert, Berlin [u. a.] 2013, S. 621-644.

$195 \mathrm{Zu}$ den Bischöfen: Wendehorst: Das Bistum Würzburg, Die Bischofsreihe bis 1254. am jeweiligen Ort. Zur Ablösung der Schrift: Bischoff/Hofmann: Libri Sancti Kyliani. S. $13 \mathrm{f}$.

196 Bischoff/Hofmann: Libri Sancti Kyliani. S. 15-18.

197 Glauche/Knaus/Bischoff (Hrsg.): MBK 4, 2. S. 960. Wendehorst: "Bischofssitz und königliche Stadt». S. 65.

198 Reinhard Düchting, »Die lateinische Literatur«, in: Geschichte der Stadt Würzburg, 1: Von den Anfängen bis zum Ausbruch des Bauernkrieges, hrsg. von Ulrich WAGNER, Stuttgart 2001, S. 450-458. Das Gedicht des in Würzburg wirkenden Stephan von Novara in Würzburg, UB, M.p.th.f. 6, f. 115v, ist ein Nachtrag des 10. Jh, siehe Norbert FickermanN und Karl Strecker (Hrsg.), MGH Poet. lat. 5, 1.2, Berlin 1937. S. 554-556. Zwei möglicherweise auch spätere poetische Fragmente bei Bıschoff/Hofmann: Libri Sancti Kyliani. S. 22f. (Würzburg, UB, M.p.th.f. 45 \& 47, Hans Thurn, Die Pergamenthandschriften der ehemaligen Dombibliothek (Die Handschriften der Universitätsbibliothek Würzburg, 3/ 1), Wiesbaden 1984. S. 34, 63).

199 Düchtıng: "Die lateinische Literatur«. S. 453. Gottfried MäLzen, "Die Bibliothek des Würzburger Domstifts", in: Würzburger Diözesangeschichtsblätter 50 (1988), S. 509-544. Rudolf ENDRES, »Schulen, Universität und Bibliotheken«, in: Unterfränkische Geschichte 2 1992, S. 531-546. S. 531f. Zu Würzburg als Missionsstandort: Hermann-Josef SchmaLoR, »Würzburg und Paderborn- Missionierung und Bistumsgründungen«, in: Eine Welt in Bewegung: unterwegs zu Zentren des frühen Mittelalters; Begleitbuch der Gemeinschaftsausstellung, hrsg. von Georg EgGEnstein und Norbert Börste, München [u. a.] 2008, S. 51-55.

200 Bischoff/Hofmann: Libri Sancti Kyliani. S. 139. Thurn: Pergamenthandschriften. S. 7072. 
Sammlung dokumentiert ein auszugsweiser Katalog vom Beginn des 9. Jh., der den Buchbestand vor der Blütezeit des Skriptoriums widerspiegelt. ${ }^{201}$ Er ist keinesfalls als vollständiges Inventar zu betrachten. ${ }^{202}$ Dort kehrt vielleicht die Juvencus-Handschrift wieder als iuuenci super euangelia (Nr. 12). Unter dem in Nr. 26. genannten liber althelmi könnten sich verschiedene Werke des Dichters verbergen; passend wäre auch die Handschrift Würzburg, UB, M.p.th.f. 21, die jedoch die Prosafassung von De Virginitate überliefert. Ein Vorliegen auch der metrischen Variante wird durch den Zusatz des Vorworts derselben im Evangeliar Würzburg, UB, M.p.th.f. 67 wahrscheinlich gemacht. ${ }^{203}$ Die weiteren, kurzen Bücherverzeichnisse vermerken keine Dichtung, sodass Überlieferung und Zeugnis der Kataloge hier exakt übereinstimmen.

Dichtung nimmt in den Würzburger Handschriften meist einen marginalen Platz ein. Der schon genannte Kodex Würzburg, UB, M.p.th.f. $21,{ }^{204}$ noch unter Bischof Hunbert entstanden, enthält die Prosafassung von Aldhelms Carmen de virginitate, die in dieser Textfassung sonst nur noch in zwei englischen Handschriften erscheint ${ }^{205}$ - ein Verwandter dieser Handschriftenfamilie ist sicherlich durch eine der zahlreichen insularen Verbindungen Würzburgs dorthin gelangt. Auf f. 1v und 50r ist die Passio Eulaliae ${ }^{206}$ aus dem Peristephanon des Prudentius nachgetragen, womit ein Vorliegen dieses weitverbreiteten ${ }^{207}$ Werkes in Würzburg angenommen werden darf. Die grobe Schrift verrät einen ungeübten Schreiber ${ }^{208}$, dem der kurze Text vielleicht als Übung aufgetragen wurde.

201 In Oxford, Bodl. Libr., Laud. Misc. 126, auf dem letzten Blatt. Glauche/KNaus/BischofF (Hrsg.): MBK 4, 2. S. 977f. Bischoff/HofmanN: Libri Sancti Kyliani. S. 143-147. Elias Avery LOWE, "An eighth-century list of books in a Bodleian manuscript from Würzburg and its probable relation to the Laudian Acts«, in: Lowe, Palaeographical Papers 1 1972, S. 239-250.

202 Glauche/Knaus/Bischoff (Hrsg.): $M B K$ 4, 2. S. 954.

203 Bischoff/Hofmann: Libri Sancti Kyliani. S. 146. Thurn: Pergamenthandschriften. S. 5254.

204 Bischoff/Hofmann: Libri Sancti Kyliani. S. 31 f. Thurn: Pergamenthandschriften. S. 15. Bischoff: Katalog, 3. Nr. 7470. BergmanN/Stricker: Katalog. Nr. 985. Ehwald (Hrsg.): Aldhelmi Opera. S. VII, $211 \mathrm{f}$.

205 Brüssel, BR, Ms. 1650, Canterbury (?) s. IX, sowie die Handschrift der Sigle P, ein codex disiectus, siehe LAPIDGE: "Aldhelmus«. S. 28.

206 SK 5589. Peristephanon III, 1-128.

207 Manitius: Handschriften antiker Autoren in mittelalterlichen Bibliothekskatalogen. Nr. 140, obwohl die Identifikation des Werkes nicht immer klar ist. Abgesehen von einer eigentlichen Prudentiushandschrift könnte auch ein Hymnar zur Quelle gedient gedient haben, wo die Eulaliapassion bisweilen als Einzeltext vorkommt, z. B. Bern Ms. 455. Siehe Mearns: Early Latin hymnaries. S. 37.

208 Bischoff/Hofmann: Libri Sancti Kyliani. S. 32. 
In einer ähnlichen Lage findet man die Prudentiusexzerpte in Würzburg, UB, M.p.th.f. $63,{ }^{209}$ f. $1 \mathrm{r} / \mathrm{v}$ und $76 \mathrm{v}-78 \mathrm{v}$, die eine Sammlung Augustinusauszüge ${ }^{210}$ einrahmen. In der Ausführung sind sie sorgfältiger als die schülerhaften Nachträge in M.p.th.f. 21; als man feststellte, dass der Haupttext sieben Seiten der letzten Lage frei ließ, entschied man sich, die Hymnen kunstgerecht schreiben zu lassen. Bemerkenswert sind die Titel, in denen das Metrum der Gedichte erläutert wird, z. B.: metrum archilochicum. constat tetrametro bucolico et tribus trocheis. ${ }^{211}$ Der Prudentiustext beider Handschriften ist vielleicht ein Reflex des Unterrichts in der Domschule, wo Prudentius, wie anderswo, zu den studierten Autoren gehört haben könnte. ${ }^{212}$

Ein Zusatz ganz eigener Art ist die kleine Sylloge ${ }^{213}$ in der Rhethorica ad Herennium der Gozbald-Gruppe Würzburg, UB, M.p.misc.f. 2, die nahe der Entstehungszeit hinzugefügt wurde (f. $75 \mathrm{v}-76 \mathrm{r}$ ). ${ }^{214}$ Sie enthält auch einige entstellte metrische Inschriften. ${ }^{215}$ Zwei der Inschriften (9 und 10) kommen auch in der Sylloge von Urbana ${ }^{216}$, einer insularen Sammlung vor; Nr. 9 teilt sogar eine Variante, mit welcher diese beiden Sammlungen in engere Beziehung gesetzt werden. ${ }^{217}$ Die meisten Inschriften sind älteren Datums, Nr. 6 jedoch wurde nachweislich erst 821 für Santa Cecilia in Trastevere erstellt - in Anbetracht der Entstehungszeit der Handschrift um die Mitte des Jahrhunderts eine erstaunlich schnelle Rezeption. Es findet sich kein Einfluss der Sylloge auf Würzburger

209 Ebd. S. 34f. Bischoff: Katalog, 3. Nr. 7496. Thurn: Pergamenthandschriften. S. 47. Prudentius: f. 1: Cathemerinon III, 46-205 (Fortsetzung von f. 78v); f. 75v-78v: Peristephanon XIII, XII, IV; Cathemerinon III, 1-45.

210 Paul-Irénée Fransen, "Description de la collection de Bède le Vénérable sur l'Apôtre«, in: Revue bénédictine 71 (1961), S. 22-70.

211 Diese metrischen Notizen sind jedoch keine Würzburger Besonderheit, sondern Teil der breiteren Prudentiustradition, so zum Beispiel in allen bodenseeischen Handschriften des Dichters (siehe S. 116-118 zu Cod. Sang. 136).

212 GLAUCHE: Schullektüre. S. 145, s.v.

213 Giovanni Battista DE Rossi, Inscriptiones christianae urbis Romae saec. VII antiquiores, vol. 2,1, Rom 1888. S. 154-157. Patrick P. Sims-Williams, "Milred of Worcester's collection of Latin epigrams and its continental counterparts", in: Anglo-Saxon England 10 (1982), S. 2138. S. 35.

214 Bischoff/Hofmann: Libri Sancti Kyliani. S. 43. Bischoff: Katalog, 3. Nr. 7450. Thurn: Pergamenthandschriften. S. $119 \mathrm{f}$.

215 De Rossi: ICUR. S. 157, Anm. 9.

216 Luitpold Wallach, "The Urbana Anglo-Saxon Sylloge of Latin Inscriptions", in: Poetry and Poetics from Ancient Greece to the Renaissance: Studies in Honor of James Hutton, hrsg. von Gordon M. KIRKwood (Cornell studies in classical philology 38), Ithaca, NY 1975, S. 134151; Dieter SCHALLER, "Bemerkungen zur Inschriften-Sylloge von Urbana«, in: Mittellateinisches Jahrbuch 12 (1977), S. 9-21.

217 Sims-Williams: »Milred of Worcester's collection«. S. 35. 
Inschriften. ${ }^{218}$ Die Assoziation mit dem Schultext der Rhethorica ad Herenni$u^{219}$ lässt eine Verbindung auch der Inschriften mit einem gehobenen schulischen Kontext vermuten.

Die bisherigen Belege deuteten auf die Schule hin. In der kleinen Handschrift Würzburg, UB, M.p.th.f. 56 haben wir dagegen ein Zeugnis des persönlichen Interesses an Dichtung und deren Einfügung in einen weiteren Textzusammenhang. ${ }^{220}$ Die 35 Blätter zählende Handschrift besteht aus zwei Teilen (f. 1-11, 12-35), die schon im 9. Jh. zusammengebunden wurden, wie eine f. $11 \mathrm{v}$ und $12 \mathrm{v}$ ergänzende Hand belegt. Der Titel, Liber Gesbaldi ep[iscop]i de resurrectione mortorum metricus est, bezieht sich auf Bischof Gozbald, in dessen Privatbesitz sich das Buch anscheinend befand. ${ }^{221}$ Der erste Teil trägt als Haupttext einen Brief des Augustinus, angereichert mit weiteren patristischen Exzerpten genereller Natur. ${ }^{222}$ Zum von Gozbald an Inschriften bekundeten Interesse, das sich in der oben behandelten Würzburger Sylloge ausdrückte, passt die Ergänzung einer römischen Inschrift aus derselben (Nr. 10) auf f. 10v. ${ }^{223}$ Welche Handschrift welcher als Vorlage diente ist unklar; festgestellt kann jedoch werden, dass Inschriften im Gozbald-Kreis zirkulierten und dass der Bischof ein persönliches Interesse daran nahm. Der zweite Teil der Handschrift, der der gesamten den Titel gab, enthält das pseudo-cyprianische Carmen de resurrectione mortuorum $^{224}$ mit Zugabe weiterer Texte zu Cyprian, darunter Briefe und die Passio Cypriani, sowie zwei der Dicta Candidi ${ }^{225}$. Das Gedicht ist nicht, wie in einer

218 Nicht erwähnt bei: Theodor Kramer, Franz-Xaver Hermann und Karl Borchardt, Die Würzburger Inschriften bis 1525 (Die Deutschen Inschriften 27), Wiesbaden 1988. S. XVIIXXI. Die einzige karolingische Inschrift ist das Epitaph für Bischof Megingoz, S. 3, Nr. 1.

219 John O. WARD, "The medieval and early renaissance study of Cicero's De inventione and the Rhetorica ad Herennium: Commentaries and Contexts", in: The rhetoric of Cicero in its medieval and early renaissance commentary tradition, hrsg. von Virginia Cox und John O. WARD (Brill's companions to the Christian tradition 2), Leiden, Boston 2006, S. 3-69.

220 Bischoff/Hofmann: Libri Sancti Kyliani. S. 32f. Bischoff: Katalog, 3. Nr. 7489-90. Thurn: Pergamenthandschriften. S. 40-42.

221 Die Vermerke der von Gozbald in Auftrag gegeben Bücher sind anderen Formats, z.B. M.p.th.f. 21: (...) Gozbaldo episcopo qui iussit eum (librum) fieri (Bischoff/Hofmann: Libri Sancti Kyliani. S. 127). Zu Gozbald ferner: Wendehorst: Das Bistum Würzburg, Die Bischofsreihe bis 1254. S. 42-46. LINDNER: Frühgeschichte. S. 227-231.

$222 \mathrm{Zu}$ verwandten Textgesellschaften: Christine E. INEICHEN-EDER, "Theologisches und philosophisches Lehrmaterial aus dem Alkuin-Kreise", in: Deutsches Archiv für Erforschung des Mittelalters 34 (1978), S. 192-201. S. 193f.

223 Aus San Pietro in Vincoli. De Rossi: ICUR. 2, S. 286. Nr. 11. Siehe auch dort die Anmerkung für weitere Textzeugen. SK 7704, mit weiterer Literatur.

224 SK 13300. Dekkers: CPL. Nr. 1463. WASzINK, »Carmen ad Flavium Felicem«, in: Florilegium Patristicum Supplementum 1 (1937), S. 47-116.

225 Mette Lebech, James McEvoy und John L. Flood, "De dignitate conditionis humanae: Translation, Commentary, and Reception History of the Dicta Albini (Ps.-Alcuin) and the Dicta Candidi«, in: Viator 40 (2009), S. 1-34. 
gleichzeitigen Lorscher Handschrift, ${ }^{226}$ direkt Cyprian zugeschrieben; die Assoziation mit weiteren Cypriana dürfte jedoch als Beweis der zeitgenössischen Identifikation hinreichend sein. Der 2. Teil der Handschrift ist demnach als eine thematische Sammlung zu dem Kirchenvater anzusehen, zu dessen besonderer Verehrung durch Gozbald sie ein weiteres Zeugnis ist. Nach dem Erwerb von Reliquien des Heiligen auf dem Reichstag von Crémieu ließ er nämlich durch seinen Vorgänger Hunbert eine Eigenkirche dieses Patroziniums in Kleinochsenfurt weihen. ${ }^{227}$ Da diese Kirchweihe noch zur Zeit seiner Abtswürde in Niederaltaich stattfand und da die Handschrift zur eng mit diesem Kloster verbundenen II. Gozbald-Gruppe ${ }^{228}$ gehört, halte ich eine dortige Entstehung in zeitlicher Nähe zu Erwerb und Stiftung der Reliquien für naheliegend.

Dichtung in Würzburger Handschriften scheint hauptsächlich auf die Schule beschränkt gewesen zu sein, wie die Marginalexzerpte von Schulautoren sowie die metrischen Erläuterungen zu Prudentius nahelegen. Erst Gozbald scheint ein näheres Interesse an Poesie genommen zu haben, das in seiner persönlichen Handschrift und der mit ihm verbundenen Sylloge seinen Ausdruck fand. Dieses Interesse schlug sich jedoch nicht in der weiteren Handschriftenproduktion nieder, sodass es mit seinem Tod ein Ende fand. Das Fehlen poetischer Handschriften überrascht besonders sowohl angesichts der relativ geschlossenen Erhaltung der Bibliothek einerseits als auch des guten Rufes der Schule. War vielleicht die eigentliche Schulbibliothek separat von der 1717 wiederentdeckten Kathedralbibliothek aufgestellt und ging spurlos unter? ${ }^{229}$ Auch scheint das erhaltene Würzburger Handschriftenkorpus verdächtig arm an schulischen Handschriften. ${ }^{230}$ Dem steht entgegen, dass zahlreiche Würzburger Handschriften aus der Schule stammende Notizen tragen, darunter Schülerverse. ${ }^{231}$ Dennoch kann durch das weitgehende Fehlen der Handschriften die Rolle der Dichtung in Würzburg nur undeutlich ausgemacht werden.

226 Vatikan, BAV, Reg. Lat. 118: Michael KAUtz, »Vatikan, Biblioteca Apostolica Vaticana, Reg. lat. 118«, https://bibliotheca-laureshamensis-digital.de/bav/bav_reg_lat_118 (abgerufen am 06.11.2018).

227 Wendehorst: Das Bistum Würzburg, Die Bischofsreihe bis 1254. S. 43.

228 Bischoff/Hofmann: Libri Sancti Kyliani. S. 19-21.

229 Hofmann spricht anlässlich des unvollständigen Katalogs von einer »bischöflichen Bibliothek« (Ebd. S. 141f.). Im Katalog findet sich nur ein grammatisches Werk: (Nr. 31) grammatica sancti augustini et sancti bonifati. Eine getrennte Schulbibliothek vermutet zum Beispiel für St. Gallen: Heinrich Brauer, Die Bücherei von St. Gallen und das althochdeutsche Schrifttum (Hermaea. Germanistische Forschungen 17), Halle a.d. Saale 1926. S. 6, 71. Siehe auch S. 301-305 zu den Büchern Madalwins.

230 Eindeutig erscheint hier nur Würzburg, UB, M.p.th.f. 29. Thunn: Pergamenthandschriften. S. $21 \mathrm{f}$.

231 Bischoff/Hofmann: Libri Sancti Kyliani. S. 22 f. 


\section{II.1.c Fulda}

Die Bibliothek der Reichsabtei Fulda ${ }^{232}$ wuchs in der ersten Hälfte des 9. Jh. zu einer der größten Sammlungen im Ostfrankenreich heran - nur wenige Klöster, St. Gallen, die Reichenau, Lorsch, konnten mit ihren Schätzen wetteifern. ${ }^{233}$ Noch am Ende des Mittelalters zogen ihre Schätze die Aufmerksamkeit der Humanisten auf sich und es gelang dort eine der aufsehenerregendsten Wiederentdeckungen, die des Tacitus Mediceus. ${ }^{234}$ Umso schwerer wiegt der Verlust fast der gesamten Bibliothek, die in den Wirren des Dreißigjährigen Krieges untergegangen ist. ${ }^{235}$ Um die Rolle der Dichtung in Fulda zu rekonstruieren, muss also mehr auf die Zeugnisse der dort wirkenden Personen als auf die Handschriften selbst zurückgegriffen werden.

Die Geschichte von Skriptorium und Bibliothek ${ }^{236}$ lässt sich zwanglos in eine Periode vor und nach Hrabanus Maurus teilen, unter dessen Leitung das Kloster

232 Wolfgang Hamberger, Thomas Heiler und Werner Kirchioff, Geschichte der Stadt Fulda, Fulda 2008. Darin insb. Ulrich Hussong, „Die Geschichte des Klosters Fulda von der Gründung bis ins 11. Jahrhundert", S. 143-165. Ferner: Janneke RAAIJMAKERs, The making of the monastic community of Fulda, c.744 - c.900 (Cambridge studies in medieval life and thought 83), Cambridge [u. a.] 2012. Marc-Aeilko ArIs u. a., »Art. Fulda, St. Salvator«, in: Germania Benedictina 7 2004, S. 213-434. Ulrich Hussong, "Studien zur Geschichte der Reichsabtei Fulda bis zur Jahrtausendwende«, in: Archiv für Diplomatik 32 (1986), S. 129304.

233 Oliver BeRgGötz, »Hrabanus Maurus und seine Bedeutung für das Bibliothekswesen der Karolingerzeit: Zugleich ein Beitrag zur Geschichte der Klosterbibliothek Fulda«, in: Bibliothek und Wissenschaft 27 (1994), S. 1-48. S. 1, nach: Paul Lenmann, »Die alte Klosterbibliothek Fulda und ihre Bedeutung", in: Lehmann, Erforschung des Mittelalters, 1, 1941, S. 213-230. S. 213. Ein Überblick über die Bestände: ARIS u. a.: »Art. Fulda, St. Salvator«. S. 276-282.

234 Ludwig Pralle, Die Wiederentdeckung des Tacitus: ein Beitrag zur Geistesgeschichte Fuldas und zur Biographie des jungen Cusanus (Veröffentlichungen des Fuldaer Geschichtsvereins 33), Fulda 1952. Reynolds/Wilson: Scribes and Scholars. A Guide to the Transmission of Greek and Latin Literature. S. 138.

235 "[W]ohl der größte literarische Verlust, den Deutschland erlitten«: CHRIsT: Bibliothek des Klosters Fulda. S. VI. Zu den Umständen der Zerstörung: BERGGöTZ: »Bibliothekswesen«. S. 3. Nach Klaus GUGEL, Welche erhaltenen mittelalterlichen Handschriften dürfen der Bibliothek des Klosters Fulda zugerechnet werden? T. 1: Die Handschriften; T. 2: Die Fragmente aus Handschriften (Fuldaer Hochschulschriften 23a-b), Frankfurt a. M. 1995. S. 20, wurde die Bibliothek größtenteils nach ihrer Verschleppung nach Kassel makuliert, hierin folgt er Konrad Wiedemann, Manuscripta theologica. Die Handschriften in Folio (Die Handschriften der Gesamthochschul-Bibliothek Kassel. Landesbibliothek und Murhardsche Bibliothek der Stadt Kassel 1), Wiesbaden 1994. S. XX, der jedoch Fulda nicht explizit erwähnt.

236 Gereon BECHT-Jördens und Wolfgang HAUBRICHs, "Fulda», in: Schreiborte des deutschen Mittelalters: Skriptorien - Werke - Mäzene, hrsg. von Martin J. Schubert, Berlin [u. a.] 2013, S. 175-216. Marc-Aeilko ARIs, "Schul- und Bildungswesen, Literatur, Bibliotheken. Zur Geschichte der Klosterschule im Frühmittelalter«, in: Geschichte der Stadt Fulda 1. Von den Anfängen bis zum Ende des Alten Reiches, hrsg. von Wolfgang Hamberger, Thomas Heiler und Werner KirchHOFF, Fulda 2009, S. 681-691. GugEL: Handschriften. Gangolf SCHRIMPF 
den Übergang von asketischer Zurückgezogenheit zu gelehrter Prominenz vollzog. Nach der Gründung durch Bonifatius im Jahre $744^{237}$ bildete die Kultur der angelsächsischen Missionskreise, auf die sich Bonifatius stützte, ${ }^{238}$ die Grundlage der klösterlichen Bildung. Es ist davon auszugehen, dass die »Handbibliothek" des Bonifatius und die Bücher seiner Gefährten den Grundstock der Fuldaer Sammlung bildeten. ${ }^{239}$ Dichtung wird in dem Bildungsprogramm, das von Bonifatius für Fulda entworfen wurde, ${ }^{240}$ eng mit der schulischen Bildung in Verbindung gestanden haben. In einem Atemzug hebt sein Biograph seine Fertigkeiten in Grammatik und Dichtung hervor. ${ }^{241}$ Auch im Schriftbild hebt sich diese frühe Phase von der späteren Entwicklung durch die Verwendung insularer Schrift $\mathrm{ab}^{242}$ Den frühen Bestand der Bibliothek bildet der erste Katalog von ca. 800 teilweise ab. ${ }^{243}$ Schon durch seine mangelhafte Form - es finden sich zahlreiche Rechtschreibfehler ${ }^{244}$ - lässt der Katalog keineswegs die spätere Entwicklung der Bibliothek erahnen. Das Verzeichnis ist nicht vollständig; zu wel-

und Josef Leinweber (Hrsg.), Mittelalterliche Bücherverzeichnisse des Klosters Fulda und andere Beiträge zur Geschichte der Bibliothek des Klosters Fulda im Mittelalter (Fuldaer Studien 4), Frankfurt a. M. 1992. Winfried BöHne (Hrsg.), Hrabanus Maurus und seine Schule: Festschrift der Rabanus-Maurus-Schule, 1980, Fulda 1980. Artur Brall (Hrsg.), Von der Klosterbibliothek zur Landesbibliothek: Beiträge zum zweihundertjährigen Bestehen der Hessischen Landesbibliothek Fulda (Bibliothek des Buchwesens 6), Stuttgart 1978. CHRIsT: Bibliothek des Klosters Fulda. Carl Scherer, Beiträge zur Rekonstruktion der alten Bibliotheca fuldensis und Bibliotheca laureshamensis (Zentralblatt für Bibliothekswesen 26), Leipzig 1902.

237 Karl Heinemeyer, "Die Gründung des Klosters Fulda im Rahmen der bonifatianischen Kirchenorganisation«, in: Fuldaer Geschichtsblätter 56 (1980), S. 83-132. 56 (1980), S. 83132.

238 Wie auch bei seinen anderen Gründungen. Einordnung in das Reformprogramm des Bonifatius in: Aris u. a.: »Art. Fulda, St. Salvator«. S. $213 \mathrm{f}$.

239 Ebd. S. 341. Zur Bibliothek des Gründers: SchüLING: „Die Handbibliothek des Bonifatius.» ARIs: »Trost der Bücher«.

240 ARIs: „Schul- und Bildungswesen, Literatur, Bibliotheken. Zur Geschichte der Klosterschule im Frühmittelalter«. S. 682. Zur Nutzung der Bibliothek in der Schule: Marc-Aeilko ARIS, "Prima puerilis nutriturae rudimenta: Einhard in der Klosterschule Fulda«, in: Einhard. Studien zu Leben und Werk, hrsg. von Hermann Schefers, Darmstadt 1997, S. 41-56. S. 4354.

241 Rau/Padberg (Hrsg.): Bonifatiusbriefe. S. 406, Z. 21-23. Siehe hierzu auch S. 42.

242 Herrad SpILling, "Angelsächsische Schrift in Fulda", in: Von der Klosterbibliothek zur Landesbibliothek. Beiträge zum 200jährigen Bestehen der Hessischen Landesbibliothek Fulda, hrsg. von Artur BRALL (Bibliothek des Buchwesens 6), Stuttgart 1978, S. 47-98.

243 SCHRIMPF/Leinweber (Hrsg.): Bücherverzeichnisse. S. 3-13. Ein vereinzelter Zweifel an der Fuldaer Herkunft des Katalogs bei: Herrad SpILling, »Das Fuldaer Skriptorium zur Zeit des Hrabanus Maurus«, in: Hrabanus Maurus. Lehrer, Abt und Bischof, hrsg. von Коттје, RAYMUND und Harald Zimmermann (Akademie der Wissenschaften und der Literatur Mainz. Geistes- und Sozialwissenschaftliche Klasse. Einzelveröffentlichungen 4), Wiesbaden 1982, S. 165-181. S. 175.

244 SChrimpf/Leinweber (Hrsg.): Bücherverzeichnisse. S. 13. 
chem Zweck die Liste aufgestellt wurde, ist unbekannt. ${ }^{245}$ In der Sammlung "pastoraler und monastischer Literatur ${ }^{246}$ findet sich nur ein Titel, hinter dem sich Dichtung verbergen könnte: libri super(?) (u)ir(g)in(it)at(e). ${ }^{247}$ Ebenso schmal ist der Befund der frühen Fuldaer Handschriften, ob dort geschrieben oder Teil der frühen Bibliothek. ${ }^{248}$ Nur eine Handschrift, Basel, Universitätsbibliothek, O IV 17, wirft noch ein Licht auf Dichtung in der frühen Abtei. ${ }^{249}$ Sie enthält, in handlichem Querformat (12,5-13 x 13-14 cm) und in insular geprägter Schrift, das Carmen Paschale des Sedulius in seiner irischen Textgestalt. Dem Text vorgesetzt sind verschiedene Texte zum hl. Martin (f. 1-10), was die Handschrift eher im hagiographisch-biblischen Kontext, als in der Schule verortet.

Der Verwandlung Fuldas aus einer zurückgezogenen Gemeinschaft in eine weithin wirkende Bildungsstätte ${ }^{250}$ ist untrennbar mit dem Wirken von Hrabanus Maurus (ca.780-856) verknüpft, der dem Kloster zeitlebens verbunden war. ${ }^{251}$ Schon als Kind wurde er ins Kloster gegeben und erhielt dort die höheren Weihen. Es darf als Zeichen des noch mangelhaften Schulwesens in Fulda gewertet werden, dass Hraban von Abt Baugulf (und später erneut von Abt Ratger) zu Alkuin nach Tours geschickt wurde, um sich dort höheren Studien zu widmen. Zu diesen gehörte auch das »enseignement poétique au plus haut niveau«. ${ }^{252}$ Alkuins

245 Ebd.

246 ArIs u. a.: »Art. Fulda, St. Salvator«. S. 343.

247 Vielleicht Aldhelm (Ehwald (Hrsg.): Aldhelmi Opera. S. 327-471) oder Augustinus: SChrimpf/Leinweber (Hrsg.): Bücherverzeichnisse. S. 5, Z. 14, S. 9, Nr. 27.

248 Passim die Daten, die auch nach Bischoff: Katalog (noch nicht herangezogen) nicht erheblich angepasst werden müssen, in: GugeL: Handschriften. Eine konzise Liste der frühen Handschriften in: BeCHT-Jördens/Haubrichs: »Fulda«. S. 176, Anm. 2.

$249 "(. .$.$) in a German centre under Anglo-Saxon influence, possibly at Fulda with which its later$ history is connected.«: Elias A. Lowe (Hrsg.), Codices Latini antiquiores VII, Switzerland, Oxford 1956. Nr. 853. Bischoff: Katalog, 1. Nr. 328. Gugel: Handschriften. S. 32 (irreführende Inhaltsangabe!). SPRINGER: Handlist. S. 35.

250 Siehe zu den Konflikten, die zwischen Alt- und Neugesinnten ausbrachen: Johannes FrIED, "Fulda in der Bildungs- und Geistesgeschichte des früheren Mittelalters«, in: Kloster Fulda in der Welt der Karolinger und Ottonen, hrsg. von Gangolf Schrimpf (Fuldaer Studien 7), Frankfurt a. M. 1996, S. 3-38. Insb. S. 23-26.

251 Norbert Kössinger, Hrabanus Maurus: Profil eines europäischen Gelehrten; Beiträge zum Hrabanus-Jahr 2006, St. Ottilien 2008. Philippe Depreux (Hrsg.), Raban Maur et son temps: (Collection Haut Moyen Âge 9), Turnhout 2010. Marc-Aeilko ArIs (Hrsg.), Hrabanus Maurus in Fulda: mit einer Hrabanus Maurus-Bibliographie (1979-2009) (Fuldaer Studien 13), Frankfurt a. M. 2010. Franz J. Felten und Karl Lehmann (Hrsg.), Hrabanus Maurus: Gelehrter, Abt von Fulda und Erzbischof von Mainz (Neues Jahrbuch für das Bistum Mainz 2006), Mainz 2006. Raymund KotтJe und Harald Zimmermann (Hrsg.), Hrabanus Maurus: Lehrer, Abt und Bischof (Abhandlungen der Geistes- und Sozialwissenschaftlichen Klasse. Akademie der Wissenschaften und der Literatur in Mainz 4), Wiesbaden 1982. BöHNE (Hrsg.): Hrabanus Maurus und seine Schule.

252 Perrin: »La poésie de cour«. S. 333. Ebenso: Becht-Jördens/Haubrichs: »Fulda«. S. 180. 
Einfluss zeigt sich schon im Formalen - Hrabanus' erstes und erfolgreichstes Werk, die Figurengedichte De Laudibus Sanctae Crucis, nimmt eine Form auf, die von Alkuin reetabliert worden war. ${ }^{253}$ Nach seiner Rückkehr nach Fulda wurde er zum Leiter der Klosterschule bestellt. ${ }^{254}$ Zur Ausbildung der jungen Mönche in der Dichtkunst stellte er eine Ars Metrica zusammen, deren Gehalt an Beispielversen jedoch hauptsächlich aus seinen Vorlagen stammt. ${ }^{255}$ Auch in seinem Werk zur Bildung der Geistlichen, De Institutione Clericorum, ${ }^{256}$ das freilich weit über schulische Aspekte hinausgeht, ${ }^{257}$ empfiehlt er im dritten Buch, das einen Abriss der Artes gibt, verschiedene Dichter zur Lektüre des Klerus. Die Liste erscheint im Kapitel De arte grammatica und nennt einige christliche Dichter, mit Schwerpunkt auf der Bibeldichtung: Iuvencus, Sedulius, Arator, Alcimus, Clemens, ${ }^{258}$ Paulinus et Fortunatus et ceteri multi, die sich alle in der Bibliothek wiederfinden. ${ }^{259}$ Die Dichtungen der Heiden empfiehlt er jedoch nur mit Vorsicht zu lesen propter florem eloquentiae. Seine Rezeption der Klassiker schwankt zwischen Anerkennung ihrer technischen Notwendigkeit und der harschen Ablehnung ihrer heidnischen und weltlichen Inhalte. ${ }^{260}$

253 PERRIN: "La poésie de cour «. S. 336-342. SCHALLER: "Die karolingischen Figurengedichte des Cod. Bern. 212." Siehe auch bei Mainz (S. 45), dem wahrscheinlichen Ursprung der Handschrift Bern, Cod. 212, mit Figurengedichten aus dem Umkreis Alkuins. Von den akrostischen Aenigmata des Klostergründers Bonifatius findet sich in Fulda keine Spur: Fr. Glorie (Hrsg.), Variae collectiones aenigmatum Merovingicae aetatis. (CCSL, 133 A), Turnhout 1968. S. 273-343.

254 Philippe Depreux, Prosopographie de l'entourage de Louis le Pieux (781-840) (Instrumenta DHIP 1), Sigmaringen 1997. S. 350, Anm. 7. Zu Hrabans Unterichtsmethoden: ARIs: »Schulund Bildungswesen, Literatur, Bibliotheken. Zur Geschichte der Klosterschule im Frühmittelalter«. S. $686 \mathrm{f}$.

255 Louis Holtz, „Raban Maur et l'Excerptio de arte grammatica Prisciani«, in: Raban Maur et son temps, hrsg. von Philippe Depreux u. a. (Collection Haut Moyen Âge 9), Turnhout 2010, S. 203-218.

256 Detlev Zimpel (Hrsg.), Hrabanus Maurus: De institutione clericorum: Über die Unterweisung der Geistlichen (Fontes Christiani 61, 1-2), Turnhout 2006. c. 3, 18. S. 532. Z. 8-10.

257 Wiewohl das betreffende Buch und Kapitel sich enger mit der Bildung befasst: GlaUchE: Schullektüre. S. $15 \mathrm{f}$.

258 Es handelt sich nicht um den griechischen Kirchenvater Clemens von Alexandria (so ZIMPEL (Hrsg.): De institutione clericorum. S. 532, Anm. 870, wohl nach BERGGöTZ: »Bibliothekswesen«. S. 45, Anm. 259), sondern um Aurelius Prudentius Clemens.

259 BergGötz: »Bibliothekswesen«. S. 45, Anm. 260. Der Nachweis spart das Problem aus, inwiefern der spätmittelalterliche Katalog (siehe unten S. 62f.), mit dem hier verglichen wird, die Bestände zu Hrabans Zeit widerspiegelt.

260 Er ergänzt ebd. Z. 17-21: Itaque et nos hoc facere solemus hocque facere debemus, quando poetas gentiles legimus, quando in manus nostras libri veniunt sapientiae saecularis, si quid in eis utile reperimus, ad nostrum dogma convertimus (...). (»Wir pflegen es zu tun und müssen es so tun, dass wir, wenn wir die heidnischen Dichter lesen, wenn uns Bücher der weltlichen Weisheit in die Hände kommen, was in ihnen nützlich ist, in unsere Lehre übersetzen.«) 
Diese Skepsis des Lehrers und späteren Abtes stand jedoch der rapiden Verwandlung der Bibliothek aus einem monastischen Grundbestand zu einer erstrangigen Sammlung nicht im Weg. Unter Hrabanus Ägide nahmen alle Aspekte der Schriftlichkeit in Fulda einen Aufschwung. ${ }^{261}$ In seine Zeit fällt auch die Etablierung der karolingischen Minuskel im Skriptorium, ${ }^{262}$ auch wenn Hrabanus selbst wahrscheinlich die insular geprägte Schrift seiner Jugend beibehielt. ${ }^{263}$ Hrabanus' Verdienste um die Bibliothek werden im Kloster lobend erinnert ${ }^{264}$ und auch er selbst lobt ihren Bestand. ${ }^{265}$ Als Ergebnis der ausgeweiteten Schriftkultur unter Hrabanus und speziell im Rahmen der verschiedenen Register-Unternehmen ${ }^{266}$ kann auch der nur fragmentarisch erhaltene Katalog aus der ersten Hälfte des 9. Jh. verstanden werden. ${ }^{267}$ Fragmente von Fuldaer Katalogen finden sich in der gleichen Handschrift, die auch die Lorscher Kataloge aufbewahrt, Vatikan, BAV, Pal. lat. 1877. Nur das größte Fragment erhält Teile eines umfassenden Bücherverzeichnisses. Leider sind in diesem Original nur die Abteilungen zu Bibel und Hieronymus erhalten; ein umso bedauernswerterer Verlust, als die Beschreibungen nicht nur allgemeine Buchtitel, sondern relativ detaillierte Inhaltsverzeichnisse der Bände geben. Ein zweites Fragment des Kataloges hat sich in Schannats Historia Fuldensis (1729) erhalten. ${ }^{268}$ Hier liegt ein Ausschnitt aus den Abteilungen zu Hraban und Alkuin vor. Hraban ist nicht überraschend mit seiner buchfüllenden Dichtung De laude sanctae crucis (S. 59,

261 »Mönchslisten, Totenannalen, Nekrologien, Gebetsverbrüderungen«: BECHT-JöRDENS/ HAUbRichs: »Fulda«. S. 179. Raymund КоттJе, »Schriftlichkeit im Dienst der Klosterverwaltung und des klösterlichen Lebens unter Hrabanus Maurus«, in: Kloster Fulda in der Welt der Karolinger und Ottonen, hrsg. von Gangolf SchrimpF (Fuldaer Studien 7), Frankfurt a. M. 1996, S. 177-192. Zur Bibliothek insb. S. 189f.

262 Die Abgrenzungen verschwimmen jedoch bei genauerer Betrachtung - karolingische Minuskel wurde vor Hrabanus geschrieben und insulare noch lange nach ihm. Vgl. SPILLINGS Studien zur Schriftentwicklung: SPILLING: »Angelsächsische Schrift in Fulda«. Herrad SPILling, "Die frühe Phase karolingischer Minuskel in Fulda«, in: Kloster Fulda in der Welt der Karolinger und Ottonen 1996, S. 249-284. SPILling: "Das Fuldaer Skriptorium zur Zeit des Hrabanus Maurus«.

$263 \mathrm{Zu}$ Hrabanus-Autographen vgl. Hartmut HoffmanN, "Autographa des früheren Mittelalters", in: Deutsches Archiv für Erforschung des Mittelalters 57 (2001), S. 1-62. S. 22-30 in Auseindersetzung mit Hans Butzmann, "Der Ezechiel-Kommentar des Hrabanus Maurus und seine älteste Handschrift», in: Bibliothek und Wissenschaft 1 (1964), S. 1-22.

264 SpIlling: »Das Fuldaer Skriptorium zur Zeit des Hrabanus Maurus«. S. 167.

265 Carm. XXIII, vss. 11-16. DüMmLER (Hrsg.): MGH Poet. lat. 2. S. 187. Das Gedicht jedoch vielleicht vor 818, als Hraban als Lehrer, noch nicht als Abt auf die Bibliothek Einfluss nehmen konnte.

266 Aris u. a.: »Art. Fulda, St. Salvator«. S. 343.

267 Schrimpf/Leinweber (Hrsg.): Bücherverzeichnisse. Katalog B5 (S. 25-56). Zur Datierung (840-850) bis heute akzeptiert: Paul LeHMANN, "Quot et quorum libri fuerint in libraria Fuldensi«, in: Bok- och bibliothekshistoriska studier tillägnade Isak Collijn, Uppsala 1925, S. 47-57. S. 51.

268 SChrimpf/LeinWeber (Hrsg.): Bücherverzeichnisse. S. 57-84. 
Z. 36) vertreten, dessen später zu erörternde Verbreitung in Fulda ihren Ausgangspunkt hatte. Ein sehr viel selteneres Werk findet sich unter den Schriften Alkuins (S. 59, Z. 23): Metrum eiusdem in Cantica canticorum; \& versus illius in diversos in I. Cod. Bei dem Metrum handelt es sich wohl um die Einleitung zum Cantica-Kommentar. ${ }^{269}$ Eine Sammlung der Gedichte Alkuins und zwar wohl der Briefgedichte in diversos, »an verschiedene Personen «, kann sonst nur für Salzburg und vielleicht für Tours selbst nachgewiesen werden. ${ }^{270}$ In Salzburg ist diese Sammlung eng mit dem Freund Alkuins, Erzbischof Arn verbunden; daher ist es wahrscheinlich, dass die Gedichtsammlung Alkuins in Fulda direkt auf eine Sammlung seines Schülers Hrabanus zurückgeht. Bemerkenswert ist hier, dass die Gedichte an verschiedene Adressaten, nicht nur an Hrabanus selbst gerichtet sind. Ebenso verhält es sich in Salzburg, wo die Gedichte den Anhang einer Briefsammlung bilden. Während sich in den Briefen eine eindeutige Sektion mit Salzburger Empfängerüberlieferung befindet, sind die Gedichte ohne klaren Salzburger Bezug. Hierzu habe ich argumentiert, dass Arns Sammlung auf eine Sammlung aus Tours zurückgeht - sollte Hraban vielleicht eine ähnliche Sammlung mit Dichtung seines Lehrers erhalten haben? Ohne Frage ist hinter der kurzen Katalognotiz die Vorlage der aus verschiedensten Gedichten stammenden Alkuin-Zitate in Hrabanus' verstreuten Gedichten zu erkennen, die von Traube der Vorlage der Ausgabe Du Chesne und von Burghardt in einem nicht weiter spezifierten Archetyp V gesucht wurde. ${ }^{271}$ Der kurze Vermerk des Katalogs lässt keine weiteren Schlussfolgerungen $\mathrm{zu}$.

Einen weiteren Blick in die Bibliothek lassen verschiedene frühneuzeitliche Kataloge zu. ${ }^{272}$ Der späte Bestand kann mit Einschränkungen Erkenntnisse über eine frühmittelalterliche Bibliothek bieten, da die kulturelle Entwicklung Fuldas und mit ihr die der Bibliothek nach dem 9. Jh. langsam, im 12. Jh. ganz zum Erliegen kam. ${ }^{273}$ Und wenn nicht ganz vereinzelt ein Thomas von Aquin oder Gratian das Bild stören würden, könnte man tatsächlich glauben, einen Katalog des 9. oder 10. Jh. vor sich zu haben. Unter den christlichen Dichtern findet sich kaum einer, der nicht von Hrabanus empfohlen oder zitiert wurde. ${ }^{274}$ Da eine

269 Ebd. S. 77, Nr. 13 \& 14.

270 Vgl. S. 271 zu Salzburg.

271 Ludwig Traube, Karolingische Dichtungen: Aedelwulf. Alchhuine. Angilbert. Rhythmen (Schriften zur germanischen Philologie 1), Berlin 1888. S. 46-110. Burghardt: Philologische Untersuchungen zur den Gedichten Alkuins. S. 270-278, 280.

272 Gemeinsam ediert von CHRIst: Bibliothek des Klosters Fulda. Siehe eine räumliche Rekonstruktion der Bibliothek im Spätmittelalter unter http://www.martinellus.de/fulda/ful da.htm.

273 Ebd. S. 65.

274 In Hrabans Kreuzgedicht finden sich folgende Autoren namentlich genannt: Porphyrius, Sedulius, Horaz; genannt aber nicht im Bücherverzeichnis: Lukrez und Prosper. Zitiert werden: Porphyrius, Sedulius, Venantius, Aldhelm. Übersicht bei Michel Jean-Louis PERRIN, 
Trennung zwischen dem Bestand der Hrabanischen Bibliothek und späteren Ergänzungen nicht möglich ist, sei hier eine Liste der vorhandenen Dichter gegeben, die eine Sammlung ohnegleichen zeigen und zugleich den Verlust der Bücher Fuldas in Erinnerung bringen. ${ }^{275}$

\begin{tabular}{|c|c|c|c|}
\hline & Autor & $\begin{array}{l}\text { F } \\
\text { (S., Ordo, Sub., Nr.) }\end{array}$ & $\begin{array}{l}\mathrm{V} \\
\text { (S., Ordo, Nr.) }\end{array}$ \\
\hline \multirow{9}{*}{$\begin{array}{l}\text { Christliche } \\
\text { Dichter }^{276}\end{array}$} & Alcimus Avitus & 256, iv, i, 11 & $112, \mathrm{xxi}, 228$ \\
\hline & Aldhelm ${ }^{277}$ & $\begin{array}{l}\text { 256, iv, i, } 12 \\
\text { 261, vi, ii, } 9 \\
\text { 264, vii, ii, } 6 \\
269, \text { ix, iv, } 2 \\
\end{array}$ & \\
\hline & Arator & 265, vii, iv, 17 & 111, xxi, 224 \\
\hline & Boethius & 257, iv, iv, 4,5 & \begin{tabular}{|l|}
102, xvi, 177 \\
150, xxxviiii, 445
\end{tabular} \\
\hline & Iuvencus & $\begin{array}{l}\text { 261, vi, iii, } 10 \\
263 \text {, vii, ii, } 16,18,19 \\
273, x, \text { iii, } 34\end{array}$ & 121, xxiii, 275 \\
\hline & Prudentius & $274, x, i v, 39$ & $\begin{array}{l}125, \text { xxv, } 304 \\
129, x x v i, 329\end{array}$ \\
\hline & Sedulius & 263, vii, ii, $8,10 ?, 27$ & $126, \mathrm{xxv}, 311$ \\
\hline & Venantius Fortunatus & & 117, xxii, 255 \\
\hline & Optatianus Porphyrius & $274, x$, iv, 27 & \\
\hline \multirow[t]{2}{*}{$\begin{array}{l}\text { Heidnische } \\
\text { Dichter }\end{array}$} & Martianus Capella & $\begin{array}{l}267, \text { viii, iv, } 4 \\
269, \text { ix, iii, } 10, \\
272, x, \text { ii, } 17\end{array}$ & \\
\hline & Horaz $^{278}$ & $\begin{array}{l}271, x, \text { ii, } 18 \\
273, x, \text { iii, } 38 \\
274, x, i v, 11,15 \\
274, x, \text { iv, } 44 \\
274, x, i v, 49\end{array}$ & $154, \mathrm{xli}, 477$ \\
\hline
\end{tabular}

"Les lectures de Raban Maur pour l'In honorem sanctae crucis: ébauche d'un bilan", in: Raban Maur et son temps, hrsg. von Philippe Depreux u. a. (Collection Haut Moyen Âge 9), Turnhout 2010, S. 219-245. S. 239f.

275 Verglichen sind die beiden voneinander abweichenden Hauptverzeichnisse F und V. Zu deren Entstehung vgl. Christ: Bibliothek des Klosters Fulda. S. 1-49. Da die frühmittelalterliche Ordnung hier zugunsten eines spätmittelalterlichen Ordo-Systems aufgebrochen wurde, ist der ursprüngliche Ort der Bände nicht mehr festzustellen, die deshalb hier nach Autoren gegliedert worden sind.

276 Aus dieser eher gewöhnlichen Sammlung sticht Optatianus Porphyrius durch seine Vorbildfunktion für Hrabans Figurengedichte hervor. Von den von Hrabanus zum Studium empfohlenen Dichtern fehlt hier nur Paulinus von Nola.

277 Das Carmen de virginitate dreimal sowie die Epistola ad Acircium.

278 Die Masse der Horaz-Handschriften dürfte einer späteren Zeit angehören. Eine frühe Vermittlung wäre durch Walahfrid möglich gewesen (siehe S. 185-188 zu Vatikan, BAV, Reg. lat. 1703 [Weißenburg]). 
(Fortsetzung)

\begin{tabular}{|c|c|c|c|}
\hline & Autor & $\begin{array}{l}\text { F } \\
\text { (S., Ordo, Sub., Nr.) }\end{array}$ & $\begin{array}{l}\text { V } \\
\text { (S., Ordo, Nr.) }\end{array}$ \\
\hline & Juvenal & $274, x$, iv, 48 & 156, xlii, 484 \\
\hline & Lukan & $\begin{array}{l}267, \mathrm{ix}, \mathrm{i}, 4 \\
268, \mathrm{ix}, \mathrm{ii}, 2 \\
270, \mathrm{x}, \mathrm{i}, 7\end{array}$ & \\
\hline & Ovid $^{279}$ & $\begin{array}{l}273, x, \text { iii, } 20 \\
273, x, \text { iii, } 49\end{array}$ & $154, x l i, 478$ \\
\hline & Persius & 273, x, iii, 24 & \\
\hline & Statius & $270, x, i, 2$ & 156, xlii, 482 \\
\hline & Terenz $^{280}$ & 268 , ix, ii, 3 & \\
\hline & Vergil & $\begin{array}{l}269, \text { ix, iv, } 6 \\
273, x, \text { ii, } 42 \\
272, x, \text { iii, } 7 \\
274, x, \text { iii, } 56 \\
274, x, \text { iv, } 19\end{array}$ & $154, x l i, 474,476$ \\
\hline & Hrabanus & & 94, xiii, 133 \\
\hline \multirow{2}{*}{$\begin{array}{l}\text { Zeitgenössische } \\
\text { Dichter }^{281}\end{array}$} & Brun Candidus & & 141, xxxiii, 390 \\
\hline & Walahfrid & & 144, xxxiii, 406 \\
\hline
\end{tabular}

Kehren wir von dieser späten Übersicht wieder zu den Handschriften und Hrabanus zurück. Dieser verstand es nämlich auch, sich das Skriptorium zur Verbreitung seiner eigenen Werke dienstbar zu machen. ${ }^{282}$ Bei keinem Werk tritt Hrabanus deutlicher als Autor und als sein eigener "Verleger" hervor als in den Figurengedichten De Laudibus Sanctae Crucis. ${ }^{283}$ Das Werk hatte schon unter

279 Otfrid von Weißenburg, der in Fulda unter Hrabanus studierte, erwähnt den ansonsten seltenen Ovid (Oskar ERdmann und Ludwig WolfF (Hrsg.), Otfrids Evangelienbuch (Altdeutsche Textbibliothek 49), Tübingen 1973. vss. 14-19).

280 Terenz erscheint zu Beginn des 10. Jh. im Ostfrankenreich: Antony Augoustakis, Ariana Traill und John E. Thorburn (Hrsg.), A companion to Terence (Blackwell companions to the ancient world 103), Chichester 2013. S. 346. Claudia Villa, "Terence's Audience and Readership in the Ninth to Eleventh Centuries", in: Terence between late antiquity and the age of printing: illustration, commentary and performance, hrsg. von Andrew J. TURNER und Giulia Torello-Hill (Metaforms 4), Leiden [u.a.] 2015, S. 239-250.

281 Siehe unten S. 65f., 69-77.

282 BERGgötz: »Bibliothekswesen«. S. 7, 47. Raymund KоттJE, "Die handschriftliche Überlieferung der Bibelkommentare des Hrabanus Maurus «, in: Raban Maur et son temps, hrsg. von Philippe Depreux u. a. (Collection Haut Moyen Âge 9), Turnhout 2010, S. 259-274. S. $264 f$.

283 Edition: Michel Jean-Louis PERrin (Hrsg.), Rabani Mauri In honorem sanctae crucis (CCCM, 100/100 A), Turnhout 1997. Die Prolegomena hierzu sind: Perrin: »Tradition manuscrite«. Als Ausgabe veraltet: Müller: De laudibus. (Siehe die Kritik hierzu bei: Raymund Коттје, »Rezension zu: Müller, Hrabanus Maurus - De laudibus sancta crucis - 
Zeitgenossen eine außerordentlich weite Verbreitung, ${ }^{284}$ an der Hrabanus, mit seiner Praxis der Dedikation an hochgestellte Personen, aktiv Anteil nahm. ${ }^{285}$ Dass sich von den neun Widmungsexemplaren wahrscheinlich keines erhalten hat ${ }^{286}$ und nichtsdestotrotz noch zahlreiche Handschriften des 9. Jh. erhalten sind, unterstreicht nur den Erfolg, den Hrabanus in der Verbreitung des Werkes hatte. Wenn Hrabanus das Gedicht auch schon in Tours begonnen haben sollte, ${ }^{287}$ so ist seine weitere Redaktion und Verbreitung doch ausschließlich auf Fulda konzentriert, wo Hrabanus überhaupt erst die Ressourcen für die aufwendige Vervielfältigung der kostbaren Kodizes zur Verfügung standen. Durch die beständige Arbeit am Werk lassen sich die Handschriften nicht auf einen Archetyp klassischer Natur, sondern auf verschiedene Entwicklungsstufen eines Arbeitsexemplars »Ur-Fulda« zurückführen, wobei ein Prachtexemplar (Vatikan, BAV, Reg. lat. 124) im Fuldaer Präsenzbestand blieb. ${ }^{288} \mathrm{Da}$ die Provenienzen der erhaltenen Handschriften und somit ihre Adressaten unklar sind, müssen die Orte der Adressaten für den weiten Kreis einstehen, in den Hrabanus sein Werk versendete. Über die Jahre ergingen Widmungen nach Mainz, Tours, an den Hof Ludwigs des Frommen, nach Rom, Friaul? (an Eberhard von Friaul), Saint Denis und Bourges. Auffällig ist das Überwiegen westfränkischer Adressaten.

Die Sorgfalt und der Eifer, mit der Hrabanus sich dem Kreuzgedicht widmete, stehen in starkem Kontrast zur Überlieferung seiner kleineren Dichtungen. Die Gedichte Hrabans haben nur geringe Verbreitung erfahren; bis auf die Sammlung

Studien zur Überlieferung und Geistesgeschichte mit dem Faksimile - Textabdruck aus Codex Reg. Lat. 124 der Vatikanischen Bibliothek«, in: Deutsches Archiv für Erforschung des Mittelalters 31 (1975), S. 597-598. Ein Forschungsüberblick vor Perrins Edition: Michele Camillo Ferrari, »Hrabanica. Hrabans De laudibus sanctae crucis im Spiegel der neueren Forschung", in: Kloster Fulda in der Welt der Karolinger und Ottonen, hrsg. von Gangolf SCHRIMPF (Fuldaer Studien 7), Frankfurt a. M. 1996, S. 493-526. Weitere Monographien: FERRARI: Liber sanctae crucis. SPILling: Opus Hrabani.

284 Handschriften: Ulrich Ernst, Carmen figuratum: Geschichte des Figurengedichts von den antiken Ursprüngen bis zum Ausgang des Mittelalters (Pictura et poesis 1), Köln [u. a.] 1991. S. 309-322, nach Mitteilung der Vorarbeiten von: КоттJE: Verzeichnis. dort S. 258 jedoch die Zahl erhöht auf 83 Handschriften.

285 PERrin: »Tradition manuscrite«. S. $194 \mathrm{f}$.

286 Ebd. S. 229-233. Ferrari: »Hrabanica«. S. 502. Für Erhalt der Exemplare: SPIlling: Opus Hrabani. S. 31-82. Liste der frühesten Handschriften: PERRIN: "Tradition manuscrite«. S. 198-202.

287 Perrin: "Tradition manuscrite«. S. 192, nach: Kurt Holter, Liber de laudibus sanctae crucis: Vollständige Faksimile-Ausgabe im Originalformat des Codex Vindobonensis 652 der Österreichischen Nationalbibliothek (Codices selecti 33), Graz 1973. S. 9.

288 Das Vorliegen verschiedener Redaktionen wurde zuerst von MüLLER: De laudibus. S. 61111, erkannt, jedoch auf der unzureichenden Textgrundlage der Dedikationen; das Stemma wurde dementsprechend in der Forschung abgelehnt (FERRARI: »Hrabanica«. S. 496). Jetzt akzeptiert ist Perrin: »Tradition manuscrite«. S. 233-235, jedoch mit Kritik am »Ur-Fulda»Konzept: FerRarI: »Hrabanica«. S. $498 \mathrm{f}$. 
im Einsiedler Kodex ${ }^{289}$ finden sich nur vereinzelte Gedichte in wenigen Handschriften. ${ }^{290}$ Die schon anlässlich dieser Handschrift gemachten Bemerkungen sollen hier nicht wiederholt werden. Eng verwandt mit der Einsiedler Handschrift ist die, aus der Christoph Brouwer den Großteil der Gedichte Hrabans in seine Ausgabe von 1617 retten konnte. ${ }^{291}$ Diese war schon zu seiner Zeit beschädigt und litt unter Blattverlusten. ${ }^{292}$ Die Handschrift stammte aus Fulda. ${ }^{293}$ Sie trug auf dem Rücken die Fuldaer Signatur Versus Hrabani de diversis XIV. Ord. XIX. ${ }^{294}$ und stand unter den Werken des Hrabanus. ${ }^{295}$ Unter diesen befand sich ein weiterer Sammelband mit ganz ähnlichem Titel: Epistolae Rabani ad diversos. ${ }^{296}$ Auch diese sind ansonsten nicht erhalten. ${ }^{297}$ Fulda war also der Ort, an dem auch diese flüchtigeren Werke des großen Abtes gesammelt wurden. Hat Hrabanus diese vielleicht schon selbst zusammengestellt? In Brouwers Handschrift befindet sich unter anderen auch das Epitaph des Dichters selbst. ${ }^{298}$ Es befand sich am Ende der Handschrift, ${ }^{299}$ jedoch inmitten einer ganzen Reihe von Epitaphien, ${ }^{300}$ sodass es nicht erst nach dem Tod des Dichters als letztes Stück hinzugefügt wurde, sondern höchstens zusammen mit den anderen Epitaphien. Es ist jedoch auch durchaus möglich, dass eine von Hrabanus begonnene Sammlung, die vielleicht in nichts weiter als seinen Unterlagen bestand, posthum in einen Kodex umgeschrieben wurde - ein Zeichen der Reverenz, mit der der Konvent sich

289 Einsiedeln, StB, Cod. 266 (1296), aus Murbach, siehe dort S. 208-215; nicht aus Fulda, auch nicht aus der Bibliothek: GugeL: Handschriften. S. 74f.

290 Siehe KоттJE: Verzeichnis. S. 236 s.v. "Carmina«. DüMmLER: »Die handschriftliche Überlieferung". S. 286-294.

291 Cristoph Brouwer (Hrsg.), Venantii Honorii Clementiniani Fortunati ... Carminum, epistolarum, expositionum libri 11 ... Accessere Hrabani Mauri Fuldensis, archiepiscopi Magontini Poemata sacra nunquam edita, Mainz 1617.

292 Ebd. S. 123: "Codicis hic mutili et hiantis sortem deplorent merito homines, antiquae historiae, \& ecclesiarum suarum originum amantes. Nam praeter inscriptiones \& lemmata, quae librarius saepenumero neglexit, plagulae membranae complures excisae." (Das Schicksal dieser verstümmelten und lückenhaften Handschrift wird jeder beklagen, dem die Geschichte der alten Zeit und der Kirche am Herzen liegt, denn nicht nur hat der Schreiber Überschriften und Inhaltsangaben oft vergessen, es sind auch zahlreiche Lagen entfallen.)

293 Angedeutet von Gugel: Handschriften. S. 74f. BECHT-JöRDENS (Hrsg.): Vita Aegil abbatis. S. XXXIV f.

294 Brouwer (Hrsg.): Hrabani Poemata. S. 2.

295 Die Abteilungen XIII-XIV, Снrist: Bibliothek des Klosters Fulda. S. 94-99. Das Verzeichnis ist nicht vollständig (Ebd. S. 15), weswegen die Handschrift dort nicht zu finden ist; es ist nicht nötig, wie BECHT-JöRDENS, S. XXXV meint, dass diese nicht vorhanden war.

296 Ebd. S. 97, xiii, 147. Von BECHT-Jördens ebd. als »Schwesterhandschrift« bezeichnet.

297 Zur Natur der »Briefe« der MGH-Edition: Ernst DüMmLER (Hrsg.), Epistolae Karolini aevi 3 (MGH Epp. 5), Berlin 1899. S. 379f.

298 Brouwer (Hrsg.): Hrabani Poemata. S. 90 (Epitaphium Rhabani Archipiscopi, Dümmler (Hrsg.): MGH Poet. lat. 2. XCVII, S. 243f.).

299 Es fehlen hier jedoch Blätter: cetera desiderantur. Ebd. S. 95.

300 Brouwer (Hrsg.): Hrabani Poemata. S. 88-95. 
seines berühmten Vorstehers erinnerte. Es ist unwahrscheinlich, dass eine Sammlung so zerstreuten Materials, wie es Briefe und Gedichte sind, jemand anderem als dem Verfasser selbst zugänglich gewesen sein sollte. So zeigt sich auch hier die Sorge Hrabans um sein Werk, wenn auch eine sehr viel geringere als er dem Liber de laudibus sanctae crucis angedeihen ließ.

Nur wenige Handschriften bewahren noch Spuren der Dichtung, die in Fulda unter Hrabanus abgeschrieben wurde, und auch bei diesen ist die Herkunft oft nicht sicher. ${ }^{301}$ Vielleicht von dort stammt die mit allerlei grammatischen Material gefüllte Handschrift Cod. Sang. $270 .^{302}$ Ab p. 39 findet sich eine bunte Mischung aus informativen kurzen Texten, darunter p. 51 das weitverbreitete Gedicht auf die Winde ${ }^{303}$ und p. 67 ein Epitaph ${ }^{304}$ und Sprichwörter. Die Handschrift steht in einem offensichtlich schulischen Zusammenhang.

Ein Vergilvers findet sich als Schreiberzusatz in der Hieronymus-Handschrift Kassel, UB, $2^{\circ}$ Ms. theol. 23, f. 56vb, die schon im frühmittelalterlichen Katalog zu finden ist. ${ }^{305}$ Der Schreiber, dem der Vers in die Feder geflossen ist, gibt sich in einem Kryptogramm als der Fuldaer Mönch Risalah zu erkennen.

Eine Rarität ganz anderen Ranges ist Vatikan, BAV, Vat. lat. 3277, die älteste Handschrift der Argonautica des Valerius Flaccus. ${ }^{306}$ Sie ist, anders als man erwarten sollte, eine grobe Schülerarbeit von mehreren Händen, ${ }^{307}$ Vorlage dieser »Übung", insofern man ein ganzes Buch als solche bezeichnen kann, war vielleicht der Fuldaer codex (...) reverendae et exosculandae vetustatis ex Germania allatus, der in Italien 1519 als Druckvorlage verwendet wurde. ${ }^{308}$ Ein weiteres Exemplar der Argonautica befand sich in St. Gallen, bevor es von Poggio aus

301 So z.B. bei zwei besonders schönen Handschriften, Florenz, Bibl. Laur. plut. XIV, 15 (Boethius, siehe Gugel S. 52f.) und Leiden Ms. Voss. Lat. F. 30 (Lukrez, siehe S. $206 \mathrm{zu}$ Murbach).

$302 »[$ Deutschland (Kontakt zu deutsch-insularem Gebiet (Fulda?)), IX. Jh., 2. Viertel]« BISCHOFF: Katalog, 3. Nr. 5712. BERGMANN/STRICKER: Katalog. Nr. 214.

303 Inc. Quattuor a quadro: RIESE/BÜCHeler (Hrsg.): Anthologia latina. Nr. 484. SK 13113.

304 Inc. Hoc subter iaceant: Johann Huemer, "Analekten zur lateinischen Anthologie», in: Wiener Studien 2 (1880), S. 71-80. S. 73. SK 7110. Das Epitaph ist sonst nur in St. Galler Handschriften erhalten (Cod. Sang. 878, Zürich, C 78, siehe S. 166).

305 Bischoff: Katalog, 1. Nr. 1802. Wiedemann: Manuscripta theologica. Die Handschriften in Folio. S. 31.

306 »Fulda, IX. Jh., etwa 30er Jahre«: Bischoff: Katalog, 1. Nr. 6869. Als Sigle V in: Edward Courtney (Hrsg.), C. Valeri Flacci Argonavticon libri octo (Bibliotheca scriptorum Graecorum et Romanorum Teubneriana), Leipzig 1970.

307 Briefliche Mitteilung BIsCHOFFs in: EHLERs: Untersuchungen zur handschriftlichen Überlieferung der Argonautica des C. Valerius Flaccus. S. 19.

308 P. Ruth TAYLOR-BRiggs, "Utere bono tuo feliciter: The Textual Transmission and Manuscript History of Valerius Flaccus' Argonautica«, in: Brill's Companion to Valerius Flaccus, hrsg. von Mark Heerink und Gesine Manuwald, Leiden 2014, S. 9-28. S. 10f. Die Entleihung oder Entführung der Handschrift würde auch das Fehlen im spätmittelalterlichen Katalog erklären, das von GugeL: Handschriften. S. 57 bemerkt wird. 
seinem "finsteren Kerker « befreit wurde und in Italien verloren ging. ${ }^{309}$ Der Fuldensis und der Sangallensis gehen beide auf einen 25-zeiligen Archetyp a zurück. ${ }^{310}$ Dessen Text ist jedoch bedeutend früher nach Fulda als nach St. Gallen gelangt, da sich der Titel nicht in den St. Galler Katalogen des 9. Jh. findet. Dass ein Text dieser Seltenheit einer Gruppe von unerfahrenen Schreibern zur Abschrift aufgegeben wurde zeigt sowohl das hohe Niveau der Bibliothek ${ }^{311}$ als auch der Ausbildung, die man in Fulda genoss.

Ein Zeugnis nicht der organisierten Schule, sondern vielleicht des individuellen Interesses eines Fuldaer Geistlichen ist erhalten in einem kleinen Heft in Einsiedeln, StB, Cod. 326 (1076). ${ }^{312}$ Er enthält, unter anderen nicht aus Fulda stammenden Teilen, auf f. 67-97 in kleinem Format $(13,5 \times 9,5 \mathrm{~cm})$ und von einer sorgfältigen Hand:

\begin{tabular}{|c|c|}
\hline $\begin{array}{l}67 \mathrm{r}- \\
79 \mathrm{v}\end{array}$ & $\begin{array}{l}\text { Inscriptiones Urbis Romae, Einsiedler Sylloge. }{ }^{313} \text { Die Sammlung römischer } \\
\text { Inschriften bewahrt viele nur hier erhaltene Texte auf. }\end{array}$ \\
\hline $\begin{array}{l}79 \mathrm{v}- \\
86 \mathrm{r}\end{array}$ & Itinerarium Urbis Romae, ein Pilgerführer (?) durch die Heilige Stadt. ${ }^{314}$ \\
\hline $\begin{array}{l}86 \mathrm{v}- \\
88 \mathrm{r}\end{array}$ & Ordo Romanus. ${ }^{315}$ \\
\hline $\begin{array}{l}88 \mathrm{v}- \\
97 \mathrm{v}\end{array}$ & $\begin{array}{l}\text { Anthologie: 88v: Quadam nocte niger (Ein Rechenrätsel, ohne die Lösung: Karl } \\
\text { STRECKER (Hrsg.), MGH Poet. lat. 4, 2.3, Berlin 1923. S. 1119); 89r: Monastica (!) } \\
\text { de erumnis XII Herculis (AL 641); 89v: Conflictus versis (!) et hiemis (Alkuin (?), } \\
\text { Carmen 58; SK 2750); 91r: Iustius inuidia nihil (SK 8588) + Titire tu fido (ohne } \\
\text { Absatz; SK 16391); 91r: Anima pro diuersis (Prosa, Auszug aus Alkuin, De }\end{array}$ \\
\hline
\end{tabular}

309 »in teterrimo quodam et obscuro carcere«: TAYLOR-BRIGGs: »Textual Transmission«. S. 12. 310 Ebd. S. 11.

311 Weitere (verlorene) Handschriften der Argonautica befanden sich in Bobbio (Sigle L) und Nordfrankreich (Cf): Ebd. S. 14, 17, Stemma S. 27.

312 »In Fulda geschulter Schreiber, IX. Jh., ca. 2. Drittel«: Bischoff: Katalog, 1. Nr. 1133. "Fulda«: Georg WALSER, Die Einsiedler Inschriftensammlung und der Pilgerführer durch Rom (Codex Einsidlensis 326) (Historia. Einzelschriften 53), Stuttgart 1987. S. 9, Anm. 30. Kein Nachweis für Bibliotheksheimat Fulda: Gugel: Handschriften. S. 60. Odo Lang, "Einsiedeln, Stiftsbibliothek, Codex 326(1076)«, http://www.e-codices.unifr.ch/en/description/sbe/0326/ (abgerufen am 28.08.2017). Gabriel MeIER, Catalogus codicum manu scriptorum qui in Bibliotheca Monasterii Einsidlensis O.S.B. servantur, Einsiedeln 1899. Theodor Mommsen und Joseph Aschвасн, "Zur lateinischen Anthologie», in: Rheinisches Museum für Philologie 9 (1854), S. 296-301, 302-304, 480.

313 Edition: WALSER: Inschriftensammlung.

314 Ebenfalls WALSER und Franz Alto BAUER, "Das Bild der Stadt Rom in karolingischer Zeit: Der Anonymus Einsidlensis«, in: Römische Quartalschrift für christliche Altertumskunde und Kirchengeschichte 92 (1997), S. 190-228. Franz Alto BAUER, "Die Stadt Rom im Spiegel spätantiker und frühmittelalterlicher Beschreibungen«, in: Das antike Rom und sein Bild, hrsg. von Hans Ulrich CAIN, Anette HAUG und Yadegar Asisi (Transformationen der Antike 21), Berlin [u. a.] 2011, S. 93-114. S. 107-109.

315 Michel ANDRIEU, Les ordines romani du haut Moyen Âge (Spicilegium sacrum Lovaniense 11, 29), Louvain 1931. 3, S. 263-272. 
anima, siehe Lang); 91v: Ad Septitianum (Martial 4, 88, vss. 9-10); 91v: Prudentius, Dittochaeum de Veteri et Novo Testamento; 97v: Mole sub hac magni (Epitaphium Geroldi, SK Nr. 9738, Ernst DüMMLER (Hrsg.), MGH Poet. lat. 1, Berlin 1881. S. 114, X); 97v: Quamvis magna piis (Epitaphium Bernaldi, Ernst DüMmLeR (Hrsg.), MGH Poet. lat. 2, Berlin 1884. S. 420-421). Die Monastica de erumnis XII Herculis und das Epitaphium Geroldi finden sich ebenfalls in Cod. Sang. 899, pp. 45, 57.

Die Handschrift geradezu als Notizbuch eines Romreisenden anzusehen, ${ }^{316}$ geht zu kurz. Die römischen Texte stellen sich als Ergebnis mehrerer Redaktionsarbeiten an einem ursprünglich längeren, auch die Stadt extra muros behandelnden Text heraus. ${ }^{317}$ Ebenfalls zeigt die Handschrift keine Zeichen eines langsamen Wachstums, sondern trägt den Charakter einer durchgehenden Kopie. ${ }^{318} \mathrm{Ob}$ die Handschrift tatsächlich in Fulda oder nur von einem der zahlreichen Fuldaer Schüler geschrieben wurde, muss wegen weiterer fehlender Indizien unklar bleiben. Die Sammlung von Inschriften fügt sich jedoch gut in Fuldaer Interessen; Hrabanus war selbst ein produktiver Epigraph. ${ }^{319}$ Die Anthologie scheint zum großen Teil eine Erweiterung der Sylloge zu sein: 91v-97r enthält Prudentius' Tituli zu biblischen Wandgemälden und zwei zeitgenössische Epitaphien. $\mathrm{Zu}$ Fulda besteht keine engere Verbindung: Es wird der Hrabanus bekannte Martial zitiert, den er an einigen Stellen seiner Ars Metrica als Beispiel benutzt, jedoch nicht der hier enthaltene Vers. ${ }^{320}$ Eine Verbindung der beiden Epitaphien mit Walahfrid ist ganz spekulativ. ${ }^{321}$ Auch eine engere Verbindung der Gedichte mit Fulda kann somit nicht festgestellt werden.

Ein weiterer Aspekt der kulturellen Blüte unter Hrabanus ist die althochdeutsche Dichtung, die in Fulda gepflegt wurde. ${ }^{322}$ Ein direktes Zeugnis ist das Hildebrandslied, das an Anfang und Ende von Kassel UB, fol. Ms. theol. 54 in

316 So Mommsen/Aschвасн: »Zur lateinischen Anthologie«. S. 297.

317 BAUER: »Beschreibungen«. S. $108 \mathrm{f}$.

318 Die Parmenser Inschrift auf 104v (Моммsen/Ascнвасн: »Zur lateinischen Anthologie«. S. 296) ist jedoch späteren Datums: LANG: "Einsiedeln, Stiftsbibliothek, Codex 326(1076)«.

319 Matthias Theodor Klof T, »Hrabanus Maurus, die stituli und die Altarweihen«, in: Raban Maur et son temps, hrsg. von Philippe Depreux u. a. (Collection Haut Moyen Âge 9), Turnhout 2010, S. 367-387. Kinsch: Laudes sanctorum. S. $967 \mathrm{f}$.

320 Holtz: »Excerptio de arte grammatica«. S. 215, Anm. 38.

321 Mommsen/Aschвасн: "Zur lateinischen Anthologie«. S. 302f. Dagegen: DüMmLer (Hrsg.): MGH Poet. lat. 1. S. 101 (zu X), vgl. auch die schwachen Parallelen in den Anmerkungen der Edition a.a.O.

322 Becht-Jördens/HAubrichs: »Fulda«. HAuBrichs: »Otfrid de Wissembourg«. Wolfgang HAuBRICHs, "Althochdeutsch in Fulda und Weißenburg - Hrabanus Maurus und Otfrid von Weißenburg«, in: Hrabanus Maurus. Lehrer, Abt und Bischof, hrsg. von Raymund KoтtjE und Harald ZimmermanN (Akademie der Wissenschaften und der Literatur Mainz. Geistesund Sozialwissenschaftliche Klasse. Einzelveröffentlichungen 4), Wiesbaden 1982, S. 182193. 
Freiräume nachgetragen wurde. ${ }^{323}$ Auch mit dem Heliand ist Fulda zumindest durch die Benutzung von Hrabans Kommentaren und der Tatian-Übersetzung verbunden. ${ }^{324}$ Hrabans Schüler Otfrid von Weißenburg empfing von dort noch lange nach seiner Heimfahrt Materialien, die er zur Verfassung seiner Evangeliendichtung verwendete. Diese wurde auch in Fulda kopiert und gelesen. ${ }^{325}$ Außer dem Hildebrandslied ist uns jedoch kein Indiz für eine gezielte Sammlung althochdeutscher Dichtung erhalten; auch die Kataloge schweigen hierzu.

Ein anderer Schüler Hrabans, der als Dichter auftrat, blieb in Fulda: Brun Candidus. ${ }^{326}$ Aber auch sein Werk scheint die Klostermauern nie verlassen $\mathrm{zu}$ haben. Die Vita Aegil, ein opus geminum aus metrischer und prosaischer Vita, fügt sich in die Fuldaer Hausliteratur zu den Äbten des Konvents. ${ }^{327}$ Brun, der auch Maler war, schmückte sein Werk mit einem nur in barocker Reproduktion erhaltenen Illustrationszyklus - auch lokal orientierte Werke, die nicht an hohe Würdenträger adressiert wurden, ${ }^{328}$ waren also der Ausschmückung wert. Die Handschrift ist verloren gegangen und das Werk wurde, wie Hrabans Gedichte, von Brouwer gerettet. ${ }^{329}$

Die Gedichte Walahfrid Strabos, ${ }^{330}$ die neben denen seines Freundes Gottschalk von Orbais ${ }^{331}$ allgemein als die künstlerisch wertvollsten des 9. Jh. ange-

323 Bischoff: Katalog, 1. Nr. 1814. Wiedemann: Manuscripta theologica. Die Handschriften in Folio. S. 72f. Klaus DüWEL und Nikolaus Ruge, »Art. Hildebrandslied«, in: Althochdeutsche und altsächsische Literatur 2013, S. 171-183. Peter-Erich Neuser, "Das karolingische Hildebrandslied. Kodikologische und rezeptionsgeschichtliche Aspekte des $2^{\circ}$ Ms. theol. 54 aus Fulda«, in: Architectura Poetica. Festschrift für Johannes Rathofer zum 65. Geburtstag, hrsg. von Ulrich ERNst und Bernhard SowinsKi (Kölner germanistische Studien 30), Köln 1990, S. 1-16.

324 Becht-Jördens/Haubrichs: »Fulda«. S. 213. Haubrichs: »Otfrid de Wissembourg«. S. 158. Haubrichs: "Althochdeutsch in Fulda und Weißenburg - Hrabanus Maurus und Otfrid von Weißenburg«. S. 186.

325 Der Codex Discissus stammt von dort: Wolfgang Kleiber und Ernst Hellgardt (Hrsg.), Otfrid von Weißenburg: 2: Edition nach der Heidelberger Handschrift P (Codex Pal. Lat. 52) und der Handschrift D Codex Discissus (Bonn, Berlin/Krakau, Wolfenbüttel) Teil 2: Einleitung und Apparat, Berlin [u. a.] 2010. S. 100-102.

326 Christine Elisabeth EDER, »Candidus-Brun von Fulda: Maler, Lehrer und Schriftsteller«, in: Hrabanus Maurus und seine Schule. Festschrift der Rabanus-Maurus-Schule, hrsg. von Winfried BöнмE, Fulda 1980, S. 182-192.

327 Becht-Jördens (Hrsg.): Vita Aegil abbatis. Dümmler (Hrsg.): MGH Poet. lat. 2. S. 94-117. KIRSCH: Laudes sanctorum. S. 625-639. Walter BERSCHIN, »Biographie im karolingischen Fulda«, in: Kloster Fulda in der Welt der Karolinger und Ottonen, hrsg. von Gangolf SCHRIMPF (Fuldaer Studien 7), Frankfurt a. M. 1996, S. 315-324. Eine Liste der Viten S. 318.

328 Inwiefern die Illustrationen mit der beabsichtigten Widmung an Ludwig den Frommen zusammenhingen, ist unklar. BECHT-JöRDENs (Hrsg.): Vita Aegil abbatis. S. XXIX f.

329 Christoph Brouwer, Sidera illustrium et Sanctorum Virorum qui Germaniam praesertim Magnam olim gestis Rebus ornarunt, Mainz 1616. s.p. (letzter Faszikel).

$330 \mathrm{Zu}$ seiner Biographie: Arno Borst, Mönche am Bodensee: 610-1525 (Bodensee-Bibliothek 5), Sigmaringen 1978. S. 48-66. BRUNHöLzL: Geschichte, 1. S. 345-358, zur Dichtung insb. ab S. 347 . 
sehen werden, sind, wie andere Kleindichtung der Epoche, zwar gesammelt, aber nur wenig verbreitet worden. Zwei Handschriften bewahren uns den Großteil seiner Gedichte auf: Cod. Sang. 869, aus St. Gallen, wo sein Freund und Lehrer Grimald seit 841 Abt war und sich für Walahfrids Wiedereinsetzung auf der nahen Reichenau einsetzte, und BAV Reg. lat. 469 aus Fulda, wo der Dichter zu höheren Studien bei Hrabanus weilte. Auch diese Handschrift wanderte schon früh nach St. Gallen ab. Der Inhalt der Fuldaer Handschrift, von einer Hand auf 47 Blättern und in handlichem Format $(21,5 \times 14,5 \mathrm{~cm})$, soll zur besseren Übersicht vorausgeschickt werden: ${ }^{332}$

\begin{tabular}{|c|c|c|c|c|}
\hline f. & Inc. & $\begin{array}{l}\text { Ed. MGH } \\
\text { Poet. 2, p. }\end{array}$ & $\begin{array}{l}\text { Cod. St. Gall. } \\
869, \text { pp. }\end{array}$ & Titel aus Reg. lat. 469 / [ohne Titel] $]^{333}$ \\
\hline $\begin{array}{l}2 \mathrm{r}- \\
18 \mathrm{v}\end{array}$ & $\begin{array}{l}\text { Legistis me- } \\
\text { minit }\end{array}$ & $275-296$ & $2-50$ & $\begin{array}{l}\text { Versus Strabi vel Strabonis de vita et } \\
\text { fine Mammae monachi (f. } 4 \text { r) }\end{array}$ \\
\hline $\begin{array}{l}18 \mathrm{v}- \\
19 \mathrm{v}\end{array}$ & $\begin{array}{l}\text { Laudem } \\
\text { beati mar- } \\
\text { tyris }\end{array}$ & 296 & $50-52$ & Ymnus in natale sancti Mammetis \\
\hline $\begin{array}{l}19 \mathrm{v}- \\
20 \mathrm{v}\end{array}$ & $\begin{array}{l}\text { Quisquis } \\
\text { tramite } \\
\text { pendulo }\end{array}$ & $\begin{array}{l}360, \mathrm{~V}, \\
\text { XIV }\end{array}$ & $222-225$ & De carnis petulantia \\
\hline $\begin{array}{l}20 \mathrm{v}- \\
21 \mathrm{v}\end{array}$ & $\begin{array}{l}\text { Nominis } \\
\text { alma tui }\end{array}$ & $\begin{array}{l}403, \mathrm{~V}, \\
\mathrm{LXI}\end{array}$ & - & Ad Prudentium magistrum \\
\hline $\begin{array}{l}21 \mathrm{v}- \\
22 \mathrm{r}\end{array}$ & $\begin{array}{l}\text { Iustum erat } \\
\text { aduentum }\end{array}$ & $\begin{array}{l}404, \mathrm{~V}, \\
\text { LXII }\end{array}$ & - & $\begin{array}{l}\text { [Ad quendam Witgerum] Beginn Z. } 6 \\
\text { ohne Zeilen-trennung, durch Asteris- } \\
\text { ken markiert. }\end{array}$ \\
\hline $\begin{array}{l}22 r- \\
23 r\end{array}$ & $\begin{array}{l}\text { Innovatur } \\
\text { nostra lae- } \\
\text { tos }\end{array}$ & $\begin{array}{l}405, \mathrm{~V} \\
\text { LXIII }\end{array}$ & $\begin{array}{l}- \\
\text { Cod. St. Gall. } \\
899, \text { pp. } 128- \\
129\end{array}$ & [In adventu Hlotharii imperatoris] \\
\hline $23 r$ & $\begin{array}{l}\text { Natus et eg- } \\
\text { regie }\end{array}$ & $\begin{array}{l}382, \mathrm{~V}, \\
\text { XXVIII }\end{array}$ & $171-172$ & Ad Carolum filium augustorum \\
\hline
\end{tabular}

331 Die Dichtungen dieses Schülers und späteren Feindes Hrabans stehen weder inhaltlich noch handschriftlich mit Fulda in Verbindung: Marie-Luise WeBER, Die Gedichte des Gottschalk von Orbais (Lateinische Sprache und Literatur des Mittelalters 27), Frankfurt a. M. 1992. S. 119-126.

332 Lagenformel (eigene Untersuchung): $\mathrm{IV}^{1-8}+\mathrm{IV}^{9-16}+\mathrm{IV}^{17-24}+\mathrm{IV}^{25-32}+\mathrm{IV}^{33-40}+(\mathrm{IV}-1)^{41-47}$. Kataloge und Inhaltsangaben: André WiLmart, Codices Reginenses Latini (Bibliothecae Apostolicae Vaticanae Codices manu scripti recensiti), Vatikan 1937. S. 629-631. »[Fulda] «: Bischoff: Katalog, 3. Nr. 6683. Bergmann/Stricker: Katalog. Nr. 824. „Um die Mitte oder im dritten Viertel des 9. Jh. in Fulda geschrieben«: Hoffmann: Buchkunst. S. $395 \mathrm{f}$. DüMmLer (Hrsg.): MGH Poet. lat. 2. S. 263 f. DüMmLER: »Die handschriftliche Überlieferung". S. 274f. Weitere Literatur: VIsSER: Sis memor. Insb. S. 15-16, 19. SolINSKI: »De uita et fine sancti Mammae«. Insb. S. 7-12. BeRnT: Epigramm. S. 242-265.

333 Wenn Gedichte nur in einer anderen Handschrift mit Titeln versehen wurden, dann wird dieser in Reg. lat. 469 fehlende [Titel] hier eingefügt. Fehlt in allen Handschriften ein Titel, werden Vissers (S. 76-80) Titelvorschläge ergänzt. 
(Fortsetzung)

\begin{tabular}{|c|c|c|c|c|}
\hline f. & Inc. & $\begin{array}{l}\text { Ed. MGH } \\
\text { Poet. 2, p. }\end{array}$ & \begin{tabular}{|l} 
Cod. St. Gall. \\
869, pp. \\
\end{tabular} & Titel aus Reg. lat. 469 / [ohne Titel] $]^{333}$ \\
\hline $\begin{array}{l}23 r- \\
24 v\end{array}$ & $\begin{array}{l}\text { Gloriam } \\
\text { nato ceci- } \\
\text { nere }\end{array}$ & $\begin{array}{l}\text { 381, V, } \\
\text { XXVa }\end{array}$ & $131-134$ & [In natali Christi hymnus] \\
\hline $\begin{array}{l}24 \mathrm{v}- \\
25 \mathrm{v}\end{array}$ & $\begin{array}{l}\text { Velox Calli- } \\
\text { ope }\end{array}$ & $\begin{array}{l}362, \mathrm{~V}, \\
\text { XVIII }\end{array}$ & $228-229$ & $\begin{array}{l}\text { [Gotesscalcho monacho, qui et Ful- } \\
\text { gentius] }\end{array}$ \\
\hline $\begin{array}{l}25 \mathrm{v}- \\
26 \mathrm{v}\end{array}$ & $\begin{array}{l}\text { Presbiter } \\
\text { ista tuo }\end{array}$ & $\begin{array}{l}\text { 407, V, } \\
\text { LXV, i-iii }\end{array}$ & - & $\begin{array}{l}\text { [De Otfrido monacho Sandionysiano } \\
\text { tria carmina] }\end{array}$ \\
\hline $\begin{array}{l}26 \mathrm{v}- \\
27 \mathrm{r}\end{array}$ & $\begin{array}{l}\text { Qui sacra } \\
\text { templa }\end{array}$ & $\begin{array}{l}\text { 408, V, } \\
\text { LXVI, i-iii }\end{array}$ & - & \\
\hline $27 \mathrm{v}$ & $\begin{array}{l}\text { Martianus } \\
\text { praesul }\end{array}$ & $\begin{array}{l}409, \mathrm{~V}, \\
\text { LXVIII }\end{array}$ & - & $\begin{array}{l}\text { In ecclesia sancti Martiani in Golhdbah } \\
(!)\end{array}$ \\
\hline $\begin{array}{l}27 \mathrm{v}- \\
28 \mathrm{r}\end{array}$ & $\begin{array}{l}\text { Percepi } \\
\text { numquam }\end{array}$ & $\begin{array}{l}409, \mathrm{~V} \\
\text { LXVII }\end{array}$ & - & De lecto Strabi duo epigrammata \\
\hline $\begin{array}{l}28 \mathrm{r}- \\
28 \mathrm{v}\end{array}$ & $\begin{array}{l}\text { Pinxit ima- } \\
\text { ginibus }\end{array}$ & $\begin{array}{l}395, \mathrm{~V}, \\
\text { XLVII, i, } \\
\text { iii, v-xi }\end{array}$ & $\begin{array}{l}195 \text { (incl. ii, } \\
\text { iv), } \\
\text { Cod. St. Gall. } \\
899 \text { p. } 130 \\
\end{array}$ & Epigrammata \\
\hline $28 \mathrm{v}$ & $\begin{array}{l}\text { Condidit } \\
\text { Erlbaldi }\end{array}$ & $\begin{array}{l}410, \mathrm{~V}, \\
\text { LXIX }\end{array}$ & - & In ecclesia \\
\hline $\begin{array}{l}28 \mathrm{v}- \\
29 \mathrm{v}\end{array}$ & $\begin{array}{l}\text { Ecce uotis } \\
\text { apta }\end{array}$ & $\begin{array}{l}406, \mathrm{~V} \\
\text { LXIV }\end{array}$ & $\begin{array}{l}\text { Cod. St. Gall. } \\
899, \text { p. } 127- \\
128\end{array}$ & In aduentum Caroli filii augustorum \\
\hline $\begin{array}{l}29 \mathrm{v}- \\
39 \mathrm{r}\end{array}$ & $\begin{array}{l}\text { (Plurima } \\
\text { tranquillae) }\end{array}$ & $335, \mathrm{IV}$ & - & $\begin{array}{l}\text { [Liber de cultura hortorum] } \\
\text { Explicit habet uersus cccc xl iiii }\end{array}$ \\
\hline $\begin{array}{l}39 \mathrm{r}- \\
40 \mathrm{r}\end{array}$ & $\begin{array}{l}\text { Si qua uiam } \\
\text { faceret }\end{array}$ & $355, \mathrm{~V}, \mathrm{VI}$ & $213-215$ & Ad Moduinum \\
\hline $40 \mathrm{r}$ & $\begin{array}{l}\text { Litterulas } \\
\text { lacrimae }\end{array}$ & $\begin{array}{l}360, \mathrm{~V}, \\
\text { XIII }\end{array}$ & 222 & Ad magistrum Tattonem \\
\hline $40 \mathrm{r}$ & $\begin{array}{l}\text { Hic lector } \\
\text { subsiste }\end{array}$ & $\begin{array}{l}410, \mathrm{~V}, \\
\mathrm{LXX}\end{array}$ & - & Epitafion Vvolfharti abbatis de Oflita \\
\hline $\begin{array}{l}40 \mathrm{r}- \\
40 \mathrm{v}\end{array}$ & $\begin{array}{l}\text { Postquam } \\
\text { primo ho- } \\
\text { mini }\end{array}$ & $\begin{array}{l}392, \mathrm{~V}, \\
\text { XLII }\end{array}$ & $190-191$ & VVerdonis \\
\hline $\begin{array}{l}40 \mathrm{v}- \\
41 \mathrm{r}\end{array}$ & Rexpie rex & $\begin{array}{l}410, \mathrm{~V} \\
\text { LXXI }\end{array}$ & $126-127$ & $\begin{array}{l}\text { Ad Hludouicum regem in persona cu- } \\
\text { iusdam presbiteri }\end{array}$ \\
\hline $\begin{array}{l}41 \mathrm{r}- \\
41 \mathrm{v}\end{array}$ & $\begin{array}{l}\text { Vita san- } \\
\text { ctorum uia }\end{array}$ & $\begin{array}{l}411, \mathrm{~V} \\
\text { LXXII }\end{array}$ & - & Ymnus de sancto Gallo \\
\hline $41 \mathrm{v}$ & $\begin{array}{l}\text { Munus in } \\
\text { officii }\end{array}$ & $\begin{array}{l}411, \mathrm{~V}, \\
\text { LXXIII }\end{array}$ & - & [De amictu] \\
\hline $42 \mathrm{r}$ & $\begin{array}{l}\text { Properate } \\
\text { quaeso cari }\end{array}$ & $\begin{array}{l}412, \mathrm{~V}, \\
\text { LXXIV }\end{array}$ & - & Metrum anacreonticum \\
\hline
\end{tabular}


(Fortsetzung)

\begin{tabular}{|l|l|l|l|l|}
\hline f. & Inc. & $\begin{array}{l}\text { Ed. MGH } \\
\text { Poet. 2, p. }\end{array}$ & $\begin{array}{l}\text { Cod. St. Gall. } \\
869, \text { pp. }\end{array}$ & Titel aus Reg. lat. 469 / [ohne Titel] \\
\hline $\begin{array}{l}42 \mathrm{v}- \\
43 \mathrm{v}\end{array}$ & $\begin{array}{l}\text { Musa no- } \\
\text { strum plan- } \\
\text { ge }\end{array}$ & $\begin{array}{l}412, \mathrm{~V}, \\
\text { LXXV }\end{array}$ & - & Metrum saphicum \\
\hline $\begin{array}{l}43 \mathrm{v}- \\
44 \mathrm{v}\end{array}$ & $\begin{array}{l}\text { Iustum erat } \\
\text { aduentum }\end{array}$ & $\begin{array}{l}404, \mathrm{~V}, \\
\text { LXII }\end{array}$ & - & vid. 21v-22r \\
\hline $\begin{array}{l}44 \mathrm{r}- \\
46 \mathrm{r}\end{array}$ & $\begin{array}{l}\text { Otia longa } \\
\text { tuis }\end{array}$ & $\begin{array}{l}413, \mathrm{~V}, \\
\text { LXVI }\end{array}$ & - & [Ad Hlotharium imperatorem] \\
\hline $\begin{array}{l}46 \mathrm{r}- \\
46 \mathrm{v}\end{array}$ & $\begin{array}{l}\text { Festa quae } \\
\text { magno }\end{array}$ & $\begin{array}{l}415, \mathrm{~V}, \\
\text { LXVII }\end{array}$ & - & [De sancti Ianuarii translatione] \\
\hline
\end{tabular}

Sind die Gedichte eine Fuldaer Sammlung, vielleicht die Sammlung eines Adressaten Walahfrids? Zuerst wäre hier an Hrabanus zu denken, an den sein Schüler drei Gedichte richtete. ${ }^{334}$ Diese finden sich jedoch nicht in der Fuldaer Handschrift, sondern nur im Sangallensis. Auch die Gedichte an zwei andere mögliche Fuldaer Adressaten, die Mönche Felix und Werdarih, sind nicht enthalten. ${ }^{335}$ Visser stellt anhand seiner Datierung der Gedichte für die Sammlung einen Terminus post quem von 840 fest - könnte es also sein, dass Walahfrid selbst im Exil ${ }^{336}$ die Sammlung nach Fulda brachte? ${ }^{337}$ Die Hypothese eines Aufenthalts Walahfrids in Fulda zur Zeit seines Exils ${ }^{338}$ scheint jedoch auf nichts weiter als auf Königs ${ }^{339}$ Vermutung zu basieren, die er selbst nur als wahrscheinlich bezeichnet. Eine unerwartete Stütze hätte dieses Argument durch eine Beobachtung Solinskis bekommen, der auf f. 4v, Z. 14-17 der Handschrift in den nach Rasur von anderer Hand eingetragenen Versen keinen geringeren als Wa-

334 Dümmler (Hrsg.): MGH Poet. lat. 2. S. 358, V, IX, i, ii, iii. Zu Walahfrids Fuldaer Aufenthalt und möglichen dort geschriebenen Gedichten siehe eingehender VISSER: Sis memor. S. 3034.

335 Felix ist vielleicht der Adressat der Vita Blaitmaic (KIRsch: Laudes sanctorum. S. 706), Werdarih dagegen wird von Walahfrid in V, XLVII, ii getadelt, was ihn wenig geneigt gemacht hätte, dessen Dichtungen zu sammeln. Das Epigramm fehlt in der Reihe XLVII, i-xi, die vollständig in Cod. Sang. 869 enthalten ist. Zu beiden Personen siehe: Gerd Althoff und Karl Schmid, Die Klostergemeinschaft von Fulda im früheren Mittelalter, 2,1: Kommentiertes Parallelregister (Münstersche Mittelalter-Schriften 8) 1978. S. 242, 272.

336 Er war politische Allianzen gegen Ludwig den Deutschen eingegangen und wurde von seinem Abtsstuhl auf der Reichenau vertrieben.

337 VISSER: Sis memor. S. 16.

$338 \mathrm{Zu}$ möglichen Aufenthaltsorten Ebd. S. 41, zu Fulda speziell Anm. 172. Fulda auch noch aufgenommen bei: Borst: Mönche am Bodensee. S. 62.

339 Joseph KöNIG, "Über Walafried Strabo von Reichenau«, in: Freiburger Diözesan-Archiv 3 (1868), S. 317-464. S. 404-405, selbst gestützt auf eine Vermutung von: Melchior GoLDAST, Scriptores Alamannicarum rerum, Frankfurt a. M. 1606. Bd, 2, 1, S. 9 - den er jedoch gerade zuvor (S. 402) den gleichen Fuldaer Aufenthalt betreffend als unsicheren Zeugen kritisiert hatte. GoldAst war, nebenbei bemerkt, der Vorbesitzer von Reg. lat. 469. 
lahfrid selbst am Werk sah. ${ }^{340}$ Ein Vergleich mit den gesicherten Autographen Walahfrids zeigt jedoch schnell, dass der Korrektor keineswegs der Dichter selbst gewesen sein kann; die markante e-r Ligatur etwa findet sich nirgends bei Walahfrid. $^{341}$ Die Handschrift scheint also weder auf Fuldenser Adressaten Walahfrids, noch auf ihn selbst zurückzugehen.

Bevor zum Schluss auf den wahrscheinlichen Sammler und Besitzer der Handschrift eingegangen werden kann, gilt es noch einige Fragen zu klären, die den späteren Standort St. Gallen und die dortige Verwendung der Handschrift betreffen. Sie wird im spätmittelalterlichen Katalog St. Gallens unter dem Titel Strabo monachus de vita sancti Mamme et de cultura ortorum genannt und trägt f. $47 \mathrm{v}$ den Stempel der Bibliothek. ${ }^{342}$ Sie wird jedoch wegen des St. Galler Charakters ihrer Zusätze »spätestens im 10. Jahrhundert « dort verortet. ${ }^{343}$ Zumindest eine frühe Überführung ist unwahrscheinlich, da die möglichen St. Galler Ergänzungen nur schwach mit dem Kloster verbunden sind und nicht notwendigerweise kurz nach Erstellung der Handschrift dort eingetragen wurden. Bei den Zusätzen handelt es sich um eine Schenkungsnotiz, ein Gedicht und zwei Formulae auf 1r-1v, sowie um weitere Formulae im Freiraum neben den Gedichten auf 18v-20v. Die Abfolge der Einträge ist folgende: Schenkungsnotiz und Gedicht (Schreiber A) füllen die oberen drei Viertel des freigebliebenen Vorsatzblattes, darauf folgen, von offensichtlich anderer Hand (B) zwei Formulae. Die vier Texte $18 \mathrm{v}-20 \mathrm{v}$ von Hand C gleichen in ihrem Schriftbild stark B, ${ }^{344}$ scheinen jedoch, da sie in einen weniger sich anbietenden Freiraum als das ehemals ganz freie Folio 1 eingetragen sind, später als $\mathrm{AB}$ zu sein. ${ }^{345}$ Die Formulae sind abgesehen vom Schriftcharakter nur schwach mit St. Gallen verbunden, wie Alice Rio feststellt: ${ }^{346}$ »The collection is not even linked to St Gall except through sharing nos 20 and 21

340 Solinski: "De uita et fine sancti Mammae«. S. 11 und Anm. 42, im Vergleich mit den Schriftproben aus: Veronika von BüREN, "Une édition critique de Solin au IXe siècle«, in: Scriptorium 50 (1996), S. 22-87. S. 40f., 56-59.

341 Bernhard Bischoff, "Eine Sammelhandschrift Walahfrid Strabos (Cod. Sangall. 878) «, in: Bischoff, Mittelalterliche Studien, 2, 1967, S. 34-51. Hoffmann: »Autographa des früheren Mittelalters«. S. 32-35. Da die Handschrift wenigstens älter als 840 ist und der Eintrag ohnehin in den hypothetischen Aufenthalt zwischen 840-842 fiele, müsste es sich um die Schriftstufe W IV handeln (BIschoff, S. 37-41), nicht W II, wie von BüreN (S. 41) meint.

342 Lehmann (Hrsg.): MBK. 1, S. 111, Z. 3.

343 Hoffmann: Buchkunst. S. $395 \mathrm{f}$.

344 Vgl. das die beiden Hände trennende kleine s am Wortende.

345 Dies widerspricht der Einschätzung Hoffmanns, dessen Datierungen folgende sind: A: »erste Hälfte des 10. Jahrhunderts«, B: -, C: »ca. 900«. Ich halte an der relativen Datierung aufgrund der Position der Einträge fest.

346 f. 1rv: Form. Sang. Misc., Nr. 19, 20 (Karl Zeumer (Hrsg.), MGH Formulae Merowingici et Karolini aevi, Hannover 1882. S. 388-389); 18v-20v: Benedictio ferri ad iudicium faciendum (EвD. S. 614-615), Form. Sang. Misc. Nr. 21-23 (Ebd. S. 389-390). Alice Rio, Legal practice and the written word in the early Middle Ages: Frankish formulae, c. 500-1000 (Cambridge studies in medieval life and thought 75), Cambridge 2009. S. 153-155, 158-160, 265 f. 
with the Collectio Sangallensis, and both of these texts could simply have been derived from a common source. [...] the fact that these formulae form the only point of contact between the Munich and Vienna manuscripts ${ }^{347}$ and Vatican 469 could make us suspicious as to exactly how or when they would have come to be included in the St Gall tradition; they may simply point to the influence of an earlier formulary on both the documents and the formulae. ${ }^{348}$ Dieser Befund wird paläographisch noch durch die Trennung der Formulae 20 und 21 auf die Hände $B$ und $C$ unterstrichen, die eine gemeinsame Übernahme aus einer (St. Galler) Vorlage unwahrscheinlich macht.

Auch für das Weihegedicht für ein Gewand ergeben sich trotz der zahlreichen Namen kaum Anhaltspunkte für seine Lokalisierung, weder nach St. Gallen noch nach Fulda. ${ }^{349}$ Folgendes Familienbild zeigt sich in dem Gedicht: Die Mutter Perachtsvind, die ursprüngliche Stifterin des Gewandes, sowie ihr Mann Sarhilo; darauf die Brüder Perinhard, Adalung, Sarhilo, Adalpreht und die Schwestern Gundpirc und Gundarada, die das Gewand nach dem Tod ihrer Mutter weiterwebt. Die Benefizienten der durch die Schenkung erworbenen Gnade sollen Gundarada, ihr Mann (?) ${ }^{350}$ Isangrim, sowie ein Sarhilo (der Bruder?) und eine Gotasdiu sein. Strecker hält einen Fuldaer Ursprung für wahrscheinlich. ${ }^{351}$ Weitere von Schmid angemerkte prosopographische Verbindungen zur Reichenau, nach St. Gallen und sogar Remiremont schwächen allerdings jede einzelne Verortung des Gedichts. ${ }^{352}$ Zum Platz des Gedichts in der Handschrift macht Mitis bei seiner Untersuchung zu Familienstiftungen eine interessante Beob-

347 München, BSB, Clm 19413 (siehe S. 283-290 und Wien, ÖNB, Cod. 1609 (siehe S. 283-290).

348 Rio: Legal practice. S. 160, 154.

349 Fickermann/STrecker (Hrsg.): MGH Poet. lat. 5, 1.2. S. 526f. Ernst DüMmLER, "Gedichte auf Gewänder", in: Zeitschrift für deutsches Altertum und deutsche Literatur 19 (1876), S. $146-148$.

350 dominus genannt wie ihr Vater Sarhilo.

351 Fickermann/Strecker (Hrsg.): MGH Poet. lat. 5, 1.2. S. 526, Anm. zu 47. Weitere Fuldaer Fundorte des Patronyms Sarhilo in: Gerd Althoff und Karl Schмid, Die Klostergemeinschaft von Fulda im früheren Mittelalter, 3: Vergleichendes Gesamtverzeichnis der fuldischen Personennamen (Münstersche Mittelalter-Schriften 8) 1978. S. 321, S. 47.

352 Karl SснміD, »Zum Stifterbild im Liller Evangelistar des 11. Jahrhunderts«, in: Frühmittelalterliche Studien 16 (1982), S. 143-160. S. 159f., Anm. 84 b, wo eine engere Verbindung zum »italienischen Pfalzgrafen Sarilo« nahegelegt wird, zu diesem dort zitiert: Eduard Hlawitschка, Franken, Alemannen, Bayern und Burgunder in Oberitalien (774-962) (Forschungen zur oberrheinischen Landesgeschichte 8), Freiburg i. Br. 1960. Nr. CXLVII, und Hagen KeLLER, "Zur Struktur der Königsherrschaft im karolingischen und nachkarolingischen Italien. Der >consiliarius regis` in den italienischen Königsdiplomen des 9. und 10. Jahrhunderts", in: Quellen und Forschungen aus italienischen Archiven und Bibliotheken 47 (1967), S. 123-223. S. 219 und S. 200, Anm. 292. 
achtung: ${ }^{353}$ Auch in der Handschrift Karlsruhe, BLB, Aug. Perg. 112, f. 111v, die am Ende Reichenauer Formeln enthält, finden sich verschiedene Familienlisten, auf die eine formularische Bitte um Aufnahme in die Gebetsverbrüderung erfolgt. ${ }^{354}$ Sollte der Schreiber B, der die Formulae nach dem Gedicht einträgt, dieses vielleicht mit der weiteren Musterliteratur assoziiert haben und dementsprechend sich zur Ergänzung der Formulae angeregt gefunden haben?

Zum Gebrauch der Handschrift in St. Gallen ist weiterhin zu prüfen, ob die aus Fulda dahingelangte Walahfrid-Handschrift dort als Vorlage für den Sangallensis gedient haben könnte, womit ein sehr früher Zeitpunkt des Bibliothekswechsels ausgemacht wäre. ${ }^{355}$ Der Variantenvergleich lässt es jedoch als ausgeschlossen erscheinen, dass der Sangallensis in den betreffenden Teilen ein descriptus von Reg. lat. 469 ist. ${ }^{356}$ Für die Vita Mammae liegt hierfür die Untersuchung Solinkis vor: ${ }^{357}$ Während zwar beide Handschriften die spätere Redaktion der Vita enthalten, ist keine der beiden von der anderen direkt abhängig; vielmehr gehen beide auf eine vielleicht von Walahfrid redigierte Vorlage $\Omega$ ' zurück. Eine Trennung der beiden Handschriften geht auch aus der Durchsicht der Varianten hervor, die Trennvarianten in allen bis auf zwei der gemeinsamen Gedichte aufzeigt. ${ }^{358}$ Zudem enthält Cod. Sang. 869 eine Vielzahl von Gedichten über Reg. lat. 469 hinaus, was allein schon eine Abschrift daraus unwahrscheinlich macht und wenigstens eine weitere St. Galler Sammlung postuliert. ${ }^{359}$ Damit ist eine spätere Überführung von Reg. lat. 469 nach St. Gallen möglich, als eine Abschrift

353 Oskar von Miтis, »Bemerkungen zu den Verbrüderungsbüchern und über deren geschichtlichen Wert«, in: Zeitschrift für schweizerische Kirchengeschichte 43 (1949), S. 28-42. S. 33f. Anm. 1.

354 Als einheitliche Formel zur Gebetsverbrüderung bei: Konrad Beyerle und Peter P. Albert (Hrsg.), Die Kultur der Abtei Reichenau: Erinnerungschrift zur zwölfhundertsten Wiederkehr des Gründungsjahres des Inselklosters 724-1924, München 1925. S. 313. Die Namen: Franz Joseph MoNe, »Reichenauer Formeln aus dem 8. Jahrhundert«, in: Zeitschrift für die Geschichte des Oberrheins 3 (1852), S. 385-397. S. 391. Die Formeln: Formulae Augienses coll. A, Nr. 21: Zeumer (Hrsg.): MGH Formulae. S. 347, wo die Namensliste nicht wiedergegeben ist. Bei den Namen kann es sich nicht um die nomina fratrum supervenientium der Formel handeln; dennoch ist die Assoziation gegeben.

355 So VISSER: Sis memor. S. 19: "[Die Handschrift] was seemingly brought to St Gall with the express object of furthering the completeness of the Walahfridian collection ".

356 So vorgeschlagen von VISSER S. 19, mit einer zusätzlichen Quelle $\alpha$. Die Gedichte, die Cod. Sang. 869 zusätzlich hat, schließen eine direkte Abhängigkeit aus. Dazu kommt die Anordnung, die nirgends Sequenzen übernimmt, wie fast immer bei Entnahme kürzerer Texte geschieht.

357 Solinski: »De uita et fine sancti Mammae«. Insb. S. 7-12.

358 DÜMmLER (Hrsg.): MGH Poet. lat. 2. S. 360, V, XIV, 2, Z. 3: polus G / solum C; 382, V, XXVIII, 1: Ad Karolum iuuenem G / Ad Carolum filium Augustorum C; 381, V, XXVa, 8, 4: pacis G / lucis C; 395, V, XLVII, iv, 2: Cereri G / cepi C; 355, V, VI 16 cudit G, vidit C; 360, V, XIII: Tattonem G / tactonem C 392; V, XLII titulum om. G / Vverdonis C.

359 Siehe das Exklusivgut von Cod. Sang. 869 gegenüber Reg. lat. 469 bei: Visser: Sis memor. S. 76-80. 
der Handschrift für den Sangallensis nötig gemacht hätte. Weder die Formulae, noch das Widmungsgedicht, noch der Textzusammenhang der Handschriften machen demnach ein frühes Abwandern der Handschrift nach St. Gallen notwendig.

Damit halte ich es für möglich, dass die Schenkungsnotiz und das Gedicht, die vor den Formulae auf der ersten Freiseite eingetragen wurden, durchaus noch aus Fulda von einem in St. Gallen ausgebildeten Schreiber stammen können. ${ }^{360}$ Die Notiz ist folgende: : Hunc libr[um] Ruodolf p[resbyter] lucratus Sancto Bonif[acio]. Die Handschrift war also Teil der Fuldaer Bibliothek, vielleicht wenigstens lange genug, um einmal kopiert zu werden. ${ }^{361}$ Wer ist nun dieser Rudolf, der die Handschrift für die Bibliothek Fuldas »erwarb «? ${ }^{362}$ Die Fuldaer Totenannalen verzeichnen sechs Personen dieses Namens, die aufgrund ihres Sterbedatums (nach 840) als Besitzer der Handschrift in Frage kommen. ${ }^{363}$ Aber nur einer von diesen erscheint als wahrscheinlicher Besitzer einer lyrischen Sammelhandschrift: Der Hagiograph und Lehrer Rudolf von Fulda. ${ }^{364}$ Abgesehen von seiner Prominenz, die ihn eher in den Stand gesetzt haben wird, eine kleine Büchersammlung zu haben, ist es seine Lehrtätigkeit und die damit verbundene Beschäftigung mit Dichtung, die uns in seinen Händen eine Walahfrid-Handschrift vermuten lässt. Auch war er selbst Dichter, seine Werke kennen wir leider nicht. ${ }^{365}$ Als Lehrer hatte er Zugriff auf das Fuldaer Skriptorium und in der Schule

360 Was als wahrscheinlicher erscheint, als dass die lokale Information der Bücherschenkung viel später in St. Gallen hätte bekannt sein sollen.

361 GugEL: Handschriften. S. 66 (die Handschrift dort unter »Vielleicht zeitweiliger Bestand», was bei der Schenkungsnotiz doch zu vorsichtig ist). Zur möglichen Abschrift: Im spätmittelalterlichen Katalog findet sich eine Vita sancti Mamme monachi et passio eius edita per Strabum, die bei der Seltenheit des Werkes durchaus eine Kopie von Reg. lat. 469 darstellen könnte (Снrist: Bibliothek des Klosters Fulda. S. 144, XXXIII, Nr. 406).

362 lucratus wird bei Fickermann/Strecker (Hrsg.): MGH Poet. lat. 5, 1.2. S. 526, Anm. zu 47, so verstanden, dass die Handschrift »für Fulda erworben, nicht, daß sie dort geschrieben wurde«, was dem paläographischen Befund widerspricht. Auch Hoffmann, S. 396, bezeichnet die Notiz als »irritierend«. lucratus sollte hier im einfachen Sinn von "geschenkt» verstanden werden.

363 Althoff/Schmid: Klostergemeinschaft, 2,1. S. 68.

364 So Bischoff in: Bernt: Epigramm. S. 244, Anm. 32 (persönliche Mitteilung), zitiert nach VISSER: Sis memor. S. 15, Anm. 52; und: Edmund Ernst STENGEL, „Die Urkundenfälschungen des Rudolf von Fulda«, in: Archiv für Urkundenforschung 5 (1914), S. 41-152. S. 43, Anm. 1. Zustimmend ebenfalls: ALtноғғ/Schмid: Klostergemeinschaft, 2,1. S. 253-255. MF 168, S. 254. Zu Rudolfs Leben und Werk siehe auch: BRUnHöLZL: Geschichte, 1. S. 343-345. Manitius: Geschichte, 1. S. 668-672.

365 Annales Fuldenses (865, Friedrich Kurze (Hrsg.), Annales Fuldenses sive annales regni Francorum orientalis (MGH SS 7), Hannover 1993. S. 63): "poeta atque omnium artium nobilissimus auctor«; Magdeburger Centurien: »vir literatus et bonus poeta«: ALtноғF/ ScHмID: Klostergemeinschaft, 2,1. S. 254, dort auch Belege zur Lehrtätigkeit Rudolfs. Ein möglicher Vers: Kurze (Hrsg.): Annales Fuldenses. S. 54. 
einen natürlichen Bedarf an Dichtung. ${ }^{366}$ Als Dichter hatte er selbst Interesse an den Werken seiner Zeitgenossen. Und als Literat in Fulda stand er in vielfältigen Beziehungen, die ihm Walahfrids Dichtung vermittelt haben könnten. ${ }^{367}$ Ohne Zweifel ist in ihm der Sammler und Besitzer der Fuldaer Walahfrid-Handschrift zu sehen. Wie er sie genutzt haben könnte, ist aufgrund des weitgehenden Mangels von Gebrauchsspuren kaum mehr festzustellen. ${ }^{368}$ Ob die Handschrift erst nach Rudolfs Tod aus seiner Handbibliothek in die Klosterbibliothek überging, oder ob er sie schon vorher übergab, lässt sich nicht mehr ausmachen.

Blicken wir zurück. Die erste Phase der Rezeption von Dichtung in Fulda war in Form und Inhalt durch die asketischen Interessen der angelsächsischen Gründergeneration geprägt. Typische Autoren wie Aldhelm und Sedulius, der letztere sogar in der in Irland tradierten Textgestalt, bildeten den bescheidenen Grundstock der frühen Bibliothek. Unter Hrabanus, der erst als Lehrer und dann als Abt die Kultur des Klosters bestimmte, wandte sich das Blatt. Die Form des Figurengedichtes, die er wohl bei seinem Lehrer Alkuin kennengelernt hatte, brachte er in seinem Liber de laudibus sanctae crucis auf eine nicht erreichte Höhe. Zur Verbreitung des Werkes, das er an hochstehende Würdenträger versandte, bediente er sich des klösterlichen Skriptoriums. Hiermit stand der Dichter selbst am Anfang und im Zentrum der Verbreitung seines Werkes. Anders erging es seiner Kleindichtung: Diese scheint, wie seine Briefe, nur in einer Fuldaer Haussammlung aufbewahrt worden zu sein, die wahrscheinlich auf die Unterlagen Hrabans zurückgeht. Die Sammlung von Dichtung erlebte unter ihm einen unerhörten Aufschwung. Neben dem christlichen Dichter-Kanon stehen auch so eng mit Hrabanus verbundene Titel wie eine Sammlung von Alkuins Briefgedichten und die Figurengedichte des Porphyrius. Auch die heidnische Dichtung ist in zahlreichen Handschriften vertreten. Insofern stand also Hrabans Skepsis gegenüber den Klassikern ihrer Pflege nicht entgegen. Während er die christlichen Dichter namentlich empfiehlt, duldet und fördert er das Studium der Alten. Exemplarisch steht hierfür die Handschrift der Argonautica, eines erlesenen und seltenen Werkes, als Gemeinschaftsarbeit einer Gruppe von Schülern. Der größte Dichter, der durch die Schule des Hrabanus ging, war Walahfrid

366 Ein Gedicht Walahfrids findet sich auch in der Schulhandschrift Clm 6404 aus Freising. Günter Glauche, Die Pergamenthandschriften aus der Bibliothek des Domkapitels Freising (Catalogus codicum manu scriptorum Bibliothecae Monacensis 3/2/1), Wiesbaden 2000. S. 198.

367 Ohne weiter spekulieren zu wollen, erscheint mir als wahrscheinlichster Übermittler sein Schüler Ermenrich von Ellwangen, der auf der Reichenau Schüler Walahfrids und später Freund Grimalds in St. Gallen war. Jan PRELOG, »Art. Ermenrich von Ellwangen«, in: Lexikon des Mittelalters, 3, 1986, S. 2157. In St. Gallen gab es einen Kodex, der Ursprung der dortigen Sammlungen war, siehe dort S. 126 und 138 zu Cod. Sang. 899 und Cod. Sang. 869.

$368 \mathrm{Zu}$ den späteren St. Galler Glossen siehe Bergmann/Stricker: Katalog. Nr. 824, S. 1571. Zwei weitere Kritzeleien auf f. 2r und 29v. 
Strabo. Seine Dichtung hat sich nicht in seinem Heimatkloster auf der Reichenau sondern in St. Gallen und eben Fulda erhalten. Hier war wahrscheinlich der Lehrer Rudolf von Fulda der Besitzer einer Sammlung seiner Gedichte, die sich damit genau an dem Schnittpunkt von Literatur und Bildung befanden, der in Fulda der Ort der Dichtung war.

\section{II.1.d St. Gallen}

Die Anfänge der Abtei St. Gallen, ${ }^{369}$ die auf die Einsiedlerzelle des heiligen Gallus zurückgeht, und die Figur des Gründers selbst liegen im Dunkeln; ${ }^{370}$ als Bildungsstätte tritt St. Gallen erst im 8. Jh. in Erscheinung, nach der Neugründung durch Otmar (719-759), ${ }^{371}$ unter dessen Nachfolgern ein Skriptorium zuerst in Urkunden, dann in Handschriften erkennbare Züge annimmt. ${ }^{372}$ Ein uns na-

369 Allgemeine Literatur: Sonja GLAUCH, »St. Gallen«, in: Schreiborte des deutschen Mittelalters : Skriptorien - Werke - Mäzene, hrsg. von Martin J. SCHuber T, Berlin [u. a.] 2013, S. 493-512. Walter Berschin, Eremus und Insula: St. Gallen und die Reichenau im Mittelalter - Modell einer lateinischen Literaturlandschaft, 2., erw. Aufl., Wiesbaden 2005. Werner WUNDERLICH und Rupert Kalkofen (Hrsg.), St. Gallen. Geschichte einer literarischen Kultur, St. Gallen 1999. Peter Ochsenbein (Hrsg.), Das Kloster St. Gallen im Mittelalter: die kulturelle Blüte vom 8. bis zum 12. Jahrhundert, Darmstadt 1999. Werner Vogler (Hrsg.), Die Kultur der Abtei Sankt Gallen, 2. Aufl., Zürich 1992. Johannes Duft, Die Abtei St. Gallen, 2. Beiträge zur Kenntnis ihrer Persönlichkeiten, Sigmaringen 1991. Johannes DuFt, Die Abtei St. Gallen, 1. Beiträge zur Erforschung ihrer Manuskripte, Sigmaringen 1990. Johannes DufT, Anton GössI und Werner VogLeR, "St. Gallen«, in: (Helvetia Sacra, III, 1, 2), Bern 1986, S. 11801369. James Migdley CLARK, The abbey of St. Gall as centre of literature and art, Cambridge 1926. Hermann Wartmann, Das Kloster St. Gallen (Neujahrsblatt St. Gallen 3-4), St. Gallen 1863.

370 Max SсHÄR, Gallus: der Heilige in seiner Zeit, Basel 2011. Max SсHÄR, «St. Gallen zwischen Gallus und Otmar 640-720.«, in: Schweizerische Zeitschrift für Religions- und Kulturgeschichte 102 (2008), S. 317-359. Zur Frühzeit des Klosters siehe die Beiträge in: Franziska SchNoor u. a. (Hrsg.), Gallus und seine Zeit. Leben, Wirken, Nachleben (Monasterium Sancti Galli 7), St. Gallen 2015.

371 Duft/Gössi/Vogler: »St. Gallen«. S. 1266-1268.

372 Zum Skriptorium grundlegend: Albert BRUCKNer, Schreibschulen der Diözese Konstanz: St. Gallen, 1 (Scriptoria medii aevi Helvetica 2), Genf 1936. Albert BRUCKNER, Schreibschulen der Diözese Konstanz: St. Gallen, 2 (Scriptoria medii aevi Helvetica 3), Genf 1938. An zahlreichen von BRUCKNERs Urteilen bestehen heute Zweifel, siehe: Beat Matthias von SCARPATETtI, "Albert Bruckner et ses `Scriptoria Medii Aevi Helvetica«", in: Scriptorium. Wesen - Funktion - Eigenheiten, hrsg. von Andreas Nievergelt u. a. (Veröffentlichungen der Kommission für die Herausgabe der mittelalterlichen Bibliothekskataloge Deutschlands und der Schweiz), München 2015, S. 543-547. Beat Matthias von ScarpatetTI, "Das St. Galler Scriptorium «, in: Das Kloster St. Gallen im Mittelalter: die kulturelle Blüte vom 8. bis zum 12. Jahrhundert, hrsg. von Peter Ochsenbein, Darmstadt 1999, S. 31-67. Beat Matthias von Scarpatetti, "Schreiber-Zuweisungen in St. Galler Handschriften des achten und neunten Jahrhunderts", in: Codices Sangallenses. Festschrift für Johannes Duft zum 80. Geburtstag, hrsg. von Peter Ochsenbein und Ernst Ziegler, Sigmaringen 1995, S. 25-56. 
mentlich bekannter Schreiber ist Winithar; ${ }^{373}$ ein ihm zugeschriebener Schreibervers jedoch, ${ }^{374}$ der uns ein bescheidenes Zeugnis der frühen in St. Gallen gepflegten Dichtung bewahrt, stammt nicht von seiner Hand. ${ }^{375}$ Dagegen finden sich von seiner Hand am Ende der Bibelhandschrift St. Gallen, StB Cod. Sang. 2 eine Reihe von Gedichten: ${ }^{376}$ pp. 553-557, der Abecedarius Inc. Asia ab oriente, ${ }^{377}$ eine nach Isidor gestaltete Weltbeschreibung, deren Text wie Prosa niedergeschrieben wurde ${ }^{378}$ und in dieser Form mit den vorhergehenden Isidor-Exzerpten in einer Reihe steht. Es folgen in dunklerer Tinte pp. 558-563 zwei spätantike Hymnen, Inc. Hymnum dicat turba und Rex aeterne domine, ${ }^{379}$ und darauf in einem Schreibvorgang pp. 563-567 Inc. Ante secula et $m u n d i^{380}$ über die Weltzeitalter, worin bei allen drei ebenfalls die Zeilenumbrüche für die Verse nicht beachtet wurden. Diese spärlichen Zeugnisse belegen die untergeordnete Rolle, die Dichtung im frühen St. Gallen spielte.

Eine Episode blieb das kurze Abbatiat Waldos (782-784), der in Folge als Abt der Reichenau deren frühe Blüte förderte. ${ }^{381}$ Vor seinem Abbatiat war er als Diakon auch als Urkundenschreiber tätig, eine von Bruckner aufgestellte Gruppe von Waldo-Handschriften - darunter keine mit Dichtung - hält jedoch näherer Prüfung nicht stand. ${ }^{382} \mathrm{Zu}$ einer Zeit also, da in Lorsch, Fulda und insbesondere auf der benachbarten Reichenau die Bibliotheken kräftig wuchsen, stand

373 Zu Winithar: Natalie MAAG, Alemannische Minuskel: (744-846 n. Chr.) Frühe Schriftkultur im Bodenseeraum und Voralpenland (Quellen und Untersuchungen zur lateinischen Philologie des Mittelalters 18), Stuttgart 2014. S. 36-59. SCARPatetTI: „Das St. Galler Scriptorium«. S. 46. Walter BERSCHIN, »Sankt-gallische Schriftkultur«, in: Die Kultur der Abtei Sankt Gallen, hrsg. von Werner VogLER, Zürich 1990, S. 69-92. S. 69 f.

374 DüMmLer (Hrsg.): MGH Poet. lat. 1. S. 89, II, aus Wien, ÖNB, Cod. 743.

375 MAAG: Alemannische Minuskel. S. 36f. Noch Winithar zugeschrieben bei: BERSCHIN: Eremus und Insula. S. 20. Der "Versus Winithari« ist zwar von seiner Hand, ist aber kein Gedicht, sondern eine Prosapredigt: Walter Berschin und Bernhard Zeller, "Winithar in Sankt Gallen (um 760-?) und der >Versus Winitharii «, in: Sermo doctorum. Compilers, preachers and their audiences, hrsg. von Maximilian Diesenberger, Yitzhak Hen und Marianne Pollheimer, Turnhout 2013, S. 153-186.

376 SCherRer: Stiftsbibliothek. S. 1-2. SCARPATETti: „Schreiber-Zuweisungen«. S. 27.

377 SK 1106. STRECKer (Hrsg.): MGH Poet. lat. 4, 2.3. S. 545-559. Fr. Glorie (Hrsg.), Itineraria et alia geographica (CCSL 175), Turnhout. S. 441-450. Georg Heinrich PERTZ, „Über eine fränkische Kosmographie des siebenten Jahrhunderts", in: Abhandlungen der Königlichen Akademie der Wissenschaften in Berlin (1845), S. 253-270.

378 In gleicher Gestaltung in St. Gallen, StB Cod. Sang. 213, pp. 176-177, vielleicht auch von der Hand Winithars (MAAG: Alemannische Minuskel. S. 20). Beide Handschriften stammen von einer gemeinsamen Vorlage ab: STRECKER (Hrsg.): MGH Poet. lat. 4, 2.3. S. $546 \mathrm{f}$.

379 SK $7445,14234$.

380 SK 878. STRECKer (Hrsg.): MGH Poet. lat. 4, 2.3. S. 559-564. Ernst DÜMMLER, »Gedicht über die sechs Weltalter«, in: Zeitschrift für deutsches Altertum und deutsche Literatur 22 (1878), S. 423-428.

381 Duft/Gössi/Vogler: „St. Gallen«. S. 1069f., 1270f. Zu Waldo siehe auch S. XX.

382 MaAg: Alemannische Minuskel. S. 56-59. SCARPATETti:»Schreiber-Zuweisungen«. S. 31-37. 
St. Gallens Blütezeit noch bevor, und von den hunderten erhaltener frühmittelalterlicher Handschriften stammen nur etwa vierzig aus dem 8. und frühen 9. Jh. ${ }^{383}$ Nur zwei hiervon enthalten Dichtung.

Zürich, ZB, C $68^{384}$ enthält die Evangeliendichtung des Juvencus ${ }^{385}(3 \mathrm{v}-71 \mathrm{v})$, Sedulius' Carmen Paschale ${ }^{386}(71 v-111 v)$ und den Cento Probae ${ }^{387}(111 r-124 r)$, von Hand zweier Hauptschreiber (2r-78v, 80r-125r) und gleicht mit dieser Textgesellschaft aufs Haar dem zweiten Teil einer zeitgenössischen Reichenauer Handschrift. ${ }^{388}$ Und in der Tat sind die beiden Handschriften in der Überlieferung von zwei der Texte auf engste verwandt und stammen von einem Exemplar $\mathrm{ab} ;^{389} \mathrm{ob}$ dieses in St. Gallen oder auf der Reichenau lag, ist unklar. Die enge Verbindung der beiden Bibliotheken ist damit in jedem Fall schon zu Beginn des 9. Jh. etabliert. Buchschmuck und Textdarbietung sind schlicht, aber geräumig und sauber und auch die Glossierung ${ }^{390}$ ist nur spärlich, sodass eine schulische Verwendung - die Handschrift wäre ja das ganze 9. Jh. hierfür verfügbar gewesen und müsste deutlichere Nutzungsspuren tragen - unplausibel erscheint. ${ }^{391}$ Dies macht auch eine Identifikation mit einem ähnlichen Eintrag in der Grammatik-

383 Hannes STEINER, »Buchproduktion und Bibliothekszuwachs im Kloster St. Gallen unter den Äbten Grimald und Hartmut", in: Ludwig der Deutsche und seine Zeit, hrsg. von Wilfried Hartmann, Darmstadt 2004, S. 161-183. S.162f.

$384 »[$ St. Gallen, (VIII./IX. Jh. oder) IX. Jh., und IX. Jh., 2. Viertel]«: Bischoff: Katalog, 3. Nr. 7575. MohlBerg: Katalog Zürich. S. 39, Nr. 98. BRUCKNer: St. Gallen, 2. S. 125.

385 Johann Huemer (Hrsg.), Gai Vetti Aquilini Ivvenci Evangeliorum libri quattuor (CSEL 24), Wien 1891. S. XXXI, XXXIX f. Sigle T. Karl Marold (Hrsg.), C. Vettii Aquilini Iuvenci Libri Evangeliorum IIII (Bibliotheca Scriptorum Graecorum et Romanorum Teubneriana), Leipzig 1886. S. XIV f. Sigle T. Davor 2r-2v De X numeris canonum, Inc. Quam inprimis, Ed.: Mario Esposito, "Hiberno-Latin manuscripts in the libraries of Switzerland", in: Proceedings of the Royal Irish Academy C 30 (1912), S. 1-14. S. 3-5. Ebenfalls in Zürich, ZB, Ms. C 78 (aber Inc. Quam in prima), siehe unten S. 144.

386 Johann Huemer und Victoria Zimmerl-Panagl (Hrsg.), Sedulii Opera omnia (CSEL, 10 [1885]), Wien 2007. S. XII f., XXX f., Sigle Z.

387 Carlo M. LuCARINI (Hrsg.), Proba: Cento Vergilianus (Bibliotheca scriptorum Graecorum et Romanorum Teubneriana 2017), Berlin 2015. S. LVI f., CVI, Sigle T. Petschenig/Schenki/ Brandes (Hrsg.): Poetae Christiani minores. S. 520, Sigle T.

388 Karlsruhe, BLB, Aug. Perg. 217, II (68-169). Siehe S. 161 f.

389 Siehe die Ausgaben oben. Iuvencus orientiert sich mehr am Text der Freisinger Handschrift Clm 6402: MARold (Hrsg.): Iuvencus. S. XIV-XV.

390 Bergmann/Stricker: Katalog. Nr. 1003. Ertmer: Juvencusglossierung. S. 371-376. Andreas Nievergelt, "St. Galler Glossenhandschriften«, in: Die althochdeutsche und altsächsische Glossographie. Ein Handbuch, 2, hrsg. von Rolf BERgManN und Stefanie STRICKER, Berlin [u.a.] 2009, S. 1462-1527. S. 1483-1485. Elvira Glaser und Andreas NieVergelt, »Griffelglossen«, in: Die althochdeutsche und altsächsische Glossographie. Ein Handbuch, 1, hrsg. von Rolf Bergmann und Stefanie Stricker, Berlin [u. a.] 2009, S. 202229. S. 216, Anm. 49.

391 Als Schulhandschrift genannt bei: BraUer: Bücherei und Schrifttum. S. 47. 
Abteilung des mittelalterlichen Bibliothekskataloges unwahrscheinlich. ${ }^{392}$ Die Freiräume der Handschriften füllten sich nach und nach mit weiterer Kleindichtung. Der Entstehungszeit nahe sind 1r-1v und 125v-126r, wo eine oder doch zwei sich sehr ähnliche Hände ${ }^{393}$ eine Hymne des Sedulius, ein Gedicht Ps. Cyprians und vom Hauptschreiber vergessene Verse nachtragen. ${ }^{394}$ All diese sind nicht offensichtlich schulischer Natur, sondern insbesondere der Nachtrag der fehlenden Verse eher Frucht einer aufmerksamen Lektüre der Handschrift. Ähnliche Sorgfalt zeigt sich darin, dass das Vorwort zum Carmen Paschale, das zu Beginn des Textes fehlt, beim Lagenwechsel nach III ${ }^{74-79}$ auf f. 80r vor das zweite Buch eingeschaltet wird. Ebenfalls der Entstehungszeit nahe stehen die zwei von anderer Hand nachgetragenen Fabeln des Avianus auf 126v-127r. ${ }^{395}$ Vielleicht war die Vorlage dieselbe illuminierte Handschrift, die im 11. Jh. ohne die Bilder in St. Gallen, StB Cod. Sang. 1396 abgeschrieben wurde. ${ }^{396}$ Die Fabeln waren in zahlreichen Klöstern der Zeit vorhanden, so auch auf der Reichenau und in Murbach. ${ }^{397}$ Am Ende der Lage III ${ }^{74-79}$ blieb ein Blatt frei und wurde in der Mitte des Jahrhunderts gefüllt mit zwei Kalendergedichten ${ }^{398}$ - vielleicht aus einer Computus-Sammlung? - und dem Epitaph Alkuins. ${ }^{399}$ Dieses findet sich ebenfalls, jedoch nicht als Zusatz, im Alkuin-Sammelband St. Gallen StB. Cod. Sang.

392 Mit weiteren abweichenden Inhalten: LeHMANN (Hrsg.): MBK. 1. S. 81, Z. 28 (Hauptkatalog Nr. 15). Einem anderen Band (Ebd. S. 81, Z. 1f.) fehlt der Cento Probae (Hauptkatalog Nr. 5); so auch ERTMER: Juvencusglossierung. S. 372.

393 So BruCKNer; Huemer, S. XIII: »eadem manu«.

394 lr-lv: Inc. Regna beata patri (Hymni II, vss. 39-110); 1v: Inc. Quid mihi ruriculas (vss. 1-6, SK 13300, Wilhelm von Hartel (Hrsg.), S. Thasci Caecili Cypriani Opera omnia (CSEL, 3,3), Wien 1871. S. 308f.). 125v-126r: Carmen Paschale V, 104-176, 196-201.

395 Nr. V und IX. Antonio Guaglianone (Hrsg.), Aviani Fabulae (Corpus scriptorum Latinorum Paravianum), Turin 1958. S. XVII, XXXVII f., LV. Nicht benutzt von Françoise GaIde (Hrsg.), Avianus: Fables (Collection des universités de France), Paris 1980.

396 W. A. Oldfather, "A Fleury text of Avianus«, in: Philological Quarterly V (1926), S. 20-28.

397 Reynolds: Texts and transmission. S. 30, nach den alten Katalogen. Die Nennung St. Gallens dort bezieht sich auf den nur unsicher lokalisierten Katalog aus St. Gallen, StB Cod. Sang. 831, siehe dazu unten S. 102f. Das Avianus-Exzerpt in Karlsruhe, BLB Aug. Perg. 73 steht in einer anderen Texttradition als das St. Galler Exzerpt (Alfred Holder, "Zu Avianus", in: Philologus 56 (1906), S. 91-96. Reynolds: Texts and transmission. S. 31).

398 Inc. Principium iani (RIese/Bücheler (Hrsg.): Anthologia latina. Nr. 640, SK 12589, ebenfalls in Cod. Sang. 250, 2. Hälfte 9. Jh., einer Computushandschrift), Inc. Prima dies Phoebi (SK 12491, Poetae latini minores, V, S. 353 f., AL 488). Siehe S. 259-261 zu Cod. Sang. 250 und Reg. lat. 438. Die enthaltenen Kalenderverse zu Beginn des Computus (SK 1716, 7613, 3727, 6489, 5264, 12589, 151) in Cod. Sang. 250 gehen wahrscheinlich auf St. Galler Quellen zurück. Zwei der Gedichte (SK 3727, 5264) auch in Grimalds Vademecum.

399 Inc. Hic rogo pauxillum (DüMmLer (Hrsg.): MGH Poet. lat. 1. S. 350). Handschrift nicht benutzt. Die anderen Textzeugen sind westfränkischer Herkunft, sodass St. Gallen der einzige ostfränkische Überlieferungsort ist. 
$272,{ }^{400}$ pp. $52-54$, und wird wohl aus dieser Handschrift übernommen worden sein. Ms. C 68 zeigt also schon zu Beginn des Jahrhunderts eine entwickelte Pflege der Dichtung in St. Gallen, die über die schulische Verwendung hinausgeht. Standardtexte werden mit der Reichenau geteilt und interessante Kleindichtung aus anderen Handschriften gesammelt und notiert.

Ein noch gezielteres Interesse an Dichtung, insbesondere an früheren Rhythmen, zeigt sich in Leiden, UB, Ms. Voss. Lat. Q. 69 (II, f. 7-47), ${ }^{401}$ wo diese nicht nur in von größeren Werken gelassenen Freiräumen, sondern in einem eigentlich anthologischen Teil gesammelt worden ist. Die Handschrift zerfällt thematisch und kodikologisch zwanglos in drei Teile: IV $^{7-14}+(I V-3)^{15-19}$ : Anthologie; 2 IV $^{20-35}$ : Leidener Glossar; ${ }^{402} \mathrm{IV}^{36-43}+\mathrm{II}^{44-47}$ : Excerpta Varia. ${ }^{403}$ Die Anthologie ist zusätzlich von den folgenden Texten dadurch getrennt, dass die letzten drei Blätter ihrer zweiten Lage freigeblieben sind, die später anscheinend zu anderen Zwecken abgetrennt worden sind; das folgende Leidener Glossar beginnt auf einer neuen Lage. Dennoch geben Format und Liniierung der Handschrift ein einheitliches Aussehen. ${ }^{404}$ Obwohl Wechsel in Schriftbild und Tinte zwei oder mehr Schreiber vermuten lassen, fällt ihre Unterscheidung schwer. ${ }^{405}$ Sicher scheint jedoch, dass ein Hauptschreiber an allen drei Teilen der Handschrift mitwirkte, und zwar mit der vollständigen Anthologie, den Exzerpten des dritten Teils, und Teilen des Glossars. ${ }^{406}$ Die zwei Freiräume im mise-en-page der Anthologie (9v, 10v) sind nicht dadurch entstanden, dass unvollständig beschriebenen Blättern weitere hinzugefügt wurden, vielmehr hat der Hauptschreiber hier in einem Arbeitsgang (durch Tinte und Schriftbild kenntlich) die Feder aus der linken Spalte in die gleiche Zeile der rechten Spalte gesetzt; der Sinn dieses Spaltensprungs ist unklar, zumal in den Freiräumen nichts ergänzt wurde. Eine kodikologische Grenze innerhalb der Anthologie wird durch das finit

$400 »[($ Westliche?) Schweiz, IX. Jh., 1. Viertel und IX. Jh., l.(/2.) Viertel] «: Bischoff: Katalog, 3. Nr. 7577. Die anderen Textzeugen sind westfränkisch.

401 »St. Gallen, VIII./IX. Jh.«: Bischoff: Katalog, 2. Nr. 2222. Elias A. LowE (Hrsg.), Codices Latini antiquiores X, Austria, Belgium, Czechoslovakia, Denmark, Egypt, and Holland, Melle 2011. Nr. 1585. Karel Adriaan de Meyier, Codices Vossiani Latini, Leiden. S. 157-165. Strecker (Hrsg.): MGH Poet. lat. 4, 2.3. S. 449. Hessels: Glossary. S. IX-LVIII. Karl STRECKer, "Zu den Karolingischen Rhythmen«, in: Neues Archiv der Gesellschaft für ältere deutsche Geschichtskunde 34 (1909), S. 599-652.

402 Bergmann/Stricker: Katalog. Nr. 372. Nievergelt: "St. Galler Glossenhandschriften«. S. 1483-1485. Hessels: Glossary.

403 Siehe Meyier S. 163f. für Detailangaben der Exzerpte.

404 Sämtlich zweispaltig, $20 \times 13 \mathrm{~cm}$.

405 Meyier, S. 159. StreCKer: »Karolingische Rhythmen«. S. 601.

406 Darin 26rv und 34ra-36ra, vgl. etwa die markante ri-Ligatur. Hessels (S. XIX f.) Unterscheidung des Wechsels zwischen zwei Hauptschreibern des Glossars lässt sich häufig nicht nachvollziehen lässt, es wären zum Beispiel nach ihm 20r und 35v von der gleichen Hand, während 34ra, Z. 27 ein Handwechsel stattfindet. 
markiert, mit dem 17v schließt; ${ }^{407}$ es folgt $17 \mathrm{r}$ ein einspaltiges Gedicht und darauf ab $17 \mathrm{v}-19 \mathrm{v}$ die thematisch abgesonderte Sylloge. Eine Tabelle soll die Übersicht über die Dichtung erleichtern: ${ }^{408}$

\begin{tabular}{|c|c|c|}
\hline f. & Inc. & Anmerkungen \\
\hline $\begin{array}{l}7 \mathrm{va}- \\
\mathrm{vb}\end{array}$ & $\begin{array}{l}\text { Lingua Propheta- } \\
\text { rum cecinit }\end{array}$ & $\begin{array}{l}\text { SK } 8941,{ }^{409} \text { (Ps. Ven. Fort.), vss. 1-44. Textliche Überein- } \\
\text { stimmungen }{ }^{410} \text { mit den späteren St. Galler Handschriften } \\
\text { Cod. Sang. 196, p. } 248 \text { ff. folgend auf Ven. Fort. Carmen VIII, } \\
3 \text { und Cod. Sang. 573, p. 276ff. als Zusatz von gleicher Hand } \\
\text { zur Martinsvita. Dort vollständig, daher keine Übernahme } \\
\text { aus Voss. Lat. Q. 69. Ein Vers enthalten in Cod. Sang. 870, } \\
\text { siehe unten S. 107. }\end{array}$ \\
\hline $\begin{array}{l}7 \mathrm{vb}- \\
8 \mathrm{va}\end{array}$ & $\begin{array}{l}\text { Arve poli condito- } \\
\text { re }\end{array}$ & $\begin{array}{l}\text { SK } 1098,{ }^{411} \text { Rhythmus/Abecedarius (R/A) über die Zerstö- } \\
\text { rung Jerusalems, Codex Unicus. }\end{array}$ \\
\hline $\begin{array}{l}8 \mathrm{va}- \\
9 \mathrm{rb}\end{array}$ & Asia ab oriente & $\begin{array}{l}\text { SK } 1106,{ }^{412} \text { R/A, Kosmographie, Strophen } 1-19,21-30,32, \\
\text { abweichend davon in der Winithar-Handschrift Cod. Sang. } \\
\text { 2, p. } 553 \mathrm{ff} .\end{array}$ \\
\hline $\begin{array}{l}\text { 9rb- } \\
\text { 9va }\end{array}$ & $\begin{array}{l}\text { Ante secula } \\
\text { mundi }\end{array}$ & $\begin{array}{l}\text { SK } 878,{ }^{413} \text { (Theodofrid von Corbie?), R/A über die Weltalter, } \\
\text { auch in Cod. Sang. 2, p. } 563 \mathrm{ff} .\end{array}$ \\
\hline $\begin{array}{l}9 \mathrm{vb}- \\
10 \mathrm{rb}\end{array}$ & $\begin{array}{l}\text { A superna caeli } \\
\text { parte }\end{array}$ & SK $37,{ }^{414} \mathrm{R} / \mathrm{A}$ unvollständig bis L. \\
\hline $\begin{array}{l}10 \mathrm{rb}- \\
10 \mathrm{va}\end{array}$ & $\begin{array}{l}\text { Angelus venit de } \\
\text { celo }\end{array}$ & $\begin{array}{l}\text { SK } 794,{ }^{415} \text { R/A. Ein früher Rhythmus, vll. ebenfalls mit } \\
\text { Theodofrid verbunden. }{ }^{416} \text { Darin Korrektur von späterer } \\
\text { Hand. }\end{array}$ \\
\hline $\begin{array}{l}10 \mathrm{vb}- \\
11 \mathrm{ra}\end{array}$ & $\begin{array}{l}\text { Gratuletur omnis } \\
\text { caro }\end{array}$ & SK 5702, ${ }^{417}$ Rhythmus, nur Strophen $1-5,7,8,10,11$. \\
\hline $\begin{array}{l}11 \mathrm{ra}- \\
11 \mathrm{vb}\end{array}$ & Audite omnes & SK $1352,{ }^{418}$ R/A über die Höllenfahrt Christi. \\
\hline
\end{tabular}

407 Ebenso auf das Glossar folgend 36r: Sicut inueni scripsi. ne reputes scriptori.

$408 \mathrm{Zu}$ den Hymnen siehe unten S. 112 zu Neapel Ms. IV G 68 und passim bei Schaller: »St. Galler Handschrift«.

409 Leo (Hrsg.): Venanti Honori opera poetica. S. 371-372. Handschrift nicht benutzt.

410 STRECKER: »Karolingische Rhythmen«. S. 605.

411 Strecker (Hrsg.): MGH Poet. lat. 4, 2.3. S. 542-545. Sigle L; siehe auch S. 449 für eine Aufzeichnung der Rhythmen. STRECKER: »Karolingische Rhythmen«. S. 618-625.

412 Strecker (Hrsg.): MGH Poet. lat. 4, 2.3. S. 545. Glorie (Hrsg.): Itineraria et alia geographica. S. 441-450. PeRTZ: »Über eine fränkische Kosmographie des siebenten Jahrhunderts«. Karl STRECKer, Der rhythmus De Asia et de universi mundi rota (Beilage zum Jahresberichte des Kgl. Luisen-Gymnasiums zu Berlin), Berlin 1909.

413 Strecker (Hrsg.): MGH Poet. lat. 4, 2.3. S. 559-564. DüMmLER: »Gedicht über die sechs Weltalter«.

414 Strecker (Hrsg.): MGH Poet. lat. 4, 2.3. S. 477-480.

415 Ebd. S. 564-565.

416 STRECKeR: »Karolingische Rhythmen«. S. 637.

417 DÜMmLer (Hrsg.): MGH Poet. lat. 2. S. 252-253.

418 Strecker (Hrsg.): MGH Poet. lat. 4, 2.3. S. 565-569. 
(Fortsetzung)

\begin{tabular}{|c|c|c|}
\hline f. & Inc. & Anmerkungen \\
\hline $\begin{array}{l}11 \mathrm{vb}- \\
12 \mathrm{rb}\end{array}$ & $\begin{array}{l}\text { Alma vera ac } \\
\text { praeclara }\end{array}$ & SK $598,{ }^{419}$ R/A, über Caritas und Avaritia. \\
\hline $\begin{array}{l}12 \mathrm{rb}- \\
12 \mathrm{va}\end{array}$ & $\begin{array}{l}\text { Angelus domini } \\
\text { maria }\end{array}$ & SK $785,{ }^{420}$ R/A, Advent. \\
\hline $\begin{array}{l}12 \mathrm{va}- \\
13 \mathrm{rb}\end{array}$ & $\begin{array}{l}\text { Ad perennis fon- } \\
\text { tem vitae }\end{array}$ & SK $195,{ }^{421} \mathrm{R} / \mathrm{A}$. De bono sacerdote. \\
\hline $\begin{array}{l}13 \mathrm{rb}- \\
13 \mathrm{va}\end{array}$ & $\begin{array}{l}\text { Aquarum meis } \\
\text { quis }\end{array}$ & $\begin{array}{l}\text { SK } 955,{ }^{422} \text { R/A. De malo sacerdote. Nur Strophen 1-11. Mit } \\
\text { dem vorhergehenden Pendant vollständig enthalten in Cod. } \\
\text { Sang. 573, pp. } 467-474 \text {. }\end{array}$ \\
\hline $\begin{array}{l}13 \mathrm{va} \\
-\mathrm{b}\end{array}$ & $\begin{array}{l}\text { Homo quidam } \\
\text { erat dives }\end{array}$ & SK $7182,{ }^{423}$ Rhythmus. Über Lazarus. \\
\hline $\begin{array}{l}13 \mathrm{vb}- \\
17 \mathrm{vb}\end{array}$ & - & $\begin{array}{l}\text { Prudentius, Hymnen, siehe Meyier für genaue Angaben. Je } \\
\text { nur Anfang und Ende, 17rb metrische Notiz als Nachtrag. }\end{array}$ \\
\hline $18 \mathrm{r}$ & $\begin{array}{l}\text { Iam dudum sau- } \\
\text { lus }\end{array}$ & $\begin{array}{l}\text { SK 7486, Damasus auf St. Paulus, einspaltig auf neuem } \\
\text { Blatt. }\end{array}$ \\
\hline $\begin{array}{l}18 \mathrm{v}- \\
19 \mathrm{va}\end{array}$ & - & $\begin{array}{l}\text { Epigramme und Inschriften. }{ }^{424} \text { "Anthologia Isidoriana» } \\
\text { und Sylloge hauptsächlich römischer Inschriften, nicht alle } \\
\text { metrisch. Letzte Inschrift von der Pfalzkapelle in Aachen. }{ }^{42}\end{array}$ \\
\hline $19 \mathrm{va}$ & Rex deus immensi & Gebet, Eugenius von Toledo. ${ }^{426}$ \\
\hline $\begin{array}{l}19 v a \\
-b\end{array}$ & - & $\begin{array}{l}\text { O quam dolenda condicio - nos materna tabernacula, } \\
\text { paränetisches Exzerpt, siehe Meyier. }\end{array}$ \\
\hline
\end{tabular}

Da die Gedichte, die Voss. Lat. Q. 69 mit anderen oben angegebenen St. Galler Handschriften teilt, entweder hier in verkürzter Form oder dort in ganz anderem Zusammenhang stehen, ist Voss. Lat. Q. 69 als Vorlage dieser ausgeschlossen und kann auch selbst als die älteste Handschrift nicht aus diesen abgeschrieben worden sein. Zumindest für Asia ab oriente ist auch eine Übernahme aus derselben Vorlage ausgeschlossen. ${ }^{427}$ Angesichts dieser isolierten Überlieferung ist der Hypothese Streckers von einer großen St. Galler Rhythmensammlung, aus der alle St. Galler Textzeugen geschöpft hätten, ${ }^{428}$ skeptisch gegenüberzustehen,

419 DÜMmLer (Hrsg.): MGH Poet. lat. 2. S. 255-257.

420 Strecker (Hrsg.): MGH Poet. lat. 4, 2.3. S. 474-477.

421 Dümmler (Hrsg.): MGH Poet. lat. 1. S. 79-81.

422 Ebd. S. 81-82.

423 Strecker (Hrsg.): MGH Poet. lat. 4, 2.3. S. 573.

424 DE Rossi: ICUR. S. 250-254, 257-258, 271, 274-276.

425 DÜMmLeR (Hrsg.): MGH Poet. lat. 1. S. 813, iii.

426 Friedrich Vollmer (Hrsg.), Eugenii Toletani episcopi carmina et epistulae (MGH AA 14), Berlin 1905. S. 232-233.

427 Stemma: Strecker (Hrsg.): MGH Poet. lat. 4, 2.3. S. 547.

428 STRECKER: »Karolingische Rhythmen«. S. 626f. 
zumal sein Kronzeuge (B), Brüssel, Bibliothèque royale de Belgique, MS. 88608867, die umfangreichste Rhythmenhandschrift, Ende des 9. Jh. in St. Bertin entstand und erst im 10. Jh. nach St. Gallen gelangte. ${ }^{429}$ Die Sammlung, aus der Voss. Lat. Q. 69 geschöpft hat, ist somit unbekannt. Die Vorlage, die, wie es scheint, bis zum finit 17v des gekürzten Prudentius gereicht hat, könnte durch diese Kombination von Rhythmik und Metrik ein Kompendium zur Dichtkunst dargestellt haben; zumindest wird der Gebrauch als solches durch die einzelne metrische Notiz auf $17 \mathrm{rb}$ wahrscheinlicher gemacht. ${ }^{430}$ Die weiteren Bestandteile der Anthologie, sowie der weiteren Handschrift, die durch den Hauptschreiber - vielleicht den Besitzer? - zusammengebunden werden, unterstreichen diesen Zweck: Inschriften als metrische Vorbilder und Muster eigener Produktionen finden sich nicht selten im Verbund mit anderer Dichtung und Grammatik. ${ }^{431}$ Die hier vorliegende Sylloge ist jedoch keinesfalls ein Reisejournal nach eigener Anschauung - vielmehr wird hier aus drei älteren Syllogen geschöpft, ${ }^{432}$ auch wenn der hier vorliegende Text, wie die gleichmäßige Abschrift vermuten lässt, als ganzes übernommen und an die Anthologie angehängt wurde. Das Leidener Glossar bildet das Lektürespektrum einer zeitgenössischen Klosterbibliothek ab: die Bücher der Bibel, Ordensregel und Kirchenväter und überraschend stark vertreten die Kirchengeschichte mit Eusebius und Orosius. Unter den Quellen der Lemmata befinden sich jedoch keine Dichter bis auf vereinzelte Spuren von Aldhelm und Vergil. ${ }^{433}$ Auch die Excerpta Varia des Schlussteils, offensichtlich en bloc übernommen, zeigen kein Interesse an Dichtung. Der Kompilator der Handschrift fügte also, nicht aus Einzelstücken, sondern aus vorliegenden Textblöcken, ein Kompendium zur Dichtung und weiteren klösterlichen Lektüre zusammen. Wenn durch den gekürzten Prudentius eine Verbindung zur Schule gegeben ist und dieser zusammen mit den Rhythmen übernommen wurde, legt dies die Existenz nicht nur von Schuldichtern, sondern von eigentlichem rhythmischen Lehrmaterial in St. Gallen am Ende des 8. Jh. nahe. Die frühe Etablierung der rhythmischen Dichtung könnte zum späteren Erblühen dieser Gattung in St. Gallen beigetragen haben.

429 Bischoff: Katalog, 1. Nr. 726. Vgl. auch die westfränkische und italienische Herkunft der anderen Hauptzeugen $V_{1}, V_{2}$ und $P$.

430 Dieser Meinung ist auch: DE Rossi: ICUR. S. 250.

431 Florian HARTMANN, »Karolingische Gelehrte als Dichter und der Wissenstransfer am Beispiel der Epigraphik«, in: Karolingische Klöster. Wissenstransfer und kulturelle Innovation, hrsg. von Julia Becker, Tino Licht und Stefan Weinfurter, Berlin [u. a.] 2015, S. 255-274. S. 265.

432 De Rossi: ICUR. S. 271.

433 Hessels: Glossary. Index B. 
Mit Abt Gozbert tritt St. Gallen in sein »Goldenes Zeitalter« ein, ${ }^{434}$ und wird unter einer beinahe ununterbrochenen Reihe von tatkräftigen und kultivierten Äbten zu einem der bedeutendsten Klöster des Reiches. Leider ist die Fülle der Handschriften, die in diesem Zeitraum entstand, in einem seltenen embarras de richesses noch nicht mit Sicherheit datiert worden, ${ }^{435}$ sodass jeder Zuweisung an einzelne Abbatiate, wie sie in der älteren Literatur häufiger zu finden sind, ${ }^{436} \mathrm{mit}$ Vorsicht zu begegnen ist. Darum sollen hier zunächst die Äbte, ihre Verbindung zur Dichtung und ihre Verdienste um die Bibliothek dargestellt werden, worauf nach Behandlung des Bibliothekskatalogs und des Schulwesens näher auf die Handschriften des »Goldenen Zeitalters« eingegangen wird.

Gozbert (816-837) löste die Abtei aus der Abhängigkeit vom Bistum Konstan $z^{437}$ und übersah eine rege Schreibtätigkeit von Urkunden und Büchern zugleich. Von der maxima penuria librorum, ${ }^{438}$ die $\mathrm{zu}$ Beginn seines Abbatiates beklagt wurde, wird bald nichts mehr zu fühlen gewesen sein. Unter ihm schreibt auch der fleißige Wolfcoz, von dessen Hand sich jedoch keine Handschriften mit Dichtung erhalten haben. ${ }^{439}$ Die St. Galler Hausliteratur dagegen war noch derart unausgebildet, dass man die Vita St. Galli auf der Reichenau von Wetti schreiben $^{440}$ und am Ende von Gozberts Amtszeit dort erneut von Walahfrid redigieren ließ, ${ }^{441}$ der anlässlich dieser Gelegenheit seinen Ymnus de S. Gallo hinzufügte.

434 Johannes DuFT, "Geschichte des Klosters St. Gallen im Überblick vom 7. bis zum 12. Jahrhundert«, in: Das Kloster St. Gallen im Mittelalter: die kulturelle Blüte vom 8. bis zum 12. Jahrhundert, hrsg. von Peter Ochsenbein, Darmstadt 1999, S. 11-30. S. 17. Johannes DuF T, »Große Äbte, blühende Abtei. Die Äbte Gozbert, Grimalt, Hartmut, Salomo«, in: Die Abtei St. Gallen, 2. Beiträge zur Kenntnis ihrer Persönlichkeiten, Sigmaringen 1991, S. 61-72. DufT/Gössi/Vogler: »St. Gallen«. S. 1194f., 1272-1279.

435 Die alten Zuweisungen nach Bruckner bei: SCARPATETTI: „Schreiber-Zuweisungen«. S. 51. Leider sind nur wenige der hier behandelten Handschriften bisher in der Neukatalogisierung der St. Galler Bestände erfasst worden: Beat Matthias von Scarpatetti, Die Handschriften der Stiftsbibliothek St. Gallen. 1. Abt. IV: Codices 547-669; Hagiographica, Historica, Geographica; 8. - 18. Jahrhundert, Wiesbaden 2003; Beat Matthias von SCARPATETTI und Philipp Lenz, Die Handschriften der Stiftsbibliothek St. Gallen, 2: Abt. III/2, Codices 450-546, Wiesbaden 2008. Philipp Lenz und Stefania Ortelli, Die Handschriften der Stiftsbibliothek St. Gallen, 3: Abt. V: Codices 670-749, Wiesbaden 2014.

436 BERSCHIN: "Sankt-gallische Schriftkultur «. S. 69.

437 Alfons Zettrer, »St. Gallen als Bischofs- und Königskloster«, in: Alemannisches Jahrbuch 2001/2002, S. 23-38. S. 33-38. Duf T: »Geschichte des Klosters St. Gallen«. S. 17.

438 "Ekkehard von St. Gallen, Casus s. Galli«, in: MGH SS 2, hrsg. von Ildefons von Arx 1829, S. 75-147. c. 16, zitiert nach: STEINER: »Buchproduktion und Bibliothekszuwachs«. S. 161. Nach BRUCKNER sind um die 70 Handschriften in Gozberts Zeit geschrieben worden (Ebd. S. 167, vgl. aber Scarpatetti a.a.O).

439 Ein Schreibervers in Cod. Sang. 20, p. 327. Zu Wolfcoz: Scarpatetti: »Schreiber-Zuweisungen«. S. 38-45. MAAG: Alemannische Minuskel. S. 80-96.

440 Walter Berschin, »Lateinische Literatur aus St. Gallen«, in: Das Kloster St. Gallen im Mittelalter: die kulturelle Blüte vom 8. bis zum 12. Jahrhundert, hrsg. von Peter Ochsenbein, Darmstadt 1999, S. 109-117. S. 111. 
Obwohl dem Kloster von Ludwig dem Deutschen unter Missachtung des Privilegs der freien Abtswahl aufgedrängt, lernten die Mönche schnell ihren neuen Abt Grimald von Weißenburg (841-872) ${ }^{442}$ und seine weitgespannten Beziehungen zu schätzen, zumal die tägliche Verwaltung des Klosters während der häufigen Abwesenheit des Abtes in Händen des beliebten Hartmut, des späteren Abtes, lag. Grimald, ausgebildet an der Hofschule und auf der Reichenau ist auf vielfältige Weise mit der Dichtung seiner Zeit verbunden, zuvorderst durch seine enge Verbindung zu seinem Reichenauer Schüler Walahfrid, der ihm drei seiner Werke widmete. ${ }^{443}$ Im Kloster Weißenburg, dem Grimald ebenfalls vorstand, redigierte Walahfrid den Weißenburger Horaz. ${ }^{44}$ Die Vita S. Galli Metrica, ${ }^{445}$ nur aus einer spätmittelalterlichen Handschrift überliefert, ging wahrscheinlich aus Grimalds und Gozberts ${ }^{446}$ Bemühung um die St. Galler Hausliteratur hervor, zu der er zuerst auswärtiges Talent gewonnen werden sollte - Walahfrid oder Ermenrich von Ellwangen - um zuletzt das Werk einem weniger begabten, unbekannten Dichter zu übertragen. ${ }^{447}$ Ermenrich von Ellwangen widmet ihm seinen mit zahlreichen poetischen Zitaten durchsetzten Lehrbrief, ${ }^{448}$ der in einer von Grimald veranlassten Abschrift überliefert worden ist. ${ }^{449}$ Unter Grimald wird uns erstmals die Schule mit einigen Namen sicher greifbar, auch ein Bibliothekar namens Uto wird um 860 zum ersten Mal genannt. ${ }^{450}$ In der Ergänzungsliste zum Hauptkatalog, wo die unter Grimald »mit Hartmuts Mit-

441 Walter Berschin, »Die Anfänge der literarischen Kultur«, in: St. Gallen - Geschichte einer literarischen Kultur. Kloster - Stadt - Kanton - Region. 1: Darstellung, hrsg. von Werner Wunderlich und Rupert Kalkofen, St. Gallen 1999, S. 111-123. S. 115.

$442 \mathrm{Zu}$ Grimald speziell: Josef Fleckenstein, Die Hofkapelle der deutschen Könige, 1. Grundlegung: die karolingische Hofkapelle (MGH Schriften 16), Stuttgart 1959. S. 168-177. Bernhard Bischoff, "Bücher am Hofe Ludwigs des Deutschen und die Privatbibliothek des Kanzlers Grimalt«, in: Bischoff, Mittelalterliche Studien, 3, 1981, S. 187-212. Duf T/Gössı/ VogLer: "St. Gallen«. 2, S. 1275-1277. Dieter GeUenich, »Beobachtungen zu Grimald von St. Gallen, Erzkaplan und Oberkanzler Ludwigs des Deutschen«, in: FS Johanne Autenrieth 1988, S. 55-68. Grupp: »Codex Sangallensis 397«. Sowie an seiner Stelle in den schon zitierten Übersichtswerken.

443 Visio Wettini, Hortulus, De Imagine Tetrici.

444 Vatikan, BAV, Reg. Lat. 1703, siehe S. 185-188 zu Weißenburg.

445 Dümmler (Hrsg.): MGH Poet. lat. 2. S. 428-473. Kirsch: Laudes sanctorum. S. 748-763.

446 Der Neffe des Abtes, Kirsch: Laudes sanctorum. S. 750.

447 BERSCHIN: Biographie und Epochenstil im lateinischen Mittelalter, 3. S. 283-285. BERsCHIN: "Die Anfänge der literarischen Kultur«. S. 119. KIRscH: Laudes sanctorum. S. 750.

448 »Ermenrici Elwangensis epistola ad Grimaldum abbatem«, in: MGH Epist. 5, hrsg. von Ernst DÜMmLER 1899, S. 534-580. Gerhard SCHмITZ, "Ermenrich von Ellwangen oder Vom Nachteil und Nutzen von Re-Editionen«, in: Deutsches Archiv für Erforschung des Mittelalters 66 (2010), S. 479-511. S. 481-484.

449 Cod. Sang. 265, Bischоғғ: »Bücher am Hofe und Privatbibliothek«. S. 200.

450 Peter Ochsenbein, »Die St. Galler Klosterschule«, in: Das Kloster St. Gallen im Mittelalter: die kulturelle Blüte vom 8. bis zum 12. Jahrhundert, hrsg. von Peter Ochsenbein, Darmstadt 1999, S. 95-107. S. 95. BERsCHIN: Eremus und Insula. S. 17. 
hilfe - cum adiutorio Hartmoti « erworbenen Bücher verzeichnet werden, ${ }^{451}$ findet sich keine Dichtung bis auf ein vereinzeltes Librum ymnorum optimum. Dagegen zeigt sich Grimalds persönliches Interesse daran im Katalog seiner Privatbibliothek, die nach seinem Tod an das Kloster ging und dort in einem separaten Bestand, vielleicht als Sonderbibliothek der Äbte, verblieb. ${ }^{452}$ Unter den wertvollen Bänden, von denen einige an höchststehende Personen verschenkt oder verliehen wurden, ${ }^{453}$ befanden sich auch: Prospers Epigramme in einem Band mit Ambrosius und kirchenrechtlichen Texten, ${ }^{454}$ Boethius' Consolatio und als letztes im Katalog ein Volumen Virgilii poetae. ${ }^{455}$ Ein Vergil findet sich sonst nur noch unter den - damals veralteten ${ }^{456}$ - Libris scottice scripti des Hauptkatalogs und sonst weder in der metrischen noch der grammatischen Abteilung. Der Kommentar des Servius, von einer späteren Hand im Hauptkatalog ergänzt, findet sich in Cod. Sang. 861/862, angeschafft vielleicht als Companion zu Grimalds Vergil. ${ }^{47}$

Da Grimalds Sammlung, wie die Entleihungen und die erhaltenen Handschriften beweisen, zahlreiche kostbare Handschriften enthielt, halte ich es nicht für unwahrscheinlich, in dem prächtigen spätantiken Vergilfragment in Cod. Sang. 1394, pp. 7-49 (Schedae Sangallenses), ${ }^{458}$ worin alle Werke des Dichters in einem Band enthalten waren, einen Überrest von Grimalds Vergil zu vermuten. Hinter einem Medicinalis liber I in quaternionibus könnte sich das antike Lehrgedicht des Quintus Serenus verbergen, das Reginbert auf der Reichenau - wo Grimald als Lehrer wirkte - von einem Colduin geschenkt bekommen hatte. ${ }^{459}$ Als ausgeschlossen dagegen kann die Identifikation der Astroligiam in I sceda mit dem Liber Astrologiae et compotus Rabani (...) des Hauptkatalogs

451 Lehmann (Hrsg.): $M B K$. 1, S. 85-86. Eine Übersicht über den Zusammenhang der verschiedenen St. Galler Kataloge bei: STEINER: »Buchproduktion und Bibliothekszuwachs«. S. 183.

452 LehmanN (Hrsg.): MBK. 1, S. 87-89. Zur »separaten Bibliothek in der Abtsresidenz«: STEINER: »Buchproduktion und Bibliothekszuwachs«. S. 182.

453 Lehmann (Hrsg.): MBK. 1, S. 88, Z. 35-39, S. 89, Z. 1-3.

454 Vielleicht zu identifizieren mit Cod. Sang. 187 aus Lorsch, siehe S. $249 f$.

455 Bruchstücke eines zeitgenössischen, aber nicht aus St. Gallen stammenden Vergil sind zu finden in der Fragmentenmappe Cod. Sang. 1394, pp. 109-112, als der Grimald-Kodex vermutet von SCHERRER: Stiftsbibliothek. S. 459, und zustimmend BISCHOFF: »Bücher am Hofe und Privatbibliothek«. S. 197, sowie Bergmann/Stricker: Katalog. Nr. 255 (II).

456 Siehe unten S. 98f. zum irischen Einfluss.

457 So Brauer: Bücherei und Schrifttum. S. 58f., der die Schreibernamen Werinbert und Uto mit denselben Persönlichkeiten aus Grimalds Zeit indentifiziert. Dagegen jedoch: ScHerRER: Stiftsbibliothek. S. 119. Die ganze Handschrift scheint jedoch späteren Datums zu sein: BischOFF: Katalog, 3. Nr. 5854.

458 »saec. V«: LowE (Hrsg.): Codices Latini antiquiores VII, Switzerland. Nr. 977.

459 Siehe zur Reichenau, S. 176, Reginbert-Liste, Nr. XXXI. 
gelten, ${ }^{460}$ da letztere Handschrift sich in dem umfangreichen und prachtvollen Cod. Sang. 902 erhalten hat. Es kann jedoch sein, dass eine kurze Version des Aratus, auch eine metrische, sich in Grimalds scheda befunden hat. Nicht in seiner Sammlung befindlich - oder zumindest nicht verzeichnet - sind die ihm gewidmeten Dichtungen. ${ }^{461}$ Trotzdem kann die Handschrift von Ermenrichs von Ellwangen Lehrbrief, Cod. Sang. 265, Grimald oder doch einem Kreis mit ihm assoziierter Schreiber zugeordnet werden, wobei es sich wohl um eine Abschrift des Widmungsexemplars handelt. ${ }^{462}$ Darin sind der Epistula als Hauptteil von anderer Hand aber gleicher Liniierung Gedichte Bedas hinzugefügt (pp. 98124); ${ }^{463}$ die darin befindliche Vita Cuthberti wurde jedoch nicht für den zweiten St. Galler Textzeugen herangezogen. ${ }^{464}$ Im Allgemeinen stammen jedoch die Handschriften Grimalds nicht aus St. Gallen und werden erst durch seine Erbschaft Teil der Klosterbibliothek.

So auch das sogenannte Vademecum Grimalds, Cod. Sang. 397, ${ }^{465}$ dessen bunter Inhalt von einer Schar von Schreibern, darunter auch zahlreichen aus St. Gallen, zusammengetragen wurde. Es enthält zu einem großen Teil chronologische und naturwissenschaftliche Materialien, um in seinen späteren Teilen in metrische und schulische Materien überzugehen. Die Handschrift besteht aus zwei Teilen: Drei unmarkierten Lagen zu Beginn (I-III), einer markierten Lage G und fünf markierten Lagen A-F, wobei anhand der Reklamanten naheliegt, dass die ursprüngliche Reihenfolge (I-III) $+(\mathrm{A}-\mathrm{F})+\mathrm{G}$ war und die Handschrift später zerfiel und falsch neu gebunden wurde. ${ }^{466} \mathrm{Ob}$ (I-III) ursprünglich vor oder hinter (A-F)+G stand oder vielleicht ganz unabhängig war, ${ }^{467}$ ist unklar. Bischoffs Kronzeuge für die Zuweisung an Grimald ist die Notiz in Cod. Sang. 899, p. 131: De lib[ro] Grim[oldi] tuli, die neben einem aus Cod. Sang. 397 entnommenen unikalen Rezept steht. Zwei weitere Stellen von gleicher Hand, die sich ebenfalls

460 Lehmann (Hrsg.): MBK. 1, S. 80, Z. 22, S. 89, 24. Identifiziert bei Brauer: Bücherei und Schrifttum. S. 59. Kritisch dagegen: BischоғF: »Bücher am Hofe und Privatbibliothek«. S. 194.

461 Bischoғf: »Bücher am Hofe und Privatbibliothek«. S. 193, Anm. 34.

462 Ebd. S. 200.

463 SCHERRER: Stiftsbibliothek. S. 100.

464 Werner JAager (Hrsg.), Bedas metrische Vita sancti Cuthberti, Leipzig 1935. S. 26, Siglen G, $\mathrm{G}_{1}$ (Cod. Sang. 263); S. 35.

465 Bischoff: Katalog, 3. Nr. 5741. Bischoff: „Bücher am Hofe und Privatbibliothek«. S. 201210. Grupp: »Codex Sangallensis 397«. SCherrer: Stiftsbibliothek. S. 135f.; BergmanN/ STRICKER: Katalog. Nr. 228. Die besten Inhaltsangaben sind: GRUPP: „Codex Sangallensis 397«. S. 453-463. SteinmeYer/SIevers (Hrsg.): Die althochdeutschen Glossen. 4, S. 450-452.

466 Zur Lagenfolge: BischоғF: »Bücher am Hofe und Privatbibliothek«. S. 202. Die Neubindung ist impliziert.

467 So Grupp, siehe unten S. 90. 
dort finden, sind mit $\mathrm{G}$ markiert. ${ }^{468}$ Ferner gleichen einige Hände (der Lagen IIII) solchen, die an anderen mit Grimald assoziierten Handschriften beteiligt waren. ${ }^{469}$ Auf dieser paläographischen Basis stehen verschiedene plausible inhaltliche Bezüge zu Grimalds Tätigkeit am Hofe. ${ }^{470}$ Gegen Bischoffs weitgehend akzeptiertes ${ }^{471}$ Urteil von der Handschrift als Grimalds Vademecum wandte sich als einziger Grupp mit folgenden Argumenten. Ausgangspunkt seiner Widerlegung oder doch Relativierung ist, dass die Handschrift ursprünglich aus zwei getrennten Teilen bestanden habe: (I-III) $+\mathrm{G}$ einerseits (»St. Galler Teil«), (A-F) andererseits (»Aachener/Regensburger Teil «). ${ }^{472}$ Die Teile seien auch thematisch und paläographisch getrennt: (A-F) hauptsächlich Computus und verwandte Themen, über lange Strecken einheitlich aus Vorlagen kopiert, (I-III)+G dagegen voll Miszellaneen und Dichtung und Stück für Stück zusammengetragen. ${ }^{473}$ Was aber mit dem Verweis De lib[ro] Grim [oldi] tuli? Diesen habe der Schreiber, ohne selbst weitere Informationen zu haben, aus dem Epitaph Grimalds auf p. 52 erschlossen, das damals auf der letzten Seite der separaten Handschrift (I-III)+G gewesen sei. ${ }^{474}$ Als Vademecum Grimalds sei also wenn überhaupt nur dieser Teil anzusprechen, während der hintere Teil ein weitgehend komputistisches Kanzleiexemplar vom Hofe darstelle. ${ }^{475}$ Die beiden Teile wurden aber noch im 9. Jh. zusammengebunden, wie Grupp bemerkt, da zeitgenössische Handschriften, die aus Cod. Sang. 397 schöpfen, dies aus beiden Teilen tun. ${ }^{476}$

Die Handschrift muss jedoch als Ganzes aus kodikologischen Gründen in Grimalds Hände zurückgelegt werden. Grupps Trennung der Teile in (I-III)+G und (A-F) überzeugt nicht, denn die zeitgenössischen Reklamanten stellen die Lage $\mathrm{G}$ (von gleicher Liniierung und Format) eindeutig hinter (A-F), mit denen sie auch thematisch durch die schon in $\mathrm{F}$ stattfindende Wendung von nur komputistischem Material zu vermischten Exzerpten verwandt ist. Wenn der Schreiber also überhaupt erst aus dem Epitaph Grimalds auf p. 52 auf den Vorbesitzer kam, dann meinte er mit dem libro Grimoldi wenigstens (A-F)+G. Derselbe Schreiber entnahm jedoch auch Stücke aus (I-III) - nota bene ist dies der Teil, in dem Schreiber weiterer Grimald-Handschriften tätig waren - darunter die mit G gekennzeichneten Stücke, sodass ihm beide Teile gleichzeitig vorgelegen haben müssen. Im selben Zeitraum entnehmen auch andere Schrei-

468 Eine Auswahl übernommener Stellen bei: Grupp: „Codex Sangallensis 397«. S. 436, Anm. 33, 36, 37. Eine Übersicht zu den Übernahmen auch unter der Tabelle zu Cod. Sang. 397.

469 Bischоғғ: «B̈̈cher am Hofe und Privatbibliothek«. S. $203 \mathrm{f}$.

470 Ebd. S. 205-209. Dagegen: Grupp: »Codex Sangallensis 397«. S. 438-451.

471 GRUPP: „Codex Sangallensis 397«. S. 426, Anm. 4.

472 Ebd. S. 427 f. und 438 (p. 52 als letzte Seite des St. Galler Teils), abschwächend jedoch S. 430.

473 Ebd. S. $428-430$.

474 Ebd. S. 437.

475 Ebd. S. 446, 451 f.

476 Ebd. S. 431, 433. 
ber in Zürich, ZB, C 78 aus beiden Teilen Exzerpte, ${ }^{477}$ sodass diese spätestens um 900 vereinigt gewesen sein müssen. Die Übernahmen sind in folgender Tabelle ohne Anspruch auf Vollständigkeit dargestellt: ${ }^{478}$

\begin{tabular}{|c|c|c|c|c|c|c|}
\hline $\begin{array}{l}\text { Cod. Sang. 397, } \\
\text { Lage }\end{array}$ & $\begin{array}{l}397 \\
\text { p. }\end{array}$ & $\begin{array}{l}\text { Cod. Sang. } \\
899 \\
\text { Dichtung, p. }\end{array}$ & $\begin{array}{l}397 \\
\text { p. }\end{array}$ & $\begin{array}{l}\text { Cod. Sang. } \\
899 \\
\text { Andere } \\
\text { Genres, p. }\end{array}$ & $\begin{array}{l}397 \\
\text { p. }\end{array}$ & $\begin{array}{l}\text { Zürich, } \\
\text { C } 78 \\
\text { p. }\end{array}$ \\
\hline I-III & 28 & $114(\mathrm{G})$ & $\begin{array}{l}22 \\
23 \\
29-30\end{array}$ & $\begin{array}{l}131 \\
\text { (De lib } \\
\text { Grim tuli) } \\
46(G) \\
104-106\end{array}$ & 21 & $79 \mathrm{r}$ \\
\hline G & $\begin{array}{l}33 \\
38 \\
39\end{array}$ & $\begin{array}{l}21 \\
48 \\
48\end{array}$ & $\begin{array}{l}38 \\
38-39 \\
39 \\
42 \\
45-47\end{array}$ & $\begin{array}{l}59 \\
48 \\
66-67 \\
64 \\
60-64\end{array}$ & & \\
\hline A-F & 147 & 65 & $141-144$ & $68-75$ & $\begin{array}{l}83 \\
85 \\
147 \\
147\end{array}$ & $\begin{array}{l}116 \mathrm{v}-117 \mathrm{v} \\
117 \mathrm{v}-118 \mathrm{r} \\
118 \mathrm{v} \\
188 \mathrm{r}\end{array}$ \\
\hline
\end{tabular}

Die einfachste Lösung ist hier, dass eine einzige vollständige Handschrift (I-III) $+(\mathrm{A}-\mathrm{F})+\mathrm{G}$ vorlag, aus der für diese zwei Handschriften und andere ${ }^{479}$ Material entnommen wurde. Dass diese, wie Grupp zu Recht betont, aus zwei Teilen besteht, schließt keineswegs aus, dass ihre Vereinigung schon von Grimald selbst veranlasst wurde. Doch woher wusste der Schreiber, dass er aus Grimalds Buch kopierte? Ich glaube nicht, wie Grupp meint, ${ }^{480}$ aus dem Epitaph, das sich zwar auf der damals letzten Seite der Handschrift befand, aber dort zwischen weiteren Tituli nur dem genauen Blick sichtbar ist. Vielmehr scheinen die Tituli nach Grimalds Tod dort ergänzt worden zu sein, gerade weil sie seine Handschrift war und dies dem Schreiber bewusst war. ${ }^{481}$ Grimalds Besitz der Handschrift scheint anderswo in einer Notiz festgehalten worden zu sein, die uns nicht erhalten ist. Es

477 Oder aus einer vermittelnden Vorlage, siehe unten S. 146f. zur Handschrift.

478 Der »Grimoldi«-Schreiber ist fett markiert.

479 Weitere umfangreiche Auszüge finden sich in der späteren Handschrift Clm 19413 (siehe unten S. 283-290 zu Salomo, sowie zu ÖNB Cod. 1609, Freising), die wahrscheinlich auf das Handbuch Salomos III. von Konstanz zurückgeht, der kurz nach Grimalds Tod die St. Galler Schule unter Notker Balbulus besuchte und von 890-919 auch Abt St. Gallens war. Die Exzerpte stammen ebenfalls aus beiden Teilen von Cod. Sang. 397 (pp. 38, 40-42, 85, 120, 121, 144).

480 GRUpP: „Codex Sangallensis 397«. S. 437.

481 So findet sich zum Beispiel auch Hrabans Epitaph am Ende der Sammlung seiner Gedichte (Brouwer (Hrsg.): Hrabani Poemata. S. 90. Siehe S. 65 und S. 214 bei Murbach und Fulda). 
ist nicht ungewöhnlich, dass der Stifter oder Vorbesitzer einer Handschrift im Katalog verzeichnet wurde, so auf der Reichenau in einer eigenen Kategorie mit zahlreichen Namen. ${ }^{482}$ Grimald selbst wird von Reginbert als Schenker einer Handschrift in seinem Katalog vermerkt. ${ }^{483}$ Und gerade in dem Katalog von Grimalds Privatbibliothek befinden sich zu Beginn vier Vermerke über von ihm weggegebene Bücher. Eine vergleichbare Notiz auf dem Band selbst oder in einem verlorenen Katalog ist also nicht unwahrscheinlich. Hinzu kommt, dass die Exzerpte in anderen Handschriften alle in die letzten Jahrzehnte des 9. Jh. fallen, dass also Grimalds Buch durchaus noch lebendige Erinnerung an den berühmten Abt gewesen sein könnte - was auch verständlich macht, warum gleich dreimal umfangreiche Auszüge erstellt wurden, deren Ursprung aus verschiedenen Teilen der Vorlage ein Studium derselben voraussetzt.

Das folgende Verzeichnis der in Cod. Sang. 397 enthaltenen Dichtung stützt sich auf Grupps Inhaltsangabe und ergänzt bibliographische und paläographische Details sowie Zusammenhänge mit anderen Handschriften. ${ }^{484}$

\begin{tabular}{|c|c|c|c|}
\hline \multicolumn{4}{|c|}{$\begin{array}{c}21,2 \times 16,4 \mathrm{~cm} \text {, ein- und zweispaltig. } \\
(\mathrm{IV}-2)^{1-12}(\mathrm{I})+\mathrm{II}^{13-20}(\mathrm{II})+\mathrm{IV}^{21-36}(\mathrm{III})+\mathrm{IV}^{37-52}(\mathrm{G})+ \\
\mathrm{IV}^{53-68}(\mathrm{~A})+\mathrm{IV}^{69-84}(\mathrm{~B})+\mathrm{IV}^{85-100}(\mathrm{C})+\mathrm{IV}^{101-116}(\mathrm{D})+\mathrm{IV}^{117-132}(\mathrm{E})+\mathrm{IV}^{133-148}(\mathrm{~F})\end{array}$} \\
\hline Lage & p. & Inc. & Anmerkungen \\
\hline \multirow[t]{3}{*}{$\mathrm{IV}^{21-36}$} & 21 & $\begin{array}{l}\text { Prima dies } \\
\text { Phoebi }\end{array}$ & $\begin{array}{l}\text { SK } 12491 .^{485} \text { Kalendergedicht. Auf neuer Lage, die } \\
\text { einzelnen Notizen im folgenden von verschiedenen } \\
\text { Händen. } \\
\text { Zürich, C } 68 \text {, f. } 79 \text { r, Nachtrag }\end{array}$ \\
\hline & 28 & $\begin{array}{l}\text { Hoc iacet in } \\
\text { tumulo }\end{array}$ & $\begin{array}{l}\text { SK } 6988^{486} \text { Epitaph Hildegards, der Tochter Ludwigs } \\
\text { des Dt. Epitaph vll. von gleicher Hand wie Memorial- } \\
\text { notiz darüber, jedoch kleineres Schriftbild. } \\
\text { Cod. Sang. } 899 \text {, p. } 114 \text {, daneben Notiz G. }\end{array}$ \\
\hline & 33 & $\begin{array}{l}\text { Condidit hoc } \\
\text { sanctum }\end{array}$ & $\begin{array}{l}\text { SK } 2536{ }^{487} " \text { Gründungsinschrift der Züricher Frau- } \\
\text { münsterkirche« (Grupp). Von anderer Hand als die } \\
\text { zusammen geschriebenen pp. } 29-33 \text { ergänzt. p. } 34 \text { leer. } \\
\text { Cod. Sang. 899, p. } 21 \text {, Schreiber wie p. 114, ohne Notiz } \\
\text { auf Herkunft. }\end{array}$ \\
\hline $\begin{array}{l}\mathrm{IV}^{37-52} \\
(\mathrm{G})\end{array}$ & 38 & Abiecta in triviis & $\begin{array}{l}\text { SK } 59 .{ }^{488} \text { Ausonius, Epigramm LXVIII über Leichen- } \\
\text { schändung und ihre verdiente Strafe. Zuvor unter der }\end{array}$ \\
\hline
\end{tabular}

482 Lehmann (Hrsg.): MBK. 1, Nr. 52. S. $255 \mathrm{f}$.

483 Nr. XX.

484 GRupP: »Codex Sangallensis 397«. S. 453-463.

485 Baehrens (Hrsg.): Poetae latini minores. V, S. 353f., Riese/BüCheler (Hrsg.): Anthologia latina. Nr. 488.

486 Paul von Winterfeld (Hrsg.), MGH Poet. lat. 4, 1, Berlin 1899. S. 335.

487 WinTERFELD. S. 335.

488 Karl Schenke (Hrsg.), Ausonii Opuscula (MGH Auct. Ant. 5, 2), Berlin 1883. S. 214.

489 Siehe S. 134, Cod. Sang. 899 zu pp. 59-66. 
(Fortsetzung)

\begin{tabular}{|c|c|c|c|}
\hline \multicolumn{4}{|c|}{$\begin{array}{c}21,2 \times 16,4 \mathrm{~cm} \text {, ein- und zweispaltig. } \\
(\mathrm{IV}-2)^{1-12}(\mathrm{I})+\mathrm{II}^{13-20}(\mathrm{II})+\mathrm{IV}^{21-36}(\mathrm{III})+\mathrm{IV}^{37-52}(\mathrm{G})+ \\
\mathrm{IV}^{53-68}(\mathrm{~A})+\mathrm{IV}^{69-84}(\mathrm{~B})+\mathrm{IV}^{85-100}(\mathrm{C})+\mathrm{IV}^{101-116}(\mathrm{D})+\mathrm{IV}^{117-132}(\mathrm{E})+\mathrm{IV}^{133-148}(\mathrm{~F})\end{array}$} \\
\hline \multirow[t]{6}{*}{ Lage } & p. & Inc. & Anmerkungen \\
\hline & & & $\begin{array}{l}\text { sinnlosen Überschrift Categorie } e^{489} \text { das Glossar Xen- } \\
\text { odochium id est. }{ }^{490} \text { Mit den folgenden zwei Versen alles } \\
\text { von einer Hand. } \\
\text { Cod. Sang. } 899 \text {, p. } 48 \text {, sicher aus Cod. Sang. 397, vgl. } \\
\text { vss. 3: Achilles, 5: non minus. }\end{array}$ \\
\hline & 39 & $\begin{array}{l}\text { Turpe pecus } \\
\text { mutinum }\end{array}$ & $\begin{array}{l}\text { Ovid, Ars. Am. } 3,249-250 . \\
\text { Cod. Sang. } 899 \text {, p. } 48 \text {, ebenfalls zwei Verse, darüber } \\
\text { jedoch wie in einem Zug geschrieben zwei Verse Inc. } \\
\text { Spicula curvato. }\end{array}$ \\
\hline & 43 & $\begin{array}{l}\text { Ver erat et } \\
\text { blando }\end{array}$ & $\begin{array}{l}\text { SK } 17074 .^{491} \text { Ps.-Ausonius. Von anderer Hand als das } \\
\text { Vorhergehende und Folgende. }\end{array}$ \\
\hline & 44 & $\begin{array}{l}\text { Quae fueram } \\
\text { quondam }\end{array}$ & $\begin{array}{l}\text { SK } 12841{ }^{492} \text { Über eine wunderliche Anekdote vom } \\
\text { kaiserlichen Hof, vgl. Walahfrid, Carmina V, xxxvii. }{ }^{493} \\
\text { Verfasser vll. Grimald selbst? }{ }^{494} \text { Ebenfalls isolierte } \\
\text { Hand. }\end{array}$ \\
\hline & 52 & $\begin{array}{l}\text { Splendida mar- } \\
\text { moreis ornata } \\
\text { et. al. }\end{array}$ & $\begin{array}{l}\text { »Versus Sangallenses «: }{ }^{495} \text { Von Strecker in abweichender } \\
\text { Reihenfolge ediert. Reihenfolge in der Handschrift: } \\
\text { Tituli (V): I; III, i, ii, v; II; III, iii (1-4), iv, iii (5-6). St. } \\
\text { Galler Bauinschriften (darunter (III, v) Grimalds Epi- } \\
\text { taph). Lagenende, alle Tituli von einer Hand. }\end{array}$ \\
\hline \multirow[t]{2}{*}{$\begin{array}{l}\text { IV }^{53-68} \\
\text { (A) }\end{array}$} & 67 & $\begin{array}{l}\text { Primus romanas } \\
\text { ordiris }\end{array}$ & $\begin{array}{l}\text { SK } 12559 .{ }^{496} \text { Versus de singulis mensibus. Merkgedicht } \\
\text { zu Monaten und Sternzeichen. } \\
\text { Ebenfalls in anderen St. Galler Computus-Handschrif- } \\
\text { ten, Cod. Sang. } 459,248 \text {. Schaffhausen, Staatsarchiv, } \\
\text { Fragment } 1,1 \mathrm{r} \text { (St. Gallen?). }\end{array}$ \\
\hline & 67 & Dira patet Iani & $\begin{array}{l}\text { SK } 3727 .{ }^{497} \text { Item versus de numero dierum singulorum } \\
\text { mensium. Kalendergedicht. } \\
\text { Ebenfalls in Cod. Sang. } 250 \text {, p. } 67 \text { (Computus; siehe }\end{array}$ \\
\hline
\end{tabular}

490 Bernice Martha KaCZynski, »Some St. Gall Glosses on Greek Philanthropic Nomenclature», in: Speculum 58 (1983), S. 1008-1017. In Cod. Sang. 899, p. 59, über Categorie tatsächlich eine Aufzählung der Kategorien.

491 R. P. H. Green (Hrsg.), The works of Ausonius, Oxford 1991. S. 669-671. SchenkL (Hrsg.): Ausonii Opuscula. S. 243-245. Riese/BüCheler (Hrsg.): Anthologia latina. Nr. 646.

492 Strecker (Hrsg.): MGH Poet. lat. 4, 2.3. S. 1113.

493 DüMmler (Hrsg.): MGH Poet. lat. 2. S. 382.

494 BischоғF: »Bücher am Hofe und Privatbibliothek«. S. 206.

495 STRECKer (Hrsg.): MGH Poet. lat. 4, 2.3. S. $1108 \mathrm{f}$.

496 SChenkl (Hrsg.): Ausonii Opuscula. S. 10. RIESE/BüCheler (Hrsg.): Anthologia latina. Nr. 639.

497 Riese/BüCheler (Hrsg.): Anthologia latina. Nr. 394. 
(Fortsetzung)

\begin{tabular}{|c|c|c|c|}
\hline \multicolumn{4}{|c|}{$\begin{array}{c}\text { 21,2 x 16,4 cm, ein- und zweispaltig. } \\
(\mathrm{IV}-2)^{1-12}(\mathrm{I})+\mathrm{II}^{13-20}(\mathrm{II})+\mathrm{IV}^{21-36}(\mathrm{III})+\mathrm{IV}^{37-52}(\mathrm{G})+ \\
\mathrm{IV}^{53-68}(\mathrm{~A})+\mathrm{IV}^{69-84}(\mathrm{~B})+\mathrm{IV}^{85-100}(\mathrm{C})+\mathrm{IV}^{101-116}(\mathrm{D})+\mathrm{IV}^{117-132}(\mathrm{E})+\mathrm{IV}^{133-148}(\mathrm{~F})\end{array}$} \\
\hline Lage & p. & Inc. & Anmerkungen \\
\hline & & & $\begin{array}{l}\text { unten S. } 239 \text { und bei Prüm zu Reg. lat. 438, S. 260). } \\
\text { Schaffhausen, Fragment 1, 1r. }\end{array}$ \\
\hline & 67 & $\begin{array}{l}\text { Hic iam mensis } \\
\text { sacer }\end{array}$ & $\begin{array}{l}\text { SK } 6489 .{ }^{498} \text { Tetrasticon autenticum. Kalenderverse nach } \\
\text { Lorscher Prototyp. }{ }^{499} \text { Die Kalenderverse in gleicher } \\
\text { Tinte wie die Memorialeinträge im vorhergehenden } \\
\text { Kalender. } \\
\text { Schaffhausen, Fragment } 1,1 \mathrm{v} \text {. }\end{array}$ \\
\hline & 68 & $\begin{array}{l}\text { Primus adest } \\
\text { aries }\end{array}$ & $\begin{array}{l}\text { SK } 12524 .^{500} \text { Versus de duodecim signis. Zum Tierkreis. } \\
\text { Schaffhausen, Fragment } 1,2 \mathrm{r} \text {. }\end{array}$ \\
\hline \multirow[t]{2}{*}{$\begin{array}{l}\mathrm{IV}^{69-84} \\
\text { (B) }\end{array}$} & 69 & Respicis apriles & $\begin{array}{l}\text { SK } 12589{ }^{501} \text { Item versus de signis XII mensium. Kalen- } \\
\text { dergedicht. Verse versetzt: } 4-12,1-3 \text {. Großzügig dop- } \\
\text { pelzeilige Ausführung in Majuskeln mit Lombarden zu } \\
\text { Zeilenbeginn. } \\
\text { Schaffhausen, Fragment } 1,3 v \text {. Ebenfalls in Cod. Sang. } \\
\text { 250, p. } 219 \text {. }\end{array}$ \\
\hline & 83 & $\begin{array}{l}\text { Conveniunt } \\
\text { subito }\end{array}$ & $\begin{array}{l}\text { SK } 2750{ }^{502} \text { Conflictus veris et hiemis. In neuer Hand, } \\
\text { jedoch auf neue Lage übergreifend. In Zürich C 78, f. } \\
116 \mathrm{v}-117 \mathrm{v} .\end{array}$ \\
\hline $\begin{array}{l}\mathrm{IV}^{85-} \\
100 \\
(\mathrm{C})\end{array}$ & 85 & $\begin{array}{l}\text { Gallia me } \\
\text { genitum } \\
\text { et. al. }\end{array}$ & $\begin{array}{l}\text { Isidor: Versus in bibliothecam IV-VII (SK 5469, 702, } \\
\text { 9582, 6806). }{ }^{503} \text { Ohne Trennung unmittelbar auf den } \\
\text { vorhergehenden Text folgend, beide offensichtlich aus } \\
\text { einer Vorlage. Die Titel (Ambrosius etc.) nachträglich, } \\
\text { aber zeitgenössisch am Rand ergänzt. Von hier ent- } \\
\text { nommen in Zürich, C 78, f. } 117 \mathrm{v}-118 \mathrm{r} \text {. }\end{array}$ \\
\hline \multirow[t]{2}{*}{$\begin{array}{l}\mathrm{IV}^{117-} \\
132 \\
(\mathrm{E})\end{array}$} & 119 & $\begin{array}{l}\text { Hoc quicumque } \\
\text { volit carmen } \\
\text { et. al. }\end{array}$ & $\begin{array}{l}\text { SK 7075, 8175, 2732. }{ }^{504} \text { Ps.-Cato Disticha, Praef. ad. l. III, } \\
\text { vss.1-2 + III, } 1+\text { II, } 6+\text { I, } 10 \text {. Aus verschiedenen } \\
\text { Disticha zusammengesetzt. Andere Hand als das Vor- } \\
\text { hergehende. }\end{array}$ \\
\hline & 120 & $\begin{array}{l}\text { Crede ratem } \\
\text { ventis }\end{array}$ & $\begin{array}{l}\text { Disticha Catonis. }{ }^{505} \text { Aus verschiedenen Disticha zusam- } \\
\text { mengesetzt (siehe Boas). Selbe Hand wie p. } 119 .\end{array}$ \\
\hline
\end{tabular}

498 Ebd. Nr. 395.

499 Arno Borst, Die karolingische Kalenderreform (MGH Schriften 46), Hannover 1998. S. 254298. Zitiert nach GRUPP: „Codex Sangallensis 397«. S. 443.

500 Riese/BüCHeler (Hrsg.): Anthologia latina. Nr. 615.

501 SCHENKL (Hrsg.): Ausonii Opuscula. S. 67.

502 DüMmLER (Hrsg.): MGH Poet. lat. 1. S. 270-272.

503 Charles Henry BEESON, Isidor-Studien (Quellen und Untersuchungen zur lateinischen Philologie des Mittelalters 4, 2), München 1913. S. $159 \mathrm{f}$.

504 BoAs (Hrsg.): Disticha Catonis. S. 149, 154, 103, 42. Handschrift nicht benutzt.

505 M. BoAs, "Neue Catobruchstücke II«, in: Philologus 75 (1918), S. 156-177. BoAs (Hrsg.): Disticha Catonis. S. XXIX-XXXV. 
(Fortsetzung)

\begin{tabular}{|c|c|c|c|}
\hline \multicolumn{4}{|c|}{$\begin{array}{c}21,2 \times 16,4 \mathrm{~cm} \text {, ein- und zweispaltig. } \\
(\mathrm{IV}-2)^{1-12}(\mathrm{I})+\mathrm{II}^{13-20}(\mathrm{II})+\mathrm{IV}^{21-36}(\mathrm{III})+\mathrm{IV}^{37-52}(\mathrm{G})+ \\
\mathrm{IV}^{53-68}(\mathrm{~A})+\mathrm{IV}^{69-84}(\mathrm{~B})+\mathrm{IV}^{85-100}(\mathrm{C})+\mathrm{IV}^{101-116}(\mathrm{D})+\mathrm{IV}^{117-132}(\mathrm{E})+\mathrm{IV}^{133-148}(\mathrm{~F})\end{array}$} \\
\hline \multirow[t]{6}{*}{ Lage } & p. & Inc. & Anmerkungen \\
\hline & 121 & $\begin{array}{l}\text { Fontibus in } \\
\text { liquidis }\end{array}$ & $\begin{array}{l}\text { SK } 5267 . .^{506} \text { TVLLII. Aus Claudian stammend und in das } \\
\text { Symposium XII sapientum integriert. }{ }^{507} \\
\text { Cod. Sang. } 273 \text {, p. 9., dort jedoch Teil der vollständigen } \\
\text { Reihe und mit Titel IUL. }\end{array}$ \\
\hline & 121 & Vulturis in siluis & $\begin{array}{l}\text { ALII. Vulturis in siluis miserum mandebat homonem /o } \\
\text { quam crudeli mandabat membra sepulcro. Von gleicher } \\
\text { Hand folgend, mit Majuskel abgesetzt. Ennius, wohl } \\
\text { zitiert aus Priscian. }{ }^{508}\end{array}$ \\
\hline & 121 & Noli archana & SK 9714. ${ }^{509}$ Disticha Catonis, II, 2. \\
\hline & 121 & $\begin{array}{l}\text { Constantine } \\
\text { decus }\end{array}$ & $\begin{array}{l}\text { SK } 2660{ }^{510} \text { Porphirii ad Constantinum imperatorem } \\
\text { christianum. Pastiche aus verschiedenen Stücken: Por- } \\
\text { phyrius: XIX, V.2 (SK 2660) + II, V. } 1 \text { (SK 14642) + } \\
\text { Dulcia mella, zwei Verse (SK 3963) })^{511}+\text { Dulce sonat, } \\
\text { zwei Verse (SK 3953) }{ }^{512}+\text { Debuit ingrato, ein Vers (SK } \\
313)^{513}+\text { Odero, si potero, zwei Verse (SK 11162) } \\
\text { Cato-Stücke und dieses von einer Hand. }\end{array}$ \\
\hline & 123 & $\begin{array}{l}\text { Naturas rerum } \\
\text { varias }\end{array}$ & $\begin{array}{l}\text { SK } 10033 .^{515} \text { Versus Bedae Presbyteri. Aus De natura } \\
\text { rerum, als Einleitung zum folgenden Computus, von } \\
\text { gleicher Hand. }\end{array}$ \\
\hline \multirow[t]{2}{*}{$\begin{array}{l}\mathrm{IV}^{133-} \\
{ }_{148}(\mathrm{~F})\end{array}$} & 145 & $\begin{array}{l}\text { Quantum Virgi- } \\
\text { lius magno }\end{array}$ & $\begin{array}{l}\text { Ovidii Nasonis. Ps.-Ovid: Monosticha über die Aeneis } \\
1 .^{516} \text { Eine ganz ähnliche Accessus-Sammlung in Vati- } \\
\text { kan, BAV, Pal. lat. } 487, \text { f. } 42 \mathrm{r}-45 \mathrm{r} \text {. }\end{array}$ \\
\hline & 145 & $\begin{array}{l}\text { Primus habet } \\
\text { pelagiminas (!) }\end{array}$ & $\begin{array}{l}\text { SK } 12544 .{ }^{517} \text { Item eiusdem de XII libris Eneidorum. } \\
\text { Inhaltsübersicht zur Aeneis. }\end{array}$ \\
\hline
\end{tabular}

506 MGH AA 10, S. 292, XII.

507 Anne Friedrich, Das Symposium der "XII sapientes«: Kommentar und Verfasserfrage (Texte und Kommentare 22), Berlin [u.a.] 2002. S. 44.

508 Heinrich KeIl (Hrsg.), Grammatici Latini, Leipzig 1855. 2, S. 206 f.

509 BoAs (Hrsg.): Disticha Catonis. II, 2. Mit Ausfall des dort eingeklammerten 2. Verses. Sigle $\mathrm{M}^{\mathrm{t}}$.

510 Iohannes Polara (Hrsg.), Publilii Optatiani Porfyrii Carmina 1973.

511 Vgl. SK 3961, Claudian: Carm. min. 14: Dulcia dona mihi semper tu, Maxime, mittis / Et, quidquid mittis, mella putare decet. (Theodor BIRT (Hrsg.), Claudiani Carmina (MGH Auct. Ant. 10), Berlin 1892. S. 293).

512 Vgl. SK 619, Riese/Bücheler (Hrsg.): Anthologia latina. Nr. 83, V. 4.

513 Ebd. Nr. 83, V. 5.

514 Ovid, Amores 3.11b, V. 3-4.

515 Charles W. Jones (Hrsg.), Bedae Venerabilis opera (CCSL, 123 A-C), Turnhout. S. 189.

516 Riese/BüCHeler (Hrsg.): Anthologia latina. Nr. 1, praefatio.

517 Ebd. Nr. 672a. 
(Fortsetzung)

\begin{tabular}{|c|c|c|c|}
\hline \multicolumn{4}{|c|}{ 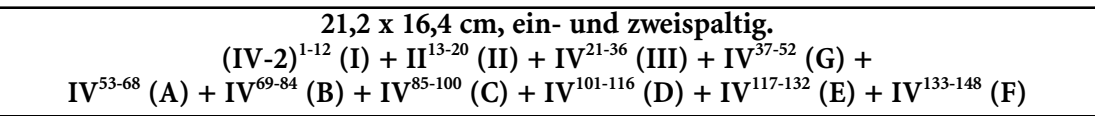 } \\
\hline Lage & p. & Inc. & Anmerkungen \\
\hline & 145 & $\begin{array}{l}\text { Aeneas primo } \\
\text { Lybicis }\end{array}$ & $\begin{array}{l}\text { Item eiusdem. Ps.-Ovid: Monosticha über die Aeneis } \\
2 .{ }^{518} \\
\text { Der gesamte Vergil-Accessus dieser Seite von einer } \\
\text { Hand. }\end{array}$ \\
\hline & 145 & Rure morans & $\begin{array}{l}\text { SK } 12442 .{ }^{519} \text { Vss. } 1-7 . \text { Am rechten Rand ergänzt von } \\
\text { anderer Hand eingetragen. }\end{array}$ \\
\hline & 147 & $\begin{array}{l}\text { Fonte lavat } \\
\text { genitor }\end{array}$ & $\begin{array}{l}\text { SK } 5264 .{ }^{520} \text { Verse auf Hyppolit. } \\
\text { Von hier entnommen in Zürich, C 78, 118v, ebenfalls a- } \\
\text { c. Auch in Cod. Sang. } 250 \text {, p. } 70 .\end{array}$ \\
\hline & 147 & Clio gesta canens & $\begin{array}{l}\text { SK } 2425{ }^{521} \text { Nomina Musarum et versus de Musis. Verse } \\
\text { auf die Musen, dazugehörig die links stehenden Nomi- } \\
\text { na Musarum. Die zwei Stücke dieser Seite von verschie- } \\
\text { denen Händen. } \\
\text { Von hier entnommen in Zürich, C } 78 \text {, f. } 118 \mathrm{r} \text { mit den } \\
\text { folgenden Divisiones musice artis, von gleicher Hand } \\
\text { wie die auch übernommenen Texte von pp. } 83-85 \text {. Cod. } \\
\text { Sang. } 899 \text {, p. 65, jedoch scheinbar in einem Zug } \\
\text { abgeschrieben mit umliegenden, nicht von hier stam- } \\
\text { menden Texten; die Divisiones musice artis hier p. } 108 \text {. }\end{array}$ \\
\hline \multicolumn{4}{|c|}{ Reg. lat. 421 (f. 21-25) } \\
\hline & $21 \mathrm{v}$ & Varia & $\begin{array}{l}\text { Tituli: }{ }^{523} \text { Inc. Te deus omnipotens; Haec est pulcra } \\
\text { domus; Splendida quadratis; In mensa beati agustini; } \\
\text { Quisquis amat dictis; Vivere post obitum. }\end{array}$ \\
\hline
\end{tabular}

Die Dichtung hier zerfällt nicht so deutlich in zwei Teile wie die Handschrift selbst. Sie schließt sich thematisch oft an umgebende Texte an, besonders deutlich im komputistischen Teil: Hier werden pp. 67-68 am Lagenende Kalenderverse ergänzt. Die in den nächsten zwei Lagen folgenden Gedichte (pp. 69-83, 83-85) sind dagegen Kerntexte und keine Ergänzungen, ebenso wie das Einleitungsgedicht zu Beda (p. 123). In den Lagen E und F lockert sich das Material thematisch auf, und man kann einem Schreiber auf pp. 119-121 beim Ergänzen

518 Ebd. Nr. 1, I-XII, je den ersten Vers.

519 Vollständig 9 Verse. Ebd. Nr. 26. v. 7; SHACKLeton Bailey (Hrsg.): Libri Salmasiani aliorumque carmina. Nr. 13, v. 7, unter dem apokryphen Titel Martialis De habitatione ruris.

520 RIESE/BüCHELER (Hrsg.): Anthologia latina. Nr. 688, 688 a-c.

521 Ebd. Nr. 664. SchenkL (Hrsg.): Ausonii Opuscula. S. 251.

522 Zur Handschrift gehörig nach Bischoff: Katalog, 3. Nr. 5741. Der ursprüngliche Ort in der intakten Handschrift ist unklar.

523 De Rossi: ICUR. S. 279. 
der einzelnen Stücke folgen. Eigentliches Schulmaterial ist nur der VergilAccessus auf p. 145. In G ist die Dichtung meist nur Ergänzung (p. 43f.). Die Dichtung in (I-III) schließt sich thematisch eng an A-G an: Kalenderdichtung und Memorialnotizen (pp. 28, 33). Trotz der großen Anzahl der enthaltenen Gedichte ist sie überall untergeordnet als Ergänzung oder poetische Variation von an sich unpoetischem Material. Dennoch fand die Dichtung in Cod. Sang. 397 großes Interesse in St. Gallen: Nicht weniger als vier Handschriften übernehmen zahlreiche Stücke zusammen mit kurzen Texten anderer Art. All diese Abschriften geschahen in den Jahrzehnten nach Grimalds Tod und es ist naheliegend, dass das Vademecum des Abtes ein gewisses Prestige besaß, das die von ihm gesammelten Texte auch späteren Sammlern interessant machte. Aus welchen Quellen der vielgereiste Grimald sein Vademecum sammelte, lässt sich nicht mehr nachvollziehen. In St. Gallen aber wurde es selbst zur Quelle einer klosterinternen Überlieferung.

Hartmut, der 872 die Leitung des Klosters übernahm und bis 883 wirkte, hatte schon vorher die Verwaltung an Grimalds Stelle seit 849 geführt und war somit unmittelbar für die Blüte St. Gallens verantwortlich, ${ }^{524}$ insbesondere für die des Skriptoriums. ${ }^{525}$ Seine Ausbildung erfuhr er bei Hrabanus in Fulda. Wie Grimald wurde auch ihm Dichtung gewidmet, er ist einer der Adressaten der Evangeliendichtung des Otfrid von Weißenburg. ${ }^{526}$ Hartmut war auch selbst als Schreiber tätig; einige seiner Handschriften versah er mit Verwünschungs- oder Widmungsversen im leoninischen Maß. ${ }^{527}$ Zwei Ergänzungslisten verzeichnen die Bücher, die Hartmut für das Kloster schreiben lassen oder in seiner Privatbibliothek gesammelt hatte. ${ }^{528}$ Unter den für die Klosterbibliothek erstellten Büchern findet sich, wie schon in der Liste der unter Grimald cum adiutorio Hartmoti angeschafften Bücher, keine Dichtung, dagegen viel Kirchenväter, Exegetik und Hagiographie. Im "Verzeichnis der Privatbibliothek «, ${ }^{529}$ die nicht im Hauptkatalog, sondern nur in einer literarischen Quelle erhalten ist, ${ }^{530}$ tritt diese nur untergeordnet auf: Ein Hymnar im Verband mit der Regula Benedicti und einem Martyrologium; je zweimal Boethius' Consolatio und Martianus

524 Duft/Gössi/Vogler: »St. Gallen«. S. 1193-1195, 1277-1279. Duft: Geschichte des Klosters St. Gallen«. S. 18f.

525 SCARPATETti: "Das St. Galler Scriptorium«. S. 33.

526 Wilhelm Wiget, »Zu den Widmungen Otfrids«, in: Beiträge zur Geschichte der deutschen Sprache und Literatur 49 (1925), S. 441-444.

527 Berschin: »Sankt-gallische Schriftkultur«. S. 73. MaAG: Alemannische Minuskel. S. $100 \mathrm{f}$.

528 Lehmann (Hrsg.): $M B K .1$, S. 85-89.

529 Ebd. S. 86.

530 Hannes SteIner (Hrsg.), Ratpert: St. Galler Klostergeschichten (MGH SS rer. Germ. 75), Hannover 2002. S. 56-66, Ed. 92-94. 
Capella; ${ }^{531}$ und wie bei Grimald ein Medicinalis liber unus, hinter dem sich Quintus Serenus verbergen könnte.

Hier auch ein Wort zu den Iren, die in St. Gallen Spuren hinterlassen haben und denen besonders in der älteren Literatur ein großer Einfluss auf die Entwicklung des Klosters zugeschrieben wird. ${ }^{532}$ Duft hat dagegen nachgewiesen, ${ }^{533}$ dass erst infolge der Normanneninvasionen ab der Mitte des Jahrhunderts, insbesondere unter Grimald und Hartmut, die Anwesenheit von Iren als gelehrte Flüchtlinge und Pilger zum Grab ihres Landsmannes nachweisbar wird.$^{534}$ Die Liste der Libri scottice scripti zu Beginn des Katalogs, ${ }^{535}$ stellen vielleicht von solchen Besuchern hinterlassene Bände dar, die wegen ihrer unleserlichen Schrift nicht zum Gebrauch in die Hauptbibliothek eingeordnet wurden. ${ }^{536}$ Unter diesen befinden sich zwei Bände von Juvencus und ein Sedulius, sowie ein Vergil, begleitet durch Bedas De Arte Metrica. Da die Bände wohl erst nach und nach eher zufällig zusammengetragen wurden, lässt sich keine Verbindung zwischen diesen Bänden herstellen. Trotzdem bemerkt Brauer, dass Bedas Metrik auf Juvencus und Sedulius aufbaut und die Bände einander im schulischen Gebrauch ergän-

531 Zwei Handschriften der Nuptiae, die in St. Gallen auch als Dichtung geschätzt wurden (siehe unten S. 110-114 zu Neapel Ms. IV G 68) stammen aus dem Umkreis St. Gallens: München, BSB, Clm 14729 und Brüssel, BR, Ms. 9565-9566 (beide »Bodenseegebiet, IX. Jh., 4. Viertel«: Bischoff: Katalog, 1. Nr. 731. Bischoff: Katalog, 2. Nr. 3252). Sie hängen textlich eng zusammen und eine Handschrift dieser Familie wurde von Notker für seine Übersetzung der Nuptiae genutzt (Jean G. PrÉAUx, »Un nouveau manuscrit de Saint-Gall: le >Bruxellensis 9565-9566«, in: Scriptorium 10 (1956), S. 221-228). Da von Martianus Capella vor Hartmut keine oder nur undeutliche Spuren in St. Gallen bestehen, scheint er das Studium dieses Prosimetrums durch seine zwei Handschriften entscheidend befördert zu haben.

532 Betreffs der Bibliothek zum Beispiel: Brauer: Bücherei und Schrifttum. S. 15.

533 Johannes DuFT, »Irische Einflüsse auf St. Gallen und Alemannien«, in: Mönchtum, Episkopat und Adel zur Gründungszeit des Klosters Reichenau, hrsg. von Arno Borst (Vorträge und Forschungen 20), Sigmaringen 1974, S. 9-35. Johannes Duf T, »Die Beziehungen zwischen Irland und St. Gallen im Rahmen der St. Gallischen Stiftsgeschichte«, in: Die irischen Miniaturen der Stiftsbibliothek St. Gallen, hrsg. von Johannes Duft und Peter Meyer, Olten 1953, S. 11-83. Überblick zur Debatte: Johannes DuFT, »Iromanie - Irophobie. Fragen um die frühmittelalterliche Irenmission exemplifiziert an St. Gallen und Alemannien", in: Zeitschrift für schweizerische Kirchengeschichte 50 (1956), S. 241-262. Michael J. ENRIGHT, "Iromanie-Irophobie revisited: a suggested frame of reference for considering continental reactions to Irish peregrini in the seventh and eighth centuries", in: Karl Martell in seiner Zeit, hrsg. von Jörg JARNUT (Beihefte der Francia 37), Sigmaringen 1994, S. 367-380.

534 Duft: "Große Äbte, blühende Abtei«. S. 67. Duft: "Beziehungen zwischen Irland und St. Gallen«. S. 34.

535 LehmanN (Hrsg.): MBK. 1, S. 71.

536 DuFt: "Irische Einflüsse«. S. 23-35. Johannes DuFt, "Irische Handschriften in der Stiftsbibliothek zu St. Gallen«, in: Du. Atlantis 30 (1970), S. 29-43. S. 30f. Darunter vielleicht auch Bücher der Lehrer Marcellus und Moengal? So: Ernst Tremp, Karl Schmuki und Johannes Huber, La Bibliothèque abbatiale de Saint-Gall: l'histoire, le lieu, les collections, St. Gallen 2004. S. 69. 
zen. ${ }^{537}$ Ebenso finden sich in zahlreichen Handschriften Verse irischen Ursprungs, ${ }^{538}$ die jedoch zu landläufig sind, als dass sie einen Iren zu ihrer Verbreitung nötig gehabt hätten, ausgenommen das Klagegedicht eines in St. Gallen weilenden Iren, der sich über die Behandlung seiner Landsleute beklagt. ${ }^{539}$

Unter Hartmut fand die Katalogisierung der St. Galler Bibliothek ihren Abschluss. Der Grundstock des Kataloges wurde schon unter Grimald angelegt und unter Hartmuts Verwaltung und Abbatiat ergänzt. ${ }^{540}$ Die Übersicht über die umfangreiche St. Galler Sammlung soll durch folgende Tabelle von darin enthaltener Dichtung erleichtert werden, wobei die schon behandelten Speziallisten ausgespart werden. ${ }^{541}$ Ebenfalls angegeben sind mit Dichtung verbundene Titel wie Metriken und Kommentare.

\begin{tabular}{|l|l|l|}
\hline Rubrik & $\begin{array}{l}\text { MBK, } \\
\text { S. }\end{array}$ & Titel \\
\hline De libris Prosperi Episcopi & 75 & $\begin{array}{l}\text { 1. Item eiusdem epigrammata in volumi- } \\
\text { nibus duobus, unum fuit Scotticum pu- } \\
\text { sillum. Require. } \text {. }^{42}\end{array}$ \\
\hline De libris Bedae Presbiteri & 75 & $\begin{array}{l}\text { 2. Miraculis Gudperti episcopi et Althelmi } \\
\text { de laude virginum liber I et note iuris } \\
\text { itemque versus alii, in volumine I. } .^{543}\end{array}$ \\
\hline $\begin{array}{l}\text { De virtutibus seu passionibus } \\
\text { sanctorum, apostolorum vel } \\
\text { martirum }\end{array}$ & 79 & $\begin{array}{l}\text { 3. Item liber ymnorum et penitentialis in } \\
\text { volumine uno parvo. }\end{array}$ \\
\hline
\end{tabular}

537 BRAuER: Bücherei und Schrifttum. S. 18.

538 Cod. Sang. 197, 250, 273, 899, an ihrer Stelle detailliert behandelt. Johannes Duft, »St. Columban in den St. Galler Handschriften «, in: Zeitschrift für schweizerische Kirchengeschichte 59 (1965), S. 285-296. S. 290.

539 SK 6756, Cod. Sang. 10, p. 3. Duf T: »Beziehungen zwischen Irland und St. Gallen«. S. $31 \mathrm{f}$.

540 SteIner (Hrsg.): Ratpert. S. 63. Schematischer Überblick: STEINER: »Buchproduktion und Bibliothekszuwachs«. S. 183. Eine Katalogisierung erst unter Hartmut beruht nur auf der Identifizierung eines einzelnen Eintrags (Metrum de vita sancti Galli in quaternionibus, volumen I) mit dem gleichnamigen Werk Notkers, so Walter BERSCHIN, "Alte und neue Handschriftenkataloge der Stiftsbibliothek St. Gallen«, in: Freiburger Diözesanarchiv 106 (1986), S. 5-8. S. 5, und wird von Steiner (Hrsg.): Ratpert. S.65, Anm. 208, abgelehnt.

541 Eigene Nummerierung. Interpunktion nach: LEHMANN (Hrsg.): MBK. 1, S. 71-82. Die unter einer Nummer versammelten Titel werden als ein Band begriffen. Die von zweiter Hand ergänzten Titel sind kursiv gesetzt.

542 Die Epigramme finden sich auch in Grimalds Bibliothek, sowie in der Abteilung De Metris. Das kleine verlorene irische Exemplar ist nicht unter die scottice scripti eingereiht worden. Warum wurde hier nach diesem gesucht (require), wenn wie DuFT meint, diese Bücher unleserlich waren?

543 Vielleicht Cod. Sang. 263 (JAAger (Hrsg.): Bedas metrische Vita sancti Cuthberti. S. 26), siehe unten S. 120f. Zu Aldhelm im Katalog siehe EHwald (Hrsg.): Aldhelmi Opera. S. 333. Folgende Katalognummern werden mit erhaltenen Handschriften in Verbindung gebracht: Nr. 2: Cod. Sang. 263; 11: Cod. Sang. 1394; 12: Zürich C 59; 13: Bremen, StUB Ms. b 52. 
(Fortsetzung)

\begin{tabular}{|c|c|c|}
\hline Rubrik & $\begin{array}{l}\text { MBK, } \\
\text { S. }\end{array}$ & Titel \\
\hline [Orthographia] $^{544}$ & 80 & 4. Item Bedae de arte metrica. ${ }^{545}$ \\
\hline De Metris $^{546}$ & 81 & \\
\hline $\begin{array}{ll}\text { 5. } & \text { Metrum Iuve } \\
\text { 6. } & \text { Metrum Aure } \\
\text { 7. } & \text { Metrum Arat } \\
\text { 8. } & \text { Metrum Alcir } \\
\text { 9. } & \text { Epigrammata } \\
\text { 10. } & \text { Metrum de vi } \\
\text { 11. } & \text { Althelmi de } n\end{array}$ & $\begin{array}{l}\text { Sedulii e } \\
\text { i VII in } \\
\text { stolorun } \\
\text { libri VI } \\
\text { ina III i } \\
\text { quatern } \\
\text { ibus ac }\end{array}$ & $\begin{array}{l}\text { piscopi volumina IIII. Require I. }{ }^{547} \\
\text { olumine I. }{ }^{548} \\
\text { l, volumina II. } \\
\text { I in volumine I. }{ }^{549} \\
\text { quaternionibus. }{ }^{550} \\
\text { ionibus, volumen }{ }^{551} \\
\text { edum regulis volumen }{ }^{552}\end{array}$ \\
\hline
\end{tabular}

544 ORTHO rubriziert, folgend jedoch hauptsächlich Passionen. Auch die zwei vorhergehenden Titel sind rubriziert, ohne Kategorien einzuleiten.

545 In Nähe der gleich folgenden Abteilung De Metris, vielleicht falsch eingeordnet.

546 Nach den Titeln 4-12. sind nicht poetische Werke ohne erkennbare Ordnung ergänzt (LeHMANN (Hrsg.): MBK. 1, S. 81, Z. 10-18). Zur Abteilung siehe auch BRAUER: Bücherei und Schrifttum. S. 46-48.

547 Nicht identisch mit Zürich, ZB Ms. C 68, siehe oben S. 80-82.

548 Vielleicht identisch mit Cod. Sang. 136 oder Berlin, SB Ms. Hamilton 542 (vll. auch Vatikan, BAV, Reg. lat. 339), die beide sieben Texte enthalten (Cathemerinon, Peristephanon, Dittochaeon, Apotheosis, Hamartigenia, Psychomachia, Contra Symmachum), siehe unten S. 116118. Kritsch zur Identifikation: SCHERRER: Stiftsbibliothek. S. 51. Nicht wahrscheinlich ist die Identifizierung mit der Reichenauer (?) Handschrift Bern, BB Ms. 264 (Richard STETTINER, Die illustrierten Prudentiushandschriften, Berlin 1895. S. 16, 22. Siehe S. 100f.).

549 Dieses von Hrabanus (und später Notker Balbulus) empfohlene Werk lag auch in Fulda, der Reichenau, Lorsch und Murbach vor (Zimpel (Hrsg.): De institutione clericorum. c. 3, 18. S. 532. Z. 8-10). Wohl identisch mit der Vorlage von Cod. Sang. 197, pp. 123-328 (siehe unten S. 121).

550 Nicht in der vorhandenen Prosper-Kategorie. Nicht identisch mit Cod. Sang. 187 (dieser Meinung Albertus G. A. Horsting (Hrsg.), Prosper Aquitanus, Liber epigrammatum (CSEL 100), Berlin [u.a.] 2016. S. 31), die aus Lorsch kommt, siehe dort (BISCHoff: Katalog, 3. Nr. 5646).

551 Wohl nicht Notkers Werk (STEINER (Hrsg.): Ratpert. S.65, Anm. 208), sondern die anonyme St. Galli Vita Metrica, DüMmLER (Hrsg.): MGH Poet. lat. 2. S. 428-473).

552 Die vollständige Epistula ad Acircium, auch zweimal auf der Reichenau vorhanden. EHWALD (Hrsg.): Aldhelmi Opera. S. 59-204.

553 Nicht von einer St. Galler Hand, aber von St. Galler Bibliotheksheimat ist Zürich, ZB, Ms. C 59 mit Aldhelms Carmen de virginitate, das auch im Text anderen Handschriften des Klosters aufs Engste verbunden ist (Sigle S, Cod. Sang. $242=S^{1}$, 263= $S^{2}$ : Ebd. S. 334-338. Zur Herkunft: »[Wohl Deutschland, IX. Jh., 1./2. Viertel] «: BischоғF: Katalog, 3. Nr. 7570; mit dem Eintrag identifiziert von MoHLberg: Katalog Zürich. S. 33, EHwald (Hrsg.): Aldhelmi Opera. S. 333. Wenn die Glossen auch in St. Gallen eingetragen wurden, besteht kein Grund mehr, diese Handschrift nicht hinter dem Eintrag zu vermuten (BERGMANN/STricKer: Katalog. Nr. 1002).

554 Welche nonnulla sanctorum opuscula gemeint sein könnten, bleibt unklar. Die Zusammenstellung insularer Werke scheint auf eine solche Vorlage zurückzugehen. Kaum identisch mit Bremen, StUB Ms. b 52, siehe unten S. 109, dieser Meinung: EHwald (Hrsg.): Aldhelmi Opera. S. 333. 
(Fortsetzung)

\begin{tabular}{|l|l|l|}
\hline Rubrik & $\begin{array}{l}\text { MBK, } \\
\text { S. }\end{array}$ & Titel \\
\hline 12. Item Althelmi de laude virginum volumen I. & .53 \\
13. Item Althelmi de enigmatibus et Bedae de metrica arte et metrum Simphosii et alia \\
nonnulla sanctorum opuscula in volumine I parvo. ${ }^{554}$
\end{tabular}

555 Zur Abteilung siehe auch Brauer: Bücherei und Schrifttum. S. 48-50.

556 Bedas Ars Metrica hier als Teil einer alle Gebiete umfassenden grammatischen Sammelhandschrift. Die beiden Titel von Honoratus Servius und Sergius (KeIL (Hrsg.): Grammatici Latini. 4, S. 475-485) finden sich in der selben Reihenfolge in Cod. Sang. 877, es folgen jedoch abweichende Texte, darunter auch Sedulius (siehe unten S. 104f.).

557 Cod. Sang. 877 enthält ebenfalls (pp. 111-115) aus einer anderen Handschrift eingebunden die Disticha Catonis.

558 Wahrscheinlich erhalten in Cod. Sang. 876 (Scherrer: Stiftsbibliothek. S. 305). Zur Handschrift auch Ernst Tremp, "L'école de l'abbaye de Saint-Gall au temps carolingien«, in: Les écoles monastiques au haut Moyen Âge (Les cahiers Columbaniens), Luxeuil-les-Bains 2014, S. 60-77. S. $73 \mathrm{f}$.

559 Der Eintrag ist nach den Ergänzungen zur Grammatikabteilung (21, Z. 10-14) wieder in der größeren Hand des Hauptschreibers.

560 Ähnlich auf der Reichenau Hauptkatalog Nr. 12 (S. 169) und VI. der Reginbert-Liste (S. 174), beide mit Glossen und nicht identifizierten versus. Im Reginbert-Band genauer als diversi versus et nonnullorum hymni sanctorum et aliquorum epitaphia sanctorum, was die auf die Hymnare folgende Einordnung erklären könnte.

561 Grimald und Hartmut besaßen Handbücher der Medizin und die Bibliothek verzeichnet im Nachtrag drei, wobei unklar ob die zwei Exemplare der Äbte hier mit eingereiht wurden. Der medizinische Sammelband Cod. Sang. 44 (pp. 185-368), der ebenfalls Quintus Serenus enthält (pp. 304-324) wird unter diesen Titeln begriffen worden sein. Dem hier enthaltenen Text fehlt die Einleitung, die sich in Zürich C 78 findet (Friedrich Vollmer (Hrsg.), Quinti Sereni liber medicinalis (Corpus medicorum latinorum 3), Leipzig 1916. S. V-XI.). Es ist diese Fassung mit Vorwort, die von Walahfrid für den Hortulus benutzt wurde.

562 Im Hauptkatalog findet sich kein Vergil, sondern nur unter den scottice scripti und in Grimalds Privatbibliothek. Die Gegenwart eines Kommentar legt jedoch die Existenz des hier nicht verzeichneten Werkes Vergils nahe. Vielleicht ist es mit dem Kommentar zusammen abhanden gekommen? Mögliche Handschriften für den Eintrag sind Cod. Sang. 861/862 und Glasgow, UB, Ms. U.6.8 (290). 
(Fortsetzung)

\begin{tabular}{|l|l|l|}
\hline Rubrik & $\begin{array}{l}\text { MBK, } \\
\text { S. }\end{array}$ & Titel \\
\hline 18. Partes Donati maiores et minores; grammatica Albini; Bedae de arte metrica et tropis \\
atque scematibus in codice uno. \\
19. Ymnorum volumen I. ${ }^{559}$ \\
20. Item in quaternionibus alius ymnarius. \\
21. Item diversoum ymnorum volumen vetus I. \\
22. Versus undecumque collecti et glosae in omnes libros divinae auctoritatis in scedula \\
una. \\
23. Libri medicinalis artis, volumina II et I parvus. Require I. ${ }^{561}$ \\
24. Expositio Servii in Virgilium, volumen I, perditum est. Require. ${ }^{562}$ \\
\hline
\end{tabular}

Die Dichtung ist, wie in Murbach, in ihre eigene Abteilung aus der Grammatik ausgegliedert worden, wo sie auf der Reichenau zum Beispiel noch steht. Es finden sich kaum Werke bei ihren Autoren (wie oft Aldhelm oder Beda), sondern fast alles wurde in Dichtung und Grammatik einsortiert. Die Auswahl der Texte ist verglichen etwa mit Lorsch oder Murbach und auch der Reichenau keineswegs bemerkenswert. In De Metris ist alles bis auf Nr. 7. und 9. herkömmliche Schulliteratur. Unterstrichen wird dies durch die große Anzahl von Exemplaren, die man von Bedas Metrik hatte (sieben im Hauptkatalog), der durch seine Einbindung in die grammatischen Sammelhandschriften Nr. 13-17 fest im Unterricht verankert wird. Ebenso Juvencus und Sedulius, die in Nr. 14. Teil einer solchen Handschrift sind, und deren große Zahl (vier Exemplare in Nr. 4.) durch dieses praktische Bedürfnis erklärt wird. Die Hymnare, die man in Lehmanns Ausgabe für Teil der grammatischen Abteilung halten könnte, ${ }^{563}$ sind in der Handschrift klar abgegrenzt und geben durch ihre große Zahl einen Vorgeschmack der Blüte dieser Gattung in St. Gallen. Auffällig ist zudem das gänzliche Fehlen klassischer Dichtung im Hauptkatalog, und auch die Separatlisten haben nur zweimal Vergil, ganz gemäß Notkers späterer Geringschätzung der heidnischen Dichter. ${ }^{564}$ Brauer nimmt deshalb an, dass eine dezidierte Schulbibliothek anderswo bestanden habe und deswegen hier nicht verzeichnet worden sei, ${ }^{565}$ worauf der zweimalige Verweis auf ad scholam zu verweisen erscheint. ${ }^{566}$ In $\mathrm{De}$ Metris und De libris grammaticae artis steht uns jedoch zweifellos die Schulbibliothek vor Augen, aus der Bücher ad scholam, dass heißt in die Unterrichtsräume, verliehen wurden. Das Verzeichnis im ohnehin späteren und nicht aus

563 Vgl. auch den Gebrauch von Hymnen als Unterrichtsmaterial in Karlsruhe, BLB, Aug. Perg. 112 (Reichenau) und vielleicht in Oxford, Bodl. Libr., MS Jun. 25 (Murbach).

564 Si uero etiam metra requisieris, non sunt tibi necessariae gentilium fabulae (...). Erwin RAUner, "Notkers des Stammlers `Notatio de illustribus uiris «, in: Mittellateinisches Jahrbuch 21 (1986), S. 34-69. S. 65, Z. 179.

565 Brauer: Bücherei und Schrifttum. S. 6, 71.

566 Lehmann (Hrsg.): MBK. 1, S. 72, Z. 5, S. 79, Z. 9. 
St. Gallen stammenden Cod. Sang. 831 (11. Jh.) kann kaum als St. Galler Schulbibliothek gelten. ${ }^{567}$

Die St. Galler Klosterschule ${ }^{568}$ blühte unter Grimald und Hartmut auf und wird Wirkungsstätte berühmter Lehrer wie Iso, Ratpert und Notker, ${ }^{569}$ und auch eines Iren Marcellus. ${ }^{570}$ Spuren von Dichtung in Verbindung zur Schule finden sich allenthalben: Ratpert widmet einem seiner Schüler ein Gedicht, Marcellus schreibt einen Kommentar zu Prudentius; ${ }^{571}$ In Cod. Sang. 64 findet sich ein Lehrgedicht zu den Kategorien des Aristoteles, vielleicht zur Memorierung. ${ }^{572}$ Das Bedürfnis der Schule nach Dichtung spricht sich deutlich in den zahlreichen

567 Brauer: Bücherei und Schrifttum. S. 64f. Lehmann (Hrsg.): MBK. 1, S. 100 f. Auf p. 182 finden sich dort in beeindruckender Dichte von einer Hand des 10. oder 11. Jh.: Vergil mit Kommentar, Persius mit Kommentar, Terenz, Sedulius, Boethius, Statius, Juvenal, Aratus, Avianus und Aldhelm. Die Handschrift, von elsässischem Schriftcharakter (Murbach? Bernhard BischоғF, Die südostdeutschen Schreibschulen und Bibliotheken in der Karolingerzeit, 2: Die vorwiegend österreichischen Diözesen, Wiesbaden 1980. S. 45f. Anm. 30) enthält auch Walahfrids Gedicht an Iskar von Murbach.

568 Tremp: „École de l'abbaye «. Pierre RichÉ, »Les écoles de Saint-Gall des origines au milieu du XIe siècle«, in: Le rayonnement spirituel et culturel de l'abbaye de Saint-Gall, hrsg. von Carole Heitz (Cahier. Centre de Recherches sur l'Antiquité Tardive et le Haut Moyen Âge 9), Paris 2000, S. 37-57. S. 138. Grotans: Reading in medieval St. Gall. RichÉ: »Les écoles de SaintGall des origines au milieu du XIe siècle«. Peter Ochsenbein, "Die Klosterschule als Fundament des literarischen Aufstiegs", in: St. Gallen. Geschichte einer literarischen Kultur, 1, hrsg. von Werner Wunderlich und Rupert Kalkofen, St. Gallen 1999, S. 125-140. OchSenbein: »Die St. Galler Klosterschule«. Christoph DetTe, "Schüler im frühen und hohen Mittelalter: die St. Galler Klosterschule des 9. und 10. Jahrhunderts", in: Studien und Mitteilungen zur Geschichte des Benediktinerordens und seiner Zweige 105 (1994), S. 7-64. Peter OchSEnBeIn, »The monastic school of St. Gall«, in: Sangallensia in Washington, hrsg. von James C. KInG, New York 1993, S. 263-275. Peter Ochsenbein, "L'enseignement et l'étude«, in: L'Abbaye de Saint-Gall: rayonnement spirituel et culturel, hrsg. von Werner Vogler, Lausanne 1991, S. 133-144. Peter OchSENBeIN, "Lehren und Lernen im Galluskloster«, in: Die Kultur der Abtei Sankt Gallen, hrsg. von Werner Voglen, Zürich 1990, S. 133-144. Glauche: Schullektüre. S. 56-61. Lambert Marie de RIJK, »On the curriculum of the arts of the trivium at St. Gall from c. 850-c. 1000«, in: Vivarium 1 (1963), S. 35-86. S. 83-89. Älter, jedoch reich an Material sind: CLARK: Abbey of St. Gall. Insb. S. 101-106. Gabriel MEIER, "Geschichte der Schule von St. Gallen im Mittelalter «, in: Jahrbuch für Schweizerische Geschichte 10 (1885), S. 33-128. H.A. NAGEL, Geschichte des Klosters St. Gallen und seiner Schulanstalten, Halle 1852.

569 Deтte: »Schüler im frühen und hohen Mittelalter«. S. 38-43.

570 Duf T: »Geschichte des Klosters St. Gallen«. S. 19. Duf T: „Beziehungen zwischen Irland und St. Gallen«. S. 35-39. Siehe die Liste der Lehrer aus Ekkehards Casus bei Tremp: »École de l'abbaye«. S. $68 \mathrm{f}$.

571 In Cod. Sang. 152, p. 277 (nicht p.77, so OchSEnbeIn:»Lehren und Lernen im Galluskloster«. S. 137).

572 pp. 408-409, SK 16570. Clark: Abbey of St. Gall. S. 118. Das Gedicht ist wohl kein St. Galler Produkt: SCHAller: »St. Galler Handschrift«. S. 284f. Siehe unten S. 110-114 zu Neapel, Ms. IV G 68 . 
erhaltenen Metrik-Lehren aus. ${ }^{573}$ Aus St. Gallen sind auch mehr als 100 althochdeutsch und ungezählte lateinisch glossierte Handschriften erhalten, ${ }^{574}$ die freilich kaum alle der Schule angehören. ${ }^{575}$ Die althochdeutsche Kleindichtung gehört in diesen paratextuellen Überlieferungszusammenhang, darunter die St. Galler Spottverse und der St. Galler Schreibervers. ${ }^{576}$ Unter den glossierten Texten finden sich Prudentius, Horaz und Vergil, ${ }^{577}$ wobei nur der Prudentius dem 9. Jh. angehört. ${ }^{578}$ Dem Schulbedarf werden in der älteren Literatur und auch in den neueren Darstellungen die Handschriften $\mathrm{zu}$ freigiebig zugerechnet, ${ }^{579}$ indem alles, was an Dichtung greifbar ist, ohne Weiteres zur Schullektüre erklärt wird. Dieses summarische Verfahren ist anhand der Handschriften zu verfeinern.

Als Schulhandschriften dürfen zuvorderst die gelten, die wie Nr. 14-23. des Hauptkatalogs Grammatik und Dichtung vereinen. Die Handschrift Cod. Sang. $877,{ }^{580}$ deren Herkunft aus St. Gallen schon von Bruckner angezweifelt wurde und von Scarpatetti ganz abgelehnt wird, ist nichtsdestotrotz durch Inhalte, Nutzungspuren $^{581}$ und allgemeine Herkunft (Bodenseegebiet) eng mit dem Kloster verbunden. Die Handschrift ist abwechselnd aus Lagen mehrerer Handschriften zusammengebunden worden. ${ }^{582}$ Sie enthält fast ausschließlich Texte, die sich auch in der Grammatik-Abteilung des Hauptkatalogs, insbesondere in Nr. 14-16,

573 Mallius Theodorus in Cod. Sang. 855, 876, 877 (Clark: Abbey of St. Gall. S. 101), sowie der schon erwähnte Beda.

574 Stefan Sonderegger, "Althochdeutsch in St. Gallen«, in: Das Kloster St. Gallen im Mittelalter: die kulturelle Blüte vom 8. bis zum 12. Jahrhundert, hrsg. von Peter Ochsenbein, Darmstadt 1999, S. 205-222. S. 212 f.

575 Z.B. Codd. Sang. 263 und 877 summarisch wegen der Glossen der Schule zugeordnet bei BRAUER: Bücherei und Schrifttum. S. $48 \mathrm{f}$.

576 Glauch: »St. Gallen«. S. 497, Anm. 20. Sonderegger: "Althochdeutsch in St. Gallen«. S. 214f. Sonderegger/VogLer: »Deutsche Sprache und Literatur in Sankt Gallen«. S. 171.

577 Glauch: »St. Gallen«. S. 499.

578 Der Horaz (Cod. Sang. 864) ist lothringisch und stammt aus dem 11. Jh.: Hartmut HofFMANN, "Italienische Handschriften in Deutschland«, in: Deutsches Archiv für Erforschung des Mittelalters 65 (2009), S. 29-82. S. 65.

579 Exemplarisch: OchSEnbein: »Die St. Galler Klosterschule«. S. 103. OchSEnbein: »Lehren und Lernen im Galluskloster«. S. 138.

580 Bischoff: Katalog, 3. Nr. 5859-60. Euw: Buchkunst. S. 356f. daraus zitiert: BruCKNER: St. Gallen, 2. S. 81. Scarpatetti: "Das St. Galler Scriptorium«. S. 233, Anm. 34.

581 St. Galler Namen auf p. 74, 82 (Euw, S. 356).

582 Nach Bischoff, Katalog: I: 1-110, 117-132, [133-163] 164-223, [224-225], 226-354, II: 111112/113-114, [115-116] 355-356/369-370, III: 357-368. Die in eckigen Klammern stehenden Seiten sind nicht bei Bischoff angegeben, der diese Seiten des Katalogs nicht mehr hat persönlich fertigstellen können, gehören aber klar dorthin (gleiche Hand und/oder gleicher Text). Bei Louis Holtz, Donat et la tradition de l'enseignement grammatical: étude sur l'Ars Donati et sa diffusion (IVe-IXe siècle) et édition critique (Documents, études et répertoires), Paris 2010. S. 374-376, der ebenfalls Bischoff zu der Handschrift konsultiert hat (S. 374, Anm. 4), ist die Einteilung der Handschrift dagegen: I) p. 3-203 ; II) p. 204-289 ; III) p. 290470 . 
finden: ${ }^{583}$ Donatus, Honoratus, Sergius, Sedulius, Ps.-Cato, Sondergut ist Victorinus. Der Text des Sedulius steht im engen Zusammenhang mit St. Gallen und der Reichenau: ${ }^{584}$ Zusammen mit der oben behandelten St. Galler Handschrift Zürich, C 68 und der Reichenauer Handschrift Aug. Perg. 217 (II: pp. 68-169) hängt er von einer gemeinsamen Vorlage $a b$, die wiederum mit einer anderen Reichenauer Handschrift Aug. Perg. 217 (I: pp. 1-67) verwandt ist. Auch die beiden letzteren stehen durch Glossen und andere Anhaltspunkte der Schule nahe. ${ }^{55}$ Im Prolog zu Donat (pp. 290-292) finden sich Spuren einer irischen Herkunft. ${ }^{586}$ Durch die Verwandtschaft mit anderen Schulhandschriften und die Übereinstimmung in den Texten mit der Grammatik-Abteilung des Hauptkatalogs kann die Verortung der Handschrift im Ganzen und von Sedulius im Speziellen im Schulbetrieb ${ }^{587}$ bestätigt werden. Zu bemerken ist, dass der ganze Bodensee-Zweig $^{588}$ der Sedulius-Überlieferung somit innerhalb der Schule stattgefunden hat. Cod. Sang. 877 ist die einzige der erhaltenen Handschriften, welche die für die Schule charakteristische Textgemeinschaft enthält, wie sie der Katalog aufzeigt.

Ein Analog zu Micos metrischem Florilegium, dessen Vorstufe vielleicht auf der Reichenau oder in St. Gallen bearbeitet wurde ${ }^{589}$ hatte St. Gallen in Cod. Sang. $870 .^{590}$ Diese Handschrift enthält pp. 6-31 das Florilegium Sangallense und pp. 31-326 Glossen und Scholien zu Juvenal. Besonders das Florilegium, ${ }^{591}$ das zahlreiche klassische Dichter, insbesondere Juvenal (243 Verse von 458), im frühen Stadium ihrer Überlieferung zitiert, hat die Aufmerksamkeit der Philologen auf sich gezogen ${ }^{592}$ und vielleicht zu einer Überschätzung des in St. Gallen vorhandenen Bestandes antiker Literatur geführt, indem pauschal alle dort ex-

583 Es besteht jedoch keinesfalls Übereinstimmung, wie bei Bergmann/STricker: Katalog. Nr. 248 vermutet.

584 Huemer/Zimmerl-Panagl (Hrsg.): Sedulii Opera omnia. S. XIII f., XXX f. Springer: Handlist. S. 99.

585 Siehe S. 161f. zur Reichenau.

586 Holtz: Donat. S. 301-307.

587 Ochsenbein: »Die St. Galler Klosterschule«. S. 103, 244, Anm. 60.

$588 \mathrm{~K}$ (Reichenau), L(Reichenau), P (St. Gallen), Z (St. Gallen): Huemer/ZimmerL-PanagL (Hrsg.): Sedulii Opera omnia. S. XXX f.

589 Siehe S. 106 zur Reichenau. Es gibt bis auf einen einzelnen Walahfrid-Vers keine Hinweise auf den Ursprung der Vorstufe des Textes.

590 Bischoff: Katalog, 3. Nr. 5856. SCHERRER: Stiftsbibliothek. S. 301.

591 Christoph Heinrich STEPHAN, "Das prosodische Florilegium der S. Gallener Handschrift $n r .870$ und sein Werth für die Iuvenalkritik«, in: Rheinisches Museum für Philologie 40 (1885), S. 263-282. Christoph Heinrich STEPHAN, "De Pithoeanis in Iuvenalem scholiis«, Bonn 1882. S. 17-26. KNoCHE: Juvenaltext. S. 232f. David ButTERFIELD, "Three unidentified verses in the 'Florilegium Sangallense «, in: Maia: Rivista di letterature classiche 61 (2009), S. 348-352.

592 Reynolds: Texts and transmission. S. 201, 202, 220, 241, 263, 293, 294, 382. 
zerpierten Dichter der Bibliothek eingereiht wurden. ${ }^{593}$ Das Florilegium besteht aus zwei Teilen, die separat behandelt werden müssen: ${ }^{54}$ Florilegium A (vss. 1190) aus verschiedenen Quellen; Florilegium B (vss. 191-455) aus hauptsächlich Juvenal und einer Handvoll Persius-Versen. Das Florilegium B ist wahrscheinlich St. Galler Ursprungs: In der Bibliothek befand sich, wie der Katalog von 1759 berichtet, ${ }^{595}$ eine Handschrift namens D 304: Persii Flacci Auli Satyrae Thebaidorum cum optimis notis marginalibus et interlinearibus. Den kuriosen Titel Satyrae Thebaidorum teilt sich dieser Band D 304 mit der Lorscher Handschrift von Juvenal und Persius, Montpellier, Bibliothèque universitaire de médecine $\mathrm{H}$ 125, f. 2r: Thebaidorum Persi Satura. ${ }^{596}$ Nun ist der Juvenaltext des Florilegiums B und der Text der sich anschließenden Scholien dem von Montpellier H 125, wo die Scholien marginal eingetragen sind, außerordentlich eng verwandt, ${ }^{597}$ womit naheliegt, dass es den Text von der gleichnamigen Handschrift D 304 rezipiert, die somit schon damals sich in St. Gallen befunden hat - wenn nicht Florilegium und Juvenal-Handschrift gemeinsam nach St. Gallen kamen. Zwar ist Cod. Sang. 870 von St. Gallischer Hand, könnte jedoch durchaus eine Kopie eines anderen, vielleicht von außen gekommenen Bandes sein. ${ }^{598}$ Die Vorlage von Montpellier $\mathrm{H}$ 125 und D 304 - und somit mittelbare Vorlage von Florilegium B - war eine verlorene Handschrift $\pi^{1}{ }^{159}$ Dass diese von der Reichenau stamme (oder sich dort befunden habe), wie Knoche meint, ${ }^{600}$ beruht zuletzt nur auf einem WalahfridZitat in einer Vorstufe von Micos Opus Prosodiacum, ${ }^{601}$ wo auch ein $\pi^{1}$ nahestehender Juvenal zitiert wird. Eine Reichenauer Herkunft der Vorlage $\pi^{1}$ ist wahrscheinlich, aber aufgrund dieser dünnen Beweislage schwer nachzuweisen. $^{602}$

Florilegium B enthält eine Auswahl von Dichtern, die weit über die verzeichneten oder erhaltenen Bestände hinausgeht. Von den sicher in St. Gallen vor-

593 Brauer: Bücherei und Schrifttum. S. 67. Reynolds: Texts and transmission. S. 220.

594 STEPHAN: »Florilegium 870«. S. 265.

595 Cod. Sang. 1281, 1282, 1400, 1401. Otto JAHN, Friedrich Leo und Franz Bücheler (Hrsg.), A. Persii Flacci, D Iunii Iuvenalis, Sulpiciae Saturae, Berlin 1932. S. VI f. Stephan: »De Pithoeanis scholiis«. S. 22.

596 Otto Seel, »Zum Persius-Titel des Codex Pithoeanus«, in: Hermes 88 (1960), S. 82-98. S. 92.

597 Knoche: Juvenaltext. S. 233, 249; zur Textgeschichte dieses ganzen Textzweiges $\Pi$ siehe S. 230-288. Zu Persius gilt das gleiche: STEPHAN: »Florilegium 870«. S. 282.

598 Butterfield: »Florilegium Sangallense«. S. 352, Anm. 21, weist auf Dittographien hin.

599 KNoche: Juvenaltext. S. 230f. Holt N. PARKer, »Manuscripts of Juvenal and Persius«, in: Companion to Persius and Juvenal (Blackwell companions to the ancient world), Chichester [u. a.] 2012, S. 137-162. S. 148 (hier als Sigle $\varepsilon$ ).

600 KNoche: Juvenaltext. S. 247-249.

601 Siehe hierzu S. 106 zur Reichenau.

602 Und wird dementsprechend nicht mehr erwähnt bei: PARKER: »Manuscripts of Juvenal and Persius«. 
handenen Dichtern enthält das Florilegium: ${ }^{603}$ Vergil, Prudentius, Sedulius, Juvencus, Arator, Beda, ${ }^{604}$ Martianus Capella ${ }^{605}$ und Quintus Serenus. ${ }^{606}$ Ansonsten nicht eindeutig belegt sind: Lukrez, ${ }^{607}$ Ovid, ${ }^{608}$ Persius, Martial, Horaz, Lukan, Claudian $^{609}$ und Laktanz $z^{610}$. Spezifische Verse legen zumindest eine Bearbeitung und Vermehrung des ursprünglichen Florilegiums in St. Gallen nahe: Ein Vers aus Ps.-Venantius stammt aus einem Gedicht, das in St. Gallen gleich dreimal überliefert wird. ${ }^{611}$ Ein Vers auf Cassiodor findet sich in einem metrischen Vorwort zu seinen Werken in Cod. Sang. 199, p. 115, das nur an dieser Stelle zu finden ist. ${ }^{612}$ Ein Vers ist Priscians seltener Periegesis entnommen. ${ }^{613}$ Einer aus Bedas Vita S. Cuthberti trägt die gleiche Variante wie ein St. Galler Textzeuge. ${ }^{614}$ Schlussendlich finden sich zwei Verse von Ennius und Isidor in Grimalds Vademecum. ${ }^{615}$ All diese Verse stehen nicht als Zusatz am Ende des Florilegiums, sondern inmitten des anderen Materials. ${ }^{616}$ Dass also das gesamte Florilegium in St. Gallen bearbeitet wurde, steht anhand der zahlreichen Parallelen mit Handschriften der Bibliothek außer Frage. Sollten deshalb nun alle von dort nicht weiter bekannten Dichter ebenfalls als vorhanden angenommen werden und damit vielleicht auch eine verlorene, nicht verzeichnete Schulbibliothek ${ }^{617}$ Dies setzt voraus, dass das Florilegium vollständig in St. Gallen gesammelt wurde und der Kompilator sich keiner Vorstufen bedienen konnte. Es ist jedoch aufgrund der allgemeinen Natur von Florilegien davon auszugehen, dass der Kompilator sich wie Mico für sein Opus Prosodiacum auf schon vorhandene Sammlungen stützen konnte. ${ }^{618}$ Dies ist eine konservativere Annahme, als die pauschale Ver-

603 Versgenaue Inhaltsangabe bei: STEPHAN: »Florilegium 870«. S. 266-278.

604 Cod. Sang. 263, 265.

605 Privatbibliothek Hartmuts.

606 Cod. Sang. 44, Zürich C 78. Aus den Varianten ist unklar, wie letztere Handschrift mit dem Florilegium A in Verbindung steht: Vollmer (Hrsg.): Liber medicinalis. S. VII.

607 Von den von Ermenrich von Ellwangen, der in St. Gallen einen Lukrez benutzt haben könnte, zitierten Versen (I, 150-156, „Ermenrici Elwangensis epistola ad Grimaldum abbatem«. S. 554) befindet sich I, 155 im Florilegium (vs. 8).

608 Aus zweiter Hand aus Priscian: Butterfield: „Florilegium Sangallense«. S. 350.

609 Nur mit der Gigantomachie vorhanden in Cod. Sang. 273, siehe unten S. 109.

610 Carmen de Phoenice.

611 Voss. Lat. Q. 69 (siehe S. 83), Cod. Sang. 196 (nicht Cod. Sang. 169 wie bei Brauer, S. 66), Cod. Sang. 573. SK 8941 (Leo (Hrsg.): Venanti Honori opera poetica. S. 373, v. 65).

612 SK 2012, Strecker (Hrsg.): MGH Poet. lat. 4, 2.3. S. 1064, XVIII. Paul LehmanN, »CassiodorStudien«, in: Lehmann, Erforschung des Mittelalters, 2, 1959, S. 38-108. S. 81-83.

613 Periegesis v. 1009: Zürich C 78.

614 Butterfield: »Florilegium Sangallense«. S. 250f. Der Vers aus Cod. Sang. 265.

615 Cod. Sang. 397, pp. 121, 85, siehe S. 94f. Aus Isidor ist es VII, v. 3, Ed. Beeson, bei Grimald sind es alle vier Verse des Epigramms.

616 Vss. 14, 123, 125, 138, 159.

617 So Brauer: Bücherei und Schrifttum. S. 6, 71.

618 Siehe S. 113f. zu einem verwandten Florilegium in Neapel, Ms. IV G 68. 
mehrung der St. Galler Bibliothek um jeden einzelnen zitierten Titel. Dass diese hypothetische Vorlage jedoch intensiv studiert wurde, zeigt die Integration der höchstwahrscheinlich aus St. Gallen stammenden Verse an den relevanten Stellen des Gesamtkorpus des Florilegiums, anstatt diese bloß anzuhängen ${ }^{619}$ Inwieweit auch andere Teile des Florilegiums - abgesehen von Juvenal, der wie schon beobachtet in D 304 vorlag - aus St. Gallen stammen, lässt sich nicht mehr rekonstruieren.

Obwohl dem Florilegium A eine metrische Annotation fehlt, ${ }^{620}$ ist es offenbar zur Unterweisung in die Dichtung zusammengestellt worden. Der Text selbst ergibt keinen Sinn, sondern reiht nur Verse aneinander, die dieselben metrischen Phänomene illustrieren wie etwa die Silbenlängen der Verb-Endungen. ${ }^{621}$ Dass das Florilegium tatsächlich in der Lehre genutzt wurde, ergibt sich aus späteren Anklängen daran: Zwei metrische Kuriosa, die sich hier finden, treten in zwei St. Galler Dichtungen wieder auf, vielleicht als Reminiszenz des Unterrichts. ${ }^{62}$ Vielleicht wurde auch Ermenrich durch die erste Seite des Florilegiums A zu seiner metrischen Frage an Grimald zur Länge der Penultima in Perfekt und Futur II veranlasst, wo er zwei Verse von Juvencus und Lukrez betreffs der Längen von -eritis und -erimus finden konnte, wobei er jedoch das Lukrez-Zitat aus anderer Quelle vervollständigen musste, ${ }^{623}$ sei es aus einer Lukrezhandschrift, sei es aus einer Vorstufe des Florilegiums. Auch das Florilegium B gibt keinen kohärenten Text, ohne dass jedoch die Auswahlkriterien so klar zutage lägen wie in A. Struktur des Textes und spätere Anklänge daran in St. Galler Dichtungen verorten das Florilegium Sangallense fest im Unterricht. Eine Rezeption von Vorstufen des Florilegiums und deren Vermehrung durch eigene Praxis ist wahrscheinlicher, als die pauschale Vermehrung der Bibliothek um alle zitierten Werke oder gar die Postulierung einer nicht verzeichneten Schulbibliothek.

Über die bloße Grammatik hinaus führt den Lernenden die Handschrift Cod. Sang. $273+$ Bremen, StUB Ms. b. 52, ${ }^{624}$ die neben zahlreicher Dichtung (Cod. Sang. 273 pp. 5-57, Ms. b. 52f. 1-34) hauptsächlich Alkuins Dialektik und Rhetorik enthält (Cod. Sang. 273, pp. 57-236). Die Handschrift ist auffällig durch ihr

619 Der Vers auf Cassiodor zum Beispiel ergänzt ein weiteres Beispiel zur Metrik von -dorus: ButTERFIELD: "Florilegium Sangallense«. S. 349.

620 Als Zusätze finden sich nur spärliche lateinische Glossen (z. B. pp. 18ff.) und Autorensiglen (p. 21).

621 Stephan: »Florilegium 870«. S. $263 \mathrm{f}$.

622 Brauer: Bücherei und Schrifttum. S. $68 \mathrm{f}$.

623 Ebd. S. $67 \mathrm{f}$.

624 »Westdeutschland(?), IX.Jh., wohl 2. Drittel«: Bischoff: Katalog, 3. Nr. 5714. Ich ordne die Handschrift wegen der engen textlichen Zusammenhänge St. Gallen zu. BergmanN/STrICKER: Katalog. Nr. 75. SCHERRER: Stiftsbibliothek. S. 103f. Irene StahL, Katalog der mittelalterlichen Handschriften der Staats- und Universitätsbibliothek Bremen, Wiesbaden 2004. S. $147 \mathrm{f}$. 
kleines Querformat ${ }^{625}$ (14-14.5 x 12-12.5 cm) und durch die Vielzahl von Schreibern, "wohl einer Schule ${ }^{626}$ An Dichtung ist folgendes enthalten:

\begin{tabular}{|l|l|}
\hline \multicolumn{2}{|l|}{ Inhalte, Anmerkungen. } \\
\hline Cod. Sang. 273 \\
\hline pp. 5- & $\begin{array}{l}\text { Symposium XII sapientum, }{ }^{627} \text { unvollständig durch Ausfall der folgenden Lage. } \\
\text { Der Text des Symposiums in Zürich C 78 (Sigle T) ist von der gleichen Vorlage } \\
\text { abhängig. Unter anderer Autorensigle (TVLLII) ein Epigramm auch in Cod. } \\
\text { Sang. 397, p. 121. Alles von einer Hand. Im folgenden Lagenausfall, da auch die } \\
\text { folgenden Glossen abrupt einsetzen. }\end{array}$ \\
\hline Bremen, StUB Ms. b 52 \\
\hline f. 1r-6v & $\begin{array}{l}\text { Glossen zu Aldhelm: Carmen de virginitate. Von einer Hand, Initialen der } \\
\text { Lemmata rubriziert. }\end{array}$ \\
\hline $\begin{array}{l}\text { f. 7r- } \\
34 \mathrm{v}\end{array}$ & $\begin{array}{l}\text { Aldhem: Aenigmata. } \\
\text { Sang. Der Text stimmt am engsten mit dem Fragment in Cod. } \\
\text { men. }{ }^{629} \text { Diese enthielt die gesamte Epistula ad Acircium und nicht nur die } \\
\text { separate Überlieferung der Aenigmata wie in Cod. Sang. 242. 7r-18v von } \\
\text { gleicher Hand wie f. 1r-6v. Darauf verschiedene Hände oder Schreibgänge, } \\
\text { schwer zu unterscheiden. Glossar und Text sind ahd. und lat. glossiert. }\end{array}$ \\
\hline Cod. Sang. 273 \\
\hline $\begin{array}{l}\text { pp. 13- } \\
\text { 37 }\end{array}$ & $\begin{array}{l}\text { Symphosius: Aenigmata. }{ }^{630} \text { Handwechsel zu Bremen, StUB Ms. b 52, f. 34v, } \\
\text { zahlreiche Hände: pp. 13, 14, 15, 16-23, 24-37. Ebenfalls vorhanden in Cod. } \\
\text { Sang. 196, jedoch in anderer Redaktion. }{ }^{631}\end{array}$ \\
\hline $\begin{array}{l}\text { pp. 38- } \\
\text { 49 }\end{array}$ & $\begin{array}{l}\text { Columban (?): Epistulae Metricae Nr. 8-10. }{ }^{632} \text { Cod. Sang. 899, p. 109-113, } \\
\text { enthält die gleichen drei Versepisteln, vielleicht von hier oder aus gemeinsamer } \\
\text { Vorlage entnommen. Sie kommen ebenfalls in Clm 6404 (siehe bei Freising, } \\
\text { S. 279-281) vor im Anhang an grammatisches Material (Alkuin, Beda). Hand- } \\
\text { wechsel p. 38-42, 42-49 (wie 24-37?). }\end{array}$ \\
\hline pp. 49- & $\begin{array}{l}\text { Claudian: Gigantomachia. }{ }^{633} \text { Einer der ältesten Textzeugen Claudians über- } \\
\text { haupt. Ohne Rücksicht auf Versumbrüche geschrieben. Eine Hand pp. 49-57. }\end{array}$ \\
\hline
\end{tabular}

625 "typique pour une copie d'élève«: Tremp: „École de l'abbaye«. S. 74.

626 Bischoff: Katalog, 3. Nr. 5714. Die Schreiber sind jedoch zumeist nicht ungeschickte Anfänger, wie etwa in Cod. Sang. 550. Warum BRUCKNER: St. Gallen, 2. S. 90 urteilt: »In der Hauptsache von 1, z. T. sehr exakten und schönen Hand«, erschließt sich mir nach Einsicht in die Handschrift nicht.

627 Friedrich: Symposium. S. 16, 21, Sigle G.

628 Ehwald (Hrsg.): Aldhelmi Opera. S. 52f., 58. Sigle S2 als »Bremensis 651«, eben unter dieser alten Signatur noch in LAPIDGE: "Aldhelmus«. S. 23.

629 Ehwald (Hrsg.): Aldhelmi Opera. S. 37, 52f.

630 Glorie (Hrsg.): Collectiones aenigmatum. S. 615, Sigle $S^{5}$ (Cod. Sang. 196: $S^{4}$ ). Edoardo D’ANGELo, „Symphosii Aenigmata , in: La trasmissione dei testi latini del Medioevo, 1, hrsg. von Paolo Chiesa und Lucia Castaldi 2004, S. 415-418. S. 418.

631 D'ANGelo: "Symphosii Aenigmata«. S. 416.

632 "Columbani epistolae«, in: MGH Epist. 3, hrsg. von Wilhelm GundLach 1892, S. 154-190. Nr. 8-10. S. 154, Sigle S1.

633 Birt (Hrsg.): Claudii Claudiani Carmina. S. XCIII f., Sigle G. 
Der Kodex scheint trotz der zahlreichen Handwechsel ein planvolles Kompendium von in St. Gallen vorhandener Schulliteratur zu sein, zu dessen Verfertigung sich ein Lehrer (pp. 42-49, 24-37?) mit seinen fortgeschrittenen Schülern zusammentat. Die mit den Textwechseln koinzidierenden Handwechsel legen nahe, dass die Handschrift nicht aus einer einzelnen Vorlage abgeschrieben wurde, sondern selbst Ort der Sammlung der einzelnen Dichtungen war. Zu dieser griff man bei Symposium XII Sapientum, Aldhelm und vielleicht Columban direkt auf St. Galler Bestände zu. Auch Symphosius war in mehr Handschriften als Cod. Sang. 196 vorhanden, so in der thematisch ganz nahe stehenden Nr. 13 des Hauptkatalogs. ${ }^{634}$ In Aldhelm, Symphosius und Columban erhält sich noch das ältere, insular geprägte Curriculum, hier wohlgemerkt nicht in einer Abschrift einer älteren Sammlung, sondern durch erneute Zusammenstellung in seiner Praktikabilität bestätigt. Nur Claudian, der auch im Florilegium Sangallense mit einem Vers erscheint, tritt hier ohne sichtbare Vorstufen wieder aus dem Dunkel der Vergangenheit. Die Handschrift ist ein Zeugnis der Nutzung der Bibliothek in der Schule, ${ }^{635}$ sowie der direkten Entstehung von Kompilationen aus schulischen Bedürfnissen.

Noch höher im Niveau erhebt sich Neapel, Biblioteca Nazionale, Ms. IV G $68,{ }^{636}$ eine Sammelhandschrift zur Dialektik und Arithmetik. Da die bisherigen Lagenformeln verbesserungswürdig sind, sei hier die korrekte mit den zeitgenössischen Reklamanten hergesetzt:

$$
\begin{gathered}
11 \mathrm{IV}^{1-88}(\mathrm{I}-\mathrm{XI})+\mathrm{II}^{89-92}(\mathrm{XII})+ \\
\mathrm{IV}^{93-100}(\mathrm{XIII})+\mathrm{IV}^{101-108}[\mathrm{XIV} ?]+\mathrm{IV}^{109-116}(\mathrm{XV})+\mathrm{V}^{117-126}(\mathrm{XVI}) \\
+\mathrm{VI}^{127-138}(\mathrm{XVII})+5 \mathrm{IV}^{139-178}(\mathrm{XVIII}-\mathrm{XXI}, \mathrm{XXIII})+ \\
4 \mathrm{IV}^{179-202}(\mathrm{XXIV}-\mathrm{XXVI})+(\mathrm{III}-1)^{203-207}[\mathrm{XXVII} ?]+ \\
\mathrm{IV}^{208-215}(\mathrm{XXVIIII})+\mathrm{III}^{216-222}(\mathrm{XXX})+\mathrm{V}^{222-232}(\mathrm{XXXI})+\mathrm{II}^{233-236}[\mathrm{XXXII} ?]
\end{gathered}
$$

Es fehlt Lage XXII in Boethius, De institutione arithmetica. Es ist unklar, ob Lagen [XXVII?] und (XXVIIII) eine Lage darstellen (hypothetisch also (VI+1

634 Item Althelmi de enigmatibus et Bedae de metrica arte et metrum Simphosii et alia nonnulla sanctorum opuscula in volumine I parvo.

635 Ebenso Tremp: „École de l'abbaye«. S. 74.

636 »St. Gallen, IX. Jh., 4. Viertel u. IX./X. Jh.«: Bischoff: Katalog, 3. Nr. 3575. »Naples, Biblioteca Nazionale: Ms. IV.G.68«, in: The Libraries of Reichenau and St. Gall, http:// www.stgallplan.org/stgallmss/viewItem.do?ark=p21198-zz00294sdx (abgerufen am 13.06. 2018). Elaine STRATTON HILD, Verse, music, and notation: Observations on settings of poetry in Sankt Gallen's ninth- and tenth-century manuscripts, Diss., University of Colorado Boulder (Musicology Graduate Theses \& Dissertations 5), Boulder 2014. S. 218-232. LeoNARDI: "I codici di Marziano Capella«. Ewald JAMmers, "Rhythmen und Hymnen in einer St. Galler Handschrift des 9. Jahrhunderts", in: Festschrift Bruno Stäblein zum 70. Geburtstag, hrsg. von Martin RuhnKe, Kassel 1967, S. 134-142. Schaller: »St. Galler Handschrift«. Marina PAssalacqua, Italy and the Vatican City (Codices Boethiani 4), London 2001. S. 254-256. BergmanN/Stricker: Katalog. Nr. 713. 
oder VII-1 ${ }^{203-215}$ ) und somit (XXVII) ausgefallen wäre, ${ }^{637}$ oder ob die letzte Seite der Lage verlorenging oder zuletzt ob auf [XXVII?] nur vergessen wurde, ${ }^{638}$ die Reklamante zu setzen. Bei Verlust von (XXVII) müsste die Psychomachia abbrechen, dies ist jedoch nicht der Fall (Ende aeternum solio diues sapientia regnet auf f. 204r). Am wahrscheinlichsten ist ein Blattverlust nach f. 207 auf der vielleicht ohnehin wegen Platzmangels in der Psychomachia hinzugesetzten Lage [XXVII?]. Obwohl die Reklamanten die Handschrift kodikologisch zusammenbinden, zerfällt sie entlang der koinzidierenden Lagen- und Textgrenzen in: Boethius: De Consolatione Philosophiae ${ }^{639}$ (4v-92r, I-XII), kleinere BoethiusTexte und De institutione arithmetica (93r-103r, 107r-178v, ${ }^{640}$ XIII-XXIII), Prudentius' Psychomachia mit zwei Glossaren (179v-204r, 182v-204r, 204v206v, XXIV-XXVII?) und Martianus Capella (De nupt. IV,327-IV,423 - Dialektik $)^{641}$ mit Glossar (208r-231v, 208r-231v, XXVIIII-XXXI), also unter den Haupttexten zwei Prosimetren und eine reine Dichtung. Prudentius gehört der $\Theta$-Rezension oder "traditio Sangallensis« an, ohne hierin genauer positioniert worden zu sein. ${ }^{642}$ Leithandschrift dieses Zweiges ist Cod. Sang. 136, ein opera omnia des Dichters, die jedoch nicht Vorlage von Ms. IV G 68 ist. ${ }^{643}$ In dieselbe $\Theta$ Rezension gehört auch der illuminierte Prudentius von Bern, BB Ms. 264 (Reichenau?), dem Ms. IV G 68 vielleicht geglichen haben würde, wenn die für Illustrationen frei gelassenen Räume ausgefüllt worden wären. ${ }^{644}$ Den Haupttexten sind als Apparat kleinere Texte angeschlossen, nicht als Zusatz, sondern schon bei Anlage der Handschrift mitbedacht. Boethius wird durch Lupus von Ferrières kurzes Traktat zu De metris Boetii eingeleitet, ${ }^{645}$ wodurch gleich zu Beginn der

637 So LeonARd: »I codici di Marziano Capella«. S. 412.

638 Wie auf [XIV?].

639 Claudio Moreschini (Hrsg.), Boethius: De consolatione philosophiae (Bibliotheca scriptorum Graecorum et Romanorum Teubneriana), München 2005. S. VI f., XIX. Sigle N.

640 Hier 26 statt wie sonst 24 Zeilen.

641 Mit Korrekturen, die auf das Vorliegen mehrerer Vorlagen hinzuweisen scheinen: Jean G. PRÉAUX, "Les manuscrits principaux du >De nuptiis Philologiae et Mercurii< de Martianus Capella", in: Lettres latines du Moyen Âge et de la Renaissance, hrsg. von Guy CAMBIER, Carl Deroux und Jean G. Préaux (Collection Latomus 158), Brüssel 1978, S. 76-128. S. 125, Anm. 144.

642 Mauricius P. Cunningham (Hrsg.), Aurelii Prudentii Clementis Carmina (CCSL 126), Turnhout 1966. S. XVI-XVIII.

643 »[St. Gallen, IX. Jh., 1./2. Viertel]«: Bischoff: Katalog, 3. Nr. 5593. Cunningham (Hrsg.): Prudentii Carmina. S. XVI, $\$ 43$. Siehe unten S. 118 zum möglichen Ursprung der bodenseeischen Prudentius-Tradition.

644 Eine Federzeichnung auf f. 119r. Euw erklärt die Nichtvollendung durch das Fehlen einer Vorlage: Euw: Buchkunst. S. $289 \mathrm{f}$.

645 Rudolf Peiper (Hrsg.), Anicii Manlii Severini Boetii philosophiae consolationis libri quinque: Accedunt eiusdem atque incertorum opuscula sacra (Bibliotheca Scriptorum Graecorum et Romanorum Teubneriana), Leipzig 1871. S. XXV-XXIX. Virginia BRown, "Lupus of Ferrières on the metres of Boethius", in: Latin Script and Letters A.D. 400-900. Festschrift 
Autor als Dichter, nichts als Philosoph vorgestellt wird. Dieselbe Textgemeinschaft findet sich in Cod. Sang. 844. ${ }^{646}$ Den Rest der Lage [XIV?], auf die kleineren Boethiana folgend, nimmt Walahfrids Traktat von den Metren ein, hier in seinem ältesten Textzeugen. ${ }^{647}$ Diese Begleittexte unterstreichen dass poetische Interesse, das man an Boethius hatte und weisen in die Schule. Auch in den Ergänzungen schlägt sich dieses Interesse nieder. Nur ein Vergilexzerpt scheint allein wegen seiner meteorologischen Aussage und nicht als Dichtung an sich ergänzt worden zu sein. ${ }^{648}$ Auf Walahfrid folgt eine anonyme metrische Sündenklage, deren Schreiber Ähnlichkeit mit denen der anderswo ergänzten Hymnen hat. ${ }^{649}$ Diese wurden an verschiedenen freien Stellen der Handschrift ergänzt und mit Neumen zur Verdeutlichung der Versstruktur versehen: ${ }^{60}$ Schreiber A, f. 207rv: Die ersten vier stimmen mit den entsprechenden aus Voss. Lat. Q. 69 überein, ${ }^{651}$ wo sie in gleicher Reihenfolge, aber mit anderen Hymnen dazwischen, zu finden sind. V. (O triplex honor) ist aus dem Peristephanon genommen, VI. von Eugenius von Toledo (Celi cives applaudite), VII. (Age iam precor) ist vielleicht durch Bedas Zitat angeregt, ${ }^{652}$ VIII. (Adam in saeculo) der Rest eines Abecedars. Von anderer, gar nicht St. Gallischer Hand wird der Schreibervers IX. (Perge frater qui adheres) ${ }^{653}$ auf f. $207 \mathrm{v}$ ergänzt. f. $231 \mathrm{v}-233 \mathrm{v}$ folgen drei weitere Hymnen von je anderer Hand. ${ }^{654}$ f. $232 \mathrm{v}$, XIII. (Tu quicumque velis) ${ }^{655}$ ist das gleiche Gedicht zu den Kategorien, das sich auch im Anschluss an Apuleius' Periermeniae in Cod. Sang. 64 findet; beide Texte stammen aus derselben fehlerhaften

Presented to Ludwig Bieler on the Occasion of his 70th Birthday, hrsg. von John Joseph O'Meara und Bernd Naumann, Leiden 1976, S. 63-79.

646 »St. Gallen, Stiftsbibliothek, Cod. Sang. 844«, in: UCLA Reichenau-St. Gall Virtual Library, 2012, https://www.e-codices.unifr.ch/en/description/csg/0844/Hendrix (abgerufen am 20.06.2018). Moreschini (Hrsg.): Boethius. S. XIX, Sigle F. Beide Handschriften gehören der Familie $\beta 1$ an. Die genaue Abhängigkeit der beiden ist ungeklärt.

647 Walter Berschin und Tino Licht, «Metrorum iure peritus: Walahfrid Strabo als Metriklehrer«, in: Mittellateinisches Jahrbuch 44 (2009), S. 377-393. Sigle N.

648 Auf f. 179r, dem Freiblatt vor Prudentius, folgt Vergil Georg. I. 438-449; I. 427-435 (über das Wetter) auf eine Stelle Bedas ähnlichen Inhalts (De natura rerum, 36).

649 Inc. Post erratus et excessus, SK 12197. Schaller: „St. Galler Handschrift«. S. 290f. Der Schreiber ist nicht der Autor, wie versetzte Vershäften zeigen.

650 Folgende Angaben nach Schaller, "St. Galler Handschrift" und Stratton Hild: Verse, music, and notation. S. 219. Zu Neumen als Hilfsmittel der Metrik siehe auch: Jan M. Zıоккошsкі, „Nota bene: why the classics were neumed in the Middle Ages", in: The journal of medieval Latin 10 (2000), S. 74-114. S. 87-89.

651 I. Ante secula mundi, II. Gratuletur omnis caro, III. Audite omnes, IV. Alma vera ac praeclara ebenfalls nur vss. 1-13, siehe S. 83 zu Voss. Lat. Q. 69 für Nachweise.

652 KeIL (Hrsg.): Grammatici Latini. SK 458.

653 SK 11889.

654 X. Tercio in flore mundus, XI. Ad dominum clamaveram, XII. Christe salus mundi nobis. SK 16306, 167, 277. Eine späte Ergänzung (10. Jh.) ist f. 233rv, XIV. Concurrite huc populi, SK 2518.

655 SK 16570. 
Vorlage. Eine besonders interessante Ergänzung findet sich in der letzten Lage, einem Binio, das überhaupt ganz frei geblieben zu sein scheint oder erst später ergänzt wurde. ${ }^{656}$ Auf $235 \mathrm{r}$ ergänzte, wie es scheint, eine Hand in mehreren Schreibgängen ein kleines metrisches Florilegium, das an das Florilegium Sangallense erinnert. Da es noch nicht untersucht wurde, sei hier kurz der Inhalt gegeben:

\begin{tabular}{|c|c|c|c|}
\hline $\begin{array}{l}\text { Autoren- } \\
\text { sigle }\end{array}$ & Text (Wechsel im Schriftbild kursiv) & \begin{tabular}{|l|} 
Florilegium \\
Sangallense, \\
v. \\
\end{tabular} & Quelle \\
\hline & $\begin{array}{l}\text { 1. illum etiam lauri etiam flevere myri- } \\
\text { cae }\end{array}$ & & Verg. Buc. X, 13 \\
\hline & $\begin{array}{l}\text { 2. pinguia corticibus sudent electra } \\
\text { myricae }\end{array}$ & & Verg. Buc. VIII, 54 \\
\hline \multirow[t]{5}{*}{ VR } & $\begin{array}{l}\text { 3. non omnes arbusta iuuant humiles- } \\
\text { que myricae }\end{array}$ & & Verg. Buc. IV, 2 \\
\hline & $\begin{array}{l}\text { 4. pinguia corticibus sudent electra } \\
\text { myricae }\end{array}$ & & Verg. Buc. VIII, 54 \\
\hline & $\begin{array}{l}\text { 5. cum primum sulcos aequant sata } \\
\text { quique paludis }\end{array}$ & & Verg. Georg. I, 113 \\
\hline & $\begin{array}{l}\text { 6. in sicco ludunt fulicae notasque } \\
\text { paludes }\end{array}$ & & Verg. Georg. I, 363 \\
\hline & $\begin{array}{l}\text { 7. nigra subest udo tantum cui lingua } \\
\text { palato }\end{array}$ & $3^{657}$ & $\begin{array}{l}\text { Verg. Georg. III, } \\
388\end{array}$ \\
\hline PSIUS & $\begin{array}{l}\text { 8. eliquat ac tenero subplantat uerba } \\
\text { palato }\end{array}$ & & Pers. I, 35 \\
\hline id & $\begin{array}{l}\text { 9. castiges trutina nec te quaesiueris } \\
\text { extra }\end{array}$ & 423 & Pers. I, 7 \\
\hline \multirow[t]{2}{*}{ IVL } & $\begin{array}{l}\text { 10. atque alia parte in trutina suspendit } \\
\text { Homerum }\end{array}$ & 236 & Iuv. VI, 437 \\
\hline & $\begin{array}{l}\text { Sieben Zeilen Definitionen zur Dialektik, } \\
\text { dann gleiche Hand wie Verse vorher: }\end{array}$ & & \\
\hline \multirow[t]{2}{*}{$\begin{array}{l}\text { IVL } \\
\text { (rechts) }\end{array}$} & $\begin{array}{l}\text { Sic sacros calamo scriptor sulcante li- } \\
\text { bellos } \\
\text { ut gaudere solet fessus iam nauta labore }\end{array}$ & & $\begin{array}{l}\text { SK } 16860 \\
16856 .\end{array}$ \\
\hline & 7 Zeilen Notizen, Definitionen. & & \\
\hline
\end{tabular}

656 Es fehlt die Reklamante XXXII. f. 233rv. Sie beginnt mit dem sauber und seitenfüllend geschriebenen Hymnus XIV. Concurrite huc populi, SK 2518, der nicht an einen Zusatz erinnert. Er wird von SCHALLER: »St. Galler Handschrift«. S. 288, ins 10. Jh. datiert, womit auch die folgenden Texte späteren Datums wären.

657 tantum] semper.

658 Fickermann/Strecker (Hrsg.): MGH Poet. lat. 5, 1.2. S. 378f. vss. 3+4. Siehe eingehender: Michael KaUtz, »Vatikan, Biblioteca Apostolica Vaticana, Pal. lat. 1581«, http://bibliothecalaureshamensis-digital.de/bav/bav_pal_lat_1631 (abgerufen am 06.12.2017). 
(Fortsetzung)

\begin{tabular}{|l|l|l|l|}
\hline $\begin{array}{l}\text { Autoren- } \\
\text { sigle }\end{array}$ & Text (Wechsel im Schriftbild kursiv) & $\begin{array}{l}\text { Florilegium } \\
\text { Sangallense, } \\
\text { v. }\end{array}$ & Quelle \\
\hline & $\begin{array}{l}\text { Concava litorei si demas brachia cancri, } \\
\text { scorpio exibit, caudaque minabitur unca }\end{array}$ & & $\begin{array}{l}\text { Ovid. Met. 15,369, } \\
\text { zit. aus Isidor XI, } \\
4,3 .\end{array}$ \\
\hline
\end{tabular}

Die Ordnung nicht nach Sinn, sondern nach metrisch problematischen Worten (myricae, paludes, palatum, trutina) gleicht genau der des Florilegium Sangallense, ohne von diesem oder überhaupt einer direkten Vorlage abhängig zu sein, denn die Wechsel im Schriftbild suggerieren, dass nacheinander vss. 1-2, 3-5, 69, 10 ergänzt wurden. Vielleicht durchblätterte der Schreiber hier ein dem Sangallense verwandtes Florilegium oder einen anderen Teil einer gemeinsamen Vorlage und kompilierte die ihn interessierenden Stellen. Die bodenseeische Tradition des metrischen Florilegiums, wie sie bei Mico und im Florilegium Sangallense erscheint, hat in Ms. IV G 68 somit einen neuen Zeugen gefunden und zwar einen, der die Kompilation entweder in einem frühen Stadium zeigt oder Zeugnis der Benutzung größerer Florilegien ist. Weitere Benutzungsspuren finden sich in den zahlreichen lateinischen und althochdeutschen Glossen, die in der Consolatio am dichtesten sind. ${ }^{659}$ Auch die Neumierung einiger Gedichte der Handschrift geschah nicht primär aus musikalischem Interesse, sondern zur Einprägung der metrischen Struktur. ${ }^{60}$ Neapel Ms. IV G 68 stellt sich somit sowohl in den Texten, deren Einrahmung und den späteren Zusätzen als Schulhandschrift zur Unterweisung in die Dichtung dar. ${ }^{661}$ Die Bibliothek lieferte die Quellen für die meisten Ergänzungen, dieselben, die auch anderen Handschriften zur Vorlage gedient hatten. ${ }^{662}$ Hier liegt also ein weiteres Zeugnis für die Zirkulation kleiner Texte innerhalb des St. Galler Handschriftennetzwerks vor.

Hier soll auch im Vorübergehen einer Handschrift gedacht werden, die auf ihrem Weg durch das karolingische Europa auch den Bodenseeraum streifte: Bern, BB Ms. $363 .{ }^{663}$ Zuletzt ist wahrscheinlich jede Beschränkung der Herkunft

659 Bergmann/Stricker: Katalog. Nr. 713. Ebenso dicht glossiert ist der oben erwähnte Cod. Sang. 844: Ebd. Nr. 242. Die Beziehung der Glossen wurde noch nicht ermittelt, Neapel Ms. IV G 68 nicht behandelt in: Werner BACH, Die althochdeutschen Boethiusglossen und Notkers Übersetzung der Consolatio. Halle, Univ., Diss., Würzburg 1934.

660 Stratton Hild: Verse, music, and notation. S. 231. Ziolkowski: »Nota bene«. S. 87-89.

661 Stella (Hrsg.): Corpus Rhythmorum Musicum Saec. IV-IX, 1. Songs in non-liturgical sources $=$ Canti di tradizione non liturgica. I, Lyrics = Canzoni. S. XCIV. GLAUCHE: Schullektüre. S. 59.

662 Voss. Lat. Q. 69, Cod. Sang. 64, vielleicht Cod. Sang. 870.

663 Siehe zur Handschrift insbesondere: Vocino: »MS Bern 363«. Zur Herkunft: »Straßburg«: Bernhard Bischoff, "Irische Schreiber im Karolingerreich", in: Bischoff, Mittelalterliche Studien, 3, 1981, S. 39-54. S. 46, aber »St. Gallen?«: BIschoff: Katalog, 1. Nr. 585. Bernhard 
auf nur ein Skriptorium aussichtslos, da die Handschrift mit ihrem Besitzer auf seiner Wanderschaft aus den Quellen verschiedener Bildungsstätten schöpfen konnte. ${ }^{664}$ Der Besitzer war ein gelehrter Ire aus dem Sedulius-Kreis, ${ }^{665}$ der teils schon vorliegende Textsammlungen mit Apparat übernahm, teils einzelne Texte an verschiedenen Orten ergänzte und mit Anmerkungen versah. ${ }^{666}$ Bern Ms. 363 enthält, wenn auch nur in Auszügen, einen der frühesten Horaztexte überhaupt, als auch einige Exzerpte aus Ovids Metamorphosen. ${ }^{667} \mathrm{Zu}$ viel trennt den Horaz von dem - von Walahfrid redigierten - Reg. lat. 1703, als dass beide von einer gemeinsamen Vorlage abstammen könnten. ${ }^{668}$ Woher die Vorlage des Horaz, $\Xi$, stammt, ist unbekannt. Eine Anmerkung in Bern Ms. 363 könnte hierzu einen Fingerzeig geben: Auf f. 25v findet sich, aus der Vorlage übernommen, ein Hinweis auf den Horaz-Kommentar des Porphyrio, den man in Lorsch finden könne. ${ }^{669}$ Diese Stelle wurde vom Besitzer der Handschrift bemerkt und präzisiert, indem er am Rande in Hlorashaimm wiederholt und die Autorensigle Sed(ulius) hinzusetzt. Sedulius hielt sich zu Studienzwecken in Lorsch auf und nutzte dort Porphyrio; ${ }^{670}$ es erscheint nicht abwegig, dass er den seltenen Horaz, der dort vorhanden war, ${ }^{671}$ abschrieb oder Auszüge erstellte und diese in seinen Schülerkreis und so in Bern Ms. 363 gelangten. Dort wurden diese als mehr als

Bischoff, »Palaeography and the Transmission of Classical Texts in the Early Middle Ages", in: Bischoff, Manuscripts and libraries in the age of Charlemagne, hrsg. von Michael M. Gorman (Cambridge studies in palaeography and codicology 1), Cambridge 1994, S. 115133. S. 125. Faksimile und Inhaltsangabe in: Hermann HaGEN (Hrsg.), Codex Bernensis 363, phototypice editus, Leiden 1897.

664 "Charles the Bald's Francia, Lothar II's Mittelreich, Louis the German's Alamannia, and Louis II's Italian kingdom can provide equally convincing grounds for attribution«: Vocino: $» M S$ Bern 363«. S. 121.

665 Das Argument wurde in seinen Grundzügen etabliert von: Ludwig TraUbE, "O Roma nobilis. Philologische Untersuchungen aus dem Mittelalter«, in: Sonderdruck aus: Abhandlungen der Historischen Klasse der Königlich-Bayerischen Akademie der Wissenschaften 19 (1891), S. 299-395. S. 50-57.

666 Vocino: »MS Bern 363«. S. 101, 106, 120. TraubE: »Roma nobilis«. S. 53. BischofF: »Irische Schreiber«. S. 46. Zu den zahllosen notae der Handschrift siehe: Evina Steinová, Notam superponere studui: the use of technical signs in the Carolingian period, Diss. Utrecht 2016. S. 207, 212, 231, 267, 280. Verzeichnis in: HAGEN (Hrsg.): Codex Bernensis 363. S. XXVIIIXLI.

667 f. 167r-186v, 187r-188v. Munk Olsen: L'étude des auteurs classiques latins. 1, S. 438, 2, S. 128.

$668 \mathrm{Zu}$ Reg. Lat. 1703 siehe S. 185-188 zu Weißenburg. Zur Verwandschaft der Horazhandschriften: Friedrich KLINGner (Hrsg.), Q. Horati Flacci opera (Bibliotheca scriptorum Graecorum et Romanorum Teubneriana), Leipzig 1959. S. XII. Edward CourTNEY, "The Transmission of the Text of Horace«, in: Brill's companion to Horace, hrsg. von HansChristian GÜNTHER, Leiden [u. a.] 2013, S. 547-560. S. 549.

669 Vocino: »MS Bern 363«. S. 95f. LICHT: »Horazüberlieferung im Frühmittelalter«. S. 122-125.

670 Vocino: »MS Bern 363«. S. 96, 100 Liснт: »Horazüberlieferung im Frühmittelalter«. S. 125.

671 HäsE: Bücherverzeichnisse. Nr 345 (Ca407). MANITIUs: Handschriften antiker Autoren in mittelalterlichen Bibliothekskatalogen. S. 55-59. 
nur als grammatische Anschauungsbeispiele rezipiert: Eine Marginalie auf Sat. I, 123-124 enthält einen Seitenhieb auf Kaiserin Engelberga. ${ }^{672}$ Vielleicht eine Frucht des Aufenthaltes im Bodenseegebiet ist die Referenz zum ansonsten ganz unbekannten Silius Italicus auf f. $147 \mathrm{v} .{ }^{673}$ Am Schluss der Handschrift findet sich eine kleine Sammlung von an Sedulius angelehnten Gedichten und weiterer Texte, die wahrscheinlich erst in Italien ergänzt wurden. ${ }^{674}$ Wenn also auch Bern Ms. 363 nicht unter die libri scottice scripti St. Gallens gezählt werden kann, ${ }^{675}$ ist vielleicht gerade diese Heimatlosigkeit der Grund, dass sie Einblicke in die Welt der wandernden Gelehrten gewährt und in deren selten sicher zu konstatierende Praxis, Texte nicht nur aus der eigenen Bibliothek oder durch Ausleihe, sondern auch durch Besuch fremder Bibliotheken zu sammeln und so zur Verbreitung seltener Texte beizutragen.

Der Schule werden auch pauschal, wie oben angemerkt, die weiteren Handschriften der Schulautoren, allen voran der altchristlichen Dichter, zugerechnet. Deren Handschriften müssen deshalb ebenfalls auf eine nähere Verbindung mit der Schule untersucht werden.

Als dux gregis der Prudentiushandschriften gilt Cod. Sang. 136, ${ }^{676}$ worin sämtliche Werke des Dichters enthalten sind ${ }^{677}$ und sonst nichts. Die Schrift ist sorgfältig und durchweg mit alternierenden roten und grünen Initialen für die Verse versehen, den Werken voraus geht eine ganz in rot und grün geschriebener Accessus zum Dichter. ${ }^{678}$ Vor den Gedichten finden sich Vermerke zum Metrum, bisweilen eine ausführliche Erläuterung desselben. Aus dem Vergleich des Textes der Psychomachia von Cod. Sang. 136 und Neapel Ms. IV G 68 ergibt sich eine starke Interpolation der St. Galler Handschriften und keine eindeutige Vorlage. ${ }^{679}$ Vielleicht ist somit Cod. Sang. 136 ein unter Nutzung verschiedener älterer Ex-

672 Vocino: »MS Bern 363«. S. 118f. Zu weiteren politisch-theologischen Zeitbezügen S. 112120.

673 Ebd. S. 106. Reynolds: Texts and transmission. S. 389. Zum zeitgenössischen Katalog ungeklärter Herkunft in Stuttgart, Württembergische Landesbibliothek, Cod. Don. 191, f. 160v-163v, (Reichenau, St. Gallen, Konstanz?), in dem Silius Italicus verzeichnet ist, siehe S. 177-179 zur Reichenau.

674 Vocino: »MS Bern 363«. S. 93, Anm. 15, S.110f. Nikolaus St AubaCh, „Sedulius Scottus und die Gedichte des Codex Bernensis«, in: Frühmittelalterliche Studien 20 (1986), S. 549-598. S. 570-591.

675 Bischoff: »Irische Schreiber«. S. $46 \mathrm{f}$.

676 Cunningham (Hrsg.): Prudentii Carmina. S. XVI f. "[St.Gallen, IX.Jh., 1./2.Viertel]«: Bischoff: Katalog, 3. Nr. 5593. Vgl. S. 100 zum Hauptkatalog, Nr. 6. Stratton HiLD: Verse, music, and notation. S. 233-246.

677 Zur Ordnung der Werke: Johann Bergmann, De codicum Prudentianorum generibus et uirtute, Wien 1908. S. 25, zur Handschrift S. 60.

678 Carl Albrecht Bernoulli (Hrsg.), Hieronymus u. Gennadius: De viris inlustribus (Sammlung ausgewählter kirchen- und dogmengeschichtlicher Quellenschriften, 11 (= 1895)), Frankfurt a. M. 1968. S. 66.

679 Cunningham (Hrsg.): Prudentii Carmina. S. XVI, $\$ 43$. 
emplare redigierter Sammelband des Dichters. In der umfangreichen Handschrift (183 fols.) finden sich insgesamt ca. 400 althochdeutsche und vor allem lateinische Glossen, die nach und nach bis ins 11 . Jh. eingetragen wurden. ${ }^{680}$ Neumierte Verse dienten der Veranschaulichung des Metrums und weisen somit vielleicht auf einen schulischen Gebrauch. ${ }^{681}$ Insgesamt zeigt sie nur mäßige Nutzungsspuren. ${ }^{682}$ Gerade in der Psychomachia ist die Tinte stark ausgeblichen, sodass eine spätere Hand mit dunklerer Tinte die Buchstaben nachzog.

In Gestaltung und Inhalt eng verwandt mit Cod. Sang. 136 ist die spätere Handschrift Berlin, SB zu Berlin, Ms. Hamilt. 542 + Vatikan, BAV, Reg. lat. 348 (f. 26-38). ${ }^{683}$ Sie enthält die Werke in gleicher Zusammenstellung ${ }^{684}$ und weist ein ähnliches Farbschema der Versinitien auf. ${ }^{65}$ Die Handschrift trägt zahllose Griffelglossen. ${ }^{686}$

Ebenfalls glossiert ist der Prudentius in Cod. Sang. 134 (pp. 1-76) ${ }^{687}$ Der Text wird durch den gleichen Accessus ${ }^{688}$ eingeleitet wie Cod. Sang. 136, es folgen aber eine kurze Übersicht über die Metren, dann Catherimenon I-X und Peristephanon I und V, also in der St. Galler Reihenfolge. Das Peristephanon beginnt merkwürdigerweise mit Incipit secundus liber. $^{689}$ Auf p. 76 beginnt noch, von Scherrer nicht notiert, Peristephanon II, darauf bricht die Handschrift ab.

680 Bergmann/Stricker: Katalog. Nr. 188. O'Sullivan: Glosses on Prudentius. S. $67 \mathrm{f}$. GLAUCHE: Schullektüre. S. 60.

681 Stratton Hild: Verse, music, and notation. S. 246.

$682 \mathrm{Zu}$ einer sehr groben Federprobe: Bernhard Bischoff, „Elementarunterricht und Probationes Pennae in der ersten Hälfte des Mittelalters«, in: Bischoff, Mittelalterliche Studien, 1, 1966, S. 74-87. S. 80.

683 »St. Gallen, ca. IX./X. Jh.«: Bischoff: Katalog, 3. Nr. 359. Bruckner: St. Gallen, 2. S. 51. Helmut Boese, Die lateinischen Handschriften der Sammlung Hamilton zu Berlin, Wiesbaden 1966. S. 261 f. Wilmart: Codices Reginenses Latini. S. 295-297, Nr. 348. CunNinghaM (Hrsg.): Prudentii Carmina. S. XIX, Siglen H, i.

684 Bergmann: De codicum Prudentianorum generibus et uirtute. S. 25. Die einleitenden Texte liegen ebenfalls vor. Ergänzt sind: f. 35v: FerRUA (Hrsg.): Epigrammata Damasiana. Nr. 71, 73; f. 194v (Ende der Handschrift): Walahfrid, carm. V, xlvi, mit abweichender Überschrift (so BoEsE) gegenüber der Walahfrid-Sammelhandschrift Cod. Sang. 869.

685 Siehe für weitere gestalterische Parallelen: Bischоғғ: „Bücher am Hofe und Privatbibliothek«. S. 201.

686 Michaela PöLzL, »BStK Online, Nr. 36, 822.«, https://glossen.germ-ling.uni-bamberg.de/ glossed_contents/12070 (abgerufen am 18.06.2018). Ergänzend zu: BERGMANN/STRICKER: Katalog. Nr. 36, 822.

687 »[St. Gallen, ca. IX.IX. Jh.]«: Bischoff: Katalog, 3. Nr 5592. Bergmann/Stricker: Katalog. Nr. 186. Scherrer: Stiftsbibliothek. S. 49f. Cunningham (Hrsg.): Prudentii Carmina. Sigle X, $₫$ 52. Wilmart: Codices Reginenses Latini. S. 263f., Nr. 339. Bergmann/Stricker: Katalog. Nr. 821 (I).

688 Jedoch die Werknamen in griechischen Buchstaben. Die Metrikvermerke sind ebenfalls die selben.

689 Vgl. S. 100 zum Hauptkatalog, Nr. 6, wo ebenfalls die Werke als libri VII verzeichnet wurden. In Cod. Sang. 136 finden sich gewöhnliche Incipits der einzelnen Werke ohne Zählung der Bücher. 
Ein weiterer Textzeuge des Prudentius in St. Gallen ist das Fragment Vatikan, BAV, Reg. lat. 339 (p. 1-6) in einer St. Galler Minuskel der Hartmut-Zeit. ${ }^{690}$ Es enthält noch Teile von Epilog, Dittochaeon und Apotheosis, somit in der gleichen Reihenfolge wie Cod. Sang. 136 und war wahrscheinlich früher ein Kodex sämtlicher Werke.

Alle fünf Handschriften stellen somit einen spezifisch St. Gallischen Typus der Prudentius-Überlieferung dar, ${ }^{691}$ der nach einer verlorenen Vorlage ${ }^{692}$ etabliert und mehrfach im Kloster reproduziert wurde. Diese Textgemeinschaft erscheint vereinzelt auch außerhalb St. Gallens, ${ }^{693}$ so in der süddeutschen Handschrift Vatikan, BAV, Vat. lat. $3860^{694}$ und im Reichenauer (?) illuminierten Prudentius Bern, BB Ms. 264. Es liegt nahe, als Stammvater der Überlieferung die lotharingische Handschrift anzunehmen, die Bern Ms. 264 zur Vorlage gedient hat. ${ }^{695}$

Ob auch Ms. IV G 68 in den nicht erfolgten Illustrationen dessen Bildprogramm übernehmen wollte, lässt sich nicht mehr sagen. In jedem Fall hat die St. Galler Prudentiusüberlieferung ihren reichen Schmuck verloren und konzentriert sich auf den praktischen Wert des Dichters, wiewohl Accessus und metrische Anmerkungen sich auch in Bern Ms. 264 finden und somit keine St. Galler Schulergänzung, sondern Teil der älteren Tradition sind. Die Glossierung aller Prudentius-Handschriften, sowie vereinzelte Neumierungen sind Zeugnis des intensiven Studiums des Dichters, in interessantem Gegensatz zur Reichenau, wo man sich eher Juvencus und Sedulius widmete.

690 Bischoff: Katalog, 3. Nr. 6669. Cunningham (Hrsg.): Prudentii Carmina. S. XVII, § 54, Sigle g. Bergmann/Stricker: Katalog. Nr. 821 (I).

691 Euw: Buchkunst. S. 283-294.

692 Interpolationen erschweren die Rekonstruktion des Archetyps: Cunningham (Hrsg.): Prudentii Carmina. S. XVI, $\$ 43$.

693 Cunningham. S. XVI, weitere Siglen in $\Theta$ : tM (westfränkisch), U (Bern 264), b (Vat. lat. 3860). Ebenfalls in Düsseldorf ULB, Ms. F 1, siehe S. 227 zu Corvey.

694 »[Süddeutschland,IX./X.Jh.(oder X.Jh., Anfang)] «: Bischoff: Katalog, 3. Nr. 6887. Enthält wie Berlin, Ms. Hamilton 542 zwischen Peristephanon XIV und III die Versus Damasi (Cunningham (Hrsg.): Prudentii Carmina. Sigle b, Familie Bb, S. XVIII). Die lexikalische Glossierung deutet auf einen Gebrauch in der Schule hin (Bergmann/Stricker: Katalog. Nr. 834). Eine Beeinflussung durch die St. Galler Prudentius-Tradition halte ich für wahrscheinlich, da gerade am Ende des Jahrhunderts, als Vat. lat. 3860 geschrieben wurde, St. Gallens Ausstrahlung auf ihrem Höhepunkt war.

695 Christoph Eggenberger, »Der Bodensee als Foyer der Überlieferung spätantiken Bild- und Bildungsgutes«, in: Geistesleben um den Bodensee im frühen Mittelalter, hrsg. von Аснім Masser und Alois Wolf (Literatur und Geschichte am Oberrhein 2), Freiburg i. Br. 1989, S. 1-11. S. 7. Ellen Judith BEER, »Überlegungen zu Stil und Herkunft des Berner PrudentiusCodex 264", in: FS Johannes Duft (1980) 1980, S. 15-70. S. 52. Hierzu stimmt, dass die Ergänzungen, mit denen in Dungals Prudentius-Handschrift Mailand Bibl. Ambr. D 36 die ausgefallenen Lagen gefüllt wurden, von der selben Vorlage wie Cod. Sang. 136 abstammen (Mirella Ferrari, "In Papia conveniant ad Dungalum», in: Italia medioevale e umanistica 15 (1972), S. 1-52. S. 40-52). Dungal kann sich dieser Vorlage bedient haben, bevor sie in den Bodenseeraum gelangte (Ebd. S. $47 \mathrm{f}$ ). 
Die Überlieferung der Gedichte des Venantius Fortunatus hat auch in St. Gallen eine Handschrift hinterlassen: Cod. Sang. $196 .{ }^{696}$ Sie enthält hauptsächlich die Carmina (pp. 2-373) von einer Hand ${ }^{697}$ und schließt mit Symphosius und Enigmata interrogativa ${ }^{698}$ (pp. 374-389). In der weitgehend auf westfränkische Textzeugen beschränkten Überlieferung der Carmina bleibt Cod. Sang. 196 im ostfränkischen Raum alleine erhalten, ${ }^{699}$ wenn auch Exemplare des Dichters auf der Reichenau sowie in Murbach vorhanden waren. ${ }^{700}$ Die weiteren westfränkischen Handschriften des Überlieferungszweiges deuten auf eine Herkunft des Textes, wenn auch nicht unbedingt der Vorlage, aus diesem Raum. ${ }^{701}$ Walahfrid verleiht, wahrscheinlich schon als Reichenauer Abt, die Werke des Venantius; ${ }^{702}$ es scheint nicht abwegig, dass der Dichter auf diesem Weg nach St. Gallen gekommen ist. Der Text des Symphosius ist unabhängig von dem in Cod. Sang. 273, ${ }^{703}$ sodass die ganze Handschrift aus auswärtigen Quellen zusammengetragen $\mathrm{zu}$ sein scheint. Die Handschrift wurde vorschnell als Schulhandschrift angesprochen, ${ }^{704}$ wobei vergessen wurde, dass Venantius schon aufgrund an den meisten Orten im Ostfrankenreich fehlender Handschriften kein etablierter Schulautor gewesen sein kann. Auch der "additional didactic content ${ }^{705}$ fällt bei genauerer Betrachtung dürftig aus: Es finden sich nur sechs volkssprachige Glossen unter den auch ansonsten nicht sehr dichten lateinischen

696 »[Wohl St.Gallen, IX.Jh., 3.Viertel]«: BischofF: Katalog, 3. Nr. 5653. Bernhard Bischoff, "Ursprung und Geschichte eines Kreuzsegens", in: Bischoff, Mittelalterliche Studien, 2, 1967, S. 275-283. S. 276. Bruckner: St. Gallen, 2. S. 39, 80. Stratton Hild: Verse, music, and notation. S. 247-254.

697 Nach BRUCKNER der gesamte Kodex von einer Hand, wiewohl ein Übergang von Venantius zu Symphosius zu beobachten ist.

698 Aus den Ioca monachorum: Walther SuCHIER, Das mittellateinische Gespräch Adrian und Epictitus nebst verwandten Texten (Joca Monachorum), Tübingen 1955. S. 122f. Frage und Antwort sind mit $\Delta$ (iscipulus) und $\mathrm{M}$ (agister) gekennzeichnet.

699 Antonio Placanica, »Venantius Fortunatus», in: La trasmissione dei testi latini del Medioevo, 2, hrsg. von Paolo Chiesa und Castaldi, Lucia 2005, S. 526-538. Marc Reydellet (Hrsg.), Venance Fortunat: Poèmes: Livres I-IV (Les Belles Lettres 315), Paris 1994. S. LXXILXXXV. Sigle G. Veraltet: Leo (Hrsg.): Venanti Honori opera poetica.

700 Siehe S. 170, $201 \mathrm{zu}$ den Katalogen. Venantius wird auch von Hrabanus in seinem Kreuzgedicht zitiert und war somit vielleicht in Fulda vorhanden.

701 Sigle V: Vat. lat. 552; D: BNF Lat. 9347; U: Brüssel B.R. 5354-5361.

702 »Walahfridi Strabi Carmina«, in: MGH Poet. lat. 2, hrsg. von Ernst DüMmLER 1884, S. 259466. V, xlv, 15.

703 D’Angelo: "Symphosii Aenigmata«. S. 416. Glorie (Hrsg.): Collectiones aenigmatum. S. 418. Sigle $S^{4}$.

704 Stratton Hild: Verse, music, and notation. S. 212, Anm. 212, aufgrund der Nennung in Alkuins Katalog der Bibliothek von York bei GLaUche: Schullektüre. S. 10-12.

705 Stratton Hild: Verse, music, and notation. S. 247. 
Synonymglossen, die bisweilen in kurze Erläuterungen auslaufen. ${ }^{706}$ Auf dem Vorsatzblatt finden sich ferner die griechischen Namen der Tierkreiszeichen, sowie zwei kleine griechisch-lateinische Glossare ohne Bezug zum Haupttext. ${ }^{707}$ Auch die Neumen zweier Gedichte illustrieren nicht, wie in Neapel Ms. IV G 68, das Versmaß, sondern haben musikalische Zwecke. ${ }^{708}$ Zuletzt erweckt auch die saubere und unverbrauchte Gestaltung der Handschrift kaum den Eindruck eines Schulexemplars, sondern vielmehr den eines sorgfältig abgeschriebenen Bandes für die Bibliothek, dessen Vorlage man sich von außerhalb zur Ergänzung der Sammlung mit diesem bisher nicht vorhandenen Autor besorgt hatte.

Eine weitere Handschrift, Cod. Sang. 263, ${ }^{709}$ soll hier bei den Autorenzentrierten Sammlungen genannt werden, da sie wahrscheinlich beim Verfasser des Eingangstextes eingereiht wurde. ${ }^{710}$ Sie enthält hauptsächlich Bedas Vita S. Cuthberti und Aldhelms Carmen de virginitate. ${ }^{711}$ Der Text Aldhelms ist eng mit dem anderer St. Galler Handschriften verwandt, ${ }^{712}$ von Bedas Vita dagegen wurden dagegen anscheinend keine Kopien gemacht oder diese gingen verloren. ${ }^{713}$ Die Gestaltung ist äußerst schlicht und der Text nur bei schwierigsten Vokabeln mit sparsamen Glossen versehen. ${ }^{714}$ Vielleicht als versus alii im Katalog vermerkt sind einige Gedichte Theodulfs an Modoin und Aigulf, sowie Modoins Antwort, ${ }^{715}$ mit denen die Handschrift schließt. Die Gedichte sind von gleicher Hand wie Aldhelm und erscheinen somit nicht nachträglich ergänzt worden zu sein. Der Hauptkatalog verzeichnet kein Werk Theodulfs, sodass die direkte

706 Bergmann/Stricker: Katalog. Nr. 200. Die "glosses explaining the poems' verse structures" (STRATton HiLD: Verse, music, and notation. S. 247) konnte ich leider nicht ausfindig machen.

707 Das obere, Inc. Xenodochium id est, auch in Clm 19413, f. 118r, und Cod. Sang. 397, p. 38, Cod. Sang. 299, p. 292f. Hierzu KaCzynski: »Some St. Gall Glosses on Greek Philanthropic Nomenclature

$708 »(\ldots)$ the neumes indicate how a repeating melody should be adjusted to different texts.«: Stratton Hild: Verse, music, and notation. S. 254.

709 »[St. Gallen, IX. Jh., 1./2. Viertel]«: Bischоғғ: Katalog, 3. Nr. 5705.

710 Hauptkatalog Nr. 2 (siehe S. 99), unter De libris Bedae Presbiteri: Miraculis Gudperti episcopi et Althelmi de laude virginum liber I et note iuris itemque versus alii, in volumine I. Identifiziert von SCHERRER: Stiftsbibliothek. S. 98, JAAGER (Hrsg.): Bedas metrische Vita sancti Cuthberti. S. 26, und EHWALD (Hrsg.): Aldhelmi Opera. S. 333f. Nicht übereinstimmend und somit eine Identifikation vielleicht ausschließend sind die note iuris; die sich an Aldhelm anschließenden Gedichte Modoins sind von gleicher Hand wie das Vorhergehende.

711 JaAger (Hrsg.): Bedas metrische Vita sancti Cuthberti. Sigle $\mathrm{G}_{1}$. S. 26. Ehwald (Hrsg.): Aldhelmi Opera. S. 327-471. Sigle S2. S. 363.

712 Ehwald (Hrsg.): Aldhelmi Opera. S. 334-338.

713 JAAGER (Hrsg.): Bedas metrische Vita sancti Cuthberti. S. 26, S. 35. G = Cod. Sang. 265, mit Ermenrichs Epistola, siehe oben S. 89.

714 Bergmann/Stricker: Katalog. Nr. 212.

715 »Theodulfi Carmina«, in: MGH Poet. lat. 1, hrsg. von Ernst DüMmLer 1881, S. 437-581. LXXII, i, ii, iii, iv (S. 563-568); LXXI (S. 560-563), LXXIII, (S. 569-573), Sigle G. Schaller: "Gedichte Theodulfs«. S. 41-68. Sigle $\mathrm{G}_{1}$ und G (Edition des Briefes an Modoin). 
Vorlage unklar ist. In anderen Klöstern dagegen gab es die Dichtung des Westgoten: In Murbach in einem Sammelband mit versus Theodolfi, ${ }^{716}$ und in Lorsch sogar mit anscheinend genau denselben Texten wie in Cod. Sang. 263: Versus Theodolfi ad Moduinum et Moduinus ad Theodolfo (!) in quaternionibus $V,{ }^{717}$ wobei der Umfang erstaunt und weitere Inhalte erahnen lässt. Schaller vermutet Empfängerüberlieferung hinter den Theodulf-Gedichten von Cod. Sang. 263, also eine Vermittlung aus Modoins Hand. ${ }^{718}$ Hier ist interessant, dass Walahfrid Modoin persönlich um Gedichte gebeten hat und somit der Nexus für die Vermittlung der kleinen Sammlung sein könnte. ${ }^{719}$ In St. Galler Handschriften vom Ende des Jahrhunderts finden sich noch mehr Gedichte Theodulfs, ${ }^{720}$ hervorzuheben ist Zürich C $78,{ }^{721}$ pp. $86 \mathrm{v}-91$ r, wo exakt die gleiche Sequenz von Gedichten zu finden ist wie in Cod. Sang. 263. Die genaue Abhängigkeit der Textzeugen voneinander ist unklar. ${ }^{722}$ Von ihrer schlichten Aufmachung her scheint die Handschrift durchaus für schulischen Gebrauch geeignet, vielleicht dazu gefertigt worden zu sein. ${ }^{723}$ Auch die Gegenwart des zeitgenössischen Dichters muss hiergegen kein Argument sein: Auf der Reichenau gab es einen grammatischen Sammelband mit einem Gedicht Modoins am Schluss, ${ }^{724}$ in Salzburg enthält Clm 6404 ein Gedicht Walahfrids. Dagegen lassen die fehlenden Nutzungsspuren darauf schließen, dass Cod. Sang. 263 nie den Weg in die Schule gefunden hat.

Vom Ende des Jahrhunderts, aus der Zeit Salomos III. und seines Kreises, datiert Cod. Sang. 197, ${ }^{725}$ der auf eine Vorlage aus der Zeit Grimalds zurückgeht.

716 GeIth/Berschin: »Bibliothekskataloge«. Nr. 24, siehe auch S. 24.

717 HäSE: Bücherverzeichnisse. Nr. (416).

718 SCHALlER: „Gedichte Theodulfs«. S. 67, spezifisch zu Carmen LXXII an Modoin (Archetyp $\mathrm{Y}^{*}$, woraus er T (Zürich C 78) und G hervorgehen lässt); dagegen rekonstruiert SCHALLER später für die Textgemeinschaft der Carmina LXXII-LXXI-LXXIII eine Überlieferung aus der Briefsammlung Theodulfs (Dieter Schaller, "Geraldus und St. Gallen - Zum Widmungsgedicht des >Waltharius «, in: Mittellateinisches Jahrbuch 2 (1965), S. 74-84.).

719 »Walahfridi Carmina«. V, vi. SCHALLER: »Gedichte Theodulfs«. S. 78-80, zieht neben Walahfrid auch eine Vermittlung durch Grimald in Betracht.

720 St. Gallen Ms. 197, 899, Zürich C 78. Vgl. die Tabelle in Schaller: "Gedichte Theodulfs«. S. 16b.

721 »[St. Gallen], (...) »um 900«): Bischoff: Katalog, 3. Nr. 7578. SchalleR: »Gedichte Theodulfs«. Sigle T.

722 Laut SCHALleR:»Gedichte Theodulfs«. S. 60-63, 67, hängt Cod. Sang. 263 (G) von Zürich C 78 (T) ab, was aufgrund der neueren Datierung zu bezweifeln ist. Auch eine gemeinsame Vorlage als Zwischenstufe $\mathrm{zu}^{*} \mathrm{Y}$, dem hypothetischen Exemplar Modoins, kann nicht ausgeschlossen werden.

723 Ebd. S. 60, vermutet SCHALLER im korrigierten Text des Briefes an Modoin »eine Frucht des St. Gallener Schulbetriebs«.

724 Siehe S. 170, Reichenau, Hauptkatalog Nr. 13.

725 "[St.Gallen, (IX./)X.Jh.]«: Bischoff: Katalog, 3. Nr. 5655. Bergmann/Stricker: Katalog. Nr. 201. Bruckner: St. Gallen, 2. S. 80f., S. 37, Anm. 183. Ernst DüMmLer, »St. Gallische 
Die Ergänzungen der Handschrift stammen aus dem Salomo-Kreis um die Jahrhundertwende. In ihr dominiert das Bibelepos des Alcimus Avitus. ${ }^{726}$ Von diesem Werk ist sie der Hyparchetyp der gesamten ostfränkischen Überlieferung. Ob die Handschrift selbst schon im Hauptkatalog (860-880) verzeichnet ist, ${ }^{727}$ hängt davon ab, ob die Gedichte Waldrams und Salomos pp. 300-328 (nach 900) eine spätere Ergänzung sind. Schon deren Umfang sollte skeptisch machen; zudem ist die gesamte Handschrift von großer Gleichförmigkeit der Schrift. ${ }^{728}$ Eine Änderung im Schriftbild ist allenfalls von p. 280-281 wahrzunehmen, dem Beginn der anonymen Praecepta Vivendi, ${ }^{729}$ von denen jedoch anzunehmen ist, dass sie als Ergänzung zu Alcimus Avitus gedacht sind. Denn Notker Balbulus, in seinem Lehrbrief zur christlichen Literatur an seine Schüler Salomo und Waldo, lobt Alcimus Avitus in einem Atemzug mit den Praecepta Vivendi, die er für ein Werk des Dichters hält und die er seinen Schülern zur Anschaffung empfiehlt. ${ }^{730}$ Dass nun ausgerechnet diese beiden Werke sich hier in einer Handschrift beieinander finden, die auch noch Gedichte des von Notker adressierten Salomos enthält, lässt vermuten, dass dieser als Abt die Textzusammenstellung in einer neuen Handschrift veranlasste, wobei auf die schon vorliegende, im Katalog verzeichnete Avitus-Handschrift zurückgegriffen wurde. ${ }^{731}$ Dem steht entgegen, dass die Praecepta hier unter dem Titel Incipit libellus cuiusdam sapientis et ut fertur beati Columbani vorliegen, also nicht mit Avitus in Verbindung gebracht

Denkmale aus der karolingischen Zeit«, in: Mitteilungen der Antiquarischen Gesellschaft in Zürich 12 (1859), S. 206-265. S. VIII.

726 Rudolf PeIPer (Hrsg.), Alcimi Ecdicii Aviti Viennensis episcopi Opera quae supersunt (MGH AA 6, 2), Berlin 1883. Sigle G, S. LXI f. Alexander ArweILER, Die Imitation antiker und spätantiker Literatur in der Dichtung "De spiritalis historiae gestis" des Alcimus Avitus: mit einem Kommentar zu Avit. carm. 4,429-540 und 5,526-703 (Untersuchungen zur antiken Literatur und Geschichte 52), Berlin [u. a.] 1999.

727 Nr. 8. Metrum Alcimi Aviti episcopi, libri VII in volumine I. So Bergmann/Stricker: Katalog. PeIPer (Hrsg.): Alcimi Aviti Opera. a.a.O.

728 DüMmLER: »St. Gallische Denkmale aus der karolingischen Zeit«. S. VII. Auch bei BISCHOFF: Katalog, 3. Nr. 5655 pp. 123-328 als Einheit verstanden. Dagegen: Bergmann/Stricker: Katalog. S. 501.

729 SK 5960, "Alcuini Carmina«, in: MGH Poet. lat. 1, hrsg. von Ernst DüMmLer 1881, S. 239241. Nr. 62. S. $275-281$.

$730 »$ Notatio«. S. S. 65, Z. 183-186:»Alcimus autem nomine auitus, licet hystoriam geneseos quasi solam assumpserit, tamen omnia nostra dulcissimo carmine decantauit et pulcherrimum librum de uirginitate ad sororem suam conscripsit et alium de institutione mortalium. Pro quo tu librum elegisti Catonianum, sed hunc quantotius facito tuum esse. « Das Werk De institutione mortalium mit den Praecepta identifiziert bei Peiper (Hrsg.): Alcimi Aviti Opera. S. LXXII. Ebenso BoAs: Alcuin und Cato. S. 15, Anm. 52, siehe diesen Artikel überhaupt zur Verfasserfrage.

731 Waldram war um die Zeit der Entstehung der Handschrift herum Bibliothekar von St. Gallen. 
werden. Aber vielleicht wurde hier auch nur, nachdem Notkers Irrtum ${ }^{732}$ bezüglich der Zuschreibung erkannt und das Werk aufgefunden worden war, der Titel der Vorlage kopiert. Ein weiteres Indiz für eine Zusammenstellung auf Veranlassung Salomos ist der folgende Faszikel der Handschrift (pp. 329-398), wenn auch vielleicht französischer Herkunft, ${ }^{733}$ der Juvencus und Sedulius enthält, ${ }^{734}$ die von Notker gleich darauf empfohlen werden. Wann die Handschrift zusammengebunden wurde, lässt sich hier nicht feststellen. Theodulfs auf die Praecepta Vivendi folgende Einleitung einer Bibelpandekte ${ }^{735}$ nimmt den Faden der Bibeldichtung wieder auf. Die kleine Anthologie der Gedichte Waldrams und Salomos (pp. 300-328) ${ }^{736}$ dagegen verlässt das Genre und widmet sich der Briefdichtung. Enthalten sind insbesondere konsolatorische Briefe Waldrams und Salomos an Dado von Verdun. Es besteht kein Zweifel, dass die Anthologie aus dem Salomo-Kreis stammt und dass also dort die Gelegenheitsdichtung gesammelt und aufbewahrt wurde. In Cod. Sang. 197 und der enthaltenen Textgemeinschaft erscheinen somit sowohl Notkers Einfluss als Lehrer und Vorbild, dessen Lektüreprogramm hier verwirklicht wurde, als auch das Selbstbewusstsein der »Dichterschule von St. Gallen«, die hier ihre vorher gesammelten Werke in einer gestalterisch durchaus anspruchsvollen, wenn auch nicht luxuriösen Handschrift kodifizierte.

In Cod. Sang. $869^{737}$ hat Walahfrid als einer der wenigen zeitgenössischen Dichter die Ehre erfahren, dass sein Werk in einer fast nur seiner Dichtung gewidmeten Sammelhandschrift zusammengefasst wurden. Bis auf Spuria in den

732 Vielleicht zurückgehend auf eine Verwechslung zwischen Alcuinus und Alcimus (Peiper (Hrsg.): Alcimi Aviti Opera. S. LXXII).

733 Bischoff: Katalog, 3. Nr. 5656. Dagegen St. Gallen: Bergmann/Stricker: Katalog. a.a.O.

734 SPRINGER: Handlist. S. 97 f. MAROLD (Hrsg.): Iuvencus. S. XV. Der Iuvencus-Text ist verwandt mit Clm 6402 aus Freising (wo Waldo Bischof war): Ebd. S. XIV-XV.

735 Quicquid ab hebraeo, SK 13427, carm. 41.1, DüMmLer (Hrsg.): MGH Poet. lat. 1. S. 532-538. KIRSCH: Laudes sanctorum. S. 973.

736 Winterfeld (Hrsg.): MGH Poet. lat. 4, 1. S. 297-314. Zur Verfasserfrage siehe die Einleitung dort. Zu Waltram vgl. Franz Josef WorstвRock, »Art. Waldram (Walth-, Walt-) von St. Gallen OSB«, in: Verfasserlexikon, 10, 1999, S. 614-617. Seine Dichtung wurde so hoch geschätzt, dass er das Empfangsgedicht für König Konrad im Jahre 911 verfassen durfte (Felix HeInzer, »Rex benedicte veni. Der Weihnachtsbesuch König Konrads I. in St. Gallen im Dezember 911«, in: Adel und Königtum im mittelalterlichen Schwaben: Festschrift für Thomas Zotz zum 65. Geburtstag, hrsg. von Andreas BiHRER (Veröffentlichungen der Kommission für geschichtliche Landeskunde in Baden-Württemberg. Reihe B 175) 2009, S. 115-126.).

737 "[St.Gallen, IX.Jh., (3./)4. Viertel] «: Bischoff: Katalog, 3. Nr. 5855. Visser: Sis memor. S. 16-19, 76-80. Herren: »The >De imagine Tetrici of Walahfrid Strabo«. S. $120 \mathrm{f}$. Alf ÖNNERFors, »Philologisches zu Walahfrid Strabo«, in: Mittellateinisches Jahrbuch 7 (1972), S. 41-92. S. 51. BernT: Epigramm. S. 242 f. BRUCKNER: St. Gallen, 2. S. 120. DüMMLER: »Die handschriftliche Überlieferung«. S. 271-274. SCHERRER: Stiftsbibliothek. S. 300. 
Nachträgen und Aldhelms Carmina Ecclesiastica ${ }^{738}$ in den letzten drei Lagen, sind nur Werke Walahfrids enthalten. Diese Handschrift, die großenteils von einer Hand geschrieben wurde, trägt den Charakter einer sorgfältigen, planvollen Autorensammelhandschrift, ${ }^{739}$ wie sie sonst nur den klassischen christlichen Dichtern zugedacht wurde. Da die Überlieferung des Walahfridschen Korpus schon bei Cod. Sang. 899 und Reg. lat. 469 behandelt ist, und Cod. Sang. 869 von Visser eingehender behandelt wurde ${ }^{740}$ gilt es hier nur noch auf einzelne Aspekte hinzuweisen und die Tradition in großen Zügen zu skizzieren.

Keine der Walahfrid-Anthologien kann Quelle der anderen gewesen sein, da jede Sondergut gegenüber den anderen enthält. Aus textkritischen Gründen scheidet spezifisch Reg. lat. 469 als Vorlage aus. ${ }^{741}$ Somit gehen die St. Galler Handschriften und vielleicht auch die Fuldaer auf eine in St. Gallen vorhandene, umfangreiche Anthologie Walahfrids zurück, die man mit Visser als $a$ bezeichnen kann. ${ }^{742}$

Die Vorlage scheint in Cod. Sang. 869 an einigen Stellen durch. Paläographisch ist folgendes zu beobachten: Der Hauptschreiber I schreibt die Handschrift nicht in einem Zuge aus einer Vorlage ab, sondern in Gruppen von Lagen oder Einzellagen, wie an einigen Freiräumen an den Lagenenden zu beobachten ist, wo Schreiber Ia und II Nachträge ergänzen. ${ }^{743}$ Die Einheiten sind folgende: I-VII (Vita Mammae, ${ }^{74}$ Vita Blaithmaic, Visio Wettini), VIII (Anthologie), VIIII (Anthologie), X-XII (Anthologie a-c), XIII-XIIII (Anthologie), [XV-XVII] (Verloren) XVIII-XX (Aldhelm, Miscellanea). ${ }^{745}$

Schreiber I fertigt also keine durchgehende Abschrift der Vorlage an, bei welcher keine Freiräume am Lagenende geblieben wären. Wie ist dieser Befund zu erklären? I-VII wurden offensichtlich en bloc aus der Vorlage übernommen

738 Ehwald (Hrsg.): Aldhelmi Opera. S. 3-32. Eine Kuriosität der Überlieferung ist, dass die Folge der Carmina Ecclesiastica in Cod. Sang. 869 exakt die gleiche ist, wie im verloren gegangenen Codex Bertinianus, der die Dichtungen Alkuins enthielt (Ebd. S. 10; siehe S. 268-271 zu Salzburg), und beide Handschriften mittelbar von einem Hyparchetyp abhängen.

739 Durchgehende Rubrizierung und zeilenübergreifende Initialen der Gedicht-Initiien.

740 VISSER: Sis memor. S. 76-80, mit Inhaltsangabe, Schreibern, Kollationierung (ohne Lagenformel).

741 Siehe S. 75f. zu Vatikan, BAV, Reg. Lat. 469.

742 VISSER, S. 21, möchte $a$ ebenfalls als diffuse Quelle verstanden wissen (»not understood as a complete or semi-complete collection, or even as a hypothetical manuscript, but as a collection of sources for those of Walahfrid's poems which do not occur in manuscripts other than Stiftbibliothek 869«).

743 Ausnahmen sind Lagen I-II, wo die Vita Mammae durchgehend kopiert wurde, und IV-VII, verbunden durch die Visio Wettini.

744 Solinski: "De uita et fine sancti Mammae».

745 Was die verlorenen Lagen XV-XVII genau enthielten, ist unklar. 
und bilden eine kodikologische Einheit. ${ }^{746}$ Die folgende Anthologie dagegen zerfällt in mehrere, unabhängige Stücke. Es scheint, dass Schreiber I einzelne, leere Lagen oder nach Bedarf Hefte zum stückweisen Exzerpieren aus der Vorlage gebrauchte und diese dann erst, als sie gebunden waren, mit den Zusätzen versehen wurden.

An einigen Stellen erscheinen noch Indizien zur größeren Struktur der Vorlage. Auf p. 202, also gegen Ende der Handschrift, beginnt die neue Lage XIII mit dem Titel Versus Strabi Walahfridi quos post annum aetatis XV edidit de rebus diversis, wo durch das de rebus diversis klar eine Anthologie bezeichnet wird, ${ }^{747}$ im Gegensatz zu den Versus in Aquisgrani palatio editi anno Hludowici imperatoris $X V I$, p. 143, die Visser ähnlich verstanden wissen will, die aber klar nur das folgende Gedicht bezeichnen. ${ }^{748}$ Dümmler postulierte deshalb eine Versetzung der Lagen XIII-XIIII vor Lage VIII, wo die eigentliche Kleindichtung nach Viten und Visio beginnt. ${ }^{749}$ Kodikologisch kann hier nichts entschieden werden, da keine lagenübergreifenden Texte die Reihenfolge feststellen ließen. Die Unabhängigkeit der Lagengruppen voneinander erleichtert jede spätere Verwirrung der Reihenfolge, wobei jedoch aus inhaltlich plausiblem Grund die Lagen XIIIXIIII, mit dem einleitenden Titel, an Anfang der Anthologie ihren Platz haben könnten; die zumindest nicht viel spätere Nummerierung der Lagen spricht jedoch für die Ursprünglichkeit der heutigen Lagenfolge. Eine andere Möglichkeit ist, dass Lagen XIII-XIIII, sowie die verlorenen XV-XVII, eine vollständige Kopie eben dieser vielleicht von Walahfrid selbst ${ }^{750}$ gesammelten Anthologie sein könnten, also aus einer separaten Vorlage stammen. Hiermit würde sich a nicht als einzelne Handschrift, sondern als lose Sammlung Walahfridschen Materials darstellen.

Weiter kompliziert wird die Lage noch durch eine zweite Reihe von Reklamanten a-c die über den Reklamanten der Lagen X-XII stehen, ohne dass klar wäre, welche die älteren sind. Diese Lagen sind auch thematisch durch ihre Konzentration auf Gedichte vom Hofe geprägt ${ }^{751}$ und durch kontinuierlichen

746 Die Vorlage wäre identisch mit der Vorlage $\Omega$ der Vita Mammae (Solınski: »De uita et fine sancti Mammae«. S. 7-12).

747 Zum Beispiel auch Alkuins versus illius in diversos in I. Cod und Hrabans Versus Hrabani de diversis in Fulda oder Fortunati libri XI de diversis rebus und Prudencius de diversis rebus et diverso metro in Murbach.

748 VISSER: Sis memor. S. 18. Das Wort wird im Epilog des Gedichtes, p. 163, wieder aufgenommen: Edidit haec Strabus. Dass Versus hier im Plural steht, hat nichts zu bedeuten, denn Versūs (=Gedicht) steht als Überschrift immer und überall im Plural, auch wenn es nur Titel eines einzelnen Gedichts oder auch nur eines Distichons ist, was nicht ungewöhnlich ist, so auch in den Überschriften in Cod. Sang. 869 selbst.

749 Ebd. Siehe dort ebenfalls zu Dümmlers quellenfernem Verfahren, in die so hergestellte Sequenz auch die anderswo überlieferten Gedichte einzuordnen.

750 BRUNHöLzL: Geschichte, 1. S. 348.

751 VISSER: Sis memor. S. 17. 
Text über die Lagenübergänge als Einheit gekennzeichnet. Die separate Nummerierung impliziert, dass diese drei Lagen zu irgendeinem Zeitpunkt als gesonderter libellus vorlagen. ${ }^{752}$ Dennoch sind sie textlich nicht vom Rest der Handschrift isoliert: Das Gedicht De imagine Tetrici fängt mit Lagenbeginn auf VIIII an und bricht merkwürdigerweise wieder ab (pp. 143-152 = vss. 1-157), worauf Schreiber I mit einem Gedicht auf die Makkabäer fortfährt und zwei Seiten frei lässt, die von Schreibern Ia und II gefüllt werden. De imagine Tetrici setzt wieder, mit dem Untertitel De Hlothario imperatore, auf Lagenbeginn von X (a) ein (pp. 157-163 = vss. 158-262). Schon in der Vorlage scheint eine Versetzung der Verse 158-238 (Lobgedichte) stattgefunden zu haben. ${ }^{753}$ Warum Schreiber I die Niederschrift des Gedichts unterbrochen hat, ist unklar; es scheint, dass schon ihm die Einheit des Werkes nicht klar war, da die Lobgedichte auf Höflinge mit ihren Untertiteln durchaus den Eindruck eigenständiger Epigramme erwecken. Die Zerstückelung des Gedichts scheint somit ebenfalls dem Verfahren des Schreibers und Kompilators, einzelne Stücke herauszukopieren, geschuldet zu sein. Dass in Lagen X-XII (a-c) die Hofdichtung dominiert, lässt jedoch auf einen ähnlichen Schwerpunkt in der Vorlage schließen.

Die St. Galler Vorlage $a$ von Cod. Sang. 869 wird durch das Verfahren des Kompilators verdunkelt; sicher ist, dass sie von bemerkenswertem Umfang und Vollständigkeit war, insbesondere insofern wir annehmen, dass sie auch die nur in Reg. lat. 469 enthaltenen Gedichte ${ }^{754}$ aufwies. Warum aber bestand Bedarf nach einer Abschrift dieser ohnehin vorhandenen Walahfrid-Anthologie, die ja das am Ende des Jahrhunderts in St. Gallen auftretende Kodifizierungsbedürfnis, wie es auch in Cod. Sang. 899 und Zürich C 78 auftritt, befriedigt hätte? Vielleicht handelte es sich bei $\alpha$ gar nicht um eine einzelne Handschrift, sondern um eine nur teilweise kodifizierte Sammlung der Gedichte Walahfrids? Die größeren Werke auf Lagen I-VII scheinen zusammenhängend vorgelegen zu haben; der Rest in mehr oder minder umfangreichen Stücken, darunter vielleicht die Anthologie des Titels Versus Strabi Walahfridi quos post annum aetatis XVeditit de rebus diversis. Ein Vorliegen von $\alpha$ in unabhängigen Heften macht auch das stückweise Verfahren des Kompilators praktikabler, als es bei einer unitären Vorlage gewesen wäre. Cod. Sang. 869 scheint somit der Versuch zu sein, das in St. Gallen vereinzelt vorliegende Werk des Dichters in eine Autorensammelhandschrift zusammenzufassen. Dass die Verfertigung der Handschrift ins »(3./) 4. Viertel« des Jahrhunderts fällt, in die Wirkungszeit Grimalds, des Freundes und Lehrers des Dichters, macht einen Impuls von seiner Seite oder vielleicht

752 Ebd. S. 17.

753 Herren: "The >De imagine Tetrici of Walahfrid Strabo«. S. 121. In dieser Edition ist die Versfolge berichtigt, leider ohne Konkordanz zur Zählung der Ausgabe Dümmlers.

754 Visser: Sis memor. S. 80. Siehe auch S. 75f. zu Reg. Lat. 469. 
einen Rückgriff auf seine eigene Sammlung der Werke des Freundes wahrscheinlich. ${ }^{755}$

In der umfangreichen hagiographischen Sammlung St. Gallens, die im Hauptkatalog verzeichnet ist, ${ }^{756}$ findet sich keine Dichtung. Dennoch ist eine Handschrift erhalten, Cod. Sang. 573, ${ }^{757}$ die fast nur metrische Viten und Visionen enthält und in denen sich also ein gezieltes Bemühen zeigt, diese Untergattung in einer dezidierten Handschrift zu sammeln. Vier Schreiber, die über Lagengrenzen hinweg arbeiten, übernehmen jeweils thematisch gesonderte Teile der Handschrift: ${ }^{758}$

A (pp. 2-172): Paulinus von Périgueux: Vita metrica Sancti Martini; De visitatione nepotuli sui. Die weiteren Textzeugen dieses Werkes, das eine Metrifikation der Vita Martini des Sulpicius Severus darstellt, ${ }^{759}$ verweisen in den westdeutsch/west-fränkischen Raum. ${ }^{760}$ Der Text von Cod. Sang. 573 wurde intensiv korrigiert und interpoliert, ${ }^{761}$ wahrscheinlich jedoch schon in der Vorlage, da die Handschrift keine Spuren der Textarbeit trägt.

B (173-293): Venantius Fortunatus: Vita metrica sancti Martini; Carmen Spurium. ${ }^{762}$ Die Vita nahm einen anderen Weg nach St. Gallen als die Carmina in Cod. Sang. 196. Die nächstverwandten Handschriften sind westfränkische Sam-

755 Ähnlich auch Ebd. S. 22.

756 LEHMANN (Hrsg.): MBK. 1, S. 77-79. Zu hagiographischen Handschriften und Hausliteratur: Ernst Tremp und Karl SснмuкI, Geschichte und Hagiographie in Sanktgaller Handschriften, St. Gallen 2003. Berschin: Biographie und Epochenstil im lateinischen Mittelalter, 3. S. 272-303.

757 pp. 1-172: »[St. Gallen keineswegs sicher, IX. Jh., ca. 3. Viertel]«; pp. 173-476: »[St.Gallen, IX.Jh, 3.Viertel (oder Mitte?)]«: Bischoff: Katalog, 3. Nr. 5805, 5807. Dagegen ganz St. Gallen zugeordnet bei: SCARPatetti: Codices 547-669. S. 84-87. Die zeitgenössischen Kustoden auf allen Lagen sprechen für eine kodikologische Einheit.

758 Nach: SCARPATETTI: Codices 547-669. S. 84. Für Hinweise auf Editionen und Literatur siehe ebendort.

759 Alston Hurd CHASE, »The metrical lives of St. Martin of Tours by Paulinus and Fortunatus and the prose life by Sulpicius Severus", in: Harvard studies in classical philology 43 (1932), S. 51-76.

760 Labarre (Hrsg.): Vie de saint Martin. S. 61f. Petschenig/Schenki/Brandes (Hrsg.): Poetae Christiani minores. S. 3-15. Labarre: "La transmission de Paulin de Périgueux«. S. 123f., 134, 146f. Bei Petschenig ist Cod. Sang. 573 (Sigle S) Schwesterhandschrift der Vorlage von Pal. lat. 845 (P; Mainz) und Vat. lat. 1664 (V; Westdeutschland? Italien?), während der codex optimus R: Reg. lat. 582 aus »Orleans (?) (oder Umkreis)« stammt (Bischoff, Katalog: V: Nr. 6861; P: 6562; R: 6707). LABARRE dagegen sieht in Montpellier H 352 den nächsten Verwandten (M; »Östliches Frankreich (?)«: BISCHOFF, Katalog, Nr. 2862). Die Überlieferung tendiert in jedem Falle ins Westfränkische: Ebd. S. 134.

761 Petschenig/Schenkl/Brandes (Hrsg.): Poetae Christiani minores. S. 10-12.

762 SK 8941. Auch in Voss. Lat. Q. 69, siehe S. 83. Es besteht keine Verbindung zwischen den Handschriften. 
melbände aus Carmina und Vita, ${ }^{763}$ wobei Cod. Sang. 573 besonders eng mit Mailand Bibl. Ambr. C. 74 sup., der Anthologie Dungals, verwandt ist.

C (294-408): Heito: Visio Wettini; Walahfrid: Visio Wettini; Visio cuiusdam pauperculae; Visio Baronti; Beda: Versus de die iudicii; Carmen acrostichon ad Lotharium regem. ${ }^{764}$ Das Korpus der Visionen, die hier aus verschiedenen Quellen vereint sind, scheint aus dem Bodenseegebiet, genauer von der Reichenau, zu stammen. Die Visio Wettini in beiden Fassungen in einer Handschrift gab es auch dort, angeschafft von Reginbert. ${ }^{765}$ Im selben Reginbert-Band befand sich auch die Visio Baronti. In Grimalds Privatbibliothek sind ebenfalls die Visiones Vvettini et Baronti verzeichnet. ${ }^{766}$ Die Visio cuiusdam pauperculae steht im nicht sicher der Reichenau zugewiesenen Katalog von Donaueschingen Cod. 191. Der Ursprung der gesammelten Texte scheint somit klar die Reichenau zu sein. Die genaue Vermittlung ist unklar; da aber auch Grimald einen Band mit einzelnen in Cod. Sang. 573 enthaltenen Texten sein eigen nannte, ist es nicht abwegig, in diesem Schüler und Verwandten Wettis den Vermittler der Visionen $\mathrm{zu}$ vermuten.

D (408-466): Vita Leodegarii metrica. ${ }^{767}$ Cod. Sang. 573 ist der einzige Textzeuge. Zu bemerken ist, dass Reginbert in einem Sammelband mit Viten (Nr. XIII) auch eine des Leodegars besaß; es ist unklar, ob diese auch die metrische war. C (466-476): Paulus Diaconus: Epigramme. ${ }^{768}$ Carmina dubia. ${ }^{769}$ Den Rest der Lage XXX, auf der sich die Vita Leodegarii nur bis p. 466 erstreckt, füllt Schreiber B mit einigen Gedichten, von denen zwei auch in der älteren St. Galler Handschrift Voss. Lat. Q. 69, 12va-13va, eines jedoch gekürzt, vorkommen. Cod. Sang. 573 stellt sich somit als eine planvolle Sammlung metrischer Viten und Visionen aus verschiedenen Quellen dar. Die Kooperation der Schreiber suggeriert eine von Anfang an zielgerichtete Herstellung des Sammelbandes, gleich der des Passionarium novum (Cod. Sang. 577), in dem zahlreiche prosaische Viten und Legenden vereint wurden. Der Impuls zur Kodifizierung ansonsten zerstreuter oder gar nur von auswärts erhältlicher Literatur trifft sich in Cod. Sang.

763 Leo (Hrsg.): Venanti Honori opera poetica. S. XXII f. Die Handschriften dieses Zweiges: B (BNF Lat. 8090) \& L (Laon Ms. 469), S (Cod. Sang. 573) \& M (Mailand, Bibl. Ambr. C 74), Bischoff, Katalog: B: Nr. 4528, L: 2129, M: 2630.

$764 »$ Walahfridi Carmina«. V, 88.

765 Erich Kleinschmidt, „Zur Reichenauer Überlieferung der >Visio Wettini< im 9. Jahrhundert«, in: Deutsches Archiv für Erforschung des Mittelalters 30 (1974), S. 199-207. S. 201, 207. Reginbert-Liste, Nr. V.

766 Lehmann (Hrsg.): MBK. 1, S. 84, Z. 30 f. Nicht erwähnt von Kleinschmidt.

767 MGH Poetae 3, S. 1-37. Kirsch: Laudes sanctorum. S. 793-804.

768 SK 11066, 237.

769 SK 195, 955, 3979, 3976, 5869. 
573 mit der Schätzung der Dichtung als separater Gattung, ${ }^{770}$ die sich auch in eigenständigen Produktionen wie der Vita St. Galli Metrica oder Notkers Metrum de vita S. Galli ausdrückt.

Die umfassendste der ostfränkischen Anthologien, Cod. Sang. $899,{ }^{771}$ hat gerade in jüngster Zeit weniger Aufmerksamkeit erfahren, als das um sich greifende Interesse für Gedichthandschriften hätte vermuten lassen sollen. ${ }^{772}$ Sie ist sie ein eindrucksvolles Zeugnis der Sammeltätigkeit in St. Gallen am Ende des Jahrhunderts, wo mit sicherem Griff aus verschiedenen Quellen Dichtung gesammelt und in einer dezidierten Gedichthandschrift verwahrt wurde. Der folgenden Diskussion soll eine Inhaltsangabe hauptsächlich der poetischen Teile der bisher nicht befriedigend katalogisierten Handschrift vorausgehen:

\begin{tabular}{|l|l|l|l|}
\hline p. & Hand & Incipit & Inhalte, Anmerkungen \\
\hline Cod. Sang. 899 & A & $\begin{array}{l}\text { Petis a me } \\
\text { litteras }\end{array}$ & $\begin{array}{l}\text { Epistola Symmachi I, XIII, ad Ausonium. }{ }^{773} \text { Über die } \\
\text { Mosella des Ausonius, gewöhnlich derselben vorange- } \\
\text { stellt. }\end{array}$ \\
\cline { 1 - 1 } 3 & Est et non cuncti & $\begin{array}{l}\text { SK } 4582 .{ }^{774} \text { Ausonius, carm. XXXI. Über die Worte Est } \\
\text { et Non. }\end{array}$ \\
\cline { 3 - 4 } & & $\begin{array}{l}\text { Ter binos } \\
\text { deciesque }\end{array}$ & $\begin{array}{l}\text { SK 16238. Ausonius, carm. XXXII. De aetatibus ani- } \\
\text { mantium Hesiodion. Über v. 1 nachgetragen: centum et }\end{array}$ \\
\hline
\end{tabular}

770 Noch untergeordnet zum Beispiel im Sammelband zu Gallus und Otmar in Wolfenbüttel, HAB, Cod. 17. 5. Aug. $4^{\circ}$, wo Hymnen an die Heiligen an deren Viten angehängt sind (Otto Heinemann, Die Augusteischen Handschriften: Codex Guelferbytanus 77.4 Aug. $2^{\circ}$ bis 34 Augusteus $4^{\circ}$, Nachdr. der Ausg. 1900 (Kataloge der Herzog-August-Bibliothek Wolfenbüttel 7), Frankfurt a. M. 1966. S. 205f. Bischoff: Katalog, 3. Nr. 7296).

771 Mit ausgefallenen Blättern in Reg. Lat. 421f. 20, 27-28, [33?]. "St. Gallen, IX. Jh., gegen Ausgang«: Bischoff: Katalog, 3. Nr. 5865. Reg. Lat. 421: Wilmart: Codices Reginenses Latini. S. 510-516.

772 Die beste Inhaltsangabe ist immer noch: Steinmeyer/Sievers (Hrsg.): Die althochdeutschen Glossen. 4, S. 456-459. Zu den enthaltenen Gedichten: DüMmLER: "Die handschriftliche Überlieferung". S. 106-108. Weitere, meist nur summarische Beschreibungen: DÜMMLER: „St. Gallische Denkmale aus der karolingischen Zeit«. S. V-VII. Ernst DüMMLER, "Gedichte aus dem Hofkreise Karls des Großen", in: Zeitschrift für deutsches Altertum und deutsche Literatur 12 (1865), S. 446-460. Scherrer: Stiftsbibliothek. S. 315f. Karl NefF (Hrsg.), Die Gedichte des Paulus Diaconus: kritische und erklärende Ausgabe (Quellen und Untersuchungen zur lateinischen Philologie des Mittelalters 3, 4), München 1908. S. XV f. Reynolds: Texts and transmission. S. 27. Bergmann/Stricker: Katalog. Nr. 251. Visser: Sis memor. S. 20. Ebenso verstreut in den Bänden der MGH Poetae, sowie in den einschlägigen Editionen der enthaltenen Dichter.

773 Schenkl (Hrsg.): Ausonii Opuscula. S. 81 f. Joachim Gruber (Hrsg.), D. Magnus Ausonius, "Mosella«: kritische Ausgabe, Übersetzung, Kommentar (Texte und Kommentare 42), Berlin 2013. S. $280-285$.

774 Zählung der Werke des Ausonius nach: Schenkl (Hrsg.): Ausonii Opuscula. Siehe je SChaller und Könsgen, Initia carminum für Verweise auf Rudolf Peiper (Hrsg.), Decimi Magni Avsonii Burdigalensis opuscula, Nachdruck 1886, Stuttgart 1976. Überall Sigle G. 


\section{(Fortsetzung)}

\begin{tabular}{|c|c|c|c|}
\hline p. & Hand & Incipit & Inhalte, Anmerkungen \\
\hline & & & $\begin{array}{l}\text { bis denos protenditur sepe per annos. Für weitere } \\
\text { Korrekturen siehe Ed. Schenkl. }\end{array}$ \\
\hline 5 & & $\begin{array}{l}\text { Ordiar unde } \\
\text { tuas }\end{array}$ & $\begin{array}{l}\text { SK } 11422 .{ }^{775} \text { Paulus Diaconus, carm. IV. Lobrede auf } \\
\text { den Comer See. }\end{array}$ \\
\hline 6 & & $\begin{array}{l}\text { Quaerebat } \\
\text { merens }\end{array}$ & SK 12918. Paulus Diaconus?: carm. XXVIII. Fabel. \\
\hline 6 & & $\begin{array}{l}\text { Temporibus } \\
\text { priscis }\end{array}$ & SK 16209. Paulus Diaconus?: carm. XXIX. Fabel. ${ }^{776}$ \\
\hline 7 & & $\begin{array}{l}\text { Iam puto nervosi } \\
\text { (!) }\end{array}$ & $\begin{array}{l}\text { SK 7539. Paulus Diaconus an Petrus Pisanus, carm. } \\
\text { XVI. Antwort auf das metrische Rätsel von carm. XV, } \\
\text { fehlend in der Handschrift. }\end{array}$ \\
\hline 8 & & $\begin{array}{l}\text { Paule sub } \\
\text { umbroso. }\end{array}$ & $\begin{array}{l}\text { SK 11758. Petrus Pisanus an Paulus Diaconus, carm. } \\
\text { XIII, vss. 1-15. Antwort auf ein nicht erhaltenes } \\
\text { Gedicht, zeitgenössisch nur hier erhalten. Fortgeführt } \\
\text { auf p. 11. }\end{array}$ \\
\hline $9-10$ & \multicolumn{3}{|c|}{ Versetztes Einzelblatt, siehe hinter Reg. lat. 421 , f. 28 r. $^{778}$} \\
\hline 11 & \multirow[t]{4}{*}{ A } & - & $\begin{array}{l}\text { SK 11758. Petrus Pisanus an Paulus Diaconus, carm. } \\
\text { XIII, vss. 16-25. Fortgeführt von p. } 8 .\end{array}$ \\
\hline 11 & & Anguis aper & $\begin{array}{l}\text { SK 798. (Ähnlich AL Nr. 160, vss. } 2+3+\text { qui pede dum } \\
\text { premitur subtrahit ille pedem. Epigramm auf einen } \\
\text { Jagdunfall mit Eber und Schlange. }\end{array}$ \\
\hline 11 & & $\begin{array}{l}\text { Dum putat esse } \\
\text { parem }\end{array}$ & SK 4050. AL 39. Epigramm auf Narziss. \\
\hline 11 & & $\begin{array}{l}\text { Dente timetur } \\
\text { aper }\end{array}$ & $\begin{array}{l}\text { SK 3488. Martial: epigr. 13, 94. Epigramm auf einen } \\
\text { Eber. Zitiert bei Beda (In Acta Apostolorum) und } \\
\text { Isidor. }{ }^{779}\end{array}$ \\
\hline
\end{tabular}

775 Für die folgenden Stücke des Paulus Diaconus und Peter von Pisa siehe: DüMmLER (Hrsg.): MGH Poet. lat. 1. Neff (Hrsg.): Die Gedichte des Paulus Diaconus. Leider ohne Konkordanz zu DüMMLER. Initien-Index S. 213f.

776 Siehe zur Verfasserfrage der beiden Fabeln: NefF (Hrsg.): Die Gedichte des Paulus Diaconus. S. 191-198. Paul von WinTER FELD, »Paulus diaconus oder Notker der Stammler?«, in: Neues Archiv der Gesellschaft für ältere deutsche Geschichtskunde 29 (1904), S. 486-471. Dieter SCHALLER, "Lateinische Tierdichtung in frühkarolingischer Zeit«, in: Das Tier in der Dichtung, hrsg. von Ute Schwab, Heidelberg 1970, S. 91-113. S. 92-95. Dieter Schaller, Studien zur lateinischen Dichtung des Frühmittelalters (Quellen und Untersuchungen zur lateinischen Philologie des Mittelalters 11), Stuttgart 1995. S. 408-410.

777 Neff (Hrsg.): Die Gedichte des Paulus Diaconus. S. 98.

778 Durch diese Transposition wird ein Großteil der von DüMmLER: „Die handschriftliche Überlieferung". S. 106. beklagten Verstümmelung behoben (weiterhin Textausfall vor p. 19).

779 BERNT: Epigramm. S. 181. 


\section{(Fortsetzung)}

\begin{tabular}{|c|c|c|c|}
\hline p. & Hand & Incipit & Inhalte, Anmerkungen \\
\hline 11 & & $\begin{array}{l}\text { Qui cupis esse } \\
\text { bonus }\end{array}$ & $\begin{array}{l}\text { SK 13218. Eugenius von Toledo.: carm. VI. }{ }^{780} \text { Ne uinum } \\
\text { inmoderate bibatur. Vss. } 11-16 \text { unter eigener Über- } \\
\text { schrift Ad ebrium, SK } 3623 \text { a. Verse } 6-7 \text { in Zürich C } 78 \text {, f. } \\
\text { 116r, darauf das Rätsel Collis sum collisque wie Reg. } \\
\text { lat. } 421, \text { f. } 27 \mathrm{v} \text {. }\end{array}$ \\
\hline 12 & & $\begin{array}{l}\text { Magnus tu } \\
\text { Bacche }\end{array}$ & SK 9226. Epigramm auf Bacchus. Unediert. ${ }^{781}$ \\
\hline 12 & & $\begin{array}{l}\text { Monte sub hoc } \\
\text { lapidum }\end{array}$ & $\begin{array}{l}\text { SK 9759. AL 261. Ps.-Vergil, Epitaph des Ballista. Aus } \\
\text { der Vita Vergilii. }\end{array}$ \\
\hline 12 & & Parva culix & $\begin{array}{l}\text { Folgend auf die vorhergehenden Verse in der Vita } \\
\text { Gudiana I, Wolfenbüttel, Cod. Gud. lat. } 70{ }^{782} \text { somit } \\
\text { wohl nicht unabhängig aus Culex } 413 \mathrm{f} \text {. geschöpft. }\end{array}$ \\
\hline 12 & & Abietine calix & $\begin{array}{l}\text { SK 1066. AL 259. De calicae fracto. Epigramm auf } \\
\text { einen Becher, im Codex Salmasanius Vergil zuge- } \\
\text { schrieben. }\end{array}$ \\
\hline 13 & & Multicolor quali & $\begin{array}{l}\text { SK } 9856{ }^{783} \text { Paulus Diaconus, carm. dubium XLVI. } \\
\text { Epigramm auf einen Thron. }\end{array}$ \\
\hline 13 & & Sic ego suscepi & $\begin{array}{l}\text { SK 15261. Paulus Diaconus, carm. XIV. Antwort auf } \\
\text { XIII. }^{784}\end{array}$ \\
\hline 15 & & $\begin{array}{l}\text { Lumine } \\
\text { purpureo }\end{array}$ & $\begin{array}{l}\text { SK 9085. Petrus Pisanus an Paulus Diaconus, carm. XV. } \\
\text { Zwei Rätsel aus dem Kreis um Karl den Großen. }{ }^{785}\end{array}$ \\
\hline 17 & & $\begin{array}{l}\text { Rustice } \\
\text { lustrivage }\end{array}$ & $\begin{array}{l}\text { SK } 14427 .{ }^{786} \text { AL } 682 . \text { Nur durch Leerzeile getrennt. In } \\
\text { Zürich, C 78, f. } 52 \text { anschließend an Quintus Serenus. }\end{array}$ \\
\hline 17 & & $\begin{array}{l}\text { Si memini } \\
\text { fuerant }\end{array}$ & SK 15058. Martial.: epigr. 1, 19. Am Rande Martial. \\
\hline 17 & & $\begin{array}{l}\text { Cinthius } \\
\text { occiduas }\end{array}$ & $\begin{array}{l}\text { SK 3283. Paulus Diaconus, carm. XVII. Antwort auf } \\
\text { carm. XV. }{ }^{787}\end{array}$ \\
\hline 18 & & $\begin{array}{l}\text { Hoc satus in } \\
\text { viridi }\end{array}$ & $\begin{array}{l}\text { SK 7094. Paulus Diaconus, carm. XXXIX, vss. 1-4. } \\
\text { Epitaph Lothars, Sohn Karls des Großen. Nicht abge- } \\
\text { setzt vom vorhergehenden Gedicht. Kustode unten: } \\
\text { VI. }\end{array}$ \\
\hline
\end{tabular}

780 Vollmer (Hrsg.): Eugenii Toletani episcopi carmina et epistulae. S. 236. Die Handschrift: "[Lyon, IX.Jh., 2.Viertel Mitte]«: Bischoff: Katalog, 3. Nr. 7309.

781 Magnus tu Bacche magna tua / Contra te certantes tu semper palmam levasti.

782 Jan M. Zıоцкошsкi und Michael C. J. Putnam, The Virgilian Tradition. The First Fifteen Hundred Years, New Haven 2008. S. 252-256.

783 DüMmLER (Hrsg.): MGH Poet. lat. 1. S. 77, XLVI.

784 Neff (Hrsg.): Die Gedichte des Paulus Diaconus. S. 101.

785 Ebd. S. 84.

786 Ediert in: Gerald Kölblinger, »Versus Panos« und >De rustico«", in: Mittellateinisches Jahrbuch 8 (1973), S. 7-27.

787 Neff (Hrsg.): Die Gedichte des Paulus Diaconus. S. 88. 


\section{(Fortsetzung)}

\begin{tabular}{|c|c|c|c|}
\hline p. & Hand & Incipit & Inhalte, Anmerkungen \\
\hline \multicolumn{4}{|c|}{ Reg. lat. $421(20,27-28,[33 ?])$} \\
\hline $27 r$ & A & - & $\begin{array}{l}\text { SK 7094. Paulus Diaconus, carm. XXXIX, vss. 5-46. Am } \\
\text { Rande Finit. }\end{array}$ \\
\hline $27 \mathrm{v}$ & \multirow[t]{5}{*}{ ? } & $\begin{array}{l}\text { Prima sonat } \\
\text { quartae }\end{array}$ & $\begin{array}{l}\text { SK 12505. AL } 770 \text { (nicht 738a). Rätsel. Die folgenden } \\
\text { Rätsel alle in einem Zug ohne Trennung kopiert. }\end{array}$ \\
\hline $27 \mathrm{v}$ & & $\begin{array}{l}\text { Collis sum } \\
\text { collisque }\end{array}$ & SK 2464. AL 685. Rätsel. \\
\hline $27 \mathrm{v}$ & & Tu qui pergis iter & SK 16549. ${ }^{788}$ Alkuin, carm. LXIII, 5, vss. 1-6. Rätsel. ${ }^{789}$ \\
\hline $28 \mathrm{r}$ & & \begin{tabular}{|l} 
Gramatibus \\
duplici
\end{tabular} & SK 5659. ${ }^{790}$ Rätsel. \\
\hline $28 \mathrm{r}$ & & $\begin{array}{l}\text { Quod cernis } \\
\text { dicor }\end{array}$ & SK 13874. AL 771 (nicht 738b). Am Rande Finit. \\
\hline $28 \mathrm{r}^{791}$ & $\mathrm{~B}$ & $\begin{array}{l}\text { Aegrum fama } \\
\text { fuit }\end{array}$ & $\begin{array}{l}\text { SK 342. Paulus Diaconus, carm. XXVII, vss. 1-40. } \\
\text { Fabel. Authentisch? }\end{array}$ \\
\hline \multicolumn{4}{|c|}{ Cod. Sang. 899} \\
\hline 9 & B & $\begin{array}{l}\text { Cumque ante } \\
\text { ora }\end{array}$ & $\begin{array}{l}\text { SK } 342 \text { (Aegrum fama fuit). Paulus Diaconus, carm. } \\
\text { XXVII., vss. 41-68. }\end{array}$ \\
\hline 10 & $\mathrm{C}$ & $\begin{array}{l}\text { Regnator caeli } \\
\text { verax }\end{array}$ & SK 14148a. Figurengedicht mit Erläuterung. ${ }^{793}$ \\
\hline \multicolumn{4}{|c|}{ Cod. Sang. 899} \\
\hline 19 & $\mathrm{D}$ & $\begin{array}{l}\text { [Q]uippe ipsum } \\
\text { multa }\end{array}$ & $\begin{array}{l}\text { Prosper (?): Poema Conjugis Ad Uxorem, }{ }^{794} \text { vss. } 65- \\
\text { 122. Textverlust vorher. Die hier nicht erhaltenen } \\
\text { Einleitungsverse Age iam precor auch in Neapel, Ms. IV } \\
\text { G 68, jedoch in ganz anderem Zusammenhang. }\end{array}$ \\
\hline
\end{tabular}

788 DÜMMLER (Hrsg.): MGH Poet. lat. 1. S. 282.

789 Vgl. Patrizia Lendinara, »A Poem for All Seasons: Alcuin's »O vos, est aetas", in: Teaching and learning in medieval Europe: essays in honour of Gernot $R$. Wieland, hrsg. von DinkovABruUn, Greti und Tristan Gary Major (Publications of the journal of medieval Latin 11), Turnhout 2017, S. 123-146. S. 137-140 und Anm. 79 ebd.

790 DüMmLer (Hrsg.): MGH Poet. lat. 1. S. 282, Anm. zu III.

791 Es folgen f. 32 von moderner Hand (Goldast?) Nachträge wahrscheinlich aus Cod. Sang. 899, 878, 397, siehe WiLmart für eine Konkordanz.

792 Die Trennung vom vorhergehenden Korpus des Briefwechsels sowie der Wechsel des Schreibers lassen eine Zuschreibung dieses Gedichts an Paulus Diaconus zweifelhaft erscheinen (es steht eben nicht »inmitten von Gedichten, die Paulus zum Verfasser haben «, so Neff (Hrsg.): Die Gedichte des Paulus Diaconus. S. 191). NefF (S. 191-198) lehnt analog die Autorschaft des Paulinus aus stilistischen Gründen ab. WINTERFELD geht sogar so weit, die Fabel Notker Balbulus zuzuschreiben, der sie an Salomo gerichtet habe (Winterfeld: "Paulus oder Notker?»).

793 ERnst: Carmen figuratum. S. 199-202.

794 Hartel/Kamptner (Hrsg.): Paulini Nolani Carmina. S. 344-348. 


\section{(Fortsetzung)}

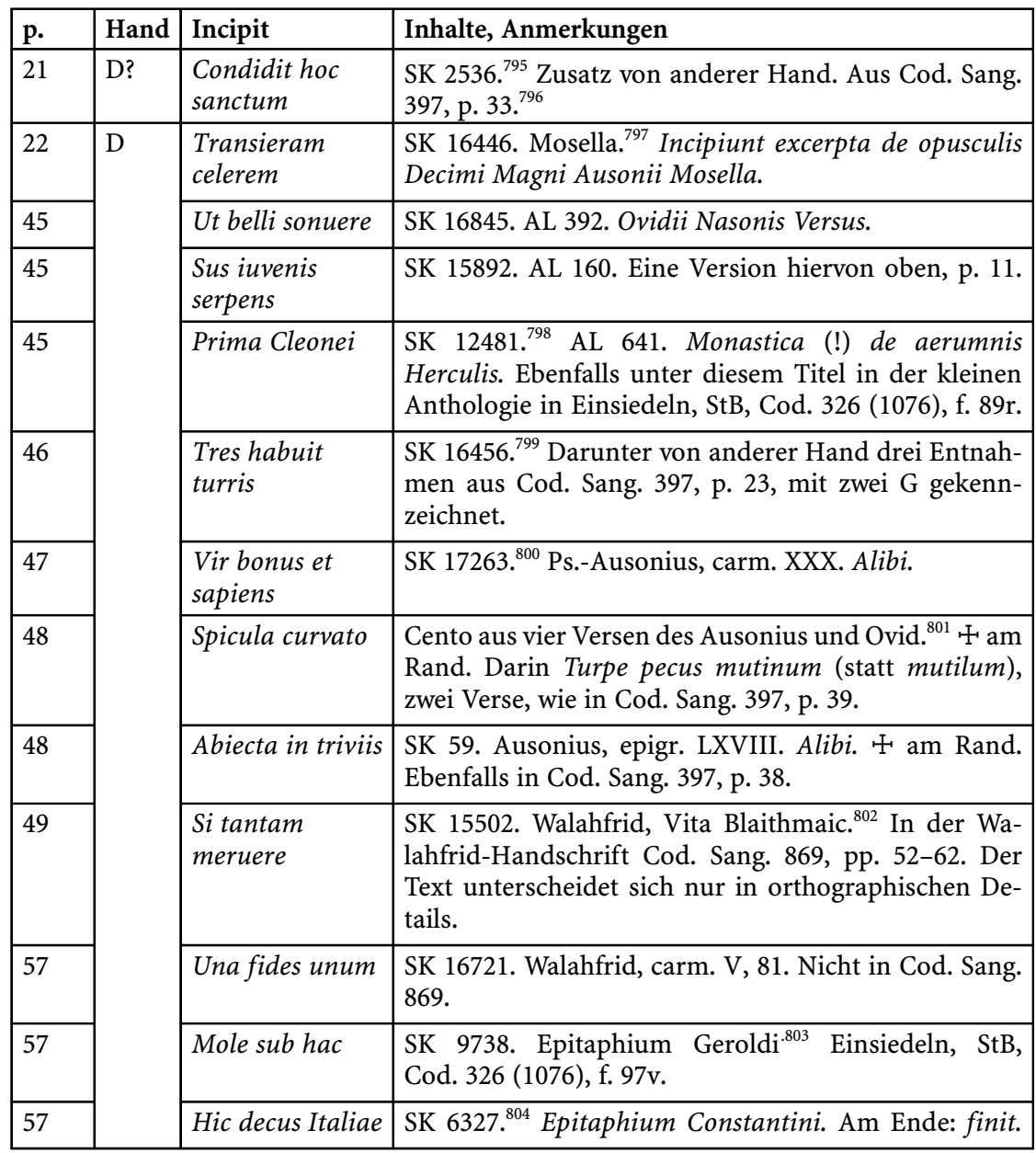

795 Winterfeld (Hrsg.): MGH Poet. lat. 4, 1. S. 335.

796 Eine Tabelle der Übernahmen oben bei Cod. Sang. 397.

797 Cod. Sang. 899 ist ältester Textzeuge des Gedichtes. Neben Schenkl und Peiper siehe: Gruber (Hrsg.): Mosella. Zur Handschrift S. 41f. Anders datiert bei: Green (Hrsg.): The works of Ausonius. S. xxxiv.

798 SChenkl (Hrsg.): Ausonii Opuscula. S. 153.

799 O. JäNICKE, "Die Verse auf Pan zum vierten Mal«, in: Jahrbücher für Philologie und Pädagogik 38. N.F. Jg. 14 (1868), S. 391.

800 SChenkl (Hrsg.): Ausonii Opuscula. S. 149f.

801 Riese/BÜCheler (Hrsg.): Anthologia latina. Nr. 641, Anm. zu 641.

$802 »$ Walahfridi Carmina«. S. 297-301.

803 DÜMmLER (Hrsg.): MGH Poet. lat. 1. S. 114, X.

804 Ebd. S. 78, L. 


\section{(Fortsetzung)}

\begin{tabular}{|c|c|c|c|}
\hline p. & Hand & Incipit & Inhalte, Anmerkungen \\
\hline $\begin{array}{l}59- \\
66\end{array}$ & & & $\begin{array}{l}\text { Glossare }{ }^{805} \text { Hervorzuheben sind: p. 59, erste zwei } \\
\text { Zeilen: Vielleicht verbunden mit Xenodochium id } \\
\text { est }{ }^{806} \text { Cod. Sang. } 397 \text {, p. } 38 \text {, diesem Glossar angehängt } \\
\text { in München, BSB, Clm 19413, f. } 118 \mathrm{r} \text { (siehe unten } \\
\text { S. 149). Categoriae. Predicamenta dort f. } 118 \mathrm{v} \text {, Augus- } \\
\text { tinus magnus } 188 \mathrm{v} \text {. Von Categoriae nur Titel in Cod. } \\
\text { Sang. 397, p. 38, darauf Augustinus magnus. p. } 60 \\
\text { Alleluia in Latinum sona, Cod. Sang. 397, p. } 45-47 .\end{array}$ \\
\hline 66 & & & $\begin{array}{l}\text { Form. Sang. Misc. Nr. 8. Collectio Sangallensis } \\
\text { Nr. } 23{ }^{807} \text { Zum Zahlenwert der griechischen Buchsta- } \\
\text { ben und Litterae Formatae. Cod. Sang. 397, p. 39-40. }\end{array}$ \\
\hline $\begin{array}{l}68- \\
75\end{array}$ & $\begin{array}{l}\text { E: } \\
70 \mathrm{ff} .\end{array}$ & & Über die Weltzeitalter. $^{808}$ \\
\hline $\begin{array}{l}75- \\
77\end{array}$ & $\mathrm{~F}$ & & Genealogie der Frankenkönige. $^{809}$ \\
\hline $\begin{array}{l}78- \\
81\end{array}$ & G & & Genealogie der Makkabäer. \\
\hline 81 & $\mathrm{H}$ & & $\begin{array}{l}\text { Erläuterung der Olympiaden. Von anderer Hand auf } \\
\text { freigebliebener Seitenhälfte ergänzt. Hand ähnelt dem } \\
\text { Hauptschreiber von Clm } 19413 \text { (siehe unten S. 150). }\end{array}$ \\
\hline $\begin{array}{l}82- \\
85\end{array}$ & $\mathrm{~J}$ & & $\begin{array}{l}\text { Häresien, Rezepte, De vestimentis sacerdotalibus. Fort- } \\
\text { gesetzt auf p. } 136 .\end{array}$ \\
\hline $\begin{array}{l}86- \\
92\end{array}$ & $\mathrm{D}^{810}$ & & $\begin{array}{l}\text { Karl der Große, Brief an Alkuin. }{ }^{811} \text { Über die Namen } \\
\text { kirchlicher Feiertage. Auch in Voss. Lat. Q. 69, f. 46v- } \\
\text { 47v (danach Textverlust). }\end{array}$ \\
\hline $\begin{array}{l}93- \\
108\end{array}$ & & & $\begin{array}{l}\text { Exzerpte. }^{812} \text { p. } 108 \text { divisiones musice artis wie Cod. } \\
\text { Sang. } 397 \text {, p. } 147 \text {, Zürich, C 78, f. 118rv. }\end{array}$ \\
\hline
\end{tabular}

805 Steinmeyer/Sievers (Hrsg.): Die althochdeutschen Glossen. 4, S. 457. Bergmann/StriCKER: Katalog. Nr. 251.

806 Kaczynski: „Some St. Gall Glosses on Greek Philanthropic Nomenclature».

807 Zeumer (Hrsg.): MGH Formulae. S. 383, 409.

808 Theodor Mommsen (Hrsg.), Chronica minora saec. IV. V. VI. VII (III) (MGH Auct. Ant. 13), Hannover 1898. S. 348-353 (Nr. 167, Karl der Große).

809 Georg WAITZ, Supplementa tomorum I-XII, pars I (MGH Scriptores 13), Hannover 1881. S. 243 Handschrift als Cod. Sang. 799 angegeben. Text S. 245 f.

$810 \mathrm{Vgl}$ ę, $\mathrm{x}, \mathrm{q}$.

811 »Alcuini sive Albini epistolae», in: MGH Epist. 4, hrsg. von Ernst DüMmLER 1895, S. 1-493. Wilfried Hartmann, "Äbte und Mönche als Vermittler von Texten auf karolingischen Synoden«, in: Karolingische Klöster. Wissenstransfer und kulturelle Innovation, hrsg. von Julia Becker, Tino Licht und Stefan Weinfurter, Berlin [u. a.] 2015, S. 211-226. S. 217.

812 Steinmeyer/Sievers (Hrsg.): Die althochdeutschen Glossen. 4, S. 457. 


\section{(Fortsetzung)}

\begin{tabular}{|c|c|c|c|}
\hline p. & Hand & Incipit & Inhalte, Anmerkungen \\
\hline $\begin{array}{l}109- \\
114\end{array}$ & & & $\begin{array}{l}\text { Columban (?): Epistulae Metricae Nr. 8, 9, } 10{ }^{813} \text { Wie } \\
\text { [Cod. Sang. 273]+Bremen, StUB Ms. b 52, p. 38-49. }\end{array}$ \\
\hline 114 & & $\begin{array}{l}\text { Hoc iacet in } \\
\text { tumulo }\end{array}$ & $\begin{array}{l}\text { SK } 6988{ }^{814} \text { Epitaph Hildegards, wie Cod. Sang. 397, } \\
\text { p. 28. G am rechten Rand. }\end{array}$ \\
\hline 114 & & Ecce superno & SK 4205. Walahfrid, carm. V, 82. \\
\hline 115 & & $\begin{array}{l}\text { Somnus abest } \\
\text { oculis }\end{array}$ & $\begin{array}{l}\text { SK } 11937 .{ }^{815} \text { Columban (?), Epistulae Metrica Nr. 9, } \\
\text { vss. 27-68. }\end{array}$ \\
\hline 117 & & $\begin{array}{l}\text { cuculum } \\
\end{array}$ & $\begin{array}{l}\text { SK } 12034 .{ }^{816} \text { Alkuin, carm. 57. Klagegedicht über einen } \\
\text { Freund. }\end{array}$ \\
\hline 118 & & $\begin{array}{l}\text { Lumen clarum } \\
\text { rite }\end{array}$ & $\begin{array}{l}\text { SK } 9078.817 \text { Anonymus, Ymnus de nativitate domini } \\
\text { metro trochaico tetrametro scriptus. }\end{array}$ \\
\hline 120 & & $\begin{array}{l}\text { Gloria laus et } \\
\text { honor }\end{array}$ & SK $5612 .{ }^{818}$ Theodulf, carm. LXIX. Versus Theotolfi Epi. \\
\hline 120 & & $\begin{array}{l}\text { Inclite Caesar } \\
\text { ave }\end{array}$ & SK 7987. Theodulf (?), carm. LXXVI. ${ }^{819}$ Versus eiusdem. \\
\hline 123 & & Albinus precibus & $\begin{array}{l}\text { SK 518. Theodulf (?), carm. LXXVIII. Ohne Über- } \\
\text { schrift, Anfang fehlt. }\end{array}$ \\
\hline 123 & & $\begin{array}{l}\text { Rumpitur } \\
\text { invidia } \\
\end{array}$ & Martial: epigr. 9, 97. \\
\hline 124 & & En adest Caesar & SK 4399. Jonas von Orleans (Theodulf, carm. XXXVII). \\
\hline $\begin{array}{l}126- \\
129\end{array}$ & & \begin{tabular}{|l|} 
Rex pie rex \\
clemens \\
Ecce votis apta \\
Innovatur no- \\
stra
\end{tabular} & $\begin{array}{l}\text { Walahfrid, carm. V, 71, 64, 63. Reg. lat. } 469 \text {, f. } 40 \mathrm{v}-41 \mathrm{r} \\
\text { 28v-29v, 22r-23r. Mit dem vorhergehenden vier Ge- } \\
\text { dichte auf den Adventus Regis. }{ }^{820}\end{array}$ \\
\hline $\begin{array}{l}130- \\
131\end{array}$ & & & $\begin{array}{l}\text { Walahfrid, carm. V, 47, i-xi. Epigramme auf Gegen- } \\
\text { stände. Cod. Sang. } 869 \text {, pp. } 195 \text { f. }\end{array}$ \\
\hline
\end{tabular}

813 »Columbani epistolae«. Nr. 8-10. S. 154, Sigle S1.

814 Winterfeld (Hrsg.): MGH Poet. lat. 4, 1. S. 335.

815 »Columbani epistolae«. S. 184.

816 »Alcuini Carmina«. S. 269f. Walther BuLst, »Alchvvines Ecloga de Cuculo«, in: Zeitschrift für deutsches Altertum und deutsche Literatur 86 (1956), S. 193-195.

817 DümmLer (Hrsg.): MGH Poet. lat. 2. S. 245 f.

818 Auch zu den folgenden Theodulf-Gedichten:»Theodulfi Carmina«. S. 558, 577, 579, 529. Guy JAROUSSEAU, "L'hymne >Gloria lausı de Théodulfe d'Orléans, un témoin de la réforme carolingienne», in: Mittellateinisches Jahrbuch 48 (2013), S. 369-398.

819 SCHALLER: "Gedichte Theodulfs«. S. $27 \mathrm{f}$.

820 Peter Willmes, Der Herrscher-»Adventus im Kloster des Frühmittelalters (Münstersche Mittelalter-Schriften 22), München 1976. S. 85-90. Walter Berschin, »Karl der Kahle als Herzog von Alemannien (829-833). Die Spur der Literatur«, in: Euphrosyne 38 (2010), S. 385390. S. 386, Anm. 4. 
(Fortsetzung)

\begin{tabular}{|c|c|c|c|}
\hline p. & Hand & Incipit & Inhalte, Anmerkungen \\
\hline 131 & $\mathrm{D} ?$ & & $\begin{array}{l}\text { Zwei Rezepte aus Cod. Sang. 397, p. 22. Unten: De lib } \\
\text { Grim tuli. }\end{array}$ \\
\hline 132 & \multirow[t]{2}{*}{$\mathrm{D}$} & & $\begin{array}{l}\text { Dicta Philosophorum. Einsiedeln, StB, Ms. } 266 \text { (1296), } \\
\text { pp. 202-203. }\end{array}$ \\
\hline $\begin{array}{l}132- \\
134\end{array}$ & & & Exzerpte. $^{821}$ \\
\hline 135 & $\mathrm{~K}$ & Pangite coeli & SK 11585. Walahfrid, carm. V, 83. \\
\hline 136 & $\mathrm{~K}$ & & Auszug aus Augustinus. ${ }^{822}$ \\
\hline $\begin{array}{l}136- \\
137\end{array}$ & $\mathrm{~J}$ & & Fortsetzung von p. 85. \\
\hline 137 & $\mathrm{H} ?$ & & Rezepte, Bibelexzerpte. \\
\hline $\begin{array}{l}138- \\
142\end{array}$ & varii. & & Rezepte. \\
\hline 144 & $\mathrm{D} ?$ & $\begin{array}{l}\text { Postquam primo } \\
\text { homini }\end{array}$ & $\begin{array}{l}\text { Walahfrid, carm. V, 42. Reg. lat. 469f. 40r-40v, dort } \\
\text { auch die Adventus-Gedichte. }\end{array}$ \\
\hline \multicolumn{4}{|c|}{ Reg. lat. 421 (f. 20, 27-28, [33?]) } \\
\hline $\begin{array}{l}20 \mathrm{r}- \\
20 \mathrm{v}\end{array}$ & $?$ & & $\begin{array}{l}\text { Hieronymus, In Zachariam, }{ }^{823} \text { Beginn c. } 8 \text {. Ursprüng- } \\
\text { liche Stelle in Cod. Sang. } 899 \text { unklar. }\end{array}$ \\
\hline \multicolumn{4}{|c|}{ Reg. lat. $421(20,27-28,[33 ?])$} \\
\hline $33 \mathrm{rv}$ & $\mathrm{D} ?$ & $\begin{array}{l}\text { Clangor tubae } \\
\text { per quaternas }\end{array}$ & $\begin{array}{l}\text { SK } 945{ }^{824} \text { Rhythmi Aevi Merovingici et Carolini, XVII, } \\
\text { str. 3-23. Ursprüngliche Stelle in Cod. Sang. } 899 \\
\text { unklar. }\end{array}$ \\
\hline
\end{tabular}

Obwohl zahllose und kaum mehr unterscheidbare Hände an der Verfertigung der Handschrift teilhatten, lassen sich dennoch zwei Hauptschreiber, A und D, ausmachen, die den Großteil der Arbeit besorgen. Die Handschrift lässt sich anhand thematischer und paläographischer Linien ungefähr in folgende Teile separieren, die vielleicht auch die Vorlagen reflektieren, aus denen die Gedichte geschöpft wurden.

I. A beginnt die Anthologie mit der einer Reihe von Gedichten, deren Schwerpunkt auf dem poetischen Briefwechsel (weitestgehend aus Rätseln bestehend) von Paulus Diaconus und Petrus Pisanus liegt (pp. 2-18, Reg. lat. 421, f. 27-28), der sich konzentriert insbesondere pp. 5-11, 13-17 findet. Die Epigramme pp. 11-12, worin sich p. 12 Spuren eines kleinen Florilegiums von Vergil-Apokrypha andeuten, ist sichtlich von A nach Absetzen der

821 Steinmeyer/Sievers (Hrsg.): Die althochdeutschen Glossen. 4, S. 458.

822 Ebd. 4, S. 458.

823 DEKKERS: CPL. Nr. 589.

824 Strecker (Hrsg.): MGH Poet. lat. 4, 2.3. S. 507-510. 
Feder eingeschaltet worden, wonach er sich wieder dem Briefwechsel widmete. Thematisch ergänzend sind die Rätsel und Fabeln in Reg. lat. 421, f. 27r-28r, Cod. Sang. 899 pp. 9-10 von Hand drei weiterer Schreiber. Rätsel und Fabeln sind der Schwerpunkt dieser gesamten Anthologie. Vorlage sind wahrscheinlich eine Rätselsammlung, mit Schwerpunkt auf Paulus Diaconus und Petrus Pisanus, sowie die verstreuten Quellen der Ergänzer.

II. Dem Teil, in dem Hauptschreiber D übernimmt, fehlt zu Beginn eine unbekannte Zahl an Blättern. Da das Poema Conjugis Ad Uxorem (pp. 19-21) häufig im Anschluss an Prospers Epigramme vorliegt, die gleich mehrfach in St. Gallen vorhanden waren, ${ }^{825}$ kann es sein, dass diese vorausgingen. Die Bauinschrift am Ende des Abschnitts ist aus Grimalds Vademecum entnommen, aus dem auch an anderen Stellen von Cod. Sang. 899 an freien Stellen einzelne Stücke übernommen wurden.

III. Mosella und Epigramme. Das Gedicht, das hier zuerst aus der Dunkelheit der Geschichte wieder auftaucht, ist sichtlich durch eine feine Rubrik und einheitliche Tinte als kodikologische Einheit gekennzeichnet. Zum Teil I. steht das Gedicht durch die dort zu findende einleitende Epistel des Symmachus in Verbindung. Dort finden sich ebenfalls pp. 2-4 und in Teil II. pp. 47-48 weitere Epigramme des Ausonius - sollte somit vielleicht eine Handschrift zur Vorlage aller Ausoniana gedient haben? Die ganze Reihe der Epigramme pp. 45-47 (+47-48?) scheint mit der Mosella in einem Zug kopiert worden $\mathrm{zu}$ sein und es sollte mich nicht überraschen, wenn A die thematisch verwandten Epigramme pp. 11-12 aus derselben Vorlage eingeschaltet hat. Die zwei Ausonianischen Epigramme pp. 47-48 finden sich ebenfalls in Cod. Sang. 397, da sie jedoch in Cod. Sang. 899 in einem Zug aus der Vorlage mit dort nicht enthaltenen Gedichten kopiert sind, scheinen eher beide Handschriften aus einer Vorlage zu schöpfen.

IV. Walahfrid (pp. 49-59) Ebenfalls durch eine sorgfältige Rubrik auf neuem Blatt ist die Vita Blaithmaic vom Vorhergehenden abgesetzt. ${ }^{82}$ Die folgenden Epitaphien sind ebenso gestaltet. Durch das finit am Ende des Epitaphium Constantini wird vielleicht das Ende der Vorlage bezeichnet. ${ }^{827}$

V. Die folgenden Glossare und Exzerpte (pp. 59-108), ebenfalls größtenteils von D geschrieben und von EFGHJ mit weiterem Miszellanmaterial erweitert, tragen mehr den Charakter einer gewachsenen Sammlung. Einige sind aus Cod. Sang. 397 entnommen.

825 Horsting (Hrsg.): Prosper Aquitanus, Liber epigrammatum. S. 23.

826 Zum Zusammenhang mit der Walahfrid-Handschrift Cod. Sang. 869 siehe S. 124 zu VI.

827 Es findet sich kein finit am Ende der vorhergehende Gedichte. 
VI. Anthologie (pp. 109-134). ${ }^{828}$ D, der schon vorher zahlreiche Exzerpte mit lockerer Hand ergänzt hat, setzt hier wieder die Feder an für den letzten Teil der Handschrift, der erneut fast ausschließlich der Dichtung gewidmet ist. Die Gestaltung ist einheitlich mit durchgehenden Rubriken, jedoch lassen gefüllte Lücken auf p. $114^{829}$ und 131 vermuten, das nicht durchgehend aus einer Vorlage kopiert wurde. Auch das Columbangedicht pp. 115-116 folgt ohne Rubrik auf den Nachtrag p. 114 und trennt somit vielleicht die zwei Blöcke pp. 109-114 (Columban, vll. aus gemeinsamer Quelle mit Bremen, StUB Ms. b 52) und pp. 117-134 (Anthologie). ${ }^{830}$ Dieser letztere Teil ist thematisch vielfältig. Auffällig sind eine Folge von Theodulf-Gedichten (pp. 120-123); Gedichte desselben Autors findet man auch in Cod. Sang. $263 .^{831}$ Ebenfalls auffällig ist die Reihe von Adventus-Gedichten pp. 124-127, darunter drei Walahfrids, die sich ebenfalls in der Fuldaer WalahfridHandschrift Reg. lat. 469, jedoch nicht in einer Reihe finden. Von Walahfrid sind ebenfalls die folgenden Epigramme, mit denen die Anthologie schließt. Wie Visser feststellt, ${ }^{832}$ enthält keine der beiden anderen Walahfrid-Anthologien (Reg. lat. 469, Cod. Sang. 869) alle in Cod. Sang. 899 enthaltenen Gedichte, ganz abgesehen davon, dass drei vielleicht zweifelhafte Gedichte Unica von Cod. Sang. 899 sind. ${ }^{833}$ Da Reg. lat. 469 ohnehin aus Fulda stammt ${ }^{834}$ stützt sich Cod. Sang. 899 somit nicht auf diese beiden Textzeugen. Es gilt somit hier das gleiche wie für Cod. Sang. 869, dass nämlich eine wie auch immer beschaffene, ältere St. Galler Sammlung der Dichtungen Walahfrids vorgelegen haben muss, aus der alle drei Handschriften geschöpft haben.

Es lassen sich somit vorsichtigerweise wenigstens fünf Handschriften teilweise rekonstruieren, aus denen die Kompilatoren von Cod. Sang. 899 geschöpft haben: Eine Rätselsammlung, Prosper, Ausonius und Epigramme, eine WalahfridAnthologie und Cod. Sang. 397. Ich zweifle nicht, dass die tatsächliche Zahl, wenn man die zahllosen nicht nachverfolgbaren Exzerpte betrachtet, um vieles größer gewesen ist. Die analogen Exzerpte in anderen Handschriften zeigen zudem, dass einige Handschriften immer wieder zur Quelle neuer Sammlungen wurden, in St. Gallen selbst und auch außerhalb (in den Einsiedler Handschriften). Obwohl der Großteil der Texte in mehr oder minder zusammenhängenden Stücken

828 Die Handschrift endet p. 144 in Exzerpten von verschiedensten Händen.

829 Hier ergänzt D aus Cod. Sang. 397 das Epitaph Hildegards.

830 pp. 132-134 Exzerpte, jedoch gestaltet wie die Anthologie vorher.

831 Siehe dort S. 120f. für Theodulf-Anthologien.

832 VISSER: Sis memor. S. 20.

$833 \mathrm{~V}, 81,82,83$, ergänzt oder anders in der Handschrift verstreut.

834 Die Texte stammt jedoch ultimativ aus St. Galler oder Reichenauer Sammlungen. 
entnommen wurde, zeigen die Einzelexzerpte aus Cod. Sang. 397 und die zahlreichen kleineren, klar paläographisch abgesetzten Stücke, dass man auch kleinste Texte suchte, fand und aufbewahrte, anstatt nur ganze Lagen en bloc zu kopieren. Die Parallelstücken zu anderen St. Galler Handschriften sind ein eindrucksvolles Zeugnis des Detailstudiums der reichen Bibliothek. Die Praxis des Sammelns gibt sich auch in den Annotationen der Handschrift zu erkennen: Bei einigen der Entnahmen aus Grimalds Vademecum wurde sogar der Ursprung durch G gekennzeichnet, worin ein Bewusstsein der persönlich gebundenen Herkunft der Zitate sichtbar wird. An anderen Stellen scheinen verschiedene Arten von Kreuzen, sowie insbesondere R-Ligaturen (Require?) neben kleineren Gedichten anzudeuten, ${ }^{835}$ dass die so gekennzeichneten Texte kopiert werden sollten und somit Cod. Sang. 899 selbst zur Quelle weiterer Sammlungen wurde. Aufmerksame Leser versehen die Gedichte bisweilen mit Korrekturen und Noten, jedoch viel spärlicher, als in den glossarisch-lexikalischen Teilen der Handschrift, wo sich die große Mehrzahl der Glossen findet. ${ }^{836}$ Es fehlt somit weitgehend der Apparat, der sich in einer Schulhandschrift erwarten ließe, und Cod. Sang. 899 erscheint vielmehr als der Versuch, ansonsten verstreute Dichtung in einer dezidierten Handschrift zu sammeln, wobei jedoch durch die Hinübernahme nicht poetischen Materials die vielfältigeren Textgemeinschaften der Quellen reflektiert werden. Um jedoch ein Vademecum im Stile derer von Grimald und Walahfrid zu sein, ${ }^{837}$ ist Cod. Sang. $899 \mathrm{zu}$ monothematisch, zu ausschließlich auf Dichtung fixiert. Seine Entstehung im letzten Viertel des Jahrhunderts scheint vielmehr einen Reflex des damals unter Salomo III. und Notker, Tutilo und Ratbert aufblühenden Interesses an Dichtung darzustellen. Als Anthologie aus den Schätzen der St. Galler Bibliothek stellt Cod. Sang. 899 somit die Ernte eines Jahrhunderts der Sammlung von Dichtung im Kloster dar.

Vom Ende des Jahrhunderts datiert auch die zweite bedeutende St. Galler Anthologie, Zürich, ZB, C 78 (451) (pp. 47-162), ${ }^{838}$ die in der Geschichtsforschung

835 An einigen Stellen weiterhin durch $d d$ und $h h$ fehlende Stellen ergänzt.

836 BergmanN/Stricker: Katalog. Nr. 251.

837 So Visser: Sis memor. S. 20.

$838 »[$ St. Gallen], (...) »um 900«)«: Bischoff: Katalog, 3. Nr. 7578. Kataloge und Beschreibungen: Mohlberg: Katalog Zürich. S. 42-44, 358. Bergmann/STricker: Katalog. Nr. 1019 b. Bruckner: St. Gallen, 2. S. 126. Wilhelm Hentze und Lutz von PAdberg, De Karolo rege et Leone papa. Der Bericht über die Zusammenkunft Karls des Grossen mit Papst Leo III. in Paderborn 799 in einem Epos für Karl den Kaiser; mit vollständiger Farbreproduktion nach der Handschrift der Zentralbibliothek Zürich, Ms. C 78 (Studien und Quellen zur westfälischen Geschichte 36), Paderborn 1999. Darin insbesondere: SтоRк: „Die Sammelhandschrift Zürich, Zentralbibliothek, C 78«. Euw: Buchkunst. Nr. 65. S. 105-118. Augusto BeCCARIA, I codici di medicina del periodo presalernitano: secoli IX, X e XI (Storia e letteratura. Raccolta di studi e testi 53), Roma 1956. S. 395-396. Günther Goldschmidt, Katalogisierung der mittelalterlichen medizinischen und alchimistischen Handschriften der Zentralbilbiothek Zürich, Aarau 1945. S. 154. Beat Matthias von Scarpatetti, Rudolf Gamper und Marlies 
insbesondere wegen des viel diskutierten Kleinepos Karolus Magnus et Leo papa Interesse gefunden hat, dessen einziger Textzeuge sie ist. Die Handschrift selbst und ihre weiteren Inhalte sind jedoch gegenüber den bloß historischen Fragen des Epos vernachlässigt worden und somit auch der Überlieferungszusammenhang desselben. Obwohl die Handschrift heute Teil eines Sammelbandes ist, steht $\mathrm{zu}$ vermuten, dass sie sich vollständig erhalten hat, wie die zeitgenössischen Reklamanten nahelegen, die an den Lagenenden unten mittig stehen. ${ }^{839}$ Meiner Einschätzung nach waren maximal acht Schreiber an der Handschrift beteiligt, die meist nicht alleine, sondern in Zusammenarbeit die Vorlagen kopierten ${ }^{840} \mathrm{An}$ einigen Stellen trägt die Handschrift mit Rubriken und roten Initialen - oder dafür freigelassenen Stellen - einen Buchschmuck, der über den eines bloßen Notizbuchs hinausgeht. Zur besseren Übersicht seien der weiteren Diskussion hier die Inhalte der Handschrift vorangestellt: ${ }^{841}$

\begin{tabular}{|l|l|l|l|}
\hline p. & Hand & Incipit & Inhalte, Anmerkungen \\
\hline $47 \mathrm{r}$ & $\mathrm{A}^{842}$ & & $\begin{array}{l}\text { Augustinus De Civ. Dei 1. XVIII 23, 2; anderer } \\
\text { Abschnitt von hier f. 157r. }\end{array}$ \\
\hline
\end{tabular}

SтÄHLI (Hrsg.), Katalog der datierten Handschriften in der Schweiz in lateinischer Schrift vom Anfang des Mittelalters bis 1550. 3: Die Handschriften der Bibliotheken St. GallenZürich in alphabetischer Reihenfolge 1991. Nr. 924. DüMMLER: "Die handschriftliche Überlieferung". S. 148.

839 58v: Mittig: I, Rand: (XVII), 66v: II (XVIII), 74v: III (XVIIII), 82v: IIII (XX), 90v: V (XXI), 98v: VI (XXII), 106v: VII (XXIII), 114v: VIII (XXIIII), 122v: - (XXV), 130v: X (XXVI), 138v: XI (XXVII), 146v: XII (XXVIII), 154v: XIII (XXVIIII), 162v: XIIII (XXX). MohlberG und im Anschluss Schaller (Aachener Epos), halten die am Seitenrand stehende Nummerierung XVII-XXX für die ältere, was ich angesichts der Position der Zahlen für unwahrscheinlich halte. pp. 1-47 tragen keine Reklamanten, sodass die Nummerierung XVII-XXX beweist, dass pp. 47-162 früher Teil einer anderen Sammelhandschrift waren. Das Binio 47r-50v, obwohl nicht unten mittig nummeriert, steht durch den Augustinus-Text in enger Verbindung mit der letzten Lage der Handschrift und darf zum ursprünglichen Umfang gezählt werden (die Reklamante VIIII 50v, unten rechts, ist von anderer Hand und Tinte als die anderen, jüngeren Reklamanten, kann aber nicht Lage VIIII der älteren Reihe sein, da diese Lage vorhanden ist, da zwar die Reklamante VIIII auf f. 122v fehlt, aber durchgehender, unbeschädigter Text zu Beginn und Anfang der Lage steht). Demnach ist STORK nicht zuzustimmen, der für die Teile der Handschrift meint »daß diese einzelnen Stücke wiederum aus größeren, offensichtlich mit Absicht fragmentierten Textsammlungen stammen " - zumindest pp. 47-162 ist vollständig.

840 A: 47r-51r; B: 51r-52r; C: 52r-54r; D: 54v-57r; E: 57v-74v; F: 75r-82r; D: 82v-83r; E: 83r-86v; F: $86 \mathrm{v}-95 \mathrm{r}$; G: 95v-98r; 98v-162v: G \& F?. Siehe auch die Inhaltsangabe unten und die Besprechung der Vorlagen. Bisher nur ungenau eingeschätzt: MohlberG: »verschiedene Hände«; Franz BRunhöLzL, De Karolo rege et Leone papa; Beiheft, Text und Übersetzung (Studien und Quellen zur westfälischen Geschichte 36), Paderborn 1999. S. 7: »drei einander mehrfach ablösende (zum Teil ungelenke) Hände» (nur betreffend das Karlsepos).

841 Mohlberg ist zu summarisch, als auch in den Literaturhinweisen veraltet, und STORK lücken- und fehlerhaft.

842 47r-50v sind ein unnumeriertes Binio (Euw: Buchkunst. S. 367). Reklamanten ab 58v. 


\section{(Fortsetzung)}

\begin{tabular}{|c|c|c|c|}
\hline p. & Hand & Incipit & Inhalte, Anmerkungen \\
\hline $\begin{array}{l}47 \mathrm{v}- \\
48 \mathrm{v}\end{array}$ & & & $\begin{array}{l}\text { Text zum Akathistos-Hymnus, dieser selbst nicht } \\
\text { wiedergegeben. }{ }^{844}\end{array}$ \\
\hline $\begin{array}{l}48 \mathrm{v}- \\
50 \mathrm{v}\end{array}$ & & Angelus ecce seni & $\begin{array}{l}\text { Versus de evangelio ad picturam. }{ }^{845} \text { Tituli zu den } \\
\text { Malereien in der Abteikirche (unter Gozbert und } \\
\text { Grimald). Hier Rubriken, rote Initialen. } 47 \mathrm{v} \text { Ligatur } \\
\text { AL am Rand. 50v fehlt die Reklamante, Beginn } 58 \mathrm{v} \\
\text { mit I. }\end{array}$ \\
\hline $\begin{array}{l}51 \mathrm{r}- \\
52 \mathrm{r}\end{array}$ & B & & $\begin{array}{l}\text { »Regeln für Heiligendarstellung» (Mohlberg) }{ }^{846} \\
\text { Glossar Morfoma g[raece] l[atine] forma. }\end{array}$ \\
\hline $\begin{array}{l}52 \mathrm{r}- \\
53 \mathrm{v}\end{array}$ & $\mathrm{C}$ & & $\begin{array}{l}\text { Worterklärungen: Decanus sub centurione; Canon } \\
\text { autem grece latine. } 53 \mathrm{v} \text { am Rand: usque huc. Vor- } \\
\text { hergehendes ab hinc fehlt. }\end{array}$ \\
\hline $\begin{array}{l}53 \mathrm{v}- \\
54 \mathrm{r}\end{array}$ & $\mathrm{C}$ & & $\begin{array}{l}\text { Kirchliche Formulare: Petitio novorum; Traditio } \\
\text { infantum; Promissio regularis. }{ }^{847}\end{array}$ \\
\hline $\begin{array}{l}54 v- \\
57 \mathrm{r}\end{array}$ & $\mathrm{D}^{848}$ & & $\begin{array}{l}\text { Confessio Pelagi. }{ }^{849} \text { Gegenüber den anderen Texten } \\
\text { stark korrigiert. }\end{array}$ \\
\hline $\begin{array}{l}57 \mathrm{v}- \\
82 \mathrm{v}\end{array}$ & $\begin{array}{l}\text { E: } \\
57 \mathrm{v}- \\
74 \mathrm{v} \\
\mathrm{F}:\end{array}$ & & $\begin{array}{l}\text { Quintus Serenus, Liber medicinalis. }{ }^{850} \text { Es handelt } \\
\text { sich bei dem Text um die von Jacobus mit einem } \\
\text { Prolog versehene und in der weiteren Überlieferung } \\
\text { fälschlich in LXII Capitula eingeteilte Version, die } \\
\text { auf der Reichenau in Reginberts Ergänzungsliste }\end{array}$ \\
\hline
\end{tabular}

843 Dieter Schaller, "Die Siebensilberstrophen de mundi transitu - eine Dichtung Columbans?«, in: Die Iren und Europa im früheren Mittelalter, hrsg. von Heinz LöwE (Veröffentlichungen des Europa Zentrums Tübingen. Kulturwissenschaftliche Reihe), Stuttgart 1982, S. 468-483. S. 477, Anm. 60.

844 Walter Berschin, Griechisch-lateinisches Mittelalter. Von Hieronymus zu Nikolaus von Kues, Bern [u. a.] 1980. S. 165.

845 Dümmler (Hrsg.): MGH Poet. lat. 2. S. 480-482. Carmina Sangallensia V, i-v. Kirsch: Laudes sanctorum. S. 966. Julius von SCHLOSSER, Schriftquellen zur Geschichte der karolingischen Kunst (Quellenschriften für Kunstgeschichte und Kunsttechnik des Mittelalters und der Neuzeit, NF 4), Wien 1892. Nr. 931, S. 326-329, 139. Zu den Malereien (mit Literatur): Euw: Buchkunst. S. 367.

846 Edition: Johann Kaspar von Orelli (Hrsg.), Helperici sive ut alii arbitrantur Angilberti Karolus Magnus et Leo papa, Zürich 1832. S. 2.

847 Bruno Albers (Hrsg.), Consuetudines monasticae, Stuttgart [u. a.] 1910. III, S. 176, 185, 177.

848 Erste drei Zeilen vll. B.

849 August Hahn, Adolf von Harnack und Ludwig Hahn (Hrsg.), Bibliothek der Symbole und Glaubensregeln der Alten Kirche, Hildesheim 1962. S. 270-272. Es handelt sich um den berühmten Ketzer Pelagius.

850 Vollmer (Hrsg.): Liber medicinalis. Sigle A, S. VII-XI. BeCCARIA: I codici di medicina del periodo presalernitano. S. 295. Quintus Serenus ist ebenfalls in St. Gallen in Cod. Sang. 44 (»Italien«, [IX. Jh., (3. oder) 4. Viertel]« (BIschofF: Katalog, 3. Nr. 5530) überliefert, dort jedoch im Kontext medizinischer Schriften und Teil eines anderen Überlieferungszweiges ist. 


\section{(Fortsetzung)}

\begin{tabular}{|c|c|c|c|}
\hline p. & Hand & Incipit & Inhalte, Anmerkungen \\
\hline & $\begin{array}{l}75 \mathrm{r}- \\
82 \mathrm{v}\end{array}$ & & $\begin{array}{l}\text { (vor 842) verzeichnet ist (Nr. XXXI). Zürich, C 78 ist } \\
\text { von einer falsch gezählten Kopie (via Jacobus) von } \\
\mathrm{A}^{\star} \text { abgeschrieben worden, der nach Beschädigung in } \\
\text { der Abschrift des Hyparchetyps B* Quelle sämtlicher } \\
\text { weiterer Handschriften wurde (Vollmer, S. XX). Ob } \\
\text { es dieser Text ist, der im Florilegium Sangallense an } \\
\text { sieben Stellen zitiert wird, ist aufgrund der nur } \\
\text { unbedeutenden Varianten nicht festzustellen. Zu- } \\
\text { mindest belegt dies den Gebrauch des Dichters in der } \\
\text { Schule. Der Text beginnt auf einer neuen Seite } \\
\text { (jedoch nicht auf neuer Lage) und ist mithin viel- } \\
\text { leicht damit Beginn der Vorlage gewesen. Interlinear } \\
\text { sind wahrscheinlich schon in der Vorlage stehende } \\
\text { Varianten angegeben (Vollmer, S. X f.). }\end{array}$ \\
\hline $\begin{array}{l}82 \mathrm{v}- \\
83 \mathrm{r}\end{array}$ & $\mathrm{D}^{851}$ & Rustice lustrivage & SK 14427. AL 682. In Cod. Sang. 899, p. 17. \\
\hline $\begin{array}{l}83 \mathrm{r}- \\
84 \mathrm{r}\end{array}$ & $\mathrm{E}^{852}$ & & De septem miraculis mundi. ${ }^{853}$ 83r am Rand: ab hinc. \\
\hline $\begin{array}{l}84 \mathrm{r}- \\
86 \mathrm{r}\end{array}$ & & & $\begin{array}{l}\text { Alkuin, Epistola 133, betreffend die Auslegung der } \\
\text { Zahl der Frauen und Konkubinen Salomos. }{ }^{84} 86 \mathrm{r} \text { am } \\
\text { Rand: usque huc. }\end{array}$ \\
\hline $\begin{array}{l}86 \mathrm{r}- \\
86 \mathrm{v}\end{array}$ & & Aurea nam decem & Bonifatius, Aenigmata, Prolog. ${ }^{855}$ \\
\hline $\begin{array}{l}86 \mathrm{v}- \\
95 \mathrm{r}\end{array}$ & $\mathrm{F}^{856}$ & & $\begin{array}{l}\text { Theodulf: Carmina LXXII, i, ii, iii, iv, LXXI, LXXIII, } \\
\text { exakt wie Cod. Sang. 263, siehe S. 121. Verhältnis der } \\
\text { Handschriften unklar, jedoch kaum, wegen des } \\
\text { Alters, Zürich, C } 78 \text { aus Cod. Sang. 263. Die Gedichte } \\
\text { wurden später, vielleicht in St. Gallen und aus dieser } \\
\text { Handschrift, von Geraldus in seinem Prolog zum } \\
\text { Waltharius zitiert. }{ }^{857} \text { Der Text weist bis auf einige mit } \\
\text { dd/hh ergänzte Verse (90v, 92r) keine Nutzungsspu- } \\
\text { ren auf. }\end{array}$ \\
\hline $\begin{array}{l}95 \mathrm{v}- \\
96 \mathrm{r}\end{array}$ & $\mathrm{G}^{858}$ & $\begin{array}{l}\text { Quid tibi mors } \\
\text { /Luciola effigies }\end{array}$ & $\begin{array}{l}\text { Epitaphium filii Catonis, SK 13567, AL 487. Oft } \\
\text { verbunden mit dem folgenden Gedicht: }{ }^{859} \text { Epitaph, } \\
\text { SK 9039, AL 684. }\end{array}$ \\
\hline
\end{tabular}

851 Übernimmt ab v. 4 des Gedichtes.

852 Übernimmt $82 \mathrm{v}$ inmitten des Textes.

853 Henri Oмоnт, "Les sept merveilles du monde au Moyen Âge«, in: Bibliothèque de l'Ecole des Chartes 43 (1882), S. 40-59, 431-432.

854 Ernst Dümmler (Hrsg.), Epistolae Karolini aevi 2 (MGH Epp. 4), Berlin 1895. S. $200 \mathrm{f}$.

855 DÜMmLER (Hrsg.): MGH Poet. lat. 1. S. 3f. Sigle T.

856 Übernimmt $86 \mathrm{v}$ inmitten des Textes.

857 SChaller: »Geraldus und St. Gallen - Zum Widmungsgedicht des >Waltharius«".

858 Übernimmt 95v den Rest von Theodulf, carm. LXXIII.

859 BoAs (Hrsg.): Disticha Catonis. S. $268 \mathrm{f}$. 
(Fortsetzung)

\begin{tabular}{|c|c|c|c|}
\hline p. & Hand & Incipit & Inhalte, Anmerkungen \\
\hline $\begin{array}{l}96 \mathrm{r}- \\
96 \mathrm{v}\end{array}$ & & & Ps.-Cato: Epistula (Prolog) + Breves Sententiae. ${ }^{860}$ \\
\hline $\begin{array}{l}96 \mathrm{v}- \\
103 \mathrm{r}\end{array}$ & $G^{861}$ & $\begin{array}{l}\text { Si Deus est ani- } \\
\text { mus }\end{array}$ & $\begin{array}{l}\text { Disticha Catonis. }{ }^{862} \text { Hier einer der ältesten Textzeu- } \\
\text { gen. Vereinzelte Varianten nachgetragen, } 98 \mathrm{r} \text { Raum } \\
\text { für Initiale freigelassen (mit entsprechendem Buch- } \\
\text { staben am Rand). }\end{array}$ \\
\hline $\begin{array}{l}103 \mathrm{r}- \\
104 \mathrm{v}\end{array}$ & G\&F? & Sum noctis socia & $\begin{array}{l}\text { De Philomela. Eugenius von Toledo, carm. XXX- } \\
\text { XXXIII. SK 15765, AL } 658 .^{863} \text { 103v Raum für Initiale } \\
\text { freigelassen. }\end{array}$ \\
\hline $\begin{array}{l}104 \mathrm{r}- \\
114 \mathrm{v}\end{array}$ & G\&F? & $\begin{array}{l}\text { Rursus in ambi- } \\
\text { guos }\end{array}$ & $\begin{array}{l}\text { Kurzepos Karolus Magnus et Leo papa. SK } 14418 .^{864} \\
\text { Codex Unicus. 104r am Rand: ab hinc; 114v: usque } \\
\text { huc. Fehlende Initialen. }\end{array}$ \\
\hline $\begin{array}{l}114 \mathrm{v}- \\
116 \mathrm{r}\end{array}$ & G\&F? & & Scholien zu Quintus Serenus. ${ }^{865}$ \\
\hline $116 \mathrm{r}$ & G\&F? & $\begin{array}{l}\text { Tantum vina } \\
\text { nocent }\end{array}$ & $\begin{array}{l}\text { SK 16026. Epigramm gegen die Trunksucht. Aus } \\
\text { Eugenius von Toledo.: carm. VI, vss. } 6-7 \text {. Dieses } \\
\text { vollständig in Cod. Sang. } 899 \text {, p. } 11 \text {. Ab hier anschei- } \\
\text { nend in einem Zug abgeschrieben bis } 118 \text { r. }\end{array}$ \\
\hline $116 \mathrm{r}$ & & $\begin{array}{l}\text { Collis sum } \\
\text { collisque }\end{array}$ & SK 2464. AL 685. Rätsel. Wie Reg. lat. 421, f. 27v. \\
\hline $\begin{array}{l}116 \mathrm{r}- \\
116 \mathrm{v}\end{array}$ & & Urbs quae tantum & $\begin{array}{l}\text { SK 16822. Lob auf die Stadt Mantua. Ebenfalls in } \\
\text { Cod. Sang. 878, p. } 70 \text {, dem Vademecum Walahfrids. }\end{array}$ \\
\hline $\begin{array}{l}116 \mathrm{v}- \\
117 \mathrm{v}\end{array}$ & & $\begin{array}{l}\text { Conveniant subi- } \\
\text { to }\end{array}$ & $\begin{array}{l}\text { SK } 2750 .{ }^{866} \text { Conflictus veris et hiemis. In Cod. Sang. } \\
397, \text { p. } 83 \mathrm{ff} \text {. }\end{array}$ \\
\hline $\begin{array}{l}117 \mathrm{v}- \\
118 \mathrm{r}\end{array}$ & & $\begin{array}{l}\text { Gallia me } \\
\text { genitum }\end{array}$ & $\begin{array}{l}\text { Isidor: Versus in bibliothecam IV-VII (SK 5469, 702, } \\
\text { 9582, 6806) }{ }^{867} \text { In Cod. Sang. } 397 \text { pp. } 85 \mathrm{ff} \text {. In einem } \\
\text { Zug wie Conflictus veris et hiemis, von einer Hand. }\end{array}$ \\
\hline
\end{tabular}

860 Ebd. S. $4-30$.

861 Bis 98r, Wechsel inmitten im Text.

862 BoAs (Hrsg.): Disticha Catonis. Sigle C, S. LXI, XIX.

863 Vollmer (Hrsg.): Eugenii Toletani episcopi carmina et epistulae. S. $253 \mathrm{f}$.

864 Ed. DüMmLer (Hrsg.): MGH Poet. lat. 1. S. 366-379, 633. BRUnhöLZL: De Karolo rege et Leone papa; Beiheft, Text und Übersetzung. Zur umfangreichen Literatur siehe "Carmen de Carolo Magno«, in: Das Digitale Repertorium »Geschichtsquellen des deutschen Mittelalters«, https://www.geschichtsquellen.de/repOpus_00769.html (abgerufen am 20.08.2018). Auch die Paläographie wird berücksichtigt bei: Dieter SCHALLER, »Das Aachener Epos für Karl den Kaiser«, in: Frühmittelalterliche Studien 10 (1976), S. 134-168. STORK: „Die Sammelhandschrift Zürich, Zentralbibliothek, $C 78$.

865 Vollmer (Hrsg.): Liber medicinalis. S. VIII f., Anm. 3.

866 DÜMMLeR (Hrsg.): MGH Poet. lat. 1. S. 270-272.

867 BeEson: Isidor-Studien. S. $159 \mathrm{f}$. 


\section{(Fortsetzung)}

\begin{tabular}{|c|c|c|c|}
\hline p. & Hand & Incipit & Inhalte, Anmerkungen \\
\hline $118 \mathrm{r}$ & & & $\begin{array}{l}\text { Nomina musarum, Verse auf die Musen (SK 2425). }{ }^{868} \\
\text { Wie Cod. Sang. 397, p. 147, ebenfalls zweispaltig } \\
\text { gestaltet. Hier vll. Neuansatz der Feder bei Wechsel } \\
\text { der Vorlage? }\end{array}$ \\
\hline $\begin{array}{l}118 \mathrm{r}- \\
118 \mathrm{v}\end{array}$ & & & $\begin{array}{l}\text { Divisiones musice artis, aus Cod. Sang. 397, ebd. } \\
\text { zusammen mit Nomina musarum, Versen auf die } \\
\text { Musen. Handwechsel G\&F zwischen Übernahme aus } \\
\text { Cod. Sang. } 397 \text { pp. } 85 \mathrm{ff} \text {. und } 147 \mathrm{ff} \text {. Ebenfalls in Cod. } \\
\text { Sang. } 899 \text {, p. } 65 \text {. }\end{array}$ \\
\hline $118 \mathrm{v}$ & & $\begin{array}{l}\text { Fonte lavat } \\
\text { genitor }\end{array}$ & $\begin{array}{l}\text { SK 5264, AL } 688-688 \text { c. }^{869} \text { Verse auf Hyppolit. Aus } \\
\text { Cod. Sang. } 397 \text { pp. } 85 \text { ff. Von dort ebenfalls in Cod. } \\
\text { Sang. 250, p. } 70 .\end{array}$ \\
\hline $\begin{array}{l}118 \mathrm{v}- \\
127 \mathrm{v}\end{array}$ & & & $\begin{array}{l}\text { Exzerpte. }{ }^{870} \text { Darunter Beda, De mansionibus filio- } \\
\text { rum Israel; Laurentius Scottus, De X numeris cano- } \\
\text { num; Testimonia Evangelistarum (122r am Rand: } a b \\
\text { hinc, } 123 \mathrm{r} \text { : usque huc). Beda mit INT und RES als } \\
\text { Frage-Antwort-Text strukturiert. }\end{array}$ \\
\hline $\begin{array}{l}128 \mathrm{r}- \\
149 \mathrm{v}\end{array}$ & G\&F? & Naturae genitor & $\begin{array}{l}\text { Priscian: Periegesis. Die Vorlage wies versetzte Lagen } \\
\text { auf. Das seltene Werk ebenfalls vorhanden in Mur- } \\
\text { bach. Im Florilegium Sangallense ein Vers des } \\
\text { Werkes zitiert. }{ }^{81} 138 \mathrm{r} \text { R-Ligatur neben Lacuna im } \\
\text { Text. 114v fehlender Vers mit de(est) notiert. }\end{array}$ \\
\hline $\begin{array}{l}149 \mathrm{v}- \\
155 \mathrm{r}\end{array}$ & G\&F? & $\begin{array}{l}\text { Sperne lucrum } \\
\text { versat }\end{array}$ & $\begin{array}{l}\text { Symposium XII Sapientum. }{ }^{872} \text { Textende nach sap. } 96 \\
\text { (= AL 590). Mit Cod. Sang. } 273 \text { (Sigle G) von } \\
\text { gemeinsamer Vorlage abhängig. Gänzlich ohne Nut- } \\
\text { zungsspuren. Text beginnt mit Handwechsel F? zu G, } \\
\text { wohl bei Wechsel der Vorlage. }\end{array}$ \\
\hline $\begin{array}{l}155 \mathrm{r}- \\
155 \mathrm{v}\end{array}$ & G\&F? & $\begin{array}{l}\text { Quam bene sub } \\
\text { patule }\end{array}$ & $\begin{array}{l}\text { SK } 12965 .^{873} \text { Ab v. } 7 \text { (Handwechsel) auch separat als } \\
\text { SK } 13620 . \text { Die letzten vier Verse Omnis mente pius, } \\
\text { ohne Trennung geschrieben, mit Columban in Ver- } \\
\text { bindung gebracht und vielleicht aus älterer St. Galler } \\
\text { Vorlage. }^{874}\end{array}$ \\
\hline
\end{tabular}

868 Riese/Bücheler (Hrsg.): Anthologia latina. Nr. 664. SCHenKL (Hrsg.): Ausonii Opuscula. S. 251.

869 RIESE/BÜCHELER (Hrsg.): Anthologia latina. Nr. 688, 688 a-c.

870 Sтовк: „Die Sammelhandschrift Zürich, Zentralbibliothek, C 78«. S. $115 \mathrm{f}$.

871 Paul van de Woestijne (Hrsg.), La Périégèse de Priscien, Édition critique, Brügge 1953. S. 10, Sigle A; S. 12, Familie c (die weiteren Handschriften spätmittelalterlich und nicht direkt auf Zürich C 78 zurückgehend). MiLDE: Bibliothekskatalog. Nr. 329. Einen anderen Text bietet V (Vat. lat. 11506, Weißenburg, Schulbuch? Siehe S. 190). Stephan: »Florilegium 870«. S. 278.

872 Friedrich: Symposium. S. 17 Sigle T; S. 21.

873 Riese/BüCheler (Hrsg.): Anthologia latina. 1, 2, S. XXIII, Anm. 17.

874 SCHALLER: "Siebensilberstrophen«. S. $477 \mathrm{f}$. 
(Fortsetzung)

\begin{tabular}{|c|c|c|c|}
\hline p. & Hand & Incipit & Inhalte, Anmerkungen \\
\hline $156 \mathrm{rv}$ & & $\begin{array}{l}\text { Iudicii signum } \\
\text { tellus }\end{array}$ & $\begin{array}{l}\text { SK } 8495 .^{875} \text { Aus De Civ. Dei 1. XVIII 23, 2, wie oben } \\
\text { 47r. Fortgeführt im folgenden Exzerpt. }\end{array}$ \\
\hline $\begin{array}{l}156 r- \\
159 r\end{array}$ & G\&F? & & $\begin{array}{l}\text { 156r-159r Exzerpte, }{ }^{876} \text { darin Augustin fortgeführt } \\
\text { auf } 157 \mathrm{r} \text { von } 47 \mathrm{r} \text {, Prosaübersetzung von Versen als } \\
\text { Pseudo-Verse geschrieben. 156v-157r: Exzerpt } D i- \\
\text { namius gramaticus, ebenso in Voss. Lat. Q. } 69,19 \mathrm{vab} \text {. }\end{array}$ \\
\hline $\begin{array}{l}159 \mathrm{r}- \\
160 \mathrm{r}\end{array}$ & G & $\begin{array}{l}\text { Mundus iste } \\
\text { transivit }\end{array}$ & $\begin{array}{l}\text { Columban (?): Epistulae Metricae Nr. } 11 . \text { SK } 9888 .{ }^{877} \\
\text { Codex unicus neben dem von Goldast genutzten. }{ }^{878}\end{array}$ \\
\hline $\begin{array}{l}160 \mathrm{r}- \\
160 \mathrm{v}\end{array}$ & & Spes ratio via vita & $\begin{array}{l}\text { SK 15583, AL 689a. Versus Silvii de cognomentis } \\
\text { salvatoris. Das Gedicht bildet auch vss. 5-11 aus SK } \\
11343 \text { Omnipotentis vis trina, das sich in Cod. Sang. } \\
878 \text { (Vademecum Walahfrids) p. } 71 \text { findet. Wahr- } \\
\text { scheinlich ein Übungsvers zu den Deklinationen. } \\
\text { Vielleicht auch das kleine folgende Exzerpt mit } \\
\text { gehäuften Adverbien zum gleichen Zweck. }\end{array}$ \\
\hline $\begin{array}{l}160 \mathrm{v}- \\
162 \mathrm{v}\end{array}$ & F? & $\begin{array}{l}\text { Contumeliam } \\
\text { nec fortis }\end{array}$ & $\begin{array}{l}\text { Publilius Syrus: Sententiae. }{ }^{879} \text { In allein stehender } \\
\text { Rezension als Collectio Turicensis. Ohne Nutzungs- } \\
\text { spuren. }\end{array}$ \\
\hline
\end{tabular}

Die Beobachtung des Ineinanderfallens von Hand- und Textwechsel ermöglicht eine Annäherung an die Vorlagen der Handschrift. Die erste Lage ist durchaus einheitlich und von einer Hand; thematisch an die Tituli zu den Malereien schließt sich das Exzerpt zu den Heiligendarstellungen an, worauf bis $57 \mathrm{r}$ einzelne Stücke von einzelnen Händen folgen; bis hier erinnert die Handschrift tatsächlich in ihrem Bric-à-Brac an Vademecum-Handschriften. Quintus Serenus $(57 \mathrm{v}-82 \mathrm{v})$ scheint von zwei Schreibern aus einer Vorlage kopiert worden $\mathrm{zu}$ sein. Theodulf, Ps.-Cato, Karlsepos, sowie die dazwischen eingestreuten kleineren Texte $(83 \mathrm{r}-114 \mathrm{v})$ dagegen, scheinen wie aus einer Vorlage übernommen $\mathrm{zu}$ sein, da die Schreiber nie beim Textwechsel, sondern immer inmitten der Texte aufeinander folgen. Auch die Gedichte 116r-118r, obwohl einige von ihnen auch in anderen St. Galler Handschriften vorkommen, sind in einem Zug und somit wohl aus einer vermittelnden Vorlage kopiert, nicht aus den uns bekannten anderen Textzeugen. Mit 118r setzen weitere Exzerpte aus St. Galler Beständen ein bis $127 \mathrm{v}$, woraufhin der gleiche Schreiber, aber auf neuer Seite, die Periegesis kopiert - wohl aus neuer Vorlage - wobei ihm ein anderer assistiert. Ab hier

875 Ebd. S. 477 und Anm. 60.

876 STоRк: »Die Sammelhandschrift Zürich, Zentralbibliothek, C 78«. S. 111.

877 Wilhelm Gundlach und Ernst Dümmler (Hrsg.), Epistolae Merowingici et Karolini aevi 1 (MGH Epp. 3), Berlin 1892. S. $189 \mathrm{f}$.

878 Ebd. S. 155. SCHALlER: »Siebensilberstrophen«. S. 477.

879 Meyer (Hrsg.): Publilii Syri Mimi Sententiae. S. 16, Sigle T; S. 12. Giancotti: Ricerche. S. 12. 
stimmen die Textgrenzen von Symposium und Publilius Syrus mit den Schreiberübergängen überein, sodass getrennte Vorlagen für beide vermutet werden dürfen. Die Wiederaufnahme des Augustinus-Exzerpts vom Beginn der Handschrift auf 157r legt mit Einschränkung nahe, dass diese recht zügig entstanden ist. ${ }^{880}$ Die Handschrift stellt sich also weniger als ein $"$ Notizbuch ${ }^{881}$ im Sinne der Vademecums Grimalds oder Walahfrids, in dem kleine und kleinste Texte nach und nach ergänzt werden, sondern um eine Sammelhandschrift aus meist größeren Stücken heraus. Dies waren zumeist Texte mittleren Umfangs mit hier und da kleineren Begleittexten oder im Falle von $83 \mathrm{r}-114 \mathrm{v}$ um eine wahrscheinlich schon gewachsene Anthologie; es hätte also schon in dieser das Karlsepos in seiner unvollständigen Form vorliegen müssen und es wäre nicht erst in Zürich, C 78, zu welchem Zweck auch immer, gekürzt worden. ${ }^{882}$ Durch die Übernahme auch der kleineren Stücke, die in den Vorlagen vorhanden waren, ist Zürich, C 78 eine Anthologie von Anthologien, die, wie Cod. Sang. 899, den Reichtum der St. Galler Bibliothek aus verschiedenen Quellen sammelt. Die Prosa-Exzerpte, die nur einen kleinen Teil der Handschrift darstellen und auch paläographisch meist abgegrenzt sind, sind wohl mehr dem Interesse der Schreiber, als dem Gesamtkonzept der Handschrift geschuldet.

Dass Zürich C 78 aus Beständen der Schulbibliothek, wo die meiste Dichtung zu finden war, geschöpft hat, sei nicht in Frage gestellt; dies macht aber den Kodex nicht uneingeschränkt zur Schulhandschrift, wie oft gemeint wurde. ${ }^{883}$ Nur Ps.-Cato wird explizit im Katalog unter den Schulschriftstellern genannt. Weiteres Indiz sind die Parallelüberlieferungen einiger Texte in den Schulhandschriften Cod. Sang. 273 und Voss. Lat. Q. 69. ${ }^{884}$ Auch die Periegesis ist mit Einschränkung als Schultext anzusehen ${ }^{885}$ Andere Texte dagegen wären für schulischen Gebrauch ungewöhnlich, namentlich Quintus Serenus, Theodulf und Karlsepos. Ganz fehlt die Grammatik, die gerade in St. Gallen fester Bestandteil dezidierter Schulhandschriften war. Zudem fehlen gänzlich die typischen Nutzungsspuren einer Schulhandschrift. Es findet sich nur eine althoch-

880 Die genaue Position des Binio 47r-50v ist unklar, jedoch sicher nicht innerhalb der nummerierten Lagen I-XIIII.

881 SCHALler: „Geraldus und St. Gallen - Zum Widmungsgedicht des >Waltharius«". S. 80.

882 Passend zu Schaller: »Aachener Epos«. S. 162, der vermutet, dass das Gedicht von vornherein als Skizze zirkuliert haben könnte.

883 SChaller: "Siebensilberstrophen«. S. 477. SтоRк: "Die Sammelhandschrift Zürich, Zentralbibliothek, C 78«. S. 108 (hier gar »im Schulunterricht aus anderen Vorlagen kopiert«). SCARPATETti/Gamper/StäHli (Hrsg.): Katalog der datierten Handschriften, 3. S. 276.

884 Nicht exklusiv schulische Parallelen in Cod. Sang. 899, Cod. Sang. 397, Cod. Sang. 878 (Reichenau).

885 Diese jedoch im Florilegium Sangallense zitiert; vgl. ebenfalls die Textgemeinschaft in Vat. lat. 11506 (Weißenburg), sowie die Platzierung des Werks bei den Grammatici, speziell bei Priscian in Lorsch (S. 248). 
deutsche Glosse, und diese zudem aus der Vorlage kopiert. ${ }^{886}$ Die Annotationen der Handschrift betreffen fast ausschließlich Orthographie und Varianten, erklärende Glossen fehlen ganz. Viel häufiger dagegen sind die Indizien, dass die Handschrift als Vorlage für verschiedene Abschriften genutzt wurde, ${ }^{887}$ jedoch bis auf das Karlsepos, das zur Abschrift markiert wurde, nur in den Prosaexzerpten. An den Rändern der Dichtung findet man dagegen oft R-Ligaturen, ${ }^{888}$ die interessante Stellen, vielleicht zu weiterem Gebrauch, markieren, was ihre Funktion als Textreservoir unterstreicht. Zürich, C 78 ist mithin nur mit Einschränkung als Schulhandschrift anzusehen, nämlich insofern sie auch schulische Texte enthält, die hier aber nicht direkt, sondern indirekt durch Exzerpt oder Abschrift im Unterricht genutzt wurden. Das Sammlungsinteresse und ordnende Prinzip der Handschrift stellt sich somit nicht als »absolute Planlosigkeit « dar, ${ }^{889}$ welcher Eindruck ohnehin einem unverhältnismäßigen Augenmerk auf die Prosaexzerpte entspringt, sondern als gezielte Sammlung von in St. Gallen vorhandener Dichtung in einer eigens dafür eingerichteten Handschrift. Ein persönliches Element der Kompilation soll hierdurch nicht ausgeschlossen werden; gerade dass mit Cod. Sang. 899 eine ganz ähnliche Handschrift in analoger Weise entstanden ist, legt nahe, dass diese beiden Kodizes keine Referenz-Exemplare für die Bibliothek, sondern unabhängig voneinander aus den Interessen ihrer Besitzer hervorgegangen sind. Diese sehe ich, wie auch bei Cod. Sang. 899, im Kreise der Dichter aus dem letzten Viertel des Jahrhunderts, die St. Gallen eine späte literarische Blüte brachten.

Im letzten Viertel des Jahrhunderts bildete sich tatsächlich eine »Dichterschule» in St. Gallen heraus, nachdem das Kloster vorher eher empfangend und bewahrend gewirkt hatte. ${ }^{890}$ Die späte Blüte St. Gallens unter dem »Dreigestirn Notker Balbulus, Ratpert und Tuotilo«, ${ }^{891}$ sowie unter dem Abbatiat von Notkers Schüler Salomo III. führt zeitlich und thematisch über unseren Gegenstand hinaus und soll hier nur noch in seinen großen Zügen, sowie anhand einer bedeutenden Handschrift umrissen werden.

886 BergmanN/Stricker: Katalog. Nr. 1019b.

887 ab hinc - usque huc an verschiedenen Stellen.

$888 \mathrm{R}=$ recipe? Vgl. Adriano CAPPELli, Lexicon abbreviaturarum, hrsg. von. Mario Geymonat, 7. Aufl. (Manuali Hoepli), Mailand 2011. S. 318.

889 SCHALLER: $»$ Aachener Epos«. S. 161.

890 Zum Begriff siehe Samuel Singer, Die Dichterschule von St. Gallen (Die Schweiz im deutschen Geistesleben 8), Leipzig 1922. Paul von Winterfeld, "Die Dichterschule St. Gallens und der Reichenau unter den Karolingern und Ottonen«, in: Neue Jahrbücher für das klassische Altertum, Geschichte und deutsche Literatur 5 (1900), S. 341-361. Anselm SCHUBIGER, Die Sängerschule St. Gallens vom 8. bis 12. Jahrhundert: ein Beitrag zur Gesanggeschichte des Mittelalters, Einsiedeln [u.a.] 1858. Zusammenfassend: Peter Ochsenbein, $» K l o s t e r l i t e r a-$ tur der Blütezeit«, in: St. Gallen. Geschichte einer literarischen Kultur, 1, hrsg. von Werner Wunderlich und Rupert Kalkofen, St. Gallen 1999, S. 161-180. S. 173.

891 Ochsenbein: »Die St. Galler Klosterschule«. S. 99. 
Stimulierend auf die St. Galler Dichter wirkte der Besuch Kaiser Karls des Dicken im Jahre $883{ }^{892}$ Notker widmete bei diesem Anlass sein Liber Hymnorum dem Erzkapellan Liutward von Vercelli. ${ }^{893}$ Aus späteren Handschriften sind Empfangsgedichte an verschiedene Könige von Notker, Hartmann und Waldram überliefert. ${ }^{894}$ Aber der dauernde Ruhm St. Gallens liegt in der Hymnendichtung, die von Ratpert, Tuotilo und Notker auf ungekannte Höhen geführt wurde. ${ }^{895}$ Dies drückt sich auch in einer Vielzahl früher musikalischer Handschriften aus, deren es in St. Gallen mehr gab als irgendwo sonst. ${ }^{896}$ Die Überlieferung der frühen Sequenzen und Tropen findet jedoch fast ausschließlich erst im 10. Jh. statt. $^{897}$

Aber auch traditionellere Formen wurden gepflegt. Endlich erhielt auch St. Gallen von der Feder seiner eigenen Schüler hagiographische Dichtung zu Ehren seines Gründers. Ratperts althochdeutsches Galluslied ist leider nur noch in lateinischen Übersetzungen aus späterer Zeit erhalten. ${ }^{898}$ Das Metrum de vita Sancti Galli, ${ }^{899}$ im Wechselgesang von Notker und seinem Schüler Hartmann entstanden, nimmt die Form des Prosimetrums, die Notker seinen Schülern empfahl. ${ }^{900}$

Am Übergang ins 10. Jh. steht eine Handschrift, die Notkers Formelbuch für seine Schüler Salomo und Waldo aufbewahrt: Clm 19413. ${ }^{901}$ Die weitgehend

892 Berschin: »Lateinische Literatur aus St. Gallen«. S. 113. Duft: „Große Äbte, blühende Abtei«. S. 65.

893 Johannes DuFt, "Die Stiftsbibliothek St. Gallen. Ein Überblick«, in: Die Abtei St. Gallen, 1. Beiträge zur Erforschung ihrer Manuskripte, Sigmaringen 1990, S. 13-32. S. 19.

894 Gesammelt bei: DüMmLER: »St. Gallische Denkmale aus der karolingischen Zeit«. S. 218-223, 255-258. Ebenfalls in: Winterfeld (Hrsg.): MGH Poet. lat. 4, 1. S. 323f., 327-329, 326 aus Cod. Sang. 381 (s. X), S. 348f. aus Cod. Sang. 360 (s. XII).

895 Wulf ARLT, "Liturgischer Gesang und gesungene Dichtung im Kloster St. Gallen«, in: Das Kloster St. Gallen im Mittelalter: die kulturelle Blüte vom 8. bis zum 12. Jahrhundert, hrsg. von Peter Ochsenbein, Darmstadt 1999, S. 137-165.

896 Johannes DuFT, "Der Beitrag des Klosters Sankt Gallen zum kirchlichen Gesang", in: Die Kultur der Abtei Sankt Gallen, hrsg. von Werner Voglen, Zürich 1990, S. 57-68. S. 60-62.

897 ARLT: »Liturgischer Gesang«. S. 142. Zum Verhältnis der Handschriften siehe Heinrich Husmann, "Die älteste erreichbare Gestalt des St. Galler Tropariums", in: Archiv für Musikwissenschaft 13 (1956), S. 25-41.

898 Peter Osterwalder (Hrsg.), Das althochdeutsche Galluslied Ratperts und seine lateinischen Übersetzungen durch Ekkehart IV. Einordnung und kritische Edition (Das Althochdeutsche von St. Gallen 6), Berlin, New York 1982. Sonderegger/Vogler: "Deutsche Sprache und Literatur in Sankt Gallen«. S 165. Zu Ratpert siehe auch: DuFт: »Der Beitrag des Klosters Sankt Gallen zum kirchlichen Gesang". S. $57 \mathrm{f}$.

899 Walter Berschin, »Notkers Metrum de vita S. Galli. Einleitung und Edition«, in: Florilegium Sangallense. Festschrift für Johannes Duft zum 65. Geburtstag, hrsg. von Otto Paul ClavaDETSCHER und Stefan Sonderegger, St. Gallen 1980, S. 17-121.

900 Zeumer (Hrsg.): MGH Formulae. S. 429, Z. $13 \mathrm{f}$.

901 Ernst Dümmler (Hrsg.), Das Formelbuch des Bischofs Salomo III. von Konstanz aus dem neunten Jahrhundert, Leipzig 1857. S. XXVI f. Ludwig RockInger (Hrsg.), Drei Formel- 
gleichen Inhalte, als auch die Absicht der Sammlung, werden schon gelegentlich der Schwesterhandschrift ÖNB Cod. 1609 (Freising), Waldos Exemplar, behandelt. ${ }^{902}$ Auch in den Ergänzungen zur Notkersammlung erweisen sich die beiden Handschriften als klar aus St. Galler Beständen geschöpft. Clm 19413 wird allgemein ins 10. Jh. datiert - spezifisch nach Salomos Tod - und fern von St. Gallen lokalisiert, ${ }^{903}$ und könnte demnach nur Abschrift einer älteren Sammlung sein, in der wir vielleicht Salomos Exemplar zu erkennen haben. Verschiedene Indizien legen jedoch eine Entstehung in St. Gallen selbst nahe. Die Handschrift ist keine durchgehende Abschrift einer Vorlage. ${ }^{904}$ Auf 1r-119v (Notkersammlung und Ergänzungen) dominieren jedoch nur zwei Hände, die bis hier durchaus eine Abschrift der Vorlage sein könnten. Eine Entstehung in St. Gallen wird wahrscheinlicher, wenn auch die Texte $113 \mathrm{v}-119 \mathrm{v}$, die wegen Lagenausfall nicht in ÖNB Cod. 1609 enthalten sind und somit keinen Vergleich gestatten, nicht Teil der ursprünglichen Notkersammlung waren ${ }^{905}$ und vor Ort an diese angehängt wurden (oder in der Vorlage Ergänzungen waren) - hier stammt fast alles aus St. Galler Beständen. ${ }^{906}$ Auch die weiteren Ergänzungen, von meist je einzelnen Händen und somit nach und nach eingetragen, enthalten zahlreiches St. Galler Material, das in dieser Fülle nur dort zu finden war. ${ }^{907}$ Einiges, darunter ein

sammlungen aus der Zeit der Karolinger: aus münchner Handschriften mitgetheilt (Quellen und Erörterungen zur bayerischen Geschichte 7), München 1857. S. 33-36. Wolfram von den STEINEN, "Notkers des Dichters Formelbuch «, in: Zeitschrift für Schweizerische Geschichte 25 (1945), S. 449-490. S. 452. "Notatio«. S. 35. Hartmut HoffmAnN, Schreibschulen des 10. und des 11. Jahrhunderts im Südwesten des Deutschen Reiches (MGH Schriften 53), Hannover 2004. S. 161; BergmAnN/Stricker: Katalog. Nr. 661. Rio: Legal practice. S. 249.

902 Siehe dort S. 283-290 für detaillierte Inhalte und Nachweis der St. Galler Parallelüberlieferung, sowie für die allgemeine Bewertung der Notkersammlung und ihrer Gedichte.

903 Südöstliches Frankenreich? Kempen? So Rio, Hoffmann a.a. O.

904 A1: 56r-103v; B: 104rv; A2: 105r-119v Z.4; C: 119v, Z. 5-18; D: 120r-127r, Z.11; E: 127r, Z.12127v; [F: 127va ab Z. 4 (5) (=A?)]; G: 127vb - 128r. Bis auf Hand F in Übereinstimmung mit HoFfmann: Schreibschulen. S. 161.

905 Wie Genreübergang von Briefdichtung in der Notkersammlung zu allgemeiner Kleindichtung nahelegt.

906 f. 115v-116r Isidor: Versus in bibliothecam V-VII: Cod. Sang. 397, p. 85; Reg. lat. 421, f. 31v; Zürich C 78f. 118r. 116r Prandeo poto cano ludo (SK 12442): Cod. Sang. 397, p. 145. 116r Fontibus in liquidis (SK 5267): Cod. Sang. 397, p. 121. 116r Noli archana (SK 9714): Cod. Sang. 397, p. 121. 116r De diuersis uocabulis nympharum: Cod. Sang. 397, p. 144. 118r-118v: Glossar Xenodochium id est: Cod. Sang. 196, Vorsatzblatt; Cod. Sang. 299, pp. 292-93, Cod. Sang. 397, p. 38, Zürich C 78, f. 160v-162v. 118v Augustinus magnus orator: Cod. Sang. 397, p. 38 .

907 120r Constantine decus (SK 2660), Cod. Sang. 397, p. 121. 121r-121v De sex generalibus synodis: Reg. lat. 421, f. 24v. 121v-124r Fulgentius, Expositio sermonum antiquorum: Cod. Sang. 397, p. 40-42, vgl. Eduard von Wölff LIN, "Aus St. Galler Handschriften«, in: Philologus 34 (1876), S. 178-179. 124r-124v Crede ratem ventis: Cod. Sang. 397, p. 120. 125r-127v ABCs und Wörterlisten: Zahlreiche Übereinstimmungen mit ÖNB Cod. 1761 (s. XI, Lorsch, siehe Michael Kautz, "Wien, Österreichische Nationalbibliothek, Cod. 1761 ", http://biblio 
Gedicht, lässt sich dagegen nicht in St. Gallen nachweisen. ${ }^{908}$ Es erscheint unwahrscheinlich, dass all diese St. Galler Texte fern vom Kloster von verschiedenen Händen kopiert worden wären. Ein weiteres Indiz ist, dass die Handschrift der Visio Wettini Reg. lat. 356 paläographisch der Hand G von Clm 19413 nahesteht ${ }^{909}$ und wahrscheinlich aus St. Gallen stammt. ${ }^{910}$ Ebenso verhält es sich mit London, British Library, Add. 34248, die St. Gallische Einflüsse aufweist und über Hand A mit Clm 19413 verwandt ist. ${ }^{911}$ Überhaupt scheint demnach die ganze Gruppe dieser Handschriften, die Hoffmann aus Provenienzgründen mit Kempen verbindet, aus dem Umkreis von St. Gallen zu stammen. Ich halte es ferner nicht für unwahrscheinlich, dass es sich bei der Vorlage für die Notkersammlung um Salomos Exemplar handelte: Die Dichtung, die noch wie in einem Zug von einer Hand $113 \mathrm{v}-119 \mathrm{v}$ kopiert wurde und die, wie schon bemerkt, nicht recht zur Briefdichtung der eigentlichen Notkersammlung passen will, könnte in der Vorlage an die Sammlung angehängt worden sein, so wie auch Waldo sein Exemplar (ÖNB Cod. 1609) mit Texten von persönlichem Interesse auffüllte. Diese Ergänzungen greifen auf denselben geteilten Fundus zurück, aus dem auch die großen Anthologien Cod. Sang. 899 und Zürich C 78 vom Ende des Jahrhunderts, also aus Salomos Zeit, zusammengestellt wurden. In den Ergänzungen zur Vorlage von Clm 19413 zeigt sich also auf dem Niveau einer persönlichen Handschrift dasselbe Interesse, das auch in den großen Sammlungen seinen Ausdruck fand. Obwohl St. Gallen am Ende des Jahrhunderts durch Hymnendichtung in die Literaturgeschichte eingeht, zeigen die Anthologien auch das ungemeine Interesse, das man an Dichtung aller Art nahm und das zweifellos die Grundlage für die poetische Exzellenz des Salomo-Kreises bildete.

Nach Salomos Tod (ca. 920) brach die Blütezeit St. Gallens durch eine Reihe von Katastrophen jäh ab: 926 wurde das Kloster durch die Ungarn verwüstet, 935 durch die Sarazenen, die von Fraxinetum her die Gegend plünderten, und was diese Scharen unberührt ließen, fiel dem großen Brand von 937 zum Opfer. Die Reichenau, wohin die Bibliothek vor den Verwüstungen gerettet wurde, ${ }^{912}$ leistete einen unschätzbaren Dienst zur Erhaltung der heute einzigartigen St. Galler Bibliothek. Auch im 10. Jh. konnte sich so das hohe Niveau der Studien in

theca-laureshamensis-digital.de/view/onb_cod1761 (abgerufen am 09.11.2017)), deren Vorlage, wie andere Übereinstimmungen zeigen, aus St. Galler Beständen stammt.

908 120r Et rex cum sanctis (SK 4678), Trauergedicht, wohl auf Ludwig den Deutschen (STRECKER (Hrsg.): MGH Poet. lat. 4, 2.3. S. S. 1034).

909 Hoffmann: Schreibschulen. S. 161.

910 »9./10. Jahrhundert«: BergmanN/Stricker: Katalog. Nr. 823 - Es handelt sich wohl um die von Goldast erwähnte Visio Wettini, die anschließend in die Bibliothek der Königin Christina überging.

911 Hoffmann: Schreibschulen. S. $160 \mathrm{f}$.

912 Haefele (Hrsg.): Casus Sancti Galli. 
St. Gallen erhalten, ${ }^{913}$ worin Dichtung, wie vorher, eine prominente Rolle einnahm, vermehrt um Autoren, die in späterer Zeit einen größeren Einfluss nehmen sollten wie Horaz oder der Homerus Latinus.

Wie auch andere Klöster hatte St. Gallen in seiner Frühzeit kaum Bedarf für Dichtung; auch aus der Schule, wo diese meist am frühesten auftritt, haben sich die typischen Autoren nicht erhalten. Frühes Zeugnis der St. Galler Begeisterung für Juvencus und Sedulius ist die Handschrift Zürich C 68, die durch ihre enge Verwandtschaft zum Reichenauer Kodex Aug. Perg. 217 schon zu Beginn des Jahrhunderts die enge Verbindung der Klöster unterstreicht. Auch dass die Handschrift noch am Ende des Jahrhunderts exzerpiert wurde (in Zürich C 78) zeigt die Kontinuität der Bibliotheksnutzung und das gerade in St. Gallen immer wieder und deutlicher als anderswo erscheinende Phänomen der Vermehrung der Bibliothek aus eigenen Beständen durch Kopie und Neuordnung. In Voss. Lat. Q. 69 erscheint durch die Integration von Schulautoren und Rhythmen schon früh die typische Vorliebe für diese Gattung; spätere Kopien aus der Handschrift schaffen auch hier eine bildungsgeschichtliche Kontinuität zwischen Beginn und Ende des Jahrhunderts.

Erst im Goldenen Zeitalter unter Gozbert und Grimald, Hartmut und Salomo begann sich auch eigene Kreativität zu regen. Die Vita St. Galli Metrica ${ }^{914}$ ist das erste bemerkenswerte Zeugnis, wenn auch noch ein auswärtiger Dichter an ihr beteiligt war. Sie steht am Übergang zwischen Auftragsliteratur, die man häufig von der Reichenau bezog, und den klostereigenen Werken vom Ende des Jahrhunderts. ${ }^{915}$ Grimald war trotz häufiger Abwesenheit ein wichtiger Impulsgeber der Entwicklung und zählte Walahfrid zu seinen Schützlingen, dessen weitere Beziehungen wiederum hinter einigen Titeln der St. Galler Bibliothek vermutet werden können (Venantius Fortunatus, Modoin). Die Wertschätzung, die Walahfrid im Kloster genoss, wird auch dadurch reflektiert, dass seine Dichtung uns nicht in einer Reichenauer, sondern in einer St. Galler Sammlung erhalten geblieben ist. Grimalds Privatbibliothek verzeichnet leider nicht die Werke, die ihm

913 Hier seien nur Gelehrte wie Notker der Deutsche und sein Schüler Ekkehard IV. genannt. Für einen Ausblick in das 10. Jh siehe Clark: Abbey of St. Gall. S. 103-104. DetTE: „Schüler im frühen und hohen Mittelalter«.

914 MGH Poetae 2, S. 428-473. Walter BERSCHIN, »Die karolingische Vita S. Galli metrica (BHL nr. 3253), Werk eines Iren für St. Gallen?«, in: Mittellateinische Studien 2, Heidelberg 2010, S. $43-62$.

915 Die offenen Fragen nach Verfasser und Entstehungszeit des Waltharius - Grimald wurde als einer von vielen als Autor vorgeschlagen - werden hier ausgespart. Die Handschriften sind allesamt späteren Datums und eine Datierung der Dichtung ins 9. Jh. ist problematisch. Siehe zu den Handschriften: Edoardo D'ANGELo, »Waltharius «, in: La trasmissione dei testi latini del Medioevo, 2, hrsg. von Paolo Chiesa und Lucia Castaldi 2005, S. 539-543.; zur Verfasserfrage: Arthur HAUG, "Gerald und Erckambald - Zum Verfasser- und Datierungsproblem des > Waltharius «", in: Jahrbuch für internationale Germanistik 34 (2002), S. 189-226. 
gewidmet worden sind; man darf aber vermuten, dass durch seinen Einfluss insbesondere der Bestand an zeitgenössischen Dichtern vermehrt wurde (Ermenrich, Walahfrid). Seine persönliche Handschrift wurde vielfach gerade in ihren poetischen Stücken exzerpiert.

Die Momentaufnahme des Bibliothekskataloges zeigt eine stattliche Bibliothek, die zu den ersten des Reiches gehört, jedoch gerade in der Dichtung hinter vergleichbaren wie Murbach und Lorsch deutlich zurückbleibt. Markant ist das Fehlen klassischer Dichter, denen gegenüber Notker später noch sein Missfallen ausdrückte und hiermit vielleicht eine spezifisch St. Gallische Abneigung zum Ausdruck brachte, die anderswo zumindest im Unterricht überwunden worden war. Der Bestand war dennoch so beträchtlich, dass er wie in Murbach in eine eigene Abteilung De Metris eingeordnet wurde, wobei die gemischten Schulhandschriften bei der Grammatik verblieben. Diese weisen einen eng gefügten und in mehreren Handschriften ähnlich repräsentierten Verbund von grammatischen Schriften, Bedas Ars Metrica zuvorderst, und Schuldichtung auf. Dass eine dieser Handschriften, Cod. Sang. 877, in ihrem Seduliustext auf die gleichen Vorlagen wie die nicht schulische Handschrift Zürich C 68 zurückgeht, zeigt die Multifunktionalität des Bibliotheksbestandes, der zu je anderen Zwecken kopiert und brauchbar gemacht werden konnte. Zeugnis des Detailstudiums sind die Florilegien wie Cod. Sang. 870, in denen endlich auch die klassischen Dichter auftreten, jedoch ganz ihres Geistes beraubt und zu prosodischen Fetzen zerschnitten.

Am Ende des Jahrhunderts zeigt sich in den zwei großen Anthologien, die in ihrem Umfang einzigartig sind, die Leidenschaft für Dichtung, die die letzte Generation des 9. Jh. erfüllte. Hierfür wurden die Bestände der Bibliothek in akribischem Kleinstudium durchgesehen und aus zahlreichen Handschriften Gedichte gesammelt. Auch die eigene Dichtung sammelte und kodifizierte man, wie Cod. Sang. 197 zeigt, eine Handschrift, in der auch die Lektüreempfehlungen Notkers Ausdruck finden. Die Werke der St. Galler Dichterschule stehen somit auf dem festen Fundament einer hundertjährigen Sammlung, die, obwohl nicht auffallend an Dichtung interessiert, doch genügend Schätze sammelte, die von einer neuen Generation in der Bibliothek entdeckt werden konnten. 


\section{II.1.e Reichenau}

»Augia Felix ${ }^{916}$, die glückliche Reichenau, 724 vom sagenumwobenen Pirmin gegründet, ${ }^{917}$ stieg ab dem Ende des 8. Jh. unter einer Reihe tatkräftiger Äbte zu einem der wichtigsten Bildungszentren des Reiches auf. ${ }^{918}$ Schon dem Gründungskonvent scheint durch Pirmin die Liebe zur Bildung in die Wiege gelegt worden zu sein, führte dieser doch laut einer spätmittelalterlichen Nachricht eine stattliche Bibliothek von fünfzig Bänden auf seinen Reisen mit sich. ${ }^{919}$ Diese vermachte er jedoch nicht der Reichenau, wie oft kolportiert wird, ${ }^{920}$ sondern sie verblieb - wenn dem Chronisten hier überhaupt Glauben zu schenken ist - in einer früheren Gründung bei Pfungen. ${ }^{921}$ Nichtsdestotrotz stattete Pirmin den jungen Konvent mit Büchern aus - vielleicht ja auch aus diesem Bestand. ${ }^{922}$ Die Zusammensetzung der frühen Bibliothek ist ganz unbekannt. Wenn es stimmt, dass Pirmin wie andere Klostergründer aus Irland oder England kam, ${ }^{923}$ mag auch naheliegen, dass die ältesten insularen Handschriften, von denen die Reichenau nicht wenige hat, noch zu den Büchern des Gründers gehören. Unter diesen befindet sich auch die Grammatik Priscians ${ }^{924}$ als frühes Zeichen einer Klosterschule. ${ }^{925}$ Der Beginn der eigentlich wissenschaftlichen Studien und die

$916 »$ Walahfridi Carmina«. S. 413, Nr. V, lxxxv, vss. 13, 4.

917 Franz Beyerle, "Bischof Perminius und die Gründung der Abteien Murbach und Reichenau«, in: Zeitschrift für Schweizerische Geschichte 27 (1947), S. 129-173. Konrad BEYERLE, "Von der Gründung bis zum Ende des freiherrlichen Klosters (724-1427)«, in: Die Kultur der Abtei Reichenau: Erinnerungschrift zur zwölfhundertsten Wiederkehr des Gründungsjahres des Inselklosters 724-1924, 1, hrsg. von Konrad BEYERLE und Peter P. Albert, München 1925, S. 55-212.

918 Allgemeine Literatur zu Geschichte und Kultur der Reichenau: Franz QUARTHAL und U.A, "Reichenau", in: Germania Benedictina 5 1987, S. 503-548. Helmut MAUrer, Die Abtei Reichenau. Neue Beiträge (Bodensee-Bibliothek 20), Sigmaringen 1974. BEYERLE/AlBERT (Hrsg.): Kultur der Abtei Reichenau.

919 Karl BRAndi (Hrsg.), Die Chronik des Gallus Öhem (Quellen und Forschungen zur Geschichte der Abtei Reichenau 2), Heidelberg 1893. S. 9, Z. 1.

920 Z.B. QUARTHAL/U.A: »Reichenau«. S. 225.

921 Brandi (Hrsg.): Gallus Öhem. S. 8, Z. 20- S. 9, Z. 3. Der Irrtum scheint auf eine ungenaue Formulierung Lehmanns zurückzugehen: »(...) bereits der Gründer Priminius soll 50 Bücher erworben [haben]. (LEHMANN (Hrsg.): MBK. 1, S. 222.) Die Verhältnisse korrekter bei: Karl Preisendanz, "Reginbert von der Reichenau. Aus Bibliothek und Skriptorium des Inselklosters«, in: Neue Heidelberger Jahrbücher (1952), S. 1-49. S. 2, der jedoch ebendort Anm. 8 Lehmann kritiklos zitiert.

922 BRANDI (Hrsg.): Gallus Öhem. S. 37, 8-11.

$923 \mathrm{Zu}$ den verschiedenen Herkunftshypothesen: BEYERLE: »Bischof Perminius«. S. 131.

924 Karlsruhe, BLB, Aug. perg. 132.

$925 \mathrm{Zu}$ weiteren insularen Handschriften: Berschin: Eremus und Insula. S. 38f. Karl PreISENDANZ, "Aus Bücherei und Schreibstube der Reichenau«, in: Die Kultur der Abtei Reichenau: Erinnerungschrift zur zwölfhundertsten Wiederkehr des Gründungsjahres des Inselklosters 724-1924, 2, hrsg. von Konrad Beyerle und Peter P. Albert, München 1925, S. 657-683. S. $676 \mathrm{f}$. 
Etablierung einer entsprechenden Bibliothek ist unter Abt Waldo (786-806) anzusetzen. ${ }^{926}$ Seine selbst für die Zeit ungewöhnliche Ämterhäufung - er war vorher Abt von St. Gallen, dann gleichzeitig Abt von St. Denis und Bischof von Pavia und Basel - setzte die Reichenau mit einem Mal zu anderen großen Zentren in Verbindung. Auf ihn folgte eine ununterbrochene Reihe fähiger Äbte, die durch ihre einflussreiche Position in der Politik des Reiches einerseits und ihre kultivierte Anteilnahme an der Bildung des Klosters andererseits die Bibliothek anhaltend förderten. ${ }^{927}$ Diese waren Haito (806-823) Erlebald (823-838), Ruadhelm (838?-842) und Walahfrid Strabo $(838,842-849) .{ }^{928}$ Die Sammlung profitierte von zahlreichen Stiftungen ihrer wohlhabenden Patrone, ${ }^{929}$ die nicht selten ihr Altenteil auf der Insel verbrachten. ${ }^{930}$ Die zahlreichen Schenkungen durch Mönche des Klosters wurden durch eine eigene Abteilung des Katalogs gewürdigt. ${ }^{931}$ Die Reichenau empfing und sandte Bücher fern - Tours, St. Denis, Niederaltaich, Nonantola - und nah - Pfäfers, Konstanz, Murbach, St. Gallen. ${ }^{932}$ Besonders eng war der Austausch mit Murbach, von wo einer der Reichenauer

926 Emmanuel P. Munding, Abt-Bischof Waldo, Begründer des goldenen Zeitalters der Reichenau (Texte und Arbeiten 1,10/11), Beuron 1924. Michael HARTIG, »Die Klosterschule und ihre Männer«, in: Die Kultur der Abtei Reichenau: Erinnerungschrift zur zwölfhundertsten Wiederkehr des Gründungsjahres des Inselklosters 724-1924, 2, hrsg. von Konrad BEYeRLE und Peter P. Albert, München 1925, S. 619-644. S. 620 f. Duft/Gössi/Vogler: „St. Gallen«. S. 1069f., 1270f. Siehe zu allen im Weiteren genannten Personen auch: Roland RappmanN und Alfons Zettler, Die Reichenauer Mönchsgemeinschaft und ihr Totengedenken im frühen Mittelalter (Archäologie und Geschichte 5), Sigmaringen 1998.

927 Zur politischen Rolle der Reichenauer Äbte: QUARTHAL/U.A: »Reichenau«. S. 505. Zum kontinuierlichen Ausbau der Bibliothek: Paul Lehmann, "Die mittelalterliche Bibliothek der Reichenau«, in: Die Kultur der Abtei Reichenau: Erinnerungschrift zur zwölfhundertsten Wiederkehr des Gründungsjahres des Inselklosters 724-1924, 2, hrsg. von Konrad BeYerLE und Peter P. Albert, München 1925, S. 645-656. S. 646.

928 Abtsreihe: QUARTHAL/U.A: »Reichenau«. S. $531 \mathrm{f}$.

929 Ebd. S. 525. LehmanN: »Bibliothek der Reichenau«. S. 649.

930 So etwa die Bischöfe Ratold und Egino von Verona sowie ein Bischof Lampert: LeHMann: "Bibliothek der Reichenau«. S. 646. Zu Ratolds Versifizierung der Moralia Gregors des Großen siehe unten S. 177-179 zum Katalog von Stuttgart, Württembergische Landesbibliothek, Cod. Don. 191 (olim Fürstenbergische Hofbibliothek Donaueschingen).

931 LehmanN (Hrsg.): MBK. 1, Nr. 52. S. 255 f.

932 Quarthal/U.A: »Reichenau«. S. 525. Die Entsendung von Büchern nach Pfäfers und Niederaltaich fällt jedoch in eine wesentlich frühere Zeit (unter Abt Etto 727-734): BRANDI (Hrsg.): Gallus Öhem. S. 36. Zu Nonantola: Richard M. Pollard, »Nonantola and Reichenau: a new manuscript of Heito's >Visio Wettini and the foundations for a new critical edition«, in: Revue bénédictine 120 (2010), S. 243-294. Zu Konstanz: Preisendanz: "Reginbert von der Reichenau«. S. 4. Zu St. Denis: Jean VÉZIN, "Les relations entre Saint-Denis et d'autres scriptoria pendant le haut Moyen Âge«, in: The role of the book in medieval culture, 1, hrsg. von Peter Felix Ganz (Bibliologia 3-4), Turnhout 1986, S. 17-39. Insb. S. 23-27. Bernhard BIschoff, »Eine Beschreibung der Basilika von Saint-Denis aus dem Jahre 799«, in: Kunstchronik 34 (1981), S. 97-103. 
Bibliothekskataloge erhalten ist ${ }^{933}$ - wohl zu Abgleich und beiderseitiger Vermehrung der Bibliotheken - und mit dem benachbarten St. Gallen. ${ }^{934}$ Es hat sich sogar ein Briefformular zum Büchertausch erhalten. ${ }^{935}$ Über Walahfrids Ausleihen sind wir durch die Erhaltung seiner Gedichte und einiger Briefe noch besser informiert: ${ }^{936}$ Bücher kamen und gingen nach »Fulda Mainz, Speyer, Murbach, Trier«; von ihm sind auch die einzigen direkten Reichenauer Zeugnisse über den Austausch von Dichtung erhalten: Er bittet Prudentius von Troyes um einen Lukan-Kommentar ${ }^{937}$ und die kleineren Vergil-Gedichte ${ }^{938}$ und sendet ihm zugleich die Gedichte Modoins. Vielleicht erhielt er diese nach einer persönlichen Bitte vom Dichter selbst. ${ }^{939}$ Einem Probus schickt er die Gedichte des Venantius Fortunatus. ${ }^{940}$ Leider hat Walahfrid nicht wie seine Vorgänger eine Ergänzungsliste der unter ihm angeschafften Bücher dem Katalog anhängen können. ${ }^{941}$

Die Anfänge der Klosterschule liegen im Dunkeln. Als erster Leiter der Schule wird vielleicht Heito, der spätere Abt, greifbar, ${ }^{942}$ zu dessen Schülern der Lehrer Wetti und der Bibliothekar Reginbert gehört haben müssten. Sicher als Lehrer

933 In Genf, Bibliothèque de Genève, Ms. lat. 21 (99) (Isabelle Jeger, Bibliotheque de Geneve, Catalogue des manuscrits latins, Genf 2016.; aus der Handschrift ediert in: BECKER: Catalogi. Nr. 33). Bei LehmanN (Hrsg.): MBK. 1, S. 240-242, im kritischen Apparat. Der Katalog aus Murbach stammt über eine Zwischenstufe vom Reichenauer Katalogrotulus ab (siehe auch Anne Grondeux, "Le rôle de Reichenau dans la diffusion du Liber glossarum «, in: Dossiers d'HEL 8 (2015), S. 79-93. S. 80: »Il serait par exemple envisageable qu'un inventaire rendu obsolète par la mise à jour de 821/822 ait été transmis à Murbach.«). Um den Murbachern zur Information über die Reichenauer Bestände zu dienen, muss der Katalog keineswegs, wie Lehmann S. 241 f. impliziert, eine um Murbacher Duplikate gekürzte Desideratliste sein; auch eine vollständige Liste kann verglichen werden. Was Dichtung angeht, hatte Murbach ohnehin die bedeutendere Sammlung, hier finden sich etwa zusätzlich gegenüber dem Katalog von 821/822 (Nummern nach: MiLDE: Bibliothekskatalog.): Alcimus Avitus (283; unter Erlebald auf die Reichenau gekommen), Cresconius Corippus (288), Appendix Vergiliana (308-315; vgl. unten zum S. 170 zum Katalog von 821/822, Nr. 24, 25), Lucan (316), Ovid (317), Lukrez (318) und Avianus (329; durch Reginbert für die Reichenau beschafft).

934 Lehmann: »Bibliothek der Reichenau«. S. 648f.

935 Formulae Augienses C, Nr. 9. Zeumer (Hrsg.): MGH Formulae. S. $369 f$.

936 Das Folgende bei: LehmanN: »Bibliothek der Reichenau«. S. 648.

937 Lukan ist laut den Katalogen nicht in der Bibliothek vorhanden gewesen.

938 Siehe unten S. 170 zum Katalog von 821/822, Nr. 24. 25.

$939 »$ Walahfridi Carmina«. V, vi.

940 Ebd. Nr. V, lxi, xlv. Bei Lehmann ist impliziert, dass Walahfrid diese Gedichte als Abt schrieb. Vorsichtiger: VISSER: Sis memor. S. 45, 138f., 140f. (826-846 [Probus], 826-849 [Prudentius]). Hier ist jedoch zu bedenken, dass Walahfrid wohl am ehesten als Abt die Ressourcen hatte, Bücher zu ent- und verleihen. Modoin und Venantius Fortunatus konnte er auch aus Reichenauer Beständen verleihen, siehe unten S. 170 zum Katalog.

941 Vgl. unten S. 177-179 zum unlokalisierten Katalog in Stuttgart, Württembergische Landesbibliothek, Cod. Don. 191.

942 Hartig: »Klosterschule«. S. 623. Ebenso in: Hubert Houben, »Art. Heito (Haito, Hatto) von Reichenau«, in: Verfasserlexikon, 3, 1981, S. 939-942. Kritisch hierzu: BerschIN: Eremus und Insula. S. 26. 
bekannt ist uns erst Wetti selbst, der nach Walahfrids nicht eindeutiger Formulierung »als erster« dort lehrte. ${ }^{943}$ Wettis eher geringes Können als Dichter kann nach seinem Widmungsgedicht zu seiner Vita St. Galli beurteilt werden, ${ }^{944}$ und spiegelt das allgemein niedrige Niveau der frühen Reichenauer Dichtung wider, ${ }^{945}$ die auch im Umfang, verglichen mit Walahfrids Werk, kümmerlich ist. ${ }^{946}$ Dass dennoch Dichtung auf hohem Niveau wenn nicht praktiziert, so doch gelehrt wurde, dafür sind die zahlreichen von Walahfrid verwandten Metren und die in der Bibliothek stehenden Dichter ein Beweis. ${ }^{947}$ Zur Unterweisung der Schüler im Latein bediente man sich auch der Volkssprache, von der sich einige Stücke von der Reichenau erhalten haben. ${ }^{948}$ In den Katalogen erscheinen gleich drei verschiedene Bände mit carmina theodisca, einer von ihnen paradoxerweise ad docendum (!) Theodiscam linguam, »zum Lehren der deutschen Sprache«. ${ }^{949}$ Ob hierunter auch die Murbacher Hymnen, deren erster Teil von einer Reichenauer Hand stammt, zu verstehen sind, ist eine offene Frage der Forschung. ${ }^{950}$ Eine ganz analoge Schöpfung ist die vielleicht von der Reichenau stammende fragmentarische Interlinearversion der Psalmen, deren von vornherein auf eine

943 Primus hic incultis mandavit semina sulcis, "Als erster hat er den unbebauten Furchen Samen anvertraut«: "Walahfridi Carmina«. Nr. IIIa., S. 334, v. 9, nach BERschin: Eremus und Insula. S. 26. Vielleicht bezieht sich das primus auf Wettis Rolle in der Elementarerziehung, denn er wird schwerlich der erste Lehrer überhaupt gewesen sein.

944 »Unbeholfen«: Jan Prelog, »Art. Wetti, Hagiograph und Schulmeister, Mönch im Kloster Reichenau († 824)«, in: Lexikon des Mittelalters, 9, 1998, S. 49-50.

945 Paul KLOPSCH, "Die karolingische Bildungsreform im Bodenseeraum«, in: Geistesleben um den Bodensee im frühen Mittelalter, hrsg. von Achim MAsser und Alois Wolf (Literatur und Geschichte am Oberrhein 2), Freiburg i. Br. 1989, S. 65-85. S. 81. Berschin: Biographie und Epochenstil im lateinischen Mittelalter, 3. S. 273. WINTER FELD: „Dichterschule«. S. $341 \mathrm{f}$.

$946 \mathrm{Zu}$ der Handvoll Reichenauer Tituli, die aus verschiedenen Handschriften und alten Drucken im Appendix zu Walahfrids Gedichten gesammelt wurden (DüMMLER (Hrsg.): $M G H$ Poet. lat. 2. S. 423-428) vgl. BernT: Epigramm. S. 262-264.

947 WINTERFELD: »Dichterschule«. S. 633.

948 Eine Liste des Erhaltenen bei: Stefan Sonderegger, »Althochdeutsch auf der Reichenau. Neuere Forschungen zur ältesten Volkssprache im Inselkloster«, in: Die Abtei Reichenau. Neue Beiträge, hrsg. von Helmut MAurer (Bodensee-Bibliothek 20, Hegau-Bibliothek 28), Sigmaringen 1974, S. 69-82. S. 74 f.

949 Lehmann (Hrsg.): $M B K .1$, im Katalog von 821-822: S. 248, Z. 4 f. (Nr. 1 der Zählung unten); im Reginbert-Katalog: S. 258, Z. 24-27 (Nr. XXI, XXII). Dass einige Reichenauer Schüler auch Deutsch lernen mussten, könnte sich durch die überregionale Anziehungskraft der Reichenauer Schule erklären lassen, die auch ihrerseits Schüler an andere Bildungsstätten entsendete (HARTIG: »Klosterschule«. S. 625). Lupus von Ferrières berichtet, wie er anhand deutscher Bücher die Sprache pflegte, und empfiehlt seinen Schülern später das Studium des Deutschen (Ep. 41, 70, „Lupi abbatis Ferrariens epistolae«, in: MGH Epist. 6, hrsg. von Ernst DÜMmLER 1925, S. 1-126, zitiert nach Grotans: Reading in medieval St. Gall. S. 135f.)

950 Die Murbacher Hymnen und ihre Handschrift (Oxford, Bodl. Libr., MS Jun. 25) sind bei Murbach behandelt. Zur Diskussion zusammenfassend siehe: Lothar VoEtz, ^Art. Murbacher Hymnen (Interlinearversion)«, in: Althochdeutsche und altsächsische Literatur, hrsg. von Rolf BergmanN, Berlin [u. a.] 2013, S. 272-288. Insb. S. 283 f. 
Glossierung ausgelegte Gestaltung auf eine regelmäßige Erstellung und Verwendung solcher Materialien im Unterricht hindeutet. ${ }^{951}$ Diese durchgehenden Glossierungen poetischer Texte befinden sich im Übergang von unsyntaktischen Paratexten auf dem Niveau von Hilfsmitteln zu eigenständiger Dichtung. ${ }^{952}$

Einen ähnlichen Hymnenbestand wie die Murbacher Hymnen, nämlich das »Fränkische Hymnar", enthält Zürich, ZB, Rh. 34, im Anschluss an den Psalter. ${ }^{953}$ Die Handschrift findet sich vielleicht im Reginbert-Katalog wieder: In XXXIX. libro habetur liber psalmorum cum diversis praefationibus ac capitulis et in fine eiusdem hymni diversi per diversas festivitates ac privatis diebus et nonnulla carmina. ${ }^{954}$ Der Eintrag zeigt, dass neben einigen Hymnen der beschädigten Lage auch einige Gedichte hier verloren gegangen sind. Hymnare sind auch schon im Katalog von 822 vermerkt, wiewohl erst Reginbert die Großzahl der Reichenauer Hymnare anschaffte. ${ }^{955}$ Diese stehen dort in Verbund mit anderen Texten monastischer Praxis wie der Benediktsregel oder dem Psalter. Die Hymnen der folgenden Handschrift dagegen haben eine ganz andere Textgesellschaft:

951 Lothar Voetz, "Art. Psalter: Fragmente einer altalemannischen Interlinearversion «, in: Althochdeutsche und altsächsische Literatur, hrsg. von Rolf BERgmanN, Berlin [u. a.] 2013, S. 384-395. Bernhard BIschoff, "Paläographische Fragen deutscher Denkmäler der Karolingerzeit», in: Bischoff, Mittelalterliche Studien, 3, 1981, S. 73-111. S. 94f. Edition und Abbildungen in: Elias von Steinmeyer (Hrsg.), Die kleineren althochdeutschen Sprachdenkmäler, Berlin 1916. Nr. XXXVIII.

952 SonDEREGGER: »Althochdeutsch«. S. 78f. Zur Interlinearversion als Studienhilfe siehe: Achim MASSER, »Aufgabe und Leistung der frühen volkssprachigen Literatur«, in: Geistesleben um den Bodensee im frühen Mittelalter, hrsg. von Achim MASSER und Alois Wolf (Literatur und Geschichte am Oberrhein 2), Freiburg i. Br. 1989, S. 87-106. S. 92.

953 »[Alemannien (Reichenau?), IX. Jh., Anfang] «: Bischoff: Katalog, 3. Nr. 7609. MohlberG: Katalog Zürich. S. 175, Nr. 401. Zu den Hymnen: Helmut Gneuss, "Zur Geschichte des Hymnars«, in: Der lateinische Hymnus im Mittelalter. Überlieferung, Ästhetik, Ausstrahlung, hrsg. von Andreas HaUg, Christoph März und Lorenz Welker (Monumenta Monodica Medii Aevi. Subsidia 4), Kassel [u. a.] 2004, S. 63-86. S. 71. Walther Bulst (Hrsg.), Hymni Latini antiquissimi LXXV, Psalmi III, Heidelberg 1956. S. 175-177. Darin Korrekturen zu: Clemens Blume, Der Cursus S. Benedicti Nursini und die liturgischen Hymnen des 6.9. Jahrhunderts in ihrer Beziehung zu den Sonntags- und Ferialhymnen unseres Breviers: eine hymnologisch-liturgische Studie, Leipzig 1908. S. 57-59. Jakob WeRnER, »Die ältesten Hymnensammlungen von Rheinau«, in: Mittheilungen der Antiquarischen Gesellschaft in Zürich 23, 3 (1891). S. 88f.

954 LehManN (Hrsg.): MBK. 1, S. 258.

955 Regula sancti Benedicti; hymni Ambrosiani in codice I. Ebd. S. 251, Z. 4. Reginbert: S. 259261, Nr. VI, XX, XXXVII, XXXIX. Zu ergänzen sind die hier die in Aug. Perg. 221 an Gregors Ezechiel-Homilien angehängten Hymnen: Audite fratres fama, Unitas in trinitate, Adiuvat nos archangelus, Rex o rector regminis, Archangelum mirum magnum. (Für Nachweise siehe Alfred Holder, Die Pergamenthandschriften (Die Reichenauer Handschriften. Neudruck mit bibliographischen Nachträgen 1), Wiesbaden 1970. S. 505). 
Traditionell mit der Schule assoziiert wird das merkwürdige Quinio, das unter dem Namen »Reichenauer Schulheft « bekannt ist. ${ }^{956}$ Der Name deutet nur auf die Bibliotheksheimat hin, denn das Schulheft ist eng verbunden mit drei Bänden von irischer Hand, die im Westfrankenreich vor 855 entstanden ${ }^{957}$ und noch im 9. Jh. auf die Reichenau gelangt sind. Es enthält, bunt gemischt mit anderen Exzerpten, ${ }^{958}$ eine beträchtliche Menge an poetischem Material: 1r: Vita Vergilii, Proöemium eines Vergil-Kommentars. ${ }^{959}$ Am Rande eine Autorensigle Io, vielleicht Johannes Scotus? ${ }^{960} 1 \mathrm{v}$ : »Pangur Ban«, ein irisches Gedicht auf einen weiBen Kater. ${ }^{961}$ 2r: Glossen zur Aeneis. ${ }^{962}$ 4v-5r: Metrik: die verschiedenen Versmaße. 6r-8r: Neues Hymnar. ${ }^{963}$ 8rv: Irische Gedichte. ${ }^{964}$ Vergilvers. Ein im Reichenauer Schulheft fehlendes Doppelblatt mit weiteren Hymnen ist eingebunden in Aug. Perg. 195, ${ }^{965}$ wo es durch ein weiteres angebundenes Blatt mit einem lateinischen Hymnus irischer Provenienz ergänzt wurde. ${ }^{966}$ In diesem Band finden sich weitere Gedichte, in den Freiräumen ergänzt oder später hinzugebunden ${ }^{967}$ Die vier irisch geprägten Handschriften, die durch gleiche Schreiber

956 St. Paul im Lavanttal, StB, Cod. 86b/1 (olim 25.2.31b, olim Sanblasianus 86). Christine Glassner, "Inventar der Handschriften des Benediktinerstiftes St. Paul im Lavanttal", http://www.ksbm.oeaw.ac.at/stpaul/inv/ (abgerufen am 09.01.2018). Hans GRöcHENIG, Günther HöDL und Erhard PASCHER, Katalog der Ausstellung. Handschriftenfragmente von 500-1500 (Armarium 1), Sankt Paul im Lavanttal 1977. Nr. 9.5, S. 155. Bischoff: Katalog, 3. Nr. 5943. Inhaltsangabe: Ludwig Christian STERN, "Über die irische Handschrift in St. Paul«, in: Zeitschrift für celtische Philologie 6 (1908), S. 546-554.

957 Karlsruhe, BLB, Aug. perg. 132 (Priscian, De arte grammatica), 167 (Computus), 195 (Augustinus \& Exzerpte). BIschoff: »Irische Schreiber«. S. 48f. Zum gleichen Schluss, was die Herkunft angeht, kommt Tristram: »Die irischen Gedichte«. S. 511-517.

958 Weitere Inhalte thematisch geordnet: Tristram: »Die irischen Gedichte«. S. 505-507.

959 Michael Petschenig, »Eine vita Vergilii«, in: Wiener Studien 4 (1882), S. 168-169.

960 Paul Lehmann, „Von Quellen und Autoritäten irisch-lateinischer Texte«, in: Lehmann, Erforschung des Mittelalters, 3, 1960, S. 143-148. S. 143f. Weitere Autorensiglen sind ag, hr, gg, cas (Tristram: »Die irischen Gedichte«. S. 518), die die Vielzahl der exzerpierten Texte widerspiegeln.

961 Whitley Stokes und John StRachan (Hrsg.), Thesaurus palaeohibernicus: a collection of old Irish glosses; scholia, prose, and verse. 2: Non-biblical glosses and scholia: Old-Irish prose: names of persons and places: inscriptions: verse: indexes, Cambridge 1903. S. 293-295. TRISTRAM: »Die irischen Gedichte«. Passim.

962 Synonymglossen, keine "Scholien" wie STERN meint (STERN: "Irische Handschrift«. S. 549f.). Siehe dort das Transkript.

963 Liste: Blume: Cursus. S. 65 (falsch: »ab Fol. 7 ff.«, lies 6ff.). Gneuss: »Zur Geschichte des Hymnars«. S. 77, 85f. Zum »Neuen Hymnar«: Ebd. S. 72-81.

964 Tristram: "Die irischen Gedichte«. S. 507, 508-511.

965 f. 45-46. Bischoff: »Irische Schreiber«. S. 49. Blume: Cursus. S. 66-68. Gneuss: »Zur Geschichte des Hymnars«. S. 77. Holder: Die Pergamenthandschriften. S. 438-444.

966 Inc. Cantemus in omni die, SK 1997.

967 1r (von anderer nicht-irischer Hand): verschiedene Verse, oft unleserlich, darunter an Dungal, Inc. O venerande pie, STRECKER (Hrsg.): MGH Poet. lat. 4, 2.3. S. 1124-1127, Nr. III. Zu den weiteren siehe Holder: Die Pergamenthandschriften. S. 439. 37v: Aspice marmoreas, SK 1131, StReCKer (Hrsg.): MGH Poet. lat. 4, 2.3. Ebd. Nr. II. 
(Aug. Perg. 132+195), gleiche Glossatorenhand (Aug. Perg. 132+167+[195, Notiz f. 38r, Trogo carissimus nobis]) und Übergang von Blättern (Aug. Perg. 195 +Schulheft) eng verbunden sind, ${ }^{968}$ erwecken auch durch ihre Themen - Grammatik, Computus, Theologie, Schul-Exzerpte - den Eindruck einer kleinen Handbibliothek, die von einem aus dem Westfrankenreich gekommenen Gelehrten - vielleicht einem Lehrer? ${ }^{969}$ - auf die Reichenau gebracht wurde. Das Reichenauer Schulheft stellt mit seinen bunt gemischten Exzerpten, die sichtlich nach und nach eingetragen wurden, das Notizbuch dieses Reisenden dar. ${ }^{970}$ Wiewohl das Schulheft und die verwandten Kodizes durch ihre elementaren Inhalte an das Curriculum erinnern, stellen die irischen Gedichte keine Schullektüre dar. Da das Lobgedicht auf König Aed ${ }^{971}$ wohl kaum unter anderen Herren auf dem Kontinent entstanden sein kann, scheint es wahrscheinlicher, dass die Gedichte Mitbringsel aus der Heimat sind oder in irischen Kreisen des Westfrankenreichs zirkulierten und dort vom Besitzer des Hefts gesammelt wurden. ${ }^{972}$

Unmittelbar in die Schule führt die Handschrift Aug. Perg. $112,{ }^{973}$ die, wenn wir sie mit einem Eintrag des Katalogs von 822 identifizieren wollen, vor diesem Datum auf der Reichenau entstand. ${ }^{974}$ Die Handschrift ist über einen längeren Zeitraum gewachsen, wie ihre Kodikologie zeigt. Ihren Kern bildet das grammatische Kompendium f. 51r-109v, das von einem Schreiber in mehreren Arbeitsgängen für die verschiedenen Texte erstellt wurde. ${ }^{975}$ Die dort enthaltene "Ars Augiensis« ist eine tiefgreifende Adaption von Donats Ars Major II, die durch zahlreiche Exzerpte anderer Autoren und Formtabellen modifiziert wurde. ${ }^{976}$ Dieser Hauptteil wird eingefasst von kleinteiligen Exzerpten f. 33-50, 109v-

968 BischoFF: »Irische Schreiber«. S. $48 \mathrm{f}$.

969 Tristram: "Die irischen Gedichte«. S. 518. Gröchenig/HödL/Pascher: Katalog der Ausstellung. S. 52.

970 Hartig: »Klosterschule«. S. 640. Lehmann: »Bibliothek der Reichenau«. S. 652. PreisenDANZ: »Bücherei und Schreibstube«. S. $680 \mathrm{f}$.

971 Stokes/Strachan (Hrsg.): Thesaurus Palaeohibernicus. S. 295, Nr. V.

972 Er ist nicht der Verfasser: Tristram: »Die irischen Gedichte«. S. 308.

973115 fols., $30 \times 22,7 \mathrm{~cm}$. Lagenformel: $\left[\mathrm{III}^{6}+\mathrm{V}^{16}+\mathrm{IV}^{24}+\mathrm{IV}^{32}\right]+\mathrm{IV}^{40}+(\mathrm{IV}+2)^{50}+\mathrm{II}^{54}+\mathrm{II}^{58}+\mathrm{III}^{64}$ $+(\mathrm{IV}-1)^{73}+\mathrm{III}^{79}+\mathrm{II}^{83}+\mathrm{III}^{89}+\mathrm{II}^{93}+\mathrm{IV}^{101}+\mathrm{IV}^{109}+(\mathrm{IV}-2)^{115}$. Hauptschreiber C1: $51 \mathrm{r}-61 \mathrm{v}, \mathrm{C} 2: 61 \mathrm{v}-$ 101v, C3: 102r-109v; A: 1r-32v-45r; B: 45v-50v, 109v, 110r-111r; D: 112r-115v. Kataloge: Holder: Die Pergamenthandschriften. S. 289-294. Rio: Legal practice. S. $244 \mathrm{f}$.

974 Bischoff: Katalog, 1. Nr. 1642. Ebenso: Holder: Die Pergamenthandschriften. S. 294. Der Eintrag lautet (LEHMANN (Hrsg.): MBK. 1, S. 252, Z. 4-7): Excerptio de libris grammaticae artis, de litera et de octo partibus; item in eodem codice praefationes Hieronymi in psalterium et quaedam pars versuum Juvenci et liber Isidori ad Florentiam. In der Handschrift fehlt jedoch Hieronymus.

975 51r-61v: Donat, Ars minor (»Octo Partes Orationis«), 61v-101v: ^Ars Augiensis«, 102r-107v: Beda, De schematibus, 107v-109v: Donat, Ars grammatica.

976 Holtz: Donat. S. 367-371, 465-466, 483-486. 
111r, darunter eine aus Isidors De fide catholica contra Iudaeos ${ }^{977}$ genommene Darstellung der Grundsätze des christlichen Glaubens und ein Florilegium, das nicht erst hier gesammelt, sondern aus der gleichen Vorlage wie ein Regensburger Kodex übernommen wurde. ${ }^{978}$ Viele der Stücke lassen eine ursprünglich insulare Herkunft des Florilegiums vermuten. ${ }^{979}$ Bis hier erweckt Aug. Perg. 112 den Eindruck eines Lehrbuches für die Schule, und zwar von einem recht elementaren Niveau, auf dem noch Konjugationen und katechetische Grundwahrheiten gelernt werden mussten. Die Dichtung der Handschrift befindet sich im vorgebundenen Teil f. 1-32 und trägt den schulisch geprägten Charakter der weiteren Handschrift. In ein grammatisch-allegorisches Traktat zum Alphabet sind bei $\mathrm{K}, \mathrm{Y}$ und $\mathrm{Z}$ wohl zur phonetischen Illustrierung der nicht lateinischen Schriftzeichen Hymnen dieses Anfangsbuchstabens beigefügt. ${ }^{980}$ Der Auszug aus der Evangelienparaphrase des Juvencus ${ }^{981}$ beginnt $13 \mathrm{v}$ ohne Titel oder Buchschmuck und wie die vorhergehenden Hymnen ohne Zeilenumbruch für die Verse. Der Text wurde an zahlreichen Stellen mit grüner (13v-14r) und schwarzer Tinte $(14 \mathrm{v}-17 \mathrm{v})$ korrigiert. ${ }^{982}$ Die grünen Korrekturen sind ausschließlich orthographischer Art, die schwarzen auch Ergänzungen fehlender Worte, also wohl nach einem Exemplar vorgenommen. ${ }^{983}$ Dass nur die ersten zwei Blätter des Textes intensiv annotiert wurden, legt nahe, dass auch nur diese im Unterricht benutzt wurden. Die Interpolationen des Textes, die bisweilen biblische Aspekte ergänzen und theologische Korrekturen vornehmen, sind kein Reichenauer Produkt. ${ }^{984}$ Eine weitere im Katalog bei Alkuin verzeichnete Juvencus-Hand-

977 CPL 1198; PL 83, 449B-527 A.

978 CARdelle de Hartmann: »Clm 14497«. S. 20.

979 Z. B. De VII gradibus sapientiae, Hywel D. EmANuEL, "The Seven Keys of Wisdom «, in: Studia Celtica 5 (1970), S. 36-47. De ponderibus, Bernhard Bischoff und Michael Lapidge (Hrsg.), Biblical commentaries from the Canterbury school of Theodore and Hadrian (Cambridge studies in Anglo-Saxon England 10), Cambridge [u. a.] 1994. S. 563-566.

980 Das Traktat ist unediert. Eine kürzere Variante bei: Hermann Hagen, Anecdota Helvetica quae ad grammaticam Latinam spectant, Leipzig 1870. S. 302-305. Die Hymnen bei: Franz Joseph Mone (Hrsg.), Hymni Latini medii aevi, Freiburg i. Br. 1853. Inc. Katerva plebis (1, S. 218) Kastitas corporis (2, S. 450) Ymnis et precibus (1, S. 97), Ymnos et psalmos (3, S. 430), Ymnisque dei (1, S. 111), Zelum elidiri (1, S. 183), Zelare castitas (2, S. 450). Der lateinischen Orthographie wird hier zum Zwecke der Veranschaulichung der Lautwerte nicht selten Gewalt angetan. $\mathrm{Zu}$ den Hymnen: Norbert Fickermann, "Zu den alten Rhythmen«, in: Revue Bénédictine 43 (1931), S. 313-321.

981 III, 1 - IV, 389. Huemer (Hrsg.): Iuvencus. S. XXVII-XXXIX, Sigle A.

982 Bei Huemer im Apparat als $\mathrm{A}^{2}$, jedoch nicht durchgehend.

983 16rb Z. 12, 17ra, Z. 13, 17va, Z. 2, 17vb, Z. 8, 18.

984 Cornel Heinsdorff, "Der interpolierte Juvencus des Codex Augiensis 112 und Severus von Malaga«, in: Vigiliae christianae 60 (2006), S. 148-170; Bernhard Bischoff u. a. (Hrsg.), Severi Episcopi (Malacitani ?) in Evangelia Libri XII: das Trierer Fragment der Bücher VIIIX, München 1994. Christian GNilka, „Über einige unechte Verse im Juvencustext«, in: Wiener Studien 114 (2001), S. 501-517. 
schrift ähnelte Aug. Perg. 112, indem sie an Juvencus Bedas Ars Metrica und Donats Ars Grammatica anschloss. ${ }^{985}$ Die restlichen Handschriften des Dichters stehen in der grammatischen Abteilung (De libris Prisciani). Von den anderen Dichtern sind nur noch Sedulius und Prosper mit einer grammatischen Schrift zusammengefasst. $^{986}$

Aug. Perg. $217^{987}$ enthält zwei weitere Reichenauer Exemplare (f. 1-67, 68-169) von den einstmals fünf der im Katalog von 822 enthaltenen Handschriften des Dichters. ${ }^{988}$ Beide Teile sind eng untereinander, sowie mit zwei St. Galler Handschriften verwandt, die beide umfangreiches grammatisches Material enthalten. ${ }^{989}$ Der erste Teil enthält die Evangeliendichtung, ${ }^{990}$ darauf von gleicher Hand folgend das Carmen Paschale des Sedulius, ${ }^{991}$ sowie einige Hymnen desselben. Beide Dichter wurden hier besonders am Beginn ihrer Werke noch im 9. Jh. stark glossiert, ${ }^{992}$ was wie bei Aug. Perg. 112 eine schulische Verwendung nahelegt. ${ }^{993}$ Ein späterer verlorener Sammelband der beiden Dichter aus Reginberts Ergänzungsliste enthielt zusätzlich grammatische und metrische Schriften. ${ }^{994}$ Die volkssprachigen Sedulius-Glossen haben einen anderen sprachlichen Charakter als die Juvencus-Glossen, was auf eine fortdauernde Verwendung durch mehrere Individuen schließen lässt. ${ }^{995}$ Der zweite Teil von Aug. Perg. 217 enthält ebenfalls Juvencus und das Carmen Paschale des Sedulius, anschließend den Vergil-Cento

985 De arte grammatica liber I; metrum Juvenci et Sedulii et Bedae de metrica ratione liber I et Donati de arte grammatica in codice I.: Lehmann (Hrsg.): MBK. 1, S. 250, Z. $24 \mathrm{f}$.

986 Item metrum Sedulii et epigrammata Prosperi ac Bedae de metrica ratione ac schematibus: Ebd. S. 252, Z. 16.

987 Holder: Die Pergamenthandschriften. S. 493-498, siehe dort zur richtigen Foliierung der versetzten Lagen.»Reichenau, 1./2. Viertel« und »1. Viertel«: BischоғF: Katalog, 1. Nr. 1707, 1708. Bergmann/STricker: Katalog. Nr. 312 (I+II). ERTMER: Juvencusglossierung. S. 258$289,336-347$.

988 Siehe unten S. 169f., Nr. 10, 14, 15, 17, 18. Lehmann (Hrsg.): MBK. 1, S. 250, Z. 25, S. 252, Z. 7 , 8, 11, 14. Eine weitere Handschrift der Evangeliendichtung findet sich in den ReginbertHandschriften, S. 258, Nr. IV, vielleicht identisch mit Nr. 10 des Hauptkatalogs.

989 Zürich, ZB Ms. C 68, Cod. Sang. 877 siehe bei St. Gallen, S. 80-82, 104f. Huemer/ZimmerLPanagl (Hrsg.): Sedulii Opera omnia. S. XIII f., XXX f.

990 Huemer (Hrsg.): Iuvencus. S. XXIX, Sigle $\mathrm{K}_{1}$, dort auch zum zweiten Teil der Handschrift $\mathrm{K}_{2}$.

991 Huemer/Zimmerl-Panagl (Hrsg.): Sedulii Opera omnia. S. XI, Sigle K. Springer: Handlist. S. $57 \mathrm{f}$.

992 Bergmann/Stricker: Katalog. Nr. 312 (I). Bergmann (Hrsg.): Ahd. und as. Literatur. S. 432, 433. Dagegen Datierung ins 10. Jh.: ERTMER: Juvencusglossierung. S. 347.

993 Vgl. jedoch unten S. 162 f. zum ebenfalls stark glossierten Prachtband Bern, BB, Ms. 264.

994 Die schon genannte Reginbert-Handschrift, LeHmann (Hrsg.): MBK. 1, S. 258, Nr. IV: In IV. Iibro sunt libri grammaticae artis Donati maiores et minores, partes orationis et de arte metrica libri Bedae presbyteri et de arte grammatica Alchvini libri et declinationes et metrum Juvenci et Sedulii super libros IV evangeliorum (...).

995 Ebenso stammen die Glossen von verschiedenen Händen: ErTMER: Juvencusglossierung. S. 335 , Anm. 5. 
der Proba, ${ }^{996}$ die allesamt aus der gleichen Vorlage wie ein St. Galler Kodex stammen. ${ }^{997}$ Im Katalog von 822 sind unter den grammatischen Titeln gleich zwei Handschriften verzeichnet, hinter denen sich dieser Teil der Handschrift verbergen könnte. ${ }^{998}$ Auch dieser Band ist durchgehend glossiert, jedoch über einen längeren Zeitraum bis ins 10. Jh. von einer Vielzahl von Händen. ${ }^{999}$ Juvencus und Sedulius zeigen sich somit, auf der Basis dreier Handschriften, ihrer Nutzungsspuren und der Katalogeinträge als eng mit der Schule verbunden. Sie dominierten das Curriculum der Reichenauer Schule und begleiteten schon die jungen Schüler auf ihrem Bildungsweg, wie aus dem sonstigen Niveau der Texte in Aug. Perg. 112 und ähnlichem Material im verlorenen Reginbert-Band geschlossen werden kann.

Die einzige weitere Reichenauer (?) Handschrift, die hauptsächlich Dichtung enthält, stammt schon vom Ende des 9. Jh., als die Bildung des Klosters sich nach den glanzvollen ersten fünfzig Jahren im Niedergang befand. Bern, BB, Ms. 264 ist, ${ }^{1000}$ obwohl sie einen Schulautor, Prudentius, ${ }^{1001}$ enthält, mit reichen Illustrationen versehen und erweckt nicht den Eindruck einer Schulhandschrift; dennoch ist sie noch reicher glossiert als die Juvencus-Handschriften. ${ }^{1002}$ Die Illustrationen sind nach einem spätantiken Vorbild ausgeführt, wahrscheinlich ver-

996 LuCARInI (Hrsg.): Proba: Cento Vergilianus. S. XII f., Sigle A'. Verwandtschaft und Stemma S. XCVIII f., CVI.

997 Zürich, ZB MS. C 68, siehe bei St. Gallen, S. 80-82.

998 Lehmann (Hrsg.): MBK. 1, S. 252, Z. 8-12 (mit Nummern aus: BeCKer: Catalogi. S. 13): (406.) Metrum Juvenci presbyteri IV evangeliorum libri IV; metrum Sedulii paschali carminis libri IV; metrum cento Probae liber I. Virgiliaca manuscripta in codice I. (407.) Item metrum Juvenci presbyteri IVevangeliorum libri IV; metrum Sedulii paschalis carminis libri III; metrum cento Probae liber I; metrum Bedae presb. de vita S. Gudberti episcopi lib. I, metrum Aldhelmi de laude virginum lib. I in cod. I. Gegen die Identifikation mit Aug. Perg. 217, offensichtlich beeinflusst von BECKERs willkürlicher Trennung sämtlicher Titel in zwei Handschriften: Petschenig/Schenkl/Brandes (Hrsg.): Poetae Christiani minores. S. 517, und: ERTMer: Juvencusglossierung. S. 261-264. Ebenso LuCARINI (Hrsg.): Proba: Cento Vergilianus. S. LXXXI.

999 Bergmann/Stricker: Katalog. Nr. 312 (II). S. 695. Ertmer: Juvencusglossierung. S. 260. $1000 »$ Alemannien (Reichenau möglich, kaum St. Gallen), IX. Jh., 3. Drittel«: BIschoff: Katalog, 1. Nr. 566. »Bodensee (Reichenau/St. Gallen/Konstanz) (...) um 900«: Otto HoMBURGER, Die illustrierten Handschriften der Burgerbibliothek Bern. Die vorkarolingischen u. karolingischen Handschriften, Bern 1962. S. 136-158. Hermann Hagen: Catalogus. S. $297 \mathrm{f}$. »St. Gallen«: Stettiner: Die illustrierten Prudentiushandschriften. S. 16, 22. Zu den Illustrationen: BEER: „Überlegungen zu Stil und Herkunft des Berner Prudentius-Codex 264". Stettiner: Die illustrierten Prudentiushandschriften. S. 70-105. Zur Diskussion siehe Euw: Buchkunst. S. 290-293.

1001 Cunningham (Hrsg.): Prudentii Carmina. S. XVII f., Sigle U. Prudentius spielte eine nur untergeordnete Rolle in der Reichenauer Bildung, nur eine Handschrift ist im Katalog von 822 verzeichnet (in volumine I mit Arators Apostelgeschichte): LeHMANN (Hrsg.): MBK. 1, S. 252, Z. $19 f$.

1002 Bergmann/Stricker: Katalog. Nr. 65. Die einzelnen Carmina sind alle gleich stark glossiert. 
mittelt über eine Zwischenkopie aus Lotharingien, von wo so viele der Hauptwerke karolingischer Buchmalerei stammen. ${ }^{1003}$

Hier endet schon das Zeugnis der Reichenauer Handschriften; Dichtung erscheint sonst nur noch als Einleitungsgedicht oder Anhang größerer Werke in untergeordneter Rolle. ${ }^{1004}$ Für eine so bedeutende Bibliothek, wie die Reichenau sie hatte, sind enttäuschend wenige direkte Zeugnisse von Dichtung erhalten. Selbst die Werke ihres berühmtesten Zöglings, Walahfrid Strabos, sind nicht in Reichenauer Handschriften erhalten. 808 geboren, ${ }^{1005}$ empfängt er auf der Reichenau von Erlebald und Wetti, Tatto und Grimald die Grundlagen seiner Bildung, wofür er sich in seinen Dichtungen dankbar zeigt. Um 827 verlässt er die Insel, um bei Hrabanus in Fulda zu studieren, weilt anschließend am Hof, um endlich wieder 838 als Abt auf die Reichenau zurückzukehren. Dieser Position infolge der Wirren nach dem Tod Ludwigs des Frommen enthoben, erlangt er die Abtswürde 842 wieder und ertrinkt 849 tragischerweise auf einer diplomatischen Mission. Der Reichenauer Einfluss auf diesen vielgereisten Gelehrten muss also in seinen Jugendwerken gesucht werden, in denen er die in der Schule gelernten Fähigkeiten zuerst anwandte. ${ }^{1006}$ Unter den kleineren Gedichten befinden sich sicher solche, die Walahfrid noch als Schüler schrieb - fing er doch vielleicht schon mit 16 an zu dichten - nur wenige davon lassen sich jedoch mit Sicherheit noch in seine Reichenauer Schulzeit datieren. ${ }^{1007}$ Dort scheinen an zwei Stellen durch Grammatiker vermittelte Zitate durch. ${ }^{1008}$ Allgemein als Frühwerke werden die Versifizierung der Jenseitsvision seines Lehrers Wetti, die Visio Wettini, sowie

1003 Eggenberger: "Der Bodensee als Foyer der Überlieferung spätantiken Bild- und Bildungsgutes". S. 6-10.

1004 Aug. Perg. $29+$ 19, Paulus Diaconus: Homiliar, mit Eingangsversen; Aug. Perg. 135, exegetischer Sammelband; darunter Sancte Sator (SK 14640) im Enchiridion Alkuins.

1005 Eine moderne Biographie Walahfrids fehlt. Siehe zum chronologischen Gerüst: Günter BERNT, "Art. Walahfrid Strabo (Strabus) OSB, Mönch und Abt der Reichenau, Dichter und Gelehrter (808/09-849)«, in: Lexikon des Mittelalters, 8, 1997, S. 1937-1938. Mit kritischer Sichtung der Literatur: VISSER: Sis memor. S. 23-46. Ältere Darstellungen: BRUNHöLzL: Geschichte, 1. S. 345-359. Eleanor Shipley Duckett, Carolingian Portraits. A study in the ninth century, Ann Arbor 1962. S. 121-160. »Walahfridi Carmina«. S. 259-263. Manitius: Geschichte, 1. S. 302-315.

1006 Visio Wettini, vss. 11-12: Non aliunde quidem primum componere carmen / disposui, quam sancta sequens praecepta priorum. Zu den Frühwerken als Schülerarbeiten: Konrad Arnold Bergmann, "Die Dichtung der Reichenau im Mittelalter", in: Die Kultur der Abtei Reichenau. Erinnerungsschrift zur zwölfhundertsten Wiederkehr des Gründungsjahres des Inselklosters 724-1924, 2, hrsg. von Konrad Beyerle und Peter P. Albert, München 1925, S. 711-755. S. 716. HARTIG: »Klosterschule«. S. 625.

1007 BRunhölzL: Geschichte, 1. S. 348 mit Anm. 32. Brunhölzl sieht die »in persona" geschrieben Gedichte als Schülerwerke an, ebenso: Visser: Sis memor. S. 49f. (eine tabellarische Übersicht der Datierungen S. 82) und Ducketт: Carolingian Portraits. S. 124f. Es handelt sich um die Carmina V, i, ii, xvii, xxx, lxxi. Vgl. Sтотz: »Dichten als Schulfach Aspekte mittelalterlicher Schuldichtung «. S. 5, Anm. 16.

1008 V. i, 49; ii, 9. Siehe VIsser im Kommentar zu den betreffenden Stellen. 
die Versvita Versus de beati Blaithmaic vita et fine angesehen, sowie vielleicht die Vita Mammae monachi. ${ }^{1009}$ In diesen Werken nahm Walahfrid ein Genre auf, das auf der Reichenau auch vorher in einer reichen Viten-Literatur gepflegt wurde. ${ }^{1010}$ Es finden sich ausgiebige Reminiszenzen von Dichtern, die Walahfrid in der Schule kennengelernt haben kann und die sämtlich im Katalog von $822 \mathrm{zu}$ finden sind: Sedulius, Juvencus, Prudentius und Venantius Fortunatus. ${ }^{1011}$ Von den antiken Dichtern zeigt Walahfrid insbesondere mit Vergil frühe Bekanntschaft, den er auch in seinen späteren Werken zur Inspiration nahm. ${ }^{1012}$ Horaz dagegen fehlt, wie auf der Reichenau, so auch in Walahfrids frühen Gedichten. Walahfrids Korrekturen und Ergänzungen im Weißenburger Horaz deuten auf eine spätere intensive Beschäftigung hin, ${ }^{1013}$ deren Ertrag sich jedoch eher in den Metren als in Zitaten findet. ${ }^{1014}$ Ovid-Reminiszenzen, die Manitius hinter jeder poetischen Wendung vermutet, ${ }^{1015}$ finden sich mit einiger Sicherheit erst in der Vita Mammae monachi. ${ }^{1016}$ Ovid wäre laut Katalog auf der Reichenau ohnehin nicht vorhanden gewesen, sodass auch von dieser Seite Solinskis Datierung »838-

1009 »Walahfridi Carmina«. Visio Wettini: S. 301-333. Vita Mammae: S. 275-296. Vita Blaithmaic: S. 297-301. Die beiden letzeren auch in: Mechthild Pörnbacher (Hrsg.), Walahfrid Strabo: Zwei Legenden (Reichenauer Texte und Bilder 7), Heidelberg 2012. Solinski: „De uita et fine sancti Mammae«. Visio Wettini: KnItTel (Hrsg.): Heito und Walahfrid Strabo: Visio Wettini. Einf., lat.-dt. Ausg. und Erl. David A. Traill (Hrsg.), Walahfrid Strabo's Visio Wettini: text, translation and commentary (Lateinische Sprache und Literatur des Mittelalters 2), Bern 1974.

1010 Berschin: Biographie und Epochenstil im lateinischen Mittelalter, 3. S. 274-279. Zur Koppelung der Visio Wettini mit der Prosavorlage in hagiographischen Sammelbänden: KLеINschміDт: "Zur Reichenauer Überlieferung der >Visio Wettini im 9. Jahrhundert«. S. 201, 207. Zu Walahfrid als Hagiograph: KIRsCH: Laudes sanctorum. S. 691-709, zur Chronologie speziell S. $707 \mathrm{f}$.

1011 Parallelen zu hier nicht genannten Dichtern halten einer näheren Überprüfung nicht stand. $\mathrm{Zu}$ frühen lyrischen Einflüssen auf Walahfrid siehe auch: KLopscH: »Bildungsreform im Bodenseeraum «. S. 83.

1012 Siehe hierzu, mit Schwerpunkt auf Georgica und Hortulus: Bernd EFfE, "Zur Rezeption von Vergils Lehrdichtung in der karolingischen >Renaissance und im französischen Klassizismus: Walahfrid Strabo und Rene Rapin«, in: Antike und Abendland 21 (1975), S. 140-163. Heinz HaffTER, »Walahfrid Strabo und Vergil«, in: Schweizer Beiträge zur allgemeinen Geschichte 16 (1958), S. 221-228.

1013 Vatikan, BAV, Reg. Lat. 1703. Siehe zu Weißenburg. Walahfrid-Autograph: BischоғF: "Sammelhandschrift«. S. 50. Lіснт: "Horazüberlieferung im Frühmittelalter«. S. 125f.

1014 David Daintree, "Non omnis moriar. The Lyrical Tradition of Horace in the Middle Ages", in: Latomus 59.4 (2000), S. 889-902. S. 896, 901. Ludwig BERnAYs, »Formale Aspekte karolingischer Lyrik des Klosters Reichenau«, in: Mittellateinisches Jahrbuch 32 (1997), S. 1127. S. 20-23. ÖNNERFORs: "Philologisches zu Walahfrid Strabo«. S. 56-58.

1015 Manitius besorgte den Similienapparat (siehe DüMMLER (Hrsg.): MGH Poet. lat. 2. S. V). Kritisch und ergänzend zu den Parallelen in Ed. DüMmLER: ÖNNERFors: »Philologisches zu Walahfrid Strabo«. S. 55-66, insb. S. 61.

1016 IV, 5; V, 4; X, 11; XIII, 10; XXII, 28. 
841 « für die Vita Unterstützung erhält. ${ }^{1017}$ Nach Walahfrids Aufbruch von der Reichenau verliert sich ihr direkter Einfluss. Auf die späteren Werke können die reichen Bibliotheken in Fulda und am Hof einen ebensolchen Einfluss hinterlassen haben wie die Schulbücher seiner Jugend. Walahfrids Werk kann keineswegs, wie es so oft in der Forschung geschieht, im Ganzen der »Kultur der Abtei Reichenau« zuerkannt werden. Nach seiner Rückkehr hatte der Dichter wieder Zugriff auf die Bibliothek seines Heimatklosters ${ }^{1018}$ und gab zu dieser Zeit seine Gelehrsamkeit an die jüngere Generation in einem eindrucksvollen Lehrgedicht auf Basis eines spätantiken Metriktraktates weiter, das auch anderswo Verbreitung fand. ${ }^{1019}$ Auch in Walahfrids Vademecum, ${ }^{1020}$ das überraschender-weise kaum Dichtung enthält, erscheint diese in einem grammatischen Kontext. Das grammatische Material, das sich relativ homogen von pp. 5-177 erstreckt, wird pp. 1-71 größtenteils von Walahfrids Hand W II, die in seine Abwesenheit von der Reichenau fällt, und pp. 72-177 von W IV, der reifen Hand des erwachsenen Walahfrid, und dem Gehilfen B geschrieben. ${ }^{1021}$ Ein Großteil der grammatischen Stücke der Handschrift findet sich ebenfalls in einem der Reginbert-Kodizes, dort mit Ergänzung von Juvencus und Sedulius. ${ }^{1022}$ Auch bei diesem handelt es sich um eine persönliche Handschrift, die Reginbert von seinem Bruder Wano überlassen und an seinen Neffen Rather weiterverliehen wurde, vielleicht, da dieser wohl bedeutend jünger als sein Onkel war, zu Studienzwecken. ${ }^{1023}$ In Walahfrids Vademecum ergänzen zwei Hände C und D auf pp. 70-71 im Anschluss an Donat mehrere Gedichte: p. 70, Inc. Urbs quae tantum (SK 16822), ein

1017 Solinski: "De uita et fine sancti Mammae«. S. 3-6, mit Forschungsdiskussion.

$1018 \mathrm{Zu}$ eventuellen Reichenauer Einflüssen auf das Spätwerk siehe: BERschin: Eremus und Insula. S. 32-35. Hermann SIERP, »Walahfrid Strabos Gedicht über den Gartenbau«, in: Die Kultur der Abtei Reichenau: Erinnerungschrift zur zwölfhundertsten Wiederkehr des Gründungsjahres des Inselklosters 724-1924, 2, hrsg. von Konrad Beyerle und Peter P. Albert, München 1925, S. 756-772. S. 757.

1019 Berschin/Licht: »Metrorum iure peritus«. S. 379 (Datierung), 387-393 (zu Verbreitung und Vorlage); Nam docuit multos metrorum iure peritus, »erfahren in der Dichtkunst lehrte er viele andere«, Hrabanus Maurus, carm. 88, zitiert nach: Ebd. Walahfrids Tätigkeit als Lehrer liegt weitgehend im Dunkeln, vgl. BERNT: »Art. Walahfrid Strabo (Strabus) OSB, Mönch und Abt der Reichenau, Dichter und Gelehrter (808/09-849)«. Sp. 1938, wo die Unterscheidung zwischen »Gelehrte[m] und Lehrer« schwerfällt.

1020 Cod. Sang. 878. Zuweisung an Walahfrid: BischofF: "Sammelhandschrift«. SCHerRer: Stiftsbibliothek. S. 307-309.

1021 Die Stufe W I steht "der Lehrzeit des Schreibers am nächsten« (BischofF: "Sammelhandschrift«. S. 36.), sodass bei Walahfrids frühem Weggang von der Reichenau die Hand W II am ehesten in die Fuldaer Zeit fällt. Inhalte und Schreiber Ebd. S. 38-41.

1022 Bischoff: »Sammelhandschrift«. S. 44, Anm. 25. LehmanN (Hrsg.): MBK. 1, S. 259, Z. 1-6. Geteilte Texte sind: Donat; Beda: Ars Metrica; »declinations«.

1023 Siehe unten S. 174 zu Nr. IV. der Reginbert-Liste. 
pseudo-vergilisches Lob auf die Stadt Mantua; ${ }^{1024}$ p. $71,{ }^{1025}$ Inc. Omnipotentis vis trina, Inc. Ardorem solis placida, Inc. Hoc subter iaceant. Die Nähe zum grammatischen Material deutet auf einen schulischen Überlieferungskontext der Gedichte; die Häufung von Substantiven verschiedener Deklinationen im zweiten Gedicht scheint geradezu auf einen pädagogischen Effekt berechnet zu sein. ${ }^{1026}$ Die Schreiber C und D erscheinen nur hier in der Handschrift und kooperieren nicht anderswo, wie zum Beispiel B, mit W(alahfrid), sodass unsicher ist, ob der Eintrag der Gedichte auf Veranlassung Walahfrids oder bei der späteren Nutzung seines Vademecums erfolgte. Auch der ältere Walahfrid lässt der Handschrift noch metrisches Material hinzufügen: pp. 91-131 findet sich, von der Hand des Gehilfen B, Bedas De arte metrica, und pp. 170-171 eine eigenhändige Notiz Walahfrids zu den Silbenlängen der Kasusendungen. Dass all diese Texte, sofern er sie nicht schon selbst als Schüler gesammelt hat, Walahfrids Lehrtätigkeit dienten, ist naheliegend. ${ }^{1027}$ Dass aber ausgerechnet Walahfrid nicht mehr Dichtung in seinem Vademecum gesammelt hat, bedeutet keinesfalls, dass er sie überhaupt nicht gesammelt hat: Wie oben gesehen bittet er seine Korrespondenten um Zusendung fehlender Werke und leiht auch selbst aus seiner Sammlung aus. ${ }^{1028}$

Da der Großteil von Walahfrids Oeuvre aus Klein- und Gelegenheitsdichtung besteht und selbst die größeren Werke - die Viten, der Hortulus - keine Handschrift füllen, ist ihre Überlieferung von vornherein vereinzelt, wozu auch die Vielzahl der Adressaten kommt, die im Besitz von je nur einer Handvoll seiner Briefgedichte waren. ${ }^{1029}$ Keine der erhaltenen Handschriften lässt sich glaubhaft mit einem der Adressaten verbinden ${ }^{1030}$ und keine kommt von der Reichenau. ${ }^{1031}$

1024 Hier unter der Überschrift MARO MECENATI SALUTEM. RIESE/BüCHELER (Hrsg.): Anthologia latina. Nr. 686. Ebenfalls überliefert in Zürich, C 78, 116r.

1025 Gedichte von p. 71 gemeinsam aus der Handschrift ediert bei: Huemer: »Analekten zur lateinischen Anthologie«. S. 72f., mit Korrekturen zu RIESE/BüCHELER (Hrsg.): Anthologia latina. Nr. 689a, der Text dort aus Zürich, C 78 , f. 160rv, nicht f. 157 wie angegeben.

1026 Inc. Omnipotentis vis trina, vss. 1, 5-11 bestehen ganz aus solchen Reihungen, z. B. Spes ratio uia uita salus sapientia mens mons. Nur diese Verse 5-11 finden sich dann in Zürich, C 78. Ähnliches, jedoch nicht metrisches Material findet sich pp. 174-176 von Walahfrids später Hand in Deklinationsübungen, z. B. Puer parvus natans limphis superpositus atque subiectus (BIschofF: „Sammelhandschrift«. S. 45-46 und Anm. 31.).

1027 Ebd. S. $45 f$.

1028 Insbesondere die Übersendung der Werke Modoins (»Walahfridi Carmina«. V, lxi), mit dem er selbst in Briefkontakt stand und ihn um Gedichte bat (V, vi), deutet auf eine aktive Teilnahme an und Sammlung von zeitgenössischer Dichtung; jedoch könnte Walahfrid auch auf den im Katalog von 821/822 verzeichneten Band zurückgegriffen haben, der ein metrum Muadvvini Nasonis enthielt (LeHMANN (Hrsg.): MBK. 1, S. 252, Z. 3. Unten Nr. 13).

1029 Einige Adressaten bei Bergmann: "Die Dichtung der Reichenau im Mittelalter«. S. 729.

1030 Handschriften: DüMmLER: »Die handschriftliche Überlieferung». S. 270-286. »Walahfridi Carmina«. S. 259-266.

1031 BERSCHIN: Eremus und Insula. S. 19. 
Die drei wichtigsten Handschriften, die uns den Großteil seiner Werke vermitteln, stammen aus Fulda und St. Gallen. ${ }^{1032}$ Sein früher, unerwarteter Tod wird Walahfrid gehindert haben, selbst eine Kodifizierung seiner Werke anzustellen; die Sammlungen seiner Gedichte, die weder ganz das Gleiche noch in gleicher Reihenfolge enthalten, machen eine zugrunde liegende auktoriale Zusammenstellung unwahrscheinlich, ${ }^{1033}$ zumindest insofern die weiteren Handschriften keine vollständigen Kopien hiervon sein können. Vielleicht liegt ein Relikt einer früheren Sammlung in einem eingestreuten Titel in Cod. 869 vor, p. 202: Versus Strabi Walahfridi quos post annum aetatis XV edidit de rebus diversis. ${ }^{1034}$

Die ganze glanzvolle Zeit der ersten Hälfte des Jahrhunderts übersah ein Mann die Geschicke der Bibliothek, der sie wie kein anderer prägte: Reginbert, für Jahrzehnte Bibliothekar der Reichenau. ${ }^{1035}$ Als Schreiber noch die ältere, alemannische Minuskel gebrauchend, ${ }^{1036}$ vermehrte er auch von eigener Hand die Bestände der Sammlung. Unter den zahlreichen erhaltenen Handschriften, an denen er beteiligt war, findet sich jedoch keine, die Dichtung enthielte. ${ }^{1037}$ Der Katalog, den er über die von ihm angeschafften Bücher anlegen ließ, enthält jedoch, wie wir sehen werden, reichlich Dichtung, sodass hier der Zufall der Überlieferung und nicht Reginberts Desinteresse zu beklagen ist. Ein metrisches Ex-libris schmückt zahlreiche der Reginbert-Bände und ist von solcher Qualität, dass eine Zuschreibung an Walahfrid erwogen wurde. ${ }^{1038}$ Als langjähriger Bibliothekar war Reginbert auch für die Verzeichnung der Bücher verantwortlich, die vom großen Katalog von 821/822 an über die Zugangsverzeichnisse der einzelnen Äbte bis zu Reginberts Ergänzungsliste ein Bild von Bestand und Wachstum der Bibliothek gibt. ${ }^{1039}$ Der Katalog wurde in der praktischen Form

1032 An ihren Schreiborten behandelt: Fulda: Vatikan, BAV, Reg. lat. 1703 (S. 185-188); St. Gallen: Cod. Sang. 869, Cod. Sang. 899 (S. 70-76, 129-139).

1033 ÖNNERFors: »Philologisches zu Walahfrid Strabo». S. 51.

1034 VIsser: Sis memor. S. 21, dort Anm. 76: BRunhölzL: Geschichte, 1. S. 348. Siehe auch bei Fulda, S. 70-77.

1035 Er diente unter vier Äbten, wohl 50 Jahre lang »sub dominatu Waldonis, Heitonis, Erlebaldi et Ruadhelmi (LehmanN (Hrsg.): MBK. 2, S. 258, Z. 9f.); PreisendanZ:»Reginbert von der Reichenau«. S. 11. BERSCHIN: Eremus und Insula. S. 23. Weitere Literatur: Herrad SPILLING, "Art. Reginbert von der Reichenau, Mönch, Lehrer, Bibliothekar und Schreiber $(\dagger 846)$ «, in: Lexikon des Mittelalters, 7, 1995, S. 578-579. Preisendanz: »Bücherei und Schreibstube«.

1036 MAAG: Alemannische Minuskel. S. 68-75.

1037 Matthias M. TISCHLER, "Reginbert-Handschriften, mit einem Neufund in Kloster Einsiedeln«, in: Scriptorium 50 (1996), S. 175-183. MAAG: Alemannische Minuskel. S. 203-205.

1038 »Walahfridi Carmina«. Appendix III. S. 424f. Die Handschriften mit Ex-Libris: LeHManN (Hrsg.): $M B K$. 1, S. 257. Würdigung: Berschin: Eremus und Insula. S. 16f. LeHmann: "Bibliothek der Reichenau«. S. 647.

1039 Lehmann (Hrsg.): MBK. 1, S. 222-267. Quarthal/U.A: »Reichenau«. S. 527. 
von zwei fortlaufenden Rotuli geführt, von denen einer zusätzlich bibliothekshistorische Nachrichten verzeichnete. ${ }^{1040}$

Der Katalog von 821/822 verzeichnet den Bestand der Bibliothek nach den Abbatiaten von Waldo (786-806) und Haito (806-823). Die Fülle der enthaltenen Dichtung findet sich zum Großteil in zwei verschiedenen Abteilungen: Bei den Autoren selbst und in der grammatischen Sammlung. Zur Übersichtlichkeit sei hier eine Tabelle von Dichtung und verwandten Titeln gegeben: ${ }^{1041}$

\begin{tabular}{|l|l|l|}
\hline Rubrik & $\begin{array}{l}\text { MBK, } \\
\text { S. }\end{array}$ & Titel \\
\hline (beschädigt) & 248 & 1. De carminibus Theodiscae volumen I. ${ }^{1042}$ \\
\hline De libris Prosperi & 249 & $\begin{array}{l}\text { 2. De vita activa et contemplativa liber I in codice I } \\
\text { 3. et epigrammatum eius liber I. }{ }^{1043}\end{array}$ \\
\hline $\begin{array}{l}\text { De opusculis Isido- } \\
\text { ri }\end{array}$ & 249 & $\begin{array}{l}\text { 4. Item notarum liber et Bedae de computo liber et Eu- } \\
\text { cherii libri III, quos supra descripsimus, et metrum } \\
\text { Marci Porci Catonis et aenigmata Tullii in codice I. }\end{array}$ \\
\hline
\end{tabular}

1040 Dieser noch von Gallus Öhem benutzte Rotulus ist bis auf die Nachrichten dieses Chronisten ganz verloren (LeHMANN (Hrsg.): MBK. 1, S. 234. BRANDI (Hrsg.): Gallus Öhem. S. 8, Anm. zu 13 [eigtl 20]); er wäre ein ganz einzigartiges Zeugnis inmitten der kargen Bücherlisten der anderen Kataloge gewesen. Der Inhalt des zweiten Rotulus ist uns erhalten geblieben bei: Johannes Egon: De viris illustribus, betreffender Auszug in: Holder/ Preisendanz: Die Reichenauer Handschriften, 3. S. 71-96. Neu ediert in Lehmann a.a. O. Die Parallelüberlieferung des Katalogs in Genf, Bibliothèque de Genève, Ms. lat. 21 bietet keine zusätzlichen Titel (siehe bei Murbach, S. 199).

1041 Nummerierung des Autors. Interpunktierung nach: Lehmann (Hrsg.): MBK. Die unter einer Nummer versammelten Titel werden als ein Band begriffen, teils abweichend von der Einteilung in Becker, Catalogi, und Holder/Preisendanz: Die Reichenauer Handschriften, 3.

1042 Die Textlücke und fehlende Rubrik ist in Egons Manuskript durch Asterisken angegeben. Man bemerke, dass die Handschrift nicht bei den Schulbüchern steht. Die Heterogenität der Kategorie kann daran ermessen werden, dass sie auch eine mappa mundi in rotulis II enthielt, vielleicht ein Vorläufer der Tabula Peutingeriana, so: Hans Lieb, "Zur Herkunft der Tabula Peutingeriana«, in: Die Abtei Reichenau. Neue Beiträge zur Geschichte und Kultur des Inselklosters, hrsg. von Helmut Maurer (Bodensee-Bibliothek 20, Hegau-Bibliothek 28), Sigmaringen 1974, S. 31-33. Zu weiteren althochdeutschen Stücken siehe unten S. 175 zum Reginbert-Katalog, dort deutsche Lieder ad docendum Theodiscam linguam.

1043 2. und 3. vielleicht in einem Band, da diese Textgemeinschaft sich ebenso findet in Cod. Sang. 187 (Lorsch) und Wolfenbüttel, HAB, Cod. Guelf. Weiss. 56 (Weißenburg); siehe hierzu Horsting (Hrsg.): Prosper Aquitanus, Liber epigrammatum. S. $24 \mathrm{f}$.

1044 Lies vielleicht rotarum für notarum (i.e. De Natura Rerum wegen der enthaltenen radförmigen Diagramme) wie Nr. 19 des Katalogs. Die Kombination von Disticha Catonis und Aenigmata in einem Band mit Isidor und Eucherius ist ungewöhnlich, vielleicht lagen ursprünglich zwei getrennte Bände vor. Die Aenigmata zumindest scheinen zum ältesten Bestand zu gehören, da Notker Balbulus berichtet, auf der Reichenau in quodam antiquissimo Augiensium libro subiecta enigmata gelesen und abgeschrieben zu haben (Preisendanz: »Reginbert von der Reichenau«. S. 27, Anm. 138. DüMmler: »St. Gallische 
(Fortsetzung)

\begin{tabular}{|c|c|c|}
\hline Rubrik & $\begin{array}{l}\text { MBK, } \\
\text { S. }\end{array}$ & Titel \\
\hline $\begin{array}{l}\text { De libris Bedae } \\
\text { presbyteri }\end{array}$ & 249 & $\begin{array}{l}\text { 5. De metrica ratione liber I et Alcuini de grammatica in } \\
\text { codice I. }\end{array}$ \\
\hline $\begin{array}{l}\text { De opusculis Ald- } \\
\text { helmi }\end{array}$ & 250 & $\begin{array}{l}\text { 6. Metrum de laude virginum in codice } \mathrm{I} \text {. } \\
\text { 7. De pedum regulis volumen } \mathrm{I} \text {. } \\
\text { 8. Item de pedum regulis et metrum de aenigmatibus in } \\
\text { codice } \mathrm{I}^{1{ }^{1045}}\end{array}$ \\
\hline $\begin{array}{l}\text { De opusculis Bo- } \\
\text { ethii }^{1046}\end{array}$ & 250 & $\begin{array}{l}\text { 9. De arithmetica libri II de geometria libri III et de dia- } \\
\text { lectica et rhetorica Alcuini; Arati de astrologia liber I; } \\
\text { artis medicinae liber I necnon et de diversis rebus libri } \\
\text { in codice I. }{ }^{1047}\end{array}$ \\
\hline $\begin{array}{l}\text { De opusculis Al- } \\
\text { cvuini diaconi }\end{array}$ & 250 & $\begin{array}{l}\text { 10. De arte grammatica liber I; metrum Juvenci et Sedulii } \\
\text { et Bedae de metrica ratione liber I et Donati de arte } \\
\text { grammatica in codice } \mathrm{I}^{1048}\end{array}$ \\
\hline De regulis & 251 & $\begin{array}{l}\text { 11. Regula sancti Benedicti; hymni Ambrosiani in codice } \\
\text { I. }{ }^{1049}\end{array}$ \\
\hline De libris glossarum & 251 & $\begin{array}{l}\text { 12. Item glossae in libros divinae historiae et de canone et } \\
\text { regula glossae et versus diversi et notae Julii in codice } \\
\text { I. }{ }^{1050}\end{array}$ \\
\hline De libris Prisciani & \multicolumn{2}{|l|}{252} \\
\hline
\end{tabular}

Denkmale aus der karolingischen Zeit«. S. 225). Zu den »aenigmata Tullii« siehe Dieter BITTERLI, Say what I am called: the Old English riddles of the Exeter Book and the AngloLatin riddle tradition (Toronto Anglo-Saxon series 2), Toronto [u. a.] 2009. S. $21 \mathrm{f}$.

1045 7. und 8. sind zwei Exemplare der Epistula ad Acircium, dem Lehrbrief zur Metrik mit Anhang der Aenigmata (7. vielleicht nur mit diesem): EHwAld (Hrsg.): Aldhelmi Opera. S. 59-204. Einer der beiden Bände ist vielleicht erhalten in Karlsruhe, BLB, Aug. Perg. 85, aus dem Reginbert-Kreis: Bischoff: Katalog, 1. Nr. 1620. Ehwald (Hrsg.): Aldhelmi Opera. S. 36, Sigle K. Preisendanz: »Bücherei und Schreibstube«. S. 666.

1046 Enthält ebenfalls De consolatione philosophiae libri V in codice I, siehe unten S. $175 \mathrm{zu}$ Bd. VIII der Reginbert-Liste.

1047 Vgl. II. der Reginbert-Liste (S. 174). Es ist unklar, welche der zahlreichen, darunter poetischen Übersetzungen des Aratus (Douglas KIdD (Hrsg.), Aratus, Phaenomena (Cambridge classical texts and commentaries 34), Cambridge [u.a.] 1997. S. XII-XIV) in diesem Artes-Sammelband enthalten war.

1048 Siehe oben S. 174 und S. 159-161 zu Aug. Perg. 112 und zu Nr. IV der Reginbert-Liste.

1049 Vgl. S. 175, zu XX. der Reginbert-Liste. Die Hymnen als Anhang wohl motiviert durch die Anweisung zum Hymnengesang in Regula Benedicti, IX, 4.

1050 Handschrift VI. der Reginbert-Liste (siehe unten S. 175) hat einen ganz ähnlichen Inhalt mit diversae glossae super istoriam veteris ac novi testamenti et super alios quam plurimos libros et notae Julii Caesaris, enthält jedoch zudem ein Martyrolog, einen Computus, sowie Plinius in Auszügen (wohl kaum vollständig: liber Plinii Secundi de natura rerum). Es handelt sich somit nicht um dieselbe Handschrift (dieser Meinung: STEINová: Technical signs. S. 87). Der Reginbert-Band enthielt diversi versus et nonnullorum hymni sanctorum et aliquorum epitaphia sanctorum, was einen Hinweis auf die nur summarisch beschriebenen versus diversi von 12. geben könnte. 


\section{(Fortsetzung)}

\begin{tabular}{|c|c|c|}
\hline RUов & & \\
\hline \multicolumn{3}{|c|}{$\begin{array}{l}\text { Isidori de octo partibus; Prisciani de partibus declinabilibus; ars } \\
\text { metrica ratione; orthographia Capri et Agroecii et metrum Mu- } \\
\text { in codice I. }{ }^{1051} \text { 14. Excerptio de libris grammaticae artis, de litera et } \\
\text {; item in eodem codice praefationes Hieronymi in psalterium et } \\
\text { ersuum Juvenci et liber Isidori ad Florentiam. }{ }^{1052} 15 \text {. Metrum Juvenci } \\
\text { angeliorum libri IV; metrum Sedulii paschali carminis libri IV; } \\
\text { robae liber I. }{ }^{1053} 16 \text {. Virgiliaca manuscripta in codice I. }{ }^{1054} 17 \text {. Item } \\
\text { presbyteri IV evangeliorum libri IV; metrum Sedulii paschalis } \\
\text { I; metrum cento Probae liber I; metrum Bedae presbyteri de vita } \\
\text { episcopi liber I; metrum Aldhelmi de laude virginum liber I in codice } \\
\text { Juvenci presbyteri IV evangeliorum IV; Sedulii operis paschalis libri } \\
\text { osperi, quod fuit epigrammata, in codice I. } 19 \text {. Item metrum Sedulii } \\
\text { Prosperi ac Bedae de metrica ratione ac schematibus; liber I rotarum } \\
\text { I. }{ }^{1056} 20 \text {. Metrum Paulini de vita sancti Felicis, libri XII in codice I. }{ }^{1057} \\
\text { toris de actibus apostolicis libri II et metrum Prudentii de diversis } \\
\text { ne I. } 22 . \text { Metrum Fortunati libri VI; Item eiusdem de laude liber I in } \\
\text { Metrum Dracontii de exameron libri II in volumine I. }{ }^{1059} 24 \text {. Metra } \\
\text { in volumine I. } 25 \text {. Item Virgilii Georgicorum libri III et Aeneidos } \\
\text { e I. }{ }^{1060}\end{array}$} \\
\hline
\end{tabular}

1051 Der zeitgenössische Dichter Modoin überrascht im grammatischen Sammelband. Es kann sich bei dem Titel nicht um die durch Walahfrid von Modoin erbetenen Gedichte handeln (»Walahfridi Carmina«. V, vi), da er bei Erstellung des Katalogs erst um die 13 Jahre alt war. Walahfrid verleiht jedoch vielleicht diesen Band (Ebd. V, lxi, 21f.), aber mit den Worten: mitto tibi Modoini carmina (nicht metrum) magni / In quibus invenies quod ferias, quod ames. »Metrum « wird jedoch häufig im Katalog benutzt ohne Rücksicht darauf ob es sich um mehrteilige oder homogene Werke handelt; ein ähnlicher Wortgebrauch in St. Gallen: Metrum Aurelii Prudentii libri VII; metrum Catonis libri IIII (Lehmann (Hrsg.): MBK. 1, S. 19).

1052 Siehe oben S. 159-161 zu Aug. Perg. 112.

1053 Siehe oben S. 161 f. zu Aug. Perg. 217.

1054 Von BeCKer: Catalogi. S. 13, mit 15. als ein Band angesehen. Es ist jedoch unklar, wie die Virgiliaca manuscripta mit den vorhergehenden drei Werken aus neun Büchern in einem Band Platz finden sollen, zumal Vergils Werke in 24., 25. in Einzelbänden vorliegen und 15. mit Aug. Perg. 217 zu identifizieren ist.

1055 Vgl. mit 15. ähnlichen Inhaltes. Im Gegensatz zu 16. könnten sich die zwei Bücher Beda und Aldhelm noch zu einer Handschrift des Umfangs von Aug. Perg. 217 hinzudenken lassen.

1056 Vgl. 4., darin notarum (=rotarum?) liber.

1057 Ebenfalls im Murbacher Katalog: Paulinus de vita Felicis XII (MiLdE: Bibliothekskatalog. Nr. 280). Ein Verwandter dieser beiden Titel ist in der Handschrift München, BSB, Clm 6412 (Prov. Freising) zu erkennen, die, aus dem Bodenseegebiet stammend (»ca. IX./X. Jh.«), dreizehn der Carmina Natalicia des Paulinus von Nola enthält, die jedoch als zwölf gezählt werden (f. 110v: Explicit liber duodecimus, darauf ohne Rubrik Carmen 32; die Zwölfzahl ist eine Eigenart der Familie $\varepsilon$ der Carmina: Franz Dolveck (Hrsg.), Paulini Nolani carmina (CCSL 21), Turnhout 2015. S. 114, Anm. 48). Dieser Handschrift eng verwandt ist Mailand, Bibl. Ambr., C 74 sup. aus dem Pariser Raum (St. Denis?). Keine der anderen Handschriften enthält eine zu den Katalogen passende Zahl von Büchern der Carmina Natalicia. GlaUCHE 
Die Dichtung im Hauptkatalog von 821/822 zeigt in allen Teilen eine starke Prägung durch die Schule. Auch die Bände, die zu den einzelnen Autoren, anstatt direkt in die grammatische Abteilung eingeordnet wurden, enthalten Dichtung oft nur in Begleitung durch pädagogische Texte (Nr. 5, 7, 8, 10). Andere Titel sind so gebräuchliche Schultexte, dass sie auch ohne direkte Assoziation mit Grammatik als Schulbücher angesehen werden dürfen $(\mathrm{Nr} .4,6,1)^{1061}$. Nur drei Bände

lässt die Vorlage der zwei Handschriften aus dem Raum Paris stammen, da dort mit zwei weiteren Textzeugen ein Schwerpunkt der Paulinus-Überlieferung liegt und die Reichenau und St. Denis im Austausch standen; auf der Reichenau kopiert, gelangt der Text von hier später nach Murbach und Freising. (Glauche: Pergamenthandschriften Freising. S. 223225. Bischoff: Katalog, 2. Nr. 3079. Dolveck (Hrsg.): Paulini Nolani carmina. Sigle F, S. 48f., 94, 98).

1058 Die Vita Martini hat vier und die Carmina elf Bücher; welche Werke hier genau gemeint sind, bleibt unklar. Eine ähnliche Textgemeinschaft ist im Lorscher Katalog verzeichnet (Nr. 364 der Konkordanz). Vielleicht ist es nur ein Versehen des Schreibers (IV zu VI)? Vielleicht liegt der Irrtum in der Zuschreibung: Paulinus von Périgueuxs Vita Martini hat sechs Bücher. Vgl. auch »Walahfridi Carmina«. V, xlv, 15: En Fortunati oratus tibi mitto libellos. Venantius Fortunatus ebenfalls vorhanden in Murbach (MildE: Bibliothekskatalog. Nr. 285, 286).

1059 Sonst nur aus Lorsch bekannt (metrum Draconcii de fabrica mundi): HäsE: Bücherverzeichnisse. Nr. 366. Bei den libri II handelt es sich wahrscheinlich um die zweiteilige Dracontius-Ausgabe des Eugenius: Friedrich Vollmer (Hrsg.), Dracontii carmina (MGH AA 14), Berlin 1905. S. XVII f.), nicht um den ebenfalls zweiteiligen, aber zu kurzen DracontiusCento (Wilhelm Meyer, "Die Berliner Centones der Laudes dei des Dracontius«, in: Sitzungsberichte der Preussischen Akademie der Wissenschaften zu Berlin (1890), S. 257-296. Vollmer (Hrsg.): Dracontii carmina. S. XII-XIV).

1060 Vgl. beide zu 16. Hier fragt sich, an welche Gedichte Walahfrid dachte, als er Prudentius von Troyes bat (»Walahfridi Carmina«. V, lxi, 24): Carmina Virgilii mitte minora, precor, denn auch die Eklogen werden in den drei Reichenauer Vergilbänden enthalten gewesen sein; sie werden zeitgenössisch zudem als egloge (Lorsch, Passau) oder Bucolicon (Murbach) bezeichnet. Man denkt hier eher an die Appendix Vergiliana. Hierdurch fällt vielleicht ein schwaches Licht auf die Überlieferung dieser Sammlung: Im Murbacher Katalog von ca. 840 ist zum ersten Mal seit der Antike die Appendix Vergiliana verzeichnet (MILDE: Bibliothekskatalog. Nr. 308-315). Murbach und die Reichenau standen, wie oben gesagt, im bibliothekarischen Austausch - warum also fragte Walahfrid nicht in Murbach nach den carmina minora? Vielleicht, so kann man vermuten, weil sie zu dieser Zeit noch nicht dort vorhanden waren und erst durch Prudentius von Troyes in das Bodenseegebiet kamen und also vielleicht erst durch Walahfrid nach Murbach vermittelt wurden. Eine weitere Verbindung von Prudentius von Troyes, Walahfrid und Murbach findet sich in einer Formelsammlung aus Murbach, deren Nr. 27 ein Brief von Prudentius - vielleicht an Walahfrid - ist, der jedoch später (nach 846) als das Korpus der Formulae (vor 800) datiert wird. Falls die Formel aus Murbach selbst stammt, läge ein Indiz für Kontakt und Austausch vor (Zeumer (Hrsg.): MGH Formulae. S. 336 (zitiert nach: Depreux: Prosopographie de l'entourage de Louis le Pieux (781-840). S. 350); vgl. aus der selben Handschrift auch Formulae Augienses, Coll. C 24., Zeumer (Hrsg.): MGH Formulae. S. 375. Rio: Legal practice. S. 149, 151. Karl ZEUMER, "Über die alamannischen Formelsammlungen«, in: Neues Archiv der Gesellschaft für ältere deutsche Geschichtskunde 8 (1883), S. 473-553. S. 480 .

1061 Zu 1. vgl. unten S. 175 zu Nr. XXI, XXII der Reginbert-Liste. 
stehen ganz oder größtenteils außerhalb dieses Sammlungsinteresse (Nr. 9, 11, $12^{1062}$ ). Der Großteil der Dichtung findet sich in der grammatischen Abteilung. Auch hier sind mehrere Sammelbände vorhanden, die Grammatik und Dichtung vereinen (Nr. 13, 14, 19). Auch die übrigen sind häufig schulisch genutzte Texte $(15,17,18,21$, mit Einschränkung Vergil 16, 24, 25). Erst am Ende der Sammlung und somit vielleicht als spätere Ergänzungen finden sich drei Seltenheiten (20, 22, 23).

Eine passende Ergänzung zum Reichenauer Unterrichtsmaterial wäre ein Florilegium gewesen, das als Vorstufe für das Opus Prosodiacum des Mico von Saint-Riquier, sowie für die Exempla diuersorum auctorum in Vatikan, BAV, Reg. lat. 215 diente. ${ }^{1063}$ Es enthielt - wenn es Micos Gestaltung glich - in dreispaltiger Aufbereitung mittig zahlreiche Dichterzitate mit den prosodisch erläuterten Worten links und Autorensiglen rechts. Aufgrund des Vorliegens eines einzelnen Walahfrid-Zitates meinte Traube, das Florilegium sei auf der Reichenau bearbeitet worden. ${ }^{1064}$ In seiner Nachfolge wurden dementsprechend in Micos Florilegium enthaltene Dichter fälschlich der Reichenauer Bibliothek zugeschrieben. ${ }^{1065}$ Schon ein Vergleich mit dem Katalog hätte hier jedoch misstrauisch machen müssen, da es kaum glaubwürdig ist, dass so viele Dichter nicht verzeichnet worden wären. ${ }^{1066}$

1062 Die Glossenbände der Abteilung, darunter ein codex grandis, scheinen eher Studien- als Lehrzwecken gedient zu haben, vgl. GRONDEux: "Le rôle de Reichenau«. S. 83-84.

1063 Opus Prosodiacum: Traube (Hrsg.): MGH Poet. lat. 3. S. 279-294. Zu den Exempla: Peiper (Hrsg.): Alcimi Aviti Opera. S. LXVIII.

1064 Opus Prosodiacum, v. 248. Traube (Hrsg.): MGH Poet. lat. 3. S. 273. Noch mit Fragezeichen in: Ludwig Traube, »Sophocles, ein Dichter der Anthologia Latina», in: Rheinisches Museum für Philologie 64 (1889), S. 478-479. Weiter kolportiert von: ManıTıus: Geschichte, 1. S. 470. Offensichtlich kann der Vers überall, wo Walahfrids Vita Mammae gelesen wurde, eingefügt worden sein, z. B. in Fulda oder insbesondere in St. Gallen (siehe dort S. 105-108 zum Florilegium Sangallense, Cod. Sang. 870). Es wäre zudem bemerkenswert, dass der Walahfrid-Vers ausgerechnet auf der Reichenau fälschlich mit der Sigle ARAT[or/us?], die in der Vorlage von Opus und Exempla stand, versehen worden sein sollte. Zum Zitat (Vita Mammae IV, 16): Solinski: "De uita et fine sancti Mammae«. S. 4, zu den Handschriften S. 7, Datierung S. 6. Durch die spätere Datierung der Vita Mammae muss auch das postquem des Opus Prosodiacum auf 838 verschoben werden. Zu bibliothekarischen Parallelen von Saint-Riquier und der Reichenau: Grondeux: »Le rôle de Reichenau«. S. 82f. Zu einer weiteren möglichen Verbindung nach Saint-Riquier siehe unten S. 173 zu Cyprian in der Erlebald-Liste.

1065 So zu Lukrez: Butterfield: Textual history of Lucretius. S. 92. Reynolds: Texts and transmission. S. 220. Juvenal: KNochE: Juvenaltext. S. $235 \mathrm{f}$.

1066 Insofern man nicht davon ausgeht, dass ein schon bestehendes Florilegium hier nur bearbeitet wurde (so Traube und Manitius; bei Reynolds ist es schon "put together at Reichenau«). Um nur einige der auf der Reichenau nicht vorhandenen klassischen Dichter des Opus Prosodiacum zu nennen: Horaz, Ovid, Lukrez, Martial, Lukan, Statius, Avienus, Priscian (Periegesis). 
Die Ergänzungen zum Katalog von 821/822 verzeichnen die späteren Zugänge. Unter Erlebald (823-838) wurden zwei Ergänzungslisten angelegt. Die unter ihm geschriebenen Bücher ${ }^{1067}$ haben fast ausschließlich patristischen oder exegetischen Charakter; die einzelne Grammatik - zudem eine Schenkung - zeigt, dass man sich in diesem Bereich gut ausgestattet und keiner Ergänzung bedürftig fühlte. Nur einer der Bände enthielt Dichtung: Alchvini magistri quaestiones super genesin et metrum Alcimi Aviti epsicopi, volumen I. Mit der GenesisDichtung des Alcimus Avitus ${ }^{1068}$ fügt sich der Band in das exegetische Sammelinteresse. Bei dem anderen Text des Bandes handelt es sich entweder um Alkuins Quaestiones in Genesim ${ }^{1069}$ oder, da Alcimus häufig in Verbund mit anderer Bibeldichtung überliefert wurde, unter falschem Titel um Cyprianus Gallus' Heptateuch-Dichtung, die zu dieser Zeit in St. Riquier und Lorsch zusammen mit Alcimus in einem Band vorhanden war. ${ }^{1070}$

Zwei weitere Ergänzungslisten aus der Zeit Erlebalds und Ruadhelms enthalten keine Dichtung. ${ }^{1071}$ Zahlreich dagegen ist sie in der unvollständigen Liste der 42 Handschriften, die durch Reginbert in die Bibliothek kamen. ${ }^{1072}$ Die sorgfältige Angabe der Inhalte gibt einen seltenen Einblick in die Inhalte der Handschriften und damit die Textgemeinschaft, in der sich die Dichtung befindet. Einige Titel haben starke Ähnlichkeit, bisweilen Identität mit denen des Hauptkatalogs, sodass Reginbert hier sein Schaffen von vor 821/822 bis zu Ruadhelms Zeit (838?-842) dokumentiert. ${ }^{1073}$

1067 Lehmann (Hrsg.): MBK. 1, S. 252-254. Zu den gleich genannten Titeln S. 253, Z. 37f., $38 \mathrm{f}$.

1068 Ebenfalls in Murbach als Einzelband (MILDE: Bibliothekskatalog. Nr. 283).

1069 Jullien: Clavis scriptorum latinorum medii aevi. Auctores Galliae, t. 2. S. 485. Die Titel vorund nachher sind ebenfalls Bücher Alkuins.

1070 Rudolf PeIPer (Hrsg.), Cypriani Galli poetae Heptateuchos: accedunt incertorum de Sodoma et Jona et ad senatorem carmina et Hilarii quae feruntur in Genesin, de Maccabaeis atque de Evangelio (CSEL 23), Wien 1891. S. I-IV. HäsE: Bücherverzeichnisse. Nr. 366.

1071 LehmanN (Hrsg.): $M B K$. 1, S. 254-256.

1072 (...) Sub dominatu Waldonis, Heitonis, Erlebaldi et Ruadhelmi (...) scripsi aut scribere feci vel donatione amicorum suscepi. EBD. 1, S. 257-262. Die Liste bricht am Ende ab (HoLDER/ Preisendanz: Die Reichenauer Handschriften, 3. S. 96). Reginbert war auch abgesehen vom Textverlust an mehr Handschriften beteiligt, als er hier angibt, vgl. die nicht erscheinenden Titel in: TISCHLER: »Reginbert-Handschriften «. Vielleicht gibt er hier nur die an, für die er sich ganz verantwortlich fühlte. Zur Reginbert-Liste zusammenfassend: Preisendanz: »Reginbert von der Reichenau«. S. 34-46.

1073 Grondeux stellt die Chronologie auf den Kopf, indem sie annimmt, dass die ReginbertListe (und in extenso die Ruadhelm- und Erlebald-Listen?) vor dem Hauptkatalog entstanden sei und die in der Zwischenzeit abgegegangenen Bücher nicht dort verzeichnet werden konnten (»Le rôle de Reichenau«. S. 82: »Pourtant ces titres [Reginbert-Liste Nr. VII] sont absents du catalogue de Reginbert [Hauptkatalog], ce qui implique qu'ils ont dû quitter Reichenau quelque part entre le moment de leur copie (...) et la rédaction du catalogue de Reginbert (821/822).«) Dies widerspricht den von ihr selbst zitierten Daten (79): "un inventaire datable des années $821 / 822(\ldots)$ enfin une liste récapitulative des textes copiés sous les abbés Waldo (786-806), Heito (806-822), Erlebald (823-838) et Ruadhelm 
\begin{tabular}{l} 
In II. libro continentur computationes regum Romanorum, caesarum consulumque; \\
deinde libri grammaticae artis Donati et de metrica arte libri Bedae presbyteri et libellus \\
de centum metris et liber de aenigmatibus Symphosii et liber fabularum Aviani poetae et \\
libri duo Boetii de arithmetica arte et libri quinque Boetii de musica arte et liber \\
astrologiae Arati et libri Boetii geometricorum et libri duo Alcuini de rhethorica et \\
dialectica arte et liber Julii Caesaris de mensione universi orbis et liber Aethici Hieronymi \\
de cosmographia et libri duo de architectura Faventini et liber unus herbarius Apulei. ${ }^{1074}$ \\
\hline In IV. Iibro sunt libri grammaticae artis Donati maiores et minores, partes orationis et de \\
arte metrica libri Bedae presbyteri et de arte grammatica Alchvini libri et declinationes et \\
metrum Juvenci et Sedulii super libros IV evangeliorum. Ipsumque librum Wano, frater \\
meus, mihi dedit et ego illum praestavi nepoti meo Ratherio; volo, ut veniat ad alios libros \\
nostros. ${ }^{1075}$ \\
\hline $\begin{array}{l}\text { In VI. libro comprehenduntur diversi versus et nonnullorum hymni sanctorum et } \\
\text { aliquorum epitaphia sanctorum et martyrologium cum computo et cyclo et versus de } \\
\text { diebus et mensibus et XII signis et diversae glossae super istoriam veteris ac novi } \\
\text { testamenti et super alios quam plurimos libros et notae Julii Caesaris et monogrammae } \\
\text { diversae et liber Plinii Secundi de natura rerum. }\end{array}$ \\
\hline
\end{tabular}

(838-842).« Abgesehen hiervon sollten aus der Unvollständigkeit eines Katalogs nie zu weitgehende Schlüsse gezogen werden, wenn man die große Zahl erhaltener, aber nicht verzeichneter Handschriften aus den katalogisierten Bibliotheken bedenkt.

1074 Grondeux, S. 82, vermutet, dass dieser Sammelband zu den Artes Liberales, da er im Hauptkatalog fehlt, nach St. Gallen oder Murbach, die beide ebenfalls die geographischen Werke des "Julius Caesar" und Aethicus besaßen, abgegangen ist. Nichtsdestotrotz tragen im Hauptkatalog Nr. 8. (Aldhelm = libellus de centum metris bei Reginbert) und 9. (Boethius: Arithmetik, Geometrie, Alkuin, Aratus, Medizin (=herbarius Apulei?), de diversis rebus libri unbekannten Inhalts) (getrennt durch eine Cantica-Auslegung) eine gewisse Ähnlichkeit mit diesem Titel. Der Sammelband hier enthält dagegen zusätzlich einen Computus, Boethius: De Musica, zwei Geographien, Avian und Faventinus. Es drängt sich der Eindruck auf, als habe Reginbert hier unter Rückgriff auf ältere Bestände (8.,9.) einen neuen, vermehrten Artes-Sammelband geschaffen, worin die Dichtung (Aldhelm, Symphosius, Avian) sich an die Grammatik anschloss. Ein Rest des Reichenauer Avians findet sich vielleicht im Exzerpt in Aug. Perg. 73 (Holder: »Zu Avianus«. Darin auch Martianus Capella: LeonARDI: "I codici di Marziano Capella«. S. 56f.).

1075 Ähnlichen Inhalt hat Hauptkatalog, Nr. 10, eine Identität der Titel ist wahrscheinlich: PREISENDANZ: »Reginbert von der Reichenau«. S. 16-18. Das Buch wäre somit vor 822 von Reginberts leiblichem Bruder Wano (frater meus im Gegensatz zu frater noster in Nr. V) diesem gegeben und in die Bibliothek eingereiht worden. Eine Ausleihe an Rather um die gleiche Zeit (unter Verweis auf Reginberts Alter Preisendanz, S. 17) halte ich dagegen für unwahrscheinlich, da diese zur Zeit der Abfassung der Reginbert-Liste dann schon 20 Jahre zurückliegen müsste - warum sollte nicht auch der ältere Reginbert einen jungen Neffen oder Großneffen - haben? Siehe zur Textgesellschaft der Handschrift auch oben S. 159-161 zu Aug. Perg. 112 über Juvencus als Schulautor.

1076 Vgl. oben S. 169 zu Nr. 10. des Hauptkatalogs, wovon IV. eine vermehrte Abschrift zu sein scheint. Fünf Fragmente dieser Handschrift wurde im 19. Jh. versteigert (Conrad HoFMANN, »Über Bruchstücke einer Handschrift mit althochdeutschen Glossen«, in: Germania 8 (1863)), worunter sich auch das Inhaltsverzeichnis - mit Reginberts Ex-Libris - erhalten hatte, das weitgehend identisch mit dem Katalog-Eintrag ist, jedoch über die poetischen Teile ausführlicher berichtet: I. Inprimis sunt diuersi uersus a scis doctoribus editi. II. Deinde aliquanti ymni in scorum et nonnulla uirorum in li.... III. In(t)er ea naq: diuersi ad diuersos 
In VIII. libro sunt libri V de philosophia consolationis Boetii et admonitiones sancti Basilii liber necessarius et in capite libri pauca de declinationibus. ${ }^{1077}$

In XX. libello est regula sancti Benedicti abbatis et hymni Ambrosianj et epistola ad regem Karolum de monasterio sancti Benedicti directa et capitula (et) res(ponsa) de statu regulae et martyrologium per anni circulum, quem Tatto et Crimolt mihi condonaverunt. ${ }^{1078}$

In XXI. libello continentur XII carmina Theodiscae linguae formata. ${ }^{1079}$

In XXII. libello habentur diversi paenitentiarum libri a diversis doctoribus editi et carmina diversa ad docendum Theodiscam linguam et de inventione corporis sancti Benedicti et caetera.

usus uersus sunt conscripti. IIII. Postmodum chronica strictim uerbis composita ac postea uersus..., dies analog zu (I) diversi versus, (II) hymni sanctorum, (III) epitaphia sanctorum. Die Handschrift scheint also besonders in I-III eine recht umfangreiche Sammlung von Gebrauchsdichtung enthalten zu haben. III. scheint eine Sammlung von Epitaphien (epitaphia) und Tituli (ad diuersos usus) gewesen zu sein. I. war vielleicht eine Sammlung von spätantik-christlicher Kleindichtung, denn Fragment V des Auktionsloses ist ein Blatt mit Versen des Paulinus von Aquileia (DüMmLer (Hrsg.): MGH Poet. lat. 1. S. 137, VI, 1-3). Welche chronica strictim uerbis composita ac postea uersus (Vers-Chronik oder Prosimetrum?) sich unter IIII verstecken könnte, bleibt unklar.

1077 Der Titel vielleicht identisch mit den De consolatione philosophiae libri V in codice I des Hauptkatalogs, wenn dort nur der Hauptteil der Handschrift katalogisiert wurde. Punktierung geändert gegenüber Lehmann: Basilii[,] liber, da die Handschrift aus dem Grimald-Kreis, St. Gallen, Kantonsbibliothek VadSlg Ms. 317, f. 1-15 (Вiscноғғ: Katalog, 3. Nr. 5483), das gleiche merkwürdige Incipit trägt: ammonitiones sci Basilii epi. Liber necessarius. Bei Identität mit dem Titel im Hauptkatalog liegt eine Kopie der GrimaldHandschrift aus einer Reichenauer Vorlage von vor 822 nahe. Aber auch eine Vermittlung durch Grimald scheint möglich (wie in Nr. XX der Reginbert-Liste, um 817), da die Admonitiones nicht bei den Werken des Basilius im Hauptkatalog stehen (LeHMANN (Hrsg.): MBK. 1, S. 246, Z. 32-36).

1078 Vgl. ähnlichen Inhalts Nr. 11 des Hauptkatalogs (S. 169). Es handelt sich wohl bei beiden Einträgen um ein und dieselbe Handschrift, die Reginbert 817 von seinen Schülern Grimald und Tatto gewidmet wurde (DüMmLer (Hrsg.): Epistolae Karolini aevi 3. S. 302, zitiert nach BischоғF: »Bücher am Hofe und Privatbibliothek«. S. 204, Anm. 78). Zur Bedeutung von Reginberts Regula-Handschrift vgl. Ludwig Traube, "Textgeschichte der Regula, S. Benedicti«, in: Abhandlungen der Historischen Klasse der Königlich-Bayerischen Akademie der Wissenschaften 21 (1898), S. 599-731. S. 124-127). Eine Abschrift (jedoch nicht des hymnischen Teiles) liegt in St. Gallen, StB Cod. Sang. 914 vor (Bischoff, in: Germain Morin u. a. (Hrsg.), Regula Benedicti: de codice 914 in bibliotheca monasterii S. Galli servato, St. Ottilien 1983. S. XII-XIV).

1079 Vgl. zu diesem und dem folgenden Titel Nr. 1 des Hauptkatalogs (S. 168). Die Murbacher Hymnen von Oxford, Bodl. Libr., MS Jun. 25 (siehe bei Murbach, S. 215) stehen im Zusammenhang mit der Reichenauer volkssprachigen Dichtung, wobei eine Identifizierung der Handschrift mit den Reichenauer Katalogeinträgen umstritten ist, siehe die Diskussion in: Bergmann (Hrsg.): Ahd. und as. Literatur. S. $283 \mathrm{f}$. 
\begin{tabular}{l}
$\begin{array}{l}\text { In XXXI. libello de arte medicinae metri(ci)s versibus Jacobus nomine ad Karolum regem } \\
\text { scribebat, comprehendens capitula LXI, quem mihi frater Coldvinus detulit et } \\
\text { donavit. }{ }^{1080}\end{array}$ \\
\hline $\begin{array}{l}\text { In XXXVII. libro habentur excerptiones de corpore psalmorum factae cum hymnis et } \\
\text { lectionibus, responsoriis, versibus per anni circulum, letania ac diversis oracionibus. }\end{array}$ \\
\hline $\begin{array}{l}\text { In XXXIX. libro habetur liber psalmorum cum diversis praefationibus ac capitulis et in } \\
\text { fine eiusdem hymni diversi per diversas festivitates ac privatis diebus et nonnulla } \\
\text { carmina. }{ }^{1081}\end{array}$
\end{tabular}

Wohl kein anderer Bibliothekar seiner Zeit hat sich um seine Sammlung derart verdient gemacht wie Reginbert in seiner jahrzehntelangen Amtszeit. Er hatte ein größeres Interesse an Dichtung als die Äbte Erlebald und Ruadhelm, in deren ansonsten umfangreichen Ergänzungslisten nur ein Titel erscheint, sodass Reginbert für alle Neuzugänge seit dem Hauptkatalog verantwortlich zu sein scheint. Erst Walahfrid wird wieder Dichtung auf eigene Initiative sammeln. Reginberts Sammelinteressen decken ein weites Feld von Gebrauchsdichtung ab, ohne Dichtung um ihrer selbst willen gesucht zu haben. Dichtung im liturgischen Umfeld nimmt die Hauptstellung ein (XX, XXXVII, XXXIX). Literatur zu den Artes brachte er in einer praktischen Sammelhandschrift zusammen (II, assoziiert Boethius in VIII), vielleicht eine ältere Sammlung vermehrend. Sein Interesse an Medizin und Botanik (II, XXXI) sollte Walahfrids Dichtung zugute kommen. Weitere Handschriften dienten der Schule (IV), darunter der Unterweisung in der Volkssprache (m.E. XXI, XXII); mit herkömmlichen Schulhandschriften - Grammatik und Dichtung - war die Reichenau, wie oben gesagt, gut ausgestattet. Zuletzt fand in einer heterogenen Sammelhandschrift (VI) eine Vielzahl von Gebrauchsdichtung Platz, darunter vielleicht eine Verschronik in Zusammenhang mit komputistischem Material. Auch Reginbert fühlte also nicht das Bedürfnis, die bei allem Reichtum doch in Hinsicht auf Dichtung relativ

1080 Hinter diesem Titel verbirgt sich Quintus Serenus, der von einem ansonsten unbekannten Jacobus mit einer metrischen Einleitung an Karl den Großen versehen wurde. Walahfrid nutzte diese Textfassung zur Komposition seines Hortulus. Quintus Serenus, mit JacobusProöm und LXII capitula fand seinen Weg nach St. Gallen in Zürich, C 78 (f. 57v-82v), siehe auch dort (Vollmer (Hrsg.): Liber medicinalis. S. V-XI). Dass auch Murbach eine Kopie besaß (MILDE: Bibliothekskatalog. Nr. 328), ist wohl beim intensiven Austausch der Klöster kein Zufall. Auch in Grimalds Privatbibliothek findet sich ein Medicinalis liber I in quaternionibus.

1081 Die beiden Bände XXXVII und XXXIX sind weitere Denkmale für Reginberts Interesse am Hymnar, die anscheinend leider nicht erhalten sind; dass sie vielleicht Hymnen, die über den zu erwartenden Bestand hinausgingen, enthalten haben, lässt ein Brevier-Fragment von (vermutlich) Reginberts Hand vermuten, dass eine unbekannte Hymne enthält (GNeuss: „Zur Geschichte des Hymnars«. S. 80 und Anm. 59; Klaus GAmber, „Ein BrevierFragment aus der 1. Hälfte des 9. Jahrhunderts.«, in: Revue bénédictine 95 (1985), S. 232239.) 
durchschnittliche Bibliothek mit Seltenheiten aus befreundeten und naheliegenden Klöstern zu vermehren.

Es existiert in einem von der Reichenau stammenden Sakramentar eine weitere Bücherliste, bei der weiterhin unklar ist, welcher Bibliothek des Bodenseegebietes sie zuzuordnen sei. ${ }^{1082}$ Sie enthält, neben zahlreichen exegetischen und patristischen Titeln eine exquisite Sammlung klassischer Autoren, ${ }^{1083}$ darunter einige seltene Dichter: Persius und Juvenal in einem Band, ${ }^{1084}$ Ovids Ars Amatoria und Metamorphosen, Silius Italicus und Statius in einem Band, sowie Claudians De raptu Proserpinae. ${ }^{1085}$ Auffallend ist das gänzliche Fehlen der spätantikchristlichen Dichtung. In der zuerst St. Gallen zugewiesenen Liste ${ }^{1086}$ stellte Holder weitgehende Parallelen zu erhaltenen Reichenauer Handschriften fest und weist die Liste dem Inselkloster $z u ;{ }^{1087}$ Lehmann schloss sich dieser Einschätzung mit einer Datierung nach 840 an. Preisendanz bemerkte dagegen die weitgehende Unstimmigkeit mit dem Reichenauer Hauptkatalog, die selbst bei großzügigen Zugeständnissen, was Ab- und Zugänge betrifft, eine Zuweisung zur Reichenauer Bibliothek ausschließe; stattdessen schlägt er das Domstift Konstanz vor. ${ }^{1088}$ Ein von Autenrieth vorgenommener Vergleich mit dem Konstanzer

1082 Stuttgart, Württembergische Landesbibliothek, Cod. Don. 191 (olim Fürstenbergische Hofbibliothek Donaueschingen), f. 160v-163v. Lehmann (Hrsg.): MBK. 1, Nr. 54, S. $263-$ 266. Zur paläographischen Einordnung: Herrad SpILling, "Schreiber und Schrift«, in: Das Sakramentar der Fürstlich Fürstenbergischen Hofbibliothek Donaueschingen Cod. Don. 191, hrsg. von Herrad SpILling (Patrimonia 85), Berlin 1996, S. 17-48. Das Sakramentar wurde auf der Reichenau benutzt, ehe es nach Konstanz ging: Felix Heinzer, "Ex authentico scriptus - Zur liturgiehistorischen Stellung des Sakramentars", in: Das Sakramentar der Fürstlich Fürstenbergischen Hofbibliothek Donaueschingen Cod. Don. 191, hrsg. von Herrad SpILling (Patrimonia 85), Berlin 1996, S. 63-84. S. 69-72.

1083 LehmanN (Hrsg.): MBK. S. 265, Z. 36 - S. 266, Z. 8.

1084 Zur möglichen Identität dieses Bandes mit $\pi^{1}$, der Vorstufe der Juvenalhandschriften des Zweiges $\pi$ : KNochE: Juvenaltext. S. $247 \mathrm{f}$. Eine Verortung der Handschrift auf die Reichenau beruht - über viele Umwege - auf einem Walahfrid-Vers in Micos Opus Prosodiacum (siehe S. 172 und S. 250 bei Lorsch zu Montpellier, Bibliothèque universitaire de médecine, $\mathrm{H}$ 125).

1085 Weitere Dichter sind der oben erwähnte Ratold von Verona mit seiner Moralia-Paraphrase (Ratoldi liber I versificatus super moralia Iob), sowie Venantius Fortunatus (Fortunati metrum in volumine I., vgl. S. 170 zum Hauptkatalog, Nr. 22).

1086 BECKER: Catalogi. Nr. 15, S. 32.

1087 Holder/Preisendanz: Die Reichenauer Handschriften, 3. S. 97-103. Hierzu Herrad SPILling, „Das Bücherverzeichnis am Schluß des Sakramentars", in: Das Sakramentar der Fürstlich Fürstenbergischen Hofbibliothek Donaueschingen: Cod. Don. 191, hrsg. von Herrad Spilling (Patrimonia 85), Berlin 1996, S. 85-106. S. 96. Lehmann wie oben, Datierung aufgrund von Amulo von Lyons Werk gegen die Juden (ca. 846: »Amulo archiepiscopus Lugdunensis, Liber contra Iudaeos", http://www.geschichtsquellen.de/rep Opus_00130.html (abgerufen am 05.03.2018).).

1088 Preisendanz: "Reginbert von der Reichenau«. S. 46-49. Konstanz auch: Bernhard BISCHOFF, „Die benediktinische Mönchtum und die Überlieferung der klassischen Literatur", in: Studien und Mitteilungen zur Geschichte des Benediktinerordens und seiner Zweige 92 (1981), S. 165-190. S. 179. 
Katalog von 1334 ergab jedoch eine ähnliche Diskrepanz wie mit dem Reichenauer Hauptkatalog. ${ }^{1089}$ Zudem datierte sie die Hand der Bücherliste in die 2. Hälfte des 10. Jh. und schuf damit Raum für Änderungen im Buchbestand wenn gleichwohl der Bücherbestand selbst aus der Mitte des 9. Jh. zu stammen scheint. ${ }^{1090}$ Einen neuen Ansatz bietet Spilling, die nach Feststellung der Reichenauer Ausbildung des Schreibers die Liste als Schatzverzeichnis, zumindest als anderswo verwahrten Sonderbestand interpretiert. Dass ein Teilbestand vorliegt, ist durch das Fehlen von Bibeln am intakten Beginn des Verzeichnisses und weiterer essentieller Literatur ausgemacht. ${ }^{1091}$ Nun scheint in der Tat die Reichenau aufgrund der Herkunft der Handschrift und dem Schriftbild der Bücherliste der Standort dieser Bücher gewesen zu sein. ${ }^{1092}$ Ein Schatzverzeichnis ist die Liste offensichtlich nicht, da nirgends von wertvollen Bücher gesprochen wird und zudem der Inhalt keinem anderen Schatzverzeichnis gleicht. ${ }^{1093}$ Also ein Sonderstandort - aber nicht die Schule, wie das Fehlen von Grammatiken zeigt, und zudem da die Schulliteratur im Hauptkatalog der Reichenau verzeichnet ist. Es ließe sich zuletzt nur noch vermuten, dass Platzmangel eine neue Räumlichkeit nötig machte. Der Katalog wäre somit ein Fortsetzungskatalog der nach Reginbert angeschafften und neu aufgestellten Bände und verzeichnet den Bestand um den Beginn der zweiten Hälfte des Jahrhunderts. ${ }^{1094}$ Nach all diesen Kombinationen steht zugegebenermaßen die Reichenauer Heimat dieses Katalogs auf nur sehr dünner Basis. Und so gern man Walahfrid, in dessen Amtszeit diese Ergänzung fiele, zum Sammler von Raritäten wie Silius und Statius machen würde - erst ein genauester Vergleich der beiden Kataloge ${ }^{1095}$ sowie mit den erhaltenen Handschriften kann hier Klarheit über die Herkunft der klassischen

1089 Johanne Autenrieth, Die Domschule von Konstanz zur Zeit des Investiturstreits. Die wissenschaftliche Arbeitsweise Bernolds von Konstanz und zweier Kleriker dargestellt auf Grund von Handschriftenstudien (Forschungen zur Kirchen- und Geistesgeschichte, NF 3), München 1956. S. 19.

1090 Zwischen Abfassung der Liste und post quem des jüngsten Autors liegen somit um die 150 Jahre: SPILLING: »Bücherverzeichnis«. S. 91.

1091 Spilling. S. 87, 91, 96.

1092 SPILling. S. 97-99.

1093 Vgl. die zeitgenössischen Verzeichnisse, die wenn überhaupt Bücher, dann liturgische enthalten: Bernhard BischоғF, Mittelalterliche Schatzverzeichnisse, 1: Von der Zeit Karls des Großen bis zur Mitte des 13. Jahrhunderts (Veröffentlichungen des Zentralinstituts für Kunstgeschichte 4), München 1967. Nr. 12, 13, 15, 18, 19, 27, 28, 33, 49, 56, 65, 80 (das eigentliche Schatzverzeichnis der Reichenau?), 82, 85, 89, 97, 107, 110.

1094 Man beachte aber die späte Niederschrift und begrenzte Form des Katalogs, in der kaum Ergänzungen möglich sind: SpILLING: »Bücherverzeichnis«. S. $91 \mathrm{f}$. Es ist somit kein laufender Katalog, sondern ein Verzeichnis und zwar die Kopie eines Verzeichnisses, da, wie SPILLING sagt, 150 Jahre ohne Ergänzung unwahrscheinlich sind. Ganz unbesprochen bleibt die Möglichkeit, ob nicht ein völlig anderes Kloster gemeint sei, so noch zögernd: LEHMANN: »Bibliothek der Reichenau«. S. 653.

1095 Der bisher nicht in Form einer Konkordanz angestellt wurde. 
Schriftsteller liefern, auf denen vielleicht fälschlicherweise der Ruhm der Reichenau für die Überlieferung der antiken Literatur besteht. ${ }^{1096}$

Die zweite Hälfte des 9. Jahrhunderts sah einen langsamen, aber stetigen Niedergang der Kultur der Abtei Reichenau und von Bibliothek, Schule und Gelehrsamkeit schweigen ab hier die Quellen. ${ }^{1097}$ Erst das 10. Jh. sah wieder einen Aufschwung in der Buchmalerei, ${ }^{1098}$ ohne dass dies jedoch den Ruhm den Ruhm der Reichenau als Bildungsstätte wieder aufgerichtet hätte. Wie andernorts auch war die Entfaltung von Schule, Bildung und, untrennbar hiermit verbunden, der Dichtung, eng an die Initiative und Interessen der Äbte gebunden. Auf die vielleicht durch Pirmin und insulare Kreise begründete Basis bauten die folgenden Äbte auf. Durch Waldos weitreichende Beziehungen wurde die Abtei auf einen Schlag mit zahlreichen anderen großen Bibliotheken in Verbindung gesetzt; Kontakte, die von den folgenden Äbten erhalten und vermehrt wurden. Der Hauptkatalog zeigt das eindrucksvolle Ergebnis dieser frühen Sammelbemühungen. Die Schule florierte zu dieser Zeit und der Großteil der Handschriften mit Dichtung darf mit ihr assoziiert werden; Schuldichter waren Juvencus, Sedulius und Prudentius; die Sammlung geht nur in vereinzelten Titeln über das Gewöhnliche hinaus. Walahfrid konnte hier die Grundlagen seiner Bildung legen, profitierte aber sicher darüber hinaus auch von den Bibliotheken, die er auf seinem weiteren Bildungsgang nutzen konnte. Zudem nutzte seine Kontakte, um Dichtung zu senden und zu empfangen. Reginberts Verdienste wurden schon oben gewürdigt - auch für ihn stand, wie für die Äbte bis Walahfrid, die Dichtung nicht im Mittelpunkt seiner Sammelinteressen. Dichtung auf der Reichenau war für ihre Sammler hauptsächlich Gebrauchsdichtung: Schul- und Hymnendichtung, Lehr- und Bibeldichtung bilden die Hauptbestandteile einer weitgehend pragmatischen Sammlung.

1096 Besonders in der Wiederentdeckung von Statius' Silvae und Silius' Punica durch Poggio: Reynolds: Texts and transmission. S. 389f., 397f. Siehe kritisch zu Reichenau: Remigio SABBADInI, Le scoperte dei codici latini e greci ne' secoli 14 e 15 (Biblioteca storica del Rinascimento, NS 2), Firenze 1905. S. 80, Anm. 38 (Constantiae ... repertum) und: Antony Augoust AKIs (Hrsg.), Brill's companion to Silius Italicus (Brill's companions in classical studies), Leiden [u.a.] 2010. S. 419 (Constantiae ... repertum est). Konstanz wird also durchaus genannt (irrtümlich: SPILLING: »Bücherverzeichnis«. S. 98 und Anm. 187).

1097 Quarthal/U.A: »Reichenau«. S. 506. LehmanN (Hrsg.): MBK. 1, S. $225 \mathrm{f}$.

$1098 \mathrm{Zu}$ dieser späten Blüte siehe die Tafeln in: Walter BERSCHIN und Ulrich KudER, Reichenauer Buchmalerei 850-1070, Wiesbaden 2015. 


\section{II.1.f Weißenburg}

Die Geschichte des Skriptoriums des elsässischen Klosters Weißenburg, die sich durch den überragenden Einfluss Otfrids in die Periode vor und nach seiner Tätigkeit dort (ab 847) einteilt, ist noch nicht abschließend behandelt worden. ${ }^{1099}$ Die Grundzüge der im Vergleich weniger erforschten Zeit vor Otfrid wurden von Butzmann gezeichnet, ${ }^{1100}$ während zur Otfrid-Zeit ebenfalls Butzmann sowie die Monographien und Editionen zum Evangelienbuch vorliegen. ${ }^{101}$ Zur Otfrid-Zeit liegen ebenfalls eingehende Studien zur Bibliotheksgeschichte vor. ${ }^{102}$

In der Zeit vor Otfrid treten die Äbte (und gleichzeitig Bischöfe von Worms) Erembert (764?-793), Bernhar (811-826) und Folkwig (826-833?) durch ihre Förderung des Klosters hervor. Ihre Beziehung zum Skriptorium bleibt unklar, da sich nur eine der frühen Handschriften mit ihnen in Verbindung bringen lässt; ebenso lässt sich eine Verbindung zum beinahe gänzlich unbekannten Skriptorium in Worms herstellen. Paläographisch zerfällt die erste Hälfte des Jahrhunderts in zwei Gruppen: Die frühere (ab 780) sammelt sich um den Namen des Schreibers Adellandus, der in der Cassiodorhandschrift Wolfenbüttel, HAB, Cod. Guelf. 14 Weiss. genannt wird, und besteht hauptsächlich aus exegetischen und patristischen Büchern. ${ }^{1103}$ Und auch zur Waldmann-Gruppe um Wolfenbüttel, HAB, Cod. Guelf. 62 Weiss. gilt, was Kleiber rückblickend auf beide sagt, dass sie "auf die elementaren geistlichen Bedürfnisse zugeschnitten « seien. ${ }^{1104}$ Dass aus dieser Periode des Skriptoriums bis auf zwei Ausnahmen die Dichtung fehlt, sollte jedoch relativiert werden angesichts des ungewöhnlichen Fehlens schulischen Materials, von Grammatikern und Schuldichtern gleichermaßen, das auf

1099 Norbert KössINGER, »Weißenburg", in: Schreiborte des deutschen Mittelalters : Skriptorien - Werke - Mäzene, hrsg. von Martin J. Schubert, Berlin [u. a.] 2013, S. 537-548. S. 537.

1100 In der Einleitung in: Hans Butzmann, Die Weissenburger Handschriften (Kataloge der Herzog-August-Bibliothek Wolfenbüttel. Neue Reihe 10), Frankfurt a. M. 1964. Auch separat ediert in: ButzmanN: »Priscian-Glossen«.

$1101 \mathrm{Zu}$ letzeren siehe unten S. 194.

1102 Wolfgang KLEIBER, Otfrid von Weissenburg: Untersuchungen zur handschriftlichen Überlieferung und Studien zum Aufbau des Evangelienbuches (Bibliotheca Germanica 14), Bern [u.a.] 1971. S. 123-160, sowie mit zahlreichen Neuentdeckungen: Ernst HeLlGARDT, Die exegetischen Quellen von Otfrids Evangelienbuch: Beiträge zu ihrer Ermittlung; mit einem Kapitel über die Weißenburger Bibliothek des Mittelalters und der Otfridzeit (Hermaea. Germanistische Forschungen, NF 41), Tübingen 1981. S. 63-99.

1103 Butzmann: Die Weißenburger Handschriften. S. 50-59.

1104 Zur Waldmann-Gruppe: Ebd. S. 42-44. Das Urteil zur Bibliothek vor Otfried: KLeIBER: Überlieferung. S. 130. Eine weitere Gruppe von drei Handschriften besteht um Cod. Guelf. 61 Weiss.: Butzmann: Die Weißenburger Handschriften. S. 44-47. 
einen Verlust einer geschlossenen Gruppe von Handschriften hinzuweisen scheint. ${ }^{1105}$

Eine der Schule zumindest näher stehende Handschrift ist Wolfenbüttel, HAB, Cod. Guelf. Weiss. 56, ${ }^{1106}$ die die Epigramme Prospers von Aquitanien enthält ${ }^{1107}$ sowie die ihm gewöhnlich auch zugeschriebene Schrift des Julianus Pomerius De vita contemplativa. Die Handschrift ist nur in den Epigrammen, dort jedoch reichlich, mit lateinischen und vereinzelten althochdeutschen Glossen versehen, ${ }^{1108}$ was, obwohl auch der Buchschmuck in diesem Teil aufwendiger ist, für einen intensiven praktischen Gebrauch spricht. Zeitgenössische Handschriften gleichen Inhaltes stammen aus Lorsch und der Reichenau. ${ }^{109}$ In beiden Bibliotheken befanden sich diese Handschriften bei den Werken des Autors und nicht in der grammatischen Abteilung, wiewohl auf der Reichenau Prosper dort mit einer anderen Handschrift vertreten ist. So steht dieser Elementartext ${ }^{1110}$ in dieser Textgemeinschaft zwischen Schullektüre und gelehrtem Studium. Auch die großzügigen Ränder erinnern, wie beim Weißenburger Horaz (siehe unten S. 185-188), an eine Gelehrtenhandschrift.

In diese Zeit gehört, auch wenn sie sich keiner der Gruppen zuweisen lässt, die vielfältige Handschrift Wolfenbüttel, HAB, Cod. Guelf. 91 Weiss. ${ }^{111}$ Die Handschrift setzt sich aus fünf durch Format, Schrift und Inhalt voneinander geschiedenen Teilen zusammen, die bei aller Verschiedenheit doch durch pastorale Anliegen zusammengehalten werden; ${ }^{112}$ die Teile sind folgende: A (f. 1-24)

1105 Hier sei auch an die in Otfrids Einleitung an Liutbert genannten lateinischen Dichter erinnert: Virgilius, Lucanus, Ovidius caeterique quam plurimi (v. 14), die freilich nicht ohne weiteres alle in Weißenburg vorauszusetzen sind, zumal Otfrid besonders die Bekanntschaft der ersteren auch in Fulda gemacht haben könnte. Auch das Ausleihverzeichnis sowie der spätere Teil-Katalog nennen keine Dichter: Hellgardt: Die exegetischen Quellen. S. 81. Otto LERCHE, »Das älteste Ausleihverzeichnis einer deutschen Bibliothek», in: Zentralblatt für Bibliothekswesen 27 (1910), S. 441-450. Vgl. zu einem ähnlichen Mangel an schulischen Handschriften auch S. 55 zu Würzburg.

1106 "[Weißenburg, IX. Jh., 2. Viertel / Mitte]«: Bischoff: Katalog, 3. Nr. 7402. Butzmann: Die Weißenburger Handschriften. S. $192 \mathrm{f}$.

1107 f. 62v-84v. Horsting (Hrsg.): Prosper Aquitanus, Liber epigrammatum. Sigle W, S. 41.

1108 BergmanN/STRICKer: Katalog. Nr. 973.

1109 Cod. Sang. 187 (Lorsch, ebenfalls im Katalog, Nr. 244: HäsE: Bücherverzeichnisse. S. 276f.) und Reichenau (siehe dort S. 168), Hauptkatalog Nr. 2 und 3. Zu späteren Handschriften mit dieser Textgemeinschaft siehe Horsting (Hrsg.): Prosper Aquitanus, Liber epigrammatum. S. 24 f, dort als eher als Gelehrten- denn als Schulhandschriften eingeschätzt.

1110 Horsting (Hrsg.): Prosper Aquitanus, Liber epigrammatum. S. 23.

1111 Bischoff: Katalog, 3. Nr. 7427. Butzmann: Die Weißenburger Handschriften. S. 258-268.

1112 Ebenso durch die zeitgenössischen Glossen und Korrekturen, die durch die gesamte Handschrift gehen: Wolfgang HAUBRICHs, "Das althochdeutsch-lateinische Textensemble des Cod. Weiss. 91 (Weißenburger Katechismus) und das Bistum Worms im frühen neunten Jahrhundert", in: Volkssprachig-lateinische Mischtexte und Textensembles in der althochdeutschen, altsächsischen und altenglischen Überlieferung, hrsg. von Rolf BERGMANN (Germanistische Bibliothek 17) 2003, S. 131-173. S. 147, Anm. 34. 
Canones; B (f. 25-88) Papstbriefe und Ordines (»Pontifikale«); C (f. 89-103, 161176) Computus; D (f. 104-126) Glaubensbekenntnisse; E (f. 127-160) Breviarien, Katechismus, Versus Wissenburgenses. Der Ursprung dieser Sammelhandschrift sowie ihrer einzelnen Teile aus Weißenburg ist nicht abschließend gesichert. Die Hypothesen reichen von einer Entstehung in Weißenburg, über eine in der weiteren Umgebung, bis hin zu Worms. ${ }^{1113}$ Eine Entstehung in Worms ist aufgrund der episkopalen und hagiographischen Bezüge der Handschrift am wahrscheinlichsten, ${ }^{1114}$ womit sie durch die Personalunion von Abtswürde und Bischofsamt der oben genannten drei Bischöfe nach Weißenburg gelangt wäre. Haubrichs grenzt die Zuschreibung auf überzeugende Weise weiter ein auf Bischof Bernhar, auf den insbesondere das Epitaph Riculfs von Mainz verweist, von dem Bernhar zum Bischof geweiht wurde und mit dem er an verschiedenen Konzilen teilnahm. ${ }^{115}$ Die Handschrift bietet in drei ihrer fünf Teile Dichtung in kleinerer und größerer Zahl. In Teil A folgt auf die Canones-Tafeln von gleicher Hand aber hellerer Tinte ein Brief Gregors des Großen, der in Titel und Textgestalt BNF Lat. 12255, f. 190v ff. ähnelt; ${ }^{116}$ beide Handschriften scheinen die einzigen zu sein, die den Brief als Sermo de mortalitate aufmachen und den letzten Absatz mit liturgischen Regelungen aussparen. Die Pariser Handschrift ist französischer Herkunft, vielleicht aus Corbie, wie ihr hinterer Teil. ${ }^{1117} \mathrm{Nach}$ zwei leeren Seiten folgen f. $24 \mathrm{v}$ zwei Gedichte, augenscheinlich von gleicher Hand wie die vorhergehenden Texte: ${ }^{1118}$ Carcere vallatus, ${ }^{119}$ auf die Befreiung des Apostels Petrus, und Sic primo Christum, ${ }^{1120}$ auf den Gekreuzigten, die beide hier in ihrem einzigen Textzeugen vorliegen. ${ }^{1121}$ Carcere vallatus ist ein Beispiel früher

1113 Weißenburg: Butzmann: Die Weißenburger Handschriften. S. 257. Vielleicht Worms: Bischоғғ: »Paläographische Fragen«. S. 92f. »Westdeutschland (Oberrhein)«: Bisсноғғ: Katalog, 3. Nr. 7427. Worms: HAUBRICHs: „Textensemble«. S. 148-151.

1114 So auch: Achim MASSER, »Art. Weißenburger Katechismus», in: Althochdeutsche und altsächsische Literatur, hrsg. von Rolf BERGMANN, Berlin [u. a.] 2013, S. 506-508.

1115 Haubrichs: "Textensemble«. S. 150 und Anm. 38. Weitere Indizien für einen Wormser Ursprung ebd. S. 141.

1116 Paul Ewald und Ludo Moritz Hartmann (Hrsg.), Gregorii I papae Registrum epistolarum. Libri VIII-XIV (MGH Epp. 2), Berlin 1892. S. 365-367, Nr. XIII, 2. Siehe auch Anm. zu XIII, S. 365.

1117 Bischoff: Katalog, 3. Nr. 4797-4798; siehe dagegen: Klaus Zechiel-Eckes, »Handschriften aus Corbie: $M G H$ «, http://www.mgh.de/datenbanken/pseudoisidor/corbie/ (abgerufen am 07.02.2017). Die Klosterkirche in Corbie war ebenfalls dem Apostel Petrus geweiht, wozu das folgende Petrusgedicht stimmen würde, sollte es aus Corbie vermittelt worden sein.

1118 Man vergleiche etwa A und P.

1119 SK 1933.

1120 SK 15295.

1121 Strecker (Hrsg.): MGH Poet. lat. 4, 2.3. S. 1087. 
rhythmischer Dichtung. ${ }^{1122}$ Beide Gedichte sind in Text und Randspalte mit Kreuzchen versehen ( $X$ und $\Psi$ ), die eine bisher ungeklärte metrische oder musikalische Funktion haben könnten. ${ }^{1123}$ Im Teil B, der mit seinen liturgischen Auszügen ein frühes Pontifikale darstellt, ${ }^{1124}$ ist auf f. $88 \mathrm{v}$, vor Lagenverlust, das ein Graduale oder Antiphonar einleitende ${ }^{1125}$ Gedicht Gregorius praesul bis zu Vers 26 erhalten. ${ }^{1126}$ Das Gedicht ist also kein Zusatz zu den Ordines, sondern wurde zusammen mit dem ihm eingeleiteten Text niedergeschrieben, ohne selbst eine liturgische Funktion zu erfüllen. Ein klarer Zusatz dagegen ist das Epitaph Riculfs von Mainz in Teil D (Symbola), f. $126 \mathrm{v}$, Te precor ex tumulo. ${ }^{1127}$ Das nachdenkliche Memento Mori wird in mehreren Handschriften mitgeteilt, sein exemplarischer Charakter drückt sich auch darin aus, dass es in Clm 19410, p. 66, durch Streichung des Namens des Bischofs formularisiert wurde. ${ }^{1128}$ Bernhar könnte das Epigramm, wie oben gesagt, als Andenken an Riculf, der ihn geweiht hatte, aufbewahrt haben. Teil E der Handschrift (f. 127-160) ist wegen der zahlreich enthaltenen althochdeutschen Texte, zuvorderst des Weißenburger Katechismus, ${ }^{1129}$ der am besten erforschte. Er zerfällt thematisch in drei Teile: f. 127-149 ist ein Brevier zu den Paulusbriefen, eingeleitet mit dem Gedicht des Damasus über die Bekehrung des Apostels. ${ }^{1130}$ Das Brevier besteht aus kurzen Inhaltsangaben zu den Kapiteln sämtlicher Paulusbriefe und dient wohl der schnellen Orientierung im Werk des Apostels. Auf f. 149 wendet sich die Handschrift ins Katechetische; der von Schreibfehlern ${ }^{1131}$ entstellte Vergil-Auszug zu

1122 Paul KLopsch, "Der Übergang von Quantitierender zu Akzentuierender Lateinischer Dichtung", in: Metrik und Medienwechsel = Metrics and the media, hrsg. von Hildegard L. C. Tristram (ScriptOralia 35), Tübingen 1991, S. 95-106. S. 103f.; Dag Norberg, An introduction to the study of medieval Latin versification, Washington, DC 2004. S. 98.

1123 Sie sind nicht Werk des Glossators. Sie können auch nicht, wie z.B. die Kreuze neben den Versus Wissenburgenses, den Textanfang markieren. Zu Kreuzen als Textanfang siehe: STEINovÁ: Technical signs. S. 215.

1124 ANDRIEU: Les ordines romani du haut Moyen Âge. 3, S. $52 \mathrm{ff}$. Zitiert nach Haubrichs: »Textensemble«. S. 135.

1125 Composuit scholae cantorum hunc rite libellum, »er verfasste für den Chorgesang dieses Buch nach rechtem Brauch".

1126 SK 5725. Siehe auch die Nummern davor und danach für Variationen des Gedichts. Strecker (Hrsg.): MGH Poet. lat. 4, 2.3. S. 1069f. (Sigle W); Clemens Blume, Tropi graduales. Tropen des Missale im Mittelalter. II. Tropen zum Proprium Missale (Analecta Hymnica 49), Leipzig 1906. S. 21-22. Zu weiteren Handschriften siehe: Joseph SMITS vaN Waesberghe, Christian MaAs und Peter Fischer, The Theory of Music, from the Carolingian Era up to 1400. I: Descriptive Catalogue of Manuscripts (Répertoire international des sources musicales), München [u.a.] 1961. S. 92.

1127 SK 6108. DümmLer (Hrsg.): MGH Poet. lat. 2. S. 432.

1128 Rio: Legal practice. S. 248f. Siehe zur Handschrift bei Passau, S. 308-313.

1129 MAsser: "Art. Weißenburger Katechismus".

1130 Ferrua (Hrsg.): Epigrammata Damasiana. Nr. 2. Bruyne: Prefaces. S. 234.

1131 HAUBRichs: »Textensemble«. S. 151. 
den Klimazonen ${ }^{1132}$ (f. 148v-149r) steht zwischen diesen Texten fremd wie eine Spolie. Er begegnet in der komputistischen Literatur, ${ }^{1133}$ scheint aber hier nicht am Platze zu sein. ${ }^{1134}$ Die weitläufige Literatur zum Weißenburger Katechismus und den ihn begleitenden althochdeutschen Texten (f. 149v-154v) ${ }^{1135}$ muss hier nicht referiert werden; ${ }^{1136}$ Konsens ist, dass die Sammlung "im Blick auf Priesterbildung und Fundierung der Geistlichen erfolgt [sei], möglicherweise als Grundlage für eine Examination durch den hierfür zuständigen und verpflichteten Bischof. « ${ }^{1137}$ An den Katechismus schließt sich eine Initiensammlung zu den Homilien Gregors des Großen, die der vorherigen zu den Paulusbriefen ganz ähnlich sieht. Es fragt sich nun, wie die hierauf folgenden Versus Wissenburgenses, die den dritten thematischen Abschnitt bilden, zu dieser Sammlung passen, mit der sie zumindest paläographisch eine Einheit bilden. ${ }^{1138}$ Die zwölf Gedichte teilen sich in zwei Gruppen, je sechs zu Christus und Petrus aus acht Versen, wobei ein Zahlenparallelismus, jedoch kein durchgehend inhaltlicher besteht. ${ }^{1139}$ Streckers Vermutung, dass die Verse zu Wandmalereien (aus Worms?) gehörten, kann nur zugestimmt werden, es ist jedoch zu bedenken, dass diese Funktion nur für den Ursprung der Verse, nicht für ihren Platz in der Handschrift gilt. Eine Funktion als Musterinschriften, wie in Wien, ÖNB Cod. 808 (unter Bischof Arn von Salzburg gesammelt), oder als grammatische Illustrationen, wie in München, BSB, Clm 6404, scheidet in Wolfenbüttel, HAB, Cod. Guelf. 91 Weiss. durch den liturgischen Charakter der Handschrift aus. Als Vergleichspunkt bietet sich vielmehr die Inschriftensammlung an, die unter Bischof Gozbald in Würzburg angestellt wurde (Würzburg, UB, M.p.misc.f. 2), und aus der der Bischof eine in seine persönliche Handschrift aufnahm (M.p.th.f. 56). Auch die von Bischof Liuphram von Salzburg der Sammlung seines Vorgängers Arn hinzugefügten Inschriften, die nicht wie die vorherigen aus der Fremde stammten,

1132 Georgica, I, 231-244.

1133 So bei Beda: De temporum ratione liber, in: Jones (Hrsg.): Bedae Venerabilis opera. 123 B, S. 263-544, c.16, Z. 68. Zur Verwendung der Stelle auch: Alfred Cordoliani, »Contribution à la littérature du comput ecclésiastique au moyen âge«, in: Studi medievali 2 (1961), S. 169208. S. 205.

1134 Die Handschrift enthält Komputistisches, jedoch in der kodikologischen Einheit C.

1135 Der gleiche Schreiber fährt bis f. 160 fort.

1136 Steinmeyer (Hrsg.): Sprachdenkmäler. Nr. 6, S. 29-38. Haubrichs: »Textensemble«. MAsser: "Art. Weißenburger Katechismus«. Widersprechen möchte ich Massers Annahme, S. 508, dass die Texte "von mehreren Händen« seien (siehe auch HaUbrichs: »Textensemble«. S. 143f.); f. 149v-160 scheinen ganz im Gegenteil von einer Hand zu stammen und zudem mit Teil A in einem engen Zusammenhang zu stehen.

1137 Masser: "Art. Weißenburger Katechismus«. S. 508.

1138 Edition: Strecker (Hrsg.): MGH Poet. lat. 4, 2.3. S. 1047-1050. KIRsCH: Laudes sanctorum. S. 968.

1139 Zum Schema: HAubRichs: »Textensemble«. S. $140 \mathrm{f}$. 
sondern aus Salzburg selbst, kommen hier ins Gedächtnis. ${ }^{1140}$ Inschriften wurden gesammelt, getauscht und von Dichtern wie Alkuin erbeten, und wenn die eigene Kirche bemerkenswerte Inschriften zu bieten hatte, wurden diese verschriftlicht, wie hier mit den Inschriften geschehen. Das in Teil D stehende Epitaph Riculfs von Mainz, zu dem Abt Bernhar eine persönliche Beziehung hatte, ist ebenfalls Ausdruck dieses persönlichen Sammelwillens. Die Teile D und E stehen damit Bernhar persönlich am nächsten und sind vielleicht noch auf seine Anweisung mit den übrigen Teilen zu einem Vademecum für ihn gebunden wurden. Von den anderen Gedichten der Handschrift lässt sich nur noch das auf Petrus, Carcere vallatus, weil es an den Wormser Patron gerichtet ist, näher mit Bernhar in Verbindung bringen; die restlichen Gedichte dagegen (das folgende Christusgedicht, der abgeschnittene Gregor-Prolog, sowie das Vergilfragment zu den Klimazonen) sind nicht derartig zuzuordnen. Die Funktion der Gedichte der Handschrift variiert mit dem Ort, an dem sie sich finden: Als persönliches Andenken, ergänzt zum Schluss der kodikologischen Einheiten; als Einleitung zu größeren Werken, im Gregor-Prolog zum verlorenen Graduale; und im scheinbar versprengten Vergilfragment als didaktische Dichtung zur Naturwissenschaft.

Es ist aber eine andere Handschrift, in der sich die kulturelle Höhe zeigt, die das Kloster Weißenburg schon vor Otfrid erreicht hatte: Die wahrscheinlich älteste Horaz-Handschrift, ${ }^{1141}$ Vatikan, BAV, Reg. lat. $1703 .{ }^{1142}$ Weißenburg ist das einzige Kloster des 9. Jh. im Ostfrankenreich, dass sich einer erhaltenen, vollständigen Handschrift der Werke des Dichters rühmen kann. ${ }^{1143}$ Der Horaz wurde in Weißenburg ${ }^{1144}$ im ersten Viertel des Jahrhunderts geschrieben und dort nach und nach dicht mit Glossen und Scholien versehen. ${ }^{1145}$ Als älteste Vertreter ihrer Familien lassen sich die zwei umfangreicheren ostfränkischen Handschriften, Reg. lat. 1703 und Bern, BB, Ms. 363 nicht auf überlieferte Vor-

1140 Im verlorenen Regensburger Kodex, siehe bei Liuphram (Regensburg).

1141 Reynolds: Texts and transmission. S. 183. Courtney: »Text of Horace«. S. 551.

1142 »[Weißenburg(?) und Walahfrid, vor 849]: Bischoff: Katalog, 3. Nr. 6798. WilmaRt: Codices Reginenses Latini. s.v. Marco Buonocore, Codices Horatiani in Bibliotheca Apostolica Vaticana, Vatikan 1992. S. 146-148. Otto Keller und Alfred Holder (Hrsg.), Horati Opera 1. Carminum libri IIII. Epodon liber. Carmen saeculare, Leipzig 1899. S. LXIILXIV, Sigle R. Klingner (Hrsg.): Q. Horati Flacci opera. Sigle R, passim. David R. Shackleton BAiley (Hrsg.), Horati Opera, 4. Aufl. (Bibliotheca scriptorum Graecorum et Romanorum Teubneriana), München 2001. Sigle R. Munk Olsen: L'étude des auteurs classiques latins. 1, S. 503 f. Hellgardt: Die exegetischen Quellen. S. 74, 79f. Siewert: Horazglossierung. S. 269-303. Abbildung in: Emile Chatelain, Paléographie des classiques latins, Paris 1884. Tafel LXXXVII.

1143 Die »irische« Handschrift (Bern, BB, Ms. 363) bietet umfangreiche Auszüge, siehe bei St. Gallen, S. 114-116.

1144 Skeptisch SIEWERT: Horazglossierung. S. 300, der die Reichenau als Entstehungsort vorschlägt.

1145 Diskussion der Datierung: SiEWERT. S. $270 \mathrm{f}$. 
bilder zurückführen (und wurden selbst auch nicht, der Überlieferung nach zu urteilen, kopiert). ${ }^{1146}$ Die Unterschiede der beiden Handschriften gehen zudem schon auf spätantike Varianten zurück, wobei Reg. lat. 1703 auch vom anderen Zweig her kontaminiert wurde. Der Kodex, pulcherrime scriptus, ${ }^{1147}$ steht in starkem Kontrast zur sonstigen Vergessenheit, in der Horaz sich anscheinend zu Beginn des Jahrhunderts befand. Das einzige andere Schlaglicht auf die zeitgenössische Horazrezeption ${ }^{1148}$ - abgesehen von Alcuins nom de plume Flaccus - ist die Verzeichnung in Katalogen: Die Ars Poetica im Bücherverzeichnis der Handschrift Berlin Diez. B. 66 wird mit dem Hofe Karls in Verbindung gebracht. ${ }^{1149}$ Eine Verbindung zwischen Weißenburg und dem Hof, obwohl auf anderen Ebenen bestehend, ${ }^{1150}$ kann für den Horaz nicht angenommen werden. Das einzige andere Kloster, das einen vollständigen Horaz besaß, scheint Lorsch gewesen $\mathrm{zu}$ sein, wo Libri Oratii poete in uno codice verzeichnet sind. ${ }^{1151}$ Es spricht für die Qualität der Klosterbibliothek, dass sie die Handschrift eines Dichters besaß, der unserem Wissen nach sonst nur noch in den vorzüglich ausgestatten Bibliotheken von Aachen und Lorsch vorhanden war. Auch das Vorbild von Reg. lat. 1703 muss ein stattliches Exemplar von großem Alter gewesen sein: ${ }^{152}$ Geschrieben in Halb-Unzialen, bewahrt es eine Vielzahl altertümlicher Schreibweisen, die sogar, wenn dem Schreiber eine gebräuchlichere in die Feder geflossen war, in einem Korrekturgang sorgfältig aus dem Exemplar wiederhergestellt wurden, ${ }^{1153}$ ein Beispiel bemerkenswerter philologischer Sorgfalt. Hellgardts Vermutung, dass Reg. lat. 1703 wegen der Marginalglossierung eine Schulhandschrift sei, ${ }^{1154}$ muss in Anbetracht der mehrstufigen Annotation der Handschrift relativiert werden. Die lexikalische Interlinearglossierung,

1146 Vgl. die Stemmata in: KLIngner (Hrsg.): Q. Horati Flacci opera. S. XII. CourTneY:»Text of Horace«. S. 549.

1147 Keller/Holder (Hrsg.): Horati Opera 1. S. LXII.

$1148 \mathrm{Zu}$ einigen dunklen Horaz-Reflexen siehe: Lіснт: »Horazüberlieferung im Frühmittelalter«.

1149 Die Verbindung zum Hofe bei: Bernhard Bischoff, "Die Hofbibliothek Karls des Großen«, in: Bischoff, Mittelalterliche Studien, 3, 1981, S. 149-170. S. 162-167; sie wurde insbesondere in der Geschichtswissenschaft rezipiert, während die Philologen skeptisch blieben: »[...] rather fancifully linked by Bischoff with Charlemagne's scourt library at Aachen, but that view seems to be generally rejected nowadays.» CourTNEY: »Text of Horace«. S. 558. Zweifel auch bei: Claudia VILla, »Die Horazüberlieferung und die >Bibliothek Karls des Großenı. Zum Werkverzeichnis der Handschrift Berlin, Diez B. 66", in: Deutsches Archiv für Erforschung des Mittelalters 51 (1995), S. 29-52. S. 49-52.

1150 KLEIBER: Überlieferung. S. 126.

1151 HäsE: Bücherverzeichnisse. S. 309, Nr. 345, (Nur in Katalog Ca, S. 165, Nr. 407). Obwohl die Bücher nicht genannt werden, kann von mehr als nur etwa Oden oder Satiren ausgegangen werden.

1152 Keller/Holder (Hrsg.): Horati Opera 1. S. LXII.

1153 Otto Keller, Epilegomena zu Horaz, Leipzig 1879. S. 675, zu Vers 31.

1154 Hellgardt: Die exegetischen Quellen. S. 80. 
lateinisch wie althochdeutsch, stammt zudem nicht aus der Entstehungszeit der Handschrift, auch nicht aus der Otfrid-Zeit, sondern von Händen des 10. und 11. Jh. ${ }^{1155}$ Die Marginalscholien dagegen scheinen der Entstehungszeit der Handschrift näher zu liegen, was auch durch die Anlage breiter Ränder vorbereitet gewesen zu sein scheint; ${ }^{1156}$ sie sind nicht von einer Hand, sondern von mehreren Schreibern in mehreren "Glossierungsgängen « nachgetragen. ${ }^{1157}$ In den Scholien drückt sich eine aktive Rezeption aus, indem ein verbreiteter, auf Porphyrio sich stützender Marginalkommentar insbesondere in stilistischer Hinsicht verbessert wurde. ${ }^{158}$ Das Vorliegen eines Scholienkommentars gehobenen Niveaus kann im Gegensatz zu der lexikalischen Glossierung ${ }^{1159}$ nicht als Indiz für eine Schulhandschrift angesehen werden, auch wenn dieselbe Handschrift später für schulische Zwecke gebraucht wurde. ${ }^{1160}$ Die großzügige Anlage der Handschrift und die philologische Sorgfalt bei ihrer Verfertigung sprechen vielmehr für den Weißenburger Horaz als eine Studienhandschrift für Gelehrte. Hierfür spricht auch, dass einer der berühmtesten seiner Zeit an der Handschrift korrigierend und ergänzend mitgewirkt hat: Walahfrid Strabo. ${ }^{161}$ Unter welchen Umständen Walahfrid in Weißenburg tätig war, entzieht sich genauerer Kenntnis; dass es mit dem Abbatiat (833-839) seines Lehrers Grimald zusammenhängt, wird allgemein angenommen. ${ }^{162}$ Der Hauptschreiber der Handschrift war nur

1155 Bergmann/Stricker: Katalog. Nr. 828, S. 1579. Siewert: Horazglossierung. S. 270.

1156 Wiewohl die Handschrift - wie jede poetische - durch die Eigenart des Verssatzes, insbesondere der verschiedenen Länge der Horazischen Metren, überall Platz am Rande lässt und Reg. Lat. 1703 keineswegs so unmissverständlich Raum für Ergänzungen lässt wie z. B. Montpellier, Bibliothèque universitaire de médecine H 125 (Juvenal und Persius, siehe bei Lorsch, S. 249f.).

1157 Siewert: Horazglossierung. S. 269. Die Scholiierung wurde jedoch nie separat paläographisch untersucht.

1158 Botschuyver H. J., »Les scholies du Sueco-vaticanus (R)«, in: Latomus 5 (1946), S. 229-231. Die Quelle der Scholien ist ediert in: Hendrik Johan Botschuyver (Hrsg.), Scholia in Horatium $\lambda \varphi \psi$ codicum Parisinorum Latinorum 7972, 7974, 7971, Amsterdam 1935.

1159 Für eine Analyse des Glossierungsverfahrens siehe: SIEWERT: Horazglossierung. S. 293-295.

1160 Wie SiEWERT, S. 300-302, für die Glossierung nachweist, wobei insbesondere der von ihm entdeckte Eintrag ita exposuit magister gunzo (f. 17v, Z. 3, rechter Rand) ins Gewicht fällt. Diesen Gunzo identifiziert er mit Gunzo von Novara, einem Gelehrten des späten 10. Jh. Nur nebenbei hingewiesen sei hier auf die sporadische Neumierung, die der Verdeutlichung des Metrums gedient haben könnte: Henry Marriott BAnnister, Monumenti Vaticani di paleografia musicale Latina, Leipzig 1913. S. 18, 65, 71f. Zum Thema weiterhin: Stuart Lyons, Music in the Odes of Horace, Oxford 2010. Silvia WäLl, Melodien aus mittelalterlichen Horaz-Handschriften: Edition und Interpretation der Quellen (Monumenta Monodica Medii Aevi. Subsidia 3), Kassel [u. a.] 2002. Yves-François Riou, "Chronologie et provenance des manuscrits classiques latins neumés«, in: Revue d'histoire des textes 21 (1991), S. 77-113.

1161 BischоғF: »Sammelhandschrift«. S. 50. Siehe auch: Licнт: »Horazüberlieferung im Frühmittelalter«. S. $125 \mathrm{f}$.

1162 Sich stützend auf BischofF: »Sammelhandschrift«. S. 50, Anm. 50. 
bis zum zweiten Buch der Satiren gelangt, sodass der Kodex noch unfertig vorlag. ${ }^{1163}$ Walahfrid hatte offenbar die Aufgabe, die fehlenden Teile zu ergänzen,

wozu ihm eine Zahl weiterer Schreiber unter seiner Anleitung zur Hand ging. ${ }^{1164}$ Ebenso ergänzte Walahfrid zwei ausgefallene Blätter, korrigierte den Text erneut und füllte Leerstellen für seltene Wörter, über die der Hauptschreiber sich unsicher gewesen $\mathrm{zu}$ sein scheint. ${ }^{1165}$ Zur Korrektur bediente er sich sowohl der Hauptvorlage, wie an den charakteristischen Archaismen in den ergänzten Texten zu erkennen ist, als auch einer weiteren Handschrift an den Stellen, wo er den schon geschriebenen Text korrigierte. ${ }^{1166}$ Walahfrids Rolle bei der Entstehung von Reg. lat. 1703 ist also weit mehr als nur die des Ergänzers einer unvollständigen Handschrift; er ist vielmehr editor in chief, der letzte Hand an den Text legt und den Kodex vollendet. Weil damit das ganze Projekt des Weißenburger Horaz in die Zeit Grimalds fällt, ist es naheliegend, in diesem Literaturliebhaber ${ }^{1167}$ den Impulsgeber für die Handschrift zu sehen. Der herausragende Weißenburger Horaz scheint somit die Frucht der Zusammenarbeit und Interessen zweier für die Kultur des 9. Jh. so bedeutender Persönlichkeiten zu sein: Walahfrid und Grimald.

Das dritte Viertel des Jahrhunderts trägt den Namen des Mannes, von dem es so entscheidend geprägt wurde: Die Otfrid-Zeit. ${ }^{1168}$ Die genauen Lebensdaten und -stationen des Mönchs und Dichters Otfrid von Weißenburg (ca. 800 - nach 870) liegen im Dunkeln. ${ }^{1169}$ Der schon im Kindesalter ins Kloster gegebene Otfrid genoss seine Grundausbildung bis zum Presbyteriat in Weißenburg, wonach er sich zu weiteren Studien unter Hrabanus nach Fulda begab (und vielleicht in der Hofkapelle Ludwigs des Deutschen tätig war). Ab 847 lässt er sich wieder in Weißenburg nieder und macht das Kloster zu seiner Wirkungsstätte. Otfrid er-

1163 Nicht verstümmelt; die Ergänzungen beginnen nach Abbruch der ersten Hand mitten im Satz ohne Blattverlust.

1164 Eine genaue Aufstellung der von Walahfrid geschriebenen Stellen bei KLINGNER (Hrsg.): Q. Horati Flacci opera. S. XIII f. Anm. 2.

$1165 »$ Doctiorem expectavisse videtur, qui omissa expleret«, »er scheint auf einen Gelehrteren gewartet zu haben, der die Leerstellen füllen könnte.» Ebd., S. XIV, fortgeführte Anm.

1166 So Ebd. S. XIV.

1167 Siehe zu seinen literarischen Interessen und weiteren vom ihm angeregten Handschriften: Bischоғғ: »Bücher am Hofe und Privatbibliothek«. Er nannte einen Vergil sein eigen: Lehmann (Hrsg.): MBK. S. 89, Z. 27. Siehe zu ihm und seinen Büchern bei St. Gallen, S. 88f.

$1168 \mathrm{Zu}$ weiteren Bezeichnungen siehe KössINGER:»Weißenburg«. S. 540 und Anm. 11. Grimald leistete jedoch in eben derselben Zeit den zweiten Teil seines Abbatiates (847-870); Spuren seines Einflusses auf die kulturelle Blüte Weißenburgs in dieser Zeit sind jedoch im Gegensatz zu Otfrid nicht dokumentiert.

1169 Für die sicheren Rahmendaten siehe: Ulrich Ernst, »Art. Otfrid von Weißenburg († nach 870)«, in: Lexikon des Mittelalters, 6, 1993, S. 1557-1559. Wolfgang HaubRICHs, Geschichte der deutschen Literatur von den Anfängen bis zum Beginn der Neuzeit. 1, 1: Die Anfänge: Versuche volkssprachiger Schriftlichkeit im frühen Mittelalter (ca. 700-1050/60), Tübingen 1995. S. 354377. Eine Diskussion bei: KLEIBER: Überlieferung. S. 131-133. 
weist sich sowohl in den Handschriften seiner eigenen Dichtung als auch in den zahlreichen Handschriften, deren Entstehung er veranlasste und an denen er schreibend, korrigierend und glossierend teilnahm, als zentrale Gestalt des Weißenburger Skriptoriums, das unter seiner Leitung seine Blütezeit erlebte. ${ }^{1170}$ Als Hauptwerk des Otfrid-Skriptoriums hat das sogenannte Bibelwerk zu gelten, ein fortlaufender Kommentar der Heiligen Schrift nebst Begleitliteratur, das in seinem weitesten Umfang mehr als dreißig Bände umfasste; ${ }^{1171}$ an fünf von diesen wirkte Otfrid persönlich mit. ${ }^{1172}$ Im Umkreis dieses Bibelwerks, das den Großteil der Produktion unter Otfrid einnimmt, ist Dichtung kaum zu erwarten. Dementsprechend finden sich auch nur eine Handvoll, zum Teil vom Hauptschreiber ergänzte Hymnen ${ }^{1173}$ auf Heilige im Bibelglossar Wolfenbüttel, HAB, Cod. Guelf. 66 Weiss. (f. 53), die in keinem Bezug zum größeren Unternehmen des Bibelwerks stehen. ${ }^{1174}$ Trotzdem gewähren zwei Hymnen einen Einblick in die Entstehungsbedingungen lateinischer Dichtung in Weißenburg. Der erste, nicht vollständig kopierte Hymnus Inclita sanctorum beginnt mit dem gleichen Vers wie der Hymnus des Hrabanus auf den hl. Bonifaz ${ }^{1175}$ und könnte somit Ausdruck des aus Fulda durch Otfrid vermittelten Bildungsgutes sein oder aber auch ein Echo von Aldhelms De virginitate, v. 18. ${ }^{1176}$ Der Hymnus Laudes dicamus auf die Heiligen Sergius und Bacchus ist dagegen Ausdruck lokaler Tradition, da Reliquien dieser Heiligen unter Grimalds Vorgänger Otgar, dem späterem Erzbischof von Mainz, nach Weißenburg gebracht wurden. ${ }^{1177}$

Dass Otfrid sein Skriptorium nicht nur anleitete, sondern selbst tätig mitwirkte, wird am augenscheinlichsten in den tausenden von Glossen, die sich von seiner Hand in zahlreichen Weißenburger Handschriften finden. ${ }^{1178}$ Die Mehrzahl der Glossen erläutert das Bibelwerk; zwei Glossenhandschriften jedoch stammen aus einem anderen, wahrscheinlich schulischen Zusammenhang. Mit

1170 Eingehender zum Skriptorium: Butzmann: Die Weißenburger Handschriften. S. 59-65.

1171 Der genaue Umfang variiert, je nachdem ob man nur die Kommentare im engeren Sinne, oder wie KLEIBER: Überlieferung. S. 136-145, auch weitere Literatur wie Josephus oder gar Otfrids Evangelienbuch selbst hinzuzählt.

1172 Dies sind Cod. Guelf. Weiss. 26, 32, 33, 36 und 59 (Kleiber. S. 102f., 119, 140, Anm. 639).

1173 Es sind dies SK 7979 Inclita sanctorum, 1790 Caeli cives in gaudio, 8750 Laudes dicamus, 2626 Conscendat usque (s. XI).

1174 Butzmann: Die Weißenburger Handschriften. S. 211-213. Bergmann/Stricker: Katalog. Nr. 974.

1175 DüMmler (Hrsg.): MGH Poet. lat. 2. S. 234 f., Nr. LXXXI.

1176 Ich danke herzlich Prof. Dr. Peter ORTH, Universität Köln, für diesen Hinweis.

1177 Michele Camillo FerRARI, ">Pangite celi, reboemus odas‘: Ein sapphischer Hymnus, sein Verfasser und seine Bearbeitung zwischen Weissenburg, Rätien und Umbrien«, in: Zeitschrift für schweizerische Kirchengeschichte 83 (1989), S. 155-176. S. 156f., 168.

1178 Rolf BERGMANN, "Weißenburger Glossenhandschriften«, in: Die althochdeutsche und altsächsische Glossographie. Ein Handbuch, 2, hrsg. von Rolf BERgMann und Stefanie STRICKER, Berlin 2009, S. 1306-1309. 
seiner Erläuterung der Institutiones Grammaticae des Priscian in Cod. Guelf. 50 Weiss. nimmt Otfrid eine weitverbreitete Praxis der schulischen Glossierung des Grammatikers auf. ${ }^{1179}$

In das Umfeld des grammatischen Unterricht gehört ebenfalls die CiceroHandschrift Vatikan, BAV, Vat. lat. 11506, die von Hellgardt als Teil der Weißenburger Bibliothek entdeckt wurde. Sie wurde zwar nur nach Weißenburg lokalisiert, jedoch noch nicht datiert, kann aber als zu Otfrids Zeit in Bibliothek und Unterricht vorliegend angenommen werden. ${ }^{1180}$ Der Text von De Inventione steht in engem Zusammenhang zur etwa gleichzeitigen Würzburger Handschrift Würzburg, UB, M.p.misc.f.3. ${ }^{1181}$ Auf De Inventione folgt in Vat. lat. 11506 von gleicher Hand (f. 62v-82v) die Übersetzung der Weltbeschreibung des Dionysius Periegetes durch Priscian, die Periegesis. ${ }^{1182}$ In der Texttradition des Werkes steht Vat. lat. 11506 in der Gruppe $d$, deren zeitgenössische Mitglieder alle aus dem Westreich stammen ${ }^{1183}$ - ein überraschendes Schlaglicht auf die ansonsten im Dunkeln liegenden Quellen von Dichtung in der Weißenburger Bibliothek. Hinter den erläuternden Glossen, die Otfrid dem Text hier und da mit aliter und vel hinzufügte, verbirgt sich kaum, wie Woestijne meint, ein weiteres Exemplar der Periegesis, aus dem der Text korrigiert worden sei; es handelt sich vielmehr um pädagogische Glossen in dieser der Schule nahestehenden Handschrift. ${ }^{1184}$

In engem Zusammenhang mit der Priscian-Handschrift steht als einzige weitere als schulisch-grammatisch einzuschätzende Handschrift, die klar in die Otfrid-Zeit fällt, die Prudentius-Anthologie in Wolfenbüttel, HAB, Cod. Guelf. 77 Weiss. ${ }^{1185}$ Die sorgfältige, von Otfrid durch Schreiben von Anfang und Schluss der

1179 Edition und Identifikation mit Otfrid: Hans Butzmann, "Althochdeutsche PriscianGlossen aus Weissenburg (1964)«, in: Hans Butzmann: Kleine Schriften: Festgabe zum 70. Geburtstag. Als Festgabe der Herzog August Bibliothek Wolfenbüttel, hrsg. von Wolfgang MILDE (Studien zur Bibliotheksgeschichte 1), Graz 1973, S. 120-129. Analyse: Wolfgang KLEIBER, "Otfrid von Weißenburg als Priscian-Glossator. Eine sprachhistorische Skizze«, in: Die althochdeutsche und altsächsische Glossographie. Ein Handbuch, 2, hrsg. von Rolf Bergmann und Stefanie Stricker, Berlin [u.a.] 2009, S. 1601-1610.

1180 Hellgardt: Die exegetischen Quellen. S. 80. Zur Weißenburger Herkunft: Bischoff: Abtei Lorsch. S. 128.

1181 Valerie M. LAgorio, "The text of Cicero's De inventione in Codex Vat. Lat. 11506", in: The Classical bulletin LV (1978), S. 12-15. S. 14.

1182 Woestijne (Hrsg.): La Périégèse de Priscien, Édition critique. Zur Handschrift, Sigle V: S. $14 \mathrm{f}$.

1183 Ebd. S. 13-20, stemmatische Analyse S. 20. Die entsprechenden Handschriften in Bischoff: Katalog: P, Nr. 4451; F, 2193; S, 6816. Zur Schwesterhandschrift B Brüssel 14792: Paul Louis Désiré Tномаs, Catalogue des manuscrits de classiques latins de la Bibliothèque royale de Bruxelles, Gand 1896. Nr. 275.

1184 Zum Schulgebrauch von De Inventione siehe WARD: »The medieval and early renaissance study of Cicero's De inventione and the Rhetorica ad Herennium«.

1185 Bischoff: Katalog, 3. Nr. 7402. BergmanN/Stricker: Katalog. Nr. 976. KLeiber: Überlieferung. S. 109f. O’Sullivan: Glosses on Prudentius. Eine Übersicht zur Rolle Prudentius' 
Texte dirigierte Handschrift, enthält eine gegenüber weiteren Textzeugen stark reduzierte Textauswahl, ${ }^{1186}$ deren Sinn sich nicht erschließt - zumindest stellt sie eine Neuerung gegenüber der gesamten weiteren Tradition dar, die jedoch keine Nachahmer gefunden hat. Dass diese Handschrift die einzige ausschließlich poetische der Otfridzeit unter so zahlreichen exegetischen ist - abgesehen natürlich von denen des Evangelienbuches - zeigt deutlich, was auch schon die Quellenstudien zu seiner Dichtung ergeben haben, ${ }^{1187}$ dass nämlich Otfrids Bezugspunkt die exegetische, nicht die poetische Literatur war. Trotzdem war ihm diese so geläufig, dass er am Ende der Handschrift (f. 50r) noch eigenhändig ${ }^{1188}$ ein Rätsel aus irischer Tradition, das er wahrscheinlich in Fulda kennengelernt hatte, ergänzte: Quadam nocte niger. ${ }^{189}$ Der Fuldenser Ursprung wird wahrscheinlich dadurch, dass es ebenfalls in der Anthologie in Einsiedeln, StB, Cod. 326 (1076), f. 88v-97r (das Gedicht 88v-89v), von einem »in Fulda geschulte[n] Schreiber « niedergeschrieben wurde - der einzigen weiteren zeitgenössischen ostfränkischen Quelle des Gedichts. ${ }^{1190}$ Merkwürdigerweise geht Otfrids Autograph nur bis zum Fuß der Seite, worauf auf dem Verso von zwei Händen des frühen 10. Jh. die restlichen vier Verse ergänzt werden, ${ }^{1191}$ sodass Jahrzehnte, nachdem Otfrid das Gedicht schrieb, die Lücke aufgefallen und gefüllt worden ist - was vielleicht dadurch zu erklären ist, dass das Gedicht an anderem Ort weiterhin als (schulische?) Denksportaufgabe in Gebrauch blieb und dementsprechend hier, nachdem die fehlenden Verse bemerkt worden waren, unter Anleitung des Lehrers, der die ersten drei Worte setzt, vervollständigt worden ist. Auf das Rätsel folgen auf den freigebliebenen Seiten (50v-52r) von einer anderen Hand hinzugesetzt die »Weißenburger Gedichte ${ }^{1192}$ Diese wurden erst später nach und nach, in der Tat eins nach dem anderen, eingetragen, ${ }^{1193}$ was

in der Zeit: S. 3-21; zur Handschrift: S. 28. Die Handschrift wurde nur sporadisch in der Edition herangezogen: Cunningham (Hrsg.): Prudentii Carmina. S. XIX, $\$ 60$; S. 144f. Anm. zu vs. 858.

1186 Vergleiche für eine Übersicht der verschiedenen Textensembles: Bergmann: De codicum Prudentianorum generibus et uirtute. S. 57-60, die Handschrift S. 58.

1187 Siehe den Stand der Forschung zusammenfassend: Werner SchröDER und Heiko HarTMANN, »Art. Otfrid von Weißenburg", in: Althochdeutsche und altsächsische Literatur, hrsg. von Rolf BergmanN, Berlin [u.a.] 2013, S. 322-345.S. $331 \mathrm{f}$.

1188 KLEIBER: Überlieferung. S. 109.

1189 SK 12816. STRECKER (Hrsg.): MGH Poet. lat. 4, 2.3. S. 1117-(1119)-1120.

1190 LANG: "Einsiedeln, Stiftsbibliothek, Codex 326(1076)«.

1191 HoffmanN: Schreibschulen. S. 316.

1192 Fickermann/Strecker (Hrsg.): MGH Poet. lat. 5, 1.2. S. 504-507. Ernst DümmLeR, "Weißenburger Gedichte», in: Zeitschrift für deutsches Altertum und deutsche Literatur 19 (1876), S. 115-118. Karl HeLm, "Otfrid-Nennungen?», in: Beiträge zur Geschichte der deutschen Sprache und Literatur 66 (1942), S. 134-145.

1193 Hoffmann: Schreibschulen. S. 316. Hand E schreibt nicht nur bis f. 51v, sondern bis f. 52r. Ich nehme einen Druckfehler an, da f. 52r erwähnt sein müsste, läge hier ein Handwechsel vor. Die von Hoffmann genannten paläographischen Merkmale (»schmales längliches g, 
auf das langsame Wachsen der Sammlung deutet. Die Dichter der beiden ersten Gedichte (I, II), Ercanbert und Ferding, finden sich ebenfalls in der schon erwähnten Ausleihliste, wo sie ihren Pflichten als respektive Diakon und Subdiakon gemäß liturgische Bücher entliehen. ${ }^{1194}$ Die Gedichte V und VI, VIII und IX sind vielleicht durch die Autorensigle $e$ am Rande ebenfalls als Werke Ercanberts gekennzeichnet. ${ }^{1195}$ Da die Gedichte bisher noch nicht in ihrer Gesamtheit kommentiert wurden, sei hier eine kurze Übersicht gegeben ${ }^{1196}$ :

I. Ercanbert: Begrüßungsgedicht an einen neuen $\mathrm{Abt}^{1197} /$ Schulmeister (? Vers 10 monitor, 5 doctus), der von einem dominus visitans (Vers 7) geschickt wurde. Liegt vielleicht ein Wortspiel auf den Namen in Vers 12 Lucidus vor? ${ }^{1198}$

II. Ferding, der Ercanbert hier als iuvenis (3) anredet, scheint diesem hier zur Erlangung einer wie auch immer gearteten Qualifikation (Diakonat?) zu gratulieren; denn dies ist doch der Sinn der maritimen Metapher in 7-10, wonach Ercanbert nunc im Geiste großmütige Fische (!) fangen könne, iamque mit seiner doctrina das Schiff der Weisheit steuern könne.

III. Ein Schüler, iuvenis (2), wendet sich an seinen Lehrer Wisiric ${ }^{1199}$ (5) mit der Bitte, etwas anderes lernen zu dürfen als nur die Grammatik (7-8). An denselben Wisiric wendet sich auch das mit $e$ gekennzeichnete Gedicht VIII.

IV. Ein Mahngedicht auf den verstorbenen »Ketzer« (3-5) Hartwig, dessen Vergehen besonders in einer Art Raubrittertum bestanden $\mathrm{zu}$ haben scheint (9-10). Das Gedicht stellt gewissermaßen ein Anti-Epitaph dar.

x geht unter die Zeile; (...) que mit Doppelpunkt gekürzt«) finden sich ebenfalls auf f. 52r. Zum Werk des Schreibers gehören ebenfalls die f. 47v interpolierten Prudentius-Verse 858 a-f, die die gleichen Merkmale aufweisen. Zu den Versen siehe: Ed. Cunningham, wie oben, S. XIX, $\$ 60$; S. 144f. Anm. zu vss. 858. Der Text steht merkwürdigerweise einer westfränkischen Handschrift (q, Bern Ms. 394, Bischoff, Kat. Nr. 590) näher, als den gleichzeitigen bodenseeischen Handschriften, die die Verse ergänzen (U, Bern Ms 264, Kat. Nr. $566 »$ Alemannien«; S, Cod. Sang. 136, Kat. Nr. 5593 »St. Gallen«).

1194 LeRCHE: »Das älteste Ausleihverzeichnis einer deutschen Bibliothek«. S. 443, Z. 4, 14.

1195 Fickermann/Strecker (Hrsg.): MGH Poet. lat. 5, 1.2. S. 504, Anm. zum Gedicht.

1196 Wenn auch wegen des dunklen Lateins einiges im Dunkeln bleiben muss (so auch STRECKER, siehe vorherige Anm.).

1197 Dies wäre in der betreffenden Zeit Hatto (891?-913?), der als Erzbischof von Mainz wenig Zeit für das Kloster gehabt haben wird; in ihm wäre eher der dominus zu sehen. Siehe seine zahlreichen Reisen bei: Winfried Wilhelmy, Glanz der späten Karolinger. Erzbischof Hatto I. von Mainz (Publikationen des Bischöflichen Dom- und Diözesanmuseums Mainz 3), Regensburg 2013. S. 14-15.

1198 Nicht gemeint sein können Ferding oder Wisiric, Ernst Wilhelm Förstemann, Altdeutsches Namenbuch (Personennamen), 1, Nordhausen 1856. Sp. 401, 1330.

1199 Vielleicht 926 beim Ungarneinfall umgekommen (DüMMLER: »Weißenburger Gedichte«. S. 118). 
V. $(e)^{1200}$ Thiodolt, der den Dichter zum Besten gehabt hatte, wird hier nun selbst mit Spott überschüttet, indem an einige seiner, freilich völlig obskuren ${ }^{1201}$ Missgeschicke erinnert wird.

VI. (e) Der Lehrer (didascule, darüber magister glossiert) soll wissen, dass die vorliegenden Gedichte (carmina quae cernis nunc) nicht aus bösen Motiven, sondern auf Veranlassung von pat[er](?) Babio (?, Babinis 3) geschrieben worden seien.

VII. Dem Gedicht ${ }^{1202}$ fehlen sieben Verse, die auf f. 51v radiert wurden, ${ }^{1203}$ wodurch ausgerechnet die Verse 8-10, in denen der einzige ausdrückliche Hinweis auf eine Lehrtätigkeit Otfrids besteht, ganz unverständlich werden. Der Spott gilt nicht dem genannten Otfrid, sondern dem puer indocte (20), vielleicht, wie auch Helm vermutet, dem schon gescholtenen Thiodolt. ${ }^{1204}$ Helms (und daraufhin Kleibers) Identifizierung des genannten Otfrid mit dem Dichter ist zuzustimmen. Otfrid und Cormac werden hier mit dem Verspotteten zu seinem Nachteil verglichen. Unverständlich ist allerdings Helms Beharren darauf, dass die Nennung Otfrids auch bedeutet, das Gedicht sei zu seiner Lebenszeit entstanden. Vielmehr wird der große Dichter, dessen Nachruhm im eigenen Kloster weiterlebte, dem puer indoctus vorgehalten.

VIII. (e) Ein Gedicht mit Wünschen um beste Gesundheit an den schon in III. genannten Wisiric.

IX. (e) Eine hexametrische Paraphrase des Gloria in Excelsis.

Die bestimmende Gestalt der Weißenburger Gedichte ist - abgesehen vom gründlich untersuchten, aber doch nur nebenbei genannten Otfrid - der Diakon Ercanbert. Wenn wir ihm insbesondere die mit $e$ gekennzeichneten Gedichte ebenfalls zuschreiben, ${ }^{1205}$ war er ein junger Mann in fortgeschrittenen Studien, schon beherzt dichtend und die niederen Weihen innehabend. Dass es sich um Gedichte eines Schülers, nicht um repräsentative Dichtung handelt, sollte man

1200 Am Rande.

1201 Nach Helm handelt es sich bei dem Siebenschläfer (5) um eine Geliebte, bei der Episode, in der ein Hund ihn in den Fluss stößt (7-8), um Kuppelei; die Schnee-Episode bleibt unklar. HeLM: »Otfrid-Nennungen?« S. $137 \mathrm{f}$.

1202 Diskussion bei KLeiber: Überlieferung. S. 132f. und Helm: »Otfrid-Nennungen?«, insb. S. 139-145.

1203 Fickermann/Strecker (Hrsg.): MGH Poet. lat. 5, 1.2. S. 505, Anm. 24. Das Gedicht ist also nicht unvollständig kopiert worden, wie HeLM: „Otfrid-Nennungen?« S. 139, meint. Zur Konjektur zu Vers 10 corporeumque pio > corpore cumque pio möchte ich nur hinzufügen, dass in III. ebenfalls dreimal corpus in diesem idiosynkratischen Sinne gebraucht wird.

1204 Eine etwaige Kennzeichnung mit $e$ für Ercanbert ist nicht zu erkennen und vielleicht mit ausradiert worden.

1205 Und damit ebenfalls Nr. III., auch an Wisiric; zusätzlich mag bei VII. das $e$ fehlen, zumal der Gegenstand dem Gedicht V. sehr ähnelt. Damit bliebe nur IV. ohne Attribution. 
bedenken, um nicht in Dümmlers vernichtendes Urteil einzustimmen. ${ }^{1206}$ Die Sammlung lässt uns einen seltenen Blick in seine Welt werfen: Befreundet ist er mit seinem Klassenkameraden ${ }^{1207}$ Ferding, der ihn wohlmöglich zur Erlangung des Diakonats beglückwünscht (II.). Sein Erzfeind und Rivale in der Dichtkunst ist Thiodolt, dessen Spott er ertragen musste (V.3) und den er nun seinerseits in (V. und VII.?) verhöhnt. Oder sind die Spottgedichte nur geistreiches Spiel, wie es das Gedicht VI. an den Lehrer Wisiric beteuert, dem auch weitere Verse gewidmet werden (III., VIII.)? Man meint dennoch einen Funken Wahrheit darin zu erkennen, gerade in den obskuren Anspielungen im V. Gedicht, die nicht als Topoi, sondern als Andeutungen für den Eingeweihten verstanden werden müssen. Dass die Gedichte, wenn auch als Schulübung, die Wirklichkeit widerspiegeln, zeigt die sehr spezifische Schilderung über den »Ketzer« Hartwig aus Brumath, den seine gerechte Strafe ereilte, was offensichtlich einiges Aufsehen erregt haben muss. Wer hat nun warum diese Gedichte in der Prudentius-Handschrift ergänzt? Ich kann hier keinen anderen, als Ercanbert selbst erkennen, aus folgenden Gründen: Die Gedichte sind durch genannte Personen, Stil und Thematik als das Werk eines einzelnen, nämlich Ercanberts, gekennzeichnet. Die Sammlung wurde nicht en bloc kopiert, sondern nach und nach, aber von einem einzelnen Schreiber, der also selbst der Sammler war, da an diesem marginalen Ort und bei der geringen Qualität der Gedichte ein höherer Auftrag zur Sammlung ausgeschlossen werden darf. Aus dem Ort der Niederschrift, einer schulischen Prudentius-Handschrift, darf angenommen werden, dass die Sammlung im Rahmen des Unterrichts selbst stattfand. Als Schreiber kommt dementsprechend nur Ercanbert in Betracht, um alle diese Bedingungen zu erfüllen. Die Weißenburger Gedichte sind somit die persönliche Sammlung eines jungen Mönches, der seine Versuche in der Dichtkunst in den freien Seiten eines Lehrbuchs sammelte.

Der Ruhm der Weißenburger Dichtung und Weißenburgs überhaupt besteht aber nicht in den ludicula (VI, 4) dieser Schülergedichte, sondern in Otfrids Evangelienbuch, das gemeinsam mit dem Heliand die weitere volkssprachige Dichtung des 9. Jh. überragt. Es ist hier nicht der Ort, die reiche Forschung, die Otfrids Werk und insbesondere dessen Handschriften in diplomatischen Ausgaben erfahren haben, zu referieren. ${ }^{1208}$ Hier soll abschließend nur der Blick

1206 »Weißenburger Gedichte«. S. 118: »in ihrer schülerhaften unbeholfenheit und mit ihren metrischen und und grammatischen mängeln zeugen diese kleinen spielereien von dem gesunkenen zustande der geistigen bildung zu anfang des zehnten jahrhunderts.»

1207 Denn als Subdiakon und Verfasser eines schülerhaften Gedichtes lässt sich Ferding nicht anders einordnen.

1208 Die maßgebende kritische Ausgabe ist weiterhin: Erdmann/WolfF (Hrsg.): Otfrids Evangelienbuch. Eine umfassende Bibliographie der Forschung bis 1975: Johanna BELKIN und Jürgen MeIER, Bibliographie zu Otfrid von Weißenburg und zur altsächsischen Bibel- 
darauf gelenkt werden, wie Otfrid sich des Weißenburger Skriptoriums zur Verbreitung seines Werkes bediente. Nur noch zwei Handschriften (V und P, s. u.) sind von dort erhalten. Hinzu kommt eine aus Freising, die dort am Ende des Jahrhunderts unter Bischof Waldo geschrieben wurde, ${ }^{1209}$ sowie eine spätere aus der Mitte des 10. Jh. (D), die in Fulda geschrieben wurde. ${ }^{1210}$ Diese zwei nicht aus Weißenburger Initiative hervorgegangenen Handschriften deuten auf eine breitere Rezeption, als das Schweigen späterer Autoren über Otfrid vermuten lässt. ${ }^{1211} \mathrm{Zu}$ den Weißenburger Handschriften kommen sicherlich noch die Exemplare, die dort für die Träger der vier Widmungen in $\mathrm{V}$ geschrieben wurden $;^{1212}$ von ihnen ist nichts erhalten. ${ }^{1213}$ Das unter Otfrid straff organisierte Skriptorium verfertigte somit wenigstens vier Handschriften für die Adressaten der Widmungen, sodass der Dichter hier quasi im Eigenverlag für die Verbreitung seines Werkes sorgte. Es kann nur beklagt werden, dass uns der Verlust dieser Widmungsexemplare keine weiteren Schlüsse mehr erlaubt, insbesondere über die Ausstattung, ${ }^{1214}$ die bei der verschiedenen Stellung der Adressaten eine durchaus variierende Stilhöhe gehabt haben könnte. Es bleiben aus Weißenburg zwei Handschriften:

Die Haupthandschrift des Evangelienbuchs ist die von Otfrid selbst redigierte, Wien, ÖNB, Cod. 2687 (Sigle V). ${ }^{1215}$ In ihr ist der vollständige Text, sowie alle vier Widmungen enthalten. Sie trägt buchstäblich Otfrids Handschrift, der sich hier, wie in schon anderen unter seiner Leitung entstandenen Kodizes als spiritus

dichtung (Heliand und Genesis) (Bibliographien zur deutschen Literatur des Mittelalters 7), Berlin 1975. Hierin sind jedoch die wichtigen Arbeiten HellgardTs sowie die diplomatischen Editionen nach den Handschriften (s.u.) noch nicht inbegriffen. Eine aktuelle Auswahlbibliographie in: Bergmann (Hrsg.): Ahd. und as. Literatur. S. 341-345.

1209 Handschrift F, die wohlmöglich direkt aus Weißenburg von einem Freisinger Bischof entliehen wurde, wie ein heute verschollenes Ausleihverzeichnis notiert; siehe bei Freising, S. 291.

1210 Kleiber/Hellgardt (Hrsg.): 2, 2, P \& D. S. 100-102.

$1211 \mathrm{Zu}$ weiteren möglichen verlorenen Textzeugen siehe: Ernst Hellgardt, ")...der alten Teutschen spraach und gottsforcht zuerlernen. Über Voraussetzungen und Ziele der Otfridausgabe des Matthias Flacius Illyricus (Basel 1571)«, in: Festschrift Walter Haug und Burghart Wachinger, hrsg. von Johannes Janota, Paul SAPPLER und Frieder Schanze, Tübingen 1992, S. 267-286. S. 277.

1212 So der Konsens der Forschung: Kössinger: »Weißenburg«. S. 542. Wolfgang KLEIBER und Ernst Hellgardt (Hrsg.), Otfrid von Weißenburg: 1: Edition nach dem Wiener Codex 2687 Teil 1: Text, Tübingen 2004. S. $10 \mathrm{f}$.

1213 Ob Ludwig der Deutsche der in Vers 88 der Widmung an ihn ergangenen Bitte nach weiterer Verbreitung nachkam, ist unbekannt.

$1214 \mathrm{Zu}$ den Illustrationen in V und P siehe: KLeiber/Hellgardt (Hrsg.): Wiener Codex 2687. S. 41-49 und Kleiber/Hellgardt (Hrsg.): 2, 2, P \& D. S. 19-46.

1215 Kleiber/Hellgardt (Hrsg.): Wiener Codex 2687; ebd. 
rector des Unternehmens erweist. ${ }^{1216} \mathrm{Er}$ bedient sich zweier Schreiber, die auch in der Heidelberger Handschrift den Großteil der Arbeit tun. ${ }^{1217}$ Am extensivsten ist Otfrids Beitrag in den Tausende[n] von Korrekturen ${ }^{1218}$, die auktoriale Verbesserungen des Dichters darstellen. Die Wiener Handschrift ist somit, um in editorischen Metaphern zu bleiben, der Korrekturbogen des Werkes.

Die zweite Weißenburger Handschrift, Heidelberg, UB, Cod. Pal. lat. 52, (P), ${ }^{1219}$ stellt die "erste Rezeptionsstufe des Wiener Otfridoriginals ${ }^{1220}$ dar. Die zwei Hauptschreiber von V zeichnen auch hier verantwortlich.Direkte Spuren einer Redaktion Otfrids gibt es nicht. Die Überarbeitung betrifft hauptsächlich Initialen und Überschriften, weniger den Text selbst. Die Funktion dieser Handschrift, die offensichtlich das Skriptorium nicht verlassen hat, ist ungeklärt. Vielleicht handelt es sich, neben Otfrids Exemplar V, um die Handschrift, die der Weißenburger Bibliothek selbst zugedacht war.

Zum frühen Weißenburger Skriptorium, erst unter den Abbatiaten der drei Wormser Bischöfe und alsdann unter Grimalds Leitung, ist festzustellen, dass Dichtung hierher von außen herangetragen wurde, durch Abt Bernhar, der sein Vademecum aus Worms mitbrachte, oder durch Grimald, der sich des Skriptoriums für den Horaz bediente. Dichtung ist hier also nicht institutionell - speziell schulisch - gebunden, sondern an die liturgischen Bedürfnisse und wissenschaftliche Initiative der leitenden Persönlichkeiten. Schon unter Grimald sehen wir aber in der kollaborativen Horaz-Handschrift und in der Revision, der diese von Walahfrid unterzogen wurde, eine eigenständige Gelehrsamkeit, der sich vollends unter Otfrid Bahn brechen sollte. Von seiner energischen Leitung des Skriptoriums werden sowohl Schriftbild wie Auswahl der Themen tiefgreifend beeinflusst. Sein Hauptaugenmerk gilt der exegetischen Literatur, die in den zahlreichen Bänden des "Bibelwerkes« erscheint. Obwohl selbst Dichter, findet Dichtung unter seiner Ägide nur in einem schulischem Umfeld statt, was sich an den wenigen derart geprägten Handschriften (Prudentius und Priscian) nachweisen ließ. Für seine eigene Dichtung dagegen nimmt er das Skriptorium ganz in

1216 Zur Paläographie in größtem Detail siehe: Kleiber/Hellgardt (Hrsg.): Wiener Codex 2687. S. 51-118, sowie Kleiber: Überlieferung. S. 40-84. Zur Leitung durch Otfrid zusammenfassend Kleiber/Hellgardt (Hrsg.): Wiener Codex 2687. S. 109-117.

1217 Kleiber/Hellgardt (Hrsg.): Wiener Codex 2687. S. 56.

1218 Ebd. S. 55.

1219 Wolfgang Kleiber und Ernst Hellgardt (Hrsg.): Otfrid von Weißenburg: 2: Edition der Heidelberger Handschrift P (Codex Pal. Lat. 52) und der Handschrift D (Codex Discissus: Bonn, Berlin/Krakau, Wolfenbüttel) Teil 1: Texte (P, D), Tübingen 2006; KLeIBer/HeLLGardt (Hrsg.): 2, 2, P \& D. Rudolf Schützeichel, Codex Pal. lat. 52. Studien zur Heidelberger Otfridhandschrift, zum Kicila-Vers und zum Georgslied, Göttingen 1982. Von den Ausgaben orientiert sich nur Paul PIPER (Hrsg.), Otfrids Evangelienbuch (Bibliothek der ältesten deutschen Litteratur-Denkmäler), Paderborn [u.a.] 1878. an der Heidelberger Handschrift.

1220 Ebd. 2, S. 47. 
Beschlag: Wenigstens sechs Handschriften des Evangelienbuches gehen aus dem Skriptorium hervor - ein Grad der organisierten Vervielfältigung eines dichterischen Werkes, wie er sich sonst nur noch bei Otfrids Lehrer Hrabanus und dessen Liber de cruce findet, das ebenfalls mehrere "Editionen « erlebte. Wie sehr die Tätigkeit des Skriptoriums an Otfrid gebunden war und wie wenig institutionelle Eigenständigkeit es entwickelt hatte, zeigt sich am Zusammenbruch der Aktivität nach Otfrids Tod. Dass jedoch weiterhin gelesen, gelernt und gedichtet wurde, zeigt sich an der wenn auch dichterisch mangelhaften, dennoch menschlich reizenden Sammlung der »Weißenburger Gedichte« des Schülers und Diakons Ercanbert, der uns dadurch einen letzten Blick in die Weißenburger Schule des 9. Jh. gewährte.

\section{II.1.g Murbach}

Von der großen Bibliothek Murbachs, ${ }^{1221}$ die sich gleichrangig neben die von St. Gallen, Lorsch oder der Reichenau stellte, sind kaum mehr als kümmerliche Reste erhalten, sodass man in die Klage des Sigmund Meisterlin, der dort im 15. Jh. als Antiquar wirkte, ${ }^{1222}$ einstimmen möchte: „Und wir haben erlebt, wie das Alter alle Dinge verzehrt und der Zahn der Zeit alles vernichtet; das konnte man an den Büchern sehen, die durch Mühe und Scharfsinn der Altvorderen (...) zusammengetragen wurden. Gestern sahen wir den Katalog durch und - welche Schande! - so viel mehr Bücher sind verloren gegangen, als erhalten geblieben sind. ${ }^{1223}$ Und in der Tat stellt sich der Zustand der Murbacher Bibliothek heute, da sie zudem zerstreut ist, noch trister dar als zu Meisterlins Zeiten. Unter den ca. 40 Handschriften - darunter ein Großteil nur Fragmente - die mit mehr oder weniger Sicherheit dem Murbacher Skriptorium zugeordnet werden können,

1221 René Bornert, "Abbaye Saint-Léger de Murbach«, in: Les monastères d'Alsace. 2: Abbayes de bénédictins des origines à la Révolution française, Straßburg 2009, S. 7-250. Ältere Darstellungen: Andreas Gatrio, Die Abtei Murbach im Elsaß, Straßburg 1895. Zur Kritik an GATRIO siehe Albert BRUCKNER, »Untersuchungen zur älteren Abtreihe des Reichsklosters Murbach «, in: Elsaß-Lothringisches Jahrbuch 16 (1937), S. 31-56. S. 31. Franz Xaver KRAUs, Kunst und Alterthum im Ober-Elsass (Kunst und Altertum in Elsaß-Lothringen 2), Straßburg 1884. S. 471-481.

1222 Katharina Colberg, "Art. Meisterlin, Sigismund", in: Verfasserlexikon, 11, 2004, S. 988. Paul Joаснімsонn, Die humanistische Geschichtsschreibung in Deutschland, Heft 1: Die Anfänge. Sigmund Meisterlin, Bonn 1895.

1223 "Profecto verum experti sumus quod uetustas omnia consummit, ac tinea antiquitatis conficit vniuersa, idque licuit videre in tot codicibus magna cura et ingenio patrum (...) repositis, prout hersternum quod reuoluebamus ostendit rotulum, quod tot describit iam proch deperdita opera, ut numerum repertorum excedant. "Dieser Brief über die Murbacher Wandteppiche (Epistola de tapeciis) wurde mehrfach ediert, ich zitiere nach: MILDE: Bibliothekskatalog. S. 12. 
findet sich nur Weniges, das den Glanz der Sammlung widerspiegelt. ${ }^{1224}$ Neben den dominierenden biblischen und patristischen Handschriften seien hier als Beispiele eines weitergehenden Interesses erwähnt zum Beispiel die Abhandlung des Vegetius zur Pferdeheilkunde (Colmar, Archives départementales du HautRhin, Fragm. 624, 7) oder die Naturgeschichte des Plinius (Leiden, UB, Ms. Lips. 7). Eigentliches Denkmal der Murbacher Bibliothek des 9. Jh. sind jedoch nicht die Handschriften, sondern der uns durch die Hand Meisterlins erhaltene Katalog. ${ }^{1225}$ Den Katalog, der von Bloch endgültig ins 9. Jh. (um 840) datiert wurde und von Milde in einer Monographie eingehend untersucht worden ist, verdanken wir dem antiquarischen Interesse Meisterlins, der ihn aus einem alten Rotulus ${ }^{1226}$ in das Kartular der Abtei Murbach kopierte. ${ }^{1227}$ Der Katalog ist unvollständig, wie schon von Gatrio festgestellt wurde: ${ }^{1228}$ Es fehlen die biblischen und liturgischen Bücher, die Liste setzt abrupt mit Cyprian ein. Die ansonstige Genauigkeit des Katalogs legt nahe, dass er kein Auszug, sondern nur beschädigt ist, also Blätter des oberen Teils des Rotulus verlorengegangen sind. Der Katalog gliedert sich in zwei Teile: Ein umfangreicher Gesamtkatalog, sowie eine spätere Ergänzung unter Abt Iskar. Zur besseren Übersicht sei die enthaltene Dichtung hier der Diskussion vorangestellt:

Der Hauptkatalog enthält um die 335 Titel, wobei die genaue Zusammenfassung einiger Einträge in Einzelwerke oder Sammelbände Gegenstand der Dis-

1224 Die Murbacher Handschriften wurden noch nicht zusammenfassend behandelt. Verschiedene Zusammenstellungen sind zu finden in: Elias Avery Lowe, Codices Latini antiquiores IX, Germany: Maria Laach - Würzburg, Oxford 1960. S. X (CLA 222, 242, 243, 731, 749, 751). Bischoff: Katalog, 1, S. 484, 2, S. 440, 3, S. 615. BischоғF: »Panorama«. S. 21. MAAG: Alemannische Minuskel. S. 149-159. Bornert: „Saint-Léger de Murbach«. S. 119154. Die Handschriftenproduktion kam schon vor den Ungarnstürmen zu erliegen: Hoffmann: Schreibschulen. S. 203. Das Kloster wurde endlich 926 von den Ungarn geplündert und niedergebrannt (BORNERT: "Saint-Léger de Murbach«. S. 20).

1225 Milde: Bibliothekskatalog. Kritisch und ergänzend hierzu: Geith/Berschin: »Bibliothekskataloge«. Erste kritische Ausgabe: Hermann BLOCH, »Ein karolingischer BibliotheksKatalog aus Kloster Murbach«, in: Strassburger Festschrift zur XLVI. Versammlung Deutscher Philologen 1901, S. 257-285.

1226 Diese Form eines Bücherverzeichnisses teilt Murbach mit der Reichenau, mit deren Bibliothek es auch sonst vielfältig verbunden ist.

1227 Colmar, Archives du Haut-Rhin, Cartulaire Abbaye Murbach Nr. 1, p. 86-91 unter dem Titel »Rotulus Codicum Manuscriptorum Bibliothecae Murbacensis». Datierung: BLocH: »Bibliotheks-Katalog«. S. 275. Ähnlich MiLdE: Bibliothekskatalog. S. 31: »Mitte des 9. Jahrhunderts, der Iskar-Katalog etwa im dritten Viertel dieses Jahrhunderts entstanden.» Zur Bezeichnung registrum, die wahrscheinlich von Meisterlin stammt, siehe BLOCH: "Bibliotheks-Katalog«. S. 274 Anm. 2. Geith/Berschin: »Bibliothekskataloge«. S. 85.

1228 Gatrio: Die Abtei Murbach im Elsaß. S. 37, nach der Ausgabe des Katalogs von: Jacques MATtER, »Bibliothèque d'une maison religieuse du XVe siècle. Catalogue de la bibliothèque de l'abbaye princière de Murbach", in: Lettres et pièces rares ou inédites, publiées et accompagnées d'introductions et de notes, Paris 1846, S. 40-76. 
kussion ist. ${ }^{1229}$ Dichtung findet sich hier in verschiedenen Abteilungen. Zuerst wird sie in der patristischen Abteilung den Autoren zugesellt, deren Werke zahlreich genug sind, um eine jeweils eigene Kategorie zu erhalten, so die Consolatio Philosophiae bei Boethius (Milde-Nr. 236) und die augustinischen Epigramme ${ }^{1230}$ bei Prosper (Nr. 209) - die Titel sind nicht nach Gattung, sondern nach Autor eingeordnet. Das Fehlen der poetischen Werke Bedas (bis auf die Vita Cuthberti, ${ }^{1231}$ Nr. 191) bemerkte auch der Bibliothekar Murbachs; er ergänzt nach Nennung der vorhandenen Werke eine lange Liste $\mathrm{zu}$ beschaffender Bücher - sequentes libros adhuc non habemus ${ }^{1232}$ - darunter: Librum ymnorum diverso metro sive rithmo [Milde: rickmo] ${ }^{1233}$ (Nr. LXXII), Librum epigramatum eroico sive eleiaco metro (Nr. LXXIII). Grundlage der Desideratenliste war die von Beda selbst am Ende der Historia Ecclesiastica hinzugefügte Liste seiner Werke, ${ }^{1234}$ nicht etwa eine von anderen Bibliotheken vermittelte Bestandsliste. Spuren beider Werke finden sich in kontinentalen Bibliotheken verstreut, wenn auch ihre genaue Gestalt im Dunkeln bleibt. ${ }^{1235}$ Die beiden Werke Bedas sind die einzigen poetischen in den umfangreichen Desideratlisten, durch die der Murbacher Katalog sich vor anderen Verzeichnissen auszeichnet. ${ }^{1236}$ Es ist zu bedauern, dass Milde bei der großen Aufmerksamkeit, die er den Desideratenlisten schenkt, einer weiteren Murbacher Liste überhaupt nicht gedenkt, die zweifellos in diesem Zusammenhang hätte behandelt werden müssen: ${ }^{1237}$ Dem Katalog der Reichenauer Bibliothek in Genf, Bibliothèque publique et universitaire, Ms. Lat. 21 (99). ${ }^{1238}$ Dass im intensiven Austausch der Klöster ${ }^{1239}$ nicht auch Bücher getauscht

1229 Ich zitiere nach den Nummern Mildes. Zur Zählung: Geith/Berschin: »Bibliothekskataloge«. S. 63. Ein Verdienst der atomistischen Zählung MiLDEs ist die exakte Referenzierbarkeit auch der umstrittenen Einzeltitel.

1230 HoRsting (Hrsg.): Prosper Aquitanus, Liber epigrammatum. Zum Katalog kurz S. 22.

1231 Das Werk stand ebenfalls in den Bibliotheken St. Gallens (Cod. Sang. 263) und der Reichenau (dort jedoch in die grammatischen Schriften eingereiht: LeH MANN (Hrsg.): MBK. 1, S. 252, Z. 13). Weitere Überlieferung: JAAGER (Hrsg.): Bedas metrische Vita sancti Cuthberti. S. 24-33.

1232 MiLdE: Bibliothekskatalog. S. 43.

1233 Vielleicht auch ein Schreibfehler Meisterlins.

1234 MiLDE: Bibliothekskatalog. S. 87-97.

1235 Liber Hymnorum: Michael LAPIDGE, »Bede the Poet», in: Lapidge, Anglo-Latin Literature 600-899, London 1996, S. 313-338, 508. Übersicht der Rekonstruktionsversuche: Walther BuLst, "Bedae Opera rhythmica?», in: Zeitschrift für deutsches Altertum und deutsche Literatur 89 (1958), S. 83-91. Liber Epigrammatum: BeRNT: Epigramm. S. 164-172. Michael LAPIDGE, "Some Remnants of Bede's Lost Liber Epigrammatum «, in: Lapidge, Anglo-Latin Literature 600-899 1996, S. 357-379, 510-512.

1236 Ähnliche Listen gibt es sonst noch aus Freising und Lorsch: MiLdE: Bibliothekskatalog. S. 106-109.

1237 So schon Geith/Berschin: »Bibliothekskataloge«. S. 62, Anm. 4.

1238 Lehmann (Hrsg.): MBK. 1, Nr. 49. Jeger: Bibliotheque de Geneve, Catalogue des manuscrits latins. S. 133-135. BIschо F: Katalog, 1. Nr. 1346. 
worden sein sollten, ist in der Tat unwahrscheinlich. ${ }^{1240}$ So wurde der Reichenauer Katalog dementsprechend wahrscheinlich für das befreundete Kloster Murbach als Bestandsverzeichnis erstellt, um eventuelle Lücken zu füllen. ${ }^{1241}$ Dieser Frage des Zweckes der Abschrift des Katalogs, der schon Lehmann nachgegangen ist, ${ }^{1242}$ kann hier nicht weiter behandelt werden. Bezüglich der Dichtung sei nur gesagt, dass abgesehen von zu erwartenden Parallelen keine bemerkenswerten Übereinstimmungen zwischen Murbach und der Reichenau, insbesondere in den rarissima, bestehen, die auf einen Austausch speziell solcher Texte hindeuten.

Die Großzahl der poetischen Werke befindet sich im Katalog in folgenden Kategorien:

\begin{tabular}{|c|c|c|}
\hline $\begin{array}{l}\text { Nummer, } \\
\text { Milde }\end{array}$ & Titel $^{1243}$ & Anmerkungen \\
\hline \multicolumn{3}{|c|}{ De poetis christianis } \\
\hline 277 & Iuvencus in quattuor ewangelia. & \\
\hline 278 & Sedulius similiter libri III. & $\begin{array}{l}\text { Aus dem Werk von fünf Büchern liegt } \\
\text { hier wahrscheinlich nur eine Auswahl } \\
\text { der das neue Testament betreffenden } \\
\text { Bücher vor. }\end{array}$ \\
\hline 279 & $\begin{array}{l}\text { Arator in actus apostolorum libri } \\
\text { II. }{ }^{1244}\end{array}$ & $\begin{array}{l}\text { Der Titel scheint, wegen der Angabe } \\
\text { der Buchzahl, durchaus ein einzelner } \\
\text { Band gewesen zu sein. }{ }^{1245} \text { Als solcher } \\
\text { lag er auch in St. Gallen vor (siehe dort } \\
\text { beim Hauptkatalog, Nr. 7., S. 100). }\end{array}$ \\
\hline
\end{tabular}

1239 Exemplarisch sei hier die Gebetsverbrüderung genannt: Uwe LudwIG, "Monastische Gebetsverbrüderung, Reichsteilung, Murbach und Weissenburg in ihren Gedenkbeziehungen zu St. Gallen und Reichenau", in: L'abbaye de Saint-Gall et l'Alsace au haut Moyen Âge, hrsg. von Jean-Luc Eichenlaub und Werner Vogler, Colmar 1997, S. 97-114.

1240 So teilt Murbach mit der Reichenau 161 Titel, aber nur 34 mit St. Gallen und 25 mit Lorsch (Bornert: »Saint-Léger de Murbach«. S. 120 f.). Siehe auch kurz hierzu: LeHMANN (Hrsg.): MBK. 1, S. 224.

1241 Dies wurde, wie die zahlreichen Parallelen zeigen, ohne Vergleich mit dem Murbacher Bestand bewerkstelligt, sodass der Katalog der Genfer Handschrift mehr als die in Murbach fehlenden Bände verzeichnet.

1242 LeHMANN (Hrsg.): MBK. 1, S. 241f. Ein numerischer Vergleich: BLoch: »BibliotheksKatalog«. S. 279.

1243 Abkürzungen aufgelöst nach MiLdE.

1244 Árpád Péter Orbán (Hrsg.), Aratoris Subdiaconi Historia apostolica (CCSL 130) 2006.

1245 Wohingegen ein größerer Sammelband vermutet bei: Lichт: »Aratoris fortuna. Aufgang und Überlieferung der Historia apostolica«. S. 171. Zu Arator-Sammelbänden siehe: ORBÁN (Hrsg.): Aratoris Historia. S. $17 \mathrm{f}$. 


\section{(Fortsetzung)}

\begin{tabular}{|c|c|c|}
\hline $\begin{array}{l}\text { Nummer, } \\
\text { Milde }\end{array}$ & Titel $^{1243}$ & Anmerkungen \\
\hline 280 & Paulinus de vita Felicis XII. & $\begin{array}{l}\text { Paulinus von Nola: Carmina Natalicia. } \\
\text { Auch im Katalog der Reichenau von } \\
821 / 822 \text {, siehe dort (S. 170) die Anmer- } \\
\text { kung zu Nr. } 20 .^{1246} \text { Die Handschrift } \\
\text { gehörte zur Klasse } \varepsilon \text {, wie man an der } \\
\text { Zahl der Bücher sehen kann, zusam- } \\
\text { men mit A (Mailand, Bibl. Ambr. C. } 74 \text {, } \\
\text { Dungals Vademecum). }\end{array}$ \\
\hline 281 & Eiusdem de vita Martini VI. & $\begin{array}{l}\text { Paulinus von Périgueux: Vita Marti- } \\
\text { ni. }{ }^{124} \text { Die zwei Paulini der beiden } \\
\text { Einträge werden fälschlich für einen } \\
\text { gehalten. Ebenfalls in Lorsch in einem } \\
\text { hagiographischen Sammelband vor- } \\
\text { handen. }{ }^{248}\end{array}$ \\
\hline 282 & Prosperi Epigramatum. ${ }^{1249}$ & \\
\hline 283 & Alchinii (!) Aviti in Genesim V. ${ }^{1250}$ & $\begin{array}{l}\text { Siehe zu Avitus bei St. Gallen (S. 100) } \\
\text { zum Hauptkatalog, Nr. } 8 .\end{array}$ \\
\hline 284 & Eiusdem ad sororem suam I. & \\
\hline 285 & Fortunati libri XI de diversis rebus. & Venantius Fortunatus: Carmina. ${ }^{1251}$ \\
\hline 286 & Eiusdem de vita Martini. ${ }^{1252}$ & $\begin{array}{l}\text { Fabricius fand im } 16 \text {. Jh. sowohl die } \\
\text { Carmina als auch die Vita in Murbach } \\
\text { vor und benutzte sie für seine Edition. } \\
\text { Die Carmina bestanden zu diesem } \\
\text { Zeitpunkt aus nur noch zwei Bü- } \\
\text { chern. }{ }^{1253}\end{array}$ \\
\hline 287 & $\begin{array}{l}\text { Prudencius de diversis rebus et di- } \\
\text { verso metro. }\end{array}$ & $\begin{array}{l}\text { Es handelt sich eher um die Kleindich- } \\
\text { tung des Prudentius (Cathemerinon, } \\
\text { Peristephanon), nicht um das gesamte } \\
\text { Werk. }{ }^{1254}\end{array}$ \\
\hline
\end{tabular}

1246 Dolveck (Hrsg.): Paulini Nolani carmina. S. 98, S. 114, Anm. 48.

1247 Labarre: "La transmission de Paulin de Périgueux». S. 128f.

1248 HäsE: Bücherverzeichnisse. Nr. 364.

1249 Horsting (Hrsg.): Prosper Aquitanus, Liber epigrammatum. S. 22.

1250 Peiper (Hrsg.): Alcimi Aviti Opera. S. 203-274. Das folgende Gedicht ad sororem S. 275279.

1251 Leo (Hrsg.): Venanti Honori opera poetica. S. 1-270.

1252 Ebd. S. 293-370.

1253 Georg FABRICIUS (Hrsg.), Poetarum veterum ecclesiasticorum opera Christiana, \&operum reliqiae atque fragmenta (...), Chemnitz 1564. Appendix, S. 56 B: Carminum variorum libri II. De divo Martino lib. 4. Da die Vita mit korrekt vier Büchern angegeben ist, glaube ich nicht, dass es sich bei den Carmina um zwei Bände handelt.

1254 Letzteres meint MiLDE: Bibliothekskatalog. S. 59. 


\section{(Fortsetzung)}

\begin{tabular}{|c|c|c|}
\hline $\begin{array}{l}\text { Nummer, } \\
\text { Milde }\end{array}$ & Titel $^{1243}$ & Anmerkungen \\
\hline 288 & $\begin{array}{l}\text { Metrum Cresconii. Siehe unten } \\
\text { S. } 204 .\end{array}$ & \\
\hline 289 & Metrum Althelmi. & $\begin{array}{l}\text { Als metrum wird das Carmen de virgi- } \\
\text { nitate }{ }^{1255} \text { auch in Lorsch und der Rei- } \\
\text { chenau bezeichnet. }\end{array}$ \\
\hline 290 & Bede in vitam Gudperti. & $\begin{array}{l}\text { Werner JAAGER (Hrsg.), Bedas metri- } \\
\text { sche Vita sancti Cuthberti, Leipzig } \\
\text { 1935. Zu dieser verlorenen Handschrift } \\
\text { siehe S. 24f. }\end{array}$ \\
\hline \multicolumn{3}{|c|}{ De poetis gentilium } \\
\hline 305 & Virgilius Bucolicon. & $\begin{array}{l}\text { Ähnlich umfangreiche Vergilsamm- } \\
\text { lungen wie die in Murbach gab es nur } \\
\text { auf der Reichenau und in Lorsch. }\end{array}$ \\
\hline 306 & Georgicon & \\
\hline 307 & Liber Eneydos & \\
\hline $308-315$ & $\begin{array}{l}\text { Eiusdem Dire; Culicis; Ethne; Copa; } \\
\text { Mecenas; Ciris; Catalepton; Pri- } \\
\text { apeya; Moretum. }\end{array}$ & $\begin{array}{l}\text { Appendix Vergiliana. Siehe unten } \\
\text { S. } 205 .\end{array}$ \\
\hline 316 & Lucanus libri X. Siehe unten S. 206. & \\
\hline 317 & Ovidius Naso libri epistolarum IV. & $\begin{array}{l}\text { Dies ist die früheste Nennung der } \\
\text { Epistulae ex Ponto. In den zeitgenös- } \\
\text { sischen Katalogen findet sich Ovid, mit } \\
\text { Ars Amatoria und Metamorphosen, } \\
\text { nur in der Liste einer unbekannten } \\
\text { Bibliothek (Reichenau? Konstanz?). }{ }^{1258} \\
\text { Im Florilegium Sangallense werden die } \\
\text { Epistulae ex Ponto nur aus Priscian } \\
\text { zitiert. }{ }^{1259} \text { Sie erscheinen erst wieder im } \\
\text { 11. Jh. }{ }^{1260}\end{array}$ \\
\hline 318 & Liber Lucrectii. Siehe unten S. $205 \mathrm{f}$. & \\
\hline 327 & $\begin{array}{l}\text { Bucolicon Olibrii. Siehe unten } \\
\text { S. } 210 .\end{array}$ & \\
\hline
\end{tabular}

1255 Ehwald (Hrsg.): Aldhelmi Opera. S. 50-47.

1256 HäsE: Bücherverzeichnisse. Nr. 336, Reichenau, Hauptkatalog, Nr. 6.

1257 Manitius: Handschriften antiker Autoren in mittelalterlichen Bibliothekskatalogen. S. 47.

1258 Stuttgart, Württembergische Landesbibliothek, Cod. Don. 191 (olim Fürstenbergische Hofbibliothek Donaueschingen), f. 160v-163v. Siehe zur Reichenau, S. 177-179.

1259 BUtTERFIELD: »Florilegium Sangallense«. S. 350. STEPHAN: »Florilegium 870«. S. $266 \mathrm{f}$.

1260 Reynolds: Texts and transmission. S. 263. 
(Fortsetzung)

\begin{tabular}{|c|c|c|}
\hline $\begin{array}{l}\text { Nummer, } \\
\text { Milde }\end{array}$ & Titel $^{1243}$ & Anmerkungen \\
\hline 328 & $\begin{array}{l}\text { Metrum Quinti Sereni de medi- } \\
\text { cina. }{ }^{1261}\end{array}$ & $\begin{array}{l}\text { Eine Version mit LXX capitula fand } \\
\text { sich auf der Reichenau und in St. Gallen } \\
\text { (Zürich, C. 78, siehe S. 141). }\end{array}$ \\
\hline 329 & $\begin{array}{l}\text { Metrum fabularum Aviani } \\
\text { poete. }{ }^{1262}\end{array}$ & \\
\hline 330 & Enigmata Simphosii. ${ }^{1263}$ & \\
\hline
\end{tabular}

Die Kategorien des Murbacher Katalogs, in die die Dichtung eingeordnet wird, sind eine kanongeschichtliche Neuerung: Überall sonst ist der Großteil der Dichtung, nämlich insofern sie sich nicht an bedeutende Namen mit genügend vorhandenen Bänden anschloss, in die Abteilung für Grammatik eingereiht: ${ }^{1264}$ De libris Prisciani (Reichenau), De libris grammaticae artis (St. Gallen), ${ }^{1265} \mathrm{De}$ arte gramatica (Passau), ${ }^{1266}$ Gramatici (Lorsch). ${ }^{1267}$ In Murbach ging man einen anderen Weg: Hier sind die Dichter größtenteils unter De poetis christianis und De poetis gentilium versammelt. ${ }^{1268}$ Dies kann nicht nur durch die außerordentliche Zahl der Dichterbände verursacht worden sein, die die Anlage einer neuen, übersichtlicheren Kategorie nahegelegt hätte, denn die Reichenau hat noch mehr Handschriften dieses Typs, ordnet sie jedoch konventionell. Die Murbacher Kategorien bewahren zudem Indizien der älteren, konventionellen Ordnung und der anschließenden Neuordnung der Bibliothek: So befinden sich noch drei Schriften zur Orthographie (Nr. 323-325) unter den heidnischen Dichtern und mehrere Grammatiken unter den Prosaklassikern (Kategorie secuntur gentiles, Nr. 297-304). Indizien einer auf Dichtung zielenden Neuordnung, im Gegensatz zu einer bloßen Umetikettierung der angeschwollenen Grammatikkategorie, finden sich ebenfalls in einigen Titeln, die auch an anderen Stellen der Bibliothek hätten Platz finden können, aber hier ihrer Gattung wegen in die Dichtung eingereiht wurden: Prospers Epigramme (Nr. 282) und Bedas

1261 Vollmer (Hrsg.): Liber medicinalis. Zum Katalog S. VII.

1262 Guaglianone (Hrsg.): Aviani Fabulae. Manitius: Handschriften antiker Autoren in mittelalterlichen Bibliothekskatalogen. S. 234-236.

1263 GlORIE (Hrsg.): Collectiones aenigmatum. S. 621-672.

1264 GLAUCHE: Schullektüre. S. 23-30.

1265 Jedoch vorher die christlichen Dichter unter De metris: LeHMANn (Hrsg.): MBK. 1, S. 81-82.

1266 Christine E. Ineichen-Eder und Bernhard Bischoff (Hrsg.), Mittelalterliche Bibliothekskataloge Deutschlands und der Schweiz, 4, 1: Bistümer Passau und Regensburg, München 1977. S. 24-26.

1267 HÄsE: Bücherverzeichnisse. S. 164, Z. 16. Der Lorscher Katalog hat jedoch auch Dichtung im Verbund an anderen Stellen.

1268 MiLDE: Bibliothekskatalog. S. 47. Weitere ungewöhnliche Kategorien sind De historiis und secuntur gentiles. 
Vita Cuthberti (Nr. 290) sind hier als Duplikate (vgl. Nr. 209 und 191) nicht in die Abteilungen ihrer Verfasser eingereiht. Der naheliegende Grund für die ungewöhnliche Ordnung der Murbacher Bibliothek scheint folgender zu sein: Eine ursprüngliche Abteilung von Grammatiken (als Grundausstattung der Bibliothek) ${ }^{1269}$ erfuhr über die Jahre einen großen Zuwachs an Schriften, die mit der Schule assoziiert waren und es in anderen Bibliotheken noch sind, namentlich heidnische und christliche Dichter, ${ }^{1270}$ sowie klassische Prosaschriftsteller (vor allem Historiker) ${ }^{1271}$. Als diese Erweiterungen endlich den alten grammatischen Bestand um ein Vielfaches überwogen (43 Titel gegen 10 grammatische) spaltete man die Kategorie in drei neue, zwei poetische, eine gentiles, wobei man die älteren grammatischen Titel ziellos mit einsortierte. Dass die poetischen Kategorien anschließend eine eigene Anziehungskraft entwickelten, sieht man an der Einordnung der Duplikate Bedas und Prospers dorthin, anstatt in die Abteilungen ihrer Autoren. ${ }^{1272}$

Widmen wir uns nun einigen hervorragenden Titeln der Murbacher Bibliothek zu. Unter den christlichen Dichtern sticht nur einer hervor, der scheinbar fehl am Platze wirkt: Cresconius Corippus (Nr. 288: Metrum Cresconii), der spätantike Dichter der libyschen Kriege und des Loblieds auf Justin II. ${ }^{1273}$ Es ist jedoch keines der beiden Werke gemeint, wie Milde annimmt, ${ }^{1274}$ sondern wahrscheinlich eine verlorene Evangeliendichtung, deren ähnlicher, aber vollständiger Eintrag in Lorsch lautet: Metrum Cresconii in evangelia, liber I. ${ }^{1275}$ Ein Austausch dieser Rarität ${ }^{1276}$ zwischen Murbach und Lorsch ist naheliegend. ${ }^{1277}$

1269 Die einzige aus Murbach erhaltene Grammatik ist noch insular geschrieben: Bernhard BISCHоғF, "Über gefaltete Handschriften, vornehmlich hagiographischen Inhalts«, in: Bischoff, Mittelalterliche Studien, 1, 1966, S. 95-100. S. 97. Weitere Handschriften insularen Charakters: BORNERT: »Saint-Léger de Murbach«. S. 134f.

1270 Eine schulische Verwendung derselben wird auch in den Juvencus-Glossen des Glossars Iunius A von Oxford, Bodl. Libr., Ms. Jun. 25, f. 158-193 reflektiert (speziell f. 168v-169v; dieser Teil der Handschrift: „Wahrscheinlich Bodenseegebiet«, Bischoff Kat. Nr. 3808).

1271 Dass diese (Livius, Nr. 291; Pompeius Trogus, Nr. 292, Historia Augusta, Nr. 293, Sallust Nr. 321, 322) ursprünglich bei der Grammatik standen, ist dadurch bewiesen, dass sie nicht in der wahrscheinlich älteren Abteilung De historiis (christliche Geschichte) eingeordnet sind, sondern unter gentiles und poetis gentilium.

1272 Sofern diese nicht schon vorher bei den Grammatiken standen.

1273 James Diggle und Francis Richard David Goodyear (Hrsg.), Flavii Cresconii Corippi Iohannidos sev de bellis Libycis libri VIII, Cambridge 1970. Serge AnTÈs (Hrsg.), Corippus: Éloge de l'empereur Justin II (Collection des universités de France), Paris 1981. Josef PARTsCH (Hrsg.), Corippi Africani Grammatici Libri qui supersunt (MGH AA, 3,2), Berlin 1879.

1274 MiLdE: Bibliothekskatalog. S. 59, Nr. 288.

1275 HäsE: Bücherverzeichnisse. Ca 427, S. 165, Z. 22f., S. 315 f. Zur Frage der Identität des Cresconius: Heinz HofmanN, "Corippus as a patristic author ", in: Vigiliae christianae XLIII (1989), S. 361-377. Insb. S. $371 \mathrm{f}$. 
Unter den Werken Vergils, die in Murbach vollständig vorliegen, hat besonders die Appendix Vergiliana (Nr. 308-315), die hier zum ersten Mal in ihrer kanonischen Form enummeriert wird, die Aufmerksamkeit der Philologen auf sich gezogen. ${ }^{1278}$ Die Inhaltsangabe im Katalog geht über die bei Servius genannten Jugendwerke hinaus und ist noch heute Grundlage der Editionen. ${ }^{1279}$ Der Murbacher Kodex, der die Texte enthielt, scheint selbst jedoch kaum auf die Tradition gewirkt zu haben: Die erhaltenen Handschriften spiegeln nicht die Anordnung der Inhaltsangabe wider. ${ }^{1280}$ In jedem Fall ist der verlorene Murbacensis ein Zeugnis der über praktische Bedürfnisse hinausgehenden Interessen der Murbacher Bibliothekare. Woher dieses äußerst seltene Werk bezogen wurde, ist unklar; auf der Reichenau zumindest erkundigt sich Walahfrid bei seinem Korrespondenten Prudentius von Troyes nach Vergils Carmina minora, ${ }^{1281}$ und eine Vermittlung über diesen Weg erscheint nicht als ausgeschlossen.

Diese spielten auch bei der Erhaltung eines weiteren äußerst seltenen Werkes eine Rolle: Murbach besaß eine Handschrift des Lehrgedichts des Lukrez (Nr. 318), das sonst in nur zwei zeitgenössischen Handschriften erhalten ist, ${ }^{1282}$ jedoch um den Bodensee herum bekannt gewesen zu sein scheint, wie Zitate nahelegen. ${ }^{1283}$ Die Textgeschichte des Lukrez wirft jedoch Licht auf den Murbacensis, da seine Textgestalt uns durch die Abschrift Poggios über die daraus abgeleiteten recentiores erhalten geblieben ist. ${ }^{1284}$ Der Murbacensis stammt

1276 Zur gefährlich dünnen Überlieferung des Werkes siehe: Heinz HofmanN, »Überlegungen zu einer Theorie der nichtchristlichen Epik der lateinischen Spätantike«, in: Philologus 132, 1-2 (1988), S. 101-159. S. 112f. Das Werk war jedoch, gerade an höchster Stelle, nicht unbekannt: SCHALLER: »Frühkarolingische Corippus-Rezeption«.

1277 Zum kulturellen (hier: annalistischen) Austausch der beiden Klöster: Helmut Reimitz, History, Frankish identity and the framing of Western ethnicity, 550-850 (Cambridge studies in medieval life and thought 101), Cambridge 2015. S. 361, 393f.

1278 Fabian ZogG, "Die Appendix Vergiliana avant la lettre: Martial, Donat, Servius und der Murbach-Katalog zu Vergils angeblichen Jugendwerken", in: Antike und Abendland 62 (2016), S. 74-85. John A. Richmond, "Quaeritur quomodo Appendicis Vergilianae poemata in unum convenerint", in: Rivista di filologia e di istruzione classica CIV (1976), S. 26-30. Generell zur Überlieferung: ReYnolDs: Texts and transmission. S. 437-439. Siehe auch S. 100 zum Reichenauer Hauptkatalog, Nr. 25.

1279 Zogg: "Appendix Vergiliana«. S. 82f.; S. 80: Servius: Ciris, Aetna, Culex, Priapeia, Catalepton, Epigrammata, Copa, Diras; in Murbach zusätzlich: Maecenas, Moretum (die Epigrammata fehlen).

1280 Reynolds: Texts and transmission. S. 437.

1281 Siehe genauer hierzu die S. 170 zur Reichenau, Hauptkatalog, Nr. 25.

1282 Cyril BaIley (Hrsg.), Titi Lucreti Cari De rerum natura libri sex. Ed. with prolegomena, critical apparatus, translation, and commentary. Reprint, Oxford [u.a.] 1986. BUTTERFIELD: Textual history of Lucretius. Handschriften und Stemma: S. 32. BRUNHöLzL: »Zur Überlieferung des Lukrez«.

1283 Reynolds: Texts and transmission. S. 219f. Zu den Zitaten siehe auch S. 107 zu Micos Opus Prosodiacum.

1284 Butterfield: Textual history of Lucretius. S. 28-33. 
demnach vom Codex Vossianus Oblongus in dessen zweiter Glossierungsstufe (s. IX) ab. ${ }^{1285}$ Der Oblongus wird immer wieder mit dem Hof Karls des Großen in Verbindung gebracht ${ }^{1286}$ - eine würdige Aufbewahrungsstätte für einen so seltenen und kostbaren Text. ${ }^{1287}$ Diese Herkunft des Murbacensis illustriert sowohl die besten Beziehungen, die Murbach zu höchsten Stellen genoss, als auch die Mühe, die man auf die Ergänzung der Bibliothek mit seltenen Titeln verwendete. In diesem Zusammenhang ist auch auf die Lucanus libri X (Nr. 316) des Katalogs hinzuweisen: ${ }^{1288}$ Lukan, obwohl in einigen westfränkischen Handschriften erhalten, ${ }^{1289}$ ist im Ostfrankenreich nur in Murbach und Lorsch ${ }^{1290}$ vorhanden, wobei wieder die Hofbibliothek der Nexus zu sein scheint.

Das im Katalog sich anschließende Breviarium librorum Isghteri (!) Abbatis bietet wenig Neues; es liegt in ihm ein Auszug aus der umfangreicheren Neukatalogisierung unter Abt Iskar vor (obmissis his qui in registro continentur pro parte). ${ }^{1291}$ Diese Überschrift legt nahe, dass es sich nicht um einen Katalog der Privatbibliothek Iskars handelt, ${ }^{1292}$ wie ähnlich von Hartmut und Grimald (St. Gallen) und Erlebald (Reichenau) überliefert. ${ }^{1293}$ Für die Abschrift der kurzen Liste einer Privatbibliothek würde sich der Schreiber kaum die Mühe gemacht haben, das umfangreiche registrum auf Duplikate durchzusehen. Und eine

1285 Ebd. S. 35. Voss. Oblongus: Leiden Ms. Voss. Lat. F. 30.

$1286 \mathrm{Ob}$ er dort entstanden ist oder nur korrigiert wurde, bleibt unklar: Ebd. S. 7. Bischoff: »Irische Schreiber«. S. 42. Bernhard BischоFF, »Das geistige Leben (Kat. Nr. 341-364)«, in: Karl der Große. Werk und Wirkung, hrsg. von Wolfgang Braunfels, Aachen 1965, S. 188205. S. 202f. Ferrari: »In Papia conveniant ad Dungalum«. S. 38, Anm. 3 (»scuola palatina«, "come il Pr. Bischoff gentilmente conferma«).

1287 Vgl. die Bücherliste aus Hofnähe, Ed. Bischoff: „Die Hofbibliothek Karls des Großen«. S. 165f. Raymund Коттје, „Ein Zeugnis für die Hofbibliothek Karls des Großen?: Zu Inhalt und Herkunft der Bücherliste in der Hs. Berlin, SBB-PK Ms.Diez.B Sant. 66.«, in: Annalen des Historischen Vereins für den Niederrhein 212 (2009), S. 45-49. Doris HABERL, "Die Hofbibliothek Karls des Großen als Kristallisationspunkt der karolingischen Renaissance: Geschichte, Umfeld, Wirkungen «, in: Perspektive Bibliothek 3 (2014), S. 111-139.

1288 Wohl kaum Wolfenbüttel, HAB, Cod. Guelf. 41.1 Aug. $2^{\circ}$ (s. XII, fälschlich s. VIII-IX bei BORNERT: »Saint-Léger de Murbach«. S. 132). Die Handschrift könnte jedoch durchaus eine Abschrift des Murbacher Lukan sein.

1289 GoтоғF: The Transmission of the Text of Lucan in the Ninth Century. S. 11-26. Siehe auch Manitius: Handschriften antiker Autoren in mittelalterlichen Bibliothekskatalogen. S. $117 f$.

1290 HÄSE: Bücherverzeichnisse. Nr. 344, Ca 406.

1291 »Ausgelassen was schon im Register enthalten ist«. Von Iskar ist kaum mehr als sein Katalog bekannt: BORNERT: "Saint-Léger de Murbach«. S. 164. BRUCKNER: »Abtreihe«. S. 34, 55. Walahfrid richtete ein Gedicht an ihn, als er noch nicht Abt von Murbach war: Berschin/Licht: »Metrorum iure peritus«. S. 371f. Zum Hergang der Kürzung des Katalogs: GeITH/Berschin: »Bibliothekskataloge«. S. 85-87.

1292 Wofür ihn MiLde: Bibliothekskatalog. S. 12, und Вцосн: »Bibliotheks-Katalog». S. 274, halten.

1293 Lehmann (Hrsg.): MBK. 1, S. 86-89, 253. 
derartig lange Liste, die den Aufwand des Vergleichs rechtfertigte, wird nicht das Verzeichnis einer Privatbibliothek gewesen sein - hat doch die Bibliothek des sehr viel prominenteren Grimalds nur um die 40 Titel aufzuweisen (gegenüber den 54 der gekürzten Liste Iskars). Das Breviarium, wie es uns erhalten ist, verzeichnet vielmehr die bis zu Iskar erfolgten Neuzugänge der Bibliothek und ist ein Zeugnis des auch später nicht ermatteten Interesses an Dichtung. Von den Dopplungen abgesehen ${ }^{1294}$ - sofern man darin keine erneuten Kopien sehen will - sind zwei Neuzugänge zu vermerken. Der Martianus Capella ist eine Ergänzung des ansonsten weit verbreiteten Werkes, ${ }^{1295}$ das der Murbacher Bibliothek nicht fehlen durfte. ${ }^{1296}$ Überlieferungsgeschichtlich bedeutender ist der Eintrag zu den versus Theodolfi volumen $I .{ }^{1297}$ Die genaue Interpretation des Katalogs ist hier unklar - Nr. 21-24 könnten durchaus einen Band gebildet haben: de compoto Astrolabio | de gramatica Foci | et Arati | et versus Theo|dolfi volumen I stehen untereinander. Die Verbindung mit et kommt noch bei Nr. 2627, 35-36, 40-41 vor. ${ }^{1298}$

Von Theodulfs Gedichten sind keine vollständigen Sammlungen erhalten; die Werke des Dichters sind vielmehr über zahlreiche Handschriften verschiedenen Charakters zerstreut. ${ }^{1299}$ Die Überlieferung bewahrt uns jedoch Spuren von mehreren Theodulf gewidmeten Anthologien.

1. Die Handschrift, die der Ausgabe Sirmonds (1646) zugrunde lag, zu der ihr Herausgeber jedoch nur verstreute und unklare Angaben macht. ${ }^{1300}$ Es scheint, dass Sirmond eine Haupthandschrift durch gelegentliche Heranziehung anderer Kodizes ergänzt hat. ${ }^{1301}$ So hat er zumindest die Paraenesis ad Iudices aus einem Codex Petavianus ergänzt (S. 278). An anderen Stellen nimmt er jedoch Bezug auf eine einzelne Handschrift (S. 284, 296). Es ist nicht klar, ob diese mit der Handschrift aus Haute-Seille (Alta Silva, S. 278) identisch ist.

1294 Die Nummern 318 (Lukrez), 329 (Fabeln) kommen in beiden Katalogen vor. Bei Nr. 23 (»Arati«) ist unklar, ob es sich um einen astronomischen Kommentar oder um das Lehrgedicht in Prosa- oder metrischer Übersetzung handelt (GeITH/Berschin: »Bibliothekskataloge«. S. 76).

1295 Vgl. PrÉAux: »Les manuscrits principaux du >De nuptiis Philologiae et Mercurii< de Martianus Capella«. S. 78-80.

1296 Geith/Berschin: »Bibliothekskataloge«. Nr. 53. Eine Übersicht nur der bedeutendsten Handschriften: James Willis (Hrsg.), Martianus Capella: De nuptiis Philologiae et Mercurii, Stuttgart 1983. S. XII-XVI. LeONARDI: »I codici di Marziano Capella«.

1297 Geith/Berschin: »Bibliothekskataloge«. Nr. 24, siehe auch S. 24.

1298 Nr. 26-27 von BERsCHin als ein Band angesehen.

1299 SCHALLER: "Gedichte Theodulfs«. S. 15-29. DüMmLER: "Die handschriftliche Überlieferungu. S. 241-250.

1300 Jacques Sirmond (Hrsg.), Theodulfi Aurelianensis episcopi opera, Paris 1646. Angaben zu mss. S. 275, 278, 284, 294, 296, 303.

1301 SCHALlER: »Gedichte Theodulfs«. S. 19. 
2. Mabillon ${ }^{1302}$ nimmt auf eine weitere Handschrift aus Saint-Vanne Bezug, die die gleichen Gedichte wie Sirmonds Handschrift und darüber hinaus weitere enthalten habe.

$\mathrm{Zu}$ diesen zwei Handschriften können wir auch die aus Murbach dokumentierte hinzuzählen. Wie gelangte Murbach nun zu dieser Theodulf-Anthologie, ohne selbst mit Theodulf in einem besonderen Verhältnis zu stehen? Zwei Vermittlungswege bieten sich an: Die Provenienz der zwei verlorenen Handschriften aus nach-karolingischen Klöstern Frankreichs lässt eine westfränkische Herkunft der Sammlungen vermuten. Die enge Verbindung Murbachs zum Hof, die sich überlieferungsgeschichtlich auch, wie oben gesagt, bei Lukrez und Lukan vermuten lässt, könnte auch bei der Vermittlung Theodulfs eine Rolle gespielt haben. Andererseits sind Theodulfs Gedichte auch in St. Gallen und Lorsch bekannt. Aus St. Gallen überliefern gleich drei Handschriften eine Handvoll Verse Theodulfs, manchmal sogar unter ähnlichen, wenn auch allgemeinen Titeln wie der Murbacher Katalogeintrag. ${ }^{1303}$ Hinzu kommt der unklare Inhalt einer verlorenen Lorscher Handschrift (Versus Theodolfi ad Moduinum et Moduinus ad Theodolfo (!) in quaternionibus V.). ${ }^{1304}$ Eine Entscheidung zwischen diesen beiden Überlieferungswegen ist kaum mehr möglich, auch wenn der Weg aus Westfranken über Murbach nach St. Gallen plausibler erscheint.

Vom Reichtum der Murbacher Bibliothek ist wenig und von der Dichtung noch weniger geblieben. Nur noch zwei Handschriften sind uns als Zeugnisse der einstmals großen Sammlung erhalten. Einsiedeln, StB, Ms. 266 (1296), p. 177224, wurde erst kürzlich von Stover, dem ich hier folge, überzeugend nach Murbach verortet, während die Handschrift vorher nur allgemein ins Bodenseegebiet verwiesen wurde. ${ }^{1305}$ Nur das Argument bezüglich der Identifikation der Handschrift mit einem Titel des Katalogs kann nicht im engeren Sinne aufrecht erhalten werden. Die Handschrift besteht aus drei von ursprünglich

1302 Jean Mabillon, Veterum analectorum tomus I, Paris 1675. S. $384 \mathrm{f}$.

1303 Cod. Sang. 899, p. 120: Versus Theotolfi episcopi; Cod. Sang. 197, p. 289 Versus Thietholfi episcopi; Cod. Sang. 263, pp. 201-219: Epistola Theodulfi etc.

1304 HäsE: Bücherverzeichnisse. Nr. 416. A99. Die Handschrift muss in fünf Quaternionen mehr enthalten haben, als nur die (erhaltenen) Modoin-Gedichte.

1305 STOVER: "Einsiedeln Eclogues«. Zur Lokalisierung insb. S. 297-296. »Bodenseegebiet«: Bischoff: Katalog, 1. Nr. 1125. »St. Gallen/Einsiedeln« ohne Differenzierung der kodikologischen Einheiten: Odo LANG, »Einsiedeln, Stiftsbibliothek, Codex 266(1296)« (900), https://www.e-codices.ch/en/list/one/sbe/0266 (abgerufen am 13.07.2018). »Einsiedeln?«: FERRARI: Liber sanctae crucis. S. 427. StOvers Argument stützt sich auf folgende Grundlagen: 1. Paläographie (ein unidentifiziertes Skriptorium des Elsass oder Bodenseeareals) 2. Bibliotheksgeschichte (eine herausragende Sammlung auch seltener Texte) 2. Assoziation enthaltener Texte mit Murbacher Eigenheiten (z.B. Orientierung an Cassiodor, "Liber Notarum») 3. Identifizierung der Carmina Einsidlensia mit dem Bucolicon olibrij des Katalogs. 
sieben Lagen (V-[VII]; pp. 192, 208, [224]), die später beschnitten und mit den weiteren Teilen der Handschrift zusammengebunden wurden. Ob auf die Lage VII noch weitere Lagen folgten und ob somit die Sammlung der HrabanusGedichte umfangreicher war, ist unklar. ${ }^{1306}$ Der starke Abrieb auf p. 224 zeigt jedoch, dass dieses Blatt lange Zeit die Außenseite der Handschrift bildete. Die thematischen Abschnitte der Handschrift sind lagenübergreifend geschrieben:

\begin{tabular}{|c|c|}
\hline pp. & Inhalt \\
\hline $\begin{array}{l}177- \\
96\end{array}$ & $\begin{array}{l}\text { Gekürzte Fassung des "Seven-Book Computus« von } 809 ;^{1307} \text { Lagenverlust } \\
\text { vorher. Eine vollständige Handschrift des Computus stammt vielleicht aus } \\
\text { Murbach. }{ }^{1308}\end{array}$ \\
\hline $\begin{array}{l}196- \\
202\end{array}$ & $\begin{array}{l}\text { Verschiedene Texte zu Maßen und Gewichten. }{ }^{1309} \text { Das Florilegium mit dem } \\
\text { vorherigen Computus auch in anderen Handschriften überliefert. }\end{array}$ \\
\hline $\begin{array}{ll}202- \\
203\end{array}$ & $\begin{array}{l}\text { Dicta philosophorum. }{ }^{1310} \text { Mit Begleittexten ebenso enthalten in Cod. Sang. 899, } \\
\text { p. 132, wohl aus gemeinsamer (entfernter) Vorlage. } .^{1311}\end{array}$ \\
\hline $\begin{array}{l}204- \\
205\end{array}$ & Auszüge aus Cassiodor, Institutiones. \\
\hline $\begin{array}{l}206- \\
207\end{array}$ & Carmina Einsidlensia. ${ }^{1312}$ Siehe unten S. 210. \\
\hline $\begin{array}{l}208- \\
224\end{array}$ & Hrabanus Maurus, Carmina. Siehe unten S. 211-215. \\
\hline
\end{tabular}

Dieses ungewöhnliche Ensemble scheint dennoch planvoll zusammengestellt und niedergeschrieben worden zu sein. ${ }^{1313}$ Es lassen sich jedoch auch merkliche paläographische Brüche zwischen einigen Texteinheiten nicht leugnen (p. 202, 208), die dem Augenschein nach nicht den Schreiber, aber wohl die Arbeits-

1306 Ebenso FerRari: Liber sanctae crucis. S. 426. Die Lagen I-IV enthielten wahrscheinlich eine gekürzte Version des Computus: Stover: „Einsiedeln Eclogues«. S. 292.

1307 Zum Computus: Eric M RAMíREZ-WEAVER, "Carolingian innovation and observation in the paintings and star catalogs of Madrid, Biblioteca Nacional, Ms. 3307. Diss.", Ann Arbor, Michigan 2008. R. W. HunT, "An investigation of some astronomical excerpts from Pliny's Natural History found in manuscripts of the earlier Middle Ages. Diss.", University of Oxford 1969. S. 28-53. Ramírez-WeAver zitiert nach: STOVER: »Einsiedeln Eclogues«. S. 292, Anm. 19.

1308 StOver: »Einsiedeln Eclogues«. S. 293.

1309 Ebd. S. 292.

1310 Birger MUNK OLSEN, »Les classiques latins dans les florilèges médiévaux antérieurs au XIII siècle, II«, in: Revue d'histoire des textes X (1980), S. 115-164. Nr. 90, zu p. 132.

1311 STOVER: »Einsiedeln Eclogues«. S. $292 \mathrm{f}$.

1312 Riese/Bücheler (Hrsg.): Anthologia latina. Nr. 725, 726. Jaqueline Amat (Hrsg.), Consolation à Livie, Élégies à Mécène, Bucoliques d’Einsiedeln (Les Belles Lettres) 1997.

1313 StOVER: „Einsiedeln Eclogues«. S. 293. 
vorgänge betreffen. ${ }^{1314}$ Die Verortung in Murbach ergibt sich, neben dem paläographischen Befund, aus der Überlieferungsgeschichte der nicht poetischen Texte. Darüber hinaus lässt sich der Katalogeintrag Bucolicon olibrij (Nr. 327) mit der Handschrift in Verbindung bringen. ${ }^{1315} \mathrm{Zu}$ Stovers Vermutung, dass das Bucolicon mit dem im Katalog folgenden Gedicht des Quintus Serenus zur Heilkunde (Nr. 328) in einem Band vereint war, besteht keine Veranlassung. ${ }^{1316}$ Die Handschrift, die dann ohnehin nur eine Abschrift, nicht der verzeichnete Titel selbst wäre, ${ }^{1317}$ zeigt keine Spuren davon. Ebenfalls stehen die medizinischen Schriften nicht zwischen Quintus Serenus und dem Liber notarum (Nr. 335), sondern es finden sich noch Avian ${ }^{1318}$ und Symphosius (Nr. 329, 330) dazwischen, sodass hier keine Einschaltung anderer Bücher bei der Katalogisierung einer einzelnen Handschrift vorliegt. ${ }^{1319}$ Der Bibliothekar ist bei Erstellung des Katalogs nicht topically vorgegangen, sondern entlang der Bücher, wie sie in der Bibliothek standen. Der Identifizierung des Eintrags zum Bucolicon mit der Handschrift selbst stehen weitere Gründe entgegen: 1. In der Handschrift liegt der Titel überhaupt nicht vor (er wurde vielleicht beschnitten) ${ }^{1320} .2$. Selbst wenn er vorgelegen hätte, wäre das Buch nach seinem Hauptteil computus ${ }^{1321}$ oder ähnlich genannt worden und 3. bei anderen komputistischen Schriften wie Nr. 196-197 oder 251-252 eingeordnet worden. ${ }^{1322}$ Die Handschrift selbst ist somit nicht mit dem Eintrag zu identifizieren. Die Herkunft der Handschrift aus Murbach sowie die Identität von Bucolicon olibrij und Carmina Einsidlensia bleiben hiervon unberührt. Der Katalogeintrag scheint vielmehr ein kleines Heft von Bukolika gewesen zu sein; welches Material es noch enthielt, ist unklar. Es erscheint jedoch nicht als unwahrscheinlich, dass das katalogisierte Heft mehr Eklogen enthielt, als nur die zwei in der Handschrift überlieferten. Denn warum

1314 FerRARI: Liber sanctae crucis. S. 429. Anders Stephan Lösch, Die Einsiedler-Gedichte: eine literar-historische Untersuchung, Tübingen 1909. S. 9, der mehrere Schreiber ausmacht, ohne einen genaueren Beweis zu führen.

1315 STOVER: »Einsiedeln Eclogues«. S. $294 \mathrm{f}$.

1316 Ebd. S. 295: »The cataloguer was proceeding topically, and it seems the Bucolicon Olybrii was contained in the same manuscript as Serenus' poetic De medicina praecepta. Hence he inserted the few medical works that Murbach possessed between the Bucolicon and the Liber notarum, which at any rate defied easy categorization."

1317 So auch Ebd. S. 296: »the most economical solution is that they are one and the same, or rather, that the latter [Carmina Einsidlensia] is part of the former [Bucolicon olibrij].»

1318 Ebenfalls im Iskar-Katalog (Nr. 40, 41) ausführlicher verzeichnet (Fabula Aviani et Esopi et Phedri et Allexandri et Didimi).

1319 Denn die Carmina Einsidlensia sind nur ein Teil von Einsiedeln, Ms. 266, und hätten, wenn wir STOVER folgen, separat katalogisiert werden müssen.

1320 Es lassen sich am Kopf der Seite noch die Namen der Unterredner ausmachen: Thamyras Ladas Midas. Ob darüber noch Platz für eine Überschrift war, ist fragwürdig.

1321 Computus-Handschriften im Katalog zusammengefasst bei BORNERT: „Saint-Léger de Murbach«. S. 147.

1322 Eine eigene Kategorie hierzu fehlt im registrum. 
sollte sonst in Ms. 266 der ungewöhnliche, nicht aus dem Text hervorgehende Titel fehlen, den die Handschrift getragen haben muss? Die katalogisierte Handschrift hatte also wenigstens zusätzlich noch den Titel der Handschrift und vielleicht ein darauf folgendes Gedicht. Ms. 266 ist demzufolge ein Auszug daraus.

Auf die zwei Eklogen folgen die Carmina Hrabani ${ }^{1323}$ - die einzige erhaltene Sammlung von Gedichten des Mainzer Erzbischofs. Die Verse sind platzsparend ohne Zeilenumbrüche für die Verse geschrieben worden. Dümmler nimmt einige geringfügige Änderungen gegenüber der Sequenz der Handschrift vor. ${ }^{1324}$ Nur Brouwers Ausgabe einer Fuldaer Handschrift gibt dieselbe Abfolge der Gedichte wie unsere Handschrift. ${ }^{1325}$

\begin{tabular}{|l|l|l|l|}
\hline p. & Incipit & Titel & $\begin{array}{l}\text { Ed. (D = Ed. } \\
\text { Dümmler, } \\
\text { MGH Poet. 2) }\end{array}$ \\
\hline 208 & $\begin{array}{l}\text { Pontificalis } \\
\text { apex }\end{array}$ & Ad Paschalem papam & D VII \\
\cline { 2 - 4 } & $\begin{array}{l}\text { Sedis aposto- } \\
\text { lice princeps }\end{array}$ & $\begin{array}{l}\text { Ad gregorium papam de libro sce crucis sancti } \\
\text { Petro directo }\end{array}$ & D I, iii \\
\hline 209 & $\begin{array}{l}\text { Praesul } \\
\text { amate Deo }\end{array}$ & $\begin{array}{l}\text { Versus Mauri ex persona Albini magistri sui de } \\
\text { libro sce crucis ad sanctum Martinum directo } \\
{[\ldots]}\end{array}$ & D I, iv \\
\cline { 2 - 5 } & $\begin{array}{l}\text { Sit longaevus } \\
\text { amor }\end{array}$ & Ad Gerfridum eoiscopum & D VIII \\
\hline 210 & $\begin{array}{l}\text { Omnipotens } \\
\text { genitor }\end{array}$ & "Oratio Mauri ad Deum« (B S.6) $)^{1326}$ & D IX \\
\hline 211 & $\begin{array}{l}\text { Salve fidus } \\
\text { amor }\end{array}$ & "Versus ad amicum« (B S.7) & D X \\
\cline { 2 - 5 } & $\begin{array}{l}\text { Vade libens } \\
\text { karta }\end{array}$ & Ad Baturicum episcopum ex persona Isanberti & D XI \\
\hline \multirow{2}{2}{212} & $\begin{array}{l}\text { O deus } \\
\text { aeterne }\end{array}$ & "Oratio ad Deum« (B S.9) & D XII \\
\cline { 2 - 4 } & $\begin{array}{l}\text { Antistes do- } \\
\text { mini meritis }\end{array}$ & "Ad praeclarum episcopum« (B S.10) & D XIII \\
\hline
\end{tabular}

1323 DÜMmLER: "Die handschriftliche Überlieferung«. S. 288-292. DüMMLER (Hrsg.): MGH Poet. lat. 2. S. 157 f. Aus einer verlorenen Fuldaer Handschrift ediert in BRouwER (Hrsg.): Hrabani Poemata.

1324 Er folgt grundsätzlich Brouwers Reihenfolge, fügt jedoch an vielen Stellen thematisch passende Gedichte aus anderen Handschriften ein.

1325 Korrekte Inhaltsangabe nur bei DüMMLER: »Die handschriftliche Überlieferung». a.a.O. Diese fehlt auch in den modernen Katalogen (bei Meier fälschlich »Hrabani Carmina IXXXVI«, bei LANG ohne weitere Inhaltsangabe).

1326 Die mit B versehenen Titel stammen aus Brouwers Ausgabe, nicht aus der Handschrift. 
(Fortsetzung)

\begin{tabular}{|c|c|c|c|}
\hline p. & Incipit & Titel & $\begin{array}{l}\text { Ed. (D = Ed. } \\
\text { Dümmler, } \\
\text { MGH Poet. 2) }\end{array}$ \\
\hline \multirow[t]{2}{*}{214} & $\begin{array}{l}\text { Omnibus in } \\
\text { horis }\end{array}$ & »Item ad eundem» (B S.12) & D XIV \\
\hline & $\begin{array}{l}\text { Perge mea } \\
\text { citius }\end{array}$ & »Item ad praeclarum episcopum» (B S.12) & $\mathrm{D} X \mathrm{XV}$ \\
\hline 215 & $\begin{array}{l}\text { Conditor } \\
\text { omnipotens } \\
\text { rector }\end{array}$ & "Item ad praeclarum» (B S.13) & D XVI \\
\hline 217 & $\begin{array}{l}\text { Spiritus alme } \\
\text { veni dulces }\end{array}$ & »Ad Fridericum episcopum» (B S.16) & D XVII \\
\hline 218 & $\begin{array}{l}\text { Spiritus alme } \\
\text { veni supera }\end{array}$ & Ad Otgarium archiepiscopum & D XVIII \\
\hline 219 & $\begin{array}{l}\text { Versibus hic } \\
\text { paucis }\end{array}$ & Ad Brunwardum corepiscopum & D XIX \\
\hline \multirow[t]{4}{*}{220} & Te pater alme & Ad Ratgerium abbatem suum & $\mathrm{D} X X$ \\
\hline & $\begin{array}{l}\text { Lex pia } \\
\text { cumque }\end{array}$ & Ad Eigilum de libro quem scripsit & D XXI \\
\hline & $\begin{array}{l}\text { Presbyter } \\
\text { aetate }\end{array}$ & Item ad eundem & D XXII \\
\hline & $\begin{array}{l}\text { Clavipotens } \\
\text { frater }\end{array}$ & Ad Gerhohum presbiterum & D XXIII \\
\hline \multirow[t]{2}{*}{221} & $\begin{array}{l}\text { Te deus om- } \\
\text { nitenens }\end{array}$ & Item ad eundem & D XXIV \\
\hline & $\begin{array}{l}\text { Vive meae } \\
\text { vires }\end{array}$ & Ad Samuelem presbiterum & D XXV \\
\hline \multirow[t]{4}{*}{222} & $\begin{array}{l}\text { Te deus } \\
\text { aeternus }\end{array}$ & »Item ad eundem» (B S. 23) & D XXVI \\
\hline & $\begin{array}{l}\text { Qui caeli } \\
\text { culmen }\end{array}$ & Item ad Samuelem presbiterum & D XXVII \\
\hline & $\begin{array}{l}\text { Est animus } \\
\text { promptus }\end{array}$ & Ad Samuelem presbiterum & D XXVIII \\
\hline & $\begin{array}{l}\text { Tu meus es } \\
\text { placitus }\end{array}$ & Item ad eundem & D XXIX \\
\hline
\end{tabular}


(Fortsetzung)

\begin{tabular}{|l|l|l|l|}
\hline p. & Incipit & Titel & $\begin{array}{l}\text { Ed. (D = Ed. } \\
\text { Dümmler, } \\
\text { MGH Poet. 2) }\end{array}$ \\
\hline 223 & $\begin{array}{l}\text { Has tabulas } \\
\text { senior }\end{array}$ & Ad Samuelem presbiterum & D XXX \\
\cline { 2 - 4 } & $\begin{array}{l}\text { Sis felix so- } \\
\text { spes }\end{array}$ & Ad Samuelem presbiterum & D XXXI \\
\cline { 2 - 4 } & $\begin{array}{l}\text { Accipe } \\
\text { primitias }\end{array}$ & Ad Isanbertum presbiterum & D XXXII \\
\cline { 2 - 4 } & $\begin{array}{l}\text { Fortia dicta } \\
\text { dabas }\end{array}$ & Ad Exulem presbiterum & D XXXIII \\
\cline { 2 - 3 } & $\begin{array}{l}\text { Omnimi } \\
\text { summi }\end{array}$ & Ad Irmingildum [presbiterum: D] & D XXXIV \\
\hline \multirow{2}{2}{224} & $\begin{array}{l}\text { Te deus } \\
\text { omnipotens }\end{array}$ & Item ad eundem (nicht in B) & D XXXV \\
\cline { 2 - 5 } & $\begin{array}{l}\text { O modus } \\
\text { (beschädigt) }\end{array}$ & $\begin{array}{l}\text { (nicht in B) Im weiteren folgt D der Ordnung in B, } \\
\text { da B folgenden der einzige Textzeuge ist. }\end{array}$ & D XXXVI \\
\hline
\end{tabular}

Die exakte Übereinstimmung der Folge und Titel der Gedichte lässt auf einen engen Zusammenhang der Murbacher und Brouwers Fuldaer Handschrift schließen. Dümmlers Identifizierung der Handschrift als eines Restes des von Brouwer in seiner Ausgabe ${ }^{1327}$ benutzten Fuldaer Kodex wurde von Stover widerlegt. ${ }^{1328}$ Dies wird auch dadurch unterstützt, dass unabhängig von der späteren Beschädigung der Handschrift schon die Titel für D XII-XVII nicht in der Murbacher Handschrift vorliegen (stattdessen Trennung durch Striche) und diese somit nicht Vorlage Brouwers, der die Titel hat, gewesen sein kann. ${ }^{1329}$ Dennoch hängen die Handschriften aufs engste zusammen, der Text ist weitgehend identisch. Der Trennfehler der in D XVI vertauschten Verse 104/106 ist nur scheinbar, da der Schreiber bei v. 104 anmerkt: hic versus debet prior stare. ${ }^{1330}$ Die Fehler sind dennoch, auch abgesehen von Brouwers vermutlicher Emendation, zahlreich genug, dass Einsiedeln, StB, Cod. 266 (1296) vermutlich nicht aus Brouwers Handschrift abgeschrieben sein kann. ${ }^{1331}$ Beide Handschriften hängen

1327 Brouwer (Hrsg.): Hrabani Poemata. Siehe bei Fulda, S. 65 f.

1328 STOVER: "Einsiedeln Eclogues«. S. 290f. Unabhängig von GUNDERMANN (zitiert nach Lösch: Die Einsiedler-Gedichte. S. 11, Anm. 6) der anscheinend zum gleichen Ergebnis kam. Dieser von Lösch offenbar falsch zitierte Aufsatz (»RhM 64 (1909)«) ist nicht auffindbar (Gugel: Handschriften. S. 75, Anm. 66).

1329 Er kann sie auch nicht selbst ergänzt haben: So ist z. B. in D XIV keine Rede davon, dass das Gedicht ad eundem sei, ebenso nicht in D XVI, dass es wiederum an Praeclarus gerichtet sei.

1330 So meine Lesart der sehr gekürzten Notiz. D XVI, S. 181, Anm. v. 104: prior stare.

1331 Die Varianten der Handschrift zu B(Rouwer) sind: D XIII, 18: capere] carpere corr. ? B |D XVIII, ii, 1 pater] pastor B | 33 vitae $a d d$. B | 44 Et te pastor sis memor et ipse mei] Te pater et 
somit mittelbar von einer weiteren Handschrift ab. Hiermit hat Hrabans Dichtung die Auszeichnung, dass sie - anders als etwa Alkuins oder Walahfrids poetische Werke - in einer standardisiert geordneten Sammlung im Umlauf war. Und der Ursprung von Brouwers Handschrift aus Fulda, dem Wirkungsort des Hrabanus, legt nahe, dass die Sammlung eben dort veranstaltet wurde - an welchem anderen Ort würde man auch eine so reiche Sammlung von Gelegenheitsgedichten erwarten? Die Sammlung in Ms. 266 besteht fast ausschließlich aus Briefgedichten, und zwei verlorene Bände der Fuldaer Bibliothek könnten genau eine solche Sammlung bezeichnet haben. ${ }^{1332}$ Zumindest hat Hrabanus die Sammlung wohl nicht selbst erstellt, da sich unter den Epitaphien auch sein eigenes befindet. ${ }^{1333}$ Aber es könnten auch einem von Hrabanus selbst erstellten Grundstock weitere Gedichte hinzugefügt worden sein; dass Brouwers Handschrift hier abbricht (»cetera desiderantur»), ist ein Indiz dafür, dass wir ans Ende der Handschrift gelangt sind, wo leicht Blätter oder Lagen und damit etwaige Zusätze verlorengehen. Warum nun das Kloster Murbach, das zu Hrabanus keine engere Verbindung hatte, ${ }^{1334}$ in den Besitz der Sammlung seiner Gedichte gelangte, kann nur Gegenstand von Spekulationen sein. ${ }^{1335}$ Dass man hier an zeitgenössischer Dichtung interessiert war, zeigen im Katalog die versus Theodolfi; und dass man guten Zugang zu den Werken Hrabanus' hatte, die eigene Katalogkategorie zu dessen Bibelkommentar. ${ }^{1336}$ Darüber hinaus lässt sich nichts Genaues feststellen. Das gleiche gilt für die Handschrift Einsiedeln, StB, Cod. 266 (1296) selbst: Ihre eigentümliche Textgesellschaft aus Computus, Metrologie und Dichtung widersetzt sich einer einfachen Einordnung. Ob sie vielleicht eine persönliche Handschrift, vielleicht ein Handbuch darstellt, wie Ferrari vermutet, möchte ich nicht entscheiden. ${ }^{1337}$ Ihr kleines Format, ihre schlichte

pastor sis memor ipse mei $\mathrm{B} \mid \mathrm{XXVI}, 4$ servetque te] servet te $\mathrm{B} \mid 9$ hicque tui cordis] hic cordis B | XXXIV, 19, pia] precans B | vll. Korrektur nach Vorlage: D XIX, 17 canit corr. de canet] canit $\mathrm{B}$.

1332 Die Versus Hrabani de diversis, aus denen Brouwer seine Ausgabe veranstaltete (siehe bei Fulda, S. 65). Aber auch die Epistolae Rabani ad diversos (CHRIsT: Bibliothek des Klosters Fulda. S. 97, xiii, 147.) können durchaus Briefdichtung enthalten haben.

1333 Brouwer (Hrsg.): Hrabani Poemata. S. 88-95, 90 (Epitaphium Rhabani Archipiscopi, D XCVII). Die Daten der Epitaphien verraten eine ungefähre chronologische Sammlung: D LXXXVII 847 (Otgar von Mainz), D LXXXVIII 849 (Walahfrid), D LXXXIX 851 (Irmingard von Tours), D XCI 855 (Lothar I.), D XCII 856 (Presbyter Isanbert), D XC 854 (Presbyter Ratlaih).

1334 Im auffallenden Gegensatz zu Alkuin und Walahfrid (BorNerT: »Saint-Léger de Murbach«. S. 19), deren Gedichte hier jedoch keine Spuren hinterließen.

1335 Versus Theodolfi und die Dicta philosophorum gab es auch in St. Gallen, wo SCHALLER eine Sammlung von Hrabanus-Gedichten vermutet (SCHALLER: „Geraldus und St. Gallen - Zum Widmungsgedicht des $>$ Waltharius « . S. 82).

1336 MildE: Bibliothekskatalog. S. 46f., Nr. 259-269.

1337 FERRARI: Liber sanctae crucis. S. 430-432. 
Ausstattung und ihr vielfältiger Inhalt lässt jedoch diese These als wahrscheinlich erscheinen. Es ist auffällig, dass auch die im Iskar-Katalog enthaltene TheodulfHandschrift, wenn sie tatsächlich mit den vorhergehenden Nummern in einem Band vereint war, ${ }^{1338}$ eine ähnliche Textgemeinschaft aus Computus, Grammatik und zeitgenössischer Dichtung enthielt.

Das Problem der Textgesellschaft stellt sich uns nicht bei der vielfältigen Sammelhandschrift Oxford, Bodl. Libr., Ms. Jun. 25, denn wann die zahlreichen Hefte verschiedenen Inhalts zu einem Kodex vereinigt worden sind, entzieht sich unserer Kenntnis. ${ }^{1339}$ Sicher wurden aber auf diese Weise viele kleinere, fragilere Handschriften aus Murbach hinter den Buchdeckeln der Sammelhandschrift vor dem Zerfall bewahrt, darunter auch die zwei Lagen der »Murbacher Hymnen «. ${ }^{1340}$ Die zwei Lagen $\left((\mathrm{IV}-2)^{116-121}+\mathrm{IV}^{122-129}\right)$ sind Produkte zweier verschiedener Skriptorien. Der zweite, ältere Teil (f. 122-129) ist ein Werk des Reichenauer Skriptoriums unter Reginberts ( $†$ 846) Leitung. ${ }^{1341}$ Reginbert war ein großer Förderer der Dichtung im Allgemeinen und der althochdeutschen Dichtung im Besonderen, wie die Liste der von ihm hinterlassenen Bücher zeigt. ${ }^{1342}$ Gleichwohl ist die Identifizierung der Handschrift mit den dort genannten XII carmina Theodiscae linguae formata oder carmina diversa ad docendum Theodiscam linguam zweifelhaft. ${ }^{1343}$ Der Reichenauer Teil des Hymnars (Hymnen I-XXI) ${ }^{1344}$ war lange genug eine selbstständige Handschrift, dass f. 122r und 129v - die Außenseiten des Quaternios - deutliche Abnutzungsspuren zeigen. Es kann zumindest nicht lange gedauert haben, bis die Handschrift nach Murbach ge-

1338 de compoto Astrolabio |de gramatica Foci | et Arati | et versus Theo |dolfi volumen I, GeITH/ BERSCHIN: »Bibliothekskataloge«. Nr. 21-24. Siehe S. 207.

1339 Zur Handschrift: Bischoff: Katalog, 2. Nr. 3799-3808. Bergmann/Stricker: Katalog. Nr. 725 (I-IV). КвотZ: Althochdeutscher Isidor. S. 212-223. ERTMER: Juvencusglossierung. S. 214-224. BischоғF: "Paläographische Fragen«. S. $80 f$.

1340 Auf f. 116r-117v; f. 122v-129v. Zu den Murbacher Hymnen: Voetz: »Art. Murbacher Hymnen (Interlinearversion) «. Siмвоцотті: Inni di Murbach. Eduard Sievers (Hrsg.), Die Murbacher Hymnen: nach der Handschrift herausgegeben (Nachdr. d. Ausg. Halle 1874), Hildesheim [u. a.] 1975. In all diesen Veröffentlichungen findet sich auch eine eingehende Behandlung der Handschrift.

1341 Bischoff: "Paläographische Fragen«. S. 81. Zu den widersprüchlichen Angaben bei BischоғF siehe: КвотZ: Althochdeutscher Isidor. S. $218 \mathrm{f}$.

1342 Lehmann (Hrsg.): MBK. 1, S. 260, Z. 24-28. Dennoch ist Reginberts Hand nicht, wie Bischoff, S. 81, meint, auf f. 122v zu sehen (MaAG: Alemannische Minuskel. S. 157).

1343 BIschоғF: »Paläographische Fragen «. S. 81. BIschoffs Haupteinwand, dass carmina nicht »Hymnen" heiße, ist dahingehend abzuschwächen, dass die betreffenden Einträge (XXI, XXII) von Hymnaren eingerahmt werden (XX, XXXVII, XXXIX), also doch eine thematische Nähe vorliegt. Eine Zusammenfassung der Diskussion bei Kвотz: Althochdeutscher Isidor. S. 222.

1344 Zählung traditionell nach SIEvers (Hrsg.): Murbacher Hymnen. S. 2. Die Anordnung in seiner Edition entspricht nicht der Handschrift (kritisch hierzu Voetz: »Art. Murbacher Hymnen (Interlinearversion)«. S. 278f.). Eine nicht so eingreifende Umstellung bei SimвоLотті: Inni di Murbach. 
langt ist - die Hand des Murbacher Teils (f. 116-121) wird ins erste Viertel des 9. Jahrhunderts datiert. ${ }^{1345}$ Ein in der Forschung vernachlässigtes Problem der Reise des Manuskripts von einem Skriptorium ins andere ist, dass das Pergament der vier Teile f. 87-129 dasselbe zu scheint. ${ }^{1346}$ Dies lässt eher auf den Besuch eines Schreibers, als auf die Reise der Handschrift schließen. Dieses Problem kann hier jedoch leider nur gestellt, nicht gelöst werden. ${ }^{1347}$ In Murbach wurde das Hymnar um ein Quaternio mit sechs Hymnen ergänzt (XXII-XXVI). Die verkehrte Reihenfolge der Stücke, vielleicht ein Versehen des Buchbinders, hat zumindest den Schreiber nicht beirrt: Die gleiche Hand, die die Hymnen (f. 116r-117v) schreibt, füllt den Rest der Lage und das freigebliebene Deckblatt des Reichenauer Teils mit verschiedenen kleineren Texten. ${ }^{1348}$ Trotz der unterschiedlichen Herkunft sind hier nicht etwa zwei nur thematisch verwandte Hefte zusammengebunden worden. Vielmehr zeigt der Murbacher Teil eine genaue, wenn auch gedrängtere Nachahmung des ausgeklügelten Layouts des Reichenauer Teils. Die Hymnen sind durch Zierinitialen, die Strophen durch Capitalis gekennzeichnet, und die Zeilen von vornherein für die Aufnahme der Interlinearversion mit großem Abstand angelegt worden. ${ }^{1349}$ Die Hymnen zu Stundengebet und Jahreskreis sind Teil des Fränkischen Hymnars, das im nordöstlichen Frankreich und südwestdeutschen Raum verbreitet war, bevor es vom Neuen Hymnar verdrängt wurde. ${ }^{1350}$ Schwerpunkt der Überlieferung im Ostfrankenreich ist die Reichenau, die gleich zwei Textzeugen hervorbrachte: Ms. Jun. 25 und Zürich C. Rh. 34. Dass die Vorlage der Hymnen (und weiterer Murbacher Teile der Handschrift) aus dem westfränkischen Raum dazu Anlass gäbe, die enge Beziehung von Reichenau und Murbach in Zweifel zu ziehen, ${ }^{1351}$ halte ich zumindest in Bezug auf das Hymnar für zu weit gegriffen, ist doch gerade die Tatsache, dass ein auf der Reichenau begonnenes Hymnar nach Murbach gelangte und dort vervollständigt werden konnte, ein Beweis für den engen Austausch zwischen den Klöstern. Die Interlinearversion stellt eine durchgehende althochdeutsche Glossierung der Hym-

1345 Bischoff: »Paläographische Fragen«. S. 80.

1346 So schon Sievers (Hrsg.): Murbacher Hymnen. S. 1 f., Nr. IV-VII. Bekräftigt nach erneuter Handschrifteneinsicht durch: Siмвоцотті: Inni di Murbach. S. XXVI (für das Hymnar). Die Herkunft der Teile »Bodenseegebiet, Murbach, Murbach, Reichenau (Bischoff a.a. O.).

1347 Eine Frage, die sich leicht durch naturwissenschaftliche Analyse lösen ließe (siehe zu solchen Ansätzen: Domenico Pangallo, Katarina Chovanova und Alena Makova, "Identification of animal skin of historical parchments by polymerase chain reaction (PCR)based methods«, in: Journal of Archaeological Science 37 (2010), S. 1202-1206.)

1348 Anderer Meinung ist: Siмвоцотті: Inni di Murbach. S. XXIII. Eine Übersicht der Ergänzungen bei Voetz: »Art. Murbacher Hymnen (Interlinearversion)«. S. 273.

1349 Nicht durch Auslassung jeder zweiten Zeile, sondern durch vorhergehende geräumige Liniierung.

1350 Gneuss: "Zur Geschichte des Hymnars«. S. 70-72, Konkordanz S. 83. Siehe zu Murbach als "centre liturgique«: BoRnerT: »Saint-Léger de Murbach«. S. $17 \mathrm{f}$.

1351 Krotz: Althochdeutscher Isidor. S. 165, 214-217, 259. 
nen, keine eigenständige dichterische Leistung dar. Sie sind in den weiteren Kreis altalemannischer Interlinearversionen einzuordnen. ${ }^{1352}$ Insofern ist sie nicht als Dichtung, sondern als Paratext zur Dichtung anzusehen. Wie auch in anderen Hymnaren unterstützt die durchgehende Glossierung den noch nicht des Latein sicheren Leser (und Sänger?). Ob dies die Murbacher Hymnen zum eigentlichen "Lehr- und Lernbuch « macht, ${ }^{1353}$ wie sicher auch das Glossar auf f. 118r-121v nahelegt, muss wegen der unsicheren Assoziation mit den weiteren pädagogischen Teilen ${ }^{1354}$ von Ms. Jun. 25 dahingestellt bleiben. Diese können auch erst später zur Textgesellschaft Ms. Jun. 25 gruppiert worden sein; es fehlen zudem das ganze Manuskript durchziehende zeitgenössische Nutzungsspuren. ${ }^{1355}$ Eine differenzierte mittlere Position nimmt Krotz ein: Das schnell wieder abgelöste Fränkische Hymnar könne als obsoleter Text umso eher in die Schule gewandert sein. ${ }^{1356}$ Dementsprechend wären die Murbacher Hymnen als geplante pädagogische Interlinearversion erst nach Ablösung des Fränkischen Hymnars einzuordnen. Zumindest eine Nähe zur Schule ist den Murbacher Hymnen nicht abzusprechen.

Nur wenig ist vom einstigen Glanz der Klosterbibliothek Murbach geblieben. Der selbst nur in Abschrift erhaltene Katalog gibt uns einen Begriff vom Rang der Sammlung, die zu den besten des Reiches gehörte. Er spiegelt in seiner Ordnung eine bibliothekarische Innovation in Bezug auf die Dichtung wieder: Während andere Bibliotheken die Dichtung noch bei der Grammatik einordneten, war der Murbacher Bestand so umfangreich geworden, dass man in mehrere neue Kategorien teilte - dies stellt einen bibliothekarischen Ausbruch der Dichtung aus dem engen bildungsgeschichtlichen Verhältnis dar, das sie zur Schule pflegte.

1352 Voetz: »Art. Murbacher Hymnen (Interlinearversion)«. S. 283-286.

1353 Gneuss: Hymnar und Hymnen im englischen Mittelalter. S. 6. Zitiert nach dem Fazit bei: Voetz: »Art. Murbacher Hymnen (Interlinearversion)«. S. 286. Ebenso: SiмвоLотті: Inni di Murbach. S. XXIV.

1354 Siehe Bischoff: Katalog, 2. Nr. 3800, 3801, 3805-3808.

1355 Hinzu kommt auch die andersartige Einordnung der doch ähnlichen Titel im Reichenauer Katalog. Vielleicht fand die Bindung der Teile erst unter Abt Bartholomäus von Andlau im 15. Jh. statt: Sімвоцотті: Inni di Murbach. S. XII. Eine Zusammenstellung vielleicht sogar erst unter Franciscus Junius ist nicht unwahrscheinlich: KRотZ: Althochdeutscher Isidor. S. 160. Dass die Handschrift restauriert wurde, sagt sie selbst auf f. 103v: paene dilapsata renovata est (ERTMER: Juvencusglossierung. S. 216f.).

1356 Квотz: Althochdeutscher Isidor. S. 222. Siehe auch die dort zitierte dahingehende Meinung Wolfgang HAUBRICHS, »Das monastische Studienprogramm der Statuta Murbacensia und die altalamannischen Interlinearversionen «, in: Sprache, Literatur, Kultur: Studien zu ihrer Geschichte im deutschen Süden und Westen. Wolfgang Kleiber zu seinem 60. Geburtstag gewidmet, hrsg. von Albrecht Greule und Uwe RUBERG, Stuttgart 1989, S. 237-261. S. 250. Ähnlich BORNERT, S. 18: »Les moines autochtones de la seconde ou troisième génération comprenaient moins le latin que leurs devanciers irlandais. Il fallait supplèer à ce que manque par des traductions en langue vernaculaire." 
Die Sammlung bietet neben einem vollständigen Programm christlicher Dichter zahlreiche Raritäten, die das unabhängige Interesse an Dichtung über die Befriedigung pädagogischer Bedürfnisse hinaus bekunden. Die Hofbibliothek mag bei der Erlangung solcher Seltenheiten wie Appendix Vergiliana, Lukrez oder Lukan eine Rolle gespielt haben. Auch zeitgenössische Dichtung wurde gesammelt: Mit Anthologien aus Theodulfs und Hrabanus' Dichtung nimmt Murbach auch in dieser Hinsicht eine hervorragende Rolle ein.

Die erhaltenen Handschriften widersetzen sich einer einfachen Einordnung. Einsiedeln, StB, Cod. 266 (1296) vereint Computus mit antiker und zeitgenössischer Dichtung in einem merkwürdigen Ensemble. Obwohl die Handschrift viele ihrer Geheimnisse bewahrt, darunter ihre endgültige Herkunft, Zusammenstellung und Quellen, ist sie als Aufbewahrungsort zweier so seltener Dichtungen ein Denkmal des hohen Niveaus der Murbacher Bibliothek. Die Murbacher Hymnen sind mit ihrer althochdeutschen Linearversion das der Schule am nächsten stehende Zeugnis des Murbacher Skriptoriums und zudem durch die doppelte Herkunft der Handschrift ein seltener handschriftlicher Beweis der engen Zusammenarbeit zwischen den Klöstern Reichenau und Murbach.

\section{II.2 Erzbistum Köln}

\section{II.2.a Köln}

Von der Kölner Dombibliothek des 9. Jh. sind der Katalog von 833 und circa dreißig Handschriften erhalten. ${ }^{1357}$ Dichtung spielte in Köln, wie es auch der Katalog reflektiert, eine nur untergeordnete Rolle. Nicht dass die Bischöfe kein

$1357 \mathrm{Zu}$ Bibliothek und Katalog: Рцотzек: „Geschichte der Dombibliothek«. Wolfgang Schмітz, »Die mittelalterliche Bibliotheksgeschichte Kölns«, in: Ornamenta Ecclesiae. Kunst und Künstler in der Romanik in Köln. Katalog zur Ausstellung des Schütgen-Museums in der Joseph-Haubrich-Kunsthalle, hrsg. von Anton LEgner, Köln 1985, S. 137-148. Peter OrTH, "Die lateinischen Klassiker in der früh- und hochmittelalterlichen Dombibliothek - Beobachtungen zu dem unedierten Lucan-Kommentar im Cod. 199«, in: Mittelalterliche Handschriften der Kölner Dombibliothek 7, hrsg. von Harald HoRst (Libelli Rhenani 79), Köln 2018, S. 177-206. Siehe auch das Projekt der Codices Electronici Ecclesiae Coloniensis (CEEC - http://www.ceec.uni-koeln.de/) und die dort bereitgestellten Materialien. Ältere Literatur: Karl LöFf LER, Kölnische Bibliotheksgeschichte im Umriß. Mit einer Nachweisung kölnischer Handschriften und einem Beitrag v. G. Frenken über den Katalog der Dombibliothek von 833, Köln 1923. Paul LeHMANn, "Erzbischof Hildebald und die Dombibliothek von Köln«, in: Zentralblatt für Bibliothekswesen 25 (1908), S. 153-157. Anton DECKER, »Die Hildebold'sche Manuskriptensammlung des Kölner Domes«, in: Festschrift der 43. Versammlung deutscher Philologen und Schulmänner, Bonn 1895, S. 215-253. Zur Kölner Schreibschule ist weiterhin grundlegend: Leslie Webber Jones, The script of Cologne from Hildebald to Hermann (The Mediaeval Academy of America. Publications 10), Cambridge, 
Interesse an Dichtung hatten, aber anders als in Salzburg, Freising oder Würzburg hinterließen die Kölner Erzbischöfe keine charakteristischen Spuren ihres Wirkens in der Bibliothek. Unter Erzbischof Hildebald (787?-818), ${ }^{1358}$ in Kirchenund Reichspolitik gleich prominent, Leiter der Hofkapelle, "Aaron « des Hofzirkels, ${ }^{1359}$ wurde der Grundstein der Dombibliothek gelegt. Zwölf ${ }^{1360}$ der erhaltenen Handschriften tragen noch den Vermerk Codex sancti Petri sub pio patre Hildebaldo archiepiscopo scriptus. ${ }^{1361}$ Zur Beschaffung seltener Texte ließ Hildebald seine Beziehungen spielen, so berichtet das Vorsatzblatt einer verlorenen Ferrandus-Handschrift, dass Wenilo von Laon den Kodex für Hildebald aus einem Exemplar kopieren ließ, das von Papst Leo an Kaiser Karl geschickt wurde $^{1362}$ - eine wahre Miniatur der weitgespannten Beziehungen des Erzbischofs. ${ }^{1363}$ Umfang und Auswahl der Bibliothek übertreffen die anderer bischöflicher Bibliotheken, wenn sie auch hinter den zeitgenössischen Klosterbibliotheken zurückbleiben. ${ }^{1364}$ Die Dichtung steht hier ganz im Dienst der Schule, wie uns der Katalog von 833 zeigt: An dessen Ende, den Grammatiken vorausgehend, ${ }^{1365}$ finden wir zwei Bände Dichtung, außerordentlich wenig für eine Bibliothek dieses Umfangs. ${ }^{1366}$ Das Exemplar der Aeneis ist vielleicht schon im

Mass. 1932. Einen zeitlich weiter gefasster Überblick in: Martin J. SchubERT, „Köln«, in: Schreiborte des deutschen Mittelalters : Skriptorien - Werke - Mäzene, hrsg. von Martin J. SCHubert, Berlin [u.a.] 2013, S. 217-262.

1358 Verena ZELL, Erzbischof Hildebald von Köln: Untersuchungen zu seiner Rolle im Reformprogramm Karls des Großen (Studien zur Geschichtsforschung des Mittelalters 33), Hamburg 2016. Zur Bibliothek speziell: S. 205-260.

1359 Mary GARRISON, "The social world of Alcuin: nicknames at York and at the Carolingian court«, in: Alcuin of York. Scholar at the Carolingian Court., hrsg. von Luuk A. J. R. Houwen und Alasdair A. MacDonald (Germania latina 3, Mediaevalia Groningana 22), Groningen 1998, S. 59-79. S. 61.

1360 Die Handschriften (darunter mehrbändige): Jones: Script of Cologne. S. 5.

1361 Plotzeк: "Geschichte der Dombibliothek«. S. 19. Heinz Finger, »Finger, Heinz: Die Dombibliothek zu Köln (2001). Vortrag, gehalten anlässlich der Präsentation der >Digitalen Handschriftenbibliothek Köln am Donnerstag, dem 31. Mai 2001«, http://www.dombiblio thek-koeln.de/publikation/finger_koelner_dombibliothek.html (abgerufen am 31.03. 2017).

1362 Plотzeк: »Geschichte der Dombibliothek«. S. 22.

1363 Kritisch zu weiteren Erwerbungen Hildebalds: LEHMANN: »Erzbischof Hildebald und die Dombibliothek von Köln«. S. 154.

1364 Die Bibliothek enthielt ca. 115 Werke in 175 Bänden (Vergleich mit anderen Beständen: Plotzeк: »Geschichte der Dombibliothek«. S. 23).

1365 Diese war nur mit einem Donat und einem Alkuin-Sammelband vorhanden: DECKER: "Die Hildebold'sche Manuskriptensammlung«. Nr. [103.] 104.

$1366 \mathrm{Ob}$ die Handschrift des Silius Italicus, die der Humanist Franciscus Modius am Ende des 16. Jh. noch in Köln auswerten konnte, eine karolingische Handschrift war, ist nicht abschließend geklärt: ORTн: »Klassiker«. S. 176, 182. Eine solche Rarität wäre zumindest im Kontext des Katalogs von 833 überraschend. 
Mittelalter verloren gegangen. ${ }^{1367}$ Der sich anschließende Band mit Prosper, Sedulius und Juvencus in uno volumine scheint ebenfalls verlorengegangen $\mathrm{zu}$ sein. ${ }^{1368}$ Diese zwei Bände sind sicher, wie Plotzek urteilt, »für einen Grundbestand ausreichend «, ${ }^{1369}$ und überraschend ist hier nicht ihr Vorhandensein, sondern das Fehlen weiterer Dichtung in einer ansonsten gut ausgestatteten Bibliothek. ${ }^{1370}$ Denn dass Dichtung durchaus in Köln gepflegt wurde und so Leser hätte finden sollen, sieht man an zerstreuten Stücken Gebrauchsdichtung, die sich in einzelnen Handschriften erhalten haben. So versieht ein Egilbert eine Sammelhandschrift Isidors mit einer poetischen Inhaltsangabe aus eigener Feder ${ }^{1371}$ und eine Handschrift Hrabans wird passenderweise mit einem Kreuzgedicht eröffnet. ${ }^{1372}$ Erzbischof Gunthar (850-863), unter dem das Skriptorium zu neuer Höhe fand, die Schule fest etabliert und die Bibliothek bedeutend vermehrt wurde, ${ }^{1373}$ führte selbst als Dichter geistlicher Lieder die Feder, wie Sedulius Scottus berichtet. ${ }^{1374}$ Aber nichts hat sich hiervon erhalten. ${ }^{1375}$ Die Dichtung blieb

1367 DeCKER: „Die Hildebold'sche Manuskriptensammlung«. Nr. 101.»Am Rande: deperditus«. Da Deckers Edition die einzige Quelle des verschollenen Kataloges ist (PlotzeK: »Geschichte der Dombibliothek«. S. 22f.), kann nicht mehr nachgeprüft werden, ob die Randnotiz zeitgenössisch ist.

$1368 »$ (Randbemerkung \# scheint das Fehlen dieses Bandes anzudeuten.)«, Decker Nr. 102.

1369 PцотZек: „Geschichte der Dombibliothek«. S. 26. In diesen Grundbestand würden sich auch Köln, DDB, Cod. 83 mit seinen grammatischen Schriften, darunter das Centimetrum des Servius, gut eingefügt haben. Wann diese nordostfranzösische Handschrift (BIschoff: Katalog, 1. Nr. 1906) jedoch in die Dombibliothek gelangte, ist unklar. Ähnliches gilt für London, BL Harley 2685 (BIschoff, Katalog, 2. Nr. 2446: „Ostfrankreich (?)«), der unter anderem die Vergil-Auslegung des Fulgentius enthält. ORTH: »Klassiker«. S. 183, nimmt ein frühes Vorhandensein beider Handschriften in Köln an.

1370 So auch : ORTH: »Klassiker«. S. 182.

1371 Köln, Erzbischöfliche Diözesan- und Dombibliothek, Cod. 99, f. 1v (РцотZeK: »Geschichte der Dombibliothek«. S. 62).

1372 Köln, DDB Cod. 110, f. 1r. Zum Gedicht (Crux Domini mecum) siehe: BischofF:»Ursprung und Geschichte eines Kreuzsegens".

1373 Jones: Script of Cologne. S. 22f. PlotzeK: »Geschichte der Dombibliothek«. S. 27f. Goswin Frenken, "Die Kölner Domschule im Mittelalter«, in: Der Dom zu Köln. Festschrift zur Feier der 50. Wiederkehr des Tages seiner Vollendung am 15. Okt. 1880, hrsg. von Erich KupHaL (Veröffentlichungen des Kölnischen Geschichtsvereins 5), Köln 1930, S. 237-256. S. 239f. Dass Meginhard von Fulda von Frenken als Lehrer genannt wird, beruht auf der falschen Zuschreibung einer apologetischen Schrift von Meinhard von Bamberg an Gunther von Bamberg (Norbert Fickermann, »Eine bisher verkannte Schrift Meinhards von Bamberg", in: Neues Archiv der Gesellschaft für ältere deutsche Geschichtskunde 49 (1932), S. 452-455.).

1374 Traube (Hrsg.): MGH Poet. lat. 3. S. 221-223, lxiix, lxix, lxxx; 226, lxxv, v. 5-8; sowie vielleicht das Encomium Gunthari (ebd. S. 238-240) aus St. Gallen, StB, Cod. Sang. 903, p. 89. Kommentar zu den Gunthar-Gedichten unter den entsprechenden Nummern in: Düchting: Sedulius Scottus. Seine Dichtung.

1375 Die von Frenken: »Die Kölner Domschule im Mittelalter«. S. 239, zitierte »Grabschrift auf den Kölner Chorbischof Hildibert« von der Hand Bischof Hilduins (842-848/849) kann ich nicht ausfindig machen. 
auf die minimalen Bedürfnisse der Schule oder das persönliche Interesse einzelner Bischöfe beschränkt und erhob sich nicht als Gattung zu eigener Würdigung in der Sammlung. Etwaige Ergänzungen der Bibliothek nach Hildebald wurden anscheinend nicht im Katalog verzeichnet.

Nur eine Handschrift bewahrt uns vielleicht ein Zeugnis von Hildebalds persönlichem Interesse an Dichtung, Köln, Cod. $106^{1376}$ - vielleicht, denn auch nach hundert Jahren Diskussion ist der Ursprung der Handschrift und somit ihre Verortung in einem bestimmten Traditionszusammenhang umstritten. Tours, ${ }^{1377}$ Köln, ${ }^{1378}$ Werden ${ }^{1379}$ und Aachen ${ }^{1380}$ wurden alle als Herkunftsorte vorgeschlagen. ${ }^{1381}$ Kompliziert wird die Lokalisierung durch Bischoffs Feststellung, „daß die Handschrift von einer Gemeinschaft von Schülern hergestellt wurde ${ }^{1382}$ und Stile verschiedener Skriptorien zeigt. Übereinstimmung besteht in der Datierung ins erste Viertel des Jahrhunderts, als auch darüber, dass die Handschrift von einer Vielzahl Schreiber unterschiedlicher Ausbildung erstellt wurde. Die Handschrift enthält die älteste vollständige Version des Enchiridions Alkuins, das dieser seinem Freund Arn von Salzburg zusammenstellte und in Eile übersandte. ${ }^{1383}$ Aus Salzburg selbst ist nur die gekürzte Version erhalten. ${ }^{1384}$ Der Eindruck der Sammelhandschrift, den Ms. 106 erweckt, ließ einige Forscher zu der Ansicht kommen, Ms. 106 sei das von Alkuin zusammengestellte Handbuch selbst. ${ }^{1385}$ Den Kern des Handbuchs ${ }^{1386}$ bilden die Lagen II-IX, die einzeln von je verschiedenen Händen geschrieben wurden. Die zahlreichen Freiräume an den

1376 Jones: »Cologne MS. 106«. Jones: Script of Cologne. S. 40-43. Fravventura (Hrsg.): Enchiridion in Psalmos. S. 28-32, 43-52. Bischoff: Katalog, 1. Nr. 1919. Bischoff: »Panorama«. S. 7, Anm. 8.

1377 Wallace Martin LindsAy, »The (Early) Lorsch Scriptorium«, in: Palaeographica latina, 3, 1924, S. 5-48. S. 7.

1378 JonEs: »Cologne MS. 106«.

1379 Richard Drögereit, Werden und der Heliand. Studien zur Kulturgeschichte der Abtei Werden und zur Herkunft des Heliand, Essen 1951. Zitiert nach Fravventura, S. 50, Anm. 204 ohne Seitenangabe. Werden m. E. auch Bischoff: »Panorama«. S. 7, Anm. 8, jedoch nicht aufgenommen in Bischoff: Katalog, Nr. 1919.

1380 Donald A. Bullough, Carolingian Renewal: Sources and Heritage, Manchester 1991. S. $239 f .$, Anm. 163.

1381 Eine Übersicht bei Fravventura a.a.O. Zusammenfassend ebenfalls: Stephan WALDHOFF, Alcuins Gebetbuch für Karl den Großen: seine Rekonstruktion und seine Stellung in der frühmittelalterlichen Geschichte der Libelli Precum (Liturgiewissenschaftliche Quellen und Forschungen 89), Münster 2003. S. 105-107.

1382 Bischoff: »Panorama«. S. 7, Anm. 8.

1383 "Alcuini epistolae«. Nr. 259, Z 19f.: Plura misissem in eum, nisi festinatio eius praeveniret me, ut non habebam tempus eum ordinare, sicut dispositum habui.

1384 Siehe S. 272-274 zu München, BSB, Clm 14446 und Wien, ÖNB, Cod. 458.

1385 LindSAY: »The (Early) Lorsch Scriptorium«. S. 7. Endgültig entkräftet durch die Textkritik: Fravventura (Hrsg.): Enchiridion in Psalmos. S. 51.

1386 22,7 x 31,5 cm; »manualem libellum « wie Alkuin selbst sagt: "Alcuini epistolae«. Nr. 259, Z. 6. Siehe ein Lagenschema bei Jones: »Cologne MS. 106«. S. 29. 
Lagenenden wurden von einer Vielzahl weiterer zeitgenössischer Schreiber gefüllt. ${ }^{1387}$ Lage I wurde später hinzugefügt, um Alkuins Brief an Arn dem Werk voranzustellen. Kleinere Lagen am Ende (X-XII) nehmen falsch kalkulierten Text der Lage IX, sowie weitere kleine Texte auf, von denen unklar ist, ob sie alle in der Vorlage zu finden waren. ${ }^{1388}$ Das von Alkuin zusammengestellte Textensemble, insbesondere der Anteil der Dichtung daran, kann durch einen Vergleich der Inhaltsverzeichnisse genauer eingegrenzt werden, die Alkuins Brief an Arn sowie f. $6 \mathrm{r}$ der Kölner Handschrift überliefern. ${ }^{1389}$ Als sichere Bestandteile des Enchiridions können nur die Gedichte gelten, die in beiden Inhaltsverzeichnissen enthalten sind. Hinzu kommen noch drei Titel, die sich nicht eindeutig den enthaltenen Gedichten zuordnen lassen: item oratio pulchra rythmico sermone composita; item oratio pulchra; item alia oratio, die vielleicht das noch lapidarere Habet et alias orationes des Briefes genauer aufschlüsseln. Von den zahlreichen weiteren in der Handschrift enthaltenen Gedichten sollten nur solche für eine Identifikation mit dem Verzeichnis erwogen werden, die nicht als vermutliche Zusätze am Lagenende und von anderer Hand geschrieben sind. Folgende Übersicht soll die Unterteilung in Korpus des Enchiridion und Zusätze verdeutlichen. ${ }^{1390}$

\begin{tabular}{|l|l|l|}
\hline Lage & Folio & Inhalt \\
\hline III & $17 \mathrm{r}-\mathrm{v}$ & $\begin{array}{l}\text { Inc. Audax est vir iuvenis. Versus de contemptu mundi. }{ }^{1391} \text { Lagenende, } \\
\text { Schreiberwechsel. }\end{array}$ \\
\hline VII & $44 \mathrm{r}$ & $\begin{array}{l}\text { Hymnen. Inc. Iam lucis orto sidere; Nunc sanctae nobis spritus; Rector } \\
\text { potens verax deus; Rerum deus tenax vigor. }\end{array}$ \\
\hline & $\begin{array}{l}44 \mathrm{v}- \\
46 \mathrm{r}\end{array}$ & $\begin{array}{l}\text { Beda, Hymnen: Hexameron \& Aethelryth. } \\
\text { zeichnis; } \text { Schreiberwechechel }\end{array}$ \\
\hline
\end{tabular}

1387 Fravventura (Hrsg.): Enchiridion in Psalmos. S. 29, 50. Detaillierte Übersicht zu den Schreibern ebd. S. 29-32, gestützt auf die Analysen in: Jones: „Cologne MS. 106«. S. 40-52.

1388 Die Dicta Bedae der Lage XI sind in beiden Inhaltsverzeichnissen enthalten.

1389 Fravventura (Hrsg.): Enchiridion in Psalmos. S. 44-46. Zum gleichen Ergebnis kommen: Gretsch/Gneuss: »Theodorean Poem«. S. 14f.

1390 Sichere Bestandteile fett gedruckt.

1391 Inc. Audax est vir iuvenis, Dieter Schaller und Ewald Könsgen, Initia carminum Latinorum saeculo undecimo antiquiorum, Göttingen 1977. 1305.

1392 Fravventura (Hrsg.): Enchiridion in Psalmos. S. 31.

1393 Hexameron: SK 12515. Fidel RäDLE, »Bedas Hymnus über das Sechstagewerk und die Weltalter«, in: Anglo-Saxonica: Beiträge zur Vor- und Frühgeschichte der englischen Sprache und zur altenglischen Literatur. Festschrift für Hans Schabram zum 65. Geburtstag, hrsg. von Klaus R. Grinda und Klaus Dieter Wetzel, München 1993, S. 53-73. Aethelryth: Kommentierte Edition: Stephen J. HARRIs, Bede and Aethelthryth: an introduction to Christian Latin poetics (Medieval european studies 18), Morgantown 2016. S. 158-163. Inhaltsverzeichnis Cod. 106: hymnus beati Bedae presbyteri de opere sex dierum primordialium et de sex aetatibus mundi; hymnus pulcherrimo elegiaco metro compositus opere pulcherrimo de virginitate Aethelrythae reginae. 
(Fortsetzung)

\begin{tabular}{|l|l|l|}
\hline Lage & Folio & Inhalt \\
\hline & $46 \mathrm{r}-\mathrm{v}$ & $\begin{array}{l}\text { Hymnen. Inc. Lucis creator optime; Olux beata trinitas; Christe qui lux es; } \\
\text { Te lucis ante terminum. }{ }^{1394} \text { Lagenende, Schreiberwechsel. }\end{array}$ \\
\hline IX & $59 \mathrm{v}$ & Hymnus, Inc. Sancte sator suffragator. ${ }^{1395}$ Schreiberwechsel. \\
\hline & $60 \mathrm{r}-\mathrm{v}$ & $\begin{array}{l}\text { Hymnus, Inc. Ad Dominum } \text { clamaveram. Im Inhaltsverzeichnis, Schrei- } \\
\text { berwechsel. }{ }^{1396}\end{array}$ \\
\hline & $\begin{array}{l}60 \mathrm{v}- \\
62 \mathrm{r}\end{array}$ & Hymnus luricae. ${ }^{1397}$ Im Inhaltsverzeichnis, Schreiberwechsel. \\
\hline XI & $\begin{array}{l}65 \mathrm{r}- \\
71 \mathrm{r}\end{array}$ & Dicta Bedae presbyteri. ${ }^{1398}$ Im Inhaltsverzeichnis, Schreiberwechsel. \\
\hline
\end{tabular}

Von den nicht klar zuzuordnenden Titeln des Inhaltsverzeichnisses der Handschrift kann nur die oratio pulchra rythmico sermone composita mit einiger Sicherheit mit dem Hymnus Sancte Sator identifiziert werden. Dieselbe Bezeichnung findet sich ebenfalls in den Inhaltsverzeichnissen von Clm 14447 (dem Salzburger Enchiridion) und ÖNB Cod. 11857 (s. XV, wahrscheinlich ein descriptus aus Ms. 106). In Clm 14447 ist der Hymnenbestand auf nur zwei reduziert worden: Ad Dominum clamaveram, im Inhaltsverzeichnis analog als hymnus de eisdem Psalmis bezeichnet, und Sancte Sator. ${ }^{1399}$ Die beiden letzten Titel des Verzeichnisses von Ms. 106, item oratio pulchra; item alia oratio, lassen sich nicht eindeutig zuordnen, zumal als orationes auch die Prosagebete f. $63 \mathrm{v}-64 \mathrm{v}, 71 \mathrm{r}-\mathrm{v}$ infrage kommen. ${ }^{1400}$

1394 Fravventura (Hrsg.): Enchiridion in Psalmos. S. 31.

1395 Gretsch/Gneuss: "Theodorean Poem». Ernst Hellgardt, "Das lateinisch-althochdeutsche Reimgebet 'Sancte sator Theodor von Tarsus / Canterbury zugeschrieben«, in: Zeitschrift für deutsches Altertum und deutsche Literatur 137 (2008), S. 1-27. Siehe zu dem Gedicht auch S. 309f. zu München, BSB, Clm 19410 (Passau).

1396 SK 167. Inhaltsverzeichnis Cod. 106: hymnus de eisdem psalmis (vorher: expositio quoque de patrum dictis brevis in psalmos XV graduum).

1397 Inc. Subfragare (!) trinitatis unitas, (SK 15745) - die »Lorica Gildae«, ein insulares Produkt: Michael Herren, "The Authorship, Date of Composition and Provenance of the So-Called >Lorica Gildae«, in: Ériu 24 (1973), S. 35-51.

$1398 »(\ldots)$ un centone poetico formato dalla giustapposizione di versetti del Salterio«: FravVentura (Hrsg.): Enchiridion in Psalmos. S. 45. Inhaltsverzeichnis Cod. 106: item beati Bedae presbyteri dulcissimi versus collecti de singulis psalmis vel laude Dei et oratione quod psalterium eiusdem patris nominatur.

1399 Gretsch/Gneuss: »Theodorean Poem«. S. 13. Man beachte, dass bei dieser Identifikation die Reihenfolge des Inhaltsverzeichnisses in Cod. 106 vertauscht ist. Eine Erklärung dieses Phänomens aus dem Schreibvorgang (Vorziehung kürzerer Texte zur Lagenfüllung) bei: Jones: „Cologne MS. 106«. S. 38, Anm. 2 (jedoch mit falscher Zuordnung der Titel des Inhaltsverzeichnisses).

1400 Am wahrscheinlichsten wäre sicher der Hymnus luricae (60v-62r), der zwischen ansonsten gesicherten Bestandteilen des Enchiridions steht. 
Da die Herkunft der Handschrift so umstritten ist, wäre jede Einordnung in einen Kölner Zusammenhang nur spekulativ. Woher sie auch stammt, selten verdeutlicht eine Handschrift so sehr das kooperative Element der Sammlung von Dichtung - kaum zwei Stücke sind von derselben Hand geschrieben. Schon das Textensemble der Vorlage selbst, das Enchiridion, stellt das Ergebnis eines Sammlungsaktes dar und die an Arn in Eile übersandte Handschrift wird dem Kölner Kodex durchaus geähnelt haben. In dieser legt sich aber über die ursprüngliche Schicht des Enchiridions noch eine weitere, am Schreibort angesammelte Schicht. In der Handschrift sind durch die bloß mechanische Ursache der verteilt geschriebenen Lagen Räume frei geworden, die eine gattungsgemäße Ergänzung aus eigenen Beständen ermöglichte. Diese fanden nicht erst später statt, sondern wurden großteils von den Schreibern der Handschrift selbst vorgenommen, ${ }^{1401}$ sodass die Auffüllung der Leerräume noch im Skriptorium selbst und nicht erst bei späterem Gebrauch stattgefunden hat. Einer der Freiräume nahm sogar ein weiteres kleines Textensemble auf, und zwar die Hymnen und Gebete 46r-v, die dort von einem einzelnen Schreiber eingetragen wurden. Der Status dieser Hymnen als bloßer Nachtrag wird jedoch dadurch kompliziert, dass davor $^{1402}$ auf $44 \mathrm{r}$ von anderer Hand vier weitere Hymnen stehen, die wie die späteren vier aus dem Neuen Hymnar stammen und in der Liturgie nach diesen ihren Platz hatten. ${ }^{1403}$ Das reduzierte Hymnar durchläuft alle kanonischen Stunden des Tages. Ob hier vielleicht aus Platzgründen Texte umgestellt wurden, wie Jones an anderer Stelle vermutet, oder ob der gesamte Hymnenbestand 41r$46 \mathrm{v}$ zum Enchiridion gehörte, lässt sich nicht entscheiden. In jedem Falle stellt Ms. 106 eine lebendige Sammlung dar, die hier in ihrer Entstehung beobachtet werden kann. Überraschend ist, dass es diese vielleicht sogar schülerhafte Handschrift war, von der die Mehrzahl der weiteren erhaltenen Handschriften des Enchiridions abstammen, und nicht der aus dem Adressatenort Salzburg stammende Text. ${ }^{1404}$ Gleichwohl liegt zwischen der Kölner Handschrift und den unteren Zweigen des Stemmas noch der Hyparchetyp $\beta$. Dieser scheint schon, wie seine Abschriften zeigen, den gesamten Hymnenbestand der Kölner Handschrift ausgespart zu haben. Die Dichtung im Enchiridion, ob originär oder später hinzugefügt, ist also ein Phänomen der frühen Rezeption, das in der späteren Auswahl aus der Sammlung ausgelassen wurde.

Aus der Kathedralbibliothek Köln ist weniger Dichtung und von geringerem Niveau erhalten, als die hohe Stellung der Bischöfe und ihr gelegentliches Interesse an dieser Gattung vermuten lassen sollten. Der Schwerpunkt lag woan-

1401 Jones: »Cologne MS. 106«. S. 39 und Anm. 3.

1402 Dazwischen die als Enchiridion-Stücke gesichterten Beda-Hymnen.

1403 Gneuss: «Zur Geschichte des Hymnars«. S. 77.

1404 Fravventura (Hrsg.): Enchiridion in Psalmos. S. 57-65. 
ders, bei Bibel und Vätern. Das Programm der Schule, die spätestens unter Bischof Gunthar etabliert war, lässt sich nicht aus den Handschriften rekonstruieren. Weder unter dem Förderer der Bibliothek Hildebald, noch unter Bischof Gunthar, der selbst dichtete, sind bemerkenswerte Zugänge zu verzeichnen. Die im Katalog enthaltenen Dichter schließen sich eng an die Schule an, sodass Dichtung in Köln eher als Teil des Curriculums und nicht als eigenständig gewürdigte Gattung anzusehen ist. Leider kann die Handschrift der Dombibliothek Cod. 106 nicht eindeutig dem Kölner Skriptorium zugeordnet werden. Ihr reicher Hymnenbestand, der teils schon im Enchiridion enthalten war, teils eigenständig ergänzt wurde, ist Zeugnis der Rezeption, Adaption und weiteren Tradition der alkuinischen Sammlung.

\section{II.2.b Corvey}

Im 822 gegründeten Kloster Corvey, ${ }^{1405}$ das anders als die weiteren hier behandelten Schreiborte nicht in den alten Kulturlandschaften des Reiches, sondern im Neuland Sachsen lag, entfaltete sich auf der Grundlage großzügiger Förderung durch Ludwig den Frommen eine rege geistige Tätigkeit, deren Werke uns insbesondere in Viten erhalten sind. Die Bibliothek, auf deren Basis die Bildung des Klosters stand, wurde jedoch, nach einer zweiten Glanzzeit unter den Ottonen, im Laufe der Jahrhunderte zerstreut, sodass heute nur noch eine Handvoll Handschriften erhalten sind. ${ }^{1406}$ Auch bewahrt kein Katalog ein Abbild der Bestände; die einzige spärliche Notiz, die dennoch vom Reichtum der Bibliothek zeugt, ist die Schenkung einer magnam copiam librorum, die der Hofkaplan Gerold bei seinem Eintritt ins Kloster mitbrachte. ${ }^{1407}$ Ein Glanzlicht der Corveyer

1405 Rhaban HaAcke, Die Benediktinerklöster in Nordrhein-Westfalen, St. Ottilien 1980. S. 236293. Zu zahlreichen paläographischen Aspekten: Paul LeHManN, »Corveyer Studien«, in: Lehmann, Erforschung des Mittelalters, 5, 1962, S. 94-178.

1406 Ca. 12 Handschriften mit variierender Gewissheit: Bischoff: Katalog, 1, S. 477, 2, S. 432, 3, S. 606. Zur Bibliothek: Schmalor: "Die Bibliothek der ehemaligen Reichsabtei Corvey«. Hermann-Josef ScHmaLoR, "Bibliotheken und Skriptorien in Corvey und Helmarshausen ", in: Die Weser. Ein. Fluß in Europa. Eine Länderübergreifende Ausstellung über 1200 Jahre Geschichte und Kultur des Weserraumes, hrsg. von Norbert Humburg und Joachim SCHWEen 2000, S. 202-211. Hermann-Josef ScHMALOR, "Bücher in Bewegung-Bibliotheken und Skriptorien in Corvey und Paderborn", in: Eine Welt in Bewegung: unterwegs zu Zentren des frühen Mittelalters; Begleitbuch der Gemeinschaftsausstellung, hrsg. von Georg Eggenstein und Norbert Börste, München [u.a.] 2008, S. 62-67. HAACKe: Die Benediktinerklöster in Nordrhein-Westfalen. S. 284-287.

1407 Als Kaplan nur in dieser Urkunde genannt: Depreux: Prosopographie de l'entourage de Louis le Pieux (781-840). Nr. 114. Vgl. Gerolds Schenkung auch mit der Madalwins, siehe bei Passau, S. 302-305. Roger Wilmans (Hrsg.), Die Kaiserurkunden der Provinz Westfalen 
Bibliothek war sicher auch der vielleicht aus Fulda stammende Tacitus. ${ }^{1408}$ Dass auch andere klassische Schriftsteller gelesen und rezipiert wurden, zeigen die Quellenanalysen der in Corvey wirkenden Schriftsteller: Bekannt waren neben anderen Vergil, Ovid und Horaz. ${ }^{1409}$ Ein kunstgeschichtliches Zeugnis der Schätzung der Antike sind ferner die Odysseus-Fresken der Klosterkirche. ${ }^{1410}$ Als Dichter tritt insbesondere Agius von Corvey hervor, der einen metrischen Epilog zu seiner Vita et obitus Hathumodae, sowie einige Kalenderverse schrieb. ${ }^{1411}$ Keines seiner Werke ist aus der Corveyer Schreibschule überliefert. Ob Agius auch der Verfasser der metrischen Gesta Karoli Magni, der sogenannte Poeta Saxo sei, ist seit bald 200 Jahren ein Zankapfel der Forschung, ${ }^{1412}$ wird aber heute allgemein verneint. ${ }^{1413}$ Auch die Annahme, dass der Poeta Saxo ein Corveyer Mönch gewesen sei, ist nicht so gesichert, wie es ihre weite Verbreitung vermuten lässt. ${ }^{1414}$ Ohnehin ist jedoch die Quellenanalyse der Gesta, die einen weiteren Einblick in die Corveyer Bibliothek gewähren könnte, nicht sehr ergiebig, da der Dichter sich eng an den Text der von ihm versifizierten Annalen hält. Vor allen anderen Dichtern fließt dem Poeta Vergil in die Feder, während die christlichen Dichter nur spärlich vertreten sind. ${ }^{1415}$ Wenn die wenigen Parallelen tatsächlich

777-1313. 1, Die Urkunden des Karolingischen Zeitalters: 777-900, Münster 1867. S. 509. Schmalor: "Die Bibliothek der ehemaligen Reichsabtei Corvey«. S. 253.

1408 Der Mediceus I (Florenz, Biblioteca Medicea Laurenziana, Ms. plut. 68.1): R. H. MARTIN, "From manuscript to print», in: The Cambridge companion to Tacitus (2009), S. 241-252. S. $243 \mathrm{f}$.

1409 SchmaloR: »Die Bibliothek der ehemaligen Reichsabtei Corvey«. S. $254 \mathrm{f}$.

1410 Hilde Claussen, Die Klosterkirche Corvey, 2: Wandmalerei und Stuck aus karolingischer Zeit (Denkmalpflege und Forschung in Westfalen, 43,2), Mainz 2007. S. 83-127. Die zwei Mönche aus Corbie, die nach Corvey umzogen, gelten heute nicht mehr als Schreiber und Maler der Terenz-Handschrift Vat. lat. 3868: Villa: »Terence's Audience and Readership in the Ninth to Eleventh Centuries«. S. 241.

1411 "Agius von Corvey, Vita et obitus Hathumodae«, in: MGH SS 4, hrsg. von Georg Heinrich Pertz 1841, S. 165-189. Der Epilog: Traube (Hrsg.): MGH Poet. lat. 3. S. 369-388. Die Kalenderverse: Strecker (Hrsg.): MGH Poet. lat. 4, 2.3. S. 937-943. Ein weiteres Gedicht wurde entdeckt von: Ewald KöNSGEN, »Eine komputistische Dichtung des Agius von Corvey«, in: Mittellateinisches Jahrbuch 14 (1979), S. 66-75.

1412 Winterfeld (Hrsg.): MGH Poet. lat. 4, 1. S. 1-71. Eine Übersicht der Diskussion in: Heinz Erich Stiene, "Agius von Corvey und der Poeta Saxo", in: Mittellateinisches Jahrbuch 22 (1987), S. 80-100. S. 81-83. Der letzte Befürworter der Identität der beiden ist: Jürgen Bohne, Der Poeta Saxo in der historiographischen Tradition des 8. bis 10. Jahrhunderts, Berlin 1963. S. 163-177.

1413 Jan Prelog, »Art. Poeta Saxo (9. Jahrhundert)«, in: Lexikon des Mittelalters, 7, 1995, S. 3536.

1414 So noch einmal skeptisch betont von: BrunhöLzL: Geschichte, 1. S. 389.

1415 Nach Winterfeld (Hrsg.): MGH Poet. lat. 4, 1. S. 1-71. Passim: Vergil: I, 186, 200, 251, 380, 385, 387, 392; II, 13, 102, 103, 273, 345, 494; III, 1, 137, 231,594; IV, 60, 75, 221, 227, 239, 362, 363, 351, 419. Sedulius: I, 74; IV, 294, 644. Iuvencus (Alkuin?): IV, 335. Prudentius: IV, 691. Venantius Fortunatus: II, 211; IV, 235. Statius: I, 297; IV, 181. Ovid: II, 125, 276; IV, 663. 
auf Zitate schließen lassen, so wurde auch der seltene Statius an zwei Stellen herangezogen.

Von diesen indirekten Zeugnissen abgesehen, bewahren uns heute nur noch zwei Handschriften Dichtung auf. Der Prudentius, der in Paris, Bibliothèque Nationale, Lat. 18554 (f. 140-168) mit anderen Dichtern zusammengebunden wurde, zeugt vom hohen Niveau des Skriptoriums und dem Prestige, das Dichtung dort genoss. ${ }^{1416}$ Der Text ist mit einigen unfertigen Federzeichnungen geschmückt, für die schon bei Anlage der Handschrift Freiräume im Textspiegel gelassen wurden. ${ }^{1417}$ Die Handschrift wurde später ausgiebig mit Glossen, darunter altsächsischen, versehen. ${ }^{1418}$ Illustrierung und Glossierung geben der Handschrift einen Doppelcharakter zwischen Schule und Scrinium, womit sie an den Lütticher Sedulius (Antwerpen, Plantin-Moretus, Cod. 17.4) erinnert. ${ }^{1419}$

Eine weitere Kostbarkeit zierte die Corveyer Bibliothek: Eine der zwei vollständigen Handschriften des altsächsischen Heliand, ${ }^{1420} \mathrm{Cgm} 25$, der einzigen aus

Siehe leicht abweichend: Ebenbauer: Carmen historicum. Untersuchungen zur historischen Dichtung im karolingischen Europa. S. 211, Anm. 1264.

1416 Mit Einschränkung: »Nordwestdeutschland (Corvey, unter Corbie-Einfluß?)«: BischоғF: Katalog, 3. Nr. $5060(5058,5059)$. »St. Mihiel in Lothringen«: Bergmann/Stricker: Katalog. Nr. 770, S. 1466. Die gesamte Handschrift als Schulhandschrift bei: GlaUCHE: Schullektüre. S. 35.

1417 Abbildung: Stettiner: Die illustrierten Prudentiushandschriften. Tafel 128.

1418 Heinrich Tiefenbach, "Die altsächsischen Glossen zur Psychomachie des Prudentius im Pariser Codex lat. 18554«28/1 (2003), S. 57-85. Zur Zuweisung an Corvey oder St. Mihiel: S. 69-80. Stefanie STRICKER, "Überblick über die Prudentius-Glossierung", in: Die althochdeutsche und altsächsische Glossographie. Ein Handbuch, 1, hrsg. von Rolf BERGMANN und Stefanie Stricker, Berlin [u. a.] 2009, S. 497-510. S. 379.

1419 Bischoffs Urteil zur ebenfalls niederdeutschen Prudentiushandschrift Düsseldorf ULB, Ms. F 1 - «Niederdeutschland, IX. Jh., 3. Drittel« (Bischoff: Katalog, 1. Nr. 1073) - wurde jüngst präzisiert (Katrinette BODARWÉ, Sanctimoniales litteratae: Schriftlichkeit und Bildung in den ottonischen Frauenkommunitäten Gandersheim, Essen und Quedlinburg (Quellen und Studien 10), Münster 2004. S. 110-117, 134-139, 272-274; siehe auch Monika E. Müller, Katrin Janz-Wenig und Irmgard Siebert, Kataloge der Handschriftenabteilung, Universitäts- und Landesbibliothek Düsseldorf. 5: Die mittelalterlichen Handschriften der Signaturengruppen E, F, G, N und P in der Universitäts- und Landesbibliothek Düsseldorf, Wiesbaden 2017. Die Handschrift entstand hiernach am Ende des Jahrhunderts in Werden, blieb jedoch unvollendet und wurde im 9. Jh. in Essen vervollständigt. Die ab f. 57 wechselnde Vorlage (von Klasse $\Gamma$ nach $\Theta$ : Cunningham (Hrsg.): Prudentii Carmina. Sigle d, S. XIV) ist somit nicht Ergebnis einer Arbeitsteilung (so Benjamin A. Victor, "Simultaneous copying of classical texts 800-1100: techniques and their consequences", in: La collaboration dans la production de l'écrit médiéval, hrsg. von Herrad SPILling (Matériaux pour l'histoire 4), Paris 2003, S. 347-358. S. 352). Die reiche althochdeutsche und altsächsische Glossierung lässt auf einen langen schulischen Gebrauch schließen.

1420 Die andere Handschrift (Sigle C): London, British Libr., MS Cotton Calig. A. VII. Beide Handschriften sind nur gegenüber den Fragmenten vollständig (bis Vers 5983): Wolfgang HAUBRICHS, »Art. Heliand«, in: Althochdeutsche und altsächsische Literatur, hrsg. von Rolf Bergmann, Berlin 2013, S. 154-163. Text: Burkhard TaEger und Otto Behaghel (Hrsg.), Heliand und Genesis (Altdeutsche Textbibliothek 4), Tübingen 1996. Handschriften ebd. 
dem deutschen Raum stammenden. ${ }^{1421}$ Die Lektüreanweisungen, die auf eine Lektion des Heliand im Laufe des Kirchenjahres hinweisen, sind in Cgm 25 weit weniger ausgeprägt als in ihrer Schwesterhandschrift. Der Text ist hier und da mit Akzenten und Neumen versehen, die sich auf den mündlichen Vortrag beziehen. ${ }^{1422}$ Der Corveyer Heliand ist somit nicht nur ein Zeugnis der schriftlichen, sondern auch der mündlichen Kultur, die im Spannungsfeld zwischen der Hochbildung der Kleriker und den illiteraten sächsischen Laien entstand. ${ }^{1423}$

Aus Corvey ist durch Verlust von Bibliothek und Katalog wenig bis nichts aus der Schule erhalten geblieben. ${ }^{1424}$ Stattdessen zeigt sich im Spiegel der Corveyer Literatur und der Handschriften eine klösterliche Kultur auf der Höhe der Zeit, in der Dichtung über die praktischen Bedürfnisse hinaus gesammelt und geschätzt wurde. Klassiker wie Horaz, Ovid und vielleicht Statius, sowie der Heliand, zeugen von einer bestens ausgestatteten Sammlung und die Corveyer Dichtung von ihrer Nutzung. Die hohe Qualität der Heliand- und PrudentiusHandschriften ist Zeichen des Prestiges, das Dichtung genoss. Es darf angenommen werden, dass auch die Werke der Dichter des Klosters, Agius' und vielleicht des Poeta Saxo, in angemessener Form kopiert und verbreitet wurden. Bemerkenswert an Corvey ist, dass dieses jüngste der hier behandelten Klöster sich in so kurzer Zeit auf eine solche Höhe schwingen konnte - eine Leistung, die ohne Unterstützung des reichen Mutterklosters Corbie sicher nicht denkbar wäre. ${ }^{1425}$

S. XVII-XXIV. Beide Handschriften bilden die Grundlage der späteren Fragmente, ebd. S. XXf., XXIV.

1421 Bischoff: Katalog, 2. Nr. 2912. Erich Petzet, Die deutschen Pergament-Handschriften Nr. 1-200 der Staatsbibliothek München, München 1920. S. 42f. Bernhard BischоF, "Die Schriftheimat der Münchener Heliand-Handschrift«, in: Bischoff, Mittelalterliche Studien, 3, 1981, S. 112-119.

1422 Taeger/Behaghel (Hrsg.): Heliand und Genesis. S. XXVII-XXIX. Zum Vortrag des Heliand: Wolfgang HAUBRICHS, »Rituale, Feste, Sprechhandlungen: Spuren oraler und laikaler Kultur in den Bibelepen des >Heliand « und Otfrids von Weißenburg", in: Orality and literacy in the middle ages: Essays in a conjunction and its consequences in honour of D. H. Green, hrsg. von Mark CHINCA und Cristopher J. Young (Utrecht Studies in medieval literacy 12), Turnhout 2005, S. 37-66. Sowie: Klaus GANTERT, Akkommodation und eingeschriebener Kommentar: Untersuchungen zur Übertragungsstrategie des Helianddichters, Tübingen 1998. S. 259-294, zu Corvey S. 277-284.

1423 Gantert: Akkommodation. S. 281.

1424 Die Glossen in BNF Lat. 18554 sind späteren Datums. Der hl. Ansgar war »magister scolae» in Corvey: Georg WaITZ (Hrsg.), Vita Anskarii auctore Rimberto. (MGH SS rer. Germ. 55), Hannover 1884. S. 26. Schon im Proto-Corvey Hethis war eine Schule vorhanden: Historia translationis sancti Viti, Georg Heinrich PERTZ (Hrsg.), Scriptores rerum Sangallensium. Annales, chronica et historia aevi Carolini (MGH SS 2), Hannover 1829. S. 579.

1425 Siehe einen Überblick der Beziehungen in: Helmut Wiesemeyer, "Corbie et le developpement de l'école monastique de Corvey, du IXe au XIe siècle«, in: Corbie abbaye royale. Volume du 13e centenaire, Lille 1963, S. 211-222. 


\section{II.2.c Lüttich}

Das Bistum Lüttich, nach der Aufteilung Lotharingiens an der westlichen Grenze des Ostfrankenreichs gelegen, hat uns nur eine, aber umso schönere Gedichthandschrift überliefert. ${ }^{1426}$ Die genaue territoriale Geschichte von Stadt und Bistum Lüttich ist aufgrund der Grenzlage und der häufigen Gebietsverschiebungen weiterhin Gegenstand von Diskussionen, ${ }^{1427}$ sodass für die Einbeziehung der Handschrift weniger die territoriale Zugehörigkeit des Skriptoriums, als die Präsenz althochdeutscher Glossen den Ausschlag gibt.

Der Sedulius (Carmen Paschale) Antwerpen, Plantin-Moretus $17.4^{1428}$ ist die einzige Handschrift des Dichters, die mit einem durchgehenden Bildprogramm versehen wurde. ${ }^{1429}$ Der biblische Bilderzyklus stimmt nicht überall mit dem zugehörigen Text überein und scheint aus entsprechenden Evangelien-Illustrationen adaptiert worden zu sein. ${ }^{1430}$ Nach Henderson könnte es sich bei der Handschrift um eine »Carolingian copy of an English copy of a late fifth-century exemplar ${ }^{1431}$ handeln. Da der Bilderzyklus laut Henderson nahezu unverändert durch zwei Kopien gegangen ist, ist hier ein bemerkenswertes Beharrungsvermögen der Gestaltung festzustellen. Ein weiteres Indiz der Reise der Vorlage ist die Subskription des Cudwin auf f. 68v, in dem Traube den Bischof von Dunwich erkennen will, der von einer Reise nach Rom Handschriften in die Heimat mitgebracht habe. ${ }^{1432}$ Textkritisch lässt sich der kunsthistorische Befund nicht

1426 Weiterhin die umfassendste Darstellung: Godefroid KurTh, La Cité de Liège au Moyen Âge, Brüssel 1909. Siehe weiterhin: Jean Lejeune, La principauté de Liège, 2. Aufl., Liège 1949. Zum Nachweis Lütticher Handschriften des 9. Jh.: BischоғF, Katalog, Register.

1427 Matthias WeRner, Der Lütticher Raum in frühkarolingischer Zeit. Untersuchungen zur Geschichte einer karolingischen Stammlandschaft (Veröffentlichungen des Max-PlanckInstituts für Geschichte 62), Göttingen 1980.

1428 Bischoff: Katalog, 1. Nr. 75. Bergmann/STricker: Katalog. Nr. 11. SPRinger: Handlist. S. 32-34. Pauly: Pommersfelden 2671 und Antwerpen 17.4. S. 32-34. Zum Ursprung aus Lüttich: Bischoff: »Panorama«. S. 9. BIschоғF: "Die Schriftheimat der Münchener Heliand-Handschrift«. S. 306. Dagegen Ursprung aus Mainz: Andreas WeINER, Die Initialornamentik der deutsch-insularen Schulen im Bereich von Fulda, Würzburg und Mainz (Quellen und Forschungen zur Geschichte des Bistums und Hochstifts Würzburg 43), Würzburg 1992. S. 21. Ursprung aus einem mit Alkuin verbundenen Kloster (St. Amand?): PAulY: Pommersfelden 2671 und Antwerpen 17.4. S. 54f. Alle von Lüttich abweichenden Lokalisierungen erklären nicht das vom Hauptschreiber ergänzte Gedicht auf Lambert, den Patron des Lütticher Doms, f. 69v.

$1429 \mathrm{Zu}$ weiteren vereinzelten Illustrationen: SPRINGER: Handlist. S. 22, Anm. 52.

1430 Carol F. Lewine, The miniatures of the Antwerp Sedulius manuscript: the early Christian models and their transformations, New York, NY, Columbia Univ., Diss., 1970.

1431 George D. S. Henderson, "Emulation and invention in Carolingian art«, in: Carolingian Culture: Emulation and Innovation, hrsg. von Rosamond MCKITTERICK, Cambridge 1994, S. 248-273. S. $253 \mathrm{f}$.

1432 Ludwig Traube, »Palaeographische Anzeigen«, in: Neues Archiv der Gesellschaft für ältere deutsche Geschichtskunde 27 (1902), S. 264-285. S. 276-278. 
nachzeichnen, da die Handschrift ohne engere Beziehung $\mathrm{zu}$ den weiteren Textzeugen steht. ${ }^{1433}$ An Sedulius (f. 1-38/41) schließen sich die Epigramme Prospers (f. 41-68v) ${ }^{1434}$ aus westfränkischer Rezension - zwei Texte, die häufig unter den grammatici beieinander stehen. ${ }^{1435}$ Hervorzuheben sind hier drei Katalogeinträge, die dieselbe Textgemeinschaft oder zumindest Autorengemeinschaft überliefern: Im Bibliothekskatalog der Reichenau von 821-822 findet sie sich unter den libris Prisciani, der grammatischen Sektion, gleich zweimal. ${ }^{1436}$ Der Kölner Katalog von 833 bietet, gefolgt von grammatischen Schriften, Epigramma Prosperi. lib. I. Sedulii lib. II. Juvenci lib. IIII in uno volumine. ${ }^{1437}$ Die Platzierung dieser Textgemeinschaft innerhalb der Grammatik legt einen ursprünglich schulischen Verwendungszweck der Texte nahe. ${ }^{1438}$ Dieser pragmatische Aspekt der Handschrift wird auch durch die zahlreichen zeitgenössischen Glossen unterstrichen, die nach und nach die Handschrift anfüllten. Diese tragen, ob in Latein oder Althochdeutsch, den Charakter von Lesehilfen, die ungewöhnliche Worte durch Synonyme erläutern. ${ }^{1439}$ Hinzu kommen einige Glossen in Geheimschrift. ${ }^{140}$ Die althochdeutsche Glossierung ist die umfangreichste der Handschriften des Dichters im 9. Jh. ${ }^{1411}$ Diesem späteren Gebrauchskontext widerspricht jedoch die Stilhöhe der illuminierten Handschrift. Sie nimmt somit eine Mittelstellung zwischen der utilitaristischen Gestaltung von Schulhandschriften und der Stilhöhe von Evangelienhandschriften ein, denen das Carmen Paschale als poetische Paraphrase nahesteht.

1433 C. CAesar, "Die Antwerpener Handschrift des Sedulius", in: Rheinisches Museum für Philologie 56 (1901), S. 247-271. S. 252.

1434 Nicht gebraucht in: Sedulius: Huemer/Zimmerl-Panagl (Hrsg.): Sedulii Opera omnia. Kollation bei CAesar: »Antwerpener Handschrift«. Prosper: Horsting (Hrsg.): Prosper Aquitanus, Liber epigrammatum. S. 26, Familie $\beta_{1}$, Sigle $\mathrm{An}_{1}$.

1435 Die zwei weiteren Handschriften in der Rezension $\beta_{1}$ (Mailand, Bibl. Ambr. 32 sup. [Bobbio], Montpellier H 218 [Ostfrankreich]) enthalten jedoch ausschließlich Prospers Werke.

1436 Sedulii operis paschalis libri III et metrum Prosperi, quod fuit epigrammata, in codice I und Item metrum Sedulii et epigrammata Prosperi ac Bedae de metrica ratione ac schematibus. LeHMANN (Hrsg.): MBK. 1, S. 252.

1437 DeCKeR: »Die Hildebold'sche Manuskriptensammlung». Nr. 102.

1438 Vgl. auch zu den beiden Autoren: Glauche: Schullektüre. Insb. S. 31-36 zu Sammelhandschriften, die diese Dichter und andere vereinigen. Speziell zu Prosper in solchen corpora poetarum als Schulbüchern: Honsting (Hrsg.): Prosper Aquitanus, Liber epigrammatum. S. 24.

$1439 \mathrm{Zu}$ den Glossen unter sprachhistorischem Gesichtspunkt: Pauly: Pommersfelden 2671 und Antwerpen 17.4. S. 114-140.

1440 Andreas Nievergelt, "Geheimschriftliche Glossen«, in: Die althochdeutsche und altsächsische Glossographie. Ein Handbuch, 1, hrsg. von Rolf BERGMann und Stefanie Stricker, Berlin [u. a.] 2009, S. 240-268. S. 247.

1441 Wogegen St. Gallen, StB, Cod. Sang. 242 stärker lateinisch glossiert ist. Claudia Wich-ReIF, "Art. Sedulius, Althochdeutsche Glossierung", in: Althochdeutsche und altsächsische Literatur, hrsg. von Rolf BERGMANN, Berlin [u. a.] 2013, S. 431-434. S. $431 \mathrm{f}$. 
Die Kleindichtung, ${ }^{142}$ die je am Ende den größeren Texten angeschlossen ist, spiegelt drei Entstehungsmomente der Handschrift wider:

\begin{tabular}{|c|c|c|}
\hline fol. & Inc. & Anmerkungen \\
\hline $38 \mathrm{v}$ & $\begin{array}{l}\text { Romulidum } \\
\text { ductor }^{1443}\end{array}$ & $\begin{array}{l}\text { Proemium des Cento Probae. }{ }^{1444} \text { Am Rande: Hoc no[n] e[st] } \\
\text { i[n] aliis libr[is], was auf weitere Sedulius-Handschriften der } \\
\text { Bibliothek hinweist. Parallele Textgemeinschaft auf der } \\
\text { Reichenau. }\end{array}$ \\
\hline $\begin{array}{l}39 r- \\
41 \mathrm{r}\end{array}$ & Cantemus socii. ${ }^{1446}$ & Sedulius, Hymnus I. \\
\hline $41 \mathrm{r}$ & $\begin{array}{l}\text { Sedulius Christi } \\
\text { miracula. }{ }^{1447}\end{array}$ & $\begin{array}{l}\text { Akrostichon auf Sedulius (seduliusantistes). Nachtrag von } \\
\text { anderer Hand. Das Gedicht ist Teil zahlreicher Handschrif- } \\
\text { ten des Dichters. }\end{array}$ \\
\hline $68 \mathrm{v}$ & $\begin{array}{l}\text { Haec Augustini ex } \\
\text { sacris. }\end{array}$ & $\begin{array}{l}\text { Einleitungsgedicht zu den Epigrammata Prospers, hier am } \\
\text { Ende des Werkes. Davor Subskription (?) des Schreibers } \\
\text { Cudwin auf 68v, Z. 3: finit fines fines Cudvvini. Am Ende die } \\
\text { Autorenangabe: Andreas Orator, diese Zuschreibung sonst } \\
\text { nur bei Aldhelm, was auf insularen Ursprung der Vorlage } \\
\text { hindeutet. }\end{array}$ \\
\hline $\begin{array}{l}68 \mathrm{v}- \\
69 \mathrm{r}\end{array}$ & $\begin{array}{l}\text { Virgo parens hac } \\
\text { luce }\end{array}$ & $\begin{array}{l}\text { SK 17345. Mariengedicht. Darauf eine Subskription; }{ }^{1450} \text { es ist } \\
\text { unklar, ob es die des Gedichtes oder die der Handschrift } \\
\text { (d.h. vielleicht auch der insularen Vorlage) }{ }^{1451} \text { ist. } \\
\text { Am Rande von } 68 \mathrm{v} \text { ergänzt aus Ps.-Cato Inc. Crede ratem } \\
\text { ventis }^{1452} \text { nur vss. } 1-4 \text {, die auch separat zirkulierten. }{ }^{1453}\end{array}$ \\
\hline $69 \mathrm{r}$ & $\begin{array}{l}\text { Ortus perpetui } \\
\text { floris }\end{array}$ & SK 11477. Mariengedicht. \\
\hline $69 \mathrm{v}$ & $\begin{array}{l}\text { Martyris hic } \\
\text { Christi fulgent }\end{array}$ & $\begin{array}{l}\text { SK 9398. Ein den Lütticher Ursprung verratendes Gedicht auf } \\
\text { den Patron der Kathedrale, den hl. Lambert. }\end{array}$ \\
\hline
\end{tabular}

1442 Besser als die Kataloge ist: CAESAR: »Antwerpener Handschrift«. S. 263-269.

1443 SK 14483.

1444 LuCarini (Hrsg.): Proba: Cento Vergilianus. S. CVIII-CXIII, Text S. 3. In Riese/BüCheleR (Hrsg.): Anthologia latina. Nr. 735, aus englischer Handschrift ediert.

1445 LehmanN (Hrsg.): MBK. S. 252, Z. 8-12.

1446 Huemer/Zimmerl-Panagl (Hrsg.): Sedulii Opera omnia. S. 155-162.

1447 Ebd. S. 307-308. SK 14841.

1448 SK 5834. In BnF Lat. 13377 (Sedulius + Prosper, sowie weitere Texte; aus Corbie, BischofF, Katalog Nr. 4748; Ebd. Sigle H, S. XVI f.) f. 56r, steht es sinngemäß vor den Epigrammen.

1449 TRAUBE: »Palaeographische Anzeigen«.

1450 Lector legat, feliciter intellegat ... Amen. Transkription: CAESAR: "Antwerpener Handschrift«. S. 266.

1451 So Traube: »Palaeographische Anzeigen«. S. 277.

1452 BoAs: »Neue Catobruchstücke II«. BoAs (Hrsg.): Disticha Catonis. S. XXIX-XXXV.

1453 SK 2850; RIESE/BÜCHELER (Hrsg.): Anthologia latina. Nr. 268. 
(Fortsetzung)

\begin{tabular}{|l|l|l|}
\hline fol. & Inc. & Anmerkungen \\
\hline $\begin{array}{l}\text { Hic patriarcha } \\
\text { pius / } \\
\text { Haec est sancta } \\
\text { domus }\end{array}$ & $\begin{array}{l}\text { SK 6586, 5896. Zwei (?) Tituli Alkuins. }{ }^{1454} \text { Der zweite Vers des } \\
\text { ersten Gedichtes ist ausradiert worden. Darauf von einer } \\
\text { Hand des späten 10. Jh. ein kleiner Dialog, }{ }^{1455} \text { darauf eine } \\
\text { Subskription: Scripsit Lambert[us] homo cui pateat paradi- } \\
\text { sus. Diese ist durch Position und Schriftcharakter eindeutig } \\
\text { später als der Haupttext und die Zusätze der Handschrift; } \\
\text { Lambertus ist somit weder Schreiber der Handschrift } \\
\text { noch der zwei Alkuin-Tituli. }\end{array}$ \\
\hline
\end{tabular}

Die Handschrift trägt durch ihre widersprüchlichen Charakteristika einen Doppelcharakter, der ihre Einordnung erschwert: Die ursprüngliche Textgemeinschaft deutet auf die Schule, während die Gestaltung, die aus der Vorlage übernommen wurde, dem widerspricht. Die lyrischen Ergänzungen der Vorlage beziehen sich auf die Haupttexte, während die in Lüttich ergänzten hagiographisch-epigraphischen Charakter tragen. Erst die Synonymglossen schließen wieder den Bogen zur schulischen Textgemeinschaft von Sedulius und Prosper. Es ist somit für die Handschrift zwischen Entstehungs- und Nutzungszusammenhang zu unterscheiden: Die Kopie einer Handschrift, die durch ihre Ausstattung für die schulische Nutzung ungeeignet oder zumindest nicht angemessen war, wurde aufgrund ihrer Texte wieder in deren ursprünglichen Gebrauchskontext hineingezogen.

\section{II.3 Erzbistum Trier}

\section{II.3.a Trier}

Die Produktion der Schreibschule von Trier, ${ }^{1458}$ die sich auf das der Kathedrale eng verbundene Kloster St. Maximin konzentrierte, ${ }^{1459}$ lässt sich durch die schweren Bestandsverluste nur schwer würdigen. Die Quellenlage zur Frühzeit

1454 DümmLer (Hrsg.): MGH Poet. lat. 1. S. 330f. Nr. CIV, I. II. Dümmlers Frage (Anm. ibid.), ob die Gedichte zusammenhängen, kann aus unserer Handschrift bejaht werden, da keine Titel oder Leerzeilen die Texte trennen.

1455 Transkript bei CAESAR: »Antwerpener Handschrift«. S. 268.

1456 So Traube: »Palaeographische Anzeigen«. S. 277.

1457 So CAESAR: "Antwerpener Handschrift«. S. 269.

1458 Zum Skriptorium: KNoblich: Bibliothek. Hoffmann: Schreibschulen. S. 444-509. Zur literarischen Produktion: Hans Hubert AnTon, Trier im frühen Mittelalter (Quellen und Forschungen aus dem Gebiete der Geschichte 9), Paderborn [u.a.] 1987. S. 208-211. Michael Емвасн, Trierer Literaturgeschichte, Das Mittelalter (Geschichte und Kultur des Trierer Landes 8), Trier 2007. S. 25-59, zur althochdeutschen Literatur ebd. S. 61-108. Zum 
des Klosters ist durch die Zerstörung seines Archivs bei der normannischen Plünderung 882 äußerst lückenhaft, sodass genaue Nachrichten zum 9. Jh., insbesondere zur Bildung im Kloster, fehlen. ${ }^{1460}$ Die Rekonstruktion der Klosterbibliothek wird durch diese Katastrophe erschwert. ${ }^{1461}$ Ist sie mit dem Archiv zerstört worden und später von auswärts ergänzt worden ${ }^{1462}$ Die geringe Zahl der nach Trier lokalisierbaren und vor das Ereignis datierbaren Handschriften macht beträchtliche Einbuße im Bestand wahrscheinlich. Die Unterscheidung des früheren Bestandes von späteren, meist aus Mainz stammenden Erwerbungen, stößt auf große Schwierigkeiten. ${ }^{1463}$ In der Tat wird selbst die konservative Einschätzung Bischoffs ${ }^{1464}$ durch Knoblich auf drei Handschriften eingeengt, ${ }^{1465}$ keine davon poetischen Charakters. Die folgenden Handschriften sind also vorsichtigerweise als Ergänzungen nach der Plünderung von 882 anzusehen, die dennoch Bedürfnisse und Interessen der Klostergemeinschaft widerspiegeln.

Bemerkenswert ist, dass in den erhaltenen Bänden der Bibliothek von St. Maximin, ob Trierer oder auswärtigen Ursprungs, keine Schuldichter und kaum Schulhandschriften enthalten sind. Die exegetischen Schriften überwiegen. ${ }^{1466}$ Horaz und Vergil sind in späteren Fragmenten erhalten. ${ }^{1467}$ Auch im Katalog des 12. Jh. fehlen die Schulschriftsteller ganz, was auf eine separate Schulbibliothek schließen lässt, ${ }^{1468}$ aus der sich auch die wenigen Trierer

Schulwesen: Hubert Bastgen, Die Geschichte des Trierer Domkapitels im Mittelalter (Görres-Gesellschaft, Veröffentlichungen der Sektion für Rechts- und Sozialwissenschaft 7), Paderborn 1910. S. 148-150.

1459 Das Kloster war mit dem Bischof durch dessen gleichzeitige Abtswürde eng verbunden: Erich Wisplinghoff, Untersuchungen zur frühen Geschichte der Abtei S. Maximin bei Trier von den Anfängen bis etwa 1150 (Quellen und Abhandlungen zur mittelrheinischen Kirchengeschichte 12), Mainz 1970. S. 9.

1460 Ebd. S. 5-22. Zum Normanneneinfall: Anton: Trier im frühen Mittelalter. S. 180 und Anm. 30 ebd.

1461 Zur Bibliothek im Speziellen: KNoвLICH: Bibliothek. Richard LAUfNer, Nom Bereich der Trierer Klosterbibliothek St. Maximin im Hochmittelalter«, in: Armaria Trevirensia, hrsg. von Gunther Franz, 2., stark erw. Aufl. (Bibliotheca Trevirensis 1), Wiesbaden 1985, S. 1543.

1462 Wisplinghoff: Abtei S. Maximin. S. 26. Zur Bibliothek im 9. Jh.: Knoblich: Bibliothek. S. $16 \mathrm{f}$.

1463 КNовцICH: Bibliothek. S. 17-85. Zu Handschriften Mainzer Herkunft allgemein dort S. 8184.

1464 Siehe die Katalognummern im folgenden. Man beachte, dass die folgenden Handschriften im 3. Teil des Kataloges nur in äußerster Kürze aus dem Nachlass beschrieben worden sind. Siehe zum Problem Ganz: "Carolingian Manuscripts. The Verdict of the Master«. S. 254.

1465 KNoвLICH: Bibliothek. S. 80.

1466 Ebd. S. 111.

1467 Ebd. S. 112.

1468 Ebd. S. 113f. Hier wird eine Trennung des Bestandes erst unter der Gorzer Reform nahegelegt (um 934). 
Handschriften von vor 882 gerettet hätten. ${ }^{1469}$ Spätere Handschriften aus St. Maximin, die für andere Klöster geschrieben wurden, sind Zeichen einer bedeutenden Sammlung: Sie enthalten Persius, Juvenal, Horaz und Terenz, ${ }^{1470}$ wobei insbesondere die letzteren ins 10 . Jh. verweisen.

Nur acht Handschriften des 9. Jh., und einige davon nicht mit Sicherheit, werden überhaupt Trier zugeordnet. ${ }^{1471}$ Was in diesen an Dichtung erhalten ist, wird ganz von gottesdienstlichen Interessen beherrscht und lässt kein autonomes Interesse an der Gattung erkennen. ${ }^{1472}$ Eng an liturgische Bedürfnisse angepasst ist der Psalter von St. Maximin, Manchester, John Rylands Library, Latin Ms. 116 (olim Crawford Lat. 133), der durch Vorsatz eines Kalenders und Zugabe der Cantica zum Handbuch der Psalmodie wird. ${ }^{1473}$ Diese geläufige Textgemeinschaft wird jedoch erweitert auf $95 \mathrm{r}-104 \mathrm{v}$ durch ein frühes Hymnar, das zur Klasse der Neuen Hymnare gehört. ${ }^{1474}$ Die Entstehung im 2. Drittel des Jahrhunderts rückt es nahe an die Kompilation der Sammlung im Reformkreis um Benedikt von Aniane am Hof Ludwigs des Frommen. ${ }^{1475}$

Eine ganz ähnliche, aber nicht in allen Stücken übereinstimmende Sammlung des neuen Hymnars bietet Trier, SB, Ms. 592/1578, f. 127-133, ${ }^{1476}$ das ebenfalls aus den Beständen St. Maximins stammt, wohin es aus dem Raum von Tours kam. ${ }^{147}$ Das Heft bildet innerhalb der Handschrift eine kodikologische Einheit, ist aber mit anderen Schriften des 9. Jh. zu einer organischen Einheit gebunden worden, die insgesamt das Gepräge eines Handbuchs für Kleriker hat, mit Texten wie Hrabans De institutione Clericorum (f. 2-38), Amalars von Metz De ecclesiasticis

1469 Ebd. S. 114, Anm. 543.

1470 Ebd. S. 114.

1471 Ebd. S. $80 \mathrm{f}$.

1472 Die Handschrift Trier, SB, Ms. 1086/2180, aus den Beständen von St. Matthias, die verschiedene Vergilkommentare erhielt, stammt aus Tours (BISchofF, Nr. 6186); ob sie schon im 9. Jh. in Trier war, ist unklar. Siehe Емвасн: Literaturgeschichte. S. 151.

1473 Montague Rhodes JAmEs, A descriptive catalogue of the latin manuscripts in the John Rylands Library at Manchester, Manchester 1921. S. 211-217. Herkunft aus Trier: BISCHоFғ: Katalog, 3. Nr. 2679; Bischoff: Panorama«. S. 9, Anm. 17. Dagegen Herkunft aus Tours: KNовLICH: Bibliothek. S. 58f., Nr. 37.

1474 GNEuss: »Zur Geschichte des Hymnars«. S. 72-77. Eine Inhaltsübersicht S. 85-86.

1475 Ebd. S. 73. Donald Auberon Bullough, "Texts, chant, and the chapel of Louis the Pious", in: Charlemagne's heir. New perspectives on the reign of Louis the Pious (814-840), hrsg. von Peter Godman und Roger Collins, Oxford 1990, S. 489-508. S. 505. Philipp August BECKER, "Vom christlichen Hymnus zum Minnesang", in: Historisches Jahrbuch 52 (1932), S. 1-39, 145-177. S. 161 .

1476 Widersprüchliche Angaben zur Paginierung in der Literatur. Die Angabe verdanke ich der freundlichen Mitteilung von Prof. Dr. Michael Емвасн, Stadtbibliothek und -archiv Trier.

1477 Gneuss: «Zur Geschichte des Hymnars«. S. 77, auf Mitteilung Bischoffs, siehe S. 71, Anm. 31. Nicht so verzeichnet in Bischoff: Katalog, 3. Nr. 6182-6184. Andere Kollationierung bei Max Keuffer und Gottfried Kentenich, Beschreibendes Verzeichnis der Handschriften der Stadtbibliothek Trier, Trier 1888. 5, S. 46-48, sowie bei KNoBLICH: Bibliothek. S. 69-72. Inhaltsübersicht bei GNEUss: »Zur Geschichte des Hymnars«. S. 85-86. 
officiis (f. 40-105), desselben Ecloge de officio missae (f. 105-115) und auf f. 115125 eine Sammlung liturgischer Anweisungen, worauf das Hymnar hinzugebunden wurde. Die Vereinigung der zwei ersten, im Geiste der Aachener Synoden (816-819) reformorientierten Texte ${ }^{1478}$ mit den pragmatischen Texten des zweiten Teils zeigt, dass die Reform in St. Maximin theoretisch und praktisch aufgegriffen wurde. Zudem ist die Assoziation des Hymnars hiermit ein weiterer Beleg für die Entstehung der neuen Hymnensammlung im Umkreis der Reform. Hier soll auch erwähnt werden, dass die an anderer Stelle zu behandelnde, in Prüm entstandene Handschrift Trier, Stadtbibliothek, Ms. 1245/597, die eine ganz ähnliche Textgemeinschaft und ein ähnliches Hymnar enthält, ebenfalls in Trier, in St. Martin, ihre Bibliotheksheimat fand.

Trier stellt sich somit, trotz des sonstigen Fehlens von poetischen Handschriften, ${ }^{1479}$ als wichtigstes Repositorium des neuen Hymnars im Ostfrankenreich heraus, das drei der vier überlieferten Textzeugen aufbewahrte. ${ }^{1480}$ Man kann vermuten, dass dieser bemerkenswerte liturgische Schwerpunkt auf die Initiative Amalars von Metz, 809 bis 814 Erzbischof von Trier, zurückzuführen ist, der eine zentrale Rolle der Liturgiereform des frühen 9. Jh. spielte. ${ }^{1481} \mathrm{Ab}$ gesehen von seinen in Trier, SB, Ms. 592/1578 gesammelten Schriften ${ }^{1482}$ gibt es jedoch keine weiteren zeitgenössischen Trierer Zeugnisse seines Wirkens. ${ }^{1483}$ Eine Verbindung mit diesem bedeutenden Liturgiker bleibt also spekulativ, so naheliegend sie auch ist. ${ }^{1484}$

1478 Zur Reform in Hrabans Pastoraltheologie: Hanns-Christoph PICKen, Pastor Doctus: Klerikerbild und karolingische Reformen bei Hrabanus Maurus (Veröffentlichungen des Instituts für Europäische Geschichte Mainz. Abt. für Abendländische Religionsgeschichte 186), Mainz 2001. Zu Amalars liturgischen Schriften: Johannes BEUMER, $\gg$ Amalar von Metz und sein Zeugnis für die Gestalt der Messliturgie«, in: Theologie und Philosophie 50 (1975), S. 416-426.

1479 Das Carmen ad Joseph in Gent, UB, Ms. 324 (SG 581) (St. Maximin, 2.-3. Viert. 9. Jh., Bischoff: Katalog, 1. Nr. 1374) ist ein Nachtrag des 10. Jh.

1480 GNeuss: »Zur Geschichte des Hymnars«. S. 77.

1481 Wolfgang Sтеск, Der Liturgiker Amalarius: eine quellenkritische Untersuchung zu Leben und Werk eines Theologen der Karolingerzeit (Münchener Theologische Studien 1), München 2000. S. 7 und passim. Zu seinem Trierer Wirken ist die Quellenlage ansonsten sehr dünn, er erscheint z.B. nicht in den frühesten Bischofslisten: Ferdinand PAULY, Aus der Geschichte des Bistums Trier (Veröffentlichungen des Bistumsarchivs Trier, 13/14 u. 18), Trier 1968. 2, S. 44.

1482 Wobei De ecclesiasticis officiis ein mit 46 Handschriften weit verbreiteter Text ist: STECK: Der Liturgiker Amalarius. S. 13.

1483 Dávid Diosi, Amalarius Fortunatus in der Trierer Tradition: eine quellenkritische Untersuchung der trierischen Zeugnisse über einen Liturgiker der Karolingerzeit (Liturgiewissenschaftliche Quellen und Forschungen 94), Münster 2006. S. 33f. Diosi geht nicht über KNoBLICH: Bibliothek hinaus.

1484 Dass St. Maximin früh einen von Benedikt von Aniane edierten Codex regularum besaß, ist ein weiteres Indiz für die Anteilnahme des Klosters an der Reform, siehe: Werner BoRNHeIM Gen. SCHILling, "St. Maximin in Trier während des 9. Jahrhunderts.", in: Corona 


\section{II.3.b Lorsch}

Das Kloster Lorsch stieg in kurzer Zeit von einem kleinen Konvent zu einer der bedeutendsten Abteien des Reiches auf und konnte sich einer Bibliothek rühmen, die weit und breit ihresgleichen suchte. ${ }^{1485}$ Gegründet als Eigenkloster der Rupertiner von Graf Cancor und seiner Mutter Williswinth wurde es durch deren Verwandten Chrodegang von Metz mit Mönchen aus seinem Reformkloster Gorze besetzt und mit den Reliquien des Nazarius ausgestattet, die eine enorme Menge von Schenkungen anzogen, durch die das Kloster zu einem der wohlhabendsten des Reiches wurde. ${ }^{1486}$ Durch die Übertragung des Klosters an Karl den Großen wurde das nunmehrige Königskloster fest an die Herrscherfamilie gebunden ${ }^{1487}$ und genoss insbesondere unter Ludwig dem Deutschen, der dort seine letzte Ruhe fand, ${ }^{1488}$ besondere Förderung.

Von der Bibliothek der Gründergeneration, die mit Sicherheit auf Beständen des entsendenden Gorze beruhte, hat sich keine Spur erhalten, ${ }^{1489}$ wenn auch einige Handschriften, die Teil der Lorscher Bibliothek waren, in die Zeit vor der Gründung zurückreichen. Das Skriptorium tritt uns vielmehr in einem schon ausgeprägten lokalen Stil am Ende des 8. Jh. entgegen. ${ }^{1490}$ Nicht zufällig beginnt

Amicorum. Alois Thomas zur Vollendung des 90. Lebensjahres von Kollegen, Freunden und Schülern dargeboten, Trier 1986, S. 35-55. S. 51-55.

1485 Zur Geschichte: Marc-Aeilko ARIs u. a., "Art. Lorsch», in: Germania Benedictina 7 2004, S. 768-853. Paul SchnitZer, Beiträge zur Geschichte des Klosters Lorsch: Karl Josef Minst zur Vollendung des 80. Lebensjahres am 26. April 1978 (Geschichtsblätter für den Kreis Bergstraße. Sonderband 4), Lorsch 1980. Friedrich KNöPP, Die Reichsabtei Lorsch, Darmstadt 1973. Darin insbesondere: Josef SEMMLER, „Die Geschichte der Abtei Lorsch von der Gründung bis zum Ende der Salierzeit 764 bis 1125«, S. 75-174.

1486 Heinrich BüTTNER, "Lorsch und St. Gallen«, in: Lorsch und St. Gallen in der Frühzeit, Konstanz 1965, S. 5-20. S. 9-14. ARIs u. a.: »Art. Lorsch«. S. 769-772.

1487 Semmler: »Geschichte der Abtei«. S. 80-82.

1488 ARIs u. a.: »Art. Lorsch«. S. 775f.

1489 Marc-Aeilko ARIs, »Art. Lorsch, Bibliotheksgeschichte«, in: Germania Benedictina 7 2004, S. 811-821. S. 811. BischofF: Abtei Lorsch. S. 59.

1490 Grundlegend hierzu: Bischoff: Abtei Lorsch. Nachträge in Tino Licht, Beobachtungen zum Lorscher Skriptorium in karolingischer Zeit«, in: Karolingische Klöster. Wissenstransfer und kulturelle Innovation, hrsg. von Julia Becker, Tino Licht und Stefan Weinfurter, Berlin [u. a.] 2015, S. 145-162. Bischoffs Erkenntnisse sind integriert in: KaUtz: Lorsch, Katalog. (Geschichtlicher Überblick S. IX-XLIII). Der Katalog ist ebenfalls in einer vorbildlichen digitalen Edition zugänglich: »Bibliotheca Laureshamensis - digital: Virtuelle Klosterbibliothek Lorsch«, http://www.bibliotheca-laureshamensis-digital.de/de/index. html (abgerufen am 06.11.2017). (Zum Projekt siehe: Alexandra BüTtNeR, »Bibliotheca Laureshamensis - digital: virtuelle Rekonstruktion einer verlorenen Bibliothek«, in: SehensWerte 8 (2013), S. 35-37.) Ein Überblick auch in: HäsE: Bücherverzeichnisse. Ältere Literatur: LindSAY: »The (Early) Lorsch Scriptorium«. Franz FALK und Carl SCHERER, "Beiträge zur Rekonstruktion der alten Bibliotheca fuldensis und Bibliotheca laureshamensis. Mit einer Beilage: Der Fuldaer Handschriftenkatalog aus dem 16. Jahrhundert.", in: Zentralblatt für Bibliothekswesen, Beiheft 26 (1902), S. 1-112. Die Rekonstruktion der 
die Geschichte des Skriptoriums mit Abt Richbod ${ }^{1491}$ (784-804), Bischof von Trier (791-804), der als Mitglied des Hofes Karls des Großen dort Alkuin kennenlernte und mit diesem in lebenslanger Freundschaft und Korrespondenz verblieb. ${ }^{1492}$ Unter ihm etablierte sich der charakteristische "ältere Lorscher Stil" (784ca. 810), ${ }^{1493}$ dessen Grundlegung jedoch vielleicht schon vor seinem Abbatiat erfolgte. ${ }^{1494}$ Die 20 erhaltenen Handschriften dieser frühen Phase haben das typische Gepräge einer Grundausstattung und konzentrieren sich auf Patristik, Asketik und Grammatik, jedoch auch Historiographie. ${ }^{1495}$

Teil des ältesten erhaltenen Bestandes bildet die Vergil-Handschrift Paris, Bibliothèque nationale de France (BNF), Lat. 7906 (f. 59-88) + 5018 (f. 78-93), ${ }^{1496}$ die mit ihrem sorgfältigen Buchschmuck und spärlichen Anmerkungen kaum wie eine Schulhandschrift anmutet. Vielmehr ist sie mit ihren weiteren Inhalten unter die historischen Handschriften einzureihen: Auf die Aeneis ${ }^{1497}$ folgen Dares Phrygius' Geschichte des Untergangs Trojas ${ }^{1498}$ und das Liber historiae Francorum, ${ }^{1499}$ sowie der chronistische Teil von Bedas De temporum ratione. ${ }^{1500}$ Augenscheinlich stellt diese ganze Sammlung ein historiographisches Kom-

Bibliothek stützt sich, nebenbei bemerkt, ganz auf die Handschriften selbst, da Lorsch keine eigene Literatur hervorbrachte, aus der auf ihre Quellen geschlossen werden könnte: Johannes Duft, "Die Klosterbibliotheken von Lorsch und St. Gallen", in: Lorsch und St. Gallen in der Frühzeit, Konstanz 1965, S. 21-45. S. 34.

1491 Josef Fleckenstein, »Art. Ricbod (Richbod), Abt von Lorsch, Bischof von Trier ( +804$)$ «, in: Lexikon des Mittelalters, 7, 1995, S. 807. SeMMLER: „Geschichte der Abtei«. S. 84-85.

$1492 »$ Alcuini epistolae«. Siehe das Register S. 627. s.v.

$1493 \mathrm{Zu}$ den Daten siehe die konzise Zusammenfassung in: Liснт: "Lorscher Skriptorium«. S. 148.

1494 Schon ab den 760er Jahren: Ebd. S. 146-153.

1495 ARIs: Art. Lorsch, Bibliotheksgeschichte«. S. 812; BischofF: Abtei Lorsch. S. 61.

1496 Michael Kautz, »Paris, Bibliothèque nationale de France, Latin 7906«, http://bibliothecalaureshamensis-digital.de/view/bnf_lat7906 (abgerufen am 14.11.2017). BischofF: Abtei Lorsch. S. 36, 83, 112f. Bischoff: Katalog, 3. Nr. 4512. Elias A. Lowe (Hrsg.), Codices Latini antiquiores, Suppl., Oxford 1971. Nr. 1744.

1497 R. A. B. Mynors (Hrsg.), P. Vergili Maronis Opera, Reprinted (with corr.) (Scriptorum classicorum bibliotheca Oxoniensis), Oxford 1983. Sigle p: S. VIII. Eingeleitet durch RIESE/ BüCHeler (Hrsg.): Anthologia latina. Nr. 634.

1498 Ferdinand Meister (Hrsg.), Daretis Phrygii de excidio Troiae historia, 2. Aufl. (Bibliotheca scriptorum Graecorum et Romanorum Teubneriana), Stuttgart 1991. Louis FaIVRE D'ARCIER, Histoire et géographie d'un mythe: la circulation des manuscrits du De exidio Troiae de Darès le Phrygien (VIIIe-XVe siècles) (Mémoires et documents 82), Paris 2006. S. $67 \mathrm{f}$.

1499 "Liber historiae Francorum«, in: MGH SS rer. Merov. 2, hrsg. von Bruno KRUSCH 1888, S. 215-328. Die Handschrift nicht benutzt. Richard A. Gerberding, "Paris, Bibliothèque nationale Latin 7906: an unnoticed very early fragment of the >Liber Historiae Francorum «, in: Traditio 43 (1987), S. 381-386.

1500 Cap. LXVI. 
pendium zur trojanischen Abstammung der Franken dar ${ }^{1501}$ - eine direkte Verbindung zu Richbod, den Alkuin scherzhaft wegen seiner Vergil-Liebhaberei tadelt, wird von Bischoff nahegelegt. ${ }^{1502}$ In jedem Falle stellt die Überlieferungssituation für diesen ältesten Vergil-Zeugen nördlich der Alpen ${ }^{1503}$ eine ungewöhnliche und ganz von schulischen Interessen getrennte Wertschätzung Vergils dar, der ansonsten insbesondere über die kontinuierliche Tradition des spätantiken Schulkanons in die Bibliotheken Eingang fand. ${ }^{1504}$ Als Komplement zu diesem im außerschulischen Zusammenhang stehenden Vergil darf auch die Handschrift des Fulgentius mythographus, BAV, Pal. lat. 1578, gelten, die, ebenfalls um 800 in einem noch unreifen älteren Lorscher Stil geschrieben, die allegorische Auslegung der Aeneis enthält. ${ }^{1505}$ Das Werk ist für den schulischen Gebrauch denkbar ungeeignet, da es Vergil moralisiert unter Ausschluss »of any concern for grammar, rhetoric, narrative skill, topical allusions, use of language, or prosody«. ${ }^{1506}$

Paläographisch und in Teilen inhaltlich dieser Handschrift nahestehend ist die kleine Handschrift Vatikan, BAV, Pal. lat. 487 (f. 31-45). ${ }^{1507}$ Zur besseren Übersicht soll hier Kautz' gedrängte Inhaltsangabe vereinfacht tabellarisch aufgeschlüsselt werden:

\begin{tabular}{|l|l|l|l|}
\hline Folio & Schreiber $^{1508}$ & Inc. & Anmerkungen \\
\hline $31 \mathrm{r}$ & - & Unde crescunt numeri & Zusatz 10. Jh. $^{1509}$ \\
\hline
\end{tabular}

1501 Bischoff: Abtei Lorsch. S. 35. Eugen Ewig, »Troja und die Franken«, in: Rheinische Vierteljahrsblätter 62 (1998), S. 1-16. S. 16.

1502 Bischoff: Abtei Lorsch. S. 35. »Alcuini epistolae«. S. 36, Z. 9-15.

1503 Reynolds: Texts and transmission. S. 435. Über weitere Herkunft und Einfluss des Textes ist wegen der großen Kontaminierung der karolingischen Handschriften nichts auszumachen.

1504 GLAUCHE: Schullektüre. S. 1-22, wo Vergil in beinahe allen Quellen eine Konstante ist. Siehe auch zu den Nutzungsspuren: Nikolaus Henkel und Rolf BergmanN, "Art. Juvenal (Decius Iunius Iuvenalis), Althochdeutsche Glossierung", in: Althochdeutsche und altsächsische Literatur, hrsg. von Rolf BERGMANN, Berlin [u. a.] 2013, S. 219-222.

1505 "Expositio Virgilianae continentiae«: Rudolf Helm (Hrsg.), Fabii Planciadis Fulgentii V.C. Opera, Ed. stereotypa ed. anni 1898. Aufl. (Bibliotheca scriptorum Graecorum et Romanorum Teubneriana), Stuttgart 1970. S. 83-107. Zur Handschrift: S. IX f., XIII.

1506 Leslie George Whitbread, Fulgentius the Mythographer, Translated from the Latin, with Introductions, Columbus, $\mathrm{OH}$ 1971. S. 104.

1507 Lagenformel: IV ${ }^{31-38}+(\mathrm{III}+1)^{39-45}$. Format: $21 \times 13,5 \mathrm{~cm}$. Michael KAUTZ, "Vatikan, Biblioteca Apostolica Vaticana, Pal. lat. 487«, http://bibliotheca-laureshamensis-digital.de/ bav/bav_pal_lat_487 (abgerufen am 14.11.2017). Die paläographische Ähnlichkeit besteht im Schreiber 33v-36v: Bischoff: Abtei Lorsch. S. 31 f. Bischoff: Katalog, 3. Nr. 6533 (f. 130: Nr. 6532).

1508 Vom Autor festgestellt, soweit nicht bei BischоғF unterschieden.

1509 Christoph MüNCH, Musikzeugnisse der Reichsabtei Lorsch: eine Untersuchung der Lorscher musikalischen Handschriften in der Bibliotheca Palatina in der Vatikanischen Bibliothek, Lorsch 1993. S. 86. 
(Fortsetzung)

\begin{tabular}{|c|c|c|c|}
\hline Folio & Schreiber ${ }^{1508}$ & Inc. & Anmerkungen \\
\hline \multicolumn{4}{|c|}{ Anthologie, Teil 1} \\
\hline $31 v$ & \multirow[t]{4}{*}{$\mathrm{A}$} & $\begin{array}{l}\text { (Musa senectutis istic can- } \\
\text { tatur amarae) Fortia quid } \\
\text { subito }\end{array}$ & $\begin{array}{l}\text { SK 9920, Ps.- Maximian, De senec- } \\
\text { tute }\end{array}$ \\
\hline $32 \mathrm{r}$ & & $\begin{array}{l}\text { Virgo columba suo } \\
\text { Ecce bonum quam } \\
\text { En laetum et pulchrum }\end{array}$ & $\begin{array}{l}\text { Lob der Jungfrau Maria } \\
\text { Lob des Mönchslebens }{ }^{1510} \\
\text { item }^{1511}\end{array}$ \\
\hline $32 \mathrm{v}$ & & \multirow{2}{*}{$\begin{array}{l}\text { Tu quicumque cupis } \\
\text { An ego raucesonum } \\
\text { Pastor o qui Christi }\end{array}$} & \multirow{2}{*}{$\begin{array}{l}\text { SK 16562, Gedicht an einen Schüler } \\
\text { über den Gesang } \\
\text { SK 749, Dialog zwischen a(lum- } \\
\text { nus?) und d(idasculus?) } \\
\text { SK 11712, Trinkgedicht }{ }^{1512}\end{array}$} \\
\hline $33 r$ & & & \\
\hline $\begin{array}{l}33 \mathrm{v} \\
(37 r) \\
(40 \mathrm{r})\end{array}$ & $\begin{array}{l}\mathrm{C} \\
\mathrm{D}_{1}\end{array}$ & $\begin{array}{l}\text { Carmina Vergili sunt } \\
\text { Maeonium quisquis Roma- } \\
\text { nus } \\
\text { Pastorum musam vario } \\
\text { Sperne lucrum versat }\end{array}$ & $\begin{array}{l}\text { SK 1971, Über die Werke Vergils } \\
\text { SK 9167, Über Homer und Vergil } \\
\text { SK 11724, Monosticha über die } \\
\text { Werke Vergils, am Rande numme- } \\
\text { riert. } \\
\text { Aus den Carmina XII sapientium, } \\
\text { Zyklus VIII, Beginn Zyklus XI. }{ }^{1513}\end{array}$ \\
\hline \multicolumn{4}{|c|}{ Anthologie, Teil 2} \\
\hline $40 \mathrm{r}$ & $\mathrm{E}$ & & $\begin{array}{l}\text { Einhard, Brief an Ludwig den } \\
\text { Frommen (ep. 40) }\end{array}$ \\
\hline $41 r^{1514}$ & $\mathrm{~F}$ & Dira patet Iani & SK 3727, Carmen de mensibus \\
\hline $\begin{array}{l}42 \mathrm{r} \\
44 \mathrm{v} \\
45 \mathrm{r}\end{array}$ & $\mathrm{D}_{2}$ & $\begin{array}{l}\text { Virgilius magno quantum } \\
\text { Aeneas primo libyae } e^{1515} \\
\text { Ergone supremis }^{1516}\end{array}$ & $\begin{array}{l}\text { Ps.-Ovid: Monosticha über die } \\
\text { Aeneis } 1 \\
\text { Ps.-Ovid: Monosticha über die } \\
\text { Aeneis } 2^{1517} \\
\text { Titel: Epigramma Augusti Caesaris } \\
\text { quod Aeneidos Uergilii cremare } \\
\text { uetuit }\end{array}$ \\
\hline
\end{tabular}

Die Entstehung der Handschrift fand in folgenden Stufen statt:

$$
\text { 1. A, 2. } \mathrm{BCD}_{1}, 3 . \mathrm{E}, 4 . \mathrm{FD}_{2} \text {. }
$$

1510 Hans WALther, Initia carminum ac versuum medii aevi posterioris latinorum: Hauptband. 1 1959. Nr. 20483, 5068.

1511 DÜMMLER: „Die handschriftliche Überlieferung«. S. 570.

1512 Alle drei, bezeichnet als "Spielereien der Schule» in: Ernst DüMmLER, »Lateinische Gedichte des neunten bis elften Jahrhunderts", in: Neues Archiv der Gesellschaft für ältere deutsche Geschichtskunde 10 (1885), S. 331-357. S. 339 f.

1513 FRIEDRICH: Symposium. S. 16, 21.

1514 41v nur Z. 1-4 beschrieben, der Rest leer.

1515 RIESE/BÜCHELER (Hrsg.): Anthologia latina. Nr. 1, praefatio.

1516 Ebd. Nr. 672.

1517 Ebd. Nr. 1, I-XII, je den ersten Vers. 
Der zweite Teil der Sammlung ist paläographisch später anzusetzen als der erste. ${ }^{1518}$ Dennoch sind die zwei Teile kodikologisch und inhaltlich eng miteinander verbunden: Die älteren Schreiber ABC, von denen B stark dem altertümlichen Stil von Pal. lat. 1578 ähnelt und der nicht ein einzelnes Gedicht, sondern in Gemeinschaft mit $C\left(D_{1}\right)$ eine einheitliche Reihe schreibt, füllen auch das erste Blatt zweiten Lage (f. 39) mit weiteren Carmina XII sapientium; im Wechsel zu f. 40 übernimmt hier mitten im Text der Carmina der jüngere Schreiber $D_{1}$, der ebenfalls nach den von Bischoff als eindeutig jünger bezeichneten Schreibern EF vergilianisches Material ergänzt. Durch Schreiber D, der sowohl zur Arbeit der älteren als auch der jüngeren beiträgt, sind diese als gleichzeitig gekennzeichnet. Hier hat somit eine Gemeinschaft älterer (ABC) und jüngerer Schreiber (DEF) zusammengearbeitet, womit die Handschrift auf einen mittleren Zeitpunkt etwa in den 820ern datiert werden müsste, als die älteren noch und die jüngeren schon schrieben. Bei den Inhalten liegt eine Verbindung zur Schule nahe, jedoch nicht zweifelsfrei. Aus dem Komplex der von A geschriebenen kleineren Gedichte stechen hier insbesondere die zwei wörtlich Schüler und Lehrer nennenden Gedichte heraus, ${ }^{1519}$ die jedoch den Gesang, nicht die Lektüre betreffen - ein Lernumfeld ist dennoch aus beiden offensichtlich. Die weiteren Kleingedichte sind nur allgemein monastisch-christlicher Natur. Der Schule näherstehend sind die Vergiliana, die sich in beiden Teilen der Anthologie finden. Im Mittelpunkt stehen hier verschiedene poetische Inhaltsangaben und Werkübersichten, die häufig in Handschriften schulischen Charakters auftreten. Sie sind somit als Lehrmaterial für die Beschäftigung mit den Werken des Dichters anzusehen. Apart von diesem Schulmaterial steht das die Handschrift eröffnende Ps.-Maximianische Gedicht über das Alter. ${ }^{1520}$ Es ist das früheste Zeichen für die Überlieferung und Imitation des spätantiken Dichters im Mittelalter. ${ }^{1521}$ Das

1518 Wiewohl Bischoff: Abtei Lorsch. S. 31f. nur »foll. 40r unten bis 41r Mitte (Einhard, ep. 40; noch jünger fol. 41r z.T. und v) « in die Mitte des 9. Jh. einordnet, scheint auch der paläographisch ähnliche Teil f. 42r-45r, wie auch KAUTz meint (»die Hand 42r-45v scheint jünger als die übrigen zu sein«) späteren Datums zu sein. Die von mir vorgenommene, bei Vergleich offensichtliche Identifikation von $D_{1}$ und $D_{2}$ ist bei Bischoff vielleicht impliziert.

1519 (32v-33r): I (Ed. DüMMLER): iuuenis ... disce ... magistro, studiose ... disce; II: a(lumnus?) d(octor?).

1520 Strecker (Hrsg.): MGH Poet. lat. 4, 2.3. S. 1084f. Wolfgang Christian Schneider (Hrsg.), Die elegischen Verse von Maximian: eine letzte Widerrede gegen die neue christliche Zeit; mit den Gedichten der Appendix Maximiana und der Imitatio Maximiani; Interpretation, Text und Übersetzung (Palingenesia 79), Stuttgart 2003. S. 147-151. Rosario LEOTTA, »Un anonimo imitatore di Massimiano. ", in: Giornale italiano di filologia 37 (1985), S. 91-106.

1521 Edition »Maximiani Elegiae«: BAenrens (Hrsg.): Poetae latini minores. V, Nr. LVII, S. 313348. Der früheste direkte Textzeuge ist Paris, BNF Lat. 2832, »Lyon oder Saint-Oyan, IX. Jh., Mitte bis 3. Viertel« (BIschoff: Katalog, 3. Nr. 4240). Vgl. auch weitere Maximianus- 
Gedicht ist von selbstständiger literarischer Qualität und vermag auch den heutigen Leser durch seine unmittelbare Naturschilderung und Empfindsamkeit zu berühren. Die Welt, die es darstellt, ist nicht die des Klosters, ja kaum explizit eine christliche - es ist vielmehr der sich der Jagd- und Kampfabenteuer seiner Jugend erinnernde Adlige, ${ }^{1522}$ der hier das Schwinden seiner Kräfte im Alter beklagt. Das Gedicht steht somit ganz fremd in seinem Überlieferungszusammenhang. Angesichts des ansonsten gänzlichen Fehlens von Dichtung aus Lorsch, halte ich es für nicht beweisbar, dass das qualitativ hochwertige Gedicht von hier stammen sollte. Von wo es stammt, und wie es seinen Weg in eine Lorscher Schulhandschrift ${ }^{1523}$ fand, ist nicht zu rekonstruieren. Eine Verbindung mit dem Hof, wo man ein Publikum vermuten kann, das sich in die dramatis persona einfühlen konnte, und wo Abt Richbod mit Alkuin befreundet war, wäre spekulativ.

Ebenfalls schulischen Bedürfnissen zu dienen scheint die frühe Handschrift Vatikan, BAV, Pal. lat. 1753. ${ }^{1524}$ Wenigstens vor 808 und wahrscheinlich früher entstanden, ${ }^{1525}$ repräsentiert sie wie keine andere der frühen Handschriften das Curriculum unter Richbod. Sie zerfällt entlang von Text-, Schrift- und Lagengrenzen zwanglos in zwei Teile:

1. f. 1-70: Zwei Traktate zu Metrik und Grammatik. ${ }^{1526}$ Cento Probae, ${ }^{1527}$ Cento Tytiri. ${ }^{1528}$

[Angehängtes Binio: f. 71-75: Zwei Auszüge zu Metrik und Grammatik. ${ }^{1529}$ ]

Remineszenzen bei Alkuin (Strecker (Hrsg.): MGH Poet. lat. 4, 2.3. S. 1084f. Anm. zu XIII).

1522 Diese Stellen jedoch vielleicht Reflex cynegetischer Topoi: Leotta: »Massimiano«. S. 99.

1523 Zur Elegie als Schuldichtung: Ebd. S. 105. Für das Hochmittelalter ist eine schulische Verwendung Maximians gut belegt: L. R. Lind, Gabriele Zerbi: Gerontocomia, on the care of the aged; and Maximianus, elegies on old age and love (Memoirs of the American Philosophical Society 182), Philadelphia : 1988. S. $313 \mathrm{f}$.

1524 Format: $25,5 \times 16 \mathrm{~cm}$, Lagenformel: $1^{1}+(\mathrm{IV}-1)^{7}+7 \mathrm{IV}^{63}+(\mathrm{III}+1)^{70}+(\mathrm{II}+1)^{75}+3 \mathrm{IV}^{99}+$ $(\mathrm{V}+1)^{110}+\mathrm{IV}^{118}$ : Michael KAutz, »Vatikan, Biblioteca Apostolica Vaticana, Pal. lat. 1753«, http://bibliotheca-laureshamensis-digital.de/bav/bav_pal_lat_1753 (abgerufen am 17.11. 2017). Bischoff: Abtei Lorsch. S. 32, 130f. Bischoff: Katalog, 3. Nr. 6593. Bergmann/ STRICKER: Katalog. Nr. 816.

1525 Vielleicht vor 790, wenn Lichтs Identifizierung einer Hand mit dem Urkundenschreiber Rado korrekt ist: Liснт: "Lorscher Skriptorium«. S. 149-153. Zu weiteren archaischen (alemannischen, vll. St. Galler) Merkmalen siehe: Natalie MAAG, »Alemannische Spuren in Lorsch«, in: Karolingische Klöster. Wissenstransfer und kulturelle Innovation, hrsg. von Julia Becker, Tino Licht und Stefan Weinfurter, Berlin [u. a.] 2015, S. 163-174. S. 169.

1526 Marius Victorinus / Aelius Festus Asmonius (!) im Auszug: KeIL (Hrsg.): Grammatici Latini. VI, S. 3-173. Aelius Festus Asmonius: De metris Horatianis: Ebd. S. S. 174-184.

1527 Lucarini (Hrsg.): Proba: Cento Vergilianus. Zur Handschrift (p) S. XLVI f.

1528 Codex unicus: Petschenig/Schenkl/Brandes (Hrsg.): Poetae Christiani minores. S. 609615.

1529 Für genauen Nachweis vgl. Kautz: »BAV Pal. lat. 1753«. 
2. f. 76-118: Aldhelm: Epistula ad Acircium (zur Metrik, inkl. Aenigmata). ${ }^{1530}$ Symphosius: Aenigmata. ${ }^{1531}$ Aenigmata Laureshamensia. ${ }^{1532}$ Kürzere grammatische Texte.

Die zwei vergilianischen Centos, die Versstücke des Dichters zu christlichen Versen amalgamieren, folgen von je anderer Hand wie Prosa geschrieben aufeinander. Der pädagogisch wichtige Dichter wird durch das Rearrangement theologisch unverdächtig gemacht und kann somit bedenkenlos den Schülern zur Übung aufgegeben werden. Der erste Teil ist somit eine Fortentwicklung des in Lorsch rezipierten antiken Curriculums, ${ }^{1533}$ das uns in den Vergil-Accessus von Pal. lat. 487 schon begegnet ist. Der zweite Teil dagegen repräsentiert die irische Tradition mit Aldhelms vollständiger Epistel zur Rätseldichtung, darin alle seine Aenigmata und ein Traktat zur Metrik, sowie weitere Rätseldichtung. ${ }^{1534} \mathrm{Nach}$ der durchgängig sauberen Abschrift Aldhelms trägt die Handschrift von f. 109v$118 \mathrm{v}$ einen ungeordneten, gewachsenen Charakter, wo jeder Text in anderer Hand geschrieben ist. Mit Symphosius' Rätsel 64 endet ein Schreiber, worauf f. 112 freiblieb. ${ }^{1535}$ Ein weiterer Schreiber trägt, ohne den vorherigen Freiraum zu nutzen, auf f. $113 \mathrm{r}$ weitere Rätsel ein, die dann auf der gegenüberliegenden Freiseite $112 \mathrm{v}$ weiter ergänzt wurden. ${ }^{1536}$ Hier wurde also beim Studium der fehlende Text bemerkt und aus der Vorlage ergänzt. ${ }^{1537}$ Ein Auszug aus Pompeius zur Metrik auf f. 113v, sowie Auszüge aus Bonifatius'(?) Ars Metrica von zwei Händen auf 114r/v, 116r/v begleiten die Verse theoretisch. ${ }^{1538}$ Der kodikologische Platz der Aenigmata Laureshamensia bleibt in der Edition undeutlich; sie stehen, getrennt durch Bonifatius auf f. 115r/v (Nr. I-IV), dort jedoch jeweils nur die ersten Zeilen über bedeutendem Freiraum einnehmend, und auf $117 \mathrm{r} / \mathrm{v}$ (Nr. V-

1530 Ehwald (Hrsg.): Aldhelmi Opera. S. 59-204. Zur Handschrift (N): S. 37f., 45, 340. GLORIE (Hrsg.): Collectiones aenigmatum. S. 383-503.

1531 GLORIE (Hrsg.): Collectiones aenigmatum. S. 621-672.

1532 Ernst DüMMLER, "Lorscher Rätsel«, in: Zeitschrift für deutsches Altertum und deutsche Literatur 22 (1878), S. 258-263. GloRIE (Hrsg.): Collectiones aenigmatum. S. 345-358.

1533 Der Text der Grammatiker enthält sogar Spuren des spätantiken Archetyps, wenn nicht sogar Antigraphs, in Form zahlreicher »notae antiquae» (KAUTZ: »BAV Pal. lat. 1753«. "Angaben zu Schrift/Schreibern«), die jedoch auch im insularen Schriftraum vorkommen (insulare Abkürzungen im selben Text: Ebd.; zum irischen Notae-System: Bischoff: $\mathrm{Pa}$ läographie des römischen Altertums und des abendländischen Mittelalters. S. 116).

1534 Vgl. zur Überlieferung auch: LAPIDGE: »Aldhelmus«. S. 19-26. Pal. lat. 1753 ist eng verwandt (Gruppe B) mit Brüssel, BR, Ms. 4433-4438 (s. IX, Saint Amand).

1535 112r im Spätmittelalter mit einem Gebet beschrieben.

1536 Querverweis von Hand f. 112v »dh» (deest hic) auf $113 \mathrm{r}$ wird $112 \mathrm{v}$ vor dem Text mit »hd» aufgenommen.

1537 Die gleiche (verlorene) Vorlage hat Pal. lat. 1719, Faszikel I (ebenfalls aus Lorsch, siehe unten S. 246f.).

1538 Auf 116v von gleicher Hand wie 116r ein Gedicht des Bonifatius (carm. 7). 
XII) von anderer Hand. Ein ursprünglicher Zusammenhang dieser zwölf Rätsel ist daher nicht gesichert. Eine insulare Herkunft liegt, wie Dümmler vermutet, ${ }^{1539}$ aufgrund des Überlieferungszusammenhanges nahe. Die beiden Teile der Handschrift befanden sich schon um 830 unter einem Buchdeckel ${ }^{1540}$ und repräsentieren zusammen das Zusammenfließen antiker und insularer Schultraditionen, verbildlicht durch eine Federprobe unter den Aenigmata Laureshamensia (f. 115v): Arma uirumque cano (...).

Die insulare Tradition findet sich ebenfalls wieder in der Handschrift Paris, BNF Lat. 16668, ${ }^{1541}$ die zudem vielleicht einen Schreiber mit Pal. lat. 1753 teilt und 41r-58r insulare Schriftmerkmale zeigt. Besonders der erste Teil (f. 1-39) zeigt auch in seinen Texten einen insularen Schwerpunkt. ${ }^{1542}$ Auf Bedas De arte metrica $^{1543}$ folgen von anscheinend gleicher Hand mit anderer Tinte vier kleinere Gedichte (21r-22v): 1. Inc. Apparebunt ante summum (SK 946, ein Bibelgedicht), ${ }^{1544}$ das genau den Vorschriften der Ars Metrica folgt. ${ }^{1545}$ 2. Drei Mahngedichte an Schüler: Inc. Audax es iuvenis (SK 1305), [Handwechsel?] Murice puniceo (SK 9909), Est mihi discipulus (SK 4607). ${ }^{1546}$ Auf den zweiten Haupttext (Aldhelm, Carmen de virginitate, De octo principalibus vitiis) ${ }^{1547}$ folgt 39r ein an Aldhelm angelehntes Gedicht (Inc. Plus amat altithronus, SK 12084). Ein rhetorisches Lehrbuch aus Boethius (f. 41r-58v) schließt im zweiten Hauptteil die Handschrift ab. BNF Lat. 16668 bedient somit mehr noch als Pal. lat. 1753 die Bedürfnisse des Triviums im Unterricht. Die kleineren Gedichte, die sich wie Beispielmaterial eng an die Texte anschließen, könnten Lorscher Ursprungs sein und Zeugnisse einer auf die Schule beschränkten dichterischen Tätigkeit dort

1539 DüMMLER: »Lorscher Rätsel«. S. 262.

1540 Die Handschrift war laut dem Katalog A wahrscheinlich schon um 830 in einem Band vorhanden: ars marci uictorini grammat et althelmi de regula metrorum et enigmata simphosii in uno cod. (HÄsE: Bücherverzeichnisse. S. 302f., Nr. 323).

1541 Format: 19,5 x 11,5-13 cm, Lagenformel: $1^{1}+4 \mathrm{IV}^{33}+$ III39 $+2 \mathrm{IV}^{55}+(\mathrm{IV}-1)^{62}$ : Michael KAUTZ, »Paris, Bibliothèque nationale de France, Latin 16668«, https://www.bibliothecalaureshamensis-digital.de/view/bnf_lat16668 (abgerufen am 17.11.2017). Bischoff: Abtei Lorsch. S. 32f., 35, 83, Anm. 38, S. 97, Anm. 20, S. 114f. Bischoff: Katalog, 3. Nr. 4982a. BergmanN/STRICKER: Katalog. Nr. 768.

1542 Der zweite Teil (f.40-62) ist durch einen lagenübergreifenden Schreiber 39v-40r und einem Aldhelm-Glossar (s. X) auf 40v eng mit dem ersten Teil verbunden.

1543 Calvin B. Kendall (Hrsg.), Beda. Libri II De arte metrica et De schematibus et tropis: the art of poetry and rhetoric (Bibliotheca Germanica, Series Nova 2), Saarbrücken 1991.

1544 Strecker (Hrsg.): MGH Poet. lat. 4, 2.3. S. 491-495.

1545 Wilhelm Meyer, Gesammelte Abhandlungen zur mittelalterlichen Rhythmik, Berlin 1905. II, S. $349 f$.

1546 Nur teilweise ediert, siehe zu Details: Kautz: »Paris, Bibliothèque nationale de France, Latin 16668«.

1547 Ehwald (Hrsg.): Aldhelmi Opera. S. 350-471. Zur Handschrift (N) S. 339-341. 
sein. ${ }^{1548}$ Dichtung in Lorsch unter Richbod war also im wesentlichen auf die Schule konzentriert, wie ihre kodikologische Verbindung mit grammatischem Material sowie ihre Themen selbst (Schüler, Inhaltsangaben etc.) beweisen. Nur Vergil, für den eine schulische Verwendung ebenfalls belegt ist, durchbricht in der »Trojaner«-Handschrift Paris, BNF, Latin $7906+5018$ dieses Muster. ${ }^{1549}$

Richbods Nachfolger Adalung (804-837) beaufsichtigte nicht nur den sprunghaften Anwuchs der Bibliothek, sondern auch territoriale Erweiterungen in politisch schwieriger Zeit. Dem Kloster war er schon vor seinem Abbatiat durch Schenkungen und vielleicht als Urkundenschreiber verbunden. ${ }^{1550}$ Unter ihm fand die Weiterentwicklung und schließlich Vervollkommnung des Lorscher Hausstils statt. Neben den »Übergangsstil« (ca. 810-ca. 825) trat noch der »SaintVaast-Stil«, geprägt von der Schreibschule des westfränkischen Klosters, dem Adalung ebenfalls vorstand. ${ }^{1551}$ Dieser ortsfremde Stil tritt in gemeinsamer Arbeit mit Lorscher Händen auf, sodass eine direkte Teilnahme von St. Vaaster Mönchen oder die Ausbildung von Schreibern dort ausgemacht ist. Dichtung stand jedoch bei der Erweiterung der Bibliothek nicht im Mittelpunkt, sodass trotz der größeren Zahl der aus Adalungs Zeit erhaltenen Handschriften nicht proportional mehr Dichtung erhalten geblieben ist; das Hauptinteresse lag eben bei den Kirchenvätern. ${ }^{1552}$

Das schon fest etablierte Studium Vergils wurde auch zu Adalungs Zeit nicht vernachlässigt, wie die vielgenutzte Handschrift Wolfenbüttel, HAB, Cod. Guelf. 66 Gud. lat. zeigt. ${ }^{1553}$ Die Kontinuität der Tradition zeigt sich in den

1548 Dies erscheint insbesondere für die nach dem Handwechsel auf f. 22v ergänzten zwei Stücke wahrscheinlich zu sein.

$1549 \mathrm{Zu}$ ergänzen sind hier die ganz in Touronenser Material eingebundenen Tituli des Martinellus in Merseburg, DStB Cod. 105 (Lorsch um 800: Michael KAUTZ, »Merseburg, Domstiftsbibliothek, Cod. 105«, https://bibliotheca-laureshamensis-digital.de/view/ dstibm_cod105 (abgerufen am 20.11.2017). J. Francis Gilardi, The Sylloge epigraphica Turonensis de S. Martino, Ann Arbor, Mich. 1984. Nr. 1-19), die in einem Zug mit den vorhergehenden De virtutibus sancti Martini geschrieben wurden. Eine Vermittlung durch Richbods Freund Alkuin, der zu der Zeit Abt in Tours war, liegt nahe - eine ganz ähnliche Vermittlung fand im zweiten Faszikel der Handschrift statt, wo zu Adalungs Zeit (gleichzeitig Abt von St. Vaast) Alkuins Vita St. Vedasti nach Lorsch kam. In denselben Vermittlungszusammenhang gehört Wien, ÖNB Cod. 550 (St. Vaast, 1. Hälfte 9. Jh.), wo die gleiche Vita mit einigen Versen und Tituli Alkuins zu St. Vaast ergänzt wird (SK 10297, 2238, 6576, 12121, 5861).

1550 Semmler: „Geschichte der Abtei«. S. 85-86.

1551 Bischoff: Abtei Lorsch. S. 37-44.

1552 Julia BECKER, "Präsenz, Normierung und Transfer von Wissen: Lorsch als spatristische Zentralbibliothek«", in: Karolingische Klöster. Wissenstransfer und kulturelle Innovation, hrsg. von Julia BeCKer, Tino Licht und Stefan Weinfurter, Berlin [u. a.] 2015, S. 71-88. S. 77.

1553 St. Vaast oder Lorsch. Format: 28,5 x 23,5 cm, Lagenformel: $6 \mathrm{IV}^{48}$ : Michael KAUTZ, "Wolfenbüttel, Herzog August Bibliothek, Cod. Guelf. 66 Gud. lat.», http://bibliotheca-lau 
die einzelnen Bücher einleitenden Versen: Es sind dieselben Ps.-Ovidischen Monosticha, die auch schon in Pal. lat. 487 und BNF Lat. $7906+5018 \mathrm{zu}$ finden waren. ${ }^{1554}$ Weiteres Zeichen des eingehenden Studiums sind die zahllosen Glossen, Korrekturen und Bemerkungen, die sich von einer Vielzahl von Händen durch die Handschrift verstreut finden. Der Großteil sind lateinische Synonymglossen, die dem Verständnis schwierigerer Vokabeln dienen; an anderen Stellen wurde kritisch gearbeitet, fehlerhafte Stellen korrigiert und fehlende ergänzt - leider liegt keine Untersuchung des Zusammenhangs mit den anderen Vergil-Handschriften Lorschs vor, die Licht auf die wissenschaftliche Arbeit der Gelehrten dort werfen könnte. ${ }^{1555}$ Ein Hilfsmittel hierzu könnten Priscians Untersuchung zu den ersten Versen der Bücher der Aeneis in Pal. lat. 1649 sein, worin ausgiebig Metrik und Grammatik diskutiert werden. ${ }^{1556}$

Die spätantike christliche Dichtung tritt überraschend spät auf den Plan und dies auch nicht mit ihren verbreitetsten Vertretern - ein Umstand, der angesichts der Fülle solcher Dichtung in den Katalogen ${ }^{1557}$ wohl mehr dem Zufall der Überlieferung als einem Mangel an Interesse zuzuschreiben ist. Es ist Ennodius, dessen Opera Omnia in Brüssel, Bibliothèque royale de Belgique Ms. 9845$9848^{1558}$ das früheste ${ }^{1559}$ Zeugnis des einst reichen Bestandes bilden. ${ }^{1560}$ Sie ist eine

reshamensis-digital.de/view/hab_mss66-gud-lat (abgerufen am 20.11.2017). ВischofF: Abtei Lorsch. S. 43, 134f. Bischoff: Katalog, 3. Nr. 7308. Bergmann/STriCKER: Katalog. Nr. 961. Munk Olsen: L'étude des auteurs classiques latins. 2, S. 794.

1554 Riese/BüCheler (Hrsg.): Anthologia latina. Nr. 1 \& 634. Wegen dieses Parallelismus halte ich eine Entstehung der Handschrift in Lorsch für wahrscheinlich. Vgl. zu den einleitenden Versen: HoLtz: »La redécouverte de Virgile«. S. 18-20.

1555 Das Digitalisat lässt leider keine Detailuntersuchung zu. Angesichts der gewissenhaften Text-Arbeit in Lorsch (BECKER: »Zentralbibliothek«. S. 80) würde ein Abgleich mit anderen Handschriften des Dichters nicht überraschen. Zu einem Detail der Marginalien (Neumierung): Heinrich RumphoRst, "Zur musikalischen Gestaltung der Verse Aeneis 4, 424436 im cod. Guelf. 66 Gud. Lat. f. 20vb«, in: Vergil. Handschriften und Drucke der Herzog August Bibliothek (Ausstellungskataloge der Herzog-August-Bibliothek 37), Wolfenbüttel 1982, S. 29-34.

1556 "Partitiones XII versuum Aeneidos principalium» (Marina PassalacQua (Hrsg.), Prisciani Caesariensis Opuscula, Vol. II. (Sussidi eruditi 48), Roma 1999. S. 43-128) in Vatikan, BAV, Pal. lat. 1649 (Nordfrankreich: Michael KAUtz, »Vatikan, Biblioteca Apostolica Vaticana, Pal. lat. 1649«, http://bibliotheca-laureshamensis-digital.de/bav/bav_pal_lat_1649 (abgerufen am 21.11.2017).) Die Handschrift im Katalog A (ca. 830) verzeichnet: Liber prisciani grammatici, partitiones versuum XII Aeneidos principalium, in uno codice. (HÄsE: Bücherverzeichnisse. Nr. 419).

1557 BECKER: »Zentralbibliothek«. S. 77.

1558 Stéphane GioAnNi (Hrsg.), Ennode de Pavie, Lettres, Livres I-II (Collection des Universités de France. Série latine 383), Paris 2006. (Sigle B, S. CXLIV, CLIV, CLXXIV). Wilhelm von Hartel (Hrsg.), Magni Felicis Ennodii opera omnia (CSEL 6), Wien 1882. (Sigle B, S. I-IIII) Friedrich Vogel (Hrsg.), Magni Felicis Ennodi opera (= 1885) (MGH AA 7), München 1961. (Sigle B, S. XXXII-XXXV). 
der Handschriften, die in St. Vaast für Lorsch unter Beteiligung von Schreibern beider Traditionen angefertigt wurden. Lorsch hat hiermit die älteste der Handschriften des Dichters, ohne jedoch Ausgangspunkt der gesamten Tradition zu sein, womit insbesondere die gattungsblinde Ordnung der Werke, die Briefe, Gedichte und Traktate durcheinander mischt, ${ }^{1561}$ nicht auf Lorsch zurückgeht. ${ }^{1562}$ Die Handschrift befindet sich im Katalog in Gemeinschaft weiterer Briefsammlungen und ist nicht den Dichtern zugeordnet. Sie ist der erste Eintrag in diesem epistolaren Corpus ${ }^{1563}$ und bildete vielleicht den Kristallisationskeim der späteren Sammlung von Briefhandschriften.

Zwei Handschriften, die nicht im St. Vaaster Stil, sondern im klostereigenen Übergangsstil entstanden, stehen wieder der Schule näher. Vatikan, BAV, Pal. lat. 1719 (Faszikel I, 1r-34v) (1564 $^{15}$ enthält, sauber getrennt durch Lagen und Schreiberwechsel, Aldhelms Aenigmata aus der Epistola ad Acircium (1v-14v), Symphosius' Aenigmata, sowie Konjugationstabellen und Nachträge (20v-34r). Die Textgemeinschaft erinnert nicht umsonst an Pal. lat. 1753 - in der Tat ist der Aldhelm-Text dem der älteren Handschrift ebenso eng verwandt wie der Symphosius-Text, ohne dass jedoch eine direkte Abschrift festgestellt wird. ${ }^{1565}$ Am nächsten liegt, dass die Vorlage von Pal. lat. 1753 hier erneut zur Erstellung einer Schulhandschrift herangezogen wurde, was die Kontinuität des Curriculums über die Jahrzehnte illustriert. ${ }^{1566}$ Bemerkenswert ist auch, dass die Vorlage

1559 Wiewohl der für die Zeit Adalungs typische St. Vaaster Stil vorliegt, ist die Lorscher Hand schon im jüngeren Lorscher Stil (ab 825) geschult; die Entstehung fällt also in die spätere Zeit von Adalungs Abbatiat.

1560 Michael KAUTZ, »Brüssel, Bibliothèque royale de Belgique, Ms. 9845-9848«, http://bibliothe ca-laureshamensis-digital.de/view/kbr_ms9845-48?ui_lang=eng (abgerufen am 21.11. 2017). Bischoff: Abtei Lorsch. S. 48, 93, Anm. 53. Bischoff: Katalog, 1. Nr. 736.

1561 Gioanni (Hrsg.): Ennode I. S. CXXXIV. Hartel (Hrsg.): Magni Felicis Ennodii opera omnia. S. XV-XXI.

1562 Die Ordnung geht vielleicht aus den Bedürfnissen der Schule in Pavia hervor und wurde in dieser Form durch Paulus Diaconus ins Frankenreich eingeführt: GioAnnI (Hrsg.): Ennode I. S. CXLI-CXLVI.

1563 Ennodius: A100 (Hauptschreiber G1), weitere Briefhandschriften A101-107 (G1, Nachtrag 1): HÄsE: Bücherverzeichnisse. S. 98, Z. 18-24, zur paläographischen Schichtung des Katalogs S. 59.

1564 Lagenformel: $2 \mathrm{IV}^{14}+\mathrm{III}^{20}+([\mathrm{IV}+1]-2 \text { ? })^{27}+\mathrm{II}^{31}+(\mathrm{I}+1)^{34}$ : Michael KAUTZ, »Vatikan, Biblioteca Apostolica Vaticana, Pal. lat. 1719«, https://bibliotheca-laureshamensis-digital.de/bav/ bav_pal_lat_1719?sid=3fd1bab4cc7391b69beff6435a776295 (abgerufen am 21.11.2017). Bischoff: Abtei Lorsch. S. 40, 91, Anm. 42.

1565 Valerie M. LAGorio, »Aldhelm's Aenigmata in Codex Vaticanus Palatinus Latinus 1719«, in: Manuscripta 15 (1971), S. 23-27. S. 26f. Chauncey E. FincH, "Symphosius in codices Pal. lat.1719, 1753 and Reg. lat.329, 2078«, in: Manuscripta 13 (1969), S. 3-11. S. 9.

1566 Dieses wird auch fortgeführt in einer erneuten Kopie von Bedas De arte metrica (schon in Paris, BNF Lat. 16668): Michael KAUTZ, »St. Gallen, Stiftsbibliothek, Cod. 1396«, http://bi bliotheca-laureshamensis-digital.de/view/stibsg_cod1396_pagg (abgerufen am 21.11. 2017). 
beider Handschriften offenbar immer wieder zur Quelle neuer Kompilationen wird, anstatt dass das Schulprogramm aus der je jüngsten Handschrift kopiert und modifiziert worden wäre, denn es wurden jeweils nur Aldhelm und Symphosius daraus entnommen, während die anderen Texte aus anderen Quellen stammen, die Zusammenstellung also bei jeder Kopie eine neue ist.

Am Ende von Adalungs Amtszeit scheint das Bedürfnis spürbar geworden zu sein, die vermehrten Bücherbestände in einem Katalog zu erfassen. Dieser liegt uns vor in den zwei frühesten Lorscher Katalogen A und B in der Handschrift Vatikan, BAV, Pal. lat. $1877 .{ }^{1567} \mathrm{~B}$ ist nichts weiter als eine weitgehend identische Kopie von A, von ortsfremden Schreibern vielleicht für ein anderes Kloster St. Vaast? - zum Abgleich der Bestände erstellt. ${ }^{1568}$ Katalog A dagegen stellt das »Handexemplar der Klosterbibliothekare ${ }^{1569}$ dar und gibt auch durch das langsame Wachstum der Einträge Einblicke in die stufenweise Vermehrung der Bibliothek. ${ }^{1570}$ Er zeichnet sich zudem durch eine sorgfältige Inventarisierung auch der Inhalte vieler Handschriften aus, was ansonsten nur in Fulda zu beobachten ist. ${ }^{1571}$ Die Gliederung in Untergruppen ist gegenüber anderen Katalogprojekten der Zeit nur sehr rudimentär, sodass der Platz der Dichtung eher aus den umstehenden Titeln als aus expliziten Kategorien ermittelt werden muss. Inmitten der Kirchenväter steht, zum Grundstock der Einträge gehörend, ein Band Prospers von Aquitanien (244), ${ }^{1572}$ der am Schluss dessen moralische Epigramme enthielt. ${ }^{1573} \mathrm{Ab}$ A70 beginnt eine Reihe von Grammatiken, worunter sich auch ein Band mit verschiedenen Metriktraktaten befindet (323), der ebenfalls zur Grundschicht der Einträge gehört. Die weitere Dichtung, die im Katalog von A79-120 zu finden ist, steht in einer sehr heterogenen Gruppe, die jede Klassifizierung scheut. ${ }^{1574}$ Das gleiche gilt für die Dichtung selbst, die den

1567 HÄsE: Bücherverzeichnisse. A: S. 55-65. Ed. 82-101. B: S. 66-71, Ed. 102-135.

1568 Ebd. S. 71.

1569 Ebd. S. 55.

1570 Ebd. S. $64 \mathrm{f}$.

1571 Duft: »Die Klosterbibliotheken von Lorsch und St. Gallen«. S. 35. Die genauen Inhaltsangaben beschränken sich jedoch auf die Werke der Kirchenväter.

1572 Die Nummerierung, wo nicht explizit auf den Katalog bezogen (z. B. A64, Ca15), nach HäsE: Bücherverzeichnisse. Kommentar, S. 175-339. Siehe auch ebd. die Konkordanz S. 340-342.

1573 Vll. identisch mit Pal. lat. 238 oder St. Gallen, StB Cod. Sang. 187 (Ebd. S. 277), obwohl in ersterer die Epigramme fehlen. Die Fehlzuschreibung der Schrift De vita contemplativa an Prosper findet sich im Titel der Handschrift, ist jedoch eine ganz landläufige Verwechslung: Jean Devisse, "L'influence de Julien Pomère sur les clercs Carolingiens. De la pauvreté aux Ve et IXe siècles", in: Revue d'histoire de l'église de France 56 (1970), S. 285-295. S. 287-289. Vgl. den ganz ähnlichen Eintrag (180, Ca236).

1574 Um nur einige Beispiele der dazwischen liegenden Titel zu nennen: Concordia canonum (A84), Antefonarium (A87), Liber epistolarum Senicae (A107), Vita Caroli imperatoris (A112). 
Rahmen herkömmlicher Schullektüre sprengt. Alle poetischen Titel gehören späteren Nachtragsschichten an. ${ }^{1575}$ Bei den Grammatiken steht die Periegesis des Prisciani grammatici (329), eine poetische Geografie, die wohl wegen ihres Autors dort zu stehen gekommen ist. Kurz darauf, in einem kleinen kirchenrechtlichen Verbund von drei Titeln, stehen im Anhang an die Benediktsregel einige Hymnen (38). Es folgen innerhalb der gleichen Nachtragsschicht Juvencus (341) und Sedulius (342), zwei christliche Klassiker, die wir schon in den Handschriften vermisst haben - sind sie doch oft die ersten Zeugen von Dichtung in der Frühzeit eines Klosters - und die auch hier paradoxerweise als Nachträge zu finden sind. Von anderer Hand schließen sich die Versus Theodolfi ad Moduinum et Moduinus ad Theodolfo (!) in quaternionibus V (416) an, eine Sammlung, die sich ansonsten geschlossen nur in Murbach lokalisieren lässt. ${ }^{1576}$ Es folgt Ennodius, der, wie schon gesagt, Teil einer epistolaren Gruppe ist. Auf diese Gruppe folgt ein Vergil (418) mit seinem Kommentator Priscian (419), der mit der oben behandelten Handschrift Cod. Guelf. 66 Gud. lat. zu identifizieren ist. Die Handschrift erscheint interessanterweise nicht im späteren Katalog Ca wieder, wiewohl sie offenbar weiterhin in Lorsch vorhanden war. Vergil spielt somit, trotz der Bedeutung, die ihm aufgrund der Handschriften zugewiesen werden muss, in den Katalogen eine geringe Rolle. Es folgt Ps.-Cato (420). Die Werke des Prudentius erscheinen in einigem Abstand in einer aus Hagiographie und Medizin merkwürdig vermischten Gruppe, sind jedoch mit drei Bänden gut vertreten (119121). Ergänzt ist eine ausführliche Beschreibung der Briefe des Paulinus von Nola (313), die nach ihrem Titel auch metra diversi generis enthielt. Der allerletzte Nachtrag in A sind Epitaphia seu ceteri versus in quaternionibus VIII (298). ${ }^{1577}$ Dichtung hat somit, nach dem Zeugnis von Katalog A zu schließen, noch keinen festen Platz in der Lorscher Bibliothek gefunden und scheint eher wahllos hier und dort mit untergestellt worden zu sein. Falls das Verhältnis von Grund- und Nachtragsschichten tatsächlich das Wachstum der Bibliothek widerspiegelt, so ist die Dichtung - hier insbesondere die christlichen Klassiker - die fast nur in Nachträgen zu finden ist, kein Grundbestandteil der Lorscher Bibliothek. Obwohl die "Schulhandschriften" (Grammatici) erst im späteren Ca-Katalog separat aufgeführt sind, ${ }^{1578}$ glaube ich nicht, dass sie als Klasse nicht in A vertreten sind, vielmehr finden sich sieben von den vierzehn Dichtern aus A in den Grammatici in Ca wieder, darunter gerade Schulschriftsteller wie Juvencus, Sedulius und Prudentius. Die Schulhandschriften hatten also zur Zeit von A noch keinen festen Platz gefunden.

1575 Bis auf Ennodius, wie oben angemerkt.

1576 Siehe dort. GeIth/Berschin: »Bibliothekskataloge«. Nr. 24.

1577 Siehe unten S. 251f. zu Vatikan, BAV, Pal. lat. 833.

1578 HäsE: Bücherverzeichnisse. S. 38. Katalognummern Ca 388-476. 
Im letzten Jahrzehnt von Adalungs Abbatiat (ab 825) prägt sich endgültig der in Lorsch bis zum Erlöschen seiner Kreativität dominierende »jüngere Lorscher Stil« aus, ${ }^{1579}$ in dem die weitaus meisten der erhaltenen Handschriften geschrieben worden sind. Der Siegeszug dieser Minuskel setzte sich auch nach dem Amtsantritt Samuels (837-856) ${ }^{1580}$ fort. Dieser war bestens vernetzt, um den Ausbau der Bibliothek zu beaufsichtigen. Selbst in Lorsch ausgebildet, lernte er anlässlich eines Studienaufenthaltes bei Alkuin den jungen Hrabanus Maurus kennen, mit dem er später in Korrespondenz stand. ${ }^{1581}$ Zwischen Hrabans Abtei Fulda und Lorsch bestanden auch kooperative Beziehungen in bibliothekarischer Hinsicht: Hrabanus kennt und schätzt die Lorscher Sammlung, wie er an deren Bibliothekar Gerhoh schreibt. ${ }^{1582}$ Vielleicht bestand auch in der Anschaffungspolitik eine Kooperation der beiden Klöster. ${ }^{1583}$ Es finden sich Fuldaer Verleihvermerke in Lorscher Handschriften. ${ }^{1584}$ Schlussendlich wurden vielleicht auch Lorscher Mönche zu höheren Studien an Hrabans berühmte Schule geschickt. ${ }^{1585}$ Auch mit anderen Zentren stand man in wissenschaftlicher Korrespondenz, so mit der Reichenau, von wo man eine Augustinus-Handschrift zur Korrektur nach Lorsch kommen ließ. ${ }^{1586}$

Vom großen Aufschwung des Skriptoriums wurde auch die Dichtung berührt, wenn auch die Verluste sich hier nur aus dem Katalog abschätzen lassen. Der Ehrenplatz unter den erhaltenen Handschriften gebührt Montpellier, Bibliothèque universitaire de médecine, $\mathrm{H} 125,{ }^{1587}$ Juvenal und Persius, ${ }^{1588}$ die am Beginn der vollständigen Überlieferung beider Dichter steht. ${ }^{1589}$ Die Vorlage der

1579 BischofF: Abtei Lorsch. S. 44-52.

1580 Semmler: "Geschichte der Abtei«. S. 86-87. Roman Deutinger, "Zur Biographie Bischof Samuels von Worms«, in: Archiv für mittelrheinische Kirchengeschichte 56 (2004), S. 79-87.

1581 Zusammenfassend: KAUTZ: Lorsch, Katalog. S. XI. Kritisch zur Identifizierung des Korrespondenten mit Samuel von Lorsch: DEUTINGER: »Biographie Bischof Samuels«. S. 27-31. Die betreffenden Gedichte Hrabans sind Carmina 27-32, DüMmLER (Hrsg.): MGH Poet. lat. 2. S. 188-191.

1582 Carm. 23-24, a.a. O. Zu Gerhoh siehe KAUtz: Lorsch, Katalog. S. XI und Anm. 12.

1583 ARIs: "Art. Lorsch, Bibliotheksgeschichte«. S. 812.

1584 HäsE: Bücherverzeichnisse. S. 34.

1585 Ebd. S. 22, Anm. 23.

1586 Kautz: Lorsch, Katalog. S. XI. Siehe zur Rolle Lorschs als Repositorium seltener Werke: BECKER: "Zentralbibliothek«.

1587 Format: 29,5 x $27 \mathrm{~cm}$, Lagenformel: $9 \mathrm{IV}^{71}+(\mathrm{IV}+1)^{80}$ : Michael KAUTz, »Montpellier, Bibliothèque universitaire de médecine, Bibliothèque interuniversitaire de«, http://bibliothe ca-laureshamensis-digital.de/view/bumm_h125 (abgerufen am 23.11.2017). Bischoff: Abtei Lorsch. S. 47-49.

1588 Sigle P: Wendell Vernon Clausen (Hrsg.), A. Persi Flacci et D. Iuni Iuvenalis Saturae. Rev. ed. (Scriptorum classicorum bibliotheca Oxoniensis), Oxford 2007.

1589 Zahlreiche Fragmente und Kataloge bezeugen jedoch auch anderwärts deren Popularität. ReYnolds: Texts and transmission. Juvenal: S. 201, Persius: S. 293. Susanna Morton Braund und Josiah Osgood (Hrsg.), A Companion to Persius and Juvenal (Blackwell companions to the ancient world), Chichester [u.a.] 2012. S. 148, 155-157. Persius: S. 159. 
Handschrift befand sich vielleicht im ersten Viertel des 9. Jh. auf der Reichenau, wo zum Beispiel Walahfrid daraus geschöpft haben könnte und eine Kopie für St. Gallen daraus gemacht worden sein soll. ${ }^{1590}$ Die Verortung der Vorlage auf die Reichenau beruht jedoch ganz auf der zweifelhaften Zuweisung der Vorstufe von Micos Opus Prosodiacum dorthin. ${ }^{1591}$ Die Handschrift kann trotz ihrer dichten Glossierung nicht als eine Schulhandschrift angesehen werden, da die Mehrzahl der Glossen aus dem 11. und 15. Jh. stammen, ${ }^{1592}$ ganz abgesehen davon, dass ein Großteil der Marginalien wissenschaftliche Scholien sind. Das großzügige Layout, das erst sehr viel später mit Anmerkungen gefüllt wurde, sowie das stattliche Format sind vielmehr Zeichen einer luxuriösen Klassikerhandschrift. ${ }^{1593}$

Großzügig angelegt und ebenso stark glossiert ist auch die Handschrift des Martianus Capella Leiden, UB, BPL 36, ${ }^{1594}$ die insbesondere in den einspaltigen Verspartien reichlich Platz für spätere Anmerkungen lässt. Die Kommentierung des Textes geht wohl auf insulare Quellen zurück. ${ }^{1595}$ Ein Gutteil der Marginalien stammt aus dem 9. Jh. und ist somit Zeugnis des wissenschaftlichen Studiums in Lorsch, das sich in diesem Fall schon in der Gestaltung der Handschrift ankündigt.

Ein Titel aus Katalog A (244, A48) begegnet uns vielleicht wieder in St. Gallen, StB Cod. Sang. 187 (Faszikel II, p. 164-304), die unter Prospers Namen die Abhandlung De vita contemplativa von Julianus Pomerius und Prospers Epi-

Knoche: Juvenaltext. S. 31-80. Zum merkwürdigen Titel (Thebaidorvm Persi satvra), der die ganze Klasse $\pi$ vereint, siehe SeEL: »Zum Persius-Titel des Codex Pithoeanus«. S. 91-96.

1590 KNoche: Juvenaltext. S. 247-249. Entgegen Bischoffs Einwand (Bischoff: Abtei Lorsch. S. 84, Anm. 69) muss durch die Umdatierung von Montpellier H 125 (P) nur die Zeit der Kopie aus der P-Vorstufe $\pi^{1}$ vordatiert werden. Zu $\pi^{1}$ siehe KNoche: Juvenaltext. S. 230; zur St. Galler Kopie Ebd. S. 233.

1591 Siehe S. 172.

1592 Bergmann/Stricker: Katalog. Nr. 439. Henkel/Bergmann: »Art. Juvenal (Decius Iunius Iuvenalis), Althochdeutsche Glossierung«. Für die Glossen fehlt eine eingehende paläographische Scheidung, während dagegen ihr Wert für die Textgestalt der Dichter eingehend erforscht wurde: Paul Wessner (Hrsg.), Scholia in Iuvenalem vetustiora (=1931) (Bibliotheca scriptorum Graecorum et Romanorum Teubneriana), Stuttgart 1967. S. IXf., XLIII. Jean G. PrÉaux, "Propositions sur l'histoire des textes des Satires de Perse et du Commentum Cornuti«, in: Hommages André Boutemy, hrsg. von Guy CAMbie R (Collection Latomus 145), Brüssel 1976, S. 299-314.

1593 Ähnlich geräumig geschrieben und mit Scholien versehen ist die Persius-Handschrift Bern, BB Cod. 257 (»Deutschland, IX./X. Jh. oder X. Jh., 1. Hälfte«: Bischof F: Katalog, 1. Nr. 564).

1594 Michael KAUTZ, »Leiden, Universiteitsbibliotheek, BPL 36«, http://bibliotheca-laureshamen sis-digital.de/view/ublei_bpl36 (abgerufen am 23.11.2017). BIschoff: Abtei Lorsch. S. 54. Bischoff: Katalog, 2. Nr. 2136.

1595 Sinéad O’Sullivan, Glossae aevi Carolini in libros I-II Martiani Capellae De nuptiis Philologiae et Mercurii (CCCM 237), Turnhout 2010. S. L-LV. 
gramme ${ }^{1596}$ enthält. ${ }^{1597}$ Die Epigramme repräsentieren eine deutsche Rezension des Textes, ${ }^{1598}$ der - von den verlorenen Handschriften aus Freising und Murbach abgesehen - stärker im Westfränkischen überliefert wird. Die Handschrift ist von großzügiger Anlage und integriert die Zitate aus Prospers Augustinus-Florilegium in den Text der Epigramme. Die Handschrift verschwand schnell wieder aus Lorsch, wie ein Nachtrag im Katalog bemerkt: non jnueni. ${ }^{1599}$ Entführt wurde die Handschrift von niemand geringerem als Grimald, dem Abt von St. Gallen, der sie mit Faszikel III versehen ließ und so in seinem Privatkatalog vermerkte. ${ }^{1600} \mathrm{Da}$ Grimald auf allen Stufen seiner illustren Karriere einen plausiblen Zugriff auf die Lorscher Bestände gehabt haben könnte, sind die genauen Umstände der Entnahme der Handschrift nicht zu rekonstruieren. Sie könnte auch im wissenschaftlichen Austausch nach St. Gallen ${ }^{1601}$ gelangt und erst dort von Grimald seiner Bibliothek eingereiht worden sein.

Dichtung die ganz außerhalb des Hauptstromes der Gattung steht ist in Vatikan, BAV, Pal. lat. 833 enthalten, der sogenannten Lorscher Sylloge. ${ }^{1602}$ Die schon im Katalog A als später Nachtrag ${ }^{1603}$ enthaltene Handschrift enthält eine Vielzahl von Inschriften, darunter auch metrische. Die Handschrift ist somit nicht zuerst eine dichterische, sondern eine epigraphische, so wie auch die vor-

1596 Horsting (Hrsg.): Prosper Aquitanus, Liber epigrammatum. S. 31, fälschlich St. Gallen zugeordnet. Dementsprechend ist die Lorscher Handschrift des Katalogs nicht verloren (so S. 22).

1597 Michael KaUtZ, »St. Gallen, Stiftsbibliothek, Cod. 187«, http://bibliotheca-laureshamensisdigital.de/view/stibsg_cod187 (abgerufen am 24.11.2017). Bischoff: Abtei Lorsch. S. 50. Zum Katalogeintrag siehe HäsE: Bücherverzeichnisse. Nr. 244, S. 277: Item eiusdem (Prosperi) de activa et contemplativa vita libri III et eiusdem epigrammata in uno codice. Wahrscheinlich ist Cod. Sang. 187 hierunter zu erkennen, da die Handschrift beide Texte und die die pseudepigraphische Zuschreibung an Prosper im Incipit enthält. Siehe auch oben S. 253 zum entsprechenden Eintrag in Katalog A.

1598 Horsting (Hrsg.): Prosper Aquitanus, Liber epigrammatum. S. 52, Familie $\varepsilon$, Sigle $G_{1}$, zusammen mit Wolfenbüttel, HAB, Cod. Guelf. Weiss. 56 (siehe bei Weißenburg, S. 181). Zur Textgesellschaft mit Julianus Pomerius S. 24f.

1599 HäsE: Bücherverzeichnisse. S. 96, Anm. zu Z. 10.

1600 Bischoff: »Bücher am Hofe und Privatbibliothek«. S. 195. LeHmann (Hrsg.): MBK. S. 89, Z. 3-5.

$1601 \mathrm{Zu}$ dieser Kooperation und der mit anderen Klöstern: BECKER: "Zentralbibliothek«. S. 80. Bischoff: Abtei Lorsch. S. 30.

1602 Faszikel II, 26r-84v: Michael KaUtz, »Vatikan, Biblioteca Apostolica Vaticana, Pal. lat. 833«, http://bibliotheca-laureshamensis-digital.de/bav/bav_pal_lat_833 (abgerufen am 24.11.2017). Bischoff: Abtei Lorsch. S. 126f. Edition (nach Schreibern in verschiedene Sammlungen geteilt): DE Rossi: ICUR. S. 36-39 (Einl.), 98-118 (Syll. IV), 126-130 (II), 144153 (I), 158 (App.), 161-173 (III). Siehe zur Trennung der Bestandteile: Hartmann: "Karolingische Gelehrte«. S. $263 \mathrm{f}$.

1603 Epitaphia seu ceteri versus in quaternionibus VIII (A129+Ca452). Von KaUtz korrekt gegen HÄSE (Nrs. 298, 387) getrennt in zwei Lorscher Syllogen: (A129+Ca452= Pal. lat. 833) und $(\mathrm{Ca} 358+\mathrm{D} 244=$ Epitaphia in basilica sancti Petri seu versus). 
herigen nach Lorsch gelangten Syllogen aus Tours und St. Vaast Appendizes zu hagiographischen Handschriften darstellten ${ }^{1604}$ Von diesen vorherigen unterscheidet sich die Lorscher Sylloge, indem sie ausschließlich Tituli enthält. Dass die Sammlung, wie Bischoff vermutet, aus dem Kontext von Adalungs Romgesandtschaft stammen könnte, ${ }^{1605}$ wird durch Adalungs auch anderwärtiges epigraphisches Interesse gestützt. ${ }^{1606}$ Vielleicht ist aber auch schon vorher in Lorsch vorhandenes Material integriert worden: Es scheint mir nicht unwahrscheinlich, dass der Text der Sylloge $\mathrm{II}^{1607}$ mit dem Titel Epytaphia apostolicorum in ecclesia beati Petri mit dem der Handschrift des älteren Kataloges Epitaphia in basilica sancti Petri seu versus identisch und somit Kopie der älteren Sammlung ist. Ebenfalls scheint nur die Sylloge I auf einen Rombesuch zurückzugehen, während die anderen, indem sie geographisch zerstreutes Material sammeln, ${ }^{1608}$ eher auf schriftliche Vorlagen zurückzuführen sind. Es handelt sich somit um eine von Adalung angeregte Sammelhandschrift des von ihm aus Rom gebrachten und dem schon in Lorsch liegenden epigraphischen Material. ${ }^{1609}$ Dass diese Sammlung Mustercharakter trug und insbesondere die stadtrömischen Inschriften als Unterpfand der epigraphischen Korrektheit galten, ${ }^{1610}$ ist nicht zu bezweifeln. Leider lässt sich eine Rezeption wegen fehlender Lorscher Inschriften oder Reminiszenzen in der Dichtung nicht mehr feststellen. Ob dagegen die saubere und sorgfältige Handschrift Pal. lat. $833 \mathrm{im}$ "schulischen Kontext zu verorten « ist, ${ }^{1611}$ mag dahingestellt bleiben. Wahrscheinlicher erscheint es, dass wenn, dann die verlorenen Vorlagen, die man sich als kleine Hefte vorzustellen hat, diese Rolle gespielt haben.

Der ganze Reichtum, den die Lorscher Bibliothek unter Adalung und Samuel erlangt hatte, wird jedoch weniger in den Handschriften, als im jüngsten der Kataloge greifbar, der um 860 unter Abt Eigilbert erstellt wurde (856-864). ${ }^{1612}$

1604 Merseburg, DStB Cod. 105 (Martinellus, unter Richbod), Wien, ÖNB Cod. 550 (Vita. St. Vedasti, unter Adalung), siehe oben S. 244.

1605 Bischoff: Abtei Lorsch. S. 99, Anm. 52.

1606 Sichtbar in ÖNB Cod. 550 aus St. Vaast und der zweiten im Adalung-Katalog Ca verzeichneten Sylloge Ca358+D244 (Epitaphia in basilica sancti Petri seu versus).

1607 36r-41r von gleicher Hand wie das Vorhergehende, jedoch mit Raum auf 35v: De Rossi: ICUR. S. 37, 126-130.

1608 Norditalien, Ravenna, Spoleto: Hartmann: »Karolingische Gelehrte«. S. 264. De Rossi: ICUR. S. $36 \mathrm{f}$.

1609 Die Hymnen 82v-84v sind späteren Datums (»10 Jahrhundert«): MÜNCH: Musikzeugnisse der Reichsabtei Lorsch. S. 91-96.

1610 Hartmann: »Karolingische Gelehrte«. S. 265.

1611 Ebd. S. 268.

1612 Katalog Ca, HäsE: Bücherverzeichnisse. S. 71-76, Ed. 136-137. Zum hiervon abhängigen und kein Sondergut bietenden Katalog D siehe Ebd. S. 76-78. Eine Würdigung der gesamten damals in Lorsch vorhandenen antiken Literatur bei: DuFT: »Die Klosterbiblio- 
Dieser führt auch als erster eine separate Kategorie von Grammatici (Ca388476), die »in einer vermischten Abteilung Dichtung, Grammatik, Monastik, Aszetik und Hagiographie ${ }^{1613}$ darbietet. Einige der in A ohne diese Kategorie verzeichneten Titel kehren jedoch hier unter den Grammatici wieder, sodass eher von einer Neuordnung der Titel, als von einer unvollständigen Katalogisierung in A auszugehen ist. Da jedoch grundsätzlich unklar bleibt, wie vollständig A ist, ${ }^{1614}$ darf nicht jeder in Ca hinzugekommene Titel als Ergänzung der Bibliothek angesehen werden, wenn auch das unterliegende Wachstum der Bibliothek im Anschwellen aller Gattungen klar erkennbar ist. ${ }^{1615}$

Außerhalb der grammatischen Abteilung findet sich Dichtung nur bei den Kirchenvätern, so hat es »Prosper ${ }^{1616}$ zu den Werken Gregors des Großen verschlagen (180). ${ }^{1617}$ Die (metrische?) Vita S. Cuthberti, zusammengebunden mit der Benediktsregel und »annalis ${ }^{1618}$ steht bei den Werken Bedas (203). Gleich hierauf folgt eine grammatische Sammelhandschrift mit Bedas Ars Metrica und Aldhelms Gedichten (204), in der man unschwer die oben behandelte Paris, BNF, Lat. 16668 wiedererkennt. Unter Isidors Werken finden wir seine Versus in Bibliothecam (238). ${ }^{1619}$ Auf die Werke des Fulgentius folgt, ohne eigene Rubrik, eine lange Liste vermischter Werke (Ca327-387), die hier offenbar recht ungeordnet aneinander gereiht wurden. ${ }^{1620}$ Dennoch befinden sich hier einige der bemerkenswertesten Stücke der Lorscher Bibliothek, darunter Plinius und Cicero. Dichtung steht hier, bis auf die schon in A enthaltenen Ennodius und Paulinus von Nola, kaum: Nur noch eine Consolatoria <ad> philosophum (!) - also Boethius - findet sich hier (281).

theken von Lorsch und St. Gallen«. S. 38f., geschöpft jedoch aus dem zu Lorsch veralteten Werk: MANiTIUs: Handschriften antiker Autoren in mittelalterlichen Bibliothekskatalogen.

1613 ARIs: »Art. Lorsch, Bibliotheksgeschichte«. S. 815.

1614 Es fehlt in A z.B. die oben behandelte Handschrift Paris, BNF, Lat. 16668 (HÄsE: Bücherverzeichnisse. Nr. 204, Ca262, geschrieben ca. 800), die schon in A hätte vorhanden sein müssen, wäre dieser Katalog vollständig. Nur ein genauer Abgleich von A mit allen frühen Handschriften, der über unser Thema hinausgeht, könnte Klarheit über dessen Vollständigkeit schaffen.

1615 Im Folgenden gebe ich nur Titel, die nicht schon in A erscheinen.

1616 Tatsächlich jedoch Julianus Pomerius, siehe oben S. 250f. zu Katalog A, Nr. 244, A48, und zu Cod. Sangall. 187.

1617 Die Nummerierung wie oben, wenn nicht auf die einzelnen Katalog bezogen (A, B, Ca etc.), nach HäsE: Bücherverzeichnisse. Kommentar, S. 175-339.

1618 Ebd. S. 263: "Kalendarisches Werk«.

1619 BeEson: Isidor-Studien. S. 133-166.

1620 Auch der Versuch einer Unterteilung, die so säuberlich nicht vorliegt, zeigt die Konfusion: HÄSE: Bücherverzeichnisse. S. 287: "Dogmatische und kirchenrechtliche Texte - Werke jüngerer christlicher Autoren - Antikes Schrifttum - Briefsammlungen - Grammatiken«. 
Die große Mehrzahl der Dichter findet sich in der grammatischen Abteilung (Ca388-476), ${ }^{1621}$ die freilich schon vor der eigentlichen Rubrik »Grammatici« mit einer Reihe von Lehrwerken beginnt (Ca382-387), darunter zwei Werke zur Metrik (Ca384). Zu den schon in Katalog A enthaltenen Werken kommen weitere hinzu. ${ }^{1622}$ Eine dichte Gruppe findet sich in Ca396-407. Nebeneinander stehen dort ein Band mit Sedulius und Prudentius (335) und ein Band mit der Ars Metrica Bedas und Aldhelms (336), darauf Prudentius (337, A120), Martial (338), Porphyrius (339), Juvencus (341, A95), Sedulius (342, A96), Juvenal (343), Lukan (344) und Horaz ${ }^{1623}$ (345). In dieser Gruppe findet keine Trennung zwischen Christen und Heiden statt, sodass ihr Beieinander funktional, sprich grammatisch-pädagogisch bedingt gewesen zu sein scheint. ${ }^{1624}$ Eine weitere gedrängte Gruppe folgt in Ca422-428, wo sich einige Seltenheiten finden: Ciceros Aratea (362), die hier ungewöhnlicherweise nicht mit anderen astronomischen Gedichten, ${ }^{1625}$ sondern mit Reden des Autors zusammengebunden ist. Es folgen Priscians Werk zu den römischen Komödien und die Fabeln des Avianus, vielleicht in einem Band (363). ${ }^{1626}$ Hierauf folgen drei bemerkenswert detaillierte Einträge zu Sammelhandschriften christlicher Dichtung, die mit der Sorgfalt der patristischen Titel des Katalogs getätigt wurden: ${ }^{1627}$

1. (364, Ca426) Eine hauptsächlich mit hagiographischer Dichtung gefüllte Handschrift, die vielleicht entlang der Zeilenabsätze in drei Bände geteilt

$1621 \mathrm{Ab}$ Ca430 kann, obwohl keine Rubrik hier den Bestand unterteilt, keineswegs mehr von Grammatik gesprochen werden. Viten und Passionen machen den Großteil der restlichen Titel aus.

1622 Zur Übersicht hier die Konkordanz der Dichtung in den Lorscher Katalogen: 36. A91, B-, Ca63, D-; 38. A83?+86?,B-, Ca65, D-; 180. A-, B-, Ca236, D-; 203. A-, B203, Ca261, D-; 204. A-, B204, Ca262, D165; 238. A-, B171, Ca298, D194; 244. A48, B138, Ca304, D200; 281.A-, B-, Ca341, D-; 298. A129?,B-, Ca358, D244; 323. A72, 8-, Ca384, D-; 328. A77, B-, Ca389, D-; 334. A-, B-, Ca395, D-; 336. A-, B-, Ca397, D-; 337. A120, B-, Ca398, D-; 338.A-, B-, Ca399, D-; 339.A-, B-, Ca400, D-; 341. A95, B-, Ca402+403, D-; 342. A96+97, B-, Ca404, D-; 343. A-, 8-, Ca405, D-; 344. A-, 8-, Ca406, D-; 345. A-, B-, Ca407, D-; 360. A119?/121?, B-, Ca422, D-; 362. A-, B-, Ca424, D-; 363. A-, B-, Ca425, D-; 364. A-, B-, Ca426, D-; 365. A-, B-, Ca427, D-; 366. A-, B-, Ca428, D-; 389. A-, B-, Ca454, D-; 416. A99; 418. A109; 420. A111.

1623 Siehe bei St. Gallen, S. 114-116, zu Bern, BB Ms. 363, dessen Horaztext vielleicht aus Lorsch stammt.

1624 Vielleicht war auch der Horaz ein Sammelband mit beigefügter Erläuterung: LICHT: »Horazüberlieferung im Frühmittelalter«. S. 125.

1625 Victor Buescu (Hrsg.), Les Aratea, Cicéron. Texte établi, trad. et comm., Reprint Bukarest 1941, Hildesheim 1966. S. 42-80 zu den ältesten Handschriften und ihren Textgesellschaften.

1626 HÄSE: Bücherverzeichnisse. S. 314 und Anm. 357 (GLAUche: Schullektüre. S. 27), identifiziert das metrum Avieni des Eintrags zögernd mit Avienus: Ora Maritima (Dietrich Stichtenoth (Hrsg.), Rufus Festus Avienus: Ora Maritima, Darmstadt 1968. Hierfür spricht der Singular des Werkes, die Nähe jedoch und der gemeinsame Eintrag mit $D e$ metris fabularum eher für eine Assoziation mit Avians Fabeln.

1627 Für Editionsnachweise siehe HäsE: Bücherverzeichnisse. S. 314-316. 
werden muss: ${ }^{1628}$ a.) Ps.-Tertullian: Carmen de resurrectione; Carmen adversos Marcionistas; Prosper: Epigrammata; Venantius Fortunatus: Vita S. Martini metrica; In laudem sanctae Mariae; b.) Paulinus von Périgueux: Vita S. Martini metrica; versus quam plurimi id est $L X X ;{ }^{1629}$ c.) Beda: Vita S. Cuthberti; Hymni LXXVI. ${ }^{1630}$

2. (365, Ca427) Bibeldichtung: a.) Das zu weiten Teilen verlorene dreiteilige Werk des Severus von Malaga, worin er einen christlichen Gegenentwurf zum Werk des Vergils schuf. ${ }^{1631}$ b.) Drei Werke des Cresconius Corippus: Evangeliengedicht, Über die heidnischen Götter und Über Schöpfung und Weltende; alle drei sind verlorengegangen. ${ }^{1632}$ c.) Arator: Historia Apostolica.

3. (366, Ca428) Bibeldichtung: ${ }^{1633}$ Cyprianus Gallus: ${ }^{1634}$ Über den Heptateuch und andere biblische Bücher; Alcimus Avitus: Carmina; Dracontius: Hexameron; Columban: Carmina.

In diesen Bänden sind viele außerordentlich seltene Werke vereint, die sich bis dahin nur in Lorsch und wenigen, ausgewählten Klöstern erhalten haben und oft nachher verloren gegangen sind. ${ }^{1635}$ Die Sorgfalt, mit der die Inhalte katalogisiert werden, ist dieselbe, die auf die Kirchenväter selbst angewandt wurde, und steht in scharfem Kontrast zur lapidaren Verzeichnung der sonstigen Dichter. Diese Handschriften stellen wohl kaum Schulhandschriften dar, sondern ihr Platz in der "grammatischen" Kategorie (die ohnehin hier keine Grammatik mehr und kaum noch Schuldichter enthält) rührt von ihrer Einordnung zu den Dichtern her, die herkömmlicherweise bei den Grammatici stehen. Sie bilden Teil der

1628 Ebd. S. 314. Labarre: »La transmission de Paulin de Périgueux«. S. 128f.

1629 Die versus LXX hier fälschlich Beda zugeschrieben: LABARRE: »La transmission de Paulin de Périgueux«. S. 128f. Es könnte sich um einen verlorenen Teil der Anthologia Latina im Codex Salmasianius handeln, der dort mit incipit uersos de singulis causis sunt uersus LXX beginnt. Im Bibliothekskatalog von Bobbio von 1493 (BECKER: Catalogi. Nr. 319) finden sich ebenfalls LXX epigrammata auctoris nomen non extat.

1630 Die Hymni stellen vielleicht das Liber Hymnorum dar.

1631 »Anti-Vergil«: Bischoff: Abtei Lorsch. S. 99f., Anm. 60, 61. Fragmente veröffentlicht in: Bischoff u. a. (Hrsg.): Severi in Evangelia.

1632 Siehe zur Identifikation: HofmANN: "Corippus as a patristic author«. S. $371 \mathrm{f}$. und zum betreffenden Katalogeintrag (metrum Cresconij) bei Murbach.

1633 Eine bemerkenswerte Ähnlichkeit mit dieser Handschrift hat Laon, BM, Ms. 279 (»Wahrscheinlich Westdeutschland, IX Jh., 1./2. Viertel«: Bischoff: Katalog, 2. Nr. 2100), die neben den seltenen Dichtern Cyprianus, Alcimus Avitus und Dracontius auch noch einen Auszug aus dem Cento Probae und Wigbods Quaestiones in Octateuchum enthält. Zudem trägt die Schrift gewisse Anklänge des Lorscher Stils und stellt vielleicht eine Kopie der seltenen Lorscher Textgemeinschaft dar. Vgl. zur Handschrift: Michael M. Gorman, "Wigbod and Biblical Studies under Charlemagne», in: Revue bénédictine 107 (1997), S. 4076. S. 62 f. Contreni: The cathedral school of Laon. S. 45.

1634 Peiper (Hrsg.): Cypriani Galli poetae Heptateuchos.

1635 Bischoff: Abtei Lorsch. S. 78. Kautz: Lorsch, Katalog. S. XIV. 
"Zentralbibliothek«, auf die andere Klöster und Gelehrte für seltene Texte zurückgreifen konnten. ${ }^{1636}$

Der Anhang des Katalogs Ca verzeichnet zuletzt eine Bücherschenkung eines Gerwards (Katalog Cb). ${ }^{1637}$ Die hohe Qualität der kleinen Privatbibliothek, wie sie aus einigen erhaltenen Bänden deutlich wird, ${ }^{1638}$ deutet auf einen Besitzer höchster Stellung und von besten Beziehungen. Als dieser wurde Gerward, der Pfalzbibliothekar Ludwigs des Frommen, identifiziert, ${ }^{1639}$ der seine Ausbildung in Lorsch erhalten hatte und schon vorher dem Kloster Güter übertragen hatte. Die einzige Dichtung in Gerwards Bibliothek ist ein Liber Virgilii (451). Es fehlen, bis auf eine Orthographie, grammatische Schriften sowie christliche Dichtung. Gerwards Bücher dienten also nicht, im Gegensatz zu denen Madalwins von Passau, als Handbibliothek eines Lehrers. Als das Liber Virgilii wurde der kostbare, spätantike Vergilius Palatinus wahrscheinlich gemacht. ${ }^{1640}$ Dieser befand sich vorher in Lyon und wurde dort annotiert und kopiert, ${ }^{1641}$ bevor er vielleicht in Gerwards Besitz und endlich nach Lorsch gelangte. Die behutsame Griffelglossierung wurde in Lorsch nicht weitergeführt, wo die Handschrift wohl, anstatt in die Schule überführt zu werden, im Komplex der Gerwardschen Bücher verblieb, ${ }^{1642}$ ein Zeugnis für ihre schon damals empfundene Kostbarkeit.

Mit dem Katalog Ca von 860 endet die Glanzzeit der Lorscher Bibliothek und ihres Skriptoriums. ${ }^{1643}$ Spätere Ergänzungen erreichen nicht wieder die unter

1636 BECKER: "Zentralbibliothek«. S. 83f. Licht: "Horazüberlieferung im Frühmittelalter«. S. 124f. Vocino: «MS Bern 363«. S. $95 \mathrm{f}$.

1637 HÄsE: Bücherverzeichnisse. S. 75f. Ed. S. 168.

1638 Paul LehmanN, "Das älteste Bücherverzeichnis der Niederlande», in: Lehmann, Erforschung des Mittelalters, 1, 1941, S. 207-212. HäsE: Bücherverzeichnisse. Kommentar Nr. 427-451.

1639 Bischoff: Abtei Lorsch. S. 64f. Heinz Löwe, "Studien zu den Annales Xantenses", in: Deutsches Archiv für Erforschung des Mittelalters 8 (1951), S. 59-99. S. 90f. Bernhard BischofF, "Die Hofbibliothek unter Ludwig dem Frommen", in: Bischoff, Mittelalterliche Studien, 3, 1981, S. 171-186. S. 172 und Anm. 19.

1640 Vatikan, BAV, Pal. lat. 1631: Michael KAUtZ, »Vatikan, Biblioteca Apostolica Vaticana, Pal. lat. 1631«, http://bibliotheca-laureshamensis-digital.de/bav/bav_pal_lat_1631 (abgerufen am 06.12.2017). BISchoff: Abtei Lorsch. S. 65. Richard SeIder, »Beiträge zur Geschichte und Paläographie der antiken Vergilhandschriften«, in: Studien zum antiken Epos, hrsg. von Herwig Görgemanns und Schmidt, ERnst (Beiträge zur klassischen Philologie 72), Meisenheim 1976, S. 129-172. S. 140-142.

1641 Griffel-Glossierung: Bergmann/Stricker: Katalog. Nr. 836c; Michael McCormick, Five hundred unknown glosses from the Palatine Virgil (Studi e testi 343), Vatikan 1992. S. 24-31. (Indirekte?) Kopie in Wolfenbüttel, HAB, Cod. Guelf. 70 Gud. lat. (»Lyon, IX.Jh., 2.Viertel/ Mitte", Bischoff: Katalog, 3. Nr. 7309): Reynolds: Texts and transmission. S. 435f.; Holtz: "La redécouverte de Virgile«. S. 24f.; Mynons (Hrsg.): P. Vergili Maronis Opera, Reprinted (with corr.). S. X.

1642 Im Gegensatz zu einer Orthographia (449: HäsE: Bücherverzeichnisse. S. 76).

1643 KaUtZ: Lorsch, Katalog. S. XXXII. 
Adalung und Samuel erreichten Höhe. ${ }^{1644}$ Trotzdem wurde selbst im sonst armen 10. Jahrhundert Dichtung gepflegt und ein Arator und ein Juvenal der Bibliothek hinzugefügt. ${ }^{1645}$

Fassen wir zusammen: Erst unter Richbod, dem vierten Abt von Lorsch, werden Skriptorium und Bibliothek sichtbar. Dass in dieser Frühphase Vergil im Zentrum steht, kann durchaus auf Richbods Vorliebe für diesen Dichter zurückgehen, für die zahlreichen Vergiliana des frühen Lorschs somit ein weiteres Beispiel liefern. Auch in der Schule lernte man anhand Vergils, dessen Werke auch in poetischen Zusammenfassungen den Schülern nahegebracht wurden. Vielleicht dichtete man auch selbst für die Schule - einige der aus Lorsch erhaltenen pädagogisch geprägten Gedichte finden sich nur hier. Neben die klassische Schultradition treten ebenbürtig insulare Einflüsse auf die Bildung. Richbods Beziehungen zu Hof und Alkuin finden sich vielleicht in der geschmackvollen Winterelegie sowie in Tituli aus Tours wieder, für die der Abt als der wahrscheinlichste Vermittler erscheint. Im Aufschwung von Skriptorium und Bibliothek unter Adalung und Samuel stand die Dichtung nicht im Mittelpunkt, auch wenn einige Seltenheiten wie Ennodius ihren Auftritt haben. Vergil bleibt im Curriculum, wie die mit zahlreichen Nutzungsspuren gespickte Handschrift Cod. Guelf. 66 Gud. lat. aus Adalungs Zeit zeigt. Gerade in den Handschriften aus dem eigenen Skriptorium, also denen, die nicht aus St. Vaast oder unter Beteiligung von Schreibern von dort stammen, zeigt sich die feste Verankerung in der Schule in Handschriften, die Grammatik und Dichtung in einem Band vereinigen. Ebenso schrieb man Texte, die schon zu Richbods Zeiten so gebraucht wurden, in ähnlich geplanten Sammelhandschriften erneut ab. Erst zu Ende von Adalungs Abbatiat und unter Samuel streift die Dichtung diese Fesseln endgültig ab. Großzügig angelegte und sorgfältig angeführte Handschriften von Juvenal und Persius oder Martianus Capella dienen nunmehr gelehrten, nicht schulischen Bedürfnissen. Im Austausch von Texten kooperiert man mit anderen großen Bibliotheken auf der Reichenau und in St. Gallen und fasst die Erträge eigener Sammelanstrengung (Syllogen) in Handschriften zusammen.

$1644 \mathrm{Zu}$ späteren Entwicklungen siehe: Hoffmann: Schreibschulen. S. 175-182. Hoffmann: Buchkunst. S. 203-226.

1645 Vatikan, BAV,Pal. lat. 1716 und Pal. lat. 1701, siehe KAUTz: Lorsch, Katalog. s.v. 


\section{II.3.c Prüm}

Das Kloster Prüm, ${ }^{1646} 721$ gegründet und 752 von Pippin reetabliert und mit westfränkischen Mönchen besetzt, wurde durch reiche Schenkungen rasch eine der hervorragenden Bildungsstätten Lotharingiens. Lothar I. wählte die Abtei zu seinem Alterssitz und brachte bei seinem Einzug neben anderen Schätzen auch zwei kostbare Bücher mit. ${ }^{1647}$ Wie so viele andere Schätze ging auch die Bibliothek des Klosters in den Stürmen der Zeit unter: Zweimal wurde das Kloster von den Normannen geplündert und 1511 ging der Rest bei einem Überlandtransport verloren. ${ }^{1648}$ So sind wir zur Rekonstruktion der in Prüm verfügbaren Dichtung großenteils auf indirekte Zeugen angewiesen. Glücklicherweise brachte Prüm in Wandalbert $^{1649}$ (813-870) einen Dichter hervor, dessen Werke uns durch die in ihnen zitierten Werke eine Spur von der Bibliothek erhalten, die den Autor prägte und auf die er zurückgreifen konnte. Neben seinen zahlreichen Werken, in denen er eine Vorliebe zu astronomischen Themen zeigt, ${ }^{1650}$ ist es besonders sein metrisches Martyrologium, ${ }^{1651}$ das eine weitere Verbreitung erfuhr. An zitierten Autoren stellt Haubrichs fest: ${ }^{1652}$ »Ovid, Horaz, Lucan, die ,Anthologia Latina', Sedulius, Juvencus, Arator und Venantius Fortunatus, « sowie Vergil und Pru-

1646 Wolfgang Haubrichs, Die Kultur der Abtei Prüm zur Karolingerzeit: Studien zur Heimat der althochdeutschen Georgsliedes (Rheinisches Archiv 105), Bonn 1979. Peter Neu, "Die Eifelabtei Prüm. Aufstieg, Glanz und Niedergang einer Benediktinerabtei in der Eifel«, in: Vor-Zeiten 4 (1988), S. 47-68. Erich WISPLINGHOFF, »Untersuchungen zur Gründungsgeschichte des Klosters Prüm«, in: Jahrbuch für westdeutsche Landesgeschichte 17 (1991), S. 128. Bernd Isphording, Prüm. Studien zur Geschichte der Abtei von ihrer Gründung bis zum Tod Kaiser Lothars I. (721-855). (Quellen und Abhandlungen zur mittelrheinischen Kirchengeschichte 116), Mainz 2005. MANitius: Geschichte, 1. S. 557-560. Nicht behandelt wird hier das erst im 11. Jh. in die Otfrid-Handschrift Heidelberg, UB Cod. Pal. lat. 52, nachgetragene Georgslied. Zum Ursprung dieses kleinen Gedichtes siehe: Wolfgang HAU BRICHS, Georgslied und Georgslegende im frühen Mittelalter: Text und Rekonstruktion (Theorie, Kritik, Geschichte 13), Königstein 1979.

1647 Zwei Bibelhandschriften: Theodor SchIEFfer (Hrsg.), Diplomata Karolinorum (Die Urkunden der Karolinger), 3: Die Urkunden Lothars I. und Lothars II. (Lotharii I. et Lotharii II., Diplomata), Hannover 1966. Nr. 122, S. 280, Z. 43, S. 281, Z. 1. Zu den Buchgeschenken: Karl Strecker, "Ist der Parisinus 266 der von Lothar dem Kloster Prüm geschenkte Codex?", in: Neues Archiv der Gesellschaft für ältere deutsche Geschichtskunde 44 (1922), S. $135-137$.

1648 Die Normannenangriffe 882 und 892. Haubrichs: Prüm zur Karolingerzeit. S. 54, siehe ebenfalls dort Anm. 119 zur späteren Bibliotheksgeschichte.

1649 Siehe neben Haubrichs auch: BRUnHöLzL: Geschichte, 2. S. 78-82. Bernt: Epigramm. S. 286-294. Seine Werke sind ediert in: DüMmLeR (Hrsg.): MGH Poet. lat. 2. S. 567-622.

1650 So zum Beispiel zum Sternenhimmel (MGH Poet. lat. 2, S. 616f.), den Monaten (S. 604-616) oder zur Sonnenuhr (S. 576-578).

1651 Zur Gattung siehe KIRSCH: Laudes sanctorum. S. 996-1000, zu Wandalbert S. 1000-1003.

1652 Haubrichs: Prüm zur Karolingerzeit. S. 95. Zu weiteren Quellen: Jacques Dubois, "Le martyrologe métrique de Wandelbert«, in: Analecta Bollandiana 79 (1961), S. 257-293. 
dentius. Am Gebrauch der Klassiker durch Wandalbert fällt der Gebrauch Ovids, insbesondere der Fasti auf. ${ }^{1653}$ Durch Rückgriff auf das seltene Werk orientierte sich der Dichter direkt an antiken Vorbildern ohne Berücksichtigung der spätantik-christlichen Tradition - ein »Klassizismus«, den Bernt auch für die Monatsgedichte konstatiert. ${ }^{1654}$ Auch die Zitate aus der »Anthologia Latina" weisen auf eine gut ausgestattete Bibliothek hin. Ob die gesicherten fünf Gedichte der Anthologia Latina vielleicht sogar im Verbund mit den Fasti vorlagen, kann nicht mehr entschieden werden; sicher ist, dass Wandalbert sich auf eine kleine Sammlung kalendarischer Gedichte stützen konnte. ${ }^{1655}$

Eine solche Sammlung ist auch in der prachtvollsten der Handschriften des Martyrologiums, ${ }^{1656}$ des erfolgreichsten Werkes Wandalberts, ergänzt worden, wiewohl die Handschrift selbst, Vatikan Reg. lat. 438, aus dem Bodenseeraum stammt. ${ }^{1657}$ Eine weitere St. Galler Handschrift des Werkes, Cod. Sang. 250, enthält zusätzlich eine Sammlung von Kalendergedichten im Rahmen eines Computus. ${ }^{1658}$ Könnten die Kalendergedichte beider Handschriften aus einer Sammlung aus Prüm stammen? ${ }^{1659}$ Die Handschriften enthalten folgende Gedichte: ${ }^{1600}$

\begin{tabular}{|l|l|}
\hline Vatikan Reg. lat. $\mathbf{4 3 8}^{1661}$ & Cod. Sang. 250 $^{1662}$ \\
\hline $\begin{array}{l}\text { f. 1r-31v: Martyrologium } \\
\text { Wandalberti }\end{array}$ & $\begin{array}{l}\text { p. 26: Inc. Garrula nunc babile (Passio Babile aus Ald- } \\
\text { helms Carmen de virginitate) }\end{array}$ \\
\hline
\end{tabular}

1653 Es sind keine Handschriften des 9. Jh. erhalten: Reynolds: Texts and transmission. S. 258, 266-268. LucK: Textgeschichte Ovids. S. 49-53.

1654 BERNT: Epigramm. S. 294, über Vergil, ohne Berücksichtigung der zahlreichen Ovid-Zitate.

1655 Zweifelhafte und mehrdeutige Zitate sind ausgelassen. Ed. DüMmLER (siehe dort den Apparat für Details): S. 579, 588, 590, 606: AL 640 (Ausonius, Inc. Principium iani; SK 12589; Peiper (Hrsg.): Decimi Magni Avsonii Burdigalensis opuscula, Nachdruck 1886. S. 102. PeIPER: Die handschriftliche Ueberlieferung des Ausonius. S. 309-312; Ed. Dümmler S. 585: AL 116 (nicht 115!) (Lob auf die Jahreszeiten, Inc. Carpit blanda suis, SK 2003; S. 595, 612, 613: AL 117 (Lob auf die Monate, Inc. Fulget honorifico, SK 5418); S. 604, 616: AL 680 (SK 1716); S. 613: AL 571 (Frühlingsgedicht, Inc. Vere gravis fundit, FrIEDRICH: Symposium. S. 54). Zum etwaigen Zusammenhang mit einer kalendarischen Sammlung Bedas siehe: Peiper: Die handschriftliche Ueberlieferung des Ausonius. S. 310.

$1656 \mathrm{Zu}$ Handschriften neben DüMmLER a.a. O. siehe auch: Dubois: »Le martyrologe métrique de Wandelbert«. S. 258-261. Haubrichs: Prüm zur Karolingerzeit. S. 60-63.

1657 Wilmart: Codices Reginenses Latini. S. 559f. „St. Gallen«: Haubrichs: Prüm zur Karolingerzeit. S. 60, Anm. 155 (cont. S. 61). Dagegen »Bodenseegebiet«: Bischof F: Katalog, 3. Nr. 6678. Reichenau: Hans-Walter STORк, Das Martyrologium für Kaiser Lothar I. entstanden nach 855 aufder Insel Reichenau. Orig.-getreue Wiedergabe der Handschrift Codex Reginensis latinus 438, Zürich 1997.

1658 Pp. 67-120. SCherrer: Stiftsbibliothek. S. 92-94. Illustrationen finden sich hier hauptsächlich bei Arator, pp. 447-522: Euw: Buchkunst. S. 449-454.

1659 So mit Bedenken: PeIPer: Die handschriftliche Ueberlieferung des Ausonius. S. 311.

1660 Parallelen sind fett markiert.

1661 Die Handschrift hat nur 36 Folia. 
(Fortsetzung)

\begin{tabular}{|c|c|}
\hline Vatikan Reg. lat. $438^{1661}$ & Cod. Sang. $250^{1662}$ \\
\hline $\begin{array}{l}\text { f. 31r: Inc. Bis sex signifere } \\
\text { (AL 678, SK 1752) }\end{array}$ & pp. 38-65: Martyrologium Wandalberti \\
\hline $\begin{array}{l}\text { f. 31v: Inc. Me legat annales } \\
\text { (AL 676, SK 4981) }\end{array}$ & pp. 65: Inc. Bis sena mensum (AL 680, SK 1716) \\
\hline $\begin{array}{l}\text { f. 31v: Inc. Bis sena mensum } \\
\text { (AL 680, SK 1716) }\end{array}$ & $\begin{array}{l}\text { pp. 67: Inc. Ianus et octimber (!) (»versus bedae prbi«, SK } \\
7613)\end{array}$ \\
\hline \multirow[t]{5}{*}{$\begin{array}{l}\text { f. 32v: Ad boreae partes (AL } \\
679, \text { SK 151) }\end{array}$} & pp. 67: Inc. Dira patet iani (AL 394, SK 3727) \\
\hline & $\begin{array}{l}\text { pp. 68: Inc. Hic iani mensis (AL 395, SK 6489, siehe S. } 261 \\
\text { zu Trier, SB, Ms.1245/597) }\end{array}$ \\
\hline & p. 70: Inc. Fonte lavat genitor (AL 688, SK 5264) \\
\hline & $\begin{array}{l}\text { p. 219: Inc. Respicit apriles (Innerhalb: Beda De tempo- } \\
\text { rum ratione, gekürzt aus Ausonius: SK 12589). }\end{array}$ \\
\hline & $\begin{array}{l}\text { p. 526: Ad boreae partes (AL 679, SK 151), neumiert; in } \\
\text { einem Kompendium zur Astronomie, pp. 523-526 Ex- } \\
\text { cerptio de astrologia, siehe unten S. } 261 \text { zu Trier, SB, } \\
\text { Ms.1245/597) }\end{array}$ \\
\hline
\end{tabular}

Schon Bestand und Anordnung ${ }^{1663}$ zeigen, dass hier keine vorherige Sammlung als Vorlage für beide Handschriften gedient haben kann. Ebenso wird keines der in den beiden Handschriften enthaltenen Gedichte von Wandalbert zitiert. Der Vergleich mit einer weiteren Handschrift aus Prüm selbst, Berlin, SB, Ms. Phillips $1869,{ }^{1664}$ zeigt zumindest einige Parallelen auf. In der Handschrift sind einem illustrierten Kalender f. 1-11 fortlaufend die passenden Kalenderverse aus folgenden Gedichten beigegeben: ${ }^{1665}$

Principium iani (AL 640, SK 12589)

Hic iani mensis (AL 395, SK 6489)

Dira patet iani (AL 394 SK 3727)

Die letzteren zwei Gedichte finden sich ebenfalls in Cod. Sang. 250, während das erste ausgiebig von Wandalbert zitiert wird. Aus diesen schwachen Parallelen

1662 Nur summarisch bei SCHERRER: »S. 67-120 Computus mit vielen Kalenderversen«, was zudem irreführend ist, da die Verse pp. 67-70 dem eigentlichen Computus pp. 71-120 vorhergehen. Die Handschrift ist eine umfangreiche Sammlung zur Zeitrechnung und vollständig (644 Seiten) mit solchem Material gefüllt.

1663 Insbesondere die kodikologisch weite Trennung von AL 680, SK 1716 und AL 679, SK 151 in Cod. Sang. 250.

1664 »IX. Jh. 2. Drittel«, also zu Wandalberts Lebzeiten: Bischoff: Katalog, 1. Nr. 438. Bischoff: Abtei Lorsch. S. 80, Anm. 110. Rose: Handschriften-Verzeichnisse. Sp. 293-295.

1665 Als Zusatz folgt auf f. 12 Inc. Si tenebrae egyptus AL 736, vgl. SCHALLER/KönsGen: Initia carminum. S. 674 . 
wird man keinen Ursprung der Sammlungen aus Prüm vermuten wollen; ganz im Gegenteil sollte in diesem Fall die Verwandtschaft viel stärker heraustreten, sodass von einer je lokalen Sammlung ausgegangen werden muss, die jeweils dann vor Ort dem Martyrologium Wandalberts beigefügt wurde.

Treten wir von dieser mikroskopischen Beobachtung noch einmal zurück, um die Ausbreitung des Martyrologiums von Prüm aus zu betrachten. ${ }^{1666}$ Aus Prüm selbst ist kein Exemplar erhalten; ebenso sind die Widmungsexemplare an Kaiser Lothar und den Kölner Geistlichen Otricus, auf die aus den Dedikationen geschlossen werden kann, verloren gegangen. ${ }^{1667}$ Von Prüm aus verbreitet sich das Werk in zwei Richtungen. Die beiden besprochenen Handschriften sind Repräsentanten des Bodensee-Zweigs; ${ }^{1668}$ eine aus diesem Stemma entspringende süddeutsche Handschrift fand sogar den Weg nach Prüm zurück. Zwei Exemplare befanden sich im Besitz des Passauer Chorbischofs Madalwin. ${ }^{1669}$ Der andere Zweig weist aus Prüm ins Westfrankenreich, mit Handschriften aus Reims, St. Oyan und Sens. ${ }^{1670}$ Durch die zeitliche Nähe (Mitte des 9 Jh.) von wenigstens sechs der erhaltenen oder rekonstruierten Handschriften ${ }^{1671}$ halte ich eine aktive Verbreitung des Werkes durch seinen Autor nicht für ausgeschlossen, wenn auch nur zwei Widmungen einen direkten Beweis davon liefern.

Das »Prümer Hymnar«, das in der Handschrift Trier, Stadtbibliothek, Ms.1245/597, ${ }^{1672}$ f. 75-87 vorliegt, enthält verschiedene Homilien, Anleitungen zur Messe und erbauliche Traktate und trägt auch durch sein kleines Format $(117 \times 188 \mathrm{~mm})$ den Charakter eines praktischen Handbuchs. Die Hymnen sind aus der Sammlung des Neuen Hymnars, das aus den Reformbestrebungen Benedikts von Aniane am Hof Ludwigs des Frommen entstanden ist. ${ }^{1673}$ Durch die Zusätze aber und durch weitere, aus Prüm stammende Hymnen zeigt sich das Kloster nicht als passiv rezipierend, sondern als aktiv teilnehmend an der Reform

1666 Ich folge hier: Haubrichs: Prüm zur Karolingerzeit. S. 60-62, Anm. 155.

1667 Die Prachthandschrift Vatikan, BAV, Reg. lat. 438, dediziert an einen unbekannten König, scheint durch ihren zumindest bodenseeischen Ursprung von dieser Identifikation ausgeschlossen zu sein.

1668 Zurückgehend auf Hyparchetyp ${ }^{\star}$ RGC, von Haubrichs in die Mitte des 9. Jh. datiert, also zu Lebzeiten Wandalberts.

1669 Siehe bei Passau, S. 303.

1670 Haubrichs: Prüm zur Karolingerzeit. S. 62.

$1671{ }^{\star} \mathrm{L},{ }^{*} \mathrm{Mico},{ }^{\star} \mathrm{Köln},{ }^{\star} \mathrm{RGC}, \mathrm{R}, \mathrm{G}$. Ebd. S. 61 .

1672 Der Teil f. 49-138 »wahrscheinlich Prüm«: Bischoff: Katalog, 3. Nr. 6195; nach: Bischoff: Abtei Lorsch. S. 88, Anm. 110. Widersprechende Seitenangaben (Martyrologium bis f. 51, nicht f. 49) bei: KeufFer/Kentenich: Beschreibendes Verzeichnis der Handschriften der Stadtbibliothek Trier. S. 256-257. Eingehend: HAUBRICHS: Prüm zur Karolingerzeit. S. 7587. GNEuss: "Zur Geschichte des Hymnars«. S. 77, zum Hymnenbestand S. 85f.

1673 Gneuss: «Zur Geschichte des Hymnars«. S. 73. Bullough: »Texts, chant, and the chapel of Louis the Pious«. 
- wie es von einem königsnahen Kloster zu erwarten ist. ${ }^{1674}$ Auch Wandalbert rezipiert in seiner Dichtung die vom Hof ausgehenden Impulse. ${ }^{1675}$

Das Kloster erweist sich somit in verschiedener Hinsicht als zentraler und weiteren Zentren nahestehender Ort. Gestützt auf eine zweifellos reich ausgestattete Bibliothek, die Klassiker über den Schulgebrauch hinaus und spezifische Genres wie die Kalenderdichtung enthielt, und bevorteilt durch seine Königsnähe, konnte die Abtei selbst Ort der Kreativität werden, wie sich in den Werken Wandalberts und der Hymnendichter zeigt. Die Verbreitung eigener Produktionen sowohl in den Westen wie in den Osten des Reiches wurde durch die zentrale lothringische Lage erleichtert. Insofern gleicht Prüm hier dem auch im Mittelreich gelegenen und von ähnlicher Lage und Königsnähe profitierenden Kloster Weißenburg. Hier wie dort drängt sich zudem das Element des Persönlichen in die Kalkulation. Wandalbert ist hier eine ebenso zentrale Gestalt wie Otfrid in Weißenburg, und mit ihm sind auf die eine oder andere Weise alle poetischen Bestrebungen in Prüm verbunden.

\section{II.4 Erzbistum Salzburg}

\section{II.4.a Salzburg}

So wie das Bistum Salzburg erst mit der Erhebung Arns zum Erzbischof zu seiner historischen Größe aufstieg, ${ }^{1676}$ so konzentriert sich auch die Sammlung von Dichtung fast ganz auf Arn und seine persönlichen Beziehungen. Das Skriptorium $^{1677}$ der Domstadt, angesiedelt wahrscheinlich im bischöflichen Kloster St. Peter, ${ }^{1678}$ hat bis zum Episkopat des Iren Virgil (745-784) keine eindeutigen

1674 Haubrichs: Prüm zur Karolingerzeit. S. 78, ebd. Anm. 268 und S. 80.

1675 Haubrichs. S. 79.

1676 Heinz Dopsch (Hrsg.), 1200 Jahre Erzbistum Salzburg: die älteste Metropole im deutschen Sprachraum; Beiträge des internationalen Kongresses in Salzburg vom 11. bis 13. Juni 1998 (Mitteilungen der Gesellschaft für Salzburger Landeskunde 1), Salzburg 1999; Franz ORTNER, Salzburger Kirchengeschichte. Von den Anfängen bis zur Gegenwart, Salzburg 1988; Heinz Dopsch, "Das Erzbistum Salzburg und der Alpen-Adria-Raum im Frühmittelalter unter besonderer Berücksichtigung der Salzburger Slawenmission «, in: Karantanien und der Alpen-Adria-Raum im Frühmittelalter, hrsg. von Günther HöDL und Johannes Grabmayer (St. Veiter Historikergespräche 2), Wien [u.a.] 1993, S. 101-150; Eberhard ZwINK, Frühes Mönchtum in Salzburg (Salzburger Diskussionen 4), Salzburg 1983.

1677 Bischoff: Schreibschulen 2. S. 52-179.

1678 Ebd. S. 52. Karl Friedrich Hermann, Geschichte der Erzabtei St. Peter zu Salzburg. 1: Frühgeschichte 696-1193, Salzburg 1996. Bibliothek und Schulwesen wurden erst unter Bischof Friedrich I. getrennt, siehe: Karl Friedrich HermanN, »Wissenschaft und Bildung«, in: Geschichte Salzburgs. Stadt und Land, 1, 2, hrsg. von Heinz Dopsch und Hans SpatZENEGGER, Salzburg 1984, S. 1071-1085. 
Spuren hinterlassen. Virgil, wegen seiner Bildung hochgerühmt, inspirierte in seinem intellektuellen Kreise vielfältige literarische Tätigkeit. ${ }^{1679}$ Den unter seiner Ägide verfassten ca. 30 Handschriften ${ }^{1680}$ mangelt es jedoch an poetischen Inhalten. Einen Hinweis auf die Beschäftigung mit Dichtung bietet jedoch das Fragment München, BSB, Clm 29270 + Wien, ÖNB, Cod. 313, das die prosodische Einführung des Victorinus, De ratione metrorum, ${ }^{1681}$ enthält; diese hätte gut durch einen Prudentius oder, angesichts Virgils Herkunft, durch einen Aldhelm komplettiert worden sein, um in der Schule zum Einsatz zu kommen. Von solch einer Ausstattung des poetischen Curriculums fehlt jedoch in den Salzburger Handschriften jede Spur, auch in Form von Nachträgen oder Federproben wie etwa in Mainz. ${ }^{1682}$

Einen ungleich tieferen Einfluss auf die Bildung seiner Diözese hatte Erzbischof Arn, der von 798 bis 821 das Bistum leitete, während er gleichzeitig von 787 bis 810 die Abtswürde von St. Amand innehatte. ${ }^{1683}$ Er war Karls des Großen Vertrauensmann in Bayern ${ }^{1684}$ und mit Alkuin in lebenslanger Freundschaft ${ }^{1685}$

1679 Siehe zum geistigen Leben zu seiner Zeit: Heinz LöwE, "Salzburg als Zentrum literarischen Schaffens im 8. Jahrhundert«, in: Mitteilungen der Gesellschaft für Salzburger Landeskunde 115 (1975), S. 99-144. Zu sämtlichen Aspekten des Wirkens Virgils siehe den Sammelband: Heinz Dopsch und Roswitha Juffinger, Virgil von Salzburg, Missionar und Gelehrter 1985. Von Virgil selbst haben sich keine Schriften erhalten, wenn man ihm nicht - wie LöwE - die Kosmographie des Aethicus zuschreiben möchte. $\mathrm{Zu}$ dieser Hypothese siehe: Otto PrInZ (Hrsg.), Die Kosmographie des Aethicus (MGH QQ zur Geistesgesch. 14), München 1993. S. 10-17.

1680 Stil I unter Einfluss von St. Denis und Stil II mit insularen Einschlägen, BischofF: Schreibschulen 2. S. 56, 57 und resp. die Nummern 1-24 und 25-30 im paläographischen Katalog. Siehe auch: Karl ForstNeR, "Das Salzburger Skriptorium unter Virgil und das Verbrüderungsbuch von St. Peter«, in: Virgil von Salzburg Missionar und Gelehrter. Beiträge des Internationalen Symposiums vom 21.-24. September 1984 in der Salzburger Residenz, hrsg. von Heinz Dopsch und Roswitha JUfFINGER 1985, S. 135-140.

1681 KeIL (Hrsg.): Grammatici Latini. VI, S. 216-228.

1682 Eine verspätete Nachricht vom reichen Bestand solcher Schriften bietet sicher noch der Katalog des Petersklosters aus dem XII. Jh., mit den libri scholares, darunter Ovid und Horaz: GotTlieb u. a. (Hrsg.): Mittelalterliche Bibliothekskataloge Österreichs, 1-5. S. $66 \mathrm{f}$. Man beachte auch den zu dieser Zeit viel geringeren Bestand der Dombibliothek nach der Teilung der Sammlung, ebd. S. 19.

1683 Zwei Dissertationen widmen sich ganz seinem Leben: Rüdiger Moldenhauer, Arno von Salzburg (785-821), Berlin 1956; Gertraud Demmelbauer, Arno, der erste Erzbischof von Salzburg, 798-821, Universität Wien 1950. Siehe ebenfalls die Aufsätze in: Meta NiederKORN-BRUCK und Anton SCHARER, Erzbischof Arn von Salzburg (Veröffentlichungen des Instituts für Österreichische Geschichtsforschung 40), Wien [u. a.] 2004.

1684 Herwig Wolfram, «Arn von Salzburg und Karl der Große«, in: 1200 Jahre Erzbistum Salzburg. Die älteste Metropole im deutschen Sprachraum, hrsg. von Heinz DopscH, Peter Franz Kramml und Alfred Stefan Weiss (Mitteilungen der Gesellschaft für Salzburger Landeskunde. Ergänzungsband 18), Salzburg 1999, S. 21-32.

1685 Maximilian Diesenberger und Herwig Wolfram, »Arn und Alkuin 790 bis 804: Zwei Freunde und ihre Schriften", in: Erzbischof Arn von Salzburg, hrsg. von NiEderkoRN- 
verbunden. Von seiner Initiative ging eine Vielzahl literarischer Unternehmen aus, darunter die Breves Notitiae zur Geschichte Salzburgs ${ }^{1686}$ und die Sammlung der Briefe Alkuins.

Unter Arns leitender Hand blühte das Salzburger Skriptorium auf: Er griff auf die Ressourcen seines Klosters St. Amand zurück und ließ sowohl dort Handschriften anfertigen, als auch eine Anzahl ausgebildeter Schreiber nach Salzburg kommen, die hier den charakteristischen regionsfremden Stil der Epoche Arns etablierten. ${ }^{1687}$ Eine großzügige Nutzung von Vorlagen aus dem Kloster ist anzunehmen. ${ }^{1688}$ Das Skriptorium war straff organisiert, und zur Verfertigung einer einzelnen Handschrift wurde regelmäßig eine große Zahl Schreiber koordiniert. ${ }^{1689}$ Arn sorgte für eine angemessene Ausstattung der Bibliothek mit grundlegenden Schriften der Kirchenväter (Cyprian, Hieronymus, Augustinus, etc. ${ }^{1690}$, sowie weiteren benötigten Texten (Kirchenrecht, Viten) aus Beständen St. Amands. ${ }^{1691}$ Die Bibliothek zeigt sich beinahe ausschließlich auf seelsorgerische, liturgische und administrative Belange beschränkt ${ }^{1692}$ und Arn beweist sich in seiner Sammlung mehr als Mann der theologischen Praxis denn als Schöngeist. ${ }^{1693}$

Bruck und Anton Scharer (Veröffentlichungen des Instituts für Österreichische Geschichtsforschung 40), Wien 2004, S. 81-106. Die beiden tauschten auch Bücher aus, wenn auch keine Dichtung: Philippe DePREux, »Büchersuche und Büchertausch im Zeitalter der karolingischen Renaissance am Beispiel des Briefwechsels des Lupus von Ferrières", in: Archiv für Kulturgeschichte 76 (1994), S. 267-284. S. 271.

1686 Fritz LošEK, »Arn von Salzburg und die karolingische Dichtung«, in: Erzbischof Arn von Salzburg, hrsg. von Meta NiEderkorn-Bruck und Anton Scharer (Veröffentlichungen des Instituts für Österreichische Geschichtsforschung 40), Wien [u. a.] 2004, S. 172-178.

1687 Bischoff: Schreibschulen 2. S. 61-73, dazu die Nummern des paläographischen Kataloges 31-60 für die Handschriften aus St. Amand und 61-104 für die in St. Amand für Salzburg geschriebenen, ferner 105-114 die in Salzburg entstandenen, wobei eine Zuordnung nach Salzburg nur mit Vorsicht vorgenommen werden kann (eindeutige Salzburger Spuren).

1688 Ebd. S. 71.

1689 BISCHOFF spricht gar von »Mannschaften«; an ÖNB Cod. 795 etwa waren ca. 30 Schreiber beteiligt. Ebd. S. $69 \mathrm{f}$.

1690 Bemerkenswerterweise nehmen die Werke Alkuins keinen großen Raum ein.

1691 Nach MaZAL: "Dom- und Klosterbibliothek«. S. 40f. ist Arn der Gründer der Bibliothek. Was dies jedoch über eine - nicht angesprochene - Errichtung von Räumlichkeiten hinaus bedeuten soll, bleibt unklar. Sicherlich sind auch Virgils Bücher als Bibliothek anzusprechen.

1692 Siehe die Übersicht bei Mazal, S. 40-56. Seine Scheidung zwischen Exegese, Patristik und Dogmatik ist jedoch insbesondere in Anbetracht des Fehlens eines zeitgenössischen Kataloges eine künstliche. Hingewiesen sei hier mit MAzAL, S. 52, auf das dogmatische Handbuch und Florilegium ÖNB Cod. 1332, das im Rahmen der Möglichkeiten der karolingischen Theologie eine bemerkenswerte Leistung darstellt.

1693 Auch LošEK muss sich in seiner Untersuchung (Arn von Salzburg und die karolingische Dichtung) auf die nicht unter Arn geschrieben Carmina Salisburgensia beschränken. 
Was ganz fehlt, ist Dichtung - im ganzen Bestand der für Salzburg gefertigten Handschriften findet sich nur in ÖNB Cod. 964 das vereinzelte Carmen de Hermenone, eine Sylloge von vier Epitaphien auf eine Adlige aus der Merowingerzeit. ${ }^{1694}$ Die Gedichte liegen in sehr entstellter Form vor und sind zu allem Überfluss durch Versehen mitten in die Quaestiones des Eucherius kopiert, ${ }^{1695}$ sodass eine geplante Beschaffung dieses Textes - eine Sammlung - ausgeschlossen werden kann.

In der Glossenhandschrift ÖNB Cod. 89 finden sich Spuren der Dichtung im Dienst der Schule: ein kleines Vergilglossar als Salzburger Zusatz zum Hauptkorpus der Handschrift (f. 10-166). ${ }^{1696}$ Die kunstgerechte Schrift der Zusätze legt die Handschrift eher in die Hände des Lehrers als in die des Schülers. Der Handschrift vorgeheftet - ob in St. Amand oder Salzburg, ist unklar - sind neun Blätter mit kleineren Texten, die mit dem Gedicht $O$ deus omnipotens nostrae spes beginnen. ${ }^{1697}$ Dass noch im 10. Jh. auf f. 9v eine Liste an Bischof Friedrich I. (958991) zurückzugebender Bücher nachgetragen werden konnte, ${ }^{1698}$ - darunter eben der folgende glossarius - legt nahe, dass die beiden Teile spätestens zu diesem Zeitpunkt vereinigt worden waren.

Die Gedichte, die Arn sammelte, waren nicht mit der Schule oder der Liturgie, sondern mit seinem eigenen Leben verknüpft, namentlich mit der Freundschaft, die ihn mit Alkuin verband. ${ }^{1699}$ Schon der meist nur halb zitierte Nekrologeintrag des 12. Jh., der seine Verdienste um die Bibliothek rühmt, impliziert die große Zahl von Alkuins vorhandenen Schriften und ihre Verbindung zu Arn, qui inter

1694 Zur Handschrift: Bischoff: Schreibschulen 2. S. 113f., Nr. 73. Edition und Kommentar: Bernhard BischоғF, „Sylloge Elnonensis. Grabinschriften aus merowingischer Zeit (um 600)«, in: Anecdota novissima. Texte des 4. bis 16. Jahrhunderts, Stuttgart 1984, S. 142-149. Für eine spätere Datierung: Wolfgang Dieter LEBEK, „Die neuen Grabgedichte der Sylloge Elnonensis ed. B. Bischoff 1984", in: Zeitschrift für Papyrologie und Epigraphik 63 (1986), S. 83-100; Wolfgang Dieter LeBEK, "Zur Sylloge Elnonensis (Mit textkritischen Beiträgen von O. Zwierlein)«, in: Zeitschrift für Papyrologie und Epigraphik 65 (1986), S. 66-68. Thomas KLEIN, »Kritische Nachlese zur ,Sylloge Elnonensis«, in: Arbor amoena comis: 25 Jahre Mittellateinisches Seminar in Bonn; 1965-1990, hrsg. von Ewald KöNsgen, Stuttgart 1990, S. 53-59.

1695 Vielleicht durch Kopie eines Nachtrags auf einem freigebliebenen Blatt einer Lage des Exemplars? BIschoff: Schreibschulen 2. S. 114.

1696 Ebd. S. 112, Nr. 72.

1697 SK 10872; Ebenfalls vorhanden in Cod. 808, siehe unten S. 274. Ediert bei den AlkuinGedichten als Carmen CXXIV in: DüMmLer (Hrsg.): MGH Poet. lat. 1, S. 1. S. 351, (»De huius carmine auctoris nihil certi affirmari potest «). In der Handschrift folgen ohne Zeilentrennung auf das Gedicht die Verse Bedas Inter florigeras fecundi cespitis (SK 8207). an das Pseudo-Alkunianische Gedicht anschließen.

1698 Gotтlieв u. a. (Hrsg.): Mittelalterliche Bibliothekskataloge Österreichs, 1-5. 4, S. 17.

$1699 \mathrm{Zu}$ Arn als Sammler der Werke Alkuins: Christiane Veyrard-Cosme (Hrsg.), Alcuin, Lettres: Tome I, Collection I (Sources chrétiennes 597), Paris 2018. S. 35-42. Siehe auch Diesenberger/Wolfram: »Arn und Alkuin 790 bis 804 «. 
alia innumera et laudabilia opera plus quam 150 volumina iussit hic conscribi, cuius vitam Albinus magister Karoli per sua scripta plurima, que hic apud nos sunt, multum collaudat et extollit. ${ }^{1700}$ Es ist auch nur aus den Briefen an Alkuin, dass wir Arn als Dichter kennen - seinen einzigen an Alkuin erhaltenen Brief beginnt und endet er mit drei Distichen über einen gemeinsamen Freund. ${ }^{1701}$ Es ist zu erwarten, dass wir mehr Gedichte von seiner Hand fänden, wenn nur von Seiten Alkuins die Briefe Arns erhalten geblieben wären.

Die große Salzburger Anthologie der Gedichte Alkuins fand nicht in St. Amand statt, wenn auch der Impuls der Sammlung von kleineren Werken Alkuins wohl von dort kam. Denn eine erste bedeutende Briefsammlung liegt schon in ÖNB Cod. 795 vor, dem sogenannten Enchiridion Arnonis, ${ }^{1702}$ das noch aus St. Amand stammt. ${ }^{1703}$ Darin befindet sich auf f. 1-4, 150-183, 192-197 eine Sammlung von Alkuinbriefen. Nur die Briefe auf f. 1-4 und 192-197 sind an Arn oder ihm nahestehende Personen gerichtet. Auf eine genaue Darlegung von Zusammensetzung und Zweck ${ }^{1704}$ dieser bedeutenden Handschrift braucht hier nicht näher eingegangen zu werden. Einige Aspekte sind jedoch der Erwähnung wert: Die Handschrift ist trotz aller planvollen Anlage und Niederschrift doch ein Konglomerat verschiedener Materialien, die Arn auf Reisen und durch Korre-

1700 « (...) der neben zahllosen anderen lobenswürdigen Werken mehr als 150 Bücher hier schrieben ließ; sein Leben wird von Alkuin, dem Lehrer Karls, in seinen Schriften sehr gelobt, von denen wir hier eine Menge haben." Siegmund Herzberg-FräNKEL, »Monumenta necrologica monasterii s. Petri Salisburgensis«, in: MGH Necrol. 2 1890, S. 3-64. S. 98, Nr. 24. Es liegt nahe, dass mit den Schriften, die Arn loben, Briefe und etwaige Widmungen gemeint sind.

1701 »Alcuini epistolae«. S. 109f., Nr. 66.

1702 So treffend Franz UNTERKIRCHER, Die datierten Handschriften der Österreichischen Nationalbibliothek bis zum Jahre 1400 (Katalog der datierten Handschriften in lateinischer Schrift in Österreich 1), Wien 1969. S.31 f. Umfassende Analyse und diplomatische Edition: Veyrard-Cosme (Hrsg.): Alcuin, Lettres I. Zur Handschrift insbesondere S. 115-129. Siehe auch Veyrard-Cosme: Tacitus Nuntius. S. 75-79. Bischoff: Schreibschulen 2. S. 115f., Nr. 75a. Franz Unterkircher, Alkuin-Briefe und andere Traktate: Im Auftrage des Salzburger Erzbischofs Arn um 799 zu einem Sammelband vereinigt; Codex Vindobonensis 795 der Österreichischen Nationalbibliothek. Faksimileausgabe (Codices selecti 20), Graz 1969. Theodor Sickel, Alcuinstudien, 1 (Sitzungsberichte. Akademie der Wissenschaften in Wien, Philosophisch-Historische Klasse 79, 9), Wien 1875. S. 10-28, Sigle Y, dessen paläographische Analyse durch Bischoff überholt worden ist. Diesenberger/Wolfram: "Arn und Alkuin 790 bis 804«. S. 89-106. Bullough: Alcuin. S. 43-56. Die Handschrift ist auch wegen ihrer gotischen Inhalte untersucht worden, siehe die Literatur in: Norbert WAGNER, "Zu den Gotica der Salzburg-Wiener Alcuin-Handschrift«, in: Historische Sprachforschung 107 (1994), S. 262-283.

1703 Zur Herkunftsfrage siehe die Diskussion bei Veyrard-Cosme (Hrsg.): Alcuin, Lettres I. S. $116 \mathrm{f}$.

1704 Diesenberger/Wolfram: »Arn und Alkuin 790 bis 804«. S. 99, bezeichnen sie als ein Handbuch zur Awarenmission, Veyrard-Cosme (Hrsg.): Alcuin, Lettres I. S. 82-96 als ein "manuel de pastorale«. 
spondenz zugeflossen waren. Die langsame Akkumulation von Texten wird unterstrichen durch den frühzeitigen, aber nach Abschluss des Hauptteils der Handschrift stattgefundenen Zusatz der zwei Brief-schedae ${ }^{1705}$ f. 1-4, 192-197. Sie ergänzen den Hauptkorpus der Briefe f. 150-183, der nicht von Arn zusammengestellt wurde, sondern vielmehr aus Alkuins Beständen stammte. ${ }^{1706}$

Wohl von diesem Vorbild einer Sammlung inspiriert, ließ Arn im Jahre 802 an ihn und andere gerichtete Briefe Alkuins, sowie dessen Gedichte, in einer großen Sammlung im Salzburger Skriptorium zusammenfassen. Diese liegt uns vor in ÖNB Cod. 808, ${ }^{1707}$ genauer in f. 101-234. Die kollaborative Erstellung der Handschrift wurde genauestens von Sickel nachgezeichnet: ${ }^{1708}$ Auf f. 102-162 wurden Briefe an Arn, hauptsächlich nach Salzburg adressierte, von mehreren Händen geschrieben, die einzeln an den sechs Sexternionen ${ }^{1709}$ arbeiteten. Der zweite Teil, f. 163-234, ist auf neun Quaternionen von zwei Schreibern verfasst worden (respektive für Briefe und Gedichte), wobei der zweite Schreiber schon im ersten Teil tätig war. Die Duplizierung einiger längerer Briefe aus dem ersten Teil legt zwei Vermutungen nahe: Entweder lag der zweite Teil schon als früher kompiliertes Exemplar in Salzburg vor oder es war in ihm eine zweite Sammlung vorgesehen, die dann doch mit Teil 1 zusammengebunden wurde. ${ }^{1710}$ Die Briefe sind bis auf drei Ausnahmen an Empfänger außerhalb Salzburgs adressiert und sind durch Übereinstimmung einiger, aber nicht aller Briefsequenzen mit Sammlungen aus Tours verbunden. ${ }^{1711}$ An diese Briefsammlung schließt sich, von einer Hand geschrieben, eine Sammlung von erneut sechs Briefen aus Salzburger Empfängerüberlieferung, dazu das Lehrgespräch Disputatio Pippini cum Albi$n o^{1712}$ und eine Anthologie von ca. ${ }^{1713} 30$ Gedichten Alkuins, der wir uns nun

1705 Bullough: Alcuin. S. 45.

$1706 »(\ldots)$ part of a >register of drafts or copy-texts maintained by Alcuin or in his immediate circle« Ebd. S. 49.

1707 Veyrard-Cosme: Tacitus Nuntius. S. 80-84. Unterkircher: Die datierten Handschriften der Österreichischen Nationalbibliothek bis zum Jahre 1400. S. 32 und Abb. 6. Karl Forstner, Die karolingischen Handschriften und Fragmente in den Salzburger Bibliotheken: (Ende des 8. Jh. bis Ende des 9. Jh.) (Mitteilungen der Gesellschaft für Salzburger Landeskunde. Ergänzungsband 3), Salzburg 1962. S. 20, 51. Franz UnTERKIRCHER, Inventar der illuminierten Handschriften, Inkunabeln und Frühdrucke der Österreichischen Nationalbibliothek (Museion. NF. Reihe 2 2), Wien 1957. S. 26. HermanN: Die frühmittelalterlichen Handschriften des Abendlandes. S. 156.

1708 Sickel: Alcuinstudien, 1. S. 28-43, Sigle Z. Konzis referiert von Bullough: Alcuin. S. 5156.

1709 Lagenformel der Handschrift: $8 \mathrm{VI}^{162}+9 \mathrm{IV}^{234}$, nach eigener Untersuchung.

1710 Siehe auch unten S. 271f. zur Verwendung der Handschrift.

1711 Bullough: Alcuin. S. 60. Bullough stellt aber im weiteren den genauen Zusammenhang der Salzburger Briefsammlung mit den »Tours collections « nicht fest. Siehe zu den Parallelen auch die Konkordanz bei Sickel: Alcuinstudien, 1. S. 88-92.

1712 Lloyd William Daly und Walther Suchier, Altercatio Hadriani Augusti et Epicteti philosophi (University of Illinois studies in language and literature, 24/1-2), Urbana 1939. 
zuwenden. Die Anthologie wurde bisher nur summarisch von Dümmler beschrieben. ${ }^{1714}$ Die größeren Anthologien von Alkuins Dichtung, die von Du Chesne und Frobenius in ihren Ausgaben genutzt wurden, ${ }^{1715}$ sind verlorengegangen. Zur leichteren Übersicht sei eine Konkordanz zu den MGH-Poetae und zur Ausgabe Du Chesnes gegeben ${ }^{1716}$ :

\begin{tabular}{|l|l|l|l|}
\hline $\begin{array}{l}\text { ÖNB Cod. 808 - } \\
\text { MGH Poetae 1 }\end{array}$ & $\begin{array}{l}\text { Du Chesne } \\
(\mathrm{Q})^{1717}\end{array}$ & $\begin{array}{l}\text { Burghardt, } \\
\text { Ug. Nr. }^{1718}\end{array}$ & Anmerkungen \\
\hline $\begin{array}{l}\text { 225v - S. 239, XVII } \\
\text { 226r - S. 240, XIX } \\
\text { 226r - S. 240, XX }\end{array}$ & $212-214$ & XXVII & An Paulinus von Aquileia \\
\hline 227r - S. 242, XXI & 215 & XXVII & An Theophilactus \\
\hline 228r - S. 243, XXII & 220 & XXVIII & An einen Schüler? \\
\hline 228r - S. 286, LXVII & 202 & XXV & Buchdedikation einer Ava \\
\hline $\begin{array}{l}\text { 228v - S. 332, CV, I) } \\
\text { 228v - S. 332, CV, II) } \\
\text { 228v - S. 332, CV, III) } \\
\text { 228v - S. 332, CV, IV), } \\
\text { vss. 1-2 }\end{array}$ & $203(15$ vss) $)$ & XXV & $\begin{array}{l}\text { Tituli auf Bibliothek und Re- } \\
\text { fektorium }\end{array}$ \\
\hline
\end{tabular}

1713 Die Trennung der Gedichte ist nicht immer klar; einige sind aus Versen anderer zusammengesetzt und wurden von Dümmler in der Edition getrennt.

1714 DüMmLer: »Die handschriftliche Überlieferung». S. 123f. DüMmLer (Hrsg.): MGH Poet. lat. 1. S. 166.

1715 André Du Chesne (Hrsg.), B. Flacci Albini, Sive Alchvvini Abbatis (...) Opera (...), Paris 1617. Frobenius Forster (Hrsg.), Beati Flacci Albini abbatis, Caroli Magni ... magistri Opera, Regensburg 1777. Zu Du Chesnes Sammlung eingehend: Burghardt: Philologische Untersuchungen zur den Gedichten Alkuins. Alfred LARGEAult, Inscriptions métriques composées par Alcuin à la fin du 8e siècle pour les monastères de Saint-Hilaire de Poitiers et de Nouaillé, Poitiers 1885. DüMmLer (Hrsg.): MGH Poet. lat. 1. S. 46-110.

1716 Frobenius' Ausgabe ordnet in den Carmina nur die der Ausgabe Du Chesne neu an (Frobenius Forster (Hrsg.): Albini Opera. 2, S. 202). Neu ergänzt sind Gedichte aus dem später von ihm entdeckten Regensburger Kodex (Ebd. 2, S. 612-617, siehe unten S. 274f.), die nicht schon bei Du CHESNE enthalten waren; dementsprechend ist nicht zu rekonstruieren, welche Stücke die Regensburger Handschrift genau enthalten hat. Zu weiteren im Codex Quercetanus enthaltenen Spuria vgl. DüMMLER: "Die handschriftliche Überlieferungu. S. $137 \mathrm{f}$.

1717 Die Sigle Q von DüMmLer vergeben nach Du CHesnes Humanistennamen Quercetanus. Verwirrenderweise spricht er die verlorene Handschrift durchgehend als Codex Bertinianus an, vergibt aber die Sigle B an zwei (!) andere Handschriften (»Alcuini Carmina«. S. 165, 168). Die Sigle Q erfährt man zudem nicht aus dem Apparat der Gedichte Alkuins, sondern aus dem des Briefwechsels von Petrus von Pisa und Paulus Diaconus (DüMmLER (Hrsg.): MGH Poet. lat. 1. S. 34).

1718 Burghardt: Philologische Untersuchungen zur den Gedichten Alkuins. S. 44-46. In der Tabelle nicht genannte Gedichte sind schon S. 13-34 als von Alkuin stammend behandelt worden.

$1719 \mathrm{Zu}$ Alkuin als Dichter von Inschriften siehe Kirsch: Laudes sanctorum. S. $967 \mathrm{f}$. 


\section{(Fortsetzung)}

\begin{tabular}{|c|c|c|c|}
\hline $\begin{array}{l}\text { ÖNB Cod. } 808 \text { - } \\
\text { MGH Poetae } 1 \\
\end{array}$ & $\begin{array}{l}\text { Du Chesne } \\
(\mathbf{Q})^{1717}\end{array}$ & $\begin{array}{l}\text { Burghardt, } \\
\text { Ug. Nr. }{ }^{1718}\end{array}$ & Anmerkungen \\
\hline $\begin{array}{l}\text { 229r - S. 333, CVI, I) } \\
229 r-S .333, \text { CVI, II) }\end{array}$ & $208-209$ & XXVI & $\begin{array}{l}\text { Inschrift einer Stephans- } \\
\text { kirche; Altarwidmung durch } \\
\text { Karl den Großen für den Hil- } \\
\text { debald-Dom (nach 787) }\end{array}$ \\
\hline $\begin{array}{l}229 v-S .321, \text { XCVI, I) } \\
229 v-S .321, \text { XCVI, II) }\end{array}$ & $128-129$ & $\mathrm{XI}$ & $\begin{array}{l}\text { Tituli auf Dormitorium und } \\
\text { Latrine }^{1720}\end{array}$ \\
\hline $\begin{array}{l}229 v-\text { S. 328, CI, I) } \\
230 r-S .328, \text { CI, II) }\end{array}$ & $162-163$ & XIV & $\begin{array}{l}\text { Tituli auf Klostergebäude } \\
\text { und Altartisch, gestiftet von } \\
\text { Magulf von Fleury (Abt 780- } \\
\text { 796) }\end{array}$ \\
\hline $230 v-S .244$, XXIV & 223 & - & $\begin{array}{l}\text { Abschiedsgedicht an die } \\
\text { Goten (798?) }\end{array}$ \\
\hline $230 \mathrm{v}-$ S. $245, \mathrm{XXV}$ & 216 & XXVII & $\begin{array}{l}\text { Abschiedsgedicht an Rom } \\
\text { und Papst Leo III (795-816) }\end{array}$ \\
\hline $\begin{array}{l}231 \mathrm{r}-\mathrm{S} .335 \text { CIX, I) } \\
\text { 231r - S. 338, CIX, XVI) } \\
231 \mathrm{v}-\text { S. 336, CIX, V) } \\
231 \mathrm{v}-\text { S. 339, CIX, XVII) } \\
231 \mathrm{v}-\text { S. 338, CIX, XV) }\end{array}$ & $224-228$ & XXIX & $\begin{array}{l}\text { Verse auf St. Peter, Salzburg; } \\
\text { Tituli auf einen Marienaltar, } \\
\text { einen Andreasaltar, eine Ma- } \\
\text { rienkirche, auf ein von Arn in } \\
\text { St. Amand erbautes Beinhaus }\end{array}$ \\
\hline $232 v-S .266, L V, I)$ & 259 & - & An einen Freund \\
\hline $\begin{array}{l}\text { 232v-233r - S. 339, CIX, } \\
\text { XVIII)-XII) }\end{array}$ & $229-231$ & XXIX & $\begin{array}{l}\text { Inschriften aus St. Peter, Salz- } \\
\text { burg }\end{array}$ \\
\hline 233r - S. 339, CIX, XXII) & 251 & XXIX & $\begin{array}{l}\text { Inschrift auf einen Altar Jo- } \\
\text { hannes des Täufers und Mar- } \\
\text { tins }\end{array}$ \\
\hline $233 r-S .235$, vss. $231-240$ & $\begin{array}{l}\text { (Q 178, } \\
\text { Auszug), } \\
\text { Frobenius, } \\
\text { S. } 226 \text {, } \\
\text { Nr. } 215\end{array}$ & - & $\begin{array}{l}\text { Verse aus dem Gedicht über } \\
\text { die Vernichtung Lindisfarnes }\end{array}$ \\
\hline $\begin{array}{l}233 r \text { - S. } 218, \text { XXXIII, vss } 1-2 \text {, } \\
13,15+\text { S. } 215, \text { XXIV vss. } 1-10 \\
+ \text { S. } 219, \text { vss. } 22-26+\text { S. } 220, \\
\text { vss. } 65-72\end{array}$ & $\begin{array}{l}\text { Frobenius } \\
\text { S. } 236 \text {, } \\
\text { Nr. } 270\end{array}$ & - & $\begin{array}{l}\text { Lobgedicht auf einen Bischof } \\
\text { aus verschiedenen Stücken }\end{array}$ \\
\hline 233r - Virgo Maria nitet & $\begin{array}{l}\text { Frobenius } \\
\text { S. 226, } \\
\text { Nr. } 205\end{array}$ & - & $\begin{array}{l}\text { Cento aus Sedulius, Hym- } \\
\text { nus } 1\end{array}$ \\
\hline
\end{tabular}

1720 Luxuriam ventris, lector, cognosce vorantis, / putrida qui sentis stercora nare tuo. / Ingluviem fugito ventris quapropter in ore: / tempore sit certo sobria vita tibi. 
(Fortsetzung)

\begin{tabular}{|l|l|l|l|}
\hline $\begin{array}{l}\text { ÖNB Cod. 808 - } \\
\text { MGH Poetae 1 }\end{array}$ & $\begin{array}{l}\text { Du Chesne } \\
(\mathbf{Q})^{1717}\end{array}$ & $\begin{array}{l}\text { Burghardt, } \\
\text { Ug. Nr. }{ }^{1718}\end{array}$ & Anmerkungen \\
\hline 234r - S. 266, LIV & Frobenius & - & Abschiedsgedicht \\
& S. 235, & & \\
Nr. 244 & & \\
\hline
\end{tabular}

Die Sammlung ${ }^{1721}$ lässt sich somit zwanglos in drei Stücke teilen: I. $225 \mathrm{v}-230 \mathrm{v}$ eine Sammlung von Briefgedichten und Tituli, die sich um Alkuin und seine Beziehungen gruppieren; II. 231r-233r Salzburger Gebrauchspoesie; III. 233r234r Exzerpte. Von diesen lässt sich nur I. datieren und zwar durch das Abschiedsgedicht an Rom und Papst Leo, das wahrscheinlich nach dem dort von Karl und Entourage verbrachten Weihnachtsfest 800 entstanden ist. Damit stimmt die Datierung der Gedichte beinahe exakt zu der Briefsammlung der Handschrift, die auf spätestens 802 datiert, und ist gleichzeitig Beleg für die Geschwindigkeit, mit der Poesie geschrieben, verbreitet und gesammelt werden konnte. Wie sind nun die einzelnen Sammlungen zustande gekommen und wie verhält sich die Salzburger Sammlung zur verlorengegangen Handschrift aus St. Bertin ${ }^{1722}$ der Edition von Du Chesne? Da der verlorengegangene Codex Bertinianus alle Gedichte des ÖNB Cod. 808 enthält, jedoch in veränderter Reihenfolge, kann er nicht dessen Vorlage gewesen sein, ${ }^{1723}$ muss aber aus ähnlichen Quellen geschöpft haben. Die genaue Form der Parallelen zwischen den beiden Sammlungen weist, meine ich, den Weg zur Auflösung der Frage: Selbst dort, wo mehrere Gedichte in gleicher Sequenz parallel vorliegen, passen diese Sequenzen immer auf ungefähr ein Blatt, z.B. Q S. 208-209 : ÖNB Cod. 808f. 229r-229v, Q 162-163 : 229v-230r oder Q 224-228 : 231r-231v, Q 229-231 : 232v-233r. Dass die Gemeinsamkeiten nicht die Länge eines Blattes überschreiten, lässt vermuten, dass die Vorlage darüber hinaus keine feste Ordnung besaß, das heißt, dass sie eine Loseblattsamlung war. ${ }^{1724}$ Dies stimmt genau zu Bulloughs Befund zu den Briefen, die ebenfalls von Alkuin zuerst lose registriert und erst anschließend in Briefsammlungen geordnet wurden. ${ }^{1725}$

1721 Von der Burghardt (S. 281-286) den größten Teil als authentisch (162, 202, 208-209, 212$214,215,216,223,224-228,229-231,251,259)$ und als wahrscheinlich authentisch (128$129,163,215,220$ ) bewertet.

1722 Nunc primum ex bibliotheca S. Bertini in lucem data, Ed. Du CHESNE S. 1673/74.

1723 Was auch durch die zahlreichen, bisweilen kreativen Varianten belegt wird.

1724 Trotz der verschiedenen relativen Anordnung der Gedichte ist eine absolute Nähe der Stücke zueinander erhalten geblieben, sodass die meisten Stücke von ÖNB Cod. 808 auch in der Sammlung Du CHEsnes eng zusammen liegen, ohne die gleiche Reihenfolge zu haben (S. 128-129, 162-163, 202, 203, 208-209, 212-214, 215, 216, 220, 223, 224-228, 229-231, 251, 259) - als ob aus dem gleichen Stapel Blätter kopiert worden sei.

1725 Bullough: Alcuin. S. 73, 99, 101, 102. 
Auch zur kleinen Sammlung von Salzburg betreffenden Gedichten (231r233r) ergeben sich weitere Schlussfolgerungen: 1. Weil diese Sammlung ebenfalls in der (wohl westfränkischen) ${ }^{1726}$ Sammlung von St. Bertin vorkommt, ist eine Autorschaft Alkuins daran wahrscheinlicher, als wenn diese Gedichte ein Zusatz zu Cod. 808 ohne Parallelüberlieferung wären. 2. Obwohl die Zusammenfassung von Salzburger Inschriften in Teil II. an eine Empfängerüberlieferung denken lässt, zeigt die sequentielle Übereinstimmung mit Du Chesnes Handschrift (224228, 229-231), dass diese Inschriften sich schon in Alkuins Register beieinander befunden haben müssen. Interessant ist in diesem Zusammenhang ein weiterer Textzeuge: Im Verbrüderungsbuch von St. Peter, ${ }^{1727}$ das zu Zeiten Virgils begonnen wurde, befindet sich auf pp. 16-17 von einer Hand des 11. Jh. eine Sammlung von Salzburger Kircheninschriften. ${ }^{1728}$ Sie enthält alle bei Du Chesne zerstreuten Inschriften, alle im ÖNB Cod. 808 enthaltenen, sowie weitere Stücke, die in keiner der beiden Sammlungen erhalten sind. Mit der Sammlung von ÖNB Cod., Cod. 808 bestehen folgende Parallelen: ${ }^{1729}$ I (1), II-IV, V (3), VI-XIV, XV (5) XVI (2) XVII (4), XVIII-XIV. Aus der veränderten Reihenfolge ist klar, dass ÖNB Cod. 808 enger mit dem Bertinianus, als mit der Sylloge des Verbrüderungsbuches zusammenhängt, dass also ÖNB Cod. 808 nicht aus der Vorlage für diese kopiert worden sein kann und die Sylloge nicht aus der Handschrift. Wie erklärt sich aber das Vorliegen der meisten Inschriften aus dem Verbrüderungsbuch im Codex Bertinianus? Man muss, denke ich, von einer doppelten Tradition ausgehen: Einzelne Blätter aus dem Register Alkuins wurden zuerst in ÖNB Cod. 808 kopiert, vermittelt durch die persönliche Beziehung zu Arn. Zu einem späteren Datum wurde dann aus Alkuins Unterlagen eine gründlichere Sammlung von Salzburger Dichtung veranstaltet, wobei nicht nach Folia, sondern nach einzelnen Inschriften kopiert und geordnet wurde. Diese kleine Sammlung, die kaum mehr als ein Bifolio umfasst haben dürfte, wurde von einem Schreiber des 11. Jh. dann auf den Freiraum im Verbrüderungsbuch kopiert.

Was war nun der Zweck von Cod. 808? Verschiedene Indizien legen nahe, dass die enthaltenen Texte als Muster und Vorbilder gebraucht wurden. In der zweiten

1726 Burghardts (S. 276-278, 280) Vermutung, dass der Bertinianus aus Salzburg selbst stamme und dass er sich mit ÖNB Cod. 808 ob als Vorlage oder Kopie beeinflusst habe, kann ich mich aufgrund der ganz anderen Anordnung der Gedichte und ihrer bisweilen verschiedenen Trennung nicht anschließen. Ob Bert. - 808 oder 808 - Bert. oder eine Salzburger Sammlung, von der beide abhängen - in allen Fällen wäre eine weitgehendere sequentielle Übereinstimmung zu erwarten.

1727 Karl Forstner, Das Verbrüderungsbuch von St. Peter in Salzburg: Vollständige FaksimileAusgabe im Originalformat der Handschrift A 1 aus dem Archiv von St. Peter in Salzburg (Codices selecti 51), Graz 1974.

1728 DüMmLer (Hrsg.): MGH Poet. lat. 1. S. 335-340, CIX, i-xxiv).

1729 In Reihenfolge des Verbrüderungsbuches (römische Ziffern), in Klammern mit Nummer der Folge in ÖNB Cod. 808. 
und dritten Ansprache des Konzilsordo 7B zitiert Arn ausgiebig aus den Briefen Alkuins. ${ }^{1730}$ Die zitierten Briefe kommen in ihrer Gesamtheit nur in ÖNB Cod. 808 vor, der hier also als Vorlage gedient haben muss. ${ }^{1731}$ Ein weiteres Indiz ist die erneute Abschrift der Briefe in der Handschrift München, BSB, Clm 14743. ${ }^{1732}$ Dort wurden die Briefe gekürzt und durch Ausschaltung von Namen und Daten als Briefformeln hergerichtet. ${ }^{1733}$ Als Vorlage diente ÖNB Cod. 808, dessen Briefe in gleicher Reihenfolge - mit Auslassungen - dargeboten werden. Das Interesse an den Alkuinbriefen als Vorlagen hat also hier den nächsten Schritt zur vollkommenen Formularisierung genommen. Für die Gedichte findet sich ein vereinzelter Hinweis auf ähnlichen Gebrauch. Dulcis amor lacrimis (f. 232v) findet sich ebenfalls in Clm 19410, pp. 51-52, in einem poetischen Cento aus verschiedenen Quellen, die zur Erstellung eines Briefmusters formularisiert wurden. Das Ergebnis für die gesamte Handschrift ist also deutlich: Arn ließ epistolares und poetisches Material, das er als Empfänger der Briefe und als Freund Alkuins erhalten hatte, in einen Kodex mustergültiger Texte sammeln, um bei Gelegenheit auf die vielfältigen Vorbilder desselben zurückgreifen zu können. ${ }^{1734}$ Arn zeigt sich also auch nach dieser eingehenden Untersuchung der von ihm gesammelten Dichtung als Mann der Praxis, dessen literarische Interessen den Anforderungen seines Amtes dienten.

Sein Nachfolger Adalram (821-836) ließ nicht annähernd so viel schreiben wie Arn, und was unter seinem Episkopat an Dichtung geschrieben wurde, ging auf diesen zurück. ${ }^{1735}$ In der Handschrift München, BSB, Clm 14447 ist ein weiteres Denkmal der Freundschaft Arns zu Alkuin erhalten geblieben, das sogenannte Enchiridion. ${ }^{1736}$ Alkuin stellte für Arn um 802 ein manualem libellum multa

1730 Herbert Schneider (Hrsg.), Die Konzilsordines des Früh- und Hochmittelalters (MGH Ordines de celebrando concilio 1), Hannover 1996. S. 55-56 (bes. Anm. 180), 329-342.

1731 "Alcuini epistolae». Nr. 20, 34, 38, 173, 184, 185, 242, 253, 267. Die Briefe stammen aus beiden Teilen der Handschrift (f. 101-162, 163-234), sodass diese zumindest praktisch als Einheit angesehen werden muss.

1732 Siehe unten S. 275f. zu den darin enthaltenen Gedichten.

1733 Theodor Sickel, »Rezension: Monumenta Alcuniana», in: Historische Zeitschrift 32 (1874), S. S. 352-365. Insb. S. 361 f. Konkordanz bei SickeL, Alcuin-Studien, S. 88-92, Siglen Z und $\mathrm{R}$.

1734 Analog stellt VeYrard-Cosme (Hrsg.): Alcuin, Lettres I. S. 82-96, wie oben schon bemerkt, für Wien, ÖNB Cod. 795 fest, dass die Handschrift Merkmale eines "manuel de pastorale» zeige; aber auch die memorialen Aspekte der Handschrift, nicht nur im Sinne des Gedenkens an Alkuin, sondern an den ganzen Kreis seiner Adressaten, sei nicht zu vernachlässigen (ebd. S. 96-114).

1735 Bischoff: Schreibschulen 2. S. 73-76 und Nr. 116-125. Das Muspilli in Clm 14098, von Adalram Ludwig dem Deutschen geschenkt, ist ein Nachtrag aus der Umgebung des Hofes.

1736 Fravventura (Hrsg.): Enchiridion in Psalmos. Siehe auch S. 221-224 zu Köln, Dombibliothek Cod. 106 (Köln). 
continentem de diversis rebus ${ }^{1737}$ zusammen, dessen Schwerpunkt auf Psalmenexegese und Hymnodie lag. ${ }^{1738}$ Arns Exemplar - vielleicht ebenfalls nur in ungebundenen Lagen übersandt ${ }^{1739}$ - hat sich nicht erhalten, ist jedoch sowohl in Salzburg im vorliegenden Kodex als auch anderwärts abgeschrieben worden. Den Kopien des 9. Jh. ist jeweils der an Arn gerichtete Lehrbrief Alkuins über die Psalmen beigegeben worden. ${ }^{1740}$ In Clm 14447 liegt keine getreue Abschrift, sondern eine Kürzung vor. ${ }^{1741}$ Die Redaktion der Kurzfassung wurde anscheinend in Salzburg veranstaltet, was durch das höhere Alter gegenüber den anderen Textzeugen derselben und durch die Nähe des Empfängerexemplars anzunehmen ist. Selbst das Streichen von Dichtung darf hier als charakteristisch gelten: Vom ursprünglichen reichen Hymnenbestand des Enchiridion blieben nur zwei $^{1742}$ am Ende übrig; der Hauptteil wurde ganz auf Psalmenexegese und Paränese ${ }^{1743}$ zusammengestrichen. ${ }^{1744}$ Diese Reduktion ist als eine Veränderung des Genres der Handschrift anzusehen: Während das Enchiridion eine frühe Übertragung der insularen Tradition der Libelli Precum auf den Kontinent darstellt, ${ }^{174}$ ist die gekürzte Version eine gewöhnlichere exegetische Handschrift,

1737 »Ein Handbuch mit allerlei Inhalten«, »Alcuini epistolae«. S. 417, Nr. 259. Der Brief ist übrigens der letzte in der Sammlung des ÖNB Cod. 808.

1738 Francesca Sara D'Imperio und Rossana E. Guglielmetti, "Alcuinus Eboracensis ep.", in: La trasmissione dei testi latini del Medioevo, 2, hrsg. von Paolo ChIEsa und Lucia CASTALDi 2005, S. 22-70. S. 22-27; Gretsch/Gneuss: »Theodorean Poem«. S. 14-16; Michael LAPIDGE, "Theodore and Anglo-Latin Octosyllabic Verse ", in: Lapidge, Anglo-Latin Literature 600-899 1996, S. 225-245, 504. S. 241 f.; Hellgardt: »Reimgebet«. S. 7. Eine Monographie hierzu ist in Vorbereitung: Fravventura (Hrsg.): Enchiridion in Psalmos. Zur Handschrift S. 32. Für die freundliche Mitteilung der Dissertation danke ich Dr. Vera FravVEnTURA.

$1739 »[\mathrm{~A}]$ >mobile« archetype«: Vera Fravventura, »Alcuin's `Enchiridion in Psalmos and its letters of presentation", in: Mittellateinisches Jahrbuch 51 (2016), S. 171-194. S. $193 \mathrm{f}$.

$1740 \mathrm{Zu}$ den Handschriften siehe Hellgard, wie Anm. 3, S. 5, BCD (nur die Handschriften des Sancte Sator Hymnus). Umfassender: Fravventura: Edizione, S. 28-32. Der Brief zu den Psalmen: "Alcuini epistolae«. S. 388, Nr. 243. Siehe hierzu: Fravventura: »Letters of presentation«.

1741 Die meisten Handschriften bieten eine gekürzte Version, jedoch nicht abhängig von Clm 14447, siehe das Stemma in: Fravventura (Hrsg.): Enchiridion in Psalmos. S. 57. Abstammung von Arns Handexemplar ( $\omega)$ : FravventURA: "Letters of presentation«. S. 190. Gretsch/Gneuss: »Theodorean Poem«. S. 15f.; Handschrift N, Reims, Bibl. mun., 438, stammt aus St. Amand und steht der Salzburger Handschrift auch zeitlich nahe.

1742 Ad Dominum clamaveram, SK 167, und Sancte sator suffragator, Nr. 14640. Zu letzterem siehe S. 310f. zu München, BSB, Clm 19410 (»Carmen ad Deum«).

1743 In Form der Ansprache an Ad pueros Sancti Martini, »Alcuini epistolae«. Nr. 131.

1744 Eine Analyse der Textauswahl bei der Kürzung: Fravventura: »Letters of presentation«. S. $191 \mathrm{f}$.

1745 Ausführlich zu Alkuins Einfluss auf das Genre: Radu Constantinescu, »Alcuin et les ‘Libelli Precum de l'époque carolingienne«, in: Revue d'histoire de la spiritualité 50 (1974), S. 17-56. 
die sich in die weiteren patristischen Ergänzungen der Salzburger Bibliothek unter Adalram einfügt. ${ }^{1746}$

Mit Bischof Liuphram (836-859) nahm das Skriptorium neuen Aufschwung. ${ }^{1747}$ Auch das Interesse an Dichtung erstarkte wieder und drückte sich in zwei Sammlungen und weiteren verstreuten Gedichten aus. Die Hauptzeugen für dieses Interesse sind zwei schon angesprochene Handschriften. Wenden wir uns zuerst der verlorengegangenen Regensburger Handschrift zu, die von Frobenius nach Abschluss seiner Edition entdeckt und in den Addenda berücksichtigt wurde. ${ }^{1748}$ Leider teilt er uns nicht den Inhalt der Handschrift mit, sondern ergänzt nur, was nicht schon bei Du Chesne enthalten war bzw. was von dessen Version abwich. ${ }^{179}$ Jedoch lässt sich auch aus diesen wenigen Hinweisen erkennen, dass hier durchaus eine Neuausgabe der Gedichte Alkuins veranstaltet wurde, die über die erste Sammlung des ÖNB Cod. 808 hinausging. ${ }^{1750}$ Die zusätzlichen oder vervollständigten Stücke sind: ${ }^{1751}$

1. Verse auf Bücher: Flumina qui metuat LXVI, II; Pontifico magno Arnoni LXVI, III; Inchoat hic comes LXXIX, Exul ab humano LXIX; Haec dator aeternus LXVI, I ${ }^{\mathrm{a}}$ (ergänzt gegenüber 808).

2. Miscellanea: Si non dura silex LVII (ergänzt gegenüber 808); Dum suetas soleat LX (An Modoin alias Homerus); "Conflictus veris et hiemis" LVIII; Posce patrum cineres XLIV (ergänzt, auch in ÖNB Cod. 795); Quamvis digna tuis (Epitaphium Hadriani, S. 113, IX); Surge meo domno (Angilbert an Karl,

1746 Im gleichen Verständnis wurde es unter Liuphram erneut kopiert in ÖNB Cod. 458, f. 81v$174 \mathrm{v}$, im Verbund mit weiteren exegetischen Schriften. Zu dieser Handschrift des Enchiridion siehe: Fravventura (Hrsg.): Enchiridion in Psalmos. S. 32-34.

1747 Bischoff: Schreibschulen 2. S. 76-83, Nr. 143-176.

1748 Frobenius Forster (Hrsg.): Albini Opera. 2, S. 612-617. Aus Frobens Transkription weitere Stücke ediert in: Bernhard BısсноғF, Salzburger Formelbücher und Briefe aus Tassilonischer und Karolingischer Zeit (Sitzungsberichte der Bayerischen Akademie der Wissenschaften, Philosophisch-Philologische und Historische Klasse 4), München 1973. S. 8 f.

1749 Porro in Codice plurima Alcuini nostri carmina deprehendi, partim jam inter edita comprehensa; partim ibi mutila, partim vero omnino inedita. Haec nunc hoc loco addimus, mutila supplemus, edita nonnullis locis inter corrigenda emendamus. FrobeNIUs Forster (Hrsg.): Albini Opera. 2, S. 612.

1750 Hier sei auch auf eine weitere verlorene Sammlung hingewiesen, die bisher unbemerkt geblieben ist: Die letzten vier Stücke des ÖNB Cod. Cod. 808, die bei FrobenIUs, aber nicht Du Chesne vorkommen (Frobenius Nr. 215, 270, 205, 244, siehe Tabelle oben S. 268-270) gibt er an ex Codice MS. pervetusto Salisburgensi kopiert zu haben; man würde sofort an den ÖNB Cod. 808 denken, wenn Frobenius nicht ergänzen würde, dass in der von ihm herangezogenen Handschrift auch die vorhergehende Nummer, Dilige pauperiem, Alcuin zugeschrieben worden sei. Ebenso ergänzt er als Nr. XII der Nachträge Tingue semel, das er in ÖNB Cod. 808 gefunden hätte. Das Gedicht ist jedoch nicht in Arns Sammlung enthalten, sodass eine weitere Sammlung bestanden haben muss, über die freilich nichts weiter gesagt werden kann, als dass sie diese Gedichte enthielt.

1751 In Reihenfolge der Edition Frobenıus; Römische Zahlen für »Alcuini Carmina«. 
S. 360, II); Tingue semel calamum XVIII (Alkuin an Arn); O Deus omnipotens CXXIV (Über das Jüngste Gericht); Quintus erat mundi (Angilbert, Über die Bekehrung der Sachsen, S. 380, VII).

3. Weiterhin teilt Bischoff mit $^{1752}$ : En vester socius (Bitte um Bücher von Agericus (von St. Amand?) an einen Lotharius); Adalrammus ovans (Weihinschrift, Adalram-Zeit); Disce frequenter (Kircheninschrift); Haec diruta domus (Weihinschrift, Adalram-Zeit); Si quis non valeas (Gedenkinschrift auf Adalram).

Besonders die im Vergleich zu ÖNB Cod. 808 vervollständigten Stücke zeigen, dass diese frühere Handschrift nicht die Vorlage gewesen sein kann. Ein anderer Schluss ist naheliegender: Die Materialsammlung, aus der ÖNB Cod. $808 \mathrm{zu}$ sammengestellt wurde, war auch zu Liuphrams Zeiten noch vorhanden. Darin fanden sich auch Stücke, die von Arn nur auszugsweise oder gar nicht in seine Sammlung aufgenommen wurden. Die in ÖNB Cod. 808 unvollständigen Stücke wurden hier vollständig aus der Vorlage übernommen. Dass die Sammlung jedoch nicht auf dem von Arn erreichten Stand verblieb, zeigt die Übernahme der Stücke aus der Zeit Adalrams, die der Sammlung ein deutlicheres Salzburger Gepräge geben.

Diese Neuausgabe der Gedichte Alkuins fügt sich in das weitere Bemühen Liuphrams um die Sammlung von Mustertexten, das in der Kompilation einer Formelsammlung aus den Briefen Alkuins seinen Ausdruck fand. Diese ist uns in der schon erwähnten Handschrift Clm 14743 erhalten, worin eine Auswahl aus den Briefen des ÖNB Cod. 808 durch Kürzung und Anonymisierung zu einer Formulae-Sammlung hergerichtet wurde. ${ }^{1753}$ Dieser Sammlung wurde, ebenso wie im ÖNB Cod. 808, eine Sammlung von Gedichten beigegeben, jedoch ganz anderen Charakters. Aus diesen sogenannten Carmina Salisburgensia wurde von Dümmler nur ediert (und neu angeordnet), was er nicht schon unter anderen Dichtern herausgegeben hatte; die Sammlung in ihrer Gesamtheit hat Wolfinger herausgegeben, dessen Einleitung und Kommentar nicht viel hinzuzufügen ist. ${ }^{1754}$ Die kleine Handschrift (173 x $115 \mathrm{~mm}$ ) ist aus einem Guss; die Verse f. 157186 sind zwar durch Handwechsel auf f. 156v von den Formulae abgesetzt, folgen

1752 Bischoff: Formelbücher. S. 8f., 27-29. Von Frobenius wurden die Stücke als nicht von Alkuin stammend nicht ediert.

1753 Karl Halm, Catalogus codicum latinorum (Clm 11001-15028) (Catalogus codicum manu scriptorum Bibliothecae Monacensis 4/2), München 1876. Zur Formularisierung: VEYRARD-Cosme: Tacitus Nuntius. S. 82.

1754 »Carmina Salisburgensia«, in: MGH Poet. lat. 2, hrsg. von Ernst DüMmLE R 1884, S. 637-646; Wolfinger: »Carmina Salisburgensia«. Ernst DüMmLER, »Beiträge zur Geschichte des Erzbisthums Salzburg im IX. bis XII. Jahrhundert", in: Archiv für österreichische Geschichte 22 (1859), S. 279-304. BischоғF: Schreibschulen 2. S. 160 f., Nr. 176. 
aber in einheitlicher Gestaltung inmitten der zehnten Lage $\left(\mathrm{IV}^{160}\right)$. Die Carmina sind den Themen nach eine heterogene Sammlung: 1. Praemicat alme tuum (Lobgedicht auf Adalram); 2. Baldo dei famule (Dungal an Baldo); 3. Fertur de Iano (Gedicht auf die Monate); 4. Haec quisquis pedibus (Inschrift eines Kirchenraumes); 5. Pone focum mensis (Gedicht auf die Monate); 6. Per montes campos (Alkuin an Arn); 7. Dicta vocatur avis (Alkuin, Gedicht über den Hahn); 8.-13. Poetische Bischofslisten; ${ }^{1755}$ 9. Hic pater et pastor (Epitaph Virgils); 10. Quisque velis criptam (Epitaph Arns); 11. Tu quod es (Epitaph Adalrams); 12. Si quis non valeas (Klagegedicht über den Tod Adalrams); 13. Palma sacerdotum (Lob Liuphrams); 14. Stellarum in caelo (Vorwort zu einer Beschreibung der Sternbilder); 15. Rex ubi versifico (Gedicht zu den Psalmendichtern); 16. Nobilis hanc aries (An Adalram); 17. Immensas grates (Ludwig der Deutsche an Baldo).

So ungleich die Inhalte auch erscheinen mögen, so sehr ist doch der allgemeine Geist dieser Anthologie bekannt: Die Mischung aus Brief-, Inschriftenund verstreuter Dichtung (in Form von etwa Buch- oder Kalenderversen) ist uns in ÖNB Cod. 808 und dem verlorenen Regensburger Kodex schon begegnet. ${ }^{1756}$ Der Unterschied insbesondere zu Arns Sammlung liegt in der stärkeren Berücksichtigung Salzburgischen Materials, das auch in Frobenius Handschrift prominenter auftrat (Nr. 3 der Inhalte, siehe oben S. 275). Dem exemplarischen Charakter der Sammlung entsprechend sind auch Namen an zwei Stellen durch ille ersetzt; die Mehrzahl der Namen blieb jedoch erhalten. ${ }^{1757}$ Auch wenn man, wie Wolfinger richtig bemerkt, ${ }^{1758}$ das Exemplarische der Sammlung nicht in jedem Detail nachweisen kann, so belegen doch die allgemeine Mischung der Themen und Gattungen, die Verbindung mit Formulae in der Handschrift, sowie die Parallelität zu ähnlichen Sammlungen ${ }^{1759}$ den Charakter der Carmina Salisburgensia als Mustersammlung.

In diesen Rahmen fügen sich auch die drei Gedichte, die sich in der FormulaeHandschrift Clm 4650 finden. ${ }^{1760}$ Durch die Aufnahme einiger Briefe Alkuins an

1755 Vielleicht auch als Inschriften zu werten, siehe WoLfinger: "Carmina Salisburgensia«. S. 236-239. Siehe auch: De ordine conprovincialium pontificum, http://www.geschichts quellen.de/repOpus_01955.html, 2016-11-29.

1756 Die von WolfiNGer nicht zum Vergleich herangezogen wurden; er scheint sie gar nicht gekannt zu haben, siehe S. 186: Der Clm 14743 sei »eine Sammlung verschiedenster Texte» statt eine formularisierende Bearbeitung des ÖNB Cod. 808.

1757 In Nr. 12 und 13 zu Passau und Säben.

1758 Wolf Inger: »Carmina Salisburgensia«. S. 234f.

1759 Formulae und Dichtung sind keine ungewöhnliche Textgemeinschaft, z. B. in Clm 19410, 19413 oder ÖNB Cod. 1609. Auch im späteren Kodex Clm 4650 (aus Salzburg?) findet sich eine Bauinschrift in Textgemeinschaft mit Formulae.

1760 Günter Glauche, Die Pergamenthandschriften aus Benediktbeuern. Clm 4501-4663 (Catalogus codicum manu scriptorum Bibliothecae Monacensis 3/1), Wiesbaden 1993. S. $283 \mathrm{f}$. Rio: Legal practice. S. 247 f. Bischoff: Katalog, 2. Nr. 2981. Bischoff: Schreibschulen 2. S. 201f. Zeumer (Hrsg.): MGH Formulae. S. 265. Zu den Formulae eingehender: 
Arn, die sich zwischen den Formulae finden, kann die Handschrift im Umkreis Salzburgs verortet werden, da diese Briefe nur dort verfügbar waren. Dichtung ist hier eng in die Formulae integriert:

- MGH Formulae Salzburgenses, Nr. 20, S. 445 (Rockinger Nr. LXXIV): Inc. Ille superne sagax. ${ }^{1761}$

- Rockinger Nr. LXXV, S. 142: Inc. Spiritus effuget, SK 15601.

- Rockinger Nr. LXXV, S. 142: Inc. Hoc opus in melius, SK 7053. ${ }^{1762}$

Der Ort der Dichtung inmitten von Musterbriefen unterstreicht noch einmal die Ergebnisse zu den anderen Salzburger Sammlungen.

Bischoff Liuphram erscheint nach dieser Untersuchung gemäß als Fortführer der von Arn etablierten Sammlungsart von Mustertexten epistolarer und poetischer Art. ${ }^{1763}$ Während Arn jedoch auf Quellen außerhalb Salzburgs zurückgriff, namentlich auf seine Beziehungen zu Alkuin selbst, konnte Liuphram schon auf einen Fundus von "Dichtung für Salzburg « ${ }^{1764}$ zurückgreifen, der sich in Themen und Gattungen eng an die von Arn importierten Vorbilder anschloss und dann selbst als vorbildhaft gesammelt werden konnte.

\section{II.4.b Freising}

Erst unter den Bischöfen Arbeo (764-784) und Atto (784-811/812) nimmt die "Domschreibstube« des bonifatianischen Bistums Freising ${ }^{1765}$, das schon in seiner Frühzeit unter dem heiligen Korbinian Bedeutung in der Mission gewonnen

Rockinger (Hrsg.): Drei Formelsammlungen. S. 5-21. Zeumer (Hrsg.): MGH Formulae. S. 438-455.

1761 MGH Poet. 2, S. 666.

1762 Diese Verse in MGH Formulae, S. 445, an die Verse von Form. Salzb. Nr. 20 angehängt. Vielleicht handelt es sich um eine Bauinschrift Liuphrams?

1763 Inwiefern der in Gedichten Nr. 2. und 17. genannte Magister Baldo an der Sammlung beteiligt war, bleibt unklar. Neben diesen beiden Zeugnissen wird er auch als Stifter genannt in den metrischen Vorworten von Clm 18524b, ÖNB Cod. 458, Graz, Landesarchiv Steiermark, Ms. 790 und Clm 15821. BischоғF identifizierte seine Handschrift in zahlreichen Salzburger Kodizes, die er korrigierte und annotierte, BischоғF: Schreibschulen 2. S. 78. Er war auch Dichter und vermachte vielleicht seine Handbibliothek dem Domstift: Bischoff: Formelbücher. S. 11.

1764 WOLFINGER: »Carmina Salisburgensia«. S. 186.

1765 Zur Geschichte siehe: Josef Mass, Das Bistum Freising im Mittelalter (Geschichte des Erzbistums München und Freising 1), München 1986. Josef Mass, Das Bistum Freising in der späten Karolingerzeit. Die Bischöfe Anno (854-875), Arnold (875-883) und Waldo (884906) (Studien zur altbayerischen Kirchengeschichte 2), München 1969. Zur Geschichte von "Domschreibstube« und Bibliothek: BIschoff: Schreibschulen 1. S. 58-130; GLAUCHE: Pergamenthandschriften Freising. S.VII-XV; Ernst HellgardT, "Freising ", in: Schreiborte des deutschen Mittelalters : Skriptorien - Werke - Mäzene, hrsg. von Martin J. Schubert, 
hatte, eine klar erkennbare Gestalt an. Die 32 aus dieser Zeit erhaltenen Handschriften ${ }^{1766}$ repräsentieren die Bemühung um die Grundausstattung der bischöflichen Bibliothek mit Texten praktisch-theologischer und rechtlicher Natur. »Es scheint, als hätte die Schreibtätigkeit [unter Atto] sich zeitweilig gerade nur auf das für praktische Bedürfnisse unumgänglich Notwendige beschränkt, und für literarische Anschaffungen sei wenig Neigung vorhanden gewesen. " ${ }^{1767} \mathrm{Im}$ lebhaften Büchertausch mit den umliegenden Bibliotheken (Würzburg, Salzburg, Benediktbeuern $)^{1768}$ blieb die Dichtung unbeachtet. Eine kleine Blüte aus einer größeren Anthologie ist uns durch die fortgesetzte Beziehung Freisings zu seinem Schüler Leidrad (745-813), Bischof von Lyon, erhalten geblieben, aus dessen Kathedralbibliothek unter anderem Werke von Augustinus und Hrabanus ausgeliehen wurden. Unter seinem Episkopat entstand eine bedeutende Anthologie, die von westgotischen Schreibern und wohl aus westgotischen Quellen erstellt wurde. ${ }^{1769}$ Diese enthält (Voss. Lat. F. 111, f 38ra-38va) ein kleines Florileg aus dem seltenen Petronius, ${ }^{1770}$ aus dem zwei Verse auf der freigebliebenen letzten Seite von München, BSB, Clm 6258 eingetragen wurde. ${ }^{1771}$ Welcher Gestalt die Handschrift war, aus der in Freising dieser Vers genommen wurde, oder ob er aus dem Gedächtnis niedergeschrieben wurde, ist nicht mehr feststellbar. Die folgenden Petronverse der Leidener Handschrift sind mit der metrischen Notiz metro falecio endecasillabo versehen, die in $\mathrm{Clm} 6258$ jedoch nicht reproduziert wird. Die Anmerkung legt jedoch nahe, dass das Florileg zur metrischen Veranschaulichung diente, zumal die aus dem Zusammenhang geris-

Berlin [u.a.] 2013, S. 151-174. Glauche/KnAus/Bischoff (Hrsg.): MBK 4, 2. S. 617-644; Franz BRunhöLzL, Die Freisinger Dombibliothek im Mittelalter; Studien zu ihrer Geschichte, ihrer Bedeutung für die literarische Überlieferung und zu ihrer Stellung im geistigen Leben Südbayerns bis zum Ausgang des zwölften Jahrhunderts, Habil. München 1961. PÖRNBACHER: "Freisings geistige Bedeutung".

1766 Bischoff: Schreibschulen 1. S. 60-64, Nr. 1-23, S. 64-65, Nr. 24-32.

1767 Ebd. S. 64. Ob das in München, BSB, Clm 14461, f. 149v (Ebd. Nr. 42), von grober Hand nachgetragene Gedicht Inc. Festum nunc celebre aus dieser Zeit stammt, ist unklar (SK 5097).

1768 GLAuche: Pergamenthandschriften Freising. S. VIII-XI.

1769 Paris, Bibliothèque nationale de France, Lat. 8093 (Bl. 1-32) + Leiden, UB, Ms. Voss. Lat. F. 111 + BnF Lat. 8093 (Bl. 33-38). Bernhard BischоғF, »Ein Brief Julians von Toledo über Rhythmen, metrische Dichtung und Prosa«, in: Bischoff, Mittelalterliche Studien, 1, 1966, S. 288-298. S. 292. BischofF: »Panorama«. S. 18.

1770 Konrad Müller (Hrsg.), Petronii Arbitri Satyricon reliquiae (Bibliotheca scriptorum Graecorum et Romanorum Teubneriana), München 2003. S. 13, 83, 91, 193-194. REYNoLDS: Texts and transmission. S. 295-300. Natalie Breitenstein (Hrsg.), Petronius: „Satyrica 115«: Text, Übersetzung, Kommentar (Texte und Kommentare 32), Berlin [u.a.] 2009. S. XIXV.

1771 f. $140 v$ aus Satyricon. c. 83, 10, vss. 3+5 (Ed. Müller S. 83). Zur Beziehung zu Lyon: Glauche: Pergamenthandschriften Freising. S. XI. Zur Handschrift: BRunHöLzL: Dombibliothek. S. 192-194. 
senen Verse keine Sinneinheit ergeben. ${ }^{1772}$ Somit ist eine Vermittlung im schulischen Zusammenhang wahrscheinlich.

Der Eintrag, wenn auch vielleicht nicht die Vermittlung dieses Verses fällt schon in die Zeit Bischof Hittos (811/812-836), der sich in seinem eigenen Wirken wie in dem Einfluss, den er auf die Bibliothek ausübte, um die Bildung verdient machte, wie die Vielzahl grammatischer Handschriften aus seiner Zeit zeigt. ${ }^{1773}$ Im Freisinger Traditionskodex, ${ }^{1774}$ der auf seine Veranlassung entstand, wird Hitto selbst als Lehrer genannt. Einige kunstfertig geschriebene Verse am Ende von Clm $6273^{1775}$ loben sein Verdienst um die Erweiterung der Bibliothek. Die Handschriften seines Nachfolgers Erchanbert (836-854) lassen sich nicht deutlich von den Hitto-Handschriften unterscheiden und bilden mit diesen eine Epoche. Erchanbert war nicht, wie die frühere Forschung noch annahm, identisch mit dem Magister Erchanbert, dessen Donatkommentar sich weiter Beliebtheit im Unterricht erfreute und auch in Freising vorhanden war. ${ }^{1776}$

Aus der Zeit dieser zwei Bischöfe stammen drei Handschriften, die ihre grammatischen und metrischen Lehrinhalte mit poetischem Anschauungsmaterial erläutern. Clm 6404 ist ein kleines Kompendium zur Grammatik und Metrik, mit Alkuins Ars grammatica und Bedas Ars metrica und De schematibus et tropis als Haupttexten. ${ }^{1777}$ Die Handschrift trägt in Form von Nachträgen zahlreiche Verse, darunter auch von späterer Hand den im Katalog des 10. Jh. vermerkten Ovid. ${ }^{1778}$ Zeitgenössische Verse gruppieren sich zu Beginn und Ende

1772 Vergleiche auch bei St. Gallen das Florilegium Sangallense in St. Gallen, StB, Cod. Sang. 870.

1773 PörnBaCher: „Freisings geistige Bedeutung«. S. 40. BischofF: Schreibschulen 1. S. 65-68, Nr. 33-87, worunter auch die unter Erchanbert geschriebenen und nicht deutlich unterscheidbaren Handschriften begriffen sind.

1774 Cozroh, quem tamen ipse [Hitto] suis sacris disciplinis edocuit; Bayerisches Hauptstaatsarchiv, Cod. HL Freising 3a, f. 3r. Theodor BitTerauf, Die Traditionen des Hochstiftes Freising (Quellen und Erörterungen zur bayerischen und deutschen Geschichte, NF 4-5), München 1905. S. 2.

1775 Inc. Antistes humilis, f. 224r (SK 110); Bernhard Bischoff, »Anecdota Carolina«, in: Studien zur lateinischen Dichtung des Mittelalters. Ehrengabe für Karl Strecker zum 3. September 1931, hrsg. von Walter STACH (Schriftenreihe zur Historischen Vierteljahrsschrift 1), Dresden 1931, S. 1-11. S. 1 f.

1776 Im Katalog des 10. Jh.: Erchanpertus maior et minor, GlaUche/Knaus/Bischoff (Hrsg.): $M B K$ 4, 2. S. 626, Z. 12. Die Identifikation bei Manitius: Geschichte, 1. S. 490-493, und Pörnbacher: „Freisings geistige Bedeutung«. Dagegen: Wendell Vernon Clausen, Erchanberti Frisingensis »Tractatus super donatum «, [University of Chicago] 1948. S. IV-VII, sowie Vivien A. LAw, "Erchanbert and the interpolator: a Christian Ars Minor at Freising (clm 6414). «, in: History of Linguistic Thought in the Early Middle Ages, hrsg. von Vivien A. Law (Studies in the History of the Language Sciences 71), Amsterdam 1993, S. 223-243.

1777 Glauche: Pergamenthandschriften Freising. S. 195-198. BRunhölzL: Dombibliothek. S. 291-297. Alle Texte sind glossiert: Bergmann/Stricker: Katalog. Nr. 537.

$1778 \mathrm{Zu}$ den späteren Versen zählen ebenfalls die auf f. 3v, Si bene non scribis verbera dura capis, siehe Bischoff: »Elementarunterricht und Probationes Pennae in der ersten Hälfte des Mittelalters«. S. 87. 
um den Beda-Text, der die letzten drei Lagen füllt: Auf f. 31v findet sich in griechischer Majuskel der schon von Donat zur Veranschaulichung der Aenigmata-Gattung verwendete Vers Mater me genuit, der Gemeingut der grammatischen Tradition wurde. ${ }^{1779}$ Zwischen den zwei Beda-Traktaten finden sich (45r) zwei vielleicht römische Weiheinschriften, die zusammen mit den Haupttexten aus der Vorlage kopiert wurden und also schon dort den Text illustriert haben. ${ }^{1780}$ Die Inschriften stammen aus einer größeren Sylloge, deren vollständige Zahl von sieben Inschriften in BNF. Lat. 9347 und 2773 (beide Reims, 9. Jh. 1. Hälfte) vorliegt; beide Handschriften sind umfangreiche Anthologien. ${ }^{1781}$ Die zweite Inschrift ist aus alkuinischen Stücken zusammengesetzt und formularisiert worden. Auf Beda folgen f. 50r-51v drei weitverbreitete, dem hl. Columban zugeschriebene Gedichte. ${ }^{1782}$ Das Gedicht ist sorgfältig und in gestalterischer Einheit mit den vorhergehenden Texten geschrieben worden. Der Verbund aus drei Gedichten befindet sich ebenfalls noch in zwei zeitgenössischen Handschriften: St. Gallen, StB, Cod. Sang. 273 und 899; beide enthalten jedoch umfangreiche Gedichtsammlungen ohne offenbaren pädagogischen Bezug, sodass die Ps.-Columbania hier singulär in einen solchen gestellt wurden. In ähnlich ungewöhnlichem Zusammenhang - wenn man die sonstige Überlieferung betrachtet - steht Walahfrids Gedicht an Abt Wenibert von Schuttern, ${ }^{1783}$ das sonst nur noch in der großen Werksammlung Cod. Sang. 869 zu finden ist. ${ }^{1784}$ Diese Ergänzung als Teil einer pädagogischen Sammlung ist überraschend, insbesondere angesichts der großen zeitlichen Nähe zu Walahfrid selbst, zu dessen Lebzeiten der Eintrag durchaus hat vorgenommen werden können. ${ }^{1785}$ Um den

1779 Holtz: Donat. S. 672, Z. 11. Zur weiteren Verwendung: GloRIE (Hrsg.): Collectiones aenigmatum. S. 723, Nr. V. Auf f. 45v findet sich ebenfalls ein Halbvers aus Vergil in griechischer Schrift.

1780 Die Inschriften sind: Aureus ac simul Justinus und Ductus amore dei martini (SK 1479, 3938). Strecker (Hrsg.): MGH Poet. lat. 4, 2.3. S. 1013-1015, Nr. V-VI. BrunhölzL: Dombibliothek. S. 295f., vermutet aufgrund der Verse zu Aureus (»Bischof von Mainz im 5. Jh.«) einen Mainzer Ursprung der Vorlage.

1781 Bischoff: Katalog, 3. Nr. 4226 und 4570.

1782 "Columbani epistolae«. Nr. 8-10. Die Verfasserschaft ist ungeklärt: Michael W. HerRen, "Some quantitative poems attributed to Columbanus of Bobbio", in: Poetry and philosophy in the Middle Ages: A festschrift for Peter Dronke, hrsg. von John Marenbon (Mittellateinische Studien und Texte 29), Leiden [u. a.] 2001, S. 99-112. Michael LAPIDGE, »Epilogue: did Columbanus compose metrical verse?«, in: Columbanus - Studies on the Latin Writings 1997, S. 274-285. Peter Christian JaCoBsen, "Carmina Columbani«, in: Die Iren und Europa im früheren Mittelalter, hrsg. von Heinz Löwe (Veröffentlichungen des Europa Zentrums Tübingen. Kulturwissenschaftliche Reihe), Stuttgart 1982, S. 434-467.

1783 Nr. V, xi, Dümmler (Hrsg.): MGH Poet. lat. 2. S. 359. Vgl. Visser: Sis memor. S. $96 f$.

1784 Hier erörtert BRUnHölzL: Dombibliothek. S. 296, einen bodenseeischen Ursprung.

1785 Die Tinte ist stark verblasst, sodass weitere paläographische Einschätzungen unmöglich sind; das Schriftbild ist jedoch durchaus zeitgenössisch. Die sich rechts an die Verse schmiegenden Glossen zu Sedulius, die weiteren Freiraum ausnutzen, sind ebenfalls nicht 
schulmäßigen Hauptteil der Handschrift versammelt sich also eine kleine Zahl von praktischen Versen wie Aenigmata und Tituli; auch sonst in anderem $\mathrm{Zu}$ sammenhang aufzufindende Verse fügen sich hier in diesen Zusammenhang. Im Ganzen bildet der poetische Inhalt der Handschrift also den subsidiären Charakter der Dichtung im Freisinger Unterricht ab.

Ähnlichen Charakters ist die nur noch unvollständige Handschrift von Aldhelms Epistola ad Acircium (daraus ein Auszug zur Metrik) ${ }^{1786}$ und Alkuins Orthographie, ${ }^{1787} \mathrm{Clm}$ 6413, wo sich an Aldhelm die Verse Angilberts an Karl den Großen von gleicher Hand anschließen. ${ }^{1788}$ Das Gedicht findet sich sonst nur noch in einem Regensburger Kodex, ${ }^{1789}$ wo es unter den Gedichten Alkuins zu finden war. Die hierauf folgende Orthographie Alkuins möchte ich ebenfalls in die Nähe Salzburgs rücken: Die hier vorliegende Redaktion b geht wahrscheinlich auf Bischof Arn von Salzburg zurück, der das Werk seines Freundes Alkuin in seine Sammelhandschrift Wien, ÖNB, Cod. 795 modifiziert aufnahm; ${ }^{1790}$ eine Vermittlung nach Freising im Verbund mit dem ebenfalls nur in Salzburg vorhandenen Angilbert-Gedicht halte ich für wahrscheinlich.

Die unter Hitto und Erchanbert niedergeschriebene Dichtung schließt sich also eng an die Bedürfnisse der Schule an und beschränkt sich auf diese. ${ }^{1791}$ Trotz dieser eingeschränkten Verwendung wurden Texte von weit her - aus Salzburg bezogen, um lokal in das Curriculum integriert zu werden. Bemerkenswert ist die Heranziehung zeitgenössischer Schriftsteller wie Walahfrid und Angilbert, die sonst nicht als Schulautoren gelten. In Freising unter Hitto und Erchanbert ging also auch die Schuldichtung mit der Zeit. Nicht aus einem pädagogischen $\mathrm{Zu}$ sammenhang scheint dagegen das nur in einer Handschrift des 11. Jh. überlieferte Carmen de Timone Comite an Ludwig den Deutschen zu sein, das wohl zu Ende von Hittos Episkopat in Freising verfasst wurde. ${ }^{1792}$ Wenn dieses Lied tatsächlich aus dem Freising des 9. Jh. stammt, ist es ein Fragment autochthoner

viel jünger, sodass beide Zusätze in zeitliche Nähe zur Produktion der Gesamthandschrift gesetzt werden können.

1786 Nicht verwendet in EHwald (Hrsg.): Aldhelmi Opera.

1787 Glauche: Pergamenthandschriften Freising. S. 225-227. Bischoff: Schreibschulen 1. Nr. 87. BRunhöLzL: Dombibliothek. S. 290f., 337f. Die verbliebenen drei Lagen sind mit IV-VI nummeriert.

1788 DüMmLer (Hrsg.): MGH Poet. lat. 1. S. 360-363.

1789 Aus Salzburg unter Bischof Liuphram, siehe S. 274.

1790 Sandra Bruni (Hrsg.), Alcuinus: De orthographia (Millennio medievale, Testi 2), Florenz 1997. S. XIII-XXV, XXXVI.

1791 In diesem Zusammenhang sei auch Clm 6281 erwähnt, wo unter anderem grammatischen Material einige metrische Traktate enthalten sind, ohne dass diese jedoch durch Beispiele erläutert würden.

1792 DüMmLer (Hrsg.): MGH Poet. lat. 2. S. 120-124. Jakob Brummer, »Das carmen de Timone comite", in: Historische Vierteljahrschrift 18 (1916), S. 102-106. ВіsсноғF: »Bücher am Hofe und Privatbibliothek«. S. 191. 
hagiographischer Dichtung, von der die Handschriften sonst kein weiteres Zeugnis ablegen. Bemerkenswert in dem Gedicht ist die gegen den Zeitgeist gehende Ablehnung des Gottesurteils, die ansonsten nur noch bei dem Schüler Freisings Leidrad von Lyon $\mathrm{zu}$ finden ist. ${ }^{1793}$

Bischof Anno (854-875) erweiterte das eher grammatische Interesse seiner beiden Vorgänger um zeitgenössische und wissenschaftliche Ergänzungen im Geiste der Artes Liberales. ${ }^{1794}$ An astronomischen Handschriften wie Clm 13084, f. 48-91, oder musikalischen wie Clm 14523, f. 49-117, wird der kulturelle Aufschwung erkennbar, der nach der gründlichen Vorbereitung durch die Vorgänger erfolgen konnte. ${ }^{1795}$ Besonders die Musik scheint unter Anno besonders gepflegt worden zu sein, sodass sogar Papst Johannes VIII. in einem Brief um eine Orgel und geschultes Personal bat. ${ }^{1796}$ Die Dichtung wurde von diesem Aufschwung jedoch nicht erfasst; das einzige Überbleibsel von Dichtung aus der Zeit Annos sind Fragmente Vergils und Ovids, die durch ihren Buchschmuck zwar ein gehobenes Niveau zeigen, durch die lateinische und althochdeutsche Glossierung jedoch auch in den Bereich des Unterrichts verweisen. ${ }^{1797} \mathrm{Zu}$ ergänzen ist hier vielleicht die Juvencus-Handschrift Clm 6402, die unter Annos Episkopat in die Bibliothek gelangt sein könnte und deren fehlende Stellen, als auch die Glossierung (s. XI), dort ergänzt wurden. ${ }^{1798}$ Von dieser stammen die St. Galler Handschriften Cod. Sang. 197 und Zürich, ZB MS. C 68 ab. ${ }^{1799}$ Sie ist auf den ersten Seiten lateinisch und althochdeutsch glossiert. ${ }^{1800}$ Leider ist der Zeitpunkt ihres Eingangs in die Freisinger Bibliothek unklar. ${ }^{1801}$

Die unter Annos Nachfolgern Arnold (875-883) und Waldo (883-906) geschriebenen Kodizes lassen sich nicht durch klare paläographische Merkmale von denen ihres Vorgängers unterscheiden; Arnolds Episkopat lässt sich überhaupt keine mit Sicherheit zuweisen. ${ }^{1802}$ Waldo dagegen tritt uns in seinem Interesse für die Dichtung klar entgegen. Dieses scheint ihm schon durch seinen Lehrer Notker in der Schule in St. Gallen vermittelt worden zu sein, die er zusammen mit seinem Bruder Salomo besuchte. Notker stellte für die Brüder die

1793 Franz Brunhölzl, Max Spindler und Andreas Kraus, Das alte Bayern: das Stammesherzogtum bis zum Ausgang des 12. Jahrhunderts, 2., überarb. Aufl., München 1981. S. 488.

1794 Bischoff: Schreibschulen 1. S. 68-71. Mass: Freising in der späten Karolingerzeit. S. 187215.

1795 BRUnhöLzL: Dombibliothek. S. 353-357.

1796 MAss: Freising in der späten Karolingerzeit. S. 202. PöRnBACHER: »Freisings geistige Bedeutung«. S. 40.

1797 Bischoff: Schreibschulen 1. Nr. 110. Bergmann/Stricker: Katalog. Nr. 502 (II).

1798 Bischoff: Schreibschulen 1. S. 149. Glauche: Pergamenthandschriften Freising. S. 190192. Bergmann/Stricker: Katalog. Nr. 536. Brunhölzl: Dombibliothek. S. 124-129.

1799 Marold (Hrsg.): Iuvencus. S. XIV-XV.

1800 ERTMER: Juvencusglossierung. S. 290-311.

1801 Aber noch im 10. Jh.: GLauche: Pergamenthandschriften Freising. S. 191.

1802 Bischoff: Schreibschulen 1. S. 70. 
sogenannte Collectio Sangallensis zusammen, ein Kompendium aus einer christlichen Literaturgeschichte, einer Brief- und Formelsammlung, sowie epistolarer Dichtung. ${ }^{1803}$ Eine Abschrift von Waldos Handexemplar, worin er das Formelbuch und weitere von ihm in St. Gallen gesammelte Texte zusammenstellen ließ, ${ }^{1804}$ liegt in der Handschrift Wien, ÖNB, Cod. 1609 vor. ${ }^{1805}$ Durch den Vergleich mit der Schwesterhandschrift München, BSB, Clm 19413, ${ }^{1806}$ die wahrscheinlich vom Exemplar Salomos abstammt, lässt sich erstens der genaue Umfang der Collectio Sangallensis feststellen, wie sie von Notker seinen Schülern übergeben wurde, zweitens lassen sich durch die persönlichen Ergänzungen Waldos eigene Interessen klarer herausstellen.

Die Parallelen zwischen den Handschriften zeigen uns die genuine, von Notker erstellte Sammlung. Es handelt sich um folgende Texte:

- Notatio de illustribus viris, eine christliche Literaturgeschichte, mit Lektürempfehlungen und Kommentaren. ${ }^{1807}$

- »Formelbuch Salomos«. ${ }^{1808}$

- Die sich an das Formelbuch anschließenden Verse wurden teilweise zusammen ediert, abhängig von der vermuteten Verfasserschaft Notkers. ${ }^{1809}$ Nur undeutlich oder gar nicht geht aus den MGH-Editionen hervor, dass nur die

1803 »Notatio«. DümmLeR (Hrsg.): Formelbuch des Bischofs Salomo. Dort als Handschrift T (Tegernsee). Kritisch zu Dümmlers Verfahren »Notatio«. Eine Übersicht zum Text auch bei Manitius: Geschichte, 1. S. 365.

$1804 \mathrm{Zu}$ Verfasserfrage und Herkunft der Handschriften siehe den Aufsatz des Verfassers: Till HeNNings, "Notker the Stammerer's compendium for his pupils«, in: Education Materialized: Reconstructing Teaching and Learning Contexts through Manuscripts (Studies in Manuscript Cultures), Berlin [im Druck].

1805 Tabulae codicum manu scriptorum praeter graecos et orientales in Bibliotheca Palatina Vindobonensi asservatorum, Wien 1864. 1, S. 261-262. Hermann Menhardt, Verzeichnis der altdeutschen literarischen Handschriften der Österreichischen Nationalbibliothek (Veröffentlichungen des Instituts für deutsche Sprache und Literatur 13), Berlin 1960. 1, S. 51; BischоғF: Schreibschulen 2. S. 220; BischоғF: Katalog, 3. S. 490. »Notatio«. S. 35. Rio: Legal practice. S. 269-270.

1806 Siehe bei St. Gallen, S. 283-290.

1807 "Notatio«. Siehe eingehender hierzu bei St. Gallen, S. 122.

1808 Ausgabe: Zeumer (Hrsg.): MGH Formulae. S. 390-433; DüMmLer (Hrsg.): Formelbuch des Bischofs Salomo. Man beachte die unterschiedliche Zählung: DüMMLER 8-48 = ZEUMER 747, da Zeumer Dümmlers 6\&7 als 6a\&b gab. Ich verwende Zeumers Nummerierung. Forschung: SteINEN: »Notkers des Dichters Formelbuch«. Rio: Legal practice. S. 152-160.

1809 Unvollständig: DüMmLeR (Hrsg.): Formelbuch des Bischofs Salomo. S. 79-82 und Kommentar S. 160-163; Paul von Winterfeld, MGH Poet. lat. 4, 1 (Monumenta Germaniae Historica. Antiquitates 1), Berlin 1899. S. 343-347; Zeumer (Hrsg.): MGH Formulae. S. 430-433; Steinen: "Notkers des Dichters Formelbuch«. S. 482-484. Wolfram von den Steinen, Notker der Dichter und seine geistige Welt, Bern 1948. II, S. 138-142 und Kommentar S. 188. Von DEN STEINEN ediert nur nach den vorherigen Ausgaben ohne Einsicht in die Handschriften. 
Gedichte I-VIII (Winterfelds Zählung ${ }^{1810}$ ) Gemeingut der Handschriften Clm 19413 und ÖNB Cod. 1609 sind, IX-X dagegen nur in Clm 19413 überliefert ist. Die zwischen VIII und IX liegende Epistola ad seniorem ist bei Zeumer ganz aus dem Zusammenhang gerissen. ${ }^{1811}$ Die Verse kommen, bis auf X, nur in diesen beiden Handschriften vor. Folgende in ÖNB Cod. 1609 enthaltenen Gedichte sind Gemeingut der beiden Handschriften: ${ }^{1812}$

\begin{tabular}{|l|l|l|}
\hline $\begin{array}{l}\text { f. } \\
\mathbf{1 6 0 9}\end{array}$ & Inc. & Anmerkungen \\
\hline 53ar & I. Inc. Antistes domini (SK 904). ${ }^{1813}$ & $\begin{array}{l}\text { Dieses paränetische Prosimetrum } \\
\text { stimmt thematisch eng zu einigen der } \\
\text { Briefe, mit denen Notker das Brüder- } \\
\text { paar zu einem der geistigen Laufbahn } \\
\text { angemessenen Lebenswandel aufruft, } \\
\text { namentlich den Nummern 41 und 43; } \\
\text { das Prosimetrum wird in Nr. 46, Z. 12ff. } \\
\text { zu Zwecken der späteren Korrespon- } \\
\text { denz empfohlen. }{ }^{1814}\end{array}$ \\
\hline $\begin{array}{l}\text { 53ar- } \\
\text { 53br }\end{array}$ & $\begin{array}{l}\text { II. Inc. Talia dictat amor (SK 15977), Inc. Sospitat incolumis, (SK 15554) } \\
\text { IV. Inc. Peior amate (SK 11817), V. Inc. } \\
\text { Avia perlustrans (SK 1559). }\end{array}$ & $\begin{array}{l}\text { Diese von Zeumer in den Kleindruck } \\
\text { verbannten Epigramme, } \\
\text { tolis haberi non possint « }{ }^{1815} \text {, eignen sich } \\
\text { ganz im Gegenteil vorzüglich für die } \\
\text { Verwendung in einem Briefwechsel der } \\
\text { von Notker angeregten Art. II, IV be- } \\
\text { klagen die Abwesenheit des Freundes } \\
\text { und seine ausbleibende Antwort, III } \\
\text { seine Krankheit. V nimmt das Thema } \\
\text { des schweren Loses des Lehrers wieder } \\
\text { auf. Gerade ihre Unverbundenheit mit } \\
\text { einem vollständigen Brief unterstreicht } \\
\text { den formelhaften Charakter dieser } \\
\text { Kleingedichte. }{ }^{1816}\end{array}$ \\
\hline
\end{tabular}

1810 Bei Zeumer als Formulae 48, 48 a,b,c,d, 49, 49 a, b; IX \& X = 50 \& 50a.

1811 Als Add. 6.

1812 Clm 19413: f. 109r-111v.

1813 Kommentar: Dümmler (Hrsg.): Formelbuch des Bischofs Salomo. S. 160.

1814 Kommentar: Ebd.

1815 Welchem Urteil er S. 431, Anm. 1 widerspricht.

1816 Siehe auch zum Alkuin-Cento in München, BSB, Clm 19410 (Passau). 
(Fortsetzung)

\begin{tabular}{|l|l|l|}
\hline $\begin{array}{l}\text { f. } \\
\mathbf{1 6 0 9}\end{array}$ & Inc. & Anmerkungen \\
\hline 53br & VI. Inc. Tardius invento (SK 16030). ${ }^{1817}$ & $\begin{array}{l}\text { Die Nennung von Rhein, Bodensee und } \\
\text { Iller, sowie die Nennung einer geliebten } \\
\text { nonna, wahrscheinlich der Geliebten } \\
\text { des jugendlichen Salomo }{ }^{1818} \text {, weisen } \\
\text { deutlich auf Notker und St. Gallen hin. } \\
\text { Trotz der Spezifität des Gedichts stimmt } \\
\text { es zum Leitthema der Klage des verlas- } \\
\text { senen Freundes und passt somit in die } \\
\text { Anthologie. }\end{array}$ \\
\hline 53bv & $\begin{array}{lll}\text { VII. Inc. Ospecies cari (SK 11054), VIIII. } \\
\text { Inc. Ex phisicis quidam (SK 4751). }{ }^{1819}\end{array}$ & $\begin{array}{l}\text { Für diese von Zeumer ebenfalls klein } \\
\text { gedruckten Stücke gilt das gleiche wie } \\
\text { für die obigen. In VII. wenden sich die } \\
\text { Schüler an ihren Lehrer, } \\
\text { antwortet in VIII. } \\
\text { Gleichnissen. ÖNB Cod. 1609 bricht hier } \\
\text { ab. }{ }^{1821}\end{array}$ \\
\hline
\end{tabular}

Die in Clm 19413 enthaltenen, in ÖNB Cod. 1609 wahrscheinlich verlorenen Stücke sind folgende, die sich thematisch eng anschließen:

\begin{tabular}{|l|l|l|}
\hline $\begin{array}{l}\text { f. } \\
\text { 19413 }\end{array}$ & Inc. & Anmerkungen \\
\hline $111 \mathrm{v}$ & $\begin{array}{l}\text { Epistola ad seniorem. } \\
\text { Summa nobilitate et sapientia }\end{array}$ & $\begin{array}{l}\text { Der in klarer Verbindung zu den nachfolgenden } \\
\text { Versus ad iuvenem (IX) stehende Brief wurde } \\
\text { von Zeumer zu den additamenta getan und ist } \\
\text { weder bei Steinen noch bei Winterfeld ediert. Es } \\
\text { ist wohl der Brief eines Schülers an seinen } \\
\text { Lehrer } \\
\text { folgenden Verse zeigen). Die Verwendung des } \\
\text { Platzhalters ille (Z. 32) markiert den Brief - und } \\
\text { die umgebenden Texte - klar als formelhaft. }\end{array}$ \\
\hline
\end{tabular}

1817 Siehe Kommentar Dümmler (Hrsg.): Formelbuch des Bischofs Salomo. S. 161. Steinen: Notker der Dichter. I, S. 58.

1818 »Ekkehard von St. Gallen, Casus s. Galli«. S. 92, Z. 17 f. Dort wird das Mädchen allerdings als virgo privigna eines vir nobilis bezeichnet.

1819 Kommentar Dümmler (Hrsg.): Formelbuch des Bischofs Salomo. S. 161; STEINEn: »Notkers des Dichters Formelbuch«. S. 483.

1820 Mit Nennung der Schulutensilien: te revocant pennae, cupiunt membrana videre.

1821 Sie ist dort jedoch nicht, wie STEINEn: »Notkers des Dichters Formelbuch«. S. 471, meint, »verstümmelt«, wie ein Blick auf Schriftbild und Rückseite des abgeschnittenen Folios zeigt.

1822 Formulae Sangallenses Add. 6, Zeumer (Hrsg.): MGH Formulae. S. 436. Kommentar SteInEN: "Notkers des Dichters Formelbuch«. S. $470 \mathrm{f}$.

1823 S. 437, Z. 5 f.: eruditor insipientium, magister infantium etc. 
(Fortsetzung)

\begin{tabular}{|l|l|l|}
\hline $\begin{array}{l}\text { f. } \\
\text { 19413 }\end{array}$ & Inc. & Anmerkungen \\
\hline $112 \mathrm{r}$ & $\begin{array}{l}\text { Versus ad iuvenem, }{ }^{1824} \text { Egregio } \\
\text { iuveni Salomoni (SK 4315) }\end{array}$ & $\begin{array}{l}\text { In diesem Encomium auf einen Pelz dankt } \\
\text { Notker Salomo für den Erhalt eines prächtigen } \\
\text { Mantels. Themen der Entfernung voneinander } \\
\text { sowie der gegenseitigen Aufmerksamkeit be- } \\
\text { stimmen auch hier wie in den anderen Gedich- } \\
\text { ten den Ton. }\end{array}$ \\
\hline $\begin{array}{l}113 \mathrm{r}- \\
113 \mathrm{v}\end{array}$ & $\begin{array}{l}\text { Quot caelum retinet stellas (SK } \\
14037)\end{array}$ & $\begin{array}{l}\text { Das Gedicht liest sich bis in die Versstruktur der } \\
\text { quot-Alliterationen wie eine Fortsetzung von IX. } \\
\text { Sicher besteht kein Grund, es als unzugehörig zu } \\
\text { IX anzusehen, wie es Zeumer durch Kleindruck } \\
\text { nahelegt. }\end{array}$ \\
\hline
\end{tabular}

Soweit reicht die durch Themen und Stil zusammengehaltene Notker-Anthologie. Hierauf folgen in Clm 19413 einige Gedichte, die, wie gleich zu erörtern sein wird, auf den ausgefallenen Seiten von ÖNB Cod. 1609 Platz hätten finden können (in jedem Fall sind sie Zeugnisse einer in St. Gallen vorgenommenen Sammlung):

\begin{tabular}{|l|l|l|}
\hline $\begin{array}{l}\text { f. } \\
19413\end{array}$ & Inc. & Anmerkungen \\
\hline $113 \mathrm{v}$ & Dulcis amica veni & $\begin{array}{l}\text { Rubrik: Versus de volucris bestiis vel iumentis. De } \\
\text { Philomela. (SK 3975) }\end{array}$ \\
\hline $\begin{array}{l}115 \mathrm{v}- \\
116 \mathrm{v}\end{array}$ & $\begin{array}{l}\text { Isidor: Versus in bibliothecam V-VII. }{ }^{1826} \text { Bei der } \\
\text { Auswahl aus den Versen, die Isidor für seine Biblio- } \\
\text { thek schrieb, handelt es sich um folgende Stücke: } \\
\text { 1. Inc. Ambrosius doctor (SK 702), 2. Inc. Mentitur qui } \\
\text { te (SK 9582), auf Augustinus, 3. Inc. Hieronime } \\
\text { interpres (SK 6806). Die drei Verse finden sich in } \\
\text { derselben Reihenfolge in weiteren zeitgenössischen St. } \\
\text { Galler Handschriften, die auch im weiteren Parallelen } \\
\text { zu Clm 19413 bieten (insbesondere Cod. Sang. 397 + } \\
\text { Vatikan, BAV, Reg. lat. 421 (Bl. 21-25), St. Gallen Mitte } \\
\text { des IX. Jh. }{ }^{1827} \text { p. 85, das sogenannte Vademecum des } \\
\text { Grimalds }{ }^{1828} \text { ). }\end{array}$ \\
\hline
\end{tabular}

1824 So die Rubrik. Siehe Kommentar Dümmler (Hrsg.): Formelbuch des Bischofs Salomo. S. 162. Steinen: »Notkers des Dichters Formelbuch». S. 483.

1825 Einleitung und Edition: Paul KLopsch, „Carmen de philomela«, in: Literatur und Sprache im europäischen Mittelalter. Festschrift für Karl Langosch zum 70. Geburtstag, hrsg. von Alf ÖNNERFors, Johannes Rathofer und Fritz WAgner, Darmstadt 1973, S. 173-194. Die Ausgabe ersetzt die zahlreichen älteren, insbesondere: RIESE/BüChELER (Hrsg.): Anthologia latina. Nr. 762.

1826 BEESON: Isidor-Studien. S. $159 \mathrm{f}$.

1827 Bischoff: Katalog, 3. Nr. 5741. 
(Fortsetzung)

\begin{tabular}{|c|c|c|}
\hline $\begin{array}{l}\text { f. } \\
19413\end{array}$ & Inc. & Anmerkungen \\
\hline $116 \mathrm{r}$ & $\begin{array}{l}\text { Romphea nam caeles- } \\
\text { tium }\end{array}$ & Fragment aus Prudentius, Peristephanon, V, 189-190. \\
\hline $116 \mathrm{r}$ & $\begin{array}{l}\text { Prandeo poto cano ludo } \\
(\text { SK 12442) }\end{array}$ & $\begin{array}{l}\text { Dieses nur einzeilige, wohl metrischen Zwecken }{ }^{1830} \\
\text { dienende Bruchstück liegt im oben genannten St. Gal- } \\
\text { ler Cod. Sang. } 397 \text { auf p. } 145 \text { von Vers 1-7 vor, endet } \\
\text { also auf den in Clm } 19413 \text { enthaltenen Einzelvers, der } \\
\text { von dort entnommen sein könnte. }\end{array}$ \\
\hline $116 \mathrm{r}$ & $\begin{array}{l}\text { Fontibus in liquidis } \\
\text { (SK 5267) }\end{array}$ & $\begin{array}{l}\text { Die zwei ursprünglich von Claudian stammenden, }{ }^{1831} \\
\text { aus seinem Vierzeiler gelösten Verse wurden in die } \\
\text { Sammlung des Symposium der XII Sapientes aufge-- } \\
\text { nommen und in der so gekürzten Form tradiert. }{ }^{132} \\
\text { Den Doppelvers sowie die Zuschreibung TVLLII, im } \\
\text { Gegensatz zur herkömmlichen an Iulianus, teilt Clm } \\
19413 \text { mit St. Gallen } 397, \text { p. } 121 \text {. }\end{array}$ \\
\hline $116 \mathrm{r}$ & Noli archana & Aus den Disticha Catonis. ${ }^{1833}$ \\
\hline
\end{tabular}

Falls die ursprüngliche Notker-Sammlung diese Verse mit einschloss, könnte sie ganz auf der verlorenen Lage von ÖNB Cod. 1609 Platz gefunden haben. Dass hier Text verlorengegangen ist, ist durch den abgebrochenen Beda-Text gesichert. ${ }^{1834}$ Der Umfang des Verlustes kann nur abgeschätzt werden, je nachdem, welche Länge man für die vollständige Sammlung annimmt. Gesichert ist der Verlust eines Blattes, das ursprünglich mit f. 61 ein Doppelblatt bildete. ${ }^{1835}$ Wenn wir davon ausgehen, dass die Handschrift nach dem Notkergedicht VII, Inc. O species cari, zumindest die Notkersammlung, sowie vielleicht die anschließenden Gedichte wie in Clm 19413 enthielt, ergibt sich folgende Füllung der verlorenen Lage $^{1836}$ :

1828 Bischoff: "Bücher am Hofe und Privatbibliothek«. Speziell S. 201-212. Kritisch zu der Zuordnung zu Grimald: Grupp: »Codex Sangallensis 397«. Siehe bei St. Gallen, S. 90 f.

1829 Vollständig 9 Verse. RIESE/BÜCHELER (Hrsg.): Anthologia latina. Nr. 26. v. 7; SHACKLETON BAILEY (Hrsg.): Libri Salmasiani aliorumque carmina. Nr. 13, v. 7, unter dem apokryphen Titel Martialis De habitatione ruris.

1830 Auf dem unteren Rand von 155v lässt sich noch die Rubrik lesen [VER]SVS IAMBICUS.

1831 BIrt (Hrsg.): Claudii Claudiani Carmina. S. 292, XII.

1832 FRIEDRICH: Symposium. S. 44.

1833 BoAs (Hrsg.): Disticha Catonis. II, 2. Mit Ausfall des dort eingeklammerten 2. Verses. Sigle $\mathrm{M}^{\mathrm{t}}$.

1834 Der Auszug aus Beda: De Temporum Ratione, VII, De nocte (Jones (Hrsg.): Bedae Venerabilis opera. 123 B, S. 299, Z. 68-78) beginnt mitten im Satz auf f. 55r.

1835 (IV-1) $)^{61}$ würde dann einfach $\mathrm{IV}^{[1+] 61}$.

1836 Bei Umrechnung der Verse von Clm 19413 auf das Format von ÖNB Cod. 1609 kann auf die Abschätzung der durchschnittlichen Wortmenge pro Zeile offensichtlich verzichtet werden. 
- Notkersammlung (Epistola - X): 69 Zeilen, ${ }^{\star}$ f. 1r, Z.1 - *f. 2r, Z. 19

- De Philomela: 99 Zeilen, ${ }^{*}$ f. 2 r, Z. $20-{ }^{*}$ f. 4r, Z. 19

- Übrige Verse (In Bibliothecam, Cato etc.): ca. ${ }^{1837} 30$ Zeilen, ${ }^{\star}$ f. 4 r, Z. 19 - ${ }^{\star}$. $4 \mathrm{v}$, Z. 24

Die übrigen Blätter des Quaternios könnten durch den Beginn des Beda-Auszugs oder, wie in Clm 19413, durch glossographisches Material gefüllt gewesen sein.

$\mathrm{Zu}$ den schon von Notker gesammelten Briefgedichten kommen weitere, von Waldo persönlich ergänzte Texte hinzu: Auf f. $4 \mathrm{r}-8 \mathrm{v}$ findet sich ein kleines Tropar, das in die Frühzeit der Tropendichtung durch Notker zurückreicht. Weakland fühlt sich mehr an ein "work sheet«, als an eine eigentliche musikalische Sammlung ${ }^{1838}$ erinnert. Die Zusammenstellung, die vom Gesamtrepertoire der für die Klostergemeinschaft nötigen Gesänge abweicht, deutet auf eine individuelle Auswahl hin. Laut Notker im Proemium zum Liber Hymnorum ${ }^{1839}$ wurden die Frühformen des Liber in rotulas und in libellum und codicillum gesammelt. Die feste Einformung der Sammlung in Hymnare fand erst gegen Ende des 10. Jh. statt, ausgehend vom St. Galler Kanon aus der Mitte des Jahrhunderts, der sich wiederum auf das ursprüngliche Liber Hymnorum und auf die Rotuli stützte. ${ }^{1840}$ ÖNB Cod. 1609 bietet einen Einblick in die Entstehungszeit dieser Sammlung, wie sie zu Notkers Lebzeiten war: Das Liber Hymnorum lag schon als Sammlung vor, wie durch das Fragment der Dedikation (f. 64r) belegt wird. Das kleine Tropar zu Beginn der Handschrift scheint jedoch kein Exzerpt daraus zu sein - Proemium und Tropen würden ja sonst beieinander stehen sondern vielmehr eine der Frühformen der Sammlung zu repräsentieren, und zwar die im Chorgesang gebrauchten Rotuli oder Schedae (libellus, codicillus). Durch diese Annahme ließe sich auch Weaklands Bemerkung erklären, dass das Tropar an ein »work sheet « erinnere.

Am Ende der Handschrift (f. 69r-69v) befindet sich ein Nachtrag, der schon auf Waldos weitere Interessen verweist, der 138. Psalm in althochdeutscher

1837 Überschriften und Leerzeilen können anders gestaltet gewesen sein.

1838 Das früheste Tropar, Cod. Sang. 484 sowie ein Hauptzeuge des Liber Hymnorum, Cod. Sang. 381, enthalten 83 von den 100 in ÖNB Cod. 1609 enthaltenen Versen und sind diesem damit am nächsten verwandt. Eine Konkordanz der beiden Handschriften bei Susan RANkIN, "Notker und Tutilo. Schöpferische Gestalter in einer neuen Zeit.", in: Schweizer Jahrbuch für Musikwissenschaft 11 (1991), S. 17-42. S. 39-42 und Rembert George WEAKLAND, "The beginnings of troping", in: The musical quarterly 44 (1958), S. 477-488. S. 481-483. Zur Einfügung von ÖNB Cod. 1609 in die Gruppe Z der Tropare (Sangall. 484 \& 381) siehe auch: Husmann: »Die älteste erreichbare Gestalt des St. Galler Tropariums«. S. 26 und 39, Anm. 1.

1839 STEInen: Notker der Dichter. S. $\$ \$ 9,10$.

1840 Zur Textgeschichte Ebd. S. 192-198, insb. S. 197. 
Übersetzung. ${ }^{1841}$ Dieser Eintrag in seinem Handexemplar zeigt - abgesehen von den weiteren Verdiensten Waldos um die althochdeutsche Dichtung - sein persönliches Interesse an dieser Gattung. Der genaue Anlass zur Übersetzung ist unklar, könnte jedoch durchaus mit Waldos politischen Verpflichtungen zusammenhängen. ${ }^{1842}$ Ein weiteres Denkmal der althochdeutschen Dichtung liegt im Petruslied, dem »älteste[n] deutsche[n] Kirchenlied «, ${ }^{1843}$ vor, das zu Waldos Zeit in eine Handschrift älteren Datums nachgetragen wurde. Eine Rückdatierung in die Zeit Erchanberts, wie von Ursprung vorgeschlagen, ${ }^{1844}$ ist spekulativ. ${ }^{1845}$ Es ist vielmehr als autochtones Denkmal der Beschäftigung mit althochdeutscher Dichtung unter Waldo anzusehen, wozu auch die Neumierung passt, die Freisinger Musiktradition und St. Galler Tropendichtung vereint. ${ }^{1846}$

ÖNB Cod. 1609 stellt sich also als eine Synthese zweier Quellenkomplexe heraus: 1. Die von Notker für beide Brüder angefertigte Sammlung. 2. Von Waldo selbst in St. Gallen gesammelte Texte. Beide Sammlungen, die wohl eine Art Bündel in Waldos Besitz gebildet haben, ließ er in Freising in die vorliegende Handschrift kopieren. Das von Rauner für die Notatio de illustribus viris aufgestellte Stemma muss dementsprechend für die Handschriften als ganzes folgendermaßen erweitert werden ${ }^{1847}$ :

1841 Steinmeyer (Hrsg.): Sprachdenkmäler. Nr. 22; Gerhard Köbler (Hrsg.), Sammlung kleinerer althochdeutscher Sprachdenkmäler (Arbeiten zur Rechts- und Sprachwissenschaft 30), Gießen 1986. S. 530-533. David R. McLintock und Heiko Hartmann, "Art. Psalter: Psalm 138«, in: Althochdeutsche und altsächsische Literatur, hrsg. von Rolf Bergmann 2013, S. 413-416. Hermann Menhardt, "Zur Überlieferung des ahd. 138. Psalms«, in: Zeitschrift für deutsches Altertum und Literatur 77 (1940), S. 76-84. Bernhard BischоғF, »Paläographische Fragen deutscher Denkmäler der Karolingerzeit«, in: Frühmittelalterliche Studien 5 (1971), S. 101-134. S. 126.

1842 Bergmann (Hrsg.): Ahd. und as. Literatur. S. 415. Zur möglichen Verwendung im Hofzeremoniell siehe: Wolfgang Haubrichs, "Arcana Regum. Der Althochdeutsche hundertachtunddreißigste Psalm und die Synode zu Tribur (895)«, in: Architectura Poetica. Festschrift für Johannes Rathofer zum 65. Geburtstag, hrsg. von Ulrich ERNst und Bernhard SowINSKi (Kölner germanistische Studien 30) 1990, S. 67-106.

1843 Max WeHRLI, Geschichte der deutschen Literatur im Mittelalter: Von den Anfängen bis zum Ende des 16. Jahrhunderts, Stuttgart 1997. S. 88. BergmanN (Hrsg.): Ahd. und as. Literatur. S. 362-364.

1844 Otto Ursprung, "Das Freisinger Petrus-Lied«, in: Die Musikforschung 5 (1952), S. 17-21. S. 18.

1845 Mass: Freising in der späten Karolingerzeit. S. 97.

1846 H. Hucke, "Die Neumierung des althochdeutschen Petruslieds", in: Organicae voces: Festschrift Joseph Smits van Waesberghe angeboten anlässlich seines 60. Geburtstages, 18. April 1961, hrsg. von Instituut voor Middeleeuwse Muziekwetenschap, Amsterdam 1963, S. 71-78.

$1847 \alpha=$ St. Galler Exemplar der Collectio Sangallensis, $\mathrm{T}=\mathrm{Clm}$ 19413, U = ÖNB Cod. 1609, $\mathrm{S}=$ Salomos Sammlung, $\mathrm{W}=$ Waldos Sammlung, $\mathrm{G}^{\mathrm{S}}=$ St. Galler Texte aus Salomos Sammlung, $\mathrm{G}^{\mathrm{W}}=$ St. Galler Texte aus Waldos Sammlung. 


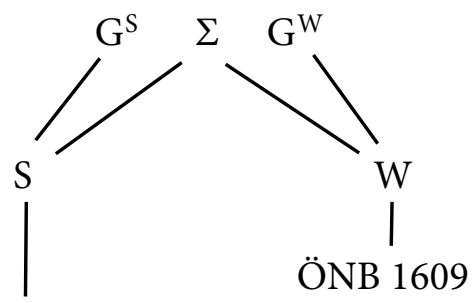

Clm 19413

Die Collectio Sangallensis, die den Kern der beiden Handschriften bildet, entstand auf dem Fundament der Lehrer-Schüler-Beziehung zwischen Notker und den Brüdern Waldo und Salomo. Dennoch heißt dies nicht, dass es sich bloß um Schultexte handelt. Sie wurden zu Ende der Anwesenheit der Brüder in St. Gallen gesammelt, ${ }^{1848}$ wohl als eine Art Abschiedsgeschenk des Lehrers. In ihrer weiteren Laufbahn nahmen die Brüder hohe Stellen im königlichen Dienst ein, deren Pflichten sich in einigen der Texte der Sammlung ankündigen. Zuvorderst die Formulae dienen als Vorbilder für Urkunden und Briefe offizieller und privater Kommunikation. Die Briefdichtung bildet in dieser Hinsicht einen integralen Bestandteil der Sammlung, da die geschliffene poetische Epistel ein prestigeträchtiges Mittel war, Freunde und Höhergestellte zu adressieren. Die Texte bilden insofern ein Handbuch des guten Stils. Die Kleintexte, die um die Sammlung kreisen, zeigen die Interessen der beiden Schüler an einer der hervorragenden Schulen des Reiches, deren Bibliothek ihnen reiches Studienmaterial bot.

Kommen wir von diesem Denkmal der persönlichen Bildungsgeschichte Salomos zu einem anderen Monument seiner kulturellen Interessen. Die kleineren althochdeutschen Einträge in Cod. 1609 werden überragt von München, BSB, Cgm 14, der Handschrift der Evangeliendichtung Otfrids von Weißenburg, die Waldo persönlich anfertigen ließ und mit der er seinem Verdienst um die althochdeutsche Dichtung ein bleibendes Denkmal setzte. ${ }^{1849}$ Der genaue Vermittlungsweg des Textes wird dadurch unkenntlich, dass Waldo zu allen Adressaten des Werkes persönliche Kontakte gehabt hatte und dass dem OtfridText der Handschrift die Widmung fehlt. ${ }^{1850}$ Es deutet jedoch alles auf eine

1848 Rio: Legal practice. S. $154 \mathrm{f}$.

1849 f. 125r: Uualdo episcopus istud euangelium fieri iussit. Ego sigihardus indignus presbiter scripsi. Zur Handschrift: Bischoff: Schreibschulen 1. Nr. 112. Hellgardt: „Freising«. S. 153-155. Karin Pivernetz (Hrsg.), Das "Evangelienbuch" in der Überlieferung der Freisinger Handschrift: (Bayerische Staatsbibliothek München, cgm. 14); Edition und Untersuchungen (Göppinger Arbeiten zur Germanistik 671), Göppingen 2000.

1850 Pivernetz (Hrsg.): Evangelienbuch. S. 9-16, 30-33. Mass: Freising in der späten Karolingerzeit. S. 205. 
Ausleihe des Werkes aus Weißenburg hin anstatt auf den Bezug via einen der Widmungsträger: Ein heute nicht mehr lesbarer Eintrag aus dem Weißenburger Ausleihverzeichnis in Cod. Guelf 35 Weiss. besagt, dass ein Fr...ng.s ep[iscopu]s habet euang[e]l[ium] theodiscum. ${ }^{1851}$ Eine schon vor Waldo bestehende Leihbeziehung zu Freising scheint im Eintrag 114r, Z. 2, belegt zu sein: Anno habet decreta pontificum romanorum. Anno eps. librum. I. Ein anderer als der Freisinger Anno lässt sich hier nicht identifizieren. ${ }^{1852}$ Waldo hätte sich zum Bezug der Handschrift an seinen Bekannten Hatto I. von Mainz wenden können, der unter anderem auch die Abtswürde in Weißenburg innehatte. ${ }^{1853}$ Die ausgeliehene Weißenburger Handschrift lässt sich in ÖNB Cod. 2687 - Otfrids Redaktionsexemplar - wiederfinden, an deren Text sich die Freisinger Handschrift grundsätzlich orientiert. ${ }^{1854}$ Der von Waldo beauftragte Schreiber Sigihard war allem Anschein nach derselbe, der schon den Nachtrag des 138. Psalmes in ÖNB Cod. 1609 vorgenommen hatte. ${ }^{1855}$ Unter Waldo ist die Sammlung von Dichtung also nicht an den weiteren Interessen der Schule, sondern am persönlichen Interesse des Bischofs selbst ausgerichtet, der neben der Sammlung kleinerer Texte

1851 Johann Nepomuk Kelle (Hrsg.), Otfrids von Weissenburg Evangelienbuch: Text, Einl., Grammatik, Metrik, Glossar, Regensburg 1856. S. XIV-XIX. Zur Handschrift: Butzmann: Die Weißenburger Handschriften. S. 146-147 mit weiterer Literatur zum Verzeichnis. Besprechung des Verzeichnisses Ebd. S. 39-41.

1852 Siehe jedoch kritisch zu diesen Zuordnungen: LeRCHE: „Das älteste Ausleihverzeichnis einer deutschen Bibliothek «, der das ganze Verzeichnis wegen der Nennung des Klosters Andlau (gegründet 880) später datiert und die Identifizierung mit Anno von Freising $(\dagger$ 875) zurückweist und das Verzeichnis in die Zeit des nächstmöglichen Anno (von Worms, 950-978) datiert. Wegen der schweren Schäden, die das Verzeichnis durch Reagenzien davongetragen hat, ist eine Entscheidung anhand der Handschrift heute nicht mehr möglich. Siehe kritisch zu Lerche: HellgardT: Die exegetischen Quellen. S. $81 \mathrm{f}$.

1853 Kelle (Hrsg.): Evangelienbuch. S. XV-XVI. Hier werden gleichwohl die Bezugsmöglichkeiten über die anderen Adressaten außer Acht gelassen.

1854 So werden etwa ursprünglich in der Vorlage transponierte Seiten kopiert, um nach Entdeckung des Irrtums mittels Verweiszeichen korrigiert zu werden. Eingehend hierzu: Pivernetz (Hrsg.): Evangelienbuch. S. 66-88. Erdmann/WolfF (Hrsg.): Otfrids Evangelienbuch. S. VI. Zu einer möglichen Verwendung von Heidelberg, UB, Pal. lat. 52 (P) siehe: Piper (Hrsg.): Otfrids Evangelienbuch. S. 233-240 und die Diskussion bei Pivernetz (Hrsg.): Evangelienbuch. a.a.O.

1855 Wolfgang MiLde, "Das ahd. Gebet des Sigihard und sein Schreiber. Eine paläographische Studie«, in: Septuaginta quinque. Festschrift für Heinz Mettke, hrsg. von Jens HaUstein, Eckhard Meinecke und Norbert Richard Wolf (Jenaer germanistische Forschungen NF 5), Heidelberg 2000, S. 285-293. Hermann Menhardt, "Zur Überlieferung des ahd. 138. Psalms", in: Zeitschrift für deutsches Altertum und deutsche Literatur 77 (1940), S. 76-84. S. 76-78. Sigihard ist jedoch nicht der Schreiber des eponymen "Gebets des Sigihard" BIsCHоғF: »Paläographische Fragen«. S. 78. 
auch seine persönlichen Beziehungen spielen ließ, um einen so bedeutenden Text wie Otfrieds Evangeliendichtung für seine Bibliothek zu beschaffen. ${ }^{1856}$

Einen Rückblick über die Bibliothek des 9. Jh. gewährt ein in Clm 6399 nachgetragenes Bücherverzeichnis des 10. Jh., das durch die genannten grammatischen Bücher aus dem Schulbereich zu stammen scheint. ${ }^{1857}$ Nach einer Reihe Grammatiker folgen die metrici: Virgilius. Prudentius. Poetius. ${ }^{1858}$ Omerus. ${ }^{1859}$ Sedulius. Iuvencus. Prosper. Arator. Cato et liber metrice artis; $;{ }^{1860}$ quos omnes habemus et colimus. Istos vero non habemus. Freholfum. Iosuphum. Alquinum. Marcianum. Terrentium. ${ }^{1861}$ Von den hier genannten sind Handschriften oder Spuren nur von Vergil und Juvencus erhalten; die ebenfalls in Einzelversen bezeugten Ovid und Petron fehlen in der Liste. Auch von den weiteren Dichtern fehlt in den erhaltenen Beständen jede Spur. Die Liste trägt das Gepräge des Curriculums des 10. Jhs. und hat Übereinstimmungen mit den von Walter von Speyer erwähnten Schulautoren seiner Jugend. ${ }^{1862}$ Einige der Dichter jedoch, wie Vergil, Prudentius, Sedulius oder Cato, können als Grundbestand einer wohlbestellten Bibliothek auch schon für die frühere Zeit angenommen werden.

Die Dichtung in Freising konnte den festen Platz, den sie in der Freisinger Schule hatte, von der Anfangszeit bis ins 10. Jh. behaupten. Vom metrisch annotierten Petron der Leidener Handschrift, von dem einige wenige Verse unter Atto nach Freising gelangten, über den aus Salzburg bezogenen Angilbert, bis zum Vorkommen Walahfrids und Ps.-Columbans in pädagogischen Handschriften ist der Freisinger "Kanon« jedoch ungewöhnlich in seiner Heranziehung schulfremder Autoren. Eine konventionellere Auswahl erscheint erst in den

1856 Zur ungeklärten Frage der eigentlichen Verwendung der Handschrift - Vorlesung oder Lektüre, privat oder gemeinschaftlich - siehe: Pivernetz (Hrsg.): Evangelienbuch. S. 3338.

1857 Glauche/Knaus/Bischoff (Hrsg.): $M B K$ 4, 2. Nr. 75, S. 626. Glauche: Pergamenthandschriften Freising. S. 184-186.

1858 Boethius.

1859 Homerus Latinus.

1860 Das liber metrice artis ist vielleicht Clm 6399 selbst, in dessen Deckspiegel ein Pergamentblatt der Aufschrift NOTITIA METRICAE ARTIS verwendet ist, das von Bischoff als Teil des alten Einbandes bewertet wird. Bischoff: Schreibschulen 1. S. 148-149.

1861 Die non habemus-Bücher sind gewünschte Anschaffungen, nicht etwa entwendete oder ausstehende Titel (vgl. MildE: Bibliothekskatalog. S. 106f.). Von den noch fehlenden Büchern muss keines unbedingt als Dichtung angesehen werden, da Alkuin und Martianus Capella mit ihren grammatischen Schriften vertreten sein könnten und Terenz damals noch als »Prosa«-Schriftsteller überliefert wurde.

1862 Peter Vossen, Der Libellus scolasticus des Walther von Speyer: ein Schulbericht aus dem Jahre 984, Berlin 1962. Fickermann/Strecker (Hrsg.): MGH Poet. lat. 5, 1.2. S. 19-20, vss. 93-105, darunter »Homer, Martianus Capella, Horaz, Persius, Iuvenal, Boethius, Statius, Terenz, Lukan, Vergil«, Max Manitius, Geschichte der lateinischen Literatur des Mittelalters. 2. Von der Mitte des zehnten Jahrhunderts bis zum Ausbruch des Kampfes zwischen Kirche und Staat: mit Index, München 1923. S. 505. 
fragmentarischen Versen aus Ovid und Vergil sowie im späteren Bücherverzeichnis. Ein ästhetisches, nicht nur funktionales Interesse an der Dichtung erscheint erst in der Gestalt Waldos, dessen persönliche Anteilnahme an althochdeutscher Dichtung sich in einigen Textzeugen, zuvorderst in Otfrids Evangelienbuch ausdrückt. Auch hier ist es also das Interesse eines einzelnen Bischofs, das der Produktion des Skriptoriums einen persönlichen Stempel aufdrückt, ohne jedoch eine Tradition begründen zu können.

\section{II.4.C Tegernsee}

Die Tegernseer Bibliothek des 9. Jh., die bei dem Reichtum des Klosters bedeutend gewesen sein muss, ist durch zahlreiche Unglücksfälle zerstört und zerstreut worden, sodass auch für diesen Schreibort die Geschichte seiner Dichtung nur aus Bruchstücken und Überbleibseln erahnt werden kann. ${ }^{1863}$ Die in Tegernsee geschriebenen Handschriften enthalten keine Dichtung. Einige Fragmente jedoch, die sich im späteren Bestand der Bibliothek in Einbänden erhalten haben, könnten schon im 9. Jh. dort gewesen sein. Ein Vergilfragment ${ }^{1864}$ sowie zehn Blätter einer Juvencus-Handschrift deuten eine schulische Ausstattung an. ${ }^{1865}$

Ein paar Verse von Dichtung aus Tegernsee haben sich in einer süddeutschen Handschrift erhalten, deren Bibliotheksheimat die Reichenau wurde: Karlsruhe, BLB, Ms. Aug. Perg. 255. ${ }^{1866}$ Die Handschrift hat exegetischen Charakter, die Haupttexte sind Bedas Apokalypsenkommentar und Poenitentialliteratur. Bedas Text wird eingeleitet durch sein Gedicht auf den Evangelisten, ${ }^{1867}$ das gleich einem Titel ganz in Rustica geschrieben wurde. Auf der Rückseite des letzten Blattes der zweiten Lage $\left(\mathrm{IV}^{15}\right)$ sind Verse von anderer Hand nachgetragen, die

1863 Zur Geschichte, jedoch mit Schwerpunkt auf dem späten 9. und 10. Jh: Lotte TABor, Die Kultur des Klosters Tegernsee in frühen Mittelalter, Bottrop 1935. Zum Skriptorium: BIschoff: Schreibschulen 1. S. 153-167. Christine Elisabeth EDER, „Die Schule des Klosters Tegernsee im frühen Mittelalter im Spiegel der Tegernsee Handschriften «, in: Studien und Mitteilungen zur Geschichte des Benediktinerordens und seiner Zweige 83 (1972), S. 6-155. Insb. S. 16-22.

1864 München, BSB, Clm 29005 (18) vielleicht aus Italien: BischоғF: Schreibschulen 1. S. 165.

1865 Clm 29334(1 (Hermann HAuKe, Katalog der lateinischen Fragmente der Bayerischen Staatsbibliothek München, 2: Clm 29315-29520 (Catalogus codicum manu scriptorum Bibliothecae Monacensis 12/2), Wiesbaden 2001. S. 314), olim Clm 29030 (so bei Bischoff: Schreibschulen 1. S. 165). Vielleicht gehören Boethius in Clm 29030, EDER: "Tegernsee«. S. 22, 108, sowie Priscian dazu (Clm 18375: Ebd. S. 21, 82). In den überlieferten Handschriften fehlen ebenfalls die Grammatiker. Der Boethius in Clm 18765 kam wahrscheinlich erst unter Froumund von Tegernsee (ca. 960 -ca. 1012) ins Kloster: Ebd. S. 22 und Nr. 79.

1866 Holder: Die Pergamenthandschriften. S. 579-584. »Süddeutschland«: Bischoff: Katalog, 1. Nr. 1736. Nicht Reichenau wie bei: EDER: "Tegernsee«. S. 22.

1867 9r, Exul ab humano, SK 8553. JAAGER (Hrsg.): Bedas metrische Vita sancti Cuthberti. S. 52. 
von Strecker als Tituli Tegernseenses veröffentlicht wurden. ${ }^{1868}$ Aus den Nennungen der Namen zweier Äbte sowie einiger Kirchen lässt sich der Tegernseer Ursprung erkennen. ${ }^{1869}$ Die Verse finden sich in der Handschrift ungetrennt geschrieben ohne Rücksicht auf die klare Sinntrennung ${ }^{1870}$ der einzelnen Inschriften. ${ }^{1871}$ Die Tituli werfen wie die Handschriftenfragmente ein Schlaglicht auf die in Tegernsee verfügbare Dichtung, die dort rezipiert wurde und zu eigenen Produktionen anregte. Der am häufigsten zitierte Dichter in den Inschriften ist Aldhelm, der mit Carmen de virginitate und Aenigmata, sowie dem dritten der Carmina Ecclesiastica, einer poetischen Bauinschrift einer Kirche, ${ }^{1872}$ in Tegernsee recht vollständig zur Verfügung stand. ${ }^{1873}$ In Vers I, 1 wird Prudentius zitiert. Interessant ist ferner die Reminiszenz in I, 7, einer weitverbreiteten und viel abgewandelten Inschrift aus Alt-St. Peter in Rom Inc. Iustitiae domus, fidei aula. ${ }^{1874}$ Wie diese Inschrift nach Tegernsee kam - vielleicht als Teil einer Sylloge? - ist unklar. ${ }^{1875}$ Das hier gleich zwei aus verschiedenen Quellen stammende Texte - Aldhelm und die römische Inschrift - zur Verfertigung neuer, ortsgebundener Inschriften verwendet wurden, ist ein Zeugnis der Kreativität des Klosters.

Mit Vergil, Juvencus, Prudentius und Aldhelm besaß die Tegernseer Bibliothek einen soliden Grundbestand an Dichtung, der für schulische Zwecke ausreichend gewesen wäre. Sicher waren jedoch damit die Bestände des reichen Klosters nicht erschöpft. Die Versus Tegernseenses deuten auf ein Interesse, das über den bloß schulischen Bedarf hinausgeht und das die erlangten Fähigkeiten zum Schmuck des eigenen Klosters anwenden will. Die Inschriften selbst wurden später als mustergültig genug angesehen, um selbst in entstellter Form weiter tradiert zu werden.

1868 Strecker (Hrsg.): MGH Poet. lat. 4, 2.3. S. 1044-1046.

1869 Adalbert II, 11; VI, 35; Odgar III, 24: Germain MoRIN, »Les inscriptions dédicatoires des premières églises de Tegernsee sous l'abbé fondateur Adalbert«, in: Revue bénédictine 29 (1912), S. 208-214.

1870 Hanc aulam; Conditur hic und dergleichen.

1871 Ebenfalls ohne Trennung sind die römischen Tituli in Clm 19410, p. 54-56, geschrieben, denen jedoch korrekt getrennte Alkuin-Tituli vorhergehen.

1872 Ehwald (Hrsg.): Aldhelmi Opera. S. 8, 14-18.

1873 Vgl. die Nachweise bei STRECKeR, passim.

1874 SK 8587. RIESE/BÜCHELER (Hrsg.): Anthologia latina. Nr. 315.

1875 Siehe für die verschiedenen Syllogen, die die Inschrift enthielten: De Rossı: ICUR. 2, S. 500, s.v. 


\section{II.4.d Regensburg}

Das von Bonifatius kanonisch errichtete Bistum Regensburg war schon vorher durch seine Stellung am Herrschaftssitz der Agilolfinger und als Wirkungsstätte des heiligen Emmeram bedeutend. ${ }^{1876}$ Das Skriptorium befand sich im Kloster St. Emmeram, dessen Abt in Personalunion stets der Bischof war. ${ }^{1877}$ Ebenso stammen die frühmittelalterlichen Handschriften Regensburgs ausschließlich aus den Beständen des Klosters, nicht des Domkapitels. ${ }^{1878}$ Dass Salzburg anstelle des zentralen Regensburgs Erzbistum wurde, scheint der Kulturentwicklung dort keinen Abbruch getan zu haben, zudem es auch schnell wieder als Pfalz Ludwigs des Deutschen an Bedeutung gewann. ${ }^{1879}$ Erst im Ausgang der Agilolfingerzeit unter Bischof Simpert (768?-791) erlangt die Schreibschule klarere Umrisse, auch wenn nur Spärliches, darunter keine Dichtung, von damals erhalten ist. ${ }^{1880}$ Die wenigen Handschriften repräsentieren die notwendige Grundausstattung der Bibliothek, wozu auch auf fremde Bestände zurückgegriffen wurde. ${ }^{1881}$ Die Schrift ist noch angelsächsisch geprägt; erst unter Bischof Adalwin (792-816/17) wird

1876 Zum Bistum: Karl Hausberger, Geschichte des Bistums Regensburg, Regensburg 1989. Peter Morsbach, Ratisbona sacra: das Bistum Regensburg im Mittelalter; Ausstellung anläßlich des 1250jährigen Jubiläums der kanonischen Errichtung des Bistums Regensburg durch Bonifatius 739-1989, München [u. a.] 1989. Josef StABER, Kirchengeschichte des Bistums Regensburg, Regensburg 1966.

1877 Zur Schreibschule: Bischoff: Schreibschulen 1. S. 172-267. Bernhard Bischoff, »Literarisches und künstlerisches Leben in St. Emmeram (Regensburg) während des frühen und hohen Mittelalters «, in: Bischoff, Mittelalterliche Studien, 2, 1967, S. 77-115. Christa BERTelsmeIER-Kierst, »Regensburg (einschließlich Prüll und Windberg) «, in: Schreiborte des deutschen Mittelalters: Skriptorien - Werke-Mäzene, hrsg. von Martin J. SCHUBER T, Berlin [u. a.] 2013, S. 459-492. Katharina BIERBRAUER, »Die Regensburger Buchmalerei des 8. und 9. Jahrhunderts", in: Regensburger Buchmalerei. Von frühkarolingischer Zeit bis zum Ausgang des Mittelalters. Ausstellung der Bayerischen Staatsbibliothek München und der Museen der Stadt Regensburg, hrsg. von Florentine MüTHERICH und Karl Dachs, München 1987, S. 15-22. Zum Kloster: Christine RÄDLINGER-Prömper, Sankt Emmeram in Regensburg. Struktur- und Funktionswandel eines bayerischen Klosters im frühen Mittelalter (Thurn-und-Taxis-Studien 16), Kallmünz 1987. Eckhard Freise, „St. Emmeram zu Regensburg", in: Ratisbona Sacra. Das Bistum Regensburg im Mittelalter. Ausstellung anläßlich des 1250jährigen Jubiläums der kanonischen Errichtung des Bistums Regensburg durch Bonifatius 739-1989, hrsg. von Peter Morsbach (Kataloge und Schriften. Kunstsammlungen des Bistums Regensburg, Diözesanmuseum Regensburg 6), München, Zürich 1989, S. 182-186.

1878 Glauche/Knaus/Bischoff (Hrsg.): $M B K$ 4, 2. S. $99 \mathrm{f}$.

1879 Thomas ZотZ, „Ludwig der Deutsche und seine Pfalzen: Königliche Herrschaftspraxis in der Formierungsphase des Ostfränkischen Reiches", in: Ludwig der Deutsche und seine Zeit, hrsg. von Wilfried Hartmann, Darmstadt 2004, S. 27-46. S. 28. Peter (Historiker) Schmid, "Civitas regia: Die Königsstadt Regensburg", in: Geschichte der Stadt Regensburg, 1, hrsg. von Peter Schmid, Regensburg 2000, S. 103-147.

1880 Bischoff: Schreibschulen 1. S. 172, 174, Nr. 1-6.

1881 Zum Beispiel aus Freising: Clm 14537, Ebd. Nr. 5. 
der karolingische Einfluss wirksam. ${ }^{1882}$ Adalwin war als missus Karls des Großen und als Freund Alkuins dem Hofe eng verbunden. ${ }^{1883}$ Er setzte die von Simpert begonnene Aufbauarbeit fort. Zeichen einer Rezeption und Anpassung der Literatur an Regensburger Verhältnisse finden sich zuerst in der Kompilation von München, BSB, Clm 14457, die den pastoralen Bedürfnissen der Mission dient, und in Sammelhandschriften zur Grammatik (Clm 14252) oder Komputistik (Clm 14456). In die Gruppe der letzten beiden, die stilistisch einen Abfall gegenüber der »erste[n] kalligraphische[n] Periode ${ }^{1884}$ darstellen, findet sich auch die erste Regensburger Sammlung von Dichtung: Clm $14248^{1885}$ enthält als Haupttext Augustinus, In psalmum 118, woran sich auf f. 159v-176v ein Hymnar mit Gebetbuch anschließt, das in Regensburg gesammelte und modifizierte Hymnen enthält. ${ }^{1886}$ Wiewohl im Genre klar vom Haupttext unterschieden, ist das Hymnar wegen des identischen Schreibers und Textübergang in der Lage als ursprünglicher Teil einer geplanten Handschrift anzusehen. Die Anrufung des heiligen Emmeram in der Litanei auf f. 169r kennzeichnet die Sammlung als lokal entstanden, nicht von anderswo übernommen. Das Hymnar zerfällt in zwei Teile: Hymnen 1-6 (f. 159v-163r) sind die geläufigen Cantica, 7-15 (f.163r-176v) sind orationes und preces in Prosa. Besonders die Prosa-Sammlung hängt eng mit insularen Vorbildern zusammen, aus denen ganze Gebete und Auszüge neu gruppiert werden. ${ }^{1887}$ Frosts Bewertung der Sammlung als »a collection of private or semi-private prayers shewing Irish influence both in their character and in their phraseology ${ }^{1888}$ darf nicht auf die gesamte Handschrift ausgeweitet werden (von der er nur den von ihm untersuchten Teil in Fotografien vorliegen hatte); nur der betreffende Teil ist als Abschrift eines solchen prayer books anzusehen. Die Herkunft des Gebetbuches wird am ehesten bei Alkuin ${ }^{189}$ über Adalwin zu

1882 Ebd. S. 174-176, Nr. 7-12, 13-23.

1883 "Alcuini epistolae«. S. 421-424. StABer: Kirchengeschichte. S. 11, 14. Hausberger: Geschichte des Bistums Regensburg. S. 34. FreIsE: „St. Emmeram zu Regensburg«. S. 182.

1884 Bischoff: Schreibschulen 1. S. 174, 176.

1885 Ingeborg Neske, Katalog der lateinischen Handschriften der Bayerischen Staatsbibliothek München. Die Handschriften aus St. Emmeram in Regensburg, 2: Clm 14131-14260 (Catalogus codicum manu scriptorum Bibliothecae Monacensis 4/2/2), Wiesbaden 2005. S. 263-265. BischofF: Schreibschulen 1. Nr. 13.

1886 Maurice Frost, »A prayer book from St. Emmeran, Ratisbon«, in: The journal of theological studies 30 (1928), S. 32-45.

1887 Ebd. S. 33. Die genannten Handschriften sind: Cambridge, University Library, MS Ll. 1. 10 (Book of Cerne), London, British Library Royal MS 2.A.XX (Royal Prayer Book) und Harley MS 2965 (Book of Nunnaminster).

1888 Ebd. S. 33.

$1889 \mathrm{Zu}$ seiner Rolle bei der Verbreitung dieser Gattung siehe: Const AnTINESCU: »Alcuin et les sLibelli Precum ‘ de l'époque carolingienne«. 
suchen sein, auch wenn die Modifizierungen im Text auf eine Regensburger Bearbeitung schließen lassen. ${ }^{1890}$

Unter Bischof Baturich (817-847) fand eine Reform des Skriptoriums statt. ${ }^{1891}$ Nach seiner Erziehung in St. Emmeram studierte Baturich in Fulda, wo er Lehrer und Freund des Hrabanus wurde. ${ }^{1892}$ Als Erzkapellan Ludwigs des Deutschen war er wie Adalwin Teil der herrschenden Elite. ${ }^{1893}$ Das Skriptorium erlebte nach der unter Baturich durchgeführten Neuordnung seine Blütezeit. Die kreative Kompilationsarbeit wurde fortgesetzt, unter anderem in hagiographischen, apologetischen und liturgischen Handschriften. Das Fehlen von Dichtung ist nicht nur durch die ansonsten breite Produktion des Skriptoriums auffällig. Durch die Freundschaft zu Hrabanus und den dementsprechenden Kontakt zu den reichen Beständen Fuldas wäre es ein Einfaches gewesen, die Bibliothek in dieser Hinsicht $\mathrm{zu}$ füllen. ${ }^{1894}$ Vielleicht aus Fulda nach St. Emmeram gekommen ist die fragmentarische Sedulius-Handschrift München, BSB, Clm 29338 (1 (olim Clm 29033a), deren stilistische Nähe zum Ragyndrudis Codex eine Nähe zu Bonifatius nahelegt. ${ }^{1895}$ Wann diese Handschrift jedoch nach St. Emmeram gelangt ist, bleibt unklar. Ein anderes stückhaftes Indiz der Dichtung unter Baturich ist der neumierte Text in München, BSB, Clm 9543, f. 199v, Psalle modulamina laudis, ${ }^{1896} \mathrm{der}$

1890 Insbesondere die Anrufung Emmerams, die nicht auf Alkuin zurückgehen kann, sowie das irische Madian für Matthias (f. 163v), das schon in den insularen Textzeugen korrigiert ist.

1891 Bischoff: Schreibschulen 1. S. 177-179, Nr. 24-55. Eine Liste der signierten Handschriften auch in: Georg SwARZENSKI, Die Regensburger Buchmalerei des X. und XI. Jahrhunderts: Studien zur Geschichte der deutschen Malerei des frühen Mittelalters, Heidelberg 1900. S. 20-21.

1892 Bischoff: Schreibschulen 1. S. 178; Staber: Kirchengeschichte. S. 16. DüMmLeR (Hrsg.): MGH Poet. lat. 2, S. 2. Zu einem alternativen Bildungsweg Baturichs über die Reichenau siehe: Emmanuel P. Munding, "Das älteste Kalendar der Reichenau: (aus Cod. Vindob. 1815 saec. IX. med.)«, in: Colligere Fragmenta: Festschrift Alban Dold zum 70. Geburtstag am 7. 7. 1952, hrsg. von Bonifatius Fischer (Texte und Arbeiten 1. Beihefte 2), Beuron 1952, S. 236-246. S. $243 \mathrm{f}$.

1893 Hausberger: Geschichte des Bistums Regensburg. S. 36.

1894 Der von Bischoff: "St. Emmeram«. S. 177, Anm. 3 (MGH Epp. 5, S. 518), erwähnte Briefwechsel betrifft jedoch eher Baturichs Eintreten für Fuldenser Interessen, als einen literarischen Austausch. Zu Handschriften aus Fulda und anderen Schreibstätten in St. Emmeram siehe: Glauche/Knaus/Bischoff (Hrsg.): MBK 4, 2. S. 102.

1895 Bischoff: Schreibschulen 1. S. 256-257. Hauke, Fragmente 2. S. 319. Weitere mögliche Handschriften dieser Herkunft: Glauche/Knaus/Bischoff (Hrsg.): MBK 4, 2. S. 101.

1896 Text: Bruno StäBlEIN, "Zwei Textierungen des Alleluia Christus Resurgens in St. Emmeram - Regensburg", in: Organicae voces: Festschrift Joseph Smits van Waesberghe angeboten anlässlich seines 60. Geburtstages, 18. April 1961, hrsg. von InstituUt voor MidDeleeuWSe MuZieKWETENSCHAP, Amsterdam 1963, S. 157-168. S. 163-165. Kommentar: Joseph SMits van WAesberghe, "Studien über das Lesen (Pronuntiare), das Zitieren und über die Herausgabe lateinischer musiktheoretischer Traktate (9-16. Jahrhundert) «, in: Archiv für Musikwissenschaft 29 (1972), S. 64-86. S. 72. Hartmut MöLleR, "Die Prosula >Psalle modulamina (Mü 9543) und ihre musikhistorische Bedeutung", in: La tradizione dei tropi liturgici, hrsg. von Claudio Leonardi und Enrico Menestò (Biblioteca del Centro 
vom Hauptschreiber Engyldeo in schneller Schrift ergänzt wurde und eine der frühesten datierbaren Neumierungen darstellt. Von diesen zwei wenig aussagekräftigen Textzeugen ${ }^{1897}$ abgesehen scheint die Dichtung unter Baturich eine nur geringe Rolle gespielt $\mathrm{zu}$ haben.

Diese Einschätzung muss jedoch relativiert werden, wenn eine Gruppe insular beeinflusster Handschriften tatsächlich von Schreibern aus dem 833 von Baturich erworbenen Kloster Mondsee stammt, die für Regensburg schrieben und mit der dortigen Schreibschule kooperierten. ${ }^{1898}$ Aus dieser Gruppe stammt eine nur noch in zerstreuten Fragmenten vorhandene glossierte und mit Kommentarzetteln versehene Aeneis, ${ }^{1899}$ die zusammen mit der vom gleichen Schreiber verfassten Consentiushandschrift München, BSB, Clm 14666 vielleicht einem Lehrer im Unterricht diente. ${ }^{1900}$ Aus dem gleichen Kreis stammen weitere Handschriften verwandten Charakters: Clm 14377, f. 1-51, enthält Alkuins Disputatio de rhetorica und De dialectica sowie dazwischen originelle Diagramme zur Einteilung der Wissenschaften. ${ }^{1901}$ Die einleitenden Verse zu Alkuins Schriften (f. 1r, f. 31v) wurden von einem unaufmerksamen Schreiber wie Prosa eingetragen, was von zweiter Hand später mit Versus Albini richtig gestellt wurde. ${ }^{1902}$ Der eigentümliche Textverbund dieser Handschrift (mit Schemata) stammt wohl aus Freising, wohin er aus Verona mit der Handschrift Clm 6407 gelangte und dort schnell nach Ankunft in Clm 13084 abgeschrieben wurde. ${ }^{1903}$ Der Text ist somit nicht, wie vielleicht die Vergil- und die Consentius-Handschrift, aus Mondseer Beständen mitgebracht worden. In den Kreis der Mond-

per il Collegamento degli studi medievali e umanistici in Umbria 3), Spoleto 1990, S. 279296.

1897 Hierzu noch die hexametrische Subskription in Clm 14727, f. 130. Bischoff: »St. Emmeram«. S. 78, Anm. 10.

1898 Bischoff: Schreibschulen 1. S. 180-181, Nr. 62-75. BischоғF: Schreibschulen 2. S. 11-12.

1899 BIschoff: Schreibschulen 1. Nr. 70, dort die verschiedenen Signaturen der Fragmente. Die Münchner Fragmente sind heute in der Mappe Clm 29216 gesammelt, Hermann HAUKE, Katalog der lateinischen Fragmente der Bayerischen Staatsbibliothek München, 1: Clm 29202-29311 (Catalogus codicum manu scriptorum Bibliothecae Monacensis 4/12/1), Wiesbaden 1994. S. 27-36, Konkordanz S. 450. Munk Olsen: L'étude des auteurs classiques latins. 2, S. 743-746. Ein weiteres St. Emmeramer Vergilfragment ist Clm 29216 (9 (olim Clm 29005 (19); es ist französischer Herkunft, der Zugang zur Bibliothek kann zeitlich nicht hinreichend eingegrenzt werden. HAuKE: Fragmente 1. S. 31.

$1900 \mathrm{Zu}$ Consentius als Schulgrammatiker siehe: Thorsten FöGEN, »Der Grammatiker Consentius«, in: Glotta 74 (1997), S. 164-192. S. 174f.

1901 Bernhard Bischoff, »Eine verschollene Einteilung der Wissenschaften«, in: Bischoff, Mittelalterliche Studien, 1, S. 273-288. S. 275 f.

1902 Friedrich Helmer u. a. (Hrsg.), Die Handschriften aus St. Emmeram in Regensburg (Catalogus codicum manu scriptorum Bibliothecae Monacensis 4/2), Wiesbaden 1995. S. 204.

1903 Bischoff: Schreibschulen 1. S. 90, Nr. 28. Heinz LöwE, "Zur Geschichte Wizos", in: Deutsches Archiv für Erforschung des Mittelalters 6 (1943), S. 363-373. 
seer Handschriften gehört auch die Boethius-Handschrift Clm 14324, f. 36-70. ${ }^{1904}$ Der Boethius-Text steht innerhalb der Familie der germanici einzigartig da, weil er durch Lesarten aus der westfränkischen Tradition kontaminiert ist, speziell solchen die Bern, BB Ms. 179 nahestehen. ${ }^{1905}$ Vielleicht liegt hierin sogar eine philologische Leistung vor, indem der im Ostfrankenreich verbreitete Text nach einer westfränkischen Handschrift korrigiert wurde; hiervon zeigt jedoch $\mathrm{Clm}$ 14324 keine direkten Spuren, da die gemeinsamen Varianten nicht als Korrekturen, sondern im Fließtext vorliegen. In jedem Fall stellt die Handschrift ein Beispiel der grenzüberschreitenden Tradition von Texten dar. Die zahlreichen lateinischen Synonymglossen sind späteren Datums (s. IX ${ }^{4}$ ), zeigen jedoch zusammen mit metrischen und rhetorischen Anmerkungen (z.B. f. 40v) einen in Regensburg nach Bedürfnissen der Schule durchgearbeiteten Text; bemerkenswert ist der durchgehende metrische Kommentar selbst dort, wo die Glossierung schon vereinzelt geworden ist (z. B. f. 67v) ${ }^{1906}$ Ein Denkmal angewandter Poesie besteht noch in einem einzelnen Blatt eines Kalendars (Clm 29790 (1, olim Clm 29081 (10), wo verschiedene Hände Kalenderverse nachgetragen haben. ${ }^{1907}$ Die unsichere Datierung der Verse macht eine Einordnung schwer; sie zeigen jedoch, das auch außerhalb der Grenzen von Liturgie und Schule die Dichtung von Einzelnen gepflegt wurde, ${ }^{1908}$ hier vielleicht als mnemonische Dichtung.

Nach Baturichs Tod ging auch das von ihm geförderte Skriptorium ein. Aus der zweiten Hälfte des 9. Jh. sind nur noch zehn Handschriften erhalten (gegenüber mehr als sechzig aus der ersten Hälfte). ${ }^{1909}$ Es ist kennzeichnend, dass in dieser für Bayern so bewegten Zeit der Jahrhundertwende ein relativ häufiger Text wie Martianus Capella aus dem fernen St. Gallen bezogen werden musste; bemerkenswert ist aber auch, dass die kulturelle Verbindung nicht abriss, wie man an dem im Umkreis des Skriptoriums entstandenen Kodex Clm 14070c erkennen kann, der sich in seinem Auszug aus den Nuptiae des Martianus Ca-

1904 Bischoff: Schreibschulen 1. Nr. 72. Helmer u. a. (Hrsg.): Die Handschriften aus St. Emmeram. S. 204-207.

1905 Moreschini (Hrsg.): Boethius. S. XIV, XIX. Der Berner Kodex: Bischoff: Katalog, 1. Nr. 548. Diese Handschrift ist späteren Datums.

1906 Genauer behandelt wurden nur die wenigen deutschen Glossen: BergmanN/STRICKER: Katalog. Nr. 572. Rudolf PeIPER, "Glossen zu Boethius", in: Zeitschrift für deutsche Philologie 5 (1874), S. 76-80.

1907 Bischoff: Schreibschulen 1. Nr. 73. Hermann HAUKE, Katalog der lateinischen Fragmente der Bayerischen Staatsbibliothek München: Band 3: Clm 29550-29990, Wiesbaden 2013. s.v.

1908 Bezeichnenderweise ähnelt dem Schreiber der Kalenderverse die Hand in Clm 14420, f. 120, wo Bedas De metrica ratione enthalten ist (Bischoff: Schreibschulen 1. S. 242). Ein weiteres Faszikel dieser Sammelhandschrift enthält einen Terenz-Kommentar (Commentum Monacense), ist aber späteren Datums und stammt nicht aus Regensburg.

1909 Ebd. S. 181-183. 
pella an der Reichenauer Tradition orientiert. ${ }^{1910}$ Die Handschrift ist nur spärlich glossiert und von schöner Gestaltung, was für eine mehr literarische als pädagogische Rezeption spricht. Es ist naheliegend, diese Handschrift mit einem Presbyter Louganpert in Verbindung zu bringen, der zur Jahrhundertwende in Regensburg wirkte und dem Kloster eine Bücherschenkung machte, ${ }^{1911}$ worunter sich ebenfalls eine aus dem Umkreis der Reichenau stammende Handschrift befindet. ${ }^{1912}$ Auch in seiner eigenen Dichtung, ${ }^{1913}$ von der nur ein Fragment erhalten ist, lehnt er sich stark an Walahfrid an, von dem ein Distichon in der eben erwähnten Handschrift zu finden ist. ${ }^{1914}$ Auch wenn also die Martianus-Handschrift Clm 14070c nicht als Geschenk Louganperts gekennzeichnet ist, darf die Verbindung zur Reichenau durchaus in seiner Person vermutet werden.

In Regensburg stand die Dichtung, auch als das Skriptorium unter Adalwin und Baturich auf seiner Höhe stand, nicht im Zentrum des Interesses. Mögliche Bezugswege, wie sie Adalwin zu Alkuin oder Baturich zu Hof und Fulda hatte, wurden diesbezüglich nicht genutzt. Vielmehr ist unter Baturich ein Import in Form der Mondseer Handschriftengruppe festzustellen, der zeigt, dass es eines Impulses von außen zur Anschaffung von Dichtung bedurfte, die in diesem Falle in einem schulischen Kontext zu verorten ist. Die angesichts der ansonsten eingebrochenen Produktion der Jahrhundertwende überraschende Präsenz des Martianus Capella kann vielleicht mit den persönlichen Beziehungen Louganperts in Verbindung gesetzt werden, der die Bibliothek St. Emmerams durch Schenkung seiner privaten Bestände vermehrte.

1910 Ebd. S. 227. Jean G. PrÉAux und Adolfus Dick (Hrsg.), Martianus Capella (Bibliotheca scriptorum Graecorum et Romanorum Teubneriana), Stuttgart 1925. S. XIX, Sigle C.

1911 Glauche/Knaus/Bischoff (Hrsg.): MBK 4, 2. S. 104.

1912 Clm 14754, f. 41-118. Bischoff: Schreibschulen 1. S. 254.

1913 DüMmLer (Hrsg.): MGH Poet. lat. 2. S. 417, LXXX, 1.

1914 Bischoff: „St. Emmeram«. S. 79. Auch der Katalog des späten 10. Jh. (unter Abt Ramwold) erwähnt »Uualahfridi II.«, die vielleicht aus der gleichen Beziehung herstammen können; da Ramwold jedoch ein großer Förderer der Bibliothek war, lassen die vermerkten Bücher nicht mit Sicherheit auf frühere Erwerbungen schließen. Die Bibliothek enthielt zu Ramwolds Zeiten: Prosper, Sedulius, Arator, Prudentius, Ps.-Cato, Avianus, Iuvencus, Wandalbert (?) und eine reiche grammatische Sammlung. Glauche/Knaus/Bischoff (Hrsg.): $M B K$ 4, 2. S. 105-106, 144-146, Walahfrid: S. 146, Z. 76. 


\section{II.4.e Passau}

Aus Bibliothek und Skriptorium des Domstifts Passau, das unter mehr Unglücksfällen als andere Orte Bayerns zu leiden hatte, ist so gut wie nichts erhalten. ${ }^{1915}$ Von den Handschriften, von denen das Bistum wenigstens zum praktischen Bedarf eine gewisse Anzahl besessen haben muss, ist nur der Traditionskodex mit Sicherheit dem bischöflichen Skriptorium zuzuweisen. ${ }^{1916}$ Andere Handschriften werden aufgrund ihrer Inhalte, nicht wegen des Schriftcharakters Passau zugeordnet. Vielleicht hatte Passau auch vor allen Verlusten einen geringeren Buchbestand als andere Domstifte, da vor Ort kein Kloster der Kathedrale als separate Bildungsstätte wie in anderen bayrischen Diözesen angeschlossen war. ${ }^{1917}$ Trotzdem ist es nicht unwahrscheinlich, dass der Bestand auch in weiterer literarischer Hinsicht nicht unbedeutend war - die Voraussetzungen scheinen für die Grundlegung der Bibliothek in den ersten drei irisch/ angelsächsischen Bischöfen Vivilo, Beatus und Sidonius gegeben, für ihre Erweiterung insbesondere in den späteren Bischöfen Hartwig, Abt von Tegernsee, Ermenrich von Ellwangen (866-874), ausgebildet in Fulda, der Reichenau und St. Gallen, sowie im Chorbischof Madalwin, dessen Interessen in seiner Bücherschenkung dokumentiert sind. ${ }^{1918}$ Auch die Existenz einer Domschule und

1915 Zur Geschichte Passaus und des Bistums: Egon Boshof, „Die Stadt im Früh- und Hochmittelalter. Unter der Herrschaft der Bischöfe«, in: Geschichte der Stadt Passau, hrsg. von Egon Boshof u. a., 2., erw. u. aktual. Aufl., Regensburg 1999, S. 63-96. Egon Boshof, Die Regesten der Bischöfe von Passau, 1: 731-1206 (Regesten zur bayerischen Geschichte 1, 1), München 1992. Max Heuwieser, Geschichte des Bistums Passau, 1 (Veröffentlichungen des Instituts für Ostbairische Heimatforschung in Passau 24), Passau 1939. Josef Oswald, Das alte Passauer Domkapitel: seine Entwicklung bis zum dreizehnten Jahrhundert und sein Wahlkapitulationswesen (Münchener Studien zur historischen Theologie 10), München 1933. Zu Bildung, Skriptorium und Bibliothek: Bischoff: Schreibschulen 1. S. 1-51, zu Passau speziell S. 2-4. BRUNHÖLZL: Studien. Egon Boshof, "Zum Bibliothekswesen und geistigen Leben in Passau im frühen und hohen Mittelalter.«, in: Passauer Jahrbuch 52 (2010), S. 79-90. Theodor Nolte, "Passau«, in: Schreiborte des deutschen Mittelalters: Skriptorien - Werke - Mäzene, hrsg. von Martin J. Schuber T, Berlin [u. a.] 2013, S. 399-424. Fritz Peter KNAPP, Die Literatur des Früh- und Hochmittelalters in den Bistümern Passau, Salzburg, Brixen und Trient von den Anfängen bis zum Jahre 1273 (Geschichte der Literatur in Österreich 1), Graz 1994. S. 17-50. InEICHEN-Eder/BIschoff (Hrsg.): Mittelalterliche Bibliothekskataloge 4, 1. S. 17-26.

1916 Bischoff: Schreibschulen 1. S. 3. Max Heuwieser, Die Traditionen des Hochstiftes Passau (Quellen und Erörterungen zur bayerischen Geschichte, NF 6), München 1930.

1917 Bosноғ: »Früh- und Hochmittelalter«. S. 69. Bosноғ: »Bibliothekswesen«. S. 79.

$1918 \mathrm{Zu}$ den frühen Bischöfen siehe: August LeIdL, Die Bischöfe von Passau (739-1968) in Kurzbiographien (Neue Veröffentlichungen des Instituts für Ostbairische Heimatforschung der Universität Passau 38), Passau 1978. Zu etwaigen irischen Einflüssen: BRUNHölzL: Studien. passim. Zu Hartwig und Ermenrich: Boshof: Regesten. S. 35f. 
die Anwesenheit einer großen Anzahl von Klerikern lassen eine entsprechende Ausstattung der Dombibliothek erwarten. ${ }^{1919}$

Wie umfangreich auch immer der Bestand der Bibliothek am Ende des Jahrhunderts war, es besteht kein Zweifel, dass sie durch die großzügige Schenkung des Chorbischofs Madalwin ${ }^{1920}$ bedeutend vermehrt wurde. Die Urkunde der Übertragung (8.9.903), worin Madalwin gegen die Nutznießung von Kirchengütern sein persönliches Eigentum nach seinem Tode der Kirche verschreibt, ${ }^{1921}$ ist nicht im Original, sondern nur im Kopialkodex des Bischofs Otto von Lonsdorf $(\dagger 1265)$ erhalten, der auch die Bibliothek seiner Zeit katalogisieren ließ. ${ }^{1922}$ Die Kategorien der Auflistung sind durch ihre Formulierung als auch vielleicht durch die Abschrift undeutlich geworden - es scheinen wenigstens drei Abteilungen zu sein:

1. totum apparatum suum, id est sicut ipse paratus ad missam solitus fuerat stare (S. 25, Z. 36-37), worauf eine Liste von Messutensilien folgt, darunter ein Evangelienplenar und ein Sakramentar.

2. et cetera omnia que ad ipsum ministerium episcopi pertinent (Z. 41-42): Es folgen Bücher von engerem liturgischen und weiterem seelsorgerischen und juristischen Gebrauch.

3. De arte grammatica (S. 27, Z.54-72). Ob diese Kategorie sich bis zum Ende der ursprünglichen Urkunde erstreckte, oder ob eine weitere Unterteilung dieser heterogenen Sammlung angedeutet war, entzieht sich durch die Überlieferungssituation unserer Kenntnis. Auch der mit der Abschrift im Kopialbuch gleichzeitige Katalog unterscheidet nur grob in »die theologischen oder theologisch orientierten Werke und die >libri scolastici «.. ${ }^{1923}$

In der Grammatik-Abteilung findet sich eine große Zahl an poetischen Handschriften, die über den bloßen schulischen Bedarf hinausgehen und ein persönliches Sammelinteresse Madalwins andeuten. ${ }^{1924}$ Der Katalog scheint Spuren

1919 Oswald: Das alte Passauer Domkapitel. S. 5f. Boshof: »Bibliothekswesen«. S. 82.

1920 Über den ansonsten wenig bekannt ist, siehe die wenigen Daten bei: Ludwig Heinrich KRICK, Das ehemalige Domstift Passau und die ehemal. Kollegiatstifte des Bistums Passau. Chronologische Reihenfolge ihrer Mitglieder von der Gründung der Stifte bis zu ihrer Aufhebung, Passau 1922. S. 206.

$1921 \mathrm{Zu}$ ähnlichen Urkunden anderer Passauer Chorbischöfe, ohne Übertragung von Büchern, siehe: Theodor Gоттьов, Der abendländische Chorepiskopat (Kanonistische Studien und Texte 1), Amsterdam 1928. S. 39-41, zu Madalwin kurz S. 44.

1922 Der Katalog: Ineichen-Eder/Bischoff (Hrsg.): Mittelalterliche Bibliothekskataloge 4, 1. S. 25-26, aus dem "Lonsdorfer Codex« f. 124v-125v: Bayerisches Hauptstaatsarchiv, HL Passau 3. Einschätzungen zum Katalog: BoshoF: "Früh- und Hochmittelalter«. S. $69 \mathrm{f}$. Boshof: »Bibliothekswesen«. S. 83f. KnAPP: Die Literatur. S. 42. Glauche: Schullektüre. S. $29 \mathrm{f}$.

1923 Ineichen-Eder/Bischoff (Hrsg.): Mittelalterliche Bibliothekskataloge 4, 1. S. 27.

1924 Ähnlich auch BoshoF: »Früh- und Hochmittelalter«. S. 70. 
der Entwicklung einer schlichten schulischen Sammlung zu einer ansehnlichen Privatbibliothek zu bewahren, zu deren Veranschaulichung folgende Tabelle ein Vorschlag sein soll:

\begin{tabular}{|c|c|c|}
\hline Schulischer Grundbestand & Ergänzung - Dichtung & Ergänzung - weiteres \\
\hline $\begin{array}{l}\text { Donatum minorem et maio- } \\
\text { rem }{ }^{1925} \text { et opus Albini in Do- } \\
\text { natum, }{ }^{1926} \text { gramatica Augus- } \\
\text { tini scilicet vel Ieronimi, quod } \\
\text { fecit Deodato filio Augustini, } \\
\text { opus Bede presbyteri de me- } \\
\text { trica ratione, }{ }^{1927} \text { opus Malii } \\
\text { Teodori }{ }^{1928} \text { de ipsa arte, } \\
\text { opus Boecii de consolatione } \\
\text { Philosophie bene }{ }^{1929} \text { glosa- } \\
\text { tum, } \\
\text { libros Martiani Minei Felicis } \\
\text { Capelle pleniter in VII libera- } \\
\text { les artes, carmen paschale } \\
\text { Sedulii in vetus et novum } \\
\text { testamentum cum prosa ipsi- } \\
\text { us, }{ }^{1930} \text { carmen Aratoris sub- } \\
\text { diaconi in actus apostolorum, } \\
\text { et libri Catonis IIII, et fabule } \\
\text { Aviani, }\end{array}$ & $\begin{array}{l}\text { et Plauti aularia, et formatas } \\
\text { epistolas, }{ }^{1931} \text { et martyrlogium } \\
\text { metro compositum, }{ }^{1932} \text { et } \\
\text { opus Wan[dalberti] dyaconi } \\
\text { in ministerium celebrationis } \\
\text { misse, et explanatio in gene- } \\
\text { sis in uno corpore, }\end{array}$ & $\begin{array}{l}\text { opus Orosii de ratione } \\
\text { anime, opus Cassiodori } \\
\text { oratoris de disputatione } \\
\text { anime, } \\
\text { et opus ipsius de dividui- } \\
\text { tate, id est apoteosis, }\end{array}$ \\
\hline
\end{tabular}

1925 Siehe für weitere Nennungen in Katalogen: Holtz: Donat. S. 338, Anm. 6.

1926 Wilhelm Sснмітz, Alcuins ars grammatica, die lateinische Schulgrammatik der karolingischen Renaissance, Greifswald 1908.

1927 Kendall (Hrsg.): De arte metrica.

1928 Francesca Romanini (Hrsg.), Malli Theodori De metris (Bibliotheca Weidmanniana 6), Hildesheim 2007. Ältere Ausgabe: KeIL (Hrsg.): Grammatici Latini. VI, S. 585-601.

1929 Auch unten wird mit pleniter, plenissimus die Vollständigkeit oder Reichhaltigkeit der Bände betont.

1930 Carmen und Opus Paschale als Opus Geminum (KIRsch: Laudes sanctorum. S. 295).

1931 Durchaus auch ein Schulthema.

1932 Siehe bei Prüm, S. 261. 
(Fortsetzung)

\begin{tabular}{|c|c|c|}
\hline Schulischer Grundbestand & Ergänzung - Dichtung & Ergänzung - weiteres \\
\hline $\begin{array}{l}\text { epigrammata Prosperi, et psi- } \\
\text { chomachia Prudentii, enig- } \\
\text { mata Simphosii et Althelmi } \\
\text { et Ioseppi, et libros bestiarum } \\
\text { Ysidori }^{1933} \text { in uno corpore, }{ }^{1934}\end{array}$ & $\begin{array}{l}\text { decem egloge, et georicon } \\
\text { Virgilii, liber Servii plenissi- } \\
\text { mus in totum Virgjlium, } \\
\text { liber officiorum et martirlo- } \\
\text { gium versibus compositum, } \\
\text { et expositio in genesis. }\end{array}$ & \\
\hline
\end{tabular}

Während über die Zusammenfassung einzelner Titel Diskussionsbedarf besteht, halte ich die grundlegende Trennung zwischen einer schulischen Arbeitsbibliothek, (der "Ausrichtung des Schulbetriebs«), und den "geistigen Interessen ${ }^{1935}$ Madalwins für augenfällig. Die Ergänzungen sind zweierlei Natur: Als sachfremd erscheinen eine Handvoll theologischer Werke, die in die Nähe des ebenfalls solche Themen berührenden Boethius gestellt wurden, ohne jedoch eine Verwendung in der Schule finden zu können. Eine Mittelstellung nehmen die Titel ein, die zwischen Schulpoesie und autonomem Bildungsinteresse stehen: Vergil; auffällig ist, dass die Aeneis nicht genannt ist; ${ }^{1936} \mathrm{zu}$ Vergil der Kommentar des Servius, der seinen Autor hier begleitet wie die Glossen das opus Boecii de consolatione Philosophie bene glosatum; und Ps.-Plautus, ${ }^{1937}$ womit Madalwins Bibliothek den einzigen uns bekannten Band dieses Dichters im Ostfrankenreich enthielt. Zeitgenössische Dichtung ist mit dem Martyrologium Wandalberts vertreten, ${ }^{1938}$ das hier in einem Sammelband mit Erläuterungen zur Messe $^{1939}$ und zur Genesis ${ }^{1940}$ auftritt. Der enge Parallelismus ${ }^{1941}$, in dem dieser

1933 Wohl Buch XII der Etymologiae.

1934 Die vorstehenden Titel könnten durchaus einen Band gebildet haben.

1935 Bosнof: »Früh- und Hochmittelalter«. S. 70.

1936 Sonstige Nennungen in den Katalogen sind oft summarischer über ein volumen oder metrum Vergilii.

1937 Es handelt sich wohl um die spätantike Bearbeitung des Aulularia-Stoffes: BRUnHöLzL/ SpINDler/Kraus: Das alte Bayern. S. 489f., nach BeCKer: Catalogi. Nr. 28. Zur ansonsten ausschließlich westfränkischen Überlieferung: ReYNolDs: Texts and transmission. S. 330332. Handschriften: Gunnar RANstrand (Hrsg.), Querolus sive Aulularia: incerti auctoris comoedia una cum indice verborum (Göteborgs Högskolas årsskrift 1), Göteborg 1951. S. III.

1938 DümmLer (Hrsg.): MGH Poet. lat. 2. S. 567-622. Zur Identifikation des »Wan« der Handschrift siehe: Max MANitius, "Geschichtliches aus mittelalterlichen Bibliothekskatalogen«, in: Neues Archiv der Gesellschaft für ältere deutsche Geschichtskunde 32 (1907), S. 647-709. S. 676, sowie: Manitius: Geschichte, 1. S. 560.

1939 Von einem etwaigen Werk Wandalberts ist nichts erhalten. 
Eintrag mit dem letzten des Katalogs steht, weist auf ein Duplikat hin, sodass die Bibliothek wahrscheinlich zwei Exemplare dieser Sammelhandschrift enthielt. Warum, ist unklar - ob vielleicht die Pflichten eines Chorbischofs zwei solcher Bände nötig machten, halte ich angesichts dessen, dass andere praktische Bücher in nur einem Exemplar vorliegen, für unwahrscheinlich. Die Verbindung mit der Erläuterung der Messe steht im Gegensatz zur sonstigen Überlieferung des Martyrologs, ${ }^{1942}$ das sonst unter anderer Dichtung oder im Zusammenhang mit komputistischen Texten vorkommt.

Die Bücher Madalwins stellen die Handbibliothek des Chorbischofs dar, die er über längere Zeit angesammelt haben muss. Aus der Sammlung betreffen wohl nur die liturgischen Titel seine Pflichten als Chorbischof. Für schulische Aufgaben dieses Amtes gibt es keine Hinweise. ${ }^{1943}$ Es ist wahrscheinlicher, dass Madalwin vorher in Passau als Lehrer tätig war und die Bücher seiner Sammlung gleichzeitig als Schulbibliothek dienten. Ein ähnlicher »Privatbesitz« der Schulbibliothek bei gleichzeitiger gemeinschaftlicher Nutzung ist aus Laon bekannt, wo die Schulbücher von einem Lehrer zum nächsten vererbt wurden, ehe sie in den unmittelbaren Besitz des Klosters gelangten. ${ }^{1944}$ Die "Privatbibliothek" Madalwins wäre somit nichts anderes als die Schulbibliothek Passaus, die nichtsdestotrotz eigentumsrechtlich von der Hauptbibliothek getrennt war, wie aus der Urkunde Madalwins geschlossen werden kann.

Das Thema schulischer Handschriften in Passau kann anhand von zwei erhaltenen Kodizes vertieft werden, die zusammen mit dem Traditionskodex die letzten Zeugen des bischöflichen Skriptoriums sind. ${ }^{1945}$ Bei beiden Handschriften ist zu beachten, dass sie nicht paläographisch, sondern jeweils nur durch den Eintrag einer Passauer Urkunde dort verortet werden. ${ }^{1946}$

1940 Wobei es sich vielleicht um Wandalberts Versifikation des Hexamerons handeln könnte (DÜMMLER (Hrsg.): MGH Poet. lat. 2. S. 619-622).

1941 Der erste Eintrag: martyrlogium metro compositum, et opus Wan(dalberti) dyaconi in ministerium celebrationis misse, et explanatio in genesis in uno corpore; der zweite: liber officiorum et martirlogium versibus compositum, et expositio in genesis.

1942 Cod. Sang. 250 (Komputistik); Vatikan, Reg.lat.438 (Martyrologium).

1943 Gоттьов: Der abendländische Chorepiskopat. S. 23-75, kann eine schulische Tätigkeit der Chorbischöfe nicht feststellen, wenn auch seine Untersuchung sich oft nur auf die Aufzählung der Chorbischöfe beschränkt. Die Rolle in der Mission betont Hieronymus Frank, Die Klosterbischöfe des Frankenreiches (Beiträge zur Geschichte des alten Mönchtums und des Benediktinerordens 17), Münster 1932. S. 148-162.

1944 Contreni: The cathedral school of Laon. S. 152. John Joseph Contreni, "Le formulaire de Laon, source pour l'histoire de l'école de Laon au début du Xe siècle«, in: Scriptorium 27 (1973), S. 21-29. S. 931. John Joseph Contreni, "The Formation of Laon's Cathedral Library in the Ninth Century «, in: Carolingian learning, masters and manuscripts (Variorum collected studies series 363), Aldershot 1992, S. 919-939, 6-7. S. 927-933.

1945 Eine kurze Würdigung der beiden bei: Nolte: »Passau«. S. $407 \mathrm{f}$.

1946 Clm 6411: Steinmeyer/Sievers (Hrsg.): Die althochdeutschen Glossen. 5, S. 527. Clm 19410: BosHof: Regesten. S. 35. 
Die grammatisch-metrische Sammelhandschrift Clm $6411^{1947}$ vereint in zwei Teilen eine Vielzahl von Lehrtexten, zwischen die sich auf Freiräumen und eingesetzten Blättern eine Vielzahl kleiner Texte gesellt, darunter eine kleine Zahl Gedichte, die hier durch die Textgemeinschaft in die Nähe der Schule gerückt werden. Während der Schriftcharakter der Handschrift durchaus festländisch ist, lassen Gestaltung und Textauswahl einen »ein[en] starke[n] insulare[n], speziell irische[n] Einfluß« erkennen. ${ }^{1948}$ Die grobe Gestalt der Schrift lässt an eine Schülerarbeit denken. ${ }^{1949}$ Im ersten Teil, f.1-67, findet sich unter anderem f. 20v-23v eine kurze Kompilation De pedibus et metris, die aus Isidor und Plotius Sacerdos zusammengesetzt ist; der Rest der Texte behandelt Elementargrammatik. Auf der Rückseite des der dritten Lage vorgesetzten Blattes mit den Kapiteln Isidors (f. 24v) sind neben andere kleine Stücke auch zwei metrische Palindrome ${ }^{1950}$ geschrieben worden - die ganze Seite ähnelt einem vollgekritzelten Notizzettel, ${ }^{1951}$ mit improvisierten Trennlinien zur Scheidung der dichten Texteinheiten. Ein ähnliches Textgemisch findet sich auf dem »im späteren IX Jh. eingelegt[en] « Trinio f. 42-45. ${ }^{1952}$ Ankertext des Heftes ist der auf f. 24 in regelmäßiger Größe geschriebene Auszug aus Sedulius Scottus' (?) Kommentar zur f. 1-20 enthaltenen Grammatik des Eutyches. ${ }^{1953}$ Die folgenden kürzeren Texte sind alle in außerordentlich kleiner Hand geschrieben: Ein Glossar aus Eutyches, Maße, Gewichte, ein Auszug aus Martianus Capella und Weiteres, alles unter maximaler Platzausnutzung in verschiedenen Stadien geschrieben. ${ }^{1954}$ f. 43 a und f. 45 sind fernerhin, wohl zur anderweitigen Verwendung des Pergaments, vor der Beschreibung beschnitten worden, sodass nur dünne Streifen den Text tragen. Vom notorischen Kuriosum des Verses $O$ Tite tute Tati abgesehen ist hier nur noch ein Gedicht zu bemerken, auf f. 44r von diesem durch einen Trennhaken

1947 Kataloge: Glauche: Pergamenthandschriften Freising. S. 216-223. Bergmann/Stricker: Katalog. Nr. 539. Zu den Glossen: Steinmeyer/Sievers (Hrsg.): Die althochdeutschen Glossen. 5, S. 527-529. Zum Schriftcharakter: Bischoff: Schreibschulen 1. S. 150. Umfassende Würdigung: Brunhölzl: Studien. S. 5-28.

1948 Bischoff: Schreibschulen 1. S. 150. Zu den Initialen: Brunhölzl: Studien. S. $11 \mathrm{f}$, zu insularen Textgestalt: S. 12-15.

1949 BRUnhölzL: Studien. S. 6.

1950 SK 14361, 14364. BischofF: »Anecdota Carolina«. S. 10.

1951 Darunter eine mythische Notiz zum Ursprung der Iren, vgl. John Joseph ConTreni, »The Egyptian Origins of the Irish: Two Ninth-Century Notes", in: Carolingian learning, masters and manuscripts (Variorum collected studies series 363), Aldershot 1992, S. XVII: 51-54, 7.

1952 Bischoff: Schreibschulen 1. S. 150. Die Lage nach Glauche: Pergamenthandschriften Freising. S. 216.

$1953 \mathrm{Zu}$ diesem Text: BrunhöLzL: Studien. S. 15f.

1954 Erkenntlich an Wechseln des Schriftbildes; ein Handwechsel ab f. 44v, unterer Rand - f. 45v (Glauche: Pergamenthandschriften Freising. S. 221). 
abgesetzt: Der Rhythmus: O cara anima. ${ }^{1955}$ Es handelt sich um das Abschiedsgedicht eines Ingilpreht, wahrscheinlich an eine Frau. Der ursprüngliche Entstehungszusammenhang - vielleicht ein tief empfundenes Gedicht eines Lehrers an seine Schülerin ${ }^{1956}$ - ist in dieser Handschrift sicher unwiederbringlich verschüttet, sodass ich hier über Ingilpreht und seine amica keine weiteren Spekulationen anstellen möchte. Der Ort der Überlieferung, eine grammatische Sammelhandschrift, ist jedoch kein so ungewöhnlicher, wie Brunhölzl nahelegt; in der Tat befindet sich auch in der anschließend von ihm untersuchten Passauer Handschrift Clm 19410 ein Abschiedsgedicht Alkuins. ${ }^{1957}$ Gedichte dieser Art finden also, unabhängig von ihrer Entstehung, leicht ihren Weg in den Unterricht. Der zweite Teil der Handschrift, f. 68-96, enthält die Ars Metrica des Cruindmelus, dessen poetische Bestandteile dem Text integral und keine späteren Zusätze sind. ${ }^{1958}$ Die beiden Teile scheinen schon vereint worden zu sein, bevor sie in ihre spätere Bibliotheksheimat Freising gelangten. ${ }^{1959}$ Die Gedichte stehen in drei verschiedenen kodikologischen Umfeldern: f. 24v als Zusatz auf freiem Raum in Teil 1; f. 44r als Bestandteil eines später eingefügten "Notizbuches«; und die Cruindmelus-Gedichte als Teil der Vorlage in Teil 2. Dementsprechend ist die Handschrift gleich dreifacher Beweis für eine schulische Verwendung von Dichtung in Passau. Den persönlichsten Zugang zur Schultätigkeit finden wir nicht in den genannten Personen und Lehrern - die Texte können ortsfremd sein - sondern in dem eingefügten »Notizbuch«f. 42-45, das, indem es einen Text aus Teil 1 kommentiert und mit weiterem schulischen Material gefüllt ist, direkte Verwendung im Unterricht gefunden haben mag, bevor es in die Handschrift gebunden wurde. Brunhölzl legt die Handschrift in die Hände eines Lehrers, der zeitweilig auch als Notar des Bischofs fungierte, da er auf f. 1r eine

1955 SK 10830. Franz BRUnhölzL, "»O cara anima.く Ein frühkarolingischer Rhythmus«, in: Mittellateinisches Jahrbuch 38 (2003), S. 19-29. Ältere Ausgabe: Guido Maria Dreves und Clemens Blume (Hrsg.), Analecta hymnica medii aevi, Leipzig [u.a.] 1886. 46, S. $219 \mathrm{f}$.

1956 Wie BrunhölzL, S. 25-27, in Anlehnung an Paulus Diaconus, carm. 2, und in Anbetracht des vielleicht verstümmelten Akrostichon OIRM[GARD?]INGILPREHT vermutet. Warum diese Schülerin nun auch noch »fürstlich« sein soll (S. 27), kann ich nicht nachvollziehen; unsicher ist ebenso, ob Ingilpreht Lehrer in Passau war.

1957 Das Genre »Schüler-Lehrer-Korrespondenz« ist häufiger Bestandteil der zeitgenössischen Anthologien, vgl. S. 67f. zu Einsiedeln, StB, Cod. 326(1076), S. 283-290 zu ÖNB Cod. 1609, S. 267-272 zu ÖNB Cod. 808.

1958 Johann Huemer, Cruindmeli sive Fulcharii Ars metrica: Beitrag zur Geschichte der karolingischen Gelehrsamkeit, Wien 1883. Die Gedichte: DüMmLER (Hrsg.): MGH Poet. lat. 2. S. 681. Die Verse auf f. 82v, die wegen der Versetzung der Texteinheiten ursprünglich am Anfang der Ars standen, sind aus der Vorlage kopiert, und die genannten Lehrer Folchard und Sidonius nicht unbedingt, wie BRunhöLZL: Studien. S. 17 vermutet, Lehrer aus Passau.

1959 BRUnHöLzL: Studien. S. 6 f. aufgrund der verzierten zweiten Reklamantenreihe zur Unterscheidung der gleichnamigen Lagen durch den Buchbinder (A, B, C, D, 'A', 'B', 'C', 'D' etc.). 
bischöfliche Urkunde eintrug und somit Zugang zum Archiv gehabt habe. Wiewohl der Schreiber der Urkunde ein anderer als der des schulischen Materials auf f. 43-44 zu sein scheint, sind doch in diesem Zusammenhang die ausgeschnittenen Stücke der Blätter f. 43a und f. 45 bemerkenswert, die das Format eines Briefes oder einer kleinen Urkunde haben, also vielleicht ein weiterer Hinweis sind auf die notariellen Pflichten des Lehrers, dem das Heft gehörte.

Eine weitere Handschrift ist durch einen nachgetragenen Passauer Bischofsbrief in die Nähe der Kathedrale gerückt, Clm 19410. ${ }^{1960}$ Weitere Hinweise auf eine Passauer Herkunft ergeben sich aus internen Indizien der enthaltenen Formelsammlung der Collectio Pataviensis. ${ }^{1961}$ Laut Bischoff ist die Handschrift überwiegend von einem Schreiber verfasst worden. ${ }^{1962}$ Starke Schwankungen in Größe und Gesamterscheinung des Schriftbildes jedoch machen zumindest eine langsame Ansammlung der Texte, vielleicht auch eine Vielzahl von Schreibern wahrscheinlich. ${ }^{1963}$ Der Inhalt der Handschrift ist vielfältiger und schwerer einzuordnen als der klar grammatisch-metrisch orientierte Inhalt von Clm 6411. Den ersten Teil (p. 1-38) nimmt eine Sammlung katechetischer und pädagogischer Texte elementaren Niveaus ein. Der größere Teil ist eine Sammlung von Fragen und Antworten; bemerkenswert darunter ist eine Sammlung zur Trinität von höherem Niveau als der Rest der Interrogationes, ${ }^{1964}$ die von Brunhölzl als ein

1960 Lagenformel nach eigener Einsicht (paginiert): Vorsatzblatt $+\mathrm{V}^{20}+\mathrm{III}^{32}+\mathrm{III}^{44}+\mathrm{IV}^{60}+\mathrm{II}^{68}$. Karl HaLm, Catalogus codicum latinorum (Clm 15121-21313) (Catalogus codicum manu scriptorum Bibliothecae Monacensis 4/3), München 1878. Bergmann/Stricker: Katalog. Nr. 660. BISCHOFF: Schreibschulen 2. S. 163f. Rio: Legal practice. S. 248f. BRUNHöLZL: Studien. Gretsch/Gneuss: »Theodorean Poem». S. 17; Bergmann/Stricker: Katalog. Nr. 660.

1961 Zeumer (Hrsg.): MGH Formulae. S. 456-460. Zuvor von Rockinger als »Epistolae Alati« herausgegeben (Rockinger (Hrsg.): Drei Formelsammlungen. S. 171-185). Der Titel stammt aus dem spätmittelalterlichen Inhaltseintrag auf dem Vorsatzblatt der Handschrift.

$1962 »(. .$.$) das meiste von einer Hand, deren Größe und Sorgfalt nicht in allen Stücken die$ gleiche ist." BIschoff: Schreibschulen 1. S. 2f., $163 \mathrm{f}$.

1963 Nach eigener Einsicht in die Handschrift ließen sich höchstens 17 verschiedene Stadien unterscheiden, inklusive der klar aus anderen Skriptorien stammenden Ergänzungen.

1964 Ed. BrunhölzL: Studien. S. 52-53. Interpretation S. 41-45. Kritisch zu Brunhölzls Einschätzung: Alexander ORTH, Die sententiae deflorate de diversis causis - Untersuchung eines frühmittelalterlichen Florilegiums samt kritischer Edition und Übersetzung, MAArbeit, Universität Hamburg 2017. S. 44f., 55. Javier SoAGE, »The Mediaeval Question-andAnswer Collection sententiae de floratibus diuersis: Standard and Non-Standard Versions", in: Sacris erudiri 55 (2016), S. 321-366. S. 353. Die restlichen Fragen und Antworten fallen in den Kreis der verbreiteten Ioca Monachorum: Text von Clm 19410 vollständig ediert bei: BRUnHölzL: Studien. S. 54-62; clm 19410 pp. 13-19 (Brunhölzlz \$\$ 71-135) ediert als Kodex F im Rahmen der Rezension $\mathrm{JM}_{1}$ der Ioca Monachorum bei: Suchier: Adrian und Epictitus. S. 114-119, dort auch S. 83f. zu Ursprung und Vielgestalt des Textes. Neuere Editionen auf Basis anderer Handschriften: Charles D. WRIGHT, "Additions to the Bobbio Missal: >De dies malus and Joca monachorum ( fols. $6 r-8 v$ ) «, in: The Bobbio Missal. Liturgy and Religious Culture in Merovingian Gaul, hrsg. von Yitzhak Hen und Rob MeEns 
Konversenkatechismus der Mission im Donauraum gedeutet wurde. Es folgt pp. 24-39 eine bunte Mischung aus Glossaren, patristischen Exzerpten und weiteren Kuriosa. Hierauf folgt, in paläographischem Verbund mit allem Vorherigen und somit wahrscheinlich mit diesem aus einer Vorlage kopiert, das Carmen ad Deum. ${ }^{1965}$ Auf dem Kontinent wurde das Gedicht hauptsächlich durch Einbindung in Alkuins Enchiridion verbreitet, ${ }^{1966}$ das an Arn von Salzburg gerichtet war. ${ }^{1967}$ Die Handschriften der Enchiridion-Tradition präsentieren das Gedicht ohne Übersetzung sowie in Einzelzeilen für die Verse (gegen kontinuierliche Schreibweise in Clm 19410). ${ }^{1968}$ Das Carmen in Clm 19410 unterscheidet ebenfalls sich in Text ${ }^{1969}$ und Präsentation vom Konsens der anderen Textzeugen, sodass eine Überlieferung via Enchiridion ausgeschlossen scheint. Schon das lateinische Gedicht steht der Schule nahe, indem es als "glossematischer» Text möglichst viele rare Vokabeln, insbesondere aus Vergil, gebraucht. ${ }^{1970}$ Die Übersetzung, eines der ältesten deutschen Sprachzeugnisse im alt-bayerischen Dialekt, ist eine simple Wort-für-Wort-Übersetzung nach Art einer Glossierung $^{1971}$, die durch das schwierige Latein ${ }^{1972}$ nötig gemacht wurde. Die Überset-

(Cambridge studies in palaeography and codicology 11), Cambridge 2004, S. 79-139. François Ploton-NicolLET, »Ioca monachorum et pseudo Interpretatio sancti Augustini «, in: Archives d'histoire doctrinale et littéraire du moyen âge 74 (2007), S. 109-159.

1965 SK 14640. Vielfach ediert, die neuesten Ausgaben sind: Auf Basis von Cambridge University Library, MS Ll. 1. 10 (Book of Cerne) in: Gretsch/Gneuss: »Theodorean Poem». Sehr übersichtlich und mit Kommentar in: Hellgardt: »Reimgebet«. Darin auch umfassend zur Editionsgeschichte. Zu Verfasser und Entstehung: LAPIDGE: "Octosyllabic Verse«. Davor eingehend: Georg BAESECKE, Das lateinisch-althochdeutsche Reimgebet (Carmen ad deum) und das Rätsel vom Vogel Federlos (Probleme der Wissenschaft in Vergangenheit und Gegenwart 1), Berlin 1948.

1966 Er zitierte es ebenfalls in: MGH Poetae 4,2.3, S. 904, I, 1. Vgl. Fravventura (Hrsg.): Enchiridion in Psalmos. S. 28-56.

1967 Dort wahrscheinlich unter alias orationes; Der Widmungsbrief an Arn: MGH, Epp. 4, no. 259, S. 417. Siehe zum Enchiridion S. 222 zu Köln, Ms. 106.

1968 Sonderüberlieferung in: (A) Cambridge University Library, MS Ll. 1. 10 (Book of Cerne), s. IX, f. 66-66v innerhalb einer Sammlung von Gebeten und Hymnen (f. 43r-87v). Enchiridion-Tradition: (B) Köln, Dombibliothek Cod. 106, s. IX, f. 59 v. Alkuin: Enchiridion; (C) Clm 14447, s. IX, f. 141-141v. Alkuin: Enchiridion; (D) Karlsruhe Aug. Perg. 135, s. IX, f. 159-160. Alkuin: Enchiridion. Liste der mss. in: Gretsch/Gneuss: »Theodorean Poem». S. 9-11. Als spätere Zeugen hier nicht berücksichtigt: Cambridge University Library Gg. 5. 35, Wien, ÖNB Cod. 11857. Ebenfalls nicht aufgeführt ist BNF Lat. 8779, Lexicon Tironianum, mit einem Text, der durch zahlreiche Varianten von der Hauptüberlieferung getrennt ist. Für alle Enchiridion-Handschriften siehe Fravventura (Hrsg.): Enchiridion in Psalmos.

196912 lat. Varianten gegen den Konsens BCD.

1970 Anton Emanuel SCHÖNBACH, »Über das >Carmen ad Deum«", in: Zeitschrift für deutsches Altertum und deutsche Literatur 42 (1898), S. 113-120. S. 117-119.

1971 Auch in der Textgestaltung ähnelt es den Glossaren der Handschrift.

1972 Viele der seltenen Worte sind selbst wiederum nur aus Glossaren belegt, siehe: SснӧNвасн: »Carmen ad Deum«. S. 118f. Zur Gattung: Georg GöтZ, »Über Dunkel- und Ge- 
zung wurde nicht erst für diese Handschrift angefertigt, da sie an zwei Stellen korrekte Lesarten des lat. Textes bewahrt, die hier korrumpiert worden sind. ${ }^{1973}$ An zwei Stellen ist der lateinische Text des Carmen gegenüber dem Konsens der übrigen Textzeugen auf markante Weise verändert und bewahrt Indizien einer lateinischen Glossierung. ${ }^{1974}$ Die Übersetzung scheint bisweilen eher von einer Glosse, als vom lat. Text auszugehen. Das Vorliegen seltener althochdeutscher Wörter in der Übersetzung, die morphologisch zu geläufigeren altenglischen passen, deutet auf die Entlehnung der althochdeutschen Wörter aus einer altenglischen Glossierung. ${ }^{1975} \mathrm{Ob}$ diese lateinischen und altenglischen Glossen schon in England oder erst auf dem Kontinent, vielleicht sogar in Passau selbst, vorgenommen wurden, lässt sich nicht feststellen. Die Indizien einer vorhergehenden Glossierung distanzieren jedoch das Carmen und die Handschrift weiter von der ansonstigen kontinentalen Überlieferung im Enchiridion. Am wahrscheinlichsten ist eine Sonderüberlieferung in der Reisebibliothek eines (vielleicht irischen oder angelsächsischen) Gelehrten.

Auf das Carmen folgt, anscheinend von anderer Hand, zumindest kleiner geschrieben als das Vorhergehende, die Formelsammlung der Collectio Pataviensis. Direkt an diese schließt sich, wenn auch vielleicht von anderer Hand geschrieben, auf pp. 51-57 eine Sammlung von Gedichten und Epitaphien. Gleich das erste Gedicht betont den engen Zusammenhang mit der Formelsammlung. Es ist ein aus Gedichten Alkuins (und Eugenius von Toledos) zusammengesetztes, anonymisiertes Gedicht-Formular, ${ }^{1976}$ das mehrere Briefschlüsse zu einem als Text unsinnigen Ganzen vereint. Die Ikten weisen auf einen pädagogischen Charakter des Werks hin. Die Zusammensetzung ist wie folgt:

- 55, 1; Verse 11-12 Te deus aeterno conseruet tempore semper/ tu memor Albini semper ubique uale ausgelassen; siehe auch unten S. 313 zur Parallelüberlieferung.

- 55, 2 nur hier erhalten.

- Eugenius von Toledo, Carmen II, vss. 3-6 + 13-14 (Ende).

- 55,3 = 52, vss. 19-24 (Schluss); Änderung: 52, 20: sis memor Albini ut semper amici tui 55, 3: sis memor [rogo $]^{1977}$ mei ut semper amice tui.

heimsprachen im späten und mittelalterlichen Latein«, in: Berichte der sächsischen Gesellschaft der Wissenschaften Leipzig 48 (1896), S. 62-92.

1973 Z. 11 caeliarche (korr. caeli arce) durch himiles nolle, Z. 20 collis (korr. costis) durch rippeo.

1974 Siehe für die verschiedenen Glossierungsschichten: Gretsch/Gneuss: »Theodorean Poem«. S. 21-32.

1975 Z. 2 ahd. kepo > ae. gifa; Z. 7 cheol > ceol; Z. 12 scozila > scytel; Z. 14 fornimu > forniman; Z. 16 rantbouc > rantbogo. Caveats ebd. S. 29.

1976 SK 3980, 11004, 7223, 1984; Aus der Handschrift in: MGH Poetae I, Alkuin: 55, 1-4; zw. 3 und 4 Eugenius Carmen II »Commonitio Mortalitatis Humanae« Vollmer (Hrsg.): Eugenii Toletani episcopi carmina et epistulae. S. 233 (SK 10951).

1977 add. Zeumer. 
- 55,4 vss. $1-2=20$, vss. $43-45 ; 55,4$ vss. $3-6$ wahrscheinlich Fragment eines verlorenen Gedichtes.

Die Gestaltung des Gedichtes als Formel setzt es von den folgenden Tituli ab und rückt es in die Nähe der vorhergehenden Formulae.

Die Tituli ${ }^{1978}$ (pp. 53-54) zu verschiedenen Räumlichkeiten sind durch Zeilenabstände voneinander sowie von der vorhergehenden lyrischen Briefformel und den folgenden Epitaphien getrennt. Sie sind Sondergut von Clm 19410. Die Assoziation zu Alkuin liegt nur durch die vorhergehenden Gedichte vor. Jedoch ist eine Urheberschaft Alkuins, der eine Vielzahl von tituli verfasste, nicht unwahrscheinlich. ${ }^{1979}$ Auf pp. 54-56 findet sich, thematisch passend, eine kleine Sylloge stadtrömischer Inschriften. ${ }^{1980}$ Diese sind wieder ohne Leerzeilen geschrieben ${ }^{1981}$ und erinnern insofern an die lyrische Formel aus Alkuin-Gedichten. Parallelüberlieferungen liegen vor und Clm 19410 bietet oft nur einen fragmentarischen Text. ${ }^{1982}$ Die Sylloge schließt mit dem Widmungsgedicht p.56:

Beda d[e] famulus scripsi uersusq[ue] notaui|

pro quisque; qui legit obsecro funde p[re]ces,

das auf Bedas verlorenes Liber Epigrammatum ${ }^{1983}$ im Speziellen und auf eine insulare Verbindung im Allgemeinen hindeutet. Weitere insulare Parallelen liegen vor: No. 11 ist ebenfalls in der Sylloge von Urbana vorhanden. ${ }^{1984}$ Das folgende kleine Prosaflorileg gibt seinen Charakter nur durch genaues Augenmerk auf die fehlende Metrik zu erkennen: Der Text ist in abgesetzten Linien geschrieben und fügt sich somit in die Anthologie ein. Zeilen 4 und 5 sind - wie die Zeilen der folgenden Gedichte - mit Autorensiglen - hier ag (wohl für Augustinus) - versehen. Die Anthologie wird abgeschlossen durch zwei Gedichte (pp. 56-57), die traditionell Hieronymus und Damasus zugeschrieben werden. ${ }^{1985}$ Die beiden Stücke, die für gewöhnlich zu den einleitenden Stücken eines Psalters gehören, stehen hier zu einem verbunden. Der angebliche Wechselgesang ist durch die Siglen $\mathrm{h} \& \mathrm{~d}$ angegeben. Hier endet die Anthologie, aber nicht die

1978 SK 6949, 7299, 1175, 5391, 5997; MGH Poetae I, Alkuin: 55, 5-9; 55, 10 ist das erste der Epitaphien, als solches von Rossi (s.u.) erkannt.

1979 Zu Alkuins Epigrammatik: BernT: Epigramm. S. 194-215.

1980 SK 9571, 428, 9183, 13027, 7704, 14746, 8822; DE Rossi: ICUR. II, S. 286.

1981 Jedoch no. 8 durch Majuskel-Æ, no. 9 durch leichten Zeileneinschub gesondert.

1982 DE Rossi: ICUR. a.a.O Anm. 7 und 9-12.

1983 Siehe zur Verbindung mit Beda: Sims-Williams: "Milred of Worcester's collection«. S. $37 \mathrm{f}$. BERNT: Epigramm. S. 164-172.

1984 Wallach: "The Urbana Anglo-Saxon Sylloge». Nähere Beziehungen zu Clm 19410: SCHALLER: "Sylloge von Urbana«. S. 16-17.

1985 SK 12730, 10728. John J. MACHIELSEN, Clavis patristica pseudepigraphorum medii aevi (CCSL), Turnhout 1990. II A, nos. 585, 595, 929. 
Arbeit des Schreibers. Bis p. 60 füllt er den Rest der vorletzten Lage mit einem dichten Netz aus Glossaren und mehreren Alphabeten.

Das folgende Binio, die letzte Lage der Handschrift und von anderen Händen als denen des Hauptteils geschrieben, ist vielleicht erst später zur Handschrift hinzugefügt worden. Nichtsdestotrotz wurde auch hier, thematisch zur Handschrift passend, einiges an Dichtung ergänzt. Auf pp. 65-66 finden sich drei Epitaphien:

- p. 65 Epitaph für Eio von Ilmmünster. ${ }^{1986}$ Gerühmt wird besonders die Translation der Reliquien des Arsatius ${ }^{1987}$ nach Ilmmünster. Das Epitaph ist vielleicht ein späterer Nachtrag von dort.

- p. 66 Epitaph für Riculf von Mainz. ${ }^{1988}$ Das ebenfalls in Wolfenbütteler und Pariser Handschriften ${ }^{1989}$ erhaltene Epitaph ist hier formularisiert, ille für Riculf in Z. 5 und 12.

- p. 66 Epitaph für Rhothroc. ${ }^{1990}$ Diese beiden Epitaphien stammen vielleicht noch aus Passau.

Insbesondere das Epitaph für Riculf verweist, indem es formularisiert wurde, auf den engen Zusammenhang zu den Formulae allgemein und dem Formelgedicht Alkuins, sodass die Ergänzungen vielleicht nicht in Passau geschrieben worden sind, jedoch den Geist der Passauer Sammlung widerspiegeln.

Die vielfältigen Inhalte von Clm 19410 widerstreben einer direkten Einordnung in die Schule. Es fehlt zum Beispiel strikt grammatisches Material und auch die Glossare geben oft ein Lexikon wieder, dass im Elementarunterricht zu anspruchsvoll gewesen wäre. Die Handschrift hat vielmehr unterschiedliche pragmatische Stufen, die in verschiedenen Verwendungsszenarios zum Einsatz kommen könnten. Der Dichtung scheint hier hauptsächlich die Funktion von Vorlagen zuzukommen, wie am deutlichsten im Alkuin-Gedicht zu sehen ist. Die Gedichte können, wie beim Carmen ad Deum, durch ihre Glossierung als fortgeschrittene Übungen im Unterricht verwendet worden sein, oder, wie die Tituli, als Vorlagen für eigene Werke, wobei Alkuin und römische Titel als exemplarisch gelten. Das Buch lag wohl in der Hand eines gebildeten Klerikers, der in seinen verschiedenen Aufgaben verschiedene Hilfen von seinem Handbuch erwartete. Die Inhalte der Handschrift spiegeln auch die kulturellen Einflüsse wider, die auf

1986 SK 10246, MGH Poetae 6, 1, S. 156f., dort auch zur Person Eios.

1987 Germain Morin, "Qui est saint Arsacius honoré à Milan et en Bavière», in: Studien und Mitteilungen zur Geschichte des Benediktinerordens und seiner Zweige 54 (1936), S. 1-6.

1988 SK 16108, MGH Poetae I, S. 432; Riculf war Erzbischof von Mainz (nicht Reims wie bei Rio a. a. O.) bis 813. Stephanie HAARLÄNDER, "Art. Ric(h)ulf(auch Richolf, Flavius Damoetas), Erzbischof von Mainz (seit 787), + 9.8.813.«, in: NDB, 21, 2003, S. 554-555.

1989 Weißenburg 91: Butzmann: Die Weißenburger Handschriften.

1990 SK 6483, MGH Poetae 4,2,3, S. 1035, Anm. dort zur Person. 
Passau vom 8. bis in die Mitte des 9. Jh. gewirkt haben. Älteres insulares Bildungsgut, darunter das Carmen ad Deum, bildet auch in der Karolingerzeit einen dauerhaften Bestandteil des Curriculums. Der zentral-fränkische Einfluss nach Eingliederung Bayerns in den Reichsverband zeigt sich durch die Integration und schöpferische Umgestaltung der Alkuin-Gedichte, für deren Verbreitung Arn von Salzburg verantwortlich war. ${ }^{1991}$ Die enge Verbindung der Alkuin zugeschriebenen Tituli mit dem älteren insularen Bildungsgut der vielleicht von Beda gesammelten Epitaphien verdeutlicht diese Synthese.

Im Rückblick auf die Dichtung in Passau zeigt sich die enge Bindung derselben an die Schule. Madalwins Bibliothek zeigt einen klaren Grundbestand an schulischen Werken, die die Vermutung aufkommen lassen, dass er selbst als Lehrer tätig war oder die Schule unter seiner Aufsicht stand. In der Tat ist der wahrscheinlichste Gebrauch der beiden erhaltenen Handschriften eben bei Personen wie dem Chorbischof Madalwin zu suchen, die neben der Schule (Clm 6411) auch mit der Abfassung von Urkunden (Collectio Patavensis) oder mit dem Ausschmuck von Gebäuden (Tituli) betraut war, ohne dabei seine eigenen geistigen Interessen zu vernachlässigen. So zeigt uns Passau trotz der schweren Verluste, die ein sicheres Urteil erschweren, in seinen erhaltenen Denkmalen ein lebendiges Bild der damaligen Verwendung von Dichtung im Unterricht und darüber hinaus.

1991 Siehe unter Salzburg, S. 267-272. 
Open-Access-Publikation im Sinne der CC-Lizenz BY 4.0

(c) 2021, Vandenhoeck \& Ruprecht GmbH \& Co. KG, Göttingen ISBN Print: 9783847112310 - ISBN E-Lib: 9783737012317 


\section{Analysen und Ergebnisse}

\section{III.1 Herkunft der Texte}

\section{III.1.a Westfrankenreich und andere Regionen}

Viele der hier behandelten Handschriften stehen am Anfang der Überlieferung und die Verbindung mit ihren Vorlagen bleibt oft im Dunkeln. Zudem sind viele Werke schon am Ende des 8. Jahrhunderts fest im Frankenreich etabliert, sodass zu einer Suche nach Handschriften in entlegenen Gegenden oft kein Anlass mehr bestand. Die Herkunft der Texte ist gerade bei den verbreitetsten Werken in der Umgebung des Skriptoriums und nicht selten in der eigenen Bibliothek zu suchen. Länder, die für die frühere Überlieferung bedeutend gewesen sind und außerhalb oder an den Grenzen des fränkischen Reiches lagen, treten in ihrer Bedeutung gegenüber der internen Zirkulation von Texten zurück.

Der insulare Einfluss, den im Ostfrankenreich Gründer wie Bonifatius oder Gelehrte wie Virgil von Salzburg verkörperten, findet auch in den Handschriften allenthalben ein Echo, am augenfälligsten in der Gestaltung, wobei jedoch ein insularer Stil der frühen Skriptorien, wie in Mainz oder Fulda, keinesfalls auch eine entsprechende Herkunft der Vorlagen impliziert. ${ }^{1992}$ Die Bücher der frühen Bibliotheken, oft noch unter starkem insularen Einfluss oder geradezu ursprünglich eine Privatbibliothek der Gründer, ${ }^{1993}$ gingen im 9. Jahrhundert in der Flut der neuen, modernen Handschriften unter, ob durch lange Nutzung abgenutzt oder durch ihre altertümliche Schrift außer Gebrauch gefallen. Natürlicherweise wurzelt die Überlieferung der insularen Schriftsteller selbst am häufigsten in ihrer Heimat. In den Handschriften Bedas, ${ }^{1994}$ Aldhelms, ${ }^{1995}$ sowie der weiteren Rätselliteratur finden sich häufiger als anderswo insulare Spuren.

1992 Vgl. Basel, O IV 17; Würzburg, M.p.th.f. 21; Wien, Cod. 969.

1993 Vgl. die Erwägungen hierzu bei Pirmin (Reichenau, S. 153f.) und Bonifatius (Fulda und Mainz, S. 57, 42).

1994 Michael LAPIDGe, "Beda Venerabilis«, in: La trasmissione dei testi latini del Medioevo, 3, hrsg. von Paolo Chiesa und Lucia Castaldi 2008, S. 44-137. S. 115. Vgl. Cod. Sang. 263. 
Der italienische Einfluss auf die Rezeption der Dichtung im Ostfrankenreich ist schwach und der Transfer aus den noch viele antike Handschriften enthaltenden Bibliotheken des Südens vollzog sich großenteils schon im 8. Jahrhundert. ${ }^{1996}$ Zeugen hiervon sind die antiken Vergilhandschriften in Lorsch und St. Gallen. ${ }^{1997}$ Neuere italienische Dichter-Handschriften sind selten und ihr zeitgenössischer Zugang in die Bibliothek oft schwer nachzuweisen. ${ }^{1998}$ Konstanten italienischen Einfluss zeigen die Syllogen, in denen kaum jemals die stadtrömischen Inschriften fehlen. Oft ist jedoch auch hier nicht zu unterscheiden zwischen persönlichen Sammlungen von Besuchern der Stadt und älteren, nur kopial zirkulierenden und oft aus verschiedenen Quellen angereicherten Sammlungen. Die ursprünglich insulare oder italienische Herkunft mancher Texte wird im 9. Jahrhundert im Ostfrankenreich durch eine vielgestaltige interne Zirkulation substituiert. ${ }^{1999}$ Einmal importierte Texte wurden durch Kopie nahe liegender Vorlagen, nicht durch erneuten Import aus fernen Ländern verbreitet, wozu auch das institutionelle Netzwerk prädisponierte, das auf persönlicher und räumlicher Nähe beruhte.

Ungleich zahlreicher sind die Verbindungen ins westfränkische Gebiet, dem das Ostfrankenreich politisch und kirchlich aufs Engste verbunden war. Oft bleibt die genaue Vermittlung unbekannt und zeigt sich nur noch textkritisch. In den Zweigen der Stemmata finden sich häufig Schwesterhandschriften »deutscher" und "französischer" Herkunft nebeneinander, ohne sich in regionale Rezensionen zu trennen. Die Hyparchetypen wirkten somit auf die Gesamtheit des Reiches. ${ }^{2000}$ Bisweilen überwiegt die westfränkische Tradition, sodass eine Vermittlung von dort wahrscheinlich erscheint, so bei Venantius Fortunatus, ${ }^{2001}$ Paulus Diaconus ${ }^{2002}$ oder Publilius Syrus. ${ }^{2003}$ In der Überlieferung einiger Texte zeigt sich eine Trennung in deutsche und französische Zweige der Überlieferung. ${ }^{2004}$

Vielfältig sind die Verbindungen ostfränkischer Klöster in den Westen. Die Entsendung von Mönchen in ein Tochterkloster war sicher auch mit dem

1995 Gotha, Forschungsbibl., Mbr. I. 75; Zürich, C. 59.

1996 ReYNolDs: Texts and transmission. S. XXI-XXIV.

1997 Die jedoch durchaus auch spätere Erwerbungen ihrer hochgestellten Besitzer sein könnten.

1998 Vgl. Clm 29005 (18).

1999 Vgl. die Beziehungen zwischen Clm 14377, Clm 6407 und Clm 13084, sowie die Vorstufen von Antwerpen, Plantin-Moretus 17.4.

2000 Vgl. z. B. die Überlieferung Aldhelms in Aug. Perg. 85 und Pal. Lat. 1753 und deren Verwandtschaften mit westfränkischen Handschriften oder die Überlieferung Paulinus' von Nola in Clm 6412.

2001 Cod. Sang. 573, Cod. Sang. 196.

2002 Cod. Sang. 899 verwandt mit Leipzig Rep. I, 74 .

2003 Wien, Cod. 969. Vgl. Reynolds: Texts and transmission. S. 327; Meyer (Hrsg.): Publilii Syri Mimi Sententiae. S. $6 \mathrm{f}$.

2004 Clm 14324 (Boethius), Antwerpen, Plantin-Moretus 17.4 (Prosper). 
Transfer von Traditionen, darunter Schuldichtung verbunden, so in Lorsch aus Gorze und in Corvey aus Corbie. Die genaue Zusammensetzung dieser Frühbestände liegt aber wie die anderer früher Sammlungen im Dunkeln. Bisweilen ergibt sich aus einem zeitweiligen Kontakt die Übermittlung einzelner Werke, wie beim Mainzer Martinellus (aus Tours?) und seinen metrischen Inschriften vermutet werden darf. ${ }^{2005}$ Bischof Arns Kontakten nach Tours verdanken wir die Salzburger Sammlungen von Alkuin-Briefen und Gedichten. ${ }^{2006}$ Auch aus der Verbindung Lorschs mit dem kaiserlichen Hof ergaben sich Möglichkeiten zur Vermittlung gerade seltener Texte, wie Lukrez oder Ps.-Maximian. ${ }^{2007}$ Fruchtbar waren auch die Verbindungen, die sich aus einer Ämterhäufung ergaben: Adalungs gleichzeitiges Abbatiat in St. Vaast etablierte eine langanhaltende Kooperation mit Lorsch und förderte den Austausch von Dichtung wie Vergil und Ennodius. $^{2008}$ Vielleicht wurde sogar eine Kopie des Lorscher Katalogs für St. Vaast erstellt. Dichtung aus der Zusammenarbeit zwischen Salzburg und St. Amand unter Bischof Arn ist dagegen nur in Spuren erhalten. ${ }^{2009}$

\section{III.1.b Ostfrankenreich}

Die Verbindungen der ostfränkischen Schreibstätten untereinander sind naturgemäß durch räumliche Nähe und institutionelle Verflechtungen am zahlreichsten. Auch hier reicht der Austausch von einmaliger, oft persönlicher Vermittlung bis $\mathrm{zu}$ festen institutionellen Verbindungen. Hierbei spielten die Grenzen zwischen Bistümern keine Rolle. Aus Mainz etwa gelangt Dichtung nach Lorsch, ${ }^{2010}$ in Freising erhält man aus Mainz, Salzburg und Weißenburg Gedichthandschriften, ${ }^{2011}$ nach Regensburg vermitteln die Beziehungen zu Fulda und zur Reichenau Texte. ${ }^{2012}$ Der seltene Cresconius wurde vielleicht zwischen Murbach und Lorsch ausgetauscht. Eng verbunden sind auch Murbach und die Reichenau, wie sich in der großen Übereinstimmung der Kataloge und in der Kooperation in Handschriften zeigt. ${ }^{2013}$ Wie zwischen Salzburg und St. Amand bestand auch zwischen Regensburg und dem Kloster Mondsee eine Kooperation, veranlasst durch den Erwerb Mondsees durch Bischof Baturich, in der Schultexte

2005 Vatikan, Pal. lat. 845.

2006 Wien, Cod. 808.

2007 Lukrez im Katalog. Ps.-Maximian: Vatikan, Pal. lat. 1578.

2008 Wolfenbüttel, Cod. Guelf. 66 Gud. lat.; Brüssel, Ms. 9845-9848.

2009 Reims, Cod. 438. Kodex Frobenius.

2010 Vatikan, Pal. Lat. 239.

2011 Clm 6413, Clm 6402, Wolfenbüttel, Cod. Guelf 35 Weiss.

2012 Clm 29338 (1). Vgl. S. 300 zu Louganpert.

2013 Oxford, Ms. Jun. 25. 
vermittelt wurden. ${ }^{2014}$ Zwischen keinen Skriptorien ist die Verbindung jedoch so eng wie zwischen St. Gallen und der Reichenau. Hier wurden verbreitete ${ }^{2015}$ und seltene Texte ${ }^{2016}$ und Textgemeinschaften ${ }^{2017}$ geteilt oder aus den verstreuten Beständen der anderen Bibliothek neue Bände zusammengestellt. ${ }^{2018}$

\section{III.1.c Aus eigener Bibliothek}

Wenig Beachtung gefunden hat die Kopie von Handschriften aus der eigenen Bibliothek, die ohne Zweifel das gewöhnliche Verfahren für die Erneuerung der Handschriftenbestände gewesen sein muss. Leider ist meist, wenn überhaupt, nur ein Exemplar eines Dichters aus einem Skriptorium erhalten und es lässt sich nicht unterscheiden, ob dieses die erste und einzige Handschrift von dort oder eine Kopie einer älteren ist. Die Anlässe einer Kopie aus eigenem Bestand begünstigen zudem den Verlust des Antigraphs: Handschriften stark genutzter Texte unterliegen einer stärkeren Abnutzung als Raritäten und die Vorlage wird oft nach Abschrift makuliert worden sein. Auch die Umstellung auf die karolingische Minuskel, die sich in unserem Untersuchungszeitraum vollzieht, gefährdete den Fortbestand der älteren, schwerer lesbaren Handschriften. Infolgedessen lassen sich Kopien aus eigener Bibliothek nur in den größten Skriptorien mit einer Vielzahl erhaltener Handschriften nachweisen. In Lorsch werden aus einer gemeinsamen Vorlage zwei Handschriften mit Rätseldichtung kopiert, ${ }^{2019}$ wobei diese jeweils neu mit Auxiliartexten angereichert wurde. Auch in Murbach lassen sich bei Dubletten im Ergänzungskatalog erneute Abschriften vermuten. ${ }^{2020}$ Auf der Reichenau lässt Reginbert aus älteren Handschriften neue, mit verwandtem Material vermehrte Abschriften erstellen. ${ }^{2021}$ Am detailliertesten lässt sich der Vorgang in St. Gallen beobachten. Hier werden Schuldichter aus älteren Handschriften entnommen und mit anderen Texten kombiniert. ${ }^{2022}$ Kleindichtung zirkuliert dort in einem Netzwerk von Handschriften, das sich vom Beginn des Jahrhunderts bis zu seinem Ende erstreckt. ${ }^{2023}$ Bemerkenswert

2014 Clm 29216, Clm 14324.

2015 Karlsruhe, Aug. Perg. 217, Cod. Sang. 877.

2016 Cod. Sang. 196 (Venantius), Zürich, C 78 (Quintus Serenus).

2017 Zürich ZB, C 68.

2018 Cod. Sang. 573.

2019 Vatikan, Pal. Lat. 1719, Pal. Lat. 1753.

2020 Im Iskar-Katalog Nummern 318 (Lukrez), 329 (Fabeln).

2021 Vgl. S. 169 zu Nr. 10. des Hauptkatalogs, S. 174 zu Reginbert-Liste Nr. IV.

2022 Cod. Sang. $273+$ Bremen, StUB Ms. b. 52.

2023 Leiden, Voss. Lat. Q. 69, Cod. Sang. 250, Cod. Sang. 397, Cod. Sang. 899, Zürich, C 78 und weitere. 
ist, dass die Kopie selten eine mechanische ist, sondern dass die Texte in immer neuen Kombinationen zusammengestellt werden.

Zuletzt stützt sich auch die Überlieferung der hauseigenen Dichtung, sofern sie nicht auch auswärts überliefert wird, was insbesondere bei lokaler Kleindichtung selten der Fall ist, auf die interne Zirkulation. Hierunter fallen unselbstständige Gedichte wie metrische Vorworte ${ }^{2024}$ und Ex-Libris, ${ }^{2025}$ aber auch kleinere Anthologien, etwa von Inschriften, ${ }^{2026}$ Heiligendichtung ${ }^{2027}$ und Briefgedichten $^{2028}$.

\section{III.2 Dichtung in Bibliothek und Katalogen}

\section{III.2.a Ordnung der Bibliotheken}

Der Großteil der Dichtung findet sich in der grammatischen Abteilung der Bibliothek $^{2029}$ oder in daraus hervorgegangenen neuen Gliederungen. ${ }^{2030}$ Die Gründe für die Einordnung von Dichtung in die "Schulbibliothek« - ein angesichts der Komplexität dieser Sammlungen oft zu allgemein gebrauchter Begriff gehen jedoch weit über die grundsätzliche Verankerung der Dichtung in der Schule hinaus. Zuerst: Dichtung findet sich durchaus auch außerhalb der grammatischen Abteilung, und zwar gemäß einer einfachen Regel: Hat der Autor genügend Werke, um seine eigene Rubrik im Katalog zu erhalten, werden seine Dichtungen dort eingeordnet; ${ }^{2031}$ nicht selten finden sich Dubletten dieser Titel dann ebenfalls in der grammatischen Abteilung. ${ }^{2032}$ Die Gattung der Hymnen findet sich ebenfalls meist nicht bei den Grammatikern, sondern assoziiert mit liturgischen und monastischen Handschriften. Das Werk der Autoren dagegen, die nur durch ihre Dichtung bekannt sind, füllt selten mehr als eine Handschrift, und hätte somit keine eigene Autoren-Abteilung erhalten können, insbesondere zu Beginn der Sammlung, als sich der Bestand an Dichtung auf zwei, drei Handschriften beschränkte. Warum aber befindet sich die Dichtung allgemein in der grammatischen Abteilung? Weil dort in der frühen Bibliothek die Dichtung

2024 Siehe bei Egilbert, S. 220.

2025 Ex-libris der Reginbert-Bände.

2026 Karlsruhe, Aug. Perg. 255.

2027 Wolfenbüttel, Cod. Guelf. 66 Weiss., Antwerpen, Plantin-Moretus 17.4, Clm 14248.

2028 Cod. Sang. 197, Wolfenbüttel, Cod. Guelf. 77 Weiss.

2029 Köln, Reichenau, Lorsch, Passau. Unvollständige Listen oder Auszüge (Würzburg, Freising, Tegernsee) kommen hier nicht in Betracht. Die Kataloge von Fulda und St. Emmeram sind späteren Datums.

2030 St. Gallen, Murbach.

2031 Boethius, Prosper, Beda, Aldhelm.

2032 Prosper auf der Reichenau, Beda in Lorsch. 
auch ihren pragmatischen Ort hatte: Eine Handvoll Grammatiken, ein paar Bände Sedulius, Prudentius und Vergil oder aus Grammatik und Dichtung gemischte Bände bildeten den Grundbestand der Schulbibliothek und das Instrumentarium des Lehrers. Neuerwerbungen wurden den schon vorhandenen Gedichthandschriften zugesellt und die so konstituierte Abteilung wuchs oft weit über die Bedürfnisse der Schule hinaus. Dass die Dichtung aus der Schule hinaustrat, wird schon anhand der zahlreichen Handschriften deutlich, die durch ihren Buchschmuck und ihr unverbrauchtes Aussehen kaum den Eindruck von Lehrbüchern aus dem Klassenraum erwecken. ${ }^{2033}$ Die grammatische Abteilung der Kataloge ist also einerseits als Schulbibliothek anzusehen - eine Funktion, die sie sicher auch in den am besten ausgestatten und somit am weitesten von der ursprünglichen Funktion entfernten Bibliotheken beibehalten hat - andererseits als Sammelbecken für die später hinzugekommenen Gedichthandschriften, gleichgültig ob diese als Schulhandschriften gebraucht wurden oder nicht. Dass ein qualitativer Übergang in der Sammlung auch von den Zeitgenossen gefühlt wurde, zeigt die Ordnung zweier herausragender Bibliotheken: In Murbach wurde die ältere Grammatikabteilung, die noch in zerstreuten Grammatiken erkennbar ist, in drei neue Kategorien gespalten, darunter eine für christliche und eine für heidnische Dichter, die ausschließlich Dichtung enthalten. In St. Gallen bleibt die grammatische Abteilung erhalten, in ihr verbleiben jedoch nur noch eigentliche Grammatiken, sowie aus Grammatik und Dichtung zusammengesetzte Sammelbände, und eine eigene Abteilung De Metris erfasst reine Gedichthandschriften. Die Loslösung - aber nicht Trennung - der Dichtung aus ihrem ursprünglich schulischen Zusammenhang ist hier in der Ordnung der Bibliothek reflektiert worden.

\section{III.2.b Separatbibliotheken}

\section{III.2.b.1 Schulbibliotheken}

In all diesen Fällen sind die Bände der Schulbibliothek zusammen mit allen anderen Handschriften verzeichnet worden, was auf einen zentralen Aufstellungsort schließen lässt. An anderen Skriptorien lässt sich dagegen aus der Abwesenheit von Schulhandschriften eine Schulbibliothek vermuten, die separat vom Hauptbestand aufgestellt war und ein anderes Schicksal als dieser erfuhr. Besonders bei den Zentren mit einer sicher attestierten Schule wie Würzburg, Köln oder Weißenburg darf aus dem weitgehenden Fehlen eindeutig schulischer Dichtung auf eine Separierung von Sammlungen dieser Art geschlossen werden.

2033 Siehe unten S. 324f. zur Ausstattung der Handschriften. 
Auch in Lorsch sind die Grammatici erst im späteren Katalog Ca verzeichnet, was ein Indiz für eine Trennung sein könnte. In Passau scheint sogar ausschließlich der Katalog der Schulbibliothek erhalten geblieben zu sein. ${ }^{2034}$ Kaum mehr unterscheiden lassen sich etwaige Separatbestände von Kathedrale und Bischofskloster, ${ }^{2035}$ wobei die Schulbibliothek und somit die Dichtung generell in letzteren zu suchen wäre - insofern überhaupt von einer Trennung der Bestände auszugehen ist.

\section{III.2.b.2 Persönliche Sammlungen}

Dichtung findet sich ebenfalls häufig, wenn auch in geringer Zahl, in den Sammlungen einzelner Personen. Zu Beginn der Bibliotheken stehen oft die »Reisebibliotheken« der Gründer, deren Zusammensetzung und Einfluss auf die späteren Sammlungen im Dunkeln liegen. Es wäre jedoch überraschend, wenn sich unter den Büchern der wandernden Angelsachsen und Iren, die ja als Vermittler insularen Bildungsgutes angesehen werden, kein Aldhelm oder Beda befunden haben sollte. Die Gruppe irischer Handschriften um das Reichenauer Schulheft darf als kleines erhaltenes Beispiel einer solchen Reisebibliothek gelten. Diese kleinen Sammlungen standen für ihre Nutzer an Stelle der institutionellen Bibliotheken und bildeten anders als die späteren Privatsammlungen wahrscheinlich ein breiteres Spektrum an Genres ab, eingeschränkt durch den geringen Umfang, den ihre Mobilität erforderte.

Auch aus den privaten Sammlungen einiger hochgestellter Persönlichkeiten gingen einige kostbare Gedichthandschriften in die Klosterbibliotheken über. Der Pfalzbibliothekar Gerward vermachte Lorsch seine Sammlung, worunter sich vielleicht auch der Vergilius Palatinus befand. Vielleicht besaß auch Grimald eine antike Vergilhandschrift, die Schedae Sangallenses, die er mit seiner Sammlung, worunter sich auch ein aus Lorsch stammender Prosper befand, St. Gallen vererbte. Auch sein Nachfolger Hartmut hinterließ in seinem Legat Handschriften von Boethius und Martianus Capella. In keiner dieser Privatsammlungen steht die Dichtung an vorderster Stelle. Interessant ist auch, dass diese Sammlungen wahrscheinlich als Separatbestände gelagert wurden, in St. Gallen vielleicht sogar in einer Abtsbibliothek. Dies spricht für die hohe Wertschätzung der kostbaren Gedichthandschriften, die durch diese getrennte Aufbewahrung vor der Abnutzung bewahrt wurden. Der praktische Nutzen dieser Sammlungen ist schwer $\mathrm{zu}$ ermitteln. Auch ein rein bibliophiles Interesse ist nicht von der Hand zu weisen; Bücherbesitz war an sich keine Seltenheit, wie die zahlreichen Bücher-

2034 In Form des Legats des Chorbischofs Madalwin, siehe S. 302-305.

2035 Mainz: St. Alban, Trier: St. Maximin, Regensburg: St. Emmeram, Salzburg: St. Peter, Freising: St. Benedikt. 
legate an die Reichenau zeigen. ${ }^{2036}$ Die größeren Privatsammlungen reflektieren damit auch die größeren Ressourcen ihrer Besitzer. Es ist ferner bezeichnend, dass die Liste von Grimalds Büchern mit einigen fehlenden und später ersetzten Titeln beginnt; die Originale hatte er an hochstehende Persönlichkeiten verschenkt. Die Bücher stellten somit ein gewisses Kapital dar, mit dem der Besitzer sich andere verbindlich machen konnte. Ob auch Gedichthandschriften auf diese Weise verschenkt wurden oder durch Schenkung in den Besitz Grimalds und Gerwards gelangten, ist nicht bekannt.

Eine Sonderstellung nimmt die Bibliothek des Passauer Chorbischofs Madalwin ein, die er 903 dem Domstift vermachte. Sie bildet einerseits seine liturgischen Pflichten ab, andererseits stellt sie eine beachtliche Schulbibliothek mit einer Vielzahl von Dichtung dar, die in einigen Titeln über bloß schulische Bedürfnisse hinausgeht. Madalwins Sammlung ist aus seinen institutionellen Pflichten - Liturgie und Schule ${ }^{2037}$ - hervorgegangen und repräsentiert damit einen grundsätzlich anderen Typus der persönlichen Sammlung als die von Gerward, Grimald und Hartmut. Es ist anzunehmen, dass seine Sammlung auch anderen Lehrern in Passau zur Verfügung stand und also auch gleichzeitig als institutionelle, nicht nur private Schulbibliothek anzusehen ist. Sonst gibt es kaum Hinweise auf weitere solche praktisch orientierten persönlichen Sammlungen. ${ }^{2038}$ Vielleicht stammt die Walahfrid-Handschrift, die der Magister Rudolf der Fuldaer Bibliothek vermachte, aus einer kleinen Handbibliothek. Unter den zahlreichen Büchern, die der Reichenau von Einzelpersonen vermacht wurden, ${ }^{2039}$ findet sich keine Dichtung, was nahelegt, dass diese sich selten in privatem Besitz befand, insbesondere insofern die »Privatbibliothek« nur aus zwei, drei, meist liturgisch-biblischen Handschriften bestand.

\section{III.3 Persönliche Einflüsse auf die Sammlung von Dichtung}

Die Erweiterung der Sammlung über den Grundbestand hinaus ist kein Automatismus und lässt sich beinahe überall, wo genug erhaltene Handschriften genauere Schlüsse ermöglichen, mit dem Engagement einzelner Persönlichkeiten in Verbindung bringen.

Oft geht der allgemeine Aufschwung des Schriftwesens auch mit einer Vermehrung der Gedichthandschriften einher, so etwa in Fulda unter Hrabanus, dessen Lektüreempfehlungen zu Dichtern sich sämtlich in Handschriften oder

2036 LehmanN (Hrsg.): MBK. 1, S. $256 \mathrm{f}$.

2037 Wie oben bemerkt muss dies nicht heißen, dass er in seiner Funktion als Chorbischof Lehrer war. Wahrscheinlicher ist, dass er diese Tätigkeit vor seinem Episkopat ausübte.

2038 Ein Beispiel ist die Sammlung der "Laon masters", siehe oben S. 305.

2039 Lehmann (Hrsg.): MBK. 1, S. $256 \mathrm{f}$. 
im (spätmittelalterlichen) Katalog wiederfinden. Seine Skepsis gegenüber den heidnischen Dichtern hat dagegen nicht verfangen: Grundlegende Autoren wie Vergil, aber auch Raritäten wie Silius Italicus wurden unter seinem Abbatiat kopiert. Weißenburg erlebte unter Otfrid eine Blütezeit, aber paradoxerweise lagen die Interessen dieses großen Dichters nicht in der Dichtung, sondern in exegetischen Werken.

Oft eröffnen die persönlichen Beziehungen der Äbte und Bischöfe temporäre Möglichkeiten zur Beschaffung von Dichtung. ${ }^{2040}$ Regensburg erhält mit Alkuin verbundene Dichtung aus den Händen seines Freundes Adalwin. ${ }^{2041}$ Unter Bischof Baturich, der mit Hrabanus befreundet war, gelangte eine SeduliusHandschrift vielleicht aus Fulda nach Regensburg. ${ }^{2042}$ Der Anteil, den das von Baturich erworbene Kloster Mondsee am Regensburger Handschriftenbestand hatte, wurde oben schon erwähnt. In Freising lässt sich die Progression vom Aufbau eines Grundstocks mit Grammatik und Schuldichtern unter den Bischöfen Hitto und Erchanbert bis zur Förderung althochdeutscher Dichtung unter Bischof Waldo verfolgen. In Salzburg ist Arn die beherrschende Gestalt: Auf den durch seine persönliche Beziehung zu Alkuin vermittelten Texten baut auch die spätere Sammeltätigkeit unter Liuphram auf, der gleichwohl einen neuen Akzent mit autochtoner Salzburger Dichtung setzt. Lorsch profitierte von den Kontakten Abt Richbods zum Hof (und seiner Liebe zu Vergil) und von Samuels Freundschaft zu Hrabanus. Auf der Reichenau beginnt das frühe Wachstum der Bibliothek nicht zufällig mit dem außerordentlich gut vernetzten Abt Waldo. Unter dem Bibliothekar Reginbert wird außerordentlich viel Dichtung gesammelt, an der er besonderes Interesse hatte, wie die Liste der unter der unter seiner Ägide ergänzten Handschriften beweist. Hier sind auch die Bände vermerkt, die er aus persönlichen Beziehungen von seinem Bruder Wano und seinen Schülern Grimald und Tatto, sowie von einem Colduin erhielt. Zuletzt sehen wir Walahfrid seine Korrespondenten um Dichtung bitten. In St. Gallen machen die Unsicherheiten der Datierung eine Zuordnung zu den einzelnen Abbatiaten schwierig. Hinter einigen bedeutenden St. Galler Erwerbungen darf Grimald vermutet werden. Fassbar wird die Verbindung zwischen einflussreichen Persönlichkeiten zur Dichtung wieder unter Notker, der von heidnischer Dichtung abrät, und seinem Schüler Salomo. ${ }^{2043}$ Notkers Abneigung gegen die

2040 Ein besonders gut dokumentiertes Beispiel des weiten Netzes an Beziehungen, die zum Erwerb von Büchern führen ist Lupus von Ferrières, siehe Depreux: "Büchersuche und Büchertausch». Leider wissen wir nicht, ob er sich auch um poetische Handschriften bemühte.

$2041 \mathrm{Clm} 14248$.

$2042 \mathrm{Clm} 29338$ (1).

2043 Cod. Sang. 197. 
Heiden scheint aber eher eine Fortführung einer St. Galler Tradition gewesen zu sein, die schon vor Notker einen konservativen Dichterkanon bevorzugte.

Über die Grundausstattung mit Dichtung hinaus scheinen also überall das persönliche Interesse und die Verbindungen bedeutender Äbte, Bischöfe, aber auch Lehrer und Bibliothekare den Anlass und die Gelegenheit für eine Erweiterung der Bibliothek mit Dichtung gegeben zu haben.

\section{III.4 Dichtung in den Handschriften}

\section{III.4.a Ausstattung}

In ihrer Gesamtheit zeichnen sich die Gedichthandschriften nicht durch besondere Pracht aus, fallen aber auch nicht unter das allgemein hohe Niveau der Schriftlichkeit des 9. Jhs. Die Ausstattung der Handschriften, die Dichtung als Haupttext enthalten, ist meist schlicht, aber klar und kompetent. Der Buchschmuck orientiert sich mehr daran, die Lektüre mittels Rubriken, Lombarden und Leerzeilen zu erleichtern, als den Leser durch Pracht zu beeindrucken. ${ }^{2044}$ Die besonderen Raumbedürfnisse verschiedener Metren werden oft durch Anpassung der Spaltenzahl befriedigt. ${ }^{2045}$ Die meisten Handschriften haben ein mittleres Format, das eine einfache Handhabung ermöglicht, ohne jedoch die Bände zu Taschenbüchern zu machen. ${ }^{2046}$ Kleineren Formats sind oft Handschriften, die den Charakter von persönlichen Sammlungen tragen. ${ }^{2047}$

Nur die wenigsten Texte wurden einer Prachtausstattung für würdig befunden. Hierunter befinden sich die klassischen christlichen Dichter, allen voran Prudentius. ${ }^{2048}$ Sedulius, obwohl weit verbreitet, ist nur in einer Handschrift mit Illustrationen nach antikem Vorbild versehen. ${ }^{2049}$ Auch Aldhelm wird einmal mit insularem Buchschmuck versehen. ${ }^{2050}$ Charakteristisch ist in einigen Fällen die Rücknahme des Buchschmucks der Vorlage, so in den St. Galler Prudentiushandschriften oder im Avian-Fragment ${ }^{2051}$ gleicher Provenienz. Heidnische Dichter werden nicht illustriert. ${ }^{2052}$

2044 Siehe zum Beispiel Cod. Sang. 136, Cod. Sang. 869, Wien, Cod. 969, Oxford, Ms. Jun. 25. 2045 Siehe zum Beispiel Cod. Sang. 134, pp. 61-62.

2046 Siehe zum Beispiel Cod. Sang. 869, Vatikan, Pal. lat. 487, Pal. lat. 1753, Pal. lat. 239.

2047 Zum Beispiel Einsiedeln, Ms. 326 (1076), Ms. 266 (1296), Clm 19413, Cod. Sang. 273.

2048 Bern, Ms 264, Paris, Lat. 18554.

2049 Antwerpen, Plantin-Moretus 17.4.

2050 Wien, Cod. 969.

2051 Zürich, C 68.

2052 Nur eine Initiale im Vergil von Paris, Lat. 7906. Im Westfrankenreich dagegen lassen sich vereinzelte Beispiele finden, wie zum Beispiel der nach antiker Vorlage illustrierte Terenz in Vat. lat. 3868. 
Eine eigene Klasse bilden die Handschriften, mit denen ein hochgestellter Dichter unter Heranziehung eines ihm dienstbaren Skriptoriums seine eigenen Werke verbreitete. Die Handschriften von Hrabanus' Kreuzgedichten sind nicht nur die prächtigsten aller hier behandelten Gedichthandschriften, sondern gehören zu den Glanzpunkten karolingischer Buchmalerei überhaupt. Es handelt sich bei diesen Handschriften um Dedikationsexemplare, mit denen sich sowohl Hrabanus selbst als auch das Kloster Fulda hochstehende Adressaten verbindlich machen wollte. Auch Otfrids Evangeliendichtung, die in Widmungsexemplaren verbreitet wurde, ist in Handschriften von höherem als gewöhnlichem Niveau enthalten. ${ }^{2053}$ Von Wandalberts Martyrologium wurde ebenfalls eine der Handschriften mit Bildern versehen. ${ }^{2054}$ Einzigartig ist, dass Brun Candidus seinem Fuldaer Mitbruder Modestus eine reich bebilderte Handschrift seiner Vita Aegil widmete - obwohl auch dieses Werk wohl ursprünglich für einen hochgestellten Adressaten, nämlich Ludwig den Frommen gedacht war.

Zur Ausstattung der Gedichthandschriften liegt somit ein scheinbar paradoxes Ergebnis vor: Während der Großteil der christlichen Dichter und die Klassiker ohne Handschriften höchsten Niveaus auskommen müssen, sind es gerade die zeitgenössischen Dichter, Hrabanus, Otfrid, Wandalbert, deren Werke reich verziert werden. Der Grund hierfür ist in der Dedikationspraxis der Zeit zu sehen. Schenkenswürdig sind zuerst Bibel- und Liturgiehandschriften, dann eigene Werke, die sowohl im Text durch die Widmung als auch im Buchschmuck den Verfasser dem Adressaten empfehlen. Dichtung ist somit nicht per se ein prestigereicher Text wie die Bibel, sondern nur insofern sie dediziert werden kann, das heißt in Werken zeitgenössischer Autoren. Gewidmete Dichtung, die nicht in prunkvollen Handschriften vorliegt, ist oft zu kurz, um eine eigene Handschrift zu füllen, ${ }^{2055}$ oder liegt nur kopial vor, sodass wir das Aussehen des Widmungsexemplares nicht kennen. ${ }^{2056}$

\section{III.4.b Schreiber und Wachstum der Handschriften}

Die Unterscheidung der verschiedenen Schreiber und ihres Anteils an der Herstellung einer Handschrift wirft ein Licht auf das Verfahren, mit dem Dichtung im Skriptorium kopiert und zu neuen Sammlungen zusammengestellt wurde. Der einfachste Fall ist, dass ein einzelner Schreiber ohne merkliche Übergänge in der Arbeit ein Exemplar reproduziert. Dies ist oft bei Handschriften mit nur

2053 P (Heidelberg, Cpl 52) und V (Wien, Cod. 2687).

2054 Vatikan, Reg. lat. 438.

2055 Zum Beispiel die Viten Walahfrids.

2056 Bern, BB, Ms. 212. Notker: Liber Hymnorum. 
einem Dichter oder einer gewöhnlichen Textgesellschaft der Fall. ${ }^{2057}$ Bisweilen wird oft eine in der Vorlage gesammelte Textgesellschaft durch einheitliche Kopie von einem Schreiber paläographisch verschmolzen. ${ }^{2058}$

Kopieren mehrere Schreiber gemeinsam eine Sammelhandschrift, ist das Kennzeichen hiervon oft der Wechsel inmitten des Textes, anstatt bei Textwechsel. Die Textgesellschaft der Vorlage wird hierbei meist ohne Änderungen übernommen. ${ }^{2059}$ Eine solche Kopie findet sich oft als Teil einer aus mehreren Vorlagen stammenden Handschrift. ${ }^{2060}$ Bisweilen leitet ein erfahrener Schreiber eine Gruppe von Amanuenses. ${ }^{2061}$

Ein Sonderfall der Schreibergruppe sind die Schülerhände, deren vom Schulleiter aufgetragene Schreibübungen in einigen Handschriften zu erkennen sind. Einzigartig ist die ganz von fortgeschrittenen Schülern geschriebene Handschrift der Argonautica. ${ }^{2062}$ Öfter finden sich Gruppen von Schülern unter Anleitung einer erfahrenen Hand $^{2063}$ oder in Zusammenarbeit mit geübten Schreibern. ${ }^{2064}$ Häufig findet sich Dichtung in ungeübten Federproben oder Ergänzungen. ${ }^{2065}$

Auf eine Zusammenstellung der Texte erst bei Verfertigung der Handschrift lässt eine Koinzidenz von Schreiber- und Textwechsel schließen. Die Kombination muss keineswegs neuartig sein, sondern vereint oft nur aus verschiedenen Exemplaren stammende zusammengehörige oder verwandte Texte. ${ }^{2066}$

Keinem vorher gefassten Plan folgen die Handschriften, die nach und nach aus verschiedenen Quellen zusammengestellt wurden. Sie unterscheiden sich von den Sammelhandschriften mit Kopien vollständiger Texte durch die Kürze des gesammelten Materials. Ist ein Hauptschreiber für die Sammlung verantwortlich, darf man in ihm den Besitzer und Nutzer der Handschrift vermuten, die damit seine Interessen und Bedürfnisse reflektiert. ${ }^{2067}$ Langsames Wachstum drückt sich aber auch in Handschriften mit mehreren Schreibern aus, ${ }^{2068}$ wobei sich

2057 Karlsruhe, Aug. Perg. 217, Vatikan, Vat. lat. 11506, Reg. lat. 469, Cod. Sang. 263, Cod. Sang. 196.

2058 Einsiedeln, Cod.326 (1076) (Sylloge); Teile von Clm 19413.

2059 Zürich, C 68.

2060 Zürich, C 78, Clm 19410, Cod. Sang. 899; Teile von Wolfenbüttel, Cod. Guelf. 91 Weiss.

2061 Otfrid in Weißenburger Handschriften; Vatikan, Reg. lat. 1703.

2062 Vatikan, Vat. lat. 3277.

2063 Cod. Sang. 273, Clm 6411.

2064 Würzburg, M.p.th.f. 21.

2065 Siehe zum Beispiel Clm 14461.

2066 Wien, Cod. 969, Cod. Sang. 573, Neapel Ms. IV G 68, Oxford, Ms. Jun. 25, Vatikan, Pal. lat. 1719, Pal. lat. 1753. Vgl. auch von nur einem Hauptschreiber zusammengestellt Cod. Sang. 869.

2067 Leiden, Voss. Lat. Q. 69, Wolfenbüttel, Cod. Guelf. 77 Weiss, Einsiedeln, StB, Ms. 266 (1296).

2068 Cod. Sang. 899, Köln, Ms. 106, Zürich, C 78. 
jedoch nicht selten ein Spiritus Rector der Sammlung in Gestalt des Besitzers oder überall beteiligten Schreibers finden lässt. ${ }^{2069}$

\section{III.4.c Textgesellschaften}

Textgesellschaften als Macrotesto, das heißt als eine auf die Einzeltexte interpretatorisch zurückwirkende Verbindung mehrerer Werke, tritt in der Überlieferung der Dichtung in einem Kontinuum von Großwerken bis zu Kleindichtung auf. Eine Assoziation von Werken, die über den einzelnen Kodex hinausgeht, liegt in der schon behandelten Sammlung in Katalogkategorien vor. Hier soll nun fortführend zusammengefasst werden, wie Texte in den Handschriften selbst gruppiert wurden.

Zwei klassische christliche Dichter, Juvencus und Sedulius, die in den Bibliotheken häufig beieinander standen, werden auch in Sammelhandschriften vereint. In St. Gallen und der Reichenau ist diese Textgemeinschaft auch eine genetische, indem die Handschriften untereinander verwandt sind und von gemeinsamer Vorlage stammen. ${ }^{2070}$ Auch im Kölner Katalog von 833 sind die beiden Dichter in einer Sammelhandschrift verzeichnet. Die Textgemeinschaft ist jedoch keinesfalls feststehend, beide Dichter kommen sowohl alleine stehend, als auch kombiniert mit anderen Autoren vor. Sedulius wird auch bisweilen mit Prosper kombiniert, jedoch nur in Sammelhandschriften größeren Ausmaßes. ${ }^{2071}$ Andere Assoziationen bestehen oft nicht spezifisch zwischen Autoren, sondern locker thematisch, wie in den Lorscher Sammelhandschriften christlicher Dichter. Weitere Aspekte der thematischen Sammelhandschriften werden in der Typologie der Handschriften erörtert.

Die Anordnung von Kleindichtung hat nirgendwo einen Grad von Komplexität und Beharrungsvermögen erhalten, wie er in den Liederhandschriften und Anthologien des Hochmittelalters zu finden ist. ${ }^{2072}$ Dies drückt sich auch darin aus, dass keine der Anthologien ein Inhaltsverzeichnis erhalten hat; diese finden sich nur in Handschriften, die Dichtung als Teil einer unitären Sammlung enthalten, ${ }^{2073}$ oder deren Dichtung von vornherein als kanonische Sammlung empfunden wurde, wie bei Prudentius zum Beispiel. Die Belege für die Tradierung von Anthologien und Textsequenzen stammen hauptsächlich aus St. Gallen, durch die Vielzahl und zeitliche Streuung der erhaltenen Handschriften. So wird

2069 Karlsruhe, Aug. Perg. 112, Cod. Sang. 397, Cod. Sang. 878.

2070 Zürich, C 68, Karlsruhe, Aug. Perg. 217 (I\&II).

2071 Antwerpen, Plantin-Moretus 17.4. So ebenfalls in den Katalogen der Reichenau und von Köln.

2072 Siehe unten S. 340-342 zu Anthologien.

2073 Köln, Ms. 106. 
zum Beispiel der Hymnenbestand übernommen und vermehrt. ${ }^{2074}$ Autorenzentriert $^{2075}$ scheinen eine Reihe von mehrfach kopierten Ps.-Columbania ${ }^{2076}$ und eine Sequenz von Theodulf-Gedichten ${ }^{2077} \mathrm{zu}$ sein. Isidors Bibliotheksverse empfehlen sich durch Autor und Thema für eine gemeinsame Überlieferung. ${ }^{2078}$ Gedichtsequenzen finden sich auch vereinzelt außerhalb der St. Galler Hausüberlieferung. ${ }^{2079}$ Mitunter sind die Sequenzen auch Produkte des Medienübergangs von einer losen Sammlung zum gebundenen Kodex. ${ }^{2080}$ Das Fehlen einer festen Reihenfolge in der Überlieferung deutet auf eine nicht abgeschlossene - oder gar nicht beabsichtigte - Kanonisierung der Anthologie. ${ }^{2081}$

Oft lässt sich nicht ausmachen, ob eine vorliegende Gedichtfolge nur eine Sequenz aus einer größeren Sammlung ist oder eine in sich geschlossene kleine Anthologie in der Zirkulation zeigt. ${ }^{2082}$ Cod. Sang. 899 zeigt hierfür mehrere Beispiele, wobei auch oft nicht poetische Texte in die durchgehende Kopie einbezogen werden, sodass ein nicht ausschließlich anthologischer Impuls den Anlass gab. Eine Gedichtsequenz, die von einer Hand mit vorhergehenden nichtpoetischen Texten kopiert wurde, indiziert oft die Kopie ganzer Handschriften oder zumindest beträchtlicher Teile davon, wie oben schon bemerkt wurde.

\section{III.4.d Auxiliartexte}

Oft findet sich Dichtung nicht eigenständig, sondern als untergeordneter Hilfstext. Solche Auxiliardichtung emanzipiert sich nur selten von ihrem übergeordneten Text, um als separate Einheit zu zirkulieren. ${ }^{2083}$ Einleitungsgedichte sind ein beliebtes Subgenre; insofern sie nicht fester Teil der Überlieferung des eingeleiteten Textes sind, ${ }^{2084}$ sind sie oft Produkte lokaler Kreativität und verbleiben an ihrem Ursprungsort. ${ }^{2085}$ Gedichte dienen nicht selten als Anschauungsmaterial $\mathrm{zu}$ metrischen Problemen oder sind in Grammatikhandschriften als Ergänzungen angebracht ${ }^{2086}$ oder in grammatische Traktakte integriert. ${ }^{2087}$

2074 Neapel, Ms. IV G 68, Leiden, Voss. Lat. Q. 69.

2075 Siehe unten S. 330-337 zur weiteren Differenzierung dieses Begriffes.

2076 Cod. Sang. 273, Cod. Sang. 899, Clm 6404.

2077 Zürich, C 78, Cod. Sang. 263.

$2078 \mathrm{Clm}$ 19413, Cod. Sang. 397.

2079 Einsiedeln, Ms. 266 (1296), Cod. Sang. 899.

2080 Alkuins Gedichte im Codex Bertinianus und in Wien, Cod. 808.

2081 Vgl. zu Walahfrid S. 70-77 und 123-127, sowie S. 205, 333 zur Appendix Vergiliana.

2082 Wolfenbüttel, Cod. Guelf. 91 Weiss, Theodulf in Cod. Sang. 263, Cod. Sang. 197.

2083 Versus Damasi in Clm 19410; Clm 14377; Zürich, C 78, f. 86r-86v.

2084 Manchester, Latin Ms. 116; Aug. Perg. 29 + 19. Gregorius praesul in Wolfenbüttel, Cod. Guelf. 91 Weiss.

2085 Köln, Cod. 99, Cod. 110.

2086 Clm 6404; Paris, Lat. 16668; Köln, Cod. 211. 
Spitze dieser wenig am Inhalt interessierten Entwicklung sind die seltenen metrischen Florilegien, die ohne Rücksicht auf den Sinn metrisch problematische Verse versammeln. ${ }^{2088}$ Einen festen Platz hat Dichtung in der Komputistik, wo Kalenderverse Daten und Phänomene veranschaulichen. ${ }^{2089}$

\section{III.4.e Dichtung als Nachtrag}

Manche Gedichte wurden ohne vorherige Planung in den freigebliebenen Stellen einer ansonsten von ihr unabhängigen Handschrift hinzugesetzt. Dennoch besteht innerhalb dieser nur formalen Kategorie eine große Vielfalt, die in Form und Inhalt einen Mikrokosmos der weiteren Dichtung darstellt. Die umfangreichsten Ergänzungen sind in solchen Handschriften möglich, die aufgrund ungenauer Raumkalkulation noch mehrere Blätter am Ende frei behielten. Diese bieten Raum für vollständige, en bloc kopierte Gedichtgruppen $^{2090}$ oder für stückweise, aber dennoch kohärente Ergänzungen von meist einer Hand, ${ }^{2091}$ oft individuellen Charakters. Die Ergänzungen reflektieren oft die Textgattungen des Haupttextes und deren Rezeption durch die Nutzer. ${ }^{2092}$ Dichtung als Kleinform eignet sich vorzüglich als marginale Ergänzung auch dort, wo nur wenig Raum geblieben ist. Aber auch in diesem scheinbar zufälligen Milieu ist die Ergänzung bisweilen geradezu systematisch und mit den Hauptschreibern verbunden. ${ }^{2093}$ Anderswo füllt bevorzugt Dichtung die kleineren Freiräume $e^{2094}$ und schließlich gibt es die zahlreichen Fälle, wo Dichtung unter anderen Ergänzungen als Füllsel dient. ${ }^{2095}$

2087 Karlsruhe, Aug. Perg. 112. Die verschiedenen Artes Metricae enthalten ebenfalls zahlreiche Beispielverse.

2088 Mico: Opus Prosodiacum; Cod. Sang. 870; Neapel, Ms. IV G 68.

2089 Cod. Sang. 250, Clm 29790 (1); Cod. Sang. 397, Zürich, C 684.

2090 Versus Wissenburgenses in Wolfenbüttel, Cod. Guelf. 91 Weiss.

2091 Clm 19413, Wolfenbüttel, Cod. Guelf. 77 Weiss.

2092 Clm 19410, Vatikan, Pal. lat. 1753, Wien, Cod. 1609, Köln, Cod. 106; Kassel, fol. Ms. theol. 54.

2093 Cod. Sang. 869, Schreiber Ia und II; Köln, Cod. 106 wird von den Hauptschreibern ergänzt.

2094 Aug. perg. 195, Neapel, Ms. IV G 68.

2095 Cod. Sang. 397, Clm 9543, Zürich, Ms. C. 129. 


\section{III.5 Typologie der Sammlungen}

\section{III.5.a Autorenhandschriften und Autoren-Sammelkodizes}

\section{III.5.a.1 Christliche Dichter}

Im Folgenden soll abschließend die traditionelle Typologie der Gedichthandschriften, die in der Einleitung ${ }^{2096}$ vorgestellt wurde, einer Prüfung anhand der neuen Erkenntnisse dieser Arbeit unterzogen werden.

Die großen christlichen Dichter der Spätantike - Sedulius, Prudentius, Juvencus, Arator und der sich in seiner Beliebtheit zu ihnen gesellende Prosper Aquitanus - gehören zur Grundausstattung der Bibliothek, wovon die zahlreichen erhaltenen und in Katalogen verzeichneten Bände ein Zeugnis ablegen. Schon der bloße Umfang ihrer Werke ermöglichte eine Sammlung in Einzelbänden. Sedulius ist in den Katalogen als Einzelband achtmal verzeichnet, ${ }^{2097}$ in Sammelhandschriften mit anderer Dichtung viermal. ${ }^{2098}$ Der Überlieferungszufall scheint aber die Sammelkodizes begünstigt zu haben. ${ }^{2099}$ Prudentius wird dagegen gern alleine überliefert, ${ }^{2100}$ aber auch seine einzelnen Gedichte finden oft ihren Weg in Sammlungen anderer Natur. ${ }^{2101}$ Obwohl Juvencus hauptsächlich in Einzelbänden verzeichnet ist, ${ }^{2102}$ tendiert auch hier die Überlieferung zu Sammelhandschriften. Auch die vier Bücher der Evangeliendichtung des Arator tendieren zum Einzelband. ${ }^{2103}$ Prosper Aquitanus, dessen poetische Paraphrase von Augustinus-Sentenzen sich weiter Beliebtheit erfreute, lag in zahlreichen Einzelhandschriften in den Bibliotheken. ${ }^{2104}$ Prosper hatte auch als einziger der

2096 S. 18-20.

2097 St. Gallen, Passau, Reichenau (2), Regensburg, Freising, Murbach, Lorsch.

2098 Sedulius \& Prudentius: Lorsch; Sedulius \& Iuvencus: St. Gallen; Sedulius \& Prosper: Reichenau; Sedulius \& Iuvencus \& Prosper: Köln.

2099 Siehe für Einzelnachweise das Werk- und Handschriftenregister.

2100 In Katalogen in St. Gallen, Passau, Regensburg, Freising, Murbach und zweimal in Lorsch. In Sammelhandschriften dagegen: Prudentius \& Arator: Reichenau; Sedulius \& Prudentius: Lorsch. Vgl. auch die fünf St. Galler Prudentius-Handschriften (S. 116-118).

2101 Siehe zum Beispiel Neapel Ms. IV G 68.

2102 Iuvencus ist einzeln verzeichnet in St. Gallen (2), Reichenau (3), Regensburg, Freising, Würzburg, Murbach, Lorsch und auf der Reichenau gemischt mit Grammatik (2). Sedulius \& Iuvencus: St. Gallen, dort ein weiterer Sammelband mit Grammatik. Sedulius \& Iuvencus \& Prosper: Köln.

2103 Einzeln verzeichnet in St. Gallen, Passau, Regensburg, Freising und Murbach; Prudentius \& Arator: Reichenau. Zur Überlieferung Arators vgl. auch Lichт: »Aratoris fortuna. Aufgang und Überlieferung der Historia apostolica«.

2104 Prosper einzeln verzeichnet in St. Gallen (2), Murbach (2), Reichenau, Regensburg, Freising und Würzburg. In Sammelhandschriften lag er in St. Gallen (Grimald), der Reichenau, Lüttich (Antwerpen, Plantin-Moretus 17.4), Köln und Passau vor. Vgl. auch Horsting (Hrsg.): Prosper Aquitanus, Liber epigrammatum. S. 23-25. 
christlichen Dichter, wie oben bemerkt, eine eigene Kategorie in den Katalogen wegen der Vielzahl seiner Werke. Die christlichen Klassiker werden mithin sowohl ihres Umfangs als auch wegen ihres Status häufig eines Einzelbandes gewürdigt. Und ebenso wie sie regelmäßig in der Bibliothek beieinander stehen, wird diese Gesellschaft auch oft durch die Schaffung gemeinsamer AutorenSammelkodizes kodikologisch verwirklicht. ${ }^{2105}$

$\mathrm{Zu}$ diesem Grundbestand gesellten sich mit der Zeit, wie oben bemerkt, weitere Dichter. Das hier prominente Thema der Bibeldichtung, das schon bei den Klassikern vorherrschend ist - Sedulius, Juvencus und Arator haben keinen anderen Gegenstand - ist schon seinem Sujet nach für die monastische Lektüre interessant und seinem Umfang nach autonom kodifizierungsfähig. Von den Bibeldichtern liegen Dracontius, Alcimus Avitus und Cresconius Corippus in Einzelbänden vor. ${ }^{2106}$ Eine besondere Sammlung solcher Autoren fand in Lorsch statt, wo in zwei Bänden Bibeldichtung vereint wurde. ${ }^{2107}$ Bei diesen muss die weite Kategorie von »Autoren-Sammelkodex" entweder erweitert oder aufgegeben werden, denn das leitende Interesse bestand bei diesen zwei Handschriften nicht in der Sammlung von Autoren, ob als Opera Omnia oder pragmatisch durch die Schule veranlasst, sondern im Genre selbst. Eine ähnliches Sammelinteresse findet sich in einer verlorenen Handschrift des Alcimus Avitus auf der Reichenau, wo die Genesis-Dichtung mit einem exegetischen Traktat zum gleichen Buch zusammengebunden wurde. ${ }^{2108}$ Derartige Zusammenstellungen sind aber zu selten, als dass sie sich als eigene Kategorie emanzipiert hätten.

Bei weiteren Dichtern kann nicht von einer autorenzentrierten Sammlung geredet werden, die auf eine vollständige Kollektion der Werke eines einzelnen Dichters abgezielt hätte. Venantius Fortunatus' Carmina liegen in einer einzelnen Handschrift vor, ${ }^{2109}$ wohingegen die Martinsvita separat zirkulierte und in hagiographische Sammlungen eingebunden wurde. ${ }^{2110}$ Auch Paulinus von Périgueuxs metrische Vita Martini findet sich in solchen Kontexten wieder, ${ }^{2111}$ ebenso Paulinus von Nolas Gedichte auf den heiligen Felix (Carmina Natalicia). ${ }^{2112}$ Bei all diesen Autoren lag das Sammelinteresse mithin an Bibeldichtung und Hagiographie, nicht so sehr am Autor selbst.

$2105 \mathrm{Zu}$ den Klassikern als Teil von Schulhandschriften siehe unten, S. 334, 338.

2106 Respektive auf der Reichenau, in St. Gallen (auch Cod. Sang. 197) und Murbach.

2107 HäSE: Bücherverzeichnisse. Nr. 365, 366 der Konkordanz.

2108 In Erlebalds Ergänzungsliste.

2109 Cod. Sang. 196 (wo im hinteren Teil noch Rätsel hinzugebunden sind). Als einzelne Handschrift sind die Carmina auch in Murbach verzeichnet.

2110 Vereint sind beide Werke dagegen öfter im westfränkischen Raum (LEo (Hrsg.): Venanti Honori opera poetica. S. XXII f.).

2111 Vatikan, Pal. lat. 845, Cod. Sang. 573. Im Katalog verzeichnet in Lorsch und Murbach.

$2112 \mathrm{Clm}$ 6412. Im Katalog verzeichnet in Murbach und auf der Reichenau. 
Die insularen Dichter Beda und Aldhelm stehen oft, wie oben bemerkt, in eigenen Katalogabteilungen. Bedas Vita Cuthberti, die oft in den Katalogen als Einzelhandschrift belegt ist, wird nicht an die Werke des Autors angehängt ${ }^{2113}$ - die Ars Metrica kommt hier als geradezu prädestiniert dazu in den Sinn sondern mit fremden Werken ${ }^{2114}$ kombiniert, zum Beispiel Aldhelm, ${ }^{2115}$ oder in hagiographische Sammlungen eingefügt. ${ }^{216}$ Obwohl also Beda als Autor mit eigner Katalogabteilung noch prominenter ist als irgendeiner der Dichter, wird seine Dichtung gerade nicht in Sammelhandschriften Bedas, sondern meist zu anderer Dichtung eingeordnet - ein Hinweis darauf, dass Form und Genre bei der Textzusammenstellung wichtiger sind als die oberflächliche Autorenkategorie und dass die christlichen Dichter oft nur deswegen "Autorensammlungen« erhalten, weil ihre Werke qua Umfang eine Handschrift füllen können. Das gleiche gilt für Columbans Handvoll Gedichte, die nicht an seine Regula oder Briefe angeschlossen werden, sondern sich in Sammelhandschriften verschiedener Natur finden. ${ }^{2117}$ Aldhelms Aenigmata aus der Epistola ad Acircium und das Carmen de virginitate befinden sich in den hier untersuchten Handschriften und Katalogen kein einziges Mal in einer Handschrift beieinander. ${ }^{2118}$ Sie werden zwar in manchen Bibliotheken in der Aldhelm-Abteilung gesammelt, jedoch anscheinend in getrennten Bänden. ${ }^{2119}$ In den Handschriften wird Aldhelm, besonders die weit verbreiteten Aenigmata, vor allem mit anderer Rätseldichtung gepaart, insbesondere Symphosius ${ }^{2120}$ oder auch mit Spruchdichtung wie $\mathrm{Pu}-$ blilius und Ps.-Cato. ${ }^{2121}$ Während diese Sammlungen auf den ersten Blick als »Autoren-Sammelkodizes« erscheinen können, sind sie vielmehr Rätsel- oder Spruchsammlungen mit Verbindung zur Schule ${ }^{2122}$ ohne ein besonderes Augenmerk auf Autoren.

Der Begriff der Autorensammlung stellt sich also als eine nur technisch korrekte, aber zuletzt wenig aussagekräftige Kategorie heraus, die uns nichts über die Intention der Sammlung lehren kann. Es gibt zahllose Autorensammlungen einfach deshalb, weil die beliebtesten Autoren - Sedulius, Prudentius, Juvencus,

2113 Vgl. vll. Murbach die Katalognummer 191 (S. 199).

2114 Cod. Sang. 265.

2115 Cod. Sang. 263.

2116 HÄSE: Bücherverzeichnisse. Nr. 203, 364 der Konkordanz.

2117 Cod. Sang. 273 + Bremen, StUB Ms. b 52, Cod. Sang. 899, Clm 6404.

2118 Die Carmina Ecclesiastica waren im Ostfrankrenreich so gut wie unbekannt und finden sich kurioserweise im Anhang an die Walahfrid-Handschrift Cod. Sang. 869.

2119 Siehe S. 100f., St. Gallen, Hauptkatalog Nr. 11-13, S. 169, Reichenau Nr. 6-8.

2120 Cod. Sang. 273 + Bremen, StUB Ms. b 52, Staatsbibliothek Ms. b. 52,5 mit Grammatik darin. Vatikan, Pal. lat. 1753. In Passau werden enigmata Simphosii et Althelmi et Ioseppi verzeichnet.

2121 Wien, Cod. 969.

2122 Vgl. zum Beispiel Paris, Lat. 16668. 
Arator - buchstarke Werke geschaffen haben, die dann auch, da ihre Zugehörigkeit zueinander traditionell und schulisch-institutionell gegeben war, zu »Autoren-Sammelkodizes« zusammengefasst wurden. Verlässt man aber den engen Kreise dieser kanonischen Dichter, trifft das Schema nur noch oberflächlich $\mathrm{zu}$, da die Dichter dann meist ohne einen sie selbst betreffenden Sammelimpuls, sondern in Hinsicht auf Genres - Bibeldichtung, Rätsel, Spruchdichtung - zusammengestellt wurden.

\section{III.5.a.2 Heidnische Dichter}

Von den heidnischen Klassikern erreicht nur Vergil eine den christlichen Dichtern vergleichbare Verbreitung, obwohl auch diese, wie in der St. Galler Skepsis gegen den Dichter deutlich wird, noch keine Selbstverständlichkeit war. Die Sammlung des Dichters wurde durch die reiche handschriftliche Tradition im Westfrankenreich befördert. ${ }^{2123}$ In sechs Bibliothekskatalogen ist Vergil mit eigenen Handschriften verzeichnet, ${ }^{2124}$ wobei auf der Reichenau und in Murbach die Zusammenfassung der Hauptwerke in uno corpore noch zweifelhaft erscheint; auch bei den anderen Vergil-Titeln ist oft unklar, ob die verzeichnete Handschrift nur die Aeneis oder auch die weiteren Hauptwerke enthielt. ${ }^{2125}$ Selbst dieser klassische Dichter schlechthin unterliegt also in der Sammlung seiner Werke noch Schwankungen und Unsicherheiten, von denen sich das Problem der Appendix Vergiliana bis heute erhalten hat. ${ }^{2126}$ Keine der hier untersuchten Handschriften stellt eine vollständige Sammlung der Werke dar, wiewohl bei den zahlreicheren Fragmenten sich der Inhalt nicht mehr feststellen lässt. ${ }^{2127}$ Dies ist sicher nur ein Bruchteil der ehemals vorhandenen Handschriften, von denen nicht wenige, wie Holtz bemerkt, ${ }^{2128}$ als »livres de travail « abgenutzt und makuliert wurden. Die indirekten Indizien für eine weite Verbreitung Vergils in der Schule sind in Zitaten und Auxiliartexten ${ }^{2129}$ gegeben. Bemerkenswert ist in diesem schulischen Zusammenhang, dass Vergil nicht, wie die christlichen Dichter, Teil von grammatischen Sammelhandschriften oder Autoren-Sammel-

2123 Vgl. Holtz: »La redécouverte de Virgile«.

2124 Reichenau, Murbach, Lorsch, Freising, Passau und Köln. In St. Gallen ist der Dichter nur in Grimalds Sammlung und in den scottice scripti aufgeführt, also nicht in der Hauptsammlung.

2125 In Passau z. B. lagen nur Georgica und Eklogen vor.

2126 Die Murbacher Reihenfolge der Werke, obwohl handschriftlich nicht belegt, erhält sich bis heute in Umfang und Reihenfolge der Editionen der Spuria Vergils.

2127 Clm 29216, Cod. Sang. 1394, Clm 29005 (18).

2128 Holtz: "La redécouverte de Virgile«. S. 16.

2129 Zum Beispiel Glossaren und Accessus. 
kodizes $^{2130}$ wird, sodass, obwohl der Umfang der Vergilhandschriften schwankt, sie dennoch immer reine Gedichthandschriften bleiben. ${ }^{2131}$

Horaz stand bekanntlich seine Renaissance im 12. Jh. noch bevor und die Kenntnis der Dichters im Ostfrankenreich ist zufällig und stückhaft. Mehr oder weniger vollständige Handschriften gab es nur in Lorsch ${ }^{2132}$ und in Weißenburg, ${ }^{2133}$ dort nicht als Schulhandschrift, sondern als von Walahfrid redigiertes, repräsentatives Exemplar. Diese Überlieferung in codice uno stellt einen ganz anderen Modus der Überlieferung dar als die umfangreichen Auszüge in der insularen Handschrift Bern Ms. 363. Gegenüber dieser florilegischen Tradition darf der Weißenburger Horaz als bewusste Rekonstituierung eines Corpus Horatianum angesehen werden, stimuliert durch das Sammelinteresse Walahfrids und Grimalds.

Einen ähnlichen Eindruck erweckt die stattliche Juvenal und Persius-Handschrift Montpellier H 125 aus Lorsch, und auch die verlorene St. Galler Handschrift mit vollständigen Scholien wird über dem Niveau einer gewöhnlichen Schulhandschrift gestanden haben. Juvenal und Persius finden sich auch im nicht-lokalisierten Katalog von Donaueschingen Cod. 191 in einer Handschrift zusammen, sodass diese auch heute noch vertraute Textgemeinschaft ${ }^{2134}$ schon im 9. Jh. etabliert war - wohl aus dem einfachen Grunde, dass Persius nur ein Buch füllt und sich somit leicht an den anderen Satiriker anschließt.

Auch Lukan, ${ }^{2135}$ Lukrez, ${ }^{2136}$ Ovid $^{2137}$ und andere Epiker ${ }^{2138}$ treten in den $\mathrm{Ka}$ talogen mit eigenen Handschriften auf, jedoch immer vereinzelt und als Kostbarkeiten einzelner Klöster. Die gleichzeitige Verwendung im Unterricht, die für Vergil ein allgemeines Interesse schuf und seine Verbreitung beförderte, lässt sich für die anderen lateinischen Großdichter nur vereinzelt feststellen. ${ }^{2139}$ Ihre Handschriften sind somit eher als punktuelle Äußerungen eines individuellen Sammelinteresses, denn als quasi-institutionelle Notwendigkeiten innerhalb des Schulunterrichts anzusehen.

2130 Nur der kuriose »historische« Vergil in Lorsch Lat. 7906+5018 fällt aus dem Schema.

2131 Diese kodikologische Integration ins Curriculum blieb dem Cento Probae Virgilianus vorbehalten: Vatikan, Pal. lat. 1753, Zürich, C 68, Karlsruhe, Aug. Perg. 217.

2132 Im Katalog Ca, Nr. 407. Die Verzeichnung in Katalog von Tegernsee vermute ich eher im 10. Jh.

2133 Vatikan, Reg. Lat. 1703.

2134 Susanna Morton BRAUnd, Juvenal and Persius (Loeb classical library 91), Cambridge, Mass. [u. a.] 2004.

2135 Murbach, Lorsch.

2136 Corvey, Murbach.

2137 In Einzelwerken: Im Katalog der Donaueschinger Handschrift: Ars Amatoria und Metamorphosen. In Murbach: Ex Ponto (siehe S. 177, 202).

2138 Silius Italicus und Statius im Katalog Donaueschingen Cod. 191.

2139 Cod. Sang, 870. 


\section{III.5.a.3 Zeitgenössische Dichter}

Bei den zeitgenössischen Dichtern und der Frage, ob sie wie die christlichen oder heidnischen Klassiker gesammelt wurden, ${ }^{2140}$ ist von vornherein zwischen ihrer Groß- und Kleindichtung zu unterscheiden. Denn die Verbreitung der größeren Werke war, ${ }^{2141}$ wie oben schon bemerkt, prompt, unproblematisch und zudem von einflussreichen Sponsoren befördert. Bei ihnen stellt sich die Frage nach zeitgenössischer Sammlung nicht.

Ganz anders dagegen gestaltete sich die Überlieferung der Kleindichtung, das heißt der zahlreichen Briefgedichte, Tituli, Gelegenheits- und Sinngedichte, die im kulturellen Fluidum des Karolingerreichs zirkulierten. Die Natur der Sache selbst macht die Sammlung dieser Werke schwierig: Sie waren unter zahlreichen Adressaten in alle Himmelsrichtungen zerstreut - die größte Erhaltungschance ergibt sich hier noch aus einem vom Autor angelegten Archiv der eigenen Werke; die Gedichte selbst konnten als Briefe oder quasi-epistolare Kommunikation nicht das Prestige ganzer gewidmeter Werke erlangen und die Verluste waren dementsprechend zweifellos hoch; zuletzt macht die Zerstreuung der GedichtCorpora jede Anthologie derselben nur tentativ und dem lokalen Überlieferungszufall unterworfen. Aus diesen Gründen darf der Vorwurf der Unvollständigkeit oder Variabilität der Anthologien keine Ansprüche an die Sammler des 9. Jh. erheben, die selbst die Textkritiker des 19. und 20. Jh. nicht erfüllen konnten, wie die vielen Dubia, Spuria und überhaupt die anonyme Kleindichtung beweisen, die sich nicht mehr ihrem Autor zuordnen lässt. Sammlung war leicht, wo es sich um epische Gedichte oder etablierte Sammlungen wie Prudentius oder Venantius Fortunatus handelt; bei Autoren, deren Schaffen gerade erst Jahrzehnte zurücklag, war sie beinahe unmöglich. Insofern zeigen die Anthologien zeitgenössischer Autoren die ehrliche Mühe der Sammler innerhalb der ihnen vom Material selbst gesetzten Grenzen.

Besonders beliebt waren Alkuins Gelegenheitsdichtungen, die in zahlreichen Handschriften, jedoch allermeist einzeln oder in kleinen Grüppchen, im Umlauf waren. $\mathrm{Zu}$ einer eigentlichen Anthologisierung kam es nur an wenigen Stellen, nämlich in Tours, Salzburg und vielleicht in Fulda. Tours, der letzte Wirkungsort Alkuins, darf als Quell der Überlieferung angesehen werden: Aus dem hier erhaltenen Archiv wurden, wie ich glaube nachgewiesen zu haben, sowohl der verlorene Codex Bertinianus, der 272 (!) Gedichte enthielt, sowie der Grundstock der Salzburger Sammlung unter Arn geschöpft. Parallele Sequenzen der Überlieferung legen eine blattweise oder zumindest zerstückelte Vorlage nahe. Was

2140 Dies wird kategorisch verneint von Godman: "Latin poetry under Charles the Bald and Carolingian poetry«. S. 294f. Siehe dort auch zu westfränkischen Sammlungen.

2141 Siehe zum Beispiel Hrabans Kreuzgedichte, Otfrids Evangeliendichtung, Wandalberts Martyrologium oder Brun Candidus' Vita Aegil. 
Arn dann aber in Salzburg aus den Vorlagen machte, war weniger eine reine Anthologie, wie der unerreichte Bertinianus, sondern eine Briefsammlung mit angeschlossener Anthologie. Das Interesse am Autor selbst ist evident; Dichtung ist hier nicht, wie so oft, nach Genre abgetrennt und separat überliefert, sondern blieb mit den Briefen unter ihrem ursprünglichen gemeinsamen kommunikativen Gesichtspunkt vereinigt. Unter Bischof Liuphram wurde aus dem selben Material, dessen man sich unter Arn bedient hatte, eine erweiterte Sammlung von Alkuins Gedichten erstellt, ${ }^{2142}$ die jedoch auch stärker lokale Salzburger Dichtung einbezog. Die Fuldaer Sammlung, von der uns nur noch ein Katalogeintrag des 16. Jh. berichtet, enthielt ebenfalls Alkuins Briefgedichte; es ist sicher bemerkenswert, dass wie bei Arn in Salzburg, so auch bei Alkuins Schüler Hrabanus in Fulda eine solche Sammlung angelegt wurde. Alkuin-Anthologien erscheinen somit entweder an den Wirkungsort des Dichters oder an den seiner Freunde und Schüler gebunden zu sein.

Auch Theodulfs Dichtung wurde offenbar gezielt gesammelt. Abgesehen von den zwei wahrscheinlich westfränkischen ${ }^{2143}$ (verlorenen) Handschriften Sirmonds und Mabillons erscheinen Anthologien seiner Dichtung in den Murbacher und Lorscher Katalogen: In Murbach vielleicht in einem eher astronomisch orientierten Sammelband und in Lorsch der Briefwechsel mit Modoin und wahrscheinlich weitere Gedichte in quaternionibus V. Auch in St. Gallen scheint eine kleinere Anthologie vorhanden gewesen $\mathrm{zu}$ sein, wo sich in mehreren Handschriften eine Handvoll Versus Theotolfi finden. ${ }^{2144}$ Der Sammelimpuls scheint hier gegenüber den großen westfränkischen Anthologien abgeschwächt zu sein und sich auf Auszüge aus dem Werk zu konzentrieren oder einfach nur in seinen Quellen eingeschränkt gewesen zu sein.

Die große Fuldaer Hrabanus-Anthologie, die Brouwer als Vorlage seiner Edition gebrauchte, ist verloren gegangen. Fulda scheint der einzige zentrale Sammelort für die Dichtung seines großen Abtes gewesen zu sein; dort wurden ebenfalls seine Briefe in einer separaten Handschrift versammelt, ${ }^{2145}$ analog dem Alkuin-Ensemble Arns in Salzburg, und vielleicht nach Hrabanus' Tod dort zusammengestellt. Diese Sammlung fand ein Echo in einer Murbacher Handschrift, wo eine Reihe der Gedichte in selber Reihenfolge - aber nicht aus der Fuldaer Handschrift - kopiert wurden, wohl aber von vornherein als Auszug aus einer größeren Sammlung und im Verbund mit nicht Hrabanischen Texten. Im Gegensatz zur Alkuin-Anthologie scheint aber hier eine in Fulda festgelegte Sequenz von Gedichten, mithin eine eigentliche Hrabanus-Anthologie, im Ge-

2142 Deren Echo im Kodex von Frobenius nachgewiesen werden kann.

2143 Orléans? So Schaller: „Geraldus und St. Gallen - Zum Widmungsgedicht des >Waltharius««. S. 77.

2144 Cod. Sang. 899, Cod. Sang. 197, Cod. Sang. 263, Zürich, C 78. 451.

2145 Beide Sammlungen im Katalog des 16. Jh. verzeichnet. 
gensatz zu einem auktorialen Archiv, beiden Textzeugen zum Vorbild gedient hat. Hrabanus' Dichtung erlangt somit einen festeren Organisationsgrad als vergleichbare Sammlungen.

Die zwei großen Anthologien ${ }^{2146}$ von Walahfrids Dichtung stammen aus St. Gallen und Fulda ${ }^{2147}$ und keine wurde aus der anderen abgeschrieben. Aus der komplexen Kodikologie der St. Galler Handschrift hat sich ergeben, dass deren Inhalte aus einer komplexen Vorlage, analog dem alkuinischen Archiv für dessen Anthologie, ausgewählt und gesammelt wurden, sodass St. Gallen unter Grimald, nicht die Reichenau, als der Aufbewahrungsort von Walahfrids Nachlass vermutet werden darf. Aus der gleichen komplexen Vorlage, aber vielleicht unter Vermittlung einer weiteren Handschrift, wurde die Fuldaer Handschrift erstellt, deren Besitzer der Magister Rudolf war. Vielleicht stammen die ersten Ansätze einer Anthologisierung von Walahfrid selbst, wie der Titel Versus Strabi Walahfridi quos post annum aetatis XV editit de rebus diversis anzudeuten scheint.

Die Anthologien der zeitgenössischen Dichter befinden sich allgemein in einem noch amorphen Stadium der Sammlung, die eng mit den Orten des Wirkens der Dichter verbunden ist. Im Gegensatz zu etablierten klassischen Anthologien wie denen von Prudentius oder Venantius Fortunatus, deren Ordnung und Einteilung in Bücher die auktoriale Sammlung deutlich macht, scheint keine der neuen Anthologien die Hand des Dichters selbst erkennen zu lassen. Die Sammlung eigener Kleindichtung beschränkte sich auf deren Archivierung, obwohl es klassische Vorbilder für deren auktoriale Anthologisierung gegeben hätte. Die Kleindichtung scheint also gegenüber den größeren Werken, für deren Verbreitung aktiv gesorgt wurde, eine untergeordnete Rolle für den Autor selbst gespielt zu haben, und zwar auch weil sie, die so häufig Briefdichtung war, ihre kommunikative Funktion schon erfüllt hatte und somit als Brief von gestern keinen unmittelbaren Verwendungszweck mehr für ihren Autor erfüllte. Erst die Nachlassverwalter der Dichter konnten deren Werke reevaluieren und sie - ob unter dem Gesichtspunkt der stilistischen Mustergültigkeit oder auch aus Pietät gegen den verstorbenen Abt, Freund oder Schüler - in umfassende Anthologien sammeln. Dass dies nicht im Rahmen einer zentralen und dann in Kopien verbreiteten Sammlung stattfand, zeigen die anscheinend durch erneuten Zugriff auf dieselbe Materialsammlung erstellten Anthologien Alkuins und Walahfrids; und die relativ höhere Einheitlichkeit der Sammlungen von Hrabanus' und Theodulfs Gedichten zeugt nicht unbedingt von einer vorhergehenden "Edition «, sondern nur von einer sekundären Kopie einer einmal gemachten Sammlung.

2146 Cod. Sang. 869, Reg. lat. 469.

2147 Oder von Fuldaer Hand. 


\section{III.5.b Schulhandschriften}

Insofern mit Schulhandschrift nichts weiter gemeint ist als eine, die im Unterricht verwendet wurde, wird sich kein einheitlicher Typus der Schulhandschrift aus der Vielzahl von der Schule nahestehenden Handschriften herausarbeiten lassen. Schuldichter und ihre Handschriften liegen auf einem Kontinuum von Prachthandschriften hin zu schulischen Exzerpten, und die Frage der schulischen Nutzung ist in ihrem Falle keine kategorische der Handschriftentypen, sondern eine pragmatische ihres mehr oder weniger intensiven Gebrauchs in der Schule.

Zum Zwecke der terminologischen Klarheit sollten als Schulhandschriften nicht solche bezeichnet werden, die in der Schule genutzt wurden, sondern solche, die von vornherein auf einen schulischen Gebrauch hin ausgelegt wurden. In unserem Falle sind dies Handschriften, in denen Grammatik (insbesondere Lehren der Metrik) und Dichtung in einem Band vereint wurden. ${ }^{2148}$ In diesen Handschriften ist eine Textgesellschaft verwirklicht, die sich in den Katalogen häufig in getrennten Handschriften beieinander findet. Schon in den Katalogen sind diese Schulhandschriften reichlich belegt. Besonders in St. Gallen unter den libris grammaticae artis und auf der Reichenau ${ }^{2149}$ kann von einer eigentlichen Lehrbuchsammlung gesprochen werden. Ähnliche Handschriften sind in Lorsch verzeichnet, fehlen jedoch auffälligerweise in Murbach.

Als Gebrauchshandschriften waren diese Schulhandschriften sicher stärkerer Abnutzung als andere ausgesetzt und die erhaltenen Beispiele sind von geringerer Zahl als die von anderen der Schule nahe stehenden Kodizes. Sie sind oft von zusammengesetzter Natur, was die Nähe zu den Textgesellschaften der Kataloge unterstreicht. Emblematische Beispiele haben sich aus St. Gallen, der Reichenau und Lorsch erhalten. ${ }^{2150}$ In diesen stellt die Grammatik den Kern der Sammlung dar, zu der die Dichtung das extensive Beispielmaterial liefert. Ein ähnliches Verhältnis vom primären Grammatiktext zur supplementären Dichtung findet sich in grammatischen Handschriften, in denen verhältnismäßig wenig Dichtung ergänzt wurde. ${ }^{2151}$ Sich dem Idealtypus der Schulhandschrift annähernd sind mehrere Handschriften, deren nicht poetisches Material mehr oder weniger der Schule nahesteht, ${ }^{2152}$ darunter einige, die an persönliche Handbücher eines Lehrers erinnern. ${ }^{2153}$

2148 Die andere Unterkategorie sind reine Grammatik-Handschriften.

2149 Hier verteilt in verschiedene Kategorien des Katalogs und in der Reginbert-Liste.

2150 Cod. Sang. 877, Vatikan, Pal. lat. 1753, Pal. lat. 1719, Karlsruhe, Aug. Perg. 112.

2151 Paris, Lat. 16668, Cod. Sang. 270, Clm 6411, Clm 6404.

2152 Leiden, Voss. Lat. Q. 69, Cod. Sang. 273 + Bremen, StUB Ms. b 52, Ms. b. 52, Vatikan, Pal. lat. 1719.

2153 Siehe S. 339 zum Vademecum. 
Angesichts der Prominenz der Dichtung in der Schule, die sich in vielen nicht ausschließlich schulischen Handschriften nachweisen lässt, überrascht der relative Mangel an dezidierten Schulhandschriften. Gerade in einer gut ausgestatteten Bibliothek jedoch, in der zahlreiche separate Bände mit Dichtung und Grammatik zu finden waren - man denke an Lorsch oder Murbach - bestand nicht unbedingt ein dringender Bedarf nach kombinierten Schulhandschriften; die Textgesellschaft der Bibliothek erfüllte diesen Zweck ebenso gut wie eine dezidierte Handschrift.

\section{III.5.c Vademecum}

Die Handschriften, die als Vademecum, Handbuch, Notizbuch und dergleichen bezeichnet werden, teilen mit den anthologischen Sammelhandschriften den langsam gewachsenen, organischen Charakter, jedoch unter Betonung des persönlichen Elements in Sammlung und Nutzung der Handschrift. Insofern hängt die Bezeichnung einer Handschrift als Vademecum oder Ähnliches auch entscheidend davon ab, ob der Forscher in ihr dieses individuelle Element zu erkennen glaubt oder nicht. ${ }^{2154}$ Darüber hinaus verbindet derartige Handschriften wenig, und ihre Inhalte und damit die enthaltene Dichtung sind durch die Interessen und Aufgaben des Besitzers bestimmt.

Personal-miszellanen Charakter tragen die persönlichen Handschriften ${ }^{2155}$ von Grimald, dessen vielfältige poetische Interessen sich darin abbilden, von Walahfrid, wo die Dichtung in der Nähe zur Grammatik steht, und Bischof Gozbald, wo dessen Heiligenverehrung eine Rolle spielt. Von kirchlich-amtlichen Interessen geleitet scheint die Notker-Sammlung mit den daraus hervorgehenden Handschriften von Waldo von Freising und Salomo III. von Konstanz, ${ }^{2156}$ die jedoch persönliche Anthologien ergänzen. Beinahe schon offiziell wirken einige kirchlich-liturgisch geprägte Kompendien mit entsprechender Dichtung. ${ }^{2157}$ Der Charakter eines eigentlichen, kleinen Notizbuches hat sich in einigen Handschriften oft schulischen Charakters erhalten. ${ }^{2158}$

2154 So wurde zum Beispiel Zürich, C 78 als »Notizbuch« bezeichnet (SCHALLER:»Geraldus und St. Gallen - Zum Widmungsgedicht des >Waltharius«". S. 80).

2155 Cod. Sang. 397 (Grimald), Cod. Sang. 878 (Walahfrid), Würzburg, M.p.th.f. 56 (Gozbald).

2156 Wien, Cod. 1609, Clm 19413.

2157 Wolfenbüttel, Cod. Guelf. 91, Trier, Ms.1245/597, Ms. 592/1578.

2158 Leiden, Voss. Lat. Q. 69, Clm 6411, St. Paul im Lavanttal, Ms. 86b/ ( (25.2.3 1b), Bern, Ms. 363, Einsiedeln Ms. 266 (1296), Ms. 326 (1076). 


\section{III.5.d Anthologien}

"Anthologie« als Begriff für Handschriften, die zum Großteil kleinere Gedichte aller Art enthalten, ist ein ebenso weiter und oft bloß technisch korrekter Begriff wie die oben besprochene "Autorensammlung«. Sollte in die Definition auch noch das Kriterium eines gewissen Umfangs der Handschrift einbezogen werden, so gäbe es in diesem strengen Sinne nur zwei große Anthologien, Cod. Sang. 899 und Zürich C 78, beide aus St. Gallen vom Ende des Jahrhunderts - wovon die letztere auch noch größere Prosa-Passagen enthält, was den Eindruck der reinen Anthologie trübt. Hinzu kommen die Handschriften, die neben einem zumindest beachtlichen Anteil von Kleindichtung auch größere Werke oder Prosa enthalten, ${ }^{2159}$ und somit per definitionem nicht unter den Begriff der Anthologie fielen, würde dieser nur auf ganze Handschriften angewandt. In großen wie in kleinen Anthologien wird jedoch das gleiche distinktive Verfahren angewandt, mit dem Kleindichtung zu größeren Einheiten zusammenwächst, sodass die großen St. Galler Sammlungen nichts anderes sind, als das Ergebnis eines langen anthologischen Prozesses, der auch schon vorher in kleineren Sammlungen Ausdruck fand. Ich möchte also den Begriff der Anthologie weniger als Bezeichnung für Handschriften, als für die Sammeltätigkeit selbst in Anspruch nehmen, deren Ergebnis Gedichtsammlungen in verschiedenen Graden der »Reinheit« sind. Der Zweck der jeweiligen Sammlung ist ganz getrennt von ihrem Verfahren zu betrachten und im je individuellen Falle anhand des Inhaltes der Gedichte und der weiteren Handschrift festzustellen.

Zur leichteren Analyse ist es zweckdienlich, die anthologische Sammeltätigkeit in zwei diachrone Entstehungsstufen zu unterscheiden, die jedoch tatsächlich oft gleichzeitig stattfinden:

1. Zuerst werden in der Primärsammlung die Einzelstücke - auch Exzerpte eines nach dem anderen gesammelt. Diese Sammeltätigkeit kann in verschiedenen Formen stattfinden: In Handschriften findet sie sich oft in Form einer paläographisch nachweisbaren stückweisen Ergänzung, wodurch vorher unverbundene Gedichte in eine neue Sequenz gesetzt werden. Andere Überlieferungsvehikel der Primärsammlung wie Einzelblätter, Schedae, Codicilli und ähnliche vergängliche Schriftträger können meist nur hinter den Handschriften vermutet, aber nicht zweifelsfrei nachgewiesen werden. Die Primärsammlung bildet oft eine thematische Einheit als Sequenz etwa von Epitaphien, Accessus, Rätseln etc. ${ }^{2160}$ Sie ist im Folgenden die Einheit der

2159 Vatikan, Pal. lat. 487, Cod. Sang. 273 + Bremen, StUB Ms. b. 52, Leiden, Voss. Lat. Q. 69, Cod. Sang. 197, Einsiedeln, StB, Cod. 326 (1076), Clm 19413, Clm 19410.

2160 Siehe auch oben S. $327 \mathrm{f}$. zu Textgesellschaften. 
Überlieferung und wird im Allgemeinen als ganzes kopiert, wobei sie mitunter gekürzt oder um Elemente erweitert wird.

2. In der Sekundärsammlung werden vorher bestehende Primärsammlungen zu größeren Anthologien zusammengefügt oder auch mit nicht-poetischen Texten kombiniert. Das Objekt der Sammeltätigkeit ist meist nicht das einzelne Gedicht, sondern die Primärsammlung, in der es sich befindet. Durch die Sekundärsammlung werden die oft losen, fragilen Primärsammlungen in einen festeren kodikologischen Zustand, das heißt in Handschriften überführt. Eine Sekundärsammlung kann in der Folge selbst zur Einheit in der Überlieferung werden und in späteren Sammlungen mit anderen kombiniert werden.

Praktisch laufen diese Prozesse meist parallel ab. Einem Schreiber liegen etwa drei Sekundärsammlungen $\mathrm{ABC}$ vor. Er kombiniert diese, und er selbst oder andere Schreiber ergänzen jeweils thematisch passende Einzelstücke und wirken somit als Primärsammler: ${ }^{2161}$

$$
\mathrm{A}[+\mathrm{ab}]+\mathrm{B}[+\mathrm{de}]+\mathrm{C}[+\mathrm{fg}]
$$

Durch Kombination von Vorstufen von verschiedenem Ausmaß erzeugt dieser Prozess komplexe Überlieferungsmuster, von denen die Handschrift selbst nur der letzte, sichtbare Ausdruck ist.

Als Ergebnis dieses Sammelprozesses ist eine reine Gedichtsammlung nur eines von vielen möglichen Ergebnissen und in der Tat ein relativ seltenes. Vielmehr werden gewöhnlicherweise Sammlungen von Prosa und Dichtung miteinander kombiniert, je wie es Zweck der Handschrift und Interessen der Sammler erfordern, zum Beispiel ein Computus mit Kalenderdichtung oder eine Metriklehre mit Beispielgedichten. Insofern ist "Anthologie» eine künstliche Kategorie, die unter Ausblendung der anderen möglichen Ergebnisse des gleichen Prozesses gewonnen wird.

Ferner ist erneut zu betonen, dass meist nicht die einzelnen Gedichte, sondern Sammlungen miteinander kombiniert werden. Dies bedeutet, dass der vom Sammler ausgewählte Text, der uns über seine Interessen unterrichtet, weniger jedes einzelne Stück der Sammlung ist, sondern vielmehr die größeren Einheiten sind. Hierdurch erklärt sich der oft deplatzierte Eindruck, den einzelne Gedichte in ihrer Umgebung machen, ${ }^{2162}$ der aus ihrem Ort in der Primärsammlung resultiert, die in der Sekundärsammlung in einen neuen Zusammenhang gestellt wurde.

2161 Vgl. exemplarisch hierzu Cod. Sang. 869.

2162 Vgl. z. B. Wien, Cod. 964, Wolfenbüttel, Cod. Guelf. 91 Weiss (f. 148v-149r). 
Zuletzt ist auch das Konstrukt der Person des "Sammlers« unter dem Gesichtspunkt der komplexen Sammeltätigkeit zu relativieren. Es ist keineswegs ein einzelner, sozusagen auktorialer Sammler, der für die Gesamtheit der Auswahl und Zusammenstellung der Gedichte verantwortlich zeichnet, sondern vielmehr ein zeitlich zurückreichendes und räumlich verteiltes Kollektiv, das in den verschiedenen Vorstufen einer Anthologie tätig war. Die Anthologien sind in diesem Sinne die historischen Monumente einer oft Jahrzehnte zurückreichenden Sammeltätigkeit, deren verstreute Ergebnisse sich erst nach und nach in den großen Sammlungen zusammengefunden haben.

\section{III.5.e Kleinere Sammlungen und Genres}

Im Folgenden soll auf Genres eingegangen werden, die selten in dezidierten Handschriften konzentriert wurden, deren Überlieferung nicht breit genug für weitergehende Schlüsse über ihre Handschriften ist oder die nicht für gewöhnlich nicht umfangreich genug für einen ganzen Kodex sind. ${ }^{2163}$

\section{III.5.e.1 Hagiographie}

Die hagiographische Dichtung steht im Schatten der viel umfangreicheren Vitenliteratur. Sie steht in den Bibliotheken bei der Dichtung, ${ }^{2164}$ nicht in der hagiographischen Abteilung, insofern sich eine solche ausmachen lässt. Wenn sich metrische Viten in Sammelhandschriften finden, werden sie gern mit weiterer hagiographischer Dichtung oder Prosa-Viten kombiniert. Der lokale Patron ist oft Anlass dieser Sammlungen. ${ }^{2165}$ Selten sind die großen Sammelhandschriften, in denen gezielt hagiographische Dichtung verschiedener Provenienz vereinigt wird. ${ }^{2166}$ Im ganzen zeichnet sich das Genre durch eine markante Schulferne aus.

\section{III.5.e.2 Inschriften, Tituli, Epitaphien}

Inschriften im weiteren Sinne, ob als Bau- und Weihinschriften, ${ }^{2167}$ Epitaphien oder Epigramme auf allerlei Gegenstände, haben eine bemerkenswerte Tendenz, sich zueinander zu gesellen und gemeinsam zu zirkulieren. Syllogen als Einzel-

2163 Bibel-, Rätsel- und Spruchdichtung werden oben anlässlich der christlichen Dichter erwähnt.

2164 So verzeichnet in Murbach und Lorsch.

2165 Wolfenbüttel, 17. 5. Aug. 4to, Vatikan, Pal lat 845. Vgl. auch die lokal verankerten hagiographischen Dichtungen von Walahfrid und Notker.

2166 Cod. Sang. 573, Lorsch (Katalog Ca Nr. 426).

2167 Auf diese wird oft der Begriff der Sylloge beschränkt. 
handschriften sind selten; hier war insbesondere in Lorsch die Sammelleidenschaft groß. ${ }^{2168}$ Oft spielt ein individuelles Interesse für die Gattung bei der Sammlung eine Rolle. ${ }^{2169}$ Inschriftensammlungen finden sich auch als Anhang zu schulnahen Handschriften. ${ }^{2170} \mathrm{Zu}$ den Sammlungen christlich-antiker, insbesondere stadt-römischer Inschriften gesellten sich zeitgenössische Inschriften oft lokaler Herkunft. Diese verbleiben oft an ihrem Entstehungsort, ${ }^{2171}$ aber zirkulieren auch über diesen engen Kreis hinaus. ${ }^{2172}$ Auch in Anthologien zeitgenössischer Autoren sind die Tituli oft in Gruppen zusammengefasst ${ }^{2173}$ und wiederholen somit in der anthologischen Ordnung das Schema der Primärsammlungen. ${ }^{2174}$

\section{III.5.e.3 Briefdichtung}

Briefdichtung ist fester Bestandteil der großen Autoren-Anthologien, ${ }^{2175}$ schon da ein großer Teil der Gelegenheitsdichtung aus Werken dieser Gattung besteht. Aber auch außerhalb dieser Sammlungen finden sich kleinere Gruppen von poetischen Briefen, oft mit einer gewissen genrefremden Einfärbung. So konzentriert sich etwa der Briefwechsel von Paulus Diaconus und Petrus Pisanus auf die Rätseldichtung, während die Gedichte Salomos und Waldrams in Cod. Sang. 197 ins Elegisch-Konsolatorische gehen. Oft hat gesammelte Briefdichtung einen Mustercharakter, ${ }^{2176}$ in Clm 19410 sind die Gedichte sogar formularisiert worden. Auffallend häufig ist die Untergattung von Briefgedichten, worin sich Lehrer und Schüler adressieren, und die oft einen humorvollen Ton anschlagen. ${ }^{2177}$ Notker integrierte sogar den Briefwechsel mit seinen Schülern in die für diese bestimmte Sammlung aus Formulae und Dichtung.

2168 Siehe die Syllogen im Katalog und Vatikan, Pal. lat. 833. Weitere Syllogen in Merseburg, Cod. 105 (Martinellus, unter Richbod) und Wien, Cod. 550.

2169 Würzburg, M.p.misc.f. 2, M.p.th.f. 56.

2170 Leiden, Voss. Lat. Q. 69, Clm 6404.

2171 Salzburg, Verbrüderungsbuch von St. Peter; Wolfenbüttel, Cod. Guelf. 91 Weiss. (Versus Wissenburgenses), Cod. Sang. 397 (Versus Sangallenses), Clm 14743 (Inschriften in Carmina Salisburgensia).

2172 Inschriften aus Worms in Wolfenbüttel, HAB, Cod. Guelf. 91 Weiss., Karlsruhe, Aug. Perg. 255 (Tituli Tegernseenses).

2173 So bei Walahfrid, Hrabanus und Alkuin.

2174 Alkuins Tituli zirkulierten auch separat, siehe S. $311 \mathrm{zu}$ Clm 19410.

2175 So bei Alkuin, Theodulf, Hrabanus, Walahfrid.

2176 Briefdichtung in den Carmina Salisburgensia, Clm 14743.

2177 Vatikan, Pal. lat. 487, Clm 6411, Versus Wissenburgenses. 


\section{III.5.e.4 Hymnen}

Hymnen finden sich in wiederkehrenden Kombinationen zusammen, die eine derartige Regelmäßigkeit aufweisen, dass von zeitlich klar unterscheidbaren Hymnar-Typen gesprochen werden kann. ${ }^{2178}$ Hymnare weisen einen Grad von fester Organisation auf, den kein anderes Genre von Kleindichtung erreicht. Hierbei steht die Hymnodie in einem bemerkenswerten Abstand zum weiteren Überlieferungsstrom der Dichtung. Handschriften, die Hymnare enthalten, enthalten meist kaum andere Dichtung und vice versa. Hymnen finden sich oft als Anhang an liturgische Handschriften ${ }^{2179}$ oder in Verbindung mit Gebeten, Bußbüchern, Mönchsregeln und ähnlichem Material. ${ }^{2180}$ Die spätere Emanzipierung der Hymnare in eigene Handschriften deutet sich auf der Reichenau und in St. Gallen schon in den Katalogen an. ${ }^{2181}$ Eine schulische Verwendung von Hymnen ist, im Gegensatz zu anderer Dichtung, selten und selbst wo sie vermutet wird, nur schwer nachzuweisen. ${ }^{2182}$

\section{III.6 Genre als pragmatische Kategorie}

Die Wahrnehmung von Genres mittelalterlicher Dichtung ist durch kritische Editionen geprägt, die den Text aus seinem handschriftlichen Kontext abstrahieren und seinen annähernd auktorialen Zustand rekonstituieren wollen. Das Genre der Dichtung ergibt sich dementsprechend gewöhnlich aus dem Urtext, nicht aus seiner späteren Verwendung. Dabei finden jedoch sowohl bei der Sammlung selbst, als auch bei ihrer späteren Verwendung Transformationen von Medium, Form und Verwendung statt, die den Text derartig aus seinem ursprünglichen pragmatischen Zusammenhang lösen, dass auch sein Genre dabei einer Wandlung unterliegt. Prinzipiell lassen sich Spannungen zwischen auktorialer Absicht und späterer Nutzung an fast allen Texten feststellen; in unserem Falle wirkte insbesondere die schulische Nutzung verzerrend, ob in der Lektüre des Textes oder ganz materiell in der Korruption des Textes durch Glossen oder ungeübte Schreiber.

An einigen Genres wird die Fluidität des Genres besonders augenfällig. Dichtung verliert bisweilen in schulischen Handschriften ihr typisches Layout

2178 GNeuss: »Zur Geschichte des Hymnars«.

2179 Trier, Ms. 592/1578, Zürich, Rh. 34.

2180 Unter Hartmuts Büchern (St. Gallen); Auf der Reichenau in der Katalogabteilung De regulis und in der Reginbert-Liste. Vgl. auch Clm 14248.

2181 Ein einzelnes Hymnar ist bei Grimald verzeichnet. Notker erstellt nicht viel später sein Liber Hymnorum.

2182 Karlsruhe, Aug. Perg. 112, Oxford, Ms. Jun. 25, Leiden, Voss. Lat. Q. 69, Neapel, Ms. IV G 68. 
mit Zeilenumbrüchen für die Verse. ${ }^{2183}$ Gerade im schulischen Kontext heißt dies, dass die elementarste metrische Struktur, der Vers, für die Leser unverständlich wurde und die Dichtung als bloßer genre-loser Beispieltext genutzt wurde. Ein extremes Beispiel ist das sowohl durch Prosa-Layout als auch durch mehrere Glossierungsschichten unkenntlich gemachte Carmen ad Deum. ${ }^{2184}$ In anderen Handschriften scheint der poetische Charakter vergessen oder einer Unachtsamkeit des Schreibers zum Opfer gefallen zu sein. ${ }^{2185}$ Der umgekehrte Prozess, nicht der Verlust, sondern die Verdeutlichung der Metrik mittels einer Fusion mit einer ganz anderen Kunst, der Musik, ist in der Neumierung zu finden. ${ }^{2186}$ Hier wird aus dem Text Gesang zu schulischen Zwecken. ${ }^{2187}$

Bemerkenswert sind auch Gattungen, die ursprünglich in einem ganz anderen Schriftmedium als dem geschriebenen Buch zuhause waren. Inschriften, insbesondere die römischen, fanden noch ihren Weg von Bauwerk, Altar oder Grabmonument in die Handschriften, in denen sie als Syllogen zirkulierten. Dieses Genre war auch bei den zeitgenössischen Dichtern beliebt - ob aber deren zahlreiche Inschriften, die oft eher epigrammatische jeux d'esprit zu sein scheinen, jemals die von ihnen beschriebenen Gegenstände schmückten, ist zweifelhaft. Vielmehr handelt es sich um die Verwandlung eines epigraphischen Genres ein literarisches, das durch die anthologische Arbeit erst definiert worden ist. Briefdichtung tritt ebenfalls beim Übergang vom einmal verschickten Brief in die Handschrift in einen grundsätzlich neuen pragmatischen Zusammenhang. Ganz verloren ist hier die kommunikative Funktion des Briefes zwischen Autor und Adressat. An vielen Beispielen konnte dagegen nachgewiesen werden, dass die Briefdichtung eine neue Rolle als Mustertext annimmt. Auf die Spitze getrieben ist diese Entwicklung in der Formulardichtung, ${ }^{2188}$ in der gezielt die Namen entfernt werden und die in einer Entwicklungslinie mit der weiteren Formularliteratur von Urkunden und Briefen steht.

2183 Cod. Sang. 273, Karlsruhe, Aug. Perg. 112, Clm 19410, Vatikan, Pal. lat. 1753.

$2184 \mathrm{Clm} 19410$.

2185 Cod. Sang. 2, Clm 14377.

2186 Neapel Ms. IV G 68, Cod. Sang. 136, Reg. Lat. 1703, Wolfenbüttel, Cod. Guelf. 66 Gud. lat.

2187 Vgl. hier ergänzend die oben S. 217, 344 genannte schulische Verwendung von eigentlichen Hymnen.

2188 Wolfenbüttel, Cod. Guelf. 91 Weiss., Clm 14743, Clm 19413, Clm 19410, Clm 6404, Wien, Cod. 1609, Carmina Salisburgensia. 


\section{III.7 Dichtung und Schule - eine Schlussperspektive}

Die überragende Rolle, die die Schule in der Überlieferung und Sammlung von Dichtung spielte, wurde auf beinahe jeder Seite dieser Arbeit klar und konnte eben noch einmal anlässlich der Ordnung der Bibliothek und der Handschriftentypen betont werden. Die Schule war zweifellos die historische "Überlieferungschance» der Dichtung, und die Erforschung ihrer mittelalterlichen Rezeption war besonders auf kodikologischer Ebene stark durch diesen Überlieferungskontext geprägt; ein Ungleichgewicht, das auszugleichen sich diese Arbeit zum Ziel gesetzt hatte. Trotzdem darf die Dominanz der Schule in der Überlieferung, da mit ihr als schriftlichem Milieu par excellence so viele Handschriften verbunden sind, uns nicht den Blick darauf verstellen, dass sie nur die erste einer Reihe von Institutionen und Praktiken ist, in denen Dichtung gebraucht, gesammelt und geschaffen wurde. In der Schule lernte sie jeder kennen, ob aus ihm ein einfacher Mönch oder ein Bischof wurde. Sie ist fraglos das Fundament, auf dem die komplexe Beschäftigung mit Dichtung im 9. Jh. ruht, sowohl für den Einzelnen, der sie dort erlernte, als auch für die Institution, deren Grundstock an Dichtung ein schulischer war. Dichtung beginnt in der Schule - aber sie endet nicht dort. Sie wird, das darf man nicht vergessen, schlicht als Lektüre geschätzt; dass Dichtung begierig gelesen und rezipiert wurde, belegen die zahllosen Zitate in zeitgenössischer Dichtung. Hier zeigt sich die allgemeine Funktion, die insbesondere die klassisch-christliche Dichtung über die Schule hinaus erfüllte, nämlich die als mustergültiges Genre, dessen Vollkommenheit man nachzuahmen strebte. Aber letztendlich ist der Zweck der Dichtung ihre Anwendung - die Schule und viele Handschriften sind hierfür nur Vorbereitung und Werkzeug. Ob als Gebet, als Brief, als Inschrift, als Vita, als Kalender: Die gehobene Form der Dichtung verleiht allen Genres die literarische Vollendung, mit der der Dichter sich als honnête homme seiner Zeit ausweisen konnte. Die Dichter des 9. Jh. schrieben nicht für die Handschrift, sondern für ihre Adressaten: Das lebendige Interesse daran, zu dichten, wurzelte nicht in der Schule, die dazu nur das Handwerkszeug lieferte, sondern in der Kommunikation mittels dieser prestigeträchtigen Form. 


\section{Bibliografie}

\section{IV.1 Quellen ${ }^{2189}$}

\section{IV.1.a Sammelwerke}

Albers, Bruno (Hrsg.), Consuetudines monasticae, Stuttgart [u.a.] 1910.

Baehrens, Aemilius (Hrsg.), Poetae latini minores, Leipzig 1879.

BeCKer, Gustav (Hrsg.), Catalogi bibliothecarum antiqui, Bonn 1885.

Bruyne, Donatien (Hrsg.), Prefaces to the Latin Bible, hrsg. von. Pierre-Maurice Bogaert und Thomas O'Loughlin (Studia traditionis theologiae 19), Turnhout 2015.

Bulst, Walther (Hrsg.), Hymni Latini antiquissimi LXXV, Psalmi III, Heidelberg 1956.

De Rossi, Giovanni Battista (Hrsg.), Inscriptiones christianae urbis Romae saec. VII antiquiores, vol. 2,1, Rom 1888.

Dreves, Guido Maria und Clemens Blume (Hrsg.), Analecta hymnica medii aevi, Leipzig [u. a.] 1886.

DüMmler, Ernst u. a. (Hrsg.), Poetae latini aevi Carolini (MGH Antiquitates), Berlin 18811939.

DüMmLer, Ernst (Hrsg.), MGH Poet. lat. 1, Berlin 1881.

DüMmLer, Ernst (Hrsg.), MGH Poet. lat. 2, Berlin 1884.

Traube, Ludwig (Hrsg.), MGH Poet. lat. 3, Berlin 1896.

Winterfeld, Paul von (Hrsg.), MGH Poet. lat. 4, 1, Berlin 1899.

Strecker, Karl (Hrsg.), MGH Poet. lat. 4, 2.3, Berlin 1923.

Fickermann, Norbert und Karl Strecker (Hrsg.), MGH Poet. lat. 5, 1.2, Berlin 1937.

DüMmLer, Ernst (Hrsg.), Epistolae Karolini aevi 2 (MGH Epp. 4), Berlin 1895.

DüMMLER, Ernst (Hrsg.), Epistolae Karolini aevi 3 (MGH Epp. 5), Berlin 1899. Fabricius, Georg (Hrsg.), Poetarum veterum ecclesiasticorum opera Christiana, \& operum reliqiae atque fragmenta (...), Chemnitz 1564.

Glauche, Günter, Hermann Knaus und Bernhard Bischoff (Hrsg.), Mittelalterliche Bibliothekskataloge Deutschlands und der Schweiz. 4, 2: Bistum Freising, Bistum Würzburg, München 1979.

2189 Editionen in unselbständiger Literatur finden sich bei den Herausgebern im allgemeinen Literaturverzeichnis. Ebenso sind dort zwecks besserer Auffindbarkeit die Einzel-Editionen der Glossen zu finden. 
Glorie, Fr. (Hrsg.), Itineraria et alia geographica (CCSL 175), Turnhout.

Glorie, Fr. (Hrsg.), Variae collectiones aenigmatum Merovingicae aetatis. (CCSL, 133 A), Turnhout 1968.

Godman, Peter, Poetry of the Carolingian Renaissance (Duckworth classical, medieval and Renaissance editions), London 1985.

Gotтlieb, Theodor u. a. (Hrsg.), Mittelalterliche Bibliothekskataloge Österreichs, 1-5, Graz [u. a.] 1915-1971.

Gundlach, Wilhelm und Ernst DüMmLer (Hrsg.), Epistolae Merowingici et Karolini aevi 1 (MGH Epp. 3), Berlin 1892.

Hahn, August, Adolf von Harnack und Ludwig Hahn (Hrsg.), Bibliothek der Symbole und Glaubensregeln der Alten Kirche, Hildesheim 1962.

Hagen, Hermann (Hrsg.), Codex Bernensis 363, phototypice editus, Leiden 1897.

Hagen, Hermann, Anecdota Helvetica quae ad grammaticam Latinam spectant, Leipzig 1870.

Hagen, Hermann, Carmina Medii Aevi maximan partem inedita, ex bibliothecis Helveticis collecta, Turin 1961.

HäsE, Angelika, Mittelalterliche Bücherverzeichnisse aus Kloster Lorsch: Einleitung, Edition und Kommentar (Beiträge zum Buch- und Bibliothekswesen 42), Wiesbaden 2002.

Herzberg-Fränkel, Siegmund (Hrsg.), »Monumenta necrologica monasterii s. Petri Salisburgensis«, in: MGH Necrol. 2 1890, S. 3-64.

Heunieser, Max, Die Traditionen des Hochstiftes Passau (Quellen und Erörterungen zur bayerischen Geschichte, NF 6), München 1930.

KeIL, Heinrich (Hrsg.), Grammatici Latini, 5. Bd., Leipzig 1855-1880.

KöBLER, Gerhard (Hrsg.), Sammlung kleinerer althochdeutscher Sprachdenkmäler (Arbeiten zur Rechts- und Sprachwissenschaft 30), Gießen 1986.

Kramer, Theodor, Hermann, Franz-Xaver und Borchardt, Karl, Die Würzburger Inschriften bis 1525 (Die Deutschen Inschriften 27), Wiesbaden 1988.

Kurze, Friedrich (Hrsg.), Annales Fuldenses sive annales regni Francorum orientalis (MGH SS 7), Hannover 1993.

Lehmann, Paul (Hrsg.), Mittelalterliche Bibliothekskataloge Deutschlands und der Schweiz. 1: Bistümer Konstanz und Chur. 2: Bistum Mainz, Erfurt (Mittelalterliche Bibliothekskataloge Deutschlands und der Schweiz), München 1918.

Mabillon, Jean, Veterum analectorum tomus I, Paris 1675.

Mommsen, Theodor (Hrsg.), Chronica minora saec. IV. V. VI. VII (III) (MGH Auct. Ant. 13), Hannover 1898.

Mone, Franz Joseph (Hrsg.), Hymni Latini medii aevi, Freiburg i. Br. 1853.

Pertz, Georg Heinrich (Hrsg.), Scriptores rerum Sangallensium. Annales, chronica et historia aevi Carolini (MGH SS 2), Hannover 1829.

Petschenig, Michael, Karl Schenkl und Klaus Brandes (Hrsg.), Poetae Christiani minores (CSEL 16), Wien 1888.

Riese, Alexander und Franz Bücheler (Hrsg.), Anthologia latina, Leipzig 1868-1926.

Schieffer, Theodor (Hrsg.), Diplomata Karolinorum (Die Urkunden der Karolinger), 3: Die Urkunden Lothars I. und Lothars II. (Lotharii I. et Lotharii II., Diplomata), Hannover 1966. 
SCHLOSSER, Julius von, Schriftquellen zur Geschichte der karolingischen Kunst (Quellenschriften für Kunstgeschichte und Kunsttechnik des Mittelalters und der Neuzeit, NF 4), Wien 1892.

SchneIDer, Herbert (Hrsg.), Die Konzilsordines des Früh- und Hochmittelalters (MGH Ordines de celebrando concilio 1), Hannover 1996.

Shackleton Bailey, David R. (Hrsg.), Horati Opera, 4. Aufl. (Bibliotheca scriptorum Graecorum et Romanorum Teubneriana), München 2001.

Steinmeyer, Elias von (Hrsg.), Die kleineren althochdeutschen Sprachdenkmäler, Berlin 1916.

Steinmeyer, Elias von und Eduard Sievers (Hrsg.), Die althochdeutschen Glossen, Berlin 1879.

Stella, Francesco (Hrsg.), Corpus Rhythmorum Musicum Saec. IV-IX, 1. Songs in nonliturgical sources $=$ Canti di tradizione non liturgica. I, Lyrics $=$ Canzoni, Firenze 2007.

WAITZ, Georg (Hrsg.), Supplementa tomorum I-XII, pars I (MGH Scriptores 13), Hannover 1881.

Wilmans, Roger (Hrsg.), Die Kaiserurkunden der Provinz Westfalen 777-1313. 1, Die Urkunden des Karolingischen Zeitalters: 777-900, Münster 1867.

Zeumer, Karl (Hrsg.), MGH Formulae Merowingici et Karolini aevi, Hannover 1882.

\section{IV.1.b Einzelausgaben}

\section{Aethicus}

Prinz, Otto (Hrsg.), Die Kosmographie des Aethicus (MGH QQ zur Geistesgesch. 14), München 1993.

\section{Agius von Corvey}

"Agius von Corvey, Vita et obitus Hathumodae«, in: MGH SS 4, hrsg. von Georg Heinrich Pertz 1841, S. 165-189.

Aldhelm

EhWALd, Rudolf (Hrsg.), Aldhelmi Opera (MGH AA 15), Berlin 1919.

\section{Alcimus Avitus}

Peiper, Rudolf (Hrsg.), Alcimi Ecdicii Aviti Viennensis episcopi Opera quae supersunt (MGH AA 6, 2), Berlin 1883.

Alkuin

»Alcuini Carmina«, in: MGH Poet. lat. 1, hrsg. von Ernst DüMmLer 1881, S. 239-241. 
"Alcuini sive Albini epistolae«, in: MGH Epist. 4, hrsg. von Ernst DüMmLER 1895, S. 1-493.

Bruni, Sandra (Hrsg.), Alcuinus: De orthographia (Millennio medievale, Testi 2), Florenz 1997.

Du Chesne, André (Hrsg.), B. Flacci Albini, Sive Alchvvini Abbatis (...) Opera (...), Paris 1617.

Fravventura, Vera (Hrsg.), L'Enchiridion in Psalmos di Alcuino di York. Edizione critica (Millennio Medievale 112, Testi 27), Florenz 2017.

Frobenius Forster (Hrsg.), Beati Flacci Albini abbatis, Caroli Magni ... magistri Opera, Regensburg 1777.

LARGEAUlt, Alfred, Inscriptions métriques composées par Alcuin à la fin du 8e siècle pour les monastères de Saint-Hilaire de Poitiers et de Nouaillé, Poitiers 1885.

Unterkircher, Franz, Alkuin-Briefe und andere Traktate: Im Auftrage des Salzburger Erzbischofs Arn um 799 zu einem Sammelband vereinigt; Codex Vindobonensis 795 der Österreichischen Nationalbibliothek. Faksimileausgabe (Codices selecti 20), Graz 1969.

Veyrard-Cosme, Christiane (Hrsg.), Alcuin, Lettres: Tome I, Collection I (Sources chrétiennes 597), Paris 2018.

\section{Anthologia Latina}

Riese, Alexander und Franz Bücheler (Hrsg.), Anthologia latina, Leipzig 1868-1926.

SHACKLETON BAILEY, David R. (Hrsg.), Libri Salmasiani aliorumque carmina (Bibliotheca scriptorum Graecorum et Romanorum Teubneriana), Stuttgart 1982.

\section{Arator}

Orbán, Árpád Péter (Hrsg.), Aratoris Subdiaconi Historia apostolica (CCSL 130) 2006.

\section{Aratus}

Buescu, Victor (Hrsg.), Les Aratea, Cicéron. Texte établi, trad. et comm., Reprint Bukarest 1941, Hildesheim 1966.

KIDD, Douglas (Hrsg.), Aratus, Phaenomena (Cambridge classical texts and commentaries 34), Cambridge [u.a.] 1997.

\section{Ausonius}

Green, R. P. H. (Hrsg.), The works of Ausonius, Oxford 1991.

Gruber, Joachim (Hrsg.), D. Magnus Ausonius, »Mosella«: kritische Ausgabe, Übersetzung, Kommentar (Texte und Kommentare 42), Berlin 2013.

Schenkl, Karl (Hrsg.), Ausonii Opuscula (MGH Auct. Ant. 5, 2), Berlin 1883.

Peiper, Rudolf (Hrsg.), Decimi Magni Avsonii Burdigalensis opuscula, Nachdruck 1886, Stuttgart 1976. 


\section{Avianus}

GAIDE, Françoise (Hrsg.), Avianus: Fables (Collection des universités de France), Paris 1980.

Guaglianone, Antonio (Hrsg.), Aviani Fabulae (Corpus scriptorum Latinorum Paravianum), Turin 1958.

\section{Avienus}

Stichtenoth, Dietrich (Hrsg.), Rufus Festus Avienus: Ora Maritima, Darmstadt 1968.

\section{Beda Venerabilis}

JAAGER, Werner (Hrsg.), Bedas metrische Vita sancti Cuthberti, Leipzig 1935.

Jones, Charles W. (Hrsg.), Bedae Venerabilis opera (CCSL, 123 A-C), Turnhout 1975-1980.

Kendall, Calvin B. (Hrsg.), Beda. Libri II De arte metrica et De schematibus et tropis: the art of poetry and rhetoric (Bibliotheca Germanica, Series Nova 2), Saarbrücken 1991.

\section{Boethius}

Moreschini, Claudio (Hrsg.), Boethius: De consolatione philosophiae (Bibliotheca scriptorum Graecorum et Romanorum Teubneriana), München 2005.

Peiper, Rudolf (Hrsg.), Anicii Manlii Severini Boetii philosophiae consolationis libri quinque: Accedunt eiusdem atque incertorum opuscula sacra (Bibliotheca Scriptorum Graecorum et Romanorum Teubneriana), Leipzig 1871.

\section{Bonifatius}

"S. Bonifatii et Lulli epistolae", in: MGH Epist. 3, hrsg. von Wilhelm GundLach 1892, S. 215-384.

GeBAUER, George John und Bengt LöFstedt (Hrsg.), Bonifatii (Vynfreth) ars grammatica: accedit ars metrica (CCSL 133B), Turnhout 1980.

LEVIson, Wilhelm (Hrsg.), Vitae sancti Bonifatii archiepiscopi Moguntini (MGH SS rer. Germ. 57), Hannover 1905.

Rau, Reinhold und Lutz E. von Padberg (Hrsg.), Briefe des Bonifatius = Bonifatii epistulae: Willibalds Leben des Bonifatius; Nebst einigen zeitgenössischen Dokumenten (Ausgewählte Quellen zur deutschen Geschichte des Mittelalters 4b), Darmstadt 2011.

\section{Brun Candidus}

Becht-Jördens, Gereon (Hrsg.), Vita Aegil abbatis Fuldensis a Candido ad modestum edita prosa et versibus: ein Opus geminum des IX. Jahrhunderts; Einleitung und kritische Edition, Marburg 1994. 
Brouwer, Christoph, Sidera illustrium et Sanctorum Virorum qui Germaniam praesertim Magnam olim gestis Rebus ornarunt, Mainz 1616.

Ps.-Cato

BoAs, Marcus (Hrsg.), Disticha Catonis, Amsterdam 1952.

»Carmen de resurrectione mortuorum«

Waszink, "Carmen ad Flavium Felicem«, in: Florilegium Patristicum Supplementum 1 (1937), S. 47-116.

Claudian

BIRT, Theodor (Hrsg.), Claudiani Carmina (MGH Auct. Ant. 10), Berlin 1892.

Columban

„Columbani epistolae«, in: MGH Epist. 3, hrsg. von Wilhelm GundLACH 1892, S. 154-190.

\section{Cresconius Corippus}

Antès, Serge (Hrsg.), Corippus: Éloge de l'empereur Justin II (Collection des universités de France), Paris 1981.

Diggle, James und Francis Richard David Goodyear (Hrsg.), Flavii Cresconii Corippi Iohannidos sev de bellis Libycis libri VIII, Cambridge 1970.

PARTsch, Josef (Hrsg.), Corippi Africani Grammatici Libri qui supersunt (MGH AA, 3,2), Berlin 1879.

\section{Cyprian}

Hartel, Wilhelm von (Hrsg.), S. Thasci Caecili Cypriani Opera omnia (CSEL, 3,3), Wien 1871.

\section{Cyprianus Gallus}

PeIPer, Rudolf (Hrsg.), Cypriani Galli poetae Heptateuchos: accedunt incertorum de Sodoma et Jona et ad senatorem carmina et Hilarii quae feruntur in Genesin, de Maccabaeis atque de Evangelio (CSEL 23), Wien 1891. 


\section{Damasus}

Ferrua, Antonio (Hrsg.), Epigrammata Damasiana (Sussidi allo studio delle antichità cristiane 2), Roma 1942.

\section{Dares Phrygius}

Meister, Ferdinand (Hrsg.), Daretis Phrygii de excidio Troiae historia, 2. Aufl. (Bibliotheca scriptorum Graecorum et Romanorum Teubneriana), Stuttgart 1991.

\section{Donat}

Holtz, Louis, Donat et la tradition de l'enseignement grammatical: étude sur l'Ars Donati et sa diffusion (IVe-IXe siècle) et édition critique (Documents, études et répertoires), Paris 2010.

\section{Dracontius}

Vollmer, Friedrich (Hrsg.), Dracontii carmina (MGH AA 14), Berlin 1905.

\section{Einhard}

Holder-Egger, Oswald (Hrsg.), Einhardi Vita Karoli Magni (MGH SS rer. Germ. 25), Hannover 1911.

\section{Einsiedler Eklogen, Carmina Einsidlensia}

Amat, Jaqueline (Hrsg.), Consolation à Livie, Élégies à Mécène, Bucoliques d'Einsiedeln (Les Belles Lettres) 1997.

\section{Ekkehard IV.}

"Ekkehard von St. Gallen, Casus s. Galli«, in: MGH SS 2, hrsg. von Ildefons von ARx 1829, S. 75-147.

Haefele, Hans Frieder (Hrsg.), Ekkehardi IV. Casus Sancti Galli, St. Galler Klostergeschichten (Ausgewählte Quellen zur deutschen Geschichte des Mittelalters. Freiherr vom Stein-Gedächtnisausgabe 10), Darmstadt 1980.

\section{Ennodius}

Gioanni, Stéphane (Hrsg.), Ennode de Pavie, Lettres, Livres I-II (Collection des Universités de France. Série latine 383), Paris 2006.

Hartel, Wilhelm von (Hrsg.), Magni Felicis Ennodii opera omnia (CSEL 6), Wien 1882. 
Vogel, Friedrich (Hrsg.), Magni Felicis Ennodi opera (= 1885) (MGH AA 7), München 1961.

\section{Erchanbert (Grammatiker)}

Clausen, Wendell Vernon, Erchanberti Frisingensis "Tractatus super donatum«, [University of Chicago] 1948.

\section{Ermenrich von Ellwangen}

"Ermenrici Elwangensis epistola ad Grimaldum abbatem «, in: MGH Epist. 5, hrsg. von Ernst DüMMLER 1899, S. 534-580.

Goullet, Monique (Hrsg.), Ermenrich d'Ellwangen, Lettre à Grimald (Sources d'histoire médiévale 37), Paris 2008.

\section{Eugenius von Toledo}

Vollmer, Friedrich (Hrsg.), Eugenii Toletani episcopi carmina et epistulae (MGH AA 14), Berlin 1905.

\section{Fulgentius}

Helm, Rudolf (Hrsg.), Fabii Planciadis Fulgentii V.C. Opera, Ed. stereotypa ed. anni 1898. Aufl. (Bibliotheca scriptorum Graecorum et Romanorum Teubneriana), Stuttgart 1970.

\section{Gallus Öhem}

Brandi, Karl (Hrsg.), Die Chronik des Gallus Öhem (Quellen und Forschungen zur Geschichte der Abtei Reichenau 2), Heidelberg 1893.

\section{Gottschalk}

Weber, Marie-Luise, Die Gedichte des Gottschalk von Orbais (Lateinische Sprache und Literatur des Mittelalters 27), Frankfurt a. M. 1992.

\section{Gregor der Große}

Ewald, Paul und Ludo Moritz Hartmann (Hrsg.), Gregorii I papae Registrum epistolarum. Libri VIII-XIV (MGH Epp. 2), Berlin 1892. 


\section{Heliand}

Taeger, Burkhard und Otto Behaghel (Hrsg.), Heliand und Genesis (Altdeutsche Textbibliothek 4), Tübingen 1996.

\section{Hieronymus}

Bernoulli, Carl Albrecht (Hrsg.), Hieronymus u. Gennadius: De viris inlustribus (Sammlung ausgewählter kirchen- und dogmengeschichtlicher Quellenschriften, 11 (= 1895)), Frankfurt a. M. 1968.

\section{Horaz}

Keller, Otto und Alfred Holder (Hrsg.), Horati Opera 1. Carminum libri IIII. Epodon liber. Carmen saeculare, Leipzig 1899.

Klingner, Friedrich (Hrsg.), Q. Horati Flacci opera (Bibliotheca scriptorum Graecorum et Romanorum Teubneriana), Leipzig 1959.

Shackleton Bailey, David R. (Hrsg.), Horati Opera, 4. Aufl. (Bibliotheca scriptorum Graecorum et Romanorum Teubneriana), München 2001.

\section{Hrabanus Maurus}

"Hrabani Mauri Carmina«, in: MGH Poet. lat. 2, hrsg. von Ernst DüMmLer 1884, S. 154213.

Brouwer, Cristoph (Hrsg.), Venantii Honorii Clementiniani Fortunati ... Carminum, epistolarum, expositionum libri 11 ... Accessere Hrabani Mauri Fuldensis, archiepiscopi Magontini Poemata sacra nunquam edita, Mainz 1617.

Holter, Kurt (Hrsg.), Liber de laudibus sanctae crucis: Vollständige Faksimile-Ausgabe im Originalformat des Codex Vindobonensis 652 der Österreichischen Nationalbibliothek (Codices selecti 33), Graz 1973.

MüLler, Hans-Georg, Hrabanus Maurus - De laudibus sancta crucis - Studien zur Überlieferung und Geistesgeschichte mit dem Faksimile - Textabdruck aus Codex Reg. Lat. 124 der Vatikanischen Bibliothek (Mittellateinisches Jahrbuch. Beihefte 11), Stuttgart 1973.

Perrin, Michel Jean-Louis (Hrsg.), Rabani Mauri In honorem sanctae crucis (CCCM, 100/ 100 A), Turnhout 1997.

Zimpel, Detlev (Hrsg.), Hrabanus Maurus: De institutione clericorum: Über die Unterweisung der Geistlichen (Fontes Christiani 61, 1-2), Turnhout 2006.

\section{Isidor}

"Isidori iunioris episcopi hispalensis Chronica maiora«, in: MGH SS Auct. Antiq. 11, hrsg. von Theodor Mommsen 1864, S. 391-506. 
Beeson, Charles Henry, Isidor-Studien (Quellen und Untersuchungen zur lateinischen Philologie des Mittelalters 4, 2), München 1913.

Juvenal und Persius

Braund, Susanna Morton (Hrsg.), Juvenal and Persius (Loeb classical library 91), Cambridge, Mass. [u.a.] 2004.

Clausen, Wendell Vernon (Hrsg.), A. Persi Flacci et D. Iuni Iuvenalis Saturae. Rev. ed. (Scriptorum classicorum bibliotheca Oxoniensis), Oxford 2007.

Jahn, Otto, Friedrich Leo und Franz Bücheler (Hrsg.), A. Persii Flacci, D Iunii Iuvenalis, Sulpiciae Saturae, Berlin 1932.

Juvencus

Huemer, Johann (Hrsg.), Gai Vetti Aquilini Ivvenci Evangeliorum libri quattuor (CSEL 24), Wien 1891.

Marold, Karl (Hrsg.), C. Vettii Aquilini Iuvenci Libri Evangeliorum IIII (Bibliotheca Scriptorum Graecorum et Romanorum Teubneriana), Leipzig 1886.

\section{»Karlsepos«}

BRUnhöLzL, Franz, De Karolo rege et Leone papa; Beiheft, Text und Übersetzung (Studien und Quellen zur westfälischen Geschichte 36), Paderborn 1999.

Hentze, Wilhelm und PAdBerg, Lutz von, De Karolo rege et Leone papa. Der Bericht über die Zusammenkunft Karls des Grossen mit Papst Leo III. in Paderborn 799 in einem Epos für Karl den Kaiser; mit vollständiger Farbreproduktion nach der Handschrift der Zentralbibliothek Zürich, Ms. C 78 (Studien und Quellen zur westfälischen Geschichte 36), Paderborn 1999.

Orelli, Johann Kaspar von (Hrsg.), Helperici sive ut alii arbitrantur Angilberti Karolus Magnus et Leo papa, Zürich 1832.

\section{Kolophone}

BÉNÉDICTINS DU Bouveret, Colophons de manuscrits occidentaux des origines au $16 e$ siècle (Spicilegium Friburgense. Subsidia 2-3), Freiburg 1965.

\section{Liber historiae Francorum}

"Liber historiae Francorum«, in: MGH SS rer. Merov. 2, hrsg. von Bruno KRUSCH 1888, S. 215-328. 


\section{Lukrez}

BAILey, Cyril (Hrsg.), Titi Lucreti Cari De rerum natura libri sex. Ed. with prolegomena, critical apparatus, translation, and commentary. Reprint, Oxford [u.a.] 1986.

\section{Lupus von Ferrières}

"Lupi abbatis Ferrariens epistolae«, in: MGH Epist. 6, hrsg. von Ernst DüMMLER 1925, S. 1-126.

\section{Mallius Theodorus}

Romanini, Francesca (Hrsg.), Malli Theodori De metris (Bibliotheca Weidmanniana 6), Hildesheim 2007.

\section{Martianus Capella}

Préaux, Jean G. und Adolfus Dick (Hrsg.), Martianus Capella (Bibliotheca scriptorum Graecorum et Romanorum Teubneriana), Stuttgart 1925.

Willis, James (Hrsg.), Martianus Capella: De nuptiis Philologiae et Mercurii, Stuttgart 1983.

\section{Maximianus}

LIND, L. R., Gabriele Zerbi: Gerontocomia, on the care of the aged; and Maximianus, elegies on old age and love (Memoirs of the American Philosophical Society 182), Philadelphia : 1988.

SChNeIder, Wolfgang Christian (Hrsg.), Die elegischen Verse von Maximian: eine letzte Widerrede gegen die neue christliche Zeit; mit den Gedichten der Appendix Maximiana und der Imitatio Maximiani; Interpretation, Text und Übersetzung (Palingenesia 79), Stuttgart 2003.

\section{»Murbacher Hymnen«}

Sievers, Eduard (Hrsg.), Die Murbacher Hymnen: nach der Handschrift herausgegeben (Nachdr. d. Ausg. Halle 1874), Hildesheim [u.a.] 1975.

Siмвоцотті, Chiara, Gli »Inni di Murbach«: Edizione critica, commento e glossario (Ms. Junius 25) (Studi e ricerche 1), Alessandria 2009.

\section{Notker Balbulus}

Berschin, Walter, "Notkers Metrum de vita S. Galli. Einleitung und Edition«, in: Florilegium Sangallense. Festschrift für Johannes Duft zum 65. Geburtstag, hrsg. von Otto Paul Clavadetscher und Stefan Sonderegger, St. Gallen 1980, S. 17-121. 
DümmLer, Ernst (Hrsg.), Das Formelbuch des Bischofs Salomo III. von Konstanz aus dem neunten Jahrhundert, Leipzig 1857.

RAUNER, Erwin, "Notkers des Stammlers `Notatio de illustribus uiris' ", in: Mittellateinisches Jahrbuch 21 (1986), S. 34-69.

STEINEN, Wolfram von den, »Notkers des Dichters Formelbuch «, in: Zeitschrift für Schweizerische Geschichte 25 (1945), S. 449-490.

\section{Otfrid von Weißenburg}

Erdmann, Oskar und Ludwig Wolff (Hrsg.), Otfrids Evangelienbuch (Altdeutsche Textbibliothek 49), Tübingen 1973.

Kelle, Johann Nepomuk (Hrsg.), Otfrids von Weissenburg Evangelienbuch: Text, Einl., Grammatik, Metrik, Glossar, Regensburg 1856.

Kleiber, Wolfgang und Ernst Hellgardt (Hrsg.), Otfrid von Weißenburg: 1: Edition nach dem Wiener Codex 2687 Teil 1: Text, Tübingen 2004.

Kleiber, Wolfgang und Ernst Hellgardt (Hrsg.), Otfrid von Weißenburg: 2: Edition der Heidelberger Handschrift $P$ (Codex Pal. Lat. 52) und der Handschrift D (Codex Discissus: Bonn, Berlin/Krakau, Wolfenbüttel) Teil 1: Texte (P, D), Tübingen 2006.

Kleiber, Wolfgang und Ernst Hellgardt (Hrsg.), Otfrid von Weißenburg: 2: Edition nach der Heidelberger Handschrift P (Codex Pal. Lat. 52) und der Handschrift D Codex Discissus (Bonn, Berlin/Krakau, Wolfenbüttel) Teil 2: Einleitung und Apparat, Berlin [u. a.] 2010.

PiPER, Paul (Hrsg.), Otfrids Evangelienbuch (Bibliothek der ältesten deutschen LitteraturDenkmäler), Paderborn [u.a.] 1878.

Pivernetz, Karin (Hrsg.), Das "Evangelienbuch" in der Überlieferung der Freisinger Handschrift: (Bayerische Staatsbibliothek München, cgm. 14); Edition und Untersuchungen (Göppinger Arbeiten zur Germanistik 671), Göppingen 2000.

\section{Paulus Diaconus}

NefF, Karl (Hrsg.), Die Gedichte des Paulus Diaconus: kritische und erklärende Ausgabe (Quellen und Untersuchungen zur lateinischen Philologie des Mittelalters 3, 4), München 1908.

\section{Paulinus von Nola}

"Pauli et Petri Diaconorum carmina«, in: MGH Poet. Lat. 1, hrsg. von Ernst DüMmLer, S. 27-86.

Dolveck, Franz (Hrsg.), Paulini Nolani carmina (CCSL 21), Turnhout 2015.

Hartel, Wilhelm von und Margit Kamptner (Hrsg.), Paulini Nolani Carmina (CSEL 30), Wien 1999. 


\section{Paulinus von Périgueux}

Labarre, Sylvie (Hrsg.), Vie de saint Martin: prologue: livres I-III / Paulin de Périgueux (Sources chrétiennes 581), Paris 2016.

\section{Petronius}

Breitenstein, Natalie (Hrsg.), Petronius: »Satyrica 1-15«: Text, Übersetzung, Kommentar (Texte und Kommentare 32), Berlin [u.a.] 2009.

Müller, Konrad (Hrsg.), Petronii Arbitri Satyricon reliquiae (Bibliotheca scriptorum Graecorum et Romanorum Teubneriana), München 2003.

\section{Ps.-Plautus}

RANSTRAND, Gunnar (Hrsg.), Querolus sive Aulularia: incerti auctoris comoedia una cum indice verborum (Göteborgs Högskolas årsskrift 1), Göteborg 1951.

\section{Porphyrius}

Polara, Iohannes (Hrsg.), Publilii Optatiani Porfyrii Carmina 1973.

\section{Priscian}

Passalacqua, Marina (Hrsg.), Prisciani Caesariensis Opuscula, Vol. II. (Sussidi eruditi 48), Roma 1999.

Woestijne, Paul van de (Hrsg.), La Périégèse de Priscien, Édition critique, Brügge 1953.

\section{Proba}

LuCarini, Carlo M. (Hrsg.), Proba: Cento Vergilianus (Bibliotheca scriptorum Graecorum et Romanorum Teubneriana 2017), Berlin 2015.

\section{Prosper Aquitanus}

Horsting, Albertus G. A. (Hrsg.), Prosper Aquitanus, Liber epigrammatum (CSEL 100), Berlin [u. a.] 2016.

\section{Prudentius}

Cunningham, Mauricius P. (Hrsg.), Aurelii Prudentii Clementis Carmina (CCSL 126), Turnhout 1966. 
Publilius Syrus

Giancotti, Francesco (Hrsg.), Publilii Syri Sententiae (Testi Universitari), Turin 1968. Meyer, Wilhelm (Hrsg.), Publilii Syri Mimi Sententiae, Leipzig 1880.

\section{Quintus Serenus}

Vollmer, Friedrich (Hrsg.), Quinti Sereni liber medicinalis (Corpus medicorum latinorum 3), Leipzig 1916.

\section{Ratpert}

Osterwalder, Peter (Hrsg.), Das althochdeutsche Galluslied Ratperts und seine lateinischen Übersetzungen durch Ekkehart IV. Einordnung und kritische Edition (Das Althochdeutsche von St. Gallen 6), Berlin, New York 1982.

StEINER, Hannes (Hrsg.), Ratpert: St. Galler Klostergeschichten (MGH SS rer. Germ. 75), Hannover 2002.

\section{Salzburger Gedichte, Carmina Salisburgensia}

„Carmina Salisburgensia«, in: MGH Poet. lat. 2, hrsg. von Ernst DüMmLER 1884, S. 637-646.

\section{Ps.-Seneca}

Barlow, Claude W. (Hrsg.), Epistolae Senecae ad Paulum et Pauli ad Senecam, Rom 1938.

\section{Sedulius}

Huemer, Johann und Victoria Zimmerl-Panagl (Hrsg.), Sedulii Opera omnia (CSEL, 10 [1885]), Wien 2007.

\section{Severus}

BISchoff, Bernhard u. a. (Hrsg.), Severi Episcopi (Malacitani ?) in Evangelia Libri XII: das Trierer Fragment der Bücher VIII-X, München 1994.

Smaragdus von St. Mihiel

Löfstedt, Bengt (Hrsg.), Smaragdus: Liber in Partibus Donati (CCCM 68), Turnhout 1986. 


\section{Syllogen}

BIschоғғ, Bernhard, "Sylloge Elnonensis. Grabinschriften aus merowingischer Zeit (um 600)«, in: Anecdota novissima. Texte des 4. bis 16. Jahrhunderts, Stuttgart 1984, S. 142149.

Gilardi, J. Francis, The Sylloge epigraphica Turonensis de S. Martino, Ann Arbor, Mich. 1984.

Wallach, Luitpold, "The Urbana Anglo-Saxon Sylloge of Latin Inscriptions«, in: Poetry and Poetics from Ancient Greece to the Renaissance: Studies in Honor of James Hutton, hrsg. von Gordon M. KIRKwood (Cornell studies in classical philology 38), Ithaca, NY 1975, S. 134-151.

\section{»Symposium XII sapientum«}

Friedrich, Anne, Das Symposium der "XII sapientes«: Kommentar und Verfasserfrage (Texte und Kommentare 22), Berlin [u.a.] 2002.

\section{Theodulf von Orléans}

"Theodulfi Carmina«, in: MGH Poet. lat. 1, hrsg. von Ernst DüMmLER 1881, S. 437-581. Sirmond, Jacques (Hrsg.), Theodulfi Aurelianensis episcopi opera, Paris 1646.

\section{Valerius Flaccus}

Courtney, Edward (Hrsg.), C. Valeri Flacci Argonavticon libri octo (Bibliotheca scriptorum Graecorum et Romanorum Teubneriana), Leipzig 1970.

\section{Venantius Fortunatus}

Leo, Friedrich (Hrsg.), Venanti Honori opera poetica (MGH AA 4, 1), Berlin 1881.

Reydellet, Marc (Hrsg.), Venance Fortunat: Poèmes: Livres I-IV (Les Belles Lettres 315), Paris 1994.

Vergil

Mynors, R. A. B. (Hrsg.), P. Vergili Maronis Opera, Reprinted (with corr.) (Scriptorum classicorum bibliotheca Oxoniensis), Oxford 1983.

\section{Walahfrid Strabo}

»Walahfridi Strabi Carmina«, in: MGH Poet. lat. 2, hrsg. von Ernst DüMmLER 1884, S. 259466.

Herren, Michael W., "The >De imagine Tetrici< of Walahfrid Strabo: edition and translation«, in: The journal of medieval Latin 1 (1991), S. 118-139. 
Knittel, Hermann (Hrsg.), Heito und Walahfrid Strabo: Visio Wettini. Einf., lat.-dt. Ausg. und Erl., 3., erw. Aufl. (Reichenauer Texte und Bilder 12), Heidelberg 2009.

Pörnbacher, Mechthild (Hrsg.), Walahfrid Strabo: Zwei Legenden (Reichenauer Texte und Bilder 7), Heidelberg 2012.

Solinski, Boris, "Le >De uita et fine sancti Mammae monachi< de Walahfrid Strabon: texte, traduction et notes", in: The journal of medieval Latin 12 (2002), S. 1-77.

Traill, David A. (Hrsg.), Walahfrid Strabo's Visio Wettini: text, translation and commentary (Lateinische Sprache und Literatur des Mittelalters 2), Bern 1974.

VIsSER, Jelle, Sis memor Strabonis. Context and communicative value of Walahfrid Strabo's poetry, RMA Thesis, Universität Utrecht 2012.

»Weißenburger Gedichte«

DüMmLER, Ernst, "Weißenburger Gedichte«, in: Zeitschrift für deutsches Altertum und deutsche Literatur 19 (1876), S. 115-118.

\section{IV.2 Literatur}

Althoff, Gerd und Schmid, Karl, Die Klostergemeinschaft von Fulda im früheren Mittelalter, 2,1: Kommentiertes Parallelregister (Münstersche Mittelalter-Schriften 8) 1978.

Althoff, Gerd und Schмid, Karl, Die Klostergemeinschaft von Fulda im früheren Mittelalter, 3: Vergleichendes Gesamtverzeichnis der fuldischen Personennamen (Münstersche Mittelalter-Schriften 8) 1978.

Amulo archiepiscopus Lugdunensis, Liber contra Iudaeos, http://www.geschichtsquellen. de/repOpus_00130.html (abgerufen am 05.03.2018).

ANDRIEU, Michel, Les ordines romani du haut Moyen Âge (Spicilegium sacrum Lovaniense 11, 29), Louvain 1931.

Andrist, Patrick, Canart, Paul und Maniaci, Marilena, La syntaxe du codex: essai de codicologie structurale, Turnhout 2013.

Anton, Hans Hubert, Trier im frühen Mittelalter (Quellen und Forschungen aus dem Gebiete der Geschichte 9), Paderborn [u. a.] 1987.

ArIs, Marc-Aeilko (Hrsg.), Hrabanus Maurus in Fulda: mit einer Hrabanus MaurusBibliographie (1979-2009) (Fuldaer Studien 13), Frankfurt a. M. 2010.

Aris, Marc-Aeilko u. a., "Art. Fulda, St. Salvator«, in: Germania Benedictina 7 2004, S. 213-434.

ARIs, Marc-Aeilko u. a., »Art. Lorsch«, in: Germania Benedictina 7 2004, S. 768-853.

Aris, Marc-Aeilko und Jürgensmeier, Friedhelm, Handbuch der Mainzer Kirchengeschichte (Beiträge zur Mainzer Kirchengeschichte, 6: 1,1; 1,2; 2), Würzburg 2000.

ARIs, Marc-Aeilko, "Der Trost der Bücher؛: Bonifatius und seine Bibliothek«, in: Bonifatius. Vom angelsächsischen Missionar zum Apostel der Deutschen, hrsg. von Michael Iмноғ und Gregor Karl SтASCH, Petersberg 2004, S. 95-110.

ArIS, Marc-Aeilko, »Art. Lorsch, Bibliotheksgeschichte», in: Germania Benedictina 72004 , S. 811-821. 
ARIS, Marc-Aeilko, »Bildung und Wissenschaft«, in: Handbuch der Mainzer Kirchengeschichte, 1. Christliche Antike und Mittelalter, hrsg. von Marc-Aeilko ARIs und Friedhelm Jürgensmeier (Beiträge zur Mainzer Kirchengeschichte 6), Würzburg 2000, S. 841-862.

ARIs, Marc-Aeilko, »Prima puerilis nutriturae rudimenta: Einhard in der Klosterschule Fulda«, in: Einhard. Studien zu Leben und Werk, hrsg. von Hermann Schefers, Darmstadt 1997, S. 41-56.

ARIS, Marc-Aeilko, »Schul- und Bildungswesen, Literatur, Bibliotheken. Zur Geschichte der Klosterschule im Frühmittelalter«, in: Geschichte der Stadt Fulda 1. Von den Anfängen bis zum Ende des Alten Reiches, hrsg. von Wolfgang Hamberger, Thomas Heiler und Werner Kirchioff, Fulda 2009, S. 681-691.

ARLt, Wulf, "Liturgischer Gesang und gesungene Dichtung im Kloster St. Gallen«, in: Das Kloster St. Gallen im Mittelalter: die kulturelle Blüte vom 8. bis zum 12. Jahrhundert, hrsg. von Peter Ochsenbein, Darmstadt 1999, S. 137-165.

ARWEILER, Alexander, Die Imitation antiker und spätantiker Literatur in der Dichtung »De spiritalis historiae gestis" des Alcimus Avitus: mit einem Kommentar zu Avit. carm. 4,429-540 und 5,526-703 (Untersuchungen zur antiken Literatur und Geschichte 52), Berlin [u.a.] 1999.

Augoustakis, Antony (Hrsg.), Brill's companion to Silius Italicus (Brill's companions in classical studies), Leiden [u. a.] 2010.

Augoustakis, Antony, Ariana Traill und John E. Thorburn (Hrsg.), A companion to Terence (Blackwell companions to the ancient world 103), Chichester 2013.

Autenrieth, Johanne, Die Domschule von Konstanz zur Zeit des Investiturstreits. Die wissenschaftliche Arbeitsweise Bernolds von Konstanz und zweier Kleriker dargestellt auf Grund von Handschriftenstudien (Forschungen zur Kirchen- und Geistesgeschichte, NF 3), München 1956.

BACH, Werner, Die althochdeutschen Boethiusglossen und Notkers Übersetzung der Consolatio. Halle, Univ., Diss., Würzburg 1934.

BAESECKE, Georg, Das lateinisch-althochdeutsche Reimgebet (Carmen ad deum) und das Rätsel vom Vogel Federlos (Probleme der Wissenschaft in Vergangenheit und Gegenwart 1), Berlin 1948.

BALDzunn, Michael, "Schoolbooks", in: Handbook of medieval studies. Terms - methods trends, hrsg. von Albrecht Classen, Berlin [u. a.] 2010, S. 2061-2068.

Baldzunn, Michael, Schulbücher im Trivium des Mittelalters und der Frühen Neuzeit: die Verschriftlichung von Unterricht in der Text- und Überlieferungsgeschichte der »Fabulae» Avians und der deutschen "Disticha Catonis» (Quellen und Forschungen zur Literatur- und Kulturgeschichte, $44=(278)$ ), Berlin [u. a.] 2009.

Bannister, Henry Marriott, Monumenti Vaticani di paleografia musicale Latina, Leipzig 1913.

BARRETt, Samuel James, Notated verse in ninth- and tenth-century poetic collections. Diss. University of Cambridge, Cambridge 2000.

Bastgen, Hubert, Die Geschichte des Trierer Domkapitels im Mittelalter (Görres-Gesellschaft, Veröffentlichungen der Sektion für Rechts- und Sozialwissenschaft 7), Paderborn 1910 . 
BAuer, Franz Alto, "Das Bild der Stadt Rom in karolingischer Zeit: Der Anonymus Einsidlensis«, in: Römische Quartalschrift für christliche Altertumskunde und Kirchengeschichte 92 (1997), S. 190-228.

BAUER, Franz Alto, "Die Stadt Rom im Spiegel spätantiker und frühmittelalterlicher Beschreibungen «, in: Das antike Rom und sein Bild, hrsg. von Hans Ulrich CAIN, Anette HAUG und Yadegar Asisi (Transformationen der Antike 21), Berlin [u. a.] 2011, S. 93114.

BAUER, Thomas, "Die Ordinatio Imperii von 817, der Vertrag von Verdun 843 und die Herausbildung Lotharingiens«, in: Rheinische Vierteljahrsblätter 58 (1994), S. 1-24.

BECCARIA, Augusto, I codici di medicina del periodo presalernitano: secoli IX, Xe XI (Storia e letteratura. Raccolta di studi e testi 53), Roma 1956.

Becht-Jördens, Gereon und Haubrichs, Wolfgang, "Fulda«, in: Schreiborte des deutschen Mittelalters: Skriptorien - Werke - Mäzene, hrsg. von Martin J. Schuber T, Berlin [u. a.] 2013, S. 175-216.

BeCKer, Julia, "Präsenz, Normierung und Transfer von Wissen: Lorsch als spatristische Zentralbibliothek «, in: Karolingische Klöster. Wissenstransfer und kulturelle Innovation, hrsg. von Julia Becker, Tino Licht und Stefan Weinfurter, Berlin [u.a.] 2015, S. 71-88.

BeCKer, Philipp August, »Vom christlichen Hymnus zum Minnesang", in: Historisches Jahrbuch 52 (1932), S. 1-39, 145-177.

BEER, Ellen Judith, »Überlegungen zu Stil und Herkunft des Berner Prudentius-Codex 264«, in: FS Johannes Duft (1980) 1980, S. 15-70.

Belkin, Johanna und MeIER, Jürgen, Bibliographie zu Otfrid von Weißenburg und zur altsächsischen Bibeldichtung (Heliand und Genesis) (Bibliographien zur deutschen Literatur des Mittelalters 7), Berlin 1975.

BERGGöTz, Oliver, "Hrabanus Maurus und seine Bedeutung für das Bibliothekswesen der Karolingerzeit: Zugleich ein Beitrag zur Geschichte der Klosterbibliothek Fulda«, in: Bibliothek und Wissenschaft 27 (1994), S. 1-48.

Bergmann, Johann, De codicum Prudentianorum generibus et uirtute, Wien 1908.

Bergmann, Konrad Arnold, "Die Dichtung der Reichenau im Mittelalter«, in: Die Kultur der Abtei Reichenau. Erinnerungsschrift zur zwölfhundertsten Wiederkehr des Gründungsjahres des Inselklosters 724-1924, 2, hrsg. von Konrad Beyerle und Peter P. Albert, München 1925, S. 711-755.

Bergmann, Rolf (Hrsg.), Althochdeutsche und altsächsische Literatur, Berlin [u. a.] 2013.

Bergmann, Rolf und Stefanie Stricker (Hrsg.), Die althochdeutsche und altsächsische Glossographie. Ein Handbuch, Berlin [u. a.] 2009.

Bergmann, Rolf und Stricker, Stefanie, Katalog der althochdeutschen und altsächsischen Glossenhandschriften, Berlin 2005.

Bergmann, Rolf, "Weißenburger Glossenhandschriften", in: Die althochdeutsche und altsächsische Glossographie. Ein Handbuch, 2, hrsg. von Rolf BERGMANN und Stefanie STRICKER, Berlin 2009, S. 1306-1309.

Bernays, Ludwig, "Formale Aspekte karolingischer Lyrik des Klosters Reichenau«, in: Mittellateinisches Jahrbuch 32 (1997), S. 11-27.

Bernt, Günter, »Art. Walahfrid Strabo (Strabus) OSB, Mönch und Abt der Reichenau, Dichter und Gelehrter (808/09-849)«, in: Lexikon des Mittelalters, 8, 1997, S. 1937-1938. 
Bernt, Günter, Das lateinische Epigramm im Übergang von der Spätantike zum frühen Mittelalter (Münchener Beiträge zur Mediävistik und Renaissance-Forschung 2), München 1968.

Berschin, Walter und Kuder, Ulrich, Reichenauer Buchmalerei 850-1070, Wiesbaden 2015.

Berschin, Walter und Licht, Tino, "Metrorum iure peritus: Walahfrid Strabo als Metriklehrer «, in: Mittellateinisches Jahrbuch 44 (2009), S. 377-393.

Berschin, Walter und Zeller, Bernhard, »Winithar in Sankt Gallen (um 760-?) und der >Versus Winitharii««, in: Sermo doctorum. Compilers, preachers and their audiences, hrsg. von Maximilian Diesenberger, Yitzhak Hen und Marianne Pollheimer, Turnhout 2013, S. 153-186.

Berschin, Walter, "Alte und neue Handschriftenkataloge der Stiftsbibliothek St. Gallen«, in: Freiburger Diözesanarchiv 106 (1986), S. 5-8.

BERSCHIN, Walter, "Biographie im karolingischen Fulda«, in: Kloster Fulda in der Welt der Karolinger und Ottonen, hrsg. von Gangolf SCHRIMPF (Fuldaer Studien 7), Frankfurt a. M. 1996, S. 315-324.

Berschin, Walter, »Die Anfänge der literarischen Kultur«, in: St. Gallen - Geschichte einer literarischen Kultur. Kloster - Stadt - Kanton - Region. 1: Darstellung, hrsg. von Werner Wunderlich und Rupert Kalkofen, St. Gallen 1999, S. 111-123.

Berschin, Walter, »Die karolingische Vita S. Galli metrica (BHL nr. 3253), Werk eines Iren für St. Gallen?«, in: Mittellateinische Studien 2, Heidelberg 2010, S. 43-62.

Berschin, Walter, "Karl der Kahle als Herzog von Alemannien (829-833). Die Spur der Literatur«, in: Euphrosyne 38 (2010), S. 385-390.

Berschin, Walter, »Lateinische Literatur aus St. Gallen«, in: Das Kloster St. Gallen im Mittelalter: die kulturelle Blüte vom 8. bis zum 12. Jahrhundert, hrsg. von Peter Ochsenbein, Darmstadt 1999, S. 109-117.

Berschin, Walter, "Sankt-gallische Schriftkultur», in: Die Kultur der Abtei Sankt Gallen, hrsg. von Werner Vogler, Zürich 1990, S. 69-92.

Berschin, Walter, Biographie und Epochenstil im lateinischen Mittelalter, 3: Karolingische Biographie 750-920 n. Chr. (Quellen und Untersuchungen zur lateinischen Philologie des Mittelalters 10), Stuttgart 1991.

Berschin, Walter, Der Septuagintapsalter in abendländischen Bibliotheken des Mittelalters, Tübingen 2012.

Berschin, Walter, Eremus und Insula: St. Gallen und die Reichenau im Mittelalter-Modell einer lateinischen Literaturlandschaft, 2., erw. Aufl., Wiesbaden 2005.

Berschin, Walter, Griechisch-lateinisches Mittelalter. Von Hieronymus zu Nikolaus von Kues, Bern [u. a.] 1980.

Bertelsmeier-Kierst, Christa, »Regensburg (einschließlich Prüll und Windberg)«, in: Schreiborte des deutschen Mittelalters : Skriptorien - Werke - Mäzene, hrsg. von Martin J. Schubert, Berlin [u.a.] 2013, S. 459-492.

BEUMER, Johannes, »Amalar von Metz und sein Zeugnis für die Gestalt der Messliturgie«, in: Theologie und Philosophie 50 (1975), S. 416-426.

Beyerle, Franz, »Bischof Perminius und die Gründung der Abteien Murbach und Reichenau«, in: Zeitschrift für Schweizerische Geschichte 27 (1947), S. 129-173. 
Beyerle, Konrad und Peter P. Albert (Hrsg.), Die Kultur der Abtei Reichenau: Erinnerungschrift zur zwölfhundertsten Wiederkehr des Gründungsjahres des Inselklosters 724-1924, München 1925.

Beyerle, Konrad, "Von der Gründung bis zum Ende des freiherrlichen Klosters (7241427)«, in: Die Kultur der Abtei Reichenau: Erinnerungschrift zur zwölfhundertsten Wiederkehr des Gründungsjahres des Inselklosters 724-1924, 1, hrsg. von Konrad BEYERLE und Peter P. Albert, München 1925, S. 55-212.

Bibliotheca Laureshamensis - digital: Virtuelle Klosterbibliothek Lorsch, http://www.biblio theca-laureshamensis-digital.de/de/index.html (abgerufen am 06.11.2017).

Bierbrauer, Katharina, »Die Regensburger Buchmalerei des 8. und 9. Jahrhunderts", in: Regensburger Buchmalerei. Von frühkarolingischer Zeit bis zum Ausgang des Mittelalters. Ausstellung der Bayerischen Staatsbibliothek München und der Museen der Stadt Regensburg, hrsg. von Florentine MÜTHERICH und Karl DaCHs, München 1987, S. 1522.

Bischоғ, Bernhard und Hofmann, Josef, Libri Sancti Kyliani: die Würzburger Schreibschule und die Dombibliothek im VIII. und IX. Jahrhundert (Quellen und Forschungen zur Geschichte des Bistums und Hochstifts Würzburg 6), Würzburg 1952.

Bischoff, Bernhard und Michael LAPIDGE (Hrsg.), Biblical commentaries from the Canterbury school of Theodore and Hadrian (Cambridge studies in Anglo-Saxon England 10), Cambridge [u.a.] 1994.

Bischоғғ, Bernhard, "Anecdota Carolina«, in: Studien zur lateinischen Dichtung des Mittelalters. Ehrengabe für Karl Strecker zum 3. September 1931, hrsg. von Walter STACH (Schriftenreihe zur Historischen Vierteljahrsschrift 1), Dresden 1931, S. 1-11.

Bischoff, Bernhard, »Bücher am Hofe Ludwigs des Deutschen und die Privatbibliothek des Kanzlers Grimalt«, in: Bischoff, Mittelalterliche Studien, 3, 1981, S. 187-212.

Bischoff, Bernhard, „Das geistige Leben (Kat. Nr. 341-364)«, in: Karl der Große. Werk und Wirkung, hrsg. von Wolfgang BRAunfels, Aachen 1965, S. 188-205.

BIschoff, Bernhard, "Die benediktinische Mönchtum und die Überlieferung der klassischen Literatur«, in: Studien und Mitteilungen zur Geschichte des Benediktinerordens und seiner Zweige 92 (1981), S. 165-190.

Biscноғғ, Bernhard, „Die Bibliothek im Dienste der Schule«, in: Bischoff, Mittelalterliche Studien, 3, 1981, S. 213-233.

BIschоғғ, Bernhard, »Die Hofbibliothek Karls des Großen«, in: Bischoff, Mittelalterliche Studien, 3, 1981, S. 149-170.

Biscноғғ, Bernhard, „Die Hofbibliothek unter Ludwig dem Frommen«, in: Bischoff, Mittelalterliche Studien, 3, 1981, S. 171-186.

BIschоғғ, Bernhard, "Die Schriftheimat der Münchener Heliand-Handschrift», in: Bischoff, Mittelalterliche Studien, 3, 1981, S. 112-119.

Bischoff, Bernhard, "Ein Brief Julians von Toledo über Rhythmen, metrische Dichtung und Prosa", in: Bischoff, Mittelalterliche Studien, 1, 1966, S. 288-298.

Biscноғғ, Bernhard, »Eine Beschreibung der Basilika von Saint-Denis aus dem Jahre 799", in: Kunstchronik 34 (1981), S. 97-103.

Bischоғғ, Bernhard, „Eine Sammelhandschrift Walahfrid Strabos (Cod. Sangall. 878)«, in: Bischoff, Mittelalterliche Studien, 2, 1967, S. 34-51.

Bischоғғ, Bernhard, "Eine verschollene Einteilung der Wissenschaften«, in: Bischoff, Mittelalterliche Studien, 1, S. 273-288. 
Bischoff, Bernhard, "Elementarunterricht und Probationes Pennae in der ersten Hälfte des Mittelalters«, in: Bischoff, Mittelalterliche Studien, 1, 1966, S. 74-87.

BIschоғF, Bernhard, "Irische Schreiber im Karolingerreich «, in: Bischoff, Mittelalterliche Studien, 3, 1981, S. 39-54.

BIschоғғ, Bernhard, "Literarisches und künstlerisches Leben in St. Emmeram (Regensburg) während des frühen und hohen Mittelalters«, in: Bischoff, Mittelalterliche Studien, 2, 1967, S. 77-115.

Bischoff, Bernhard, "Palaeography and the Transmission of Classical Texts in the Early Middle Ages", in: Bischoff, Manuscripts and libraries in the age of Charlemagne, hrsg. von Michael M. Gorman (Cambridge studies in palaeography and codicology 1), Cambridge 1994, S. 115-133.

BIschоғF, Bernhard, "Paläographie und frühmittelalterliche Klassikerüberlieferung", in: Bischoff, Mittelalterliche Studien, 3, 1981, S. 55-72.

BısсноғF, Bernhard, "Paläographische Fragen deutscher Denkmäler der Karolingerzeit«, in: Frühmittelalterliche Studien 5 (1971), S. 101-134.

Bısсноғғ, Bernhard, "Paläographische Fragen deutscher Denkmäler der Karolingerzeit«, in: Bischoff, Mittelalterliche Studien, 3, 1981, S. 73-111.

Bischоғғ, Bernhard, "Panorama der Handschriftenüberlieferung aus der Zeit Karls des Großen«, in: Bischoff, Mittelalterliche Studien, 3, Stuttgart 1981, S. 5-38.

BIsсноғғ, Bernhard, "Über gefaltete Handschriften, vornehmlich hagiographischen Inhalts«, in: Bischoff, Mittelalterliche Studien, 1, 1966, S. 95-100.

Bischoff, Bernhard, "Ursprung und Geschichte eines Kreuzsegens", in: Bischoff, Mittelalterliche Studien, 2, 1967, S. 275-283.

Bısсноғ, Bernhard, Die Abtei Lorsch im Spiegel ihrer Handschriften (Geschichtsblätter für den Kreis Bergstraße. Sonderband 10), Lorsch 1989.

Bischoff, Bernhard, Die südostdeutschen Schreibschulen und Bibliotheken in der Karolingerzeit, 1: Die bayerischen Diözesen, Wiesbaden 1960.

Bischoff, Bernhard, Die südostdeutschen Schreibschulen und Bibliotheken in der Karolingerzeit. 1: Die bayerischen Diözesen. 2. Die vorwiegend österreichischen Diözesen., Wiesbaden 1960.

BIschоғF, Bernhard, Die südostdeutschen Schreibschulen und Bibliotheken in der Karolingerzeit, 2: Die vorwiegend österreichischen Diözesen, Wiesbaden 1980.

BIschоғF, Bernhard, Katalog der festländischen Handschriften des neunten Jahrhunderts, 1: Aachen - Lambach (Veröffentlichungen der Kommission für die Herausgabe der mittelalterlichen Bibliothekskataloge Deutschlands und der Schweiz), Wiesbaden 1998.

BIschоғF, Bernhard, Katalog der festländischen Handschriften des neunten Jahrhunderts (mit Ausnahme der wisigotischen). 3. Bände. (Veröffentlichungen der Kommission für die Herausgabe der mittelalterlichen Bibliothekskataloge Deutschlands und der Schweiz), Wiesbaden 1998.

BIschоғғ, Bernhard, Katalog der festländischen Handschriften des neunten Jahrhunderts, 2: Laon - Paderborn (Veröffentlichungen der Kommission für die Herausgabe der mittelalterlichen Bibliothekskataloge Deutschlands und der Schweiz), Wiesbaden 2004.

BIschоғғ, Bernhard, Katalog der festländischen Handschriften des neunten Jahrhunderts, 3: Padua - Zwickau (Veröffentlichungen der Kommission für die Herausgabe der Mittelalterlichen Bibliothekskataloge Deutschlands und der Schweiz), Wiesbaden 2014. 
BIschоғғ, Bernhard, Mittelalterliche Schatzverzeichnisse, 1: Von der Zeit Karls des Großen bis zur Mitte des 13. Jahrhunderts (Veröffentlichungen des Zentralinstituts für Kunstgeschichte 4), München 1967.

Bischoff, Bernhard, Paläographie des römischen Altertums und des abendländischen Mittelalters, 4., durchges. und erw. Aufl. (Grundlagen der Germanistik 24), Berlin 2009.

Bisсноғ, Bernhard, Salzburger Formelbücher und Briefe aus Tassilonischer und Karolingischer Zeit (Sitzungsberichte der Bayerischen Akademie der Wissenschaften, Philosophisch-Philologische und Historische Klasse 4), München 1973.

Bitterauf, Theodor, Die Traditionen des Hochstiftes Freising (Quellen und Erörterungen zur bayerischen und deutschen Geschichte, NF 4-5), München 1905.

BitTERLI, Dieter, Say what I am called: the Old English riddles of the Exeter Book and the Anglo-Latin riddle tradition (Toronto Anglo-Saxon series 2), Toronto [u. a.] 2009.

Bittner, Franz, Studien zum Herrscherlob in der mittellateinischen Dichtung, [Diss. Universität Würzburg] 1962.

BLoch, Hermann, "Ein karolingischer Bibliotheks-Katalog aus Kloster Murbach«, in: Strassburger Festschrift zur XLVI. Versammlung Deutscher Philologen 1901, S. 257-285.

Blume, Clemens, Der Cursus S. Benedicti Nursini und die liturgischen Hymnen des 6.9. Jahrhunderts in ihrer Beziehung zu den Sonntags- und Ferialhymnen unseres Breviers: eine hymnologisch-liturgische Studie, Leipzig 1908.

Blume, Clemens, Tropi graduales. Tropen des Missale im Mittelalter. II. Tropen zum Proprium Missale (Analecta Hymnica 49), Leipzig 1906.

BoAs, M., »Neue Catobruchstücke II«, in: Philologus 75 (1918), S. 156-177.

BoAs, Marcus, "Die Lorscher Handschrift der sog. Monosticha Catonis", in: Rheinisches Museum für Philologie 72 (1917), S. 594-615.

BoAs, Marcus, Alcuin und Cato, Leiden 1937.

BoDARWÉ, Katrinette, Sanctimoniales litteratae: Schriftlichkeit und Bildung in den ottonischen Frauenkommunitäten Gandersheim, Essen und Quedlinburg (Quellen und Studien 10), Münster 2004.

Bozse, Helmut, Die lateinischen Handschriften der Sammlung Hamilton zu Berlin, Wiesbaden 1966.

Bohne, Jürgen, Der Poeta Saxo in der historiographischen Tradition des 8. bis 10. Jahrhunderts, Berlin 1963.

BöHne, Winfried (Hrsg.), Hrabanus Maurus und seine Schule: Festschrift der RabanusMaurus-Schule, 1980, Fulda 1980.

BoINET, Amédée, "Notice sur deux manuscrits carolingiens à miniatures exécutés à l'abbaye de Fulda«, in: Bibliothèque de l'Ecole des Chartes 65 (1904), S. 355-363.

BORNERT, René, "Abbaye Saint-Léger de Murbach «, in: Les monastères d'Alsace. 2: Abbayes de bénédictins des origines à la Révolution française, Straßburg 2009, S. 7-250.

BornheIm Gen. Schilling, Werner, "St. Maximin in Trier während des 9. Jahrhunderts.", in: Corona Amicorum. Alois Thomas zur Vollendung des 90. Lebensjahres von Kollegen, Freunden und Schülern dargeboten, Trier 1986, S. 35-55.

Borst, Arno, Die karolingische Kalenderreform (MGH Schriften 46), Hannover 1998.

Borst, Arno, Mönche am Bodensee: 610-1525 (Bodensee-Bibliothek 5), Sigmaringen 1978.

Bosнof, Egon, "Die Stadt im Früh- und Hochmittelalter. Unter der Herrschaft der Bischöfe«, in: Geschichte der Stadt Passau, hrsg. von Egon Boshof u. a., 2., erw. u. aktual. Aufl., Regensburg 1999, S. 63-96. 
Boshof, Egon, »Zum Bibliothekswesen und geistigen Leben in Passau im frühen und hohen Mittelalter.«, in: Passauer Jahrbuch 52 (2010), S. 79-90.

Boshof, Egon, Die Regesten der Bischöfe von Passau, 1: 731-1206 (Regesten zur bayerischen Geschichte 1, 1), München 1992.

Botschuyver H. J., "Les scholies du Sueco-vaticanus (R)«, in: Latomus 5 (1946), S. 229231.

Botschuyver, Hendrik Johan (Hrsg.), Scholia in Horatium $\lambda \varphi \psi$ codicum Parisinorum Latinorum 7972, 7974, 7971, Amsterdam 1935.

Bourgain, Pascale, "Réflexions sur la genése des chansonniers latins", in: Convivio. Estudios sobre la poesía de cancionero, hrsg. von Beltrán PePió und Juan Salvador Paredes NúñEz, Granada 2006, S. 241-262.

Brall, Artur (Hrsg.), Von der Klosterbibliothek zur Landesbibliothek: Beiträge zum zweihundertjährigen Bestehen der Hessischen Landesbibliothek Fulda (Bibliothek des Buchwesens 6), Stuttgart 1978.

Brauer, Heinrich, Die Bücherei von St. Gallen und das althochdeutsche Schrifttum (Hermaea. Germanistische Forschungen 17), Halle a.d. Saale 1926.

Braund, Susanna Morton und Josiah Osgood (Hrsg.), A Companion to Persius and Juvenal (Blackwell companions to the ancient world), Chichester [u.a.] 2012.

BRown, Virginia, "Lupus of Ferrières on the metres of Boethius", in: Latin Script and Letters A.D. 400-900. Festschrift Presented to Ludwig Bieler on the Occasion of his 70th Birthday, hrsg. von John Joseph O’Meara und Bernd Naumann, Leiden 1976, S. 63-79.

BRUCKNER, Albert, »Untersuchungen zur älteren Abtreihe des Reichsklosters Murbach«, in: Elsaß-Lothringisches Jahrbuch 16 (1937), S. 31-56.

BRUCKNer, Albert, Schreibschulen der Diözese Konstanz: St. Gallen, 1 (Scriptoria medii aevi Helvetica 2), Genf 1936.

BRUCKNeR, Albert, Schreibschulen der Diözese Konstanz: St. Gallen, 2 (Scriptoria medii aevi Helvetica 3), Genf 1938.

BRÜHL, Carlrichard, Deutschland-Frankreich. Die Geburt zweier Völker, Köln, Wien 1995.

BRummer, Jakob, "Das carmen de Timone comite», in: Historische Vierteljahrschrift 18 (1916), S. 102-106.

BRUnhölzL, Franz, ">O cara anima.« Ein frühkarolingischer Rhythmus«, in: Mittellateinisches Jahrbuch 38 (2003), S. 19-29.

BRUNHöLZL, Franz, "Zur Überlieferung des Lukrez«, in: Hermes XC (1962), S. 97-104.

BRunhölzl, Franz, Die Freisinger Dombibliothek im Mittelalter; Studien zu ihrer Geschichte, ihrer Bedeutung für die literarische Überlieferung und zu ihrer Stellung im geistigen Leben Südbayerns bis zum Ausgang des zwölften Jahrhunderts, Habil. München 1961.

BrunhölzL, Franz, Geschichte der lateinischen Literatur des Mittelalters, 2: Die Zwischenzeit vom Ausgang des karolingischen Zeitalters bis zur Mitte des 11. Jahrhunderts, München 1992.

BRUnHöLzL, Franz, Geschichte der lateinischen Literatur des Mittelalters, 1: Von Cassiodor bis zum Ausklang der karolingischen Erneuerung, München 1996.

Brunhölzl, Franz, Spindler, Max und Kraus, Andreas, Das alte Bayern: das Stammesherzogtum bis zum Ausgang des 12. Jahrhunderts, 2., überarb. Aufl., München 1981.

BRUnhöLzL, Franz, Studien zum geistigen Leben in Passau im achten und neunten Jahrhundert (Abhandlungen der Marburger Gelehrten Gesellschaft 26), München 2000. 
Bullough, Donald A., Carolingian Renewal: Sources and Heritage, Manchester 1991.

Bullough, Donald Auberon, "Texts, chant, and the chapel of Louis the Pious", in: Charlemagne's heir. New perspectives on the reign of Louis the Pious (814-840), hrsg. von Peter Godman und Roger Collins, Oxford 1990, S. 489-508.

Bullough, Donald Auberon, Alcuin: achievement and reputation (Education and society in the Middle Ages and Renaissance 16), Leiden [u.a.] 2002.

Bulst, Walther (Hrsg.), Hymni Latini antiquissimi LXXV, Psalmi III, Heidelberg 1956.

Bulst, Walther, »Alchvvines Ecloga de Cuculo«, in: Zeitschrift für deutsches Altertum und deutsche Literatur 86 (1956), S. 193-195.

Bulst, Walther, »Bedae Opera rhythmica?«, in: Zeitschrift für deutsches Altertum und deutsche Literatur 89 (1958), S. 83-91.

Buonocore, Marco, Codices Horatiani in Bibliotheca Apostolica Vaticana, Vatikan 1992.

BüREN, Veronika von, "Une édition critique de Solin au IXe siècle«, in: Scriptorium 50 (1996), S. 22-87.

Burghardt, Hans-Dieter, Philologische Untersuchungen zur den Gedichten Alkuins, [Universität Heidelberg] 1960.

Busetto, Giorgio, "Art. Canzoniere«, in: Lexikon des Mittelalters, 2, 1983, S. 1468-1469.

Butterfield, David J., The early textual history of Lucretius' De rerum natura, Cambridge 2013.

ButTERfEld, David, "Three unidentified verses in the >Florilegium Sangallense«, in: Maia: Rivista di letterature classiche 61 (2009), S. 348-352.

BütTNER, Alexandra, »Bibliotheca Laureshamensis - digital: virtuelle Rekonstruktion einer verlorenen Bibliothek«, in: SehensWerte 8 (2013), S. 35-37.

BüTTNER, Heinrich, »Lorsch und St. Gallen«, in: Lorsch und St. Gallen in der Frühzeit, Konstanz 1965, S. 5-20.

Butzmann, Hans, "Althochdeutsche Priscian-Glossen aus Weissenburg (1964)«, in: Hans Butzmann: Kleine Schriften: Festgabe zum 70. Geburtstag. Als Festgabe der Herzog August Bibliothek Wolfenbüttel, hrsg. von Wolfgang MiLde (Studien zur Bibliotheksgeschichte 1), Graz 1973, S. 120-129.

Butzmann, Hans, "Der Ezechiel-Kommentar des Hrabanus Maurus und seine älteste Handschrift«, in: Bibliothek und Wissenschaft 1 (1964), S. 1-22.

Butzmann, Hans, "Die Weissenburger Handschriften. Einleitung zum Katalog (1964)«, in: Hans Butzmann: Kleine Schriften: Festgabe zum 70. Geburtstag. Als Festgabe der Herzog August Bibliothek Wolfenbüttel, hrsg. von Wolfgang Milde (Studien zur Bibliotheksgeschichte 1), Graz 1973, S. 48-103.

Butzmann, Hans, Die Weissenburger Handschriften (Kataloge der Herzog-August-Bibliothek Wolfenbüttel. Neue Reihe 10), Frankfurt a. M. 1964.

CAESAR, C., "Die Antwerpener Handschrift des Sedulius«, in: Rheinisches Museum für Philologie 56 (1901), S. 247-271.

Cappelli, Adriano, Lexicon abbreviaturarum, hrsg. von. Mario Geymonat, 7. Aufl. (Manuali Hoepli), Mailand 2011.

Cardelle de Hartmann, Carmen, »La miscelánea del códice München, BSB, Clm 14497, el De ortu et obitu patriarcharum y el $>$ De numeris pseudoisidoriano«, in: Filologia mediolatina. Rivista della Fondazione Ezio Franceschini 19 (2012), S. 9-44. 
Carmen de Carolo Magno, in: Das Digitale Repertorium "Geschichtsquellen des deutschen Mittelalters" , https://www.geschichtsquellen.de/repOpus_00769.html (abgerufen am 20.08.2018).

ChASE, Alston Hurd, »The metrical lives of St. Martin of Tours by Paulinus and Fortunatus and the prose life by Sulpicius Severus«, in: Harvard studies in classical philology 43 (1932), S. 51-76.

Chatelain, Emile, Paléographie des classiques latins, Paris 1884.

Chiesa, Paolo und Castaldi, Lucia, La trasmissione dei testi latini del Medioevo, 5 Bd. (Millennio medievale. Strumenti e studi), Florenz 2004.

Christ, Karl, Die Bibliothek des Klosters Fulda im 16. Jahrhundert: die HandschriftenVerzeichnisse (Zentralblatt für Bibliothekswesen 64), Leipzig 1933.

Clark, James Migdley, The abbey of St. Gall as centre of literature and art, Cambridge 1926.

Classen, Peter, "Bayern und die politischen Mächte im Zeitalter Karls des Großen und Tassilos III.«, in: Classen, Ausgewählte Aufsätze (Vorträge und Forschungen 28), Sigmaringen 1983, S. 231-248.

Claussen, Hilde, Die Klosterkirche Corvey, 2: Wandmalerei und Stuck aus karolingischer Zeit (Denkmalpflege und Forschung in Westfalen, 43,2), Mainz 2007.

ClAY, John-Henry, "Gift-giving and books in the letters of St Boniface and Lul«, in: Journal of Medieval History 35 (2009), S. 313-325.

Colberg, Katharina, »Art. Meisterlin, Sigismund«, in: Verfasserlexikon, 11, 2004, S. 988.

Constantinescu, Radu, "Alcuin et les >Libelli Precum de l'époque carolingienne«, in: Revue d'histoire de la spiritualité 50 (1974), S. 17-56.

Contreni, John J., »Learning for God: Education in the Carolingian Age«, in: The Journal of Medieval Latin 24 (2014), S. 89-129.

ConTreni, John Joseph, »Le formulaire de Laon, source pour l'histoire de l'école de Laon au début du Xe siècle», in: Scriptorium 27 (1973), S. 21-29.

Contreni, John Joseph, "The Egyptian Origins of the Irish: Two Ninth-Century Notes«, in: Carolingian learning, masters and manuscripts (Variorum collected studies series 363), Aldershot 1992, S. XVII: 51-54, 7.

Contreni, John Joseph, »The Formation of Laon's Cathedral Library in the Ninth Century«, in: Carolingian learning, masters and manuscripts (Variorum collected studies series 363), Aldershot 1992, S. 919-939, 6-7.

Contreni, John Joseph, Codex Laudunensis 468. A Ninth-Century Guide to Virgil, Sedulius, and the Liberal Arts (Armarium codicum insignium 3), Turnhout 1984.

CONTRENI, John Joseph, The cathedral school of Laon from 850 to 930: its manuscripts and masters (Münchener Beiträge zur Mediävistik und Renaissance-Forschung 29), München 1978.

CoRdoliani, Alfred, "Contribution à la littérature du comput ecclésiastique au moyen âge«, in: Studi medievali 2 (1961), S. 169-208.

Corpus Rhythmorum Musicum (saec. IV-IX)«, http://www.corimu.unisi.it/ (abgerufen am 15.01.2019).

Courtney, Edward, "The Transmission of the Text of Horace«, in: Brill's companion to Horace, hrsg. von Hans-Christian GüNTHER, Leiden [u. a.] 2013, S. 547-560.

CrüWell, G.A., »Die Verfluchung der Bücherdiebe«, in: Archiv für Kulturgeschichte 4 (1906), S. 197-223. 
D’Angelo, Edoardo, "Symphosii Aenigmata«, in: La trasmissione dei testi latini del Medioevo, 1, hrsg. von Paolo Chiesa und Lucia Castaldi 2004, S. 415-418.

D’ANgelo, Edoardo, »Waltharius«, in: La trasmissione dei testi latini del Medioevo, 2, hrsg. von Paolo Chiesa und Lucia Castaldi 2005, S. 539-543.

D’Imperio, Francesca Sara und Guglielmetti, Rossana E., "Alcuinus Eboracensis ep.", in: La trasmissione dei testi latini del Medioevo, 2, hrsg. von Paolo Chiesa und Lucia CAstaldi 2005, S. 22-70.

Daintree, David, "Non omnis moriar. The Lyrical Tradition of Horace in the Middle Ages«, in: Latomus 59.4 (2000), S. 889-902.

Daly, Lloyd William und SuchIER, Walther, Altercatio Hadriani Augusti et Epicteti philosophi (University of Illinois studies in language and literature, 24/1-2), Urbana 1939.

Decker, Anton, "Die Hildebold'sche Manuskriptensammlung des Kölner Domes", in: Festschrift der 43. Versammlung deutscher Philologen und Schulmänner, Bonn 1895, S. 215-253.

DekKers, Eligius, Clavis patrum Latinorum (CCSL), Turnhout 1995.

Demmelbauer, Gertraud, Arno, der erste Erzbischof von Salzburg, 798-821, Universität Wien 1950.

Depreux, Philippe (Hrsg.), Raban Maur et son temps: (Collection Haut Moyen Âge 9), Turnhout 2010.

Depreux, Philippe, „Büchersuche und Büchertausch im Zeitalter der karolingischen Renaissance am Beispiel des Briefwechsels des Lupus von Ferrières", in: Archiv für Kulturgeschichte 76 (1994), S. 267-284.

Depreux, Philippe, Prosopographie de l'entourage de Louis le Pieux (781-840) (Instrumenta DHIP 1), Sigmaringen 1997.

Derolez, Albert, Les catalogues de bibliothèques (Typologie des sources du moyen âge occidental 3), Turnhout 1979.

Dette, Christoph, „Schüler im frühen und hohen Mittelalter: die St. Galler Klosterschule des 9. und 10. Jahrhunderts«, in: Studien und Mitteilungen zur Geschichte des Benediktinerordens und seiner Zweige 105 (1994), S. 7-64.

Deutinger, Roman, "Zur Biographie Bischof Samuels von Worms«, in: Archiv für mittelrheinische Kirchengeschichte 56 (2004), S. 79-87.

Deutsche Forschungsgemeinschaft / Unterausschuss für HandschriftenkaTAlogisierung, Richtlinien Handschriftenkatalogisierung, 5., erweiterte Aufl., BonnBad Godesberg 1992.

Devisse, Jean, »L'influence de Julien Pomère sur les clercs Carolingiens. De la pauvreté aux Ve et IXe siècles«, in: Revue d'histoire de l'église de France 56 (1970), S. 285-295.

Diesenberger, Maximilian und Wolfram, Herwig, "Arn und Alkuin 790 bis 804: Zwei Freunde und ihre Schriften«, in: Erzbischof Arn von Salzburg, hrsg. von NIEDERKORNBRUCK und Anton SCHARER (Veröffentlichungen des Instituts für Österreichische Geschichtsforschung 40), Wien 2004, S. 81-106.

Diosı, Dávid, Amalarius Fortunatus in der Trierer Tradition: eine quellenkritische Untersuchung der trierischen Zeugnisse über einen Liturgiker der Karolingerzeit (Liturgiewissenschaftliche Quellen und Forschungen 94), Münster 2006.

DoležAlové, Lucie und Rivers, Kimberly Ann, Medieval manuscript miscellanies (Medium aevum quotidianum. Sonderband 31), Krems 2013. 
Dopsch, Heinz (Hrsg.), 1200 Jahre Erzbistum Salzburg: die älteste Metropole im deutschen Sprachraum; Beiträge des internationalen Kongresses in Salzburg vom 11. bis 13. Juni 1998 (Mitteilungen der Gesellschaft für Salzburger Landeskunde 1), Salzburg 1999.

Dopsch, Heinz und Juffinger, Roswitha, Virgil von Salzburg, Missionar und Gelehrter 1985.

Dopsch, Heinz, „Das Erzbistum Salzburg und der Alpen-Adria-Raum im Frühmittelalter unter besonderer Berücksichtigung der Salzburger Slawenmission«, in: Karantanien und der Alpen-Adria-Raum im Frühmittelalter, hrsg. von Günther HöDL und Johannes Grabmayer (St. Veiter Historikergespräche 2), Wien [u. a.] 1993, S. 101-150.

Drögereit, Richard, Werden und der Heliand. Studien zur Kulturgeschichte der Abtei Werden und zur Herkunft des Heliand, Essen 1951.

Drogin, Marc, Anathema! Medieval Scribes and the history of Book Curses, Montclair, N.J. 1983.

Dronke, Peter und Hasler, Peter, Die Lyrik des Mittelalters: Eine Einführung (DTB. Wissenschaftliche Reihe 4287), München 1977.

Dronke, Peter, »Le antologie liriche del Medioevo latino«, in: Critica del testo. II, 1 (1999), S. $1000-1017$.

DuвоIs, Jacques, "Le martyrologe métrique de Wandelbert«, in: Analecta Bollandiana 79 (1961), S. 257-293.

Düchting, Reinhard, "Die lateinische Literatur«, in: Geschichte der Stadt Würzburg, 1: Von den Anfängen bis zum Ausbruch des Bauernkrieges, hrsg. von Ulrich WAGNER, Stuttgart 2001, S. 450-458.

Düchting, Reinhard, Sedulius Scottus. Seine Dichtung, München 1968.

Ducketr, Eleanor Shipley, Carolingian Portraits. A study in the ninth century, Ann Arbor 1962.

Duft, Johannes, "Der Beitrag des Klosters Sankt Gallen zum kirchlichen Gesang", in: Die Kultur der Abtei Sankt Gallen, hrsg. von Werner Vogler, Zürich 1990, S. 57-68.

DuFT, Johannes, "Die Beziehungen zwischen Irland und St. Gallen im Rahmen der St. Gallischen Stiftsgeschichte«, in: Die irischen Miniaturen der Stiftsbibliothek St. Gallen, hrsg. von Johannes Duft und Peter Meyer, Olten 1953, S. 11-83.

DuFT, Johannes, "Die Klosterbibliotheken von Lorsch und St. Gallen«, in: Lorsch und St. Gallen in der Frühzeit, Konstanz 1965, S. 21-45.

DuF T, Johannes, »Die Stiftsbibliothek St. Gallen. Ein Überblick«, in: Die Abtei St. Gallen, 1. Beiträge zur Erforschung ihrer Manuskripte, Sigmaringen 1990, S. 13-32.

DuFT, Johannes, "Geschichte des Klosters St. Gallen im Überblick vom 7. bis zum 12. Jahrhundert«, in: Das Kloster St. Gallen im Mittelalter: die kulturelle Blüte vom 8. bis zum 12. Jahrhundert, hrsg. von Peter Ochsenbein, Darmstadt 1999, S. 11-30.

Duft, Johannes, "Große Äbte, blühende Abtei. Die Äbte Gozbert, Grimalt, Hartmut, Salomo«, in: Die Abtei St. Gallen, 2. Beiträge zur Kenntnis ihrer Persönlichkeiten, Sigmaringen 1991, S. 61-72.

Duft, Johannes, »Irische Einflüsse auf St. Gallen und Alemannien«, in: Mönchtum, Episkopat und Adel zur Gründungszeit des Klosters Reichenau, hrsg. von Arno Borst (Vorträge und Forschungen 20), Sigmaringen 1974, S. 9-35.

Duf T, Johannes, »Irische Handschriften in der Stiftsbibliothek zu St. Gallen«, in: Du. Atlantis 30 (1970), S. 29-43. 
DuFT, Johannes, "Iromanie - Irophobie. Fragen um die frühmittelalterliche Irenmission exemplifiziert an St. Gallen und Alemannien", in: Zeitschrift für schweizerische Kirchengeschichte 50 (1956), S. 241-262.

DufT, Johannes, "St. Columban in den St. Galler Handschriften«, in: Zeitschrift für schweizerische Kirchengeschichte 59 (1965), S. 285-296.

DuFt, Johannes, Die Abtei St. Gallen, 1. Beiträge zur Erforschung ihrer Manuskripte, Sigmaringen 1990.

Duft, Johannes, Die Abtei St. Gallen, 2. Beiträge zur Kenntnis ihrer Persönlichkeiten, Sigmaringen 1991.

DuFt, Johannes, Gössi, Anton und Vogler, Werner, »St. Gallen«, in: (Helvetia Sacra, III, 1, 2), Bern 1986, S. 1180-1369.

Duf T, Johannes, Mittelalterliche Schreiber; Bilder, Anekdoten und Sprüche aus der Stiftsbibliothek St. Gallen, St. Gallen 1961.

DüMMLER, Ernst, »Beiträge zur Geschichte des Erzbisthums Salzburg im IX. bis XII. Jahrhundert«, in: Archiv für österreichische Geschichte 22 (1859), S. 279-304.

DÜMMLER, Ernst, »Die handschriftliche Überlieferung der lateinischen Dichtungen aus der Zeit der Karolinger«, in: Neues Archiv der Gesellschaft für ältere deutsche Geschichtskunde 4 (1879), S. 87-159, 239-322, 511-582.

DüMMLER, Ernst, »Gedicht über die sechs Weltalter«, in: Zeitschrift für deutsches Altertum und deutsche Literatur 22 (1878), S. 423-428.

DüMMLER, Ernst, "Gedichte auf Gewänder«, in: Zeitschrift für deutsches Altertum und deutsche Literatur 19 (1876), S. 146-148.

DüMMLER, Ernst, "Gedichte aus dem Hofkreise Karls des Großen«, in: Zeitschrift für deutsches Altertum und deutsche Literatur 12 (1865), S. 446-460.

DüMMLER, Ernst, "Lateinische Gedichte des neunten bis elften Jahrhunderts«, in: Neues Archiv der Gesellschaft für ältere deutsche Geschichtskunde 10 (1885), S. 331-357.

DüMMLER, Ernst, »Lorscher Rätsel«, in: Zeitschrift für deutsches Altertum und deutsche Literatur 22 (1878), S. 258-263.

DüMMLER, Ernst, "St. Gallische Denkmale aus der karolingischen Zeit«, in: Mitteilungen der Antiquarischen Gesellschaft in Zürich 12 (1859), S. 206-265.

DüWel, Klaus und Ruge, Nikolaus, »Art. Hildebrandslied«, in: Althochdeutsche und altsächsische Literatur 2013, S. 171-183.

Ebenbauer, Alfred, Carmen historicum. Untersuchungen zur historischen Dichtung im karolingischen Europa (Philologica Germanica 4), Wien 1978.

EDER, Christine Elisabeth, »Candidus-Brun von Fulda: Maler, Lehrer und Schriftsteller«, in: Hrabanus Maurus und seine Schule. Festschrift der Rabanus-Maurus-Schule, hrsg. von Winfried BöHme, Fulda 1980, S. 182-192.

EDER, Christine Elisabeth, »Die Schule des Klosters Tegernsee im frühen Mittelalter im Spiegel der Tegernsee Handschriften«, in: Studien und Mitteilungen zur Geschichte des Benediktinerordens und seiner Zweige 83 (1972), S. 6-155.

EFFE, Bernd, "Zur Rezeption von Vergils Lehrdichtung in der karolingischen $>$ Renaissance und im französischen Klassizismus: Walahfrid Strabo und Rene Rapin«, in: Antike und Abendland 21 (1975), S. 140-163.

Eggenberger, Christoph, „Der Bodensee als Foyer der Überlieferung spätantiken Bildund Bildungsgutes«, in: Geistesleben um den Bodensee im frühen Mittelalter, hrsg. von 
Achim Masser und Alois Wolf (Literatur und Geschichte am Oberrhein 2), Freiburg i. Br. 1989, S. 1-11.

EHLERs, Widu-Wolfgang, Untersuchungen zur handschriftlichen Überlieferung der Argonautica des C. Valerius Flaccus (Zetemata 52), München 1970.

Emanuel, Hywel D., »The Seven Keys of Wisdom«, in: Studia Celtica 5 (1970), S. 36-47.

Емвасн, Michael, Trierer Literaturgeschichte, Das Mittelalter (Geschichte und Kultur des Trierer Landes 8), Trier 2007.

ENDREs, Rudolf, »Schulen und Hochschulen«, in: Geschichte der Stadt Würzburg, 1: Von den Anfängen bis zum Ausbruch des Bauernkrieges, hrsg. von Ulrich WAGNER, Stuttgart 2001, S. 313-321.

ENDREs, Rudolf, »Schulen, Universität und Bibliotheken«, in: Unterfränkische Geschichte 2 1992, S. 531-546.

ENRIGHT, Michael J., "Iromanie-Irophobie revisited: a suggested frame of reference for considering continental reactions to Irish peregrini in the seventh and eighth centuries", in: Karl Martell in seiner Zeit, hrsg. von Jörg JARnut (Beihefte der Francia 37), Sigmaringen 1994, S. 367-380.

ERKens, Franz-Reiner, "'Divisio legitima und sunitas imperiir. Teilungspraxis und Einheitsstreben bei der Thronfolge im Frankenreich «, in: Deutsches Archiv für Erforschung des Mittelalters 52 (1996), S. 423-485.

ERKens, Franz-Reiner, »Zerfall der Einheit - Die Reichsteilungen des 9. Jahrhunderts«, in: Um Glaube und Herrschaft (600-1650) (Brockhaus. Die Bibliothek. Die Weltgeschichte 3), Leipzig 1998, S. 170-181.

ERnst, Ulrich, »Art. Otfrid von Weißenburg († nach 870)«, in: Lexikon des Mittelalters, 6, 1993, S. 1557-1559.

ERnst, Ulrich, Carmen figuratum: Geschichte des Figurengedichts von den antiken Ursprüngen bis zum Ausgang des Mittelalters (Pictura et poesis 1), Köln [u.a.] 1991.

ERTMER, Dorothee, Studien zur althochdeutschen und altsächsischen Juvencusglossierung (Studien zum Althochdeutschen 26), Göttingen 1994.

EscH, Arnold, "Überlieferungs-Chance und Überlieferungs-Zufall als methodisches Problem des Historikers", in: Historische Zeitschrift 240 (1985), S. 529-570.

Esposito, Mario, »Hiberno-Latin manuscripts in the libraries of Switzerland «, in: Proceedings of the Royal Irish Academy C 30 (1912), S. 1-14.

Euw, Anton von, Die St. Galler Buchkunst vom 8. bis zum Ende des 11. Jahrhunderts (Monasterium Sancti Galli 3), St. Gallen 2008.

EwIG, Eugen, »Die ältesten Mainzer Patrozinien und die Frühgeschichte des Bistums Mainz«, in: Spätantikes und fränkisches Gallien. Gesammelte Schriften 1, hrsg. von Hartmut Aтsma (Beihefte der Francia 3, 2), München 1979, S. 154-170.

EwIG, Eugen, »Troja und die Franken«, in: Rheinische Vierteljahrsblätter 62 (1998), S. 1-16.

FAIVRE D'ARCIER, Louis, Histoire et géographie d'un mythe: la circulation des manuscrits du De exidio Troiae de Darès le Phrygien (VIIIe-XVe siècles) (Mémoires et documents 82), Paris 2006.

FALK, Franz und Scherer, Carl, "Beiträge zur Rekonstruktion der alten Bibliotheca fuldensis und Bibliotheca laureshamensis. Mit einer Beilage: Der Fuldaer Handschriftenkatalog aus dem 16. Jahrhundert.«, in: Zentralblatt für Bibliothekswesen, Beiheft 26 (1902), S. 1-112. 
FALK, Franz, Die ehemalige Dombibliothek zu Mainz, ihre Entstehung, Verschleppung und Vernichtung nach gedruckten und ungedruckten Quellen (Zentralblatt für Bibliothekswesen. Beiheft 18), Leipzig 1897.

Felten, Franz J. und Karl Lehmann (Hrsg.), Hrabanus Maurus: Gelehrter, Abt von Fulda und Erzbischof von Mainz (Neues Jahrbuch für das Bistum Mainz 2006), Mainz 2006.

Ferrari, Michele Camillo, »Pangite celi, reboemus odası: Ein sapphischer Hymnus, sein Verfasser und seine Bearbeitung zwischen Weissenburg, Rätien und Umbrien«, in: Zeitschrift für schweizerische Kirchengeschichte 83 (1989), S. 155-176.

FERrari, Michele Camillo, »Hrabanica. Hrabans De laudibus sanctae crucis im Spiegel der neueren Forschung", in: Kloster Fulda in der Welt der Karolinger und Ottonen, hrsg. von Gangolf SchrimpF (Fuldaer Studien 7), Frankfurt a. M. 1996, S. 493-526.

Ferrari, Michele Camillo, Il »Liber sanctae crucis« di Rabano Mauro. Testo, immagine, contesto (Lateinische Sprache und Literatur des Mittelalters 30), Bern 1999.

FERrARI, Mirella, »In Papia conveniant ad Dungalum«, in: Italia medioevale e umanistica 15 (1972), S. 1-52.

FickermanN, Norbert, "Eine bisher verkannte Schrift Meinhards von Bamberg", in: Neues Archiv der Gesellschaft für ältere deutsche Geschichtskunde 49 (1932), S. 452-455.

FickermanN, Norbert, "Zu den alten Rhythmen«, in: Revue Bénédictine 43 (1931), S. 313321.

Finch, Chauncey E., »Symphosius in codices Pal. lat.1719, 1753 and Reg. lat.329, 2078«, in: Manuscripta 13 (1969), S. 3-11.

FInGer, Heinz, »Finger, Heinz: Die Dombibliothek zu Köln (2001). Vortrag, gehalten anlässlich der Präsentation der >Digitalen Handschriftenbibliothek Köln am Donnerstag, dem 31. Mai 2001«, http://www.dombibliothek-koeln.de/publikation/finger_koelner_ dombibliothek.html (abgerufen am 31.03.2017).

Fleckenstein, Josef, »Art. Ricbod (Richbod), Abt von Lorsch, Bischof von Trier ( $\dagger 804) \lll$, in: Lexikon des Mittelalters, 7, 1995, S. 807.

Fleckenstein, Josef, Die Hofkapelle der deutschen Könige, 1. Grundlegung: die karolingische Hofkapelle (MGH Schriften 16), Stuttgart 1959.

FöGEN, Thorsten, »Der Grammatiker Consentius«, in: Glotta 74 (1997), S. 164-192.

Förstemann, Ernst Wilhelm, Altdeutsches Namenbuch (Personennamen), 1, Nordhausen 1856.

FORSTNER, Karl, „Das Salzburger Skriptorium unter Virgil und das Verbrüderungsbuch von St. Peter«, in: Virgil von Salzburg Missionar und Gelehrter. Beiträge des Internationalen Symposiums vom 21.-24. September 1984 in der Salzburger Residenz, hrsg. von Heinz Dopsch und Roswitha JUfFINGER 1985, S. 135-140.

Forstner, Karl, Das Verbrüderungsbuch von St. Peter in Salzburg: Vollständige FaksimileAusgabe im Originalformat der Handschrift A 1 aus dem Archiv von St. Peter in Salzburg (Codices selecti 51), Graz 1974.

ForSTNER, Karl, Die karolingischen Handschriften und Fragmente in den Salzburger Bibliotheken: (Ende des 8. Jh. bis Ende des 9. Jh.) (Mitteilungen der Gesellschaft für Salzburger Landeskunde. Ergänzungsband 3), Salzburg 1962.

Frank, Hieronymus, Die Klosterbischöfe des Frankenreiches (Beiträge zur Geschichte des alten Mönchtums und des Benediktinerordens 17), Münster 1932.

Fransen, Paul-Irénée, "Description de la collection de Bède le Vénérable sur l'Apôtre«, in: Revue bénédictine 71 (1961), S. 22-70. 
Fravventura, Vera, »Alcuin's $>$ Enchiridion in Psalmos and its letters of presentation«, in: Mittellateinisches Jahrbuch 51 (2016), S. 171-194.

Freise, Eckhard, »St. Emmeram zu Regensburg», in: Ratisbona Sacra. Das Bistum Regensburg im Mittelalter. Ausstellung anläßlich des 1250jährigen Jubiläums der kanonischen Errichtung des Bistums Regensburg durch Bonifatius 739-1989, hrsg. von Peter Morsbach (Kataloge und Schriften. Kunstsammlungen des Bistums Regensburg, Diözesanmuseum Regensburg 6), München, Zürich 1989, S. 182-186.

Frenken, Goswin, »Die Kölner Domschule im Mittelalter«, in: Der Dom zu Köln. Festschrift zur Feier der 50. Wiederkehr des Tages seiner Vollendung am 15. Okt. 1880, hrsg. von Erich Kuphal (Veröffentlichungen des Kölnischen Geschichtsvereins 5), Köln 1930, S. 237-256.

FRIED, Johannes, »Fulda in der Bildungs- und Geistesgeschichte des früheren Mittelalters", in: Kloster Fulda in der Welt der Karolinger und Ottonen, hrsg. von Gangolf ScHRIMPF (Fuldaer Studien 7), Frankfurt a. M. 1996, S. 3-38.

FriIs-Jensen, Karsten, Munk Olsen, Birger und Smith, Ole Langwitz, »Bibliography of classical scholarship in the Middle Ages and the early Renaissance (9th to 15th centuries)«, in: Medieval and Renaissance Scholarship, hrsg. von Nicholas MANN und Birger Munk Olsen (Mittellateinische Studien und Texte 21), Leiden 1997, S. 197-251.

Frost, Maurice, "A prayer book from St. Emmeran, Ratisbon«, in: The journal of theological studies 30 (1928), S. 32-45.

GAmber, Klaus, »Ein Brevier-Fragment aus der 1. Hälfte des 9. Jahrhunderts. «, in: Revue bénédictine 95 (1985), S. 232-239.

Gamber, Klaus, Codices liturgici latini antiquiores (Spicilegium Friburgense. Subsidia 1, 1-3), Freiburg i. Ue. 1968.

GANTERT, Klaus, Akkommodation und eingeschriebener Kommentar: Untersuchungen zur Übertragungsstrategie des Helianddichters, Tübingen 1998.

Ganz, David, "Carolingian Manuscripts. The Verdict of the Master«, in: Francia 42 (2015), S. 253-274.

GARRISON, Mary, "The social world of Alcuin: nicknames at York and at the Carolingian court", in: Alcuin of York. Scholar at the Carolingian Court., hrsg. von Luuk A. J. R. Houwen und Alasdair A. MacDonald (Germania latina 3, Mediaevalia Groningana 22), Groningen 1998, S. 59-79.

Gatrio, Andreas, Die Abtei Murbach im Elsaß, Straßburg 1895.

Geith, Karl-Ernst und Berschin, Walter, »Die Bibliothekskataloge des Klosters Murbach aus dem IX. Jahrhundert «, in: Zeitschrift für Kirchengeschichte 83 (1972), S. 61-87.

Gerberding, Richard A., "Paris, Bibliothèque nationale Latin 7906: an unnoticed very early fragment of the 'Liber Historiae Francorum «, in: Traditio 43 (1987), S. 381-386.

Geuenich, Dieter, "Beobachtungen zu Grimald von St. Gallen, Erzkaplan und Oberkanzler Ludwigs des Deutschen «, in: FS Johanne Autenrieth 1988, S. 55-68.

Giancotтi, Francesco, Ricerche sulla tradizione manoscritta delle sentenze di Publilio Siro, Messina 1963.

Gibson, Margaret Templeton, „Carolingian glossed psalters«, in: The Early Medieval Bible. Its Production, Decoration and Use, hrsg. von Richard Gameson (Cambridge studies in palaeography and codicology), Cambridge 1994, S. 78-100. 
Glaser, Elvira und Nievergelt, Andreas, "Griffelglossen«, in: Die althochdeutsche und altsächsische Glossographie. Ein Handbuch, 1, hrsg. von Rolf BERGMANn und Stefanie STRICKER, Berlin [u. a.] 2009, S. 202-229.

Glassner, Christine, "Inventar der Handschriften des Benediktinerstiftes St. Paul im Lavanttal«, http://www.ksbm.oeaw.ac.at/stpaul/inv/ (abgerufen am 09.01.2018).

GLAUCH, Sonja, „St. Gallen«, in: Schreiborte des deutschen Mittelalters : Skriptorien - Werke - Mäzene, hrsg. von Martin J. Schubert, Berlin [u. a.] 2013, S. 493-512.

Glauche, Günter, "Die Rolle der Schulautoren im Unterricht von 800 bis 1100«, in: La scuola nell'Occidente latino dell'alto medioevo (Settimane di studio del Centro italiano di studi sull'alto medioevo 19) 1972, S. 617-636.

Glauche, Günter, Die Pergamenthandschriften aus Benediktbeuern. Clm 4501-4663 (Catalogus codicum manu scriptorum Bibliothecae Monacensis 3/1), Wiesbaden 1993.

Glauche, Günter, Die Pergamenthandschriften aus der Bibliothek des Domkapitels Freising (Catalogus codicum manu scriptorum Bibliothecae Monacensis 3/2/1), Wiesbaden 2000.

Glauche, Günter, Schullektüre im Mittelalter. Entstehung und Wandlungen des Lektürekanons bis 1200 aus den Quellen dargestellt (Münchener Beiträge zur Mediävistik und Renaissance-Forschung 5), München 1978.

Gneuss, Helmut, "Zur Geschichte des Hymnars", in: Der lateinische Hymnus im Mittelalter. Überlieferung, Ästhetik, Ausstrahlung, hrsg. von Andreas Haug, Christoph März und Lorenz Welker (Monumenta Monodica Medii Aevi. Subsidia 4), Kassel [u.a.] 2004, S. 63-86.

GNeuss, Helmut, Hymnar und Hymnen im englischen Mittelalter: Studien zur Überlieferung, Glossierung und Übersetzung lateinischer Hymnen in England; mit einer Textausgabe der lateinisch-altenglischen Expositio Hymnorum (Buchreihe der Anglia 12), Tübingen 1968.

GNILKA, Christian, »Über einige unechte Verse im Juvencustext», in: Wiener Studien 114 (2001), S. 501-517.

Godman, Peter, "Il periodo carolingio«, in: Lo Spazio Letterario del Medioevo, 1. Il Medioevo Latino. 3. La Ricezione del Testo, Rom 1995, S. 339-373.

Godman, Peter, "Latin poetry under Charles the Bald and Carolingian poetry«, in: Charles the Bald. Court and kingdom, hrsg. von Margaret Templeton GiBson und Janet Loughland NeLson (BAR International series 101), Oxford 1981, S. 293-309.

Godman, Peter, "Louis `the Pious and his poets«, in: Frühmittelalterliche Studien 19 (1985), S. 239-289.

Godman, Peter, Poets and emperors: frankish politics and Carolingian poetry, Oxford 1987.

Goldast, Melchior, Scriptores Alamannicarum rerum, Frankfurt a. M. 1606.

GoldsснміDт, Günther, Katalogisierung der mittelalterlichen medizinischen und alchimistischen Handschriften der Zentralbilbiothek Zürich, Aarau 1945.

Gorman, Michael M., »Wigbod and Biblical Studies under Charlemagne», in: Revue bénédictine 107 (1997), S. 40-76.

Goтоғf, Harold C., The Transmission of the Text of Lucan in the Ninth Century, Cambridge 1971.

Gоттьов, Theodor, Der abendländische Chorepiskopat (Kanonistische Studien und Texte 1), Amsterdam 1928. 
Göтz, Georg, "Über Dunkel- und Geheimsprachen im späten und mittelalterlichen Latein «, in: Berichte der sächsischen Gesellschaft der Wissenschaften Leipzig 48 (1896), S. 62-92.

Gretsch, Mechthild und Gneuss, Helmut, "Anglo-Saxon Glosses to a Theodorean Poem?", in: Latin Learning and English Lore. Studies in Anglo-Saxon Literature for Michael Lapidge, hrsg. von O'BRIEN O'KeEFFE und Andy OrChARD (Toronto old English series 14), Toronto 2005, S. 9-46.

GRÖBER, Gustav, Übersicht über die lateinische Litteratur von der Mitte des 6. Jahrhunderts bis zur Mitte des 14. Jahrhunderts [Neue Ausgabe des II. Bandes des Grundrisses der romanischen Philologie], München 1963.

Gröchenig, Hans, Höds, Günther und Pascher, Erhard, Katalog der Ausstellung. Handschriftenfragmente von 500-1500 (Armarium 1), Sankt Paul im Lavanttal 1977.

Grondeux, Anne, »Le rôle de Reichenau dans la diffusion du Liber glossarum «, in: Dossiers d'HEL 8 (2015), S. 79-93.

Grotans, Anna A., Reading in medieval St. Gall (Cambridge studies in palaeography and codicology 13), Cambridge 2006.

Gruber, Joachim, »Art. Anthologie«, in: Lexikon des Mittelalters, 1, 1980, S. 695-699.

GRUPP, Uwe, "Der Codex Sangallensis 397 - ein persönliches Handbuch Grimalds von St. Gallen?", in: Deutsches Archiv für Erforschung des Mittelalters 70 (2014), S. 425-463.

GugeL, Klaus, Welche erhaltenen mittelalterlichen Handschriften dürfen der Bibliothek des Klosters Fulda zugerechnet werden? T. 1: Die Handschriften; T. 2: Die Fragmente aus Handschriften (Fuldaer Hochschulschriften 23a-b), Frankfurt a. M. 1995.

Gullick, Michael, »How fast did scribes write?: Evidence from Romanesque manuscripts«, in: Making the medieval book: techniques of production, hrsg. von Linda L. BROWNRIGG (Proceedings of the ... conference of the Seminar in the History of the Book to 15004 ), Los Altos Hills, Calif. 1995, S. 39-58.

Gumbert, Johann Peter, "One book with many texts: the Latin tradition«, in: Codices Miscellanearum. Brussels Van Hulthem Colloquium, hrsg. von JANSEN-Sieben und Hans van DıjK (Archives et bibliothèques de Belgique. Numéro spécial 60), Brüssel 1999, S. 27-36.

HAACKE, Rhaban, Die Benediktinerklöster in Nordrhein-Westfalen, St. Ottilien 1980.

HAARLÄnder, Stephanie, "Art. Ric(h)ulf (auch Richolf, Flavius Damoetas), Erzbischof von Mainz (seit 787), † 9.8.813. «, in: NDB, 21, 2003, S. 554-555.

HaberL, Doris, "Die Hofbibliothek Karls des Großen als Kristallisationspunkt der karolingischen Renaissance: Geschichte, Umfeld, Wirkungen«, in: Perspektive Bibliothek 3 (2014), S. 111-139.

HAEFEle, Hans Frieder, » Decerpsi pollice flores. Aus Hrabans Vermischten Gedichten«, in: Tradition und Wertung. Festschrift für Franz Brunhölzl zum 65. Geburtstag, hrsg. von Günter Bernt, Fidel Rädle und Gabriel Silagi, Sigmaringen 1989, S. 59-74.

HAFFter, Heinz, "Walahfrid Strabo und Vergil«, in: Schweizer Beiträge zur allgemeinen Geschichte 16 (1958), S. 221-228.

HäGermann, Dieter, "Reichseinheit und Reichsteilung. Bemerkungen zur Divisio regnorum von 806 und zur Ordinatio Imperii von 817«, in: Historisches Jahrbuch 95 (1975), S. 278-307.

HaLm, Karl, Catalogus codicum latinorum (Clm 11001-15028) (Catalogus codicum manu scriptorum Bibliothecae Monacensis 4/2), München 1876. 
Halm, Karl, Catalogus codicum latinorum (Clm 15121-21313) (Catalogus codicum manu scriptorum Bibliothecae Monacensis 4/3), München 1878.

Hamberger, Wolfgang, Heiler, Thomas und Kirchhoff, Werner, Geschichte der Stadt Fulda, Fulda 2008.

Handschriftencensus |Otfrid von Weißenburg: `Evangelienbuch`, http://www.handschriften census.de/werke/1285 (abgerufen am 11.01.2019).

HARris, Stephen J., Bede and Aethelthryth: an introduction to Christian Latin poetics (Medieval european studies 18), Morgantown 2016.

Hartig, Michael, „Die Klosterschule und ihre Männer«, in: Die Kultur der Abtei Reichenau: Erinnerungschrift zur zwölfhundertsten Wiederkehr des Gründungsjahres des Inselklosters 724-1924, 2, hrsg. von Konrad Beyerle und Peter P. Albert, München 1925, S. 619-644.

Hartmann, Florian, "Karolingische Gelehrte als Dichter und der Wissenstransfer am Beispiel der Epigraphik«, in: Karolingische Klöster. Wissenstransfer und kulturelle Innovation, hrsg. von Julia BeCKer, Tino Licht und Stefan Weinfurter, Berlin [u.a.] 2015, S. 255-274.

Hartmann, Wilfried, "Äbte und Mönche als Vermittler von Texten auf karolingischen Synoden", in: Karolingische Klöster. Wissenstransfer und kulturelle Innovation, hrsg. von Julia Becker, Tino Licht und Stefan Weinfurter, Berlin [u. a.] 2015, S. 211-226.

Hartmann, Wilfried, "Die Mainzer Synoden des Hrabanus Maurus«, in: Hrabanus Maurus. Lehrer, Abt und Bischof, hrsg. von Raymund KotтJe und Harald ZimmerMANN (Akademie der Wissenschaften und der Literatur Mainz. Geistes- und Sozialwissenschaftliche Klasse. Einzelveröffentlichungen 4), Wiesbaden 1982, S. 130-144.

Haubrichs, Wolfgang, "Althochdeutsch in Fulda und Weißenburg - Hrabanus Maurus und Otfrid von Weißenburg", in: Hrabanus Maurus. Lehrer, Abt und Bischof, hrsg. von Raymund Коттje und Harald Zimmermann (Akademie der Wissenschaften und der Literatur Mainz. Geistes- und Sozialwissenschaftliche Klasse. Einzelveröffentlichungen 4), Wiesbaden 1982, S. 182-193.

Haubrichs, Wolfgang, "Arcana Regum. Der Althochdeutsche hundertachtunddreißigste Psalm und die Synode zu Tribur (895)«, in: Architectura Poetica. Festschrift für Johannes Rathofer zum 65. Geburtstag, hrsg. von Ulrich ERnst und Bernhard SowinsKi (Kölner germanistische Studien 30) 1990, S. 67-106.

Haubrichs, Wolfgang, "Art. Heliand", in: Althochdeutsche und altsächsische Literatur, hrsg. von Rolf BERgMANN, Berlin 2013, S. 154-163.

Haubrichs, Wolfgang, "Das althochdeutsch-lateinische Textensemble des Cod. Weiss. 91 (Weißenburger Katechismus) und das Bistum Worms im frühen neunten Jahrhundert", in: Volkssprachig-lateinische Mischtexte und Textensembles in der althochdeutschen, altsächsischen und altenglischen Überlieferung, hrsg. von Rolf BERGMANN (Germanistische Bibliothek 17) 2003, S. 131-173.

HAUBRICHs, Wolfgang, "Das monastische Studienprogramm der Statuta Murbacensia und die altalamannischen Interlinearversionen «, in: Sprache, Literatur, Kultur: Studien zu ihrer Geschichte im deutschen Süden und Westen. Wolfgang Kleiber zu seinem 60. Geburtstag gewidmet, hrsg. von Albrecht Greule und Uwe Ruberg, Stuttgart 1989, S. 237 261. 
Haubrichs, Wolfgang, "Otfrid de Wissembourg, élève de Raban Maur, et l'héritage de l'école de Fulda au monastère de Wissembourg", in: Raban Maur et son temps, hrsg. von Philippe Depreux u. a. (Collection Haut Moyen Âge 9), Turnhout 2010, S. 155-172.

HaUbrichs, Wolfgang, "Rituale, Feste, Sprechhandlungen: Spuren oraler und laikaler Kultur in den Bibelepen des >Heliand und Otfrids von Weißenburg", in: Orality and literacy in the middle ages: Essays in a conjunction and its consequences in honour of D. H. Green, hrsg. von Mark CHINCA und Cristopher J. Young (Utrecht Studies in medieval literacy 12), Turnhout 2005, S. 37-66.

HaUbRICHs, Wolfgang, Die Kultur der Abtei Prüm zur Karolingerzeit: Studien zur Heimat der althochdeutschen Georgsliedes (Rheinisches Archiv 105), Bonn 1979.

HaUbrichs, Wolfgang, Georgslied und Georgslegende im frühen Mittelalter: Text und Rekonstruktion (Theorie, Kritik, Geschichte 13), Königstein 1979.

Haubrichs, Wolfgang, Geschichte der deutschen Literatur von den Anfängen bis zum Beginn der Neuzeit. 1, 1: Die Anfänge: Versuche volkssprachiger Schriftlichkeit im frühen Mittelalter (ca. 700-1050/60), Tübingen 1995.

HaUg, Arthur, "Gerald und Erckambald - Zum Verfasser- und Datierungsproblem des , Waltharius «, in: Jahrbuch für internationale Germanistik 34 (2002), S. 189-226.

HaUKe, Hermann, Katalog der lateinischen Fragmente der Bayerischen Staatsbibliothek München, 1: Clm 29202-29311 (Catalogus codicum manu scriptorum Bibliothecae Monacensis 4/12/1), Wiesbaden 1994.

Hauke, Hermann, Katalog der lateinischen Fragmente der Bayerischen Staatsbibliothek München, 2: Clm 29315-29520 (Catalogus codicum manu scriptorum Bibliothecae Monacensis 12/2), Wiesbaden 2001.

HAUKe, Hermann, Katalog der lateinischen Fragmente der Bayerischen Staatsbibliothek München: Band 3: Clm 29550-29990 (Catalogus codicum manu scriptorum Bibliothecae Monacensis 12/3), Wiesbaden 2013.

Hausberger, Karl, Geschichte des Bistums Regensburg, Regensburg 1989.

HAYE, Thomas, Das lateinische Lehrgedicht im Mittelalter: Analyse einer Gattung (Mittellateinische Studien und Texte 22), Leiden [u.a.] 1997.

Hedtke, Britta und Winterer, Christoph, »Mainz«, in: Schreiborte des deutschen Mittelalters: Skriptorien - Werke - Mäzene, hrsg. von Martin J. Schubert, Berlin [u.a.] 2013, S. 347-372.

Heinemann, Otto, Die Augusteischen Handschriften: Codex Guelferbytanus 77.4 Aug. $2^{\circ}$ bis 34 Augusteus $4^{\circ}$, Nachdr. der Ausg. 1900 (Kataloge der Herzog-August-Bibliothek Wolfenbüttel 7), Frankfurt a. M. 1966.

Heinemeyer, Karl, "Die Gründung des Klosters Fulda im Rahmen der bonifatianischen Kirchenorganisation «, in: Fuldaer Geschichtsblätter 56 (1980), S. 83-132.

Heinsdorff, Cornel, „Der interpolierte Juvencus des Codex Augiensis 112 und Severus von Malaga«, in: Vigiliae christianae 60 (2006), S. 148-170.

HeInzer, Felix, "Ex authentico scriptus - Zur liturgiehistorischen Stellung des Sakramentars«, in: Das Sakramentar der Fürstlich Fürstenbergischen Hofbibliothek Donaueschingen Cod. Don. 191, hrsg. von Herrad SpILling (Patrimonia 85), Berlin 1996, S. 6384.

HeInzer, Felix, »Rex benedicte veni. Der Weihnachtsbesuch König Konrads I. in St. Gallen im Dezember 911 «, in: Adel und Königtum im mittelalterlichen Schwaben: Festschrift für Thomas Zotz zum 65. Geburtstag, hrsg. von Andreas BiHRER (Veröffentlichungen der 
Kommission für geschichtliche Landeskunde in Baden-Württemberg. Reihe B 175) 2009, S. 115-126.

HellgaRdT, Ernst, "'...der alten Teutschen spraach und gottsforcht zuerlernen. Über Voraussetzungen und Ziele der Otfridausgabe des Matthias Flacius Illyricus (Basel 1571)«, in: Festschrift Walter Haug und Burghart Wachinger, hrsg. von Johannes JANota, Paul SAPpler und Frieder Schanze, Tübingen 1992, S. 267-286.

HellgardT, Ernst, „Das lateinisch-althochdeutsche Reimgebet \Sancte sator Theodor von Tarsus / Canterbury zugeschrieben", in: Zeitschrift für deutsches Altertum und deutsche Literatur 137 (2008), S. 1-27.

Hellgardt, Ernst, "Freising", in: Schreiborte des deutschen Mittelalters : Skriptorien Werke - Mäzene, hrsg. von Martin J. Schubert, Berlin [u. a.] 2013, S. 151-174.

Hellgardt, Ernst, Die exegetischen Quellen von Otfrids Evangelienbuch: Beiträge zu ihrer Ermittlung; mit einem Kapitel über die Weißenburger Bibliothek des Mittelalters und der Otfridzeit (Hermaea. Germanistische Forschungen, NF 41), Tübingen 1981.

HeLm, Karl, »Otfrid-Nennungen?«, in: Beiträge zur Geschichte der deutschen Sprache und Literatur 66 (1942), S. 134-145.

Helmer, Friedrich u. a. (Hrsg.), Die Handschriften aus St. Emmeram in Regensburg (Catalogus codicum manu scriptorum Bibliothecae Monacensis 4/2), Wiesbaden 1995.

Henderson, George D. S., »Emulation and invention in Carolingian art«, in: Carolingian Culture: Emulation and Innovation, hrsg. von Rosamond MCKiтTERICK, Cambridge 1994, S. 248-273.

Henkel, Nikolaus und Bergmann, Rolf, »Art. Juvenal (Decius Iunius Iuvenalis), Althochdeutsche Glossierung", in: Althochdeutsche und altsächsische Literatur, hrsg. von Rolf Bergmann, Berlin [u.a.] 2013, S. 219-222.

HenNings, Till, »Notker the Stammerer's compendium for his pupils«, in: Education Materialized: Reconstructing Teaching and Learning Contexts through Manuscripts (Studies in Manuscript Cultures), Berlin [im Druck].

Hermann Hagen, Catalogus codicum bernensium 1878.

Hermann, Hermann Julius, Die frühmittelalterlichen Handschriften des Abendlandes (Beschreibendes Verzeichnis der illuminierten Handschriften in Österreich, 8,1), Leipzig 1923.

Hermann, Karl Friedrich, »Wissenschaft und Bildung", in: Geschichte Salzburgs. Stadt und Land, 1, 2, hrsg. von Heinz Dopsch und Hans Spatzenegger, Salzburg 1984, S. 10711085.

Hermann, Karl Friedrich, Geschichte der Erzabtei St. Peter zu Salzburg. 1: Frühgeschichte 696-1193, Salzburg 1996.

Herren, Michael W., "Some quantitative poems attributed to Columbanus of Bobbio«, in: Poetry and philosophy in the Middle Ages: A festschrift for Peter Dronke, hrsg. von John Marenbon (Mittellateinische Studien und Texte 29), Leiden [u.a.] 2001, S. 99-112.

Herren, Michael, »The Authorship, Date of Composition and Provenance of the So-Called \Lorica Gildae«", in: Ériu 24 (1973), S. 35-51.

Herren, Michael W., »The >De imagine Tetrici of Walahfrid Strabo: edition and translation«, in: The journal of medieval Latin 1 (1991), S. 118-139.

Herzog, Reinhart, Die Bibelepik der lateinischen Spätantike (Theorie und Geschichte der Literatur und der schönen Künste 37), München 1975. 
Hessels, John Hendrik, A Late Eighth-Century Latin-Anglo-Saxon Glossary Preserved in the Library of the Leiden University, Cambridge 1906.

Heumieser, Max, Geschichte des Bistums Passau, 1 (Veröffentlichungen des Instituts für Ostbairische Heimatforschung in Passau 24), Passau 1939.

Hlawiтschка, Eduard, Franken, Alemannen, Bayern und Burgunder in Oberitalien (774962) (Forschungen zur oberrheinischen Landesgeschichte 8), Freiburg i. Br. 1960.

HlawitschKa, Eduard, Lotharingien und das Reich an der Schwelle der deutschen Geschichte (MGH Schriften 21), Stuttgart 1968.

Hoffmann, Hartmut, "Autographa des früheren Mittelalters«, in: Deutsches Archiv für Erforschung des Mittelalters 57 (2001), S. 1-62.

Hoffmann, Hartmut, »Bernhard Bischoff und die Paläographie des 9. Jahrhunderts", in: Deutsches Archiv für Erforschung des Mittelalters 55 (1999), S. 549-590.

Hoffmann, Hartmut, "Italienische Handschriften in Deutschland«, in: Deutsches Archiv für Erforschung des Mittelalters 65 (2009), S. 29-82.

Hoffmann, Hartmut, "Zum 2. Band von Bernhard Bischoffs >Katalog der festländischen Handschriften des 9. Jahrhunderts«", in: Deutsches Archiv für Erforschung des Mittelalters 61 (2005), S. 53-72.

Hoffmann, Hartmut, Buchkunst und Königtum im ottonischen und frühsalischen Reich (MGH Schriften 30, 1-2), Stuttgart 1986.

Hoffmann, Hartmut, Schreibschulen des 10. und des 11. Jahrhunderts im Südwesten des Deutschen Reiches (MGH Schriften 53), Hannover 2004.

HoFmanN, Conrad, „Über Bruchstücke einer Handschrift mit althochdeutschen Glossen«, in: Germania 8 (1863).

Hofmann, Heinz, »Corippus as a patristic author«, in: Vigiliae christianae XLIII (1989), S. 361-377.

Hofmann, Heinz, „Überlegungen zu einer Theorie der nichtchristlichen Epik der lateinischen Spätantike«, in: Philologus 132, 1-2 (1988), S. 101-159.

Holder, Alfred und Preisendanz, Karl, Grundstock der Bibliothek; die alten Kataloge; Zeugnisse zur Bibliotheksgeschichte. Neudr. d. Ausg. 1918 (Die Reichenauer Handschriften, 3. 1,2), Wiesbaden 1973.

Holder, Alfred, »Zu Avianus«, in: Philologus 56 (1906), S. 91-96.

Holder, Alfred, Die Pergamenthandschriften (Die Reichenauer Handschriften. Neudruck mit bibliographischen Nachträgen 1), Wiesbaden 1970.

Holtz, Louis, "La redécouverte de Virgile aux VIIIe et IXe siècles d'après les manuscrits conservés«, in: Publications de l'École française de Rome 80 (1985), S. 9-30.

Holtz, Louis, »Raban Maur et l'Excerptio de arte grammatica Prisciani«, in: Raban Maur et son temps, hrsg. von Philippe Depreux u. a. (Collection Haut Moyen Âge 9), Turnhout 2010, S. 203-218.

Homburger, Otto, Die illustrierten Handschriften der Burgerbibliothek Bern. Die vorkarolingischen $u$. karolingischen Handschriften, Bern 1962.

Houben, Hubert, »Art. Heito (Haito, Hatto) von Reichenau«, in: Verfasserlexikon, 3, 1981, S. 939-942.

Hucke, H., "Die Neumierung des althochdeutschen Petruslieds", in: Organicae voces: Festschrift Joseph Smits van Waesberghe angeboten anlässlich seines 60. Geburtstages, 18. April 1961, hrsg. von Instituut voor Middeleeuwse Muziekwetenschap, Amsterdam 1963, S. 71-78. 
Huemer, Johann, »Analekten zur lateinischen Anthologie«, in: Wiener Studien 2 (1880), S. 71-80.

Huemer, Johann, Cruindmeli sive Fulcharii Ars metrica: Beitrag zur Geschichte der karolingischen Gelehrsamkeit, Wien 1883.

Hunt, R. W., "An investigation of some astronomical excerpts from Pliny's Natural History found in manuscripts of the earlier Middle Ages. Diss.", University of Oxford 1969.

Husmann, Heinrich, »Die älteste erreichbare Gestalt des St. Galler Tropariums", in: Archiv für Musikwissenschaft 13 (1956), S. 25-41.

Hussong, Ulrich, "Die Geschichte des Klosters Fulda von der Gründung bis ins 11. Jahrhundert«, in: Geschichte der Stadt Fulda, 1. Von den Anfängen bis zum Ende des Alten Reiches, hrsg. von Wolfgang Hamberger, Thomas Heiler und Werner KirchHoff, Fulda 2008, S. 143-165.

Hussong, Ulrich, »Studien zur Geschichte der Reichsabtei Fulda bis zur Jahrtausendwende«, in: Archiv für Diplomatik 32 (1986), S. 129-304.

Ineichen-Eder, Christine E. und Bernhard Bischoff (Hrsg.), Mittelalterliche Bibliothekskataloge Deutschlands und der Schweiz, 4, 1: Bistümer Passau und Regensburg, München 1977.

IneICHEN-EDeR, Christine E., "Theologisches und philosophisches Lehrmaterial aus dem Alkuin-Kreise«, in: Deutsches Archiv für Erforschung des Mittelalters 34 (1978), S. 192201.

IsPhording, Bernd, Prüm. Studien zur Geschichte der Abtei von ihrer Gründung bis zum Tod Kaiser Lothars I. (721-855). (Quellen und Abhandlungen zur mittelrheinischen Kirchengeschichte 116), Mainz 2005.

Jacobsen, Peter Christian, "Carmina Columbani«, in: Die Iren und Europa im früheren Mittelalter, hrsg. von Heinz Löwe (Veröffentlichungen des Europa Zentrums Tübingen. Kulturwissenschaftliche Reihe), Stuttgart 1982, S. 434-467.

James, Montague Rhodes, A descriptive catalogue of the latin manuscripts in the John Rylands Library at Manchester, Manchester 1921.

JAMmers, Ewald, "Rhythmen und Hymnen in einer St. Galler Handschrift des 9. Jahrhunderts«, in: Festschrift Bruno Stäblein zum 70. Geburtstag, hrsg. von Martin Runnke, Kassel 1967, S. 134-142.

JÄNICKE, O., "Die Verse auf Pan zum vierten Mal«, in: Jahrbücher für Philologie und Pädagogik 38. N.F. Jg. 14 (1868), S. 391.

Jarousseau, Guy, "L'hymne `Gloria laus` de Théodulfe d'Orléans, un témoin de la réforme carolingienne", in: Mittellateinisches Jahrbuch 48 (2013), S. 369-398.

Jeger, Isabelle, Bibliotheque de Geneve, Catalogue des manuscrits latins, Genf 2016.

Jenny, Markus, »Art. Cantica«, in: Theologische Realenzyklopädie, 7, 1981, S. 624-628.

JoAснімsonn, Paul, Die humanistische Geschichtsschreibung in Deutschland, Heft 1: Die Anfänge. Sigmund Meisterlin, Bonn 1895.

Jones, Leslie Webber, »Cologne MS. 106: A Book of Hildebald«, in: Speculum 4 (1929), S. 2761.

Jones, Leslie Webber, The script of Cologne from Hildebald to Hermann (The Mediaeval Academy of America. Publications 10), Cambridge, Mass. 1932.

Jong, Mayke de, The penitential state: authority and atonement in the age of Louis the Pious, 814-840, Cambridge [u.a.] 2010. 
Jullien, Marie-Hélène, Clavis scriptorum latinorum medii aevi. Auctores Galliae, t. 2, Turnhout 1999.

JÜrgenSMeIER, Friedhelm, Das Bistum Mainz: von der Römerzeit bis zum II. Vatikanischen Konzil (Beiträge zur Mainzer Kirchengeschichte 2), Frankfurt a. M. 1988.

Kaczynski, Bernice Martha, "Some St. Gall Glosses on Greek Philanthropic Nomenclature«, in: Speculum 58 (1983), S. 1008-1017.

KARTSCHOKE, Dieter, Bibeldichtung: Studien zur Geschichte der epischen Bibelparaphrase von Juvencus bis Otfrid von Weißenburg, München 1975.

KAutz, Michael, »Brüssel, Bibliothèque royale de Belgique, Ms. 9845-9848«, http://biblio theca-laureshamensis-digital.de/view/kbr_ms9845-48?ui_lang=eng (abgerufen am 21. 11.2017).

KAUtz, Michael, »Leiden, Universiteitsbibliotheek, BPL 36«, http://bibliotheca-lauresha mensis-digital.de/view/ublei_bpl36 (abgerufen am 23.11.2017).

Kautz, Michael, »Merseburg, Domstiftsbibliothek, Cod. 105«, http://bibliotheca-lauresha mensis-digital.de/view/dstibm_cod105 (abgerufen am 20.11.2017).

KAUTZ, Michael, "Montpellier, Bibliothèque universitaire de médecine, Bibliothèque interuniversitaire de«, http://bibliotheca-laureshamensis-digital.de/view/bumm_h125 (abgerufen am 23.11.2017).

KAUTZ, Michael, »Paris, Bibliothèque nationale de France, Latin 16668«, http://bibliothecalaureshamensis-digital.de/view/bnf_lat16668 (abgerufen am 17.11.2017).

KAUTZ, Michael, »Paris, Bibliothèque nationale de France, Latin 7906«, http://bibliothecalaureshamensis-digital.de/view/bnf_lat7906 (abgerufen am 14.11.2017).

KAUTZ, Michael, »St. Gallen, Stiftsbibliothek, Cod. 1396«, http://bibliotheca-laureshamen sis-digital.de/view/stibsg_cod1396_pagg (abgerufen am 21.11.2017).

KAUTZ, Michael, »St. Gallen, Stiftsbibliothek, Cod. 187«, http://bibliotheca-laureshamensisdigital.de/view/stibsg_cod187 (abgerufen am 24.11.2017).

Kautz, Michael, »Vatikan, Biblioteca Apostolica Vaticana, Pal. lat. 239«, http://bibliothecalaureshamensis-digital.de/bav/bav_pal_lat_239?ui_lang=eng (abgerufen am 05.11. 2018).

KAUtz, Michael, »Vatikan, Biblioteca Apostolica Vaticana, Pal. lat. 1581«, http://bibliothe ca-laureshamensis-digital.de/bav/bav_pal_lat_1631 (abgerufen am 06.12.2017).

Kautz, Michael, »Vatikan, Biblioteca Apostolica Vaticana, Pal. lat. 487«, http://bibliothecalaureshamensis-digital.de/bav/bav_pal_lat_487 (abgerufen am 14.11.2017).

Kautz, Michael, »Vatikan, Biblioteca Apostolica Vaticana, Pal. lat. 1753«, http://bibliothe ca-laureshamensis-digital.de/bav/bav_pal_lat_1753 (abgerufen am 17.11.2017).

Kautz, Michael, »Vatikan, Biblioteca Apostolica Vaticana, Pal. lat. 1649«, http://bibliothe ca-laureshamensis-digital.de/bav/bav_pal_lat_1649 (abgerufen am 21.11.2017).

KAUtz, Michael, »Vatikan, Biblioteca Apostolica Vaticana, Pal. lat. 1719«, http://bibliothe ca-laureshamensis-digital.de/bav/bav_pal_lat_1719?sid=3fd1bab4cc7391b69beff6435a 776295 (abgerufen am 21.11.2017).

KAutz, Michael, »Vatikan, Biblioteca Apostolica Vaticana, Pal. lat. 833«, http://bibliothecalaureshamensis-digital.de/bav/bav_pal_lat_833 (abgerufen am 24.11.2017).

Kautz, Michael, »Vatikan, Biblioteca Apostolica Vaticana, Pal. lat. 1631 «, http://bibliothe ca-laureshamensis-digital.de/bav/bav_pal_lat_1631 (abgerufen am 06.12.2017).

KaUtz, Michael, »Vatikan, Biblioteca Apostolica Vaticana, Reg. lat. 118«, https://bibliothe ca-laureshamensis-digital.de/bav/bav_reg_lat_118 (abgerufen am 06.11.2018). 
KaUtz, Michael, »Wien, Österreichische Nationalbibliothek, Cod. 1761«, http://bibliothecalaureshamensis-digital.de/view/onb_cod1761 (abgerufen am 09.11.2017).

KAUtz, Michael, »Wolfenbüttel, Herzog August Bibliothek, Cod. Guelf. 66 Gud. lat.«, http:// bibliotheca-laureshamensis-digital.de/view/hab_mss66-gud-lat (abgerufen am 20.11. 2017).

KaUtz, Michael, Bibliothek und Skriptorium des ehemaligen Klosters Lorsch: Katalog der erhaltenen Handschriften, Wiesbaden 2016.

Keller, Hagen, »Zur Struktur der Königsherrschaft im karolingischen und nachkarolingischen Italien. Der >consiliarius regis` in den italienischen Königsdiplomen des 9. und 10. Jahrhunderts", in: Quellen und Forschungen aus italienischen Archiven und Bibliotheken 47 (1967), S. 123-223.

Keller, Hans-Erich, »Art. Chansonnier«, in: Lexikon des Mittelalters, 2, 1983, S. 1709.

Keller, Otto, Beschreibung der wichtigsten Horazhandschriften, Leipzig 1899.

Keller, Otto, Epilegomena zu Horaz, Leipzig 1879.

Keuffer, Max und Kentenich, Gottfried, Beschreibendes Verzeichnis der Handschriften der Stadtbibliothek Trier, Trier 1888.

KIRSCH, Wolfgang, Laudes sanctorum. Geschichte der hagiographischen Versepik vom IV. bis X. Jahrhundert (Quellen und Untersuchungen zur lateinischen Philologie des Mittelalters 14), Stuttgart.

KleIBER, Wolfgang, "Otfrid von Weißenburg als Priscian-Glossator. Eine sprachhistorische Skizze«, in: Die althochdeutsche und altsächsische Glossographie. Ein Handbuch, 2, hrsg. von Rolf Bergmann und Stefanie STricker, Berlin [u. a.] 2009, S. 1601-1610.

KLEIBER, Wolfgang, Otfrid von Weissenburg: Untersuchungen zur handschriftlichen Überlieferung und Studien zum Aufbau des Evangelienbuches (Bibliotheca Germanica 14), Bern [u.a.] 1971.

KLEIN, Thomas, "Kritische Nachlese zur >Sylloge Elnonensis«", in: Arbor amoena comis: 25 Jahre Mittellateinisches Seminar in Bonn; 1965-1990, hrsg. von Ewald Könsgen, Stuttgart 1990, S. 53-59.

KLEINSCHMIDT, Erich, "Zur Reichenauer Überlieferung der >Visio Wettini< im 9. Jahrhundert«, in: Deutsches Archiv für Erforschung des Mittelalters 30 (1974), S. 199-207.

KLof T, Matthias Theodor, "Hrabanus Maurus, die >tituli< und die Altarweihen«, in: Raban Maur et son temps, hrsg. von Philippe Depreux u. a. (Collection Haut Moyen Âge 9), Turnhout 2010, S. 367-387.

KLopsch, Paul, "Carmen de philomela«, in: Literatur und Sprache im europäischen Mittelalter. Festschrift für Karl Langosch zum 70. Geburtstag, hrsg. von Alf ÖNNERFors, Johannes Rathofer und Fritz WAgner, Darmstadt 1973, S. 173-194.

KLOPSCH, Paul, "Der Übergang von Quantitierender zu Akzentuierender Lateinischer Dichtung«, in: Metrik und Medienwechsel = Metrics and the media, hrsg. von Hildegard L. C. Tristram (ScriptOralia 35), Tübingen 1991, S. 95-106.

KLOPsch, Paul, „Die karolingische Bildungsreform im Bodenseeraum «, in: Geistesleben um den Bodensee im frühen Mittelalter, hrsg. von Achim Masser und Alois Wolf (Literatur und Geschichte am Oberrhein 2), Freiburg i. Br. 1989, S. 65-85.

KLOPsch, Paul, Einführung in die Dichtungslehren des lateinischen Mittelalters (Das lateinische Mittelalter), Darmstadt 1980. 
Knapp, Fritz Peter, Die Literatur des Früh- und Hochmittelalters in den Bistümern Passau, Salzburg, Brixen und Trient von den Anfängen bis zum Jahre 1273 (Geschichte der Literatur in Österreich 1), Graz 1994.

Knoblich, Isabel, Die Bibliothek des Klosters St. Maximin bei Trier bis zum 12. Jahrhundert, Trier 1996.

KNoche, Ulrich, Handschriftliche Grundlagen des Juvenaltextes (Philologus, Supplement 1), Leipzig 1940.

KNöpp, Friedrich, Die Reichsabtei Lorsch, Darmstadt 1973.

KöHLER, Christopher, »Würzburg", in: Schreiborte des deutschen Mittelalters : Skriptorien - Werke - Mäzene, hrsg. von Martin J. Schubert, Berlin [u. a.] 2013, S. 621-644.

KöLblinger, Gerald, » Versus Panos` und >De rustico«", in: Mittellateinisches Jahrbuch 8 (1973), S. 7-27.

KöNIG, Joseph, »Über Walafried Strabo von Reichenau«, in: Freiburger Diözesan-Archiv 3 (1868), S. 317-464.

KöNsgen, Ewald, "Eine komputistische Dichtung des Agius von Corvey«, in: Mittellateinisches Jahrbuch 14 (1979), S. 66-75.

KornrumpF, Gisela, "Art. Liederbücher, Liederhandschriften «, in: Lexikon des Mittelalters, 5, 1991, S. 1971-1974.

KöSSINGER, Norbert, »Weißenburg ", in: Schreiborte des deutschen Mittelalters : Skriptorien - Werke - Mäzene, hrsg. von Martin J. Schubert, Berlin [u.a.] 2013, S. 537-548.

Kössinger, Norbert, Hrabanus Maurus: Profil eines europäischen Gelehrten; Beiträge zum Hrabanus-Jahr 2006, St. Ottilien 2008.

Kotтje, Raymund und Harald Zimmermann (Hrsg.), Hrabanus Maurus: Lehrer, Abt und Bischof (Abhandlungen der Geistes- und Sozialwissenschaftlichen Klasse. Akademie der Wissenschaften und der Literatur in Mainz 4), Wiesbaden 1982.

Коттје, Raymund, "Die handschriftliche Überlieferung der Bibelkommentare des Hrabanus Maurus", in: Raban Maur et son temps, hrsg. von Philippe Depreux u. a. (Collection Haut Moyen Âge 9), Turnhout 2010, S. 259-274.

Kоттје, Raymund, „Ein Zeugnis für die Hofbibliothek Karls des Großen?: Zu Inhalt und Herkunft der Bücherliste in der Hs. Berlin, SBB-PK Ms.Diez.B Sant. 66. «, in: Annalen des Historischen Vereins für den Niederrhein 212 (2009), S. 45-49.

Коттје, Raymund, »Rezension zu: Müller, Hrabanus Maurus - De laudibus sancta crucis Studien zur Überlieferung und Geistesgeschichte mit dem Faksimile - Textabdruck aus Codex Reg. Lat. 124 der Vatikanischen Bibliothek«, in: Deutsches Archiv für Erforschung des Mittelalters 31 (1975), S. 597-598.

Коттје, Raymund, »Schriftlichkeit im Dienst der Klosterverwaltung und des klösterlichen Lebens unter Hrabanus Maurus«, in: Kloster Fulda in der Welt der Karolinger und Ottonen, hrsg. von Gangolf ScHRIMPF (Fuldaer Studien 7), Frankfurt a. M. 1996, S. 177192.

Коттје, Raymund, Verzeichnis der Handschriften mit den Werken des Hrabanus Maurus (MGH Hilfsmittel 27), Hannover 2012.

Kraus, Franz Xaver, Kunst und Alterthum im Ober-Elsass (Kunst und Altertum in ElsaßLothringen 2), Straßburg 1884.

Krick, Ludwig Heinrich, Das ehemalige Domstift Passau und die ehemal. Kollegiatstifte des Bistums Passau. Chronologische Reihenfolge ihrer Mitglieder von der Gründung der Stifte bis zu ihrer Aufhebung, Passau 1922. 
Krotz, Elke, Auf den Spuren des althochdeutschen Isidor: Studien zur Pariser Handschrift, den Monseer Fragmenten und zum Codex Junius 25 ; mit einer Neuedition des Glossars Jc (Beiträge zur älteren Literaturgeschichte), Heidelberg 2002.

Kurth, Godefroid, La Cité de Liège au Moyen Âge, Brüssel 1909.

Labarre, Sylvie, "La transmission de Paulin de Périgueux: les principes d'une nouvelle édition«, in: Revue d'histoire des textes 7 (2012), S. 117-158.

Lagorio, Valerie M., "Aldhelm's Aenigmata in Codex Vaticanus Palatinus Latinus 1719", in: Manuscripta 15 (1971), S. 23-27.

LAgorio, Valerie M., »The text of Cicero's De inventione in Codex Vat. Lat. 11506«, in: The Classical bulletin LV (1978), S. 12-15.

Lammers, Walther (Hrsg.), Die Eingliederung der Sachsen in das Frankenreich (Wege der Forschung 185), Darmstadt 1970.

LANG, Odo, »Einsiedeln, Stiftsbibliothek, Codex 266(1296)« (900), https://www.e-codices. ch/en/list/one/sbe/0266 (abgerufen am 13.07.2018).

LANG, Odo, »Einsiedeln, Stiftsbibliothek, Codex 326(1076)«, http://www.e-codices.unifr.ch/ en/description/sbe/0326/ (abgerufen am 28.08.2017).

LAPIDGE, Michael, "Aldhelmus Malmesberiensis abb. et Scireburnensis ep.", in: La trasmissione dei testi latini del Medioevo, 4, hrsg. von Paolo Chiesa und Lucia Castaldi 2012, S. 14-38.

LAPIDGE, Michael, »Beda Venerabilis«, in: La trasmissione dei testi latini del Medioevo, 3, hrsg. von Paolo Chiesa und Lucia Castaldi 2008, S. 44-137.

LAPIDGE, Michael, »Bede the Poet«, in: Lapidge, Anglo-Latin Literature 600-899, London 1996, S. 313-338, 508.

LAPIDGE, Michael, »Epilogue: did Columbanus compose metrical verse?«, in: Columbanus Studies on the Latin Writings 1997, S. 274-285.

LAPIDGE, Michael, "Some Remnants of Bede's Lost Liber Epigrammatum«, in: Lapidge, Anglo-Latin Literature 600-899 1996, S. 357-379, 510-512.

LAPIDGE, Michael, "Theodore and Anglo-Latin Octosyllabic Verse", in: Lapidge, AngloLatin Literature 600-899 1996, S. 225-245, 504.

LAUfNer, Richard, "Vom Bereich der Trierer Klosterbibliothek St. Maximin im Hochmittelalter«, in: Armaria Trevirensia, hrsg. von Gunther Franz, 2., stark erw. Aufl. (Bibliotheca Trevirensis 1), Wiesbaden 1985, S. 15-43.

LAW, Vivien A., "Erchanbert and the interpolator: a Christian Ars Minor at Freising (clm 6414).", in: History of Linguistic Thought in the Early Middle Ages, hrsg. von Vivien A. LAw (Studies in the History of the Language Sciences 71), Amsterdam 1993, S. 223-243.

Lebech, Mette, McEvoy, James und Flood, John L., "De dignitate conditionis humanae: Translation, Commentary, and Reception History of the Dicta Albini (Ps.-Alcuin) and the Dicta Candidi«, in: Viator 40 (2009), S. 1-34.

LEBEK, Wolfgang Dieter, "Die neuen Grabgedichte der Sylloge Elnonensis ed. B. Bischoff 1984«, in: Zeitschrift für Papyrologie und Epigraphik 63 (1986), S. 83-100.

Lebeк, Wolfgang Dieter, "Zur Sylloge Elnonensis (Mit textkritischen Beiträgen von 0. Zwierlein)«, in: Zeitschrift für Papyrologie und Epigraphik 65 (1986), S. 66-68.

Lehmann, Paul, »Cassiodor-Studien«, in: Lehmann, Erforschung des Mittelalters, 2, 1959, S. 38-108.

Lehmann, Paul, »Corveyer Studien«, in: Lehmann, Erforschung des Mittelalters, 5, 1962, S. 94-178. 
Lehmann, Paul, "Das älteste Bücherverzeichnis der Niederlande«, in: Lehmann, Erforschung des Mittelalters, 1, 1941, S. 207-212.

Lehmann, Paul, "Die alte Klosterbibliothek Fulda und ihre Bedeutung", in: Lehmann, Erforschung des Mittelalters, 1, 1941, S. 213-230.

Lehmann, Paul, „Die mittelalterliche Bibliothek der Reichenau«, in: Die Kultur der Abtei Reichenau: Erinnerungschrift zur zwölfhundertsten Wiederkehr des Gründungsjahres des Inselklosters 724-1924, 2, hrsg. von Konrad Beyerle und Peter P. Albert, München 1925, S. 645-656.

Lehmann, Paul, »Erzbischof Hildebald und die Dombibliothek von Köln«, in: Zentralblatt für Bibliothekswesen 25 (1908), S. 153-157.

Lehmann, Paul, "Quot et quorum libri fuerint in libraria Fuldensi«, in: Bok- och bibliothekshistoriska studier tillägnade Isak Collijn, Uppsala 1925, S. 47-57.

Lehmann, Paul, »Von Quellen und Autoritäten irisch-lateinischer Texte«, in: Lehmann, Erforschung des Mittelalters, 3, 1960, S. 143-148.

LEIDL, August, Die Bischöfe von Passau (739-1968) in Kurzbiographien (Neue Veröffentlichungen des Instituts für Ostbairische Heimatforschung der Universität Passau 38), Passau 1978.

Lejeune, Jean, La principauté de Liège, 2. Aufl., Liège 1949.

Lendinara, Patrizia, »A Poem for All Seasons: Alcuin's »O vos, est aetas«, in: Teaching and learning in medieval Europe: essays in honour of Gernot R. Wieland, hrsg. von DinKova-BruUn, Greti und Tristan Gary Major (Publications of the journal of medieval Latin 11), Turnhout 2017, S. 123-146.

Lenz, Philipp und Ortelli, Stefania, Die Handschriften der Stiftsbibliothek St. Gallen, 3: Abt. V: Codices 670-749, Wiesbaden 2014.

Leonardi, Claudio, »I codici di Marziano Capella«, in: Aevum 34 (1960), S. 1-99, 411-524.

LeotTA, Rosario, "Un anonimo imitatore di Massimiano.", in: Giornale italiano di filologia 37 (1985), S. 91-106.

LERCHE, Otto, »Das älteste Ausleihverzeichnis einer deutschen Bibliothek«, in: Zentralblatt für Bibliothekswesen 27 (1910), S. 441-450.

LESNE, Émile, Les livres, "Scriptoria « et Bibliothèques du commencement du VIII. à la fin du XI. siècle (Histoire de la propriété ecclésiastique en France IV (Mémoires et travaux 46)), Lille 1938.

Levine, Philip, »Rezension zu: Colophons de manuscrits occidentaux des origines au XVIe siècle«, in: Speculum 44 (1969), S. 107-110.

Lewine, Carol F., The miniatures of the Antwerp Sedulius manuscript: the early Christian models and their transformations, New York, NY, Columbia Univ., Diss., 1970.

LIснт, Tino, "Aratoris fortuna. Aufgang und Überlieferung der Historia apostolica«, in: Quaerite faciem eius semper. Studien zu den geistesgeschichtlichen Beziehungen zwischen Antike und Christentum als Dankesgabe für Albrecht Dihle aus dem Heidelberger "Kirchenväterkolloquium «, hrsg. von Andrea JöRdens u. a. (Studien zur Kirchengeschichte 8), Hamburg 2008, S. 163-179.

LICHT, Tino, "Beobachtungen zum Lorscher Skriptorium in karolingischer Zeit«, in: Karolingische Klöster. Wissenstransfer und kulturelle Innovation, hrsg. von Julia BECKER, Tino Licht und Stefan Weinfurter, Berlin [u.a.] 2015, S. 145-162.

Lіснт, Tino, »Horazüberlieferung im Frühmittelalter«, in: Ex Praeteritis Praesentia: Sprach-, literatur- und kulturwissenschaftliche Studien zu Wort- und Stoffgeschichten; 
Festschrift zum 70. Geburtstag von Theo Stemmler, hrsg. von Matthias Eitelmann und Nadine Stritzke (Anglistische Forschungen 370), Heidelberg 2006, S. 109-134.

Lieb, Hans, "Zur Herkunft der Tabula Peutingeriana», in: Die Abtei Reichenau. Neue Beiträge zur Geschichte und Kultur des Inselklosters, hrsg. von Helmut MAUrer (Bodensee-Bibliothek 20, Hegau-Bibliothek 28), Sigmaringen 1974, S. 31-33.

LINDNER, Klaus, Untersuchungen zur Frühgeschichte des Bistums Würzburg und des Würzburger Raumes (Veröffentlichungen des Max-Planck-Instituts für Geschichte 35), Göttingen 1972.

Lindsay, Wallace Martin und Lehmann, Paul, »The early Mayence scriptorium«, in: $P a$ laeographica latina, 4, 1925, S. 15-39.

Lindsay, Wallace Martin, »The (Early) Lorsch Scriptorium«, in: Palaeographica latina, 3, 1924, S. 5-48.

Lo spazio letterario del medioevo. 1. Il medioevo latino, 1-5, Roma 1992.

LÖFf LER, Karl, Kölnische Bibliotheksgeschichte im Umriß. Mit einer Nachweisung kölnischer Handschriften und einem Beitrag v. G. Frenken über den Katalog der Dombibliothek von 833, Köln 1923.

LOHMEYer, Hermann, Vergil im deutschen Geistesleben bis auf Notker III (Germanische Studien 96), Berlin 1930.

Lösch, Stephan, Die Einsiedler-Gedichte: eine literar-historische Untersuchung, Tübingen 1909.

LošeK, Fritz, "Arn von Salzburg und die karolingische Dichtung«, in: Erzbischof Arn von Salzburg, hrsg. von Meta Niederkorn-Bruck und Anton Scharer (Veröffentlichungen des Instituts für Österreichische Geschichtsforschung 40), Wien [u.a.] 2004, S. 172-178.

Lowe, Elias A. (Hrsg.), Codices Latini antiquiores VII, Switzerland, Oxford 1956.

Lowe, Elias A. (Hrsg.), Codices Latini antiquiores X, Austria, Belgium, Czechoslovakia, Denmark, Egypt, and Holland, Melle 2011.

Lowe, Elias A. (Hrsg.), Codices Latini antiquiores, Suppl., Oxford 1971.

LowE, Elias Avery, "An eighth-century list of books in a Bodleian manuscript from Würzburg and its probable relation to the Laudian Acts", in: Lowe, Palaeographical Papers 1 1972, S. 239-250.

Lowe, Elias Avery, Codices Latini antiquiores IX, Germany: Maria Laach - Würzburg, Oxford 1960.

LöwE, Heinz, "Salzburg als Zentrum literarischen Schaffens im 8. Jahrhundert«, in: Mitteilungen der Gesellschaft für Salzburger Landeskunde 115 (1975), S. 99-144.

LöwE, Heinz, „Studien zu den Annales Xantenses«, in: Deutsches Archiv für Erforschung des Mittelalters 8 (1951), S. 59-99.

LöwE, Heinz, »Zur Geschichte Wizos«, in: Deutsches Archiv für Erforschung des Mittelalters 6 (1943), S. 363-373.

LucK, Georg, Untersuchungen zur Textgeschichte Ovids (Bibliothek der klassischen Altertumswissenschaften 29), Heidelberg 1969.

Ludwig, Uwe, "Monastische Gebetsverbrüderung, Reichsteilung, Murbach und Weissenburg in ihren Gedenkbeziehungen zu St. Gallen und Reichenau«, in: L'abbaye de SaintGall et l'Alsace au haut Moyen Âge, hrsg. von Jean-Luc Eichenlaub und Werner Vogler, Colmar 1997, S. 97-114.

Lyons, Stuart, Music in the Odes of Horace, Oxford 2010. 
MAAG, Natalie, »Alemannische Spuren in Lorsch«, in: Karolingische Klöster. Wissenstransfer und kulturelle Innovation, hrsg. von Julia BECKer, Tino Licht und Stefan WeINFurter, Berlin [u.a.] 2015, S. 163-174.

MAAg, Natalie, Alemannische Minuskel: (744-846 n. Chr.) Frühe Schriftkultur im Bodenseeraum und Voralpenland (Quellen und Untersuchungen zur lateinischen Philologie des Mittelalters 18), Stuttgart 2014.

MaChIElsen, John J., Clavis patristica pseudepigraphorum medii aevi (CCSL), Turnhout 1990.

MäLzer, Gottfried, „Die Bibliothek des Würzburger Domstifts«, in: Würzburger Diözesangeschichtsblätter 50 (1988), S. 509-544.

Manitius, Max, "Geschichtliches aus mittelalterlichen Bibliothekskatalogen«, in: Neues Archiv der Gesellschaft für ältere deutsche Geschichtskunde 32 (1907), S. 647-709.

Manitius, Max, "Micons von St. Riquier De Primis syllabis«, in: Münchener Museum für Philologie des Mittelalters und der Renaissance 1 (1912), S. 121-177.

Manitius, Max, Geschichte der lateinischen Literatur des Mittelalters. 1. Von Justinian bis zur Mitte des zehnten Jahrhunderts, München 1911.

Manitius, Max, Geschichte der lateinischen Literatur des Mittelalters. 2. Von der Mitte des zehnten Jahrhunderts bis zum Ausbruch des Kampfes zwischen Kirche und Staat: mit Index, München 1923.

Manitius, Max, Handschriften antiker Autoren in mittelalterlichen Bibliothekskatalogen (Zentralblatt für Bibliothekswesen. Beiheft 67), Leipzig 1935.

Marböcк, Johann, Das Eindringen der Versio Gallicana des Psalteriums in die Psalterien der Benediktinerklöster Oberösterreichs (Dissertationen der Universität Graz 5), Graz 1970.

Martin, R. H., "From manuscript to print», in: The Cambridge companion to Tacitus (2009), S. 241-252.

MAss, Josef, Das Bistum Freising im Mittelalter (Geschichte des Erzbistums München und Freising 1), München 1986.

MAss, Josef, Das Bistum Freising in der späten Karolingerzeit. Die Bischöfe Anno (854-875), Arnold (875-883) und Waldo (884-906) (Studien zur altbayerischen Kirchengeschichte 2), München 1969.

MAsser, Achim, "Art. Weißenburger Katechismus«, in: Althochdeutsche und altsächsische Literatur, hrsg. von Rolf BergmanN, Berlin [u.a.] 2013, S. 506-508.

MASSER, Achim, "Aufgabe und Leistung der frühen volkssprachigen Literatur», in: Geistesleben um den Bodensee im frühen Mittelalter, hrsg. von Achim MASser und Alois Wolf (Literatur und Geschichte am Oberrhein 2), Freiburg i. Br. 1989, S. 87-106.

MAtter, Jacques, "Bibliothèque d'une maison religieuse du XVe siècle. Catalogue de la bibliothèque de l'abbaye princière de Murbach«, in: Lettres et pièces rares ou inédites, publiées et accompagnées d'introductions et de notes, Paris 1846, S. 40-76.

Maurer, Helmut, Die Abtei Reichenau. Neue Beiträge (Bodensee-Bibliothek 20), Sigmaringen 1974.

Mazal, Otto, "Die Salzburger Dom- und Klosterbibliothek in karolingischer Zeit", in: Bibliothekswesen und Forschung. Festgabe für Otto Mazal (Studien zur Bibliotheksgeschichte 4), Graz 1982, S. 40-60.

McСовміск, Michael, Five hundred unknown glosses from the Palatine Virgil (Studi e testi 343), Vatikan 1992. 
McLintock, David R. und Hartmann, Heiko, »Art. Psalter: Psalm 138«, in: Althochdeutsche und altsächsische Literatur, hrsg. von Rolf BERGMANn 2013, S. 413-416.

Mearns, James, Early Latin hymnaries, Cambridge 1913.

MEARns, James, The canticles of the christian church eastern and western in early and medieval times, Cambridge 1914.

MeIER, Gabriel, »Geschichte der Schule von St. Gallen im Mittelalter«, in: Jahrbuch für Schweizerische Geschichte 10 (1885), S. 33-128.

MeIER, Gabriel, Catalogus codicum manu scriptorum qui in Bibliotheca Monasterii Einsidlensis O.S.B. servantur, Einsiedeln 1899.

Menhardt, Hermann, „Zur Überlieferung des ahd. 138. Psalms«, in: Zeitschrift für deutsches Altertum und Literatur 77 (1940), S. 76-84.

Menhardt, Hermann, „Zur Überlieferung des ahd. 138. Psalms«, in: Zeitschrift für deutsches Altertum und deutsche Literatur 77 (1940), S. 76-84.

Menhardt, Hermann, Verzeichnis der altdeutschen literarischen Handschriften der Österreichischen Nationalbibliothek (Veröffentlichungen des Instituts für deutsche Sprache und Literatur 13), Berlin 1960.

Meyer, Wilhelm, "Die Berliner Centones der Laudes dei des Dracontius", in: Sitzungsberichte der Preussischen Akademie der Wissenschaften zu Berlin (1890), S. 257-296.

Meyer, Wilhelm, Die Sammlungen der Spruchverse des Publilius Syrus, Leipzig 1877.

MeYer, Wilhelm, Gesammelte Abhandlungen zur mittelalterlichen Rhythmik, Berlin 1905.

Meyier, Karel Adriaan de, Codices Vossiani Latini, Leiden.

Milde, Wolfgang, "Das ahd. Gebet des Sigihard und sein Schreiber. Eine paläographische Studie«, in: Septuaginta quinque. Festschrift für Heinz Mettke, hrsg. von Jens Haustein, Eckhard MeINECKE und Norbert Richard Wolf (Jenaer germanistische Forschungen NF 5), Heidelberg 2000, S. 285-293.

Milde, Wolfgang, Der Bibliothekskatalog des Kloster Murbach aus dem 9. Jahrhundert: Ausgabe und Untersuchung von Beziehungen zu Cassiodors "Institutiones" (Euphorion. Beihefte 4), Heidelberg 1968.

Mitis, Oskar von, »Bemerkungen zu den Verbrüderungsbüchern und über deren geschichtlichen Wert", in: Zeitschrift für schweizerische Kirchengeschichte 43 (1949), S. $28-$ 42.

Mohlberg, Leo Cunibert, Katalog der Handschriften der Zentralbibliothek Zürich. 1: Mittelalterliche Handschriften, Zürich 1951.

Mонг, Walter, »Von der >Francia Orientalis`zum >Regnum Teutonicum`«, in: Archivum latinitatis medii aevi 27 (1957), S. 27-49.

Moldenhauer, Rüdiger, Arno von Salzburg (785-821), Berlin 1956.

MöLler, Hartmut, »Die Prosula >Psalle modulaminaく (Mü 9543) und ihre musikhistorische Bedeutung", in: La tradizione dei tropi liturgici, hrsg. von Claudio LeONARDI und Enrico Menestò (Biblioteca del Centro per il Collegamento degli studi medievali e umanistici in Umbria 3), Spoleto 1990, S. 279-296.

Mommsen, Theodor und Аsснвасн, Joseph, "Zur lateinischen Anthologie», in: Rheinisches Museum für Philologie 9 (1854), S. 296-301, 302-304, 480.

Mone, Franz Joseph, „Reichenauer Formeln aus dem 8. Jahrhundert«, in: Zeitschrift für die Geschichte des Oberrheins 3 (1852), S. 385-397.

Morin, Germain u. a. (Hrsg.), Regula Benedicti: de codice 914 in bibliotheca monasterii S. Galli servato, St. Ottilien 1983. 
Morin, Germain, "Les inscriptions dédicatoires des premières églises de Tegernsee sous l'abbé fondateur Adalbert«, in: Revue bénédictine 29 (1912), S. 208-214.

Morin, Germain, "Qui est saint Arsacius honoré à Milan et en Bavière«, in: Studien und Mitteilungen zur Geschichte des Benediktinerordens und seiner Zweige 54 (1936), S. 1-6.

Morsbach, Peter, Ratisbona sacra: das Bistum Regensburg im Mittelalter; Ausstellung anläßlich des 1250jährigen Jubiläums der kanonischen Errichtung des Bistums Regensburg durch Bonifatius 739-1989, München [u.a.] 1989.

Müller, Monika E., Janz-Wenig, Katrin und Siebert, Irmgard, Kataloge der Handschriftenabteilung, Universitäts- und Landesbibliothek Düsseldorf. 5: Die mittelalterlichen Handschriften der Signaturengruppen E, F, G, N und $P$ in der Universitäts- und Landesbibliothek Düsseldorf, Wiesbaden 2017.

MüNCH, Christoph, Musikzeugnisse der Reichsabtei Lorsch: eine Untersuchung der Lorscher musikalischen Handschriften in der Bibliotheca Palatina in der Vatikanischen Bibliothek, Lorsch 1993.

Munding, Emmanuel P., "Das älteste Kalendar der Reichenau: (aus Cod. Vindob. 1815 saec. IX. med.)«, in: Colligere Fragmenta: Festschrift Alban Dold zum 70. Geburtstag am 7. 7. 1952, hrsg. von Bonifatius Fischer (Texte und Arbeiten 1. Beihefte 2), Beuron 1952, S. $236-246$.

Munding, Emmanuel P., Abt-Bischof Waldo, Begründer des goldenen Zeitalters der Reichenau (Texte und Arbeiten 1, 10/11), Beuron 1924.

Munk Olsen, Birger, "Bibliographie de la reception de la litterature classique du IXe au XVe siècle«, in: The classical tradition in the middle ages and the Renaissance, hrsg. von Claudio Leonardi und Birger Munk Olsen (Medioevo Latino. Biblioteca 15), Spoleto 1995.

Munk OLSEN, Birger, "Les classiques latins dans les florilèges médiévaux antérieurs au XIII siècle», in: Revue d'histoire des textes IX (1979), S. 47-121.

Munk Olsen, Birger, "Les classiques latins dans les florilèges médiévaux antérieurs au XIII siècle, II«, in: Revue d'histoire des textes X (1980), S. 115-164.

Munk Olsen, Birger, I classici nel canone scolastico altomedievale (Quaderni di cultura mediolatina 1), Spoleto 1991.

Munk Olsen, Birger, L'étude des auteurs classiques latins aux XIe et XIIe siècles, 4 Bände (Documents, études et répertoires), Paris 2009.

Munk Olsen, Birger, Munk Olsen, L'étude des auteurs classiques latins 3, 1 (Documents, études et répertoires), Paris 1987.

MunzI, Luigi, »Prologhi poetici latini di età carolingia«, in: Les prologues médiévaux, hrsg. von Jacqueline Hamesse (Textes et études du Moyen Âge 15) 2000, S. 87-111.

Nagel, H.A., Geschichte des Klosters St. Gallen und seiner Schulanstalten, Halle 1852.

Naples, Biblioteca Nazionale: Ms. IV.G.68, in: The Libraries of Reichenau and St. Gall, http://www.stgallplan.org/stgallmss/viewItem.do?ark=p21198-zz00294sdx (abgerufen am 13.06.2018).

NeSKE, Ingeborg, Katalog der lateinischen Handschriften der Bayerischen Staatsbibliothek München. Die Handschriften aus St. Emmeram in Regensburg, 2: Clm 14131-14260 (Catalogus codicum manu scriptorum Bibliothecae Monacensis 4/2/2), Wiesbaden 2005.

Neu, Peter, »Die Eifelabtei Prüm. Aufstieg, Glanz und Niedergang einer Benediktinerabtei in der Eifel«, in: Vor-Zeiten 4 (1988), S. 47-68. 
Neuser, Peter-Erich, "Das karolingische Hildebrandslied. Kodikologische und rezeptionsgeschichtliche Aspekte des $2^{\circ}$ Ms. theol. 54 aus Fulda«, in: Architectura Poetica. Festschrift für Johannes Rathofer zum 65. Geburtstag, hrsg. von Ulrich ERNST und Bernhard Sowinski (Kölner germanistische Studien 30), Köln 1990, S. 1-16.

Niederkorn-Bruck, Meta und Scharer, Anton, Erzbischof Arn von Salzburg (Veröffentlichungen des Instituts für Österreichische Geschichtsforschung 40), Wien [u.a.] 2004.

Nievergelt, Andreas, "Geheimschriftliche Glossen", in: Die althochdeutsche und altsächsische Glossographie. Ein Handbuch, 1, hrsg. von Rolf BERGMANn und Stefanie Stricker, Berlin [u.a.] 2009, S. 240-268.

Nievergelt, Andreas, "St. Galler Glossenhandschriften«, in: Die althochdeutsche und altsächsische Glossographie. Ein Handbuch, 2, hrsg. von Rolf BERgmann und Stefanie STRICKer, Berlin [u.a.] 2009, S. 1462-1527.

Nolte, Theodor, »Passau«, in: Schreiborte des deutschen Mittelalters : Skriptorien - Werke - Mäzene, hrsg. von Martin J. Schubert, Berlin [u. a.] 2013, S. 399-424.

Norberg, Dag, An introduction to the study of medieval Latin versification, Washington, DC 2004.

O'Sullivan, Sinéad, Early medieval glosses on Prudentius' Psychomachia: the Weitz tradition (Mittellateinische Studien und Texte 31), Leiden [u. a.] 2004.

O'Sullivan, Sinéad, Glossae aevi Carolini in libros I-II Martiani Capellae De nuptiis Philologiae et Mercurii (CCCM 237), Turnhout 2010.

Ochsenbein, Peter (Hrsg.), Das Kloster St. Gallen im Mittelalter: die kulturelle Blüte vom 8. bis zum 12. Jahrhundert, Darmstadt 1999.

Ochsenbein, Peter, "Die Klosterschule als Fundament des literarischen Aufstiegs", in: St. Gallen. Geschichte einer literarischen Kultur, 1, hrsg. von Werner WundERLICH und Rupert Kalkofen, St. Gallen 1999, S. 125-140.

OchsenbeIn, Peter, „Die St. Galler Klosterschule«, in: Das Kloster St. Gallen im Mittelalter: die kulturelle Blüte vom 8. bis zum 12. Jahrhundert, hrsg. von Peter Ochsenbein, Darmstadt 1999, S. 95-107.

Ochsenbein, Peter, »Klosterliteratur der Blütezeit«, in: St. Gallen. Geschichte einer literarischen Kultur, 1, hrsg. von Werner Wunderlich und Rupert Kalkofen, St. Gallen 1999, S. 161-180.

Ochsenbein, Peter, »L'enseignement et l'étude«, in: L'Abbaye de Saint-Gall: rayonnement spirituel et culturel, hrsg. von Werner VogLER, Lausanne 1991, S. 133-144.

Ochsenbein, Peter, »Lehren und Lernen im Galluskloster«, in: Die Kultur der Abtei Sankt Gallen, hrsg. von Werner VogLER, Zürich 1990, S. 133-144.

Ochsenbein, Peter, »The monastic school of St. Gall«, in: Sangallensia in Washington, hrsg. von James C. KING, New York 1993, S. 263-275.

Oldfather, W. A., "A Fleury text of Avianus«, in: Philological Quarterly V (1926), S. 20 28.

Omont, Henri, "Les sept merveilles du monde au Moyen Âge«, in: Bibliothèque de l'Ecole des Chartes 43 (1882), S. 40-59, 431-432.

ÖNNERFors, Alf, "Philologisches zu Walahfrid Strabo«, in: Mittellateinisches Jahrbuch 7 (1972), S. 41-92. 
OrTh, Alexander, Die sententiae deflorate de diversis causis - Untersuchung eines frühmittelalterlichen Florilegiums samt kritischer Edition und Übersetzung, MA-Arbeit, Universität Hamburg 2017.

ORTH, Peter, "Die lateinischen Klassiker in der früh- und hochmittelalterlichen Dombibliothek - Beobachtungen zu dem unedierten Lucan-Kommentar im Cod. 199«, in: Mittelalterliche Handschriften der Kölner Dombibliothek 7, hrsg. von Harald HoRsT (Libelli Rhenani 79), Köln 2018, S. 177-206.

Ortner, Franz, Salzburger Kirchengeschichte. Von den Anfängen bis zur Gegenwart, Salzburg 1988.

Oswald, Josef, Das alte Passauer Domkapitel: seine Entwicklung bis zum dreizehnten Jahrhundert und sein Wahlkapitulationswesen (Münchener Studien zur historischen Theologie 10), München 1933.

Pangallo, Domenico, Chovanova, Katarina und Makova, Alena, "Identification of animal skin of historical parchments by polymerase chain reaction (PCR)-based methods", in: Journal of Archaeological Science 37 (2010), S. 1202-1206.

PARKer, Holt N., "Manuscripts of Juvenal and Persius", in: Companion to Persius and Juvenal (Blackwell companions to the ancient world), Chichester [u. a.] 2012, S. 137-162.

Passalacqua, Marina, Italy and the Vatican City (Codices Boethiani 4), London 2001.

Pauly, Ferdinand, Aus der Geschichte des Bistums Trier (Veröffentlichungen des Bistumsarchivs Trier, 13/14 u. 18), Trier 1968.

Pauly, Peter, Die althochdeutschen Glossen der Handschriften Pommersfelden 2671 und Antwerpen 17.4: Untersuchungen zu ihrem Lautstand (Rheinisches Archiv 67), Bonn 1968.

PeIPER, Rudolf, »Glossen zu Boethius«, in: Zeitschrift für deutsche Philologie 5 (1874), S. 7680.

PeIPeR, Rudolf, Die handschriftliche Ueberlieferung des Ausonius, Leipzig 1879.

Perrin, Michel Jean-Louis, "Autour de la datation des poèmes d'Alcuin, Joseph Scot et Théodulf d'Orleans réunis dans le manuscrit Bernensis 212«, in: Rerum gestarum scriptor. Histoire et historiographie au Moyen Âge. Hommage à Michel Sot, hrsg. von Magali Coumert u. a., Paris 2012, S. 575-587.

PERrin, Michel Jean-Louis, "La poésie de cour carolingienne, les contacts entre Alcuin et Hraban Maur et les indices de l'influence d'Alcuin sur l'In honorem sanctae crucis«, in: Annales de Bretagne 111 (2004), S. 333-352.

Perrin, Michel Jean-Louis, "Le De laudibus sanctae crucis de Raban Maur et sa tradition manuscrite au IXe siècle«, in: Revue d'histoire des textes 19 (1989), S. 191-251.

PERRIN, Michel Jean-Louis, »Les lectures de Raban Maur pour l'In honorem sanctae crucis: ébauche d'un bilan«, in: Raban Maur et son temps, hrsg. von Philippe Depreux u. a. (Collection Haut Moyen Âge 9), Turnhout 2010, S. 219-245.

PERTZ, Georg Heinrich, „Über eine fränkische Kosmographie des siebenten Jahrhunderts«, in: Abhandlungen der Königlichen Akademie der Wissenschaften in Berlin (1845), S. 253-270.

Petschenig, Michael, "Eine vita Vergilii«, in: Wiener Studien 4 (1882), S. 168-169.

Petzet, Erich, Die deutschen Pergament-Handschriften Nr. 1-200 der Staatsbibliothek München, München 1920. 
Picker, Hanns-Christoph, Pastor Doctus: Klerikerbild und karolingische Reformen bei Hrabanus Maurus (Veröffentlichungen des Instituts für Europäische Geschichte Mainz. Abt. für Abendländische Religionsgeschichte 186), Mainz 2001.

Placanica, Antonio, "Venantius Fortunatus«, in: La trasmissione dei testi latini del Medioevo, 2, hrsg. von Paolo Chiesa und Castaldi, Lucia 2005, S. 526-538.

Ploton-Nicollet, François, »Ioca monachorum et pseudo Interpretatio sancti Augusti$n i \lll$, in: Archives d'histoire doctrinale et littéraire du moyen âge 74 (2007), S. 109-159.

Plotzeк, Joachim M., „Zur Geschichte der Kölner Dombibliothek«, in: Glaube und Wissen im Mittelalter. Katalogbuch zur Ausstellung, München 1998, S. 15-64.

Pollard, Richard M., "Nonantola and Reichenau: a new manuscript of Heito's >Visio Wettini and the foundations for a new critical edition «, in: Revue bénédictine 120 (2010), S. 243-294.

PölzL, Michaela, »BStK Online, Nr. 36, 822.«, https://glossen.germ-ling.uni-bamberg.de/ glossed_contents/12070 (abgerufen am 18.06.2018).

PörnBACHER, Johannes, »Freisings geistige Bedeutung im 8. und 9. Jahrhundert: Die Anfänge von Domschule und Bibliothek«, in: Jahresbericht. Dom-Gymnasium Freising (1960), S. 38-48.

Pralle, Ludwig, Die Wiederentdeckung des Tacitus: ein Beitrag zur Geistesgeschichte Fuldas und zur Biographie des jungen Cusanus (Veröffentlichungen des Fuldaer Geschichtsvereins 33), Fulda 1952.

PrÉAux, Jean G., "Les manuscrits principaux $d u>$ De nuptiis Philologiae et Mercurii de Martianus Capella«, in: Lettres latines du Moyen Âge et de la Renaissance, hrsg. von Guy Cambier, Carl Deroux und Jean G. Préaux (Collection Latomus 158), Brüssel 1978, S. 76-128.

Préaux, Jean G., "Propositions sur l'histoire des textes des Satires de Perse et du Commentum Cornuti «, in: Hommages André Boutemy, hrsg. von Guy CAMBIER (Collection Latomus 145), Brüssel 1976, S. 299-314.

Préaux, Jean G., »Un nouveau manuscrit de Saint-Gall: le >Bruxellensis«9565-9566«, in: Scriptorium 10 (1956), S. 221-228.

Preisendanz, Karl, »Aus Bücherei und Schreibstube der Reichenau«, in: Die Kultur der Abtei Reichenau: Erinnerungschrift zur zwölfhundertsten Wiederkehr des Gründungsjahres des Inselklosters 724-1924, 2, hrsg. von Konrad Beyerle und Peter P. Albert, München 1925, S. 657-683.

Preisendanz, Karl, „Reginbert von der Reichenau. Aus Bibliothek und Skriptorium des Inselklosters", in: Neue Heidelberger Jahrbücher (1952), S. 1-49.

Prelog, Jan, »Art. Ermenrich von Ellwangen«, in: Lexikon des Mittelalters, 3, 1986, S. 2157.

Prelog, Jan, »Art. Poeta Saxo (9. Jahrhundert)«, in: Lexikon des Mittelalters, 7, 1995, S. 3536.

Prelog, Jan, "Art. Wetti, Hagiograph und Schulmeister, Mönch im Kloster Reichenau $(†$ 824)«, in: Lexikon des Mittelalters, 9, 1998, S. 49-50.

Prete, Sesto, "La tradition textuelle et les manuscrits d'Ausone«, in: Revue française d'histoire du livre 46 (1985), S. 101-157.

QUARThal, Franz und U.A, »Reichenau«, in: Germania Benedictina 5 1987, S. 503-548.

QuINT, Maria-Barbara, Untersuchungen zur mittelalterlichen Horaz-Rezeption (Studien zur klassischen Philologie 39), Frankfurt a. M. 1988. 
RAAIJMAKers, Janneke, The making of the monastic community of Fulda, c.744 - c.900 (Cambridge studies in medieval life and thought 83), Cambridge [u.a.] 2012.

RABY, Frederic James Edward, A history of Christian-Latin poetry from the beginnings to the close of the middle ages, Oxford 1953.

RABY, Frederic James Edward, A history of secular Latin poetry in the middle ages, Oxford 1957.

RÄDlE, Fidel, »Bedas Hymnus über das Sechstagewerk und die Weltalter«, in: Anglo-Saxonica: Beiträge zur Vor- und Frühgeschichte der englischen Sprache und zur altenglischen Literatur. Festschrift für Hans Schabram zum 65. Geburtstag, hrsg. von Klaus R. Grinda und Klaus Dieter Wetzel, München 1993, S. 53-73.

RÄDLINGER-PrömPER, Christine, Sankt Emmeram in Regensburg. Struktur- und Funktionswandel eines bayerischen Klosters im frühen Mittelalter (Thurn-und-Taxis-Studien 16), Kallmünz 1987.

Ramírez-WeAver, Eric M, „Carolingian innovation and observation in the paintings and star catalogs of Madrid, Biblioteca Nacional, Ms. 3307. Diss.«, Ann Arbor, Michigan 2008.

Rankin, Susan, «Notker und Tutilo. Schöpferische Gestalter in einer neuen Zeit.«, in: Schweizer Jahrbuch für Musikwissenschaft 11 (1991), S. 17-42.

Rappmann, Roland und Zettler, Alfons, Die Reichenauer Mönchsgemeinschaft und ihr Totengedenken im frühen Mittelalter (Archäologie und Geschichte 5), Sigmaringen 1998.

Reimitz, Helmut, History, Frankish identity and the framing of Western ethnicity, 550-850 (Cambridge studies in medieval life and thought 101), Cambridge 2015.

Reynhout, Lucien, "Codicologie quantitative et paradigmes scientifiques. Une typologie des formules latines des colophons de manuscrits occidentaux«, in: Gazette du livre médiéval 39 (2001), S. 1-9.

Reynhout, Lucien, "Pour une typologie des colophons de manuscrits occidentaux», in: Gazette du livre médiéval 13 (1988), S. 1-5.

Reynhout, Lucien, Étude sur le formulaire latin des colophons de manuscrits occidentaux (IIIe-XVIe siècle), Brüssel 2000.

Reynhout, Lucien, Formules latines de colophons (Bibliologia 25), Turnhout 2006.

Reynolds, Leighton Durham und Wilson, Nigel Guy, Scribes and Scholars. A Guide to the Transmission of Greek and Latin Literature, Oxford 1968.

REynolds, Leighton Durham, Texts and transmission: a survey of the Latin classics, Oxford 1983.

REYNOLDS, Leighton Durham, The medieval tradition of Seneca's letters (Oxford classical \& philosophical monographs), London 1965.

Reynolds, Suzanne, »Glossing Horace: Using the Classics in the Medieval Classroom«, in: Medieval manuscripts of the Latin classics. Production and use, hrsg. von Claudine A. Chavannes-Mazel und Margaret McFadden Smith, Los Altos Hills, Calif. 1996, S. 103-117.

Riché, Pierre, "Les écoles de Saint-Gall des origines au milieu du XIe siècle«, in: Le rayonnement spirituel et culturel de l'abbaye de Saint-Gall, hrsg. von Carole Heitz (Cahier. Centre de Recherches sur l'Antiquité Tardive et le Haut Moyen Âge 9), Paris 2000, S. 3757. 
RICHÉ, Pierre, Ecoles et enseignement dans le haut Moyen Âge. Fin du Ve s. - milieu du XIe, Paris 1989.

Richmond, John A., "Quaeritur quomodo Appendicis Vergilianae poemata in unum convenerint «, in: Rivista di filologia e di istruzione classica CIV (1976), S. 26-30.

RIGG, Arthur George, »Anthologies and florilegia«, in: Medieval Latin. An introduction and bibliographical guide 1996, S. 708-712.

RIGG, Arthur George, »Medieval Latin Poetic Anthologies I-III«, in: Mediaeval Studies 39, $41,49$.

RigG, Arthur George, »Medieval Latin Poetic Anthologies«, in: Mediaeval Studies 39 (1977), S. 281-330.

RIJK, Lambert Marie de, »On the curriculum of the arts of the trivium at St. Gall from c.850c. 1000«, in: Vivarium 1 (1963), S. 35-86.

Rio, Alice, Legal practice and the written word in the early Middle Ages: Frankish formulae, c. 500-1000 (Cambridge studies in medieval life and thought 75), Cambridge 2009.

Riou, Yves-François, "Chronologie et provenance des manuscrits classiques latins neumés", in: Revue d'histoire des textes 21 (1991), S. 77-113.

RiQuer, Alejandra de, Teodulfo de Orleans y la epistola poética en la literatura carolingia (Instituto de Estudios Histórico - Literarios), Barcelona 1994.

Rockinger, Ludwig (Hrsg.), Drei Formelsammlungen aus der Zeit der Karolinger: aus münchner Handschriften mitgetheilt (Quellen und Erörterungen zur bayerischen Geschichte 7), München 1857.

Roger, Maurice, L'enseignement des lettres classiques d'Ausone à Alcuin, Paris 1905.

Rose, Valentin, Die Handschriften-Verzeichnisse der Königlichen Bibliotheken zu Berlin, 13: Verzeichniss der lateinischen Handschriften, Berlin 1901.

Rumphorst, Heinrich, "Zur musikalischen Gestaltung der Verse Aeneis 4, 424-436 im cod. Guelf. 66 Gud. Lat. f. 20vb«, in: Vergil. Handschriften und Drucke der Herzog August Bibliothek (Ausstellungskataloge der Herzog-August-Bibliothek 37), Wolfenbüttel 1982, S. 29-34.

RuPPEL, Aloys, "Der heilige Bonifatius als Dichter«, in: Universitas: Dienst an Wahrheit und Leben; Festschrift für Bischof Dr. Albert Stohr, 2, hrsg. von Ludwig LenHART 1960, S. $28-$ 41.

SABBADINI, Remigio, Le scoperte dei codici latini e greci ne' secoli 14 e 15 (Biblioteca storica del Rinascimento, NS 2), Firenze 1905.

Scarpatetti, Beat Matthias von und Lenz, Philipp, Die Handschriften der Stiftsbibliothek St. Gallen, 2: Abt. III/2, Codices 450-546, Wiesbaden 2008.

SCARpatetti, Beat Matthias von, "Albert Bruckner et ses >Scriptoria Medii Aevi Helvetica«", in: Scriptorium. Wesen - Funktion - Eigenheiten, hrsg. von Andreas NiEvergelT u. a. (Veröffentlichungen der Kommission für die Herausgabe der mittelalterlichen Bibliothekskataloge Deutschlands und der Schweiz), München 2015, S. 543-547.

SCARPAtetti, Beat Matthias von, »Das St. Galler Scriptorium«, in: Das Kloster St. Gallen im Mittelalter: die kulturelle Blüte vom 8. bis zum 12. Jahrhundert, hrsg. von Peter Ochsenbein, Darmstadt 1999, S. 31-67.

SCARPATEtTi, Beat Matthias von, "Schreiber-Zuweisungen in St. Galler Handschriften des achten und neunten Jahrhunderts", in: Codices Sangallenses. Festschrift für Johannes Duft zum 80. Geburtstag, hrsg. von Peter OchSEnbein und Ernst Ziegler, Sigmaringen 1995, S. 25-56. 
Scarpatetti, Beat Matthias von, Die Handschriften der Stiftsbibliothek St. Gallen. 1. Abt. IV: Codices 547-669; Hagiographica, Historica, Geographica; 8. - 18. Jahrhundert, Wiesbaden 2003.

Scarpatetti, Beat Matthias von, Rudolf Gamper und Marlies StäHli (Hrsg.), Katalog der datierten Handschriften in der Schweiz in lateinischer Schrift vom Anfang des Mittelalters bis 1550. 3: Die Handschriften der Bibliotheken St. Gallen - Zürich in alphabetischer Reihenfolge 1991.

SCHALler, Dieter und KöNSGEN, Ewald, Initia carminum Latinorum saeculo undecimo antiquiorum, Göttingen 1977.

SCHALlER, Dieter, "Bemerkungen zur Inschriften-Sylloge von Urbana«, in: Mittellateinisches Jahrbuch 12 (1977), S. 9-21.

Schaller, Dieter, "Das Aachener Epos für Karl den Kaiser«, in: Frühmittelalterliche Studien 10 (1976), S. 134-168.

SCHALlER, Dieter, "Die karolingischen Figurengedichte des Cod. Bern. 212.«, in: Medium aevum vivum: Festschrift für Walther Bulst, hrsg. von Hans Robert Jauss und Dieter SCHALLER, Heidelberg 1960, S. 22-47.

SCHALler, Dieter, "Die Siebensilberstrophen de mundi transitu - eine Dichtung Columbans?«, in: Die Iren und Europa im früheren Mittelalter, hrsg. von Heinz LöwE (Veröffentlichungen des Europa Zentrums Tübingen. Kulturwissenschaftliche Reihe), Stuttgart 1982, S. 468-483.

SCHALlER, Dieter, »Frühkarolingische Corippus-Rezeption«, in: Wiener Studien 105 (1992), S. $173-187$.

SCHALlER, Dieter, "Frühmittelalterliche lateinische Dichtung in einer ehemals St. Galler Handschrift", in: Zeitschrift für deutsches Altertum und deutsche Literatur 93 (1964), S. 272-291.

SCHALlER, Dieter, »Geraldus und St. Gallen - Zum Widmungsgedicht des > Waltharius«", in: Mittellateinisches Jahrbuch 2 (1965), S. 74-84.

SCHALLER, Dieter, »Lateinische Tierdichtung in frühkarolingischer Zeit «, in: Das Tier in der Dichtung, hrsg. von Ute Schwab, Heidelberg 1970, S. 91-113.

SCHALler, Dieter, "Philologische Untersuchungen zu den Gedichten Theodulfs von Orléans«, in: Deutsches Archiv für Erforschung des Mittelalters 18 (1962), S. 13-91.

SCHALleR, Dieter, "Vortrags- und Zirkulardichtung am Hof Karls des Grossen«, in: Mittellateinisches Jahrbuch 6 (1970), S. 14-36.

SCHALlER, Dieter, Studien zur lateinischen Dichtung des Frühmittelalters (Quellen und Untersuchungen zur lateinischen Philologie des Mittelalters 11), Stuttgart 1995.

Sснӓв, Max, "St. Gallen zwischen Gallus und Otmar 640-720.», in: Schweizerische Zeitschrift für Religions- und Kulturgeschichte 102 (2008), S. 317-359.

Sснёr, Max, Gallus: der Heilige in seiner Zeit, Basel 2011.

SCHERER, Carl, Beiträge zur Rekonstruktion der alten Bibliotheca fuldensis und Bibliotheca laureshamensis (Zentralblatt für Bibliothekswesen 26), Leipzig 1902.

SCHERRER, Gustav, Verzeichniss der Handschriften der Stiftsbibliothek von St. Gallen, Halle 1875.

SCHIEFFER, Theodor, "Die Krise des karolingischen Imperiums", in: Aus Mittelalter und Neuzeit. Festschrift für Gerhard Kallen zum 70. Geburtstag, hrsg. von Josef ENGEL und Hans Martin KLinkenberg, Bonn 1957, S. 1-15. 
SCHIEGG, Markus, "Scribes' Voices: The Relevance and Types of Early Medieval Colophons", in: Studia Neophilologica (2015), S. 1-19.

Schipperges, Thomas, "Vesperpsalmen, Hymnen, Cantica, Magnificat, Lamentationen«, in: Geschichte der Kirchenmusik. 1: Von den Anfängen bis zum Reformationsjahrhundert, hrsg. von Wolfgang Hochstein und Christoph Krummacher, Laaber 2011, S. 288-300.

Schmalor, Hermann-Josef, "Bibliotheken und Skriptorien in Corvey und Helmarshausen«, in: Die Weser. Ein. Fluß in Europa. Eine Länderübergreifende Ausstellung über 1200 Jahre Geschichte und Kultur des Weserraumes, hrsg. von Norbert Humburg und Joachim SCHWEen 2000, S. 202-211.

SCHMALOR, Hermann-Josef, „Bücher in Bewegung-Bibliotheken und Skriptorien in Corvey und Paderborn«, in: Eine Welt in Bewegung: unterwegs zu Zentren des frühen Mittelalters; Begleitbuch der Gemeinschaftsausstellung, hrsg. von Georg EgGENSTEIN und Norbert Börste, München [u.a.] 2008, S. 62-67.

Schmalor, Hermann-Josef, "Die Bibliothek der ehemaligen Reichsabtei Corvey«, in: Westfälische Zeitschrift 147 (1997), S. 251-270.

Schmalor, Hermann-Josef, »Würzburg und Paderborn- Missionierung und Bistumsgründungen «, in: Eine Welt in Bewegung: unterwegs zu Zentren des frühen Mittelalters; Begleitbuch der Gemeinschaftsausstellung, hrsg. von Georg EgGENSTEIN und Norbert Börste, München [u.a.] 2008, S. 51-55.

SснміD, Karl, „Zum Stifterbild im Liller Evangelistar des 11. Jahrhunderts«, in: Frühmittelalterliche Studien 16 (1982), S. 143-160.

Schmid, Peter (Historiker), »Civitas regia: Die Königsstadt Regensburg“, in: Geschichte der Stadt Regensburg, 1, hrsg. von Peter SснміD, Regensburg 2000, S. 103-147.

Sснмітz, Gerhard, "Ermenrich von Ellwangen oder Vom Nachteil und Nutzen von ReEditionen «, in: Deutsches Archiv für Erforschung des Mittelalters 66 (2010), S. 479-511.

Sснмітz, Wilhelm, Alcuins ars grammatica, die lateinische Schulgrammatik der karolingischen Renaissance, Greifswald 1908.

Sснмітz, Wolfgang, "Die mittelalterliche Bibliotheksgeschichte Kölns", in: Ornamenta Ecclesiae. Kunst und Künstler in der Romanik in Köln. Katalog zur Ausstellung des Schütgen-Museums in der Joseph-Haubrich-Kunsthalle, hrsg. von Anton LEgNer, Köln 1985, S. 137-148.

Schnitzer, Paul, Beiträge zur Geschichte des Klosters Lorsch: Karl Josef Minst zur Vollendung des 80. Lebensjahres am 26. April 1978 (Geschichtsblätter für den Kreis Bergstraße. Sonderband 4), Lorsch 1980.

SchNoor, Franziska u. a. (Hrsg.), Gallus und seine Zeit. Leben, Wirken, Nachleben (Monasterium Sancti Galli 7), St. Gallen 2015.

SснӧNвACH, Anton Emanuel, »Über das >Carmen ad Deum«", in: Zeitschrift für deutsches Altertum und deutsche Literatur 42 (1898), S. 113-120.

SCHrimpf, Gangolf und Josef Leinweber (Hrsg.), Mittelalterliche Bücherverzeichnisse des Klosters Fulda und andere Beiträge zur Geschichte der Bibliothek des Klosters Fulda im Mittelalter (Fuldaer Studien 4), Frankfurt a. M. 1992.

Schröder, Werner und Hartmann, Heiko, "Art. Otfrid von Weißenburg", in: Althochdeutsche und altsächsische Literatur, hrsg. von Rolf Bergmann, Berlin [u.a.] 2013, S. 322-345. 
Schubert, Martin J. (Hrsg.), Schreiborte des Mittelalters. Skriptorien, Werke, Mäzene, Berlin [u. a.] 2013.

Schubert, Martin J., "Köln«, in: Schreiborte des deutschen Mittelalters: Skriptorien Werke - Mäzene, hrsg. von Martin J. Schubert, Berlin [u.a.] 2013, S. 217-262.

Schubert, Martin J., Der Schreiber im Mittelalter (Das Mittelalter 7, 2), Berlin 2002.

SCHubiger, Anselm, Die Sängerschule St. Gallens vom 8. bis 12. Jahrhundert: ein Beitrag zur Gesanggeschichte des Mittelalters, Einsiedeln [u. a.] 1858.

SchüLING, Hermann, "Die Handbibliothek des Bonifatius.«, in: Archiv für Geschichte des Buchwesens 4 (1961), S. 285-348.

Schützeichel, Rudolf, Codex Pal. lat. 52. Studien zur Heidelberger Otfridhandschrift, zum Kicila-Vers und zum Georgslied, Göttingen 1982.

Seel, Otto, "Zum Persius-Titel des Codex Pithoeanus", in: Hermes 88 (1960), S. 82-98.

SEIDEL, Kurt Otto, "Tres digiti scribunt totum corpusque laborat. Kolophone als Quelle für das Selbstverständnis mittelalterlicher Schreiber«, in: Das Mittelalter 7 (2002), S. 145156.

SEIDER, Richard, "Beiträge zur Geschichte und Paläographie der antiken Vergilhandschriften ", in: Studien zum antiken Epos, hrsg. von Herwig GörgEmanNs und SCHMIDT, ERNst (Beiträge zur klassischen Philologie 72), Meisenheim 1976, S. 129-172.

SEMmLer, Josef, "Die Geschichte der Abtei Lorsch von der Gründung bis zum Ende der Salierzeit 764 bis 1125«, in: Die Reichsabtei Lorsch, 1, hrsg. von Friedrich KNöpp 1973, S. 75-174.

Sickel, Theodor, "Rezension: Monumenta Alcuniana«, in: Historische Zeitschrift 32 (1874), S. S. 352-365.

Sickel, Theodor, Alcuinstudien, 1 (Sitzungsberichte. Akademie der Wissenschaften in Wien, Philosophisch-Historische Klasse 79, 9), Wien 1875.

SIERP, Hermann, » Walahfrid Strabos Gedicht über den Gartenbau«, in: Die Kultur der Abtei Reichenau: Erinnerungschrift zur zwölfhundertsten Wiederkehr des Gründungsjahres des Inselklosters 724-1924, 2, hrsg. von Konrad Beyerle und Peter P. AlBert, München 1925, S. 756-772.

SIEWERT, Klaus, Die althochdeutsche Horazglossierung (Studien zum Althochdeutschen 8), Göttingen 1986.

Sims-Williams, Patrick P., "Milred of Worcester's collection of Latin epigrams and its continental counterparts", in: Anglo-Saxon England 10 (1982), S. 21-38.

Singer, Samuel, Die Dichterschule von St. Gallen (Die Schweiz im deutschen Geistesleben 8), Leipzig 1922.

Smits van Waesberghe, Joseph, »Studien über das Lesen (Pronuntiare), das Zitieren und über die Herausgabe lateinischer musiktheoretischer Traktate (9-16. Jahrhundert)«, in: Archiv für Musikwissenschaft 29 (1972), S. 64-86.

Smits van Waesberghe, Joseph, Maas, Christian und Fischer, Peter, The Theory of Music, from the Carolingian Era up to 1400. I: Descriptive Catalogue of Manuscripts (Répertoire international des sources musicales), München [u.a.] 1961.

SoAGE, Javier, "The Mediaeval Question-and-Answer Collection sententiae de floratibus diuersisı: Standard and Non-Standard Versions", in: Sacris erudiri 55 (2016), S. 321-366.

Sonderegger, Stefan und Vogler, Werner, "Deutsche Sprache und Literatur in Sankt Gallen«, in: Die Kultur der Abtei Sankt Gallen, hrsg. von Werner Vogler, Zürich 1990, S. 161-184. 
Sonderegger, Stefan, "Althochdeutsch auf der Reichenau. Neuere Forschungen zur ältesten Volkssprache im Inselkloster«, in: Die Abtei Reichenau. Neue Beiträge, hrsg. von Helmut Maurer (Bodensee-Bibliothek 20, Hegau-Bibliothek 28), Sigmaringen 1974, S. 69-82.

Sonderegger, Stefan, "Althochdeutsch in St. Gallen«, in: Das Kloster St. Gallen im Mittelalter: die kulturelle Blüte vom 8. bis zum 12. Jahrhundert, hrsg. von Peter OchsenBEIN, Darmstadt 1999, S. 205-222.

SPILling, Herrad, "Angelsächsische Schrift in Fulda«, in: Von der Klosterbibliothek zur Landesbibliothek. Beiträge zum 200jährigen Bestehen der Hessischen Landesbibliothek Fulda, hrsg. von Artur Brall (Bibliothek des Buchwesens 6), Stuttgart 1978, S. 47-98.

SpIlling, Herrad, "Art. Reginbert von der Reichenau, Mönch, Lehrer, Bibliothekar und Schreiber ( $†$ 846) «, in: Lexikon des Mittelalters, 7, 1995, S. 578-579.

SPILling, Herrad, »Das Bücherverzeichnis am Schluß des Sakramentars«, in: Das Sakramentar der Fürstlich Fürstenbergischen Hofbibliothek Donaueschingen: Cod. Don. 191, hrsg. von Herrad Spilling (Patrimonia 85), Berlin 1996, S. 85-106.

SPILling, Herrad, »Das Fuldaer Skriptorium zur Zeit des Hrabanus Maurus«, in: Hrabanus Maurus. Lehrer, Abt und Bischof, hrsg. von Kotтje, Raymund und Harald ZimmerMANN (Akademie der Wissenschaften und der Literatur Mainz. Geistes- und Sozialwissenschaftliche Klasse. Einzelveröffentlichungen 4), Wiesbaden 1982, S. 165-181.

SPILling, Herrad, „Die frühe Phase karolingischer Minuskel in Fulda«, in: Kloster Fulda in der Welt der Karolinger und Ottonen 1996, S. 249-284.

SpILling, Herrad, »Schreiber und Schrift«, in: Das Sakramentar der Fürstlich Fürstenbergischen Hofbibliothek Donaueschingen Cod. Don. 191, hrsg. von Herrad SPILling (Patrimonia 85), Berlin 1996, S. 17-48.

SpIlling, Herrad, Opus Magnentii Hrabani Mauri in honorem sanctae crucis conditum. Hrabans Beziehung zu seinem Werk (Fuldaer Hochschulschriften 18), Frankfurt a. M. 1992.

SPRINGER, Carl P. E., The manuscripts of Sedulius: a provisional handlist (Transactions of the American Philosophical Society 5), Philadelphia 1995.

Spunar, Pavel, "Les distiques de Caton dans le codex 969 de Vienne (Analyse paléographique)", in: Listy filologické / Folia philologica 81 (1958), S. 50-53.

Spunar, Pavel, "Versus de Libris", in: Calames et cahiers. Mélanges de codicologie et de paléographie offerts à Léon Gilissen, hrsg. von Jacques Charles LemaIre und Emile van Balberghe (Scriptorium. Publications 9), Brüssel 1985, S. 177-181.

St. Gallen, Stiftsbibliothek, Cod. Sang. 844, in: UCLA Reichenau-St. Gall Virtual Library, 2012. , https://www.e-codices.unifr.ch/en/description/csg/0844/Hendrix (abgerufen am 20.06.2018).

StAAв, Franz, "Die Mainzer Kirche im Frühmittelalter«, in: Handbuch der Mainzer Kirchengeschichte, 1. Christliche Antike und Mittelalter, hrsg. von Marc-Aeilko ARIs und Friedhelm JÜRGENSMEIER (Beiträge zur Mainzer Kirchengeschichte 6), Würzburg 2000, S. 87-194.

StABER, Josef, Kirchengeschichte des Bistums Regensburg, Regensburg 1966.

StÄвlein, Bruno, "Zwei Textierungen des Alleluia Christus Resurgens in St. Emmeram Regensburg", in: Organicae voces: Festschrift Joseph Smits van Waesberghe angeboten anlässlich seines 60. Geburtstages, 18. April 1961, hrsg. von Instituut voor MidDeleeuwse MuZiekwetenschap, Amsterdam 1963, S. 157-168. 
STAHL, Irene, Katalog der mittelalterlichen Handschriften der Staats- und Universitätsbibliothek Bremen, Wiesbaden 2004.

Staubach, Nikolaus, "Sedulius Scottus und die Gedichte des Codex Bernensis", in: Frühmittelalterliche Studien 20 (1986), S. 549-598.

STECK, Wolfgang, Der Liturgiker Amalarius: eine quellenkritische Untersuchung zu Leben und Werk eines Theologen der Karolingerzeit (Münchener Theologische Studien 1), München 2000.

Steinen, Wolfram von den, Notker der Dichter und seine geistige Welt, Bern 1948.

SteINER, Hannes, »Buchproduktion und Bibliothekszuwachs im Kloster St. Gallen unter den Äbten Grimald und Hartmut«, in: Ludwig der Deutsche und seine Zeit, hrsg. von Wilfried Hartmann, Darmstadt 2004, S. 161-183.

Steinová, Evina, Notam superponere studui: the use of technical signs in the Carolingian period, Diss. Utrecht 2016.

STElla, Francesco, "Mito del libro e poesia libraria in età carolingia«, in: CentoPagine 4 (2010).

Stella, Francesco, "Poesia e comunicazione in eta carolingia», in: Comunicare e significare nell'alto medioevo (Settimane di studio del Centro italiano di studi sull'alto medioevo 25), Spoleto 2005, S. 615-649.

Stella, Francesco, La Poesia carolingia (Le Lettere università 1, Le Antologie III), Florenz 1995.

Stella, Francesco, La poesia carolingia latina a tema biblico (Medioevo Latino. Biblioteca 9), Spoleto 1993.

STENGEL, Edmund Ernst, „Die Urkundenfälschungen des Rudolf von Fulda«, in: Archiv für Urkundenforschung 5 (1914), S. 41-152.

Stephan, Christoph Heinrich, "Das prosodische Florilegium der S. Gallener Handschrift nr. 870 und sein Werth für die Iuvenalkritik«, in: Rheinisches Museum für Philologie 40 (1885), S. 263-282.

Stephan, Christoph Heinrich, "De Pithoeanis in Iuvenalem scholiis", Bonn 1882.

STERN, Ludwig Christian, »Über die irische Handschrift in St. Paul«, in: Zeitschrift für celtische Philologie 6 (1908), S. 546-554.

Stettiner, Richard, Die illustrierten Prudentiushandschriften, Berlin 1895.

Stevenson, Enrico und Rossi, I. B. de, Codices Palatini Latini Bibliothecae Vaticanae, Rom 1866.

Stiene, Heinz Erich, "Agius von Corvey und der Poeta Saxo", in: Mittellateinisches Jahrbuch 22 (1987), S. 80-100.

STOKES, Whitley und John STRACHAN (Hrsg.), Thesaurus palaeohibernicus: a collection of old Irish glosses; scholia, prose, and verse. 2: Non-biblical glosses and scholia: Old-Irish prose: names of persons and places: inscriptions: verse: indexes, Cambridge 1903.

STORк, Hans-Walter, "Die Sammelhandschrift Zürich, Zentralbibliothek, C 78«, in: De Karolo rege et Leone papa. Der Bericht über die Zusammenkunft Karls des Großen mit Papst Leo III. in Paderborn 799 in einem Epos für Karl den Kaiser, hrsg. von Wilhelm Hentze (Studien und Quellen zur westfälischen Geschichte 36), Paderborn 1999, S. $105-118$.

STORк, Hans-Walter, Das Martyrologium für Kaiser Lothar I. entstanden nach 855 auf der Insel Reichenau. Orig.-getreue Wiedergabe der Handschrift Codex Reginensis latinus 438, Zürich 1997. 
Störmer, Wilhelm, Die Baiuwaren. Von der Völkerwanderung bis Tassilo III. (Beck'sche Reihe 2181), München 2007.

Sтотz, Peter, "Dichten als Schulfach - Aspekte mittelalterlicher Schuldichtung", in: Mittellateinisches Jahrbuch 16 (1981), S. 1-16.

SтотZ, Peter, Dichten als Stoff-Vermittlung: Formen, Ziele, Wirkungen; Beiträge zur Praxis der Versifikation lateinischer Texte im Mittelalter, Zürich 2008.

STOVER, Justin, »Olybrius and the Einsiedeln Eclogues«, in: The Journal of Roman Studies 105 (2015), S. 288-321.

STRATTON HiLd, Elaine, Verse, music, and notation: Observations on settings of poetry in Sankt Gallen's ninth- and tenth-century manuscripts, Diss., University of Colorado Boulder (Musicology Graduate Theses \& Dissertations 5), Boulder 2014.

STRECKer, Karl, "Ist der Parisinus 266 der von Lothar dem Kloster Prüm geschenkte Codex?«, in: Neues Archiv der Gesellschaft für ältere deutsche Geschichtskunde 44 (1922), S. $135-137$.

STRECKer, Karl, »Zu den Karolingischen Rhythmen«, in: Neues Archiv der Gesellschaft für ältere deutsche Geschichtskunde 34 (1909), S. 599-652.

Strecker, Karl, Der rhythmus De Asia et de universi mundi rota (Beilage zum Jahresberichte des Kgl. Luisen-Gymnasiums zu Berlin), Berlin 1909.

Streib, A., "Wer ist der Verfasser der Praecepta vivendi?«, in: Münchener Museum für Philologie des Mittelalters und der Renaissance 2 (1913), S. 343-364.

STRICKer, Stefanie, »Überblick über die Prudentius-Glossierung", in: Die althochdeutsche und altsächsische Glossographie. Ein Handbuch, 1, hrsg. von Rolf BERGMANN und Stefanie STricKer, Berlin [u.a.] 2009, S. 497-510.

SUCHIER, Walther, Das mittellateinische Gespräch Adrian und Epictitus nebst verwandten Texten (Joca Monachorum), Tübingen 1955.

SwARZENSKI, Georg, Die Regensburger Buchmalerei des X. und XI. Jahrhunderts: Studien zur Geschichte der deutschen Malerei des frühen Mittelalters, Heidelberg 1900.

SzÖVÉRfFy, Joseph, Weltliche Dichtungen des lateinischen Mittelalters. Ein Handbuch, 1: Von den Anfängen bis zum Ende der Karolingerzeit, Berlin 1979.

TABOR, Lotte, Die Kultur des Klosters Tegernsee in frühen Mittelalter, Bottrop 1935.

Tabulae codicum manu scriptorum praeter graecos et orientales in Bibliotheca Palatina Vindobonensi asservatorum, Wien 1864.

TANGL, Michael, »Studien zur Neuausgabe der Bonifatius-Briefe«, in: Neues Archiv der Gesellschaft für ältere deutsche Geschichtskunde 40 (1916), S. 639-790.

TAYloR-BRIGgs, P. Ruth, »Utere bono tuo feliciter: The Textual Transmission and Manuscript History of Valerius Flaccus' Argonautica«, in: Brill's Companion to Valerius Flaccus, hrsg. von Mark Heerink und Gesine Manuwald, Leiden 2014, S. 9-28.

Tномаs, Paul Louis Désiré, Catalogue des manuscrits de classiques latins de la Bibliothèque royale de Bruxelles, Gand 1896.

Thurn, Hans, "Die Würzburger Domschule von ihren Anfängen bis zum Ausgang des Mittelalters: religionis et rei publicae seminarium?«, in: Würzburgs Domschule in alter und neuer Zeit, hrsg. von Günter Koch und Josef Pretscher, Würzburg 1990, S. 11-33.

Thurn, Hans, Die Pergamenthandschriften der ehemaligen Dombibliothek (Die Handschriften der Universitätsbibliothek Würzburg, 3/ 1), Wiesbaden 1984.

Tiвветts, T. N. S., Uses of the psalter in Carolingian St Gallen (Dissertation), Cambridge 2003. 
Tiefenbach, Heinrich, "Die altsächsischen Glossen zur Psychomachie des Prudentius im Pariser Codex lat. 18554«28/1 (2003), S. 57-85.

Tischler, Matthias M., »Reginbert-Handschriften, mit einem Neufund in Kloster Einsiedeln«, in: Scriptorium 50 (1996), S. 175-183.

Traube, Ludwig, "O Roma nobilis. Philologische Untersuchungen aus dem Mittelalter«, in: Sonderdruck aus: Abhandlungen der Historischen Klasse der Königlich-Bayerischen Akademie der Wissenschaften 19 (1891), S. 299-395.

Traube, Ludwig, »Palaeographische Anzeigen«, in: Neues Archiv der Gesellschaft für ältere deutsche Geschichtskunde 27 (1902), S. 264-285.

Traube, Ludwig, "Sophocles, ein Dichter der Anthologia Latina«, in: Rheinisches Museum für Philologie 64 (1889), S. 478-479.

Traube, Ludwig, "Textgeschichte der Regula, S. Benedicti«, in: Abhandlungen der Historischen Klasse der Königlich-Bayerischen Akademie der Wissenschaften 21 (1898), S. 599-731.

Traube, Ludwig, Karolingische Dichtungen: Aedelwulf. Alchhuine. Angilbert. Rhythmen (Schriften zur germanischen Philologie 1), Berlin 1888.

Tremp, Ernst und Schmuki, Karl, Geschichte und Hagiographie in Sanktgaller Handschriften, St. Gallen 2003.

Tremp, Ernst, "L'école de l'abbaye de Saint-Gall au temps carolingien«, in: Les écoles monastiques au haut Moyen Âge (Les cahiers Columbaniens), Luxeuil-les-Bains 2014, S. 60-77.

Tremp, Ernst, Schmuki, Karl und Huber, Johannes, La Bibliothèque abbatiale de SaintGall: l'histoire, le lieu, les collections, St. Gallen 2004.

Tristram, Hildegard L. C., "Die irischen Gedichte im Reichenauer Schulheft», in: Studia celtica et indogermanica: Festschrift für Wolfgang Meid zum 70. Geburtstag, hrsg. von Peter Anreiter und Erzsébet Jerem, Budapest 1999, S. 503-529.

Übersicht über die in Deutschland seit 1991 erschienenen Kataloge abendländischer Handschriften, in: Das Mittelalter 14 (2009), S. 17-28.

Unterkircher, Franz, Die datierten Handschriften der Österreichischen Nationalbibliothek bis zum Jahre 1400 (Katalog der datierten Handschriften in lateinischer Schrift in Österreich 1), Wien 1969.

UnterkirCher, Franz, Inventar der illuminierten Handschriften, Inkunabeln und Frühdrucke der Österreichischen Nationalbibliothek (Museion. NF. Reihe 2 2), Wien 1957.

Ursprung, Otto, "Das Freisinger Petrus-Lied«, in: Die Musikforschung 5 (1952), S. 17-21.

Veyrard-Cosme, Christiane, Tacitus Nuntius: recherches sur l'écriture des Lettres d'Alcuin (Collection des Études Augustiniennes : Série Moyen Âge et Temps modernes 50), Paris 2013.

VÉZIN, Jean, »Les relations entre Saint-Denis et d'autres scriptoria pendant le haut Moyen Âge", in: The role of the book in medieval culture, 1, hrsg. von Peter Felix Ganz (Bibliologia 3-4), Turnhout 1986, S. 17-39.

Victor, Benjamin A., "Simultaneous copying of classical texts 800-1100: techniques and their consequences", in: La collaboration dans la production de l'écrit médiéval, hrsg. von Herrad SpILling (Matériaux pour l'histoire 4), Paris 2003, S. 347-358.

VIlla, Claudia, "Die Horazüberlieferung und die >Bibliothek Karls des Großen . Zum Werkverzeichnis der Handschrift Berlin, Diez B. 66«, in: Deutsches Archiv für Erforschung des Mittelalters 51 (1995), S. 29-52. 
Villa, Claudia, »I manoscritti di Orazio«, in: Aevum 66, 67, 68 (1992), S. 95-135, 55-103, 117-146.

VILlA, Claudia, "Terence's Audience and Readership in the Ninth to Eleventh Centuries", in: Terence between late antiquity and the age of printing: illustration, commentary and performance, hrsg. von Andrew J. Turner und Giulia Torello-Hill (Metaforms 4), Leiden [u. a.] 2015, S. 239-250.

VISSER, Jelle, Sis memor Strabonis. Context and communicative value of Walahfrid Strabo's poetry, RMA Thesis, Universität Utrecht 2012.

Vocino, Giorgia, »A Peregrinus's Vade Mecum: MS Bern 363 and the >Circle of Sedulius Scottus «, in: The Annotated Book in the Early Middle Ages, hrsg. von Mariken TeEuwen und Irene van Renswoude (Utrecht Studies in Medieval Literacy 38), Turnhout 2017, S. 87-123.

Voetz, Lothar, "Art. Murbacher Hymnen (Interlinearversion) «, in: Althochdeutsche und altsächsische Literatur, hrsg. von Rolf BERGMANN, Berlin [u. a.] 2013, S. 272-288.

Voetz, Lothar, "Art. Psalter: Fragmente einer altalemannischen Interlinearversion«, in: Althochdeutsche und altsächsische Literatur, hrsg. von Rolf BERGMANN, Berlin [u.a.] 2013, S. 384-395.

Vogler, Werner (Hrsg.), Die Kultur der Abtei Sankt Gallen, 2. Aufl., Zürich 1992.

Vossen, Peter, Der Libellus scolasticus des Walther von Speyer: ein Schulbericht aus dem Jahre 984, Berlin 1962.

WAGNER, Norbert, „Zu den Gotica der Salzburg-Wiener Alcuin-Handschrift«, in: Historische Sprachforschung 107 (1994), S. 262-283.

WAGNeR, Ulrich (Hrsg.), Geschichte der Stadt Würzburg, 1, Von den Anfängen bis zum Ausbruch des Bauernkriegs, Stuttgart 2001.

WAITZ, Georg (Hrsg.), Vita Anskarii auctore Rimberto. (MGH SS rer. Germ. 55), Hannover 1884.

WALDHoff, Stephan, Alcuins Gebetbuch für Karl den Großen: seine Rekonstruktion und seine Stellung in der frühmittelalterlichen Geschichte der Libelli Precum (Liturgiewissenschaftliche Quellen und Forschungen 89), Münster 2003.

WALlach, Luitpold, "The Urbana Anglo-Saxon Sylloge of Latin Inscriptions«, in: Poetry and Poetics from Ancient Greece to the Renaissance: Studies in Honor of James Hutton, hrsg. von Gordon M. KIRKwood (Cornell studies in classical philology 38), Ithaca, NY 1975, S. 134-151.

WäLLI, Silvia, Melodien aus mittelalterlichen Horaz-Handschriften: Edition und Interpretation der Quellen (Monumenta Monodica Medii Aevi. Subsidia 3), Kassel [u. a.] 2002.

WALSER, Georg, Die Einsiedler Inschriftensammlung und der Pilgerführer durch Rom (Codex Einsidlensis 326) (Historia. Einzelschriften 53), Stuttgart 1987.

WALTHER, Hans, Initia carminum ac versuum medii aevi posterioris latinorum: Hauptband. 11959.

WARD, John O., "The medieval and early renaissance study of Cicero's De inventione and the Rhetorica ad Herennium: Commentaries and Contexts", in: The rhetoric of Cicero in its medieval and early renaissance commentary tradition, hrsg. von Virginia Cox und John O. WARD (Brill's companions to the Christian tradition 2), Leiden, Boston 2006, S. 3-69.

Wartmann, Hermann, Das Kloster St. Gallen (Neujahrsblatt St. Gallen 3-4), St. Gallen 1863. 
Wattenbach, Wilhelm, Das Schriftwesen im Mittelalter. Unveränd. Abdr. der 3. verm. Aufl., Hirzel, Leipzig 1896, Graz 1958.

WEAKLAND, Rembert George, "The beginnings of troping", in: The musical quarterly 44 (1958), S. 477-488.

WeHRLI, Max, Geschichte der deutschen Literatur im Mittelalter: Von den Anfängen bis zum Ende des 16. Jahrhunderts, Stuttgart 1997.

WeINER, Andreas, Die Initialornamentik der deutsch-insularen Schulen im Bereich von Fulda, Würzburg und Mainz (Quellen und Forschungen zur Geschichte des Bistums und Hochstifts Würzburg 43), Würzburg 1992.

WENDEHORST, Alfred, „Bischofssitz und königliche Stadt: Von der Karolingerzeit bis zum Wormser Konkordat «, in: Geschichte der Stadt Würzburg, 1: Von den Anfängen bis zum Ausbruch des Bauernkrieges, hrsg. von Ulrich WAGNER, Stuttgart 2001, S. 62-73.

Wendehorst, Alfred, Das Bistum Würzburg, Die Bischofsreihe bis 1254 (Germania sacra 1), Berlin 1962.

WERNER, Jakob, "Die ältesten Hymnensammlungen von Rheinau«, in: Mittheilungen der Antiquarischen Gesellschaft in Zürich 23, 3 (1891).

Werner, Matthias, Der Lütticher Raum in frühkarolingischer Zeit. Untersuchungen zur Geschichte einer karolingischen Stammlandschaft (Veröffentlichungen des MaxPlanck-Instituts für Geschichte 62), Göttingen 1980.

Wessner, Paul (Hrsg.), Scholia in Iuvenalem vetustiora (=1931) (Bibliotheca scriptorum Graecorum et Romanorum Teubneriana), Stuttgart 1967.

Whitbread, Leslie George, Fulgentius the Mythographer, Translated from the Latin, with Introductions, Columbus, $\mathrm{OH} 1971$.

Wich-Reif, Claudia, "Art. Sedulius, Althochdeutsche Glossierung", in: Althochdeutsche und altsächsische Literatur, hrsg. von Rolf BERGMANN, Berlin [u. a.] 2013, S. 431-434.

Wiedemann, Konrad, Manuscripta theologica. Die Handschriften in Folio (Die Handschriften der Gesamthochschul-Bibliothek Kassel. Landesbibliothek und Murhardsche Bibliothek der Stadt Kassel 1), Wiesbaden 1994.

WiEland, Gernot R., »The glossed manuscript: classbook or library book? «, in: Anglo-Saxon England 14 (1985), S. 153-173.

Wiesemeyer, Helmut, "Corbie et le developpement de l'école monastique de Corvey, du IXe au XIe siècle«, in: Corbie abbaye royale. Volume du 13e centenaire, Lille 1963, S. 211-222.

Wiget, Wilhelm, „Zu den Widmungen Otfrids«, in: Beiträge zur Geschichte der deutschen Sprache und Literatur 49 (1925), S. 441-444.

Wilhelmy, Winfried, Glanz der späten Karolinger. Erzbischof Hatto I. von Mainz (Publikationen des Bischöflichen Dom- und Diözesanmuseums Mainz 3), Regensburg 2013.

Willmes, Peter, Der Herrscher-»Adventus « im Kloster des Frühmittelalters (Münstersche Mittelalter-Schriften 22), München 1976.

Wilmart, André, Codices Reginenses Latini (Bibliothecae Apostolicae Vaticanae Codices manu scripti recensiti), Vatikan 1937.

Winterfeld, Paul von, "Die Dichterschule St. Gallens und der Reichenau unter den Karolingern und Ottonen«, in: Neue Jahrbücher für das klassische Altertum, Geschichte und deutsche Literatur 5 (1900), S. 341-361.

Winterfeld, Paul von, »Paulus diaconus oder Notker der Stammler?«, in: Neues Archiv der Gesellschaft für ältere deutsche Geschichtskunde 29 (1904), S. 486-471. 
Wisplinghoff, Erich, »Untersuchungen zur Gründungsgeschichte des Klosters Prüm«, in: Jahrbuch für westdeutsche Landesgeschichte 17 (1991), S. 1-28.

Wisplinghoff, Erich, Untersuchungen zur frühen Geschichte der Abtei S. Maximin bei Trier von den Anfängen bis etwa 1150 (Quellen und Abhandlungen zur mittelrheinischen Kirchengeschichte 12), Mainz 1970.

WöLfflin, Eduard von, »Aus St. Galler Handschriften«, in: Philologus 34 (1876), S. 178179.

Wolfinger, Lukas, "Die sogenannten >Carmina Salisburgensia und der Clm. 14743«, in: Quellen zur Salzburger Frühgeschichte, hrsg. von Herwig Wolfram (44), Wien 2006, S. 179-262.

Wolfram, Herwig, "Arn von Salzburg und Karl der Große«, in: 1200 Jahre Erzbistum Salzburg. Die älteste Metropole im deutschen Sprachraum, hrsg. von Heinz DopscH, Peter Franz KRAmml und Alfred Stefan Weiss (Mitteilungen der Gesellschaft für Salzburger Landeskunde. Ergänzungsband 18), Salzburg 1999, S. 21-32.

Worstвrock, Franz Josef, »Art. Waldram (Walth-, Walt-) von St. Gallen OSB«, in: Verfasserlexikon, 10, 1999, S. 614-617.

Wright, Charles D., "Additions to the Bobbio Missal: >De dies malus and \Joca monachorum (fols. $6 r-8 v$ )«, in: The Bobbio Missal. Liturgy and Religious Culture in Merovingian Gaul, hrsg. von Yitzhak Hen und Rob MeEns (Cambridge studies in palaeography and codicology 11), Cambridge 2004, S. 79-139.

Wunderlich, Werner und Rupert Kalkofen (Hrsg.), St. Gallen. Geschichte einer literarischen Kultur, St. Gallen 1999.

ZechieL-EcKes, Klaus, »Handschriften aus Corbie: $M G H «$, http://www.mgh.de/datenban ken/pseudoisidor/corbie/ (abgerufen am 07.02.2017).

ZeLL, Verena, Erzbischof Hildebald von Köln: Untersuchungen zu seiner Rolle im Reformprogramm Karls des Großen (Studien zur Geschichtsforschung des Mittelalters 33), Hamburg 2016.

ZettLer, Alfons, "St. Gallen als Bischofs- und Königskloster«, in: Alemannisches Jahrbuch 2001/2002, S. 23-38.

Zeumer, Karl, "Über die alamannischen Formelsammlungen«, in: Neues Archiv der Gesellschaft für ältere deutsche Geschichtskunde 8 (1883), S. 473-553.

Ziolkowsкi, Jan M. und Putnam, Michael C. J., The Virgilian Tradition. The First Fifteen Hundred Years, New Haven 2008.

Ziolкошsкi, Jan M., »Nota bene: why the classics were neumed in the Middle Ages", in: The journal of medieval Latin 10 (2000), S. 74-114.

Zogg, Fabian, "Die Appendix Vergiliana avant la lettre: Martial, Donat, Servius und der Murbach-Katalog zu Vergils angeblichen Jugendwerken", in: Antike und Abendland 62 (2016), S. 74-85.

ZотZ, Thomas, "Ludwig der Deutsche und seine Pfalzen: Königliche Herrschaftspraxis in der Formierungsphase des Ostfränkischen Reiches", in: Ludwig der Deutsche und seine Zeit, hrsg. von Wilfried HaRtmann, Darmstadt 2004, S. 27-46.

ZuRLI, Loriano, The manuscript transmission of the »Anthologia Latina" (Anthologiarum Latinarum parerga 6, Anthologiarum Latinarum manuscripta 3), Hildesheim 2017.

Zwınk, Eberhard, Frühes Mönchtum in Salzburg (Salzburger Diskussionen 4), Salzburg 1983. 


\section{Register}

\section{V.1 Abkürzungen}

$\begin{array}{ll}\text { BAV } & \text { Biblioteca Apostolica Vaticana } \\ \text { BB } & \text { Burgerbibliothek (Bern) } \\ \text { BGE } & \text { Bibliothèque de Genève } \\ \text { BR } & \text { Bibliothèque royale (Brüssel) } \\ \text { BUM } & \text { Bibliothèque universitaire de médecine (Montpellier) } \\ \text { BHL } & \text { Bibliotheca Hagiographica Latina } \\ \text { BLB } & \text { Badische Landesbibliothek } \\ \text { BNF } & \text { Bibliothèque nationale de France } \\ \text { BSB } & \text { Bayerische Staatsbibliothek } \\ \text { CCCM } & \text { Corpus Christianorum. Continuatio medievalis } \\ \text { CCSL } & \text { Corpus Christianorum. Series latina } \\ \text { CPL } & \text { Clavis Patrum Latinorum } \\ \text { CSEL } & \text { Corpus Scriptorum Ecclesiasticorum Latinorum } \\ \text { DDB } & \text { Erzbischöfliche Diözesan- und Dombibliothek } \\ \text { DstB } & \text { Domstiftsbibliothek (Merseburg) } \\ \text { HAB } & \text { Herzog August Bibliothek } \\ \text { ICUR } & \text { De Rossi, Inscriptiones christianae urbis Romae } \\ \text { MGH } & \text { Monumenta Germaniae Historica } \\ \text { AA } & \text { Auctores Antiquissimi } \\ \text { Capit. } & \text { Capitularia regum Francorum } \\ \text { Conc. } & \text { Concilia } \\ \text { Epp. } & \text { Epistulae } \\ \text { Epp. Sel. } & \text { Epistulae Selectae } \\ \text { Libri mem. N.S. } & \text { Libri Memoriales, Nova Series } \\ \text { LL } & \text { Leges } \\ \text { LL nat. Germ. } & \text { Leges Nationum Germanicarum } \\ \text { Poet. Lat. } & \text { Poetae Latini Aevi Carolini } \\ \text { QQ zur Geistesgesch. } & \text { Quellen zur Geistesgeschichte } \\ \text { SS } & \text { Scriptores } \\ \text { SS rer. Germ. } & \text { Scriptores Rerum Germanicarum } \\ \text { SS rer. Langob. } & \text { Scriptores Rerum Langobardicarum et Italicarum saec. VI-IX } \\ & \end{array}$




\begin{tabular}{ll}
\multicolumn{1}{c}{ SS rer. Merov. } & Scriptores Rerum Merovingicarum \\
ÖNB & Österreichische Nationalbibliothek \\
PL & Patrologia Latina \\
SB & Staatsbibliothek (Berlin) / Stadtbibliothek (Trier) \\
SK & Schaller \& Könsgen, Initia Carminum \\
StB & Stiftsbibliothek \\
StUB & Staats- und Universitätsbibliothek \\
UB & Universitätsbibliothek \\
ULB & Universitäts- und Landesbibliothek \\
ZB & Zentralbibliothek
\end{tabular}

\section{V.2 Handschriften}

Antwerpen, Museum Plantin-Moretus

Ms. 17.4 227, 229-232, 316, 319, 324, 327, 330

Basel, Universitätsbibliothek

F III $15 \mathrm{e} \quad 48 \mathrm{f}$.

O IV 1758,315

Berlin, Staatsbibliothek

Ms. Hamilton $542 \quad 100,117,118$

Ms. Phillips 1869260

Bern, Burgerbibliothek

Ms. 179299

Ms. 212 45, 59, 325

Ms. 264 264, 100 f., 118, 161, 162f., 192, 324

Ms. 363 114-116, 185, 254, 334, 340

Ms. 394394

Ms. 45552

Bremen, Staats- und Universitätsbibliothek

Ms. b 52 Siehe St. Gallen StB, Cod. Sang. 273

Brüssel, Bibliothèque Royale de Belgique

Ms. 165053

Ms. $4433-4438 \quad 243$

Ms. 5354-5361 120

Ms. $8860-8867 \quad 85$

Ms. $9565-9566 \quad 98$

Ms. 9845-9848 245f., 318

Ms. 10470-10473 29

Ms. 14792190 
Cambridge, University Library

MS Ll. $1.10 \quad 309$

Gg. 5.35309

Colmar, Archives départementales du Haut-Rhin

Fragm. 624, $7 \quad 198$

Cartulaire Abbaye Murbach Nr. $1 \quad 198$

Donaueschingen, siehe Stuttgart, Württembergische Landesbibliothek

Düsseldorf, Universitäts- und Landesbibliothek

Ms. F 1 34, 118, 227

Einsiedeln, Stiftsbibliothek

Cod. 266 65, 136, 208-215, 218, 325, 327, 329, 340

Cod. $302(450) \quad 43$

Cod. 326 (1076) 67f., 133, 191, 307, 324, 326, 339, 340

Florenz, Biblioteca Medicea Laurenziana

Ms. plut. XIV, 1566

Ms. plut. 68.1226

Genf, Bibliothèque de Genève

Ms. lat. 21 (99) 155, 168, 199

Gent, Universitätsbibliothek

Ms. 324 (SG 581) 235

Glasgow, Universitätsbibliothek

Ms. U.6.8 (290) 102

Graz, Landesarchiv Steiermark

Ms. 790277

Heidelberg, Universitätsbibliothek

Cod. Pal. lat. $52 \quad$ 196, 258, 291

Karlsruhe, Badische Landesbibliothek

Aug. Fr. $8 \quad 13$

Aug. Perg. 19 163, 329

Aug. Perg. 29 163, 329

Aug. Perg. 73 81, 174

Aug. Perg. $85 \quad$ 169, 316

Aug. Perg. 112 75, 102, 159-161, 169, 170, 174, 327, 329, 338, 344, 345

Aug. Perg. 132 153, $158 \mathrm{f}$.

Aug. Perg. 135 163, 309 
Aug. Perg. 167 158f.

Aug. Perg. 195 158f., 329

Aug. Perg. 217 80, 105, 151, 161f., 170, 318, 327, 334

Aug. Perg. $221 \quad 157$

Aug. Perg. 255 293, 319, 343

Aug. Perg. $308 \quad 38$

Kassel, Universitätsbibliothek

UB, $2^{\circ}$ Ms. theol. 2366

UB, fol. Ms. theol. 54 68f., 329

Köln, Erzbischöfliche Diözesan- und Dombibliothek

Cod. 83220

Cod. 99 220, 329

Cod. 106 221-224, 225, 272, 309, 326, 327, 329

Cod. 110220

Laon, Bibliothèque municipale

Ms. 279255

Leiden, Universitätsbibliothek

BPL $36 \quad 250$

Lips. $7 \quad 198$

Voss. Lat. F. $30 \quad$ 66, 206

Voss. Lat. F. 111278

Voss. Lat. Q. 69 14, 82-85, 107, 112, 114, 127, 128, 134, 145, 318, 328, 338, 340, 343, 344

London, British Library

Add. $34248 \quad 150$

Cotton Calig. A. VII. 227

Harley 2685220

Harley 2965296

Royal MS 2.A.XX 296

Manchester, John Rylands Library

Latin Ms. 116 (olim Crawford Lat. 133) 234, 328

Mailand, Biblioteca Ambrosiana

C 74 sup. $128,171,201$

C 32 sup. 230

D $36 \quad 118$

Merseburg, Domstiftsbibliothek

Cod. 105 244, 252, 343 
Montpellier, Bibliothèque universitaire de médecine

H 125 106, 177, 187, 249f., 334

H 218230

H 352127

München, Bayerisches Hauptstaatsarchiv

HL Passau 3302

München, Bayerische Staatsbibliothek

Cgm 14 290-292

Cgm $25227 \mathrm{f}$.

Clm 4650 276f.

Clm 6258 278f.

Clm $6273 \quad 279$

Clm $6281 \quad 281$

Clm 6399292

Clm $6402 \quad 80,123,282,318$

Clm 6404 77, 109, 121, 184, 279-281, 328, 332, 338, 343, 345

Clm $6407 \quad 298,316$

Clm 6411 305, 306-308, 313, 326, 338, 339, 343

Clm $6412 \quad 170,316,331$

Clm $6413 \quad 281,317$

Clm $8107 \quad 41$

Clm $9543 \quad 297329$

Clm $13084 \quad 282,298,316$

Clm 14248 296f.,

Clm $14252 \quad 319,323,344$

Clm $14324 \quad 299,316,318$

Clm 14377 298, 316, 328, 345

Clm 14420299

Clm 14447 223, 272-274, 309

Clm $14456 \quad 296$

Clm $14457 \quad 296$

Clm $14461 \quad 278,326$

Clm 14070c $299 \mathrm{f}$.

Clm $14497 \quad 160$

Clm $14641 \quad 47$

Clm $14666 \quad 298$

Clm $14727 \quad 298$

Clm $14729 \quad 98$

Clm 14743 272, 275f., 343, 345

Clm $14523 \quad 282$

Clm $14537 \quad 295$

Clm $15821 \quad 277$

Clm $18375 \quad 293$

Clm 18524b 277 
Clm 18765293

Clm $19410 \quad 183,223,272,273,276,284,294,305,307,308-313$

Clm $1941374,91,120,134,148-150,276,283-290,324,326,328,329,339,340,345$

Clm 29005 (19) 298

Clm 29005 (18) 293

Clm 29030293

Clm 29033a 297

Clm $29081(10) \quad 299$

Clm $29216 \quad 298,318,334$

Clm 29216 (9) 298

Clm $29270 \quad 263$

Clm 29334 (1) 293

Clm 29338 (1) 297, 318, 324

Clm 29790 (1) 299, 329

Neapel, Biblioteca Nazionale

Ms. IV G 68 14, 83, 98, 103, 107, 110-114, 116, 120, 132, 326, 328, 329, 330, 344, 345

Oxford, Bodleian Library

Laud. Misc. 12652

MS Jun. $25 \quad 102,156,175,204,215-217,317,324,326,344$

Paris, Bibliothèque nationale de France

Lat. $2423 \quad 45$

Lat. $2676 \quad 47$

Lat. $2773 \quad 280$

Lat. 5018 237f., 244, 245, 334

Lat. $7641 \quad 47$

Lat. $7906 \quad 237 f$ f., 244, 245, 334

Lat. $8093 \quad 278$

Lat. $8779 \quad 309$

Lat. $9347 \quad 119,280$

Lat. $10910 \quad 48$

Lat. $12255 \quad 182$

Lat. 13377231

Lat. $13759 \quad 49$

Lat. 16668 243f., 246, 253, 328, 332, 338

Lat. $18554 \quad 227,228,324$

Reims, Bibliothèque municipale

Ms. 438 273, 317

Schaffhausen, Staatsarchiv

Fragment 1 93, 94 
St. Gallen, Kantonsbibliothek

VadSlg Ms. $317 \quad 175$

St. Gallen, Stiftsbibliothek

Cod. Sang. 2 79, 83, 345

Cod. Sang. 1099

Cod. Sang. 1739

Cod. Sang. 2039

Cod. Sang. 233639

Cod. Sang. 2739

Cod. Sang. $44 \quad$ 101, 107, 141

Cod. Sang. $64 \quad 103,112,114$

Cod. Sang. 134 117, 324

Cod. Sang. $136 \quad 53,100,111,116-118,192,324,345$

Cod. Sang. $187 \quad 88,100,168,181,247,250 f$.

Cod. Sang. $196 \quad 83,107,109,127,149,316,318,331$

Cod. Sang. 197 14, 99, 100, 121-123, 152, 208, 282, 319, 323, 328, 331, 336, 340

Cod. Sang. 199 37, 107

Cod. Sang. 21379

Cod. Sang. $242 \quad 46,100,109,230$

Cod. Sang. 24893

Cod. Sang. $250 \quad 81,93,94,96,99,144,259-261,305,318,329$

Cod. Sang. $263 \quad 89,99,100,104,107,120 f ., 138,142,199,208,315,326,328,332,336$

Cod. Sang. $265 \quad 87,89,107,332$

Cod. Sang. $270 \quad 66,338$

Cod. Sang. $272 \quad 81 \mathrm{f}$.

Cod. Sang. 273 95, 99, 107, 108-110, 119, 135, 144, 146, 280, 318, 324, 326, 328, 332, 332, 338, 340,345

Cod. Sang. 299 120, 149

Cod. Sang. $381 \quad 148,288$

Cod. Sang. 397 89-97, 107, 109, 120, 132-139, 143, 144, 146, 149, 286, 287, 318, 327, 328, 329, 339, 343

Cod. Sang. 45993

Cod. Sang. 484288

Cod. Sang. $573 \quad 83,84,107,127-29,316,318,326,331,342,342$

Cod. Sang. $577 \quad 128$

Cod. Sang. $831 \quad 81,102 \mathrm{f}$.

Cod. Sang. $844 \quad 112,114$

Cod. Sang. 855104

Cod. Sang. 861/862 88, 101

Cod. Sang. $864 \quad 104$

Cod. Sang. 869 70-76, 117, 123-127, 133, 135, 137, 138, 167, 280, 324, 326, 329, 332, 337, 341

Cod. Sang. $870 \quad 37,83,105-108,114,152,172,279,329,334$

Cod. Sang. 876 101, 104

Cod. Sang. 877 101, 104f., 152, 161, 318, 338 
Cod. Sang. 899 15, 68, 70, 71, 77, 89, 91, 92, 93, 96, 99, 109, 121, 124, 126, 129-139, 142, 143, $144,146,146,147,150,167,208,209,280,316,318,326,328,332,336,340$

Cod. Sang. $902 \quad 89$

Cod. Sang. 903220

Cod. Sang. $914 \quad 175$

Cod. Sang. $1394 \quad 88,99,109,333$

Cod. Sang. 1396 81, 246

St. Paul im Lavanttal, Stiftsbibliothek

Cod. 86b/1 (olim 25.2.31b, olim Sanblasianus 86) 158f., 339

Stuttgart, Württembergische Landesbibliothek

Cod. Don. 191 116, 128, 154, 155, 177-179, 202, 334

Trier, Stadtbibliothek

Ms. 592/1578 234f., 339, 344

Ms. $1086 / 2180 \quad 234$

Ms. $1245 / 597 \quad 235,261 \mathrm{f}, . ., 339$

Vatikan, Biblioteca Apostolica Vaticana

Pal. lat. $238 \quad 247$

Pal. lat. 239 48, 317, 324

Pal. lat. 487 95, 238-241, 242, 245, 324, 340, 343

Pal. lat. $833 \quad 248,251 \mathrm{f}$., 343

Pal. lat. $845 \quad 49,127,317,331,342$

Pal. lat. $1578 \quad 238,240,317$

Pal. lat. $1631 \quad 113,256$

Pal. lat. 1649245

Pal. lat. 1701257

Pal. lat. 1716257

Pal. lat. 1719 242, 246f., 318, 326, 338

Pal. lat. $1753 \quad 241-243,246,275,316,318,324,326,329,332,334,338,345$

Pal. lat. $1877 \quad 60,247$

Reg. lat. 11855

Reg. lat. $124 \quad 64$

Reg. lat. $215 \quad 172$

Reg. lat. $339 \quad 100,118$

Reg. lat. $42196,129,130,131,136,137,143,149,149,286$

Reg. lat. $438 \quad 81,94,259-261,305,325$

Reg. lat. $348 \quad 117$

Reg. lat. 356150

Reg. lat. $46970-77,124,126,135,136,138,326,337$

Reg. lat. $582 \quad 127$

Reg. lat. $1703 \quad 62,87,115,164,167,185-188,326,334,345$

Vat. lat. 552119

Vat. lat. $1664 \quad 127$ 
Vat. lat. 3277 66f., 326

Vat. lat. 3860118

Vat. lat. $3868 \quad 226,324$

Vat. lat. $11506 \quad 144,146,190,326$

Wien, Österreichische Nationalbibliothek

Cod. 89265

Cod. 313263

Cod. $458 \quad 221,274,277$

Cod. 550 244, 252, 343

Cod. $743 \quad 79$

Cod. $751 \quad 43$

Cod. 795 264, 266f., 272, 274, 281

Cod. 808 184, 265, 267-272, 273, 274, 275, 276, 307, 317, 328

Cod. 969 45-47, 315, 316, 324, 326, 332

Cod. 964 265, 341

Cod. 1332264

Cod. 1609 74, 91, 149, 150, 276, 283-290, 291307, 329, 339, 345

Cod. $1761 \quad 149$

Cod. 2687 195f., 291, 325

Cod. 11857 223, 309

Wolfenbüttel, Herzog August Bibliothek

Cod. Guelf. 17.5. Aug. $4^{\circ} 129$

Cod. Guelf. 41.1 Aug. $2^{\circ} \quad 129,206$

Cod. Guelf. 66 Gud. lat. 244f., 248, 257, 317, 345

Cod. Guelf. 70 Gud. lat. 256

Cod. Guelf. 14 Weiss. 180

Cod. Guelf. 26 Weiss. 189

Cod. Guelf. 32 Weiss. 189

Cod. Guelf. 33 Weiss. 189

Cod. Guelf. 35 Weiss. 291, 317

Cod. Guelf. 36 Weiss. 189

Cod. Guelf. 50 Weiss. 190

Cod. Guelf. 56 Weiss. 168, 181, 251

Cod. Guelf. 61 Weiss. 180

Cod. Guelf. 62 Weiss. 180

Cod. Guelf. 66 Weiss. 189,319

Cod. Guelf. 77 Weiss. 14, 190-194, 319, 326, 329

Cod. Guelf. 91 Weiss. 34, 181-185, 326, 328, 329, 339, 341, 345

Würzburg, Universitätsbibliothek

UB, M.p.misc.f. 2 53f., 184

UB, M.p.misc.f. 3. 190, 343

UB, M.p.th.f. 651

UB, M.p.th.f. $21 \quad 52,53,315,326$ 
UB, M.p.th.f. $29 \quad 43,55$

UB, M.p.th.f. $45 \& 47 \quad 51$

UB, M.p.th.f. 56 54f., 184, 339, 343

UB, M.p.th.f. 6353

UB, M.p.th.f. 6752

UB, M.p.th.f. 145, Fragm. 23 (Reuß-Mappe) 51

Zürich, Zentralbibliothek

C $12 \quad 38$

C 68 80-82, 92, 100, 105, 151, 152, 161, 162, 282, 324, 326, 334

C 5999,100

C $7815,43,66,80,91,94,96,96,101,107,109,121,126,131,131,134,139-147,149,150,151$, $166,176,326,328,336,340$

C 12946,329

Rh. 34 157, 216, 344

Rh. $95 \quad 47$

\section{V.3 Initien ${ }^{2190}$}

A superna caeli parte 83

Abiecta in triviis 92, 133

Abietine calix 131

Accipe sancte pater Otgari 44

Ad boreae partes 260

Ad dominum clamaveram 112, 223, 273

Ad perennis fontem vitae 84

Adalrammus ovans 275

Adam in saeculo 112

Adiuvat nos archangelus 157

Aegrum fama fuit 132

Aeneas primo libyae 239

Aeneas primo lybicis 96

Albinus precibus 135

Alma vera ac praeclara 84,112

Ambrosius doctor 286

An ego raucesonum 239

Angelus domini maria 84

Angelus ecce seni 141

Angelus venit de celo 83

Anguis aper 130

2190 Nicht vermerkt sind hier die Initien größerer Werke, sowie die Initien der Einzelgedichte der Autorenanthologien, siehe zu diesen im Allgemeinen Verzeichnis zu den einzelnen Dichtern. 
Ante secula (et) mundi $79,83,112$

Antistes domini 211, 284

Antistes humilis 279

Apparebunt ante summum 243

Aquarum meis quis 84

Archangelum mirum magnum 157

Ardorem solis placida 166

Arve poli conditore 83

Asia ab oriente $79,83,84$

Audax es iuvenis / Audax est vir iuvenis 222, 243

Audite fratres fama 157

Audite omnes 83

Auferat hunc librum nullus 36

Aureus ac simul Justinus 280

Avia perlustrans 284

Baldo dei famule 276, 277

Bis sena mensum 260

Bis sex signifere 260

Caeli cives in gaudio 189

Cantemus in omni die 158

Cantemus socii 231

Carcere vallatus 182,185

Carmina Vergili sunt 239

Carpit blanda suis 259

Celi cives applaudite 112

Christe qui lux es 223

Christe salus mundi nobis 112

Cinthius occiduas 131

Clangor tubae per quaternas 136

Clio gesta canens 96

Collis sum collisque $131,132,143$

Concurrite huc populi $112 \mathrm{f}$.

Condidit hoc sanctum 92, 133

Constantine decus 95, 149

Contumeliam nec fortis 145

Conveniunt subito 94

Crede ratem ventis 94, 149, 231

Cumque ante ora 132

Dente timetur aper 130

Dicta vocatur avis 276

Dira patet Iani 93, 239, 260

Disce frequenter 275 
Ductus amore dei martini 280

Dulcia dona mihi 95

Dulcis amica veni 286,288

Dulcis amor lacrimis 272

Dum putat esse parem 130

Dum suetas soleat 274

Ecce bonum quam 239

Ecce superno 135

Ecce votis apta 71,135

Egregio iuveni Salomoni 286

En adest Caesar 135

En laetum et pulchrum 239

En vester socius 275

Ergone supremis 239

Est et non cuncti 129

Est mihi discipulus 243

Ex phisicis quidam 285

Exul ab humano 274, 293

Fertur de Iano 276

Festum nunc celebre 278

Flumina qui metuat 274

Fonte lavat genitor 96, 144, 260

Fontibus in liquidis $95,149,287$

Fortia quid subito 239

Fulget honorifico 259

Gallia me genitum 94, 143

Garrula nunc babile 259

Gloria laus et honor 135

Gramatibus duplici 132

Gratuletur omnis caro 83, 112

Gregorius praesul 183,328

Haec Augustini ex sacris 231

Haec dator aeternus 274

Haec diruta domus 275

Haec est pulcra domus 96

Haec quisquis pedibus 276

Hic decus Italiae 133

Hic iani mensis / Hic iam mensis 94, 260

Hic pater et pastor 276

Hic rogo pauxillum 81

Hieronime interpres 286 
Hoc iacet in tumulo 92,135

Hoc opus in melius 277

Hoc quicumque volit carmen 94

Hoc satus in viridi 131

Hoc subter iaceant $\quad 66,166$

Homo quidam erat dives 84

Hymnum dicat turba 79

Iam dudum saulus 84

Iam lucis orto sidere 222

Iam puto nervosi 130

Ianus et octimber 260

Ille superne sagax 277

Immensas grates 276

In mensa beati agustini 96

Inchoat hic comes 274

Inclita sanctorum 189

Inclite Caesar ave 135

Innovatur nostra 70,135

Iudicii signum tellus 145

Iustitiae domus, fidei aula 294

Iustius inuidia nihil 67

Laudes dicamus 189

Lingua Prophetarum cecinit 83

Luciola effigies 142

Lucis creator optime 223

Lumen clarum rite 135

Lumine purpureo 131

Luxuriam ventris lector 269

Maeonium quisquis Romanus 239

Magnus tu Bacche 131

Martyris hic Christi fulgent 231

Mater me genuit 280

Me legat annales 260

Mentitur qui te 286

Mole sub hac magni $\quad 68,133$

Monte sub hoc lapidum 131

Multicolor quali 131

Mundus iste transivit 145

Murice puniceo 243

Naturae genitor 144

Naturas rerum varias 95 
Nobilis hanc aries 276

Noli archana 95, 149, 287

Non dubitet autem 36

Nunc sanctae nobis spritus

O cara anima 307

O deus omnipotens 265,275

O lux beata trinitas 223

O species cari 285,287

O Tite tute Tati 306

O triplex honor 112

$O$ venerande pie 158

Omnipotentis vis trina 145,166

Ordiar unde tuas 130

Ortus perpetui floris 231

Palma sacerdotum 276

Pangite coeli 136

Parva culix 131

Pastor o qui Christi 239

Pastorum musam vario 239

Paule sub umbroso 130

Peior amate 284

Per montes campos 276

Perge frater qui adheres 112

Plangamus cuculum 135

Plus amat altithronus 243

Pone focum mensis 276

Pontifico magno Arnoni 274

Posce patrum cineres 274

Post erratus et excessus 112

Postquam primo homini 136

Praemicat alme tuum 276

Prandeo poto cano ludo 149, 287

Prima Cleonaei 67f., 133

Prima dies Phoebi 81, 92

Prima sonat quartae 132

Primus adest aries 94

Primus habet pelagiminas 95

Primus romanas ordiris 93

Principium iani 81,259

Psalle modulamina laudis 297

Quadam nocte niger 67, 191

Quae fueram quondam 93 
Quaerebat merens 130

Quam bene sub patule 144

Quamvis digna tuis 274

Quamvis magna piis 68

Quantum Virgilius magno 95

Qui cupis esse bonus 131

Quid mihi ruriculas 81

Quid tibi mors 142

Quintus erat mundi 275

Quisque velis criptam 276

Quisquis amat dictis 96

Quod cernis dicor 132

Quot caelum retinet stellas 286

Rector potens verax deus 222

Regna beata patri 81

Regnator caeli verax 132

Rerum deus tenax vigor 222

Respicis apriles 94, 260

Rex aeterne domine 79

Rex deus immensi 84

Rex o rector regminis 157

Rex pie rex clemens 135

Rex ubi versifico 276

Romphea nam caelestium 287

Romulidum ductor 231

Rumpitur invidia 135

Rure morans 96

Rursus in ambiguos 143

Rustice lustrivage $\quad 131,142$

Sancte sator suffragator $223,273,309 \mathrm{f} ., 312,345$

Sedulius Christi miracula 231

Si bene non scribis 279

Si Deus est animus 143

Si non dura silex 274

Si quis non valeas 275,276

Si tenebrae egyptus 260

Sic ego suscepi 131

Sic primo Christum 182

Somnus abest oculis 135

Sospitat incolumis 284

Sperne lucrum 144, 239

Spes ratio via vita 145

Spicula curvato 92,133 
Spiritus effuget 277

Splendida marmoreis ornata 93

Splendida quadratis 96

Stellarum in caelo 276

Subfragare trinitatis unitas

Sum noctis socia 143

Surge meo domno 274

Sus iuvenis serpens 133

Talia dictat amor 284

Tantum vina nocent 131,143

Tardius invento 285

Te deus aeterno 310

Te deus omnipotens 96, 213

Te lucis ante terminum 223

Te precor ex tumulo 183

Temporibus priscis 130

Ter binos deciesque 129

Tercio in flore mundus 112

Tingue semel calamum 275

Titire tu fido 67

Tres habuit turris 133

Tu qui pergis iter 132

Tu quicumque cupis 239

Tu quicumque velis 112

Tu quod es 276

Turpe pecus mutinum 93, 133

Una fides unum 133

Unitas in trinitate 157

Urbs quae tantum 143,165

Ut belli sonuere 133

Ver erat et blando 93

Vere gravis fundit 259

Vir bonus et sapiens 133

Virgilius magno quantum 239

Virgo columba suo 239

Virgo Maria nitet 269

Virgo parens hac luce 231

Vivere post obitum 96

Vulturis in silvis 95 


\section{V.4 Allgemeines Verzeichnis: Personen, Werke, Orte, Begriffe ${ }^{2191}$}

Aachen $\quad 47,50,84,90,186,221$

Accessus 95f., 116f., 242, 334, 340

Adalram (Erzbischof von Salzburg) 272-276

Adalung (Abt von Lorsch) 244-249, 252, 257

Adalwin (Bischof von Regensburg) 295f., 300

Adventus regis $123,135,138,148$

Aenigmata 42, 59, 67, 109, 119f., 130f., 136f., 142f., 168f., 191, 203, 242f., 246, 281, 294, $316,318,332 \mathrm{f} ., 341$

Aenigmata Laureshamensia $242 \mathrm{f}$.

Agius von Corvey $17,226,228$

Akrostichon 43, 59, 231, 307

Alcimus Avitus 62, 122f., 155, 173, 201, 255, 331

Aldhelm 42f., 52, 58, 61 f., 77, 85, 99f., 102, 103, 109f., 120, 124, 162, 169, 170, 174, 189, 202, 231, 242f., 246f., 253, 254, 263, 281, 294, 315f., 320, 321, 324, 332

Alkuin 22, 37, 45, 48, 58f., 60f., 67, 77, 81, 108, 163, 174, 179, 185, 214, 219, 221-224, 229, 232, 237f., 241, 244, 249, 257, 263f., 265-277, 280f., 292, 294, 296, 298, 300, 307, 309f., $310-313,317,323,328,337$

Althochdeutsch 33, 68f., 80, 104, 114, 117, 148, 156f., 168, 174, 181, 183f., 194-196, 215217, 227f., 230, 282, 288f., 290f., 310, 323

Amalarius von Metz $234 \mathrm{f}$.

Amorbach 34

Angelomus von Luxeuil 16

Angelsächsischer Einfluss, siehe Insularer Einfluss

Angilbert 274, 275, 281, 292

Anno (Bischof von Freising) 282, 291

Anthologia Latina 27, 66, 81, 92-96, 133, 144, 166, 209, 231, 237, 239, 245f., 258, 259, 287, 294

Anthologie $18-20,27 \mathrm{f} ., 340-342$

Arator $59,62,100,107,162,170,200,255,257,258,259,292,300,303,330 f$.

Aratus $89,103,169,172,174$

Arbeo (Bischof von Freising) 277

Arn (Erzbischof von Salzburg) 61, 184, 221-224, 262, 263-267, 269, 271f., 275, 277, 281, 309, 313, 317, 323, $335 f$.

Arnold (Bischof von Freising) 282

Astronomie 88, 207, 254, 258, 260, 282, 336

Atto (Bischof von Freising) 277f., 292

Augsburg 34

Ausleihe, siehe Leihe

Ausonius 92, 93, 129, 133, 137, 138, 259, 260

2191 Bei sehr häufigen Begriffen (z.B. »Anthologie«, »Bibliothek« oder »Schulhandschrift«), deren vollständige Verzeichnung das Register unhandlich machen würde, wird auf die Abschnitte des Schlusskapitels verwiesen, wo die betreffenden Handschriften, Personen und Institutionen über die Fußnoten erschlossen werden können. 
Autograph 60, 73, 164, 191, 193

Autorenhandschrift $330-337$

Autorensigle $108,109,115,158,172,192,311$

Avianus 13, 81, 103, 155, 174, 203, 210, 254, 300, 303, 324

Avienus 172, 254

Baturich (Bischof von Regensburg) 211, 297-300, 317, 323

Baugulf (Abt von Fulda) 58

Beatus (Bischof von Passau) 301

Beda 89, 96, 98f., 101f., 104, 107, 109, 112, 120, 128, 130, 144, 152, 160 f., 165 f., 199, 202-204, 222, 237, 243, 246, 253-255, 259f., 265, 279, 280, 287f., 293, 299, 311, 313, 315, 321, 332

Benediktbeuern 34, 278

Benediktsregel 97, 157, 169, 175, 248, 253

Bernhar (Abt von Weißenburg) 180, 182f., 185, 196

Bibeldichtung 21, 59, 123, 173, 179, 255, 331, 333

Bibliotheken 319-324

Kathedralbibliothek 321

Schulbibliothek 320f.

Privatbibliothek $321 \mathrm{f}$.

Reisebibliothek 153,159, 159, 310, 321

Bibliothekskatalog 319f.

Bildungsprogramm, siehe Curriculum

Boethius $62,66,88,97,103,108-112,174,175,176,199,243,253,292,293,299,303,304$, $316,319,321$

Bonifatius $42-44,50,55,57,59,142,189,242 \mathrm{f}$., 295, 297, 315

Bourges 45, 64

Briefe, Briefsammlung $14,38,43 \mathrm{f} ., 46,54,61,65 \mathrm{f} ., 77,87,89,120-123,132,134,136,155$, $166,169,171,175,182,214,222,239,246,248,253,264,266$ f. , 270, 272f., 275f., 277, 284f., 290, 297, 303, 308, 317, 332, 335-337, 343, 345

Briefgedicht, Briefdichtung $14,16,37,38,42,61,77,109,123,129,135,143,149,150,166$, 208, 214, 270, 272, 277, 280, 288, 290, 335, 336, 337, 343, 345

Brun Candidus $16,22,63,69,325,335$

Büchertausch $33,42,154,155,171,176,199,200,204,216,251,257,264,278,317$

Buchmalerei 46, 69, 80, 81, 94, 111, 116, 118, 124, 140f., 160, 163, 179, 181, 216, 227, 237, 282, 320, $324 \mathrm{f}$.

Burkart (Bischof von Würzburg) $50 \mathrm{f}$.

Cantica 38f., 234, 296

Carmen ad Deum 223, 273, 309f., 312, 345

Carmen de Hermenone 265

Carmen de Timone Comite $281 \mathrm{f}$.

Carmina Centulensia 29

Carmina Salisburgensia 264, 275-277, 343, 346

Cassiodor $37,43,107,108,180,209,303$

Cato, Ps. $13,46,48$ f., 94, 95, 101, 105, 123, 142, 145, 146, 168, 170, 231, 248, 288, 292, 301, 303,332 
Cento Probae $80 f ., 161 f ., 170,231,241,255,334$

Cento Tytiri 241

Christian von Stablo 16

Chrodegang von Metz 236

Chur 34

Cicero 53f., 190, $253 \mathrm{f}$.

Claudian 95, 107, 109, 110, 177, 287

Columban $\quad 48,109,110,122,135,138,144,145,255,280,292,328,332$

Computus 81, 90, 92-97, 158, 168f., 174f., 176, 182, 184, 209f., 214f., 218, 226, 259, 260, $262,276,296,299,305,329,341,346$

Corbie $49,182,226,227,228,231,317$

Corvey 34, 118, 225-229, 317, 334

Cresconius Corippus 155, 204f., 255, 331

Cruindmelus (Grammatiker) 307

Cudwin (Bischof von Dunwich?) 229, 231

Curriculum 14, 57, 110, 123, 159, 162, 225, 241f., 246, 247, 257, 263, 281, 292, 313, 334

Cyprian 54f., 81, 172, 198, 264

Cyprianus Gallus 173, 255

Dado von Verdun 14, 123

Damasus 37, 84, 183, 311

Dares Phrygius 237

Dedikation, siehe Widmung

Dhuoda 16

Dicuil 16

Diomedes (Grammatiker) 101

Disentis 34

Donat (Grammatiker) 38, 101f., 105, 159, 161, 165, 169f., 174, 219, 279, 280, 303

Duddo (Abt) $42 \mathrm{f}$.

Dungal $16,118,128,158,201,276$

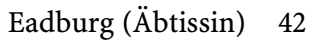

Echternach 34

Egilbert (Schreiber in Köln) 220, 319

Egino (Bischof von Verona) 154

Eichstädt 34

Eigilbert (Abt von Lorsch) 252

Einhard 16, 239, 240

Einleitung, metrisch $16,36-39,52,61,81,95,101,107,123,132,163,176,181,185,231$, 276f., 319, 328

Ellwangen 34

Engyldeo (Schreiber in Regensburg) 298

Ennius 95, 107

Ennodius 245f., 248, 253, 257, 317

Epigramm 71f., 84, 88, 92, 99, 107, 109, 126, 128, 130f., 135-138, 143, 183, 239, 284, 311

Epigraphie, siehe Inschriften 
Epitaphien $47,54,65,66,68,81,90,91,92,101,131,133,135,137,138,142,169,174,175$, $182,183,185,192,214,248,251,252,265,274,276,310,311,312,313,340,342$ f.

Ercanbert (Mönch in Weißenburg) 192-194, 197

Erchanbert (Bischof von Freising) 279, 281, 289, 323

Erchanbert (Grammatiker) 16

Erembert (Abt von Weißenburg) 180

Erlebald (Abt der Reichenau) 154f., 163, 173, 176, 206, 331

Ermenrich von Ellwangen $16,77,87,89,107 \mathrm{f} ., 120,301$

Ermoldus Nigellus 16

Essen (Nonnenstift) 227

Eucherius von Lyon 168, 265

Eugenius von Toledo 84, 131, 143, 310

Eutyches (Grammatiker) 306

Fabeln 13, 81, 130, 132, 137, 174, 203, 207, , 210, 254, 303, 318

Federprobe $35,117,243,263,326$

Felix (Mönch in Fulda) 72

Felwald (Schreiber in St. Gallen) 37

Ferding (Mönch in Weißenburg) 192, 194

Figurengedicht $43,45,59,62,63,77,132$

Florilegium 113f., 136, 160, 172, 209, 264, 278, 311, 329, 334

Florilegium Sangallense $105-108,110,142,144,146,152,202,279$

Florus von Lyon 16

Folkwig (Abt von Weißenburg) 180

Format $48,58,67,70,82,90,109,181,214,250,261,324$

Formulae 14, 73-76, 134, 155, 171, 272, 275-277, 283f., 290, 308, 311, 312

Formulardichtung 14, 20, 148, 183, 280, 284, 310, 312, 343, 345

Frage und Antwort, siehe Interrogationes

Frechulf von Lisieux 16,38

Freising 77, 80, 91, 109, 123, 149, 170, 171, 195, 199, 219, 251, 277-293, 295, 298, 307, 317, $321,323,330,333,339$

Fulda $34,39,44,47,49,50,56-78,79,91,97,100,119,124 f ., 138,155,163,165,167,172,181$, 188f., 191, 195, 211, 213, 214, 226, 247, 249, 297, 300f., 315, 317, 319, 322, 323, 325, 335, 336,337

Fulgentius $149,220,238,253$

Galluslied 148

Gebetbuch, siehe Libelli Precum

Geographie, geographische Dichtung 79, 83, 107, 144-146, 172, 174, 190, 248, 254

Gerhoh (Bibliothekar von Lorsch) 212, 249

Gerold (Hofkaplan) 225

Gerward (Pfalzbibliothekar) 256, $321 \mathrm{f}$.

Gesang 16, 38, 148, 169, 183, 239, 240, 288, 311, 345

Gesta Karoli Magni, siehe Poeta Saxo

Glossare $82,85,93,109,111,120,134,137,139,141,149,169,189,204,217,243,265,306$, $309,312,333$ 
Glossen 30, 45, 47, 77, 93, 100 f., 104f., 108f., 114, 117, 119f., 139, 147, 158, 161, 172, 174, $181,185,189,190,204,227,229,230,232,245,250,265,299,304,309,310,344$

Gorze 233, 236, 317

Gottschalk von Orbais 16,70

Gozbald (Bischof von Würzburg) 51, 53-55, 184, 339

Gozbert (Abt von St. Gallen) 86, 87, 141, 151

Grabinschrift, siehe Epitaphien

Grammatik 42, 43, 47, 55, 57, 59, 66, 80 f., 85, 88, 101 f., 104, 105, 108f., 116, 146, 152f., 159, 160-163, 165, 168f., 170-174, 176, 178, 180f., 184, 190, 192, 199, 203f., 215, 217, 219, 220, 230, 237, 241-245, 247f., 253-257, 279, 281f., 292f., 296, 298, 300, 302f., 306-308, 312, $319-321,323,328,330,332 \mathrm{f} ., 338 \mathrm{f}$.

Gregor der Große 36f., 154, 157, 182, 184, 185, 253

Grimald (Abt von St. Gallen) 70, 77, 81, 87-97, 98f., 101, 103, 107 f., 121, 126, 128, 137, 139, 141, 146, 151, 163, 175f., 187f., 196, 206f., 251, 286f., 321f., 323, 330, 333, 334, 337, 339, 344

Gunthar (Erzbischof von Köln) 220, 225

Hagiographie, Hagiographische Dichtung $21,49,58,69,70,75,76,86-89,97,99,100,107$, 120, 124f., 127-129, 133, 137, 148, 151, 156, 164f., 170-172, 182, 199, 201 f., 204, 226, 232, 244, 248, 252-255, 282, 297, 325, 331f., 335, 342f., 346

Haistulf (Erzbischof von Mainz) 44

Haito (Abt der Reichenau) 154, 168

Halberstadt 34

Hartmann (Abt von St. Gallen) 148

Hartmut (Abt von St. Gallen) 35, 87, 97, 98, 99, 103, 206, 321, 344

Hartwig (Bischof von Passau) 301

Hatto (Erzbischof von Mainz) 192, 291

Heidnische Dichtung 59, 62, 77, 102, 203, 204, 320, 323, 324, $333 \mathrm{f}$.

Heiric von Auxerre 16

Heliand 69, 194, $227 \mathrm{f}$.

Herford 34

Hersfeld 34

Hieronymus $37,60,66,136,159,264,311$

Hildebald (Erzbischof von Köln) 219-221, 225

Hildebrandslied $68 \mathrm{f}$.

Hildesheim 34

Hilduin (Erzbischof von Köln) 220

Hitto (Bischof von Freising) 279, 281, 323

Hof 33, 45, 93, 289

Karl der Große $\quad 31,186,206,208,219,257,317,323$

Karl der Kahle 15

Ludwig der Deutsche 300

Ludwig der Fromme 64, 163, 165, 234, 241, $261 \mathrm{f}$.

Homerus Latinus 151, 292

Honoratus (Grammatiker) 101, 105 
Horaz 62, 87, 104, 107, 115, 151, 164, 172, 181, 185-188, 196, 226, 228, 233f., 241, 254, 258, $263,292,334$

Hrabanus Maurus 16, 22, 45, 50, 56, 58-70, 72, 77, 91, 97, 100, 119, 125, 163, 165, 188f., 197, 209, 211-214, 218, 220, 234f., 249, 297, 322f., 325, 335-337, 343

Hunbert (Bischof von Würzburg) $51 \mathrm{f}$., 55

Hymnen 22, 53, 79, 81, 83f., 97, 101 f., 112f., 129, 141, 148, 150, 156-158, 160 f., 169, $174-$ 176, 179, 189, 199, 215-218, 222-225, 234f., 248, 252, 255, 261 f., 273, 288, 296, 309, 319, $328,344 \mathrm{f}$.

Illuminierung, siehe Buchmalerei

Inschriften $20,47,53,54,67,68,84,85,93,137,184,185,251,252,265,268,269,271,275$, 276, 277, 280, 294, 311, 316, 317, 319, 342f., $345 \mathrm{f}$.

Insularer Einfluss $\quad 43,46-48,50-53,57 f ., 60,66,77,100,110,153,160,179,204,223,231$, 242f., 250, 257, 263, 273, 295-298, 301, 306, 310f., 313, 315f., 321, 324, 332, 334

Interrogationes $119,144,308$

Irischer Einfluss $\quad 58,88,98,99,105,158 \mathrm{f} ., 185,191,242,262,297,301,306,310,321$

Isidor von Sevilla $48,79,94,101,107,114,130,143,149,160,168,170,220,253,286,306$, 328

Iskar (Abt von Murbach) 103, 198, 206, 207, 210, 215, 318

Iso (Lehrer in St. Gallen) 103

Italienischer Einfluss 316

Iuvenal, siehe Juvenal

Iuvencus, siehe Juvencus

Johannes Scotus Eriugena 16,158

Johannes VIII. 282

Jonas von Orleans 135

Josephus Scottus 45

Julianus Pomerius 168, 181, 247, 250, 251, 253

Juvenal $63,103,105 f ., 108,172,177,187,234,238,249,254,257,334$

Juvencus $51,59,62,80,98,100-102,108,118,123,151,159,160-162,164 f ., 169 f ., 174,179$, $200,204,215,217,220,226,230,248,254,258,282,292,293 f ., 300,327,330-332$

Kalenderdichtung, siehe Computus

Karl der Dicke 148

Karl der Große, siehe Hof

Karl der Kahle, siehe Hof

Karlsepos 140f., 143, 145-147

Kirchenväter $\quad 41 \mathrm{f} .$, 54, 85, 97, 173, 177, 180, 198f., 237, 244, 247, 253-255, 264, 274, 309

Koblenz 34

Kochel 34

Köln 33, 39, 218-225, 230, 272, 309, 319

Kolophon 35

Konstanz 34, 116, 154, 162, 177-179

Kornelimünster 34 
Korrekturen $83,111,127,129,139,157,160,164,166,181,186-188,188-190,196,214,245$, 249, 277, 291, 297, 299

Kremsmünster 34

Lehrer, siehe Schüler und Lehrer

Leidrad von Lyon 278,282

Leihe $17,33,66,88,102,116,119,155,165,166,170,174,181,192,195,249,278,291$

Libelli Precum 273, 296

Liturgie $\quad 39,51,67,224,235,261,299,305,322,325$

Liuphram (Erzbischof von Salzburg) 184, 185, 274-277, 281, 323, 336

Liutward von Vercelli 148

Lorica Gildae 223

Lorsch $94,100,102,106,115,121,149,152,168,171,173,177,181,186,187,199-204,206$, 208, 236-257, 316-319, 321, 323, 327, 330-334, 336, 338f., $342 \mathrm{f}$.

Louganpert (Presbyter in Regensburg) 300, 317

Ludwig der Deutsche, siehe Hof

Ludwig der Fromme, siehe Hof

Lukan $\quad 63,107,155,172,206,208,218,254,292,334$

Lukrez 61, 66, $107 \mathrm{f} ., 155,172,205,207 \mathrm{f} ., 218,317 \mathrm{f} ., 334$

Lul (Erzbischof von Mainz) 43

Lupus von Ferrières $16,111,156,264,323$

Lüttich 227, 229-232, 330

Lyon 131, 240, 256, 278, 282

Madalwin (Chorbischof von Passau) 55, 225, 256, 261, 301, 302-305, 313, 321, 322

Magulf (Abt von Fleury) 269

Mainz 33, 39, 41-50, 59, 64, 127, 155, 229, 233, 263, 280, 315, 317, 321

Mallius Theodorus (Grammatiker) 104

Marcellus (Lehrer in St. Gallen) 98, 103

Martial $\quad 42,68,96,107,130,131,135,172,254,287$

Martianus Capella $\quad 62,97,98,107,111,174,207,250,257$, 292, 299, 300, 306, 321

Martinellus 49, 252, 317, 343

Martyrologium 97, 174, 175, 258, 259-261, 304, 305, 325, 335

Megingoz (Bischof von Würzburg) 51, 54

Metrik 14, 43, 85, 98, 99, 102, 104, 108, 112, 117, 158, 165, 169, 241f., 245, 247, 254, 279, 281, $311,338,341,345$

Mico von Saint-Riquier $\quad 38,105-107,114,172,177,205,250,261,329$

Modoin 16, 38, 71, 120f., 151, 155, 166, 170, 208, 208, 248, 274, 336

Moengal (Lehrer in St. Gallen) 98

Mönchsregel 38, 85, 97, 157, 169, 175, 235, 248, 253, 332, 344

Mondsee 298, 300, 317, 323

Münsterschwarzach 34

Murbach 32, 65f., 81, 91, 100, 102f., 119, 121, 125, 152, 154-157, 168, 170f., 173-176, 197 $218,248,251,255,317-320,330-334,336,338 \mathrm{f} ., 342$

Murbacher Hymnen $156,157,175,215-218$ 
Nachträge 329

Neumen 112, 114, 117f., 120, 187, 228, 260, 289, 298, 345

Niederaltaich 34

Nonantola 154

Notae $139,158,169,174,183,192,242,291$

Notizbuch, siehe Vademecum

Notker Balbulus 13-15, 91, 98-100, 102f., 122f., 129, 130, 132, 139, 147-150, 152, 168, $282-$ $290,323-325,339,342-344$

Optatianus Porphyrius $61,62,77,254$

Opus geminum 69, 303

Otfrid von Weißenburg 22, 63, 69, 97, 180f., 188-191, 193, 194-197, 258, 262, 290, 291, 293, 323, 325, 326, 335

Otgar (Erzbischof von Mainz) 44f., 189, 212, 214

Otmar (Abt von St. Gallen) $\quad 78,129$

Otricus (Kölner Geistlicher) 261

Ovid $63,93,95,96,107,114,115,133,155,164,172,177,181,202,226,228,239,245,258$, $259,263,279,282,292,293,334$

Paschasius Radbertus 16

Passau 171, 183, 203, 223, 225, 256, 261, 276, 284, 301-314, 319, 321f., 330, $332 \mathrm{f}$.

Patristische Literatur, siehe Kirchenväter

Paulinus von Aquileia $16,175,268$

Paulinus von Nola $48,62,132,170,201,248,253,316,331$

Paulinus von Périgueux 127, 171, 201, 255

Pavia 154, 246

Persius 63, 103, 106, 107, 177, 187, 234, 249f., 257, 292, 334

Petronius 278, 292

Petrus Pisanus 16, 130f., 136f., 268, 343

Petruslied 289

Pfäfers 154

Pfungen 153

Pirmin 153, 179, 315

Plautus $303 \mathrm{f}$.

Plotius Sacerdos (Grammatiker) 306

Poeta Saxo 226, 228

Pompeius (Grammatiker) 242

Porphyrio (Horaz-Kommentator)

Praecepta vivendi $49,122 \mathrm{f}$.

Priscian 95, 101, 107, 144-146, 153, 158, 161, 169, 170, 172, 190, 196, 202f., 230, 245, 248, 254, 293

Prosimetrum 98, 111, 148, 284

Prosper Aquitanus 61, 88, 99f., 132, $137 \mathrm{f} ., 161,168,170,181,199,201,203 \mathrm{f} ., 220,230-232$, 247, 250f., 253, 255, 292, 300, 304, 316, 319, 321, 330 
Prudentius 52, 53, 55, 59, 62, 68, 84, 85, 100, 103f., 107, 111f., 116-118, 162, 164, 170, 179, $190,192,194,196,201,205,226-228,248,254,263,287,292,294,300,304,320,324,327$, $330,332,337$

Prudentius von Troyes 70, 155, 171, 205

Prüm 32, 94, 258-262, 235, 303

Ps.-Maximian 239, 240f., 317

Psalter, Psalmen 13, 16, 36-39, 156f., 176, 234, 273, 288, 291, 311

Publilius Syrus 46f., $145 \mathrm{f}$, 316

Quintus Serenus $88,98,101,107,131,141,143,146,176,210,318$

Rado (Urkundenschreiber in Lorsch) 241

Radulf von Bourges 45

Ratger (Abt von Fulda) 58, 212

Ratold (Bischof von Verona) 154, 177

Ratpert (St. Gallen) 35, 103, $147 \mathrm{f}$.

Rätsel, siehe Aenigmata

Regensburg 90, 185, 268, 274, 276, 281, 295-300, 317, 321, 323, 330

Reginbert (Bibliothekar auf der Reichenau) 88, 92, 101, 128, 141, 155, 156, 157, 161, 162, $165,167-169,171,173-179,215,318 f ., 323,338,344$

Regula, siehe Mönchsregel

Reichenau 38, 46, 47, 56, 70, 72, 74f., 77-82, 86-88, 92, 100-102, 105f., 116, 118f., 121, 128, 138, 141, 146, 150f., 153-179, 181, 185, 197f., 200-203, 205f., 215-218, 230f., 249f., 257, 259, 293, 297, 300f., 315, 317-319, 321-323, 327, 330-333, 337f., 344

Reims 261, 280, 312

Reisen 33, 67f., 85, 98, 153, 159, 192, 216, 229, 266, 310, 321

Reklamanten 89, 90, 110f., 113, 125, 140f., 307

Remigius von Auxerre 16

Remiremont 74

Rhythmen 14, 82, 83-85, 136, 151, 183, 307

Richbod (Abt von Lorsch) 237f., 241, 244, 252, 257, 323, 343

Riculf (Erzbischof von Mainz) 182f., 185, 312

Rom $\quad 42,54,64,67$ f., 84, 229, 252, 269-280, 294, 311, 312, 316, 343, 345

Rotulus $155,168,197,198,288$

Ruadhelm (Abt der Reichenau) 173, 176

Rudolf von Fulda 16, 76-78, 322, 337

Sakramentar 177,302

Salomo III. von Konstanz 13-15, 91, 121-123, 132, 139, 147-149, 150f., 282f., 285f., 289f., $323,339,343$

Salzburg 33, 39, 61, 121, 124, 184f., 219, 221, 223f., 262-277, 281, 292, 309, 313, 317, 321, $323,335 f ., 343$

Samuel (Abt von Lorsch) 249, 252, 257, 323

Schenkung, Schenkungsnotiz $\quad 73,74,76,154,173,225,236,244,256,258,300,301,322$

Scholien 17, 105f., 143, 185, 187, 250, 334

Schreiber $\quad 325-327$ 
Schreiberverse $16,35,36,86,104,112$

Schule, Schulbibliothek, Schulhandschriften $320,338 \mathrm{f}$.

Schüler und Lehrer $13-17,55,60 f ., 66,68-70,76-78,87 f$., 88, 98, 103, 110, 115, 122f., 126, 128, 147f., 155f., 159, 162f., 165f., 175, 187, 191-194, 197, 220f., 224, 239f., 240, 242-244, 256f., 265f., 268, 278f., 282-285, 290, 297f., 305-308, 313, 320, 322-324, 326, 336f., 338, 343

Schülerverse $16,55,148,192-194,285$

Schuttern 34,280

Sedulius $58 f ., 61$ f., 77, 80f., 98, 101-103, 105, 107, 116, 118, 123, 151f., 161 f., 164f., 179, 200, 220, 226f., 229-232, 248, 254, 258, 269, 280, 292, 297, 300, 306, 320, 323f., 327, 330332

Sedulius Scottus $16,22,220,306$

Seligenstadt 34

Seneca (Ps.) 46

Sens 261

Sergius (Grammatiker) 101, 105, 189

Servius (Grammatiker) 88, 101, 205, 220, 304

Sidonius (Bischof von Passau) 301

Silius Italicus $116,177-179,219,323,334$

Simpert (Bischof von Regensburg) $295 \mathrm{f}$.

Smaragdus von St. Mihiel 16, 38

St. Alban 41, 45f., 48, 321

St. Amand $\quad 45,229,242,263-266,269,273,275,317$

St. Bertin 85, 124, 268, 270f., 328, 335, 336

St. Denis $64,154,170,171,263$

St. Emmeram 295-300, 319, 321

St. Gallen 13f., 33f., 36f., 39, 42f., 46, 50, 55f., 67, 70, 72-78, 78-152, 154f., 161f., 167, 170, 172, 174, 175-177, 185, 188, 192, 197, 199, 200-203, 206, 208, 214, 220, 228, 230, 247, 250f., $254,257,259,279,280,282$ f., 285-287, 289f., 299, 301, 305, 316, 318-321, 323, 327, 330$333,336-338,340,343 \mathrm{f}$.

St. Galler Spottverse 104

St. Maximin 232-235, 321

St. Oyan 240, 261

St. Peter (Kloster in Salzburg) 262, 321

St. Riquier $47,172,173$

St. Vaast $244,246 \mathrm{f}$, , 252, 257, 317

Statius $63,103,172,177-179,226-228,334$

Stifter, Stiftung $\quad 36,74,92,154,277$

Straßburg 34,114

Syllogen $\quad 53-55,68,83-85,244,251$ f., 257, 265, 271, 280, 294, 311, 316, 326, 342f., 345

Symphosius 109f., 119, 174, 210, 242, 246, 332

Symposium XII sapientum 95, 109f., 144, 146, 239, 259, 287

Tatto (Mönch in St. Gallen) $71,163,175,323$

Taufers 34

Tegernsee 283, 293f., 301, 319, 334, 343 
Terenz $\quad 63,103,226,234,292,299,324$

Theodulf von Orléans $16,22,43-45,120 f ., 123,135,138,142,145 f$., $207 f ., 215,218,328$, 336f., 343

Titel (siehe auch Bibliothekskatalog) 36, 54, 65, 94, 95, 96, 106, 122, 123, 125, 126, 133, 134, $160,167,173,174,182,210,247,252,293$

Tituli Tegernseenses 294, 343

Tituli, siehe Inschriften

Tours $49,58,61,64,154,221,234,244,252,257,267,317,335$

Trier $33,39,155,232-235,237,260,321$

Tropen 148, $288 \mathrm{f}$.

Tutilo 139

Übersetzung 98, 145, 148, 156, 169, 190, 207, 216f., 289f., $309 f$.

Vademecum 68, 81, 89-97, 137, 139, 140, 143, 145f., 159, 165f., 185, 196, 201, 214, 221, 234, $261,264,266,273,286,290,306 f ., 312,339$

Valerius Flaccus 66f., 77, 326

Venantius Fortunatus 49, 61, 62, 83, 107, 119f., 127f., 151, 155, 164, 171, 177, 201, 226, 255, $258,316,318,331,335,337$

Vergil 42f., 63, 66, 85, 88, 96-98, 101-104, 107, 112, 131, 136, 155, 158, 161, 164, 166, 170 $172,183,185,188,202,205,218,220,226,233 f ., 237-240,242,244 \mathrm{f} ., 248,255-259,265$, 280, 282, 292-294, 298, 304, 309, 316f., 320f., 323, 324, 328, $333 \mathrm{f}$.

Versus Sangallenses 93, 343

Versus Wissenburgenses 182, 183, 329, 343

Victorinus, Marius (Grammatiker) 241, 263

Virgil (Bischof von Salzburg) 262-264, 271, 276, 315

Visio Wettini (Heito) 128

Vita Leodegarii metrica 128

Vita S. Galli Metrica $87,100,129,151$

Vita, siehe Hagiographie

Vivilo (Bischof von Passau) 301

Volkssprache, siehe Althochdeutsch

Vorwort, metrisch, siehe Einleitung, metrisch

Walahfrid Strabo 16, 22, 33, 62f., 68-77, 86f., 93, 101, 103, 105f., 112, 115, 117, 119, 121, 123-127, 128, 133, 135-139, 143, 145f., 151-156, 163-167, 170-172, 176-179, 185, 187f., 196, 205f., 214, 250, 280f., 292, 300, 322f., 325, 328, 332, 334, 337, 339, 342f.

Waldo (Abt von St. Gallen und der Reichenau) 79, 154, 167, 168, 173, 179

Waldo (Bischof von Freising) 122f., 148-150, 195, 282f., 288-291, 293, 323, 339

Waldram (Bibliothekar von St. Gallen) 122f., 148, 343

Waltharius 142,151

Wandalbert von Prüm 58-62, 300, 304f., 325, 335

Weißenburg $62,87,115,144,146,164,168,180-197,251,262,291,312,317,320,323,326$, 334

Weißenburger Gedichte 191-195, 197

Weltenburg 34 
Wenibert von Schuttern 280

Wenilo von Laon 219

Werden 34, 227

Wetti (Mönch auf der Reichenau) 86, 128, 155f., 163

Widmung 16, 33, 35, 37f., 43f., 45, 50, 58, 64, 69, 76, 87, 89, 97, 103, 148, 152, 156, 175, $194 \mathrm{f}$., 261, 266, 268, 288, 290f., 309, 311, 325, 335

Winithar (Mönch und Schreiber in St. Gallen) $\quad 79,83$

Wolfcoz (Mönch und Schreiber, St. Gallen) 39, 86

Wolfgar (Bischof von Würzburg) 51

Worms 34, 180, 182, 184f., 196, 291, 343

Würzburg $39,50-55,181,184,190,278,315,319,320,326,330,339,343$

\section{V.5 Tabellarische Übersicht der Dichter in den Skriptorien}

M Handschrift. Sammelhandschriften mit verschiedenen Autoren werden mehrfach verzeichnet.

m Handschrift unsicherer Zuordnung oder Datierung, sowie kopiale Überlieferung und neuzeitliche Drucke aus karolingischen Handschriften.

K Katalogeintrag

$\mathrm{k}$ Katalogeintrag, unsicher.

E Einzelgedicht, Exzerpt oder kleine Sammlung in Sammelhandschriften.

Z Zitat oder Nennung in literarischen Quellen oder Florilegien. 


\begin{tabular}{|c|c|c|c|c|c|c|c|c|c|c|c|c|c|c|c|c|c|c|c|c|c|}
\hline nesse $_{d}$ & & 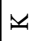 & & 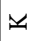 & & & 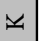 & & 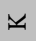 & & & 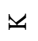 & & & & & & & & & \\
\hline 8.xnqsuəฮిวy & & & & & & & & & $\Sigma$ & & & & & & & & & & & & \\
\hline วəsuณəภว $\mathrm{L}$ & & $N$ & & & & & & & & & & & & & & & & & & & \\
\hline 8u!s!̣. & & $\Sigma$ & $N$ & 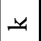 & & & & & 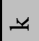 & & & $\ddot{4}$ & & & 山 & & & & & & 디 \\
\hline 8..nqzies & & & $\Sigma$ & & & & & & & & & & & & & & & & & & $\Sigma$ \\
\hline unn. $x_{d}$ & & & & $N$ & & & & 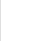 & & & & & & & & & & & N & & \\
\hline Чวs.IOT & $\because$ & $\frac{y}{\Sigma}$ & & $\approx$ & $\approx$ & & $\simeq$ & 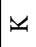 & $\because$ & . & & $\simeq$ & $\Sigma$ & & 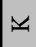 & 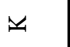 & & $\because$ & 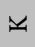 & & $\simeq$ \\
\hline 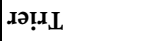 & & & & & & & & & & & & & & & & & & & E & & $\Sigma$ \\
\hline чग!ฺnฺ & & & & & & & & & & & & & $\mathrm{N}$ & & & & & & & & \\
\hline Кәм.оО & & & & & & & & & & & & & & & & & & & $N$ & & \\
\hline u[ơ & & & & & & & & & & & & & & & & & & & & & \\
\hline чreq.inW & 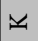 & 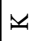 & & 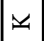 & $\approx$ & & 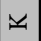 & 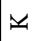 & $\approx$ & & & & & & & 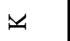 & & & & $\Sigma$ & $\Sigma$ \\
\hline 8.xnquəy!’ $M$ & & & & & & & & & & & & & & & & & & & $\Sigma$ & & \\
\hline пеиәчग!ә & 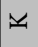 & 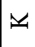 & & 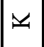 & 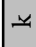 & & $\simeq$ & $\approx$ & 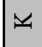 & & & 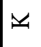 & $\stackrel{3}{\Sigma}$ & 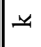 & & & & 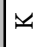 & & & $\asymp$ \\
\hline 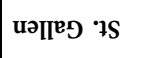 & $\stackrel{\sharp}{\Sigma}$ & $\frac{v}{\Sigma}$ & 띠 & 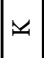 & $\not$ & $\Sigma$ & 디 & $\Sigma$ & 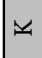 & 川1 & & $\stackrel{y}{\Sigma}$ & $\Sigma$ & 卌 & 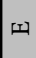 & & 띠 & & 띨 & & $\stackrel{y}{\Sigma}$ \\
\hline epp ${ }^{n_{H}}$ & $\underline{N}$ & $\because$ & 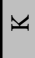 & $\underline{N}$ & & & & & है & & है & & & & & & & & 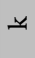 & 家 & \\
\hline S..nqz.ṇM $M$ & & $\frac{1}{\Sigma}$ & & & & & & & & & & & & & & & $\Sigma$ & & & & \\
\hline zu!̣eW & & $\Sigma$ & 되 & & & & & & & $\mathrm{N}$ & & $\Sigma$ & & & & & & & & $N$ & \\
\hline & 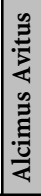 & 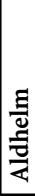 & 童 & 泀 & 莺 & 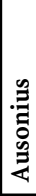 & 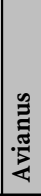 & ڤేّ & 总 & 胥 & 疍 & $\begin{array}{c}0 \\
\stackrel{0}{0} \\
0 \\
1 \\
\dot{0} \\
0\end{array}$ & 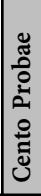 & Uี & $\begin{array}{l}\text { हี } \\
\text { है } \\
\text { है } \\
\text { ठ }\end{array}$ & 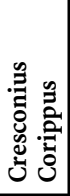 & 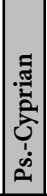 & 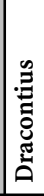 & 츨 & 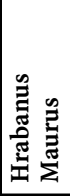 & 氞 \\
\hline
\end{tabular}




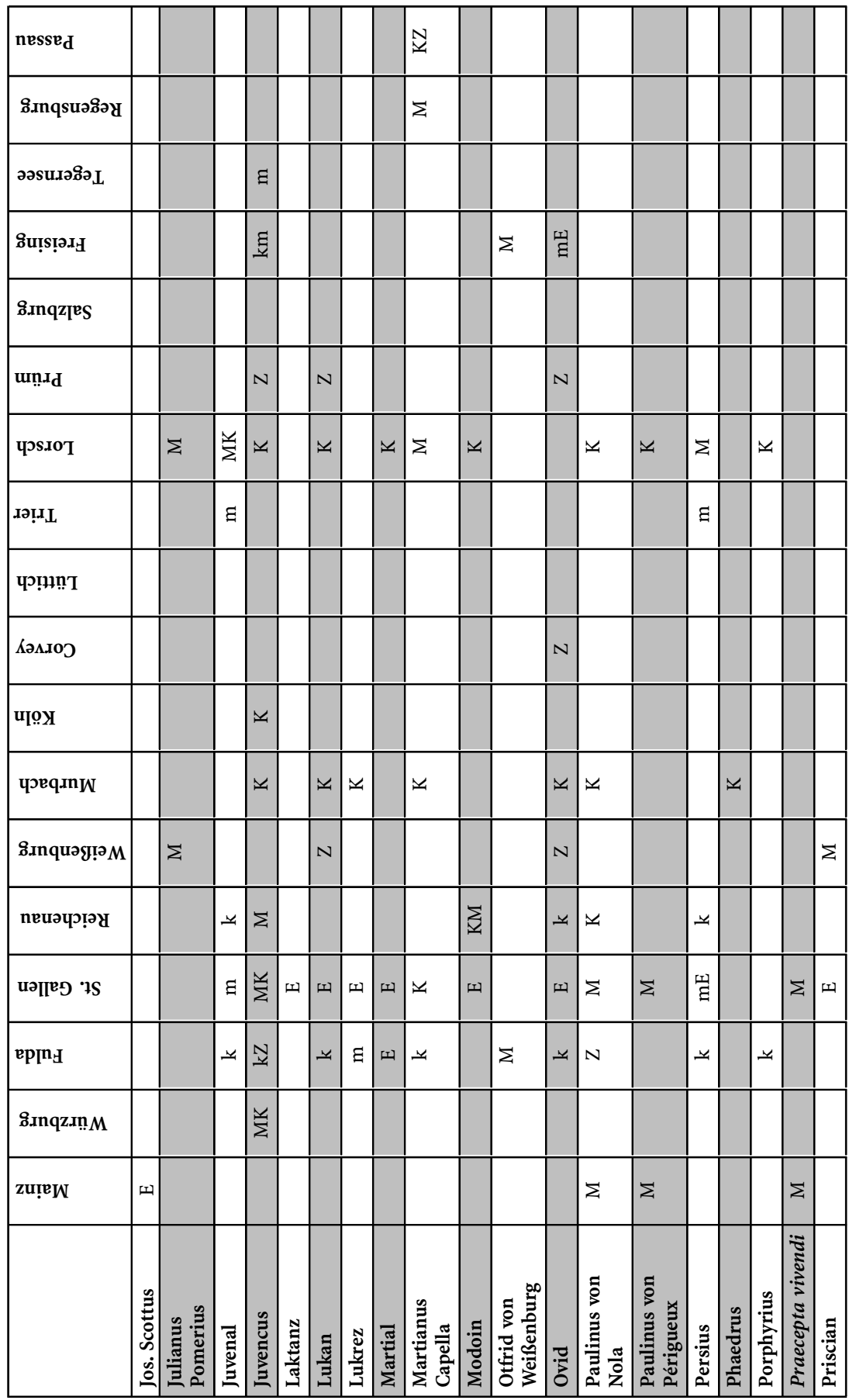




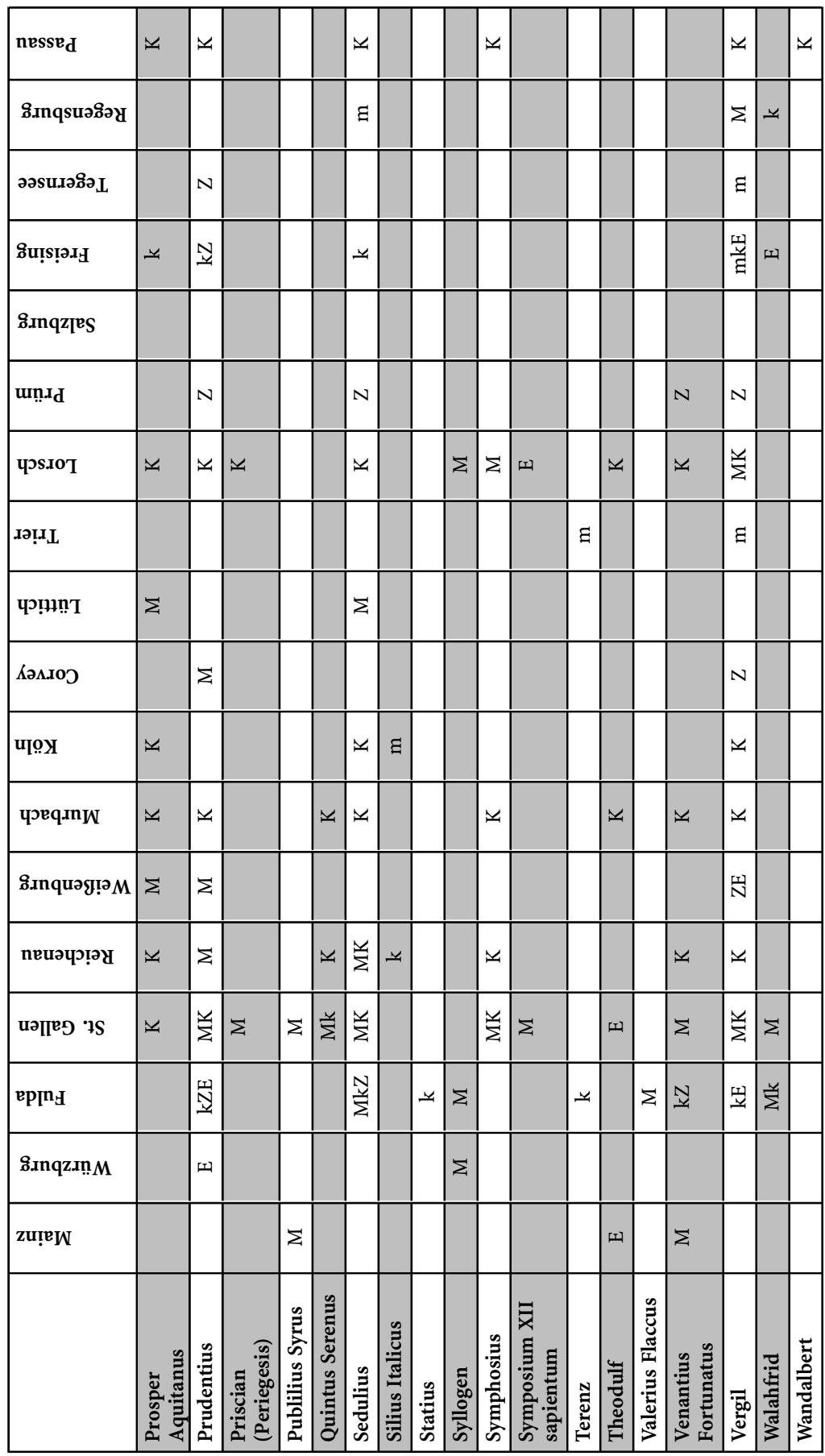


Open-Access-Publikation im Sinne der CC-Lizenz BY 4.0

(c) 2021, Vandenhoeck \& Ruprecht GmbH \& Co. KG, Göttingen ISBN Print: 9783847112310 - ISBN E-Lib: 9783737012317 